Karin

Müller-Kelwing

Zwischen

Kunst,
Die Staatlichen

Sammlungen

für Kunst und

Wissenschaft

in Dresden und

ihre Mitarbeiter

im National-

sozialismus

\title{
Wissenschaft
}

und

Politik
Hg. von

den Staatlichen

Kunstsammlungen

Dresden und

Gilbert Lupfer

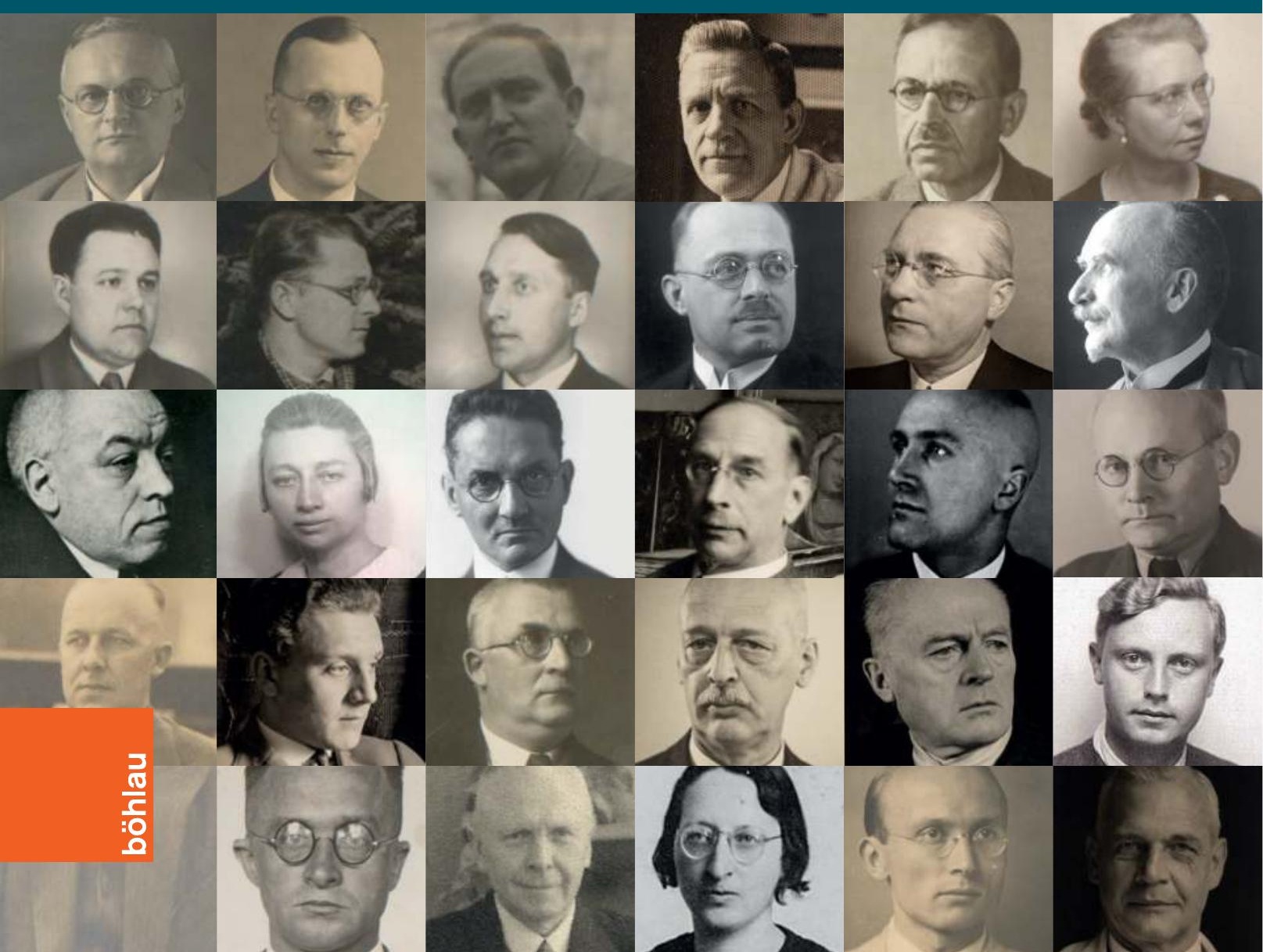




\section{ZWISCHEN KUNST, WISSENSCHAFT UND POLITIK}

Die Staatlichen Sammlungen für Kunst und Wissenschaft in Dresden

und ihre Mitarbeiter im Nationalsozialismus

Herausgegeben von den Staatlichen Kunstsammlungen Dresden und Gilbert Lupfer

BÖHLAU VERLAG WIEN KÖLN WEIMAR 


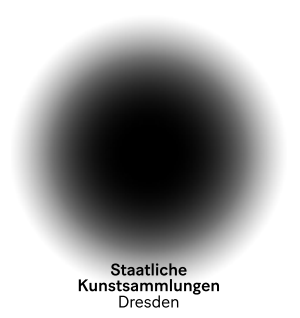

\section{Gefördert durch \\ DG $\begin{aligned} & \text { Deutsche } \\ & \text { Forschungsgemeinschaft }\end{aligned}$}

Bibliografische Information der Deutschen Nationalbibliothek:

Die Deutsche Nationalbibliothek verzeichnet diese Publikation in der

Deutschen Nationalbibliografie; detaillierte bibliografische Daten sind im Internet über http://portal.dnb.de abrufbar.

(C) 2020 by Böhlau Verlag GmbH \& Cie, Lindenstraße 14, D-50674 Köln,

(C) 2020 Staatliche Kunstsammlungen Dresden und Autoren

Dieses Material steht unter der Creative-Commons-Lizenz Namensnennung - Nicht kommerziell 4.0 International. Um eine Kopie dieser Lizenz zu sehen, besuchen Sie http://creativecommons.org/licenses/by-nc-nd/4.0/.

Umschlagabbildung: Siehe Abbildungsnachweis S. 522

Korrektorat: Constanze Lehmann, Berlin

Lektorat: Maria Obenaus, Thomas Rudert

Satz: Punkt für Punkt · Mediendesign, Düsseldorf

Vandenhoeck \& Ruprecht Verlage | www.vandenhoeck-ruprecht-verlage.com

ISBN (Print) 978-3-412-51863-9

ISBN (OA) 978-3-412-51865-3

https://doi.org/10.7788/9783412518653 


\section{Inhaltsverzeichnis}

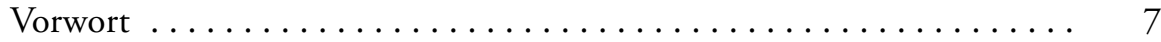

Einleitung $\ldots \ldots \ldots \ldots \ldots \ldots \ldots \ldots \ldots \ldots \ldots \ldots \ldots \ldots \ldots \ldots \ldots \ldots \ldots, 11$

Die Staatlichen Sammlungen für Kunst und Wissenschaft ......... 35

Struktur der Staatlichen Sammlungen .................... 35

„[...] seit längerer oder kürzerer Zeit vacant“ -

Die Personalausstattung der Sammlungen ................. 46

"Jede Sammlung muß eine Hitlerehrung besitzen“ -

Politisierung der Arbeit . . . . . . . . . . . . . . . . . . . . . . 103

„Nationalsozialistische Erziehungsstätten“-

Kulturgutschutz versus Bildungsarbeit ................... 139

Ausblick - Die Situation der Staatlichen Sammlungen

nach Kriegsende .......................... 223

Die Institutionen der Staatlichen Sammlungen _............. . 229

Ausstellungen zwischen 1933 und $1945 \ldots \ldots \ldots \ldots \ldots \ldots \ldots \ldots . \ldots 235$

Die wissenschaftlichen Mitarbeiterinnen und Mitarbeiter $\ldots \ldots \ldots \ldots 253$

Personen aus dem Umfeld der wissenschaftlichen Mitarbeiterinnen und Mitarbeiter . .......................... 477

Abkürzungsverzeichnis . . . . ....................... 490

Quellenverzeichnis .............................. 491

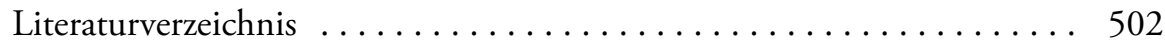

Abbildungsverzeichnis . ........................ 522

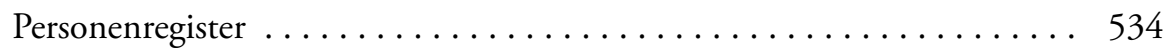




\section{Vorwort}

Dresden hatte von den späten 1930er-Jahren bis 1945 eine wichtige Funktion als Drehscheibe des NS-Kunstraub- und Kunsttransfersystems. Die Direktoren der Gemäldegalerie, Hans Posse und sein Nachfolger Hermann Voss, waren in Personalunion „Sonderbeauftragte“ Adolf Hitlers und damit Schlüsselfiguren in diesem System. So ist es naheliegend, dass sich fachöffentliches Interesse und Forschung zunächst auf diese beiden Protagonisten und den mit ihnen verbundenen „Sonderauftrag Linz“ konzentrierten, wenn es bisher um die Rolle der Dresdner Museen in der NS-Zeit ging. Zu nennen sind in diesem Zusammenhang zuvörderst die grundlegenden Studien von Birgit Schwarz; Untersuchungen von Hanns Christian Löhr sind ebenfalls zu erwähnen. Auch in Dresden selbst wurde substantielle Forschung geleistet, niedergelegt in mehreren, Posse gewidmeten Aufsätzen Thomas Ruderts sowie Birgit Dalbajewas. Mit allen Facetten von Posses Wirken beschäftigte sich 2013 auch ein Kolloquium, nachzulesen im Tagungsband. Die Tätigkeit von Voss untersuchte Kathrin Iselt in ihrer Dissertation. Doch mit dem Alltag der anderen Dresdner Museen im NS-Staat haben diese Forschungen wenig zu tun, denn der "Sonderauftrag“ war nicht in die Museumsarbeit integriert, sondern lediglich über die Personalunion angebunden.

Ein von der Fritz Thyssen Stiftung finanziertes Forschungsprojekt zur Geschichte der Dresdner Museen von 1918 bis 1989 („Museum und Kunst in totalitären Systemen “, 2004-2008) blickte weit über das Wirken von Posse und Voss hinaus, ohne jedoch aufgrund des viel größeren zeitlichen Rahmens wirklich in die Tiefe gehende Ergebnisse zum Museumsalltag liefern zu können. Gerade das Agieren der Museumsdirektoren, zunächst in der sich formierenden NS-Diktatur und dann unter den Bedingungen des Krieges, wurde zum Abschluss dieses Projektes als weiter untersuchenswert identifiziert.

Wenige Jahre später bot sich dann die Gelegenheit, diese Lücke zu schließen: Die Kunsthistorikerin Karin Müller-Kelwing entwickelte zusammen mit dem Projektleiter ein Forschungsprojekt, das von der Deutschen Forschungsgemeinschaft für drei Jahre gefördert wurde.

Zunächst, im ersten Konzeptentwurf, sollte primär auf das Agieren der Direktoren im fraglichen Zeitraum fokussiert werden. Doch die Beschränkung auf die Direktorenebene wurde der komplexen Realität keineswegs gerecht und der Blick musste ausgeweitet werden. Auch leitende Konservatoren, wissenschaftliche Mitarbeiter und Restauratoren waren einzubeziehen. Ein Grund dieser Ausweitung lag darin, dass mit zunehmender Kriegsdauer die Personaldecke der 
Museen dünner wurde und damit weitere Personen vorübergehend in verantwortliche Positionen gelangten. Schließlich wurde ein Kreis von mehreren Dutzend Mitarbeitern der Staatlichen Sammlungen für Kunst und Wissenschaft identifiziert, denen die Aufmerksamkeit hinsichtlich des museumsorganisatorischen, wissenschaftlichen und politischen Agierens gelten sollte. Dabei war die Zeit von 1933 bis 1945 nicht isoliert zu betrachten. Um das Handeln der Protagonisten ab 1933 zu verstehen und Veränderungen zu erkennen, musste man ihre vorherige Positionierung kennen. Und natürlich war es von Belang, ob, wie und wo Karrieren nach dem Kriegsende ihre Fortsetzung fanden.

Schon in der Konzeptionsphase klärte sich auch, dass zwar ein personenbezogener Ansatz gewählt werden, ein biografisches Lexikon aber nicht das alleinige wenn auch das wichtigste - Ergebnis sein konnte. Denn die Untersuchung würde auch Erkenntnisse über die Museumsarbeit an und für sich abwerfen.

Eine weitere Vorbemerkung zum Zuschnitt der Untersuchung ist noch notwendig: Struktur und Umfang der Staatlichen Sammlungen für Kunst und Wissenschaft von 1933 bis 1945 wichen gravierend von den heutigen Staatlichen Kunstsammlungen Dresden (SKD) ab. An dem damaligen, wesentlich größeren Umfang an Institutionen galt es sich zu orientieren. Deshalb sind auch die Mitarbeiter derjenigen Einrichtungen einbezogen, die in der frühen Nachkriegszeit aus dem damals neu formierten Verbund der SKD ausschieden, also bspw. der Landesbibliothek, der naturkundlichen und archäologischen Sammlungen.

Die nach dreijähriger Projektarbeit nun veröffentlichten Forschungsergebnisse füllen große Lücken im institutionsgeschichtlichen Wissen der SKD und anderer Dresdner Institutionen. Parallel zur Buchpublikation werden über die Website der SKD die Berufsbiografien aller untersuchten Mitarbeiter zu recherchieren sein; dieses Angebot richtet sich auch an ein breiteres Publikum.

Die Projektergebnisse werden hoffentlich über Dresden hinaus Beachtung finden, denn es lassen sich Erkenntnisse über exemplarische Karrieren von Wissenschaftlern ableiten. Bei der Betrachtung dieser Dresdner Karrieren wird man feststellen, dass es nur wenige aktive Nationalsozialsisten gegeben hat, aber auch nur wenige, die gegen das Regime Stellung bezogen. Die große Mehrheit dürfte irgendwo dazwischen anzusiedeln gewesen sein. Eine systematische Scheidung im Aufbau der Publikation zwischen Tätern und Opfern wäre wissenschaftlich nicht sinnvoll gewesen.

Es gab nur wenige jüdische Mitarbeiter. Zu den Ergebnissen zählt auch, dass ein jüdischer Wissenschaftler identifiziert werden konnte, Fritz van Emden, der nach England emigrieren musste. Zum Andenken an ihn wurde auf Initiative des Projektes ein „Stolperstein“ am Eingang des Zwingers verlegt. 
Neben dem prosopografischen Ansatz sollte, wie schon erwähnt, das Funktionieren der Museen überhaupt in den Blick genommen werden, ihre Instrumentalisierung für die nationalsozialistische Prägung der Gesellschaft und die Stärkung der Moral an der "Heimatfront" sowie ihr Fortbestand unter Kriegsbedingungen. Hierzu haben sich aus bisher weitgehend unerschlossenem Material bemerkenswerte Erkenntnisse ergeben. So kann man jedenfalls nicht mehr davon ausgehen, dass die Vermittlungsarbeit der Museen synchron mit der kriegsbedingten Schließung ihrer Schausammlungen zum Erliegen gekommen wäre. Ganz im Gegenteil: es entfaltete sich vielmehr ein reges Vermittlungsprogramm, das hier erstmals dokumentiert wird.

Die vorliegende Untersuchung ersetzt nicht völlig eine noch ungeschriebene Geschichte der Dresdner Sammlungen im fraglichen Zeitraum, stellt aber doch, zusammen mit den eingangs erwähnten Publikationen, alle wesentlichen Elemente dafür bereit. Parallel zu ihrem Engagement in der Provenienzforschung wollen die SKD zum Ausdruck bringen, wie wichtig ihnen die Aufarbeitung ihrer Geschichte auch zu wenig glanzvollen Zeiten ist.

Schließlich sei erwähnt, dass dieses Projekt eine weitere Gelegenheit für die gute Kooperation zwischen SKD und der Technischen Universität Dresden bot. Ergebnisse flossen in die Ringvorlesung „Museen im Nationalsozialismus“ am Institut für Kunst- und Musikwissenschaft ein und wurden mit Studierenden, Kollegen und der Öffentlichkeit diskutiert.

Die Realisierung einer Publikation, die ein dreijähriges Forschungsprojekt erfolgreich abschließt, ist mit Dank an viele Beteiligte und Unterstützer verbunden. Dieser Dank gilt zunächst Karin Müller-Kelwing, die den Anstoß gegeben und dann die Forschungsarbeit übernommen hat. Neben ihr sollen auch die studentischen Mitarbeiterinnen genannt werden, vor allem Fine Kugler und Meike Paula Thar. In der Abteilung Forschung und wissenschaftliche Kooperation der SKD waren vor allem Thomas Rudert und Maria Obenaus höchst engagierte und kenntnisreiche Begleiter. Die regelmäßigen Besprechungen haben wesentlich zum Gelingen beigetragen. Aus dieser Abteilung hatte auch die Archivarin Vera Wobad wichtigen Anteil. Martin Zavesky hat die Online-Stellung begleitet. Natürlich gilt der Dank auch allen Kolleginnen und Kollegen aus den einzelnen Sammlungen - aus denen, die heute noch zu den SKD gehören wie aus denen, die inzwischen selbständig sind - für die Unterstützung in Gesprächen und mit Materialien. Den Mitarbeiterinnen und Mitarbeitern zahlreicher Archive sei für ihre Hilfe gedankt, ebenso denen des Böhlau Verlages.

Besonderer Dank gilt der Deutschen Forschungsgemeinschaft für die Förderung.

Gilbert Lupfer 


\section{Einleitung}

Wissenschaftler unterschiedlichster Disziplinen, wie beispielsweise Kunsthistoriker, Historiker, Archäologen, Germanisten, Geologen oder Zoologen, prägten maßgeblich die Entwicklung der Staatlichen Sammlungen für Kunst und Wissenschaft in Dresden zwischen 1933 und 1945. Diese Akteure gestalteten als Direktoren, Kustoden oder wissenschaftliche Mitarbeiter die Arbeit in den Museen und der damals zum Verbund gehörenden Sächsischen Landesbibliothek aktiv und agierten bisweilen in enger Verbindung zu politischen Entscheidungsträgern. Doch die Erforschung der Biografien dieser Protagonisten stellt bisher noch weitgehend ein Desiderat dar, obwohl diese Biografien untrennbar miteinander sowie mit der Objekt- und Sammlungsgeschichte verwoben sind.

Mit der zunehmenden Bedeutung der Provenienzforschung, die in den Staatlichen Kunstsammlungen Dresden (SKD) seit 2008 im „Daphne-Projekt“ und in der Sächsischen Landesbibliothek - Staats- und Universitätsbibliothek Dresden (SLUB) seit 2009 intensiv, systematisch und für andere Institutionen vorbildhaft betrieben wird, ${ }^{1}$ offenbarte sich die Wichtigkeit und Dringlichkeit, die Erforschung der Institutionsgeschichte und der Provenienzen von Kunstwerken und Kulturobjekten noch stärker mit den Biografien der Handlungsträger zu verknüpfen. Aus den Staatlichen Sammlungen für Kunst und Wissenschaft standen bisher vor allem zwei Protagonisten der NS-Zeit im Fokus des wissenschaftlichen Interesses: die Direktoren der Gemäldegalerie Hans Posse und Hermann Voss, die zugleich als „Sonderbeauftragte“ für das „Führermuseum Linz“ tätig waren.

Die Gemäldegalerie war indes nur eine von vielen Abteilungen der Staatlichen Sammlungen für Kunst und Wissenschaft, im Folgenden Staatliche Samm-

\footnotetext{
1 Vgl. Lupfer, Gilbert: „Daphne“. Das Provenienzrecherche-, Erfassungs- und Inventurprojekt der Staatlichen Kunstsammlungen Dresden, in: Koordinierungsstelle für Kulturgutverluste Magdeburg (Hg.): Die Verantwortung dauert an. Beiträge deutscher Institutionen zum Umgang mit NS-verfolgungsbedingt entzogenem Kulturgut, Magdeburg 2010, S. 127-136; ders.: Das Daphne-Projekt der Staatlichen Kunstsammlungen Dresden. Eine kurze Bestandsaufnahme nach acht Jahren Arbeit, in: Provenienz \& Forschung, H. 1, 2016, S. 48-53; Kocourek, Jana u. Norman Köhler: Spurensuche. Im April 2009 startete an der SLUB ein Projekt zur ProvenienzerschlieBung, in: BIS - Das Magazin der Bibliotheken in Sachsen 3, 2010, 2, S. 110-111, http:// nbn-resolving.de/urn:nbn:de:bsz:14-qucosa-39121, Zugriff: 6.12.2019; vgl. https://nsraubgut. slub-dresden.de/slub-projekte/ns-raubgut-erw-1933-1945/ und https://nsraubgut.slub-dresden. de/slub-projekte/ns-raubgut-erw-nach-1945/, Zugriff: 6.12.2019.
} 
lungen genannt. Wer aber waren die anderen handelnden Personen? Wer führte die Dienstgeschäfte in Dresden, wenn Posse und später Voss abwesend waren? Wer leitete die anderen Sammlungen? Wie funktionierte die Museumsarbeit in den Jahren zwischen 1933 und 1945? Aus diesen Überlegungen heraus entstand die Idee für ein Forschungsprojekt, dessen Ergebnisse in dieser Publikation vorgelegt werden.

In Ergänzung zur Provenienzforschung, die zuvorderst das Aufklären der Biografien von Kunstwerken und anderen Kulturgütern beinhaltet, widmete sich das von der Deutschen Forschungsgemeinschaft (DFG) geförderte Forschungsprojekt „Zwischen Kunst, Wissenschaft und Politik: Museen im Nationalsozialismus. Die Staatlichen Sammlungen für Kunst und Wissenschaft in Dresden und ihre wissenschaftlichen Mitarbeiter" der SKD von 2016 bis 2019 den Lebenswegen und Berufsbiografien dieser Handlungs- und Entscheidungsträger. Es analysierte zugleich den institutionellen Aufbau und die wissenschaftliche Arbeit eines der größten Museumsverbünde in Europa unter den Bedingungen der nationalsozialistischen Diktatur.

Mit der Verknüpfung der Biografieforschung mit Institutions- und Wissenschaftsgeschichte wurde ein breiter methodischer wie auch interdisziplinärer Ansatz gewählt. Trotz aller Personenbezogenheit wurde der Weg der monografischen biografischen Forschung verlassen. Das Projekt untersuchte vielmehr das Ineinandergreifen von Wissenschaft, Museumsarbeit und Politik. Dabei vermischten sich in besonderem Maße Aspekte der zeit- und kunsthistorischen, institutions- und sammlungsgeschichtlichen, wissenschaftshistorischen und biografischen Forschung. Interdisziplinarität ergab sich auch aus den unterschiedlichen Berufen der Protagonisten. Indem diese Publikation zwischen einer synchronen und diachronen Betrachtungsweise wechselt, trägt sie zu einer multiperspektivischen (Regional)Geschichtsschreibung bei.

Ursprünglich standen „nur" die Direktoren und wissenschaftlichen Mitarbeiter im Fokus der Untersuchungen. Während der Recherchen offenbarte sich jedoch die Notwendigkeit der Erweiterung des Personenkreises, da im Zweiten Weltkrieg auch Mitarbeiter des technischen Personals, wie Restauratoren und Präparatoren, Verantwortung für die Sammlungen übernehmen mussten, wie z. B. Alfred Beck im Mathematisch-Physikalischen Salon und Rudolf Schwarze im Museum für Mineralogie und Geologie.

Eine zentrale Rolle spielte der Kunsthistoriker Fritz Fichtner, der als Direktor der Porzellansammlung zugleich das Kunstgewerbemuseum leitete und als Referent für die Staatlichen Sammlungen im Sächsischen Ministerium für Volksbildung tätig war. Diese Aufgabenkonzentration warf die Frage nach den Wechselwirkungen zwischen Politik, Verwaltung und Museum auf. Gegenstand des 
Forschungsprojektes war daher auch die Analyse der Vernetzung der Protagonisten in das politische Leben und die staatliche Verwaltung sowie ihr Agieren im Spannungsfeld von Kunst, Wissenschaft und Politik bzw. nationalsozialistischer Ideologie. Die zum Teil höchst ambivalenten Handlungsweisen erforderten eine differenzierte Beurteilung der Protagonisten. Um ihre persönliche Haltung gegenüber dem NS-Regime nachzuzeichnen, wurde ihre berufliche Entwicklung vor 1933 und nach 1945 einbezogen.

Für die Erforschung der Lebenswege, die zukünftig im Sinne einer prosopografischen Geschichtsschreibung als Grundlage für eine noch zu schreibende Kollektivbiografie der Museumsmitarbeiter in der NS-Zeit dienen können, wurden zunächst die überlieferten Personalakten ausgewertet. Parallel dazu wurden ausgehend von den Jahresberichten der Staatlichen Sammlungen die Sachakten einzelner Sammlungen aus den Jahren von 1933 bis 1945 auf biografische Überlieferungen überprüft.

Bei den aufgrund ihrer Arbeit am „Führermuseum Linz" bereits seit längerem im Interesse der Öffentlichkeit und der Wissenschaft stehenden und daher schon biografisch gut erforschten Galeriedirektoren Hans Posse und Hermann Voss wurde weitgehend auf die vorhandene Sekundärliteratur zurückgegriffen. Grundsätzlich wurde bei fehlender Überlieferung von Primärquellen wie Personalakten auf die Sekundärliteratur, soweit vorhanden, zurückgegriffen.

Im Fokus der Recherchen standen neben den Personen auch die Strukturen und Funktionsweisen der Museumsarbeit im NS-Staat. Schließlich sollte das komplexe System von Anpassung, Mitwirkung, Unterwerfung, gesellschaftlichem Aufstieg, Distanz, Verweigerung, Karriereende, Vertreibung oder Flucht näher beleuchtet werden, wobei folgende Fragen eine Rolle spielten: Welchen Themen widmeten sich die Dresdner Sammlungsdirektoren in ihrer Arbeit zwischen 1933 und 1945? Fanden sie fachliche Anerkennung für ihre wissenschaftlichen Leistungen? Waren sie von der Entlassungswelle ab 1933 betroffen, wurden sie nach 1945 entlassen? Inwiefern eröffneten im Einzelfall die Entlassung bzw. Vertreibung von Wissenschaftlern aus dem Amt systembedingte Karrierechancen für andere? Konnten sie nach 1945 ihre Karriere fortsetzen? Traten sie der NSDAP oder anderen NS-Organisationen bei? Welche Bedeutung kam Einzelpersonen und ihren Handlungen im Gesamtgefüge der Staatlichen Sammlungen einerseits und des nationalsozialistischen Kulturbetriebes andererseits zu? Existierten hilfreiche Kontakte zu Eliten aus Politik oder Wirtschaft? Wie wurden die fachlichen und organisatorischen Herausforderungen während des Zweiten Weltkriegs gemeistert?

Der Leitgedanke des Forschungsprojektes war die Frage nach der Kontinuität und den Brüchen in der Museumsarbeit einerseits und in den Biografien der 
Protagonisten andererseits. Die Analyse des umfangreichen Beziehungsgeflechtes der Protagonisten ließ deutlich werden, dass die Kategorien Opfer und Täter in vielen Fällen nicht deutlich zu unterscheiden sind. Bei der Beurteilung des Verhaltens einzelner Personen war Vorsicht geboten - so wie nicht jedes Parteimitglied sogleich ein überzeugter Nazi war, so war nicht jedes Nicht-Mitglied ein Widerstandskämpfer. Unzählige Nuancen dazwischen existierten. In den Staatlichen Sammlungen arbeiteten Personen, die von den Nationalsozialisten aus ideologischen und rassistischen Gründen entlassen wurden, die dem NS-Staat und seiner Ideologie kritisch gegenüberstanden, während andere bereitwillig zu Mitläufern wurden, die sich in vorauseilendem Gehorsam übten, die aus karrieristischen und opportunistischen Motiven handelten oder die ihrer nationalsozialistischen Überzeugung folgten. Die Frage nach den Möglichkeiten und Konsequenzen eines eigenverantwortlichen Handelns im Rahmen der Arbeitsabläufe, nach sachlichen Erfordernissen und politischen Vorgaben schwingt dabei mit. Eindeutige Aussagen dazu sind kaum möglich, ohne spekulativ zu werden, denn durch die überlieferten Quellen werden Handlungen und Entscheidungen sichtbar, jedoch selten die Motive. Als unbedingt notwendig erwies sich das Hinterfragen von Legendenbildungen, zu denen die Protagonisten selbst beigetragen haben, wie z. B. Fritz Fichtner und Hans Kummerlöwe, die nach 1945 ihre Rolle im NS-Staat aktiv verschleierten.

\section{Struktur}

Den ersten Teil der Publikation bildet ein Essay, der sich den Staatlichen Sammlungen in der NS-Zeit widmet, ihre Organisations- wie auch Personalstruktur vorstellt und wesentliche Personalveränderungen - wie Entlassungen der jüdischen Mitarbeiter, vorzeitige Pensionierungen, Einberufungen zum Militärdienst - thematisiert. Anhand von einzelnen Beispielen wird erläutert, wie ministerielle Anordnungen zu einer wachsenden Politisierung führten und den Arbeitsalltag veränderten, nicht nur indem sie eine aktive Beteiligung am politischen Leben forderten. Der Text beschreibt, wie sich die Arbeitsaufgaben wandelten. Dabei zeigt sich, dass der Schutz des Kulturgutes und die offensive Bildungsarbeit Hauptaufgaben waren. Erwähnung finden die kriegsbedingten sukzessiven Schließungen der Schausammlungen wie auch die Bergung bzw. Auslagerung der Objekte. Darüber hinaus wird das reichhaltige Vermittlungsprogramm aus Vorträgen, Führungen und Ausstellungen analysiert. Der Essay erhebt keinen Anspruch auf Vollständigkeit, sondern zeigt vielmehr anhand von Einzelbeispielen die Arbeit in den Staatlichen Sammlungen unter den Bedingungen der nationalsozialistischen Diktatur. 
Anschließend werden die einzelnen zu den Staatlichen Sammlungen gehörenden Institutionen mit ihren Direktoren bzw. den für sie Verantwortung tragenden Mitarbeiterinnen und Mitarbeitern im Überblick aufgelistet. Namensänderungen und Umstrukturierungen finden ebenso Erwähnung wie kriegsbedingte Schließzeiten.

Das folgende Ausstellungsverzeichnis gewährt erstmals einen Überblick über alle in Archivalien und Tageszeitungen erwähnten Ausstellungen der Staatlichen Sammlungen von 1933 bis 1945 .

Den Hauptteil des Buches bilden die Biografien der Direktoren und wissenschaftlichen Mitarbeiter der Staatlichen Sammlungen für Kunst und Wissenschaft in Dresden während des Nationalsozialismus. Alphabetisch geordnet dienen sie als biografisches Lexikon. Jeder einzelne Eintrag beginnt mit den Lebensdaten und der Nennung der beruflichen Positionen der betreffenden Person in den Staatlichen Sammlungen. Der anschließende Text skizziert deren Leben, schildert ihre Ausbildung, beschreibt ihre Tätigkeit, nimmt Bezug auf ihr politisches Verhalten. Die Frage, ob Mitarbeiter aus eigenem Antrieb oder aus politischem Zwang handelten, ob es gelang, politisch gewährte oder geduldete Handlungsspielräume zu nutzen, spielt dabei eine Rolle. Gleichfalls wird berücksichtigt, ob sie nach dem Kriegsende weiterhin in Dresden arbeiteten oder ihre Karrieren andernorts fortsetzten. Der Fokus liegt jedoch auf der Tätigkeit der Protagonisten in den Dresdner Sammlungen während der NS-Zeit. Anschließend an jede Biografie gewährt eine Auswahlbibliografie einen Überblick über wissenschaftliche Leistungen. Zum Schluss werden die jeweils konsultierten Quellen benannt.

Der Anhang enthält neben dem üblichen wissenschaftlichen Apparat ein umfangreiches Personenverzeichnis. Es informiert knapp über das Berufsleben jener Personen, die in engem Kontakt mit einzelnen oder mehreren Mitarbeiterinnen und Mitarbeitern der Staatlichen Sammlungen standen - etwa als akademische Lehrer oder Fachkollegen anderer Institutionen - und deshalb in den Biografien Erwähnung fanden. Zugleich bildet es das weitläufige Netzwerk ab, in dem die Dresdner Sammlungsmitarbeiter agierten.

\section{Definitionen}

An manchen Stellen des Textes war es zum Verständnis unumgänglich, die Sprache der Täter zu benutzen. Diese wird zur Distanzwahrung durch die Verwendung von "“gekennzeichnet. Ortsnamen und geografische Bezeichnungen werden in der zeitgenössischen Form verwendet, d.h., da diese Territorien damals zu Deutschland gehörten, in Deutsch. 
Die Nutzung der männlichen Personen- und Berufsbezeichnungen in dieser Publikation trägt ebenfalls dem zeithistorischen Kontext Rechnung. Sie spiegelt die Tatsache wider, dass das wissenschaftliche Personal der Museen zum weit überwiegenden Teil aus Männern bestand. Sind im jeweiligen Sachzusammenhang ausdrücklich auch Mitarbeiterinnen gemeint, werden die weiblichen Formen verwendet.

Unabdingbar ist der Hinweis auf die Abgrenzung der Begriffe „Direktor“ und "Leiter", die in der vorliegenden Publikation nicht synonym Verwendung finden. In die Position eines Direktors wurden die jeweiligen Personen berufen und waren damit für diese Sammlung verantwortlich. Wurden Mitarbeiter hingegen zum Leiter ernannt, so verblieben sie in ihrer bisherigen Position - meist als Kustos - und übernahmen zusätzlich dauerhaft die Führung der Dienstgeschäfte der Sammlung. Zwar entsprachen die Aufgaben von Direktor und Leiter einander weitgehend, doch wies die Vergütung der Tätigkeiten erhebliche Unterschiede auf - ein Leiter erhielt weiterhin sein Gehalt der früheren Position. In der NS-Zeit und vor allem während des Zweiten Weltkrieges wurde in Dresden letztlich die Form der „Kommissarischen Leitung“ bevorzugt, d. h. eine Person wurde unter Belassung in ihrer bisherigen Position vorübergehend damit beauftragt, die Leitung einer Sammlung zu übernehmen. Bei den Angaben über einzelne berufliche Positionen wurden im Allgemeinen nur jene von mehr als einem Monat Dauer verzeichnet. Vertretungsregelungen während der Urlaubszeit, im Krankheitsfall oder bei Dienstreisen wurden nicht berücksichtigt.

In manchen Fällen waren für die Beförderungen der Mitarbeiter oder die Präsentation von Ausstellungen, wenn überhaupt, nur die Jahreszahlen oder Monatsangaben zu ermitteln. Nicht eindeutig nachweisbare Datumsangaben stehen daher in den Biografien und im Ausstellungverzeichnis in eckigen Klammern.

Infolge der teilweise lückenhaften Überlieferung war im Rahmen des Projektes trotz intensiver Recherchen keine vollständige Rekonstruktion aller Biografien der Protagonisten wie der Sammlungsgeschichte möglich, wodurch die Publikation an einigen Stellen fragmentarisch bleiben muss.

\section{Forschungsstand}

Nach einer ersten zeitnahen Bestandsaufnahme der NS-Kunstpolitik durch Paul Rave $^{2}$ blieb das Interesse der kunsthistorischen sowie der einschlägig fokussierten historischen Forschung an der Zeit des Nationalsozialismus lange Zeit wenig ausgeprägt und museumsspezifische Aspekte wurden kaum berücksichtigt. In den

2 Rave, Paul Ortwin: Kunstdiktatur im Dritten Reich, Hamburg 1949. 
1960er-Jahren veröffentlichten mehrere Autoren, darunter Hildegard Brenner ${ }^{3}$, erstmals Originaldokumente. Diese Quellensammlungen bildeten die Grundlage für die weitere, immer noch sehr zurückhaltende kunsthistorische Forschung in den 1980er-Jahren. Dies hat sich in den letzten Jahrzehnten grundlegend geändert.

Das wissenschaftliche Interesse an der NS-Zeit wuchs seit etwa 1995, also 50 Jahre nach deren Ende, rapide. Obwohl sich das Projektthema an der Schnittstelle von kunsthistorischer und historischer Forschung verortet, würde ein Darlegen des Standes der zeithistorischen Forschung zum „Dritten Reich“ an dieser Stelle zu weit führen. Zu zahlreichen Einzelthemen wurde unterdessen publiziert, wobei sowohl Opfer als auch Täter des NS-Staates im Fokus standen. In seinen biografischen Lexika veröffentlichte Ernst Klee ab 2003 erstmals umfassende Verzeichnisse von Akteuren der NS-Zeit. ${ }^{4}$

Hinsichtlich der Erforschung und kritischen Auseinandersetzung mit ihrer eigenen jüngeren Vergangenheit als Wissenschaft steht auch die Kunstgeschichte inzwischen nicht mehr am Anfang. Eine erste Überblicksdarstellung zur Kunstgeschichte und ihren Vertretern im Nationalsozialismus legte Heinrich Dilly bereits 1988 vor. ${ }^{5}$ Umfangreichere Studien zu diesem Thema erschienen dann aber erst 2003 unter der Herausgeberschaft von Jutta Held und Martin Papenbrock sowie 2005 von Nikola Doll, Christian Fuhrmeister und Michael H. Sprenger. ${ }^{6}$ 2008 erschien „Kunstgeschichte im ,Dritten Reich'. Theorien, Methoden, Praktiken “, herausgegeben von Ruth Heftrig, Olaf Peters und Barbara Schellewald. ${ }^{7}$ Auch Frank-Rutger Hausmann widmete sich 2011 in seiner umfangreichen Stu-

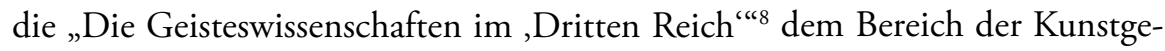

\footnotetext{
3 Brenner, Hildegard: Die Kunstpolitik des Nationalsozialismus, Reinbek bei Hamburg 1963. 4 Klee, Ernst: Das Personenlexikon zum Dritten Reich. Wer war was vor und nach 1945?, Frankfurt a. M. 2003 (akt. Ausg. 2007); ders.: Das Kulturlexikon zum Dritten Reich. Wer war was vor und nach 1945, Frankfurt a. M. 2007 (überarb. Ausg. 2009).

5 Dilly, Heinrich: Deutsche Kunsthistoriker 1933-1945, Berlin 1988.

6 Held, Jutta u. Martin Papenbrock (Hg.): Kunstgeschichte an den Universitäten im Nationalsozialismus (Kunst und Politik. Jahrbuch der Guernica-Gesellschaft, Bd. 5), Göttingen 2003; Doll, Nikola, Fuhrmeister, Christian u. Michael H. Sprenger (Hg.): Kunstgeschichte im Nationalsozialismus. Beiträge zur Geschichte einer Wissenschaft zwischen 1930-1950, Weimar 2005. 7 Heftrig, Ruth, Peters, Olaf u. Barbara Schellewald (Hg.): Kunstgeschichte im „Dritten Reich“. Theorien, Methoden, Praktiken (Schriften zur modernen Kunsthistoriographie, Bd. 1), Berlin 2008.

8 Hausmann, Frank-Rutger (Hg.) unter Mitarbeit von Elisabeth Müller-Luckner: Die Rolle der Geisteswissenschaften im Dritten Reich 1933-1945 (Schriften des Historischen Kollegs: Kolloquien 53), München 2002.
} 
schichte. Doch in den genannten Studien und Projekten wurde primär das Wirken von Kunsthistorikern im universitären Bereich untersucht.

Mit Blick auf die Museen stellt sich die Situation anders dar. Sie beschäftigten sich lange nur zögernd mit ihrer Vergangenheit, obwohl sie u. a. durch Restitutionsansprüche längst dazu gezwungen wurden, sich damit auseinanderzusetzen. Dieses Dilemma zeigte Gilbert Lupfer 2012 beim Internationalen Kunsthistoriker-Kongress auf.?

Die SKD widmen sich seit 2004 verstärkt der Erforschung ihrer Institutionsgeschichte im 20. Jahrhundert. Zunächst leitete Lupfer gemeinsam mit Thomas Rudert das Forschungsprojekt „Museum und Kunst in totalitären Systemen Zur Geschichte der Staatlichen Sammlungen für Kunst und Wissenschaft bzw. der Staatlichen Kunstsammlungen Dresden seit 1918“, welches sich auf die Sammlungs- und Institutionsgeschichte, insbesondere in der Zeit der gesellschaftlichen Umbrüche konzentrierte und somit zur Basis der Dresdner Provenienzforschung wurde. ${ }^{10}$ Biografiegeschichtliche Aspekte spielten dabei - von einzelnen Protagonisten wie Posse und Voss abgesehen - zunächst keine zentrale Rolle. Allerdings zog das Dresdner Forschungsvorhaben wichtige Projekte, Tagungen und Publikationen nach sich. Aus ihm ging 2008 das Provenienzrecherche-, Erfassungs- und Inventurprojekt „Daphne“ hervor, das seither die über 1,5 Millionen Objekte im Bestand der SKD in einer eigenen Datenbank digital erfasst sowie alle Zugänge der Museen seit 1933 einer systematischen Prüfung unterzieht. ${ }^{11}$ Ebenfalls aus dem institutionsgeschichtlichen Forschungsprojekt hervorgegangen sind die Dissertation von Kathrin Iselt über den Galeriedirektor und „Sonderbeauftragten " Hitlers, Hermann Voss, ${ }^{12}$ und die 2013 in Dresden

\footnotetext{
9 Vgl. Lupfer, Gilbert: Provenienzforschung und Kunstgeschichte. Spannungen und Perspektiven, in: Die Herausforderung des Objekts. 33. Internationaler Kunsthistoriker-Kongress Nürnberg 2012, Congress Proceedings - Part 4, Nürnberg 2013 (32. Wissenschaftlicher Beiband zum Anzeiger des Germanischen Nationalmuseums, Bd. 32,4), S. 1385-1387.

10 Vgl. Lupfer, Gilbert: Forschungsprojekt zur Geschichte der Dresdner Sammlungen zwischen 1928 und 1989, in: Dresdener Kunstblätter, 48. Jg., H. 5, 2004, S. 342-345.

11 Siehe Anm. 1.

12 Iselt, Kathrin: „Sonderbeauftragter des Führers“. Der Kunsthistoriker und Museumsmann Hermann Voss (1884-1969), Köln 2010 (Studien zur Kunst 20) (Zugl. Dresden, Univ., Diss., 2009). Vgl. dies.: Hermann Voss - Seine Ernennung zum „Sonderbeauftragten für Linz“ und Direktor der Staatlichen Gemäldegalerie Dresden, in: Dresdener Kunstblätter, 52. Jg., H. 1, 2008, S. 26-35; dies.: Hermann Voss. Direktor der Staatlichen Gemäldegalerie Dresden und Hitlers „Sonderbeauftragter für Linz“, in: Pieper, Christine, Schmeitzner, Mike u. Gerhard Naser (Hg.): Braune Karrieren. Dresdner Täter und Akteure im Nationalsozialismus, Dresden 2012, S. 270-277.
} 
organisierte Tagung „Forschungen zu Hans Posse“. ${ }^{13}$ Von den 2015 publizierten Tagungsbeiträgen sind die „Bausteine zu einer Biografie Hans Posses“ von Rudert und die Aufsätze von Birgit Dalbajewa hervorzuheben. ${ }^{14}$

Der „Sonderauftrag Linz" steht seit etwa 15 Jahren im Fokus der Forschung, als Hanns Christian Löhr und Birgit Schwarz begannen, darüber zu publizieren. ${ }^{15}$ Schwarz widmete sich den Themen NS-Kunstraub und Posse als „Sonderbauftragter" seither mehrfach und arbeitet derzeit an der „Kommentierte[n] Online-Edition der fünf Reisetagebücher Hans Posses (1939-1942)“ mit. ${ }^{16}$

In den vergangenen zehn Jahren setzten sich mehrere kunst- und kulturhistorische Museen mit ihrer Geschichte in der NS-Zeit auseinander. Die Ergebnisse wurden in umfassenden Publikationen veröffentlicht, beginnend mit dem Deutschen Museum in München 2010 und dem Städel in Frankfurt am Main 2011. ${ }^{17}$ Zwei Jahre später erschien der von Jörn Grabowski und Petra Winter herausgegebene Sammelband „Zwischen Politik und Kunst. Die Staatlichen Museen zu Berlin in der Zeit des Nationalsozialismus". ${ }^{18}$ Die Nationalgalerie Berlin widmete

13 Lupfer, Gilbert u. Thomas Rudert (Hg.): Kennerschaft zwischen Macht und Moral. Annäherungen an Hans Posse (1879-1942), Wien/Köln/Weimar 2015.

14 Rudert, Thomas: Konservativer Galeriedirektor - Kulturdiplomat der Weimarer Republik NS-Sonderbeauftragter. Bausteine zu einer Biografie Hans Posses, in: Lupfer/Rudert 2015, S. 61-149; Dalbajewa, Birgit: „Mittelgut können wir nicht gebrauchen.“ Hans Posse als Kommissar des deutschen Pavillons in Venedig 1922 und 1930, in: ebd., S. 219-238; dies.: „... selbst auf die Gefahr einzelner Irrtümer hin ...“- Die „Sammlung moderner Malerei“ in der Gemäldegalerie unter Hans Posse 1918 bis 1933, in: ebd., S. 239-270.

15 Löhr, Hanns Christian: Das Braune Haus der Kunst - Hitler und der „Sonderauftrag Linz“. Visionen, Verbrechen, Verluste, Berlin 2005; Schwarz, Birgit: Hitlers Museum. Die Fotoalben „Gemäldegalerie Linz“, Wien/Köln/Weimar 2004.

16 Schwarz, Birgit: Der sogenannte Linz-Bestand im Kupferstich-Kabinett der Staatlichen Kunstsammlungen Dresden, in: Dresdener Kunstblätter, 56. Jg., H. 2, 2012, S. 143-149; dies.: Auf Befehl des Führers. Hitler und der NS-Kunstraub, Darmstadt 2014; dies.: Hans Posse als Sonderbeauftragter, in: Lupfer/Rudert 2015, S. 329-348; dies.: Hitlers Sonderauftrag Ostmark. Kunstraub und Museumspolitik im Nationalsozialismus, Schriftenreihe der Kommission für Provenienzforschung 7, Wien/Köln/Weimar 2018 sowie Kommentierte Online-Edition der fünf Reisetagebücher Hans Posses (1939-1942), https://editionhansposse.gnm.de/, Zugriff: 6.12.2019.

17 Vaupel, Elisabeth u. Stefan L. Wolff (Hg.): Das Deutsche Museum in der Zeit des Nationalsozialismus. Eine Bestandsaufnahme, Deutsches Museum. Abhandlungen und Berichte, N. F., Bd. 27, Göttingen 2010; Fleckner, Uwe u. Max Hollein (Hg.): Museum im Widerspruch. Das Städel und der Nationalsozialismus, Schriften der Forschungsstelle „Entartete Kunst“, Bd. VI, Berlin 2011.

18 Grabowski, Jörn u. Petra Winter (Hg.): Zwischen Politik und Kunst. Die Staatlichen Museen zu Berlin in der Zeit des Nationalsozialismus (Schriften zur Geschichte der Berliner Museen, Bd. 2), Wien/Köln/Weimar 2013. Vgl. auch Kühnel-Kunze, Irene: Bergung - Evakuierung - Rückführung. Die Berliner Museen in den Jahren 1939-1959, Jahrbuch Preußischer Kulturbesitz, Sonderband 2, Berlin 1984. 
sich 2015 diesem Thema in der Ausstellung „Die Schwarzen Jahre“ ${ }^{19}$ Nähe und Distanz zwischen den Berliner Museen und der Politik untersuchte Timo Saalmann 2014. ${ }^{20}$ Im selben Jahr thematisierte ein Sammelband die Geschichte des Germanischen Nationalmuseums in Nürnberg. ${ }^{21}$ Mit den Museen in München in der NS-Zeit befassen sich wenige Einzelaufsätze und Publikationen zu ihrer allgemeinen Geschichte. ${ }^{22}$ Zuletzt widmete sich ein Sammelband über „Museen im Nationalsozialismus" neben den Orten und der Politik auch explizit den Akteuren. ${ }^{23}$

Bezüglich der naturhistorischen Sammlungen ist die Tendenz zur Aufarbeitung ihrer Geschichte im Nationalsozialismus nicht derart deutlich zu erkennen. Nach einem frühen Start mit der Untersuchung der Anthropologischen Abteilung des Wiener Naturhistorischen Museums in der NS-Zeit durch Maria Teschler-Nicola und Margit Berner 1998 im Rahmen eines umfangreicheren Forschungsprojektes zur Anatomischen Wissenschaft in Wien ${ }^{24}$ war das Interesse an dieser Thematik eher verhalten. Ein Forschungsprojekt zur NS-Geschichte des Salzburger Museums „Haus der Natur“ unter Leitung des Historikers Robert Hoffmann mündete 2014 in einer Ausstellung - die angekündigte Publikation steht indessen noch aus. ${ }^{25}$ Im Rahmen der Aufarbeitung der Geschichte des

19 Scholz, Dieter u. Maria Obenaus für die Nationalgalerie, Staatliche Museen zu Berlin (Hg.): Die schwarzen Jahre. Geschichten einer Sammlung 1933-1945, Berlin 2015.

20 Saalmann, Timo: Kunstpolitik der Berliner Museen 1919-1959, Schriften zur modernen Kunsthistoriographie, Bd. 6, hg. v. Anne-Marie Bonnet, Olaf Peters u. Barbara Schellewald, Berlin 2014.

21 Löw, Luitgard Sofie u. Matthias Nuding (Hg.): Zwischen Kulturgeschichte und Politik. Das Germanische Nationalmuseum in der Weimarer Republik und der Zeit des Nationalsozialismus, Nürnberg 2014.

22 Vgl. Schawe, Martin: Vor 50 Jahren - Die Bayerischen Staatsgemäldesammlungen im Zweiten Weltkrieg, in: Bayerische Staatsgemäldesammlungen. Jahresbericht 1994, S. 9-27; Semff, Michael (Hg.): Künstler zeichnen - Sammler stiften. 250 Jahre Staatliche Graphische Sammlung München, Bd. 3, Ostfildern 2008.

23 Baensch, Tanja, Kristina Kratz-Kessemeier u. Dorothee Wimmer (Hg.): Museen im Nationalsozialismus. Akteure - Orte - Politik, Köln/Weimar/Wien 2016.

24 Teschler-Nicola, Maria u. Margit Berner: Die Anthropologische Abteilung des Naturhistorischen Museums in der NS-Zeit: Berichte und Dokumentation von Forschungs- und Sammlungsaktivitäten, in: Senatsprojekt der Universität Wien. Untersuchungen zur anatomischen Wissenschaft in Wien 1938-1945. Wien 1998, S. 333-358.

25 Die Publikation soll unter dem Titel „Ein Museum zwischen Innovation und Ideologie. Das Salzburger ,Haus der Natur' in der Ära von Eduard Paul Tratz, 1913-1976“ erscheinen und den Aufsatz „Ein Museum für Himmler? Das Haus der Natur 1939-1945“ von Robert Hoffmann enthalten. Für einen Auszug aus dem Manuskript dankt die Autorin Robert Hoffmann. 
Naturhistorischen Museums in Hamburg widmete sich Susanne Köstering 2018 auch der NS-Zeit. ${ }^{26}$

Die Situation der europäischen Kunstmuseen im Zweiten Weltkrieg wird ebenfalls erforscht. Sowohl der Exodus der National Gallery London als auch des Louvre in Paris und des Prado in Madrid wurden in den vergangenen Jahren in Publikationen umfangreich beschrieben, als Autoren sind u. a. Suzanne Bosman und Arturo Colorado Castellary zu nennen. ${ }^{27}$ Tagungen zur Situation von $\mathrm{Mu}-$ seen im Krieg aus historischer und zeitaktueller Perspektive fanden zuletzt 2018 in London und 2019 in Madrid statt. ${ }^{28}$

Als Beispiel für die Aufarbeitung der NS-Vergangenheit anderer geisteswissenschaftlicher Fächer, die im Rahmen der Dresdner Staatlichen Sammlungen relevant waren, sei die Ethnologie genannt. Vertreter dieses Faches setzen sich seit 1995 mit diesem Thema auseinander. ${ }^{29}$ Ingrid Kreide-Damiani widmete sich in ihrer Studie „Ethnologie im Nationalsozialismus“ 2010 u. a. der Karriere von Martin Heydrich in Dresden und Köln. ${ }^{30}$

Die Sächsische bzw. Dresdner Zeitgeschichte in der NS-Zeit steht seit Ende der 1990er-Jahre im Fokus. Mit „Dresden unterm Hakenkreuz“ setzte sich aus Historikersicht eine 1998 von Reiner Pommerin edierte Aufsatzsammlung auseinander. ${ }^{31}$ Bezüglich der Analyse von Verwaltung und Politik sowie deren Vertreter ist auf die zahlreichen Publikationen der vergangenen 15 Jahre insbesondere von Clemens Vollnhals, Mike Schmeitzner und Andreas Wagner zu verweisen. ${ }^{32}$

26 Köstering, Susanne: Ein Museum für Weltnatur. Die Geschichte des Naturhistorischen Museums in Hamburg, Abhandlungen des Naturwissenschaftlichen Vereins Hamburg, N. F., Bd. 46, Hamburg 2018.

27 Vgl. Bosman, Suzanne: The National Gallery in Wartime, London 2008; Musée du Louvre (Hg.): Le Louvre pendant la guerre. Regards photographiques 1938-1947, Ausstellungskatalog, Paris 2009; Colorado Castellary, Arturo: Arte, revancha y propaganda. La instrumentalización franquista del patrimonio durante la Segunda Guerra Mundial, Madrid 2018.

28 „Museums, Collections \& Conflicts, 1500-2010“, Museums and Galleries History Group, London 2018 und „Museo, guerra y posguerra. Protección del patrimonio en los conflictos bélicos“, Museo del Prado, Madrid 2019. Die Publikation der Vorträge ist in Vorbereitung.

29 Vgl. Hauschild, Thomas (Hg.): Lebenslust und Fremdenfurcht. Ethnologie im Dritten Reich, Frankfurt/M., 1995. Zu anderen Fächern siehe auch Hausmann 2002.

30 Kreide-Damani, Ingrid (Hg.): Ethnologie im Nationalsozialismus. Julius Lips und die Geschichte der „Völkerkunde“, Wiesbaden 2010.

31 Pommerin, Reiner (Hg.): Dresden unterm Hakenkreuz, Köln/Weimar/Wien 1998.

32 Vollnhals, Clemens (Hg.): Sachsen in der NS-Zeit, Leipzig 2002; Wagner, Andreas: „Machtergreifung" in Sachsen. NSDAP und staatliche Verwaltung 1930-1935, Köln 2004; Schmeitzner, Mike u. Andreas Wagner (Hg.): Von Macht und Ohnmacht. Sächsische Ministerpräsidenten im Zeitalter der Extreme 1919-1952, Beucha 2006; Wagner, Andreas: Martin Mutschmann. Der braune Gaufürst (1935-45), in: Schmeitzner/Wagner 2006, S. 279-308. 
Der Sammelband „Braune Karrieren“33 zeichnete 2012 den Werdegang von über 50 Personen aus Justiz, Medizin, Wirtschaft, Wissenschaft und Kunst nach und porträtierte Dresden als eine wichtige Gauhauptstadt im „Dritten Reich“. In umfangreichen Einzelstudien wurden das Dresdner Theaterleben im Nationalsozialismus wie auch die spezifische Situation der bildenden Künstler analysiert. ${ }^{34}$ Zur Dresdner Ausstellung „Entartete Kunst“ publizierten nach Christoph Zuschlag auch Lupfer und Rudert; der Dresdner Geschichtsverein widmete ihr 2004 ein „Dresdner Heft“. .35

Publikationen der SKD und ihrer Mitarbeiterinnen und Mitarbeiter, die sich mit einzelnen Aspekten der NS-Zeit beschäftigten, thematisierten mehrfach den NS-Kunstraub und die Provenienzforschung in ihren vielen Facetten. ${ }^{36}$ Dies spiegelte auch die Ausstellung „Kunstbesitz Kunstverlust. Objekte und ihre Her-

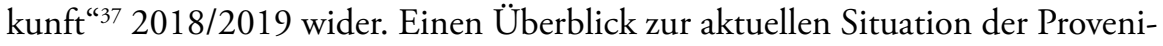
enzforschung in Sachsen gibt Elisabeth Geldmacher in ihrer 2019 publizierten Masterarbeit. ${ }^{38}$

33 Pieper, Christine, Schmeitzner, Mike u. Gerhard Naser (Hg.): Braune Karrieren. Dresdner Täter und Akteure im Nationalsozialismus, Dresden 2012.

34 Vgl. Schneider, Hansjörg: Dresdner Theater 1933-1945. „Spiel war die Lust und Spiel die Gefahr“, Berlin 2003; Müller-Kelwing, Karin: „Die Dresdner Sezession 1932“ - Eine Künstlergruppe im Spannungsfeld von Kunst und Politik, Hildesheim u. a. 2010 (Zugl. Dresden, Univ., Diss., 2008).

35 Vgl. Zuschlag, Christoph: „Entartete Kunst“. Ausstellungsstrategien in Nazi-Deutschland, Worms 1995 (Heidelberger Kunstgeschichtliche Abhandlungen, N. F., Bd. 21) (Zugl. Heidelberg, Univ., Diss., 1991). Vgl. Rudert 2015b, S. 130-136; Lupfer, Gilbert: Die Staatlichen Sammlungen für Kunst und Wissenschaft von 1918 bis 1945. Fürstenabfindung und 2. Weltkrieg, in: Dresdner Geschichtsverein e. V. (Hg.): Die Dresdner Kunstsammlungen in fünf Jahrhunderten, Dresdner Hefte, Sonderausgabe 2004, S. 71-83; Zuschlag, Christoph: Hans Posse und die „Entartete Kunst“, in: Lupfer/Rudert 2015, S. 319-328; ders.: Neues Rathaus Dresden: Die Ausstellung „Entartete Kunst“ 1933, in: Hermann, Konstantin (Hg.): Führerschule, Thingplatz, „Judenhaus“. Orte und Gebäude der nationalsozialistischen Diktatur in Sachsen, Dresden 2014, S. 154-158 sowie Dresdener Geschichtsverein e. V. (Hg.): Die Ausstellung „Entartete Kunst“ und der Beginn der NS-Kulturbarbarei in Dresden, Dresdner Hefte. Beiträge zur Kulturgeschichte, 22. Jg., H. 77, 1/2004.

36 Vgl. Themenheft: Provenienzforschung, Dresdener Kunstblätter, 56. Jg., H. 2, 2012; Müller, Claudia Maria u. Carina Merseburger: Provenienzforschung an den Staatlichen Kunstsammlungen Dresden. Visualisierung und Vermittlung, in: Provenienz \& Forschung, H. 1, 2018, S. 52-58.

37 Staatliche Kunstsammlungen Dresden, Abteilung Forschung und wissenschaftliche Kooperation und Daphne-Projekt (Hg.): Kunstbesitz Kunstverlust. Objekte und ihre Herkunft, Dresden 2018. Auf ausführliche Erläuterungen zum Forschungsstand zu Provenienzforschung und NS-Kunstraub wird aus Platzgründen verzichtet.

38 Geldmacher, Elisabeth: NS-Raubgut. Zum Stand der Provenienzforschung in Sachsen, Ohorn 2019. 
Zur Geschichte der Dresdner Museen im Zweiten Weltkrieg und der Auslagerung ihrer Kunst- und Kulturschätze wurde seit etwa 2004 mehrfach publiziert. Lupfer und Christine Nagel, aber auch Petra Martin schrieben über die Staatlichen Sammlungen im Zweiten Weltkrieg. ${ }^{39}$ Diese Aufsätze widmeten sich primär den Objekten und ihrem Schutz, erwähnten aber gleichfalls einige Akteure, wie z. B. Fritz Fichtner. Die Bergung der Staatlichen Sammlungen thematisierten u. a. Rudert, Nagel, Roland Enke und Alexander Hänel. ${ }^{40}$ Über die NS-Histoire des Münzkabinetts schrieb Emanuele Sbardella. ${ }^{41}$

Jan-Michael Lange und Ellen Kühne widmeten sich 2006 in der „Geschichte des Museums für Mineralogie und Geologie “42 auch den Jahren zwischen 1933 und 1945. Ein Sammelband über die Zoologischen Sammlungen in Deutschland von 2018 geht hingegen nur kurz auf die Geschichte des Dresdner Museums für Tierkunde ein. ${ }^{43}$

Im Rahmen eines von der DFG geförderten Projektes erforschten Judith Schachtmann und Thomas Widera die Institutions- und Wissenschaftsgeschichte der Archäologie in Sachsen. Daraus gingen zahlreiche Publikationen hervor, u. a. über die archäologischen Ausstellungen in Dresden, über Heinz Amberger und

39 Vgl. Lupfer 2004a; ders. u. Christine Nagel: Die Staatlichen Kunstsammlungen für Kunst und Wissenschaft im Zweiten Weltkrieg, in: Schölnberger, Pia u. Sabine Loitfellner: Bergung von Kulturgut im Nationalsozialismus. Mythen - Hintergründe - Auswirkungen, Köln/Weimar/Wien 2016, S. 271-286; Martin, Petra: Ein dunkles Kapitel mit weitreichenden Folgen. Das Dresdener Völkerkundemuseum von 1939 bis 1957, in: Kunst im Krieg, Dresdener Kunstblätter, H. 3, 2015, S. 30-43.

40 Vgl. Rudert, Thomas: Die kriegsbedingte Bergung der Kunstwerke aus der Staatlichen Gemäldegalerie Dresden ab August 1939; Nagel, Christine: Kriegsbedingte Auslagerungen des Grünen Gewölbes und des Historischen Museums, beide in: Kunst im Krieg 1939-1945, Dresdener Kunstblätter, H. 3, 2015, S. 5-17, 18-29; Enke, Roland: Schloss Weesenstein als Auslagerungsort für die Werke der Dresdner Gemäldegalerie; Hänel, Alexander: Die Auslagerung von Kunst- und Kulturgütern in die Burgen und Schlösser Sachsens, beide in: Staatliche Schlösser, Burgen und Gärten Sachsen (Hg.): Bombensicher! Kunstversteck Weesenstein 1945, Dresden 2018, S. 61-74, 33-43.

41 Vgl. Sbardella, Emanuele: Das Dresdener Münzkabinett im Nationalsozialismus, in: Dresdener Kunstblätter, 63. Jg., H. 2, 2019, S. 48-55.

42 Lange, Jan-Michael u. Ellen Kühne (Hg.): Geschichte des Museums für Mineralogie und Geologie in den Staatlichen Naturhistorischen Sammlungen Dresden. Von der kurfürstlichen Kunstkammer zum staatlichen Forschungsmuseum, Dresden 2006.

43 Fritz, Uwe, Raffael Ernst u. Uwe Kallweit u. a.: The Senckenberg Natural History Collections Dresden, in: Beck, Lothar A. (Hg.): Zoological Collections of Germany. The Animal Kingdom in its Amazing Plenty at Museums and Universities, Cham 2018, S. 341-354, hier: S. $343-$ 344. 
Walter Kersten. ${ }^{44}$ Vorausgegangen war diesem Projekt eine Tagung zur Rolle der Prähistoriker im Nationalsozialismus, deren Beiträge 2009 publiziert wurden. ${ }^{45}$

In den späten 1980er-Jahren wuchs das wissenschaftliche Interesse an „Bibliotheken im Nationalsozialismus", aber ähnlich wie in den Museen führte erst die Frage nach dem Umgang mit NS-Raubgut zu einer intensiven Beschäftigung mit diesem Thema. In der Sächsischen Landesbibliothek - Staats- und Universitätsbibliothek Dresden (SLUB) stellt man sich der Aufarbeitung der Bibliotheksgeschichte in der NS-Zeit seit Beginn der 2000er-Jahre. ${ }^{46}$ Die Forschung mündete 2006 in einem Aufsatz von Thomas Bürger zum 450-jährigen Jubiläum der Bibliothek und im SLUB-Lexikon sowie in den 2009 von Konstantin Hermann veröffentlichten Aufsätzen. ${ }^{47}$ Zahlreiche Biografien der wissenschaftlichen Bibliothekare fanden Eingang in das Onlinelexikon „Sächsische Biografie“ des Instituts für Sächsische Geschichte und Volkskunde der Technischen Universität Dresden, ${ }^{48}$ als Autoren hervorzuheben sind Konstantin Hermann und Katrin Nitzschke.

\footnotetext{
44 Vgl. Schachtmann, Judith u. Thomas Widera: Von der Prähistorischen Sammlung zum Sächsischen Landesmuseum für Vorgeschichte - Überlegung zur Museumspolitik, in: Jahrbuch der Staatlichen Kunstsammlungen Dresden, Bd. 36, 2010, Dresden 2012, S. 132-140; Schachtmann, Judith: Heinz Amberger (1907-1974) und die archäologischen Ausstellungen des Dresdner Museums für Vorgeschichte zwischen 1935 und 1938, in: Archaeo. Archäologie in Sachsen, Bd. 12, 2015, S. 44-49; Schachtmann, Judith u. Thomas Widera: Wissenschaftler und Nationalsozialist. Der Vorgeschichtler Walter Kersten (1907-1944) in Sachsen, in: Archaeo. Die Archäologie der Kriege. Die Burgen von Hohburg in der Hohburger Schweiz, Bd. 10, 2013, S. 30-36.

45 Schachtmann, Judith, Michael Strobel u. Thomas Widera (Hg.): Politik und Wissenschaft in der prähistorischen Archäologie. Perspektiven aus Sachsen, Böhmen und Schlesien, Berichte und Studien 56, Göttingen 2009.

46 Vgl. Koch, Christine: Das Bibliothekswesen im Nationalsozialismus. Eine Forschungsstandanalyse, Marburg 2003; Knoche, Michael u. Wolfgang Schmitz (Hg.): Wissenschaftliche Bibliothekare im Nationalsozialismus. Handlungsspielräume, Kontinuitäten, Deutungsmuster, Wolfenbütteler Schriften zur Geschichte des Buchwesens, Bd. 46, Wiesbaden 2011.

47 Vgl. Bürger, Thomas: Wandel und Kontinuität in 450 Jahren. Von der kurfürstlichen Liberey zur Sächsischen Landesbibliothek - Staats- und Universitätsbibliothek Dresden, in: Wissenschaftliche Zeitschrift der Technischen Universität Dresden, 55, 2006, 1-2, S. 29-36, https:// nbn-resolving.org/urn:nbn:de:bsz:14-ds-1204804136305-26740, Zugriff: 6.12.2019; Bürger, Thomas u. Konstantin Hermann (Hg.): Das ABC der SLUB. Lexikon der Sächsischen Landesbibliothek - Staats- und Universitätsbibliothek Dresden, Dresden 2006; Hermann, Konstantin: Die sächsische Landesbibliothek in der nationalsozialistischen Zeit, in: Neues Archiv für sächsische Geschichte, 80, 2009, S. 277-290; Hermann, Konstantin: Die sächsische Landesbibliothek 1933-1945. Martin Bollert und Hermann Neubert - zwei Epochen in zwölf Jahren?, in: Knoche/ Schmitz 2011, S. 289-308.

48 Institut für Sächsische Geschichte und Volkskunde e. V. (Hg.): Sächsische Biografie, Bearb. v. Martina Schattkowsky, Online-Ausgabe: http://saebi.isgv.de/, Zugriff: 2.1.2020.
} 
Zeitzeugenberichte sind überliefert in den Lebenserinnerungen des Bibliothekars Helmut Deckert, in den Tagebüchern des Dresdner Romanisten Victor Klemperer sowie in den posthum publizierten Erinnerungen der in der Skulpturensammlung tätigen Ragna Enking. ${ }^{49}$

Biografische Einzelstudien über die in den Staatlichen Sammlungen beschäftigten Wissenschaftler finden sich unter anderem im 2003 publizierten Professorenlexikon der Technischen Universität Dresden. ${ }^{50}$ Aus Platzgründen werden andere einschlägige monografische Publikationen, wie Aufsätze und Nachrufe, nicht an dieser Stelle verzeichnet. Sie sind in den Quellenangaben der einzelnen Biografien sowie im Literaturverzeichnis notiert.

Infolge des immensen Projektumfanges - es galt allein die Biografien von 90 Protagonisten zu erforschen - und den Überschneidungen von Forschungsgebieten, können in der vorliegenden Publikation manche Themen nicht ausführlich behandelt werden. Dies betrifft insbesondere alle mit den Objekten in Zusammenhang stehenden Themen, die im Kontext der Provenienzforschung thematisiert werden und wurden: das Erweitern der Sammlungsbestände durch Ankäufe, Schenkungen oder Integration von NS-Raubgut wie z. B. durch Beschlagnahmung privater Sammlungen ebenso wie die Reduzierung der Bestände durch Abgaben oder Beschlagnahmung von „Entarteter Kunst“. Die kriegsbedingten Auslagerungen werden ebenfalls nicht detailliert wiedergegeben, sondern nur allgemein erwähnt, da diesbezüglich mehrere Publikationen vorliegen. Auch die in den Staatlichen Sammlungen arbeitenden Kriegsgefangenen und wolhyniendeutschen Aussiedler bleiben in dieser Studie unberücksichtigt, da sie nicht zum wissenschaftlichen Personal zählten. ${ }^{51}$ Die Bedeutung dieser Themen soll dadurch keineswegs missachtet werden.

49 Vgl. Deckert, Helmut: Bibliothekar aus Leidenschaft, Lebens- und Bibliothekserinnerungen (Typoskript), 4 Bde., 1987, SLUB, Mscr.Dresd.App.2600,A1; Victor Klemperer. Ich will Zeugnis ablegen bis zum Letzten. Tagebücher 1933-1945, hg. von Walter Nowojski, überarbeitete Neuausgabe, 2 Bde., Berlin 2015; Enking, Ragna: Dresden im Mai 1945. Ein Bericht, in: Die Dresdner Kunstsammlungen in fünf Jahrhunderten, 2004, S. 84-92; dies.: Die Dresdner Kunstsammlungen gegen Ende des Zweiten Weltkrieges, aus: Georga. Zwei Welten, in: Kolb, Karin u. Staatliche Kunstsammlungen Dresden (Hg.): Zukunft seit 1560, Bd. 3, Berlin 2010, S. 206-214. 50 Petschel, Dorit: 175 Jahre TU Dresden. Band 3: Die Professoren der TU Dresden 18282003. Hg. im Auftrag der Gesellschaft von Freunden und Förderern der TU Dresden e. V. von Reiner Pommerin, Köln u. a. 2003.

51 Sie wurden u. a. bei Ausgrabungen an der Heidenschanze Dresden-Coschütz und für Transportarbeiten im Rahmen der kriegsbedingten Auslagerung im Historischen Museum eingesetzt. Vgl. Jünger, Konstanze u. Judith Schachtmann: „Eine 3000 Jahre alte Stadt“. Die Ausgrabungen auf der Heidenschanze von Dresden-Coschütz und ihre Darstellung in der Öffentlichkeit, in: Arbeits- und Forschungsberichte zur sächsischen Bodendenkmalpflege, Bd. 21, 2010, S. 27-35, hier: 32-34; Nagel 2015, S. 26. 


\section{Quellenlage}

Die Quellenlage für dieses Forschungsprojekt erwies sich als äußerst heterogen. Die Aktenüberlieferung ist unterschiedlich, im Allgemeinen für die Kriegsjahre geringer als für die Jahre 1933 bis 1938. Die Zerstörung der Stadt durch Luftangriffe der Alliierten wenige Monate vor und der Abtransport von Kunstwerken, Bibliotheken sowie Archivalien in die Sowjetunion nach Kriegsende führten zu erheblichen Verlusten der Überlieferung. Dies betrifft sowohl die Personalakten aus der NS-Zeit als auch die sammlungsrelevanten Akten. Dieser Situation und den späteren Trägerwechseln der Institutionen geschuldet befinden sich die entsprechenden Archivalien heute im Wesentlichen an drei Stellen: im Sächsischen Staatsarchiv, Hauptstaatsarchiv Dresden (Hauptstaatsarchiv Dresden bzw. HStA Dresden), im Archiv der SKD und in der SLUB. ${ }^{52}$

Eine wesentliche Quelle bilden die zahlreichen Personalakten der ehemaligen Mitarbeiterinnen und Mitarbeiter der Staatlichen Sammlungen, die im Hauptstaatsarchiv Dresden und zum Teil in der SLUB überliefert sind. Sie enthalten in vielen Fällen jene Personalbögen, die im NS-Staat im Rahmen der Durchführung des "Gesetzes zur Wiederherstellung des Berufsbeamtentums“ angelegt worden sind. Jedoch sind nicht alle Personalakten überliefert und die vorhandenen nicht in jedem Falle lückenlos. ${ }^{53} \mathrm{Da}$ auch nach der Sichtung dieser Akten nur von etwa der Hälfte der Personen die Geburts- und Sterbedaten und -orte bekannt waren, wurden ergänzend bei Standesämtern und Stadtarchiven die Einträge in Personenstandsregistern abgefragt. In vielen Fällen konnten dadurch die Lebensdaten korrigiert bzw. ergänzt werden.

Dienstakten der einzelnen Institutionen der Staatlichen Sammlungen verwahren sowohl das Hauptstaatsarchiv Dresden als auch das Archiv der SKD. Im SKD-Archiv wurden insbesondere die Bestände der Porzellansammlung, des Kunstgewerbemuseums, des Kupferstich-Kabinetts und der Skulpturensammlung sowie die sogenannten Vorakten genutzt. Weitere sammlungsbezogene Unterlagen konnten in den SKD im Münzkabinett und im Mathematisch-Physikalischen Salon eingesehen werden. Wichtige Informationsquellen sind die "Jahresberichte der Staatlichen Sammlungen für Kunst und Wissenschaft zu Dresden“ der Jahre 1933 bis 1945, die jedoch nur noch für die Jahre bis 1937

\footnotetext{
Für die einzelnen Signaturen siehe Quellenverzeichnis, ab S. 491.

53 Dabei gibt es auch Widersprüchliches. So schrieb Arthur Leuschner im November 1945 an Wolfgang Balzer, dass Fritz Fichtner die Personalakten der Porzellansammlung verbrannt habe, die Personalakten von Fichtner und Leuschner sind jedoch im Hauptstaatsarchiv Dresden überliefert (HStA Dresden, 13859, Nr. 1553, Nr. 1960, Nr. 4970). Vgl. Leuschner an Kunstgewerbemuseum, Balzer, 12.11.1945, SKD Archiv, 02/VA 41, Bd. 2, fol. 225.
} 
publiziert wurden. ${ }^{54}$ Die Einzelberichte der Sammlungen wie auch die entsprechenden Zusammenfassungen für alle Sammlungen sind bis 1945 in diversen Einzelakten, wiederum im Archiv der SKD und im Hauptstaatsarchiv Dresden, erhalten. ${ }^{55}$ Letzteres verwahrt in den Aktenbeständen des Sächsischen Ministeriums des Kultus und Öffentlichen Unterrichts ebenfalls Unterlagen einzelner Sammlungen wie Gemäldegalerie, Kunstgewerbemuseum, Kupferstich-Kabinett, Museum für Völkerkunde, Münzkabinett, Porzellansammlung etc., sowie sammlungsrelevante Archivalien in den Beständen des Ministeriums des Innern, des Ministeriums der Finanzen und der Staatskanzlei.

Auch die früheren Dienstakten aus dem Museum für Tierkunde und dem Museum für Mineralogie, Geologie und Vorgeschichte befinden sich im Hauptstaatsarchiv Dresden. Im Gegensatz zu Aktenbeständen der kunst- und kulturhistorischen Sammlungen sind sie nicht tiefenerschlossen - wodurch die Einsicht der personalrelevanten Akten zur Herausforderung wurde. Besonders schwierig ist die Quellenlage bezüglich des Sächsischen Armeemuseums, von dem aus der NS-Zeit lediglich ein schmales Konvolut im Hauptstaatsarchiv Dresden und Einzelblätter im Bundesarchiv Berlin überliefert sind; Personalakten zu Ernst von Koerner waren nicht auffindbar. Auch das Bibliotheksarchiv der SLUB weist für die NS-Zeit große Lücken auf. ${ }^{56}$

Der Schriftwechsel der einzelnen Sammlungsdirektoren mit ihrer vorgesetzten Behörde, dem Sächsischen Ministerium für Volksbildung bzw. dessen Referat für die Staatlichen Sammlungen, ist für den Zeitraum von 1933 bis 1945 unvollständig überliefert. Er ist nicht als Konvolut erhalten, sondern vielmehr in Einzeldokumenten in den Sammlungsakten zu finden. Das umfangreiche Berichtswesen im NS-Staat produzierte infolge des „Führerprinzips“ eine Vielzahl von Dokumenten und Abschriften von diesen. Jede schriftliche Dienstanweisung zog einen Bericht über deren Umsetzung nach sich. Die zentralistische Verwaltungsstruktur der Staatlichen Sammlungen führte dazu, dass die entsprechenden Dokumente in jede Sammlung gesendet wurden. Dadurch sind trotz der kriegsbedingten Verluste einige der Dokumente in den Archivalien der einen oder anderen Sammlung erhalten. Ihr Auffinden erforderte eine detektivische Arbeit, denn nur selten wurden die in einem Sachzusammenhang stehenden Dokumente gemeinsam überliefert. So konnte die Beauftragung von Alfred Beck mit

\footnotetext{
54 Berichte über die Verwaltung der Staatlichen Sammlungen für Kunst und Wissenschaft zu Dresden 1929-1937, Dresden o. J. (1940).

55 Vgl. Jahresberichte der Staatlichen Sammlungen, HStA Dresden, 11125, Nr. 19003; Nr. 19028 u. Nr. 23053 sowie 13842, Nr. 115.

56 Vgl. Hermann 2011, S. 291.
} 
der stellvertretenden Verwaltung des Mathematisch-Physikalischen Salons 1942 durch ein bei den Unterlagen des Münzkabinetts befindliches Dokument belegt werden. ${ }^{57}$ Auch lassen sich einige der Verwaltungsvorgänge heute nur noch durch Einträge in den Registranden nachweisen.

Diverse Personennachlässe und -teilnachlässe von unterschiedlichem Umfang und Inhalt sind überliefert: In der SLUB die Nachlässe von Wolgang Balzer, Martin Bollert, Helmut Deckert, Otto Fiebiger, Erich Haenel, Hans Hofmann und Ewald Jammers, im Hauptstaatsarchiv Dresden die Nachlässe von Georg Bierbaum, Kurt Zoege von Manteuffel und der Familie von Watzdorf und im Museum für Völkerkunde der äußerst umfangreiche Nachlass von Bernhard Struck.

Weitere für das Projekt relevante Aktenbestände verwahrt das Bundesarchiv Berlin. Dort wurden anhand der NSDAP-Zentralkartei und NSDAP-Gaukartei sowie mittels der Bestände der Sammlung Berlin Document Center die Mitgliedschaften in der NSDAP, SS, SA und anderer NS-Organisationen überprüft. Personenbezogene Überlieferungen befinden sich in den Beständen der SS-Forschungs- und Lehrgemeinschaft „Das Ahnenerbe“ und des Nationalsozialistischen Lehrerbundes wie auch des Reichsministeriums für Wissenschaft, Erziehung und Volksbildung und des Reichsministeriums für Volksaufklärung und Propaganda. Darüber hinaus wurden Akten der Deutschen Forschungsgemeinschaft aus der NS-Zeit konsultiert. Im Bestand Kurator der deutschen wissenschaftlichen Hochschulen in Wien sind Unterlagen zum Wechsel von Hans Kummerlöwe von Dresden nach Wien überliefert.

Im Zentralarchiv der Staatlichen Museen zu Berlin wurden die Akten des Deutschen Museumsbundes gesichtet, um die Mitgliedschaften und das Engagement der Dresdner Museumsbeamten zu eruieren. Darüber hinaus verwahrt das Archiv Korrespondenz von Peter Halm, Karl Wilhelm Jähnig, Robert Oertel und Bernhard Struck mit Berliner Wissenschaftlern.

Archivalien, die das Berufsleben eines der Hauptprotagonisten, Fritz Fichtner, nach 1945 dokumentieren, bewahren das Universitätsarchiv der OttoFriedrich-Universität Bamberg, das Universitätsarchiv der Friedrich-Alexander-Universität Erlangen-Nürnberg und das Bayerische Hauptstaatsarchiv München.

Ebenfalls eine wichtige Quelle stellen die zeitgenössischen Periodika dar, d.h. die von 1933 bis 1945 erscheinenden Tageszeitungen, Zeitschriften und Fachmagazine. Da sie trotz „Gleichschaltung“ der Presse im NS- Staat Auskunft über

Vgl. Leiter Sächsisches Ministerium für Volksbildung (SMV), Göpfert, an Direktoren der Staatlichen Sammlungen, 11.12.1942, SKD, MK, 1942-1945, fol. 137. 
Ereignisse in Dresden wie auch über die Außenwahrnehmung der fachlichen Arbeit der Staatlichen Sammlungen, z. B. über ihre Ausstellungstätigkeit, geben, wurden vor allem die in Dresden erscheinenden Tageszeitungen systematisch ausgewertet.

Bilddokumente sind aus den Jahren zwischen 1933 und 1945 nur wenige überliefert. Dies gilt sowohl für Porträtaufnahmen, die zumeist aus den Personalakten stammen, als auch für Fotografien, die Einblicke in die Schausammlungen und Sonderausstellungen gewähren. Aufgrund der Bedeutung dieser meist einzigen Fotografien als historische Dokumente werden sie trotz manch qualitativer Einschränkungen abgebildet.

Infolge des immensen Projektumfanges und des Fehlens mehrerer Personalunterlagen musste in einigen Fällen auf Sekundärliteratur zurückgegriffen werden. Im Falle von Hans Posse und Hermann Voss geschah dies aufgrund der bereits erwähnten, seit Jahren vorhandenen, fundierten Forschung. In anderen Fällen, wie z. B. bei Walter Grünberg und Otto Kleemann, bildeten Nachrufe die einzige Informationsquelle für biografische Informationen. Da sie im Allgemeinen Etiketten folgen und oft unkritisch nur positive Details aufführen, wurden sie einer kritischen Lektüre unterzogen.

Zeitzeugeninterviews konnten aufgrund des historischen Abstandes zum Untersuchungsgegenstand nur noch mit Vertretern der nachfolgenden Generationen der Kinder und Enkel geführt werden. Die Gespräche wurden stichpunktartig protokolliert. Die Erkenntnisse aus den bisweilen anekdotischen Erzählungen wurden stets hinterfragt und quellenkritisch überprüft.

\section{Dank}

Besondere, emotional berührende Momente waren mit der Erforschung der Biografien der von den Nationalsozialisten entlassenen jüdischen Mitarbeiterinnen und Mitarbeiter verbunden. Dazu gehört die Entdeckung des Namens von Anna Löwenthal auf der Passagierliste des Dampfers, mit dem sie in die USA emigrierte, wie auch das Lesen der Karteieinträge der Ermordung der Eltern von Lucie Walter. Bei der Suche nach Löwenthal und Walter unterstützten in Washington Marisa Bourgoin von den Archives of American Art, Smithsonian Institution und in Jerusalem Rachel Shapiro vom Reference and Information Service, Yad Vashem, The World Holocaust Remembrance Center. Helmut van Emden, der als kleiner Junge mit seiner Familie nach England emigrieren musste, stellte schriftliche Erinnerungen an seinen Vater, den Zoologen Fritz van Emden, der 1933 von den Nationalsozialisten aus dem Museum für Tierkunde entlassen worden war, zur Verfügung. Herzlichen Dank dafür. 
Nach langer vergeblicher Suche führte vor wenigen Monaten überraschend eine Spur zu der in den Akten nur kurz erwähnten Anneliese Rohne: ein Ausstellungskatalog aus Leipzig von 1955. ${ }^{58}$ Eberhard Patzig, Leiter der Bibliothek und Grafischen Sammlung des Grassi Museum für Angewandte Kunst in Leipzig, konnte weitere Informationen beitragen, so, dass nun eine Biografie der Kunsthistorikerin, die aufgrund von drei Ehen im Laufe ihres Lebens vier verschiedene Nachnamen hatte, in diesem Band enthalten ist. Erwähnung findet sie als Anneliese Hanisch, dem Namen, unter dem sie die längste Zeit lebte und am meisten publizierte.

Außergewöhnlich ist die Entdeckung, dass die Biografien von bisher vermutlich zwei verschiedenen Personen gleichen Namens - ein Bibliothekar und ein Orgelspezialist - nunmehr zu einer zusammengeführt werden können: Ulrich Dähnert. Auch in den Institutionen, für die er vor und nach 1945 arbeitete, ahnte dies niemand. Erst im Dialog mit Katrin Nitzschke, Leiterin des Buchmuseums der SLUB, und Horst Hodick, Orgel- und Glockensachverständiger im Landesamt für Denkmalpflege Sachsen, gelang die Zuordnung.

Wie diese Beispiele zeigen, ist die erfolgreiche Durchführung eines derart umfangreichen Projektes nur mit Hilfe zahlreicher Unterstützer möglich. An vorderster Stelle gebührt mein Dank dem Projektleiter Gilbert Lupfer, Leiter der Abteilung Forschung und wissenschaftliche Kooperation der SKD. Von der Weiterentwicklung der ersten Idee über den gesamten Projektverlauf bis hin zur Buchpublikation stand er als Mentor jederzeit beratend und ermutigend, bisweilen auch kritisch hinterfragend zur Verfügung. Ihm sowie dem Generaldirektor der SKD, Hartwig Fischer, und seiner Nachfolgerin Marion Ackermann, dem Kaufmännischen Direktor Dirk Burghardt sowie allen Direktorinnen und Direktoren sei für den Entschluss, sich als Institution einem solchen Projekt zu stellen, und für das Vertrauen, das mir entgegengebracht wurde, gedankt.

Der Deutschen Forschungsgemeinschaft danke ich für die Förderung des Projektes und der Publikation. Da es sich um Fördermittel aus öffentlicher Hand handelt, sei auch Ihnen, den Lesern und Steuerzahlern, gedankt.

Inspirierend war der monatliche Jour fixe, bei dem gemeinsam mit Gilbert Lupfer, Maria Obenaus und Thomas Rudert Fragestellungen weiterentwickelt und Rechercheergebnisse diskutiert wurden. Für ihren Rat, ihre interessierten Fragen und wohlmeinenden Tipps danke ich ebenso herzlich wie für die geduldige und kritische Durchsicht des Buchmanuskriptes.

58 Rohne, Anneliese: Neuerwerbungen 1950-1955. Museum für Kunsthandwerk im Grassimuseum, Leipzig 1955. 
Den Erfolg des Projektes beförderten ein wunderbares kollegiales Umfeld sowie reibungslose Verwaltungsabläufe. Dafür sei der Abteilung Forschung und wissenschaftliche Kooperation inklusive der Kunstbibliothek ebenso gedankt wie der Verwaltung, insbesondere der Abteilung Rechnungswesen und Controlling, stellvertretend Lisa Klamka und Romy Kraut. Ruth Cruse unterstützte den Aufbau eines projekteigenen Sharepoints, der die Recherchearbeit erheblich erleichterte.

Der systematischen Recherche der zeitgenössischen Presse widmeten sich die studentischen Hilfskräfte des Projektes, insbesondere Fine Kugler und Meike Paula Thar. Sie sichteten geduldig Mikrofilm um Mikrofilm und exzerpierten Hinweise auf das Vermittlungsprogramm. Dafür danke ich herzlich. Die erfassten Daten bilden zugleich die Grundlage für das Ausstellungsverzeichnis.

Mein besonderer Dank gilt Vera Wobad, die im Archiv der SKD geduldig alle gewünschten Archivalien - mehrere laufende Meter - vorlegte, gelegentlich auf andere Quellen verwies und zahlreiche Dokumente digitalisierte. Eine erste vage Projektidee wurde schon 2013 mit dem damaligen Direktor der Porzellansammlung Ulrich Pietsch und der Oberkonservatorin Anette Loesch im Zwinger diskutiert. Beiden danke ich für ihre Ermutigung und uneingeschränkte Unterstützung, nicht nur in der Vor- und Frühphase des Projektes. An dieser Stelle kann allein aus Platzgründen nicht allen Mitarbeiterinnen und Mitarbeitern der SKD, die das Projekt und die Publikation in vielfältiger Weise unterstützten, namentlich gedankt werden - neben den bereits Genannten seien Silvia Dolz und Petra Martin vom Museum für Völkerkunde, Rainer Grund vom Münzkabinett, Michael Korey und Peter Müller vom Mathematisch-Physikalischen Salon, Christine Nagel von der Rüstkammer und Dirk Weber vom Grünen Gewölbe, Olaf Simon vom Kupferstich-Kabinett sowie Barbara Bechter vom Kunstgewerbemuseum stellvertretend erwähnt. Dem Medieninformatiker Martin Zavesky von der Generaldirektion danke ich für die Entwicklung einer nun auf der SKD-Website zur Verfügung stehenden Online-Recherchemöglichkeit zu Mitarbeitern in der NS-Zeit. Die dafür notwendigen Daten erfasste die studentische Hilfskraft Friedrich Wolf.

Explizit gedankt für ihre Unterstützung sei den Direktorinnen und Direktoren sowie den Mitarbeiterinnen und Mitarbeitern der Institutionen, die heutige Nachfolger jener Sammlungen sind, die in der NS-Zeit zu den Staatlichen Sammlungen für Kunst und Wissenschaft zählten: Landesamt für Archäologie Sachsen, Militärhistorisches Museum der Bundeswehr, Senckenberg Naturhistorische Sammlungen Dresden und SLUB.

Von der SLUB seien die Personalabteilung, die Abteilung Handschriften, Alte Drucke und Landeskunde, das Buchmuseum und die Deutsche Fotothek er- 
wähnt, welche die Einsicht in die Personal- und Bibliotheksakten aus der NSZeit ermöglichten, Nachlässe zugänglich machten und Fotomaterial zur Verfügung stellten. Namentlich danke ich Jana Kocourek, Katrin Nitzschke, Martin Munke und Kerstin Schellbach, die bereitwillig Auskunft gaben und Kontakte vermittelten. Von Mitarbeitern der SLUB und des Hannah-Arendt-Instituts für Totalitarismusforschung der Technischen Universität Dresden wurde für das Projekt ein separater Zugang zur Forschungsdatenbank „Der Freiheitskampf ${ }^{\text {“59 }}$ eingerichtet.

Bezüglich des Landesmuseums für Vorgeschichte konnte auf Ergebnisse eines Forschungsprojektes des Landesamtes für Archäologie Sachsen zurückgegriffen werden. ${ }^{60}$ Michael Strobel danke ich für die Überlassung von Bildmaterial, wertvolle Informationen erhielt ich ebenfalls von Judith Schachtmann und Thomas Widera, die beide auch Einblick in bisher unveröffentlichtes Material gewährten.

Für die Bereitstellung von unzähligen Archivalien ist drei weiteren Institutionen zu danken, die einen großen Teil der überlieferten Akten bewahren: Im Sächsischen Staatsarchiv - Hauptstaatsarchiv Dresden standen mir u.a. Uta Bottin, Volker Schubert und Ragna Petrak beratend zur Seite. Petra Winter, Sven Haase und Beate Ebelt-Borchert unterstützten die Recherchen im Zentralarchiv der Staatlichen Museen zu Berlin, während ich wichtige Hinweise auf projektrelevante Bestände im Bundesarchiv Berlin Andrea Frank und Nicolai M. Zimmermann verdanke. Für Unterstützung sei ebenfalls den Mitarbeiterinnen und Mitarbeitern folgender Institutionen gedankt: Archiv des Erzbistums Bamberg, Universitätsarchiv der Otto-Friedrich-Universität Bamberg, Stiftung Sächsische Gedenkstätten - Gedenkstätte Bautzen, Sorbisches Kulturarchiv am Sorbischen Institut in Bautzen, Archiv der Max-Planck-Gesellschaft zur Förderung der Wissenschaften e. V. in Berlin, Landesarchiv Berlin, Universitätsarchiv der Technischen Universität Berlin, Abteilung Handschriften und Rara der Universitätsund Landesbibliothek Bonn, Stadtarchiv und Stadthistorische Bibliothek in Bonn, Zoologisches Forschungsmuseum Alexander König Bonn, Staatsarchiv Bremen, Archiv für deutsche Polarforschung in Bremerhaven, Archiv der Hochschule für Bildende Künste Dresden, Historisches Archiv der Sächsischen Staatstheater in Dresden, Abteilung Handschriften der Universitätsbibliothek der Friedrich-Alexander-Universität Erlangen, Universitätsarchiv der FriedrichAlexander-Universität Erlangen-Nürnberg, Kreisarchiv Erzgebirgskreis, Archiv

\footnotetext{
59 Siehe https://hait.tu-dresden.de/ext/forschung/der-freiheitskampf.asp und https://www. slub-dresden.de/sammlungen/sonstige-spezialbestaende/der-freiheitskampf/, Zugriff: 6.12.2019. 60 Siehe S. $23 \mathrm{f}$.
} 
des Landratsamtes Mittelsachsen in Freiberg, Ehemalige Universitätsbibliothek Helmstedt, Archiv der Philipps-Universität Marburg, Kreisarchiv Meißen, Bayerisches Hauptstaatsarchiv München und Suchdienst des Deutschen Roten Kreuzes in München. Dank gebührt darüber hinaus den Mitarbeiterinnen und Mitarbeitern der Standesämter und Stadtarchive wie auch einzelner Kirchgemeinden in Bad Reichenhall, Bischofswerda, Bochum, Coburg, Dohna, Döbeln, Dresden, Düren, Erlangen, Freiberg, Grimma, Helgoland, Helmstedt, Hohenstein-Ernstthal, Kassel, Lauffen a. Neckar, Oschatz, Radeberg, Radebeul, Radeburg, Rostock, Villingen-Schwenningen, Werdau und Zwickau. Stellvertretend für alle Unterstützer aus diesem Bereich sei Sandra Rother vom Stadtarchiv Dresden genannt, die für dieses Projekt wohl die meisten Personendaten ermittelte.

Für beratende Gespräche und Bereitstellung von Materialien danke ich Maria Teschler-Nicola vom Naturhistorischen Museum Wien sowie Robert Lindner vom Haus der Natur Salzburg und Robert Hoffmann von der Universität Salzburg.

Für ihre Gastfreundschaft und die intensiven Gespräche bzw. den schriftlichen Austausch über ihre Väter bzw. Urgroßväter danke ich Frances und Peter Holzhausen, Hans-Jürgen Holzhausen und Uta Jatzwauk. Letzterer sowie Familie Deckert und Andreas Förster sei für die Überlassung von Fotografien gedankt.

Bei Tagungen in Barcelona, Dresden, London, Madrid, Oldenburg und Thurnau konnte ich bereits Teilergebnisse des Forschungsprojektes zur Diskussion stellen und erfuhr vielseitige Anregungen im Austausch mit Kolleginnen und Kollegen.

Darüber hinaus danke ich an dieser Stelle allen hier aus Platzgründen nicht erwähnten Institutionen und Personen ausdrücklich. Nicht zuletzt sei dem Böhlau Verlag, namentlich Kirsti Doepner, Julia Beenken und Bettina Waringer, für die Zusammenarbeit bei der Entstehung dieses Buches gedankt.

Unterstützung erfuhr ich auch in meinem Freundeskreis, wo ich in zahlreichen Gesprächen die aus den Recherchen gewonnenen Erkenntnisse ordnen und Schlussfolgerungen diskutieren konnte sowie fortwährend Ermutigung fand.

Besonders danke ich meinen Eltern Regine $(\dagger)$ und Peter Müller. Sie gaben mir die Freiheit, Kunstgeschichte zu studieren - aus Leidenschaft für Kunst und Interesse an Geschichte - und stärkten mir den Rücken, auch, als ich in der DDR eigene Erfahrungen mit ideologischer Beeinflussung sammeln musste. Ihnen verdanke ich jene Geduld und Ausdauer, die bei der Recherchearbeit unabdingbar sind. Dankbar bin ich meiner Tochter Rebecca für die gemeinsamen Wochenenden, die für den nötigen Abstand zum Projekt sorgten. Die Erkennt- 
nis, wie die NS-Zeit heute in der Schule vermittelt wird, ist Ansporn, weitere historische Details der Vergessenheit zu entreißen.

Möge dieses biografische Handbuch durch die erstmalige Erschließung umfangreichen personen- und sammlungsbezogenen Archivmaterials einen Beitrag zur weiteren Erforschung der Kontexte von NS-Raubkunst und Provenienzforschung leisten. 


\section{Die Staatlichen Sammlungen für Kunst und Wissenschaft}

\section{Struktur der Staatlichen Sammlungen}

Als am 30. Januar 1933 Reichspräsident Paul von Hindenburg in Berlin Adolf Hitler zum Reichskanzler ernannte, war am Vortag in Dresden im Semperbau am Zwinger der Deutsche Saal der Gemäldegalerie wiedereröffnet worden und die Staatlichen Sammlungen für Kunst und Wissenschaft bereiteten eine ihrer wohl bedeutendsten Ausstellungen der 1930er-Jahre vor: „August der Starke und seine Zeit“. ${ }^{1}$ Niemand ahnte damals, welche weitreichenden Veränderungen die „Machtübernahme" durch die Nationalsozialisten mit sich bringen würde und wie sich diese auf die Kulturinstitutionen auswirken könnten. In Dresden konzentrierten sich die Sammlungsdirektoren und ihre wissenschaftlichen Mitarbeiterinnen und Mitarbeiter indes auf die Ausstellung, mit der sie der Zeit der Sächsischen Kurfürsten, der Kunst und Kultur des Barock huldigen wie auch ihre Wurzeln feiern wollten und die im Sommer 1933 gut 135.000 Besucher anlocken sollte.

Die Staatlichen Sammlungen für Kunst und Wissenschaft gingen nach dem Ersten Weltkrieg aus der im 16. Jahrhundert gegründeten Kunstkammer der sächsischen Kurfürsten, den späteren Königlichen Sammlungen, hervor. ${ }^{2}$ In der Zeit des Nationalsozialismus umfassten sie zwölf bzw. dreizehn unterschiedliche Museen - und zwar sowohl die kunst- bzw. kulturhistorischen als auch die naturhistorischen Sammlungen - sowie die Sächsische Landesbibliothek, die seit 1831 als Königliche Öffentliche Bibliothek zu den Königlichen Sammlungen für Kunst und Wissenschaft zählte.

$\mathrm{Zu}$ den kunst- und kulturhistorischen Sammlungen gehörten neben der Gemäldegalerie und dem Kupferstich-Kabinett auch die Porzellansammlung, die Skulpturensammlung, das Grüne Gewölbe, das Historische Museum sowie das Münzkabinett. Zu den naturkundlichen Sammlungen zählten in der NS-Zeit der Mathematisch-Physikalische Salon, die Museen für Tierkunde und Völkerkunde, die am 1. Januar 1942 in Museen für Tierkunde, Rassenkunde und Völkerkunde umbenannt wurden, sowie das Museum für Mineralogie, Geologie und Vorgeschichte, das zum 1. April 1938 in zwei Museen aufgeteilt wurde:

\footnotetext{
1 Vgl. Haenel, Erich: Der Deutsche Saal der Gemäldegalerie nach seiner Erneuerung, in: Dresdner Neueste Nachrichten (DNN), 29.1.1933, S. 2 und Dresdner Jubiläumssommer 1933, in: Der Freiheitskampf (FK), 28.1.1933, S. 6.

2 Vgl. Lupfer 2004a.
} 
das Museum für Mineralogie und Geologie sowie das Landesmuseum für Vorgeschichte.

Zwei weitere Museen bilden gewissermaßen Ausnahmen - das Kunstgewerbemuseum und das Sächsische Armeemuseum. Als „Lehrmittelsammlung für Lehrer und Schüler der Kunstgewerbeschule ${ }^{\text {“ } 3}$ war das Kunstgewerbemuseum auch noch Anfang der 1930er-Jahre der Kunstgewerbeakademie angegliedert und unterstand wie diese dem Sächsischen Ministerium des Innern. Allerdings fand es ab 1933 als Staatliche Sammlung Erwähnung, weil es der Leiter der Porzellansammlung, $\triangleright$ Fritz Fichtner, seit dem 15. Dezember 1933 in Personalunion mitverwaltete. Doch erst im April 1939 wurde das Kunstgewerbemuseum tatsächlich den Staatlichen Sammlungen zugeordnet. ${ }^{4}$ Das Sächsische Armeemuseum war in der NS-Zeit dem Sächsischen Ministerium für Volksbildung unterstellt und wurde zu den Staatlichen Sammlungen gezählt. ${ }^{5}$ Auf Befehl Hitlers wurde es am 18. Januar 1940 als Heeresmuseum Dresden rückwirkend zum 1. November 1939 in Reichseigentum überführt und dem Chef der Heeresmuseen unterstellt. ${ }^{6}$

\section{Standorte}

Zu Beginn der 1930er-Jahre waren die Staatlichen Sammlungen für Kunst und Wissenschaft in verschiedenen historischen Gebäuden im Stadtzentrum untergebracht. ${ }^{7}$ Das Museum für Mineralogie, Geologie und Vorgeschichte, der Mathe-

\footnotetext{
3 Vgl. Ministerium des Innern, 9.7.1914, HStA Dresden, 11125, Nr. 17971, fol. 131-134, hier: 131.

4 Vgl. Kunstgewerbemuseum, Fichtner, an Berling, 18.04.1939, SKD Archiv, 01/KGM 10, o. Pag. Fichtner schrieb: „Für Ihren Glückwunsch anläßlich der Überführung des Kunstgewerbemuseums in die Verwaltung der übrigen Museen danke ich Ihnen bestens. Es ist damit wieder zurückerobert, was dem Museum 1933 verloren gegangen ist und darüber hinaus eine Vereinheitlichung der Verwaltung herbeigeführt."

5 Siehe Berichte über die Verwaltung ... o. J. (1940), S. 28 f. Zuvor war es dem Ministerium des Innern unterstellt.

6 Vgl. Reichsministerium für Wissenschaft, Erziehung und Volksbildung (RMWEV), Rust, an Reichsminister und Chef der Staatskanzlei, 24.7.1939; Chef der Heeresmuseen an RMWEV, 3.7.1939 (Abschrift) und Reichsminister der Finanzen an den Sächsischen Finanzminister, 18.11.1939, BArch, R 43/II/1236a, fol. 82, 83, 86. Vgl. auch Armeemuseum wird Heeresmuseum, in: DNN, 19.1.1940, S. 4; Armeemuseum jetzt „Heeresmuseum“, in: Dresdner Anzeiger (DA), 19.1.1949, S. 5. Vgl. Lisewski, Eugen u. Hans Mehlhorn: Von der Arsenal-Sammlung zum Armeemuseum Dresden (1897-1945), in: Prittwitz und Gaffron/Militärhistorisches Museum Dresden 1997, S. 9-26, hier: $21 \mathrm{f}$.

7 Vgl. Ministerium für Volksbildung zu Dresden (Hg.): Führer durch die Staatlichen Sammlungen zu Dresden, Dresden 1932. Vgl. auch Kuhlmann-Hodick, Petra: Der Einzug des Kupferstich-Kabinetts in Sempers Galeriegebäude 1856, in: Dresdener Kunstblätter, 4. Jg., H. 1, 2004, S. 31-37.
} 


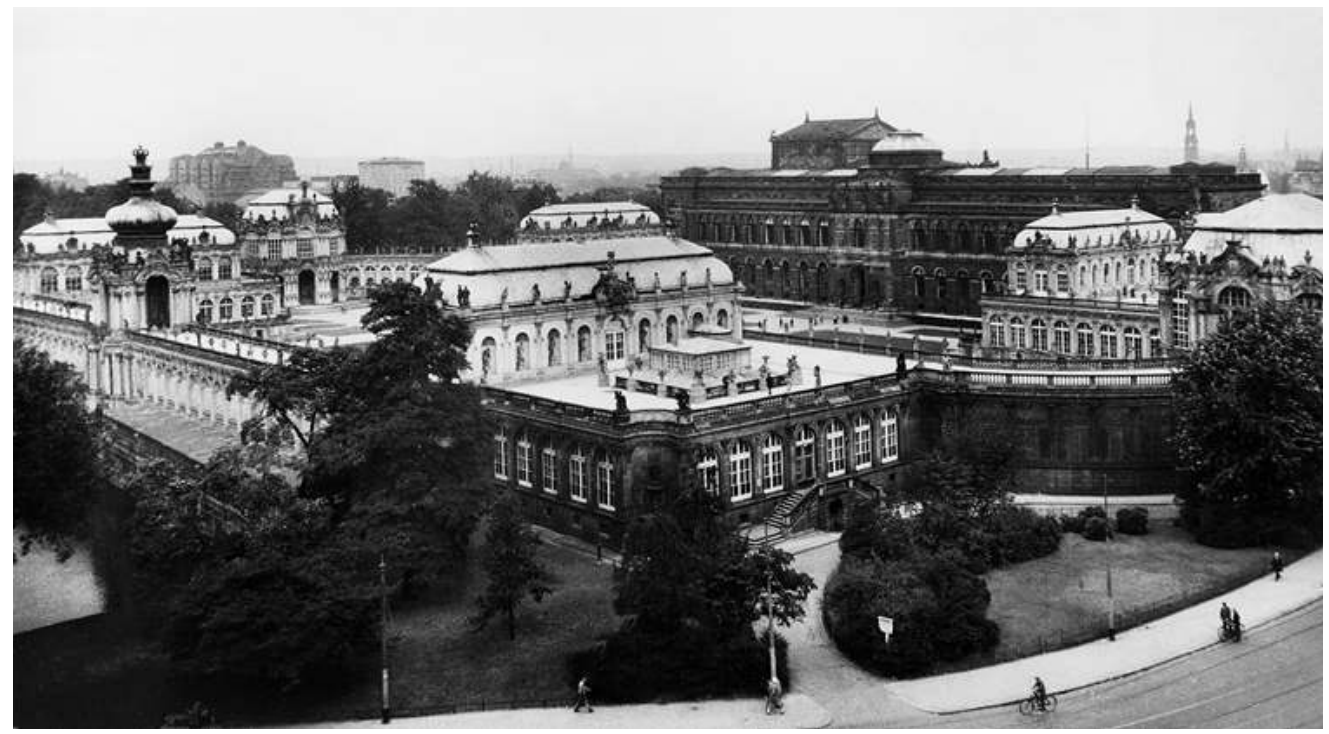

1 Dresden, Blick von der Sophienkirche auf den Zwinger, um 1935

matisch-Physikalische Salon und die Museen für Tierkunde und Völkerkunde befanden sich im aus dem 18. Jahrhundert stammenden Zwinger von Matthäus Daniel Pöppelmann und Balthasar Permoser. Dessen 1855 eröffneter, von Gottfried Semper errichteter Anbau am Theaterplatz beherbergte das KupferstichKabinett und die Gemäldegalerie, die darüber hinaus ab 1932 eine neue Abteilung im Gebäude der Sekundogenitur auf der Brühlschen Terrasse unterhielt, wo die Kunstwerke des 19. Jahrhundert präsentiert wurden. Das Grüne Gewölbe befand sich im Erdgeschoss des Westflügels des Residenzschlosses. Das Johanneum am Neumarkt beherbergte neben dem Historischen Museum mit der Rüstkammer und der Gewehrgalerie auch die Porzellansammlung, von der Teile auch im Turmzimmer im Residenzschloss präsent waren. ${ }^{8}$ Das Münzkabinett befand sich im Erdgeschoss des Kanzleigebäudes im Stallhof, die Skulpturensammlung im Albertinum.

8 Zum Porzellankabinett und dessen Wiedereröffnung 2019 vgl.: Staatliche Kunstsammlungen, Porzellansammlung, Anette Loesch (Hg.): Das Porzellankabinett im Hausmannsturm des Dresdner Residenzschlosses, Dresden 2019 und Loesch, Anette: Vom Silberbuffet zum Porzellankabinett im Hausmannsturm des Dresdener Residenzschlosses, in: Dresdener Kunstblätter, H. 4, 2019, S. 14-23. 
Lediglich der Standort des Kunstgewerbemuseums in der Kunstgewerbeakademie an der Eliasstraße, ab 1938 in Güntzstraße umbenannt, lag knapp zwei Kilometer vom Zwinger und Residenzschloss entfernt am Rande der Pirnaischen Vorstadt, während die Sächsische Landesbibliothek im Japanischen Palais am Neustädter Elbufer untergebracht war, das bereits ab 1786 die kurfürstliche Bibliothek beherbergte. Das Sächsische Armeemuseum hatte sein Domizil in der Albertstadt im Dresdner Norden, etwa vier Kilometer vom Stadtzentrum entfernt, im ehemaligen Arsenalhauptgebäude am damaligen Königsplatz.

Im Allgemeinen waren die Bestände der einzelnen Museen unterteilt in eine Schausammlung und eine Studiensammlung. In den Schausammlungen, die für die Öffentlichkeit zu bestimmten Öffnungszeiten - teils unentgeltlich, teils gegen einen festgesetzten Eintrittspreis - zugänglich waren, wurde jeweils eine Auswahl bedeutender Objekte präsentiert. Die Studiensammlung umfasste hingegen den Großteil der Bestände, der im Depot verwahrt wurde, jedoch auf Anfrage für Fachwissenschaftler zu Studienzwecken zugänglich war.

Die Unterbringung der Sammlungen, insbesondere der naturwissenschaftlichen, wurde aufgrund der Platznot durch die wachsenden Sammlungsbestände und infolge neuer Präsentationsbedürfnisse bereits seit den 1920er-Jahren seitens der Direktoren diskutiert. Diverse Pläne reiften, von denen manche umgesetzt wurden und zu wesentlichen Veränderungen führten. So bezog das Tierkundemuseum 1937 ein neues Domizil im ehemaligen Logengebäude an der OstraAllee, das nach der Zwangsauflösung der Freimaurerlogen enteignet und umgebaut worden war. Die frei werdenden Räume im Zwinger sollten bald von der Porzellansammlung genutzt werden, deren Umzug parallel begann. In die dadurch leeren Räume im Johanneum zog 1940 das Museum für Völkerkunde. ${ }^{9}$

\section{Übergeordnete Dienststelle}

Dienstrechtlich unterstanden die Staatlichen Sammlungen für Kunst und Wissenschaft während der NS-Zeit dem Sächsischen Ministerium für Volksbildung. Dieses wurde von März 1933 bis Februar 1935 von Minister Wilhelm Hartnacke geleitet, der zuvor Stadtschulrat in Dresden gewesen war. Nach dem „RöhmPutsch" 1934 wurde Hartnacke beurlaubt. Sein Nachfolger wurde ab März 1935 als Kommissarischer Leiter im Auftrag des Reichsstatthalters der ehemalige Volksschullehrer Arthur Göpfert, der als Mitglied der NSDAP 1930 Gauobmann des Nationalsozialistischen Lehrerbundes (NSLB) Sachsen und 1933 Beigeordneter des Staatskommissars für Sachsen geworden war und 1933 das

Siehe S. $186 \mathrm{ff}$. 
„Bekenntnis der Professoren an den deutschen Universitäten und Hochschulen zu Adolf Hitler und dem nationalsozialistischen Staat ${ }^{\text {"10 }}$ initiiert hatte. Allerdings wurde Göpfert nie zum Minister ernannt, sondern blieb bis Mai 1945 lediglich Kommissarischer Leiter des Sächsischen Ministeriums für Volksbildung. Dieses wurde jedoch ab 10. April 1943 als Abteilung der Landesregierung unterstellt, nachdem Reichsstatthalter Martin Mutschmann alle Ministerien aufgelöst hatte. $^{11}$

\section{Referat „Kunstpflege und Sammlungen“ im Ministerium für Volksbildung}

Seit Januar 1919, nachdem die frühere Generaldirektion aufgelöst worden war, verfügten die einzelnen Sammlungen der Staatlichen Sammlungen für Kunst und Wissenschaft über eigenständige Verwaltungen. Ihre Direktoren waren jeweils gegenüber dem Sächsischen Ministerium für Volksbildung (SMV) weisungsabhängig und rechenschaftspflichtig. Diese Art der Verwaltung wurde zunächst nach der „Machtübernahme“ durch die Nationalsozialisten beibehalten, wobei die Entscheidungsgewalt letztlich beim Reichsstatthalter lag. Erst im April 1937 wurde innerhalb des Ministeriums ein neues Referat XIV für „Kunstpflege und Sammlungen“ eingerichtet, das unter der Leitung von Oberregierungsrat Groß ${ }^{12}$ stand. Mit der „Allgemeinen Anordnung Nr. 99“ des SMV wurde zum 1. April 1937 als verantwortlicher Referent für die Staatlichen Sammlungen für Kunst und Wissenschaft und Kommissarischer Leiter des Referats der bereits genannte $\triangleright$ Fritz Fichtner eingesetzt. Dieser Kunsthistoriker war Mitglied der NSDAP und hatte sich seit 1933 als Leiter der Porzellansammlung und des Kunstgewerbemuseums bewährt. ${ }^{13}$ Obwohl Göpfert als Kommissarischer Leiter

\footnotetext{
10 Nationalsozialistischer Lehrerbund Deutschland/Sachsen (Hg.): Bekenntnis der Professoren an den deutschen Universitäten und Hochschulen zu Adolf Hitler und dem nationalsozialistischen Staat. Dresden 1933, in: https://archive.org/details/bekenntnisderpro00natiuoft, Zugriff: 6.12.2019.

11 Zu Hartnacke und Göpfert siehe Wagner 2004, S. 167 f., 330 f.; Amlung, Ullrich: Schulwesen, in: Starke, Holger u. Uwe John (Hg.): Geschichte der Stadt Dresden. Bd. 3, Von der Reichsgründung bis zur Gegenwart, Stuttgart 2006, S. 454-461 und Hermann, Konstantin: Arthur Göpfert. Zehn Jahre kommissarischer Leiter des Volksbildungsministeriums, in: Pieper/ Schmeitzner/Naser 2012, S. 222-227. Zu den Kabinettaufstellungen vgl. Schmeitzner/Wagner 2006, S. 390 f. Im Schriftwechsel wurde Göpfert später auch als Leiter des Ministeriums bezeichnet.

12 Sein Vorname war nicht ermittelbar.

13 Sächsisches Ministerium für Volksbildung (SMV), Göpfert, an alle Referenten und Geschäftsstellen, Allgemeine Anordnung Nr. 99, 28.4.1937, SKD, MPS, 1937, E.-Reg. Nr. 155; ebenso: SKD Archiv, 01/PS 44, Bd. 1, fol. 48.
} 


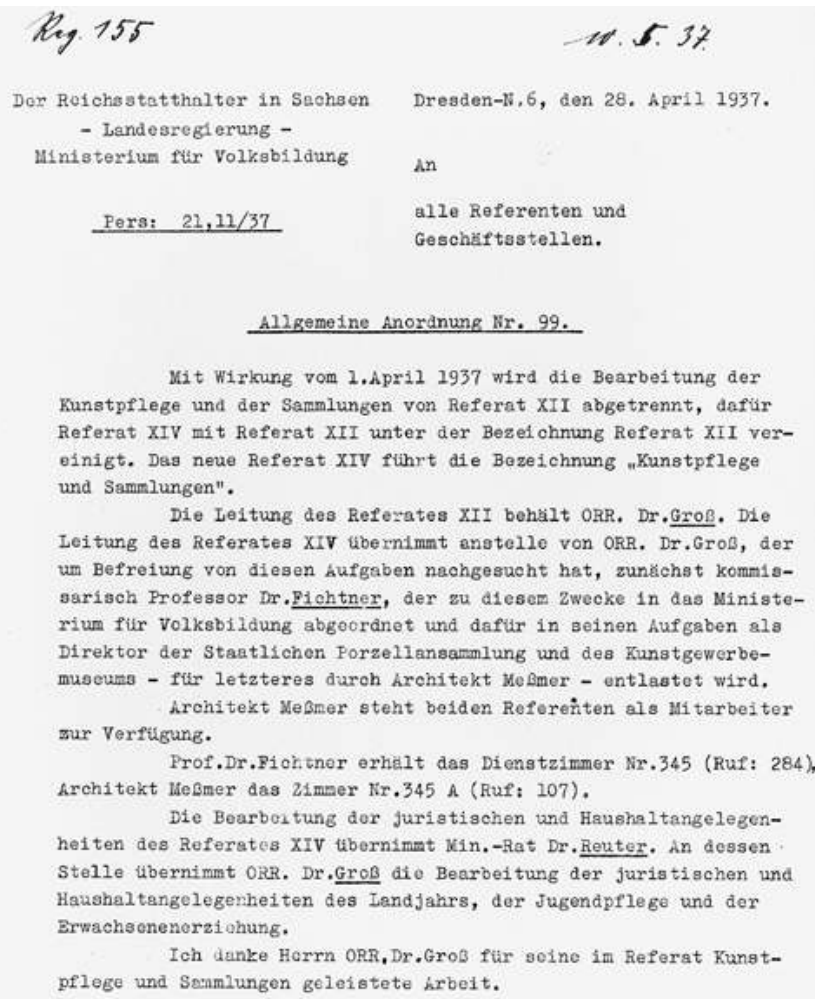

(gez.) G o p fert

Leiter dos Ministoriums fur Volksbildung.

Ausgefortigt: den 28.hpril 1937 fourchers

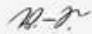

2 Allgemeine Anordnung Nr. 99, Sächsisches Ministerium für Volksbildung, Arthur Göpfert, an alle Referenten und Geschäftsstellen, 28.4.1937

des SMV festlegte, dass Fichtner ,abgeordnet und dafür in seinen Aufgaben als Direktor der Staatlichen Porzellansammlung und des Kunstgewerbemuseums für letzteres durch Architekt Messmer - entlastet wird“14, übernahm Fichtner dieses Amt letztlich zusätzlich zu seinen bisherigen Aufgaben als Museumsdirektor. Im Referat Kunstpflege und Sammlungen unterstützten ihn Ministerialrat Hans Reuter und der Hilfsreferent Messmer. ${ }^{15}$

14 SMV, Göpfert, an alle Referenten und Geschäftsstellen, Allgemeine Anordnung Nr. 99, 28.4.1937, SKD, MPS, 1937, E-Reg. 155; ebenso: SKD Archiv, 01/PS 44, Bd. 1, fol. 48.

15 Der Vorname von Messmer war nicht ermittelbar. 
Mitte April 1940 wurde das SMV auf Veranlassung des Reichsministeriums für Wissenschaft, Erziehung und Volksbildung (RMWEV) neu strukturiert. In einem persönlichen Gespräch informierte Göpfert Fichtner darüber, dass er fortan als Abteilungsleiter verantwortlich sei für ,alle in seinem Amtsbereich sich abspielenden Dinge“, „zugleich auch den Haushalt“ zu führen und „die gesamte Disziplinar-Gewalt über das ihm unterstellte Personal " ${ }^{\text {"16, }}$ also über das gesamte Personal der Staatlichen Sammlungen, habe. Damit erhielt Fritz Fichtner als Referent der Staatlichen Sammlungen im Ministerium „eine größere und geschlossenere Amtsbefugnis ${ }^{17}$ und war gewissermaßen, ohne diesen Titel je zu tragen, ihr Generaldirektor. Im Sinne des nationalsozialistischen „Führerprinzips“ hatte er lediglich dem Leiter des Ministeriums, Göpfert, und Reichsstatthalter Martin Mutschmann Rechenschaft über seine Arbeit abzulegen und zu berichten. Die beiden ihm seit 1933 anvertrauten Museen - Porzellansammlung und Kunst-

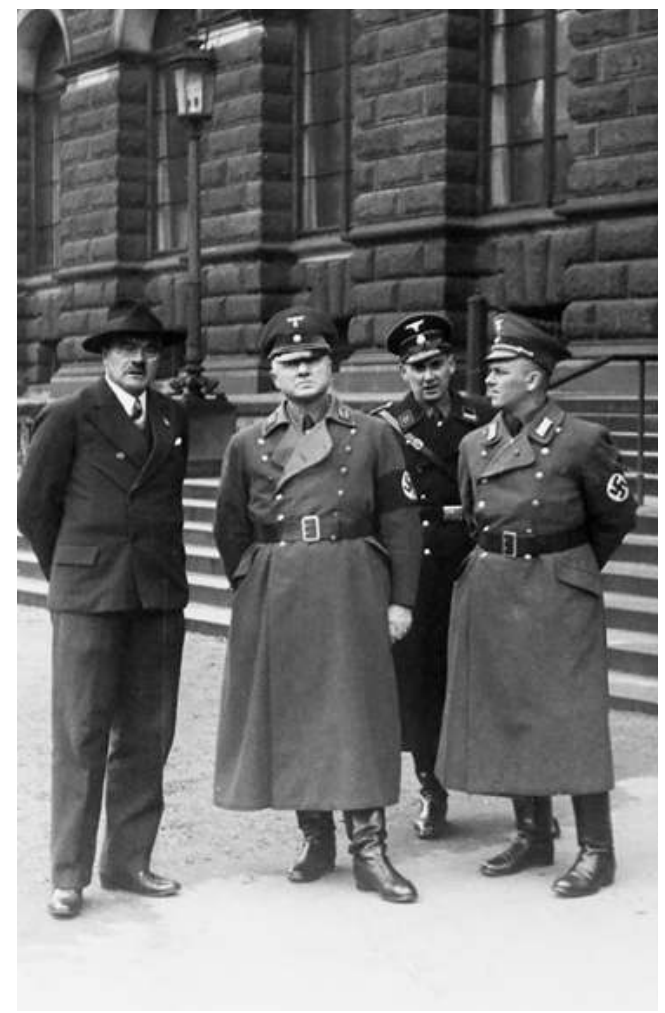

3 Fritz Fichtner (1.v.l.) mit Reichsstatthalter Martin Mutschmann (2.v.l.) vor der Gemäldegalerie in Dresden, um 1940 gewerbemuseum - leitete er weiterhin, auch als er 1941 zum Militärdienst einberufen wurde. Die von Göpfert angestrebte Zentralverwaltung der Staatlichen Sammlungen in der Altstädter Wache neben dem Zwinger, deren Leitung er Fichtner übergeben wollte, wurde jedoch nicht realisiert. ${ }^{18}$

Bei einer weiteren Umstrukturierung der Verwaltung, die Reichsstatthalter Mutschmann mit der Auflösung der sächsischen Ministerien vornahm, wurde Fichtner per Verfügung ab 14. April 1943 die Leitung der neuen, nun mit der Abteilung für Volksbildung der Staatskanzlei unterstellten Abteilung IV/7 zur

16 Fichtner, Protokoll der Besprechung mit dem Leiter SMV, 16.4.1940, SKD Archiv, 01/PS 43, Bd. 3, fol. 81.

17 Ebd.

18 Vgl. Fichtner an SMV, 29.5.1940, SKD Archiv, 01/PS 43, Bd. 2, fol. 101-103. 
Verwaltung der Staatlichen Sammlungen für Kunst und Wissenschaft und der Staatlichen Schlösser und Gärten übertragen. Damit war er nur noch dem Reichsstatthalter gegenüber weisungsgebunden. ${ }^{19}$

Doch als sich Fichtners Dienstzeiten bei der Wehrmacht veränderten, beantragte er im September 1944 die Entbindung von seinem Amt als ministerialer Abteilungsleiter. Zugleich sicherte er zu, dass er „dem Herrn Reichsstatthalter stets zur Verfügung gestellt werde, falls er für mich einmal Befehle haben sollte" und dass er die „Geschäfte als Dir. der St. Porzellansammlung u. Leiter des St. Kunstgewerbemuseums [...] nach Maßgabe der [...] zur Verfügung stehenden Zeit wahrnehmen" ${ }^{\text {"20 }}$ werde. Am 14. September 1944 endete Fichtners Tätigkeit als Referent für die Staatlichen Sammlungen, das heißt als Leiter der Abteilung IV/7 der Landesregierung Sachsen. Regierungsdirektor Arthur Graefe übernahm dieses Amt. ${ }^{21}$

Bedingt durch seine verschiedenen Aufgabenbereiche hatte Fichtner mehrere Dienstorte in Dresden. Einerseits nutzte er jeweils die Direktorenzimmer der von ihm geleiteten Sammlungen. Mit der Ernennung zum Referenten der Staatlichen Sammlungen verfügte er ab 1937 auch über ein eigenes Dienstzimmer im SMV. Dieses gab er Ende November 1939 auf und ließ sich fortan täglich gegen Mittag die Akten aus dem Ministerium in sein neu eingerichtetes Direktorenzimmer in der Porzellansammlung im Zwinger bringen. ${ }^{22}$ Damit war es ihm möglich, seine unterschiedlichen Aufgaben möglichst zeitsparend zu koordinieren und konzentriert zu erledigen. Auch konnte er im Bedarfsfall die anderen Museen schnell erreichen, um seiner Dienstaufsichtspflicht nachzukommen. Mit der Einberufung als Kriegsverwaltungsrat 1941, bei der er seine Aufgaben in den Staatlichen Sammlungen weiterführte, hatte er obendrein einen Arbeitsplatz im Heeresmuseum. ${ }^{23}$

Die anderen Direktoren verfügten jeweils in der von ihnen geleiteten Sammlung über Direktorenzimmer, die auch von den Kommissarischen Leitern der Museen genutzt wurden.

\footnotetext{
19 Vgl. Fichtner an Sächsische Kommission für Geschichte, Leipzig, 28.6.1943, HStA Dresden, 11125, Nr. 22896, o. Pag. Vgl. auch Hermann 2012, S. 226.

20 Fichtner an Reichsstatthalter Mutschmann, 8.9.1944, HStA Dresden, 13859, Nr. 1553, fol. 61 .

${ }_{21}$ Vgl. Reichsstatthalter an Fichtner, 14.9.1944, ebd., fol. 62 und Gruve, Protokoll der Dienstberatung vom 25.10.1944, HStA Dresden, 11125, Nr. 23054, fol. 183-187, ebenso: HStA Dresden, 10701, Nr. 320/2, fol. 15-19.

22 Vgl. Porzellansammlung, Fichtner, an Leiter SMV, 30.11.1939, SKD Archiv, 01/PS 48, fol. 189.

23 Bisher lässt sich die von ihm ausgeführte Tätigkeit in dieser Funktion nicht rekonstruieren.
} 


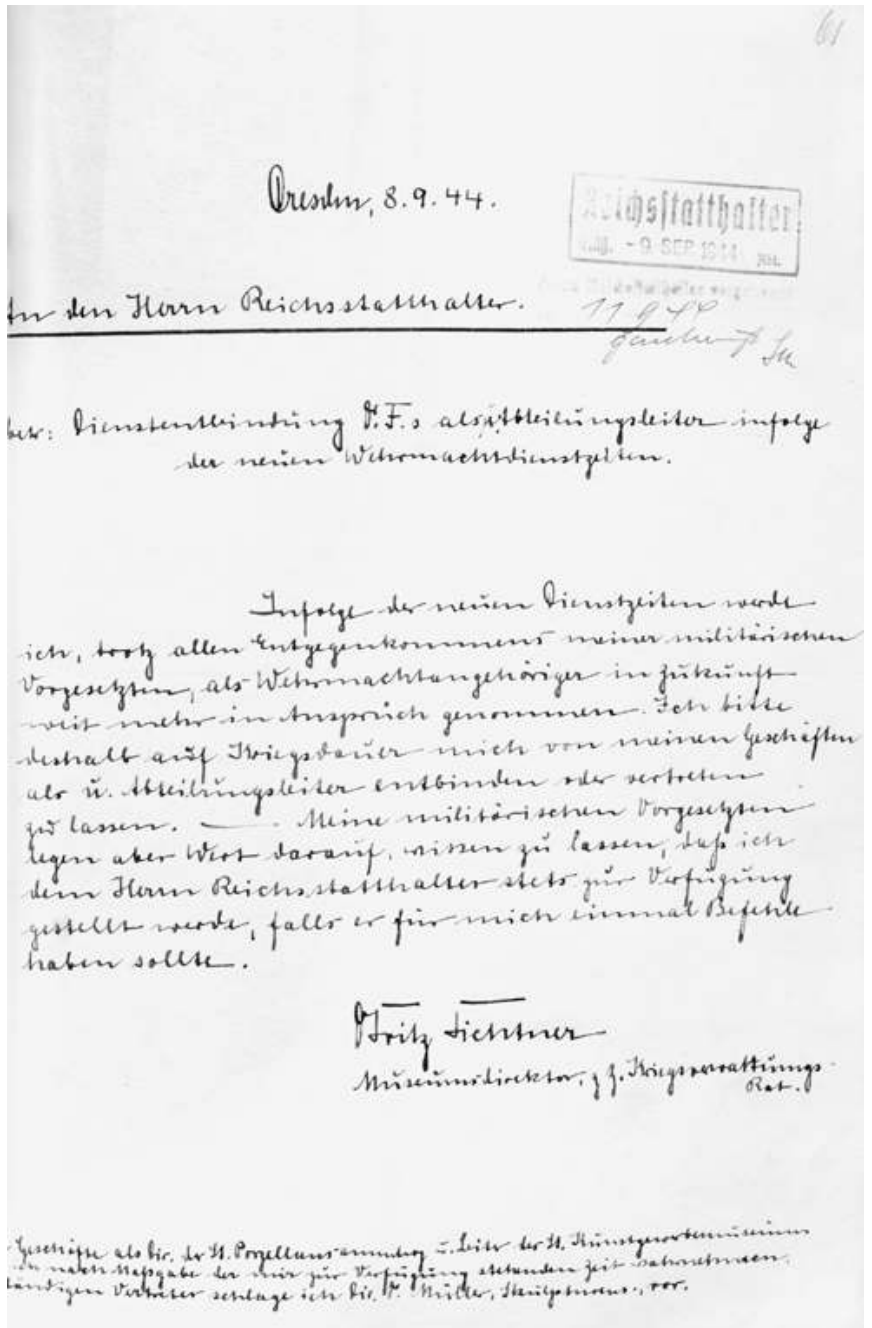

4 Brief von Fritz Fichtner an Reichsstatthalter Martin Mutschmann, 8.9.1944

\section{Arbeitszeiten}

Die reguläre Arbeitszeit bestand für die Mitarbeiter der Staatlichen Sammlungen in einer 6-Tage-Arbeitswoche von Montag bis Sonnabend mit 48 Arbeitsstunden, wobei das Ministerium diese verbindlich festlegte. Vor allem die Museumsbeamten empfanden diese „vom Reichsstatthalter höchst persönlich erzwungene Dienstzeit aller höheren Beamten von 8 - 41/2 (Sommer 71/2-4) “24, so Kustos

24 Struck an Danzel, 6.2.1936, SKD, MfV Archiv, MVD n20;25/2, o. Pag. 
- Bernhard Struck, als Zumutung. Die unterschiedlichen Aufgaben, die in den Museen anfielen, und die abweichenden Arbeitszeiten, die Öffnungszeiten an Sonntagen oder die Forschungsarbeit in den Abendstunden oder an Sonntagen mit sich brachten, führten zu einem Dauerkonflikt zwischen der Verwaltung und den Museumsmitarbeitern. So erhielt $>$ Franz Schubert vom Kupferstich-Kabinett im September 1941 einen schriftlichen Verweis aus dem SMV, nachdem Amtmann Albert Gruve vom Ministerium ihn morgens telefonisch nicht hatte erreichen können und der Kanzleiangestellte $\triangleright$ Fritz Wiedemann behauptet hatte, Schubert komme oft erst nach 9 Uhr zum Dienst. Schubert musste sich rechtfertigen und erklärte, er habe

in fast täglichen Überstunden und vielfach auch Sonntags dienstliche Arbeiten in meiner Privatwohnung für das Kupferstichkabinett durchgeführt, zu denen ich im Dienste aus Arbeitsüberlastung und Zeitmangel wie auch aus Mangel an Ruhe zur ungestörten Konzentration wegen dauernder anderweitiger Inanspruchnahme nicht komme ${ }^{25}$.

Im Ministerium zeigte man für die Situation der Wissenschaftler in den Museen wenig Verständnis; die Einhaltung der allgemein angeordneten Dienstzeiten wurde regelmäßig eingefordert. ${ }^{26}$

\section{Direktorenkonferenz}

Ein wesentliches Instrument der Arbeitsorganisation bildete die Direktorenkonferenz. $\mathrm{Zu}$ dieser gehörten die Direktoren und Leiter aller zu den Staatlichen Sammlungen für Kunst und Wissenschaft zählenden Institutionen. Sie trafen sich regelmäßig zu Beratungen, an denen auch Vertreter der übergeordneten Dienststelle, also des SMV bzw. der Abteilung Sammlungen, später der Staatskanzlei, teilnahmen. Diese Zusammenkünfte dienten der Koordination der Arbeit in den einzelnen Sammlungen und vereinfachten die Kommunikation zwischen diesen und dem zuständigen Ministerium. Leider sind die Protokolle dieser damaligen Dienstbesprechungen nicht lückenlos überliefert. Einzelne Einladungen und Protokolle sind in diversen Aktenbeständen der Einzelsammlungen erhalten, auch spiegelt sich ihr Versand in erhaltenen Registranden wieder.

25 Schubert an Leiter SMV, 22.9.1941, HStA Dresden, 11125, Nr. 22889, fol. 97 f. Vgl. ebd., fol. 94, 96.

26 Vgl. SMV, Göpfert, an alle Dienststellen, 10.4.1935, SKD Archiv, 01/PS 38, fol. 12; Registrande, 11.4.1935, 01/PS 133, 1935, Nr. 7. Ähnliche Schreiben auch am 30.6.1938, 20.9.1940 u. 4.8.1941, SKD Archiv, 01/PS 136, fol. 79; 01/PS 137, fol. 359; ebd., fol. 183. 
Eine Rekonstruktion der Abfolge der Dienstberatungen ist daher ebenso wenig möglich, wie eine lückenlose Dokumentation ihrer wesentlichen Inhalte.

In der Regel versammelten sich die Sammlungsdirektoren einmal monatlich, bei besonderer Dringlichkeit zweimal. Jeweils einer von ihnen wurde für mehrere Jahre zum Geschäftsführer der Direktorenkonferenz ernannt. Er verschickte die Einladungen zu einzelnen Sitzungen unter Bekanntgabe der jeweiligen Tagesordnung, bereitete diese Dienstberatungen inhaltlich vor und leitete sie. Diese Aufgabe übernahm bis Mitte April $1935>$ Arnold Jacobi, danach $>$ Martin Bollert. ${ }^{27}$ Ab April 1937 oblag die Organisation der Direktorenkonferenz dem neuen Referat für die Staatlichen Sammlungen im SMV. Anfang der 1930er-Jahre, noch unter der Leitung von Jacobi, fanden die Zusammenkünfte in der Skulpturensammlung im Albertinum statt. Später, als Bollert die Leitung übernommen hatte, im Direktorenzimmer der Sächsischen Landesbibliothek. Nach der Schaffung des Referates Sammlungen kamen die Beteiligten im Kleinen oder im Großen Sitzungssaal des Ministeriums zusammen, selten auch im dortigen Dienstzimmer von Fritz Fichtner. Ab Februar 1940 tagte man meist in den Räumen der Porzellansammlung im Zwinger.

Hauptthema der Direktorenkonferenz war die Museumsarbeit. Es wurden Absprachen über die Ausstellungsplanung und das Angebot an Vorträgen und Führungen getroffen und die Pressearbeit vorbereitet. Ab 1936 fanden auch kulturpolitische Anweisungen Eingang in die Beratungen, die meist ohne größere Diskussionen zur Kenntnis genommen wurden. Die Direktoren verständigten sich über die Struktur und Organisation sowie über die Aufgaben der Staatlichen Sammlungen und sprachen über einzelne Personalangelegenheiten. Ab Dezember 1937 spielte auch der Schutz der Objekte eine Rolle, der dann nach Kriegsbeginn zum Hauptthema der Zusammenkünfte der Sammlungsvertreter wurde.

27 Museen für Tierkunde und Völkerkunde, Jacobi, an Direktoren der Staatlichen Sammlungen, 6.4.1935, SLUB, Bibl.Arch.III.G,Vol.686.c, o. Pag. u. Jacobi an Bollert, 12.4.1935, SLUB, Bibl.Arch.III.G.Vol.686.d, o. Pag. 


\section{„[...] seit längerer oder kürzerer Zeit vacant“ - Die Personalausstattung der Sammlungen}

Symptomatisch für die Entwicklung der Personalsituation an den Staatlichen Sammlungen für Kunst und Wissenschaft in Dresden während der NS-Zeit ist die Situation, die $\triangleright$ Klaus Günther, Wissenschaftlicher Hilfsarbeiter an den Museen für Tierkunde und Völkerkunde, im August 1941 für das Münzkabinett beklagte:

Die so lange freie Stelle seines Leiters ist noch nicht besetzt, und die Führung der einschlägigen Geschäfte durch die Kräfte gelegentlich dieses, gelegentlich jenes anderen Museums hat ihre notwendigen bedeutenden Nachteile; sie muss umso eher zu Misslichkeiten führen, als auch an den übrigen der hiesigen Museen nicht ganz wenige der ohnehin zu zahlarmen wissenschaftlichen Stellen seit längerer oder kürzerer Zeit vacant sind. ${ }^{1}$

Bereits Anfang der 1930er-Jahre, in der Endphase der Weimarer Republik, ist die Personalausstattung der Staatlichen Sammlungen keineswegs üppig gewesen. Die Auswirkungen der Weltwirtschaftskrise hatten die sächsische Regierung zu drastischen Sparmaßnahmen gezwungen, die auch in Gehaltskürzungen und Stellenstreichungen im Kulturbereich mündeten. In der Regel wurden die einzelnen Museen damals von einem promovierten Fachwissenschaftler geleitet, dem bestenfalls ein Kustos, ein Wissenschaftlicher Hilfsarbeiter - heute wäre das ein Wissenschaftlicher Mitarbeiter - und ein Freiwilliger Wissenschaftlicher Hilfsarbeiter - heute wäre das ein Volontär - zur Seite gestellt waren. Meist arbeiteten letztere für etwa zwei Jahre unbezahlt an einem Museum, manchmal jedoch über mehrere Jahre, wie $\triangleright$ Franz Schubert und $\triangleright$ Erna von Watzdorf. Nur selten erhielten sie dafür eine geringe finanzielle Unterstützung wie durch Werkverträge oder das Notopfer des Landesverbandes der Höheren Beamten Sachsens, das arbeitslose junge Akademiker förderte. Darüber hinaus gab es in jedem Museum einen Restaurator bzw. Präparator sowie einen Kanzleiangestellten für die Erledigung der Verwaltungsaufgaben und Schreibarbeiten. Diese Personen waren im Allgemeinen verbeamtet. Außerdem verfügten die Museen mindestens über einen Handwerker sowie mehrere Aufsichtskräfte, dazu eine Garderoben- und eine Reinigungskraft. Die Anzahl dieses technischen Personals, das als Angestellte oder Arbeiter eingestellt war, divergierte und war von der Größe der Museen abhängig.

Münzkabinett, Günther, an Kuester, Stadt Wehlen, 9.8.1941, SKD, MK, 1925-1941, fol. 80 . 
In einigen Fällen führten die Personaleinsparungen aus der Weimarer Republik zu seltsamen Konstellationen, die auch in der NS-Zeit noch zu spüren waren: So wurde in der Porzellansammlung nach der Pensionierung des Direktors $\triangleright$ Ernst Zimmermann die zuvor eingesparte Kustodenstelle 1933 reaktiviert und mit - Fritz Fichtner besetzt, der gleichzeitig die Leitung der Sammlung übernahm, während die Direktorenstelle vakant blieb. Als Fichtner dann 1937 zum Direktor ernannt wurde, entfiel im Gegenzug die Kustodenstelle. Neben Fichtner arbeiteten in der Porzellansammlung lediglich ein Inspektor und technisches Personal. Im Münzkabinett und im Mathematisch-Physikalischen Salon, den beiden kleinsten Sammlungen, war die Situation etwas anders. So berichtete zum Beispiel $\triangleright$ Walter Schwinkowski, der Leiter des Münzkabinetts 1935:

Im Münzkabinett, wo außer dem Leiter der Präparator der einzige Beamte ist, muß der Präparator außer dem Aufsichtsdienst und den Instandhaltungs- und Reproduktionsarbeiten für die Sammlung auch sämtliche Kanzleiarbeiten machen und dauernd bei den Arbeiten des Leiters Hilfe leisten²

\section{Mitarbeiterinnen}

Obwohl sich Frauen seit Ende des 19. Jahrhunderts an deutschen Universitäten immatrikulieren konnten und es Anfang des 20. Jahrhunderts erste Absolventinnen gab, war die akademische Welt in der NS-Zeit immer noch männlich dominiert. In den Museen gab es unter den wissenschaftlichen Mitarbeitern, wenn überhaupt, nur wenige Frauen. Sie wurden seltener befördert und verblieben meist deutlich länger als ihre männlichen Kollegen in der Position der Freiwilligen Wissenschaftlichen Hilfsarbeiter, also der unbezahlten Volontärinnen. Unter dem längerfristig in den Museen der Staatlichen Sammlungen in Dresden tätigen akademischen Personal befanden sich in der NS-Zeit mit $\triangleright$ Erna von Watzdorf im Grünen Gewölbe und Historischen Museum sowie $>$ Ragna Enking in der Skulpturensammlung lediglich zwei Frauen. Zwei weitere, $>$ Elfriede SchulzeBattmann und $\triangleright$ Anneliese Hanisch (Rohne), waren jeweils nur für knapp zwei Jahre am Kupferstich-Kabinett bzw. am Historischen Museum tätig. Auch bezüglich der Gehälter waren Frauen deutlich benachteiligt, wie das Beispiel von Erna von Watzdorf zeigt. Erst nachdem sie über zehn Jahre lang als Freiwillige Wissenschaftliche Hilfsarbeiterin weitgehend unbezahlt tätig gewesen war, wurde sie als Wissenschaftliche Hilfsarbeiterin eingestellt, jedoch deutlich geringer entlohnt als ihre Kollegen:

2 Münzkabinett, Schwinkowski, an SMV, 9.12.1935, SKD, MK, 1935-1936, fol. 225. 
Als einzige Wissenschaftl. Hilfsarbeiterin war sie in Verg.-Gr. IV eingereiht, die eigentlich für Angestellte ohne abgeschlossene Hochschulbildung vorgesehen ist, während alle übrigen Wiss. Hilfsarbeiter der Staatl. Sammlungen in Verg.-Gr. III eingestuft sind. ${ }^{3}$

Hinsichtlich der Personalsituation wie auch der Anzahl an Mitarbeiterinnen bildet die Sächsische Landesbibliothek eine Ausnahme. Ihr wissenschaftliches Personal bestand 1933 einschließlich des Direktors aus elf Beamten und vier Wissenschaftlichen Hilfsarbeitern. ${ }^{4}$ Dazu kamen die Angestellten im Mittleren Dienst und im niederen, dem Magazindienst. Insgesamt zählte die Bibliothek 57 festangestellte Mitarbeiterinnen und Mitarbeiter im Jahr 1929 und 62 im Jahr $1943 .^{5}$

Ähnlich wie im Museumsdienst begann die typische Bibliothekskarriere im Höheren Dienst in der Regel nach einem mit Promotion abgeschlossenen Universitätsstudium mit einem zweijährigen unbezahlten Volontariat, das jedoch die praktische Ausbildung zum Bibliothekar umfasste, die in Sachsen mit einem mindestens halbjährigen Aufenthalt an der Universitätsbibliothek Leipzig und der Prüfung für den Höheren Bibliotheksdienst endete. Anschließend kehrten die Kandidaten als Wissenschaftliche Hilfsarbeiter an die Sächsische Landesbibliothek zurück. Erschienen sie geeignet, wurden sie, sobald eine Stelle als Bibliotheksassistent und später als Landesbibliothekar frei war, befördert. Dieser Aufstieg in der Bibliothekshierarchie konnte sich jedoch, wie bei $>$ Gottfried Benndorf oder $>$ Ulrich Dähnert, über mehrere Jahre hinziehen.

Ein Foto von 1932, aufgenommen im Innenhof des Japanischen Palais, zeigt 46 Personen, davon 18 Frauen - das sind 39 \%. Doch obwohl Frauen in Sachsen der Zugang zum Höheren Bibliotheksdienst seit 1919 möglich war, arbeiteten sie auch in der NS-Zeit primär im Mittleren Dienst, wie zum Beispiel $>$ Dorothee Denecke, $>$ Charlotte Holzhausen, $>$ Margarethe Storch und $>$ Dorothee von Watzdorf. ${ }^{6}$ Zwischen 1933 und 1945 gab es an der Landesbibliothek mit - Helene Barthel und >Charlotte Boden lediglich zwei Wissenschaftliche Bibliothekarinnen, die über neun bzw. elf Jahre als Wissenschaftliche Hilfsarbeiterin-

\footnotetext{
3 Direktion Staatliche Sammlungen, Fischer, an Landesverwaltung Sachsen, Inneres und Volksbildung, Kulturabteilung, 12.9.1945, SKD Archiv, 02/VA 166, fol. 11r.

4 Vgl. Boden, Kästner und Büscher, Sächsische Landesbibliothek, an SMV, 3.7.1933, HStA Dresden, 11125, Nr. 19345, fol. 222-224.

5 Vgl. Hermann 2011, S. 298.

6 Vgl. Jank, Dagmar: Frauen im Höheren Bibliotheksdienst vor dem Zweiten Weltkrieg, in: Plassmann, Engelbert u. Ludger Syré (Hg.): Verein Deutscher Bibliothekare 1900-2000, Festschrift, Wiesbaden 2000, S. 302-313.
} 


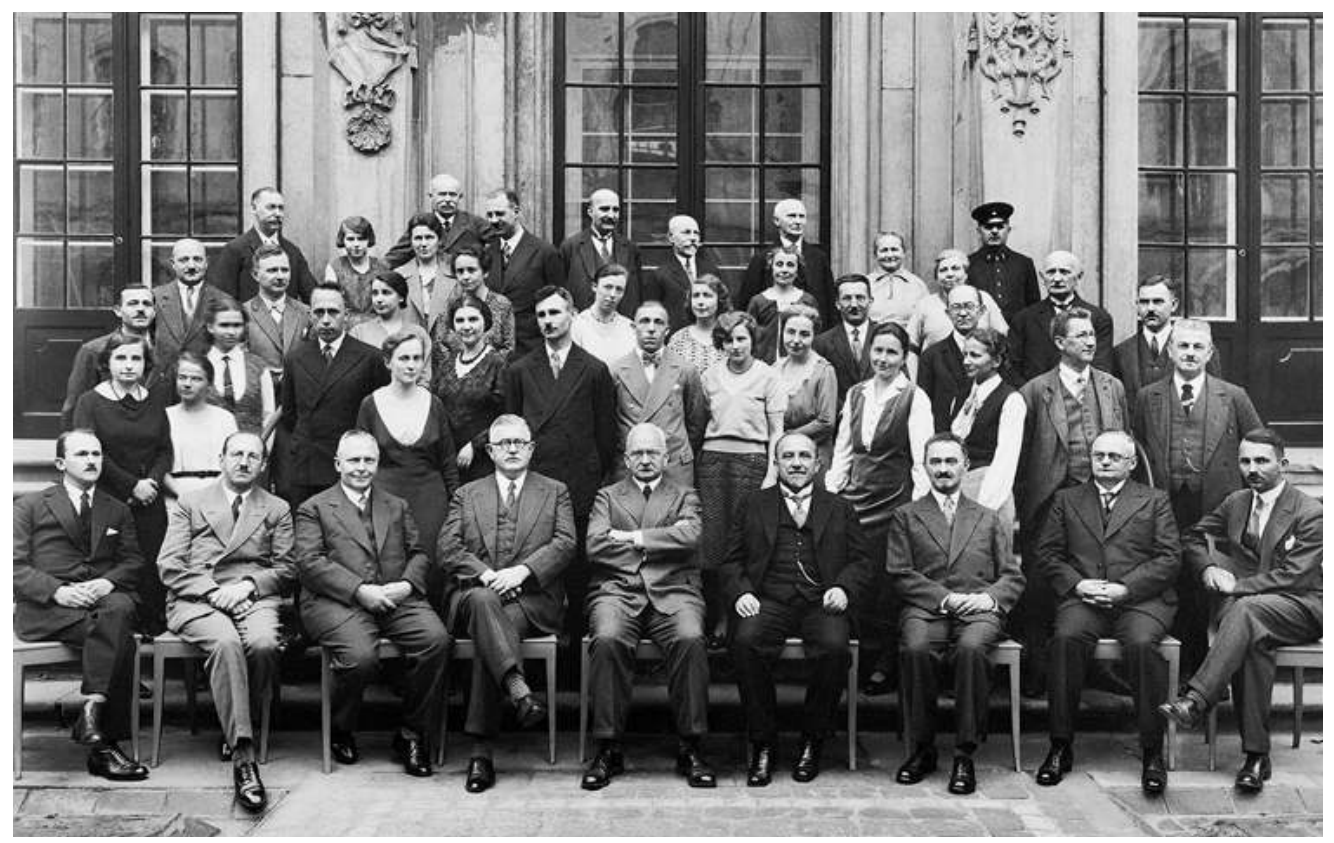

5 Das Personal der Sächsischen Landesbibliothek im Innenhof des Japanischen Palais, 1932 (1.R.v.l.n.r.: Gottfried Benndorf, Walther Frieser, Jacob Jatzwauk, Hubert Richter, Martin Bollert, Otto Fiebiger, Bruno Faass, Karl Assmann, Hans Hofmann; 2.R.4.v.1.: Charlotte Boden; 3.R.4.v.l.: Lucie Walter, 4.R.v.l.: Helmut Schneider (2.), Charlotte Holzhausen (4.); 5.R.v.l.: Margarethe Storch (3.), Ewald Jammers (4.))

nen eingestellt waren und nicht befördert wurden. Hingegen waren im selben Zeitraum 16 Männer als Wissenschaftliche Bibliothekare tätig, von denen nur •Ulrich Dähnert und $\triangleright$ Erhart Kästner länger als sechs Jahre in der Position als Wissenschaftliche Hilfsarbeiter verblieben, was vor allem durch ihre Einberufung zum Militärdienst bzw. Kästners Tätigkeit bei Gerhart Hauptmann verursacht wurde. Sie wurden in dieser Zeit weiter als Mitarbeiter geführt.

Während in der Landesbibliothek der Personalstamm in der NS-Zeit zumindest im Höheren Bibliotheksdienst, bei den Wissenschaftlichen Bibliothekaren, im Wesentlichen konstant bei ca. 15 Mitarbeiterinnen und Mitarbeitern blieb, kam es in den Museen zu zahlreichen Veränderungen. Anfang 1933, d.h. zur Zeit der „Machtübernahme“ durch die Nationalsozialisten, wurden die damals zwölf Museen der Staatlichen Sammlungen von elf Direktoren betreut. Lediglich das Grüne Gewölbe und das Historische Museum wurden bereits seit 1924 zusammen von $\triangleright$ Erich Haenel geleitet. Dazu kamen sieben Kustoden, fünf Wissenschaftliche Hilfsarbeiter und vier Freiwillige Wissenschaftliche Hilfsarbeiter. 


\section{Politisch motivierte Eingriffe in die Personalstruktur}

Ab Mai 1933 kam es zu ersten politisch motivierten Eingriffen in die Personalstruktur der Staatlichen Sammlungen. Infolge des „Gesetzes zur Wiederherstellung des Berufsbeamtentums" vom 7. April 1933 mussten Personalbögen mit Angaben über Herkunft, ,arische Abstammung“, Mitgliedschaften in Parteien und anderen Organisationen angelegt werden. Die damit verbundenen Befragungen aller Beamten und Angestellten im öffentlichen Dienst mündeten bald schon in Entlassungen. Betroffen waren jüdische und politisch missliebige Mitarbeiterinnen und Mitarbeiter.

„Ich bin Jüdin “" - diese drei Worte schrieben sowohl $\triangleright$ Anna Löwenthal als auch $>$ Lucie Walter von der Sächsischen Landesbibliothek selbstbewusst am 24. Juni 1933 in die neuen Fragebögen. Dadurch sah sich Bibliotheksdirektor - Martin Bollert gezwungen, die beiden jüdischen Mitarbeiterinnen des Mittleren Bibliotheksdienstes zur Entlassung zu melden. Das SMV verfügte am 20. Juli 1933 ihre Entlassung zum 31. August 1933 unter Zahlung der Dienstbezüge für einen weiteren Monat und Übergangsgeld für zwei Monate. ${ }^{8}$ Die rechtliche Basis für diese Entscheidung bildete $\$ 15$ des „Gesetzes zur Wiederherstellung des Berufsbeamtentums", der die sinngemäße Anwendung der Vorschriften auf Angestellte umfasste, womit indirekt $\$ 3$ zur Anwendung kam, der die Entlassung von Beamten, „die nicht arischer Abstammung sind“" mittelte Bollert diese Kündigung an Löwenthal und Walter. Am 26. Juli 1933 stellte er ihnen gute Arbeitszeugnisse aus, mehr Unterstützung war ihm als Staatsbeamter in dieser Situation nicht möglich. ${ }^{10}$ Löwenthal konnte Ende November 1938 an Bord des Dampfschiffs „Washington“ von Hamburg aus nach New York emigrieren, wo sie im Mai 1939 ihre Einbürgerung beantragte. ${ }^{11}$ Walter gelang es, nach Palästina auszuwandern.

\footnotetext{
Fragebögen zur Durchführung des Gesetzes zur Wiederherstellung des Berufsbeamtentums, 24.6.1933, HStA 11125, Nr. 19345, fol. 163 f. (Löwenthal), fol. 165 f. (Walter).

8 Vgl. Landesbibliothek, Bollert, an SMV, 3.7.1933 u. SMV an Direktion der Landesbibliothek, 20.7.1933, HStA 11125, Nr. 19345, fol. 161, 167.

9 „Gesetz zur Wiederherstellung des Berufsbeamtentums“, 7.4.1933, $\$ 3$ (1), in: RGBl., Teil 1, 1933, Nr. 34, S. 175.

10 Vgl. Sächsische Landesbibliothek, Bollert, an Löwenthal und Walter, 24.7.1933 sowie Bollert, Arbeitszeugnisse, 26.7.1933, SLUB, PA Löwenthal und PA Walter.

11 „New York, Southern District, U.S District Court Naturalization Records, 1824-1946“, database, (https://familysearch.org/ark:/61903/1:1:QP7X-8N52, Zugriff: 3.12.2019), Anna Loewenthal, 1939; citing Immigration, New York, United States, 280350, NARA microfilm publication M1972, Southern District of New York Petitions for Naturalization, 1897-1944. Records of District Courts of the United States, 1685-2009, RG 21. National Archives at New
} 
6 Anna Löwenthal, Absichtserklärung für die Einwanderung in die USA, 17.5.1939

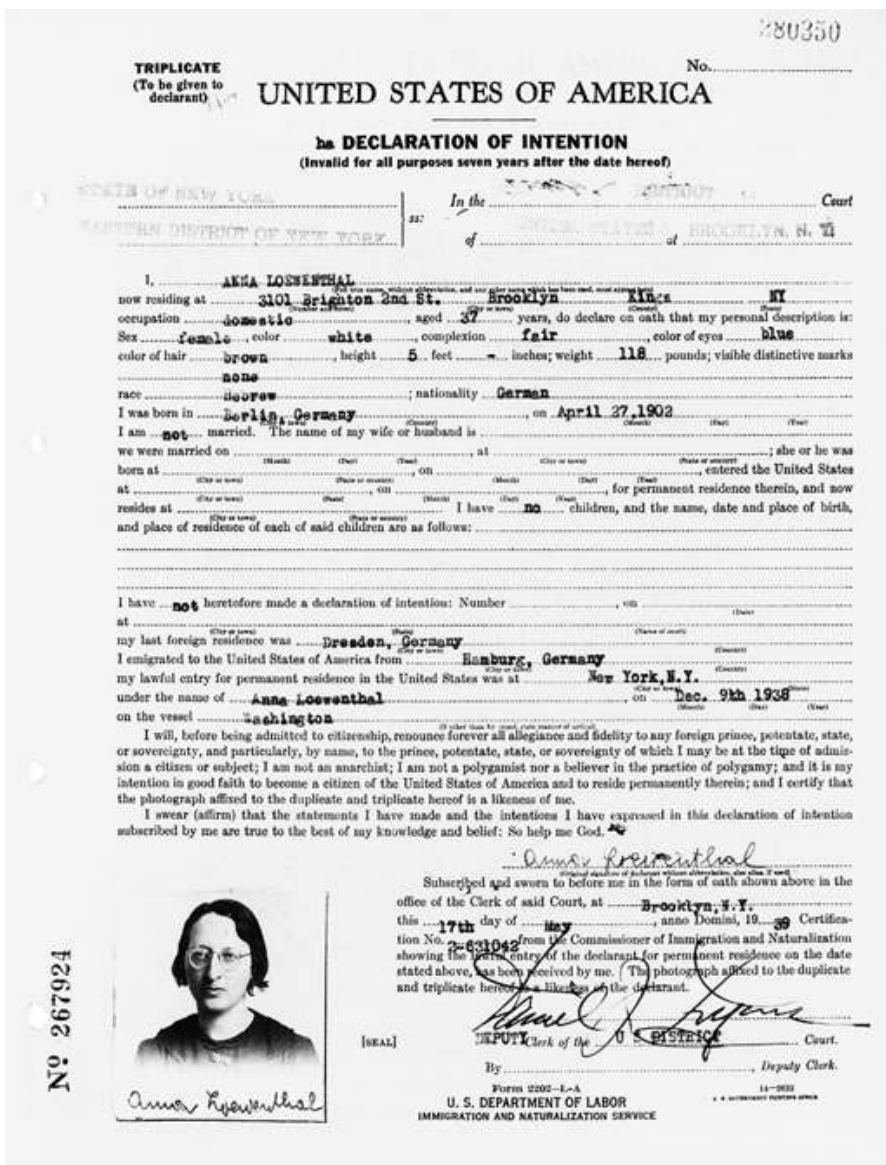

Ebenfalls im Zusammenhang mit den Personalfragebögen informierte der Direktor der Museen für Tierkunde und Völkerkunde, \Arnold Jacobi, im Juli 1933 pflichtgemäß das SMV, dass der Kustos für Entomologie > Fritz van Emden „nicht arischer Abstammung“ und „voraussichtlich zu entlassen“ sei, und betonte sogleich, „dass der Verlust seiner Arbeitskraft für die Leistungsfähigkeit und den Ruf der Anstalt auf dem wissenschaftlich entomologischen Gebiete ein sehr schwerer, in gewisser Richtung sogar unersetzlicher sein würde. "12

York. Für diese Informationen dankt die Autorin Marisa Bourgoin, Archives of American Art, Smithsonian Institution.

12 Museen für Tierkunde und Völkerkunde, Jacobi, an SMV, 12.7.1933, HStA Dresden, 13842, Nr. 047, o. Pag. 


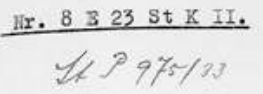

Auf Vorschlag des Ministeriuns fur Volksoilaung versetze ich hiermit den Kustos bei den Vuseen fü Tierkunde und volkerkunde in Dresden

$$
\text { Dr. Pritz van } D m \text { d } e n
$$

auf Grund von $\$ 3$ des Gesetzes zur wiederherstellung des Berufsbeatatentums vom 7. April 1933 (Reichsgesetzbl. I S. 175) in den kuhestand.

Der Reichsstatthalter in Sachsen.

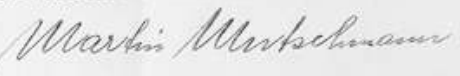

7 Reichsstatthalter Martin Mutschmann, Versetzung von Fritz van Emden in den Ruhestand, 18.9.1933

Am 18. September 1933 ordnete Reichsstatthalter Mutschmann Emdens Versetzung in den Ruhestand an, das Ministerium verfügte aufgrund $\$ 3$ des „Gesetzes zur Wiederherstellung des Berufsbeamtentums" die Entlassung zum Monatsende unter Fortzahlung der Bezüge bis zum Jahresende, wie Jacobi am 27. September 1933 seinem Kustos per Einschreiben mitteilte. ${ }^{13}$ Er schrieb ihm ein gutes Arbeitszeugnis und ermöglichte ihm weiterhin die Nutzung der Museumsbibliothek sowie der entomologischen Präparate der Sammlung für die private Forschung. ${ }^{14} 1936$ konnte Emden mit seiner Frau und den beiden Söhnen nach London emigrieren, wo er am Imperial Institute of Entomology am Natural History Museum Arbeit fand.

\footnotetext{
13 Vgl. Reichsstatthalter Mutschmann, Anordnung der Versetzung in den Ruhestand, 18.9.1933 u. SMV, Woelker, an Museen für Tierkunde und Völkerkunde, 26.9.1933, beide: ebd., o. Pag. sowie Museen für Tierkunde und Völkerkunde, Jacobi, an Emden, 27.9.1933, HStA Dresden, 13842, Nr. 114, Bd. 1, o. Pag.

14 Vgl. Museen für Tierkunde und Völkerkunde, Jacobi, an Emden, 24.11.1933 und 28.11.1933, beide: ebd., o. Pag. sowie Museen für Tierkunde und Völkerkunde, Jacobi, an unbekannten Adressaten, 23.4.1934, HStA Dresden, 13842, Nr. 047, o. Pag.
} 
Im Falle von $\triangleright$ Rudolf Berge, Freiwilliger Wissenschaftlicher Hilfsarbeiter am Grünen Gewölbe, der in einer Verleumdung gegen seinen Vorgesetzten, Direktor -Erich Haenel, Erwähnung fand, ist unklar, ob er tatsächlich jüdische Vorfahren hatte und möglicherweise deshalb Ende Mai 1933 nicht weiter beschäftigt oder entlassen wurde. ${ }^{15}$

Zum 30. November 1933 wurde der Direktor des Kunstgewerbemuseums - Wolfgang Balzer nach zehnjähriger Tätigkeit im Alter von 49 Jahren zwangspensioniert. Die Grundlage dafür bildete $\$ 4$ des „Gesetzes zur Wiederherstellung des Berufsbeamtentums". Balzer war ein halbes Jahr zuvor wegen seines Engagements für die SPD für einige Tage verhaftet worden, damit zählte er zu den Beamten, „die nach ihrer bisherigen politischen Betätigung nicht die Gewähr dafür bieten, dass sie jederzeit rückhaltlos für den nationalen Staat eintreten"16.

Ab Oktober 1935 wurde die Abstammung aller Mitarbeiter infolge der sogenannten Nürnberger Gesetze, insbesondere des „Gesetzes zum Schutze des deutschen Blutes und der deutschen Ehre" und des „Reichsbürgergesetzes“, erneut überprüft. ${ }^{17}$ Damals meldete die Geschäftsstelle der Staatlichen Sammlungen:

Unter den bei den Staatl. Sammlungen für Kunst und Wissenschaft beschäftigten Angestellten und Verwaltungsarbeitern befinden sich keine Juden mehr. Soweit sie vorhanden waren, sind sie bereits im Jahre 1933 entlassen worden ${ }^{18}$.

Doch bereits im September 1936 forderte das SMV, den Anweisungen des Reichsministeriums des Innern folgend, auch den Abstammungsnachweis der Ehefrauen aller Mitarbeiter. Ein Jahr später verfügte es die Entlassung von Beamten, deren Ehegatten Juden oder ,jüdische Mischlinge“ waren. ${ }^{19}$ Die Museumsdirektoren waren in diese Überprüfung involviert, sie mussten die Unterlagen ihrer Mitarbeiter kontrollieren, wie ein Brief belegt, in dem $\triangleright$ Bernhard Struck, Kustos an den Museen für Tierkunde und Völkerkunde, berichtete, er habe „am

15 Vgl. Gackstatter an Kulturpolitische Abteilung und Abteilung Film, 5.7.1933, HStA Dresden, 11125, Nr. 22882, fol. 21.

16 „Gesetz zur Wiederherstellung des Berufsbeamtentums“, 7.4.1933, \$ 4, in: RGBl., Teil I, 1933, Nr. 34, S. 175.

17 Vgl. „Gesetz zum Schutze des deutschen Blutes und der deutschen Ehre“ u. „Reichsbürgergesetz“, 15.9.1935, RGBl., 1935, Teil I, Nr. 100, S. 1146 f. Dazu gehörte auch das „Reichsflaggengesetz", ebd. S. 1145.

18 Geschäftsstelle Sammlungen, Frenzel, 25.10.1935, HStA Dresden, 11125, Nr. 18960, fol. 354

19 Vgl. SMV an alle nachgeordneten Stellen, 10.10.1936, SKD, MPS, 1936, E.-Reg. Nr. 289 u. Leiter SMV an Direktoren der Staatlichen Sammlungen, 28.10.1937, HStA Dresden, 13842, Nr. 115, o. Pag. 
Dresden, den 25.0ktober 1935.

Unter den bel den Staatl.Sammlungen für Kunst und Wissenschaft beschätigten Angestellten und Verwaltungsarbeitern befinden sich keine Juden mehr. Soweit sie vorhanden waren, sind sie bereits im Jahre 1933 entlassen worden, und zwar:

Dr.van Emden, Kustod bei den Museen für Tierk.und Völkerk., Walter, Lucle, Angestellte bel der Landesbibliothek, Löwenthal, Anna,

Geschäftsstelle S.
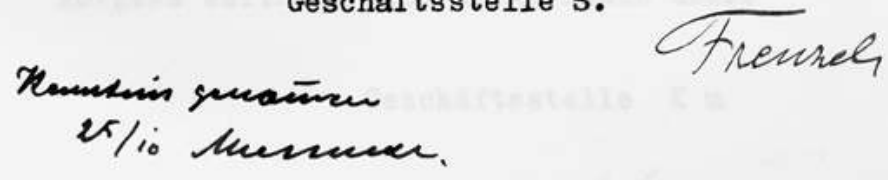

8 Mitteilung der Geschäftsstelle der Staatlichen Sammlungen, Frenzel, an das Sächsische Ministerium für Volksbildung 25.10.1935

Donnerstag Grosskampftag infolge eines neuen Termins in der nun ganz extensiven Jagd nach den arischen Grossmüttern unserer Frauen “20. Ende Oktober 1937 wurde der Kustos der Gemäldegalerie $\triangleright$ Karl Wilhelm Jähnig entlassen, weil er mit einer Jüdin verheiratet war und den „Nürnberger Gesetzen“ zufolge als ,jüdisch versippt" galt. Jähnig verweigerte die Ehescheidung und ging mit seiner Frau in die Schweiz ins Exil.

Insgesamt wurden sechs Mitarbeiterinnen und Mitarbeiter der Staatlichen Sammlungen auf der juristischen Grundlage des „Gesetzes zur Wiederherstellung des Berufsbeamtentums“ bzw. der „Nürnberger Gesetze“ entlassen bzw. nicht weiter beschäftigt: vier Personen aufgrund ihrer jüdischen Abstammung, eine aufgrund ihres jüdischen Ehepartners und eine aus politischen Gründen. ${ }^{21}$ An

20 Struck an Bellmann, 14.9.1936, SKD, MfV Archiv, MVD n20;25/1, o. Pag.

21 Weitere Fälle sind bisher unbekannt. Die Erforschung der Biografien des technischen Personals der Staatlichen Sammlungen für Kunst und Wissenschaft in Dresden steht noch aus. 
den beiden Staatstheatern in Dresden waren acht Ensemblemitglieder, an der Technischen Hochschule neun Hochschullehrer aufgrund ihrer jüdischen Abstammung entlassen worden. ${ }^{22}$ An den Staatlichen Museen zu Berlin, die aufgrund ihrer Größe und Struktur am ehesten mit den Dresdner Staatlichen Sammlungen zu vergleichen sind, waren 13 wissenschaftliche Mitarbeiter ihres Amtes enthoben, beurlaubt oder entlassen worden. ${ }^{23}$

\section{Zunehmender Antisemitismus}

Doch auch über die vom SMV weitergegebenen Verhaltensregeln breitete sich der staatlich verordnete und in der Gesellschaft zunehmende Antisemitismus ungehindert im Kulturbereich aus. Den Museumsmitarbeitern wurde der Einkauf in von Juden geführten Geschäften verboten und der jüdischen Bevölkerung der Zutritt zu den Staatlichen Sammlungen verwehrt. Auf ministerielle Anordnung vom 18. November 1938 war an jedem Museum ein Schild auszuhängen: „Juden ist der Zutritt verboten ${ }^{\text {“24. }}$.

Von der Bibliotheksbenutzung wurden Juden einen Monat später, ab Dezember 1938, generell ausgeschlossen, infolge des Erlasses des Reichsministers für Wissenschaft, Erziehung und Volksbildung, Bernhard Rust, zum Ausschluss von Juden an Hochschulen vom 8. Dezember 1938. ${ }^{25}$ Einschränkungen der Bibliotheksbenutzung für Juden hatte die Sächsische Landesbibliothek jedoch bereits früher als eine der ersten wissenschaftlichen Bibliotheken in Deutschland eingeführt. So berichtet der Romanist Victor Klemperer in seinem Tagebuch, dass er ab 9. Oktober 1936 Bücher nicht mehr im Lesesaal benutzen durfte, sondern nur noch im Katalogsaal oder zu Hause. Der Bibliotheksdirektor $>$ Martin Bollert

\footnotetext{
22 Vgl. Schmeitzner, Mike: Tödlicher Hass: Antisemitismus und Judenverfolgung in Dresden 1933-1945, in: Medaon. Magazin für jüdisches Leben in Forschung und Bildung, 10, 2016, S. 1-28, hier: 7, siehe https://www.medaon.de/de/artikel/toedlicher-hass-antisemitismus-undjudenverfolgung-in-dresden-1933-1945/, Zugriff: 6.12.2019.

23 Grabowski, Jörn: „Versäumen Sie ihren arischen Nachweis nicht!“. Die Staatlichen Museen zu Berlin und ihr Umgang mit Bürgern jüdischer Abkunft 1933-1939, in: Grabowski/Winter 2013, S. 29-59, hier: 34-35. Für das Kunsthistorische Museum Wien ist für die Zeit nach dem „Anschluss“ Österreichs die antisemitisch motivierte Entlassung von zehn wissenschaftlichen Mitarbeitern überliefert. Vgl. Löscher, Monika u. Susanne Hehenberger: Akteurinnen und Akteure im Kunsthistorischen Museum Wien. Personelle Kontinuitäten und Brüche 1933/34 1938 - 1945, in: Baensch/Kratz-Kessemeier/Wimmer 2016, S. 129-146, hier: $131 \mathrm{f}$.

24 SMV an Direktoren der Staatlichen Sammlungen, 18.11.1938, SKD Archiv, 01/PS 45, Bd. 1, fol. 35. Vgl. SMV an Direktoren der Staatlichen Sammlungen u. a., 19.9.1935, SKD Archiv, 01/PS 38, fol. 240; ebenso: HStA Dresden, 13842, Nr. 115, o. Pag.

25 Vgl. Hermann 2011, S. 304 und Koch 2003, S. 79.
} 


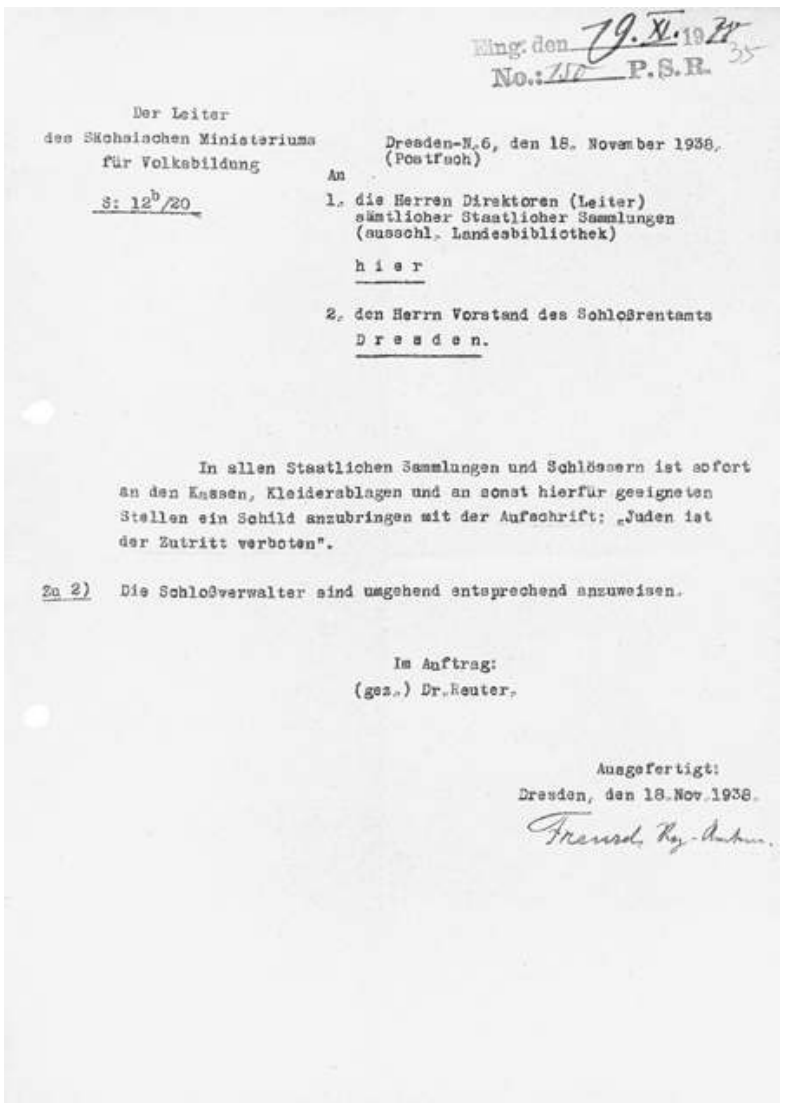

9 Brief des Leiters des Sächsischen Ministeriums für Volksbildung an die Direktoren der Staatlichen Sammlungen, 18.11.1938

soll jüdischen Lesern sogar angeboten haben, von ihnen gewünschte Bücher in den Dienstzimmern der wissenschaftlichen Mitarbeiter zu benutzen. ${ }^{26}$ Bereits 1933 hatte er für die beiden aus dem Bibliotheksdienst entlassenen jüdischen Mitarbeiterinnen $\triangleright$ Anna Löwenthal und $>$ Lucie Walther äußerst positive Arbeitszeugnisse verfasst.

Bollert nutzte die wenigen verbliebenen Freiräume durchaus geschickt aus, doch konnte er sich als Direktor nicht allen Dienstanweisungen entziehen. So war die Sächsische Landesbibliothek eine der ersten wissenschaftlichen Bibliotheken, die eine „NS-Handbibliothek“ einrichteten. Ihre Aufstellung mit an-

\footnotetext{
26 Vgl. Victor Klemperer, Tagebucheintrag, 9.10.1936, in: Victor Klemperer. Ich will Zeugnis ablegen bis zum Letzten. Tagebücher 1933-1941, hg. von. Walter Nowojski, überarbeitete Neuausgabe, Berlin 2015, Bd. 1, S. 256 f. und Hermann 2011, S. 304.
} 
fänglich 300 Bänden im Januar 1934 wurde mit einer Ansprache von Bollert und einer im Frühjahr stattfindenden Vortragsreihe von NSDAP-Gauschulungsleiter Werner Studentkowski öffentlichkeitswirksam zelebriert. ${ }^{27}$

Aber auch andere Sammlungsleiter unterwanderten die antijüdischen Dienstanweisungen. Der Direktor der Museen für Tierkunde und Völkerkunde, -Arnold Jacobi, gewährte dem ehemaligen Kustos $>$ Fritz van Emden auch nach dessen aus rassistischen Gründen erfolgten Entlassung, weiterhin die Nutzung der Sammlungsressourcen. ${ }^{28}$

\section{Personalabordnungen an andere Institutionen}

Die antisemitisch und politisch motivierten Entlassungen infolge des „Gesetzes zur Wiederherstellung des Berufsbeamtentums" waren nicht die einzigen Ursachen für Veränderungen im Personalbestand der Staatlichen Sammlungen. Auch die bald folgenden Einberufungen von Mitarbeitern zum Militärdienst während der "Sudetenkrise“ 1938 und im August/September 1939 wirkten sich auf die Mitarbeiteranzahl aus, ebenso die nach Kriegsbeginn häufiger werdenden Abordnungen.

In der Regel dienten diese dazu, Personalengpässe zu schließen, als „kriegswichtig" deklarierte Aufgaben zu übernehmen oder die Verwaltung in den besetzten Gebieten zu unterstützen. Von den Abordnungen waren insgesamt dreizehn Mitarbeiterinnen und Mitarbeiter aus unterschiedlichen Sammlungen betroffen. Tageweise oder für wenige Monate wurden an die Gemeinschaftliche Ministerialbibliothek in Dresden 1937 Dorothee Denecke, 1940 > Ulrich Dähnert in Teilzeit sowie 1942 • Erna von Watzdorf abgeordnet, während - Ragna Enking in der Sächsischen Landesbibliothek arbeiten musste. An das SMV wurden 1938 > Fritz Wiedemann und Ende 1939 > Arthur Leuschner abgeordnet, während $>$ Walter Holzhausen 1944 in Teilzeit Aufgaben im Statistischen Landesamt übernahm. Im „Heimatwerk Sachsen“ arbeiteten jeweils für etwa ein Jahr Ragna Enking, $\triangleright$ Elfriede Schulze-Battmann und $\triangleright$ Siegfried Wolf. Die beiden Letztgenannten, beide Freiwillige Wissenschaftliche Hilfsarbeiter an den Staatlichen Sammlungen, wechselten auf bessere berufliche Perspektiven hoffend 1939 zum „Heimatwerk Sachsen“. Für mehr als zwei Jahre wurden hin-

\footnotetext{
27 Vgl. „Eine NS-Bibliothek in der Landesbibliothek“; „Nationalsozialismus im Buch“ sowie „Nationalsozialismus im Buch II“, in: FK, 18.1.1934, S. 3; 16.5.1934, S. 5 u. 13.5.1934, S. 24; „Ehe Hitler kam“, in: DA, 15.5.1934, S. 3. Vgl. auch Hermann 2011, S. 301 f.

28 Vgl. Jacobi an Emden, 28.11.1933, u. Emden an Museen für Tierkunde und Völkerkunde, 14.4.1934, HStA Dresden, 13842, Nr. 114, Bd. 1, o. Pag.
} 
gegen $>$ Dorothee von Watzdorf an die Universitäts- und Staatsbibliothek Straßburg und $\gg$ Hans Hofmann an die Staatsbibliothek Krakau abgeordnet.

Drei weitere Mitarbeiter wurden für partei-, verwaltungs- und kulturpolitische Aufgaben freigestellt. An die Gauschule Hammerleubsdorf wurde • Hellmuth Buck als Leiter parteipolitscher Lehrgänge und späterer Schulleiter abgeordnet. ${ }^{29}$ Der Anthropologe $>$ Michael Hesch wurde für die Durchführung anthropologischer Untersuchungen an das Rasse- und Siedlungshauptamt der SS (RuSHA) beurlaubt und $\triangleright$ Rolf Hetsch an das Reichsministerium für Volksaufklärung und Propaganda (RMVP), wo er in die „Aktion Entartete Kunst“ involviert war.

Ursprünglich waren alle Abordnungen im nationalsozialistischen Staat dazu gedacht, Personalengpässe in der Verwaltung zu überwinden. Allerdings verursachten diese Versetzungen neue Leerstellen, wie eine Anmerkung in der Registrande vom Mai 1940 belegt: „Es ist unbedingt nötig, daß der Betrieb der Landesbibliothek aufrecht erhalten wird. Dies ist aber jetzt schon kaum mehr möglich! [...] Bitte von einer Abordnung abzusehen " ${ }^{\text {"30 }}$. Andererseits wurde Ende April 1942 die Abordnung von Erna von Watzdorf vom Historischen Museum an die Landesbibliothek aufgehoben, „da die Genannte zur Durchführung der dringlichen Bergungsarbeiten im Historischen Museum benötigt ${ }^{\text {“31 }}$ wurde.

\section{Auswirkungen der „Sudetenkrise“ 1938}

Stärker als die Abordnung von Personal wirkten sich die Einberufungen zum Militärdienst aus. Sie erreichten die Staatlichen Sammlungen aufgrund der politischen Lage während der "Sudetenkrise“ ab 1938. Unter den wissenschaftlichen Mitarbeitern waren davon zunächst nur zwei Wissenschaftliche Hilfsarbeiter von den Museen für Tierkunde und Völkerkunde betroffen, der Anthropologe $\triangleright$ Berthold Pfaul sowie der Zoologe $>$ Wilhelm Meise, die nach wenigen Wochen wieder an die Sammlungen zurückkehrten. Doch schon ein Jahr später, ab 1939, sollte sich die Situation des Wissenschaftlichen Personals an den Staatlichen Sammlungen weiter verändern und die Einberufungen zum Militärdienst zunehmen.

Zu Jahresbeginn 1939 gab es dreizehn Museen in den Staatlichen Sammlungen mit elf Direktoren, denn im April 1938 war das Landesmuseum für Vorgeschichte aus dem Museum für Mineralogie, Geologie und Vorgeschichte ausge-

\footnotetext{
Siehe S. 112.

30 Vgl. Registrande, Nr. 599, Referat Sammlungen an Leiter SMV, 16.5.1940, SKD Archiv, 01/PS 139, Nr. 599.

31 SMV, Gruve, an Direktion Historisches Museum, z. H. Fichtner, 14.7.1942, HStA Dresden, 11125, Nr. 18991, Bd. 4, fol. 89.
} 
gliedert und verselbständigt worden. Die gemeinsame Verwaltung von Grünem Gewölbe und Historischem Museum durch $\triangleright$ Erich Haenel blieb bestehen, der Direktor der Porzellansammlung leitete zugleich das Kunstgewerbemuseum, und das Münzkabinett hatte nach der Pensionierung von $>$ Walter Schwinkowski keinen hauptamtlichen Direktor mehr. Die Anzahl der Kustoden war seit 1933 auf vier gesunken, die der Freiwilligen Wissenschaftlicher Hilfsarbeiter auf einen. Die entstandenen Personalengpässe versuchte man möglichst sparsam durch die Erhöhung der Anzahl der Wissenschaftlichen Hilfsarbeiter auf zehn auszugleichen. Sie verrichteten mittlerweile dieselbe Arbeit wie Kuratoren oder Direktoren, erhielten aber geringere Gehälter.

Auswirkungen der „Mobilmachung“ 1939

Ende August 1939, unmittelbar vor dem Überfall der Deutschen Wehr-

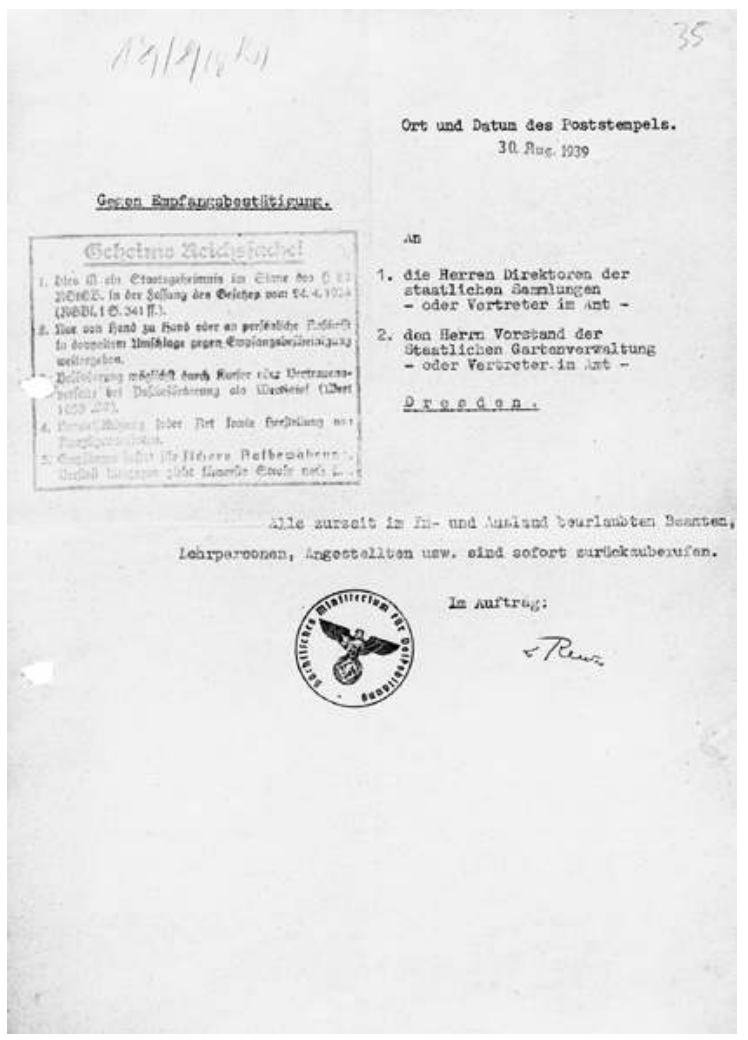

10 Brief des Sächsischen Ministeriums für Volksbildung an die Direktoren der Staatlichen Sammlungen, 30.8.1939 macht auf Polen, d.h. wenige Tage vor Beginn des Zweiten Weltkrieges, liefen im Rahmen der allgemeinen Mobilmachung auch die Vorbereitungen für die Sicherungsmaßnahmen an den Museen an. Dazu zählten die vom SMV am 30. August 1939 als „Geheime Reichssache“ angeordnete Urlaubssperre und der Rückruf aller im In- und Ausland im Urlaub befindlichen Beamten und Angestellten. ${ }^{32}$ Noch bevor das Ministerium diese Anordnungen an die Sammlungsdirektoren sandte, waren die im Urlaub befindlichen Wissenschaftler zurückbeordert worden.

32 Vgl. SMV an Direktoren der Staatlichen Sammlungen, 30.8.1939, SKD Archiv, 02/VA 50, fol. 35,36 . 
Bereits am 28. August 1939 hatte das RMWEV in Berlin reichsweit den Schutz von Kunstwerken innerhalb der Museen angeordnet. ${ }^{33}$ Noch am selben Tag wurde der Wissenschaftliche Hilfsarbeiter $\triangleright$ Klaus Günther von seinem Direktor $\triangleright$ Hans Kummerlöwe aus dem Urlaub im italienischen Amalfi zurückgerufen. Dieser schrieb: „Infolge Ausfalles einer Kraft am Museum muss ich Sie hierdurch dienst-

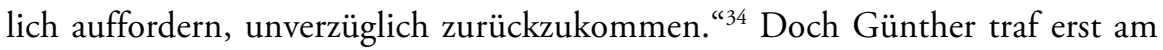
8. September 1939 in Dresden ein, weshalb ihn Kummerlöwe rügte:

Im Einverständnis mit dem Ministerium muss ich Ihnen hierdurch mein stärkstes Befremden und dienstliches Missfallen ausdrücken, dass Sie zurückzukehren erst heute für notwendig finden. Es ist für staatliche Angestellten und Beamten [sic!] bekanntlich eine Selbstverständlichkeit [...], dass sie unter gespannten politischen Verhältnissen unverzüglich ihren Erholungsurlaub abbrechen und zurückkehren. ${ }^{35}$

Ebenfalls am 28. August 1939 wurde der Wissenschaftliche Hilfsarbeiter $\triangleright$ Walter Holzhausen zurückbeordert, „um die Sicherstellung der Sammlungen des Grünen Gewölbes zu leiten"36. Er unterbrach seinen Urlaub in Prerow und ließ, da „[w]eder die Eile der sofort anzutretenden Rückreise noch die Beförde-

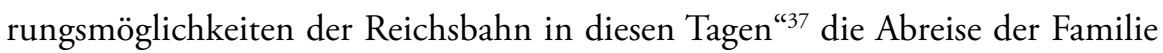
gestatteten, seine Frau mit den Kindern an der Ostsee zurück und holte sie zwei Wochen später ab. Inzwischen war auch der Direktor des Grünen Gewölbes, Erich Haenel, aus dem Erholungsurlaub zurückgekehrt. ${ }^{38}$ Die Anordnung der unverzüglichen Rückkehr von Mitarbeitern der Staatlichen Sammlungen aus ihrem Jahresurlaub war einerseits wegen des Objektschutzes in Anbetracht der unmittelbar bevorstehenden, von der Wehrmacht gezielt herbeigeführten Kriegshandlungen notwendig, andererseits, weil im August mehrere Mitarbeiter ihre Einberufungsbefehle erhalten hatten und weitere zu erwarten waren.

\footnotetext{
33 Vgl. Reichsminister für Wissenschaft, Erziehung und Volksbildung, Berlin, an die Landesregierungen, 28.8.1939, HStA Dresden, 10701, Nr. 320/1, Bd. 1, fol. 1. Siehe S. 147 ff.

34 Museum für Tierkunde, Kummerlöwe, an Günther, 28.8.1939, HStA Dresden, 13842, Nr. 114, Bd. 1, o. Pag. Der Wortlaut des Briefes legt die Vermutung nahe, dass es sich hierbei um eine codierte Nachricht handelt - es war kein Mitarbeiter erkrankt oder anderweitig ausgefallen.

35 Museum für Tierkunde, Kummerlöwe, an Günther, 8.9.1939, ebd., o. Pag.

36 Holzhausen, Grünes Gewölbe, an SMV, 5.9.1939, HStA Dresden, 11125, Nr. 22882, fol. 47.

37 Ebd.

38 Vgl. ebd.
} 
Zum Militärdienst eingezogen wurden am 15. August 1939 •Alfred Beck, der jedoch bereits Anfang Oktober seine Arbeit als Restaurator am Mathematisch-Physikalischen Salon fortsetzen konnte, am 22. August 1939 der Wissenschaftliche Hilfsarbeiter $\triangleright$ Wilhelm Meise vom Museum für Tierkunde, der erst nach dem Krieg und Kriegsgefangenschaft nach Dresden zurückkehrte, sowie am 26. August 1939 Restaurator A Alfred Unger, der ab Anfang 1940 wieder in der Gemäldegalerie arbeitete. Am 27. August 1939 wurde der Wissenschaftliche Bibliothekar $\triangleright$ Helmut Schneider eingezogen, obwohl er nach dem Tod seiner Frau mit seinem noch minderjährigen Sohn allein war. Schneider kehrte Anfang April 1940 an die Landesbibliothek zurück, wurde jedoch im Februar 1945 zum Volkssturm eingezogen. Von September bis Dezember 1939 war außerdem - Herbert Bellmann einberufen worden, der bei der Technischen Nothilfe in Dresden eingesetzt wurde.

Um die durch die zahlreichen Einberufungen zur Wehrmacht entstandenen Personallücken aufzufüllen, wurde vier Tage nach Kriegsbeginn in der Presse dazu aufgefordert, dass bereits pensionierte Beamte binnen dreier Tage an ihre alten Arbeitsplätze zurückkehren sollten. ${ }^{39}$ Dies hatte zur Folge, dass auch pensionierte Museumsmitarbeiter ihre ehemaligen Arbeitgeber kontaktierten. Primär waren dies Aufsichts- und Reinigungskräfte sowie Handwerker aus fast allen Staatlichen Sammlungen. ${ }^{40}$ Der seit Mai 1938 im Ruhestand befindliche Präparator des Münzkabinetts, der 66-jährige Johannes Neubert, meldete der Direktion, „daß sich sein Gesundheitszustand noch nicht gefestigt hat, was aus beifolgendem Zeugnis zu ersehen ist“"41, er also nicht wieder arbeiten könne. - Reinhard Schmelzer, der seit Juni 1937 pensionierte Inspektor des Kunstgewerbemuseums, wurde hingegen von seinem ehemaligen Vorgesetzten $>$ Fritz Fichtner gebeten, wieder im Museum tätig zu werden. Am 29. August 1939 informierte Fichtner das SMV, dass Schmelzer ins Museum zurückkehren solle, sobald dessen Nachfolger, Inspektor Helmuth Weidensdorfer, zum Militärdienst einberufen werde. Zwei Tage später erhielt Schmelzer von Ministerialrat Hans Reuter die Aufforderung, sich im Falle einer Mobilmachung sofort bei Fichtner zu melden. ${ }^{42}$ Dieses Szenario trat kurz darauf ein und Schmelzer setzte ab Herbst

\footnotetext{
39 Vgl. „Meldepflicht innerhalb von drei Tagen. Die Verordnung zur Wiederverwendung der Ruhestandsbeamten“, in: FK, 5.9.1939, S. 10.

40 Vgl. SMV, Fichtner, an Leiter SMV, 19.6.1942, HStA Dresden, 11125, Nr. 18962, fol. 49.

41 J. Neubert an die Direktion des Münzkabinetts, 7.9.1939, SKD, MK, 1939, fol. 172.

42 Vgl. Kunstgewerbemuseum, Fichtner, an SMV, Reuter, 29.8.1939 u. SMV, Reuter, an Kunstgewerbemuseum, Fichtner, 31.8.1939, beide: SKD Archiv, 02/VA 53, Bd. 2, o. Pag.
} 
1939 im Alter von 65 Jahren seine Tätigkeit als Inspektor am Kunstgewerbemuseum fort, wo er bis 1945 vor allem für Ausstellungsvorbereitungen, Führungen und Bergungsarbeiten zuständig war. Am 9. September 1939 meldete sich auch der ehemalige Direktor der Porzellansammlung,, Ernst Zimmermann, der seit seiner Pensionierung 1933 seinen Nachfolger Fichtner bei der Arbeit im Museum unterstützt hatte, zum Dienst zurück. Allerdings konnte er diesen aufgrund seiner eingeschränkten Gesundheit nicht mehr antreten.

\section{Freistellungen vom Militärdienst}

Um trotz der Einberufungen von Mitarbeitern zum Militärdienst die Museumsarbeit während des Zweiten Weltkrieges fortführen zu können, wurde für mehrere Mitarbeiter deren Nichteinziehung bzw. eine befristete oder widerrufliche Entlassung aus dem Militärdienst beantragt, eine sogenannte „Unabkömmlichkeitsstellung“, auch Uk-Stellung genannt. Als „unabkömmlich“ konnten Fachkräfte gestellt werden, die zur Durchführung der Reichsverteidigung in der Kriegswirtschaft, im Verkehr oder der Verwaltung unentbehrlich und unersetzbar waren. Da sich Museen dem Erlass „Museen während des Kriegszustandes" des Reichsministers für Wissenschaft, Erziehung und Volksbildung vom 8. Dezember 1939 zufolge „aktiv in die innere Front des uns aufgezwungenen Abwehrkampfes eingliedern" ${ }^{43}$, also an der „Heimatfront" kämpften, und zu ihren Aufgaben im Krieg der Schutz des ihnen anvertrauten Kulturgutes wie auch das „Aufmuntern“ der Bevölkerung zählte, galt die Museumsarbeit als „kriegswichtig“. ${ }^{44}$ Daher konnte auch für Museumsmitarbeiter, für die es aufgrund ihrer spezialisierten Fachkenntnisse keinen Ersatz gab, eine Uk-Stellung beantragt werden. Diesen Uk-Antrag stellte die jeweilige Museumsdirektion über - Fritz Fichtner bzw. das Referat der Staatlichen Sammlungen im SMV und den Leiter dieses Ministeriums beim Wehrbezirkskommando Dresden. Auf diesem Weg wurden zahlreiche wissenschaftliche Mitarbeiter mehrfach, oft über Jahre hinweg, uk-gestellt: darunter $\triangleright$ Walter Holzhausen, $\triangleright$ Robert Oertel, $\triangleright$ Franz Schubert, $\triangleright$ Alfred Unger, $\triangleright$ Richard Schmidt, $\triangleright$ Alfred Beck, $\triangleright$ Herbert Bellmann,

43 Erlass des Reichsministers für Wissenschaft, Erziehung und Volksbildung, 8.12.1939, übermittelt durch Leiter SMV an Direktoren der Staatlichen Sammlungen, 18.12.1939, SKD Archiv, 02/VA 50, fol. 101-103.

44 Siehe auch S. 152, 169. 


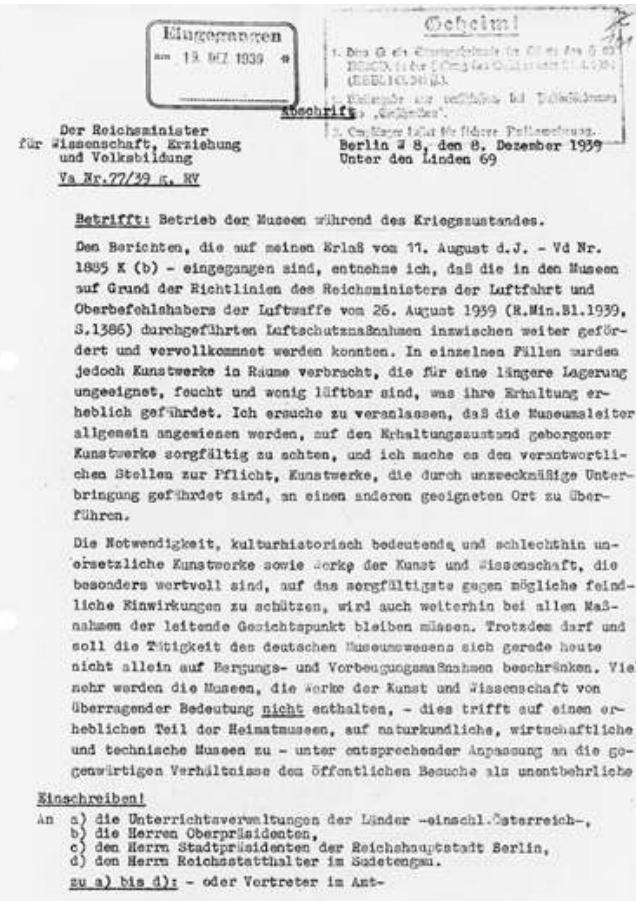

$-2-$

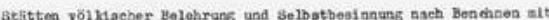

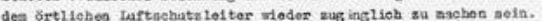
Aber auck bel cen kueeen, die don groseren oder efnen erhebllohen Toll throu Qutes gebergoe haben und ve1torhin borgen missen, lat

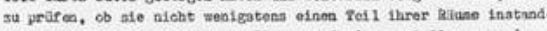
cotzon und in thnce Tollassstellunjen, Sonderausatellungen und

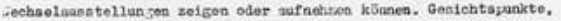

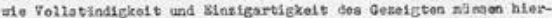

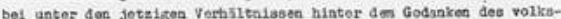
blidaeriachen und kulturellea Eineatzes surlicktreten.

Iol habe von dee entaprechenden sir aus dea Rreilee der deutsohon Museansleat ter, der doutschos Gecoinden und Ger Lendeountercichta-

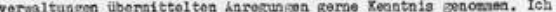
crase

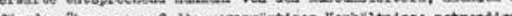
vot arbelten in zesentilehon beendet aind, da\& wio die Soutechon Haseen aktiv in die innere Froat dos una nufgezmungonen Absehrizasples oisgliedero. Jedes, sel es auch behelfsslaig und anopruchalos, geöffuete Wuseun gibt zathrelehos Volksgenoasen Anregung und Proude und stirkt a10 in inres Vertraues.

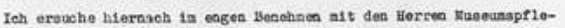
gom, denen feh einon Abaruck dioseo Belasaes Jlelehzeltig unittelbar tbergende, das Rrforterliche zu veranlagson.

$$
\text { goz. } R \text { u a t. }
$$$$
\text { -... }
$$

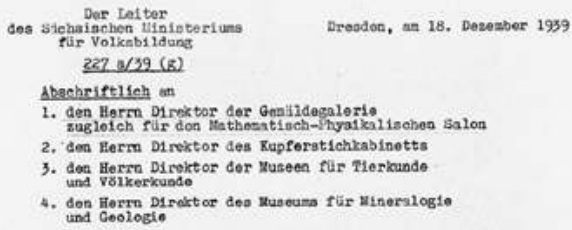

11 Erlass des Reichsministers für Wissenschaft, Erziehung und Volksbildung, Betrieb der Museen während des Kriegszustandes, 8.12.1939

•Martin Heydrich, • Walther Fischer, • Walter Häntzschel, • Klaus Günther, $\triangleright$ Robert Reichert, $\triangleright$ Helmut Hofer und $\triangleright$ Ewald Jammers. ${ }^{45}$

Die Begründungen der Anträge ähnelten sich. Im Falle von Holzhausen, dem „die Bewahrung und Erhaltung der unschätzbaren Kunstwerke des Grünen Gewölbes allein verantwortlich" übertragen war, wurde angeführt, er sei

der einzige, der über die einzelnen Werke nach Art, Erhaltung, Wert und Anzahl Bescheid weiß. Ihre kriegsmässige Bergung in nicht musealen Räumen macht eine ständige Kontrolle durch ihn als einzigen Sachverständigen notwendig. ${ }^{46}$

45 Aus den überlieferten Akten im Archiv der Staatlichen Kunstsammlungen und im Sächsischen Staatsarchiv, Hauptstaatsarchiv Dresden geht hervor, dass auch für technisches Personal, wie für Handwerker und Aufsichtskräfte, Uk-Anträge gestellt wurden. Diese Personen wurden im Rahmen der Bergung für das Verpacken der Objekte und den Transport an die Auslagerungsorte benötigt. 46 Leiter SMV, 16.11.1942, HStA Dresden, 11125, Nr. 22882, fol. 213. 
Bei Fischer vom Museum für Mineralogie und Geologie wurden dessen Vertretung für Museumsdirektor $\triangleright$ Eberhard Rimann in der Lehre an der Technischen Hochschule und seine „Aufträge von Feldgeologenstäben“ betont, außerdem sei er „auf Grund seines Gesundheitszustandes nicht mehr frontverwendungsfähig “ ${ }^{* 7}$. Kurz und prägnant war 1941 der Antrag für Günther formuliert: „Dr. Günther ist der einzige Zoologe, der beim Museum für Tierkunde noch vorhanden ist. Wenn er eingezogen wird, müsste die ganze wissenschaftliche Arbeit abgebrochen und das Museum geschlossen werden. " ${ }^{48}$

Ein wesentliches Argument war der Kulturgutschutz. Im Uk-Antrag für Schubert betonte $\triangleright$ Hans Posse, der Direktor der Gemäldegalerie, 1941 noch die „im öffentlichen Interesse liegende Offenhaltung des Kupferstichkabinetts“ und wies darauf hin, dass es „,neben dem allgemeinen Publikumsbesuch weitgehende Bedeutung als Forschungsinstitut für die Wissenschaft als auch für das gesamte Verlagswesen und die Presse hat" und seine Bestände „wertvollstes, national wichtiges deutsches Kulturgut ${ }^{\text {“ }}{ }^{49}$ seien. 1942 argumentierte er, dass sonst

eine der grössten und berühmtesten Sammlungen ihrer Art in der Welt ohne einen Bescheid wissenden Wissenschaftler und ohne jede konservatorische Betreuung dastände, was besonders im Hinblick auf die kriegsbedingten Luftschutzsicherungen und die Bergungsmassnahmen zu schwersten Schädigungen wertvollstem nationalen Kunstbesitzes führen würde. ${ }^{50}$

Fichtner formulierte indes in pragmatischer Reduktion:

Mit Rücksicht auf die Vorfälle in Lübeck und Rostock birgt das Staatl. Kupferstichkabinett z.Zt. sämtliche Kunstwerke und verbringt sie nach außerhalb. Da [...] die Direktorenstelle noch nicht wieder besetzt worden ist, hat die gesamte Bergungsarbeit Dr. Schubert durchzuführen. Ersatz für ihn ist nicht vorhanden. [...] hier liegt aber im Interesse der Sicherung des unwiederbringlichen Nationalvermögens ein ganz besonders gelagerter Fall vor ${ }^{51}$.

\footnotetext{
47 Leiter SMV, 12.1940, HStA Dresden, 13843, Nr. 267, fol. 66.

48 Museen für Tierkunde und Völkerkunde, Hesch, an SMV, 18.6.1941, HStA Dresden, 13859, Nr. 2571, fol. 55.

49 Kupferstich-Kabinett, Direktor i. V. Posse, an SMV, 3.1.1941, HStA Dresden, 11125, Nr. 22889, fol. 86.

50 Kupferstich-Kabinett, Direktor i. V. Posse, an Leiter SMV, 18.5.1942, ebd., fol. 112.

51 SMV, Fichtner, an Leiter SMV, 18.5.1942, ebd., fol. 113. Siehe S. 85.
} 


\section{Weitere Einberufungen}

Aufgrund einer nicht oder nicht mehr erfolgenden Uk-Stellung wurden indes im Verlauf des Krieges weitere Mitarbeiter der Staatlichen Sammlungen zum Militärdienst einberufen. An der Front kämpften ab $1940 \triangleright$ Helmut Hofer, $\triangleright$ Erhart Kästner sowie kurzzeitig $\triangleright$ Martin Heydrich und $\triangleright$ Karl Assmann. $\triangleright$ Artur Pietzsch wurde 1941 zum Kriegsdienst eingezogen. Weitere Einberufungen erhielten 1942 • Walter Häntzschel, \Michael Hesch, der seinen Militärdienst nicht an der Front, sondern beim RuSHA ableistete, sowie • Ulrich Dähnert und 1943 -Alfred Beck. Auch 1944 wurden mehrere wissenschaftliche Mitarbeiter trotz ihrer verantwortungsvollen Tätigkeit nach mehrfacher Uk-Stellung zum Militärdienst eingezogen, darunter $\triangleright$ Klaus Günther am 23. August 1944 und $\triangleright$ Ewald Jammers am 25. September 1944 sowie im Rahmen des „Deutschen Volkssturms“ im Oktober 1944 noch ^Georg Bierbaum, ^Helmut Deckert und - Robert Oertel..$^{52}$ Sie alle kehrten im Mai 1945 aus dem Krieg oder spätestens 1947 aus der Kriegsgefangenschaft zurück.

-Franz Schubert, der bereits am 31. Januar 1944 eingezogen worden war, gilt seit 1945 als kriegsbedingt vermisst. \& Walter Grünberg, der ab 1940 an der Front kämpfte, fiel im Juli 1943. Tragisch endete das Leben von $>$ Helmut Schneider, der im März 1945 zum „Volkssturm“ eingezogen, einen Monat später in einem Dresdner Lazarett starb und einen noch minderjährigen Sohn hinterließ..$^{53}$

Für andere Mitarbeiter wurden seitens der Staatlichen Sammlungen keine Uk-Stellungen mehr beantragt. So meldete Fichtner im Januar 1941: „Nach zweimaliger Rücksprache [...] mit Dr. Hesch ist eine weitere uk-Stellung des Herrn Dr. Bellmann z. Zt. nicht mehr zu vertreten." ${ }^{4}$

\footnotetext{
52 Vgl. Günther an Abt. IV/7, Reichsstatthalter, 21.8.1944, HStA Dresden, 13859, Nr. 2571, fol. 64; SLUB Mscr.Dresd.App.2830, fol. 66 sowie SLUB PA Jammers; Fragebogen Georg Bierbaum, 17.7.1945, HStA Dresden, 19117, Nr. 1794, PA Bierbaum; Gemäldegalerie, Voss, an Leiter SMV, 23.10.1944, HStA Dresden, 13859, Nr. 6178, fol. 74. Der „Volkssturm“ war per Führererlass am 25.9.1944 ausgerufen worden. Vgl. „Erlaß des Führers über die Bildung des Deutschen Volkssturms“, 25.9.1944, RGBl., Teil I, 1944, Nr. 53.

53 Vgl. Kupferstich-Kabinett, i. V. Voss, an Abteilung IV/7, Reichsstatthalter, 31.1.1944, HStA Dresden, 11125, Nr. 22889, fol. 143 u. Landesverwaltung, Abt. Museen, Enking, an Grohmann, Kulturabteilung, 3.8.1945, SKD Archiv 02/VA 162, fol. 4 f.; Landesmuseum für Vorgeschichte, Bierbaum, am Leiter SMV, 6.6.1940, HStA Dresden, 13843, Nr. 267, Bl. 41; Vgl. Schachtmann/Widera 2013, S. 31; Sächsische Landesbibliothek, Neubert, an SMV, Abt. IV/7, 7.3.1945 u. 27.3.1945, beide: SLUB PA Schneider.
}

54 Eintrag in der Registrande, 15.1.1942, HStA Dresden, 11125, Nr. 22847, A.-Nr. 2305. 


\section{Verbleibende Mitarbeiter}

Ein Ausnahme bildete vor allem $>$ Fritz Fichtner. Er war zum 1. Dezember 1941 als Kriegsverwaltungsrat beim Heeresmuseum zum Militärdienst einberufen worden, ${ }^{55}$ konnte aber seine Tätigkeit für die Staatlichen Sammlungen weiterhin fortsetzen. Er selbst schlug vor:

Geschäfte als Sammlungsdirektor der Staatl. Porzellangalerie und des Staatl. Kunstgewerbemuseums können von mir, solange ich in Dresden liege, selbst weitergeführt werden. Vertretung in meiner Abwesenheit übernehmen Direktor Prof. Dr. Müller und Direktor Dr. Hesch. Geschäfte als Abteilungsleiter führt in Vertretung Herr Reg.-Direktor Dr. Dedering. Zur Sachbearbeitung und Erledigung von Akten stehe ich mit Wissen meiner militärischen Vorgesetzten Dienstag und Freitag zur Verfügung. ${ }^{56}$

Erst im Juli 1942 stellte der Leiter des SMV einen Uk-Antrag für Fichtner, denn dieser müsse

für seine eigentlichen Aufgaben als Museumsdirektor und zwar nicht nur für seine eigenen Sammlungen - Porzellangalerie und Kunstgewerbesammlung -, sondern auch als Stellvertreter bei den direktionslosen Sammlungen (Historisches Museum nebst Gewehrgalerie, Kupferstichkabinett, Münzkabinett, Mathematisch-Physikalischer Salon und Skulpturensammlung), wie auch zur Vertretung des zur Zeit erkrankten Direktors der Gemäldegalerie wieder in vollem Umfange frei gemacht werden. ${ }^{57}$

Darüber hinaus war Fichtners Anwesenheit ,im Interesse einer schnelleren und reibungslosen Durchführung der dringenden Bergungsmassnahmen " 58 notwendig, schließlich hatte ihn der Reichsstatthalter damit beauftragt. Nachdem dieser Uk-Antrag zunächst unbeantwortet blieb, wurde er im November 1942 nach erneuter Anfrage mit Verweis auf eine allgemeine Sperre von Uk-Genehmigungen abgelehnt. ${ }^{59}$ Allerdings zog diese Entscheidung keine Konsequenzen nach sich - Fichtner arbeitete weiterhin an seinen verschiedenen Dienststellen als Museumsdirektor, Referent der Staatlichen Sammlungen im SMV und als Kriegsverwaltungsrat.

\footnotetext{
55 Oberbefehlshaber des Heeres Berlin an Fichtner, Abschrift, 25.11.1941 u. Einberufungsbefehl, Wehrmeldeamt Dresden, Abschrift, o. Dat., HStA Dresden, 13859, Nr. 1553, fol. 47 f.

56 Fichtner, Porzellansammlung, an Leiter SMV, 3.12.1941, HStA Dresden, 11125, Nr. 22891, fol. 64 .

57 Leiter SMV an Reichsstatthalter, 23.7.1942, HStA Dresden, 13859, Nr. 1553, fol. 53-55, 75-78, hier: $55 \mathrm{r}$

58 Ebd. Siehe S. 156.

59 Vgl. Wehrersatz-Inspektion Dresden an Leiter SMV, 18.11.1942, ebd., fol. 65.
} 
Die Direktoren der Gemäldegalerie wurden im Zweiten Weltkrieg ebenfalls nicht zum Militär einberufen. Der 1879 geborene $>$ Hans Posse hatte im Ersten Weltkrieg an der Front gekämpft, sein fünf Jahre jüngerer Nachfolger $\triangleright$ Hermann Voss war beim Kriegspresseamt eingesetzt gewesen. Durch ihre Aufgaben als „Sonderbeauftragte des Führers“ für den Aufbau des „Führermuseums“ in Linz standen sie unter besonderem Schutz. Dieser wurde ebenfalls $\gg$ Gottfried Reimer und $\triangleright$ Fritz Wiedemann zuteil, die als Referent bzw. Rechnungsführer für den „Sonderauftrag Linz" tätig waren. > Hellmuth Buck wurde vermutlich aufgrund seiner engen Verbindungen innerhalb der NSDAP und der an der Gauschule Hammerleubsdorf und später im SMV übernommenen Aufgaben von einer Einberufung verschont. Lediglich zu einer ideologischen Betreuung der deutschen Truppen in Norwegen wurde er im Frühjahr 1942 abkommandiert.

Der Direktor der Sächsischen Landesbibliothek, $\downarrow$ Hermann Neubert, hatte als Soldat im Ersten Weltkrieg seine rechte Hand verloren und war vom Militärdienst zurückgestellt worden. Er brauchte keine Einberufung zu befürchten, ebenso $\triangleright$ Walter Müller, Direktor der Skulpturensammlung, der als 1877 Geborener das Pensionsalter fast erreicht hatte.

Trotz der mehrheitlich über längere Zeit positiv beschiedenen Uk-Anträge und der relativ gering erscheinenden Quote an Einberufungen von wissenschaftlichen Mitarbeitern der Staatlichen Sammlungen verschlechterte sich die Personalsituation mit jedem Kriegsjahr. Die Stellen der zur Wehrmacht einberufenen oder an andere Dienststellen abgeordneten Mitarbeiter mussten freigehalten werden, jene Stellen der in den Ruhestand tretenden, verstorbenen oder im Krieg gefallenen Mitarbeiter wurden aus Sparsamkeitsgründen oftmals nicht wieder besetzt. ${ }^{60}$ Weitere Museumsverwaltungen wurden zusammengelegt.

Anfang 1945 existierten in den Staatlichen Sammlungen noch zwölf Museen - das Armeemuseum war im November 1939 in Verwaltung des Heeres übergegangen. Nur noch drei Museen wurden von eigenen Direktoren geleitet: die Gemäldegalerie von Voss, die Porzellansammlung von Fichtner und die Skulpturensammlung von Müller. Die anderen Museen wurden von diesen Direktoren mitverwaltet oder von den verbliebenen drei Kustoden und sechs Wissenschaftlichen Hilfsarbeitern bzw. von Restauratoren betreut. Dies hatte Reichsstatthalter Mutschmann am 11. August 1944 angeordnet. ${ }^{61}$

\footnotetext{
${ }^{60}$ Anders als in England wurden keine Frauen als Ersatz eingestellt. Vgl. Vortrag von Catherine Pearson "I knew what I wanted to do and just went ahead': The experiences of museum staff during the Second World War", London, 14.7.2018. Die Publikation ist in Vorbereitung.

${ }_{61}$ Vgl. Reichsstatthalter Mutschmann an Fichtner, SMV, Abteilung IV/7, 11.8.1944, HStA Dresden, 11125, Nr. 23058, fol. 84a.
} 


\section{Der Reichsstatthalter in Sachsen \\ - Landesregierung - \\ $w 50^{3}$}

Herm

Professor Dr. Bichtner

Abteilung IV,?
(10) Dresden A 1, am 11.Aug. 1944

Postschliebfach 78

Fernaprecher 24371

Fernatheibet 013 to

Betr.: Preigabe der Wissenschaftler an den Statl. Iuseen

Ich bestimme, daß die wissenschaftlichen Krafte der Staatlichen Sarmlungen der Jahrgänge 1897 und junger, je nachdem sie aufgerufen werden, freizustellen sind. Sollte ein Nuseum uber keinen Missenschaftler mehr verfugen, hat die Verantwortung uber die Huseumsbestände und die Depots der Konservator bezw. Präparator im Binvernehmen wit dem Leiter eines noch zu bestimmenden benachbarten lluseums zu thernehmen.

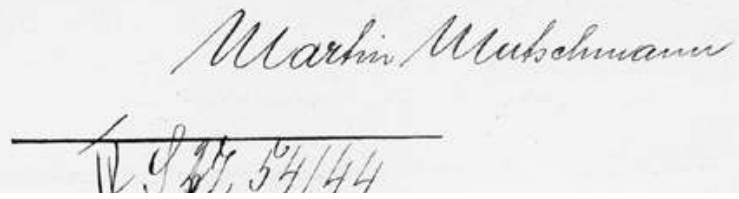

12 Brief von Reichsstatthalter Martin Mutschmann an Fritz Fichtner, Abteilung IV/7 des Sächsischen Ministeriums für Volksbildung, 11.8.1944

Konservatoren, Präparatoren und Inspektoren mit Sammlungsverantwortung waren in den letzten Kriegsmonaten für die Gemäldegalerie $>$ Alfred Unger, das Kupferstich-Kabinett $\triangleright$ Max Hahn, die Porzellansammlung $\triangleright$ Arthur Leuschner und $\triangleright$ Richard Schmidt, das Grüne Gewölbe $\triangleright$ Kurt Köhn, das Historische Museum $\triangleright$ Curt Sander, $\triangleright$ Kurt Hoppe fürs Münzkabinett, $>$ Paul Täubrich für die Skulpturensammlung, $>$ Reinhard Schmelzer im Kunstgewerbemuseum, - Robert Reichert und $>$ Johannes Draeseke für die Museen für Tierkunde, Rassenkunde und Völkerkunde sowie $>$ Rudolf Schwarze für das Museum für Mineralogie und Geologie, das Landesmuseum für Vorgeschichte und den Mathematisch-Physikalischen Salon. ${ }^{62}$

Insgesamt war das wissenschaftliche Personal in den Museen der Staatlichen Sammlungen seit der „Machtübernahme“ durch die Nationalsozialisten, d.h. in nur zwölf Jahren, um mehr als die Hälfte von 27 auf 13 Personen reduziert worden, während die Anzahl der Mitarbeiterinnen und Mitarbeiter in der Sächsi-

62 Vgl. SMV, Fichtner, an den Reichsstatthalter, 11.8.1944, ebd., fol. 84b. 
schen Landesbibliothek weitgehend gleich geblieben war. Bei sich stark veränderten Aufgaben, die im Folgenden noch ausführlich erläutert werden, führte diese Situation zu einer enormen Mehrbelastung des verbleibenden Personals.

Insbesondere die personellen Veränderungen in den Direktorenstellen sind interessant: Zwischen 1933 und 1943 - also innerhalb von nur zehn Jahren - waren vier Direktoren der Staatlichen Sammlungen gestorben und sieben weitere aus unterschiedlichen Gründen aus ihrem Amt ausgeschieden.

\section{Personalia: Porzellansammlung}

Als sich abzeichnete, dass der mittlerweile 66-jährige Direktor der Porzellansammlung $>$ Ernst Zimmermann demnächst in den Ruhestand versetzt werden würde, bat Oberregierungsrat Groß vom SMV am 10. Januar 1933 Ludwig Schnorr von Carolsfeld vom Schloßmuseum in Berlin um seinen Rat bezüglich

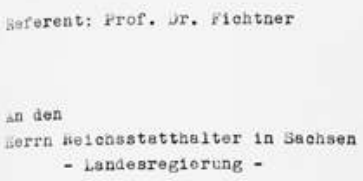

Auf Grund der Veroranung des Herra Re1chaststhalters, freigebe aller dissenchoftler der Jahrginge 1897 und jenger an ten Wuseen schlage toh folgenden Organisationsplen vor:

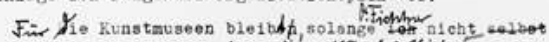
zum Frontdienst terengezogen wirdp, the taterhesfich bie pripnretoren dor elnzelnen Saralungen, bez. Inspektoren sind for des seohgemben Zustand pes Kuseimagutea in den Depots verentivortich.

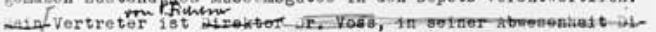
Dentor pror. Or. Jaller.

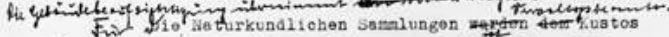
ur. Fischer, der nieht wit sinziehung zu rechnen hat, unterateilt. Ihm sind die einzelnen Fripotetoren der einzelnen filuseen far den sachgeminBen Zustand der Depots verantwortlloh. Vertreter fur ur. Jischer lst Jr. Blerbeum.

Bur die abtellung IV ? bleibe loh, ale bisher, verantrortich. Wein Vertreter ist oberreg. Hat or. Riohter. Die rur die einzelnen tuseen verontwortilohes nonservatoren, Friparatoren und Inspektoren sind rolgende:

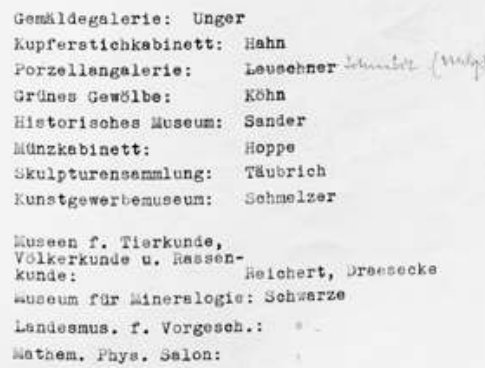

13 Brief von Sammlungsreferent Fritz Fichtner an

Reichsstatthalter Martin Mutschmann, 11.8.1944 der Auswahl eines Nachfolgers für Zimmermann. Als Kandidaten benannte dieser in absteigender Reihenfolge Leopold Reidemeister, Kustos der Ostasiatischen Abteilung in Berlin, \& Walter Holzhausen und $\triangleright$ Fritz Fichtner, beide an den Staatlichen Sammlungen in Dresden tätig, sowie Kurt Roeder, Kustos der Großherzoglichen Porzellansammlung Darmstadt. ${ }^{63}$ Schnorr von Carolsfeld empfahl Roeder und bemerkte, dass Fichtner zwar „das besondere Vertrauen von Herrn Professor Zimmermann“ genieße,

63 Vgl. SMV, Groß, an Schnorr von Carolsfeld, Berlin, 10.1.1933, HStA Dresden, 11125, Nr. 19192, fol. 39-42. Zum gesamten Vorgang der Stellenbesetzung in der Porzellansammlung vgl. ebd., fol. 26-118. 
„[a]ber eine vollwertige Kraft würde die Porzellansammlung [...] mit ihm nicht gewinnen"64. Nur wenige Tage später, am 19. Januar 1933 sprach Fichtner persönlich bei Groß im Ministerium vor. Dort wurde auch überlegt, ob die Porzellansammlung zukünftig mit dem Historischen Museum in Personalunion durch Holzhausen geleitet werden könne. Doch dagegen protestierte Zimmermann vehement, denn

Sachsen würde sich damit vor dem Urteile aller berufenen Kenner blamieren. Es sei überall, und zwar im Inlande und im Auslande, leider nur allzu gut bekannt, welche Aspirationen auf diesem Gebiete die Direktion des Hist. Mus. habe, ohne sachlich irgendwie die Voraussetzung hierfür zu erfüllen. ${ }^{65}$

Zimmermann setzte sich ,ausschließlich und mit aller Energie“ für Fichtner ein, denn er „gäbe auch durch seine langjährige Arbeit mit Z. die Gewähr, daß er sich, namentlich bei Ankäufen, der Erfahrung Z. und seiner Ratschläge auch wirklich versichern werde ${ }^{\text {66 }}$. Am 6. Februar 1933 wurde Galeriedirektor $\triangleright$ Hans Posse im Ministerium zu seiner Meinung befragt. Er hatte unterdessen die Direktoren des Germanischen Nationalmuseums Nürnberg und des Ostasiatischen Museums in Berlin, Heinrich Zimmermann und Otto Kümmel, um Rat gebeten. Während H. Zimmermann für Roeder plädierte, hielt Kümmel „die Besetzung der Stelle mit nur einem Kustoden für keinen Schaden für die Sammlung. Aber die Sammlung müsse aus der Atmosphäre eines keramischen Kaufhauses heraus ${ }^{\text {"67 }}$. Der Rektor der Technischen Hochschule Dresden, Oscar Reuther, sprach sich ebenfalls für Fichtner aus. Unterdessen schlug der Direktor des Historischen Museums und Grünen Gewölbes, ^Erich Haenel, im März 1933 vor, er würde die Leitung der Porzellansammlung zusätzlich übernehmen und man könne Holzhausen für diese als Kustos anstellen. Die Möglichkeiten der Stellenbesetzung in der Porzellansammlung waren vielfältig und die Anzahl der Diskutierenden enorm. Im Ministerium war man unentschieden und befragte nun die Direktoren der Staatlichen Museen in Berlin und des Bayerischen Nationalmuseums München, Wilhelm Waetzoldt und Hans Buchheit. Waetzoldt stimmte für Roeder und hielt Fichtner für eine Notlösung, Buchheit plädierte gar für Haenel. Eine Entscheidung zeichnete sich noch immer nicht ab. Mitte Juni 1933 stimmte Direktor Zimmermann bei Minister Wilhelm Hartnacke erneut für Fichtner. Unterdessen hatte sich auch der aus politischen Grün-

\footnotetext{
Schnorr von Carolsfeld an SMV, Groß, 15.1.1933, ebd., fol. 43, hier: 43v.

65 Gesprächsnotiz Groß, SMV, 31.1.1933, ebd., fol. 56 f.

66 Ebd.

67 Gesprächsnotiz SMV, 6.2.1933, ebd., fol. 60.
} 
den entlassene Generaldirektor der Porzellanmanufaktur Meißen, Max Adolf Pfeiffer, um die Stelle beworben. Mitte September 1933 kam endlich Bewegung in die „Causa Zimmermann“. Zimmermann schlug nun, da die Entlassung von - Wolfgang Balzer aufgrund $₫ 6$ des „Gesetzes zur Wiederherstellung des Berufsbeamtentums" bereits im Raume stand, im Ministerium vor, Fichtner die Leitung der Porzellansammlung und des Kunstgewerbemuseum anzuvertrauen. Zwei Wochen später, am 29. September 1933, kam man bei einer Beratung bei Minister Hartnacke dem Ziel der Neubesetzung endlich näher. Nach einem persönlichen Gespräch mit Fichtner am 3. Oktober 1933 teilte Oberregierungsrat Groß drei Wochen später dem Finanzministerium mit, dass man beabsichtige, Fichtner „die Kustos-Stelle zu übertragen, die im Staatshaushaltsplan anstelle der früheren Direktorenstelle eingesetzt ist“, dieser habe sich „bereit erklärt, auch die Leitung des Kunstgewerbemuseums unentgeltlich mit zu übernehmen "68. Zum 15. Dezember 1933 wurde Zimmermann nach mehr als 25 Jahren als Direktor regulär in den Ruhestand verabschiedet und Fichtner zum Kustos und Leiter der Porzellansammlung sowie zum Leiter des Kunstgewerbemuseums ernannt, da Balzer unterdessen zwangspensioniert worden war.

Entgegen allen Empfehlungen von namhaften Kunsthistorikern hatte man sich in Dresden für eine sammlungsinterne Minimallösung entschieden, mit der zwei weitere Sammlungen in Personalunion geleitet wurden. Posse kommentierte dies seinem Berliner Kollegen Kümmel gegenüber kritisch: „Aber das Malheur ist, daß wir hier in Dresden (außer Zimmermann) keinen einzigen Fachmann haben“, und fügte hinzu: „Man macht es sich sehr bequem: die Leitung übernimmt dann einer der Sammlungsdirektoren im Nebenamt und dieser setzt dort einen seiner Hilfsarbeiter hin, der nie mit Porzellan zu tun gehabt hat. ${ }^{\text {“69 }}$

\section{Personalia: Skulpturensammlung}

Am 18. Mai 1934 wählte $\triangleright$ Bruno Schröder, seit 1925 Direktor der Skulpturensammlung, den Freitod. Ohne lange Diskussionen wurde nur wenige Wochen später der langjährige Kustos • Walter Müller, der bereits seit 1913 in der Sammlung arbeitete, ab Juni 1934 zum neuen Direktor berufen und gleichzeitig die Kustodenstelle eingezogen. ${ }^{70}$

68 SMV, Minister Hartnacke, an Sächsisches Finanzministerium, 25.10.1933, ebd., fol. 113.

69 Posse an Kümmel, 14.12.1933, SKD Archiv, 01/PS 36, Bd. 1, fol. 1.

70 Vgl. SMV, Hartnacke, an Skulpturensammlung, Müller, 18.7.1934, HStA Dresden, 13859, Nr. 5861, fol. 56. 


\section{Personalia: Museen für Tierkunde und Völkerkunde}

Ebenfalls bemerkenswert sind die Personalwechsel in den Museen für Tierkunde und Völkerkunde. Zum 30. April 1935 wurde der seit knapp drei Jahrzehnten amtierende Direktor, der Zoologe $>$ Arnold Jacobi, regulär in den Ruhestand verabschiedet. Obwohl dies vorhersehbar war, wurde erst im April 1935 aktiv nach einem Nachfolger gesucht. Das Ministerium für Volksbildung schlug dem Reichsstatthalter den bisher in Museumskreisen unbekannten Zoologen $>$ Hans Kummerlöwe als neuen Direktor vor. Zwar verfügte dieser über keinerlei Museumserfahrung, aber er war „ein besonders bewährter Vorkämpfer der Bewegung $^{\text {" } 71}$ und bereits 1925 in die NSDAP eingetreten. Den Ministerialbeamten war offensichtlich weniger an einer erfahrenen, fachlich kompetenten Persönlichkeit als Nachfolger für Jakobi gelegen als vielmehr an einem zuverlässigen Nationalsozialisten. Da sich Kummerlöwes Ernennung zum Direktor verzögerte, ${ }^{72}$ wurde vorerst der Kustos für Anthropologie $\triangleright$ Bernhard Struck mit der kommissarischen Leitung beauftragt. Als erfahrenem Museumsmitarbeiter kam ihm bei Kummerlöwes Ernennung zum 1. Januar 1936 die Aufgabe zu, diesen als neuen Direktor einzuarbeiten, weshalb er sich als dessen „Kindermädchen“ betrachtete, denn

auch eine hervorragend anständige Gesinnung, ein einwandfrei guter Ton mit den Beamten und Angestellten helfen eben nicht darüber hinweg, wenn jede museale Erfahrung fehlt, wenn nicht einmal museale Interessen vorhanden sind, wenn verwaltungstechnisch wichtige, oder doch wenigstens ordentlich zu erledigende Dinge aus dem Handgelenk verarztet, wissenschaftliche oder persönliche Kleinigkeiten in den Vordergrund gestellt werden ${ }^{73}$.

In der Tat schien Kummerlöwe von den Mitarbeitern eher gelitten als gemocht gewesen zu sein. Aus der Zeit unter Direktor Jacobi waren sie ein wissenschaftliches, fachbetontes, kollegiales Arbeiten gewohnt, das unter Kummerlöwe einer zunehmenden Politisierung weichen sollte.

Als Karrierist ergriff Kummerlöwe bereitwillig und ohne Zögern die sich bietende Gelegenheit eines weiteren Karrieresprunges, als ihm das Ministerium für innere und kulturelle Angelegenheiten in Wien im Herbst 1938 die Leitung der

\footnotetext{
SMV an Reichsstatthalter in Sachsen, 27.4.1935, BArch, R 76/I/59, fol. 84.

72 Vgl. Reichs- und Preußischer Minister für Wissenschaft, Erziehung und Volksbildung Berlin an Reichsstatthalter in Sachsen, 11.12.1935 u. Sächsische Staatskanzlei an Kommissarischen Leiter des SMV, 7.12.1935, ebd., fol. 99, 101.

73 Struck an Thorbecke, 23.7.1937, SKD, MfV Archiv, MVD n20;25/7/8, o. Pag.
} 
Wissenschaftlichen Museen in Wien anbot. ${ }^{74}$ Da sich sein Arbeitsbeginn in Wien jedoch bis August 1939 verzögerte, konnte in Dresden kein Nachfolger eingestellt werden. Stattdessen wurde der dienstälteste Kustos aus dem Museum für Völkerkunde $>$ Martin Heydrich als Kommissarischer Leiter eingesetzt, denn Struck war unterdessen zum Professor für Anthropologie an die Universität Jena berufen worden. Zuvor hatte sich Struck als seinen Nachfolger im Kustodenamt in Dresden $>$ Michael Hesch gewünscht und „die Anforderungen schon möglichst auf Hesch zugeschnitten, der ja auch in Parteiorganisationen (z. B. als Schulender bei der Leipziger SS-Standarte) eine reiche Erfahrung hat ${ }^{\text {"75 }}$.

Wann Hesch seine Bewerbung einreichte, ist unklar. Der noch amtierende Direktor Kummerlöwe äußerte während des Bewerbungsverfahrens, dass er Hesch „gelegentlich der Zusammenarbeit bei der Kulturausstellung des Kreises Leipzig der NSDAP im Herbst 1934 recht gut, wenn auch nicht sehr gut" kannte und fügte unentschlossen hinzu: „Andererseits weiss ich nicht, ob die Stelle u. U. ausgeschrieben werden soll, und was dann noch für weitere Bewerber zur Verfügung stehen würden “76. Anfang Dezember 1937 betonte Kummerlöwe gegenüber Hesch, dass er "ganz besonderen Wert auf enge Zusammenarbeit der Anthropologischen Abteilung und ihres Leiters mit dem Rassenpolitischen Amt der Gauleitung und auch dem der Kreisleitung lege“ und „nur Mitarbeiter in Frage kämen, die selbst beispielgebend in bevölkerungspolitischer Hinsicht vorangehen" ${ }^{\text {"77. }}$.

In seiner Antwort kurz vor Jahresende pries Hesch die Nützlichkeit seiner Privatbibliothek für das Museum an und versprach, mit dem Rassenpolitischen Amt und der Kreisleitung der NSDAP zusammenzuarbeiten und „das Hindernis meines Unverheiratetsein ${ }^{178}$ zu beseitigen. Im Hintergrund agierten indes weiterhin Struck und Otto Reche. So informierte Struck im März 1938 Reche, dass Kummerlöwe Hesch erst zum Kustos ernennen lassen will, „wenn Pfaul versorgt ist" und daher sei es „dringend notwendig, das Eisen (?) Kummerlöwe nun zu schmieden, so lange es heiss ist“, denn der „Kernpunkt ist die Kandidatur Heschs, die nun definitiv sichergestellt werden muss ${ }^{\text {“79. }}$. Doch dessen Einstellung

\footnotetext{
74 Vgl. Kummerlöwe an SR Hohenauer, 10.10.1938, BArch, R 76/I/59a, fol. 36-40.

75 Vgl. Struck an Reche, 4.10.1936, SKD, MfV Archiv, MVD, n20;25/15u16, o. Pag. Mit seiner Empfehlung für Michael Hesch folgte Bernhard Struck einer früheren Bitte von Otto Reche. Vgl. Reche an Struck, 26.6.1933, ebd., o. Pag.

76 Kummerlöwe an SMV, 15.5.1936 und 3.9.1936, HStA Dresden, 13842, Nr. 048, o. Pag.

77 Kummerlöwe an Hesch, 6.12.1937, HStA Dresden, 13842, Nr. 114, Bd. 1, o. Pag.

78 Hesch an Kummerlöwe, 28.12.1937, HStA Dresden, 13842, Nr. 114, Bd. 1, o. Pag.

79 Struck an Reche, 5.3.1938, SKD, MfV Archiv, MVD, n20;25/13u14, o. Pag. > Berthold Pfaul wechselte im Oktober 1938 als Assistent von Hans F. K. Günther nach Berlin.
} 
als Kustos verzögerte sich, da die Stelle erst zur Neubesetzung freigegeben wurde, als Struck im März 1938 in Jena die Bestallungsurkunde erhielt. Als Hesch im November 1938 die Stelle erhalten sollte, musste er zu seiner schwer erkrankten Mutter nach Siebenbürgen reisen. Erst nach seiner Rückkehr wurde er im Januar 1939 endlich als Kustos in Dresden eingestellt. Struck kommentierte aufgrund seiner persönlichen Erfahrung, dass

Hesch nicht allzu lange brauchen wird, um der Mangelhaftigkeit der vorhandenen Dresdner Einrichtungen bewusst zu werden, dann also nach neuen Möglichkeiten an der dortigen T. H. sich bemühen dürfte, genau wie ich und meine beiden Vorgänger. ${ }^{80}$

Damit spielte er auf die wenig komfortablen Bedingungen und den häufigen Personalwechsel in den Museen für Tierkunde und Völkerkunde an. Zwar hatte die Tierkundesammlung seit Oktober 1937 ein neues Domizil, doch für die völkerkundlichen und anthropologischen Sammlungen wurden noch immer geeignete Räume gesucht. ${ }^{81}$ In der Tat blieb seit der Pensionierung Jacobis kaum ein Wissenschaftler lange in Dresden. Nur elf Monate nach Kummerlöwes Fortgang nach Wien gab es die nächste Personalveränderung: Heydrich wechselte im Juli 1940, ohne Fortzahlung seiner Bezüge in Dresden freigestellt, nach Köln, wo er als ordentlicher Professor an die Universität und als Direktor des RautenstrauchJoest-Museums berufen wurde. Einen Nachfolger für ihn gab es in Dresden vorerst nicht. Als Kommissarischer Leiter wurde Hesch eingesetzt, der sich bereits um die vakante Direktorenstelle beworben hatte. ${ }^{82}$ Bewerber dafür gab es viele, jedoch mangelte es an einer klaren Entscheidung. Noch im August 1940 diskutierte Heydrich mit $\triangleright$ Fritz Fichtner über geeignete Kandidaten. Er schlug Paul Germann aus Leipzig, Hermann Niggemeyer aus Frankfurt am Main und Walter Nippold aus Göttingen vor. ${ }^{83}$ Im November 1940 übermittelte Fichtner dem Ministerium die Namen folgender Kandidaten: die Zoologen Hans von Boetticher, Bernhard Rentsch, Erich Reisinger oder den Dresdner Ethnologen Hesch für das Museum für Tierkunde, die Ethnologen Ludwig Kohl-Larsen, Niggemeyer oder Hesch für das Museum für Völkerkunde sowie ebenfalls Hesch für die Abteilung für Rassenkunde. Letzteren benannte er als „Spitzenkandidat“ für die Stelle des Museumsdirektors, „für den Fall, daß die Naturkundl. Museen

\footnotetext{
Struck an Breitinger, 23.1.1939, SKD, MfV Archiv, MVD, n20;25/2, o. Pag.

Siehe S. 186, $188 \mathrm{ff}$.

82 Siehe Referent der Staatlichen Sammlungen, Fichtner, an Hesch, SKD Archiv, 01/PS 53, Bd. 3, fol. 152 und Registrande, SMV an Staatliche Sammlungen, 25.6.1940, SKD Archiv, 01/ PS 139, Nr. 832.

83 Protokoll einer Besprechung, 7.8.1940, SKD Archiv, 01/PS 53, Bd. 3, fol. 198.
} 
in Personalunion weiter verwaltet würden “84. Am 12. Dezember 1940 beschlossen der Leiter des Ministeriums, Göpfert, und Fichtner, die Museen für Tierkunde und Völkerkunde sowie die Abteilung für Anthropologie nach dem Krieg in drei separate Museen aufzuteilen. Bis dahin aber sollte weiterhin ein Direktor alle Bereiche betreuen. Als Kandidaten für diese noch immer vakante Stelle benannten sie nun neben Kohl-Larsen auch den Ethnologen Kurt Stülpner. ${ }^{85}$ Bei einer weiteren Beratung am 22. April 1941 in der Staatskanzlei fiel dann die Entscheidung für Hesch. ${ }^{86}$ Aber seine Ernennung erfolgte erst im September 1941. Die erneute Verzögerung war unter anderem seiner häufigen Abwesenheit infolge der Tätigkeit für das RuSHA geschuldet. Anlässlich seiner Amtseinführung betonte Fichtner vor den Mitarbeitern: „steht jedem unserer Museen ein rüstiger und in der neuen Lebensanschauung aufgewachsener Mann an der Spitze, wie Sie es sind, dann wird Dresden ganz automatisch seinen Beitrag zum Kulturaufbau Deutschlands liefern. ${ }^{\text {"87 }}$

Doch Hesch blieb nicht lange in Dresden. Im Oktober 1942 wurde er zum Militärdienst einberufen, den er als Mitarbeiter beim RuSHA absolvierte. Nach gut einem Jahr hatten die Museen für Tierkunde, Rassenkunde und Völkerkunde erneut keinen Direktor. Nun wurde der Zoologe und Wissenschaftliche Hilfsarbeiter $>$ Klaus Günther zum Kommissarischen Leiter ernannt. Als dieser im August 1944 ebenfalls zum Militärdienst einberufen wurde, folgte ihm Oberkonservator $\triangleright$ Robert Reichert im Amt und ab 8. September $1944 \sim$ Walther Fischer, Kustos und Kommissarischer Leiter des Museums für Mineralogie und Geologie.

\section{Personalia: Sächsische Landesbibliothek}

Die Neubesetzung der Direktorenstelle der Sächsischen Landesbibliothek verlief im Vergleich dazu geradezu unkompliziert. Im Februar 1937 stellte der 60-jährige - Martin Bollert einen Antrag auf Versetzung in den vorzeitigen Ruhestand. Als seinen Nachfolger empfahl er $\triangleright$ Hermann Neubert. Dieser hatte fast seine gesamte Bibliothekslaufbahn bei ihm absolviert, lediglich ab November 1929 war er als Leiter der Bibliothek der Technischen Hochschule Dresden tätig gewesen. Doch 1934 holte ihn Bollert als Oberbibliothekar an die Landesbibliothek zurück, da unter den

\footnotetext{
${ }^{84}$ Referent der Staatlichen Sammlungen, Fichtner, an Leiter SMV, 4.11.1940, SKD Archiv, 01/PS 53, Bd. 3, fol. 130-133, hier: 130.

85 Protokoll einer Besprechung mit dem Leiter SMV, 12.12.1940, ebd., fol. 175 f.

86 Vgl. SMV, Dedering, Protokoll der Besprechung in der Staatskanzlei, 22.4.1941, HStA Dresden, 11125, Nr. 22889, fol. 105.

87 Rede von Fichtner zur Amtseinführung von Hesch, 9.1941, SKD Archiv, 01/PS 53, Bd. 3, fol. 115 .
} 
„überhaupt infrage kommenden Bibliothekaren an der Landesbibliothek" keiner dafür so „vorzüglich geeignet“ sei wie Neubert, „[ü]berdies ist er Schwerkriegsbeschädigter (Verlust des rechten Armes) und Familienvater (4 Kinder) "888. Auch 1937 setzte Bollert Neubert an die erste Stelle der Bewerber, vor den Direktor der Universitätsbibliothek Berlin Gustav Abb und [Ernst?] Wernke aus Berlin, denn Neubert kannte die Bibliothek gut, stand „in der Tradition“, war „überlegt und kritisch“, „streng, aber gerecht ${ }^{\text {“89 }}$ und hatte sich als Vertreter Bollerts bewährt. Nachdem Bollert Ende September 1937 pensioniert und am 26. Oktober 1937 in Anwesenheit seiner Mitarbeiter vom Leiter des SMV, Arthur Göpfert, Ministerialrat Reuter und $\diamond$ Fritz Fichtner festlich verabschiedet worden war, ${ }^{90}$ kam es bei der Stellenbesetzung ohne ersichtlichen Grund zu Verzögerungen. Neubert, der im Sommer 1937 in die NSDAP eingetreten war, leitete die Landesbibliothek daher zunächst nur kommissarisch, erst am 1. Juni 1939 wurde er zum Direktor ernannt.

\section{Personalia: Münzkabinett}

Ein Paradebeispiel für mehrfach wechselnde provisorische Lösungen bei der Besetzung einer Sammlungsleitung stellt das Münzkabinett dar. Diese Situation entstand durch mehrere Verzögerungen und Fehlentscheidungen. Sie lässt auf eine geringschätzende Behandlung des Kabinetts schließen, die keineswegs der Bedeutung der Sammlung gerecht wurde, zu einem Abbruch der wissenschaftlichen Arbeit führte und eine tiefe Zäsur in der Geschichte des Münzkabinetts darstellte. Fernab der Öffentlichkeit, ohne Erwähnung in der Presse war eine Vielzahl von Institutionen und Personen - von Sammlungsdirektoren und $\mathrm{Nu}$ mismatikern bis hin zu politischen Entscheidungsträgern - an der Findung eines geeigneten Kandidaten beteiligt. Indes schien es durch die Schließung seiner Schausammlung, als existiere das Kabinett nicht mehr. Eine Situation, die der Jahresbericht der Staatlichen Sammlungen 1944 beklagte:

Die personellen Unzulänglichkeiten in der Wahrnehmung der Leitung des Münzkabinetts [...] machen sich für dessen wissenschaftlichen und öffentlichen Aufgabenbereich je länger desto nachteiliger bemerkbar, und dies um so mehr, als das Dresdner Münzkabinett zu den ganz wenigen großen deutschen Sammlungen seiner Art gehört. ${ }^{91}$

\footnotetext{
88 Aktennotiz, Gespräch Bollert und Groß bei Leiter SMV, 3.10.1933, HStA Dresden, 11125, Nr. 19336, fol. 198.

89 Vgl. Notizen von Bollert, o. Dat. [1937?]), SLUB, Mscr.Dresd.App.1378a,122.

90 Vgl. Aktennotiz, 29.10.1937, SLUB PA Bollert II, o. Pag.

91 Jahresbericht des Münzkabinetts 1942-1944, SKD, MK, 1942-1945, o. Pag.
} 


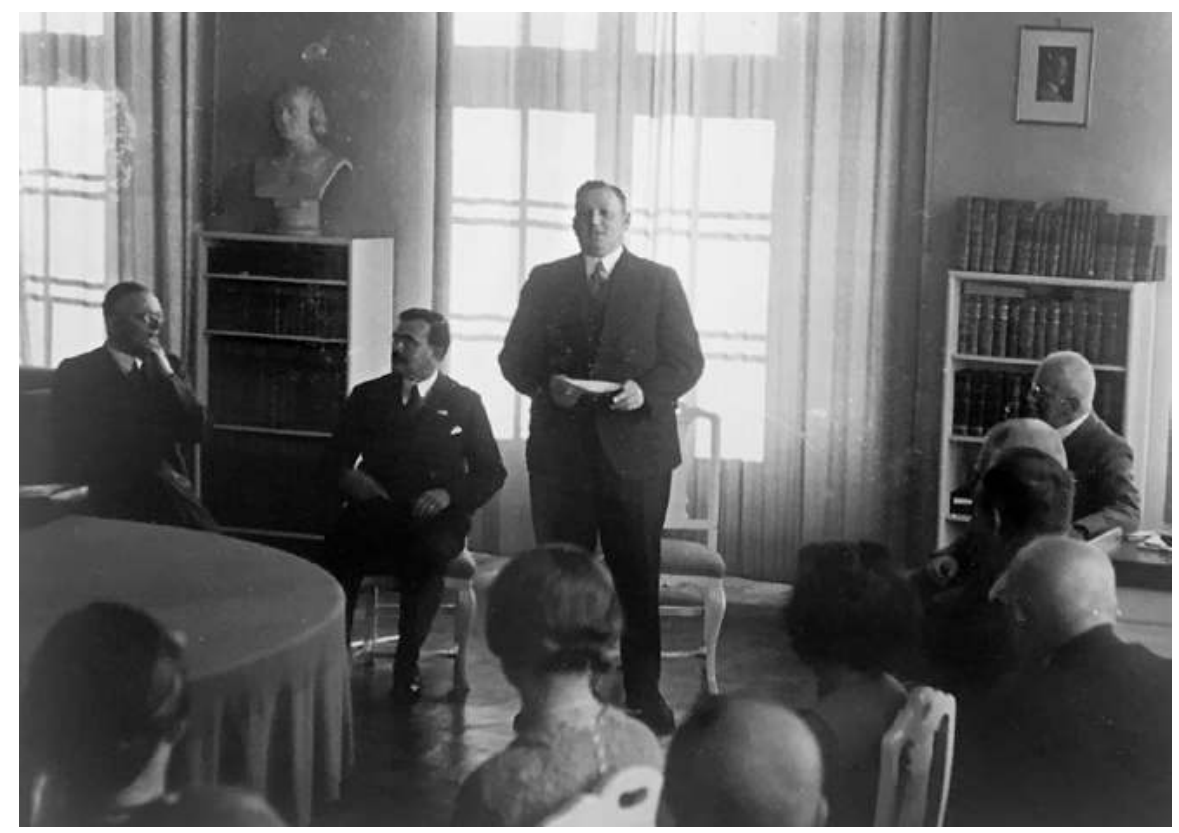

14 Verabschiedung von Martin Bollert in der Sächsischen Landesbibliothek am 26.10.1937 (v.l.n.r.: Erhart Kästner, Fritz Fichtner, Arthur Göpfert, Martin Bollert)

Bereits im Mai 1937, zwei Monate vor seiner krankheitsbedingten vorzeitigen Pensionierung, hatte $\bullet$ Walter Schwinkowski, seit 1909 am Münzkabinett tätig und seit 1924 dessen Leiter, gegenüber dem Sammlungsreferenten $\triangleright$ Fritz Fichtner die Numismatiker Hans Gebhardt, Walter Haevernick, Paul Grotemeyer, Walter Hellige oder Siegfried Rühle als kompetente potentielle Nachfolger für die Leitung des Kabinetts vorgeschlagen. ${ }^{92}$ Doch das Ministerium setzte sich darüber hinweg. Die im Sommer 1937 eingehenden Bewerbungen blieben unberücksichtigt. Statt an einen numismatisch versierten Nachfolger musste Schwinkowski auf Anordnung des SMV die Dienstgeschäfte des Münzkabinetts an seinen Direktorenkollegen • Erich Haenel vom Grünen Gewölbe und Historischen Museum übergeben. Für Haenel, der ihn mehrfach während des Urlaubs und im Krankheitsfalle vertreten hatte, bedeutete dies eine zusätzliche Last. ${ }^{93}$ Was bisher jeweils für kurze Zeit funktioniert hatte, konnte jedoch keine Dauerlösung sein. Um die Qualität der wissenschaftlichen Arbeit des Kabinetts einigermaßen zu erhalten

92 Vgl. Schwinkowksi an Fichtner, 7.5.1937, HStA Dresden, 11125, Nr. 22896, fol. 3-5, 10-35.

93 Vgl. SMV, Fichtner, an Haenel, 31.3.1938, HStA Dresden, 11125, Nr. 22895, fol. 33. 
und sich die Expertise Schwinkowskis zu sichern, beantragte Haenel vorsorglich, dessen stundenweise Tätigkeit über die Pensionierung hinaus, ${ }^{94}$ wozu es allerdings durch dessen Umzug nach Königsberg nicht mehr kam.

Als auch noch der langjährige Präparator des Münzkabinetts, Johannes Neubert, Ende April 1938 regulär pensioniert wurde, hatte dieser zuvor seinen Nachfolger $\triangleright$ Kurt Hoppe zwei Monate lang eingearbeitet und mit den Beständen vertraut gemacht. Damit war zumindest eine gewisse fachliche Kontinuität gewahrt, und Hoppe verfügte über Spezialkenntnisse, die der zeitgleich am 1. April 1938 als Kommissarischer Leiter des Münzkabinetts und Kustos der Porzellansammlung neu hinzukommende $>$ Rolf Hetsch nicht besaß. Weil er bereits im Oktober 1937 bei seiner Bewerbung mitgeteilt hatte, dass er „gegebenenfalls auch bereit wäre, die Geschäfte des Staatl. Münzkabinetts mit zu übernehmen ${ }^{\text {“95 }}$, hatte ihn Fichtner im Januar 1938 Reichsstatthalter Mutschmann als Leiter des Münzkabinetts vorgeschlagen. Fichtner betonte:

Es soll daher versucht werden, bei der Neubesetzung der durch die Pensionierung Professor Dr. Schwinkowskis freigewordenen Stelle so schnell wie möglich eine Entlastung des Direktors der Porzellansammlung herbeizuführen. Aus diesem Grunde sehe ich demnächst davon ab, [...] wieder einen Numismatiker in Vorschlag zu bringen [...] Ich beabsichtige vielmehr, einen Kunsthistoriker zu verpflichten, der neben der einstweiligen Leitung des Münzkabinetts die Unterstützung des Direktors der Porzellansammlung übernehmen kann, also eine vielseitige Ausbildung hat. ${ }^{96}$

Mit Hetschs Berufung verband Fichtner also die Hoffnung, dass sie zur Entspannung der prekären Personalsituation sowohl in der Porzellansammlung als auch im Münzkabinett beitragen würde, wobei die fachlichen Belange des Münzkabinetts nachrangig waren. Nichtsdestotrotz kündigte Fichtner, der mit dieser Entscheidung die Interessen der von ihm geleiteten Porzellansammlung und damit seine eigenen in den Vordergrund stellte, an, dass Hetsch „vermutlich im Früh-

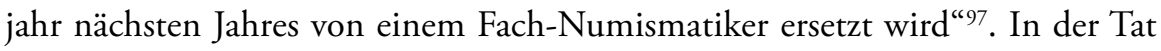
blieb Hetsch nicht lange in Dresden. Doch dies lag weniger an Fichtners etwaigen Bemühungen um einen Numismatiker als vielmehr daran, dass Hetsch mehrfach vom RMVP in Berlin angefordert wurde, um „die vom Führer befohlene Abwicklung und Verteilung der durch Gesetz vom 31.5.1938 beschlag-

94 Vgl. Haenel an SMV, 15.6.1937, HStA Dresden, 11125, Nr. 22895, fol. 31.

95 Hetsch an Fichtner, 15.10.1937, BArch, R 9361-V/2981, fol. 32.

96 SMV, Fichtner, an Reichsstatthalter, 11.1.1938, ebd., fol. 38-42.

97 Fichtner an E. Schwinkowski, 22.6.1938, SKD Archiv 01/PS 45, Bd. 2, fol. 26. 
nahmten Werke als Referent zu bearbeiten "98. Bereits im Juli 1938 äußerte sich Fichtner deshalb enttäuscht über Hetsch: „Ich selbst bin auf das schwerste enttäuscht. [...] Seit Jahren besitze ich jetzt zwar einen Assistenten, aber habe von ihm keinen fühlbaren Nutzen. "'99 Wenige Monate nach Kriegsbeginn, Ende Dezember 1939, wechselte Hetsch endgültig nach Berlin. Bereits zuvor, während seiner Abwesenheiten, hatten ihn der Direktor der Gemäldegalerie, $\triangleright$ Hans Posse, oder der Direktor des Kupferstich-Kabinetts, $\triangleright$ Kurt Zoege von Manteuffel, vertreten. Nun, ab November 1939, wurde $>$ Walter Müller, der Direktor der Skulpturensammlung, als Kommissarischer Leiter für das Münzkabinett eingesetzt. ${ }^{100}$

An der prekären Personalsituation hatte sich noch immer nichts Grundlegendes verändert. Im Dezember 1939 umfasste die Bewerberliste für die Leiterstelle zwölf Kandidaten, darunter neben den bereits durch Schwinkowski benannten Numismatikern, Münzsammlern und -händlern auch Rolf Walther, Ferdinand Kraus, Tassilo Hoffmann, Richard Gaettens, Gerhard Krug, Friedrich Wieland, Eberhard Mertens sowie den Zoologen $>$ Klaus Günther von den Museen für Tierkunde und Völkerkunde in Dresden. Günther hatte sich während seines Studiums ein wenig mit Numismatik beschäftigt und publizierte seit 1938 gelegentlich als Autodidakt über numismatische Themen. Daher war er im Oktober 1939 von Direktor $\triangleright$ Hans Kummerlöwe bezüglich seiner Ambitionen, die Leitung des Münzkabinetts zu übernehmen, befragt worden. ${ }^{101}$ Ein ursprünglich für Dezember 1939 geplantes Gespräch von Fichtner und Generaldirektor Kümmel aus Berlin fand erst im Juli 1940 statt: Kümmel plädierte für Walther und Gebhardt. ${ }^{102}$ Drei Monate später reichte Fichtner seine Vorschläge für die Besetzung bei der Staatskanzlei ein, wobei er an dritte Stelle nach den von Kümmel

\footnotetext{
98 Handschriftlicher Lebenslauf Hetsch, o. Dat., BArch, NS 21/1520, fol. 187-189, hier: 188. 99 Fichtner an Leiter SMV, 26.7.1939, BArch, R 9361-V/2981, fol. 101-104, hier: 103 . Vgl. Fuhrmeister, Christian: Dr. iur. Dr. phil. Rolf Hetsch, „einziger zünftiger Kunsthistoriker“ im Reichsministerium für Volksaufklärung und Propaganda, in: Fuhrmeister, Christian, Stephan Klingen, Iris Lauterbach u. a.: „Führerauftrag Monumentalmalerei“. Eine Fotokampagne 19431945, Köln 2006, S. $221 \mathrm{ff}$.

100 Vgl. RMVP an SMV, 16.10.1940, HStA Dresden, 11125, Nr. 22891, fol. 42 u. Leiter SMV, Fichtner, an Gemäldegalerie, Posse, 20.8.1938, HStA Dresden, 11125, Nr. 22895, fol. 10. Vgl. diverse Schriftstücke Münzkabinett, Leiter i. V. Müller, HStA Dresden, 11125, Nr. 22894, fol. 67-75.

101 Vgl. Museen für Tierkunde und Völkerkunde, Kummerlöwe, an Leiter SMV, 12.10.1939, HStA Dresden, 11125, Nr. 22897, fol. 1.

102 Vgl. Aktennotiz von Fichtner, 23.7.1940, HStA Dresden, 11125, Nr. 22896, fol. 59 f.; vgl. SKD Archiv, 01/PS 43, Bd. 3, fol. 102-108 und HStA Dresden, 11125, Nr. 22896, fol. $55 \mathrm{f}$.
} 
benannten Favoriten Günther setzte. ${ }^{103}$ Mit dem Tod von Haenel im Dezember 1940, d. h. nach dem Ausfall eines weiteren Direktors, wurde auch die Besetzung der Leiterstelle im Münzkabinett dringender. Doch die Entscheidung verzögerte sich weiter. In Anbetracht der durchaus vorhandenen kompetenten Bewerber, die bald andernorts neue Stellen innehatten, muss hierbei von einem politischen Kalkül ausgegangen werden. ${ }^{104}$ Bei der Gauleitung der NSDAP Dresden war unterdessen um Auskunft über Günthers politische Zuverlässigkeit ersucht worden, die erst Monate später, im Februar 1941, eintraf und vernichtend ausfiel. Die Parteileitung schrieb:

Günther ist ein durchaus unpolitischer Mensch, der wohl auferlegte Pflichten getreulich erfüllt, aber kaum aus eigener Initiative handeln wird. Seine Einstellung zu Staat und Bewegung ist zweifelsohne bejahend. [...] Wir stehen auf dem Standpunkt, daß für dieses rein wissenschaftliche Institut als Leiter nur Persönlichkeiten gefordert werden, die durch Mitgliedschaft zur NSDAP zunächst einmal die Gewähr bieten, politisch und weltanschaulich gefestigt zu sein. Es ist auch sehr fraglich, ob ausgerechnet ein Museumszoologe systematischer Richtung für die Leitung eines ganz anderen Gebietes geeignet ist. Auf Grund des vollständig unpolitischen Gesamtverhaltens des G. stimmen wir dem beabsichtigten Vorschlag zurzeit nicht zu. $^{105}$

Da die NSDAP-Gauleitung die Zustimmung zu Günthers Berufung insbesondere aufgrund der fehlenden Parteimitgliedschaft verweigerte, wurde nun - Michael Hesch, Kommissarischer Leiter der Museen für Tierkunde und Völkerkunde und damit Günthers direkter Vorgesetzter, vom SMV beauftragt, „sich um Dr. Günthers Hintansetzung im polit. Leben zu kümmern "106. Im Zuge dessen, d. h. erst nachdem weiterer Druck auf ihn ausgeübt wurde, beantragte Günther im Februar 1941 seine Aufnahme in die NSDAP und wurde zum 1. April 1941 Parteimitglied. Am 5. September 1942 beauftragte das Ministerium Günther endlich „mit der laufenden Überwachung und Betreuung der Bestände des Staatlichen Münzkabinetts“ und wies ihn an, „dem mit der stellvertretungsweisen Leitung des Münzkabinetts beauftragten Direktor der Staatlichen Skulptu-

103 Vgl. Fichtner an Staatskanzlei, 14.10.1940, u. Günther an Leiter SMV, 9.10.1940, ebd., fol. 61 und Nr. 22897, fol. 4.

104 Vgl. Sbardella 2019, S. 49.

105 Gauleitung der NSDAP Dresden an Leiter SMV, 5.2.1941, HStA Dresden, 11125, Nr. 22897, fol. 7. Vgl. auch SMV an Gauleitung der NSDAP Sachsen, 21.11.1940 u. 18.1.1941, ebd., fol. 5,6 .

106 Notiz von Regierungsdirektor Dedering, 22.2.1941 auf dem Brief von Fichtner, SMV, an Leiter SMV, 11.2.1941, ebd., fol. 8. 
rensammlung, Prof. Dr. Müller von Zeit zu Zeit Revisionsberichte zu erstatten “107. Doch damit war das Besetzungsproblem keinesfalls gelöst. Im Oktober 1942 wurden Max Bernhart, Direktor der Staatlichen Münzsammlung München, und der ehemalige Stellenbewerber Hävernick, beides ausgewiesene Numismatiker, um ihr fachliches Urteil über Günther gebeten. Die Antworten fielen ernüchternd aus. Bernhart riet dringend „zum Verzicht“, denn Günther „kann für sich den Ruf eines Numismatikers, der zur Führung des Münzkabinetts geeignet wäre, nicht in Anspruch nehmen "108. Ungeachtet der kritischen Stimmen aus Fachkreisen reichte das SMV schließlich am 29. Dezember 1942 beim RMWEV in Berlin eine Kandidatenliste für die vakante Direktorenstelle ein, bei der, anders als bisher, nun Günther an erster Stelle stand. ${ }^{109}$ Im Januar 1943 erneut um Rat befragt, favorisierte Kümmel weiterhin Walther. ${ }^{110}$ Der zuständige Referent im RMWEV stellte im Juni 1943 fest: „Günther, den ich nicht kenne, scheint in der Tat die geringsten Voraussetzungen zu besitzen "111, während der um seine Meinung gebetene SS-Obersturmführer Georg Jentsch vom Sicherheitsdienst des Reichsführers SS Abschnitt Dresden bestätigte, dass Günthers „politische Haltung staatsbejahend“112 sei. Es folgten weitere Gespräche zwischen dem Sammlungsreferenten Fichtner und Reichsstatthalter Mutschmann, doch an der Situation im Münzkabinett änderte sich nichts. Ende März 1944 reichte Günther erneut eine Bewerbung ein, wobei er ausdrücklich auf seine NSDAP-Mitgliedschaft verwies und betonte, dass

nach mir mündlich gewordenen Aussagen des damaligen Herrn Leiters meiner vorgesetzten Dienststelle, ebenso wie des Herrn Leiters des Personalamts bei der Landesregierung, meiner Betreuung mit der angestrebten Stelle nichts mehr im Wege stehen ${ }^{113}$

sollte. Wenige Monate später führte die Einberufung Günthers zur Wehrmacht am 23. August $1944 \mathrm{zu}$ einer weiteren Interimslösung. Am 8. September 1944

\footnotetext{
107 SMV, Dedering, an Günther, 5.9.1942, ebd., fol. 13.

108 Bernhart, Staatliche Münzsammlung München, an Reichsstatthalter Sachsen, Personalamt, 14.12.1942, ebd., fol. 17. Siehe auch fol. 16, 18-20.

109 SMV, Dedering, an RMWEV, Ministerialrat Herrmann, 29.12.1942, HStA Dresden, 11125, Nr. 22896, fol. $67 \mathrm{f}$.

110 Generaldirektor der Staatlichen Museen Berlin, Kümmel, 15.1.1943, ebd., fol. 70.

111 RMWEV, Ministerialrat Herrmann, an SMV, Dedering, 12.6.1943, ebd., o. Pag.

112 Sicherheitsdienst des Reichsführers SS SD-Leitabschnitt Dresden, Jentsch, an SMV, Dedering, 15.1.1943, HStA Dresden, 11125, Nr. 22897, fol. 21. Vgl. HStA Dresden, 11125, Nr. 22896, fol. $71 \mathrm{f}$.

113 Günther an Reichsstatthalter Sachsen, Landesregierung, Abteilung IV/7, 30.3.1944, HStA Dresden, 11125, Nr. 22897, fol. 25.
} 
übertrug Fichtner $~$ Walter Holzhausen die kommissarische Leitung des Münzkabinetts, die „Überwachung und Durchsicht der Sammlungsgegenstände sowie die sachgemäße Lagerung und Pflege des geborgenen Museumsgutes" ${ }^{\text {"114 }}$ hatte fortan Präparator $>$ Kurt Hoppe zu übernehmen. Eine Situation, die bis zum Kriegsende Bestand haben sollte.

\section{Personalia: Mathematisch-Physikalischer Salon}

Als eklatant erwies sich auch die Personalsituation im Mathematisch-Physikalischen Salon. Direktor $\triangleright$ Paul Werkmeister ließ sich infolge einer Erkrankung im Mai 1938 nach dreizehn Jahren im Amt vorzeitig pensionieren. Damals wurde der Direktor des Grünen Gewölbes und Historischen Museums, • Erich Haenel, mit der kommissarischen Leitung beauftragt. Als dieser im Dezember 1940 starb, übernahm $>$ Fritz Fichtner selbst die kommissarische Leitung, ,da kein anderer Direktor mehr zur Verfügung stand. (Dr. Posse im Auftrage des Führers, Dr. Müller durch Krankheit häufig abwesend) "115. Im Mai 1941 schlug er dann vor, Restaurator A Alfred Beck in Belassung auf seiner Stelle, die er seit Oktober 1928 innehatte, „mit der Leitung des Salons zu beauftragen“, denn „so verstreicht keine Zeit, die ein neuer Direktor zur Orientierung erst benötigt " ${ }^{\text {"116. }}$. Dies war aufgrund seiner Sammlungskenntnisse insbesondere in Anbetracht des mittlerweile zur Hauptaufgabe gewordenen Objektschutzes von großem Nutzen. Doch erst mehr als ein Jahr später, am 12. Dezember 1942, wurde Beck vom Leiter des SMV mit der kommissarischen Leitung des Mathematisch-Physikalischen Salons beauftragt. Als er wenige Monate später, im Juni 1943, trotz bisheriger Uk-Stellung doch zum Militärdienst einberufen wurde, übernahm - Walther Fischer vom Museum für Mineralogie und Geologie die kommissarische Leitung.

\section{Personalia: Historisches Museum und Grünes Gewölbe}

Bereits Anfang 1940 hatte sich abgezeichnet, dass $\triangleright$ Erich Haenel, Direktor des Historischen Museums und Grünen Gewölbes, bald zu pensionieren sei, denn er hatte die Altersgrenze dafür fast erreicht und sein Gesundheitszustand ver-

\footnotetext{
114 SMV, Fichtner, an Holzhausen und SMV, Fichtner, an Landeshauptkasse, 8.9.1944, HStA Dresden, 11125, Nr. 22895, fol. $54 \mathrm{f}$.

115 Fichtner, Referent der Staatlichen Sammlungen, an Leiter SMV, 14.5.1941, SKD Archiv, 01/PS 53, Bd. 3, fol. 11-13, hier: 11.

116 Ebd., fol. $11 \mathrm{f}$.
} 
schlechterte sich. Das erste aktenkundig gewordene diesbezügliche Gespräch führte Haenel mit $>$ Fritz Fichtner im Anschluss an die Direktorenkonferenz am 14. Februar 1940. Dabei äußerte Haenel, dass der Wissenschaftliche Hilfsarbeiter $\triangleright$ Walter Holzhausen, der sich bereits beworben hatte, zwar mit der Leitung des Grünen Gewölbes betraut werden könne, aber kein geeigneter Direktor für das Historische Museum sei. ${ }^{117}$ So kam es, dass Fichtner im Gespräch mit dem Berliner Generaldirektor Otto Kümmel im Juli 1940 neben der Nachfolge im Münzkabinett auch jene im Historischen Museum diskutierte. Kümmel „vertrat die Ansicht, daß nach Dresden, einer der größten und wichtigsten Waffensammlungen überhaupt, ein wirklicher Fachmann gehöre, oder ein solcher, der es zu werden verspreche ${ }^{\text {"118 }}$ und favorisierte Bruno Thomas von der Rüstkammer in Wien sowie Fritz Häberlein, Hauptkonservator der Bayerischen Verwaltung der Schlösser und Gärten in München. Haenel selbst, der vorerst im Amt blieb, benannte neben Thomas auch Torsten Lenk aus Stockholm und Heinz Uhlemann, der 1930/1931 als Freiwilliger Wissenschaftlicher Mitarbeiter am Grünen Gewölbe tätig gewesen war, als potentielle Nachfolger. Bewerbungen lagen indes von Holzhausen, > Rudolf von Arps-Aubert, der bis 1936 Wissenschaftlicher Hilfsarbeiter im Grünen Gewölbe und nun Leiter des König-Albert-Museums in Zwickau war, Uhlemann und Häberlein vor. Wie bei den Stellenbesetzungen in den Vorjahren wurden weitere Persönlichkeiten um ihren Rat gebeten, diesmal Major Gilardone, Direktor des Bayerischen Armeemuseums München, Leopold Rupprecht, Direktor der Waffensammlung Wien, sowie Heinrich Kohlhaussen, Direktor des Germanischen Nationalmuseums Nürnberg. ${ }^{119}$

Anfang Dezember 1940 beantragte Holzhausen selbst, ihm nach der Pensionierung Haenels die kommissarische Leitung des Historischen Museums zu übertragen. ${ }^{120}$ Mit dem Tod Haenels am 26. Dezember 1940 wurde die Regelung der Nachfolge dringend. Knapp zwei Wochen später, am 7. Januar 1941, teilte Fichtner dem Ministerium mit, dass die benannten Kandidaten nicht in Frage kämen und $\triangleright$ Ernst von Koerner, Direktor des Heeresmuseums Dresden, das bis Anfang 1940 als Sächsisches Armeemuseum zu den Staatlichen Sammlungen gehört hatte, die kommissarische Leitung übernehmen solle. Nur drei Tage danach benannte er jedoch Arps-Aubert als Kandidaten. ${ }^{121}$ Indes wurde Mitte Januar 1941 der Direktor der Skulpturensammlung, + Walter Müller,

\footnotetext{
117 Vgl. Fichtner an SMV, 14.2.1940, HStA Dresden, 11125, Nr. 22882, fol. 74.

118 SMV, Fichtner, Aktennotiz, 23.7.1940, SKD Archiv, 01/PS 53, Bd. 2, fol. 144-146, hier: 144.

119 Vgl. ebd., fol. 145.

120 Vgl. Holzhausen an Leiter SMV, 3.12.1940, HStA Dresden, 11125, Nr. 22882, fol. 77.

121 Vgl. SMV, Fichtner, 7.1.1941 und 10.1.1941, SKD Archiv, 01/PS 53, Bd. 2, fol. 120 f., 117.
} 
kommissarisch mit der Leitung des Historischen Museums und Grünen Gewölbes beauftragt. ${ }^{122}$ Drei Monate später kamen bei einer Beratung in der Staatskanzlei in absteigender Rangfolge Holzhausen, Arps-Aubert und Christian Gündel aus Breslau in die engere Wahl. ${ }^{123}$ Letztlich wurde jedoch Anfang Juli $1942 \mathrm{dem}$ drei Monate zuvor zum Kustos ernannten Holzhausen die kommissarische Leitung des Grünen Gewölbes übergeben. Fortan hatte er bei allen Geschäftsvorgängen mit „mit der Leitung beauftragt ${ }^{“ 124}$ zu zeichnen. Am 23. November 1942 entschied der Leiter des SMV:

Ich beauftrage Sie mit sofortiger Wirkung bis auf weiteres mit der stellvertretungsweisen Leitung des Staatlichen Historischen Museums nebst Gewehrgalerie. Ihr hauptamtliches Aufgabengebiet als Kustos und Leiter des Grünen Gewölbes erfährt durch den vorstehenden Sonderauftrag keine Änderung. ${ }^{125}$

Damit war Holzhausen der Kommissarische Leiter beider Sammlungen und eine weitere vakante Direktorenstelle der Staatlichen Sammlungen war trotz geeigneter Kandidaten von außerhalb nicht neu besetzt worden. Die anfallenden Aufgaben wurden stattdessen wieder nur kommissarisch vom eigenen Personal übernommen, wodurch Gelder eingespart wurden. Dennoch erfolgte Ende Dezember 1942 eine Aktualisierung der Kandidatenliste. Dabei stand der kommissarisch amtierende Holzhausen an erster Stelle, gefolgt von Uhlemann und Häberlein. Selbst im Februar 1944 nahm Fichtner noch eine inhaltlich nicht weiter dokumentierte Rücksprache mit Uhlemann bezüglich seiner Bewerbung. ${ }^{126}$

\section{Personalia: Kupferstich-Kabinett}

Als der 59-jährige Direktor des Kupferstich-Kabinetts, • Kurt Zoege von Manteuffel, im Januar 1941 überraschend starb, übernahm zunächst Galeriedirektor - Hans Posse die kommissarische Leitung des Kabinetts. Sofort bemühte sich -Fritz Fichtner als Referent der Staatlichen Sammlungen, dem Wunsch Zoege von Manteuffels entsprechend, $>$ Peter Halm, der die Sammlung durch seine frühere Tätigkeit als Wissenschaftlicher Hilfsarbeiter kannte, als Nachfolger zu

\footnotetext{
122 Vgl. Leiter SMV, Göpfert, an Skulpturensammlung, Müller, 15.1.1941, ebd., fol. 116.

123 Vgl. SMV, Dedering, Bericht über die Beratung, 22.4.1941, HStA Dresden, 11125, Nr. 22889, fol. 105.

124 Fichtner an Leiter SMV, 2.7.1942, SKD Archiv, 01/PS 53, Bd. 2, fol. 64.

125 SMV, Göpfert, an Grünes Gewölbe, Holzhausen, 23.11.1942, ebd., fol. 60.

126 Vgl. SMV, Dedering, an RMWEV, Herrmann, 29.12.1942, HStA Dresden, 11125, Nr. 22896, fol. 67 f. sowie Eintrag in der Eingangsregistrande, 29.2.1944, HStA Dresden, 11125, Nr. 22875, Nr. 14a/9.
} 
gewinnen. ${ }^{127}$ Das SMV forderte dennoch eine Liste mit mehreren Kandidaten ein. Wie bei anderen Vakanzen fragte Fichtner daher Kunsthistoriker in anderen Städten um fachlichen Rat, diesmal die Direktoren der Graphischen Sammlungen in Wien, Berlin und München: Anton Reichel, Friedrich Winkler und Alfred Seyler. Neben Halm und dem seit 1929 in Dresden tätigen $>$ Franz Schubert, der während der Abwesenheiten von Posse die Vertretung übernahm, wurden ^Gert Adriani aus Wien, der von 1936 bis 1938 am Kupferstich-Kabinett in Dresden tätig war, sowie Bernhard Degenhardt aus Wien, Heinrich Theodor Musper aus Stuttgart und Erhard Göpel aus München benannt. ${ }^{128}$

Letztlich stand eine Entscheidung zwischen den Favoriten Halm und Schubert an, die jedoch nie getroffen wurde. Die Bemühungen um Halm waren längst gescheitert, da dieser Militärdienst leistete und nicht freigegeben wurde, dennoch wurde er im Januar 1943 vom Generaldirektor der Berliner Museen empfohlen. ${ }^{129}$ Schubert arbeitete seit 1935 unverändert als Wissenschaftlicher Hilfsarbeiter im Kupferstich-Kabinett, alle Versuche, ihn zum Kustos befördern zu lassen, scheiterten daran, dass er nicht in die NSDAP eintrat. Fichtner setzte ihn auf die Kandidatenliste an zweite Stelle, da er sich „in der Vertretung des Direktors und anläßlich der Bergung der Kunstgüter bisher bewährt ${ }^{\text {"130 hatte }}$ und übertrug ihm die wissenschaftliche Verantwortung für die Sammlung. Posse erklärte, dass Schubert „selbstverständlich alle Arbeit zu machen hätte ${ }^{“ 131}$. Dieser Status quo blieb auch nach Posses Tod erhalten: Schubert übernahm weiterhin alle Aufgaben und leitete de facto das Kupferstich-Kabinett bis er Ende Januar 1944 zum Militärdienst einberufen wurde.

\section{Personalia: Gemäldegalerie}

Mit dem Tod des seit 1910 amtierenden Direktors der Gemäldegalerie, $\triangleright$ Hans Posse, der nach schwerer Krankheit am 7. Dezember 1942 starb, waren nun vier

\footnotetext{
127 Vgl. Fichtner an SMV, 12.2.1941, SKD Archiv, 01/PS 53, Bd. 2, fol. 198.

128 Vgl. Staatliche Sammlungen, Fichtner, an Reichel, Winkler und Seyler, 22.5.1942, sowie deren Antworten, 5.1942, u. Fichtner an SMV, 16.6.1942, SKD Archiv, 01/PS 53, Bd. 2, fol. 180-193.

${ }_{129}$ Vgl. Fichtner, Dienstaufsichtsbericht, 2.1941, ebd., Bd. 1, fol. 182-184; SMV, Dedering, an RMWEV, Ministerialrat Herrmann, 29.12.1942 u. Generaldirektor der Staatlichen Museen Berlin, Kümmel, 15.1.1943, Abschrift, HStA Dresden, 11125, Nr. 22896, fol. 67 f., 70.

${ }_{130}$ Staatliche Sammlungen, Fichtner, an SMV, 20.8.1942, SKD Archiv, 01/PS 53, Bd. 1, fol. 179 .

131 Kupferstich-Kabinett, Schubert, an Leiter SMV, 22.9.1941, HStA Dresden, 11125, Nr. 22889, fol. 97 f. Siehe S. 64 f.
} 
Direktorenstellen in den Staatlichen Sammlungen unbesetzt bzw. kommissarisch besetzt, also vakant. Das betraf neben der Gemäldegalerie das Kupferstich-Kabinett, das Münzkabinett sowie die zusammengelegte Verwaltung des Historischen Museums und Grünen Gewölbes. ${ }^{132}$ Wenige Tage nach Posses Tod teilte $\triangleright$ Fritz Fichtner dem Leiter des SMV die Übernahme der Kommissarischen Leitung der Gemäldegalerie durch $\triangleright$ Robert Oertel mit. Obwohl Fichtner schon 1938, als Posse aus seinem Amt gedrängt werden sollte, ${ }^{133}$ Kurt Luthmer, Direktor der Staatlichen Museen Kassel, und Walter Manowsky, Direktor des städtischen Museums Danzig, als Nachfolger vorgeschlagen hatte, gab er nun zu bedenken, „daß man in der Frage der Neubesetzung unbedingt die Entscheidung des Führers herbeiführen müßte"134.

In der Tat entschied diesmal nicht, wie sonst üblich, das SMV, sondern Adolf Hitler persönlich über die Neubesetzung der Stelle. Er ernannte $>$ Hermann Voss zum Nachfolger als Direktor der Gemäldegalerie und auch zum „Sonderbeauftragten“ für den „Sonderauftrag Linz“. ${ }^{135}$ Damit entschied er sich für einen aus der Berliner Bode-Schule stammenden, gut in die Welt der Museen und des Kunsthandels vernetzten Kenner der Italienischen Malerei. Nach einem Vorgespräch mit Reichsminister Joseph Goebbels Anfang Februar 1943 in Berlin traf Voss am 16. Februar 1943 im Führerhauptquartier Rastenburg (Ostpreußen) mit Hitler zusammen. Offiziell sollte Voss seinen Dienst in Dresden am 1. März 1943 antreten. Allerdings war er damals bereits für den "Sonderauftrag Linz“ unterwegs und konnte die Dienstgeschäfte der Gemäldegalerie erst am 9. März 1943 von Oertel übernehmen, nachdem er sich am Tag zuvor persönlich bei Reichsstatthalter Mutschmann und im Ministerium für Volksbildung vorgestellt hatte. ${ }^{136}$ Damit war zumindest eine der vakanten Stellen innerhalb kurzer Zeit durch die Neueinstellung eines Spezialisten von außerhalb besetzt worden.

\section{Personalia: Museum für Mineralogie und Geologie}

Ende März 1943 ließ sich der Direktor des Museums für Mineralogie und Geologie, $>$ Eberhard Rimann, krankheitsbedingt vorzeitig pensionieren - die Verwaltung des Museums übernahm der bisherige Mitarbeiter $\bullet$ Walther Fischer.

\footnotetext{
132 Vgl. Leiter SMV, Amtsleiter V, Dedering, an Geschäftsstelle Personal, 21.1.1942, HStA Dresden, 11125, Nr. 18962, fol. 78a u. SMV, Dedering, an RMWEV, Herrmann, 29.12.1942, HStA Dresden, 11125, Nr. 22896, Bl. 67 f.

133 Vgl. Rudert 2015b. Siehe S. 98, 404.

134 SMV, Fichtner, an Leiter SMV, 17.12.1942, SKD Archiv, 01/PS 53, Bd. 2, fol. 10 f., hier: 11.

135 Vgl. HStA Dresden, 11125, Nr. 18962, fol. 187 ff. sowie Iselt 2010, S. 186, 322.

136 Vgl. ebd., S. 180-196.
} 
Aus den erläuterten Beispielen ist ersichtlich, dass bei der Wiederbesetzung von frei gewordenen Stellen von Sammlungsdirektoren in Dresden sammlungsinterne Lösungen bevorzugt wurden, z. B. durch die weitere Zusammenlegung von Verwaltungsaufgaben oder den Einsatz von Kommissarischen Leitern und Direktoren. Seitens der Sammlungen bemühte man sich stets, qualifizierte Kandidaten zu finden, weshalb meist mehrere Fachkollegen um ihren Rat gefragt wurden, häufig Generaldirektor Otto Kümmel in Berlin. Oft verzögerte sich die Suche geeigneter Nachfolger über mehrere Jahre, in denen sich diverse Interimslösungen abwechselten. Nur selten wurden Bewerber von außerhalb an den Staatlichen Sammlungen für Kunst und Wissenschaft eingestellt, wie 1936 bei der Berufung des neuen Direktors der Museen für Tierkunde und Völkerkunde - Hans Kummerlöwe aus Leipzig oder 1943 bei der Berufung des Nachfolgers für $\triangleright$ Hans Posse in der Gemäldegalerie $\triangleright$ Hermann Voss aus Wiesbaden.

Bei personellen Engpässen übernahm $>$ Fritz Fichtner, als Verantwortlicher der Staatlichen Sammlungen im Ministerium, zusätzlich zu seinen ohnehin zahlreichen Aufgaben die Vertretung der abwesenden oder erkrankten Sammlungsdirektoren bzw. die kommissarische Leitung der Sammlungen mit vakanter Direktorenstelle. So war er im Sommer 1940 kurzzeitig für sieben Sammlungen zuständig: neben der Porzellansammlung und dem Kunstgewerbemuseum verwaltete er zusätzlich das Münzkabinett, den Mathematisch-Physikalischen Salon, das Historische Museum, das Grüne Gewölbe und die Skulpturensammlung. ${ }^{137}$ Bereits im Frühjahr 1938 hatte Fichtner, als dem verwaisten Münzkabinett die Münzsammlung des Buchdruckers Jehne aus Dippoldiswalde zum Kauf angeboten wurde, „da z. Zt. kein Fachmann für Münzkunde im Staatlichen Münzkabinett vorhanden ist, die Besichtigung "138 kurzerhand selbst übernommen.

Die Konzentration der Verwaltungsaufgaben bei den wenigen verbliebenen Beamten zeigt sich auch im Falle von $~$ Walter Müller. Zusätzlich zu seinen Aufgaben als Direktor der Skulpturensammlung und Kommissarischer Leiter des Münzkabinetts wurde ihm im Januar 1941 nach dem Tod von $\triangleright$ Erich Haenel die Verantwortung für das Grüne Gewölbe und das Historische Museum übertragen. ${ }^{139}$

\footnotetext{
${ }_{137}$ Vgl. Fichtner, Bericht über die Dienstaufsicht, 8.1940, SKD Archiv, 01/PS 53, Bd. 1, fol. 209 .

138 Aktennotiz von Fichtner, 31.3.1938, HStA Dresden, 11125, Nr. 22894, fol. 51.

139 Vgl. Leiter SMV, Göpfert, an Skulpturensammlung, Müller, 15.1.1941, HStA Dresden, 11125, Nr. 22884, fol. 68.
} 


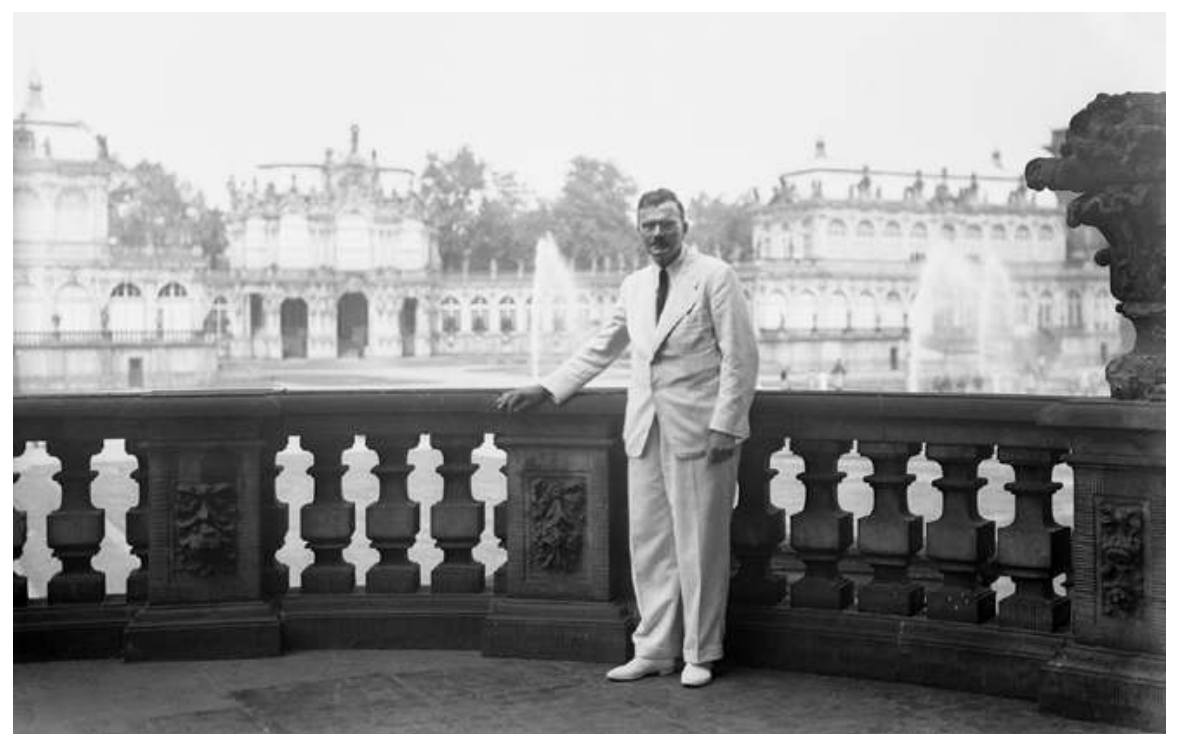

15 Fritz Fichtner im Dresdner Zwinger, um 1939

\section{Generationswechsel}

Darüber hinaus zeichnet sich bei der Besetzung der Stellen für wissenschaftliche Mitarbeiter an den Staatlichen Sammlungen in der NS-Zeit ein Generationswechsel ab. Durch das Ausscheiden älterer erfahrener Mitarbeiter ging wichtige Sachkenntnis verloren. War es einst selbstverständlich, als Fachwissenschaftler über Jahrzehnte hinweg an einer Sammlung zu arbeiten und damit eine präzise Bestandskenntnis zu erlangen, wurden nun - wenn überhaupt - unerfahrene, aber politisch zuverlässige Mitarbeiter nachbesetzt, die meist zusätzlich über eine Lehrbefähigung verfügten. Beispielhaft dafür sind die Biografien von $\triangleright$ Fritz Fichtner und $\triangleright$ Hans Kummerlöwe, die sich beide bereitwillig den Erfordernissen der Zeit anpassten. Während der Weimarer Republik studierten sie und strebten eine akademische Laufbahn an, Fichtner als Geisteswissenschaftler, Kummerlöwe als Naturwissenschaftler. Eingedenk der Arbeitsmarktsituation nach dem Ersten Weltkrieg und der steigenden Arbeitslosigkeit in der Weltwirtschaftskrise legten sie neben der Promotion auch ein pädagogisches Staatsexamen in ihrem Fachgebiet ab, um eine berufliche Perspektive als Lehrer finden zu können, falls ihre akademische Karriere nicht gelingen sollte. Nach mehrjähriger Tätigkeit im Schuldienst bot sich ihnen die Chance eines Wechsels in den Museumsbereich, wobei sich ihre NSDAP-Mitgliedschaft und ihr parteipolitisches Engagement 
karrierefördernd auswirkten. Mit Blick auf die von den Museen geforderte Bildungsarbeit sollten sich ihre pädagogischen Studienabschlüsse ebenfalls als Vorteil erweisen. ${ }^{140}$ Unter den Naturwissenschaftlern an den Staatlichen Sammlungen befanden sich während der NS-Zeit weitere Mitarbeiter mit vergleichbaren Lebenswegen, die als Fachwissenschaftler über eine zusätzliche pädagogische Ausbildung verfügten und deren Parteieintritt ihrer Karriere zuträglich war, wie -Wilhelm Meise, + Walter Häntzschel und \Martin Heydrich.

\section{Mitgliedschaften in der NSDAP}

Bereits im Zusammenhang mit der Besetzung von vakanten Stellen zeichnete sich ab, dass der Zugehörigkeit zur NSDAP und anderen nationalsozialistischen Organisationen ab 1933 wachsende Bedeutung zukam. Von den wissenschaftlichen Mitarbeiterinnen und Mitarbeitern, die zwischen 1933 und 1945 in den Staatlichen Sammlungen für Kunst und Wissenschaft in Dresden tätig waren, traten etwa $45 \%$ in die NSDAP ein. ${ }^{141}$ Von den 39 Direktoren, Kustoden und Restauratoren, die in der NS-Zeit die einzelnen Sammlungen leiteten bzw. Verantwortung für diese zu übernehmen hatten, waren 18 Personen Parteimitglieder.

Bereits vor 1933 waren der NSDAP $>$ Dorothee von Watzdorf und $\triangleright$ Helene Barthel von der Sächsischen Landesbibliothek sowie $>$ Hans Kummerlöwe, • Hellmuth Buck, $\triangleright$ Artur Krüss und $\triangleright$ Berthold Pfaul von den Museen für Tierkunde und Völkerkunde beigetreten, Watzdorf und Kummerlöwe schon im Sommer 1925. ${ }^{142}$ Sie müssen allein aufgrund ihres frühen Parteibeitritts, der frei von jeglichen Zwängen erfolgte, als überzeugte Nationalsozialisten gelten.

Nur zwei von ihnen, Watzdorf und Buck, arbeiteten bereits damals in den Staatlichen Sammlungen. Die anderen wurden später eingestellt. So auch Kummerlöwe, der erst 1936 die Leitung der Museen für Tierkunde und Völkerkunde übernahm. Als „Alter Kämpfer“ achtete er in seinen drei Jahren als Direktor darauf, vor allem politisch ähnlich ambitionierte, fachlich interessierte junge Mitarbeiter um sich zu scharen. Vor diesem Hintergrund ist die Einstellung von Krüss und Pfaul zu sehen, vor allem aber auch jene von $>$ Helmut Hofer. Dieser trat 1933 in Wien in die NSDAP ein und kam 1938, nachdem er während des

\footnotetext{
140 Siehe S. $168 \mathrm{ff}$.

141 Die NSDAP-Mitgliedschaften des technischen Personals der Staatlichen Sammlungen wurden bisher nicht systematisch überprüft, wodurch keine Aussagen zum Gesamtanteil von Parteimitgliedern unter den Beschäftigten getroffen werden können.

142 Damals hatte die NSDAP noch weniger als 4600 Mitglieder in Sachsen, während es im Januar 1933 über 87.000 waren. Vgl. Wagner 2004, S. 54. Vgl. Vollnhals, Clemens: Der gespaltene Freistaat: Der Aufstieg der NSDAP in Sachsen, in: Vollnhals 2002, S. 9-40.
} 
österreichischen NSDAP-Verbots als Student parteipolitisch aktiv gewesen war, als Wissenschaftlicher Hilfsarbeiter an die Museen für Tierkunde und Völkerkunde.

Mehrere wissenschaftliche Mitarbeiter der Staatlichen Sammlungen traten im Frühjahr 1933 in die NSDAP ein. Von den bereits in den Staatlichen Sammlungen tätigen Personen waren es $\triangleright$ Martin Heydrich, $\triangleright$ Alfred Beck, $\triangleright$ Kurt Köhn, -Alfred Unger. Von jenen, die erst einige Monate nach ihrem Parteieintritt zu den Sammlungen kamen, waren es $\triangleright$ Fritz Fichtner, $\triangleright$ Michael Hesch, $\triangleright$ Ulrich Dähnert, $\triangleright$ Otto Kleemann und $\triangleright$ Fritz Wiedemann. Das waren mehrheitlich junge Menschen, die, wie Fichtner, überzeugt von den nationalsozialistischen Ideen waren, sich aus politischem Kalkül ihre beruflichen Vorteile von diesem Schritt erhofften oder als unkritische Mitläufer handelten, wie zum Beispiel Dähnert.

Die Anzahl der 1937 in die NSDAP eintretenden Mitarbeiter war vergleichsweise hoch. An der Sächsischen Landesbibliothek zählten dazu neben > Hermann Neubert, der damals für das Direktorenamt im Gespräch war, es aber erst 1939 übernahm, auch $\triangleright$ Gottfried Benndorf und $\triangleright$ Hans Hofmann sowie $\triangleright$ Charlotte Boden und $\triangleright$ Dorothee Denecke. $\triangleright$ Eberhard Rimann, der das Museum für Mineralogie, Geologie und Vorgeschichte neben seiner Professur an der Technischen Hochschule leitete, wurde nun, nachdem er 1933 bereits das „Bekenntnis der Professoren an den deutschen Universitäten und Hochschulen zu Adolf Hitler und dem nationalsozialistischen Staat ${ }^{\text {"143 }}$ unterschrieben hatte, 1937 auch Parteimitglied.

Für die Wissenschaftlichen Hilfsarbeiter $~-$ Wilhelm Meise vom Museum für Tierkunde und $~$ Walter Holzhausen vom Grünen Gewölbe bzw. Historischen Museum verband sich der Eintritt in die NSDAP mit der Hoffnung, nun endlich zum Kustos befördert zu werden.

Die Freiwilligen Wissenschaftlichen Hilfsarbeiter $\triangleright$ Gert Adriani und $\triangleright$ Siegfried Wolf erhofften sich von ihrer Parteimitgliedschaft vermutlich ebenfalls bessere Karrierechancen, wohl auch der Wissenschaftliche Hilfsarbeiter $\triangleright$ Heinz Amberger. Ähnliche Gründe bewogen die Präparatoren und Handwerker $\triangleright$ Kurt Hoppe, $\triangleright$ Hans Loos, $\triangleright$ Curt Sander, $\triangleright$ Rudolf Schwarze und $\triangleright$ Paul Täubrich zum Eintritt in die NSDAP. $~$ Walter Häntzschel und $\bullet$ Robert Oertel traten ebenfalls 1937 in die Partei ein, wurden aber erst später in den Staatlichen Sammlungen angestellt.

• Bruno Faass und $\triangleright$ Erhart Kästner von der Sächsischen Landesbibliothek sowie $\triangleright$ Arthur Leuschner und $\triangleright$ Richard Schmidt von der Porzellansammlung

143 Nationalsozialistischer Lehrerbund Deutschland/Sachsen 1933. 
entschieden sich hingegen erst 1940 unter erheblichem Druck zu einem Parteieintritt. 1941 wurde $>$ Klaus Günther NSDAP-Mitglied, auf den diesbezüglich im Zusammenhang mit einer in Aussicht gestellten Ernennung zum Kustos am Museum für Tierkunde und zum Leiter des Münzkabinetts länger eingewirkt worden war. Ebenfalls 1941 trat $\triangleright$ Rolf Hetsch in die Partei ein, der damals jedoch nicht mehr in Dresden, sondern bereits im RMVP in Berlin tätig war.

Viele dieser Mitarbeiter, wie Faass, Günther, Häntzschel oder Holzhausen, waren zwar pro forma in die NSDAP eingetreten, betätigten oder äußerten sich aber nicht explizit politisch. Neben diesen rein nominellen Parteimitgliedern gab es auch jene Mitarbeiterinnen und Mitarbeiter, die nicht in die NSDAP eintraten. Mehrere Beispiele zeigen, dass es im Einzelfall durchaus möglich war, die Parteimitgliedschaft zu umgehen. Hilfreich dabei war die Mitgliedschaft in mindestens einer anderen nationalsozialistischen Organisation, wie dem Reichsbund der Deutschen Beamten (RDB), der Nationalsozialistischen Volkswohlfahrt (NSV), dem Nationalsozialistischen Lehrerbund (NSLB), dem Reichsluftschutzbund (RLB) oder dem Opferring der NSDAP. Diesen Weg gingen zum Beispiel - Georg Bierbaum, $\triangleright$ Martin Bollert, $\downarrow$ Walther Fischer, $>$ Erich Haenel, $>$ Kurt Zoege von Manteuffel, • Walter Müller, • Bruno Schröder, $\triangleright$ Walter Schwinkowski, $\triangleright$ Paul Werkmeister und $\triangleright$ Hermann Voss. Ausnahmen bilden der im November 1933 aus politischen Gründen zwangspensionierte $•$ Wolfgang Balzer und der im Dezember 1933 regulär pensionierte $>$ Ernst Zimmermann, die in keine dieser Organisationen eintraten.

Am ehesten konnten sich jene Mitarbeiter einer Parteimitgliedschaft entziehen, die bereits in leitender Position in den Staatlichen Sammlungen tätig waren, wie Bollert, Haenel, ^Arnold Jacobi, Müller, Zoege von Manteuffel, Schwinkowski und Werkmeister. Ihre politische Einstellung wurde nicht mehr oder kaum noch durch Anfragen bei der NSDAP-Kreisleitung überprüft.

Auffällig ist jedoch, dass mehrere dieser Personen ab 1937, jenem Jahr mit den meisten Parteieintritten unter den wissenschaftlichen Mitarbeitern der Staatlichen Sammlungen, auf eigenen Wunsch hin vor Erreichen der Altersgrenze pensioniert wurden.

Die meisten davon waren zum Zeitpunkt ihrer Pensionierung 61-jährig, Schwinkowski vom Münzkabinett gar erst 53 Jahre alt. Sie begründeten ihre Ruhestandsgesuche stets durch einen schlechten Gesundheitszustand - Schwinkowski und Rimann starben tatsächlich nur wenige Monate später. Die Zahl von allein drei vorzeitigen Pensionierungen in den Staatlichen Sammlungen im Jahr 1937 - neben Schwinkowski und Bollert auch $>$ Karl Wanderer - legen die Vermutung nahe, dass dabei möglicherweise der schlechte Gesundheitszustand genutzt wurde, um der zunehmenden Ideologisierung der Gesellschaft sowie den 
wachsenden politischen Repressionen am Arbeitsplatz zu entgehen. Wenngleich dies im Einzelfall nicht klar nachzuweisen ist, bot die Erkrankung zumindest eine Gelegenheit, sich der Ideologisierung zu verweigern und in eine private wissenschaftliche Tätigkeit zurückzuziehen.

Für jene Mitarbeiter, die 1933 zusätzlich ein Lehramt an der Technischen Hochschule Dresden innehatten oder die als Professoren dieser im Nebenamt eine der Sammlungen leiteten, war die Unterzeichnung des „Bekenntnis der Professoren an den deutschen Universitäten und Hochschulen zu Adolf Hitler und dem nationalsozialistischen Staat “ ${ }^{144}$ essentiell. Dieses „Bekenntnis“ unterschrieben $>$ Fritz Fichtner, $\triangleright$ Arnold Jacobi, $\triangleright$ Eberhard Rimann, $\triangleright$ Bruno Schröder, $\triangleright$ Bernhard Struck und $\triangleright$ Paul Werkmeister. An eine Parteimitgliedschaft war die Unterschrift erstaunlicherweise nicht gebunden; von den hier genannten Unterzeichnern war damals nur Fichtner in der NSDAP, Rimann trat erst 1937 in die Partei ein.

Für jüngere Mitarbeiterinnen und Mitarbeiter, die am Anfang ihres Berufsweges standen, war das Umgehen einer Parteimitgliedschaft jedoch kaum möglich. In diesen Fällen, wie bei $\triangleright$ Franz Schubert, $\triangleright$ Wilhelm Meise und $\triangleright$ Klaus Günther, war das Nichteintreten in die NSDAP meist mit weiteren Überprüfungen und Druck verbunden, letztlich auch mit der erheblichen Verzögerung oder der Verweigerung von Beförderungen. Diesen Weg einzuschlagen, erforderte Charakterfestigkeit und bedeutete in der Regel den Verzicht auf eine berufliche Karriere und damit auf ein besseres Gehalt. Im Falle von Schubert führte er durch die nicht mehr verlängerte Uk-Stellung zum Einsatz an der Ostfront. ${ }^{145}$

\section{Überprüfung der politischen Zuverlässigkeit}

Bei jeder Neueinstellung und Beförderung von Museumsmitarbeitern überprüfte das SMV deren politische Zuverlässigkeit bei der NSDAP-Kreisleitung, denn Staatsbeamte hatten dem NS-Staat treu zu dienen. Dies belegt u. a. das bereits erwähnte Beispiel des Zoologen $>$ Klaus Günther aus dem Museum für Tierkunde. Bereits 1934 verzögerte sich die Einstellung von Günther durch das Mitspracherecht, welches der NSDAP bei Personalentscheidungen zustand. Museumsdirektor $>$ Arnold Jacobi kommentierte dies gegenüber Günther kritisch:

\footnotetext{
144 Ebd. Kummerlöwe zählte trotz seiner langjährigen NSDAP-Mitgliedschaft nicht zu den Unterzeichnern: Er war damals im Schuldienst beschäftigt, nicht aber an einer Hochschule oder Universität.

145 Vgl. Kupferstich-Kabinett, i.V. Voss, an Abteilung IV/7, Reichsstatthalter, 31.1.1944, HStA Dresden, 11125, Nr. 22889, fol. 143 u. Landesverwaltung, Abt. Museen, Enking, an Grohmann, Kulturabteilung, 3.8.1945, SKDArch 02/VA 162, fol. 4 f. Siehe S. 64 f.
} 
Die Hintergründe, warum Sie nicht schon längst berufen sind, decken sich mit dem bestehenden Misstrauen der auch in wissenschaftlichen Personalfragen ausschlaggebenden Parteistellen gegen jeden Kandidaten, der seine positive Einstellung zu heutigen Staatsgedanken noch nicht bewiesen hat. Es herrschen in unserer Staatsregierung so labile Zustände, dass eine Meinungsverschiedenheit zwischen den Instanzen über einen solchen Fall grösste Verdriesslichkeiten mit sich bringen kann. ${ }^{146}$

Im Rahmen der Übertragung der Betreuung des Münzkabinetts auf Günther wurde seine politische Zuverlässigkeit erneut penibel überprüft. Doch erst nachdem er im April 1941 in die NSDAP eingetreten war, wurde ihm die neue Aufgabe anvertraut. ${ }^{147}$

Auch als $>$ Franz Schubert, der seit September 1935 als Wissenschaftlicher Hilfsarbeiter im Kupferstich-Kabinett tätig war, zum Kustos befördert werden sollte, worum sich der Direktor des Kabinetts, $\triangleright$ Kurt Zoege von Manteuffel, und -Fritz Fichtner über Jahre bemühten, nahm die Partei eine Kontrollfunktion und ihr Widerspruchsrecht wahr. Bereits bei Schuberts Einstellung 1935 urteilte die zuständige NSDAP-Ortsgruppe, er sei „immer zurückhaltend gewesen“ und „hat bis jetzt noch keine Beweise erbracht, dass er mit der nationalsozialistischen Weltanschauung verbunden ist"148. Im November 1936 beobachtete die Kreisleitung der NSDAP, er „besucht keine Veranstaltungen der Partei, hißt keine Hakenkreuzfahne, ist nicht Mitglied des Opferringes und der NSV“ und urteilte, dass „er keinesfalls ein Nationalsozialist ist, wie ihn das Dritte Reich als Staatsbeamter benötigt “149. Groß vom Ministerium wies Zoege von Manteuffel an, Schubert aufzufordern, sich in seiner Ortsgruppe der NSDAP zur Verfügung zu stellen. Doch dieser stellte klar, dass Schubert dem NSV und der Deutschen Arbeitsfront (DAF) angehörte und legte zu Schuberts Verteidigung sogar die Kaufquittung einer Hakenkreuzfahne vom März 1936 vor. ${ }^{150} 1938$ stellte der Kreisleiter der NSDAP etwas positiver fest, dass Schuberts „politische Einstellung zum heutigen Staat und zur Bewegung [...] in Anbetracht dessen, daß er im Staatsdienst beschäftigt ist, nicht ungünstig“ sei, jedoch „[v]iel Interesse für den

146 Museen für Tierkunde und Völkerkunde, Jacobi, an Günther, 18.2.1934, HStA Dresden, 13842, Nr. 114, Bd. 1, o. Pag.

147 Siehe S. $79 \mathrm{ff}$.

148 NSDAP Gauleitung Sachsen, Kreis Dresden Stadt, Ortsgruppe Moltke, an NSDAP Kreisleitung, 29.6.1935, HStA Dresden, 11125, Nr. 22889, o. Pag.

149 NSDAP Kreisleitung Dresden, Beurteilung, 2.11.1936, ebd., o. Pag.

150 Vgl. SMV, Gesprächsprotokoll, 18.1.1937 u. Kupferstich-Kabinett, Zoege von Manteuffel, an SMV, 22.1.1937, ebd., fol. $41 \mathrm{f}$. 
Nationalsozialismus bringt er nicht auf ${ }^{\alpha 151}$ - noch immer war Schubert nicht der Partei beigetreten. Indes begründete Zoege von Manteuffel im Mai 1938 seinen Antrag der Ernennung Schuberts zum Kustos damit, dass dieser „eine einwandfreie nationale Haltung" habe, er "nahm an allen Feiern und Apellen teil und hat selbst während ich verreist war, im März 1936 die täglichen Apelle vor der Reichstagswahl in wirkungsvoller Weise zu gestalten verstanden "152. Nach dem Tod von Zoege von Manteuffel setzte sich auch dessen Witwe, Alexandra Zoege von Manteuffel, 1941 für eine Beförderung Schuberts zum Kustos ein. Posse, der die kommissarische Leitung des Kupferstich-Kabinetts übernommen hatte, befürwortete die Beförderung, denn „erfahrene Fachleute sind im Augenblick sehr selten und man sollte sich eine solche Fachkraft wie Dr. Schubert für Sachsen nicht entgehen lassen "153. Diesmal sprach sich die NSDAP-Gauleitung klar dagegen aus - zwar sei er „politisch zuverlässig“ und „Mitglied der NSV, des NSLB und des RDB“, aber „Mitglied der NSDAP ist er aus finanziellen Gründen nicht" ${ }^{* 154}$.

Aktiv betätigt er sich weder in der Partei noch in einer Gliederung oder einem angeschlossenen Verband. Die Voraussetzungen nach $₫$ 8a der Reichsgrundsätze über Einstellung, Anstellung und Beförderung sind daher zurzeit nicht erfüllt ${ }^{155}$,

lautete das Fazit. Im Oktober 1941 wurde Schubert, diesmal persönlich von Regierungsdirektor Kurt Dedering, aufgefordert, sich in einer Parteiorganisation zu betätigen. ${ }^{156}$ Doch er trat nicht in die NSDAP ein, weshalb er in Dresden nie zum Kustos ernannt wurde. Wohl aber wurden ihm im Sommer 1942 ,im Einverständnis mit dem Führer die millionenschweren und reichen Bestände der graphischen Sammlung des Führermuseums zur Aufbewahrung und Sicherung übergeben"157.

\footnotetext{
$151 \quad$ NSDAP Gauleitung Sachsen, Kreisleiter, an SMV, 5.3.1938, ebd., o. Pag.

152 Kupferstich-Kabinett, Zoege von Manteuffel, an SMV, 30.5.1938, ebd., fol. 47-50, hier: 50.

153 Kupferstich-Kabinett, Posse, an Leiter SMV, 2.5.1941, ebd., fol. 106.

154 NSDAP Gauleitung Sachsen, Gaupersonalamt, an Leiter SMV, 28.6.1941, ebd., fol. 108.

155 Ebd.

156 Handschriftliche Bemerkung, SMV, Dedering, 17.10.1941, ebd.

157 Vgl. Kupferstich-Kabinett, i. V. Posse, an Leiter SMV, 29.8.1942, ebd., fol. 122. Siehe auch S. 144 .
} 


\section{Netzwerke}

Nicht bei allen Stellenbesetzungen wurde konsequent auf eine Parteimitgliedschaft der Kandidaten geachtet. $\triangleright$ Hermann Voss war kein Mitglied der NSDAP. Dennoch wurde er 1943 von Hitler als Nachfolger für $>$ Hans Posse, der ebenfalls kein Parteimitglied gewesen war, als Direktor der Gemäldegalerie und als „Sonderbeauftragter" für das „Führermuseum“ in Linz eingesetzt. Auch der als Referent für den "Sonderauftrag Linz" tätige `Gottfried Reimer trat nicht in die NSDAP ein.

Eine weitere Ausnahme bildete $>$ Georg Bierbaum. Er war seit 1923 am Museum für Mineralogie, Geologie und Vorgeschichte tätig, ab 1927 als Kustos. Als die Abteilung für Vorgeschichte aus diesem ausgegliedert und zum 1. April 1938 als Landesmuseum für Vorgeschichte verselbständigt wurde, wurde Bierbaum zu dessen Leiter ernannt, obwohl er kein NSDAP-Mitglied war. Diese Entscheidung trug einerseits der Bedeutung, die der Vor- und Frühgeschichte im nationalsozialistischen Wissenschaftskanon beigemessen wurde, Rechnung, andererseits der Tatsache, dass Bierbaum sich nicht nur stark für die archäologische Denkmalpflege in Sachsen eingesetzt hatte, sondern auch für die Ausbildung des wissenschaftlichen Nachwuchses. Allerdings war es ihm aufgrund fehlender Anstellungsmöglichkeiten nicht gelungen, junge Mitarbeiter - wie $>$ Walter Kersten, $\triangleright$ Otto Kleemann oder $\triangleright$ Heinz Amberger - in Dresden zu halten, die andernorts weitaus bessere Berufsaussichten hatten. ${ }^{158}$

Ein Beispiel für eine auf der Parteimitgliedschaft basierenden Karriere ist hingegen der Aufstieg von $\triangleright$ Hans Kummerlöwe. Sein langjähriges parteipolitisches Engagement war im April 1935 dafür ausschlaggebend, dass er ohne Museumserfahrung zum Direktor der Museen für Tierkunde und Völkerkunde in Dresden ernannt wurde. Im Ministerium war man sich sicher, dass er „allen Anforderungen der ihm zu übertragenden Stelle gewachsen"159 sei und entschied sich bewusst für einen zuverlässigen Nationalsozialisten. Er selbst formulierte seine karrieristischen Ziele deutlich:

158 Vgl. Geupel-Schischkoff, Kristina: Dr. Georg Bierbaum (13. August 1889-22. Juni 1953). Der Weg vom Zoologen, Mediziner und Lehrer zum Direktor des Landesmuseums für Vorgeschichte Dresden und Landespfleger für Bodenaltertümer Sachsens, in: Arbeits- und Forschungsberichte zur sächsischen Bodendenkmalpflege, Bd. 21, 2010, S. 19-26; Schachtmann/Strobel/ Widera 2009.

159 SMV an Reichsstatthalter in Sachsen, 27.4.1935, BArch, R 76/I/59, fol. 84. Siehe auch S. 72 . 
Es wird keiner weiteren Begründung bedürfen, dass der Unterfertigte, der Kampf und Aufstieg der Hitlerbewegung seit 1925 aktiv vom Flugblattverteilen, Saaldienst bis zu den Reichsparteitagen 1926, 1927, 1929 usw. mitgemacht hat, den dringenden Wunsch hegt, nun endlich bald eine halbwegs gesicherte Lebensgrundlage und die Möglichkeit einer Familiengründung zu gewinnen. In Frage hierfür käme [...]: eine Kustoden- oder Assistenten-Stelle an einem Naturkunde-, Heimatkunde- beziehungsweise zoologischen Museum, an einem zoologischen Garten, an einem zool. Universitäts- oder Forschungsinstitut, an einer Regierungsstelle für Heimatschutz- und ähnliche Fragen (auch Organisation des deutschen wissenschaftlichen Forschungsdienstes) usw. - oder als Lehrer für Naturwissenschaften an eine höhere Lehranstalt des staatlichen- Gemeinde- oder Parteilebens (aus wissenschaftlichen und Parteigründen möglichst in Leipzig oder einer anderen Großstadt). ${ }^{160}$

Um seinem Ziel näher zu kommen, suchte Kummerlöwe sehr bewusst den Kontakt zu Politikern. Nur wenige Wochen nach seiner Amtseinführung in Dresden fragte er beim sächsischen Innenminister Karl Fritsch: „wann ich Ihnen meinen Besuch machen darf. Auf Grund früheren Zusammentreffens und meiner Zugehörigkeit zur alten Garde der NSDAP darf ich wohl zustimmenden Bescheid Ihrerseits erwarten" 161 .

Kummerlöwe vernetzte sich fortwährend in die Politik und Verwaltung. Dabei vergaß er nie, seine frühe NSDAP-Mitgliedschaft zu erwähnen sowie seine Beteiligung an der Gründung der ersten NS-Hochschulgruppe in Leipzig 1925, über die er später publizierte. ${ }^{162}$ Diese Methode wandte er ebenso nach seinem Wechsel in Wien an.

Die Vernetzung von $>$ Fritz Fichtner lässt sich gut an den überlieferten Adressaten, denen er im Oktober 1943 seinen Aufsatz „Blütezeit der türkischen Fliese“ zuschickte, ablesen. ${ }^{163}$ Selbstverständlich überreichte er Reichsstatthalter Mutschmann ein Exemplar, ebenso den Abteilungsleitern und einigen ausgewählten Mitarbeitern des SMV, wie Ministerialrat Reuter aus seiner eigenen Abteilung IV, aber auch Regierungsoberbaurat Hubert Ermisch, der die Restaurierung des Zwingers und den Umbau des Japanischen Palais' verantwortete, wie dem Architekten Martin Hammitzsch, der Schwager von Adolf Hitler war und seit 1938

\footnotetext{
160 Kummerlöwe an unbekannt, 30.7.1935, HStA Dresden, Nr. 13471, Nr. ZA VI 2801 Akte 12, o. Pag.

161 Museum für Tierkunde und Völkerkunde, Kummerlöwe, an Minister des Innern, Fritsch, Dresden, 9.3.1936, HStA Dresden, 13842, Nr. 115, o. Pag.

162 Siehe S. 379, Anm. 3.

163 Vgl. Fichtner an diverse Adressaten, 10.1943, SKD Archiv, 01/PS 142, fol. 169-187.
} 
die Bauabteilung im SMV leitete, ${ }^{164}$ sowie dem Leiter des Heeresmuseum $\triangleright$ Ernst von Koerner und dem Kunsthistoriker Eberhard Hempel an der Technischen Hochschule in Dresden. Neben dem Gaustudentenführer Werner Starke in Dresden bedachte er in Berlin Ministerialrat Hermann im RMWEV, Brigadeführer Albrecht aus der Adjutantur des Führers und Intendant Kammberg in der Alten Reichskanzlei mit Sonderdrucken. Über die Deutsche Keramische Gesellschaft verteilte er gleichfalls Exemplare unter den Keramikproduzenten, d.h. an die Porzellanindustrie. Er bedachte dabei seine Vorgesetzten und seinen obersten Dienstherrn ebenso wie Fachkollegen und Vertreter der Politik, Verwaltung und Industrie auf der regionalen wie nationalen Ebene.

Als Kunsthistoriker und Direktoren der Gemäldegalerie verfügten $>$ Hans Posse ebenso wie sein Nachfolger $\triangleright$ Hermann Voss über zahlreiche Kontakte zu anderen Museumsdirektoren wie auch zum Kunsthandel. ${ }^{165}$ Diese Verbindungen waren zugleich nützlich wie unabdingbar für ihre Tätigkeit als „Sonderbeauftragte" des „Sonderauftrags Linz“.

Insbesondere das Beispiel von Posse lässt die Bedeutung von Beziehungsgeflechten erahnen. Als Museumsdirektor und Spezialist für die Italienische Kunst des Barock hatte er sich einen veritablen Ruf geschaffen und war bestens im europäischen Museumswesen vernetzt. Doch 1933 wurde Posse vor allem durch die Protagonisten der NSDAP-Gaufachgruppe der Bildenden Künste in Dresden vehement angefeindet. Im Frühjahr 1933 beantragte er seine Aufnahme in die NSDAP, wurde aber später mit dem Vermerk „Aufnahme abgelehnt“ aus der Mitgliederkartei gestrichen. Im März 1938 wurde Posse vom Leiter des SMV gedrängt, seinen Ruhestand zu beantragen. Nach einem regulären mehrwöchigen Urlaub war er ab April 1938 wieder in Dresden, jedoch nicht mehr als nomineller Direktor tätig. Als sich Hitler am 18. Juni 1938 bei seinem Besuch in Dresden von Posse durch die Gemäldegalerie führen lassen wollte, war er nicht in der Galerie anwesend, stattdessen standen Fichtner und $\gg$ Gert Adriani bereit. Hitler insistierte und Posse wurde herbeigeholt. Durch die Intervention Hitlers wurde Posse im Juli 1938 wieder ins Direktorenamt eingesetzt, ungeachtet dessen, dass er damals kein NSDAP-Mitglied mehr war. Ein Jahr später, im Juni 1939, ernannte ihn Hitler zu seinem „Sonderbauftragten“ für den „Sonderauftrag Linz“ . ${ }^{166}$

164 Hammitzsch hatte 1936 in zweiter Ehe die Halbschwester Hitlers, Angela geb. Hitler, verw. Raubal (1883-1949), geheiratet.

165 Siehe Biografien $>$ Hans Posse und $\triangleright$ Hermann Voss. Vgl. Rudert 2015b; Rudert, Konstanze: Paul Ferdinand Schmidt, Robert Sterl, Alois Schradt, Will Grohmann und Hans Posse Allianzen zur Förderung der Moderne in Dresden während der Weimarer Republik, in: Lupfer/ Rudert 2015, S. 295-318; Schwarz 2014; Iselt 2010.

166 Vgl. Rudert 2015b, bes. S. 128, 142. Siehe S. 143 f., 407. 


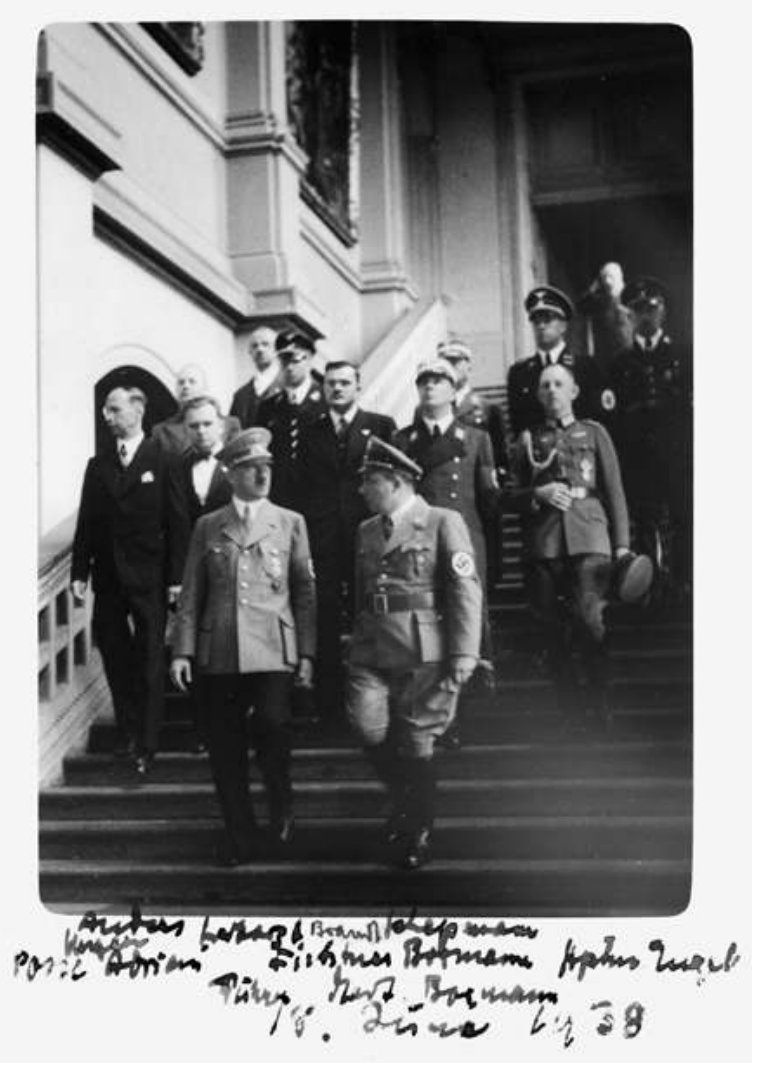

16 Besuch von Adolf Hitler in der Gemäldegalerie am 18. Juni 1938 (v.l.n.r.: 1.R.: Adolf Hitler, Martin Bormann; 2.R.: Hans Posse, Gert Adriani, Fritz Fichtner, ?, ?; 3.R.: Alfred Unger, ?)

Über die Kontakte, die $\triangleright$ Bernhard Struck pflegte, gibt sein umfangreicher, in Dresden verwahrter Nachlass Auskunft. Er korrespondierte mit einer Vielzahl auch internationaler Fachkollegen, wobei er fachwissenschaftliche Fragen diskutierte, bibliografische Angaben erfragte oder übermittelte und kollegiale Neuigkeiten wie auch Berichte über die Situation der jeweiligen Museen austauschte.

\section{Indienstnahme oder Indienststellung}

Das Beispiel Struck bezeugt zugleich, dass die Grenze zwischen Indienstnahme und Indienststellung oft nicht eindeutig zu identifizieren ist. Er trat nicht in die NSDAP ein, unterzeichnete aber das „Bekenntnis der Professoren zu Hitler“. Als Wissenschaftler - als Ethnologe, Anthropologe und Afrikanist - erforschte er, begünstigt durch diese bereits 1907 gewählt Fächerkombination, die „Abstam- 
mung" der Bevölkerung in Afrika, beschäftigte sich mit „Rassentheorien“ und „kolonialen Fragen“. International war er als Spezialist anerkannt und im NSStaat als Wissenschaftler gefragt, denn es waren exakt jene Themen, die für die nationalsozialistische Ideologie relevant waren. Diese Überschneidung von Interessen führte letztlich dazu, dass er, obwohl er kein NSDAP-Mitglied war, eine Professur in Jena erhielt.

Welchen Stellenwert das Beziehungsgeflecht der einzelnen Wissenschaftler hatte, zeichnete sich bereits bei der Betrachtung der Stellenbesetzungen ab. Ein bemerkenswertes Beispiel ist die Bewerbung von $>$ Robert Oertel in Dresden 1937. Nachdem er als Freiwilliger Wissenschaftlicher Hilfsarbeiter in Berlin tätig gewesen war, arbeitete er als Wissenschaftlicher Hilfsarbeiter am Deutschen Kunsthistorischen Institut in Florenz. Noch ehe die Stelle in Dresden durch die Entlassung von $>$ Karl Wilhelm Jähnig frei wurde, hatte Oertel über Heinrich Zimmermann in Berlin und Friedrich Kriegbaum in Florenz von der bevorstehenden Vakanz gehört. Trotz dieser persönlichen Beziehungen war letztlich seine von allen stets betonte Fachkenntnis ausschlaggebend für die Einstellung. ${ }^{167}$

Das Interagieren der wissenschaftlichen Mitarbeiterinnen und Mitarbeiter der Staatlichen Sammlungen mit den Vertretern der Politik war sehr unterschiedlich. Die Beteiligten entwickelten oft äußerst differenzierte, individuelle Strategien, die von vorauseilendem Gehorsam und serviler Unterordnung über vorsichtiges Agieren bis hin zum Ausnutzen und Ausweiten von Freiräumen reichten. Im Allgemeinen sind diese Strategien nur schwer zu rekonstruieren, da sie selten direkt überliefert wurden. Hinweise darauf finden sich in der privaten und dienstlichen Korrespondenz, in Protokollen über Telefonate oder Dienstberatungen. Manchmal lassen sich Kontakte einzig dadurch nachweisen, dass sie in den Registranden durch Posteingänge oder -ausgänge aktenkundig geworden sind. Auskunft über die Vernetzung zwischen den Staatlichen Sammlungen und der Politik geben darüber hinaus Presseberichte über Ausstellungseröffnungen und andere Veranstaltungen, im seltenen Falle auch Fotografien.

Beispiele für das Ausnutzen der wenigen Freiräume, wie durch $>$ Arnold Jacobi und $\gg$ Martin Bollert, zeigten sich bereits im Zusammenhang mit den Entlassungen aufgrund des "Gesetzes zur Wiederherstellung des Berufsbeamtentums“. ${ }^{168}$ Mehrere Mitarbeiter der Sächsischen Landesbibliothek, wie • Ewald Jammers und • Helmut Deckert bezeichneten Bollert nach dem Zweiten Weltkrieg in seiner „menschlichen Güte“ als „Vorbild“. Deckert sprach davon, dass „die meisten der

167 Siehe Biografie $\triangleright$ Robert Oertel.

168 Siehe S. $50 \mathrm{ff}$. 
hier tätigen Damen und Herren keine Nazis waren, sondern etwa als national gesinnte Demokraten zu klassifizieren gewesen wären" ${ }^{169}$. So habe die Landesbibliothek während der NS-Zeit als „ein Refugium für systemkritische Mitarbeiter und Nutzer" gegolten, nach 1937 „freilich abgeschwächt" ${ }^{\text {“170 }}$.

In vielen Fällen prägten jedoch ein angepasstes Agieren sowie bisweilen vorauseilender Gehorsam die Handlungsweisen. Restaurator > Alfred Beck vom Mathematisch-Physikalischen Salon erkundigte sich im November 1936 bei der NSDAP-Kreisleitung Dresden nach dem Autor einer fachlichen Anfrage, bevor er diese bearbeitete. Er hegte den Verdacht, dass dieser, der Jurist und Hauptmann der Reserve Hans Pick, möglicherweise „nichtarischer Herkunft“ sein könne. ${ }^{171}$

Bezüglich einer Leihanfrage durch den Fürsten von Schönburg für eine Ausstellung im Schloß Waldenburg fragte $>$ Fritz Fichtner im Juni und August 1938 sogar zweimal hintereinander bei der Kreisleitung der NSDAP des Kreises Glauchau nach, ob diese Bedenken gegen diese Ausstellung habe. ${ }^{172}$ Erst nach einer Unbedenklichkeitserklärung durch die NSDAP-Kreisleitung gab Fichtner sein Einverständnis der Leihgabe aus dem Münzkabinett.

Im Februar 1938 war Fichtner daran beteiligt, als das SMV bei der Geheimen Staatspolizei in Dresden Ermittlungen gegen den Landesbibliothekar $\triangleright$ Jacob Jatzwauk beauftragte:

Es besteht der Verdacht, daß er sich zusammen mit dem Musikdirektor Schneider in Dresden für Wenden-Sonderbestrebungen einsetzt. Ich bitte um entsprechende Ermittelungen [sic!] und um Mitteilung der Ergebnisse. ${ }^{173}$

Im Mai meldete der Reichsstatthalter diese Angelegenheit an den Reichsminister für Wissenschaft, Erziehung und Volksbildung und forderte, Jatzwauk in einen anderen Teil Deutschlands zu versetzen, wo er keinen Kontakt zu Sorben hätte. ${ }^{174}$ Doch diese Forderung wurde nicht erfüllt, Jatzwauk konnte weiterhin an der Sächsischen Landesbibliothek arbeiten.

169 Deckert, Bd. 1, S. 97. Vgl. auch Jammers an Bollert, 3.10.1956, SLUB, Mscr.Dresd. App.2830,30. Siehe auch $>$ Martin Bollert.

${ }_{170}$ Hermann 2011, S. 306.

171 Vgl. Mathematisch-Physikalischer Salon, Beck, an NSDAP-Kreisleitung, 9.11.1936, SKD, MPS, 1936, A.-Reg. Nr. 337.

172 Vgl. HStA Dresden, 11125, Nr. 22894, fol. 54-60.

173 SMV, Lohde, Reuter, Ausf.: Frenzel, Fichtner, an Geheime Staatspolizei Polizeileitstelle Dresden, 8.2.1938, HStA Dresden, 13859, Nr. 3710, fol. 44.

174 Vgl. Reichsstatthalter in Sachsen an Reichsminister für Wissenschaft, Erziehung und Volksbildung, 23.5.1938, HStA Dresden, 13859, Nr. 3710, fol. 50. 
Auch im Rahmen der Beschlagnahmung der Sammlung des Dresdner jüdischen Bankiers Gustav von Klemperer, dessen Familie 1938 gezwungen war, Deutschland endgültig zu verlassen, hatte Fichtner Kontakt zur Geheimen Staatspolizei. Diese hatte „verschiedene Museumsdirektoren ersucht, Kunstwerke des Hauses Klemperer sicherzustellen“ und „legte Wert darauf, daß die Sicherstellung rasch geschah ${ }^{\text {"175 }}$, darunter neben Fichtner die Direktoren der Gemäldegalerie, des Kupferstich-Kabinetts, der Skulpturensammlung und der Sächsischen Landesbibliothek. Nachdem Fichtner sich bei Hans Reuter im Ministerium rückversichert und festgestellt hatte, dass das Ministerium „keinerlei Bedenken gegen eine Sicherstellung " ${ }^{176}$ habe, engagierte er sich diesbezüglich.

Diese servile, sich stets gegenüber seinen Vorgesetzten absichernde Handlungsweise, veranlasste Fichtner auch, sich sofort an Reichsstatthalter Mutschmann zu wenden, als der Sicherheitsdienst des Reichsführers SS (SD) ihn im November 1939 kontaktiert hatte. Fichtner teilte mit, „daß Herren des SD Interesse an meiner Mitarbeit hätten und mich hierzu aufgefordert haben. [...] Ich habe meine Beziehungen zum SD in früheren Fällen zum Vorteil der Museen ausnützen können. “177 Ob Fichtner letztlich für den Sicherheitsdienst tätig wurde, bleibt unklar, der Reichsstatthalter hatte ihm geraten, „eine feste Bindung mit dem SD nicht einzugehen, gestattete aber die Abgabe von Berichten "178.

Der Freiwillige Wissenschaftliche Hilfsarbeiter des Grünen Gewölbes, - Rudolf von Arps-Aubert, arbeitete indes seit 1936 als „Vertrauensmann des S.D.-Oberabschnittes Mitte" ${ }^{\text {“179. }}$. Diese Tätigkeit übte er auch nach seiner Ernen-

175 Protokoll einer Beratung, Ministerium für Volksbildung, 23.1.1939, SKD Archiv, 01/PS 43, Bd. 2, fol. 91-96. Die Sammlung wurde beschlagnahmt; 1991 und 2010 erfolgte die Restitution an die Familie, ein Teil der Objekte verblieb als Geschenk in der Porzellansammlung. Vgl. Loesch, Anette: Das Schicksal der Porzellansammlung Gustav von Klemperers, in: Häder, Ulf (Bearb.): Beiträge öffentlicher Einrichtungen der Bundesrepublik Deutschland zum Umgang mit Kulturgütern aus ehemaligem jüdischen Besitz (= Veröffentlichungen der Koordinierungsstelle für Kulturgutverluste, 1), Magdeburg 2001, S. 56-77. Vgl. auch Staatliche Kunstsammlungen Dresden, Abteilung Forschung und wissenschaftliche Kooperation und Daphne-Projekt 2018, S. 38-39. Zur Beschlagnahmung und Restitution der Inkunabelsammlung von Victor von Klemperer vgl. https://nsraubgut.slub-dresden.de/restitutionen/1991/, Zugriff: 2.1.2020.

176 Fichtner, Porzellansammlung, an SMV, 1.12.1938, SKD Archiv, 01/PS 43, Bd. 2, fol. 86.

177 Fichtner, Abt. Sammlungen, an Leiter SMV, Protokoll der Besprechung mit dem Reichsstatthalter, 30.11.1939, ebd., fol. 97.

${ }_{178}$ Fichtner, Abt. Sammlungen, an Leiter SMV, Protokoll der Besprechung mit dem Reichsstatthalter, 30.11.1939, SKD Archiv, 01/PS 43, Bd. 2, fol. 97.

179 Arps-Aubert, Lebenslauf, 14.4.1938, HStA Dresden, 13471, ZD 7921 A6, fol. 9 f., hier: 10. Vgl. Schreiber, Carsten: Elite im Verborgenen: Ideologie und regionale Herrschaftspraxis des Sicherheitsdienstes der SS und seines Netzwerks am Beispiel Sachsens, München 2008, S. 433 f. 
nung zum Leiter des König-Albert-Museums in Zwickau aus. Seine Bewerbung um die Direktorenstelle des Grünen Gewölbes in Dresden 1940 blieb allerdings trotz der Unterstützung durch den SD erfolglos. ${ }^{180}$

Die Tätigkeit des Anthropologen und Ethnologen $>$ Michael Hesch für das RuSHA ab 1941 wurde bereits erwähnt. ${ }^{181}$ Auch der Prähistoriker $\triangleright$ Heinz Amberger arbeitete für das RuSHA, allerdings erst nach seiner Tätigkeit als Wissenschaftlicher Hilfsarbeiter in Dresden.

Einzelne Direktoren der Staatlichen Sammlungen wurden im Rahmen ihrer fachlichen Arbeit zu diversen Gutachtertätigkeiten für den NS-Staat herangezogen. Der Reichsminister für Wissenschaft, Erziehung und Volksbildung ernannte im Juli $1941 \triangleright$ Hans Posse, Fichtner, Hesch und $\triangleright$ Hermann Neubert zu Sachverständigen in Sachsen für den Ankauf von Kulturgut durch die Reichskammer der bildenden Künste. ${ }^{182}$ Diese Tätigkeit stand im direkten Zusammenhang zum nationalsozialistischen Kunstraub. Sie betraf die Begutachtung von Wert- und Kunstgegenständen aus jüdischem Besitz, die nach der Verordnung über den Einsatz jüdischen Vermögens vom 3. Dezember 1938 verkauft oder anderweitig verteilt wurden. Auf diese Verordnung, die „Verwertung der Schmuck- und Kunstgegenstände aus jüdischem Besitz", verwies ein Rundschreiben vom RMWEV vom 15. März 1941 explizit. ${ }^{183}$

Die Direktoren der Gemäldegalerie, Hans Posse und $\triangleright$ Hermann Voss, waren durch ihre Funktion als „Sonderbeauftragte“ für das „Führermuseum Linz“ besonders in den nationalsozialistischen Kunstraub involviert, worauf an anderer Stelle zurückgekommen wird. ${ }^{184}$

\footnotetext{
180 Siehe S. $83 \mathrm{f}$.

181 Siehe S. 58, 75.

182 Vgl. Leiter SMV an Staatskanzlei, Personalamt, Durchschlag, 6.8.1941, HStA Dresden, 13859, Nr. 3205, fol. 64.

${ }_{183}$ Vgl. Verordnung über den Einsatz jüdischen Vermögens, 3.12.1938, RGBl. I, 1938, S. 1709 f. Vgl. Registrandeneintrag, 15.3.1941, HStA Dresden, 11125, Nr. 22874, E.-Nr. 1821. 184 Siehe S. $142 \mathrm{ff}$.
} 


\section{„Jede Sammlung muß eine Hitlerehrung besitzen“ - Politisierung der Arbeit}

Die politischen und gesellschaftlichen Veränderungen unmittelbar nach der „Machtübernahme" durch die Nationalsozialisten machten sich in den Staatlichen Sammlungen für Kunst und Wissenschaft alsbald bemerkbar. Gemäß dem „Führerprinzip“ wurden diverse Vorschriften, wie jene, die Umgangsformen und Verhaltensregeln betrafen, zentral von den jeweiligen Reichsministerien in Berlin angeordnet und über die sächsischen Ministerien, insbesondere das SMV, auch an die Staatlichen Sammlungen weitergegeben. Die Mitarbeiter hatten für die Kenntnisnahme zu zeichnen. Meist mussten auch entsprechende Meldungen und Berichte über die Umsetzung der Anweisungen erstattet werden.

Vom Hissen der Hakenkreuzfahne auf öffentlichen Gebäuden als öffentlichkeitswirksames Zeichen der „Machtübernahme“, wie es beispielsweise für die Akademie der Bildenden Künste in Dresden für den 8. März 1933 überliefert ist, ${ }^{1}$ waren die Staatlichen Sammlungen nicht ausgeschlossen. Auf der Kunstgewerbeakademie, in der sich das Kunstgewerbemuseum befand, und auf der Gemäldegalerie wurden am 9. März 1933 „Hitlerfahnen“ gehisst. Aus diesem Anlass hielt Walther Gasch, Leiter der Gaufachgruppe der bildenden Künste der NSDAP, in Anwesenheit der Direktion und der Beamten der Galerie im Zwingerhof eine Ansprache, wie „Der Freiheitskampf“ berichtete. ${ }^{2}$

\section{Korrektes Grüßen und „soldatische“ Haltung}

Im Juli 1933 wurde in den Staatlichen Sammlungen der „Hitlergruß“ eingeführt, wie das entsprechende Schreiben mit den Unterschriften der Mitarbeiter des Kupferstich-Kabinetts belegt. ${ }^{3}$ Nur einen Monat später wies die Sächsische Staatskanzlei alle Ministerien darauf hin, dass es der Gauleitung der NSDAP missfalle, dass „bei der Ausübung des Hitlergrußes vielfach die Worte ,Mahlzeit', ,Guten Morgen' [...] zugesetzt werden" und dass alle Mitarbeiter darauf hinzuweisen seien, dass „der Hitlergruß lediglich in der Erhebung des rechten

Vgl. Weber, Stephan: Die Gleichschaltung der Kunstakademie, in: Dresdner Hefte, 22. Jg., H. 77, 2004, S. 26-35, hier: S. 26.

2 Vgl. Hissung der Hitlerfahnen auf der Kunstgewerbeakademie und Gemäldegalerie, in: FK, 11.3.1933, S. 6.

3 Vgl. Abschrift aus dem Sächsischen Verwaltungsblatt 1933, Nr. 69, Nr. 439, 19.7.1933, SKD Archiv, 01/KK 3, Bd. 8, fol. 510. 


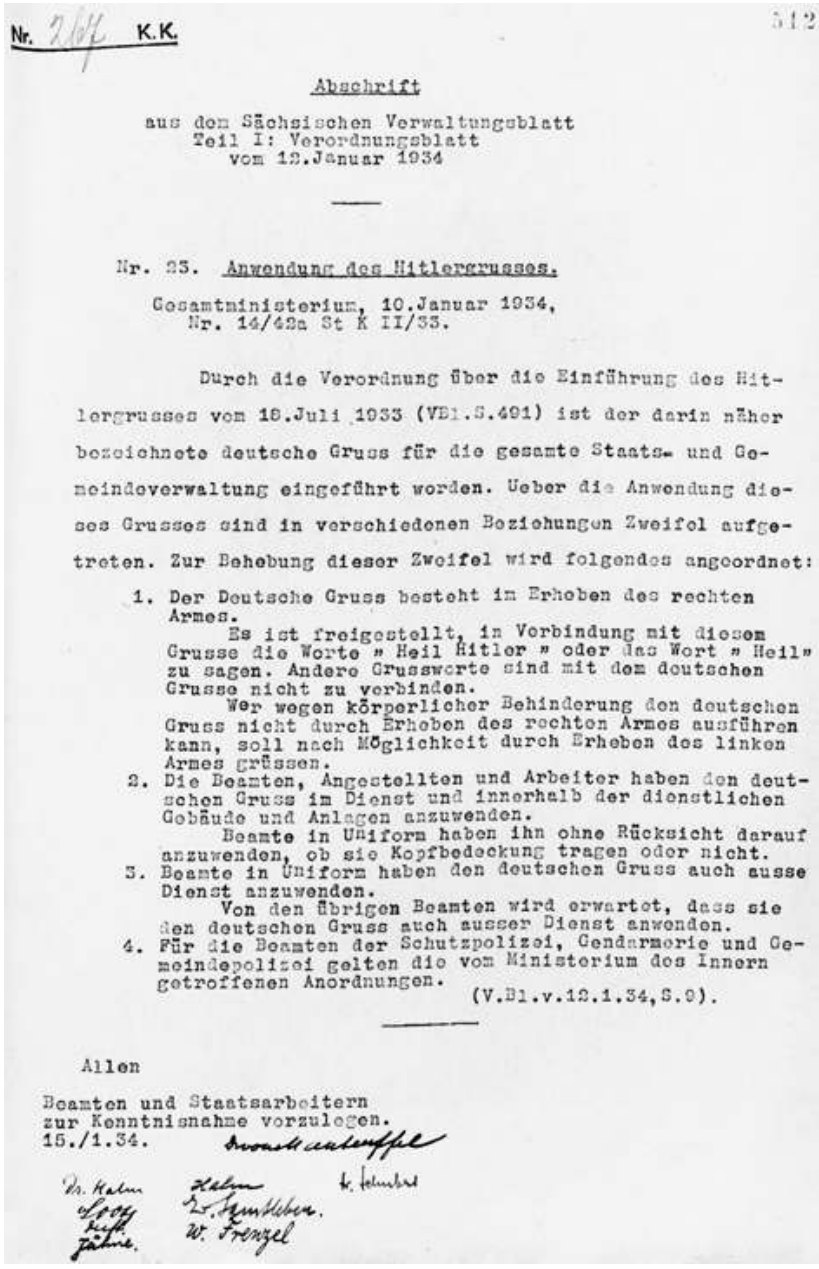

17 Abschrift aus dem Sächsischen Verwaltungsblatt, Teil 1, Verordnungsblatt vom 12.1.1934

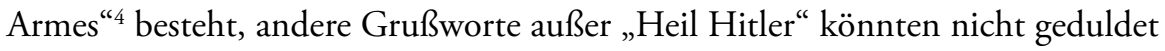
werden. Die neue Art des nationalsozialistischen Grüßens hatte sich offensichtlich noch nicht durchgesetzt. Daher wurde wenige Monate später erneut auf die „Anwendung des Hitlergrusses“ verwiesen. ${ }^{5}$

4 Staatskanzlei an die Ministerien der Sächsischen Landesregierung, 28.8.1933, SKD Archiv, 01/PS 037, Bd. 1, fol. 79 sowie SKD, MPS, 1933, E.-Reg. Nr. 169 u. HStA Dresden, 13842, Nr. 047, o. Pag.

5 Vgl. Abschrift aus dem Sächsischen Verwaltungsblatt, Teil 1, Verordnungsblatt vom 12.1.1934, Nr. 23, 15.1.1934, SKD Archiv, 01/KK 3, Bd. 8, fol. 512. 
Was mit der Maßregelung wegen des nichtkorrekten Grüßens begann, mündete bald schon in ein strenges, auf alle Bereiche des gesellschaftlichen Lebens ausgedehntes Kontrollsystem und in rigorose Maßnahmen, die das soziale Leben im Allgemeinen wie auch den kollegialen Umgang innerhalb der Staatlichen Sammlungen stark veränderten.

Als präventive Maßnahme gegen einen angeblich bevorstehenden Putsch der SA ermordeten Kommandos der SS auf Befehl Hitlers in der Nacht vom 30. Juni auf den 1. Juli 1934 die Führungskräfte der SA um deren Stabschaf Ernst Röhm. Dieser „Röhm-Putsch“ sollte als abschreckendes Beispiel dienen und wurde zum Anlass genommen, auf sämtlichen Hierarchieebenen der Verwaltung des nationalsozialistischen Staates Gehorsam einzufordern. So wurden auch die Beamten der Staatlichen Sammlungen für Kunst und Wissenschaft in Dresden durch das SMV auf die Anordnung des Reichsministers des Innern, Wilhelm Frick, vom 1. Juli 1934 hingewiesen: Sie „schulden nach den gesetzlichen Bestimmungen ihren Vorgesetzten unbedingten und ausschließlichen Gehorsam, Treue und Hingebung an ihre Amtspflichten. Sie sind ihnen allein hierin voll verantwortlich. “" Nun wurde die strikte Umsetzung des „Führerprinzips“ eingefordert. Dies führte dazu, dass alle Beamten im August 1934 einen neuen Diensteid ablegen und schwören mussten: „Ich werde dem Führer des Deutschen Reiches und Volkes, Adolf Hitler, treu und gehorsam sein, die Gesetze beachten und meine Amtspflichten gewissenhaft erfüllen, so wahr mir Gott helfe. "7 Der Vollzug der Vereidigung war dem zuständigen Ministerium unverzüglich zu melden.

Nicht ohne Grund wurden die Mitarbeiter in ihrer Gesamtheit während der NS-Zeit als „Gefolgschaft" bezeichnet. Wie die nachfolgenden Beispiele belegen, war es kaum möglich, sich der nationalsozialistischen Ideologie am Arbeitsplatz zu entziehen. Für jedwede schriftliche Verlautbarung, die im Geschäftsbereich der sächsischen Ministerien verfasst wurde, wurde im November 1934 die Verwendung in der Ich-Form angeordnet. ${ }^{8}$

Die Verwendung einer NS-konformen Sprache, das Vermeiden von Fremdwörtern sowie eine soldatische Haltung im Dienst hatte Reichsstatthalter Mutschmann am 21. Dezember 1936 von allen Mitarbeitern der sächsischen Minis-

\footnotetext{
6 SMV an nachgeordnete Stellen, 12.7.1934, SKD Archiv, 01/PS 37, Bd. 2, fol. 298 sowie SKD, MPS, 1934, E.-Reg. Nr. 170; HStA Dresden, 11127, Nr. 28, fol. 271 u. HStA Dresden, 13842, Nr. 047, o. Pag.

7 SMV an Direktoren der Staatlichen Sammlungen, 22.8.1934, SKD Archiv, 01/PS 37, Bd. 2, fol. 315; 01/KK 3, Bd. 9, fol. 34 sowie HStA Dresden, 13842, Nr. 047, o. Pag.

8 SMV an alle Dienststellen, 6.11.1934, SKD Archiv, 01/PS 37, Bd. 2, fol. 346; 01/PS 133, Eing.-Nr. 74 sowie SKD, MPS, 1934, E.-Reg. Nr. 246.
} 
terien und ihren nachgeordneten Abteilungen gefordert. Diese Anweisung wurde entsprechend an alle Sammlungsdirektoren weitergegeben. ${ }^{9}$

In diese Richtung zielten auch die vermutlich regelmäßig angebotenen Lehrgänge für Sprecherziehung. Diese lehnte $\gg$ Fritz Fichtner im Februar 1938 ab und erklärte gegenüber seinen Vorgesetzten im Ministerium, diesbezüglich durch sein gutes Vorbild und ständige Erinnerung in den Appellen einwirken zu wollen. ${ }^{10}$ Doch Jahre später konnte er sich diesen Schulungen nicht mehr entziehen. Für den 1. Mai 1942 wurde er selbst neben $\bullet$ Hans Posse, $>$ Franz Schubert, $>$ Robert

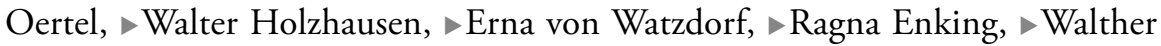
Fischer, $\triangleright$ Georg Bierbaum, $\triangleright$ Michael Hesch, $\triangleright$ Klaus Günther, $\triangleright$ Walter Häntzschel und wohl auch $\bullet$ Walter Müller zu einem solchen Kurs gebeten - das waren sämtliche zu diesem Zeitpunkt noch an den Museen der Staatlichen Sammlungen tätigen Wissenschaftler. ${ }^{11}$

Im Sinne einer „soldatischen“ Haltung wurde auch auf reine Äußerlichkeiten großer Wert gelegt, um die nationalsozialistische Weltanschauung demonstrativ nach außen zu zeigen. Am 2. August 1937 ordnete der Reichsstatthalter an, dass die Beamten „bei öffentlichen Veranstaltungen stets die Parteiuniform zu tragen haben, soweit sie den Gliederungen der Partei angehören oder eine Uniform verliehen erhalten haben "12. Damit war sofort und unmittelbar erkennbar, wer sich der NSDAP und ihren Gliederungen aktiv angeschlossen hatte. Neben dem Wiedererkennungswert wurde zugleich ein Gemeinschaftsgefühl evoziert.

Wie wichtig manchem „Parteigenossen“ seine Uniform war, belegt ein Schreiben von $>$ Hans Kummerlöwe, seit 1925 Parteimitglied. 1934, als er zwei Jahre vor seiner Berufung als Direktor der Museen für Tierkunde und Völkerkunde noch in Riesa im Schuldienst tätig war, wollte er an einer Parteitagung in Chemnitz teilnehmen. Allerdings besaß er keine Parteiuniform mehr, da er durch seine längere Studienreise nach Kleinasien vorübergehend von seinen Parteiämtern entbunden worden war. Er schrieb an die NSDAP:

9 Vgl. Reichsstatthalter an alle sächsischen Ministerien, 21.12.1936 u. Leiter SMV an Direktoren der Staatlichen Sammlungen, 5.1.1937, HStA Dresden, 13842, Nr. 048, o. Pag. u. HStA Dresden, 11127, Nr. 29, o. Pag., ebenso: SKD, MPS, 1937, E.-Reg. Nr. 10. Zum Propagieren einer reichsdeutschen Hochsprache durch Gauleiter Mutschmann vgl. Hermann 2012, S. 225 f. 10 Vgl.Porzellansammlung, Fichtner, an SMV, 21.2.1938, SKD Archiv, 01/PS 45, Bd. 1, fol. 4. 11 Vgl. ebd. sowie Leiter SMV, 27.4.1942, HStA Dresden, 11125, Nr. 22874, Eintrag 2397 u. Skulpturensammlung, Müller, an Porzellansammlung, Fichtner, 27.4.1942, SKD Archiv, 01/PS 141, fol. 37. Eine Beteiligung von Müller ist anzunehmen, da er u. a. an Fichtner die Einladung schickte. Häntzschel steht auf der Einladungsliste, wurde aber unmittelbar vor dem Lehrgang, am 27.4.1942, zum Militärdienst eingezogen.

12 SMV an Direktoren der Staatlichen Sammlungen, 10.8.1937, HStA Dresden, 13842, Nr. 115, o. Pag. sowie SKD, MPS, 1937, E.-Reg. Nr. 236. 
Wenn auch infolge wechselnder Aufenthalte augenblicklich ohne Amt, bin ich doch schließlich viele Jahre lang Amtswalter gewesen und möchte jetzt nicht plötzlich abseits stehen! [...] Wie steht es ferner mit der neuen Uniform, die doch jetzt von der polit. Leitung verliehen wird? [...] es erscheint ebenso ungerecht wie unhaltbar, wenn ich als alter Nationalsozialist trotz meines Ehrenzeichens keine Uniform mehr tragen darf, während ,Jahrgang 1933‘ als Blockwart usw. dieses Recht als selbstverständlich hat. ${ }^{13}$

Von $>$ Fritz Fichtner ist überliefert, dass er regelmäßig in der Parteiuniform zum Dienst in den Staatlichen Sammlungen erschien, insbesondere wenn Dienstappelle durchzuführen waren. ${ }^{14}$ Ein Foto zeigt ihn bei einer Ansprache, die er anlässlich der Reichstagswahl im März 1936 vor den Angestellten der Porzellansammlung im Direktorenzimmer hielt, neben seinem Schreibtisch, auf dem eine Hitler-Büste steht. ${ }^{15}$

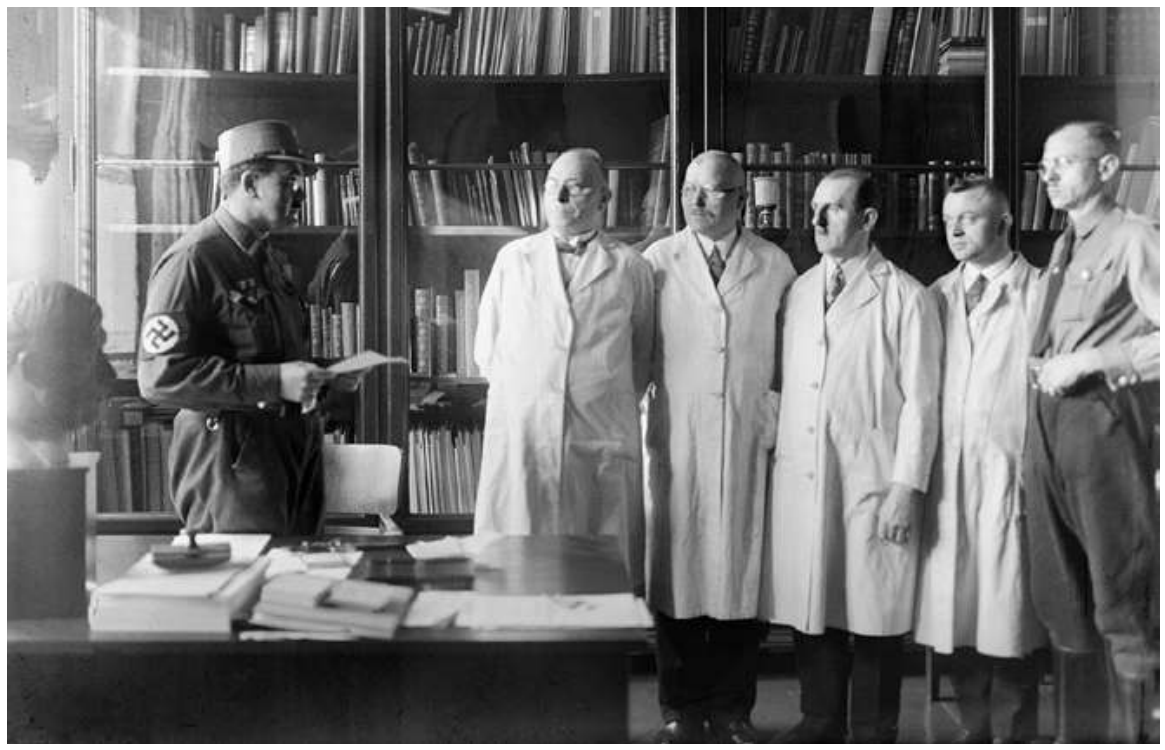

18 Appell in der Porzellansammlung am 20.3.1936 (v.l.n.r.: Fritz Fichtner, Albin Spiegler, [?] Kind, Albert Büttner, Willy Jentsch, Hellmuth Gründer)

13 Kummerlöwe, Riesa, an Geschäftsstelle der NSDAP Leipzig, Werner Kropp, 20.2.1934, HStA Dresden, Nr. 13471, Nr. ZA VI 2801 Akte 12, o. Pag.

14 Siehe S. $117 \mathrm{f}$.

15 Ob es sich hierbei um jene eigens in der Porzellanmanufaktur Meißen aus Böttgersteinzeug gefertigte Büste handelt, ließ sich nicht verifizieren. Siehe Fichtner, Porzellansammlung, 30.11.1939, SKD Archiv, 01/PS 43, Bd. 1, fol. 220. 


\section{Aufstellen von Hitler-Büsten}

Das Aufstellen von Adolf-Hitler-Büsten wurde meist publikumswirksam inszeniert. Eine solche vom Bildhauer Fritz Maskos wurde am 30. Januar 1935, zum zweiten Jahrestag der „Machtergreifung“, öffentlich in der Sächsischen Landesbibliothek, in der ersten Etage der Treppenhalle des Japanischen Palais, aufgestellt. Nach der Rezitation des Gedichtes „Hitler“ von Baldur von Schirach durch >Dorothee von Watzdorf, seit 1925 NSDAP-Mitglied, hielt Direktor > Martin Bollert, der kein Parteimitglied war, eine kurze Ansprache. ${ }^{16}$

Obwohl die Porzellansammlung bereits über eine Hitler-Büste verfügte, forderte Fichtner in Vorbereitung der Neueinrichtung der Porzellansammlung im Zwinger bei der Mittelanforderung für das Haushaltsjahr 1939: „Jede Sammlung muß eine Hitlerehrung besitzen. Die neue Porzellansammlung benötigt sowohl für den Gemeinschaftsraum, wie auch für den Spiegelsaal eine künstlerisch wertvolle Führerbüste. " 17

Nachdem Fichtner im März 1939 darum gebeten hatte, dass das SMV beim RMVP eine Hitler-Büste anfordere, fragte er selbst zwei Monate später bei Bildhauer Arno Breker in Berlin nach einer „Führerbüste“ an. ${ }^{18}$ Es ist davon auszugehen, dass in fast jeder der Sammlungen eine Porträtbüste Hitlers aufgestellt wurde. Das Armeemuseum erhielt seine im August 1939 über die Porzellansammlung. Im Treppenhaus des Museums für Tierkunde wurden erst vier Jahre nach der Einweihung des neuen Domizils, am 19. Juli 1941, eine Hitler-Büste von Bildhauer Paul Berger enthüllt, wie auch Büsten von Gregor Mendel und Charles Darwin, geschaffen von Ernst Hermann Grämer. Die Ansprache bei der öffentlichen Feierstunde hielt $>$ Michael Hesch. ${ }^{19}$

Ende April 1935 forderte der Leiter des SMV alle Mitarbeiter der nachgeordneten Stellen, also auch alle Mitarbeiterinnen und Mitarbeiter der Staatlichen Sammlungen, dazu auf,

\footnotetext{
16 Vgl. „Eine Hitlerbüste in der Landesbibliothek“, DA, 31.1.1935, S. 6 u. „Weihe einer Hitler-Büste“, in: DNN, 31.1.1935, S. 7.

17 Fichtner an SMV, 1939, SKD Archiv, 01/PS 48, fol. 12-15, hier: 12.

18 Vgl. Fichtner, Porzellansammlung, an SMV, 9.3.1939 und Fichtner, Porzellansammlung, an Breker, 13.5.1939, ebd., fol. 66 u. 01/PS 42, Bd. 1, fol. 36. Die Umsetzung dieser Pläne konnte bisher nicht nachgewiesen werden.

19 Vgl. Porzellansammlung, Sprungk, 1.8.1939, SKD Archiv, 01/PS 42, Bd. 1, fol. 9, 11 u. Jahresbericht des Museums für Tierkunde 1941, HStA Dresden, 11125, Nr. 23053, fol. 37.
} 


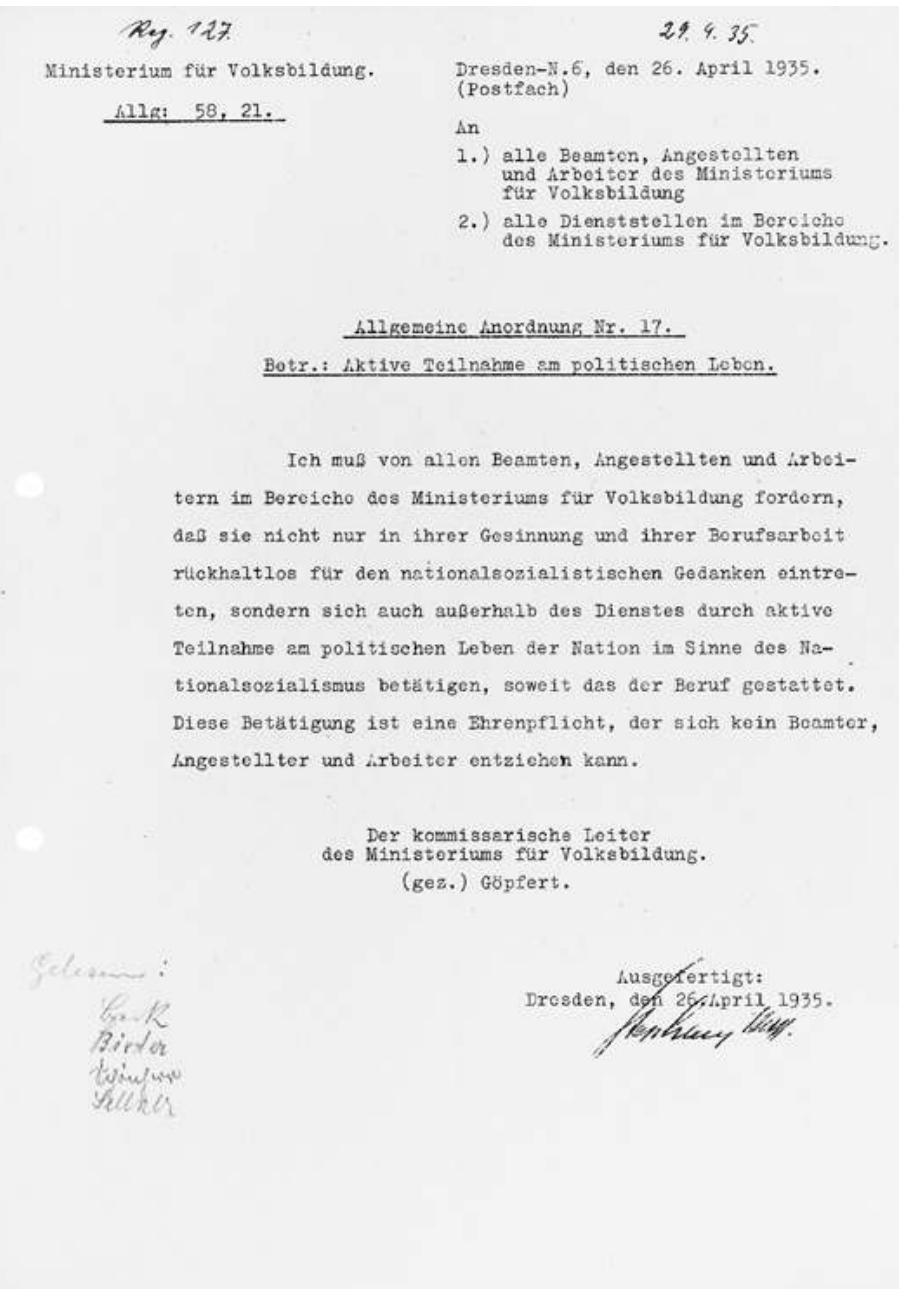

19 Allgemeine Anordnung Nr. 17, Leiter des Sächsischen Ministeriums für Volksbildung an alle Dienststellen, 26.4.1935

daß sie nicht nur in ihrer Gesinnung und ihrer Berufsarbeit rückhaltlos für den nationalsozialistischen Gedanken eintreten, sondern sich auch außerhalb des Dienstes durch aktive Teilnahme am politischen Leben der Nation im Sinne des Nationalsozialismus betätigen ${ }^{20}$.

20 Leiter SMV an alle Dienststellen, Allgemeine Anordnung Nr. 17, 26.4.1935, HStA Dresden, 13842, Nr. 047, o. Pag. ebenso: SKD, MK, 1935-1936, fol. 42 u. SKD, MPS, 1935, E.Reg. Nr. 127. 


\section{Parteipolitische Schulungen}

Diese „aktive Teilnahme am politischen Leben “21 beinhaltete unter anderem landesweite, für Beamte verpflichtende, parteipolitische Schulungen. Ein Schreiben des Ministeriums informierte am 23. November 1935 alle nachgeordneten Stellen und betonte die Notwendigkeit der Vorbildwirkung:

Die Beamten dürfen im nationalsozialistischen Staate kein unpolitisches Sonderdasein, abgeschlossen von ihren Amtsstuben, führen, sondern müssen im Volke stehen, mit ihm fühlen und ihr persönliches und dienstliches Denken und Tun immer wieder nach der nationalsozialistischen Weltanschauung und ihren Begriffen von Volk und Staat ausrichten. ${ }^{22}$

$\mathrm{Zu}$ den entsprechenden sechstägigen Lehrgängen, die für Sachsen in der Gauschule der NSDAP auf der Augustusburg stattfanden, wurden ab 1936 auch die wissenschaftlichen Mitarbeiter der Staatlichen Sammlungen abgeordnet. Ihnen sollten dort die „wichtigsten politischen Kenntnisse“ und das ,aufrüttelnde Erlebnis der Kameradschaft ${ }^{\text {“23 }}$ vermittelt werden. Die Abordnung erfolgte unter Fortzahlung der Dienstbezüge ohne Anrechnung auf den Jahresurlaub, jedoch war die Teilnehmergebühr von 12 RM selbst zu entrichten. An den Lehrgängen in der Augustusburg nahmen $1936 \triangleright$ Alfred Beck, $\triangleright$ Gottfried Benndorf, $\triangleright$ Georg Bierbaum, $\triangleright$ Walther Fischer, $\downarrow$ Jacob Jatzwauk und $\triangleright$ Alfred Unger teil, ebenso - Johannes Draeseke, der damals zum Oberkonservator am Museum für Tierkunde befördert wurde. Martin Heydrich, der erst zwei Jahre später zu einer solchen Schulung reiste, kommentierte: „Fischer und Bierbaum sind begeistert und frisch aufgebügelt von der Augustusburg wiedergekommen“24. 1937 wurden - Max Hahn, • Walter Müller, $\triangleright$ Arthur Leuschner, $>$ Hans Loos, $>$ Robert Reichert und $\triangleright$ Curt Sander in der Augustusburg geschult, $1938 \triangleright$ Rudolf Schwarze und - Paul Täubrich, der anschließend zum Präparator an der Skulpturensammlung ernannt wurde. Die Teilnahme + Walter Häntzschels 1939 stand vermutlich im Zusammenhang mit seiner Verbeamtung als Kustos am Museum für Mineralogie und Geologie.

21 Ebd.

22 Leiter SMV an alle Dienststellen, 23.11.1935, SKD Archiv, 01/PS 38, fol. 305 sowie 01/KK 3, Bd. 9, fol. 243 und SKD, MPS, 1935, E.-Reg. Nr. 374. Zum Schulungswesen der NSDAP vgl. Schmeitzner, Mike: Totale Herrschaft durch Kader? Parteischulung und Kaderpolitik von NSDAP und KPD/SED, in: Totalitarismus und Demokratie. Zeitschrift für internationale Diktatur- und Freiheitsforschung, 2, 2005, S. 71-99, hier: 74-85.

23 Leiter SMV an alle Dienststellen, 23.11.1935, SKD Archiv, 01/PS 38, fol. 305 sowie 01/KK 3, Bd. 9, fol. 243 u. SKD, MPS, 1935, E.-Reg. Nr. 374.

24 Heydrich an Struck, 12.11.1936, SKD, MfV Archiv, MVD n20;25/6, o. Pag. 
Eine kürzere parteipolitische Schulung von nur dreitägiger Dauer in der Kreisschule der NSDAP in Seifersdorf erhielten $>$ Hermann Neubert 1937, als sich seine Ernennung zum Direktor der Sächsischen Landesbibliothek abzeichnete, und 1938 Benndorf und Loos nach ihrer Aufnahme in die NSDAP. Ebenfalls 1938 in Seifersdorf wurden $\triangleright$ Gert Adriani und $\triangleright$ Kurt Hoppe, wenige Monate nach seiner Beförderung zum Präparator am Münzkabinett, geschult, 1939 auch Sander.

In Bad Tölz wurde hingegen ein dreiwöchiges Reichslager für Beamte durchgeführt. Im Juli 1938 informierte das SMV über eine Verordnung des Reichsministeriums des Innern, dass nach

Übereinkommen mit dem Stellvertreter des Führers [...] alle Anwärter des höheren

Dienstes in der allgemeinen und inneren Verwaltung [...] vor ihrer planmäßigen Anstellung an einem Lehrgang des Reichslagers für Beamte teilzunehmen ${ }^{25}$

haben. An den NSDAP-Schulungen in Bad Tölz nahmen 1938 zeitgleich Müller, $\triangleright$ Klaus Günther und $\triangleright$ Rolf Hetsch teil, danach $\triangleright$ Wilhelm Meise. Hetsch war damals gerade zum Kustos der Porzellansammlung ernannt worden, er und Günther konkurrierten als Kandidaten für die Leitung des Münzkabinetts, während Meise sich für die in Erwägung gezogene Ernennung zum Kustos am Museum für Tierkunde politisch beweisen musste. Im Falle von Müller, der 1934 Direktor der Skulpturensammlung geworden, aber noch immer kein Mitglied der NSDAP war, erhoffte man sich von der verordneten Lehrgangsteilnahme wohl, sie möge ihn zu einem vorbildlichen nationalsozialistischen Beamten formen.

Am ersten Schulungslehrgang auf der Leuchtenburg in Thüringen hatte bereits im Oktober 1934 - Michael Hesch teilgenommen.

Dass man sich diesen politischen Schulungen, wenn überhaupt, nur schwer entziehen konnte, belegt das Beispiel von $\gg$ Franz Schubert. Als er im Juni 1938 zum Reichslager für Beamte in Bad Tölz einberufen wurde, bat er aufgrund seiner dienstlichen Belastung um Zurückstellung. Daraufhin forderte das RMWEV beim SMV eine Erklärung. Sammlungsreferent $\triangleright$ Fritz Fichtner verteidigte Schubert, dieser habe eine Zurückstellung erbeten und keine Entbindung von der Teilnahme. Auch der unmittelbare Vorgesetzte Schuberts, der Direktor des Kupferstich-Kabinetts, $\triangleright$ Kurt Zoege von Manteuffel, musste eine Stellungnahme abgeben. ${ }^{26}$

\footnotetext{
25 Leiter SMV an Direktoren der Staatlichen Sammlungen, 30.7.1938, SKD, MPS, 1938, E.-Reg. Nr. 205, ebenso: HStA Dresden, 13842, Nr. 115, o. Pag.

26 Vgl. RMWEV an Leiter SMV, 21.6.1938; Fichtner, SMV, an RMWEV, 11.7.1938, Kupferstich-Kabinett, Zoege von Manteuffel, an Leiter SMV, 29.7.1938, HStA Dresden, 11125, Nr. 22889, fol. 66-76. Spätere Einberufungen Schuberts nach Bad Tölz sind nicht bekannt.
} 
Eine Sonderstellung bezüglich der NSDAP-Schulungen nimmt $>$ Hellmuth Buck, Konservator an den Museen für Tierkunde und Völkerkunde, ein. Nachdem er selbst an diversen parteipolitischen Schulungen in der SA-Führerschule in Hammerleubsdorf bei Chemnitz und in der Gauführerschule II auf Schloss Friedrichsburg bei Dresden teilgenommen hatte, wurde er ab 1934 als Kreisschulungsleiter der NSDAP tätig. Im April 1936 beauftragte ihn die Gauleitung Sachsen der NSDAP mit der Durchführung von Lehrgängen an der Gauschule Hammerleubsdorf, deren Leitung er von 1937 bis 1940 übernahm, wofür er vom Museumsdienst beurlaubt wurde. ${ }^{27}$

\section{Übertragung der Rundfunk-Propagandareden}

Zur „aktiven Teilnahme am politischen Leben“ zählte ebenfalls die Kenntnis der NS-Propaganda-Reden des Reichskanzlers Adolf Hitler und des Reichsministers für Volksaufklärung und Propaganda Joseph Goebbels. Zentral durch das SMV wurde die stundenweise Schließung der Museen geregelt, um allen Mitarbeitern das gemeinsame Hören der Rundfunkübertragung von NS-Propaganda-Reden in der Gemäldegalerie zu ermöglichen, wofür extra eine Tonanlage angeschafft wurde. Belegt sind solche Veranstaltungen unter anderem für den 10. November 1933, zwei Tage vor der Reichstagswahl, als Adolf Hitlers „Rede an das schaffende deutsche Volk" aus den Siemenswerken in Berlin gesendet wurde, und für den 21. März 1934, als Hitler an der Reichsautobahn-Baustelle Unterhaching bei München die zweite „Arbeitsschlacht“ eröffnete, um Deutschland von der hohen Arbeitslosigkeit zur Vollbeschäftigung zu führen. ${ }^{28}$ Diese Art von Veranstaltungen war für alle Betriebe und damit auch für die Staatlichen Sammlungen Pflicht. Am 21. März 1934 wies die Presse an:

Am heutigen Vormittag muß in jedem deutschen Betrieb durch Rundfunk die Kundgebung der Reichsregierung übertragen werden [...] Kein einziger schaffender Deutscher Volksgenosse darf sich von diesen Kundgebungen ausschließen. ${ }^{29}$

\footnotetext{
27 Vgl. Leiter SMV, Göpfert, an Direktor der Museen für Tierkunde und Völkerkunde, 14.4.1936, HStA Dresden, 13842, Nr. 048, o. Pag. Vgl. BArch, R 76/I/59, fol. 84 u. Personalakten Buck, HStA Dresden, 13859, Nr. 844. Mit der in den Akten erwähnten Bezeichnung "Schloss Friedrichsburg" ist vermutlich das Friedrichsschlösschen in Großsedlitz gemeint. Zu Hammerleubsdorf vgl. Schmeitzner 2014.

${ }_{28}$ Vgl. SMV an Direktoren der Staatlichen Sammlungen (ohne Landesbibliothek, Armeemuseum), 8.11.1933, SKD, MPS, 1933, E.-Reg. Nr. 200, ebenso: SKD Archiv, 01/PS 37, Bd. 1, fol. 124; 01/KK 3, Bd. 8, fol. 527; HStA Dresden, 13842, Nr. 047, o. Pag. u. SMV an Direktoren der Staatlichen Sammlungen (ohne Landesbibliothek, Armeemuseum), 20.3.1934, SKD, MPS, 1934, E.-Reg. Nr. 79, ebenso: SKD Archiv, 01/PS 131, E 104; 01/PS 137, 2, Nr. 187.

29 Die Deutsche Arbeiterschaft hört den Führer, in: DA, 21.3.1934, S. 5.
} 
Selbst der exakte Ablauf dieser Veranstaltungen wurde zentral vorgegeben:

10.45 die Belegschaft einschließlich der Unternehmer ist im Betrieb angetreten 10.50 der Betriebsführer spricht zu seiner Gefolgschaft

10.55 der Betriebsobmann der NSBO oder DAF bzw. der Beauftragte der DAF leitet zur Übertragung von München über

11.00 Beginn der Übertragung aus München

11.25-11.45 Rede des Führers

11.45 je eine Strophe des Deutschland- und des Horst-Wessel-Liedes

11.50 Ende der Kundgebung und der Rundfunkübertragung ${ }^{30}$.

Die Funktion des Betriebsfunkwartes übernahm $>$ Alfred Beck, Restaurator am Mathematisch-Physikalischen Salon. Damit war er für die Übertragungen der RadioPropaganda-Reden von Hitler und Goebbels verantwortlich, die für die "Gefolgschaft" der Staatlichen Sammlungen im Erdgeschoss der Gemäldegalerie veranstaltet wurden. Auch die technische Durchführung der Radio-Übertragung der Trauerfeierlichkeiten für Reichspräsident Paul von Hindenburg Anfang August 1934 verantwortete Beck - in einer entsprechenden Erfolgsmeldung an die Kreisleitung der NSDAP berichtete er von 350 Zuhörern. ${ }^{31}$

Im Januar 1936 untersuchte Beck, ob „im Bereich des Zwingers überhaupt störungsfreier Empfang des Bezirks- und des Deutschlandsenders möglich ist" und stellte fest: „Als Veranstaltungsort für die Ge-

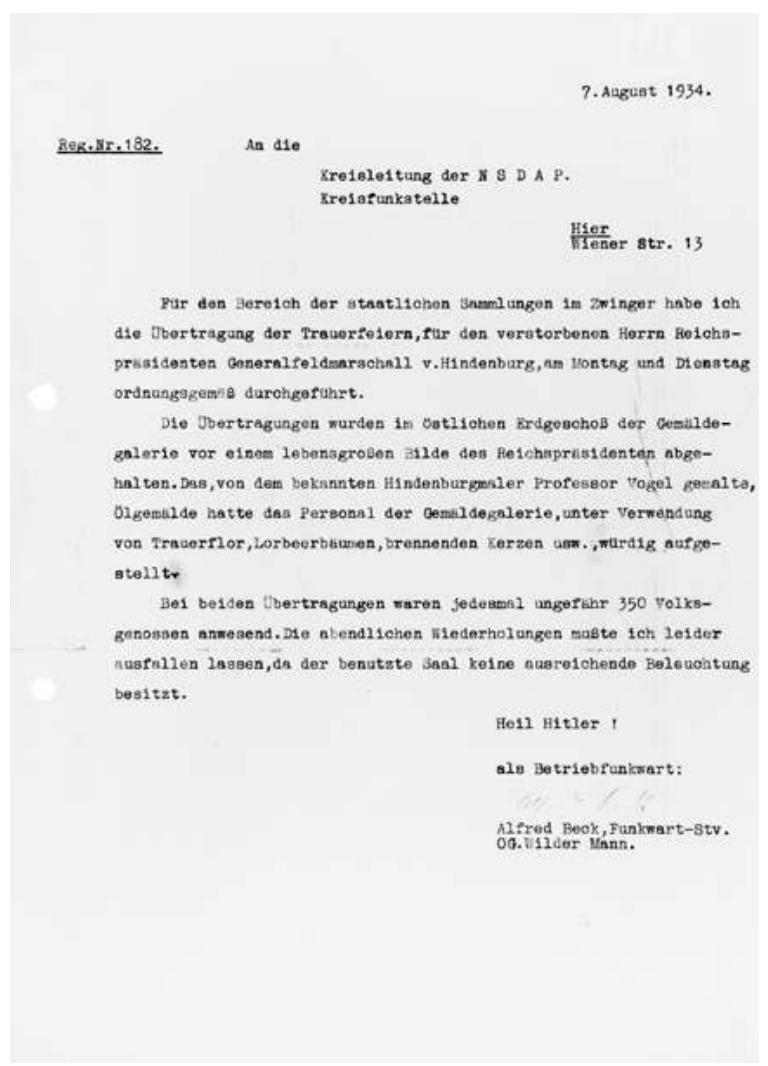

20 Brief von Alfred Beck an die Kreisleitung der NSDAP, 7.8.1934

\footnotetext{
30 Ebd.

31 Vgl. Beck an Kreisleitung der NSDAP, 7.8.1934, SKD, MPS, 1934, A.-Reg. Nr. 182. Vgl. auch SKD, MPS, 1935, A.-Reg. Nr. 134 u. 1936, A.-Reg. Nr. 5.
} 
meinschaftsempfänge scheint aus akustischen und technischen Gründen der Saal im Pavillon D geeigneter zu sein als der bisher benutzte Saal in der Gemäldegalerie. "32 Von weiteren Versammlungen der Mitarbeiter, um gemeinsam die Übertragung der Rundfunkreden anzuhören, ist auszugehen, wenngleich sie im Einzelnen nicht mehr nachweisbar sind. Allein die Bemühungen, die dabei genutzte Technik zu optimieren, legen dies nahe.

\section{Teilnahme an politischen Großveranstaltungen}

Ebenfalls anlässlich diverser gesellschaftlicher bzw. politischer Großveranstaltungen in der Stadt wurde vom SMV die meist stundenweise Schließung der Staatlichen Sammlungen angeordnet, um allen Mitarbeitern die Teilnahme zu ermöglichen. Da diese Veranstaltungen meist während der regulären Dienstzeit stattfanden, bestand für die Mitarbeiter eine Verpflichtung zur Teilnahme. Auf diese Weise war klar geregelt, dass die Mitarbeiter sich diesen Veranstaltungen und Ereignissen nicht entzogen. Sie hatten ihre Vorbildfunktion als Staatsbeamte in der Öffentlichkeit wahrzunehmen. Letztlich war damit auch die Anwesenheit von ausreichend jubelndem Publikum gewährleistet.

So war die jährliche Teilnahme an den Feierlichkeiten zum 1. Mai für alle Mitarbeiter der Staatlichen Sammlungen verpflichtend. Überliefert sind unter anderem die Aufforderungen zur Teilnahme an den Feiern in den Jahren 1933 und 1935. ${ }^{33}$ Zum 1. Mai 1934 fand in Anwesenheit von Reichsstatthalter Martin Mutschmann, Innenminister Karl Fritsch, Wirtschaftsminister Georg Lenk und Oberbürgermeister Ernst Zörner sowie weiteren Vertretern aus Politik und Verwaltung die „Maifeier des deutschen Sozialismus“ auf der Dresdner Vogelwiese am Elbufer statt. ${ }^{34}$ Unter den 500.000 Teilnehmern waren auch $\triangleright$ Franz Schubert, $\triangleright$ Walter Holzhausen und $\triangleright$ Karl Wilhelm Jähnig, wie ein im KupferstichKabinett erhaltenes Foto belegt.

\footnotetext{
32 Mathematisch-Physikalischer Salon, Beck, an [unbekannt], 13.1.1936, SKD, MPS, 1936, A.-Reg. Nr. 5.

33 Vgl. Protokoll Direktorenkonferenz 28.4.1933, SKD Archiv, 01/SKS 184, o. Pag.; Betriebsobmann Ehrler an Beamte und Angestellte der Staatlichen Sammlungen, 29.4.1933, SKD, MPS, 1933, E.-Reg. Nr. 89; Leiter SMV an Direktoren der Staatlichen Sammlungen, 25.4.1935, HStA Dresden, 13842, Nr. 047, o. Pag., ebenso SKD Archiv, 01/PS 38, fol. 41; HStA Dresden, 11127, Nr. 28, fol. 414.

34 Vgl. 500.000 auf der Dresdner Vogelwiese! Pg. Mutschmann und Pg. Peitsch sprechen zu den schaffenden Volksgenossen, in: FK, 2.5.1934, S. $1 \mathrm{f}$.
} 


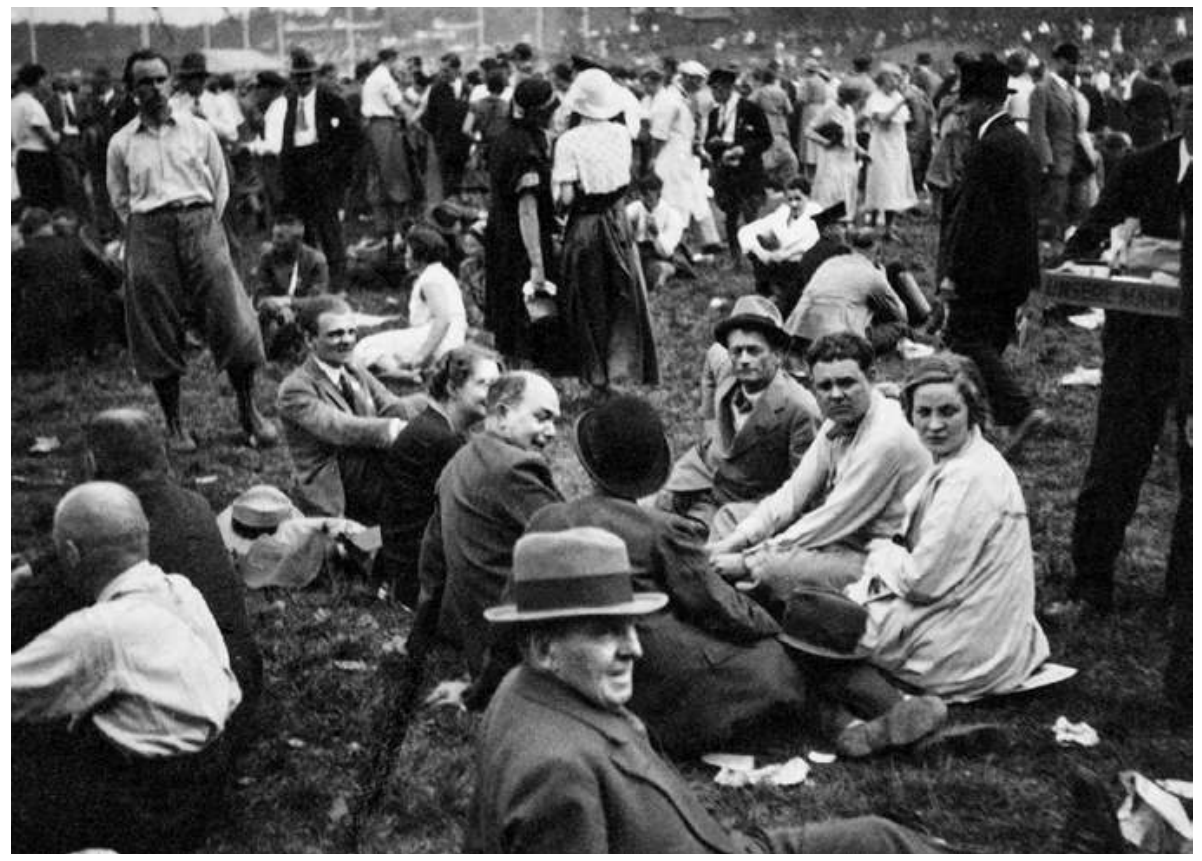

21 „Maifeier des deutschen Sozialismus“ am 1.5.1934 am Elbufer in Dresden (Franz Schubert (1. stehend), Walter Holzhausen (2.v.r. sitzend), und Karl Wilhelm Jähnig (3.v.r. sitzend))

Kurz nach den Veranstaltungen mussten die Direktoren die Teilnehmeranzahl an das Ministerium melden. ^ Bernhard Struck bestätigte 1935 für die Museen für Tierkunde und Völkerkunde 15 Teilnehmer von insgesamt 22 Mitarbeitern, • Hans Posse für die Gemäldegalerie 35 von insgesamt 46, die anderen galten jeweils aufgrund von Erkrankungen oder anderen nicht weiter benannten Gründen als entschuldigt. ${ }^{35}$ Der Direktor der Landesbibliothek $>$ Martin Bollert nahm mehrfach nicht an Veranstaltungen teil. Zu seiner Entschuldigung schrieb er 1935: „Ich bitte, mich von der Teilnahme an den Feiern des 1. Mai zu beurlauben, da mein Gesundheitszustand infolge eines schweren Unfalles, den ich vor einigen Jahren erlitten habe, mir längeres Stehen unmöglich macht. ${ }^{\text {“36 }}$

\footnotetext{
35 Vgl. Museen für Tierkunde und Völkerkunde, Struck, an SMV, 3.5.1935, HStA Dresden, 13842, Nr. 047, o. Pag. u. Gemäldegalerie, Posse, an SMV, 2.5.1935, HStA Dresden, 11127, Nr. 28, fol. 415. Hierbei sind alle Mitarbeiter gezählt, vom Direktor bis zur Reinigungskraft. 36 Sächsische Landesbibliothek, Bollert, an SMV, 25.4.1935, SLUB PA Bollert II, Vgl. auch Sächsische Landesbibliothek, Bollert, an SMV, 27.4.1937, ebd.
} 
Während der Reichstagswahlen blieben die Staatlichen Sammlungen ebenfalls auf ministerielle Anordnung geschlossen, so zum Beispiel am 5. März 1933. ${ }^{37}$ Zwar wurden nach den Wahlen keine Teilnahme- bzw. Erfolgsmeldungen an das Ministerium übermittelt, jedoch fragte das Ministerium Ende Mai 1936 mit den Vermerken „Eilt sehr" und "Streng vertraulich" bei den Sammlungsdirektoren nach, wer von den Mitarbeitern sich nicht an der Reichstagswahl im März 1936 beteiligt hatte und warum. ${ }^{38}$

Diese Vorgänge zeigen in ihrer Gesamtheit betrachtet, dass die Sammlungsdirektoren nach und nach im Auftrag ihrer vorgesetzten Dienststelle eine Kontrollfunktion über das gesellschaftliche Engagement und Privatleben ihrer Mitarbeiter wahrzunehmen hatten. Das „Führerprinzip“ kam auf allen Ebenen als Kontrollmechanismus zur Anwendung.

Geschlossen wurden die Sammlungen, wie alle Geschäftsbereiche und nachgeordneten Stellen des SMV, zum Beispiel auch anlässlich der Rede von Reichsinnenminister Wilhelm Frick in Dresden im Juni 1935 oder während des Staffellaufes der olympischen Fackelträger im Juli 1936. ${ }^{39}$ Eine Einladung der NSDAP-Gauleitung Sachsen zum Gauappell der NSDAP und zur Sonnenwendfeier am 20./21. Juni 1936, die allen Sammlungsdirektoren zugestellt wurde, reichte $>$ Kurt Zoege von Manteuffel mit der Bemerkung „Allen Beamten und Angestellten zur Kenntnisnahme und mit dem Hinweis darauf, daß eine zahlreiche Teilnahme höchst erfreulich wäre“ ${ }^{40}$ an die Mitarbeiter im KupferstichKabinett weiter.

Ob die Mitarbeiter der Staatlichen Sammlungen auch an anderen politischen Veranstaltungen, wie zum Beispiel an den regelmäßigen SA-Aufmärschen, als deren Bühne der Innenhof des Dresdner Zwingers benutzt wurde, teilnahmen oder teilnehmen mussten, oder an Veranstaltungen wie der "Totengedenkfeier“ im November 1935, bei der „Pg. Buck““11 sprach, oder einer „Kriegsfeierstunde“ im Februar 1943, bei der der Reichsminister für die deutschen Ostgebiete,

\footnotetext{
37 Vgl. SMV an Direktoren der Staatlichen Sammlungen, 3.3.1933, SKD, MPS, 1933, E.-Reg. Nr. 45a sowie SMV an SMV, Abt. Sammlungen, 4.3.1933, SKD Archiv, 01/PS 131, E.-Reg. Nr. 94. 38 Vgl. Leiter SMV an Dienststellen im Bereich des SMV, 28.5.1936, SKD; MPS, 1936, E.Reg. 179, ebenso: SKD Archiv, 01/PS 40, fol. 111.

39 Vgl. NSDAP Amt für Beamte, Rundschreiben, 12.6.1935, SKD Archiv, 01/KK 3, Bd. 9, fol. 184 u. Reichsstatthalter an Leiter SMV, 24.7.1936, SKD, MPS, 1936, E.-Reg. Nr. 218.

40 Zoege von Manteuffel, handschriftliche Anmerkung, NSDAP Gauleitung Sachsen an alle Behördenvorstände, 18.6.1936, SKD Archiv, 01/KK 3, Bd. 9, fol. 302. Vgl. auch fol. 303 f.

41 Vermutlich $>$ Hellmuth Buck von den Museen für Tierkunde und Völkerkunde, der eine Karriere als Parteiredner absolvierte und im Frühjahr an die Gauschule Hammerleubsdorf abgeordnet wurde.
} 
Alfred Rosenberg, der mit dem Einsatzstab Reichsleiter Rosenberg für den NSKunstraub in den besetzten Gebieten verantwortlich war, und Reichsstatthalter Mutschmann sprachen, ist nicht überliefert. ${ }^{42}$

Betriebs- und Gemeinschaftsappelle

Zur politischen Motivierung der Mitarbeiter sollten auch die sogenannten Betriebs- bzw. Gemeinschaftsappelle beitragen, die meist jeweils zum Monatsbeginn zentral für mehrere Sammlungen, bisweilen auch nur für einzelne Sammlungen, unregelmäßig stattfanden. Nicht alle Appelle sind dokumentiert und überliefert. Eine dieser Veranstaltungen, die Belegschaftsversammlung der „Zelle Staatliche Sammlungen", d.h. der Mitglieder der NSDAP und der DAF, im Hörsaal des Albertinums, wurde sogar am 8. Juni 1933 in „Der Freiheitskampf angekündigt. ${ }^{43}$ Für die Mitarbeiter der Gemäldegalerie fand am 24. Mai 1935 ein Appell im Eingangssaal der Galerie statt. Galeriedirektor $\triangleright$ Hans Posse hatte auf der Einladung sogleich vermerkt „Betriebsappell ist Dienst“, um sicherzugehen, dass auch alle Mitarbeiter daran teilnehmen würden. ${ }^{44}$

Der erste dokumentierte Gemeinschaftsappell für alle Sammlungsmitarbeiter fand am 28. September 1935, einem Sonnabend und somit regulären Arbeitstag, im Erdgeschoss der Gemäldegalerie statt. Er war nur drei Tage vorher in einer Dienstberatung vom SMV angeordnet worden. ${ }^{45}$

Appelle, bei denen anlässlich der wöchentlichen Dienstausgaben die Tagesparole verlesen wurde, veranstalteten mehrere Sammlungen, angeregt durch die DAF und den RDB. Durch regelmäßige Betriebsappelle „sollten Betriebsführer und Gefolgschaft einander nähergebracht und eine geschlossene Einheit von Betriebsführer bis zum letzten Gefolgschaftsmitglied hergestellt werden“, mit dem Ziel „eine geschlossene nationalsozialistische Betriebs- und Leistungsgemeinschaft zu schaffen " ${ }^{46}$. Sie sollten, wie es der DAF-Vertreter in den Staatlichen Sammlungen, Betriebszellenobmann Walter Lassé, Hilfsaufseher in der

42 Vgl. Dresdner Nachrichten (DNa), 19.1.1936, S. 5; DA, 11.11.1935, S. 5; 27.1.1936, S. 3; 20.4.1936, S. 7; 20.2.1943, S. 1; DNN, 1.3.1943, S. 3.

43 Vgl. Zelle Staatliche Sammlungen, in: FK, 8.6.1933, S. 6.

44 Gemäldegalerie, Posse, 22.5.1935, HStA Dresden, 11127, Nr. 28, Rg.-Nr. 437.

45 Vgl. Museen für Tierkunde und Völkerkunde, Struck, 26.9.1935, HStA Dresden, 13842, Nr. 047, o. Pag.

46 Reichsbund der Deutschen Beamten Gau Sachsen und Deutsche Arbeitsfront Gauwaltung Sachsen, Gaubetriebsgemeinschaft Verkehr und öffentliche Betriebe, Gemeinsame Anweisung an die RDB-Walter und DAF-Walter bei den Reichs- und Staatsbetrieben und Verwaltungen [etc.], Februar 1936, SKD, MPS, 1936, E.-Reg. o. Nr. 


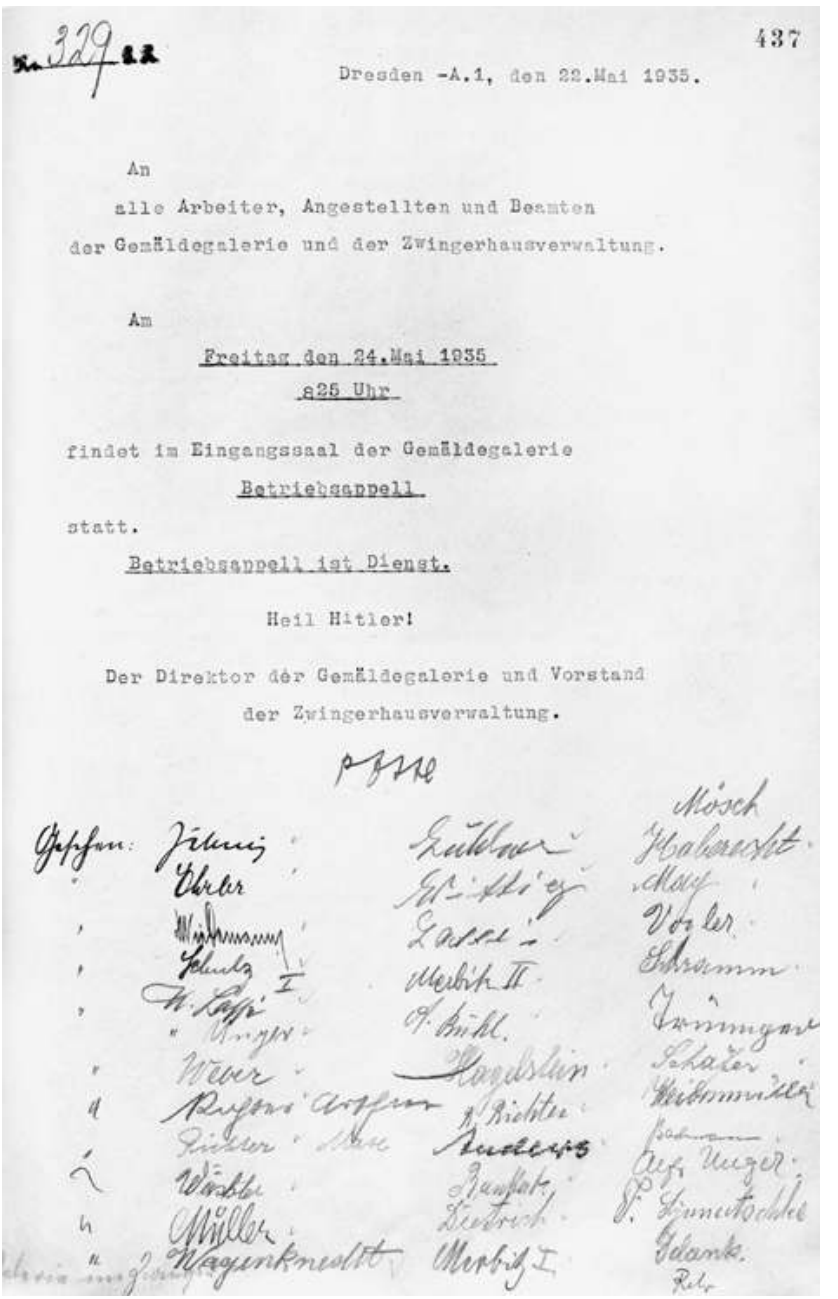

22 Anordnung eines Betriebsappells, Gemäldegalerie, Hans Posse, an das Personal der Gemäldegalerie, 22.5.1935
Gemäldegalerie, im Januar 1937 betonte, dazu dienen, dass alle Mitarbeiter sich in die nationalsozialistische „Betriebsgemeinschaft“ einreihen, „damit auch wir ein Musterbetrieb werden, und wie es der Führer will, das Deutschland gross und stark werde ${ }^{\text {“ } 47}$.

Vertreter der DAF, namentlich der Verwaltungsinspektor der Gemäldegalerie Ottomar Ehrler und der Hilfsaufseher der Porzellansammlung Hellmuth Gründer, regten an, diese Appelle, die zunächst in der Gemäldegalerie stattfanden, auch in anderen Sammlungen $\mathrm{zu}$ veranstalten. In der Direktorenkonferenz am 9. April 1936 diskutierten die Sammlungsdirektoren $>$ Fritz Fichtner, Martin Bollert, - Kurt Zoege von Manteuffel, - Walter Müller sowie • Bernhard Struck als Vertreter für -Hans Kummerlöwe über die Betriebsappelle. Anlass war der Wunsch nach einer einheitlichen Regelung der Durchführung von Betriebsappellen, den Zoege von Manteuffel geäußert hatte. Fichtner appellierte an die Direktoren, selbst aktiv zu werden und Vorschläge zu unterbreiten, sich jedoch nicht weiter von der Arbeitsfront nötigen zu lassen. So sollte beim SMV die Einrichtung von Montagsappellen erfragt werden. ${ }^{48}$

47 Lassé an alle Staatliche Sammlungen, 7.1.1937, SKD, MK, 1936-1937, E.-Reg. Nr. 251.

48 Vgl. Fichtner, Protokoll der Dienstberatung, 9.4.1936, SLUB, Bibl.-Arch.III.G,Vol.686, o. Pag. Ob dies auf diese Weise geschah, bleibt ebenso unklar wie die Häufigkeit der Appelle. 
23 Brief des Kommissarischen Leiters des Sächsischen Ministeriums für Volksbildung, Arthur Göpfert, an die Direktoren der Staatlichen Sammlungen, 30.4 .1936

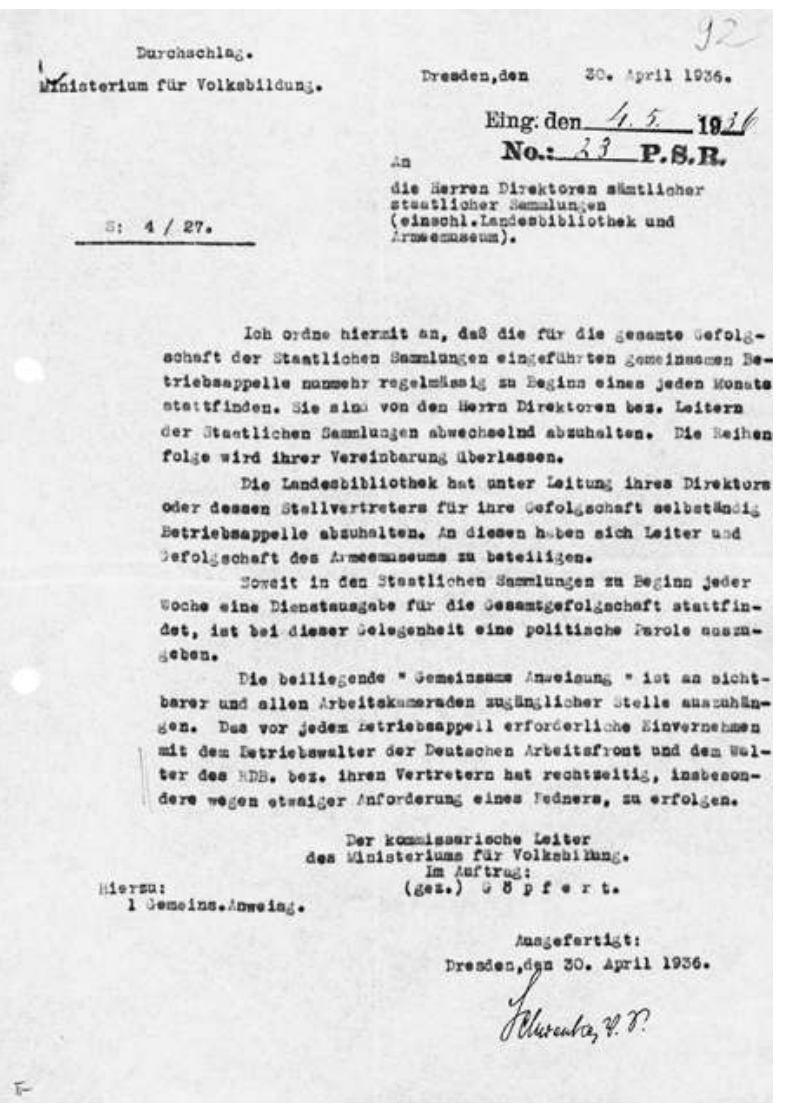

Prinzipiell wurden die Gemeinschaftsappelle jeweils von einem der Sammlungsdirektoren oder -leiter inhaltlich vorbereitet und fanden außerhalb der Öffnungszeiten der Sammlungen statt. Sie waren willkürlich festgelegt, berücksichtigten aber im nationalsozialistischen Staat wichtige Daten und Ereignisse, wie bevorstehende Wahlen, den 1. Mai oder den „Führergeburtstag“. Für den Appell am 20. April 1936, der an Hitlers 47. Geburtstag stattfand, war Kummerlöwe verantwortlich. Da er jedoch zu dieser Zeit dienstlich auf Helgoland weilte, ließ er sich durch seinen Kustos für Anthropologie, Struck, vertreten. ${ }^{49}$

Am 30. April 1936 ordnete der Leiter des SMV an, „daß die für die gesamte Gefolgschaft der Staatlichen Sammlungen eingeführten gemeinsamen Be-

49 Vgl. Kummerlöwe an Struck, 17.4.1936, HStA Dresden, 13842, Nr. 114, Bd. 2, o. Pag. 


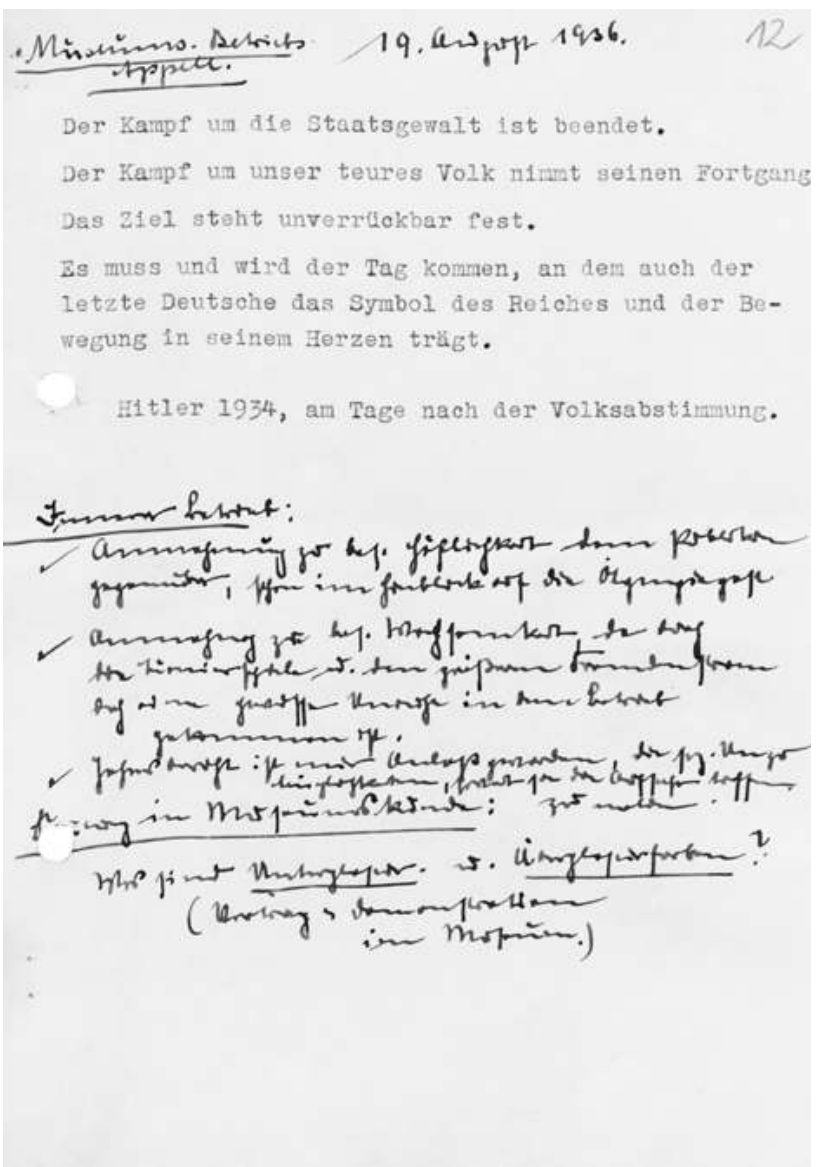

24 Notizen von Fritz Fichtner für den Betriebsappell am 19.8.1936

triebsappelle nunmehr regelmäßig zu Beginn eines jeden Monats stattfinden" ${ }^{\text {50 }}$. Die Direktoren bzw. Leiter sollten diese in Absprache untereinander abwechselnd durchführen. Lediglich die Landesbibliothek sollte unter Leitung ihres Direktors eigene Betriebsappelle veranstalten, an denen sich die Mitarbeiter des Sächsischen Armeemuseums zu beteiligen hatten. Darüber hinaus ordnete Göpfert an, dass, wenn „zu Beginn jeder Woche eine Dienstausgabe für die Gesamtgefolgschaft stattfindet, [...] bei dieser Gelegenheit eine politische Parole auszugeben" ${ }^{\text {"51 }}$ sei. Die Anordnung der Dienstappelle bewirkte bei den Sammlungsdirektoren Diskussionsbedarf und avancierte zum Hauptthema der nächsten Direktorenkonferenz am 12. Mai 1936.52

Ende Mai kündigte eine Einladung den nächsten Gemeinschaftsappell für den 3. Juni 1936 sowie danach ,jeden ersten Dienstag im Monat [...] regelmäßig im östlichen Flügel der Gemäldegalerie“ an, „an dem sämtliche Gefolgschaftsmitglieder teilzunehmen haben“"53. Der Museumsbetriebsappell am 19. August 1936 wurde

50 Leiter SMV, Göpfert, an Direktoren aller Staatlichen Sammlungen, 30.4.1936, SKD Archiv, 01/PS 40, fol. 92; 01/KK 3, Bd. 9, fol. 307; SKD, MPS, 1936, E.-Reg. Nr. 53; HStA Dresden, 13842, Nr. 048, o. Pag.

51 Ebd.

52 Vgl. Historisches Museum, Haenel, an Kupferstich-Kabinett, Zoege von Manteuffel, 8.5.1936, SKD Archiv, 01/KK 3, Bd. 9, fol. 308 u. SKD, MK, 1936-1937, fol. 33.

53 [?] an Direktion Kupferstich-Kabinett, 26.5.1936, SKD Archiv, 01/KK 3, Bd. 9, fol. 299. 
von Fichtner genutzt, die Mitarbeiter zu „Höflichkeit dem Publikum gegenüber“ und zu „Wachsamkeit" ${ }^{\text {"54 }}$ aufzufordern; wie bei diesen Appellen üblich, mit Verlesung eines Zitates von Hitler.

Anfang November 1937 fand eine Betriebsversammlung für alle Beamten der Staatlichen Sammlungen im Hörsaal der Skulpturensammlung im Albertinum statt. In der Einladung wurde sogleich erlaubt, dass die Einzelbetriebsappelle für diesen Monat dadurch entfallen könnten, ${ }^{55}$ eine Regelung, die sich schnell durchsetzte.

Die Betriebsappelle erfüllten unterschiedliche Funktionen. Sie sollten die Mitarbeiter politisch schulen und motivieren, aber auch Spendensammlungen unterstützen, wie zum Beispiel am 14. Oktober 1938, als zur Beteiligung am Winterhilfswerk aufgefordert wurde. ${ }^{56}$ Die Einladungen für die Betriebsappelle am 12. Oktober 1940 und am 1. Februar 1941, die im Spiegelsaal der Porzellansammlung bzw. im Hörsaal des Albertinums stattfanden, kündigten hingegen politische Reden des ehemaligen Konservators vom Museum für Tierkunde, • Hellmuth Buck, an, der seit April 1940 im SMV tätig war. ${ }^{57}$ Der Appell im Februar 1941 diente auch dazu ,auf das Winterhilfswerk aufmerksam zu machen, um die anschließende Sammlung günstig zu beeinflussen“. Allerdings war das Ergebnis „bedauerlicherweise nicht befriedigend“58.

Besonders zelebriert wurden die Gemeinschaftsappelle am Vorabend des 1. Mai, wie zum Beispiel am 30. April 1941 im Vortragssaal der Porzellansammlung, bei der Uniformträger im Dienstanzug zu erscheinen hatten. Damals, eineinhalb Jahre nach Kriegsbeginn, sprach Fichtner „Vom Adel unserer Museumsarbeit". 59

Hinsichtlich seiner politischen Bemühungen und der Schulung des Personals war Fichtner einer der eifrigsten Museumsdirektoren in Dresden. Dem Ministerium berichtete er von der Porzellansammlung, ab 20. März 1936 werde ,jeden Morgen eine kleine Ansprache zur Wahl gehalten und die Parole des Tages ver-

54 Fichtner, Notizen zum Betriebsappell am 19.8.1936, SKD Archiv, 01/PS 40, fol. 12.

55 Vgl. SMV an Direktoren der Sammlungen (ohne Landesbibliothek, Armeemuseum), 30.10.1937, SKD Archiv, 01/PS 44, Bd. 1, fol. 141.

56 Vgl. Heydrich an Kummerlöwe, 13.10.1938, HStA Dresden 13842, Nr. 114, Bd. 2, o. Pag.

57 Vgl. Fichtner an Gefolgschaften der Staatlichen Sammlungen, 28.1.1941, SKD, MPS, 1941, E.-Reg. Nr. 25, ebenso: HStA Dresden, 11127, Nr. 29.

58 Fichtner, Bericht über Maßnahmen der Dienstaufsicht, 2.1941, SKD Archiv, 01/PS 53, Bd. 1, fol. 182-184, hier: 183.

59 Vgl. Fichtner an Betriebsführer und Gefolgschaften der Staatlichen Sammlungen, 26.4.1941, HStA Dresden, 11127, Nr. 29. Vgl. Fichtner, Typoskript der Rede zum 1. Mai, vermutlich 1941, SKD Archiv, 01/PS 53, Bd. 1, fol. 79-95. 
lesen und erklärt. Der Appell fand im Direktorenzimmer vor der Büste des Führers statt." 60

Auch über die Durchführung der Betriebsappelle und die Teilnahme der Mitarbeiter musste dem SMV Meldung erstattet werden. Überliefert sind entsprechende Berichte des Mathematisch-Physikalischen Salons. Eine Meldung vom September 1935 berichtete, dass vier von fünf Personen anwesend waren und sich Direktor $\triangleright$ Paul Werkmeister aufgrund seiner Arbeit an der Technischen Hochschule entschuldigt habe. Eine andere, vom Oktober 1941, nannte keine Personenanzahl. Anhand der Datierung ist jedoch zu vermuten, dass der Appell von den letzten beiden im Salon verbliebenen Mitarbeitern abgehalten wurde, von Restaurator $\triangleright$ Alfred Beck und Sammlungshandwerker Alfred Bieder, eine aus heutiger Sicht absurd anmutende Situation. ${ }^{61}$

All diese unterschiedlichen Appelle dienten der politischen Schulung der Mitarbeiter sowie deren Indoktrinierung und verfolgten damit das Ziel der Politisierung und Ideologisierung der Arbeit.

\section{Gemeinschaftsabende}

Eine andere Funktion hatten die Gemeinschaftsabende, auch „Kameradschaftsabende" genannt. Sie dienten dem geselligen Beisammensein der "Gefolgschaft" und sollten deren Gemeinschaftsgefühl fördern und stärken. Sie wurden in unterschiedlicher Art durchgeführt. Meist veranstalteten mehrere Museen diese Betriebsvergnügen gemeinsam. Am 5. März 1938 feierten die Mitarbeiter des Museums für Mineralogie, Geologie und Vorgeschichte gemeinsam mit denen des Mathematisch-Physikalischen Salons. ${ }^{62}$ Für die Mitarbeiter des Grünen Gewölbes, des Historischen Museums, der Skulpturensammlung, der Porzellansammlung und des Münzkabinetts wurde am 28. März 1938 ein Gemeinschaftsabend im Restaurant „Herzog Albrecht“ veranstaltet, mit musikalischen Darbietungen, Zigarren für die Herren und einer kleinen Aufmerksamkeit für die Damen. 91 Personen nahmen daran teil. ${ }^{63}$ Für beide Veranstaltungen zahlte das

60 Porzellansammlung, Fichtner, an SMV, 31.3.1936, HStA Dresden, 11125, Nr. 19192, fol. 265, ebenso: SKD Archiv, 01/PS 38, fol. 412.

61 Mathematisch-Physikalischer Salon an SMV, 28.9.1935 und 30.10.1941, SKD, MPS, 1935, A.-Reg. Nr. 300 u. 1941, A.-Reg. Nr. 237.

62 Vgl. Mathematisch-Physikalischer Salon, Beck, an SMV, 10.2.1938, SKD, MPS, 1938, A.Reg. Nr. 39.

63 Vgl. Grünes Gewölbe, Holzhausen, an SMV, 18.3.1938 und 15.4.1938, HStA Dresden, 11125, Nr. 22882, fol. $42 \mathrm{ff}$. 
25 Brief von Fritz Fichtner, Porzellansammlung, an das Sächsische Ministerium für Volksbildung, 31.3.1936

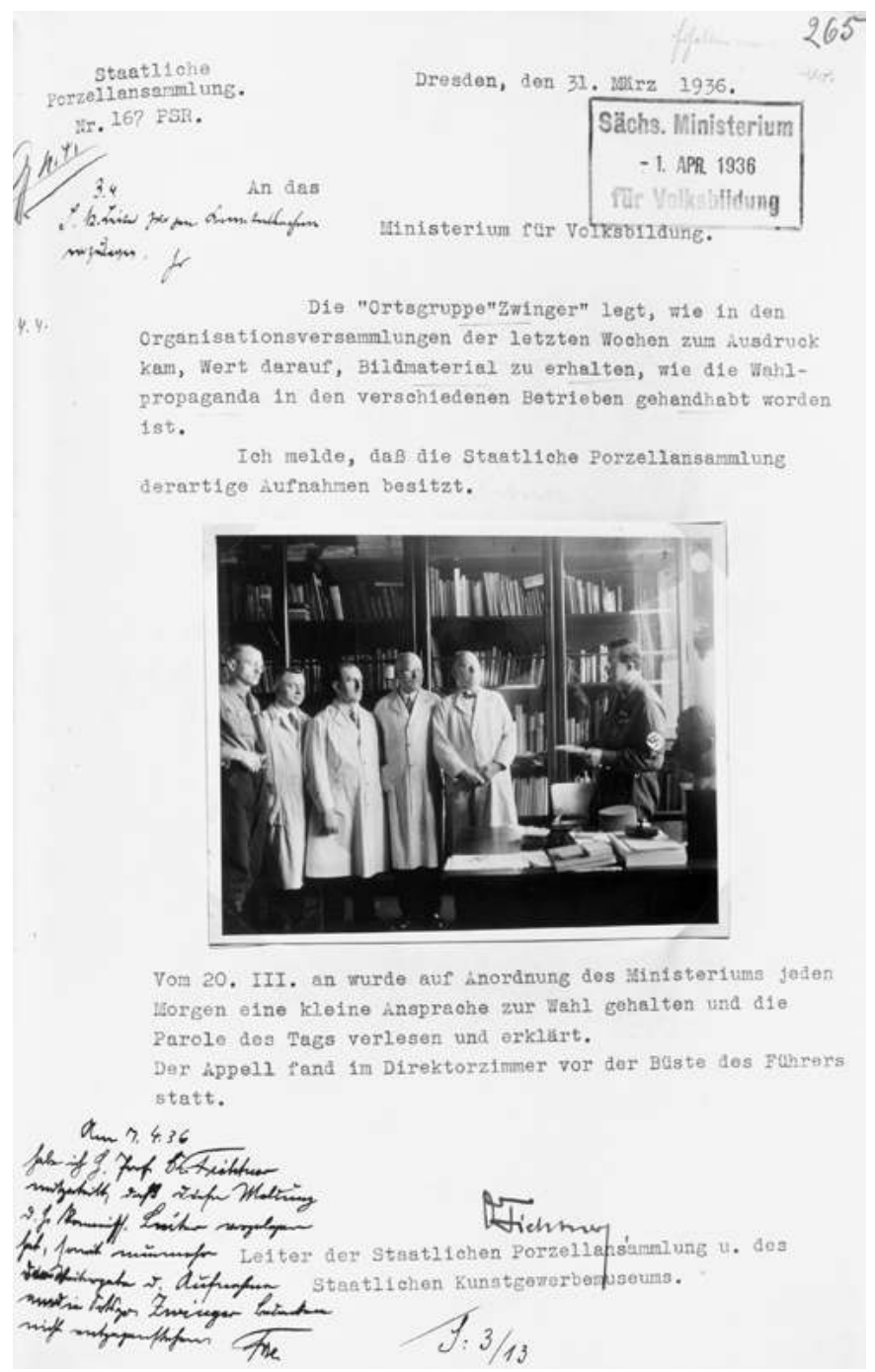

Ministerium einen Zuschuss von 2,50 RM pro Person. ${ }^{64}$ Auch für die Mitarbeiter der Gemäldegalerie und des Kupferstich-Kabinetts wird ein solcher „Kameradschaftsabend“ im März 1938 stattgefunden haben - ein konkretes Datum ist

64 Vgl. Mathematisch-Physikalischer Salon, Beck, an SMV, 10.2.1938, SKD, MPS, 1938, A.Reg. Nr. 39 und Grünes Gewölbe, Holzhausen, an SMV, 18.3.1938, HStA Dresden, 11125, Nr. 22882, fol. 42. 
nicht überliefert. Zumindest informierte $\gg$ Hans Posse vorab: „Für die Gefolgschaft selbst ist das Erscheinen an dieser Feier Dienst, daher unbedingte Pflicht. "“55

Ein Jahr später, am 25. März 1939, feierten die Mitarbeiter aller Staatlichen Sammlungen für Kunst und Wissenschaft gemeinsam einen „1. Gemeinschaftsabend" in Hammers Hotel in Dresden-Striesen. Daran nahmen insgesamt etwa 360 bis 400 Personen teil, die Direktoren und wissenschaftlichen Mitarbeiter sogar vollzählig. ${ }^{66} \mathrm{Zu}$ Beginn der vom RDB und der DAF organisierten Veranstaltung hielt - Fritz Fichtner, stellvertretend für den durch andere dienstliche Verpflichtungen verhinderten Leiter des Ministeriums, eine Rede. Das soeben beendete Geschäftsjahr resümierend, das in den Staatlichen Sammlungen stets von Anfang April des einen bis Ende März des nächsten Jahres lief, stellte Fichtner fest: „Wir sind wieder ein Jahr gute Hüter und Vermittler der Kulturschätze unserer Nation gewesen und haben so einen wichtigen Beitrag geliefert zum Aufbau des deutschen Geistes. ${ }^{\text {"G7 }}$

Auch an die „Sudetenkrise“ erinnerte er, denn „[n] och im September vorigen Jahres mußten wir unsere Museumsschätze in hastiger Arbeit bergen, weil uns Langrohrgeschütze bedrohten“. Er dankte allen für ihren täglichen Einsatz in den Sammlungen und beschloss seine Rede mit den damals üblichen Worten „Dem Reichskanzler und Führer des Großdeutschen Reiches Sieg Heil! Sieg Heil! Sieg Heil!“68

Weitere dieser großen, sammlungsübergreifenden Gemeinschaftsabende ließen sich bisher nicht nachweisen. Daher ist zu vermuten, dass diese Veranstaltungen für die Mitarbeiter der Staatlichen Sammlungen im Krieg nicht fortgeführt wurden. Kleinere Veranstaltungen fanden jedoch weiterhin statt. So planten die Porzellansammlung und das Kunstgewerbemuseum, also die von Fichtner betreuten Museen, am 13. Dezember 1941 eine gemeinsame Weihnachtsfeier, zu der auch die Ehefrauen der an der Front kämpfenden Mitarbeiter eingeladen wurden, wie die Frau von Inspektor Helmuth Weidensdorfer vom Kunstgewerbemuseum. Den Versorgungsengpässen während des Krieges geschuldet bat $>$ Arthur Leuschner vorher:

Es ist vorgesehen, einen kleinen Imbiss in Form von Kartoffelsalat und Würstchen einzunehmen. Wir müßten Sie aber bitten, [...] die benötigte Fleischmarke von ev. 50 Gramm mitzusenden. Weitere Kosten entstehen Ihnen nicht. ${ }^{69}$

\footnotetext{
65 Betriebsführer Posse an die Mitarbeiter der Gemäldegalerie, 4.3.1938, HStA Dresden, 11127, Nr. 29, o. Pag.

66 Vgl. Fichtner, Notiz, o. Dat., SKD Archiv, 01/PS 53, Bd. 2, fol. 152.

${ }^{67}$ Fichtner, Typoskript der Rede, 25.3.1939, ebd., fol. 153-156, hier: 153.

68 Ebd., fol. 156.

69 Kunstgewerbemuseum, Leuschner, an Weidensdorfer, 4.12.1941, SKD Archiv, 01/KGM 11, o. Pag.
} 


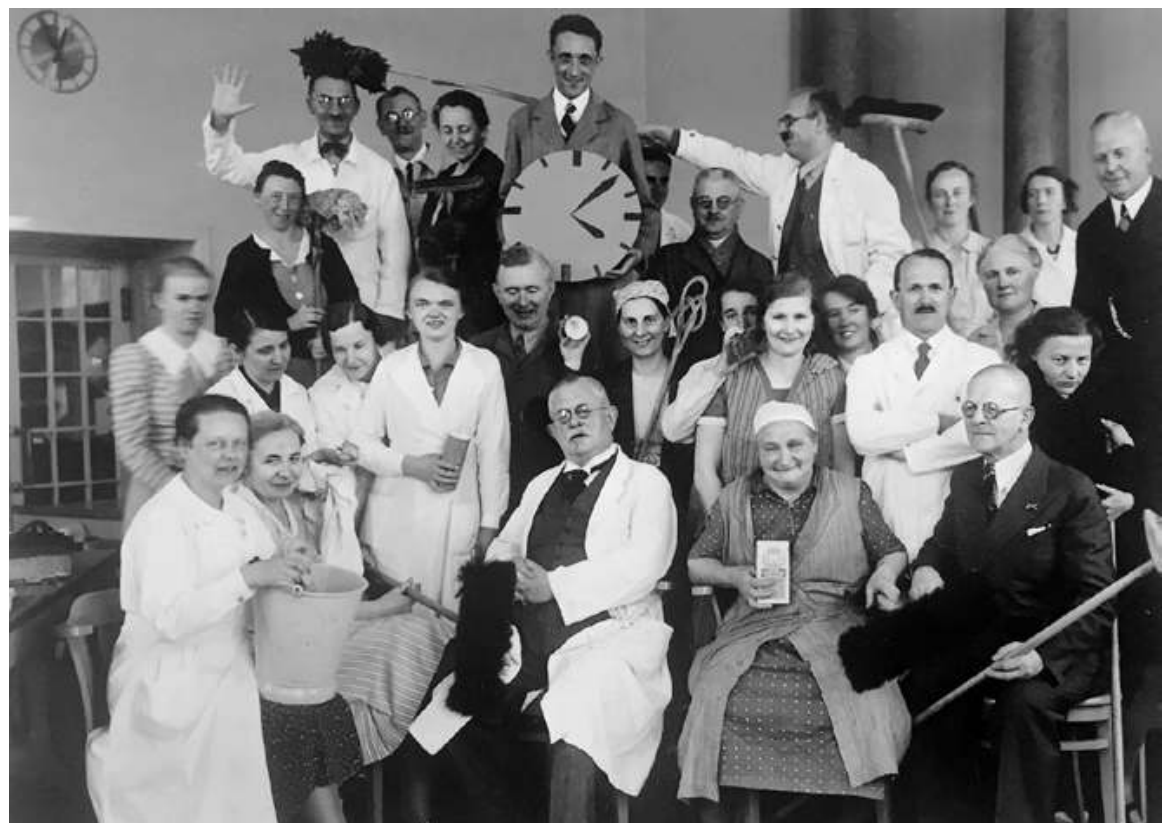

26 „Pfingstputzen“ in der Sächsischen Landesbibliothek, 1939 (1.R.v.l. Dorothee Denecke (1.), Hubert Richter (3.); 2.R.2.v.r. Gottfried Benndorf; 4.R.v.l. Hans Hofmann (2.), Charlotte Holzhausen (3.), Ewald Jammers (6.), Jacob Jatzwauk (9.))

Selbst an die zur Wehrmacht eingezogenen Mitarbeiter wurde zu Weihnachten besonders gedacht. Ihnen wurden Päckchen mit Briefpapier, Bleistiften und Zigaretten an die Front gesendet, wie zum Beispiel 1942 an $>$ Wilhelm Meise oder 1943 an $>$ Helmut Hofer. ${ }^{70}$

An der Sächsischen Landesbibliothek wurden neben Weihnachtsfeiern auch gemeinsame Faschingsfeiern organisiert ${ }^{71}$ selbst das traditionelle Pfingstputzen in der Bibliothek geriet zum Fest. Dienstjubiläen, runde Geburtstage und Verabschiedungen, zum Beispiel jene von $\triangleright$ Otto Fiebiger im Dezember 1933 und - Martin Bollert im Juli 1937, boten Anlässe für feierliche Zusammenkünfte. ${ }^{72}$

70 Vgl. Meise an SMV, 31.12.1942, HStA Dresden, 11125, Nr. 22882, fol. 216, 229 u. Museen für Tierkunde, Rassenkunde und Völkerkunde an Hofer, 12.1.1944, HStA Dresden, 13842, Nr. 114, Bd. 2, o. Pag.

71 Vgl. Jammers 2002, S. 313.

72 Vgl. Otto Fiebigers Abschied von der Landesbibliothek, Dresden am 20.1.1934, Mscr. Dresd.App.1378.b,33a u. Dankesrede Bollert, SLUB, Mscr.Dresd.App.1378.a,136; SMV an Bollert, Sächsische Landesbibliothek, 11.11.1936; Bollert, Umlauf Sächsische Landesbibliothek, 27.11.1936; Bollert an Sächsische Landesbibliothek, 4.7.1937, SLUB, PA Bollert II, o. Pag. 
Die Mitarbeiterinnen und Mitarbeiter der Landesbibliothek nannten sich selbst untereinander „Labianer“, denn sie pflegten einen intensiven, nicht selten familiären Kontakt, unternahmen gemeinsame Ausflüge, gingen wandern oder in der Sächsischen Schweiz klettern. Dadurch entwickelte sich ein Zusammengehörigkeitsgefühl, welches über Jahrzehnte intensiv nachwirkte und sich letztlich auch in der für Bollert organisierten privaten Trauerfeier offenbarte. ${ }^{73}$

\section{Einschränkung der internationale Zusammenarbeit}

Bereits ab Herbst 1933 erreichten die Staatlichen Sammlungen über ihre vorgesetzte Behörde Anweisungen und Vorschriften, die sich sukzessive auch auf ihre inhaltliche Arbeit auswirkten, indem sie zum Beispiel die Kontakte zu Fachkollegen im In- und Ausland beeinflussten und zunehmend einschränkten. Diese pflegten die Direktoren und Wissenschaftler seit jeher, wovon neben dem überlieferten Schriftwechsel der Sammlungen auch der Austausch von Publikationen, die privaten Korrespondenzen und die regen Tagungsteilnahmen der Mitarbeiter zeugen. ${ }^{74}$ Dieser internationale wissenschaftliche Austausch war ein wichtiger Bestandteil der regulären Museumsarbeit und trug maßgeblich zum guten Ruf der Sammlungen bei. Im „Dritten Reich“ sollte sich dies jedoch bald ändern.

Im Dezember 1933 übermittelte das SMV eine Anweisung des RMWEV vom 14. November 1933, die besagte, dass die Betreuung ausländischer Besucher zu dessen Obliegenheiten zähle. Daher war ab sofort jede Ankündigung eines Besuchers aus dem Ausland beim Ministerium zu melden. ${ }^{75}$ Diese Maßnahme zielte darauf, den direkten, persönlichen Kontakt zu ausländischen Gästen und Kollegen zu kontrollieren, ihn einzuschränken und letztlich zu verhindern.

Die Bedeutung der Kontakte im In- und Ausland betonte $\downarrow$ Walter Müller selbst noch 1942, als er sich nach der kriegsbedingten Schließung der ihm unterstellten Skulpturensammlung gegenüber der Verwaltung dafür rechtfertigen musste, dass er sein Büro im Albertinum weiterhin nutzte und beheizte. Müller schrieb:

Wenn ein Museum von heute auf morgen geschlossen und die Verwaltung aufgelöst wird, so können seine Verpflichtungen nicht ebenso plötzlich abgedrosselt werden. Diese bestehen in: Beantwortung von Anfragen aus Deutschland und dem

\footnotetext{
73 Siehe S. 285.

74 Siehe S. 134, $160 \mathrm{ff}$.

75 Vgl. SMV an Direktoren der Staatlichen Sammlungen, 9.12.1933, SKD, MPS, 1933, E.Reg. Nr. 219.
} 
Ausland, die sich auf die Kunstwerke beziehen. Bestellungen von Photos. Bestellung von Gipsabgüssen. (Beides bringt dem Staat Einnahmen.) ${ }^{76}$

Doch bereits im Dezember 1935 war ein „Verbot des unmittelbaren Schriftverkehrs mit dem Ausland"77 erfolgt. Sämtliche Post an ausländische Empfänger musste danach über das SMV weitergereicht und durfte nicht mehr direkt gesendet werden. Während der „Sudetenkrise“ wurde diese Anweisung im Juni 1938 durch ein weiteres Rundschreiben des Ministeriums „Betr. Schriftverkehr mit fremden Staatsangehörigen im Auslande" ${ }^{\text {78 }}$ erneuert. Zwei Jahre nach Kriegsbeginn, im September 1941, gemahnte das Ministerium alle Sammlungsdirektoren an deren „Pflicht, im dienstlichen und persönlichen Verkehr mit Ausländern größte Zurückhaltung zu bewahren" ${ }^{\text {"79 }}$.

Bereits im November 1936 ordnete ein „Führererlass“ an, dass alle in Deutschland stattfindenden nationalen wie internationalen Tagungen und Kongresse vorab beim RMVP anzumelden seien. Darüber informierte - offensichtlich erneut - im Juli 1941 ein Schreiben vom Chef der Reichskanzlei, Reichsminister Hans Heinrich Lammers, an die Reichsstatthalter und Landesregierungen, das auch an die Staatlichen Sammlungen weitergegeben wurde. ${ }^{80}$

Seit Dezember 1936 erschwerte ein Runderlass des Reichsministers und Chefs der Reichskanzlei Reisen von Beamten und Angestellten ins Ausland, denn diese mussten mindestens 20 Tage vorher beim Reichsstatthalter beantragt werden. ${ }^{81}$ Eine Ausnahme bildeten lediglich private Erholungsreisen, die zunächst weiterhin ohne Einschränkungen möglich waren. Im März 1937 erinnerte das SMV die Direktoren der Staatlichen Sammlungen nochmals an die Meldepflicht von Auslandsreisen, indem es eine Abschrift eines entsprechenden Schreibens aus der Reichskanzlei übersandte. ${ }^{82}$ Unterdessen hatte auch der Rektor der Technischen Hochschule im Januar 1937 die Dozentenschaft, und somit

\footnotetext{
76 Skulpturensammlung, Müller, an Leiter SMV 24.4.1942, HStA Dresden, 11125, Nr. 22899, fol. 30 .

77 SMV an [?], 2.12.1935, SKD, MPS, 1935, E.-Reg. Nr. 384.

78 Leiter SMV an [?], 1.6.1938, SKD Archiv, 01/PS 136, fol. 65.

79 Leiter SMV an Direktoren der Staatlichen Sammlungen, 22.9.1941, SKD Archiv, 01/SKS 44, o. Pag.

80 Vgl. Reichsminister und Chef der Reichskanzlei an Reichsstatthalter und Landesregierungen, Abschrift, 5.7.1941, ebd., o. Pag.

${ }_{81}$ Vgl. Leiter SMV an Direktoren der Staatlichen Sammlungen, 25.3.1938, HStA Dresden, 13842, Nr. 115, o. Pag.

82 Vgl. SMV an Direktoren der Staatlichen Sammlungen, 10.3.1937, SKD Archiv, 01/PS 44, Bd. 1, fol. 33 .
} 
auch $\triangleright$ Fritz Fichtner, über eine Anordnung des RMWEV informiert, derzufolge sie sich bei Studien-, Forschungs- oder Vortragsreisen ins Ausland sofort nach der Ankunft bei der deutschen Auslandsvertretung und der Auslandsorganisation der NSDAP melden müssen, sowie wissenschaftliche Auslandsreisen einer Genehmigung des Reichsministers für Wissenschaft, Erziehung und Volksbildung bedürfen. ${ }^{83}$ Eine Meldepflicht bei der NSDAP-Auslandsorganisation oder ähnliche Anweisungen galten vermutlich ebenfalls für die Museumsmitarbeiter.

\section{Besuche von Persönlichkeiten des öffentlichen Lebens}

An eine Meldepflicht anderer Art wurden die Direktoren der Staatlichen Sammlungen durch Arthur Göpfert Ende August 1937 erinnert: an die Meldepflicht außergewöhnlicher Vorkommnisse, die bereits seit knapp einem Jahr bestand. Das SMV war sofort und unverzüglich über alle

Besuche hervorragender Persönlichkeiten des öffentlichen Lebens, aber auch beamteter oder nichtbeamteter Persönlichkeiten, die die Sammlungen im Auftrage von Reichsministerien oder von Reichsdienststellen der Partei aufsuchen ${ }^{84}$

$\mathrm{zu}$ informieren.

Persönlichkeiten des öffentlichen Lebens des NS-Staates kamen häufig nach Dresden und besuchten gelegentlich auch die Staatlichen Sammlungen. Adolf Hitler ließ sich am 29. Mai 1934 von $\triangleright$ Hans Posse durch die Gemäldegalerie führen. Diese war ebenfalls am 10. Februar 1935 für einen Besuch von Reichsminister Hermann Göring für das Publikum geschlossen, dem die neuerworbene „Apotheose von August dem Starken“ von Balthasar Permoser präsentiert wurde. Bernhard Rust, Reichsminister für Wissenschaft, Erziehung und Volksbildung, besichtigte am 25. Mai 1935 die Sächsische Landesbibliothek, kurz nach deren Wiedereröffnung. Als die Tochter von Benito Mussolini im Juni 1936 in Dresden weilte, wurde auch sie von Posse durch die Gemäldegalerie begleitet. Der Besuch des „Führers“ im Juni 1938 wurde bereits erwähnt. ${ }^{85}$ Generalbauinspektor Albert Speer besichtigte am 18. Mai 1939 die Bau- und Aufstellungsarbeiten in der neuen Porzellangalerie im Zwinger und ließ sich von $>$ Fritz Fichtner „die

\footnotetext{
83 Vgl. Rektor der Technischen Hochschule Dresden, 246. Rundschreiben an die Dozentenschaft, 22.1.1937, ebd., fol. 32.

${ }^{84}$ Vgl. SMV, Göpfert, an Direktoren der Staatlichen Sammlungen, 31.8.1937, SKD Archiv, 01/PS 44, Bd. 1, fol. 77; ebenso: SKD, MPS, 1937, E.-Reg. Nr. 243.

85 Siehe S. 98. Vgl. auch DA, 30.5.1934, S. 3; 10.2.1935, S. 2 u. 12.6.1936, S. 5; DNa, 30.5.1934, S. 3 u. 28.5.1935, S. 5; FK, 11.2.1935, S. 5.
} 


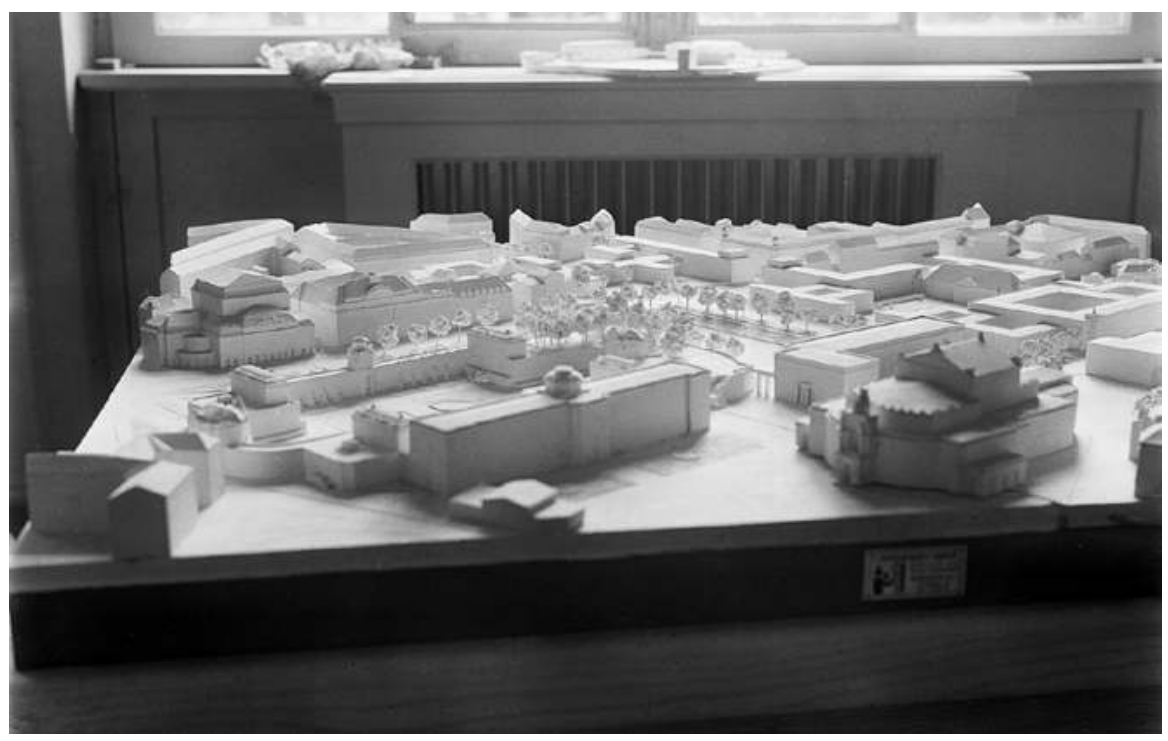

27 Modell des Dresdner Museumsprojekts, 1938, Entwurf von Ernst Dutzmann

Leitgedanken des Dresdner Museumsprojektes vortragen und am Modell demonstrieren"86.

Diese Besuche von Politikern und anderen Persönlichkeiten brachten stets eine große öffentliche Aufmerksamkeit mit sich und wurden mehrfach in der Presse erwähnt.

\section{Einschränkungen der Reisen}

Der „Anschluss“ von Österreich 1938 führte zunächst zu weiteren Reiseeinschränkungen, die auch die Mitarbeiter der Staatlichen Sammlungen betrafen. In einem Brief des Reichsministers des Innern an die Reichsstatthalter und Landesregierungen, den das SMV an alle Sammlungsdirektoren weiterleitete, wurde am 14. März 1938 über das Verbot von Reisen von Beamten nach Österreich durch Göring informiert. Nur Dienstreisen waren davon ausgenommen. ${ }^{87}$

86 Fichtner, Aktennotiz, 18.5.1939, SKD Archiv, 01/PS 43, Bd. 1, fol. 210. Vgl. ebd., fol. 210214 u. HStA Dresden, 11125, Nr. 22873, fol. 71 f. Speer war zuvor bei Posse in der Gemäldegalerie. Vgl. Rudert 2015b, S. 89.

87 Vgl. Leiter SMV an Direktoren der Staatlichen Sammlungen, 17.3.1938, HStA Dresden, 13842, Nr. 115, o. Pag. 
Begeistert von den Ereignissen in Österreich schrieb $>$ Hans Kummerlöwe, der gern spontan nach Wien gefahren wäre, an $>$ Helmut Hofer in Wien, den er kurz darauf an die Museen für Tierkunde und Völkerkunde nach Dresden holte:

Lieber Parteigenosse Hofer! Wie eigenartig, das erste Mal offiziell diese Anrede! Herzlichen Dank für Ihre Karte, die ebenso erstmalig mit Heil Hitler unterschrieben war. Ja, wer hätte das so rasch erwartet! Auch hier im Alt-Reich herrscht überall ein direktes Glücksgefühl und stolz wehen die Fahnen. [...] Da ich annehme, dass Dr. Sassi nicht mehr im Amte ist, hatte ich ernstlich die Möglichkeit erwogen, vergangenen Montag selbst herunterzukommen, [...] und nicht zuletzt des Führers triumphalen Einzug mitzuerleben. Leider hat mir das vorgesetzte Ministerium hierfür keinen Urlaub gegeben ${ }^{88}$.

Wenige Tage später, noch im März 1938, erinnerte der Leiter des SMV die Direktoren der Staatlichen Sammlungen abermals an die seit 1936 bestehende Antragsfrist für Auslandsreisen von 20 Tagen. ${ }^{89}$ Ab April 1940 wurden die Dienstreisen in das „Protektorat Böhmen und Mähren“, ab August 1940 auch jene in das „Generalgouvernement" eingeschränkt. Alle „Reisen zu Forschungs-, Studien-, Vortrags- und ähnlichen Zwecken " ${ }^{\text {"90 }}$ bedurften nun der Genehmigung des Leiters des SMV, in Sonderfällen des RMWEV. Daran erinnerte das Ministerium auch 1941 mehrfach. ${ }^{91}$ Ab Februar 1941, eineinhalb Jahre nach Kriegsbeginn, wurden Auslandsreisen, unabhängig davon, ob sie dienstlichen oder privaten Zwecken dienten, durch das RMWEV weiter erschwert. Um ins Ausland zu reisen, benötigte man nun einen Sichtvermerk, d.h. eine Genehmigung des Auswärtigen Amtes. ${ }^{92}$ Im Oktober 1942 wies das SMV wiederholt auf die „wegen der Kriegsverhältnisse gebotenen Einschränkung und zweckmässige Handhabung des Dienstreiseverkehrs“ hin, der „auf unumgänglich dringende Fälle zu beschränken ${ }^{\text {“93 }}$ sei.

\footnotetext{
88 Kummerlöwe an Hofer, 16.3.1938, HStA Dresden, 13842, Nr. 114, Bd. 2, o. Pag. Gemeint ist der Wiener Zoologe Moritz Sassi (1880-1967).

89 Vgl. Leiter SMV an Direktoren der Staatlichen Sammlungen, 25.3.1938, HStA Dresden, 13842, Nr. 115, o. Pag. Siehe S. 127.

90 Leiter SMV an Direktoren der Staatlichen Sammlungen, 17.6.1940, SKD Archiv, 01/PS 137, Nr. 306.

${ }^{11}$ Vgl. Leiter SMV an Direktoren der Staatlichen Sammlungen, 26.8.1940; 11.6.1941; 3.9.1941, SKD Archiv, 01/KGM 7, fol. 100c, 100b, 103.

92 Vgl. Leiter SMV an Direktoren der Staatlichen Sammlungen, 14.3.1941, HStA Dresden, 11127, Nr. 29, o. Pag.

93 Leiter SMV an nachgeordnete Behörden, 22.10.1942, SKD Archiv, 01/SKS 345, o. Pag.
} 


\section{Materialzuteilungen}

Unterdessen war es seit Kriegsbeginn zu einer Reihe weiterer Einschränkungen gekommen. Die „Kriegswirtschaftsverordnung“ vom 4. September 1939 besagte unter anderem:

Die zur Verteidigung von Volk und Reich notwendige Zusammenfassung aller Kräfte und Mittel macht es auf dem Gebiete des Haushaltswesens zur selbstverständlichen Pflicht, alle Ausgaben der Staatsverwaltung auf das äußerste Maß, das gerade noch die Lebensnotwendigkeiten des Volkes erfordern, einzuschränken. ${ }^{94}$

So war der Papierverbrauch „auf das Äußerste zu beschränken“ und der Aufwand für Heizung, Beleuchtung und Reinigung „tunlichst zu vermindern“ ${ }^{95}$, wie das SMV den Sammlungsdirektionen am 21. Oktober 1939 mitteilte. Sämtliches Material wurde nun kontingentiert, egal ob Papier, Holz, Metall oder Kraftstoff. Dies schränkte nicht nur die Ausstellungs- und Öffentlichkeitsarbeit stark ein, sondern wirkte sich unmittelbar auch auf die außerhalb der Staatlichen Sammlungen kaum wahrnehmbare Arbeit aus, vor allem auf den Schutz der Objekte und deren Auslagerung. Denn für den Erwerb von der für die Anfertigung der Kisten, die meist in den Sammlungen selbst passgenau hergestellt wurden, benötigten, streng kontingentierten Eisen- und Holzwaren mussten zuvor zentral Berechtigungsscheine beantragt werden. So beantragte Fichtner im November 1940 für die Bergung der Porzellansammlung die Zuweisung von 30 Packungen mit je $5 \mathrm{~kg}$ Holzschrauben und 8 Packungen mit je $15 \mathrm{~kg}$ Nägeln sowie einen Bezugsschein über $155 \mathrm{~kg}$ Eisen für die Anschaffung einer Kreissäge und eines Ambosses - Materialien, die für den Bau von Kisten benötigt wurden. Die Genehmigung aus dem Sächsischen Finanzministerium traf zwei Monate später ein. Der Antrag auf Bereitstellung von 300 RM für den Erwerb von Kisten und Holzwolle im Februar 1941 wurde hingegen innerhalb von nur zwei Tagen genehmigt. ${ }^{96}$ Ähnliche Anträge auf Bezugsscheine für Eisen und Holz sind in den Akten von nahezu allen Sammlungen erhalten. Die Sächsische Landesbibliothek beantragte unter anderem im August 1943 für die Bergung ihrer Bestände

94 SMV an alle Staatlichen Sammlungen, 21.10.1939, SKD, MPS, 1939, E.-Reg. Nr. 306. Vgl. „Kriegswirtschaftsverordnung“, 4.9.1939, RGBl., 1939, Teil I, Nr. 163, S. 1609 ff.

95 Ebd.

96 Vgl. Porzellansammlung an Leiter SMV, 16.11.1940; Finanzministerium, Hochbaudirektion an Porzellansammlung, 17.1.1941; Porzellansammlung an Leiter SMV, 14.2.1941 und SMV, Dedering, an Porzellansammlung, 16.2.1941, HStA Dresden, 11125, Nr. 22890, fol. 53, $55,60,63 \mathrm{f}$. 
1700 RM für 300 Kisten, Öl- und Packpapier und Transport, die innerhalb von zwei Wochen genehmigt wurden. ${ }^{97}$

Das nunmehr streng limitierte Papierkontingent behinderte die bisher reiche Publikationstätigkeit in den Staatlichen Sammlungen wie auch ihrer Mitarbeiterinnen und Mitarbeiter. So wurde der im Herbst 1943 von Sammlungsreferent Fichtner beim RMWEV eingereichte Antrag auf Zuweisung von Papier zum Druck eines Kataloges der Sächsischen Landesbibliothek „unter kriegswichtigen Gesichtspunkten "98 abgelehnt.

Doch für seine eigenen Publikationen fand Fichtner sogar noch im November 1944 Wege, um an Papier zu gelangen. Unterstützt wurde er dabei von Hans Lehmann, Direktor von Villeroy \& Boch in Dresden, mit dem er in der Deutschen Keramischen Gesellschaft zusammenarbeitete. Fichtner dankte ihm

für die Vermittlung beim Zustandekommen dieser Drucksachen herzlichst [...], denn ohne Zubuße des Papiers und sonstiger Vermittelungen [sic!] wäre es im sechsten Kriegsjahre nicht möglich gewesen, noch zu drucken.99

„Aller Papierknappheit zum Trotz"100 konnte er dadurch seine Aufsätze „Die Blütezeit der türkischen Fliese" und „Der Stil des chinesischen Porzellans" als Sonderdrucke veröffentlichen.

\section{Geheimhaltungspflicht}

Trotz der streng überwachten Papierzuteilungen wurde das Berichtswesen ausgedehnt, insbesondere bezüglich der Sicherung des Kulturgutes nach Kriegsbeginn und der später erfolgenden Auslagerungen der Sammlungsbestände. So wurden regelmäßig Berichte über die „Sicherstellung des Museumsgutes“ und den „Zustand der geborgenen Gegenstände“ eingefordert sowie „über die Eignung der verwendeten Räume und die Änderung, die sich in der Unterbringung seit 2.9.1939 nötig " ${ }^{101}$ machte.

97 Sächsische Landesbibliothek, Neubert, an Reichsstatthalter, Staatskanzlei, 30.8.1943, HStA Dresden, 11125, Nr. 19338, fol. 140 f.

98 RMWEV an Reichsstatthalter, Landesregierung Sachsen, 30.9.1943, HStA Dresden, 11125, Nr. 19338, fol. 147. Vgl. auch Fichtner an RMWEV, 16.7.1943, ebd., fol. 145.

99 Fichtner an Hans Lehmann, Villeroy \& Boch Dresden, 15.12.1944, SKD Archiv, 01/PS 54, Bd. 2, fol. 219.

100 Fichtner an Artur Hennig, Mettlach, 1.11.1944, ebd., fol. 46.

101 Leiter SMV an Direktoren der Staatlichen Sammlungen, 7.10.1939, SKD, MPS, 1939,

E.-Reg. Nr. 287. Siehe S. $150 \mathrm{f}$. 
Über die dienstlichen Belange war Verschwiegenheit zu bewahren. Insbesondere mit dem Beginn des Zweiten Weltkrieges bekam die Geheimhaltung dienstlicher Angelegenheiten eine besondere Bedeutung, auch für die Museen und Bibliotheken. Alle Schriftstücke, die im Zusammenhang mit der Sicherung oder der späteren Bergung der Sammlungsbestände standen, waren entsprechend als „Geheimsache“ oder „Geheim“ gekennzeichnet. Bei einem Gemeinschaftsappell wurden am 31. Juli 1942 alle Mitarbeiterinnen und Mitarbeiter der Staatlichen Sammlungen „zur Geheimhaltung verpflichtet durch Unterzeichnung einer Verpflichtungserklärung " ${ }^{102}$. Zuvor sprach $\triangleright$ Fritz Fichtner über die Notwendigkeit der Geheimhaltung der Auslagerung der Kunstschätze, die in den Wochen zuvor vorgenommen wurde, denn der „Feind fliegt mit sehr großem Aufgebot Städte an und schont dabei offene Kulturstätten keineswegs " ${ }^{\text {"103 }}$.

Ende Januar 1943 wies das Ministerium erneut darauf hin, dass alle Bergungsmaßnahmen der Geheimhaltungspflicht unterlägen. Die Mitarbeiter der Sammlungen mussten für die Kenntnisnahme erneut unterschreiben. ${ }^{104}$ Nur wenige Monate später wurden sie wiederholt an die Verschwiegenheit erinnert, als das Ministerium im Juni 1943 eine Anweisung „Betr. Nachteilige Beeinflussung der Volksstimmung durch Behördenangehörige" des Reichsministers und Chefs der Reichskanzlei vom 22. April 1943 weiterleitete. Darin wurde auch auf die Zurückhaltung bei Unterhaltungen verwiesen, da bei nachteiliger Beeinflussung der Volksstimmung Strafen wegen Landesverrats und Zersetzung der Wehrkraft drohten. ${ }^{105}$

Post mit der Kennzeichnung „Geheim“ durfte nur von den Adressaten, in der Regel die Direktoren der Sammlungen, geöffnet werden. Eine Sondergenehmigung erteilte der Leiter des SMV im Oktober 1939 - Walther Fischer und - Walter Häntzschel vom Museum für Mineralogie und Geologie, da $\triangleright$ Eberhard Rimann nur im Nebenamt Direktor war und nicht täglich im Zwinger weilte. So konnten die beiden Kustoden ,eingehende Verschlußsachen in Empfang [zu] nehmen "106, und die schnelle Übermittlung aller die Sammlung betreffenden Informationen war gesichert.

\footnotetext{
102 Vgl. Niederschrift Gruve, o. Dat., HStA, 11125, Nr. 23063, fol. 66.

103 Fichtner, Typoskript, 31.7.1942, SKD Archiv, 01/PS 53, Bd. 1, fol. 51-55, hier: 54 f.

104 Vgl. Leiter SMV, i. A. Dedering, an Direktoren der Staatlichen Sammlungen, 29.1.1943, SKD Archiv, 02/VA 53, Bd. 2, o. Pag.

105 Vgl. Leiter SMV an Direktoren der Sammlungen, 9.6.1943, SKD Archiv, 01/SKS 44, o. Pag.

106 Leiter SMV an Rimann, 3.10.1939, SKD Archiv, 02/VA 50, fol. 40.
} 


\section{Geheim!}

1. Dies ift ein Gtantsgetheiminis im Ginne dzs \& 83 26tOB. fu der Sa, ung des Gejetyes vom 24:4.1934 (RGB.. I 5.341 ff.).

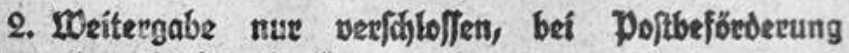
als "Cinfíwreíben".

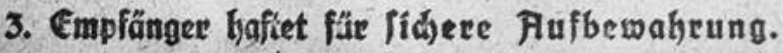

28 Stempel auf der Post des Sächsischen Ministeriums für Volksbildung, September 1939

Insbesondere die Einschränkungen der Reisen ins Ausland und das Verbot des direkten Kontaktes zu ausländischen Kollegen beeinträchtigten den internationalen wissenschaftlichen Austausch. Tauschten die Museen für Tierkunde und Völkerkunde ihre „Abhandlungen und Berichte“ 1934 noch gegen Publikationen von zahlreichen Museen in den USA, in Brasilien, Australien, Neuseeland, Japan, Belgien, Dänemark, Frankreich, Italien, Norwegen und Österreich, in der Schweiz, der Sowjetunion und in den Niederlanden, ${ }^{107}$ so ging dieser Schriftentausch in den Folgejahren deutlich zurück. Einerseits wurden die Kontakte durch die Kontrollen erschwert und bisweilen unterbunden, andererseits konnten infolge der Zuteilung von Papier nach Erlass der Reichskriegsverordnung bald keine Jahrbücher mehr gedruckt werden. Infolge der Reiseeinschränkungen und Kürzung von Reisemitteln wurde den Wissenschaftlern nur höchst selten die Teilnahme an internationalen Kongressen im Ausland genehmigt, nationale Tagungen fanden kaum noch statt. Die fatale Folge dieser ideologisch motivierten Anordnungen war die Isolation von der internationalen Forschungsgemeinschaft und damit einhergehend das Abgleiten in Provinzialität.

Für die gestandenen Wissenschaftler im Dienst der Staatlichen Sammlungen waren all diese Maßnahmen überaus degradierend. Alle Bereiche ihrer Tätigkeit unterlagen dem „Führerprinzip“, d. h. alles musste bei der vorgesetzten Dienststelle beantragt werden und über jede erledigte Tätigkeit, selbst über die verpflichtende Teilnahme an politischen Veranstaltungen, hatte Bericht erstattet zu werden. ${ }^{108}$ Dienstanweisungen häuften sich und wurden in steter Penetranz wiederholt. Ein eigenständiges und freies wissenschaftliches Arbeiten war damit kaum noch möglich.

\footnotetext{
107 Vgl. Liste der Partner für Schriftentausch, 1934 HStA 13842, Nr. 115, o. Pag.

108 Siehe S. $115 \mathrm{f}$.
} 


\section{Veränderungen im kollegialen Umgang}

Die politischen Veränderungen, die ideologische Bevormundung und Kontrolle durch das „Führerprinzip“, beeinträchtigten das kollegiale Miteinander, führten zu Spannungen und in mehreren Fällen zu Denunziationen. Welche Ausmaße und vor allem welche Folgen diese angespannte Situation haben konnte, zeigt das Beispiel des Direktors der Gemäldegalerie $>$ Hans Posse, dem 1938 das Beantragen einer vorzeitigen Pensionierung nahegelegt worden war. ${ }^{109}$ Nach Posses Tod 1942 führte die Ernennung seines Nachfolgers $>$ Hermann Voss zu Unstimmigkeiten zwischen diesem und den Mitarbeitern, die zwischenzeitlich die Galerie und den „Sonderauftrag Linz" kommissarisch geleitet hatten. Diesen, $\triangleright$ Gottfried Reimer und $\gg$ Robert Oertel, war die Personalie nicht vor dem Amtsantritt von Voss mitgeteilt worden.

Der Landesbibliothekar $\triangleright$ Ewald Jammers war 1939 denunziert worden, er pflege Umgang mit Juden und verweigere den Hitlergruß, wovon er durch eine Kollegin erfuhr. Jammers sah sich genötigt, Bibliotheksdirektor $\triangleright$ Hermann Neubert darüber zu informieren. Doch dieser gab den „Bericht von Dr. J[ammer]s. vom 30.11.39 zur verschlossenen Aufbewahrung zu den Pers.-Akten“"110.

Ebenfalls wegen „Unterlassung des ,Deutschen Grusses“" sowie wegen „Staatsfeindlicher Gesinnung" und „Beleidigung der Partei “"111 war $~$ Walter Müller denunziert worden. Trotz einer Beratung zwischen $\triangleright$ Fritz Fichtner und Regierungsdirektor Kurt Dedering im Ministerium, bei der die Beschwerde geklärt werden konnte, wurde ein Verfahren gegen Müller eröffnet, das anderthalb Jahre dauerte und im Juli 1942 mit einem Verweis endete. ${ }^{112}$

Eine Denunziation, die sich gegen zwei Personen im Grünen Gewölbe richtete, war die Behauptung von Rudolf Gackstatter, dass Direktor $\triangleright$ Erich Haenel den Juden $>$ Rudolf Berge als Privatperson eingestellt habe, um die Reichsgesetze zu umgehen. Gackstatter berief sich dabei auf „Gewährsleute“, die er allerdings nicht benannte, denn er habe sich „bei Nationalsozialisten in den verschiedenen Sammlungen erkundigt ${ }^{\text {" }}{ }^{113}$.

\footnotetext{
109 Siehe S. 98, 407.

110 Vgl. SLUB, PA Jammers. Die Kenntnis des Inhalts dieses Briefes verdankt die Autorin einer E-Mail von Katrin Nitzschke, SLUB, 22.7.2019.

111 Müller, Skulpturensammlung, an SMV, 8.11.1945, SKD Archiv, 01/SKS 413, o. Pag.

112 Vgl. Fichtner, Protokoll, 25.6.1941, SKD Archiv, 01/PS 53, Bd. 1, fol. 124.

113 Gackstatter an die Kulturpolitische Abteilung und Abteilung Film, 5.7.1933, HStA Dresden, 11125, Nr. 22882, fol. 21. Die Identität von Rudolf Gackstatter konnte bisher nicht geklärt werden.
} 
Besonders konfliktreich war die Situation an den Museen für Tierkunde und Völkerkunde, insbesondere nachdem im Januar 1936 > Hans Kummerlöwe Direktor geworden war. Der bisherige kommissarische Leiter des Museums, - Bernhard Struck, fühlte sich zurückgesetzt, denn er musste seine Zeit im Museum nun „mit der nützlichen Tätigkeit des Kindermädchens für unseren neuen Chef, einen blutjungen jeder Museumserfahrung bislang baren Zoologen" ${ }^{114}$ verbringen. Das Verhältnis zwischen Struck und Kummerlöwe hat sich während der wenigen gemeinsamen Monate am Dresdner Museum zwischen Januar und September 1936 kaum verändert. So beschrieb Struck, der unterdessen in Jena tätig war, im Zusammenhang mit der Auswahl seines Nachfolgers in Dresden

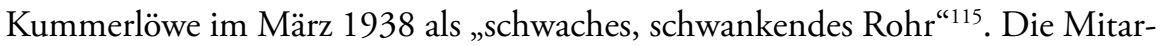
beiter im Museum versuchten indes, dem Parteiideologen als Direktor mit sächsischem Humor zu begegnen. Untereinander sprachen sie unisono vom „Sorgentiger". So berichtete Struck an seinen Kustos-Kollegen > Martin Heydrich:

,Sorgen ... - Plate, der emeritierte Zoologe, [...] erzählte ahnungslos, man habe ihn früher ,Freudentiger' gehiessen. Chapeau!! Der alte Herr hat sich gewiss gewundert, warum ich gerade diesem [sic!] seinen Witz so herzlich belachen musste. ${ }^{116}$

Die Kanzleiangestellte Erika Weisswange schrieb 1939 an Struck über „Sorgentigerchen“: „Er ist schon ein grosser Schwätzer. “117 Dass Kummerlöwe lieber redete als zu arbeiten, das war in Dresden bekannt und gewiss ein Grund für diese Spannungen. $>$ Herbert Bellmann berichtete seinem Doktorvater Struck nach Kriegsbeginn: „Kummerlöwe tigert auch noch herum, und die Anderen packen das Museum ein. ${ }^{\text {"118 }}$

Doch auch zwischen Kummerlöwe und $>$ Fritz Fichtner, die sich in ihrem parteipolitischen Engagement ähnelten, kam es zu Spannungen, die ihre Ursache im Umzug des Museums für Tierkunde und der Abgabe der Räume im Zwinger an die Porzellansammlung hatten. Es kam zu einem „Kräftemessen“ zwischen beiden Direktoren. Am 16. Januar 1939 teilte Kummerlöwe Fichtner telefonisch mit, dass er die Werkstatt im Zwinger nicht freiwillig räume, sondern eine Räumungsverfügung erwarte, was Fichtner sofort an das Ministerium meldete, worauf Ministerialrat Reuter die Räumung verfügte. ${ }^{119}$

\footnotetext{
114 Struck an Kollegen in Berlin, 10.1.1936, SMB-ZA, EM, Archiv, I/MV 0817. Siehe S. 72 f. 115 Struck an Reche, 5.3.1938, SKD, MfV Archiv, MVD n20;25/13u14, o. Pag.

116 Struck an Heydrich, 28.6.1937, SKD, MfV Archiv, MVD n20;25/6u7, o. Pag. Der Zoologe Ludwig Plate (1862-1937) war bis 1934 Professor an der Universität Jena.

117 Weisswange an Struck, 8.10.1939, SKD, MfV Archiv, MVD n20;25/15u16, o. Pag.

118 Bellmann an Struck, 6.9.1939, SKD, MfV Archiv, MVD n20;25/1, o. Pag.

11 Fichtner, Porzellansammlung, an SMV, 17.1.1939, SKD Archiv, 01/PS 43, Bd. 1, fol. 203 f.
} 
Bereits zwischen Fichtner und $\triangleright$ Arnold Jacobi hatte der Standortwechsel des Museums für Konfliktpotential gesorgt. Jacobi reichte Fichtner bei einer Begegnung im Museum im August 1937 nicht die Hand zum Gruß, da dieser „sein“ Museum aus dem Zwinger gedrängt habe. Fichtner fühlte sich gekränkt und erstattete im Ministerium Bericht:

Ob Herrn Direktor Jakobi bekannt ist, daß er den Referenten des Ministeriums in einem ihm unterstellten Gebäude im Beisein eines Dritten, des jetzigen Direktors, beleidigt oder ob er in mir nur den Direktor der Porzellansammlung treffen, also die Beziehung zu einem Kollegen abbrechen wollte, ist mir unbekannt. Ich empfinde aber beides gleich schwer. ${ }^{120}$

Erst nach der Wiedereröffnung des Museums, am 15. Oktober 1937 entschuldigte sich Jacobi persönlich bei Fichtner, weshalb dieser „den Herrn Leiter“ bat, „von weiteren Maßnahmen gegen Herrn Direktor Jacobi abzusehen “121.

Ein weiterer Konflikt schwelte zwischen $\triangleright$ Hellmuth Buck und $\triangleright$ Wilhelm Meise. Meise sah sich durch Buck der "politischen Verfolgung" ausgesetzt und gezwungen, in die NSDAP einzutreten. ${ }^{122}$ So berichtete auch $~+$ Walther Fischer, in den 1930er-Jahren Kustos am Museum für Mineralogie, Geologie und Vorgeschichte, dass Buck „Dr. Meise schon 1933 als ,Gegner der Bewegung bezeichnet und geraten [habe], Meises Posten mit einem nationalen Kämpfer zu besetzen. " ${ }^{123}$ Meise sei

nur um den dauernden Anfeindungen seitens des Konservators Buck zu entgehen, zunächst in die SA (weil die Partei damals nicht aufnahm und die SA als Vorbereitung zur Aufnahme angeraten wurde) und 37 in die NSDAP eingetreten ${ }^{124}$.

Der Parteiideologe Buck wurde insbesondere nach seiner Rückkehr von der mehrjährigen Tätigkeit als Leiter der Gauschule Hammerleubsdorf von den Sammlungsmitarbeitern gemieden. Selbst Fichtner befürchtete einen zu großen Ideologieeinfluss und versuchte, Buck möglichst fern der Staatlichen Sammlungen einzusetzen:

\footnotetext{
$120 \quad$ Fichtner an Leiter SMV, 25.8.1937, SKD Archiv, 01/PS 53, Bd. 3, fol. 156 f.

121 Fichtner an Leiter SMV, 19.10.1937, ebd., fol. 155.

122 Vgl. Meise an Struck, 9.7.1948, SKD, MfV Archiv, MVD n20;25/8/9/10, o. Pag.

123 Fischer, Landesverwaltung Sachsen an Grohmann, Kulturabteilung, 3.8.1945, SKD Archiv,

02/VA 162, fol. 1-3, hier: 2 r.

124 Ebd.
} 
Buck muß, seinen Verdiensten um die Bewegung entsprechend, ein Amt im Kreis oder Gau erhalten. Ein Posten als Propagandaleiter aller Museen setzt einen Polyhistor im besten Sinne voraus; eine derartige Stelle würde aber die einzelnen $\mathrm{Mu}$ seen und ihre wissenschaftlichen Kräfte in ihren Absichten vermutlich nur hemmen. ${ }^{125}$

Dennoch wurde Buck ihm im Ministerium als technischer Betriebsleiter der Staatlichen Sammlungen zur Seite gestellt. Die Sammlungsdirektoren legten Wert darauf, „daß der einzelne Direktor ihn heranziehen kann, aber nicht muß"126. Wie all diese Beispiel zeigen, durchdrang die nationalsozialistische Ideologie nicht nur die Gesellschaft und den Alltag der Menschen, sondern auch die Museumsarbeit immer stärker.

125 Porzellansammlung, Fichtner, an SMV [?], 7.11.1939, SKD Archiv, 01/PS 43, Bd. 3, fol. 53. Siehe S. 112, 287 f.

126 Protokoll der Besprechung der Museumsdirektoren, 16.7.1940, ebd., Bd. 1, fol. 115-120, hier: 118. 


\section{„Nationalsozialistische Erziehungsstätten“ - Kulturgutschutz versus Bildungsarbeit}

Unter dem starken Einfluss der nationalsozialistischen Ideologie veränderte sich auch der Stellenwert der traditionellen Museumsaufgaben - Sammeln, Bewahren, Forschen, Ausstellen und Vermitteln. Die Aktivitäten der Staatlichen Sammlungen gilt es daher in ihren Ambiguitäten zu betrachten: Jede Bemühung, das kulturelle Leben fortzuführen und die klassischen Museumsaufgaben zu erfüllen, war im Nationalsozialismus zugleich Teil einer ideologischen Mission.

Einerseits fordert der Krieg, daß die Museumsschätze jeden nur erdenklichen Schutz erfahren. [...] Andererseits aber haben gerade die für Museen verantwortlichen Direktoren den Wunsch, das Bedürfnis des deutschen Volkes nach Erhebung, Freude und Wissen mit aller noch verbleibenden Kraft befriedigen zu helfen [...] Die Staatlichen Sammlungen für Kunst und Wissenschaft in Dresden wollen in diesem Sinne lebendige Kunstvermittler sein, die unermüdliche Frontarbeit auch in der Heimat leisten! ${ }^{1}$

Diese Worte aus dem „Bericht über die Museumsaktivitäten im Winter 1939/1940“ beschreiben die Herausforderungen, vor denen die Mitarbeiter der Museen und der Sächsischen Landesbibliothek während des Zweiten Weltkriegs standen. Sie mussten die von ihnen betreuten Objekte erhalten und vor Beschädigung, Zerstörung sowie Verlust schützen, während sie gleichzeitig ihre Vermittlungsaufgaben fortzusetzen und durch Ausstellungen, Vorträge wie andere Aktivitäten ihren Bildungsauftrag zu erfüllen hatten. Dies waren äußerst ambivalente Aufgaben. ${ }^{2}$

\section{Erwerbungen}

Die Fortführung des Sammelns war bereits in der Weimarer Republik schwierig geworden. Infolge des Ersten Weltkrieges und der Weltwirtschaftskrise war die Finanzierung der Museen seitens des Staates stark eingeschränkt worden. Die Ankaufsetats waren dementsprechend gering. Da diese in der NS-Zeit nicht erhöht wurden, kam es auch nach 1933 in den Staatlichen Sammlungen eher zu einzelnen Erwerbungen. ${ }^{3}$ Der Gemäldegalerie waren 1933 die Ankaufsmittel gestrichen

\footnotetext{
Bericht über die Museumsaktivitäten im Winter 1939/1940, SKD Archiv, 01/PS 43, Bd. 1, fol. $136 \mathrm{f}$.

2 Vgl. Lupfer 2004a; Lupfer/Nagel 2016.

3 Vgl. Berichte über die Verwaltung ... o. J. (1940) sowie HStA Dresden, 11125, Nr. 19003 u. Nr. 23053.
} 
worden. ${ }^{4}$ Die Sammlungen, deren Bestände im „Dritten Reich“ am stärksten zunahmen, waren die Museen für Tierkunde und Völkerkunde und die Sächsische Landesbibliothek, die weiterhin vor allem Gegenwarts- d. h. NS-Literatur erwarb. Ihre Bestände vermehrten sich bis 1945 um ca. 200.000 Bände, jährlich kamen also etwa 20.000 Neuerwerbungen hinzu. ${ }^{5}$ Das Museum für Tierkunde tätigte häufiger Erwerbungen nach Expeditionen und Forschungsreisen, wie den Ankauf von 222 Säugetieren und ca. 1000 Vogelbälgen 1931/1932 nach der Reise von - Robert Reichert und Bildhauer Franz Naumann in das ostafrikanische Matengo-Hochland. 1936 erwarb es einen Teil der Sammlung, die der frühere Tierpräparator des Museums, Max Hinsche, im kanadischen Yukon-Gebiet zusammengetragen hatte. Mit Unterstützung des Landesvereins Sächsischer Heimatschutz kaufte es 1936 knapp 3000 Objekte aus der Sammlung des Leipziger Ornithologen Richard Schlegel. ${ }^{6}$ Dem Museum für Mineralogie und Geologie gelang es 1940, die international bekannte, 10.000 Schaustufen umfassende Mineraliensammlung von Richard Baldauf zu erwerben. ${ }^{7}$ Alle anderen Sammlungen verzeichneten nur verhältnismäßig geringe Zugänge von selten mehr als 100 Objekten pro Jahr durch Ankäufe, Schenkungen oder Tausch. Eine Ausnahme hierbei war das Kupferstich-Kabinett, das 1937 mit dem Vermächtnis von Johann Friedrich Lahmann knapp 2000 Zeichnungen bekam. Diese präsentierte es anschließend in einer mehrteiligen Ausstellungsfolge. ${ }^{8}$

\section{„Entartete Kunst“}

In der NS-Zeit hatten die Staatlichen Sammlungen, insbesondere die Gemäldegalerie, das Kupferstich-Kabinett und die Skulpturensammlung, infolge der Aktion „Entartete Kunst“ auch Bestandsverluste zu beklagen. Zunächst, als 1933 erste Werke unerwünschter Kunst von den Nationalsozialisten aus den Beständen des Stadtmuseums Dresden als ,entartet" beschlagnahmt wurden, waren die Staatlichen Sammlungen von diesen rigorosen Maßnahmen noch nicht betroffen. ${ }^{9}$ Allerdings protestierte im Juni 1933 die Gaufachgruppe der bildenden Künste der NSDAP, namentlich die Dresdner Bildhauer Paul Lindau und Johannes Ernst

\footnotetext{
4 Zu den Ankäufen in dieser Zeit vgl. Rudert 2015b, S. 94; SKD Archiv 01/GG 6a, Bd. 1, fol. 44-75.

5 Vgl. Hermann 2011, S. $295 \mathrm{ff}$.

6 Vgl. Berichte über die Verwaltung ... o. J. (1940), S. 30.

7 Vgl. SKD Archiv, 01/PS 043, Bd. 2, fol. 82 f.; 01/PS 139, Nr. 396, 447, 469. Siehe S. 182.

8 Vgl. Berichte über die Verwaltung ... o. J. (1940), S. 9 f. Siehe S. 196, 242 ff.

9 Vgl. Rudert 2015b, S. 130-136. Vgl. auch Lupfer 2004a, Zuschlag 2015 sowie Dresdener Geschichtsverein e. V. 2004.
} 
Born, in einem durch ihren Vorsitzenden Walther Gasch übermittelten Brief an den Direktor der Skulpturensammlung, \Bruno Schröder, gegen die im Albertinum ausgestellte Skulptur "Josef und Maria“ von Gerhard Marcks. ${ }^{10}$ Sie bezeichneten diese und andere nicht explizit erwähnte Werke des Künstlers als „Schandmal“. Dabei beriefen sie sich auf Wilhelm Hartnacke, sächsischer Minister für Volksbildung und damit oberster Dienstherr der Staatlichen Sammlungen, der am 2. April 1933 im Rundfunk erklärt hätte, „dass die Kunst des Untermenschentums keinen

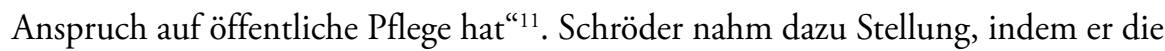
künstlerischen Qualitäten dieser Werke aufzählte und konstatierte: „Auch scheint innerhalb der N.S.D.A.P. noch keine einheitliche Beurteilung der Zeitgenössischen Kunst festgelegt zu sein "12. Seine Erläuterungen und die Briefe der Gaufachgruppe reichte er mit der Bitte um Klärung an das zuständige Ministerium. Im August 1933 wies das Ministerium Schröder die Rückgabe der als Leihgaben präsentierten Skulpturen „Badende“ und „Läufergruppe“ von Marcks an, ebenso die Verbringung der Plastiken „Josef und Maria“ von Marcks und „Kniende“ von Ernesto de Fiori ins Depot. ${ }^{13}$ Damit hatten die Nationalsozialisten erstmals direkt in die Ausstellungsarbeit der Staatlichen Sammlungen in Dresden eingegriffen.

Allerdings hingen im Sommer 1937 noch Werke von Künstlern, die seit 1933 als „entartet“ galten - wie Lovis Corinth, Otto Dix, Oskar Kokoschka - in der Gemäldegalerie im Semperbau. ${ }^{14}$ Am 16. August 1937 wies der Leiter des Ministeriums für Volksbildung alle Sammlungsdirektoren an, ,innerhalb von 10 Tagen [...] noch vorhandene Produkte von Vertretern dieser Kunstrichtung abzuhängen und einzulagern, ebenso die Bilder von Liebermann und anderen jüdischen Künstlern “15. Galeriedirektor $\triangleright$ Hans Posse hatte unterdessen die meisten dieser Bilder im Juli 1937 aus der Ausstellung entfernt und deponiert. Schlussendlich wurden aus dem Besitz der Staatlichen Sammlungen insgesamt 23 Gemälde, 28 Zeichnungen, 333 grafische Blätter, 12 Künstlerbücher und 24 Skulpturen beschlagnahmt. ${ }^{16}$

10 Gaufachgruppe der bildenden Künste, Lindau u. Born, an Skulpturensammlung, 27.6.1933, SKD Archiv, 01/SKS 179, fol. 2.1.

11 Ebd.

12 Skulpturensammlung, Schröder, an SMV, 3.7.1933, ebd., fol. 23-25.

13 Vgl. SMV, Reuter, an Direktion Skulpturensammlung, 22.8.1933; Gaufachgruppe der Bildenden Künste, Gasch, an Direktion Skulpturensammlung, 30.6.1933 u. Skulpturensammlung, Schröder, an Gaufachgruppe der Bildenden Künste Sachsen, 1.7.1933, SKD Archiv, 01/SKS 179, fol. 20-27.

14 Vgl. Rudert 2015b, S. 132 f.

15 Leiter SMV an Porzellansammlung, Fichtner, SKD Archiv, 01/PS 44, Bd. 1, fol. $90 \mathrm{f}$.

16 Vgl. Lupfer 2004a, S. 77 u. Rudert 2015b, S. 134 ff. Lupfer benannte 41 Gemälde, doch Rudert wies darauf hin, dass aus dem Besitz der Gemäldegalerie 23 Werke beschlagnahmt wor- 


\section{Beteiligung am nationalsozialistischen Kunstraub}

Andererseits waren Museumsbeamte der Staatlichen Sammlungen maßgeblich am nationalsozialistischen Kunstraub beteiligt. Sie wirkten aktiv am „Sicherstellen“ von Kulturgütern aus jüdischem Besitz mit, wie etwa $\triangleright$ Fritz Fichtner, der, wie bereits erwähnt, in die Beschlagnahmung der Sammlung von Gustav von Klemperer involviert war. ${ }^{17}$ Doch der NS-Kunstraub von privaten Sammlungen einschließlich von privaten Bibliotheken soll hier nicht weiter thematisiert werden. ${ }^{18}$

Im November 1939 reisten drei Museumsbeamte aus Dresden mit politischem Auftrag in das „Generalgouvernement“. Fichtner hatte am 5. November 1939 von Reichsstatthalter Mutschmann den Auftrag erhalten, Meißner Porzellan in Museen und Privatsammlungen im besetzten Polen ausfindig zu machen und nach Sachsen ,zurückzuführen“ ${ }^{19}$ Bereits drei Tage darauf trat er diese Reise an, wobei er zunächst nach Berlin fuhr, um sich bei Otto Kümmel beraten zu lassen. Bis zum 20. November 1939 bereiste er Krakau, Warschau und Breslau. Anschließend berichtete er Mutschmann von der Reise und sandte ihm am 11. Dezember 1939 einen „Bildbericht mit eigenen Aufnahmen, die heute schon historisch geworden sind, denn das Schloß Warschau ist [...] gesprengt worden ${ }^{\text {"20. }}$. Wenige Tage später erhielt Fichtner vom Reichsstatthalter den Auftrag, mit „Staatssekretär Mühlmann in Krakau unmittelbar wegen der Auslieferung

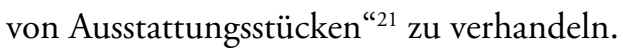

Auch Galeriedirektor $\triangleright$ Hans Posse war unterdessen in seiner Funktion als „Sonderbeauftragter“, die im Folgenden kurz vorgestellt werden soll, am 25. November 1939 in die besetzten polnischen Gebiete gereist. Zunächst hielt er sich in Krakau auf, wo er sich über beschlagnahmte Kunstwerke informierte sowie das Nationalmuseum, die Städtische Galerie, Privatsammlungen und Kirchen inspizierte. Fünf Tage später fuhr er nach Warschau, wo er den „Sonderbeauf-

\footnotetext{
den sind, die anderen waren Leihgaben und befanden sich u. a. in Besitz des Patronatsvereins oder der Stadt Dresden.

17 Siehe S. 101.

18 Bezüglich der Beteiligung der Dresdner Sammlungsmitarbeiter wurde und wird diese Thematik im Rahmen der Provenienzforschung erforscht und in Publikationen wie Ausstellungen öffentlich zugänglich gemacht.Vgl. Themenheft: Provenienzforschung, Dresdener Kunstblätter, 56. Jg., H. 2, 2012; Staatliche Kunstsammlungen Dresden, Abteilung Forschung und wissenschaftliche Kooperation und Daphne Projekt 2018.

19 Vgl. Porzellansammlung, Fichtner, an Generaldirektor Kümmel, Berlin, 6.11.1939 SKD Archiv, 01/PS 42, Bd. 1, fol. 238.

20 Fichtner an Reichsstatthalter Mutschmann, SKD Archiv, 01/PS 43, Bd. 2, fol. 130. Vgl. auch SKD Archiv, 01/PS 43, Bd. 1, fol. 6-8.

${ }^{21}$ Reichsstatthalter Mutschmann an Fichtner, 20.12.1939, ebd., Bd. 2, fol.133.
} 
tragten für den Schutz und die Sicherung von Kunstwerken in den besetzten Ostgebieten" Kajetan Mühlmann traf und das Schloss, das Nationalmuseum und weitere Privatsammlungen besichtigte. Am 3. Dezember reiste Posse zunächst zurück nach Krakau und in den Folgetagen wieder nach Dresden. ${ }^{22}$

Der Direktor der Museen für Tierkunde und Völkerkunde, $\triangleright$ Hans Kummerlöwe, war etwa zeitgleich im „Generalgouvernement" unterwegs. Er reiste am 11. November 1939 ,in Eile“ mit einem „Polizeiauto zur etwa 14-tägigen PolenInspektion “23 aus Dresden ab und kehrte am 28. November 1939 zurück. Doch weder seine Auftraggeber noch seine Reiseroute lassen sich nach aktuellem Kenntnisstand benennen.

Zumindest ein Beispiel für die Zuweisung von NS-Raubkunst nach Dresden sei hier benannt: Im Spätherbst 1939 wurden im Nationalmuseum in Warschau die Krönungsinsignien von August III. beschlagnahmt. Sie wurden 1942 an das Grüne Gewölbe in Dresden überwiesen. ${ }^{24}$

\section{„Sonderauftrag Linz“}

Ebenfalls dem NS-Kunstraub dienend und dementsprechend politisch motiviert war die intensive Reisetätigkeit von Galeriedirektor $>$ Hans Posse und dessen Nachfolger $\triangleright$ Hermann Voss in die von den Deutschen besetzten Gebiete, wie in die „Ostmark“, nach Italien, Frankreich und in die Niederlande. Beide waren dort als „Sonderbeauftragte des Führers“ für den „Sonderauftrag Linz“ unterwegs. Mit diesem Auftrag hatte Adolf Hitler verfügt, für ein in Linz an der Donau geplantes „Führermuseum“ durch Ankauf und Beschlagnahmung eine umfangreiche Gemäldesammlung zusammenzutragen. Hier sei der „Sonderauftrag“ aufgrund seiner personellen Verflechtung mit der Dresdner Gemäldegalerie kurz angesprochen. ${ }^{25}$

\footnotetext{
22 Vgl. Hans Posse: 1. Reisetagebuch, Juli-Dezember 1939, DKA, NL Posse, Hans, I,B-2, https:// editionhansposse.gnm.de/tagebuch/DKANLPosseHansIB2, Zugriff: 6.12.2019. Vgl. Schwarz 2014, S. 114-125 sowie Haase 2008, S. 205 ff. Vgl. auch Dehnel, Regine: Der nationalsozialistische Kunstraub in Polen 1939-1945 und die Restitution von Kunstwerken durch die Alliierten 1945-1949: ausgewählte Beispiele, in: Langer, Andrea (Hg.): Der Umgang mit dem kulturellen Erbe in Deutschland und Polen im 20. Jahrhundert, Warschau 2004, S. 307-333, hier: 318 f.

23 Kummerlöwe an Heydrich, 11.11.1939, HStA Dresden, 13842, Nr. 114, Bd. 2, o. Pag. Vgl. ebd., Kummerlöwe an Heydrich, 28.11.1939.

24 Vgl. Staatliche Kunstsammlungen Dresden u. Werner Schmidt (Hg.): Unter „einer“ Krone. Kunst und Kultur der sächsisch-polnischen Union, Katalog der Ausstellung, Dresden 1997/1998, Leipzig 1997, S. 386 f.; Schwarz 2015, S. 345.

${ }_{25} \mathrm{Zu}$ den Beschlagnahmungen und Erwerbungen durch den „Sonderauftrag Linz" inklusive der damit verbundenen Reisetätigkeit von Posse und Voss siehe Löhr 2005, Schwarz 2004, dies. 2014, dies. 2015 u. dies. 2018 sowie Iselt 2010, S. 161-314.
} 
Zum ersten „Sonderbeauftragten“, d. h. Leiter dieses Projektes, ernannte Hitler im Juni 1939 Galeriedirektor Posse. Dadurch wurde Dresden zum Verwaltungssitz des „Sonderauftrags Linz“, der organisatorisch an die Gemäldegalerie angebunden war. Zum festen Mitarbeiterstab zählten $\triangleright$ Gottfried Reimer, zunächst als Assistent, ab Juni 1941 als Referent, und $\triangleright$ Fritz Wiedemann, der als Rechnungsführer für die Büroarbeiten zuständig war. Darüber hinaus arbeiteten auch Mitarbeiter der Staatlichen Sammlungen für den „Sonderauftrag Linz“: > Robert Oertel, Kustos der Gemäldegalerie, führte Inventarisierungsarbeiten aus und erstellte eine Fotokartei der Linzer Sammlung, der Restaurator der Gemäldegalerie, -Alfred Unger, betreute die Gemälde konservatorisch und > Franz Schubert, Wissenschaftlicher Hilfsarbeiter am Kupferstich-Kabinett, übernahm Katalogisierungsarbeiten für die grafische Sammlung für Linz. Nach Posses Tod führten Oertel und Reimer den „Sonderauftrag Linz“ kommissarisch, bis im März 1943 Voss von Hitler zum „Sonderbeauftragen“ und Direktor der Gemäldegalerie ernannt wurde. Durch die Verantwortung für und Mitarbeit an diesem Großprojekt waren daher sowohl Posse, Voss, Oertel, Reimer und Wiedemann als auch Schubert und Unger direkt bzw. mittelbar am nationalsozialistischen Kunstraub beteiligt.

\section{Maßnahmen zum Schutz des Kulturgutes}

Der Aufgabe des Bewahrens kam im Nationalsozialismus - insbesondere während des Zweiten Weltkrieges - eine besondere Bedeutung zu. Die Planung von Maßnahmen zum Schutz des Kulturgutes reichen jedoch weiter zurück. Spätestens durch die Zerstörung der Kathedrale von Reims im Ersten Weltkrieg war deutlich geworden, dass Krieg auch zu verheerenden Zerstörungen von Kulturgut führen kann. ${ }^{26}$ In Dresden selbst hatte man im März 1920 erlebt, wie bei einer Straßenschlacht im Umfeld des Kapp-Putsches eine verirrte Kugel ein Rubens-Gemälde in der Gemäldegalerie traf. ${ }^{27}$ Notfallplanungen und Schutzmaßnahmen waren daher für Institutionen, die Kulturgut verwahrten, dringend geboten.

In Dresden fand Anfang Dezember 1932 eine Beratung im SMV statt, bei der die Notwendigkeit von Schutzmaßnahmen für die Staatlichen Sammlungen thematisiert wurde. Im Anschluss wurden die Sammlungsdirektoren gebeten,

\footnotetext{
${ }^{26}$ Zu Museen im Ersten Weltkrieg siehe Kott, Christina u. Bénédicte Savoy (Hg.): Mars und Museum: Europäische Museen im Ersten Weltkrieg, Köln 2016.

27 Siehe Staatliche Kunstsammlungen Dresden (Hg.): Kunst im Aufbruch. Dresden 1918-1933, Dresden 1980, S. 339. Am 17.3.1920 veröffentlichte Akademieprofessor Oskar Kokoschka einen Aufruf in der Presse, in dem er forderte, solche kriegerischen Auseinandersetzungen nicht vor der Gemäldegalerie auszutragen.
} 
einen Fragebogen über „Maßnahmen des zivilen Luftschutzes für die Staatlichen Sammlungen" auszufüllen und über die zu schützenden Gegenstände sowie die gewünschte Art von deren Unterbringung im Notfall Auskunft zu geben. ${ }^{28}$ Überliefert sind die Antworten der Direktoren der Gemäldegalerie und des Kupferstich-Kabinetts, die beide eine Sicherung der Kunstwerke in Dresden bevorzugten, da sie weite Transporte nach außerhalb der Stadt für gefährlich hielten. Während $\triangleright$ Hans Posse die Notwendigkeit der Bergung von 500-1500 Gemälden und Pastellen erwähnte, wofür etwa 40 Personen benötigt würden, von denen zehn in der Gemäldegalerie vorhanden wären, kündigte $>$ Kurt Zoege von Manteuffel den Bedarf der Bergung von 30-50 $\mathrm{m}^{2}$ Handzeichnungen und Kupferstichen durch sechs bis acht Personen an. ${ }^{29}$

Ende November 1933 forderte das Sächsische Ministerium des Innern, dass Luftschutzwarte ausgebildet werden, wofür Männer, die „körperlich rüstig genug sind“ und „politisch einwandfreie Gesinnung haben “"30 in Frage kämen, die entsprechende Lehrgänge absolvieren sollten. Einen Monat später benannte Galeriedirektor Posse in seiner Funktion als Vorstand der Zwingerhausverwaltung neben Oswald Lützner auch die Handwerksmeister und Präparatoren $>$ Max Hahn, Rudolf Schmidt, Theodor Jacobi, Max Helbig sowie Max Trenkler als Luftschutzwarte für die im Zwinger untergebrachten Museen. ${ }^{31}$

Im Februar 1934 wurden in Dresden weitere Informationen zur Planung von Sicherheitsvorkehrungen gesammelt. Im Auftrag des Finanzministeriums erfragte - Erich Haenel als damaliger Leiter der Direktorenkonferenz bei seinen Kollegen, wieviel Personal erforderlich sei, „um die wichtigsten Stücke Ihrer Sammlung in einem Zeitraum von 24 Stunden in die Kasematten der Brühlschen Terrasse zu schaffen“ und „,[w] ieviel Transportmittel (Tragen, Kisten, Wagen) ${ }^{\text {“32 }}$ dafür benötigt würden. Noch ging es nur um die Planung der Evakuierung der Kunstwerke, ein gewöhnlicher Vorgang im Museumsalltag.

Am 17. August 1934 wurde im Sächsischen Verwaltungsblatt die Verordnung über „Luftschutzmaßnahmen in den Staatlichen Gebäuden“ veröffentlicht. ${ }^{33}$

28 Vgl. SMV an Gemäldegalerie, Posse, 20.12.1932, HStA Dresden, 11127, Nr. 8, fol. 2 f.

29 Vgl. Gemäldegalerie, Posse, an SMV, 19.12.1932, u. Kupferstich-Kabinett, Zoege von Manteuffel, 20.12.1932, ebd., fol. 4 f., 9.

30 Sächsisches Ministerium des Innern, Luftamt, an SMV, 27.11.1933, ebd., fol. $10 \mathrm{f}$.

31 Vorstand der Zwingerhausverwaltung, Posse, an Schutzpolizei-Hauptwache Dresden, 28.12.1933, ebd., fol. 13 .

32 Direktion Historisches Museum, Haenel, an Direktion Mathematisch-Physikalischer Salon, 13.2.1934, SKD, MPS, 1934, E.-Reg. Nr. 53.

33 Vgl. Sächsisches Verwaltungsblatt, Teil 1, Verordnungsblatt, Nr. 64, Dresden, 17.8.1934, Nr. 528, HStA Dresden, 11127, Nr. 8, fol. 18 f. 
Mitte November 1935 informierte Posse das SMV, dass „bei drohenden Gefahren (Luftangriff, Feuer usw.) der Gemäldegalerie keine Räumlichkeiten zur Verfügung stehen, in denen wenigstens die wertvollsten Gemälde in Sicherheit gebracht werden könnten“, und daher „eine Freilegung der östlichen Kellergeschoßräume“ wie auch der „Ausbau eines Luftschutzkellers [...], wie solche bereits in anderen deutschen Museen (z. B. Germanisches Museum in Nürnberg) eingerichtet worden $\operatorname{sind}^{\text {“ } 34}$, dringend erfolgen müsse.

1937 wurden die Maßnahmen präzisiert und der Schutz der Objekte sowie die Bereitstellung von Luftschutzkellern in den Staatlichen Sammlungen vermehrt thematisiert. Ausschlaggebend dafür waren die Bombardierung des Museo del Prado in Madrid im November 1936 und die verheerenden Zerstörungen nach der Bombardierung der baskischen Stadt Guernica durch die deutsche „Legion Condor“ und die italienische „Aviazione Legionaria“ im April 1937 im Spanischen Bürgerkrieg. Am 14. Dezember 1937 fand in Dresden eine Begehung der Kellerräume der Museumsgebäude statt, um Luftschutzräume festzulegen, an der neben Vertretern der Polizei, des SMV und des Landbauamtes auch $\triangleright$ Fritz Fichtner und Posse teilnahmen. Dabei wurde festgelegt, dass Münzkabinett, Porzellansammlung und Skulpturensammlung für die Bergung ihrer Objekte eigene Räume nutzen sollen und die Hauptwerke des Grünen Gewölbes vor Ort im Residenzschloss verbleiben, „da sie durch Gewölbe und eiserne Fensterläden

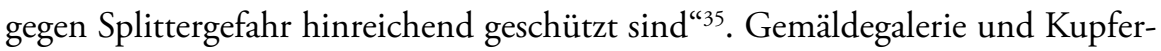
stich-Kabinett sollten ihre wichtigsten Objekte ins Albertinum bringen und dabei einen Weg durch die Innenstadt nutzen. Darüber hinaus wurde festgestellt, dass die naturkundlichen Museen im Zwinger „nicht derartige erstklassige Werke, die unbedingt geschützt werden müssen wie die Kunstmuseen“ besäßen und über eigene Räume verfügten, ,in denen sich die wertvollsten Dinge stapeln lassen "36. Man plante also, im Notfall die Objekte in den Museumsgebäuden selbst oder in anderen Räumen im Stadtzentrum zu bergen. Diese Ergebnisse hätten angesichts der Zerstörungen durch die Luftangriffe in Madrid und Guernica keineswegs zufriedenstellen dürfen.

Noch im Dezember 1937 mussten die Direktoren eine Einteilung des Museumsgutes in drei Gruppen vornehmen sowie einen Alarmplan vorlegen. Als Gruppe I wurden in der Regel die kostbarsten und bedeutendsten Objekte bezeichnet, die im Ernstfall zuerst zu bergen waren. Die weniger wertvollen

34 Gemäldegalerie, Posse, an SMV, 13.11.1935, ebd., fol. 24.

35 Fichtner: Bericht über die Untersuchung von Luftschutzkellern für die Staatlichen Museen Dresden, 17.12.1937, SKD, MPS, 1937, E.-Reg. Nr. 358, S. 3.

36 Ebd. 
Objekte zählten zur Gruppe II, während Gruppe III den Depotbestand umfasste. ${ }^{37}$ Obwohl diese Kategorisierung nie verbindlich festgelegt wurde, existierte damit eine Notfallplanung. Die Zuordnung der Objekte zu einer der Gruppen erfolgte subjektiv und konnte alternieren, da keine verbindlichen Listen darüber angefertigt wurden.

Im Januar und Februar 1938 erhielten die Mitarbeiter der Staatlichen Sammlungen eine Ausbildung im Luftschutz, die an zwölf Terminen vor der Öffnungszeit der Museen stattfand, damit die Teilnahme aller Mitarbeiter möglich war. Mit der Einladung zu diesen Schulungen erhielten die Sammlungen eine Aufstellung über die „Maßnahmen zur Sicherung des Sammlungsgutes bei Luftgefahr“, die für den Ernstfall eine „sofortige Schließung des Museums“, die „Bergung des Museumsgutes im Sinne des ausgearbeiteten örtlichen Bergungsplanes“ und die „Einteilung einer Wache für das Sammlungsgut “38 vorsahen. Außerdem wurden die Mitarbeiter der Sammlungen zur regelmäßigen Teilnahme an Luftschutzübungen verpflichtet.

Erste in der Öffentlichkeit wahrnehmbare Schutzmaßnahmen wurden in Dresden während der „Sudetenkrise“ im August/September 1938 ergriffen. Damals schlossen einige Museen - wie die Gemäldegalerie und das Grüne Gewölbe vorsorglich für mehrere Tage bzw. Wochen ihre Schausammlungen, verpackten die Objekte und sicherten diese in den eigenen Räumen. ${ }^{39}$ Nach dem Abschluss des Münchener Abkommens öffneten sie wieder für das Publikum.

\section{Bergungsarbeiten im Zweiten Weltkrieg}

Ein Jahr später, nur wenige Tage vor dem Überfall der deutschen Wehrmacht auf Polen am 28. August 1939, erreichte die Verantwortlichen der Staatlichen Sammlungen in Dresden eine Anweisung aus dem RMWEV in Berlin. Darin hieß es: „Der Schutz von Kulturgütern und Kunstwerken ist, soweit noch nicht geschehen, vorsorglich innerhalb der Museumsgebäude usw. vorzubereiten. “ ${ }^{40}$

\footnotetext{
37 Vgl. SMV an Direktoren der Staatlichen Sammlungen, 15.12.1937, SKD Archiv, 01/PS 44, Bd. 1, fol. 133.

38 SMV an Direktoren der Staatlichen Sammlungen, 8.1.1938, SKD, MPS, 1938, E.-Reg. Nr. 3, fol. 2.

39 Vgl. Jahresberichte der einzelnen Sammlungen, HStA Dresden, 11125, Nr. 23053. Auch in anderen Städten wurden die Museen während der „Sudetenkrise“ geschlossen: u.a. in Berlin, sogar in London und Paris. Vgl. Grabowski/Winter 2013, Bosman 2008, S. 17-25; Musée du Louvre 2009.

40 Reichsminister für Wissenschaft, Erziehung und Volksbildung, Berlin, an Landesregierungen, 28.8.1939, HStA Dresden, 10701, Nr. 320/1, Bd. 1, fol. 1.
} 


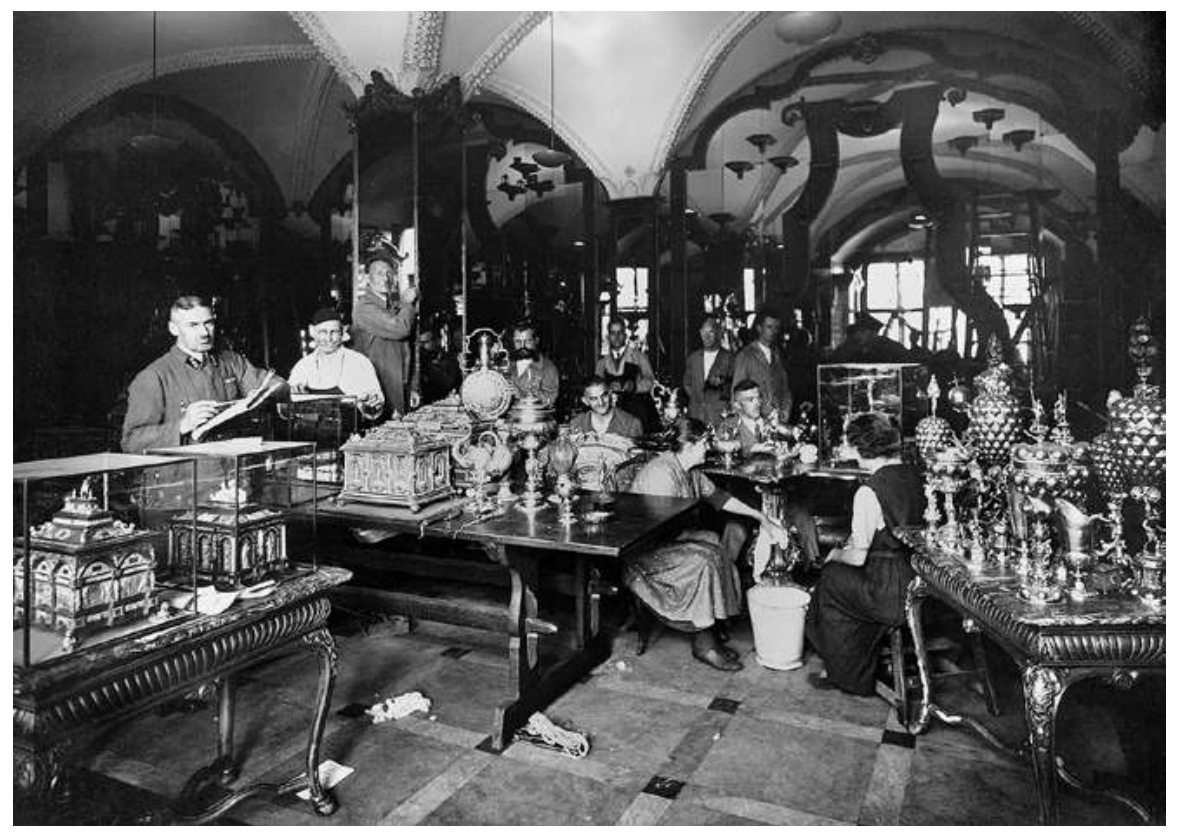

29 Bergungsarbeiten im Grünen Gewölbe während der „Sudetenkrise“, September 1938

Sofort wurden die Dresdner Sammlungen geschlossen. Die wertvollsten Objekte - Gruppe I - wurden in Kisten verpackt und in den Museumsräumen selbst, den Gebäudekellern oder in anderen Schutzräumen innerhalb der Stadt geborgen. Objekte der Gruppen II und III verblieben, in Kisten und Schränken verstaut, in den Museums- und Depoträumen. ${ }^{41}$ Bereits am 1. September 1939 informierte Fichtner, nachdem er von seinen Direktorenkollegen die entsprechenden Berichte erhalten hatte, das SMV über den Stand der Bergungsarbeiten: „Sämtliche Museen sind geschlossen. Alle Vorträge und Führungen sind abgesagt worden. Urlauber sind restlos zurückbeordert. “42

Erst als die Bergungsarbeiten in Dresden bereits erledigt waren, erreichte die Sammlungsdirektoren am 11. September 1939, vermutlich durch den Kriegsbeginn verspätet, jener Erlass des Reichsministers der Luftfahrt und Oberbefehlshabers der Luftwaffe, Hermann Göring, vom 26. August 1939, der die Richtlinien für die Durchführung des Luftschutzes in Museen, Büchereien, Archiven und

${ }_{41} \mathrm{Zu}$ den Auslagerungen der einzelnen Sammlungen im Zweiten Weltkrieg vgl. Rudert 2015a; Nagel 2015; Martin 2015.

42 Fichtner, 1.9.1939, HStA Dresden, 10701, 320/1, Bd. 1, fol. 6-8, hier: 8. 


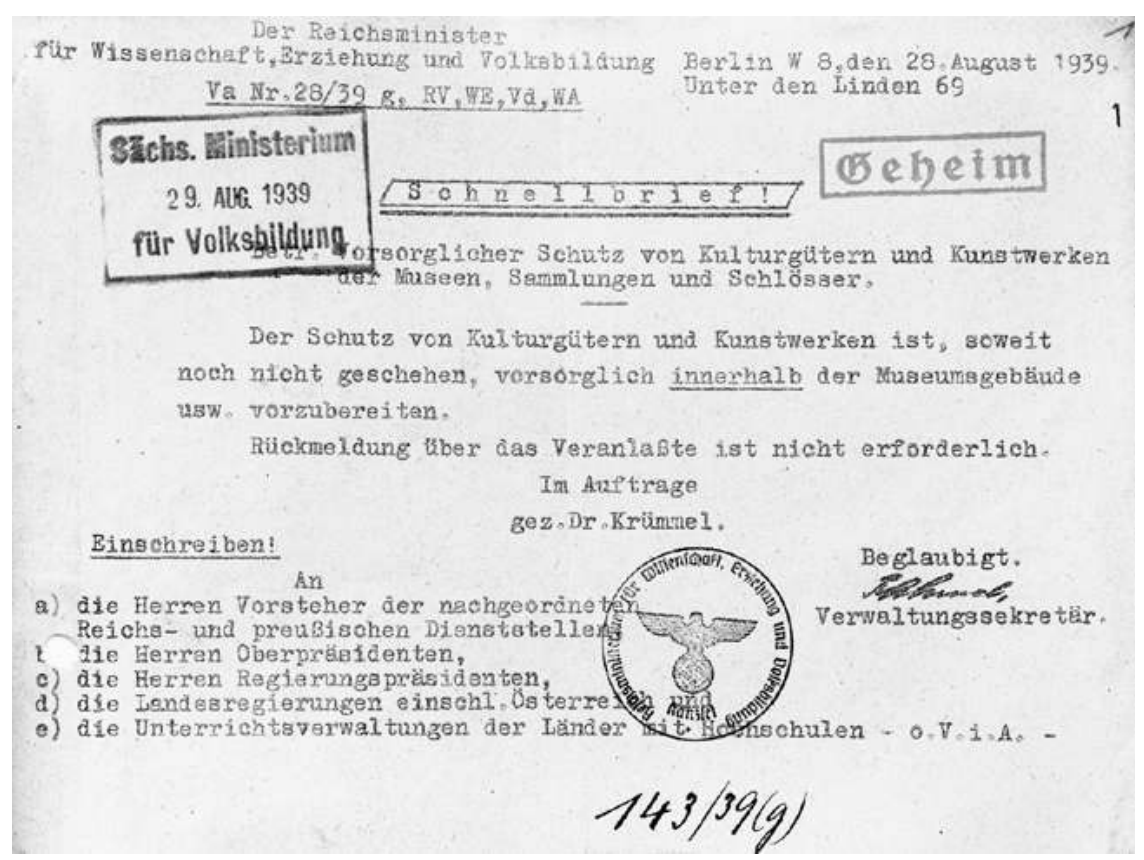

30 Brief vom Reichsminister für Wissenschaft, Erziehung und Volksbildung, Berlin, an die Landesregierungen, 28.8.1939

ähnlichen Kulturstätten vorschrieb. Gefordert wurde darin eine Einteilung der Sammlungsobjekte in drei Gruppen. ${ }^{43}$ Gruppe A umfasste ,[k]ulturhistorisch bedeutende und schlechthin unersetzliche Kunstwerke“, für die eine „Verbringung in sichere, nach Möglichkeit bomben- und feuersichere Räume" vorzubereiten sei; Gruppe B jene „Werke der Kunst und Wissenschaft, die besonders wertvoll aber nicht zu a zu rechnen“ waren und ,in den Keller und unteren Geschossen“ der Gebäude Schutz finden sollten, und Gruppe C „[a]lle übrigen Kulturgegenstände“, die ,in den Räumen in denen sie friedensmäßig untergebracht sind““44, bleiben sollten. Die seit Dezember 1937 in Dresden erarbeiteten Bergungsmaßnahmen entsprachen also der von der Reichsregierung vorgegebenen Norm. ${ }^{45}$

43 Leiter SMV, Reuter, an Direktoren der Staatlichen Sammlungen, 11.9.1939, SKD, MPS, 1939, E.-Reg. Nr. 268. Vgl. Reichsministerialblatt. Zentralblatt für das Deutsche Reich, Nr. 40, 1.9.1939, S. 1386.

44 Ebd.

45 Siehe S. 146 f. Die Dresdner Einteilung in die Gruppen I, II und III entsprach den Gruppen A, B, C. 
Nachdem die Presse nur wenige Tage nach Kriegsbeginn, am 4. September 1939, darüber informiert hatte, dass durch Museen und Bibliotheken „, [u]nersetzliche Kunstwerke [...] in bomben- und feuersichere Räume zu bringen“46 seien, erschien am folgenden Tag lediglich der kurze Hinweis: „Die Führungen durch die staatlichen Sammlungen und Museen fallen bis auf weiteres aus “" ${ }^{\text {"7 }}$. Am 6. September 1939 berichtete die Presse trotz aller Geheimhaltungsmaßnahmen zur Beruhigung der Bevölkerung über die Bergungsarbeiten, ohne jedoch Details preiszugeben. So verkündete der Dresdner Anzeiger, dass die Gemälde „bombensicher verstaut, und an den unteren Außenfenstern der Gebäude [...] zur weiteren Sicherung Sandsäcke aufgestapelt ${ }^{\star 48}$ seien, und erwähnte explizit das berühmteste Bild der Gemäldegalerie, Raffaels „Sixtinische Madonna“, als besonders verwahrten Kunstschatz. Ausdrücklich wurde darauf verwiesen, dass die Sächsische Landesbibliothek weiterhin geöffnet sei und lediglich das Buchmuseum seine kostbaren Schätze gesichert habe. Die Dresdner Neuesten Nachrichten berichteten unter dem Titel „Götterwanderung":

Und diese Götter [...] sind jetzt von ihren Sockeln herabgestiegen - vielmehr die kräftigen und behutsamen Hände der Museumsmitarbeiter haben sie herabgehoben - und suchen nun ein bombensicheres Versteck. [...] Über 6000 Bildwerke, von den antiken Bronzegeräten bis zu den Plastiken unserer Tage, waren zu verwahren. ${ }^{49}$

Im Oktober 1939 forderte Fichtner in seiner Funktion als Referent im Ministerium von den Sammlungsdirektoren einen Bericht über ihre Erfahrungen bei der Bergung des Museumsgutes und über die Eignung der Schutzräume. ${ }^{50}$ So berichteten die Mitarbeiter des Mathematisch-Physikalischen Salons: „Vorträge und Führungen können im Sammlungsraum nicht abgehalten werden, da die Schauschränke mit Brettern verschalt sind. "51 Stellvertretend für den Galeriedirektor informierte $>$ Kurt Zoege von Manteuffel, dass ,in etwa vierzehntätiger Arbeit die Bestände der Gemäldegalerie einschließlich der Neuen Galerie (mit Ausnahme einiger wegen ihres großen Formats nicht transportablen [sic!]

\footnotetext{
46 Luftschutz in Museen, in: DA, 4.9.1939, S. 4.

DNN, 5.9.1939, S. 6.

48 Wertvolle Kulturschätze wurden gesichert. Vorsichtsmaßnahmen in Dresdener Sammlungen und Museen, in: DA, 6.9.1939, S. 5.

49 „Götterwanderung“ im Albertinum, in: DNN, 7.9.1939, S. 4.

50 Vgl. SMV, Fichtner, an Direktoren der Staatlichen Sammlungen, 7.10.1939, SKD, MPS, 1939, E.-Reg. Nr. 287.

51 Mathematisch-Physikalischer Salon an SMV, 24.10.1939, SKD, MPS, 1939, A.-Reg. Nr. 304.
} 
Gemälde) aus den Ausstellungsräumen entfernt“ worden seien, doch „die bisherige Sicherung nur als behelfsmäßig anzusehen “52 sei. Die Gemälde waren im Vestibül des Galeriegebäudes, im Studiensaal des Kupferstich-Kabinetts, in Verwaltungs- wie auch Kellerräumen des Semperbaus untergebracht worden. Ebenfalls dort im Keller wurden die wertvollsten Bestände des Kupferstich-Kabinetts geborgen.

Ein vermutlich von Fichtner verfasster Bericht stellte 1940 allerdings fest: „Dresden kann z. Zt. seinen Kunstschätzen noch keine genügende Sicherheit bieten - am besten sind die Werke des Grünen Gewölbes und der Skulpturensammlung untergebracht." ${ }^{\text {3 } 3}$

Schon damals war man sich bewusst, dass mehrere verschiedene Schutzräume besser seien als ein Zentralbunker, damit ein eventueller Bombentreffer nicht den Gesamtbestand vernichten würde, dass die „Verpackung in handliche, von 2 Männern zu bewältigende, mit Griffen versehene Kisten "“4 am praktikabelsten sei, sowie, dass Verzeichnisse über die Inhalte der Kisten und Stapelpläne während der Auslagerung angefertigt werden müssen.

Ebenfalls in den monatlichen Dienstberatungen war der Objektschutz ein wichtiges Thema. In einer Direktorenkonferenz im Februar 1940 sprach Fichtner über „Erfahrungen, Bergung von Museumsgut und Luftschutzmaßnahmen betreffend, auf Grund der in Polen gemachten Beobachtungen "55, wobei er auf eigene Beobachtungen während seiner Dienstreise im Spätherbst 1939 zurückgriff. Als überzeugter Nationalsozialist stellte er arrogant fest, dass „die Erfahrungen am Feind und nicht an den eigenen Maßnahmen gesammelt werden konnten“, und „der Angriff und die überlegene Stärke der eigenen militärischen Waffe

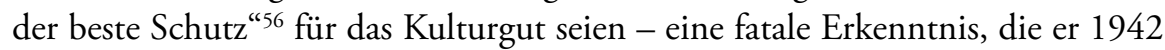
durch die Anpassung der Schutzmaßnahmen in Dresden revidierte. ${ }^{57}$

Unmittelbar vor der Dienstberatung im März 1940 hielt der Archäologe - Walter Müller, Direktor der Skulpturensammlung, im Spiegelsaal der Porzellansammlung vor allen wissenschaftlichen Sammlungsmitarbeitern und vor Vertretern des Ministeriums einen Dia-Vortrag über den „Denkmalschutz im

52 Gemäldegalerie, i.V. Zoege von Manteuffel, an Leiter SMV, 10.10.1939, HStA Dresden, 10701, Nr. 320/1, Bd. 1, fol. 31. Vgl. auch ebd., fol. 32.

53 Fichtner (?), 1940, SKD Archiv, 01/PS 43, Bd. 1, fol. 147 f., hier: 148.

54 Ebd., fol. 147.

55 Vgl. Fichtner an Direktoren der Staatlichen Sammlungen, 30.1.1940, HStA Dresden, 11125, Nr. 23054, fol. 43; ebenso: SKD, MK, 1940, fol. 19. Siehe S. 142.

56 Fichtner: Beobachtungen zu Fragen des Luft- und Denkmälerschutzes im polnischen Kriege, 14.2.1940, HStA Dresden, 11125, Nr. 23054, fol. 47-54, hier: 48.

57 Siehe S. $155 \mathrm{ff}$. 


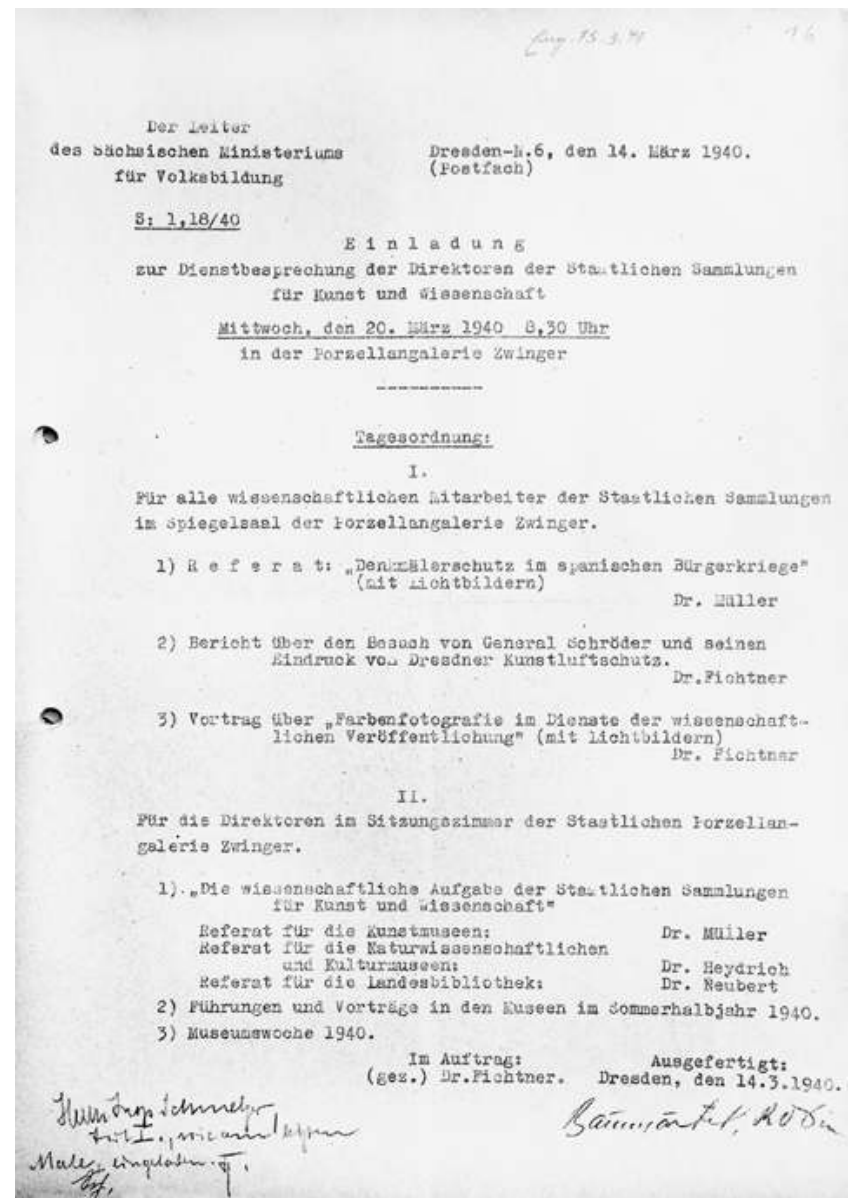

31 Einladung zur Direktorenkonferenz am 20.3.1940

spanischen Bürgerkrieg“, in dem er berichtete, wie die Kunstschätze des Prados in Madrid geschützt worden waren. ${ }^{58}$ Danach sprach Fichtner über den Luftschutz der Dresdner Museen.

\footnotetext{
58 Fichtner an Direktoren der Staatlichen Sammlungen, 14.3.1940, u. Protokoll 4. Dienstbesprechung 1940, 20.3.1940, HStA Dresden, 11125, Nr. 23054, fol. 63a; 70-75, hier: S. 71. Die Lichtbilder, die dabei gezeigt wurden, sind nicht überliefert. Da bisher kein Nachweis für einen Spanienaufenthalt Müllers während des Bürgerkrieges gefunden wurde, ist zu vermuten, dass er seine Informationen aus der Zeitschrift „Mouseion. Bulletin de l'Office internationale des musées" entnommen hat, die mehrfach darüber berichtet hatte, 1939 sogar mit einen Sonderband: Office International des Musées u. Josep Renau (Hg.): Lorganisation de la défense du patrimoine artistique espagnol pendant la guerre civil, Extrait de la revue Mouseion, Bd. 39-40, 1937. Die Autorin dankt Rebeca Saavedra Arias für den Hinweis auf die Sonderausgabe.
} 
Museen an der „Heimatfront“ - Wiedereröffnung der Schausammlungen

Das Bergen der Kunstschätze und Schließen der Schausammlungen bedeutete jedoch keineswegs das Ende der Museumsarbeit im Zweiten Weltkrieg. Im Dezember 1939 forderte der Reichsminister für Wissenschaft, Erziehung und Volksbildung, Bernhard Rust, dass sich

die deutschen Museen aktiv in die innere Front des uns aufgezwungenen Abwehrkampfes eingliedern. Jedes, sei es auch behelfsmäßig und anspruchslos, geöffnete Museum gibt zahlreichen Volksgenossen Anregung und Freude und stärkt sie in ihrem Vertrauen. ${ }^{59}$

Damit war klargestellt, dass den Museen im Krieg neben dem Schutz der Objekte die Aufgabe oblag, ein normales Leben zu suggerieren und die Bevölkerung zum Durchhalten zu motivieren. In diesem Sinne war die Museumsarbeit Bestandteil der „Heimatfront" und wurde als „kriegswichtig“ anerkannt.

Es verwundert daher wenig, dass nach nur drei Monaten, zum Jahresanfang 1940, ein Großteil der Museen in Dresden wieder öffnete, wenngleich meist mit reduzierten Präsentationen. Das Echo in den Tageszeitungen war entsprechend groß. ${ }^{60}$ Das Grüne Gewölbe öffnete nicht mit seiner bisherigen Schausammlung, sondern mit einer Gemeinschaftsausstellung von Skulpturensammlung, Porzellansammlung und Kupferstich-Kabinett gezeigt. ${ }^{61}$ Diese neue Präsentationsform ermöglichte die Erfüllung der in der NS-Zeit wichtigsten Aufgaben der Museen - Bewahren und Vermitteln -, indem der Großteil der Objekte weiterhin gesichert war und gleichzeitig eine kleine Auswahl für das Publikum zugänglich und für die Bildungsarbeit nutzbar blieb. Die Gemäldegalerie im Semperbau blieb geschlossen. Nur ihre Ausstellungsarbeit in den Räumen an der Brühlschen Terrasse wurde fortgesetzt, wo ab Mai 1940 die Ausstellung „Caspar David Friedrich zum 100. Geburtstag“ gezeigt wurde. Im Semperbau begannen unterdessen die Arbeiten für einen Heizungsumbau und die Verlegung neuer Fußböden. ${ }^{62}$

59 Dekret des Reichsministers für Wissenschaft, Erziehung und Volksbildung, Rust, 8.12.1939, SKD Archiv, 02/VA 50, fol. 101-103. Siehe S. 168-170.

${ }^{60}$ Vgl. Holzhausen, Walter: Grünes Gewölbe im neuen Glanze, in: DA, 29.12.1939, S. 5; Dresdner Museen wieder geöffnet, in: DNN, 29.12.1939, S. 2; Wiedereröffnung der Staatlichen Museen zu Dresden, in: DNa, 29.12.1939, S. 3.

${ }^{61}$ Vgl. Kind, Margot: Aus drei mach eins. Drei Museen haben Stelldichein im Grünen Gewölbe. Bronze, Porzellan und Kostbarkeiten, in: DNa, 30.12.1939, S. 4. Siehe auch S. 248.

62 Vgl. Kunstpflege der Staatl. Museen Dresden. Winterhalbjahr 1939/1940, SKD Archiv, 01/ PS 43, Bd. 1, fol. 138 ff. hier: 138; Jahresbericht HStA Dresden, 11125, Nr. 23053, fol. 143. 
Drei Museen blieben jedoch für die Besucher geschlossen: die Porzellansammlung, das Münzkabinett und der Mathematisch-Physikalische Salon. ${ }^{63} \mathrm{Am}$ 1. Oktober 1940 schloss außerdem das Museum für Völkerkunde im Zwinger für seinen bevorstehenden Umzug in das Johanneum. ${ }^{64}$

An das RMWEV in Berlin übermittelte das SMV jedoch einen geschönten Bericht und meldete nur die Schließung der Gemäldegalerie und Porzellansammlung:

Bomben- und splittersicher sind nur die Kunstwerke der Gruppe I [...] untergebracht. Das übrige Sammelgut wird gezeigt. Seit 1.I.1940 sind, mit Ausnahme der Staatlichen Gemäldegalerie (deren Heizanlage erneuert werden muß) und der Staatlichen Porzellangalerie (deren Neuaufstellung noch in Bearbeitung ist), alle Sammlungen geöffnet und erfreuen sich eines sehr regen Besuches. ${ }^{65}$

Die Sammlungsdirektoren traten indes selbst im November 1940 noch dafür ein, „daß die Sammlungen, wie bisher, offen gehalten werden, da der Zuspruch ein außerordentlich großer ist und die Besucherzahlen ständig im Steigen begriffen sind ${ }^{“ 66}$. In Dresden wähnte man sich weiterhin sicher, da die Stadt noch außerhalb der Reichweite der alliierten Bomber lag.

\section{Anpassung der Sicherungsmaßnahmen und Auslagerungen}

In den Folgejahren wurden die Sicherungsmaßnahmen an die jeweiligen kriegsbedingten Notwendigkeiten angepasst und je nach Sammlung unterschiedlich stark modifiziert. Kurz nach Jahresbeginn 1942 wurden die nächsten Museen geschlossen: Zum 16. Januar das Historische Museum und die Skulpturensammlung. ${ }^{67}$ Dies veranlasste das SMV, auch die Wiedereröffnung des Mathematisch-Physikalischen Salons nicht mehr zuzulassen:

\footnotetext{
63 Vgl. Kunstpflege der Staatl. Museen Dresden. Winterhalbjahr 1939/1940, SKD Archiv, 01/ PS 43, Bd. 1, fol. 138 ff., hier: 138.

64 Vgl. Jahresbericht 1941/1942, 9.3.1943, HStA Dresden, 11125, Nr. 23053, fol. 47-50, hier: 47.

65 SMV, Göpfert, am RMWEV, 25.10.1940, HStA Dresden, 10701, Nr. 320/1, Bd. 1, fol. 58.

${ }_{66}$ SMV, Fichtner, an Leiter SMV, 23.11.1940, ebd., fol. 59-62. Vgl. Fichtner, Bericht über Wahrnehmung der Dienstaufsicht, 4.12.1940, SKD Archiv, 01/PS 53, Bd. 1, fol. 192 f., hier: 193. Siehe S. $171 \mathrm{f}$.

67 Vgl. Leiter SMV an Direktor Skulpturensammlung, 14.1.1942, SKD Archiv, 01/SKS 44, o. Pag. Vgl. auch SKD Archiv, 01/PS 137, fol. 133; HStA Dresden, 11125, Nr. 23053, fol. 77.
} 
Zu einem Zeitpunkt, da aus kriegsbedingten Notwendigkeiten zwei weitere Sammlungen geschlossen worden sind, kann die Wiedereröffnung des Mathematisch-Physikalischen Salons nicht in Betracht gezogen kommen. [sic!] Auch die Aufstellung einer Sonderschau muß aus den gleichen Gründen zur Zeit unterbleiben. $^{68}$

Mit der Schließung der Skulpturensammlung wurde das Personal an andere Dienststellen abgeordnet, $>$ Ragna Enking zum Beispiel an die Sächsische Landesbibliothek. ${ }^{69}$ Der Protest des Direktors $\triangleright$ Walter Müller, der anmerkte, dass eine „[d]auernde Stillegung sonst nirgends bekannt“ sei und selbst die Waffensammlung in Wien „die Verwaltung nach kurzer Unterbrechung wieder aufgenommen "70 habe, war erfolglos. Allerdings belegt sein Einspruch, dass das Dresdner Sammlungspersonal noch immer Kontakte mit Kollegen pflegte und gut über die Situation andernorts informiert war.

Nach den ersten schweren Luftangriffen auf deutsche Städte - wie Lübeck, Augsburg und Rostock - folgten die nächsten dauerhaften Schließungen, und die bisherige Bergung der Kunstschätze innerhalb der Museen selbst bzw. innerhalb der Stadt wurde kritisch hinterfragt. ${ }^{71}$ Am 30. April 1942 wurde das Kupferstich-Kabinett und am 15. Juni das Grüne Gewölbe geschlossen. ${ }^{72}$ Nur drei Museen - Museum für Tierkunde, Museum für Mineralogie und Geologie, Landesmuseum für Vorgeschichte - und die Sächsische Landesbibliothek blieben weiterhin geöffnet. ${ }^{73}$

Im April 1942 schrieb Fichtner an das Ministerium:

${ }_{68}$ Leiter SMV, Dedering, an Direktion Mathematisch-Physikalischer Salon, 4.2.1942, SKD, MPS, 1942, E.-Reg. Nr. 31.

69 Vgl. SKD Archiv, 01/SKS 137, fol. 34, 37-41, 76. Siehe auch S. 57 f.

70 Skulpturensammlung, Müller, an Leiter SMV, 24.2.1942, SKD Archiv, 01/SKS 179, fol. 38 f., hier: 39 .

71 Auf die Bombardierung von Lübeck (29.3.1942), Augsburg (17.4.1942) und Rostock (24.27.4.1942) und die drohende Gefahr für Dresden verwies Fichtner in Briefen an Göpfert. Vgl. SMV, Fichtner, an Leiter SMV, 7.4.1942, 29.4.1942, SKD 02/VA 50, fol. 137, 138.

72 Grünes Gewölbe: Vgl. SMV, Dedering, an Direktor Grünes Gewölbe, 12.6.1942, SKD Archiv 02/VA 50, fol. 147 sowie HStA Dresden 10701, Nr. 329/1, fol. 101, 103. Vgl. auch Nagel 2015, S. 24; Kupferstich-Kabinett: Vgl. Jahresbericht 1941/1942, HStA Dresden, 11125, Nr. 23053, fol. 79 f., hier: 80v.

73 Vgl. SMV, Fichtner, an Leiter SMV, 4.4.1942, SKD Archiv, 01/PS 44, Bd. 2, fol. 72 u. Fichtner an Reichsstatthalter, Jahresbericht der Staatlichen Sammlungen, 4.7.1944, HStA Dresden, 11125, Nr. 23053, fol. $151 \mathrm{f}$. 
Dresden war bisher stolz darauf, die Museen noch immer als aktuelle Volksbildungsmittel offen gehalten zu haben. Das Risiko, unter Umständen, wie in Lübeck, Totalverlust zu erleiden, kann aber nicht eingegangen werden, deshalb wird vorgeschlagen sämtliche Museen zu schließen ${ }^{74}$.

Er betonte: „Neu ist die Notwendigkeit der vollständigen Räumung der inneren, historischen Stadt und Bergung aller Kunstwerke (auch der Gruppe II und III) "75. Das heißt, noch vor der Schließung der letzten Museen wurden die bisherigen Schutzmaßnahmen in Dresden überdacht und an die Situation angepasst. Die verantwortlichen Direktoren suchten jetzt nach geeigneten Standorten: fernab von Großstädten, militärischen Anlagen, „abseits von Kriegsindustrie und Bahnverkehr“, „trocken, diebes- und einbruchssicher"76.

Auf Befehl des Reichsstatthalters Mutschmann wurden die Kunstschätze der Staatlichen Sammlungen ab April 1942 dezentral ausgelagert, außerhalb von Dresden, an über 40 Orten in Sachsen, vor allem in Burgen, Schlössern und Herrenhäusern, zudem in ehemaligen Bergwerken. Als Hauptauslagerungsorte dienten die Albrechtsburg Meißen, die Festung Königstein und Schloss Weesenstein, alle zwischen 25 und 40 Kilometer von Dresden entfernt. ${ }^{77}$ Die Leitung der Bergungsmaßnahmen wurde Fichtner Anfang Juni 1942 anvertraut. $^{78}$

Angesichts der umfangreichen Bestände, der geringen Mitarbeiterzahlen und mangelnder Transportmöglichkeiten war die gesamte Auslagerung der Sammlungsobjekte eine enorme logistische Leistung. Als sie weitgehend abgeschlossen war, erhielten auch die Mitarbeiter im Dezember 1943 die Möglichkeit, Privateigentum an den Auslagerungsorten zu bergen. ${ }^{79}$ Dies nutzten u.a. Ragna Enking, - Walter Holzhausen, > Franz Schubert und $>$ Wilhelm Meise.

In einer Rede vor den Mitarbeiterinnen und Mitarbeitern erinnerte Fichtner im Juli 1942, also während der Bergungsarbeiten und Transporte an die Auslagerungsorte, an die zwingend notwendige Geheimhaltungspflicht jedes einzelnen. Dabei beschrieb er die aktuelle Situation:

\footnotetext{
74 SMV, Fichtner, an Leiter SMV, 24.4.1942, SKD Archiv, 02/VA 50, fol. 138-142, hier: 142. Ebd. fol. 140.

SMV, Fichtner, an Leiter SMV, 26.5.1942, HStA Dresden, 10701, Nr. 320/1, Bd. 1, fol. $92 \mathrm{f}$, hier: $93 \mathrm{v}$.

$77 \mathrm{Zu}$ den Auslagerungen der Kunstschätze der Staatlichen Sammlungen außerhalb von Dresden vgl. Enke 2018; Hänel 2018. Vgl. S. 23, Anm. 40.

78 Vgl. Aktenvermerk Gruve, SMV, 5.6.1942, HStA Dresden, 11125, Nr. 23063, Nr. 41.

79 Landesregierung, Abteilung IV/7, Fichtner, an Direktoren der Staatlichen Sammlungen, 9.12.1943, SKD, MPS, 1943, E.-Reg. Nr. 204.
} 
Der Feind fliegt mit sehr großem Aufgebot Städte an und schont dabei offene Kulturstätten keineswegs. Die Museen haben daraus ihre Folgerungen gezogen und in den letzten Wochen den größten Teil ihrer Bestände auf das Land verlegt. Dabei ist allergrößte Sorgfalt auf die Vertrauenswürdigkeit derer gelegt worden, die unsere Kulturgüter beherbergen. Es sind eingehende Verhandlungen mit der Sicherheits- und Feuerschutzpolizei gepflogen worden. Die Transportfirmen und -Arbeiter sind sorgfältigst ausgewählt, so daß eine Geheimhaltung nach menschlichem Ermessen gewahrt sein dürfte. ${ }^{80}$

Trotz der verordneten Geheimhaltung berichtete die Presse weiterhin über die Bergung der Kulturgüter. Bereits im Vorjahr, im Juni 1941, war in der Zeitschrift „Die

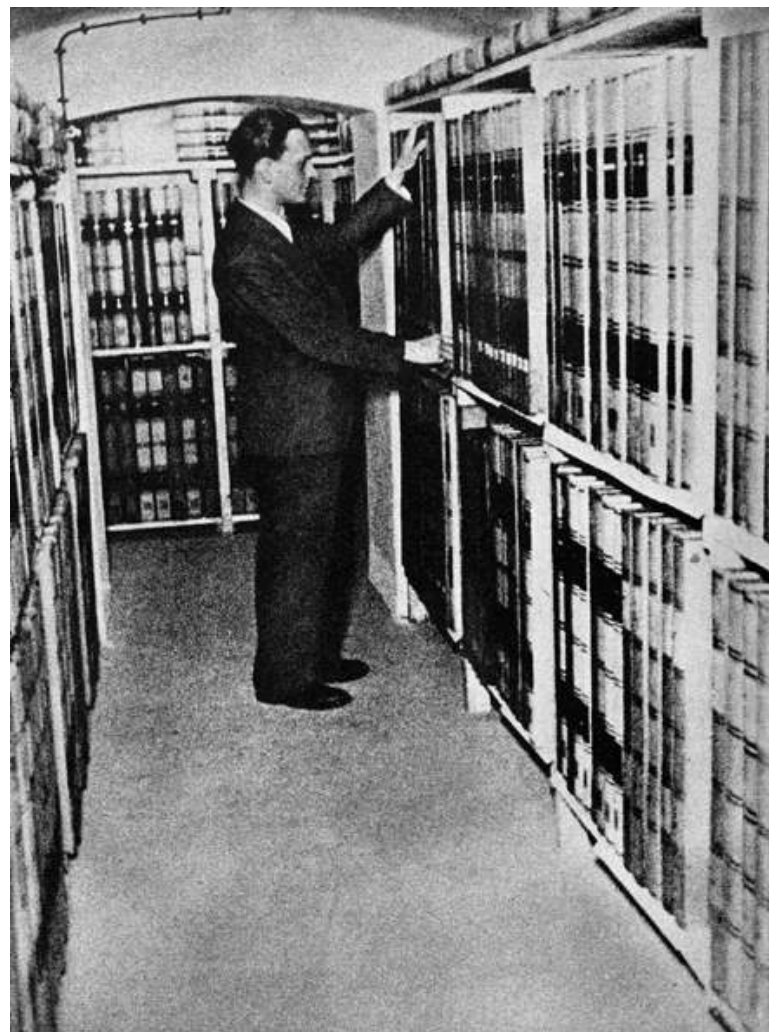

32 Franz Schubert im Bergungsraum des Kupferstich-Kabinetts im Semperbau, März 1941 Sirene" des Reichsluftschutzbundes ein Artikel „Kunst im Luftschutzraum. Luftschutz auch für die deutschen Kunstschätze ${ }^{\text {“81 }}$ erschienen. Der Autor mit den Initialen A. G. berichtete anonymisiert - ohne die Nennung konkreter Orte, Personen oder Objekte - über die Bergung der Kunstwerke, die ihm drei Monate zuvor in Dresden bei einer Führung für Vertreter des Luftschutzgaues IV erläutert worden waren. Dem Artikel waren sechs Fotografien beigefügt, von denen eine $\triangleright$ Fritz Fichtner bei der Ablesung eines Thermohygrometers zeigt, eine andere $\triangleright$ Franz Schubert in einem vom Kupferstich-Kabinett genutzten Bergungsraum im Keller des Semperbaus.

80 Fichtner, Manuskript der Rede zur Geheimhaltung, 31.7.1942?, SKD Archiv, 01/PS 53, Bd. 1, fol. 51-55, hier: 54 f. Siehe auch S. $132 \mathrm{ff}$.

81 A. G.: Kunst im Luftschutzraum. Luftschutz auch für die deutschen Kunstschätze, in: Die Sirene. Illustrierte Zeitschrift des Reichsluftschutzbundes, Nr. 13, Juni 1941, S. 291 ff. 
Andere Artikel in der Tagespresse informierten nur sehr allgemein über den notwendigen Schutz des Kulturgutes, während sich Fichtner im Rahmen der öffentlichen Museumsvorträge am 14. November 1943 explizit den „Bergungsarbeiten an den Dresdner Museumsschätzen " widmete. ${ }^{82}$

Im Juli 1944 veröffentlichte wiederum ein anonymer Autor nach einem Gespräch mit Galeriedirektor • Hermann Voss in der Wochenzeitschrift „Das Reich“ einen Artikel über „Museen im Kriege“" ${ }^{\text {"83 }}$. Er schilderte die Aufgaben der Wissenschaftler:

Die Aemteranhäufung ist selbstverständlich ein durch den Krieg bedingter Notstand aber keineswegs eine Ausnahme: wie viele Museumsbeamte müssen für einberufene oder sonstwie ausgefallene Kollegen einspringen und wenigstens die dringlichsten der laufenden Arbeiten miterledigen! [...] Die Bergungsaktion hat viel Kopfzerbrechen gemacht. Um so mehr, als im Laufe der Kriegsjahre die Voraussetzungen dafür sich änderten. Was 1939 noch als sicher galt war es nicht mehr 1944. Da hieß es immer wieder nachprüfen und bessere Möglichkeiten suchen. Vor allem aber an den Bergungsorten für die richtigen Lebensbedingungen sorgen. [...] Es wäre also verkehrt, nur an Bomben zu denken, die Klimatisierungsanlagen, die Hygrometer, die Heizung müssen in Ordnung sein und laufend beobachtet werden. $^{84}$

Diese Beschreibung belegt, dass die Aufgaben des wenigen verbliebenen Personals wuchsen. Neben der alltäglichen Museums- und Verwaltungsarbeit mussten neue Tätigkeiten übernommen werden: Zunächst der Schutz der im Museum gesicherten Objekte und der Luftschutz in bzw. an den Gebäuden, alsbald, ab 1942, das erneute Verpacken und die Auslagerung der Objekte sowie deren Bewachung und konservatorische Betreuung an den Auslagerungsorten. Darüber hinaus musste dem SMV alle zwei Monate über den Zustand der geborgenen Kunstwerke berichtet werden.

Trotz der Bergung der Objekte blieben die letzten drei Museen auch im Sommer 1943 weiterhin für vier Stunden täglich geöffnet: Das Museum für Tierkunde, das Museum für Mineralogie und Geologie und das Landesmuseum für

\footnotetext{
82 Vgl. Kriegswichtige Aufgaben der Gemeinden, in: Dresdner Zeitung (DZ), 18.10.1943, S. 3 u. Kulturgüter vor Fremdeinwirkung schützen, in: DZ, 22.3.1944, S. 3 und Dr. H. Stegmann: Dresdner Museen einst und jetzt, in: DZ, 16.11.1943, S. 3. Siehe auch S. $210 \mathrm{ff}$.

83 Museen im Krieg. Neue Aufgaben zu alten Zielen der Galerien, in: Das Reich, Nr. 27, 2.7.1944. Vgl. HStA Dresden, 11125, Nr. 22878, fol. 43.

84 Ebd.
} 
Vorgeschichte. ${ }^{85}$ Die längere Öffnung der beiden Letztgenannten war möglich, da sie, den neuesten Methoden folgend, in ihren Dauerausstellungen viele Nachbildungen verwendeten. ${ }^{86}$ Doch im fünften Kriegsjahr, im Juni 1944, sah sich Fichtner gezwungen, „[a] uf Veranlassung des Herr Polizeipräsidenten in Dresden als örtlichen Luftschutzleiter [...] aus kriegsbedingten Gründen mit sofortiger Wirkung die Schließung des Landesmuseums für Vorgeschichte im Wallpavillon des Zwingers ${ }^{\text {“87 }}$ anzuordnen.

Im Sommer 1944 kam es auch in der Verwaltung der Staatlichen Sammlungen zu Veränderungen. Infolge der Personalknappheit regelte Reichsstatthalter Mutschmann nach Absprache mit Sammlungsreferent Fichtner am 11. August 1944 die Zuständigkeiten in den Museen neu. Er erklärte nun im Falle der Abwesenheit der Wissenschaftler die Konservatoren bzw. Präparatoren zu Sammlungsverantwortlichen.$^{88}$ Einen Monat später erfolgte die Ablösung Fichtners als Sammlungsreferent in der Abteilung IV/7 durch Regierungsdirektor Arthur Graefe. $^{89}$

Am 7. Oktober 1944 wurde bei einem Luftangriff der Alliierten auf Dresden das Museum für Tierkunde getroffen und durch einen Brand zerstört. Dadurch wurde deutlich, dass die bisherige, in der Öffentlichkeit wahrnehmbare $\mathrm{Mu}$ seumsarbeit in Dresden keinesfalls weitergeführt werden konnte. Sie endete mit der Schließung des letzten noch geöffneten Museums, des Museums für Mineralogie und Geologie, am 30. Dezember 1944. ${ }^{90}$ Die Staatlichen Sammlungen hatten ihren nationalsozialistischen Bildungsauftrag damit erfüllt, „solange es die Sicherung des staatlichen Kulturgutes überhaupt erlaubte ${ }^{\text {"91 }}$. Lediglich die Sächsische Landesbibliothek setzte ihren Leihverkehr weiterhin fort.

Drei Wochen später, am 19. Januar 1945, erklärte Reichsstatthalter Mutschmann:

85 Vgl. SMV, 7.4.1943, SKD, MPS, 1943, E.-Reg. Nr. 54.

86 Vgl. Schachtmann 2010, S. 61 und Schachtmann 2015, S. 46.

87 Landesregierung, Fichtner, an Direktoren der Staatlichen Sammlungen, 19.6.1944, SKD, MPS, 1944/1945, E.-Reg. Nr. 95.

88 Vgl. Reichsstatthalter Mutschmann an Fichtner, SMV, Abteilung IV/7, 11.8.1944, HStA Dresden, 11125, Nr. 23058, fol. 84a. Siehe S. 67 ff.

89 Vgl. Reichsstatthalter an Fichtner, 14.9.1944, HStA Dresden, 13859, Nr. 1553, fol. 62. Siehe S. 42.

90 Vgl. Museum für Mineralogie und Geologie, Fischer, an Landesregierung, Abt. IV/7, 2.1.1945, Abschrift, HStA Dresden, 11125, Nr. 19295/2, fol. 168.

${ }_{91}$ Fichtner an Reichsstatthalter, Jahresbericht der Staatlichen Sammlungen, 4.7.1944, HStA Dresden, 11125, Nr. 23053, fol. 151 f., hier: 151. 
Für die Leiter der Sammlungen darf es zurzeit keine andere Sorge geben, als Tag und Nacht über die letzten Möglichkeiten der Erhaltung aller ihnen anvertrauten Gegenstände einschließlich der Büchereien und des Inventars nachzudenken und entsprechend zu handeln. Die laufenden wissenschaftlichen Arbeiten haben demgegenüber völlig zurückzutreten. ${ }^{92}$

Nun war der Schutz der Objekte die alleinige Aufgabe der Mitarbeiter der Staatlichen Sammlungen.

\section{Wissenschaftliche Arbeit an den Staatlichen Sammlungen}

Wie aber war es im Nationalsozialismus um die inhaltliche und praktische Arbeit der Staatlichen Sammlungen - das Forschen, Ausstellen und Vermitteln - tatsächlich bestellt? In den ersten Jahren nach 1933 publizierten die Wissenschaftler sehr rege und nahmen an nationalen wie internationalen Tagungen teil.

Davon, dass der wissenschaftlichen Arbeit, auch nach Kriegsbeginn, eine hohe Bedeutung beigemessen wurde, zeugen die Einladungen und Protokolle der Direktorenkonferenzen vom 14. Februar und 20. März 1940. ${ }^{93}$ In beiden Beratungen wurde neben der Bergung der Kulturgüter auch der wissenschaftliche Auftrag der Sammlungen thematisiert. Im März referierten - Walter Müller, - Martin Heydrich und $>$ Hermann Neubert jeweils aus der Perspektive ihrer Sammlungen über „Die wissenschaftlichen Aufgaben der Staatlichen Sammlungen für Kunst und Wissenschaft ${ }^{\text {" }}{ }^{4}$ Aus den Manuskripten der Referate exzerpierte $>$ Fritz Fichtner eine Liste mit Aufgaben, die er dem Leiter des SMV sandte. Darin notierte er den systematischen Ausbau der Sammlungen, die Inventarisation, die Erforschung der Bestände, die Veröffentlichungen, den Ausbau der jeweiligen Sammlung zum Spezialforschungsinstitut von zentraler Bedeutung sowie die fachliche Ausbildung des wissenschaftlichen Nachwuchses. Als Forderungen fügte er hinzu: den Ausbau des Stabes der wissenschaftlichen Hilfsarbeiter, das Bereitstellen von Studienbeihilfen und Reisebeihilfen, die Erleichterung von Studienurlaub, den Ausbau der Handbibliothek, das Erschließen neuer Veröffentlichungsmöglichkeiten sowie neue Arbeitszeitregelungen. ${ }^{95}$ Die Liste

\footnotetext{
92 Reichsstatthalter Mutschmann an Direktoren der Staatlichen Sammlungen, 19.1.1945, SKD, MK, 1945, fol. 2.

93 Vgl. SKD Archiv, 01/KGM 7, fol. 6, 16; HStA Dresden, 11125, Nr. 23054, fol. 42 ff.

94 Vgl. SKD Archiv, 01/PS 139, fol. 188; 01/PS 43, Bd. 1, fol. 111; 01/KGM 7, fol. 16 u. HStA Dresden, 11125, Nr. 23054, fol. 42-54, 63a, 67-82, 97 f., 100-146.

95 Vgl. SMV, Fichtner, an Leiter SMV, 19.3.1940, HStA Dresden 11125, Nr. 23054, fol. 65 f., ebenso in: SKD Archiv, 01/PS 43, Bd. 1, fol. 42 f.
} 
belegt, dass die wissenschaftlichen Aufgaben nicht nur diskutiert wurden, sondern weiterhin ernsthaft verfolgt werden sollten.

Für die Forschung notwendig sowie für die Zusammenarbeit und den Austausch mit Fachkollegen unabdingbar waren die Mitgliedschaften in Berufsverbänden und Fachgremien. Mehrere Museumsbeamte aus Dresden waren Mitglieder im „Deutschen Museumsbund“, wie ^Erich Haenel, ^Bruno Schröder und $\triangleright$ Karl Wanderer, die bereits 1929 an dessen Tagung in Danzig teilgenommen hatten. ${ }^{96}$ Wanderer wie auch $>$ Arnold Jacobi, $\triangleright$ Eberhard Rimann und später $\triangleright$ Klaus Günther und $\triangleright$ Wilhelm Meise engagierten sich innerhalb des Museumsbundes im „Bund der deutschen naturwissenschaftlichen Museen“, wobei Wanderer von 1936 bis 1938 sogar Beisitzer im Vorstand war. $\triangleright$ Hans Kummerlöwe kontaktierte den Museumsbund, denn er wollte sich für einen internationalen Museologenaustausch engagieren - worüber er auf der 5 . Tagung des „Bundes der deutschen naturwissenschaftlichen Museen " 1936 referierte. ${ }^{97}$ Mitglieder der „Deutschen Ornithologischen Gesellschaft" und des „Vereins Sächsischer Ornithologen“ waren unter anderem Jacobi und Meise. Der „Naturwissenschaftlichen Gesellschaft ,Isis“ zu Dresden" gehörten mindestens Jacobi und ^ Walther Fischer an, Jacobi seit 1904 mehrfach in leitenden Funktionen. Fischer übernahm 1942 deren Vorsitz.

Im „Internationalen Verband von Museumsbeamten zur Abwehr von Fälschungen und Unlauterem Geschäftsgebaren" waren • Erich Haenel, •Ernst Zimmermann, $\triangleright$ Hans Posse, $\triangleright$ Kurt Zoege von Manteuffel und $\triangleright$ Bruno Schröder Mitglieder. ${ }^{98}$ Zoege von Manteuffel, langjähriges Mitglied im „Deutschen Verein für Kunstwissenschaft", wurde 1934 Leiter von dessen Grafik-Abteilung. Haenel übernahm 1938 nach mehrjähriger Mitgliedschaft den Vorsitz im „Verein für Historische Waffen- und Kostümkunde“, während > Ragna Enking 1942 zum korrespondierenden Mitglied des Archäologischen Institutes des Deutschen Reiches ernannt wurde. $>$ Martin Heydrich und Jacobi waren Gründungsmitglieder der „Gesellschaft für Völkerkunde“. Als Mitglieder des „Reichsbundes für Deutsche Vorgeschichte“ waren $\triangleright$ Heinz Amberger und $\triangleright$ Georg Bierbaum bei der Gründung einer Dresdner Ortsgruppe des Reichsbundes im November 1936

\footnotetext{
96 Vgl. HStA Dresden, 13842, Nr. 204.

97 Vgl. Kummerlöwe, Hans: Über die Notwendigkeit eines internationalen wissenschaftlichen Museologen-Austausches, Bund der deutschen naturwissenschaftlichen Museen (Abt. B des Deutschen Museumsbundes), 30. Flugblatt, Berlin, November 1936, S. 1-6.

98 Vgl. Internationaler Verband von Museumsbeamten zur Abwehr von Fälschungen und Unlauterem Geschäftsgebaren (Hg.): Verzeichnis der Mitglieder des Internationalen Verbandes von Museumsbeamten, Berlin, August 1936, www.digishelf.de/objekt/berl66/1/LOG_0003/, Zugriff: 6.12.2019.
} 
anwesend. Langjähriges Mitglied des „Numismatischen Vereins“ und später dessen Vorsitzender war $\triangleright$ Walter Schwinkowski. $\triangleright$ Fritz Fichtner engagierte sich ab 1937 in der Deutschen Keramischen Gesellschaft, deren Kunstausschuss er ab November 1941 leitete.

Mit dem Engagement in verschiedenen Vereinen und Berufsverbänden eng verbunden waren die Reisen zu nationalen Tagungen und internationalen Kongressen, die dem Austausch mit Fachkollegen dienten. Die Naturwissenschaftler, insbesondere die Zoologen, nutzten diese Möglichkeit rege, wie $\triangleright$ Wilhelm Meise, $\triangleright$ Hans Kummerlöwe, $\triangleright$ Klaus Günther sowie $\triangleright$ Walther Fischer. Die Museumsbeamten der kunst- und kulturhistorischen Sammlungen reisten hingegen primär, um Erwerbungen zu tätigen, an Auktionen teilzunehmen und Ausstellungen zu besuchen, oder sie unternahmen Studienreisen. ${ }^{99} \triangleright$ Fritz Fichtner und - Martin Heydrich reisten im Februar 1936 nach London zur „International Exhibition of Chinese Art", an der die Porzellansammlung als Leihgeber beteiligt war. ${ }^{100} \triangleright$ Robert Oertel fuhr unmittelbar vor seinem Dienstantritt an der Gemäldegalerie in Dresden nach Genf, um dort im Juli 1939 die Ausstellung der infolge des Spanischen Bürgerkrieges ausgelagerten Kunstwerke des Museo del Prado zu sehen, worüber er ein Jahr später bei den Museumsvorträgen in Dresden sprach. ${ }^{101}$

Fichtner hielt auch noch 1943 und 1944 Vorträge bei diversen lokalen Gruppierungen der Deutschen Keramischen Gesellschaft, u. a. in Karlsbad, Saalfeld, Posen, Wien sowie im Dezember 1944 im schlesischen Waldenburg. ^ Erna von Watzdorf sprach im Februar 1944 in Pfaffroda über „Turniere in Sachsen“ und -Walther Fischer hielt im März 1944 sechs Vorträge über „Georg Agricola“, u. a. in Zwickau, Chemnitz und Freiberg. ${ }^{102}$

Darüber hinaus wurden in Dresden mehrere Tagungen und Kongresse unter maßgeblicher Beteiligung der Staatlichen Sammlungen organisiert. Im Juli 1934 tagte die Deutsche Geologische Gesellschaft, im November 1935 die Bezirks-

\footnotetext{
99 Vgl. HStA Dresden, 13842, Nr. 047, Nr. 048; HStA Dresden, 11125, Nr. 19003. Die unterschiedliche Häufigkeit der Tagungsteilnahmen von Geistes- und Naturwissenschaftlern kann diverse Ursachen haben, die aufgrund der Lücken in der Überlieferung nicht abschließend zu ermitteln sind - möglicherweise wurden im Bereich der Geisteswissenschaften weniger Tagungen veranstaltet.

100 Vgl. Heydrich an SMV, 17.1.1936, HStA Dresden, 13842, Nr. 048, o. Pag.; Fichtner an Reichsminister Rust, 25.10.1935, SKD Archiv, 01/PS 38, fol. 170 ff.

101 Vgl. Oertel an Posse, Gemäldegalerie, 12.6.1939, HStA Dresden, 13859, Nr. 6178, fol. 50 u. Oertel an Leiter SMV, 25.2.1941, HStA Dresden, 11127, Nr. 29, o. Pag. Der Vortrag fand am 11.2.1940 statt. Vgl. HStA Dresden, 11125, Nr. 23053, fol. 62. Siehe S. 211.

102 Vgl. SKD Archiv, 01/PS 54, Bd. 1 u. HStA Dresden, 11125, Nr. 23053, fol. 110, 123.
} 
gruppe Sachsen der Deutschen Keramischen Gesellschaft. Das umfangreichste wie auch vielseitigste Tagungsangebot offerierten die Dresdner Wissenschaftler 1936: nach dem 24. Sächsischen Ornithologentag im April fanden im Juni der 32. Deutsche Bibliothekartag und die Tagung des Vereins für Historische Waffenkunde statt, im September gefolgt von der 94. Versammlung Deutscher Naturforscher und Ärzte und der Tagung der Physischen Anthropologie. Im Juli 1937 fanden die 55. Jahresversammlung der Deutschen Ornithologischen Gesellschaft und der Deutsche Ornithologentag statt. Im Dezember 1940 organisierte Fichtner die 20. Hauptversammlung der Deutschen Keramischen Gesellschaft in Dresden. ${ }^{103}$ Trotz der zu erkennenden großen Vielfalt reduzierte sich die Anzahl der veranstalteten nationalen wie internationalen Tagungen nach der Einführung der Meldepflicht dieser Veranstaltungen beim RMVP ab November 1936. Weitere Einschnitte brachten die Verordnungen über Auslandskontakte und -reisen, die auch Dienstreisen betrafen. ${ }^{104}$ In Verbindung mit den knappen Geldmitteln und den im Krieg zunehmenden Reiseeinschränkungen erschwerten sie den wissenschaftlichen Austausch und führten zu einer Isolation von der internationalen Forschungsgemeinschaft.

Nur noch wenige Auslandsreisen wurden genehmigt. So nahmen Heydrich und Kummerlöwe 1938 am 2. Internationalen Kongress für Anthropologie und Ethnologie in Kopenhagen teil, und Kummerlöwe und Meise reisten zum 9. Internationalen Ornithologentag ins französische Rouen. Meise arbeitete von Mai bis Juni 1938 am Museé Royal d'Histoire Naturelle in Brüssel. • Walter Häntzschel war im April 1940 in Montelupo Fiorentini in Italien an einem paläontologischen Forschungsprojekt beteiligt. ${ }^{105}$

Einen wesentlichen Aspekt der Forschungsarbeit in den Staatlichen Sammlungen bildete die Publikationstätigkeit. In den 1930er-Jahren wurden Kataloge oder andere Begleitpublikationen meist nur für die großen und wichtigen Ausstellungen produziert, wie für „August der Starke und seine Zeit“, „Sächsische Zeichnungen aus vier Jahrhunderten“ und „Malerei des Barock“ (alle 1933), „Ludwig Richter zum 50. Todestag“ (1934), „Sächsisch-Polnische Kunst“ (1935), „Gedächtnisausstellung zum 200. Todestag von Matthäus Daniel Pöppelmann“

\footnotetext{
103 Im Einzelnen lassen sich diese durch Artikel in der Presse oder Hinweise in den Akten der entsprechenden Sammlungen nachweisen - zum 32. Deutschen Bibliothekartag vgl. DA, 6.6.1936; DNa, 7.6.1936; SLUB, Mscr.Dresd.App.1378.a,75-77. Vgl. auch Haase, Yorck Alexander: Die Bibliothekertage in der Zeit des Nationalsozialismus, in: Plassmann/Syré 2000, S. 81-100, hier: 90-92.

$104 \mathrm{Zu}$ den Verordnungen siehe S. 126-130.

105 Vgl. HStA Dresden, 13842, Nr. 211 o. Pag.; Nr. 115 o. Pag. u. HStA Dresden, 13843, Nr. 267, fol. 9-14, 21-33.
} 
(1936) und „Caspar David Friedrich zum 100. Todestag“ (1940). Auch für die aus Berlin übernommene Ausstellung „Veit Stoß“ (1944) wurde ein Katalog gedruckt. ${ }^{106}$

Die hauseigenen „Jahresberichte der Staatlichen Sammlungen für Kunst und Wissenschaft zu Dresden“ wurden in der NS-Zeit nur einmalig für die Jahre 1929 bis 1937 veröffentlicht und erst 1940 gedruckt. ${ }^{107}$

Wissenschaftliche Arbeiten einzelner Mitarbeiterinnen und Mitarbeiter erschienen selten als eigenständige Publikationen, wie aus den Auswahlbibliografien ersichtlich ist. ${ }^{108}$ Primär publizierten sie in den sammlungseigenen Jahrbüchern bzw. Sammelbänden, wie in den „Abhandlungen und Berichte[n] aus den Staatlichen Museen für Tierkunde und Völkerkunde zu Dresden“ und den „Mitteilungen aus dem Museum für Mineralogie, Geologie und Vorgeschichte zu Dresden“. Dort veröffentlichten u. a. \Martin Heydrich, • Hans Kummerlöwe, ^Wilhelm Meise, ^Siegfried Wolf, ^Georg Bierbaum, ^Walther Fischer, - Walter Häntzschel, ^Eberhard Rimann und $>$ Karl Wanderer.

Einige Mitarbeiter waren als Herausgeber von Schriftenreihen tätig, andere veröffentlichten in diversen Zeitschriften. Bierbaum verantwortete von 1937 bis 1942 die Publikationsreihe „Sachsens Vorzeit“, in der auch • Walter Grünberg veröffentlichte. In den „Sitzungsberichte[n] und Abhandlungen der Naturwissenschaftlichen Gesellschaft Isis Dresden" publizierten Fischer, Häntzschel und Rimann. Für die Herausgabe der „Deutschen Entomologischen Zeitschrift ,Iris"“ zeichnete von 1936 bis 1944 > Klaus Günther verantwortlich. Seit 1907 gab $\triangleright$ Erich Haenel die „Zeitschrift für historische Waffen- und Kostümkunde“ heraus, für die gelegentlich auch $\triangleright$ Erna von Watzdorf schrieb. $\triangleright$ Martin Heydrich publizierte ab 1928 den „Ethnologischen Anzeiger“. Einige, wie > Rudolf Arps-Aubert und Erna von Watzdorf, veröffentlichten in der „Zeitschrift des Deutschen Vereins für Kunstwissenschaft", während • Walter Holzhausen und - Walter Müller auch für das "Jahrbuch der Preußischen Kunstsammlungen“ schrieben. Im „Jahrbuch des Deutschen Archäologischen Instituts“ publizierte neben Müller auch $>$ Ragna Enking.

Doch während des Krieges verringerte sich die Anzahl der Publikationen signifikant, da das Papier streng kontingentiert war. $\triangleright$ Fritz Fichtner publizierte dennoch rege - er akquirierte Drittmittel über die Industrie, um seine Vorträge in den „Berichte[n] der Deutschen Keramischen Gesellschaft“ zu veröffentlichen

\footnotetext{
106 Siehe Verzeichnis der Ausstellungen 1933-1945, ab S. 235 sowie S. 217 ff.

107 Berichte über die Verwaltung ... o. J. (1940). Siehe DNN, 21.4.1940, S. 3.

108 Siehe jeweilige Biografie ab S. 253.
} 
und davon auch Sonderdrucke zu erhalten. ${ }^{109}$ Weitere Möglichkeiten zur Veröffentlichung kurzer Texte über Ausstellungen oder einzelne Objekte boten die lokalen Tageszeitungen. ${ }^{110}$

Viele der Forschungsprojekte und Publikationen der Mitarbeiterinnen und Mitarbeiter der Staatlichen Sammlungen wären ohne die finanzielle Unterstützung von Dritten nicht möglich gewesen. Der wichtigste Förderer war die Deutsche Forschungsgemeinschaft (DFG). Bereits 1931 hatte $\triangleright$ Fritz Fichtner einen Druckkostenzuschuss für die „Wandmalereien der Athos-Klöster" erhalten. ${ }^{111}$ 1933/1934 förderte die DFG gemeinsam mit der Stadt Dresden die archäologischen Ausgrabungen an der Heidenschanze in Dresden-Coschütz, die von - Walter Kersten und $\triangleright$ Otto Kleemann geleitet wurden. ${ }^{12}$ Für die Mitarbeit am „Katalog der sächsisch-polnischen Architekturzeichnungen“, den Eberhard Hempel an der Technischen Hochschule Dresden erstellte, erhielt $\triangleright$ Franz Schubert 1935 einen durch die DFG finanzierten Werkvertrag. ${ }^{113}$-Eberhard Rimann wurde ab 1935 mehrmals bei seiner Forschung unterstützt, zunächst bis 1937 für die „Systematische[n] Untersuchungen über die qualitative und quantitative Verbreitung wirtschaftlich wichtiger Schwermineralien in sächsischen Gesteinen“ und 1937/1938 für „Magnetometrische Messungen in der Lausitz“ zur Erkundung der Granitvorkommen. 1943 bewilligte ihm die DFG für „Versuche über Mineralsynthesen" Gelder vom Reichsforschungsrat, die er jedoch aufgrund seiner Erkrankung zurückgab. ${ }^{114} \triangleright$ Martin Heydrich beantragte mehrfach Druckkostenzuschüsse für den „Ethnologischen Anzeiger“, erhielt einen solchen aber erst 1943 und 1944. ${ }^{115}$ Ewald Jammers bewilligte die DFG 1936 eine Förderung der "Studien zur antiphonalen Musik“" ${ }^{116}$ •Erna von Watzdorf erhielt von 1937 bis 1939 Sachbeihilfen für ihre geplante Dinglinger-Monografie, die jedoch erst 1962 erschien. ${ }^{117} 1940$ zahlte die DFG an $>$ Kurt Zoege von Manteuffel einen

\footnotetext{
$109 \quad$ Siehe S. 132.

110 Siehe S. $173 \mathrm{f}$.

111 Vgl. BArch, R 73/16141. Fichtner, Fritz: Wandmalereien der Athos-Klöster. Grundsätzliches zu den Planungen der Bildfolgen des 14.-17. Jahrhunderts. Welt- und Lebensanschauung, Ritus, Architektur, Malerei, Berlin 1931.

112 Vgl. Jünger/Schachtmann 2010.

113 Vgl. Lebenslauf Schubert, 2.5.1935, HStA Dresden, 11125, Nr. 22889, fol. $4 \mathrm{f}$.

114 Vgl. BArch, R 73/13988.

115 Vgl. BArch, R 73/10300 und R 73/11675.

116 Vgl. BArch, R 73/11926. Jammers, Ewald: Der gregorianische Rhythmus, Leipzig 1937.

${ }_{117}$ Vgl. BArch, R 73/15519. Watzdorf, Erna von: Johann Melchior Dinglinger. Der Goldschmied des deutschen Barock, Berlin 1962.
} 
Zuschuss zur Veröffentlichung der Zeichnungen von Alfred Rethel. ${ }^{118}$ Nachdem - Hans Kummerlöwe für seine „Bibliographie der zoologischen Arbeiten über die Türkei und ihre Grenzgebiete" 1938 einen Druckkostenzuschuss erhalten hatte, wurde die Förderung der „Abhandlungen und Berichte der Staatlichen Museen für Tierkunde und Völkerkunde in Dresden“ 1939 abgelehnt. Jedoch bewilligte ihm die DFG 1940 eine Sachbeihilfe für „Anthropologische Erhebungen an polnischen Kriegsgefangenen“, die er von Wien aus beantragt hatte. ${ }^{19}$

Nicht zuletzt aufgrund der Vielzahl von Publikationen hielt Fichtner nach eineinhalb Jahren Krieg, im März 1941, in seinem Dienstaufsichtsbericht fest: „Es ist, trotz des Krieges und vieler ungünstiger Voraussetzungen, eine erstaunliche wissenschaftliche Regsamkeit in allen Museen festzustellen. "120 Doch durch den Krieg und die damit einhergehenden Einschränkungen kam das wissenschaftliche Arbeiten bald zum Erliegen. Die Notwendigkeit der Bergung der Objekte und deren konservatorische Überwachung an den Auslagerungsorten wirkten sich ebenfalls negativ aus. Darüber hinaus wurde im Nationalsozialismus durch die zunehmende Ideologisierung die geistige Freiheit immer stärker eingeschränkt. Schon im Sommer 1933 zeigten sich deutliche Auswirkungen, wie ein Schreiben, das Direktor Martin Bollert in der Sächsischen Landesbibliothek zur Kenntnisnahme in Umlauf gab, belegt:

Die verschiedenen Bestimmungen der letzten Zeit über die Ausleih-Sperre für staatsfeindliche Literatur werden im folgenden noch einmals [sic!] zusammengefasst. Staatsfeindliche d.h. kommunistisch-marxistische und antinationalsozialistische Literatur darf nur unter der Voraussetzung ausgeliehen werden, dass die Bibliothek nach besten Wissen und Gewissen Gewähr dafür übernehmen kann, dass die Druckschriften lediglich zu wissenschaftlichen Zwecken entliehen werden. [...] 1.) Die Benutzung zu wissenschaftlichen Zwecken kann als gewährleistet angesehen werden, wenn der Benutzer einem wissenschaftlichen (akademischen) Beruf angehört. Das Gleiche gilt für solche nichtakademische Benutzer, von denen der Bibliothek bekannt ist, dass sie sich wissenschaftlich beschäftigen. ${ }^{121}$

\footnotetext{
118 Vgl. BArch, R 73/16034. Vermutlich wegen des überraschenden Todes des Autors 1941 wurde nur ein Aufsatz publiziert: Zoege von Manteuffel, Kurt: Zur Geschichte der Karlsfresken Alfred Rethels im Aachener Rathaus, in: Zeitschrift des Aachener Geschichtsvereins, Bd. 61, 1940, S. 65-131.

119 Vgl. BArch, R 73/13352 und R 73/12517.

120 Fichtner, Bericht über Maßnahmen der Dienstaufsicht, 3.1941, SKD Archiv, 01/PS 53, Bd. 1, fol. 181.

121 Bollert, Umlauf Sächsische Landesbibliothek, 30.8.1933, SLUB, Bibl.Arch.III.J.859.b. Vgl. Hermann 2011, S. 302 f.
} 
Die betroffenen Werke wurden im Buch selbst und im Bibliothekskata$\log$ mit zwei blauen Kreuzen gekennzeichnet und im Magazin in einem besonderen Bereich, der mit Maschendrahtzaun abgesperrt war, aufgestellt. ${ }^{122}$

Trotz der zunehmenden Einschränkungen, versuchten die einzelnen Sammlungen so lange wie möglich, auch sammlungsfremden Personen das wissenschaftliche Arbeiten zu ermöglichen. Ein Beispiel dafür ist das Kupferstich-Kabinett. Nach seiner Schließung mit Kriegsbeginn bot es ab Februar 1941 an, dass Besuchern nach einer Vorbestellung die originalen Zeichnungen und Druckgrafiken im Studiensaal vorgelegt werden. Bis März 1942 nutzten 1518 Personen diese Möglichkeit und ließen sich 4554 Mappen vorlegen. ${ }^{123}$ Darüber berichtete, selbstverständlich anonym, die Zeitschrift „Die Sirene“:

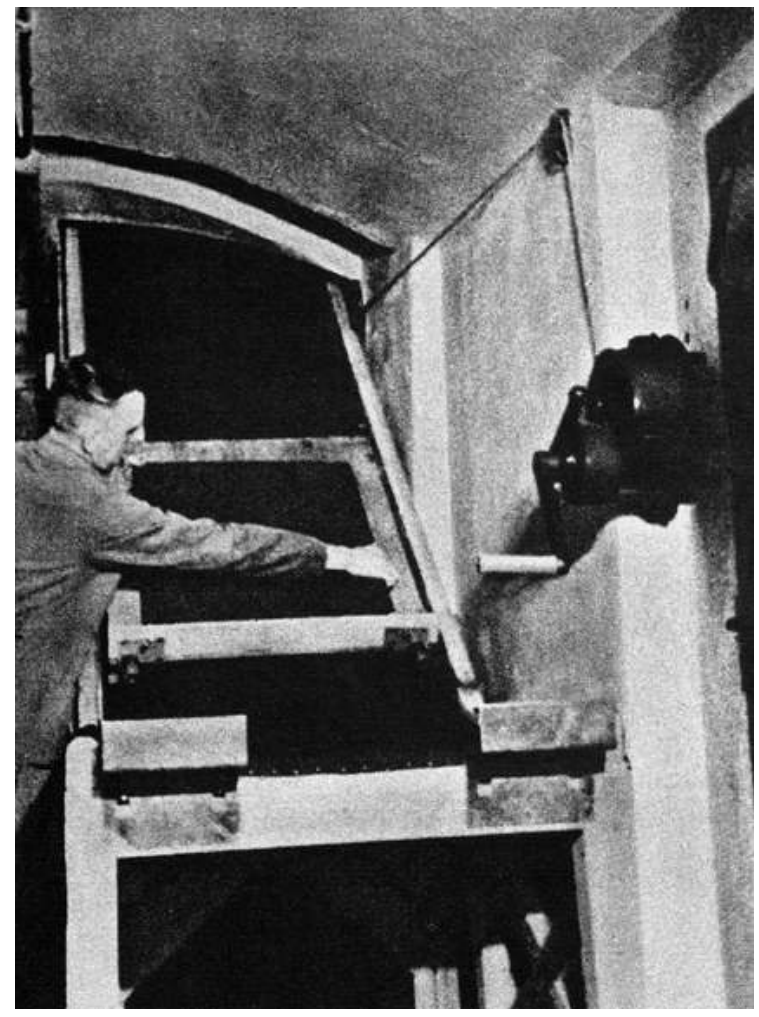

33 Einrichtung zum Mappentransport im Bergungsraum des Kupferstich-Kabinetts im Semperbau, März 1941

[...] alles ist in gewaltigen Mappen in einem bombensicheren Luftschutzraum untergebracht. [...] Vom Luftschutzraum geht nach oben in den Lesesaal eine schräge Bahn auf der die schweren Mappen leicht hinaufbefördert werden können. Wer sich also oben eine Mappe zur Einsicht bestellt, bekommt sie kurze Zeit später vorgelegt. ${ }^{124}$

Fichtner informierte das SMV im März 1941: „Damit ist das Dresdner Kupferstichkabinett, soweit ich in Erfahrung bringen konnte, die einzige graphische

\footnotetext{
122 Vgl. Hermann 2011, S. 303.

123 Vgl. Jahresbericht 1941/1942, HStA Dresden, 11125, Nr. 23053, fol. 79 f., hier: 80v.

124 A. G.: Kunst im Luftschutzraum. Luftschutz auch für die deutschen Kunstschätze, in: Die Sirene. Illustrierte Zeitschrift des Reichsluftschutzbundes, Nr. 13, Juni 1941, S. 291 ff., hier: 293.
} 
Sammlung Deutschlands, die auch während des Krieges der Öffentlichkeit uneingeschränkt zur Verfügung stand. “125

Auch nachdem die Bestände in Schloss Weesenstein ausgelagert worden waren, ging das Kupferstich-Kabinett außergewöhnliche Wege. Unter Beachtung der Benutzerordnung, die im Juni 1943 in Kraft trat, gewährte es in dringenden Einzelfällen für „die wissenschaftlichen Beamten und Angestellten anderer Museen“ sowie für "Wissenschaftler und Doktoranden zu Forschungszwecken“ am Auslagerungsort die „Einsichtnahme in die geborgenen Bestände “126. Der Antrag dafür musste schriftlich gestellt und eine Geheimhaltungserklärung unterschrieben werden.

Letztlich konnten diese einzelnen Bemühungen jedoch nicht darüber hinwegtäuschen, dass die Forschung wie auch Publikationen kaum mehr möglich waren. Im bereits erwähnten Beitrag „Museen im Krieg“ war daher 1944 über Dresden zu lesen: „Die wissenschaftliche Arbeit tritt gegenwärtig hinter die Anforderungen des Tages zurück. Für die Fortsetzung fachlicher Veröffentlichungen fehlt die Zeit und fehlen die erforderlichen Hilfsmittel.“"127

\section{Nationalsozialistischer Bildungsauftrag}

Während die Museumsbeamten der berühmten Museen in Europa, wie der National Gallery in London und des Musée du Louvre in Paris, mit Beginn des Zweiten Weltkrieges ihre öffentliche Arbeit bis auf wenige Ausnahmen komplett einstellten, keine Ausstellungen mehr zeigten und ihre Aufmerksamkeit ganz der Bergung der Kunstschätze ihrer Sammlungen widmeten, versuchten die Mitarbeiter der Staatlichen Sammlungen in Dresden, ähnlich wie jene der Staatlichen Museen zu Berlin, die Museumsaufgabe des Ausstellens und Vermittelns fortzuführen. ${ }^{128}$ Sie wollten dem Publikum wenigstens ein Minimum der Kunstschätze

\footnotetext{
125 Fichtner: Bericht über Maßnahmen zur Wahrnehmung der Dienstaufsicht, KupferstichKabinett, 31.3.1941, SKD Archiv 01/PS 53, Bd. 1, fol. 179 f., hier: 180. In München wurde der Studiensaal des Kupferstichkabinetts mindestens noch 1940 genutzt, für September 1942 wurde die Nicht-Nutzung gemeldet. Vgl. Semff 2008, S. 26.

126 Ordnung für die Benutzung der auswärtigen Bergungsbestände des Kupferstichkabinetts Dresden, 26.6.1943, SKD Archiv 01/KK 17, Bd. 1, fol. 188. Eine ähnliche Verfahrensweise konnte bisher für keine andere Sammlung nachgewiesen werden.

127 Museen im Krieg. Neue Aufgaben zu alten Zielen der Galerien, in: Das Reich, Nr. 27, 2.7.1944. Vgl. HStA Dresden, 11125, Nr. 22878, fol. 43. Siehe S. 158.

128 Vgl. Lupfer 2015; Bosman 2008; Musée du Louvre 2009; Colorado Castellary 2018, S. 25-61; Colorado Castellary, Arturo: Éxodo y exilio del arte. La odisea del Museo del Prado durante la Guerra Civil, Madrid 2008, S. 31-230 u. Grabowski/Winter 2013. Eine Ausnahme bildete London: In der National Gallery wurde für die Dauer des Krieges monatlich ein anderes
} 
präsentieren. Ihre Triebkraft bestand einerseits in der großen Sorge um die Sammlungen und in ihrer Leidenschaft für die Museums- und Bildungsarbeit, andererseits in ihrem Pflichtbewusstsein als Staatsbeamte, der Affinität zum NSStaat und in der Angst davor, doch noch zur Wehrmacht eingezogen zu werden.

Museen hatten im NS-Staat „dem Vaterland und der Nation zu dienen“"129 und „nationalsozialistische Erziehungsstätten “ 130 zu sein, wie auch $\triangleright$ Fritz Fichtner bereits im Oktober 1937 anlässlich der Wiedereröffnung des Museums für Tierkunde betonte. Wenige Tage zuvor hatte er den Sammlungsdirektoren in Dresden mitgeteilt, dass ,in Zukunft sowohl bei Zusammenstellung der Themen wie auch bei Durchführung der Vorträge als Parole deutlich in Erscheinung zu treten“ habe, dass Museen "Stätten der kulturellen Erziehung des deutschen Volkes"131 seien. Daran änderten auch all jene Maßnahmen nichts, die seit Anfang der 1930er-Jahre vorbereitet und während der „Sudetenkrise“ 1938 bzw. spätestens mit Beginn des Zweiten Weltkrieges 1939 ergriffen wurden, um die Kunstwerke der Staatlichen Sammlungen zu schützen. Parallel zur Bergung der Objekte wurde die Aufgabe des Vermittelns fortgeführt. Sie gewann sogar an Bedeutung, denn der Bildungsauftrag der Museen wurde - selbst nach Kriegsbeginn - allseits betont. So forderte Rust in dem schon erwähnten Erlass vom 8. Dezember 1939, Museen als „unentbehrliche Stätten völkischer Belehrung und Selbstbesinnung “ ,aktiv in die innere Front" ${ }^{132}$ einzugliedern. Damit war die Bedeutung der Fortführung der öffentlichkeitswirksamen Museumsarbeit festgeschrieben.

Auch die Sächsische Landesbibliothek sei „eine Schatzkammer, ein Arbeitsfeld und eine Erbauungsstätte für alle Volksgenossen“, ein „museum usui publico

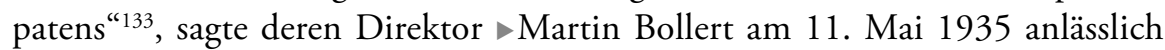
ihrer Einweihung nach dem Umbau, an die Worte der Inschrift im Giebelfeld des Portals des Japanischen Palais erinnernd.

\footnotetext{
Werk gezeigt, das eigens dafür aus dem Exil in Nordwales zurück nach London gebracht wurde. Vgl. Bosman 2008 und Lupfer 2015, S. 58.

${ }_{129}$ Tierkundemuseum in neuem Heim, in: DNN, 4.10.1937, S. 6.

130 Museen - nationalsozialistische Erziehungsstätten, in: DNN, 4.10.1937, S. 2.

131 SMV, Fichtner, an Direktoren der Staatlichen Sammlungen, 29.9.1937, SKD, MPS, 1937, E.-Reg. Nr. 265.

132 Erlass des Reichsministers für Wissenschaft, Erziehung und Volksbildung, 8.12.1939, übermittelt durch Leiter SMV an Direktoren der Staatlichen Sammlungen, 18.12.1939, SKD Archiv, 02/VA 50, fol. 101-103. Siehe S. 152.

133 Bollert, Rede, 11.5.1935, SLUB, Mscr.Dresd.App.1378.b,38. Die lateinische Inschrift Museum, dem öffentlichen Gebrauch geöffnet - war beim Umbau 1785/86 hinzugefügt worden.
} 
Den Staatlichen Sammlungen kam die Aufgabe zu, mit ihren Aktivitäten die nationalsozialistische Ideologie zu stützen und zu verbreiten. Schon Anfang Dezember 1934 hatte Göpfert betont:

Ich begrüsse den Vorschlag der Direktorenkonferenz der staatlichen Sammlungen, durch Veranstaltung regelmässiger Führungen die Volksgenossen noch mehr als bisher zum Besuche und zum Studium der Sammlungen anzuregen und zu gewinnen. ${ }^{134}$

\section{Öffnungszeiten und Eintrittsgelder}

Neben der Planung eines für Besucher interessanten Veranstaltungsprogrammes standen im Zentrum dieser Überlegungen auch die Öffnungszeiten sowie eine Neuregelung der Eintrittspreise. Die Öffnungszeiten der einzelnen Sammlungen waren relativ einheitlich gestaltet. Geöffnet waren sie meist an Sonntagen und Feiertagen von 10 bis $13 \mathrm{Uhr}$, wochentags - das heißt montags bis sonnabends von 9 bis 15 Uhr. Einige Sammlungen öffneten im Sommer bis 16 Uhr. Das Kupferstich-Kabinett hatte jedoch montags geschlossen, öffnete dafür freitags von 13 bis 18 Uhr. Für die Sächsische Landesbibliothek galten andere Öffnungszeiten, ab Oktober 1934 öffnete sie werktags von 9.30 bis 19 Uhr.

Anfang der 1930er-Jahre existierte in den Staatlichen Sammlungen in Dresden für die Erhebung von Eintrittsgeldern ein sehr kompliziertes System. Die naturwissenschaftlichen Museen, zu denen der Mathematisch-Physikalische Salon zählte, und das Münzkabinett konnten kostenfrei besichtigt werden. Das Historische Museum, die Skulpturensammlung, die Gemäldegalerie sowie das Kupferstich-Kabinett boten an unterschiedlich vielen Tagen freien Eintritt an, während in der Porzellansammlung und im Grünen Gewölbe immer bezahlt werden musste. Die erhobenen Eintrittsgelder waren unterschiedlich hoch, divergierten von Sammlung zu Sammlung und waren darüber hinaus je nach Wochentag verschieden. Die Preise schwankten zwischen 25 Rpf. bis 1,50 RM. Einige Sammlungen offerierten zusätzlich ermäßigte Gebühren. Dieses sehr unübersichtliche System sollte nach dem Vorbild der Staatlichen Museen in Berlin vereinheitlicht werden, weshalb das SMV im Dezember 1934 von den Dresdner Sammlungsdirektoren eine Stellungnahme einforderte. ${ }^{135}$

Im Februar 1935 informierte Oberregierungsrat Groß, er habe sich

134 SMV an Direktoren der Staatlichen Sammlungen, 21.12.1934, SKD Archiv, 01/SKS 171, o. Pag.

135 Vgl. SMV, Groß, an Direktor Skulpturensammlung, 7.12.1934, SKD Archiv, 01/SKS 171, o. Pag. 
nach Einvernehmen mit dem Herrn Finanzminister entschlossen, für den Besuch der Staatlichen Sammlungen neue Anordnungen zu treffen, und zwar im allgemeinen die gleichen Bestimmungen einzuführen, die jetzt für den Besuch der Staatlichen Museen in Berlin bestehen. ${ }^{136}$

Zum 1. März 1935 wurden die Eintrittspreise verändert. Sie betrugen, mit Ausnahme des Grünen Gewölbes, für dessen Besichtigung pro Person 50 Rpf. zu zahlen waren, für alle kunst-und kulturhistorischen Sammlungen 10 Rpf. Im Mathematisch-Physikalischen Salon musste nun auch Eintritt gezahlt werden, während der Besuch der anderen naturhistorischen Sammlungen weiterhin unentgeltlich möglich war. Arbeitslose konnten die Museen kostenlos besichtigen, Schulklassen wurden Ermäßigungen gewährt. Teilnehmer von Tagungen und Kongressen, die in Dresden stattfanden, durften die Sammlungen kostenfrei besichtigen, wenn es die Veranstalter zuvor beantragt hatten, wie im März 1937 während der Reichskulturtagung der NSDAP. ${ }^{137}$ Freier Eintritt in alle Sammlungen wurde ebenfalls - bereits seit November 1934 - den Mitgliedern der Reichskammer der Bildenden Künste gewährt. Über die neuen Eintrittspreise der „Museen als Volksbildungsinstitute "138 informierte die Presse sofort und erwähnte, dass damit die Besucherordnung aus Berlin in Dresden eingeführt worden sei.

\section{Besucherzahlen}

Doch schon bald nach der Einführung der neuen Eintrittspreise, die den Wegfall der Tage mit entgeltfreiem Eintritt in den kunst- und kulturhistorischen Sammlungen bedeutete, beklagten die Sammlungsdirektoren einen Rückgang der Besucherzahlen. Im Mathematisch-Physikalischen Salon sank die Besucherzahl von rund $30.000 \mathrm{im}$ Geschäftsjahr 1934, als der Eintritt noch unentgeltlich möglich war, auf nur noch 8570 Besucher 1935, d.h. sie reduzierte sich um mehr als $70 \% .{ }^{139}$ Ähnlich dramatisch verringerten sich die Besucherzahlen im Münzkabinett, von 13.819 auf nur noch 3299. Generell gingen die Besucherzahlen in den meisten Sammlungen nach der Vereinheitlichung der Eintrittsgelder zunächst zurück, meist um 30 bis $40 \%$.

136 SMV, Groß, an Direktoren der Staatlichen Sammlungen, 27.2.1935, ebd., o. Pag., ebenso in: SKD, MPS, 1935, E.-Reg. Nr. 50.

${ }_{137}$ Vgl. entsprechende Mitteilungen in Dresdner Anzeiger, 7.11.1934, S. 2 u. DNa, Abendausgabe, 8.11.1934, S. 3. Vgl. SKD, MPS, 1937, E.-Reg. Nr. 92.

138 Die Museen als Volksbildungsinstitute. Nur 10 Pfennig Eintrittsgeld in Staatlichen Sammlungen, in: $\mathrm{DNa}$, 1.3.1935, S. 6.

139 Vgl. Jahresbericht 1935, SKD, MPS, 1936, A.-Reg. Nr. 177a. 
Lediglich am Grünen Gewölbe war das öffentliche Interesse weiterhin ungebrochen. Dort stiegen die Besucherzahlen, die in den Vorjahren zurückgegangen waren, sogar von 58.449 Besuchern 1934 nach der Einführung der neuen Preise auf 87.736 im Jahr 1935 an, d. h. um $50 \% .1936$ erreichten sie mit 120.885 Besuchern ihren Höchststand. ${ }^{140}$ Ein Grund dafür war, dass das Grüne Gewölbe die einzige Sammlung war, in der sich mit nun 50 Rpf. die Eintrittspreise erheblich reduziert hatten, denn vorher war dort an einzelnen Tagen das Dreifache zu bezahlen.

Da die Besucherzahlen nicht lückenlos überliefert wurden, sind über deren Entwicklung nur allgemeine Aussagen möglich. So wurden z. B. die zahlreichen Besuche von Schulklassen nur selten einzeln aufgelistet, wie im Museum für Tierkunde und in der Skulpturensammlung. Hatten Schulklassen 1938 einen Anteil an der Gesamtzahl von 61.891 Besuchern im Museum für Tierkunde von 7 \%, so war 1939 etwa jeder fünfte Besucher ein Schulkind, in den Folgejahren wieder nur etwa jeder zehnte. In der Skulpturensammlung lag der Anteil an Schülern 1935 bei knapp 17 \%, sank im Jahr des Kriegsbeginns bei einer Gesamtbesucheranzahl von 9855 auf knapp $14 \%$, um im Folgejahr wieder anzusteigen. Die wenigen überlieferten Zahlen belegen jedoch, dass im Geschäftsjahr 1939 - d. h. von April 1939 bis März 1940 - die Besucherzahlen stark zurückgingen. Dies lag vor allem an der kriegsbedingten Schließung der Sammlungen von Ende August bis zum Jahresende 1939. 1940, d. h. nach der erneuten Öffnung der meisten Sammlungen, stiegen die Besucherzahlen wieder an. 1943, im vierten Kriegsjahr, als nur noch drei Museen geöffnet waren, kamen ins Museum für Tierkunde 28.336, ins Museum für Mineralogie und Geologie 44.718 und ins Landesmuseum für Vorgeschichte 81.666 Besucher. ${ }^{141}$

\section{Pressearbeit}

Die Frage nach den Ursachen für die hohen Besucherzahlen lässt zwangsweise die Bemühungen der Staatlichen Sammlungen, mehr Besucher anzulocken, in den Fokus rücken. Allein die kulturpolitische Forderung, „nationalsozialistische Erziehungsstätten" zu sein, und der Wille der Beamten, volksbildend tätig zu werden, waren dafür sicherlich nicht ausreichend. Wie also waren die Sammlungen in der Öffentlichkeit präsent? Wie haben sie für ihre Ausstellungen und das

140 Vgl. Jahresberichte der Staatlichen Sammlungen, HStA Dresden, 11125, Nr. 19003 u. Nr. 23053 sowie 13842, Nr. 115 u. SKD Archiv, 01/SKS 173 u. 01/SKS 174.

141 Vgl. ebd. 
reichhaltige Veranstaltungsangebot geworben? Welche Art der „Propaganda“ wie man Werbung damals nannte - wurde genutzt?

Wie bereits vor 1933 waren alle Staatlichen Sammlungen in Dresden auch während des Nationalsozialismus in den Adressbüchern der Stadt verzeichnet. ${ }^{142}$ Sie wurden jeweils kurz mit ihren Beständen vorgestellt unter namentlicher Erwähnung ihrer Beamten und Auflistung der Öffnungszeiten und Eintrittsgelder.

Ein wichtiger Partner für die Bewerbung der Staatlichen Sammlungen und ihrer Aktivitäten - wie Ausstellungen, Führungen und Vorträge - waren die lokalen Tageszeitungen, wie „Dresdner Anzeiger“, „Dresdner Nachrichten“, „Dresdner Neueste Nachrichten“ und „Der Freiheitskampf“. In der Regel erschienen in der Presse regelmäßig kurze Hinweise auf die unterschiedlichen Veranstaltungen der Sammlungen. Mitunter wurden auch ausführliche Rezensionen veröffentlicht und ab 1935/1936 mehrten sich Ausstellungsbesprechungen. Die Staatlichen Sammlungen hatten mit einer gezielten Pressearbeit begonnen, nachdem der Kommissarische Leiter des SMV angekündigt hatte,

die Aufmerksamkeit der deutschen Presse besonders aber auch der führenden ausländischen Tageszeitschriften mehr als bisher auf die Dresdner Staatlichen Sammlungen zu lenken. Darin sehe ich ein besonders wirksames Werbemittel nicht nur für den Besuch der Sammlungen selbst, sondern auch für die Fremdenstadt Dresden und für Sachsen überhaupt. ${ }^{143}$

Neben Journalisten und freien Mitarbeitern der Zeitungen betätigten sich auch die Sammlungsmitarbeiterinnen und -mitarbeiter als Autoren, wie $\triangleright$ Fritz Fichtner, $\triangleright$ Erich Haenel, ^Walter Holzhausen, $\triangleright$ Walther Fischer, $\triangleright$ Charlotte Boden und $\triangleright$ Erhart Kästner. 1938 forderte Göpfert, „daß von jedem Direktor und Kustos, aber auch jeder anderen wissenschaftlichen Kraft bei den Sammlungen mindestens ein Artikel zur Propaganda für die Museums-Woche beigesteuert wird "144.

Auch über die Ausstellungs- und Umbaupläne sowie über die Veränderungen in den Schausammlungen wurde geschrieben. Eine besondere Pressekampagne begleitete den Umzug des Museums für Tierkunde und der Porzellansammlung. Sie begann 1935 mit der Ankündigung der Umzugspläne, berichtete später über Baufortschritte und sollte mit der Vorstellung von Sammlungsobjekten die Neugier der Leser wecken, zum Beispiel mit Artikeln über die Präsentation des von

142 Vgl. Adressbuch für Dresden und Vororte, Bde. 1933-1945, Dresden, Online-Ausgabe: http://adressbuecher.sachsendigital.de/startseite/, Zugriff: 6.12.2019.

143 Leiter SMV an Porzellansammlung, Fichtner, 25.6.1935, SKD Archiv, 01/PS 38, fol. 101; ebenso in: HStA Dresden, 11127, Nr. 41, fol. 323.

144 Leiter SMV an Direktoren der Staatlichen Sammlungen, 27.5.1938, SKD, MPS, E.-Reg. Nr. 149. 
> Robert Reichert präparierten Milu-Hirsches. ${ }^{145}$ Zahlreich waren die Berichte über die Eröffnung des Museums für Tierkunde am neuen Standort. Die Kampagne setzte sich fort mit Beiträgen zur Porzellansammlung. ${ }^{146}$

In den Kunstzeitschriften wurde in der NS-Zeit eher selten und nur kurz über die Dresdner Museen und ihre Ausstellungen berichtet, etwa in „Pantheon“ 1933 über „August der Starke und seine Zeit“, 1934 über „Sächsische Landschaft“, 1935 über die „polnische Ausstellung" und 1937 über die „Erwerbungen im Historischen Museum “. ${ }^{147}$ Allerdings bedienten manche Mitarbeiter auch Fachzeitungen mit Beiträgen über Ausstellungen und Objekte aus den Sammlungen, wie >Alfred Beck die „Uhrmacher Woche“ und „Uhrmacherkunst“.

\section{Plakate, Einladungskarten und Veranstaltungspläne}

Plakate wurden vor allem für die Bewerbung der sonntäglichen Museumsvorträge gedruckt, für Ausstellungen hingegen seltener, zumindest lassen dass die wenigen überlieferten Plakate vermuten. Eine Ausnahme bildet das Plakat zum „Dresdner Jubiläumssommer 1933“, das neben der Ausstellung „August der Starke und seine Zeit“ im Residenzschloss auch die Schau „Richard-Wagner Jahr der Staatsoper“ im Rathaus und die „Kunstausstellung Sachsen 1933“ im Städtischen Ausstellungspalast ankündigte. Umso erstaunlicher ist es, dass für die Ausstellung „Kostbarkeiten des Grünen Gewölbes im Lichtbild“ 1943 ein kleinformatiges Plakat im Zweifarbdruck in einer Auflage von 125 Exemplaren entstand, wovon 25 in Schulen ausgehängt werden sollten. ${ }^{148}$ Für die Sonntagsvorträge wurden Plakate bisweilen sogar im Dreifarbdruck angefertigt.

145 Erste Artikel zu Umzugsplänen der Porzellansammlung: DNa, 10.2.1935, S. 9; 17.8.1935, S. 3. Erste Erwähnung des Umzug des Museums für Tierkunde: DNa, 7.11.1936, S. 7; DA, 14.11.1936, S. 5. Artikel zur Präsentation des Milu-Hirsches in: DA, 9.2.1937, S. 2; DNa, 9.2.1937, S. 5; FK, 9.2.1937, S. 6. Vgl. auch Museen für Tierkunde und Völkerkunde, Kummerlöwe, an Mathematisch-Physikalischer Salon, Werkmeister, 2.2.1937, SKD, MPS, E.-Reg. Nr. 38. Siehe S. $186 \mathrm{f}$.

146 Vgl. DA, 15.12.1938, S. 5; FK, 18.12.1938, S. 5; DNN, 15.3.1939, S. 7; DNa, 11.7.1939, Morgenausgabe, S. 5.

${ }_{147}$ Vgl. Pantheon, 11.1933, S. 197; 14.1934, S. 224; 4.1935, S. 145; 20.1937, S. 257 . Zu den Ausstellungen siehe S. 191-196.

148 Vgl. HStA Dresden, 11125, Nr. 23087, fol. Geplant war ursprünglich der Druck von 200 Exemplaren, von denen die Hälfte für 7 Tage an Litfaßsäulen geklebt werden sollten. Zur Ausstellung siehe S. 214-217. 


\section{Muleumsvorteng 1943/44}

34 Plakat für den Museumsvortrag von Hermann Voss über Lorenzo Bernini am 12.12.1943
Sonntag, Den 12. Dezember 1943, 10.30 uhr im Spiegel|jaal Der 5taatlichen Dorzellangalerie (Jwinger)

\section{[orenjo Bernini} Der Meifter des römifchen Barock

prof. Dr. fiermann Doss

mit ridhtbilioen

Einteitt feei

Eingang: porjellangalerie [jwinger), gegenüber Der Sophienkitde

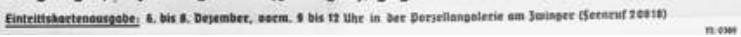

35 Plakat der Ausstellung „Kostbarkeiten des Grünen Gewölbes im Lichtbild“, September 1943
Staafliche Sammlungen für Kunst und Wissenschaft

\section{Ausstellung}

im Grünen Gewölbe zu Dresden (Eingang Schlolzhof) Laswartititen des Grïnen Gewölibes im Lichthild Aus musealer Kulfurarbeit

Phofos von Edm. Kesting, Dresden

Geallset. Wedklags von 10-16 Uhr, sonnlags von 10-13 Uhe , Einiritt: Erwachsene 0.25 RM, Kinder 0.10 RM Welumadi 0.10 RM, Kriegibeschadigle frei

$\mathrm{Zu}$ Ausstellungseröffnungen wurde meist mit zweifarbig gedruckten Postkarten eingeladen, die in der Regel nicht bebildert waren. Selbst für die Sonntagsvorträge wurden noch bis Frühjahr 1944 Einladungskarten gedruckt.

Für die Museumswochen, die ab 1937 stattfanden, druckte man in der Sächsischen Landesbibliothek einfache Faltblätter mit dem Programm der Sonderausstellungen und Veranstaltungen, die auch von dort aus verteilt wurden. Für 1938 ist überliefert, dass die einzelnen Sammlungen 50 Faltblätter erhielten, 200 gingen an den Verkehrsverein, 200 an die NS-Organisation „Kraft durch 


\section{Dresoen}

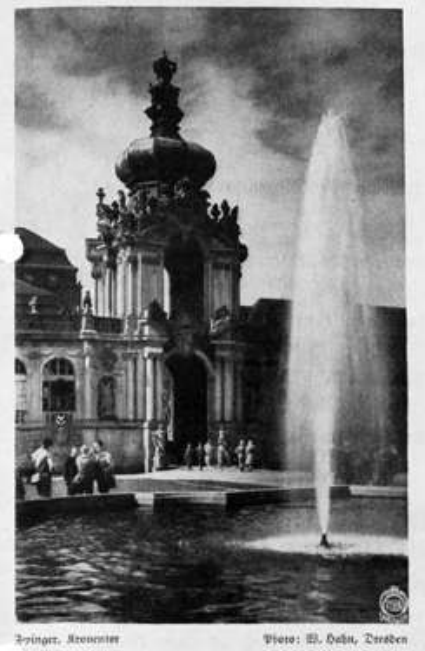

\section{führungen}

in Den Staatlichen Sammlungen für funft uno Wiffenfchaft

in Oen monaten April bis Septem ber 1938

ferauegegeben oom Verhehreamt Der Staot Dreoen unD Dreobuer Nerkehroverein

36 Faltblatt „Führungen in den Staatlichen Sammlungen für Kunst und Wissenschaft", April bis September 1938
Freude" $(\mathrm{KdF})$, weitere Exemplare wurden an die DAF, an Betriebe und Schulen verteilt. ${ }^{149}$

Mitte der 1930er-Jahre wurden für die Staatlichen Sammlungen halbjährlich eigene Veranstaltungspläne als werbewirksame Faltblätter mit dem Foto eines Museumsgebäudes auf der Vorderseite gedruckt, herausgegeben vom Verkehrsamt der Stadt Dresden und dem Dresdner Verkehrsverein. In den Kriegsjahren, ab Oktober 1940, wurden diese Veranstaltungsprogramme allerdings nur noch als mit der Schreibmaschine geschriebene Listen mittels Durchschlägen vervielfältigt und an den Kassen der Museen ausgelegt. ${ }^{150}$ Darüber hinaus druckte das Verkehrsamt der Stadt ein Faltblatt „Dresden und seine Museen und Sammlungen", für das die Sammlungsdirektoren Textbeiträge und Fotos lieferten. Über die von $\triangleright$ Kurt Zoege von Manteuffel koordinierte Zusammenarbeit mit dem Verkehrsamt war zuvor in den Direktorenkonferenzen im November 1934 und April 1935 beraten worden. ${ }^{151}$ Auch für die Broschüre „Das ist Dresden“, die um 1942 von der Stadt produziert wurde, waren mit $\triangleright$ Alfred Beck, Walther Fischer, - Walter Holzhausen und $>$ Franz Schubert Sammlungsmitarbeiter als Autoren tätig.

Dazu kamen selbstverständlich Publikationen über die Staatlichen Sammlungen, die von Mitarbeitern verfasst wurden, wie z. B. der Bibliotheksführer von 1925 und der „Führer durch die Staatlichen Sammlungen" von 1932, die in der NS-Zeit Folgeauflagen erfuhren. ${ }^{152}$

\footnotetext{
149 Vgl. Sächsische Landesbibliothek, Neubert, an Direktor Mathematisch-Physikalischer Salon, 22.7.1938, SKD, MPS, 1938, E.-Reg. 198. Zu den Museumswochen siehe S. 198-203. 150 Vgl. SMV, Fichtner, an Leiter SMV; 16.10.1940, SKD Archiv, 01/PS 44, Bd. 2, fol. 202. 151 Vgl. Kupferstich-Kabinett, Zoege von Manteuffel, an Fichtner, SMV, 13.11.1934, ebd., fol. 5; Jacobi an Direktoren der Staatlichen Sammlungen, 6.4.1935, HStA Dresden, 11127, Nr. 28, fol. 402. Faltblatt vgl. SKD Archiv, 01/PS 44, Bd. 2, fol. 209 ff.

152 Assmann, Karl: Führer für die Benutzer der Sächsischen Landesbibliothek, 1925; Ministerium für Volksbildung zu Dresden (Hg.): Führer durch die Staatlichen Sammlungen zu Dresden, Dresden 1932.
} 


\section{Rundfunk und Film}

Auch die damals „neuen Medien“, wie Rundfunk und Film, wurden zur Werbung für die Staatlichen Sammlungen eingesetzt. Zumindest nutzte man die sich bietenden Gelegenheiten, um bei Radiosendungen und mit bewegten Bildern über die Staatlichen Sammlungen und ihre Kunstschätze zu berichten.

Nachdem unter anderem Direktor $>$ Martin Bollert im November 1926 im Rundfunk einen Vortrag über die Sächsische Landesbibliothek gehalten hatte, wurde 1934 und 1935 eine Folge von elf Sendungen mit Vorträgen von $\triangleright$ Erich Haenel und $\triangleright$ Erna von Watzdorf zu Themen aus dem Grünen Gewölbe und Historischen Museum ausgestrahlt. Im November 1936 sprach $~$ Walter Schwinkowski im Radio über Münzsammlungen und Münzforschung. ${ }^{153}$ Partner hierbei war die Sendestelle Dresden des Reichssenders Leipzig, ehemals Mitteldeutsche Rundfunk AG. Diese übertrug auch im Mai 1935 die Einweihungsfeier der Sächsischen Landesbibliothek und sendete die Reihe „Dresdner Bilderbogen“, die über spezifische Dresdner Themen berichtete und spätestens ab November 1937 einzelne Sendungen in Zusammenarbeit mit den Staatlichen Sammlungen produzierte. Diese stellten u. a. die Gemäldegalerie, das Grüne Gewölbe, die Porzellansammlung und die Sächsische Landesbibliothek in den Mittelpunkt. ${ }^{154}$

Als Werbemittel für die Sammlungen wurde auch der Film genutzt. Mehrfach gab es Kontakt zwischen den Staatlichen Sammlungen und der Produktionsgesellschaft Boehner-Film von Fritz Boehner aus Dresden, die primär Werbe- und Kulturfilme produzierte. ${ }^{155}$ Im Oktober 1933 dokumentierte die Boehner-Film die archäologischen Grabungsarbeiten an der Heidenschanze in Dresden-Coschütz, die von $~$ Walter Kersten geleitet wurden, in dem etwa 4-minütigen Stummfilm „Eine 3000 Jahre alte Stadt“. 156

153 Vgl. SLUB, Mscr.Dresd.App.1378.b, fol. 11; HStA Dresden, 11125, Nr. 19003, fol. 213 u. SKD, MK, 1935/1936, fol. 44.

${ }_{154}$ Vgl. DNa, 11.5.1935, S. 5 u. 10.7.1939, S. 2; DA, 24.11.1937 u. 10.11.1938, S. 7 u. 10.7.1939,S. 3; DNN, 23.8.1938, S. 3 u. SKD Archiv, 01/PS 45, Bd. 2, o. Pag.

155 Bisher konnten keine eindeutigen Hinweise gefunden werden, ob die Zusammenarbeit von Boehner-Film oder den Staatlichen Sammlungen ausging. Unklar bleibt ebenso, ob andere Firmen in der NS-Zeit Filme über oder für die Staatlichen Sammlungen produzierten. Bisher deutet Vieles darauf hin, dass das Medium Film nicht in dem Umfang wie beispielsweise in den Staatlichen Museen zu Berlin genutzt wurde. Vgl. Eckardt, André: Im Dienst der Werbung. Die Boehner-Film 1926-1967, Berlin 2004; Savoy, Bénédicte: „Vom Faustkeil zur Handgranate“ Filmpropaganda für die Berliner Museen 1934-1939, Köln/Weimar/Wien 2014. Trotz erster Erkenntnisse bleibt dieses Kapitel der Dresdner Museumsgeschichte vorerst ein Desiderat.

156 „Eine 3000 Jahre alte Stadt“, 1933, s/w, Produktionsfirma: Boehner-Film (Dresden), Produzent: Fritz Boehner, ca. 4 min. Vgl. Jünger/Schachtmann 2010 S. 29 ff. In Eckardt 2014 nicht erwähnt. 

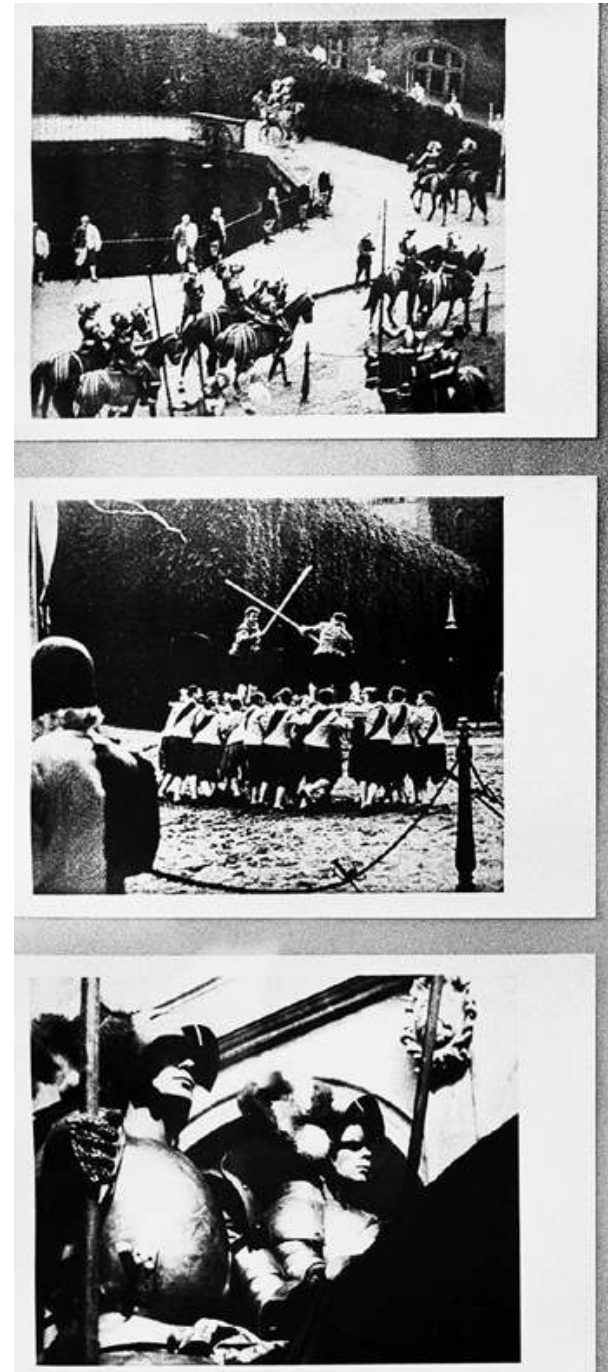
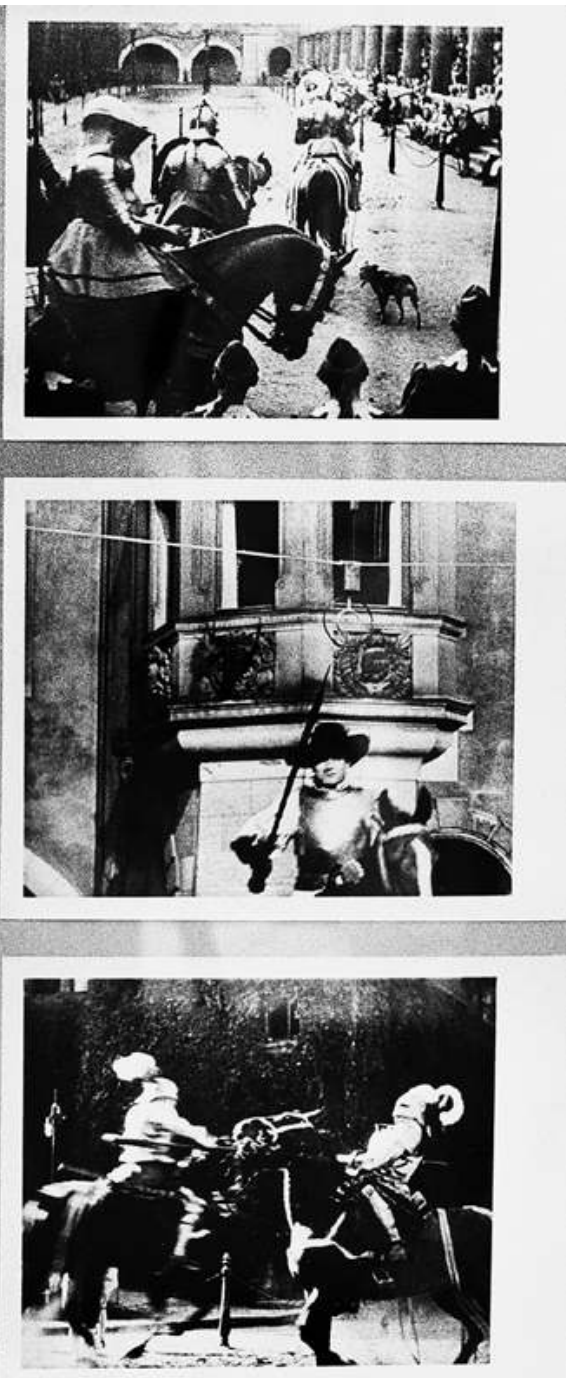

37 Szenen aus dem Dokumentarfilm „Mit Federbusch und Harnisch“, 1937

Während des Jubiläumssommers 1933 mit der Ausstellung „August der Starke und seine Zeit“ wurde ein Film „von den herrlichen Schätzen des Grünen Gewölbes" ${ }^{\text {157 }}$ gezeigt.

157 Museumsbesuch wie noch nie. Der Kulturfilm erschließt Schätze der bildenden Kunst, in: FK, 19.9.1935, S. 2. Bisher konnten keine weiteren Angaben zu diesem Film gefunden werden. 
Im Rahmen der Turnierspiele, die von Juni bis September 1937 im Stallhof veranstaltet wurden, entstand, ebenfalls durch Boehner-Film, der Film „Mit Federbusch und Harnisch“, für den $\triangleright$ Erich Haenel wissenschaftlich beratend tätig war. Dieser Film wurde in Ausschnitten in „FOX Tönerne Wochenschau“ und in der "Ufa-Tonwoche“ in den Kinos gezeigt, bevor er Ende September 1937 vor den Mitwirkenden der Turnierspiele erstmals komplett vorgeführt wurde. ${ }^{158}$

In dem 1938 von der Boehner-Film produzierten Film „2000 Jahre Sachsen“ wurden Brakteaten aus dem Bestand des Münzkabinetts vor historischen Landkarten gezeigt. ${ }^{159}$

Im Mai 1939 wollte Boehner in einem von der Stadtverwaltung beauftragten Film über Dresdens Schönheiten und Sammlungen die Porzellansammlung porträtieren, wurde aber darüber informiert, dass diese noch nicht fertiggestellt sei. ${ }^{160}$

Das wichtigste Element bezüglich der Werbung für die Staatlichen Sammlungen waren jedoch die Museen und die Sächsische Landesbibliothek selbst, mit ihren vielfältigen Ausstellungen und Veranstaltungen. Stets versuchten sie, in der Präsentation der Schausammlungen modern zu sein und passten diese - meist schrittweise - an neueste Trends an.

\section{Veränderungspläne und Denkschriften}

Ehrgeizige Pläne für Veränderungen der Sammlungspräsentationen existierten seit Langem. Museumsdirektoren und Kustoden reichten zwischen 1933 und 1945 eine Vielzahl von sogenannten Denkschriften ein, die meist strategische Schreiben waren. Viele thematisierten die räumliche Situation der jeweiligen Sammlung und unterbreiteten Verbesserungsvorschläge. Einige der Autoren be-

158 „Mit Federbusch und Harnisch“, 1937, Kurzdokumentarfilm, s/w, Regie/Kamera/Schnitt: Richard Groschopp, Produktionsfirma: Boehner-Film (Dresden), Produzent: Fritz Boehner, Länge: $357 \mathrm{~m}, 13 \mathrm{~min}$, Format: $35 \mathrm{~mm}, 1: 1.33$. Vgl. www.filmportal.de/film/mit-federbuschund-harnisch_6e30541153c844538eddb1a26e0b94bb, Zugriff: 6.12.2019. Für den Hinweis auf diesen Film dankt die Autorin Fine Kugler. Vgl. DNN, 27.9.1937, S. 5; Dresdner Anzeiger, 27.9.1937, S. 6. Vgl. Eckardt 2014, S. 80, 125. 1938 fertigte Boehner-Film einen 14-minütigen Lehrfilm für Schulen „Anlegen eines Harnischs - deutsches Turnier“, ebenfalls beraten durch Erich Haenel, die Filmaufnahmen waren im September 1937 entstanden. Vgl. ebd., S. 79 f., 127. Siehe S. $192 \mathrm{f}$.

159 „2000 Jahre Sachsen“, 1938, Kurzdokumentarfilm, s/w, Produktionsfirma: Boehner-Film (Dresden), Produzent: Fritz Boehner, Länge: $582 \mathrm{~m}, 21 \mathrm{~min}$, Format: $35 \mathrm{~mm}$, 1:1,33. Siehe www.filmportal.de/film/2000-jahre-sachsen_4e221d62d57940cdbe23845ddc2d7a50, Zugriff: 6.12.2019. Vgl. Sbardella 2019, S. 52 f. In Eckardt 2014 nicht erwähnt.

160 Vgl. SKD Archiv, 01/PS 42, Bd. 1, fol. 33 f. 
zogen Stellung zur Personalsituation und intendierten damit die Stärkung oder Verbesserung ihrer eigenen Position. Längst nicht alle Vorschläge wurden umgesetzt - eine Auswahl sei hier dennoch vorgestellt.

Bereits in den 1920er-Jahren strebte $>$ Arnold Jacobi, nachdem er die Umbenennung der von ihm betreuten Sammlungen in Museen für Tierkunde und Völkerkunde durchgesetzt hatte, die Trennung in zwei selbständige Museen an. Zumindest die räumliche Trennung des Museums für Tierkunde unter $\gg$ Hans Kummerlöwe 1937 schien die Realisierung seiner Pläne näher rücken zu lassen. ${ }^{161}$

Im Januar 1940, als die Pensionierung von Direktor $\triangleright$ Erich Haenel bevorstand, reichte $~$ Walter Holzhausen eine „Denkschrift zur weiteren Führung des Historischen Museums und des Grünen Gewölbes“ ein. Darin hielt er abschließend fest:

Ich würde es als Abrundung meines seit anderthalb Jahrzehnten begonnen Lebenswerkes in den Dresdner Museen ansehen, die Führung des Historischen Museums und des Grünen Gewölbes zu übernehmen. Als Parteigenosse und langgedienter SA-Mann ist es mir eine Selbstverständlichkeit, sie im Sinne des Führers auszurichten. ${ }^{162}$

Direktor wurde er jedoch nicht. ${ }^{163}$

In seiner Denkschrift „Über die Zukunft des Johanneums“ schlug $>$ Erich Haenel im August 1940 vor, die nach dem Auszug der Porzellansammlung leeren Räume im zweiten Obergeschoss dem Heeresmuseum zur Präsentation der sächsischen Militärgeschichte des 18. und 19. Jahrhunderts zu überlassen, da diese eine inhaltliche Einheit mit den Beständen des Historischen Museums bildeten. Doch Fichtner merkte handschriftlich an, dass diese Räume vorerst als Magazin für das Museum für Völkerkunde genutzt würden, das zukünftig einen Neubau benötige, weshalb man über diese Pläne sprechen könne. ${ }^{164}$ Allerdings wurden sie später nie umgesetzt.

Eine der umfangreichsten und inhaltlich weitgreifenden Denkschriften verfasste •Fritz Fichtner im Mai 1937 und überarbeitete sie 1941. Seine strategischen Überlegungen mit dem programmatischen Titel „Den Staatlichen Sammlungen Dresdens muß geholfen werden!“ umfassten 40 Seiten. ${ }^{165}$ Die ,unerträgliche Raumnot"

161 Siehe S. $186 \mathrm{f}$.

162 Holzhausen an SMV, Dedering, 11.1.1941, HStA Dresden, 11125, Nr. 22882, fol. 84-89, hier: 89. Zur Vakanz dieser Direktorenstelle siehe S. $82 \mathrm{ff}$.

163 Siehe S. 84.

164 Vgl. HStA Dresden, 11125, Nr. 22883, fol. 12-16.

165 Fichtner: Den Staatlichen Sammlungen Dresdens muß geholfen werden!, 1937/1941, SKD Archiv, 01/PS 43, Bd. 4. 
und den „katastrophale[n] Personalmangel“166 beklagend, schilderte Fichtner frühere Museumspläne, wie z. B. die unter $\triangleright$ Ernst Zimmermann gereifte Idee der Verlegung der Porzellansammlung in den Zwinger sowie den Wunsch eines Neubaus für die naturkundlichen Sammlungen von 1927. Ausführlich begründete er

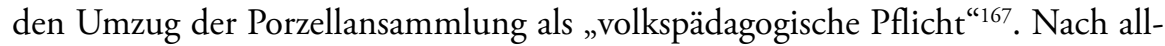
gemeinen Gedanken zum Museumswesen regte er für die Zeit nach dem Krieg den Ausbau einer „Museumsinsel“ ${ }^{“ 68}$ mit Zwinger, Oper und Schloss sowie eines „Museumsgürtels" mit Neubauten für die einzelnen naturkundlichen Museen an. Darüber hinaus forderte er die Schaffung von zusätzlichen Stellen: sechs Direktoren, sieben Kustoden, dreizehn Wissenschaftliche Hilfsarbeiter und fünf Konservatoren bzw. Präparatoren. Doch Fichtners Pläne wurden größtenteils nicht realisiert, selbst die mittlerweile in den Zwinger übergesiedelte Porzellansammlung wurde kriegsbedingt nicht für das Publikum geöffnet. ${ }^{169}$

Neugestaltung des Museums für Mineralogie und Geologie sowie Ausgliederung des Landesmuseums für Vorgeschichte

Im Museum für Mineralogie, Geologie und Vorgeschichte, das im Zwinger räumlich sehr beengt untergebracht war, mühte sich Kustos $\triangleright$ Karl Wanderer bereits ab 1927 um eine Neuaufstellung der Schausammlung. ${ }^{170}$ Dabei widmete er jeder der dargestellten erdgeschichtlichen Formationen - Diluvium, Tertiär, Kreide und Jura - eine in sich geschlossene Abteilung und schuf für die populärwissenschaftlichen Erklärungen neue Schautafeln mit Skizzen und erläuternden Texten. Durch diese Umgestaltung, die bis 1937 fortdauerte, und die in der Presse erfolgende Berichterstattung, wuchs das Publikumsinteresse am Museum.

Parallel dazu hatte $>$ Walther Fischer mit der Umgruppierung der bisherigen Mineralien-Schausammlung nach modernen, chemischen Grundsätzen begonnen. Im April 1930 wurde die von ihm kuratierte neue Schausammlung mit

\footnotetext{
166 Ebd. S. 2a.

167 Ebd. S. 16.

168 Womit er zweifelsohne auf die Berliner Museumsinsel anspielte.

169 Siehe S. $187 \mathrm{f}$.

170 Vgl. Kühne, Ellen, Jan-Michael Lange u. Daniela Erler: Die Geschichte des Museums für Mineralogie und Geologie in Dresden, in: Lange/Kühne 2006, S. 13-95, hier: 47-53 sowie Häntzschel, Walter: Zum Gedenken an Karl Wanderer (1876-1945), in: Jahrbuch des Staatlichen Museums für Mineralogie und Geologie zu Dresden, 1956/57, S. 6-14, hier: 10. Häntzschels Behauptung, das Museum sei „nach der Gemäldegalerie stets die meistbesuchte staatliche Sammlung" gewesen, ist allerdings falsch. Das Grüne Gewölbe hatte höhere Besucherzahlen. Siehe Jahresberichte der Staatlichen Sammlungen, wie S. 172, Anm. 140.
} 


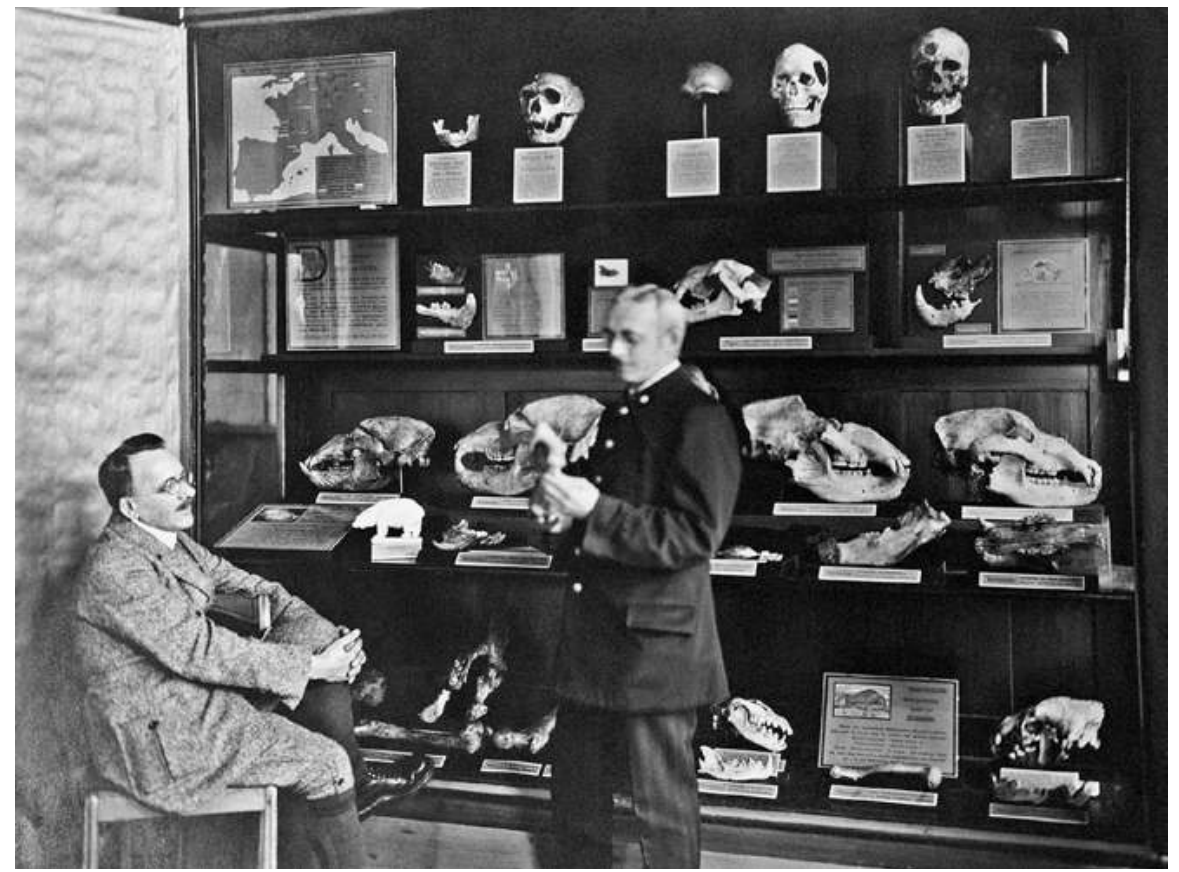

38 Karl Wanderer (l.) und Rudolf Schwarze (r.) vor dem Schrank „Menschen und Raubtiere des Diluviums“, Neuaufstellung der geologisch-paläontologischen Sammlung, 1925

dem Titel „Bildung und wirtschaftliche Bedeutung der Mineralien“ eröffnet. Nachdem durch Direktor $\triangleright$ Eberhard Rimann die umfangreiche Mineraliensammlung von Richard Baldauf angekauft worden war, wurde diese ab 1941 zum Teil im Zwinger präsentiert. ${ }^{171}$ Um eine Verbesserung der räumlichen Situation des Museums für Mineralogie, Geologie und Vorgeschichte bemühten sich ab 1934 neben Rimann auch Wanderer und Kustos ^ Georg Bierbaum, zunächst jedoch vergeblich. ${ }^{172}$

Die erhoffte Ausgliederung der vorgeschichtlichen Abteilung, deren Präsentation zuletzt 1933 durch $~$ Walter Kersten überarbeitet worden war, als Landesmuseum für Vorgeschichte, zu dessen Leiter Bierbaum ernannt wurde, erfolgte

${ }_{171}$ Vgl. Lange/Kühne/Erler 2006, S. 52-57. Vgl. auch SKD Archiv, 01/PS 44, Bd. 2, fol. 164-167; DNN, 14.1.1941, S. 4. Siehe S. 140, 196.

172 Museum für Mineralogie, Geologie und Vorgeschichte an SMV, 22.1.1934 (Rimann), 28.8.1934 (Wanderer), 11.5.1935, 12.6.1935 (Bierbaum), HStA Dresden, 11125, Nr. 19295, fol. 51-56, 105, 141-144, $294 \mathrm{f}$. 
erst zum 1. April 1938. ${ }^{173}$ Der Standort der Sammlung blieb unverändert im Wallpavillon des Zwingers. Zum Zwecke der Neugestaltung der vorgeschichtlichen Sammlung war diese im April 1937 geschlossen worden, doch die für die Museumswoche 1937 angekündigte Eröffnung wurde verschoben. ${ }^{174}$ Sie verzögerte sich bis Juni 1938, als die von $>$ Heinz Amberger kuratierte Ausstellung "Germanen in Sachsen" als neue Dauerausstellung mit der Museumswoche eröffnete wurde. Allerdings wurde diese Eröffnung des neuen Landesmuseums für Vorgeschichte, im Gegensatz zu jener des Museums für Tierkunde im Vorjahr, kaum in der Öffentlichkeit wahrgenommen. ${ }^{175}$ Dies erstaunt umso mehr, als die Verselbständigung des Museums einen politischen Impetus hatte und der in der NS-Zeit zunehmenden Bedeutung und Instrumentalisierung der Vorgeschichte folgte.

\section{Gemäldegalerie}

Die Gemäldegalerie hatte im August 1931 ihre moderne Abteilung mit Werken des 19. Jahrhunderts im Sekundogenitur-Gebäude auf der Brühlschen Terrasse eröffnet und zeigte ab Juni 1932 Gemälde des 20. Jahrhunderts in der unteren Etage des Semperbaus. Am 29. Januar 1933 wurde dann der Deutsche Saal mit Werken von Lucas Cranach und Albrecht Dürer im Zwinger eröffnet. ${ }^{176}$

\section{Sächsisches Armeemuseum}

Im Januar 1935 wurde die Neuaufstellung der Schausammlung im Sächsischen Armeemuseum beendet. Sie wurde sogleich von Minister Hartnacke und Generalmajor Raschick besichtigt, wie die Presse berichtete. ${ }^{177}$ Auch in der Folgezeit präsentierte Direktor $\triangleright$ Ernst von Koerner mehrfach andere Teile der Sammlung, wohingegen er, abgesehen von „Der soldatische Mensch. Arbeiten von Fritz Tröger“

\footnotetext{
173 Vgl. Landesmuseum für Vorgeschichte, in: DA, 4.4.1938, S. 13; Vgl. auch Schachtmann/ Widera 2012, S. 135; Strobel, Michael: Anmerkungen zur Institutionalisierung der archäologischen Denkmalpflege in Sachsen zwischen 1918 und 1945, in: Schachtmann/ Strobel/ Widera 2009, S. 169-192, hier: 188.

174 Museum für Mineralogie, Geologie und Vorgeschichte, Fischer, an Mathematisch-Physikalischer Salon, Werkmeister, 2.7.1937, SKD, MPS, 1937, E.-Reg. Nr. 213.

175 Vgl. DA, 17.5.1938, S. 2; 11.6.1938, S. 5; 15.6.1938 u. DNa, 11.6.1938, S. 3. Vgl. auch Schachtmann 2015, S. 48 f.; dies. 2010.

176 Vgl. Dresdner Volkszeitung (DVz), 9.8.1931, S. 2; u. 3.6.1932, S. 2; DNN 29.1.1933, S. 2; DA, 29.1.1933, S. 2; DNa, Morgenausgabe, 20.1.1933, S. 5.

177 Vgl. DNa, 13.1.1935, S. 7.
} 


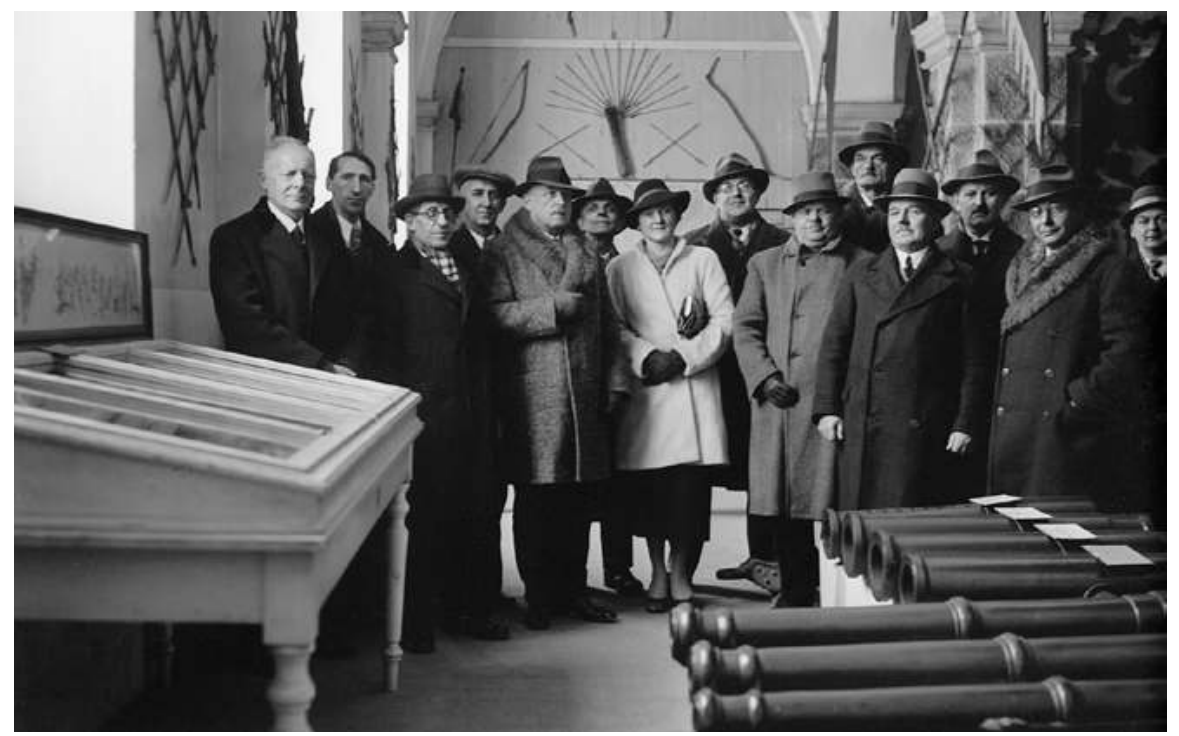

39 Ernst von Koerner (1.v.l.?) am großen chinesischen Geschütz im Sächsischen

Armeemuseum

(1937) „25-jährige Wiederkehr des 1. Mobilmachungstages“ und „Erbeutete polnische Waffen und Ausrüstungsstücke" (beide 1939), kaum Sonderschauen organisierte.

\section{Umbau der Sächsischen Landesbibliothek}

Die Sächsische Landesbibliothek im Japanischen Palais erfuhr ab 1925 unter Direktor $\triangleright$ Martin Bollert eine komplette Erneuerung und Umstrukturierung. Begonnen hatte der stufenweise durchgeführte Umbau mit der Errichtung des neuen Magazins im zweiten Obergeschoss, damit der Bibliotheksbetrieb nicht unterbrochen werden musste. ${ }^{178}$ Nach zehnjährigem Umbau präsentierte sie sich am 11. Mai 1935 als nunmehr modernste deutsche Bibliothek. Sie verfügte über ein Buchmuseum, einen zusätzlichen Lesesaal für Musikalien und einen Vortragssaal mit neuester Technik, wie ein Aufnahmegerät für Schallplatten, um Vorträge aufzuzeichnen. Gleichzeitig wurde der Service der Bibliothek erheblich

178 Vgl. Benndorf, Gottfried u. Hans Hofmann: Die Sächsische Landesbibliothek 1920-1936, in: Neubert, Hermann (Hg.): Festschrift Martin Bollert zum 60. Geburtstage, Dresden 1936, S. 1-14, hier: 11 . 
erweitert, indem die Öffnungszeiten verlängert, eine Lesesaalauskunft eingerichtet und insgesamt 17 Bücherausgabestellen in der gesamten Stadt geschaffen wurden. ${ }^{179}$ Diese Veränderungen ließen die Sächsische Landesbibliothek zu einer modernen leserfreundlichen Institution werden.

Zur Eröffnung, die im Rundfunk übertragen wurde, ${ }^{180}$ sprach neben Bollert auch der Kommissarische Leiter des SMV, der die Bibliothek als "geistige Rüstkammer des Gaues Sachsen " bezeichnete, die „geistige Gifte“ bekämpfe und die ,volkstümliche Bildung " ${ }^{\text {"181 }}$ zum Auftrag habe. Die Presse berichtete, dass die Dresdner Politprominenz mit Reichsstatthalter Mutschmann, Oberbürgermeister Ernst Zörner und Heinrich Salzmann, Propagandaleiter der NSDAPGauleitung Sachsen, bei der Feier zugegen war. Reichserziehungsminister Bernhard Rust besichtigte die Landesbibliothek zwei Wochen später gemeinsam mit Göpfert. ${ }^{182}$

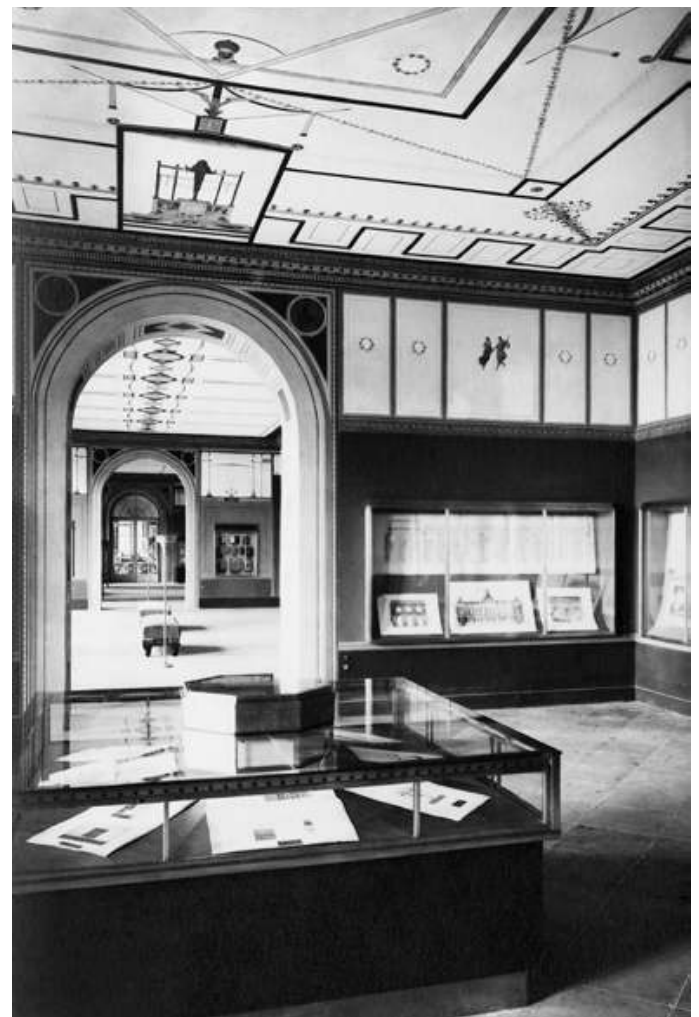

40 Saal für Sonderausstellungen im Buchmuseum der Sächsischen Landesbibliothek, Japanisches Palais, um 1935

\section{Skulpturensammlung}

In der Skulpturensammlung wurde die bereits unter $\triangleright$ Bruno Schröder begonnene Neuaufstellung von $~$ Walter Müller fortgeführt: 1935 öffneten der Lichthof im Albertinum, und die Säle mit Skulptur der Gegenwart im ersten Ober-

\footnotetext{
179 Vgl. Kunze, Horst: Über den motorisierten Bibliothekar, in: Hofmann, Hans (Hg.): Martin Bollert zum 80. Geburtstag am 11. Oktober 1956, Festschrift, Dresden 1956, S. 29-35, hier: 34. 180 Siehe S. 177.

181 Hermann 2011, S. 294. Hermann bezieht sich auf SLUB, Bibl.Arch.III.J.Vol.859b.

182 Vgl. DNN, 11.5.1935, S. 4 u. 12.5.1935, S. 2; DA, 11.5.1935 u. 12.5.1935 sowie DNa, 28.5.1935.
} 
geschoss. Im Mai 1939 und im Mai 1940 folgten weitere neue Säle der Abgusssammlung. Über diese Veränderungen berichtete die Presse stets. ${ }^{183}$

\section{Umzug des Museums für Tierkunde}

Nach ihrer Genehmigung durch das SMV wurden im November 1936 die Umzugspläne für die Porzellansammlung und das Museum für Tierkunde, über die man intern längst debattierte, in der Presse verkündet. ${ }^{184}$ Schon im Februar 1936 hatte $\triangleright$ Bernhard Struck geklagt, dass sich „die Absichten höherer Stelle, die Porzellansammlung in den Zwinger zu legen und uns hinauszutun, zunächst ohne zu bauen (!) in provisorische, schlechterdings unmögliche Räume“ verdichteten, doch ,alle acht Tage schwankt das Programm, wer zuerst fliegt, Zoologie oder Völkerkunde “185. Nun stand es fest. Im April 1937 wurde das Museum für Tierkunde geschlossen ${ }^{186}$ und die Bestände für den Umzug in das ehemalige Logengebäude an der Ostra-Allee vorbereitet. Dieses war nach der von Innenminister Frick angeordneten zwangsweisen Auflösung aller Logen im August 1935 von den Nationalsozialisten enteignet worden. Bereits einen Monat später hatte -Fritz Fichtner dem SMV die Nutzung des Hauses für die naturkundlichen Sammlungen vorgeschlagen, um dadurch seine Umzugspläne für die Porzellansammlung realisieren zu können. ${ }^{187}$ Doch erst im Herbst 1936 stimmte die Staatskanzlei der Verlegung der Museen zu, und der Umbau konnte beginnen. Ab Januar 1937 wurden die Bibliothek und die Bestände des Museums mit dem Lieferwagen der Landesbibliothek ins ehemalige Logenhaus transportiert. ${ }^{188}$ Zur Wiedereröffnung am neuen Standort anlässlich der Museumswoche am 4. Oktober 1937 sprachen der Leiter des Ministeriums und Museumsdirektor $>$ Hans Kummerlöwe, worüber die Presse ausführlich berichtete. ${ }^{189}$

\footnotetext{
183 Vgl. DNa, 14.1.1935, Abendausgabe, S. 3; 20.9.1935, S. 4; 27.5.1939, S. 3; DA, 15.1.1935, S. 2; FK, 20.9.1935, S. 13 u. DNN, 26.5.1939, S. 2.

184 Vgl. SMV, 21.10.1936, SKD Archiv, 01/PS 134, fol. 111 u. Logenhaus wird Museum, in: DNa, 7.11.1936, S. 7; DA, 14.11.1936, S. 5. Siehe auch S.173 ff.

185 Struck an Danzel, 6.2.1936, SKD, MfV Archiv, MVD n20;25/2, o. Pag.

186 Vgl. Jahresbericht 1937/1938, HStA Dresden, 13842, Nr. 115, o. Pag.

187 Vgl. Porzellansammlung, Fichtner, an Leiter SMV, 8.9.1935, SKD Archiv, 01/PS 38, fol. 134; SMV an Landbauamt, 20.10.1936, HStA Dresden, 13842, Nr. 048, o. Pag.

188 Vgl. Weisswange an Struck, 29.1.1937, SKD, MfV Archiv, MVD n20;25/15u16, o. Pag. u. HStA Dresden, 11125, Nr. 19003, fol. 260.17.

189 Vgl. FK, 3.10.1937, S. 16; DNN 4.10.1937, S. 6; DNa 4.10.1937, Morgenausgabe, S. 3 u. DA 5.10.1937, S. 3. Auch in der Folge erschienen noch zahlreiche Artikel.
} 
Kummerlöwe benannte in seiner Rede drei Hauptaufgaben des Museums: das Sammeln ausgewählten Materials aus der Tierwelt, die Auswertung dieses Materials und das Ausstellen von Teilen des Sammlungsgutes. Die Schausammlungen seien „so volksbezogen zu machen wie irgend möglich“, um „dabei unmerklich zugleich zu leiten, zu beeinflussen und zu erziehen "190. Tatsache sei, „daß es in dieser Zeit nichts mehr geben kann und darf [...] das nicht politisch-durchtränkt und ausgerichtet ist oder wenigstens einer letzthin politisch-völkischen Sinngebung unterliegt. “" ${ }^{191}$ Damit stellte Kummerlöwe klar, dass Museumsarbeit politisch-ideologische Arbeit zu sein habe. Die Kanzleiangestellte des Museums, Erika Weisswange, berichtete Struck entsetzt von dieser Rede:

Der Vortrag unseres Sorgentigers war formal und auch inhaltlich ziemlich miserabel. Er las ab und zwar in einem Tempo - ca. 200 Silben die Minute und nuschelte in sein Manuskript, daß man das Ende der Sätze kaum verstehen konnte. Na und der Inhalt? Ich bin diese Dosis von n.s. Kämpfertum nicht mehr so recht gewohnt. ${ }^{192}$

\section{Umzug der Porzellansammlung}

Als das Tierkundemuseum aus den Räumen im Zwinger ausgezogen war, begannen sogleich die Bauarbeiten für den bevorstehenden Einzug der Porzellansammlung. Bereits im Mai 1934 hatte Fichtner seine Pläne gegenüber

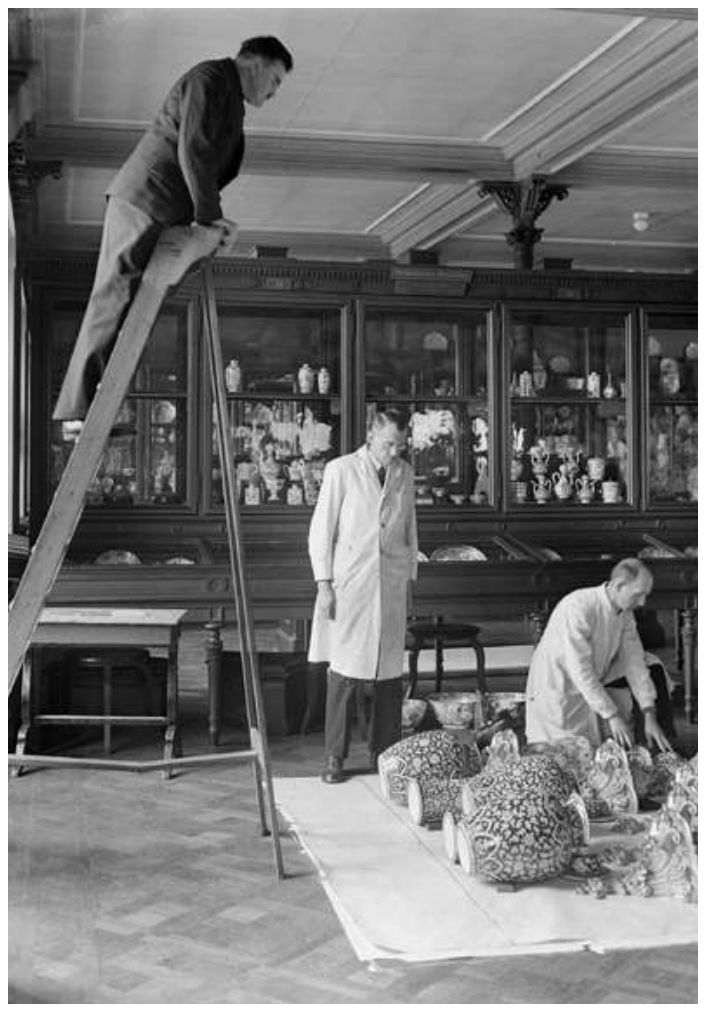

41 Fritz Fichtner im Johanneum bei der Besichtigung eines Probearrangements aus chinesischem Porzellan der Ära Kangxi, 1700-1720, für die Ausstellung im Zwinger, um 1937

\footnotetext{
190 Kummerlöwe, Hans: Geschichte und Aufgaben des Staatlichen Museums für Tierkunde in Dresden, in: Abhandlungen und Berichte aus den Staatlichen Museen für Tierkunde und Völkerkunde in Dresden, Bd. 20, 1939, Reihe A: Zoologie, N. F. Bd. 1, H. 1, S. 1-15, hier: 12. 191 Ebd., S. 8.

192 Weisswange an Struck, 5.10.1937, SKD, MfV Archiv, MVD n20; 25/15u16, o. Pag.
} 


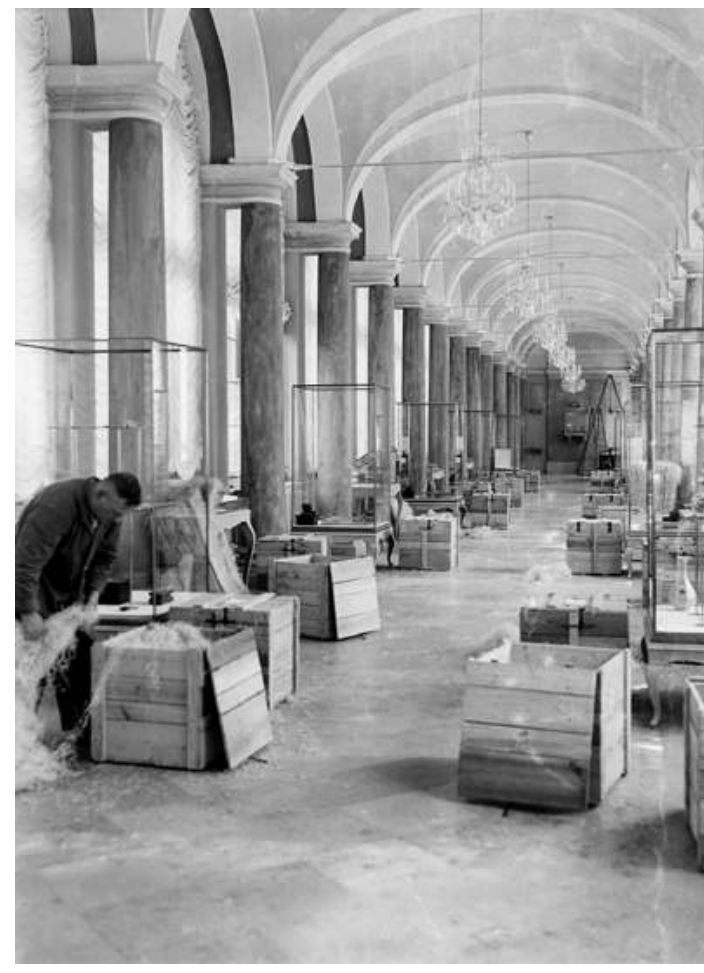

42 Bergung der Porzellansammlung im Zwinger, September 1939

dem Ministerium erläutert und im August 1935 im Johanneum in einer Ausstellung die weißen Altmeißner Porzellangruppen vor rotem Samt gezeigt, um eine neue Präsentationsform zu erproben. ${ }^{193}$ Auch waren verschiedene neue Aufstellungen für die Zwingerräume im Johanneum simuliert worden.

Bei diversen Dienstreisen suchte Fichtner nach der bestmöglichen Ausstattung für die Räume, begutachtete Stoffe in Berlin und Kristallleuchter in Böhmen. ${ }^{194}$ Ein erster Transport vom Johanneum zum Zwinger fand bereits im April 1937 statt, weitere folgten. Im April 1939 informierte Göpfert, dass die Porzellansammlung nach ihrem Umzug in den Zwinger nun den Namen „Staatliche Porzellangalerie Dresden“195 trage, wie es Fichtner bereits im November 1937 beantragt hatte. Die mehrfach verschobene Eröffnung sollte im September 1939 stattfinden, die Vitrinen waren längst eingerichtet, doch mit Kriegsbeginn mussten die Objekte geborgen werden und das Projekt stagnierte. ${ }^{196}$

\section{Museum für Völkerkunde}

Die durch den Umzug der Porzellansammlung leer gewordenen Räume im Johanneum boten für die räumlichen Veränderungswünsche bezüglich des

193 Vgl. Porzellansammlung, Fichtner, an SMV, 5.1934 u. 22.5.1935, SKD Archiv, 01/PS 37, Bd. 2, fol. 245-252 u. 01/PS 038, fol. 81 f. Vgl. DNN, 18.8.1935; DNa, 17.8.1935, S. 3; DA, 8.9.1935, S. 3 u. 18.9.1935, Abendausgabe, S. 2.

194 Vgl. SKD Archiv, 01/PS 43, Bd. 1, fol. 26 ff., 200 ff. u. 01/PS 45, Bd. 2, fol. 124 ff., 146. 195 Leiter SMV an Direktoren der Staatlichen Sammlungen, 15.4.1939, SKD, MPS, 1939, E.Reg. Nr. 104. Der neue Name fand nur im internen Schriftverkehr Verwendung und setzte sich in der Öffentlichkeit infolge der ausbleibenden Eröffnung der neuen Schausammlung nicht durch.

196 SKD Archiv, 01/PS 135, fol. 50, 68, 72; 01/PS 43, Bd. 1, fol. 206 ff. 
Museums für Völkerkunde nach unzähligen vergeblichen Bemühungen eine neue Perspektive. Bereits 1935 hatte $\triangleright$ Bernhard Struck dessen prekäre Situation beklagt: „Mit unserm Erwerbungsetat von RM 150,- (einhundertfünfzig) kennzeichnet sich die Lage des völligen Andiewandgedrücktseins wohl hinreichend!" ${ }^{197}$ Im Herbst 1940 wurde das Museum für den Umzug geschlossen. Doch auch diese Arbeiten stagnierten und Strucks Nachfolger, $\triangleright$ Michael Hesch, berichtete: „Die Eröffnung der Schausammlung dort wird aber wohl nicht vor Sommer 1942 erfolgen können. [...] Die Völkerkunde muss sich im Johanneum nach der Decke stecken und die Rassenkunde kämpft weiter um ihr Lebensrecht. " ${ }^{198}$

\section{Vorbereitungen für ein Museum für Rassenkunde}

Zur Einrichtung einer Schausammlung für diese anthropologische Abteilung hatte Hesch bereits im Mai 1939 Räume gefordert, denn das Fehlen dieser sei „im nationalsozialistischen Deutschland, wo die Erziehung nach dem Willen des Führers durch den Rassegedanken ausgerichtet wird, nicht zu verantworten "199. Vehement plädierte er für die Errichtung eines Rassenkundemuseums in Dresden. Noch im Oktober 1939, also einen Monat nach Kriegsbeginn, legte Hesch einen Entwurf für ein „Staatliches Museum für Erb- und Rassenbiologie“ bzw. „Museum für Rassenkunde und Rassenpflege“ vor, die eine Präsentation rassenkundlicher Themen in Einklang mit der nationalsozialistischen Ideologie vorsah. ${ }^{200}$ Verschiedene Optionen der räumlichen Unterbringung eines solchen $\mathrm{Mu}$ seums wurden geprüft. Im Oktober 1939 besichtigte Hesch gemeinsam mit Direktor Kummerlöwe die Räume im Johanneum. Doch die in Erwähnung gezogene Unterbringung scheiterte ebenso wie im Deutschen Hygiene-Museum, Residenzschloss oder Taschenbergpalais. Die Gespräche wurden fortgeführt und Hesch kämpfte weiter um Räume für die Anthropologische Abteilung, da er „die Verselbständigung der Abteilung als besonderes Museum für organisch und von der Zeit gefordert ${ }^{“ 201}$ hielt. Unterdessen war mit dem Ausbau der Sammlung

\footnotetext{
197 Struck an Bunzendahl, 29.9.1935, SKD, MfV Archiv, MVD n20;25/2, o. Pag.

198 Hesch an Kummerlöwe, 25.10.1941, HStA Dresden, 13842, Nr. 114, Bd. 2, o. Pag. Vgl. Welt in tausend Kisten. Das Museum für Völkerkunde zieht um, in: DNa, 7.3.1941, S. 5.

199 Hesch an Kummerlöwe, 21.5.1939, SKD, MfV Archiv, MVD, Akte Haushalt/Anthropologie. Zitiert nach: Martin 2016, S. 27.

200 Vgl. Martin 2016, S. 27. Petra Martin bezieht sich auf: Hesch an Kummerlöwe, 18.7.1939 u. 3.10.1939, SKD, MfV Archiv, MVD, Akte Haushalt/Anthropologie.

201 SMV, Fichtner, an Leiter SMV, 9.5.1940, SKD Archiv, 01/PS 43, Bd. 1, fol. 254 ff., hier: 254.
} 
begonnen worden. ${ }^{202}$ Für die im Sommer 1939 in Dresden gezeigte „Deutsche Kolonialausstellung" hatte Hesch von Dresdner Bildhauern lebensgroße Plastiken von „Idealtypen“" verschiedener „Rassen“ anfertigen lassen. Sie bildeten den Grundstock für das Rassenkundemuseum. Weitere Skulpturen wurden 1941 beauftragt, wofür die hohe Summe von 12.000 RM genehmigt wurde. ${ }^{203}$ Auch wurden dem Museum vom Ministerium „39 Bilder unerwünschter Kunst zum Zwecke des Unterrichts und der Schulung im engeren Kreise (Führungen und Führungsvorträge) “204 leihweise überlassen, nachdem Hesch die Übernahme von Werken „Entarteter Kunst“ im Oktober 1941 beantragt hatte. Er wollte diese „zur Veranschaulichung abartiger, dem deutschen Wesen fremder Darstellung in der Kunst" verwenden und sie jenen „künstlerischen Darstellungen, die unserem deutschen Wesen entsprechen“, gegenüberstellen, um „die fremdrassischen seelischen Voraussetzungen für das Zustandekommen solcher entarteter Kunst ${ }^{\text {" } 205} \mathrm{zu}$ veranschaulichen. Die Bestände wurden indes im Gebäude der Orangerie im Herzogingarten untergebracht, wo Hesch 1941 sechs „Führungsvorträge“ anbot, und die dem Museum angegliederte „Erb- und rassebiologische Forschungsstelle" nahm ihre Arbeit auf. ${ }^{206}$ Neue Hoffnung, seine Pläne umsetzen zu können, schöpfte Hesch nach seiner Ernennung zum Direktor. Er schrieb an das RuSHA in Berlin, er habe „nun auch bessere Möglichkeiten zum Ausbau des von

\footnotetext{
202 Vgl. Porzellansammlung, Fichtner, 26.10.1939, SKD Archiv 01/PS 43, Bd. 2, fol. 90; Heydrich an Hesch, 3.2.1940, HStA Dresden, 13842, Nr. 114, Bd. 1, o. Pag.; Leiter des SMV, 30.1.1940, SKD Archiv, 01/KGM 7, fol. 6 u. Registrande, 21.2.1940, SKD Archiv, 01/PS 139, fol. 188 sowie Fichtner an Leiter SMV, 9.5.1940, SKD Archiv, 01/PS 43, Bd. 1, fol. 254 ff. u. SKD Archiv, 01/PS 139, Nr. 889.

203 Vgl. Anthropologische Abteilung [Jahresbericht 1939?], HStA Dresden, 13842, Nr. 211, o. Pag.; Jahresbericht des Museums für Rassenkunde 1941/42, HStA Dresden, 11125, Nr. 23053, fol. 40-46; Hesch an Kummerlöwe, 6.1.1941, HStA Dresden, 13842, Nr. 114, Bd. 2, o. Pag. Vgl. auch Martin 2016, S. 27. Martin bezieht sich auf: SMV, Dedering, an Hesch, 14.12.1940, SKD, MfV Archiv, MVD Akte Haushalt/Anthropologie. Die beauftragten Künstler waren Reinhold Ansorg (1890-?), Eduard R. Binder (1869-?), Ernst Hermann Grämer (18991966), Kurt Loose (1913-2011), Willi von Powik (?), Friedrich Press (1904-1990), Walter Reinhold (1898-1982) und Hans Tröger (1894-1963). Auch Adolf Liebermann (1891-1945) und Lottermoser (?), Gustav Reißmann (1887-1954) und Curt Tausch (1899-1969) fanden im Zusammenhang mit den Aufträgen Erwähnung. Vgl. Wernsing, Susanne, Christian Geulen und Klaus Vogel (Hg.): Rassismus. Die Erfindung von Menschenrassen, Ausstellungskatalog, Deutsches Hygiene-Museum Dresden, Göttingen 2018, S. 96-101, hier: 98.

204 Jahresbericht 1941/1942, HStA Dresden, 13842, Nr. 115, o. Pag.

205 Hesch an SMV, 4.10.1941, ebd., o. Pag.

206 Vgl. Jahresbericht des Museums für Rassenkunde 1941/42, HStA Dresden, 11125, Nr. 23053, fol. 40-46, hier: 42-43. Zu „Führungsvorträgen“ siehe auch S. 206 f.
} 
mir geplanten Museums“207. Im Oktober 1941 stimmte dann auch der Reichsstatthalter "grundsätzlich der Errichtung des Museums für Rassenkunde ${ }^{208} \mathrm{zu}$, bevor das Museum zum 1. Januar 1942 als äußeres, programmatisches Zeichen in Staatliche Museen für Tierkunde, Rassenkunde und Völkerkunde umbenannt wurde. Damit erhielt die Rassenkunde „die ihr gebührende Stellung, was in unserer Zeit der Erneuerung des deutschen Lebens von den Rassischen Grundlagen aus auch unbedingt notwendig war ${ }^{\text {"209. }}$. Die Presse berichtete davon und betonte, dass

die Rassenkunde als eine der wichtigsten Grundlagen unseres deutschen Lebens künftig in größerem Ausmaße, als das bisher möglich war, eingesetzt werden soll in der Aufklärungs-, Schulungs- und Erziehungsarbeit. ${ }^{210}$

Allerdings gelang es Hesch durch den Wechsel in eine hauptamtliche Tätigkeit beim RuSHA im Oktober 1942 nicht mehr, seine ehrgeizigen Museumspläne zu vollenden - das Museum für Rassenkunde wurde nie für das Publikum geöffnet.

\section{Ausstellungen}

Wie aber nahmen die Staatlichen Sammlungen die Aufgabe des Ausstellens und Vermittelns in der NS-Zeit wahr? Anhand der Jahresberichte und der in der zeitgenössischen Presse enthaltenen Hinweise und Rezensionen lässt sich eine umfangreiche Ausstellungstätigkeit in den Staatlichen Sammlungen während der NS-Zeit nachweisen. ${ }^{211}$

Hinsichtlich der öffentlichen Wahrnehmung ihrer Veranstaltungen feierten die Staatlichen Sammlungen gleich zu Beginn des „Dritten Reiches“ einen großen Erfolg, dessen Vorbereitung freilich in die Weimarer Republik zurückreichte. Unter Beteiligung aller Sammlungen kuratierte $\triangleright$ Erich Haenel die Ausstellung „August der Starke und seine Zeit“, die in vierzig Sälen im Residenzschloss den Kurfürsten von Sachsen erstmals in seiner Bedeutung für die Kunst und Kultur des Barock präsentierte. Diese Schau lockte von April bis Oktober 1933 etwa

207 Hesch an den SS-Gruppenführer Hofmann, Chef des Rasse- und Siedlungshauptamtes SS, Berlin, 1.9.1941, BArch, R 9361-VI/1172, o. Pag.

208 Hesch an Kummerlöwe, 25.10.1941, HStA Dresden, 13842, Nr. 114, Bd. 2, o. Pag.

209 Hesch, 9.3.1942, Jahresbericht 1941, HStA Dresden, 11125, Nr. 23053, fol. 27-50, hier: 27.

210 Rassenkunde - lebenswichtiger Wissenszweig. Neubenennung Dresdner Museen, in: DA, 6.2.1942, S. 2 .

211 Eine chronologische Auflistung aller bisher nachweisbaren Ausstellungen bietet das Ausstellungsverzeichnis ab S. 235. Auf einzelne Quellenangaben wurde aus Platzgründen verzichtet. 


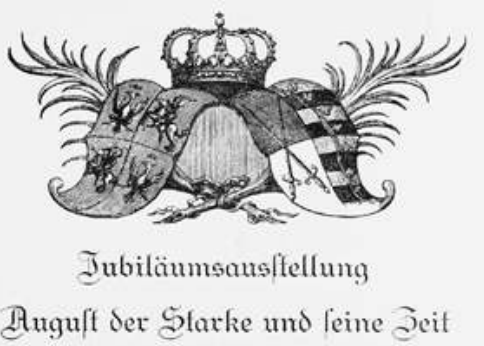

43 Einladung zur Eröffnung der Ausstellung „August der Starke und seine Zeit", April 1933

135.000 Besucher an, von denen 10.000 die 218 angebotenen Führungen nutzten. Insgesamt 21.000 Kataloge wurden verkauft. ${ }^{212}$

An diesen Erfolg versuchte man in Dresden im Olympia-Jahr mit der ebenfalls von Haenel kuratierten „Deutsche[n] Turnierschau“, die von Mai bis September 1936 im Historischen Museum präsentiert wurde, anzuknüpfen. Bei den gleichzeitig veranstalteten „Turnierspiele[n]“ im Stallhof kooperierte das Historische Museum mit dem Staatstheater, der Wehrmacht und NS-Sportorganisationen, um mit ca. 800 Mitwirkenden nicht nur einen Jagdzug aus der Zeit Kurfürst Johann Georgs I., sondern auch Fechtspiele und Ringelstechen in historischen Kostümen vorzuführen. ${ }^{213}$ In Zusammenarbeit mit Haenel hatte Hans Strohbach, Oberspielleiter am Staatstheater, die Turnierspiele inszeniert, für die Musik war Staatskapellmeister Kurt Striegler verantwortlich. Noch während die "Turnierspiele" stattfanden, stellte sie Haenel im August 1936 bei der 32. Versammlung der Museumsbeamten in Freiburg i. Br. als „neue Form der Museumspropaganda ${ }^{214}$ vor.

\footnotetext{
212 Vgl. DA, 12.4.1933; 14.4.1933, S. 2; DNa, 13.10.1933, Abendausgabe, S. 3. Den mit dieser Ausstellung erwirtschafteten Überschuss wollten die Direktoren gern für die weitere Ausstellungsarbeit nutzen. Vgl. Direktoren der Sammlungen, Müller, an SMV, 4.11.1933, SKD Archiv, 01/PS 37, Bd. 1, fol. 122 f. Ähnlich große Ausstellungen unter Beteiligung mehrerer Sammlungen waren 1932 „Kurfürstin Anna von Sachsen“ und die „Goethe-Ausstellung“ im Sächsischen Kunstverein.

213 Die „Turnierspiele“ wurden unter Verwendung von originalen Objekten aus der Sammlung des Historischen Museums bzw. der Rüstkammer vom 27.6.-2.9.1936 aufgeführt. Vgl. DNa, 28.5.1936, S. 2; 12.7.1936, S. 6; DNN, 14.6.1936, S. 5; 12.7.1936, S. 6; DA, 30.8.1936, S. 7. 214 Vgl. Verhandlungen der zweiunddreißigsten Versammlung des Verbandes von Museumsbeamten zur Abwehr von Fälschungen und unlauterem Geschäftsgebaren, Freiburg i. Br. und Basel, 24.-30.8.1936, S. 13, https://digi.ub.uni-heidelberg.de/diglit/verhversverbmb1936,
} 


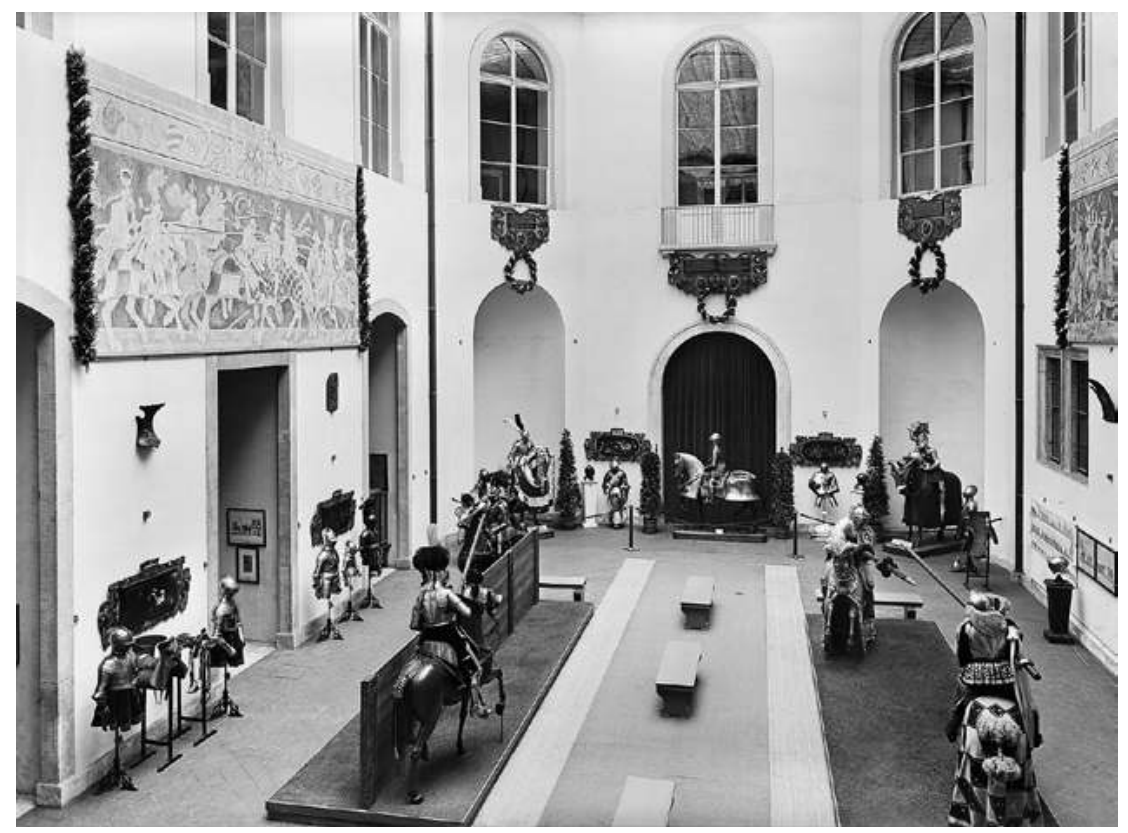

44 „Deutsche Turnierschau“ im Historischen Museum, Johanneum, Mai bis September 1936

Im Sommer 1937 wurden die Turnierspiele aufgrund ihres großen Erfolges wiederholt, abermals von Haenel vorbereitet und von Strohbach inszeniert. Der Filmemacher Fritz Boehner aus Dresden dokumentierte die Show in seinem Film „Mit Federbusch und Harnisch“. ${ }^{215}$ Im Johanneum wurde diesmal gleichzeitig die ebenfalls von Haenel kuratierte Ausstellung „25 Jahre Ausbau des Historischen Museums. Erwerbungen 1913-1937“ gezeigt.

In den folgenden Jahren verzichteten die Staatlichen Sammlungen auf die Durchführung derartiger Großveranstaltungen. Stattdessen beteiligten sie sich an den großen, von anderen Institutionen organisierten Ausstellungen in Dresden, wie den Jahresschauen. Bereits 1935 hatte Haenel die historische Abteilung für „Der rote Hahn. Deutsche Volksschau für Feuerschutz und Rettungswesen“ konzipiert. 1938 waren Beiträge bzw. Leihgaben der Staatlichen Sammlungen in

\footnotetext{
Zugriff: 6.12.2019. Haenel sprach bei der 3. Sitzung am 27.8.1936 im Augustinermuseum in Freiburg i. Br. Eberhard Hanfstaengel soll sich nach dem Vortrag gegen die Verwendung von historischen Originalen bei solchen Anlässen positioniert haben und Haenel entgegnete, dass nur Objekte genutzt wurden, die in großen Serien in der Sammlung vorhanden seien. 215 Vgl. DNN, 27.9.1937, S. 5. Siehe S. 179.
} 
„Sachsen am Werk“ zu sehen, 1939 in der Schau „Große Männer Sachsens“ vom „Heimatwerk Sachsen“. Für die vom Reichskolonialbund und der Stadt Dresden veranstalteten „Deutsche[n] Kolonial-Ausstellung“ schufen die Museen für Tierkunde und Völkerkunde die Dioramen „Melanesisches Fischerdorf“ und „Großwild in der afrikanischen Steppe“. ${ }^{216}$

An der 1933 vom Deutschen Hygiene-Museum organisierten Ausstellung „Volk und Familie" beteiligten sich das Historische Museum und das Münzkabinett, während 1937 Fritz Fichtner mit dem Kunstgewerbemuseum und der Porzellansammlung an „Deutsche Erden - Steine und Erden“ mitarbeitete. In den ehemaligen Räumen der Porzellansammlung im Johanneum wurde 1940 die von der „Dienststelle des Beauftragten des Führers für die Überwachung der gesamten geistigen und weltanschaulichen Schulung und Erziehung der NSDAP“, Amt Rosenberg, und vom Rassenpolitischen Amt der NSDAP veranstaltete Wanderausstellung „Frau und Mutter. Lebensquell des Volkes“ gezeigt. Als die Gemäldegalerie ihre Räume an der Brühlschen Terrasse kriegsbedingt nicht mehr für Ausstellungszwecke nutzte, präsentierte dort 1943 der Landeskulturverwalter der NSDAP die Ausstellung „Soldat und Künstler“ und 1944 das Sächsische Heimatwerk „Das schöne Bild in der Reproduktion “217, um nur einige Beispiele zu nennen.

Die Staatlichen Sammlungen richteten nach ihren erfolgreichen großen Ausstellungen 1933 mehrheitlich kleinere Sonderausstellungen aus. Dies war meist der beengten Raumsituation geschuldet, z. B. standen im Kunstgewerbemuseum und auch im Mathematisch-Physikalischen Salon nur wenige Vitrinen in der Schausammlung für diese Zwecke zur Verfügung. Andererseits wirkte sich auch die angespannte Haushaltslage einschränkend aus. So informierte das SMV im Mai 1936:

So sehr ich es begrüße, daß sich die Staatlichen Museen auch auf diese Weise in den Dienst der allgemeinen Volksbildung stellen, so stehen mir zu meinem Bedauern Mittel, die sächlichen und persönlichen Kosten solcher Ausstellungen zu übernehmen, nicht zur Verfügung. ${ }^{218}$

\footnotetext{
216 Vgl. Jahresberichte 1939, Museum für Tierkunde u. Museum für Völkerkunde, HStA Dresden, 13842, Nr. 115, o. Pag. Die Ausstellung zählte mehr als 400.000 Besucher. Vgl. DA, 11.09.1939, S. 5. Vgl. Schöfert, Arne: Das größte Projekt des Reichskolonialbundes: Die Kolonialausstellung Dresden 1939, in: Internetmagazin des Traditionsverband ehem. Schutz und Überseetruppen e. V. 2010, überarb. 2013, http://www.traditionsverband.de/download/pdf/ Kolonialausstellung_Dresden.pdf, Zugriff: 6.12.2019.

217 Anlässlich der Ausstellung, die 20.000 Besucher zählte, verteilte das „Heimatwerk Sachsen“ 250.000 Reproduktionen von Gemälden an der Front, in Lazaretten und über Zeitungen. Vgl. DZ, 25.3.1944, S. 3; 5.5.1944, S. 3.

218 SMV an Direktoren der Staatlichen Sammlungen, 20.5.1936, SKD, MPS, 1936, E.-Reg. Nr. 171
} 
45 Ausstellung „Deutsche Meisterwerke aus Zinn“im Kunstgewerbemuseum, Juni bis September 1938

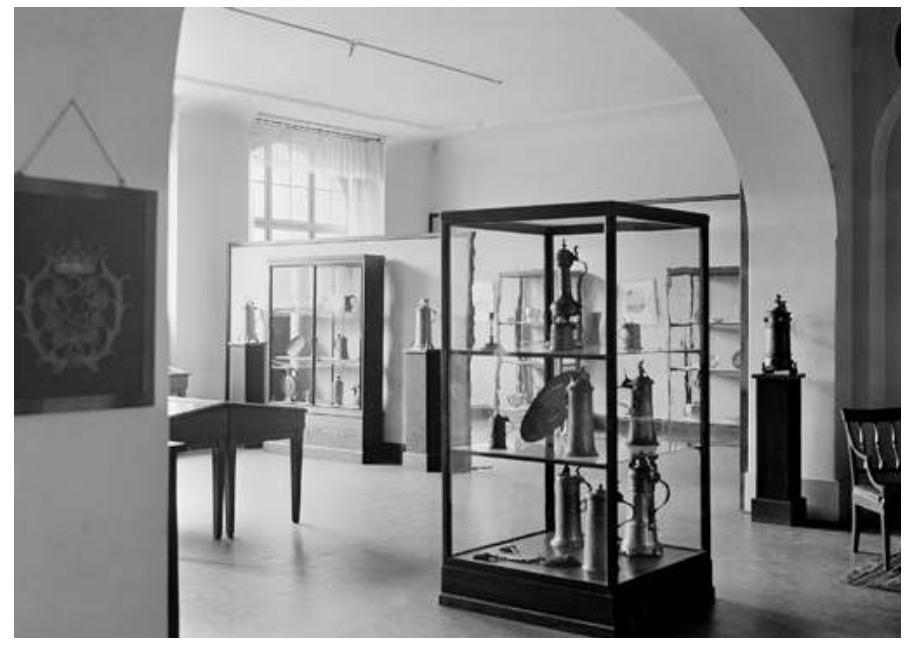

46 Tafelaufsatz von Johann Christian Neuber, 1775, in der Ausstellung „Sächsisches Edelgestein“ im Residenzschloss, August 1936

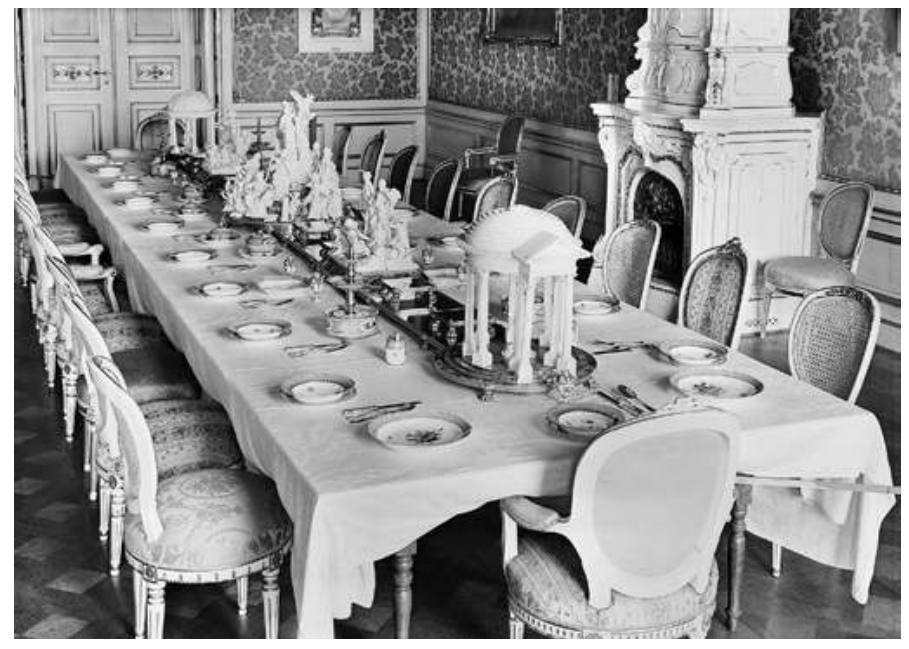

Dessen ungeachtet wurde die Ausstellungsarbeit fortgesetzt, auch im Zweiten Weltkrieg. Die Vielzahl und thematische Vielfalt der Ausstellungen überrascht. Sie berücksichtigten Jubiläen, insbesondere im Kupferstich-Kabinett und der Gemäldegalerie, wie „Anton Graff und seine Zeitgenossen. Zum 200. Geburtstag“ (1936), „Carl Gustav Carus. Zum 150. Geburtstag“ (1939) und „Caspar David Friedrich zum 100. Todestag“ (1940). \Fritz Fichtner erinnerte in der Porzellansammlung an „225 Jahre Staatliche Porzellanmanufaktur Meissen“ (1935). • Erich Haenel und > Walther Fischer präsentierten „Sächsisches Edelgestein. Zum 200. Geburtstag von Johann Christian Neuber" (1936) im Residenzschloss. 
Zahlreiche regionale Themen fanden Eingang in die Präsentationen aller Sammlungen, wie z. B. „Sächsische Landschaft um 1800“ (1934) im Kupferstich-Kabinett, „Musik in Sachsen“ (1936) und „Verklungene Feste und Feiern in Sachsen“ (1937) in der Sächsischen Landesbibliothek, „Zur Rassenkunde des sächsischen Stammes“ (1937) im Museum für Völkerkunde sowie „Die Minerale des Plauenschen Grundes“ (1941) im Museum für Mineralogie und Geologie. Mehrere Ausstellungen widmeten sich diversen Epochen, u. a. „Malerei des Barock“ (1933), „Musik der Renaissance“ (1937), „Die Entwicklung der Taschenuhr in drei Jahrhunderten“ (1938) sowie „Italienische Graphik des 15.-18. Jahrhunderts“ (1939). Zahlreiche andere thematische Ausstellungen wurden angeboten, wie „Dichter der Gegenwart als Maler, Zeichner und Bildhauer“ (1938), „Festkleid, Schmuck und Orden“ (1939), „Der Vogelzug und seine Erscheinungen in Sachsen“ (1939) oder „Deutsche Eisenerzlagerstätten“ (1942). Die Ausstellungen im Kunstgewerbemuseum widmeten sich meist einzelnen Werkstoffen, Handwerkstechniken oder Gegenständen, wie „Altes und Neues Zinn“ (1934), „Die Vase“ (1935), „Licht und Leuchter“ (1937), „Klöppelspitze im 17. Jahrhundert“ (1941). Auch Erwerbungen und Schenkungen wurden präsentiert, wie die Kanada-Sammlung von Max Hinsche (1938) im Museum für Tierkunde, die Mineraliensammlung von Richard Baldauf $(1940,1941)$ im Museum für Mineralogie und Geologie und das Vermächtnis von Johann Friedrich Lahmann mit einem achtteiligen Ausstellungszyklus (1937-1941) im Kupferstich-Kabinett.

Die Kuratoren der Ausstellungen wurden nicht immer benannt. Mehrfache Erwähnung fanden $\triangleright$ Hans Posse, $\triangleright$ Erich Haenel und $\triangleright$ Fritz Fichtner. Die Ausstellungen im Buchmuseum kuratierten primär $\triangleright$ Charlotte Boden und $\triangleright$ Erhart Kästner. Einer der aktivsten Ausstellungsmacher der naturkundlichen Sammlungen war $\triangleright$ Walther Fischer. Seltener kuratorisch tätig waren $~$ Walter Holzhausen, - Peter Halm und $\triangleright$ Gert Adriani, ebenso $\triangleright$ Martin Heydrich, $\triangleright$ Alfred Beck, -Wilhelm Meise und $\triangleright$ Walter Häntzschel. $>$ Walter Müller konzentrierte sich auf die Neuaufstellung in der Skulpturensammlung und präsentierte in einer Zusammenarbeit mit dem Grünen Gewölbe „Die Bronzen der Kurfürstlichen Kunstkammer" (1936). ^Kurt Zoege von Manteuffel und ^Franz Schubert, die maßgeblich für die Ausstellungen des Kupferstich-Kabinetts verantwortlich waren, fanden in den Rezensionen keine Erwähnung.

\section{„Kunstwerk des Monats“}

Die Dresdner Museumsbeamten erwiesen sich als ideenreich: Sie nutzen Althergebrachtes und entwickelten innovative Ausstellungsformate und Vermittlungskonzepte. Unter dem Titel „Kunstwerk des Monats“ präsentierten vornehmlich 
die kunst- und kulturhistorischen Sammlungen zunächst in der Gemäldegalerie auf der Brühlschen Terrasse, ab Herbst 1936 im Lichthof des Johanneums, d.h. im Historischen Museum, jeweils für einen Monat ein Objekt, selten ergänzt durch wenige Beigaben. Die erste dieser Miniaturausstellungen, die mindestens dreieinhalb Jahre lang - von November 1935 bis Mai 1939 - stattfanden, zeigte „Kunst um Friedrich den Weisen“, die letzte präsentierte den „Intarsienschrank Kurfürst Augusts“. Die Bandbreite reichte von der ägyptischen „Statuette des Imeri“ (Februar 1938) über „Albrecht Dürers Skizzenbuch“ (Januar 1937) bis hin zu einer „Altjapanische[n] No-Maske“ (Mai 1938).

Aufgrund der Kleinheit des Ausstellungsformates konnte das „Kunstwerk des Monats" von den jeweils verantwortlichen Museumsbeamten schnell und unkompliziert vorbereitet werden. Es bot dadurch die Möglichkeit, auf aktuelle Ereignisse zu reagieren. Unmittelbar nach dem „Anschluss“ Österreichs 1938 wurden in dieser Ausstellungsreihe mehrfach Objekte österreichischer Herkunft präsentiert, wie „Wiener Porzellan“ (April), ,Wiener Harnisch“ (Mai), „Österreichisches Buch“ und „Prunkharnisch Kaiser Ferdinand I.“ (Juni), „Tiroler Textilien“ (Juli) sowie „Österreichische Graphik" (August) und „Spielkasten aus Wien“ (November), die aus der Porzellansammlung und Landesbibliothek, dem Historischen Museum, Kunstgewerbemuseum und Kupferstich-Kabinett stammten. In der Tagespresse wurde im April 1938 über „Deutschösterreichische Kunst in Dresdens Staatlichen Sammlungen " berichtet. ${ }^{219}$ Die Ausstellungsmacher reagierten unisono auf die politische Situation, womit diese Objektpräsentationen einen ideologischen Charakter hatten. Die politische Bedeutung der „Kunstwerk[e] des Monats" wurde zudem gesteigert, indem von Mai bis Juli wie auch im November 1938 erstmals jeweils zwei Werke parallel gezeigt wurden. Gleichzeitig trugen 1938 mehrere Ausstellungen - vor allem jene der „Museumswoche“ im Juni „deutsch“ im Titel. Porzellansammlung und Kunstgewerbemuseum zeigten „Deutsche Art in Gefäßformen vergangener Jahrhunderte“ und „Deutsche Meisterwerke aus Zinn“. Die Gemäldegalerie stellte „Deutsche Kunst vom 15.18. Jahrhundert“ aus, das Münzkabinett „Meisterwerke deutscher Münzkunst“. Das Buchmuseum präsentierte „Erstausgabe deutscher Dichter“, während „Tierwelt deutscher Kolonien“ und „Rassen und Völker in den deutschen Kolonien“ von den Museen für Tierkunde und Völkerkunde veranstaltet wurden.

Ideologiefrei waren diese Ausstellungen 1938 keineswegs. Doch im Gegensatz zu zahlreichen anderen, politischen Dienstanweisungen, die den Staatlichen Sammlungen in steter Regelmäßigkeit durch das SMV übermittelt wurden, las-

219 Vgl. Deutschösterreichische Kunst in Dresdens Staatlichen Sammlungen, in: DA, 7.4.1938, S. 2. Vgl. DNa, 7.4.1938, S. 3. 
sen sich nach derzeitigem Erkenntnisstand bezüglich der Ausstellungen keine Vorgaben seitens der Verwaltung nachweisen. Es ist anzunehmen, dass es keine schriftlichen Anweisungen zu Themen oder Inhalten von Ausstellungen gegeben hat. Auch mündliche Aufforderungen sind nicht dokumentiert. So muss weiterhin offenbleiben, ob und inwiefern die Entscheidungen über Themen und Inhalte von Ausstellungen tatsächlich im Ermessen der jeweiligen Direktoren und Kustoden lag. Anhand der überlieferten Titel lassen sich Tendenzen ablesen, wie bei jenen, die 1938 das „Deutsche" und „Österreichische“ hervorhoben. Eine der Rezensionen betonte, es genüge „diese Nennung der Ausstellungstitel, um den deutschen Grundcharakter der Dresdner Museumswoche darzutun "220. Die Hervorhebung des „Deutschen“ wie auch der Bezug zu kolonialen Themen, zur Rassenforschung wie zu (historischen) Waffen, der sich bei mehreren Ausstellungen ab 1938 anhand der Titel vermuten lässt, spiegeln die für die nationalsozialistische Ideologie bedeutenden Themen wider. Wenngleich die Titel der Ausstellungen wenig über deren Inhalte aussagen, zeigen sie, dass die Museumsbeamten die nationalsozialistischen Topoi bedienten und sich bemühten, den Anforderungen des NS-Staates zu genügen.

\section{Museumswochen}

Die Politisierung der inhaltlichen Museumsarbeit betraf insbesondere die Museumswochen, die von 1937 bis 1941 organisiert wurden. Sie waren ein neues Instrument der Vermittlung in Dresden. Die Idee und jeweiligen Konzepte entwickelten die Sammlungsdirektoren unter der Leitung von $\triangleright$ Fritz Fichtner in den Direktorenkonferenzen. Unter ein bestimmtes Motto gestellt, begannen die Museumswochen in der Regel mit einem Festvortrag und umfassten mehrere Sonderausstellungen sowie zahlreiche Vorträge und Führungen. Ziel dieser offensiven Bildungsarbeit war es, breiten Gruppen der Bevölkerung einen Zugang zu den Museen und der Sächsischen Landesbibliothek zu ermöglichen - Wehrmachtsangehörigen, Polizisten, SA-Gruppen, Mitgliedern NSDAP-naher Organisationen, Studenten ebenso wie Schulklassen und Familien.

Die erste Museumswoche fand im Oktober 1937 anlässlich der Gaukulturwoche Sachsen, einer regionalen kulturellen Großveranstaltung wie sie in den 1930er-Jahren in vielen Gauen zelebriert wurde, statt. Diese Museumswoche stand unter dem Motto „Die Museen zum Volk!“ und widmete sich primär regionalen, sächsischen Themen. Eröffnet wurde sie im Ballsaal des Residenz-

220 Dr. S.: Kulturmetropole Dresden. Deutsche Kunst auf der Dresdner Museumswoche vom 11. bis 17. Juni, in: DA, 11./12.6.1938, S. 5 . 


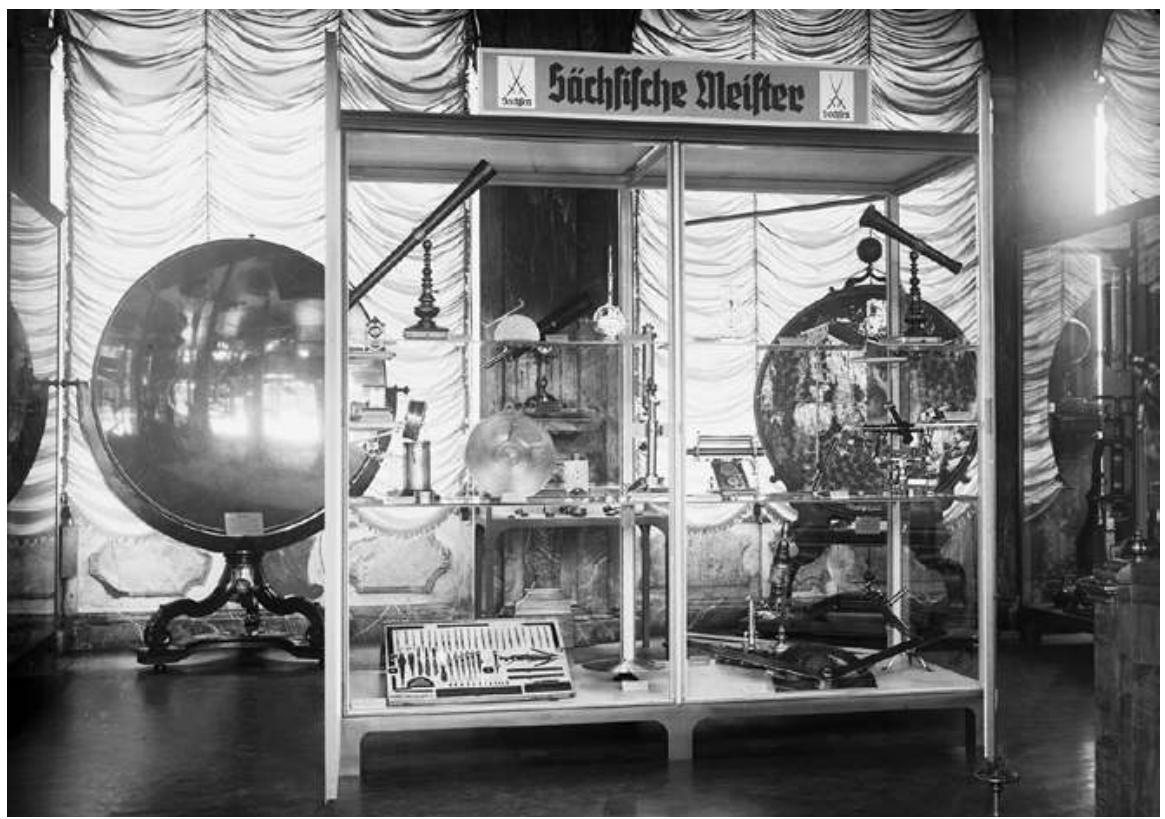

47 Ausstellung „Instrumente und Uhren Sächsischer Meister“ im MathematischPhysikalischen Salon, Museumswoche 1937

schlosses in musikalischer Begleitung durch das Kammerorchester der Staatsoper. Göpfert - Mutschmann ließ sich 1937 und auch in den Folgejahren stets entschuldigen - betonte in seiner Rede, dass die Museen „Schatzhäuser einzigartiger Kultur- und Kunstgüter des sächsischen Gaues " ${ }^{\text {“221 }}$ seien und „der Erziehung, Bildung und Erhebung des ganzen Volkes zu dienen“ hätten, weshalb sie „lebendig und wirksam formend, gestaltend und also erziehend gemacht werden "222 müssten. Anschließend referierte $\triangleright$ Fritz Fichtner über „Die Staatlichen Museen im nationalsozialistischen Aufbau, ein Vergleich zwischen einst und jetzt", wobei er auch auf seine ehrgeizigen Museumspläne einging. ${ }^{223}$ Die ursprünglich geplante Vorführung der Filme „Aus Dresdner Museen“ und „Mit Federbusch und Harnisch" entfiel aus unbekannten Gründen. ${ }^{224}$ - Walter Holzhausen berichtete im Dresdner Anzeiger über die „großen volkserzieherischen Aufgaben“ der Aus-

\footnotetext{
221 Eine Museumswoche in Dresden. Im Dienste des Heimatwerkes, in: DA, 23.9.1937, S. 6.

222 Rausch, Paul: Museen - Nationalsozialistische Erziehungsstätten. Eröffnungsfeier der Dresdner Museumswoche, in: DNN, 4.10.1937, S. 2.

223 Siehe S. $180 \mathrm{f}$.

224 Vgl. SKD, MPS, 1937, E.-Reg. Nr. 213, S. 2. Siehe S. 179.
} 
stellungen, die „zum intensiven Besuch der Museen anspornen“225 sollten. Die Hauptereignisse der Woche waren zweifelsohne die Eröffnung des Museums für Tierkunde ${ }^{226}$ und die Lucas-Cranach-Ausstellung in der Gemäldegalerie.

Im Juni 1938 stand die Museumswoche mit dem Titel „Deutsche Kunst und deutsche Wissenschaft“ unter dem Motto „Das Volk zu den Museen!“. Eröffnet wurde sie wieder von Göpfert und Fichtner im Ballsaal des Residenzschlosses, diesmal musikalisch umrahmt vom Kreuzchor. „, $[\mathrm{U}] \mathrm{m}$ den deutschen Charakter Dresdens eindringlich sinnfällig zu machen“, stand die Woche „unter dem Leitgedanken Deutsche Kunst ${ }^{\text {“227 }}$ - was sich in den bereits erwähnten Sonderausstellungen und deren Titel offenbarte.

Die Presse lobte die Museumswoche als „bisher in Deutschland einzigartiges Unternehmen "228, an dem sich neben den staatlichen nun auch städtische $\mathrm{Mu}$ seen beteiligten. Die zwölf Sonderausstellungen der Staatlichen Sammlungen wurden wiederum von eigenen Mitarbeitern, von Holzhausen und $>$ Walter Häntzschel, in der Presse vorgestellt, wobei die neue Ausstellung „Germanen in Sachsen "im während der Museumswoche eröffneten Landesmuseum für Vorgeschichte nur beiläufig Erwähnung fand. ${ }^{229}$

Mit ihrem Motto „Volk und Museen gemeinsam für Großdeutschland!“ nahm die Museumswoche im Mai 1939 unverkennbar Bezug auf die aktuelle politische Situation. Im Vorjahr hatte der „Anschluss“ Österreichs stattgefunden und nach der "Sudetenkrise“ war im April 1939 der Reichsgau „Sudetenland“ geschaffen worden. Schon bei der Eröffnung der Museumswoche im Ballsaal des Residenzschlosses war diese Politisierung zu spüren. Göpfert betonte in seiner Rede: die Ausstellung „Italienische Graphik“ demonstriere die Verbundenheit mit Italien, die „Japanische Kleinkunst" die Freundschaft mit Japan und die Schau „Jugoslawien und Albanien“ die Zusammenarbeit mit Osteuropa. ${ }^{230}$ Letztlich hatte auch die Ausstellung „Mineralien und Fossilien aus dem Sudetengau“

\footnotetext{
225 Holzhausen, Walter: Die Ausstellungen der Dresdner Museumswoche, in: DA, 2.10.1937, S. 2.

226 Siehe S. $186 \mathrm{f}$

227 Dr. S.: Kulturmetropole Dresden. Deutsche Kunst auf der Dresdner Museumswoche vom 11. bis 17. Juni, in: DA, 11./12.6.6.1938, S. 5. Siehe S. 197 f.

228 Dr. H-e.: Dresdner Museumswoche festlich eröffnet, in: DA, 13.6.1938; S. 9

229 Vgl. Holzhausen, Walter: Deutsche Kunst in Dresdner Museen, in: DA, 13.6.1938, Abendausgabe, S. 6 u. Häntzschel, Walter: Natur und Technik in Dresdner Museen, in: DA, 15.6.1938, S. 11. Siehe S. 183.

230 Vgl. Rede von Arthur Göpfert, Museumswoche 1939, SKD Archiv, 01/PS 43, Bd. 2, fol. 24-32, hier: 30. Vgl. auch DA, 22.5.1939, S. 10. Italien und Japan waren Verbündete des Deutschen Reiches. Mit Japan hatte Deutschland 1936 den „Antikominternpakt“ unterzeichnet, dem Italien 1937 beitrat. Am 22.5.1939 wurde der Bündnisvertrag, der „Stahlpakt“, zwischen
} 
im Museum für Mineralogie und Geologie Bezug zu den aktuellen Ereignissen. Den Festvortrag „Die deutschen Museen und die neue Zeit" hielt 1939 der Generaldirektor der Berliner Museen, Otto Kümmel. Er sprach über die Bildungsaufgabe der Museen und die Notwendigkeit der Zusammenarbeit mit Schulen sowie der KdF. Auf die Berliner Erfahrungen verweisend, propagierte er den Einsatz von Führungen und Lichtbildervorträgen als neue Mittel der Vermittlung, ebenso den Film. ${ }^{231}$ Nachdem das Ministerium in den Vorjahren für die Organisation der Museumswochen einen Sonderetat von 30 RM je Sammlung zur Verfügung gestellt hatte, zahlte es 1939 je 90 RM. $^{232}$ Ein bereits gedrucktes, vom Grafiker Arno Drescher entworfenes Plakat durfte nach dem Veto von Göpfert, dem die Gestaltung missfiel, ,im Straßenbild nicht in Erscheinung tre-

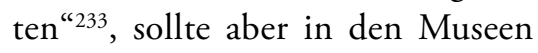

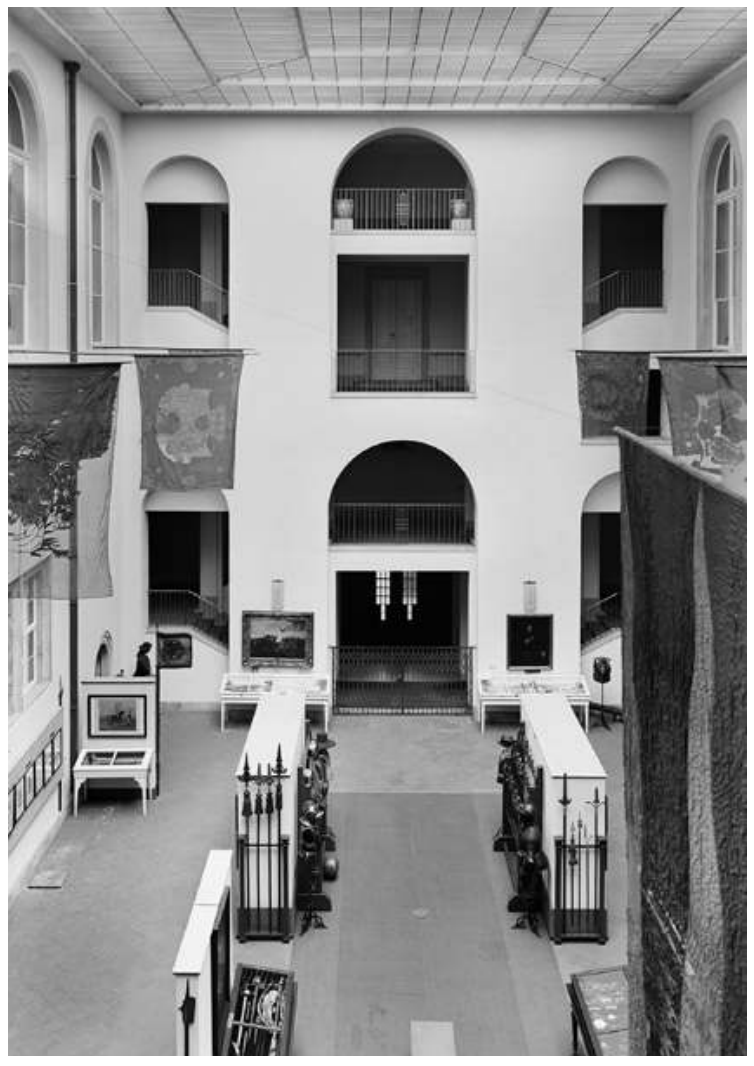

48 Ausstellung „Alte Wehr im deutschen Heer“ im Historischen Museum, Juni bis September 1938 ausgehängt werden. Mit ihrem großen Angebot an Sonderausstellungen, Führungen und Vorträgen verlief die Museumswoche abermals erfolgreich.

Deutschem Reich und Italien unterzeichnet. Das Königreich Albanien war im April 1939 von Italien besetzt und in ein Protektorat umgewandelt worden.

231 Vgl. Rede Otto Kümmel, Museumswoche 1939, SKD Archiv, 01/PS 43, Bd. 2, fol. 33-41.

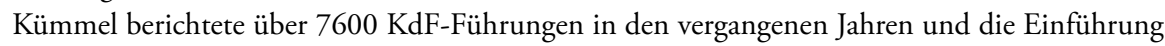
eines KdF-Tages im Monat bei freiem Eintritt in den Berliner Museen, der im September 1938 an einem Tag 40.000 Besucher gebracht habe. Vgl. ebd., fol. 39 f. Vgl. auch Savoy 2014.

232 Vgl. SKD, MPS, 1938, E.-Reg. Nr. 159 u. 1939, E.-Reg. Nr. 140.

233 Fichtner, Aktenvermerk, 14.5.1939, SKD Archiv, 01/PS 43, Bd. 2, fol. 20. Bemängelt wurde die Gestaltung mit einem Putto nach Cranach und Schwertern, die auf Sachsen verweisen sollten. 
Unmittelbar danach begann Fichtner mit der Planung für 1940. Er wollte Reichsminister Rust für eine Rede über die „Stellung der Museen im Erziehungsplan der Nation" einladen. Die Berliner Erfahrungen aufgreifend, sollten sich die Veranstaltungen stärker an Schulen und KdF richten. Auch plante er, diesmal die Vorträge anschließend zu publizieren. Selbst die Verantwortlichkeiten für die einzelnen Bereiche der Vorbereitung waren bereits festgelegt worden. ${ }^{234}$ Doch dann begann der Krieg.

Dennoch wurde auch 1940 eine Museumswoche veranstaltet. Sie stand im „Dienst an der Heimatfront“ und hatte „einen Ersatz zu bieten für die ausfallenden Anregungen der Urlaubs- und Wochenendreisen “235. Unter dem Motto „Volk, lerne deine Führer in Kunst und Wissenschaft kennen!“ widmete sie sich Künstlern wie Caspar David Friedrich und Johann Melchior Dinglinger. Wie in den Vorjahren gab es neben Sonderausstellungen auch Führungen und Vorträge. Nur die Eröffnungsfeier wurde in Anbetracht des Krieges auf einen Vortrag reduziert: Fichtner sprach über „Meißner Porzellane in Polen und Rußland“, und berichtete über seine Erfahrungen von seiner, dem nationalsozialistischen Kunstraub dienenden Reise vom Vorjahr. ${ }^{236}$ Diesmal wurden etwa 150 Plakate in der Stadt verteilt, vor allem an Museen, Behörden und Schulen. ${ }^{237}$

Im Mai 1941 bot die Museumswoche - es war die letzte - unter dem Motto „Natur und Mensch“ keine Ausstellungen mehr, sondern lediglich acht Vorträge. An vier Abenden sprachen je zwei Sammlungsmitarbeiter nacheinander: • Walter Häntzschel und $\triangleright$ Klaus Günther, $\triangleright$ Michael Hesch und $\triangleright$ Georg Bierbaum, - Walter Müller und $\triangleright$ Fritz Fichtner, $\triangleright$ Walter Holzhausen und $\triangleright$ Robert Oertel. Wie die Presse berichtete, sollten dabei „die Lebensgesetze deutlich werden, die Blut und Boden auf den einzelnen wie auch auf ganze Völker ausüben “238. Die Vorträge präsentierten die Darstellung des Menschen in verschiedenen Kunstformen, thematisierten „De[n] Ursprung des Menschen und seiner Rassen“ und

\footnotetext{
234 Vgl. Fichtner, Planung für die Museumswoche 1940, ebd., fol. 42-50. Fichtner wollte 1940 mit $>$ Walter Müller die Zusammenarbeit mit Schulen organisieren. Die Kontakte zu DAF und KdF sollten $\triangleright$ Hans Hofmann und $\triangleright$ Walther Fischer pflegen, zur Studentenschaft $\triangleright$ Hans Posse und $\triangleright$ Martin Heydrich, zu Fachkollegen $\triangleright$ Kurt Zoege von Manteuffel. Für die Pressearbeit waren Müller, $\triangleright$ Franz Schubert sowie $\triangleright$ Walter Holzhausen vorgesehen. $\triangleright$ Hermann Neubert, -Karl Assmann sowie Hofmann sollten die Drucksachen erarbeiten. Es ist anzunehmen, dass die Aufgabenverteilung in den Vorjahren ähnlich erfolgte.

235 p. r.: Museumsgut vor neuen Aufgaben. Auch im Kriege „Dresdner Museumswoche“, in: DNN, 3.5.1940, S. 5.

236 Vgl. ebd. Vgl. HStA Dresden, 11125, Nr. 23054, fol. 47-58. Siehe S. 142.

237 Vgl. Verteilungsplan für Plakate und Programme, 1940, SKD Archiv, 01/PS 43, Bd. 2, fol. $17 \mathrm{f}$.

238 DNN, 27.5.1941; Vgl.; SKD Archiv, 01/PS 44, Bd. 2, fol. 168.
} 
„Lebewesen im Kampf ums Dasein im Tierleben der Gegenwart“ ${ }^{239}$ Der Titel der Vortragswoche „Die Museen zum Volk“, der das Motto von 1937 wiederholte, war durchaus pragmatisch - vier Sammlungen waren bereits kriegsbedingt für Besucher geschlossen. Von der Reduktion des Angebotes berichtete auch -Alfred Beck:

An Stelle unserer sonst seit einigen Jahren üblichen Museumswoche, mit Sonderausstellungen in allen Sammlungen, haben wir dieses Jahr - mit Rücksicht auf die zum Teil geschlossenen Museen - eine, Vortragswoche veranstaltet, die in der vergangenen Woche an 4 Tagen je 2 Vorträge bot. ${ }^{240}$

\section{Führungen}

Wichtiger Bestandteil der Museumswochen wie des gesamten Vermittlungsprogrammes der Staatlichen Sammlungen waren die Führungen. Sie fanden in jeder Sammlung statt, meist zweimal im Monat, und widmeten sich unterschiedlichen Themenbereichen aus den Schausammlungen wie auch den Sonderausstellungen. Selbst die Landesbibliothek offerierte Führungen zum modernen Bibliotheksbetrieb, zur Geschichte des Japanischen Palais und durch ihr Buchmuseum. Das Angebot war so reichhaltig, dass in der Regel täglich mindestens eine Führung in einer der Sammlungen angeboten wurde. ${ }^{241}$

In dieses anspruchsvolle wie ambitionierte Programm war das gesamte wissenschaftliche Personal involviert, wobei manche Direktoren, wie $\triangleright$ Eberhard Rimann und $\gg$ Paul Werkmeister, nicht zuletzt aufgrund ihrer Verpflichtungen an der Technischen Hochschule, eher selten Führungen übernahmen. Im Kunstgewerbemuseum hielt ab 1940 Inspektor $\diamond$ Reinhard Schmelzer die Führungen, denn Direktor $\triangleright$ Fritz Fichtner war aufgrund seiner anderen Aufgaben kaum anwesend. Im Mathematisch-Physikalischen Salon leistete Restaurator $\triangleright$ Alfred Beck die Vermittlungsarbeit.

In einigen Sammlungen widmeten sich die Mitarbeiter in Führungszyklen speziellen Themen oder vermittelten den Verlauf der Kunstgeschichte anhand ausgestellter Objekte. Letzteres Konzept verfolgte $\triangleright$ Walter Müller in der Skulpturensammlung. ^ Gert Adriani zeigte ab Oktober 1936 in der Gemäldegalerie in mehreren Führungen „Malerei der Renaissance in den romanischen Ländern“,

\footnotetext{
239 Vgl. DA, 24.5.1941, S. 5; HStA 11125, Nr. 23054, fol. 168.

240 Mathematisch-Physikalischer Salon, Beck, an Protze, Berlin, 3.6.1941, SKD, MPS, 1941, A.-Reg. Nr. 130.

${ }^{241}$ Vgl. HStA Dresden, 11125, Nr. 23080. Vgl. auch SKD Archiv, 01/SKS 171; 01/SKS 172.
} 


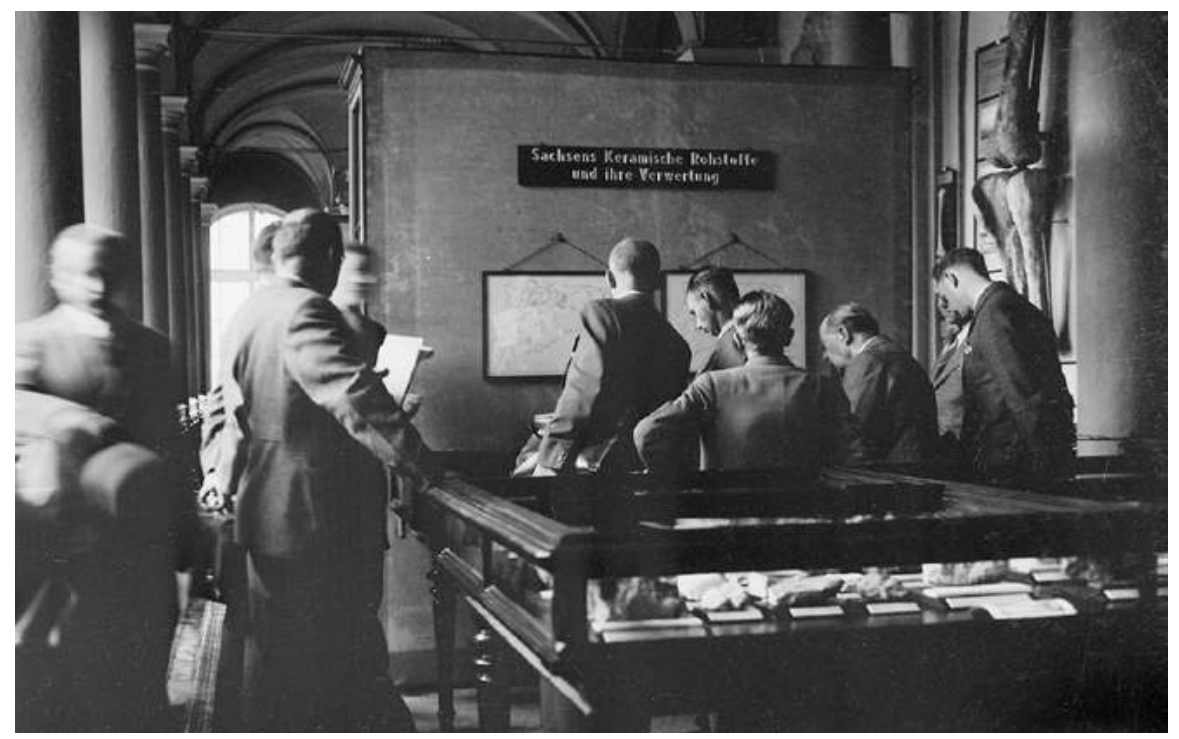

49 Führung durch die Sonderausstellung „Sachsens keramische Rohstoffe und ihre Verwertung", Dezember 1940

gefolgt von „Malerei des Barock in den romanischen Ländern“ ab Januar 1937. ${ }^{242}$ - Franz Schubert stellte hingegen im Herbst 1935 „Druckgraphische Techniken und ihre Geschichte" in einer mehrteiligen Veranstaltungsfolge im Kupferstich-Kabinett vor. Dieser Reihe folgten ab Dezember 1936 Adrianis Führungen zum Thema „Handzeichnungen“. ${ }^{243}$ Ab 1942 wurden infolge der Schließung weiterer Sammlungen deutlich weniger Führungen angeboten. Dennoch bemühte sich das Museum für Tierkunde, auch 1944 noch eine Führung im Monat anzubieten, was bis zum September gelang. ${ }^{24}$

Die Teilnehmerzahlen sind nur für einzelne Führungen überliefert, denn sie wurden nicht systematisch erfasst. Durchschnittlich nahmen etwa 15 bis 20 Besucher diese Angebote wahr. Dabei gab es Ausnahmen: Als $\triangleright$ Wilhelm Meise am 25. Juli 1935 das „Leben der Paradiesvögel“ erläuterte, lauschten ihm zwei Besucher, während sich 96 Zuhörer drängten, als Fichtner am 11. März 1936 „Wunderwerke der Porzellankleinplastik“ zeigte. ${ }^{245}$

\footnotetext{
242 Vgl. SKD Archiv, 01/SKS 172; DNN, 25.10.1936; DA, 10.1.1937.

243 Vgl. SKD Archiv, 01/SKS 171 u. 01/SKS 172.

244 Siehe S. 159.

245 Vgl. HStA Dresden, 13842, Nr. 047, o. Pag. u. SKD Archiv, 01/PS 40, fol. 83 ff. Tendenzen, welche Führungen bei den Besuchern beliebt waren, lassen sich aus den überlieferten Daten nicht ableiten.
} 


\section{Zusammenarbeit mit Schulen, KdF und Volksbildungsstätte}

Eng war die Zusammenarbeit mit Schulen. Sie wurde durch das SMV ausdrücklich gewünscht, das die Schulen explizit auf das Angebot der Staatlichen Sammlungen hinwies. ${ }^{246}$ Eine eigene Abteilung, wie „Schule und Museum“ in den Staatlichen Museen zu Berlin, wurde jedoch nicht eingerichtet. ${ }^{247}$ Zusätzliche Führungen wurden für verschiedene Vereine aus Dresden, als Rahmenprogramm bei Tagungen, aber ebenfalls für Gruppen der Wehrmacht und diverser NSOrganisationen angeboten. Fichtner hielt z. B. 1934/1935 acht Führungen für Amtswalter der NSDAP. Im Sommer 1935 wurde die „SA-Führerschule“ ausdrücklich darauf hingewiesen, dass die Staatlichen Sammlungen für die Lehrgangsteilnehmer jederzeit Führungen halten würden. ${ }^{248}$

Ein wesentlicher Beitrag zum nationalsozialistischen Volksbildungsauftrag der Staatlichen Sammlungen war deren Kooperation mit der KdF. Zahlreiche Führungen in allen Museen und in der Sächsischen Landesbibliothek wurden für KdF-Gruppen vor allem von Frl. Brückner angeboten. ${ }^{249}$ Regelmäßig übermittelten die Staatlichen Sammlungen Informationen über ihr Programm an diese Organisation, auch Faltblätter zur Museumswoche wurden so verteilt. Ob an den Staatlichen Sammlungen ein regelmäßiger, eintrittsfreier KdF-Tag eingeführt wurde, wie er in den Staatlichen Museen in Berlin angeboten wurde, ist nicht überliefert. ${ }^{250}$ Allerdings mobilisierte die Organisation am 6. Februar 1939 über 6000 Dresdner, um ihre Stadt kennenzulernen, wovon viele mit KdF-Führungen auch die Museen besichtigten. ${ }^{251}$

Mindestens ab 1935 kooperierten die Staatlichen Sammlungen mit der Dresdner Volksbildungsstätte des Deutschen Volksbildungswerkes, auch „Heimatschule Dresden“" genannt. ${ }^{252}$ Regelmäßig offerierten Sammlungsmitarbeiter

\footnotetext{
246 Vgl. SMV an diverse Schulen, 24.5.1934, SKD, MPS, 1934, E.-Reg. Nr. 133. Siehe S. $174 \mathrm{ff}$.

247 Vgl. Amlung, Ullrich: Die Abteilung „Schule und Museum“ am Staatlichen Museum für Deutsche Volkskunde in Berlin und ihr Leiter Adolf Reichwein 1939-1944, in: Grabowski/ Winter 2013, S. 409-426.

248 Vgl. Fichtner, Jahresbericht 1934, 12.6.1935, HStA Dresden, 11125, Nr. 19003, fol. 215.4 u. SMV an SA-Führerschule, 25.7.1935, SKD, MPS, 1936, E.-Reg. Nr. 200.

249 Vgl. FK, 1.6.1935, 2.11; DA, 11.7.1940, S. 3. Anhand der Presse lässt sich Brückners Aktivität mindestens von Juni 1935 bis Juli 1940 nachweisen. Biografische Daten zu Brückner sind nicht überliefert; vermutlich war sie für KdF tätig und nicht bei den Staatlichen Sammlungen angestellt.

250 Siehe S. 201, Anm. 231.

251 Vgl. DA, 6.2.1939, Abendausgabe, S. 5.

252 Vgl. Deutsches Volksbildungswerk Gau Sachsen, Volksbildungsstätte Dresden, an Fichtner, 25.5.1935, SKD Archiv, 01/PS 41, Bd. 1, fol. 81. Als „Volksbildungsstätten“ wurden die ehema-
} 
für diese Führungen und mehrteilige Kurse. In den Kursen 1936 und 1937 referierten $\triangleright$ Hans Kummerlöwe über die heimische Vogelwelt und $\triangleright$ Siegfried Wolf über Volksmärchen aus aller Welt. Außerdem sprach Wolf über Wissenswertes aus dem Museum für Völkerkunde, während $>$ Martin Heydrich über „Afrika, wie es war und wie es ist - und die deutsche Kolonialfrage" referierte. > Klaus Günther stellte einheimische Insekten vor. ${ }^{253}$ Am 8. April 1938 mussten jedoch die bereits angekündigten Führungen für die Volksbildungsstätte ausfallen, denn alle Betriebe mussten im Rundfunk die Übertragung des „Tages des Großdeutschen Reiches" anhören. ${ }^{254}$

\section{„Führungsvorträge“}

Ab 1935 wurden in der Porzellansammlung und im Kupferstich-Kabinett „Führungsvorträge" angeboten. Sie verbanden einen Vortrag mit dem Vorzeigen ausgewählter originaler Objekte aus der Sammlung und waren somit nicht an eine Ausstellung gebunden. $>$ Fritz Fichtner beschrieb diese Eigenart der „Führungsvorträge" gegenüber dem Ministerium:

Die zur Besprechung stehenden Objekte wurden den Vitrinen entnommen und so eine Art Museums-Demonstrationskolleg gehalten. Die Objekte waren so nicht gefährdet, die Besucher konnten sitzend und in Ruhe die Gegenstände genießen. ${ }^{255}$

Eine Konjunktur erlebte diese neue Veranstaltungsart jedoch erst mit Beginn der kriegsbedingten, sukzessiven Schließungen der Schausammlungen. Nun dienten die „Führungsvorträge" als Ersatz für die entfallenden regulären Führungen. In bescheidenem Umfang konnte damit die Vermittlungsarbeit fortgeführt werden und das Publikum musste nicht auf den Anblick ausgewählter Einzelobjekte verzichten.

Insbesondere in der Anthropologischen Abteilung der Museen für Tierkunde und Völkerkunde, dem späteren Museum für Rassenkunde, das über keine Schausammlung verfügte, waren sie ein probates Mittel und wurden von $>$ Herbert Bellmann sowie $>$ Michael Hesch rege genutzt. Die thematische Ausrichtung dieser Veranstaltungen, die in der Orangerie in der Art eines Schaudepots die „Rasseplastiken“ vorführten und „Die Rassenverhältnisse im früheren polnischen

\footnotetext{
ligen Volkshochschulen bezeichnet, die ab 1934 mit dem Volkshochschulwesen - in der NS-Zeit „Deutsches Volksbildungswerk“ - als Unterorganisation der KdF dem Reichsschulungsamt der NSDAP und dem DAF unterstellt wurden.

253 Vgl. Museen für Tierkunde und Völkerkunde, Kummerlöwe, an SMV, 15.10.1936 u. 11.3.1937, HStA Dresden, 13842, Nr. 048, o. Pag.

254 Vgl. DA, 8.4.1938, S. 8. Siehe auch S. $112 \mathrm{f}$.

255 Porzellansammlung, Fichtner, an Leiter SMV, 10.4.1935, SKD Archiv, 01/PS 40, fol. 83 ff.
} 


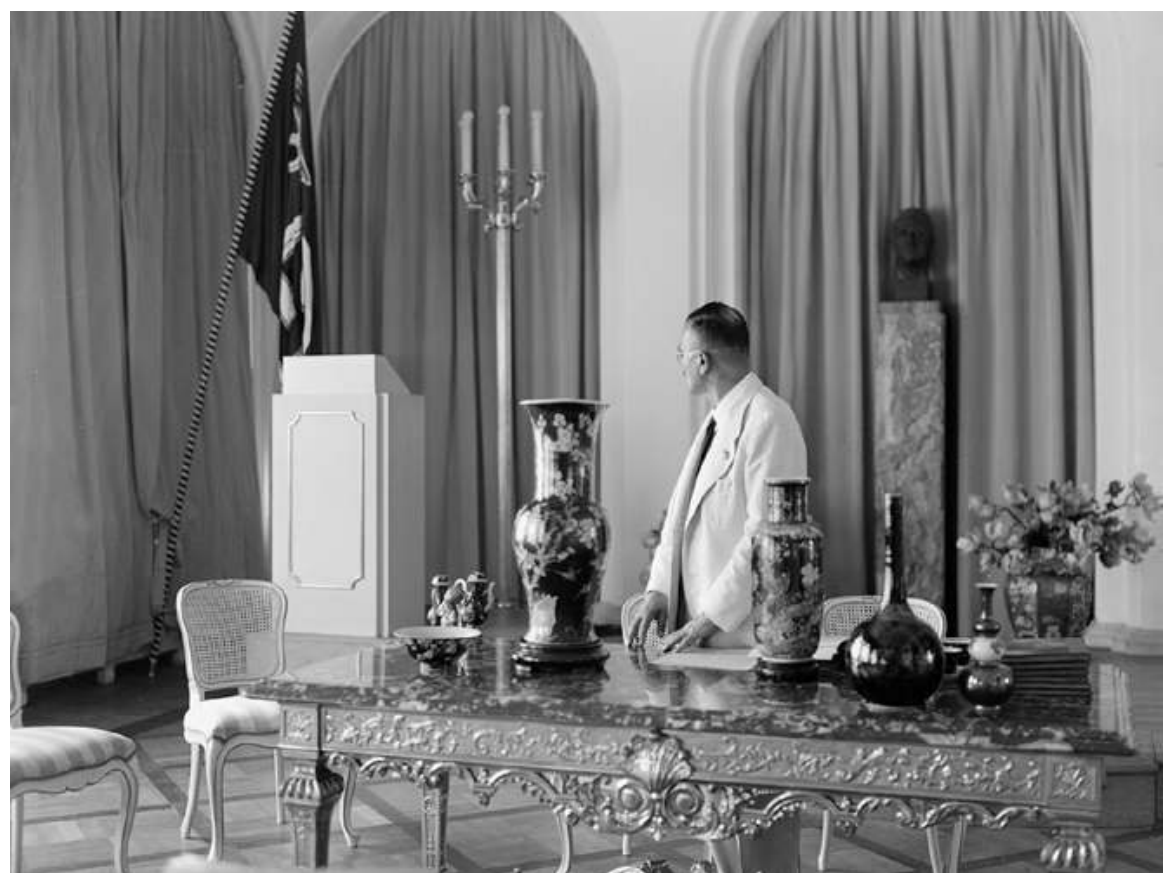

50 Fritz Fichtner bei der Vorbereitung eines Führungsvortrages in der Porzellansammlung, um 1940

Raum und Protektorat“, „Volk und Rasse in Südosteuropa“, „Das Judentum als Fremdkörper unter den Völkern Europas“ oder „Die Verwertbarkeit der verschiedenen Negerrassen in den Kolonien" vermittelten, belegt zugleich deren Ideologisierung und ihre Nutzung zur nationalsozialistischen Unterweisung der Besucher. ${ }^{256}$

\section{„Lautsprecherführungen“}

Für das Museum für Tierkunde ist eine weitere Art der Führung überliefert: Die „Lautsprecherführung“, eine Frühform multimedialer Ausstellungspräsentation, die in Dresden seit 1930 im Deutschen Hygiene-Museum genutzt wurde. ${ }^{257}$ Im Museum

256 Vgl. SKD Archiv, 01/PS 44, Bd. 2; HStA Dresden, 11125, Nr. 23053; HStA Dresden, 13842, Nr. 115.

257 Kombiniert mit einer aufwendigen Lichtregie dienten sie der Präsentation des dort produzierten und ausgestellten „Gläsernen Menschen“. Erstmals präsentiert wurde diese Figur auf der 
für Tierkunde wurden „Lautsprecherführungen“ ab Oktober 1937 am neuen Standort in der Ostra-Allee angeboten. Dort war im zweiten Obergeschoss ein Ausstellungsraum geschaffen worden, der sich der Thematik „Tiere und Wirtschaft" widmete. Es wurden Wirtschaftszweige, wie Pelztier- und Pferdezucht sowie Walfang, vorgestellt, die der Devisenbeschaffung dienten. Auch informierte dieser Teil der Schausammlung über Schädlinge, die, wie der Kartoffelkäfer, Ernten stark beeinträchtigen konnten. Zur Erläuterung der Exponate ließ man in diesem Raum eine Schallplatte ablaufen, auf der zuvor ein Begleittext aufgenommen worden war. ${ }^{258}$

\section{Filmvorführungen}

Der Umzug des Tierkundemuseums bot die Möglichkeit, nun auch in Dresden das Medium Film in die Museumspräsentation einzubinden. Dafür wurde am neuen Standort ein Vortrags- und Filmvorführraum eingerichtet. Anregung dazu hatte nicht zuletzt der Abend über den Einsatz naturwissenschaftlicher Filme im Unterricht gegeben, den die Naturwissenschaftliche Gesellschaft „Isis“ - nach dem Erlaß „Unterrichtsfilm und amtliche Bildstellen“ des RMWEV von 1934 im November 1935 in Dresden veranstaltet hatte. ${ }^{259}$

Beginnend mit seiner Eröffnung am 4. Oktober 1937 wurden im Museum für Tierkunde im monatlichen Wechsel zweimal täglich zwei verschiedene Tierfilme gezeigt, die bei der Reichsstelle für den Unterrichtsfilm bzw. bei der Sächsischen Landesbildstelle entliehen wurden. Die Presse stellte das „Filmtheater im Museum “260 vor und kündigte später jeweils das neue Programm an. Die Vorstellungen begannen 1937 mit den Filmen „Heuschrecken und Grillen“ und „Saga, die Riesenschnecke“ des Berliner Zoologen Willy Ramme. ${ }^{261}$ Später wurden mehrheitlich Filme gezeigt, die der Zoologe und Pionier des biologischen Kul-

II. Internationalen Hygiene-Ausstellung in Dresden 1930, 1935 wurde sie in Berlin bei der Propaganda-Ausstellung „Das Wunder des Lebens“ vorgeführt und 1937 bei der Weltausstellung in Paris gezeigt. Vgl. Wernsing/Geulen/Vogel 2018, S. 71 sowie Roth, Martin: Menschenökonomie oder Der Mensch als technisches und künstlerisches Wunderwerk, in: Beier, Rosmarie und Martin Roth (Hg.): Der Gläserne Mensch - Eine Sensation. Zur Kulturgeschichte eines Ausstellungsobjekts, Stuttgart 1990, S. 39-67, hier: 41-43. Savoy erwähnte die Erprobung des Schallplatteneinsatzes ab $1931 \mathrm{im}$ Deutschen Museum in München und im Märkischen Museum in Berlin. Vgl. Savoy 2014, S. 35 ff.

258 Vgl. Lautsprecherführungen im Tierkundemuseum, in: DA, 18.10.1937, S. 5. Bisher konnte nicht geklärt werden, ob für die Schallplattenaufnahmen die in der Sächsischen Landesbibliothek vorhandene Technik genutzt wurde.

259 Vgl. Der Film in naturwissenschaftlichen Unterricht, DA, 28.11.1935, S. 18.

260 DNa, Morgenausgabe, 12.10.1937, S. 5.

261 Vgl. DA, 11.10.1937, S. 5. 
turfilmes Ulrich Schulz für die Ufa-Kulturabteilung schuf, wie „Tiere als Jagdgehilfen des Menschen“, „Räuber im Vogelreich“, „Gläserne Wundertiere“ und „Von Schwarzkitteln und Schaufelträgern“. ${ }^{262}$ Oft standen die in einem Monat gezeigten Filme in keinem thematischen Zusammenhang, sondern stellten unterschiedliche Tiere vor, wie im April 1942 „Afrikanische Steppentiere und Dickhäuter" und „Der König der Lüfte“.263

Zum Einsatz kamen Tonfilme, aber auch Stummfilme, die meist erläuternde Zwischentexte einblendeten. Diese wurden zuvor von den Museumsmitarbeitern überprüft und bei Bedarf durch eigene Kommentare ergänzt, wie der Jahresbericht 1938/1939 schilderte:

Zur Erläuterung des Dezember-Stummfilmes ,Die Wasserspinne wurde eine Schallplatte zweiseitig besprochen und vorgespielt. Dies ist manchmal bei Filmen der Reichsstelle für den Unterrichtsfilm nötig, weil sie zu wenig oder gar keine Zwischentexte bieten. ${ }^{264}$

Die Vorführungen endeten im September 1943 mit „An den Quellen des Amazonas", als das Vorführgerät durch die Wehrmacht eingezogen wurde. Davon berichtete $\triangleright$ Klaus Günther an $>$ Michael Hesch:

Gerade heute lasse ich unseren Kino-Apparat fortschaffen. Er ist von der Heereswirtschaftsstelle beschlagnahmt worden, um für militärische Zwecke Verwendung zu finden. Es ist, wie sich herausstellte, ein Einspruch gegen diese Beschlagnahme unmöglich. Sehr nachteilig wird sich diese Ablieferung auf den Besuch des Museums auswirken, der in den letzten Jahren doch sehr wesentlich von den Filmvorführungen abgehangen hat. ${ }^{265}$

In der Presse informierte ein kurzer Hinweis: „Die Vorführung von Tierfilmen wird bis auf weiteres ausgesetzt. ${ }^{\text {"266 }}$

262 Vgl. ebd.; DA, 12.1.1942, S. 5 u. DNN, 2.3.1939, S. 7. Siehe www.difarchiv.deutschesfilminstitut.de/dt2tp0146.htm, Zugriff: 6.12.2019.

263 Vgl. DNN, 9.4.1942, S. 4; 25.4.1942, S. 4.

264 Museen für Tierkunde und Völkerkunde, Meise, Jahresbericht Zoologie, 1938/39, HStA Dresden, 13842, Nr. 115, o. Pag.

265 Günther an Hesch, 18.9.1943, HStA Dresden, 13842, Nr. 114, Bd. 1, o. Pag. Vgl. Jahresbericht Museum für Tierkunde, 1943/1944, HStA Dresden, 13842, Nr. 115, o. Pag. Vgl. auch DZ, 10.9.1943, S. 3.

266 DZ, 18.9.1943, S. 4. 
Mit dem Start des Museumskinos stiegen die Besucherzahlen: 1938 wurden 61.891 Besucher gezählt, 12.475 davon hatten eine Filmeintrittskarte gelöst. ${ }^{267}$ Die Filmvorführungen im Museum für Tierkunde erwiesen sich als Publikumsmagnet. Dies war ein Grund dafür, dass $>$ Fritz Fichtner Ähnliches in der Porzellansammlung im Zwinger plante. Dort hatte er einen Saal mit Schmalfilmapparat einrichten lassen, wo er „Schmalfilme über die Gebiete der Keramik, insonderheit Porzellane, über China und Japan “268 zeigen wollte. Dafür fragte er bei der Ufa in Berlin nach deren Filmbestand und den Leihbedingungen. Kriegsbedingt wurde diese Idee jedoch nicht mehr in die Tat umgesetzt.

\section{Museumsvorträge}

Meist einmal im Monat, an einem Sonntagvormittag, boten die Staatlichen Sammlungen Museumsvorträge mit Lichtbildern an. Zunächst fanden diese im Hörsaal des Albertinums statt, ab 1939 im Spiegelsaal der Porzellansammlung im Zwinger. Bis 1944 wurden die Vorträge gesondert durch Postkarten und Plakate beworben. Darüber hinaus wurde das Programm in der Presse veröffentlicht. ${ }^{269}$ Der Eintritt war frei, allerdings musste man sich vorher eine Eintrittskarte für den Einlass abholen und im Winter bestand eine Abgabepflicht der Garderobe zum Preis von 10 Rpf.

Bei den Museumsvorträgen sprachen reihum Mitarbeiter aus verschiedenen Sammlungen. Fichtner referierte z. B. am 28. März 1943 über „Soldaten und Jäger aus Alt-Meißner Porzellan“270. Am 14. November 1943 sprach er zur Eröffnung der Vorträge im Winter 1943/1944 über die „Bergungsarbeiten an den Dresdner Museumsschätzen“, wobei er die Museumsvorträge als „Kriegsbeitrag der Museumsleiter und ihrer Mitarbeiter “ ${ }^{\text {“271 }}$ bezeichnete. Einen Monat später referierte $\triangleright$ Hermann Voss über Lorenzo Bernini. ${ }^{272}$ Einer der wenigen Sonntagsvorträge, von dem mit 125 Personen die Anzahl der Zuhörer überliefert wurde, war jener von $\triangleright$ Erna von Watzdorf im November 1941 über Objekte im Historischen

\footnotetext{
267 Darunter waren 152 Schulklassen mit insgesamt 4382 Kindern. Vgl. Jahresbericht 1938/39, HStA Dresden, 13842, Nr. 115, fol. 1.

268 Porzellansammlung, Fichtner, an UFA Berlin, 28.7.1939, SKD Archiv, 01/PS 42, Bd. 2, fol. 461. Der Schmalfilmapparat war im März 1939 vom Photohaus Martin Richter, Dresden, geliefert worden. Vgl. ebd., fol. 377.

269 Vgl. Sonntagsvorträge der Staatlichen Sammlungen zu Dresden 1941/42, HStA Dresden, 11125, Nr. 23081, fol. 12. Siehe S. 174 ff.

270 Vgl. Einladungskarte, HStA Dresden, 11125, Nr. 23081, fol. 127.

271 Dr. H. Stegmann: Dresdner Museen einst und jetzt, in: DZ, 16.11.1943, S. 3.

272 Vgl. HStA Dresden, 11125, Nr. 23081, fol. $184 \mathrm{f}$.
} 
51 Ankündigung der Sonntagsvorträge in den Dresdner Nachrichten, 5.10.1941

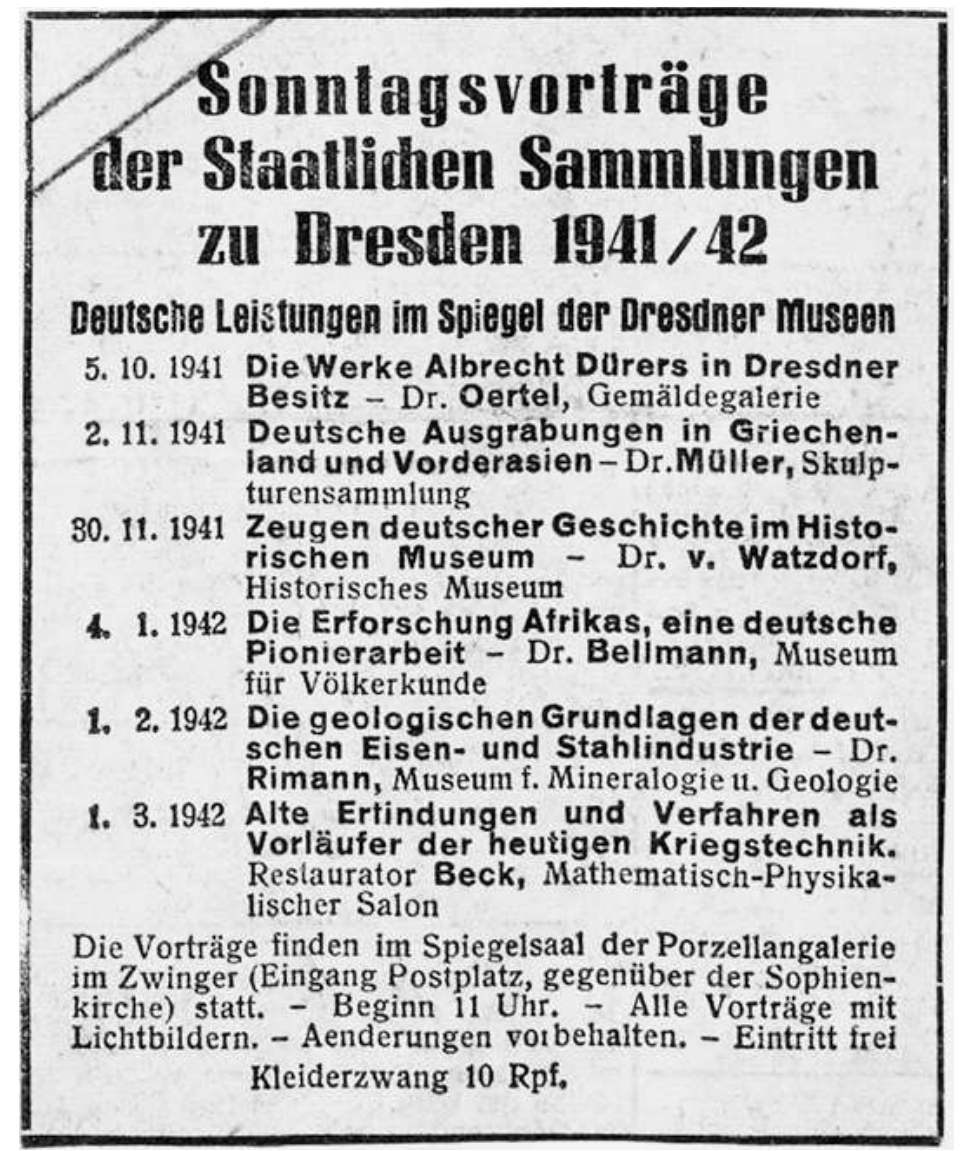

Museum. ${ }^{273}$ Die Ankündigung des Vortrages von > Eberhard Rimann über „Die geologischen Grundlagen der deutschen Eisen- und Stahl-Industrie“ im Kriegswinter 1942 betonte: „Der Vortragsraum ist geheizt, Eintritt frei“274.

Anlässlich des Vortrages von > Robert Oertel am 11. Februar 1940 über „Die Ausstellung des Spanischen Kunstbesitzes in Genf" im Vortragssaal des Albertinums verwies die Presse explizit darauf, dass dies einer der Vorträge sei, die den Museen mit geschlossenen Schausammlungen weiterhin die Möglichkeit gäben, in der Öffentlichkeit präsent zu sein. ${ }^{275}$ Die beiden Sonntagsvorträge, die > Alfred

\footnotetext{
273 Vgl. ebd., fol. 37; DNN, 21.11.1941, S. 4.

274 DA, 30.1.1942, S. 4.

275 Vgl. DA, 7.2.1940, S. 6. Siehe S. 229-233.
} 
Eintrittskarte Nr. 300 zum 2. Museumsvortrag 1943/44 at 28. November 1943, $10.30 \mathrm{Uhr}$ im Spiegelsaal der Porzellangalerie (Zwinger) Es wird gebeten, die Oberklelder obrugeben. Kleiderabloge $10 \mathrm{Rpt}$ Moves Wintiat trei

52 Eintrittskarte zum 2. Museumsvortrag 1943 am 28.11.1943
Beck vom Mathematisch-Physikalischen-Salon im März 1942 und im Februar 1943 über „Alte Erfindungen und Verfahren als Vorläufer der heutigen Kriegstechnik“ und „Die Frühzeit der Feinmechanik in Sachsen" hielt, zählten ebenso dazu, wie die Ausführungen von > Klaus Günther über „Deutsche Münzkunst der Hohenstaufenzeit.

Geistige und politische Kräfte des Deutschen Reiches der Hohenstaufen im Spiegel der Münzen“ im November 1943. ${ }^{276}$

Wenige Tage bevor er zum Militärdienst eingezogen wurde, referierte $\triangleright$ Franz Schubert vom Kupferstich-Kabinett im Januar 1944 über „Altdeutsche Graphik und ihre Beziehungen zur Plastik“. Im letzten sonntäglichen Museumsvortrag sprach am 19. März 1944 - Walther Fischer vom Museum für Mineralogie und Geologie im Spiegelsaal der Porzellansammlung über „Georg Agricola“.277

\section{Gtaatliđ̣e 5ammlungen für frunft und mil[en/d’aft}

\section{Muleumsvorteag 1943/44}

Sonntag, den 28. November 1943, 10.30 Uhr im Spiegel/aal Der Staatlichen porzellangalerie (3winger)

\section{Deutfche Münzkunft der fiohenftaufenzeit \\ Seiftige und politi(dhe fieâfte des Deut|chen Reidhes der fiohenftaufen im Spiegel dee muinjen mit fidatbilbeen De. Flaus Günther}

Eingang: Dorjellangalerie (jowinger), gegenüber Jer Sophienkirđe

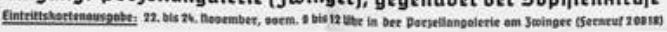

53 Plakat für den Museumsvortrag von Klaus Günther über „Deutsche Münzkunst der Hohenstauferzeit" am 28.11.1943

Anpassung der Vermittlungsstrategien im Krieg

Das hier vorgestellte, reichhaltige Spektrum unterschiedlicher Vermittlungsangebote, das die Staatlichen Sammlungen - auch während des Krieges - offerierten,

\footnotetext{
276 Vgl. DNN, 27.2.1942, S. 4; 13.2.1943; DA, 10.2.1943, S. 2; SKD, MPS, 1942/1943, E.-Reg. Nr. 49; HStA Dresden, 11125, Nr. 23081, fol. 1, 114, 172 f.

277 Vgl. HStA Dresden, 11125, Nr. 23053, fol. 94, 110; Nr. 23081, fol. 161, 213.
} 
54 Einladungskarte für die Museumsvorträge im Winterhalbjahr 1943/1944

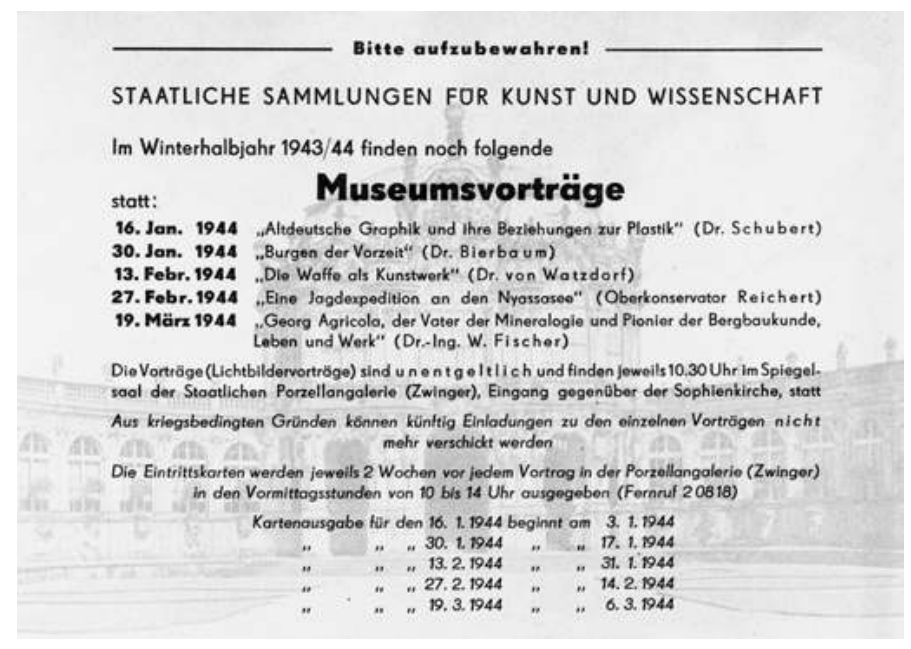

überrascht angesichts der Tatsache, dass die Sammlungsobjekte geschützt und erste Schausammlungen kriegsbedingt geschlossen werden mussten. Dieses umfangreiche Ausstellungs- und Veranstaltungsprogramm wurde seitens der Politik und Verwaltung nachhaltig gefordert. Noch im Februar 1941 instruierte der Leiter des SMV die Sammlungsdirektoren:

In einer Zeit, in der der größte Teil der Museumsschätze infolge ihrer Sicherstellung den Volksgenossen nicht in den Sammlungen selbst vorgeführt werden können [sic!], müssen Mittel und Wege gefunden werden, gerade der an den Staatlichen Sammlungen für Kunst und Wissenschaft so stark interessierten werktätigen Bevölkerung das wertvolle Kulturgut durch Vorträge und soweit möglich Veranstaltungen von Lichtbildwiedergaben mehr denn je nahe zu bringen. ${ }^{\text {278 }}$

Als Beweis für die kulturellen Bedürfnisse der Bevölkerung führte Göpfert deren Lichtspielhausbesuche an Sonntagvormittagen an. Er forderte explizit neue Mittel und Wege bei der Vermittlungsarbeit, d. h. eine innovative Angleichung der bisher genutzten Veranstaltungsformate an die kriegsbedingten Gegebenheiten.

Die intensive Nutzung der „Führungsvorträge“ und die zahlreichen Museumsvorträge an Sonntagvormittagen sind Reaktionen auf diese Forderungen. Fichtner berichtete dem Ministerium im Dezember 1942, dass die Organisation von Son-

${ }_{278}$ Leiter SMV, Göpfert, an Direktoren der Staatlichen Sammlungen (ohne Landesbibliothek, Münzkabinett), 13.2.1941, SKD, MPS, 1941, E.-Reg. Nr. 29; ebenso: SKD Archiv, 01/SKS 172, o. Pag. u. 01/KGM 7, fol. 74. 
derausstellungen auf große technische Schwierigkeiten stoße, aber dennoch wünschenswert sei. Unter Berücksichtigung der voranschreitenden Auslagerung der Objekte schlug er drei Alternativen für eine veränderte Ausstellungsstrategie vor:

1. Übernahme von geschlossenen Kollektionen von Ausstellungen, die schon an anderen Orten gezeigt wurden [...]

2. Bilderschauen [d.h. Ausstellungen von Fotografien, Anm. d. Autorin]. Diese wirken fast stets langweilig, wenn es nicht möglich ist, das Großfoto in den Dienst der Veranstaltung zu stellen.

3. Ausstellungen aus dem Depot der Sammlungen (Gruppe III) ${ }^{279}$.

$\mathrm{Zu}$ diesem Zeitpunkt öffneten zumindest noch drei Museen ihre Schausammlungen halbtags - das Museum für Tierkunde, das Museum für Mineralogie und Geologie sowie das Landesmuseum für Vorgeschichte.

Trotz aller Personal- und Budgetknappheit, trotz des dominierenden Objektschutzes und des immensen Aufwandes, den die Auslagerung von Objekten und deren konservatorische Betreuung an den Auslagerungsorten bedeutete, und trotz der Luftangriffe der Alliierten auf benachbarte Großstädte - wie Berlin ab Januar 1943 und Leipzig im Dezember 1943 - offerierten die Dresdner Museen noch bis 1944 Vorträge an Sonntagvormittagen und zeigten einzelne Sonderausstellungen. ${ }^{280}$ Die letzten Ausstellungen sollen hier als Beispiele für die Anpassung und Veränderung der Vermittlungsstrategien explizit vorgestellt werden.

\section{Ausstellung „Kostbarkeiten des Grünen Gewölbes im Lichtbild“}

Mit der kriegsbedingten Auslagerung der Objekte stellte sich die Frage, wie man die „Kostbarkeiten des Grünen Gewölbes im Lichtbild“ präsentieren könnte, obwohl die Museumsräume leer stehen. Der seit 1942 mit der Leitung des Grünen Gewölbes beauftragte Kustos, Kunsthistoriker $~$ Walter Holzhausen, hatte eine clevere Idee: Er thematisierte kurzerhand die Abwesenheit der Objekte in einer Ausstellung. Vom 19. September bis 15. November 1943 zeigte er eine großzügige Auswahl von Fotografien des Dresdner Künstlers Edmund Kesting in den damals nach der Bergung leer stehenden Räumen. ${ }^{281}$

\footnotetext{
279 Fichtner an SMV, 12.1942, HStA Dresden, 11125, Nr. 23054, fol. 177.

280 In den Staatlichen Museen zu Berlin wurden nur bis 1942 eigene Ausstellungen gezeigt, bis 1943 auch Schauen externer Veranstalter. Vgl. Ausstellungen der Staatlichen Museen zu Berlin 1933-1943, in: Grabowski/Winter 2013, S. 429-446.

${ }^{281}$ Vgl. W. Pr.: Die Kamera entdeckte ungeahnte Schönheiten. Kostbarkeiten des Grünen Gewölbes im Lichtbild, in: FK, 27.9.1943, S. 5; Ausstellung im Grünen Gewölbe verlängert, in: DZ, 11.11.1943, S. 3.
} 
Für Kesting hatte die Zusammenarbeit große Bedeutung. ${ }^{282} \mathrm{Er}$, der Kontakt zu Künstlern der Avantgarde pflegte, hatte 1933 auf Betreiben der Nationalsozialisten seine beiden privaten, an Bauhausideen orientierten Kunstschulen „Der Weg“ in Dresden und Berlin schließen müssen. Nach mehrfacher Durchsuchung seiner Wohnung und seines Ateliers hatten ihm die Nationalsozialisten untersagt, sein malerisches Werk auszustellen. Seiner bisherigen Einkommensmöglichkeiten beraubt, wurde nun die Fotografie, mit der er seit den 1920er-Jahren experimentierte, zur Haupterwerbsquelle. Bereits in den 1930er-Jahren hatte Kesting für Holzhausen die Kunstschätze im Grünen Gewölbe fotografiert. Doch seine Aufnahmen waren weit mehr als dokumentarische Fotografien - sie waren eigenständige Kunstwerke.

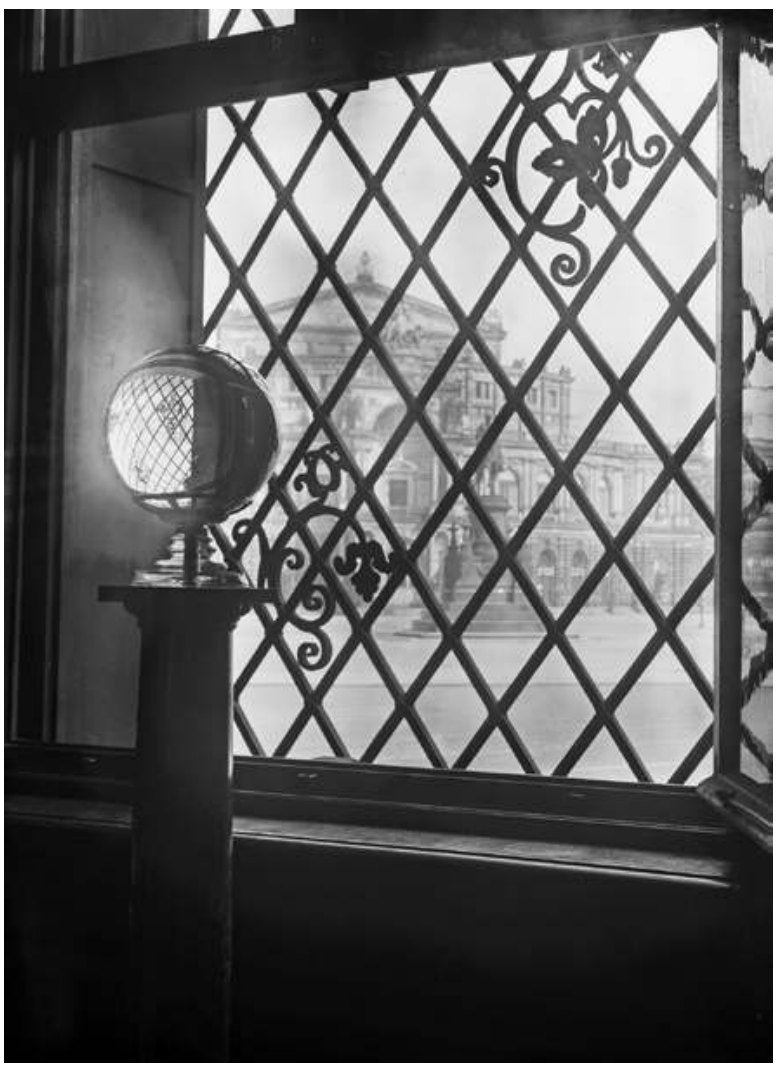

55 Bergkristallkugel, Fotografie von Edmund Kesting, um 1935

Er inszenierte die Objekte mittels

eines raffinierten Licht- und Schattenspiels und wählte neue, ungewohnte Blickwinkel. Nun, 1943, fertigte Kesting für die Ausstellung, die im Sinne des „Kampfes an der Heimatfront“ als „kriegswichtig“ angesehen wurde, Abzüge von den damals belichteten Glasnegativen an. Dadurch hatte er ein Einkommen und entging für die Zeit der Vorbereitungen der Einberufung zur Wehrmacht.

${ }^{282}$ Zu Kesting in der NS-Zeit vgl. Müller-Kelwing, Karin: Die Dresdner Sezession 1932 Eine Künstlergruppe im Spannungsfeld von Kunst und Politik, Hildesheim u. a. 2010 (Zugl. Dresden, Univ., Diss., 2008), S. 106, 143, 188, 372. Vgl. auch Werner, Klaus (Hg.): Edmund Kesting. Ein Maler fotografiert, Leipzig 1987; Wedhorn, Katja: Licht und Schatten. Neue Gestaltungsweisen in der Fotografie von 1920 bis 1960 und der Beitrag Edmund Kestings, Marburg 2012 (Zugl. Greifswald, Univ., Diss., 2009). 


\section{Kastbackeiten im Geïnen Gewölbe}

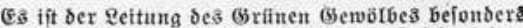
aut banfen, Daḱ fie ießs, wäbrent die Rofitbarfeiten ielber in fiderer Sut geborgen fint, eintge ber íbön. iten Stitde biejer weltberithmten Samminng im Qid)to bilb seigt. Und menn mu aud bie obotos teinen Er. fab ju bieten vermbigen fitr Die fehlende 28 irflidfeit. bent oft gerabezu erregenden 3 auber, ber von bicien funitbanbiverfliden Gegenitünben aus (Solb, Silber, Email und (Edelitein auteging, io gelingt es thren ood), einen शbglanz und \$3ideridbein von bem su geben, mas bier cinit lebentoia war. Dazu foumt, Dấ im Piфtbils _- Das oft aud auf sic Taritellumg von

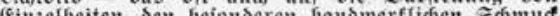

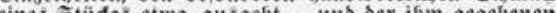

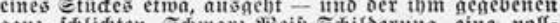

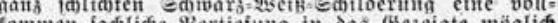
fommen fadifoe tit, in ber fid mandes offenbaren mas, was bem Q⿱üge

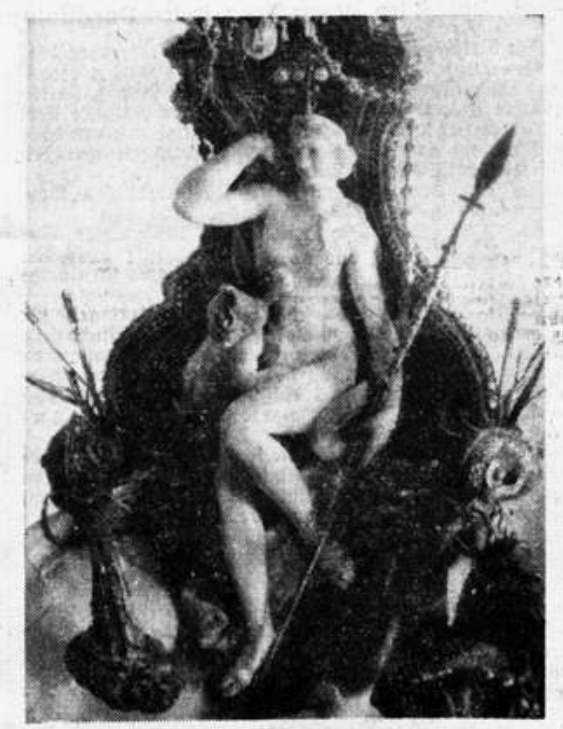

Johann Meldior Dinglinger: Das Bad der Diana Aufn. Kesting, Dresden

in bem fprifbenben GIana ber 2sirffidfeit untergeøt. 3um anderen aber auth - und in bicier Daxitellungs weife offenbart fid bam bie befondere tednifide und

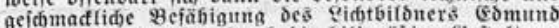
seid e it it - werben Durd die bilbmäsige Geitaltum ses photos. Sur die Einbezichuta eines bejonderen bes thes, ober inbezichum Sinterictes.

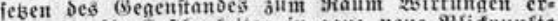
3ielt, sie die goitbarteiten in gand neite BIfdpunfte ritfen. (Man bente sum Beifpier an Das $\$$ boto bes

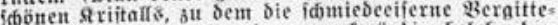
rum des fieniters in einen merfuitiois belebenden routrait tritt und bas mit ber (Eimbeatiebung aud) nod) gentrait trittsblifs auf das Evernfaus eine uns gemeine Bielfalt von Einsrüdent in eine. Sefautiobau gemteine jwintat.) griat, bab man me wie fie

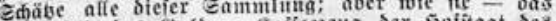
Der sofitatat bes (v) Qiditbilo Dem \&etrabter genentiberiteben, find fie inm

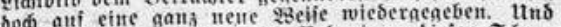

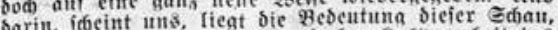
barin, redite Qidjt iebt. Leonore Kupke.

56 Dresdner Zeitung, 25.9.1943
Der Mut des Kustos, diesen Künstler zu beauftragen, wurde belohnt. In Erinnerung an die prachtvollen Gold- und Silberschmiedearbeiten der Sammlung lockten seine Fotos mitten im Krieg in nur zwei Monaten über 7600 Besucher an. ${ }^{283}$ Die Resonanz in der Presse war beeindruckend. Eine Rezension erwähnte explizit jenes „Photo des schönen Kristalls, zu dem die schmiedeeiserne Vergitterung des Fensters in einem merkwürdig belebenden Kontrast tritt $^{\text {" } 284}$. Aufgrund ihres Erfolges wurde die Ausstellung im Herbst 1943 in zwei anderen Städten - in Posen und Zwickau - gezeigt. ${ }^{285}$

Die Komplexität der Interpretationsmöglichkeiten allein dieser Ausstellung offenbart die unscharfe Grenze zwischen Anpassung und aktivem Nazitum. Holzhausen, seit 1937 Mitglied der NSDAP, pflegte seine seit den 1920er-Jahren bestehenden Verbindungen zu Künstlern der Avantgarde auch in der NS-Zeit, wie die Beauftragung Kestings zeigt. Gleichzeitig folgte er den kulturpolitischen Forderungen der $\mathrm{Na}$ tionalsozialisten - schließlich hatte Fichtner die Präsentation von großformatigen Fotos als adäquates Mittel der Ausstellungsgestaltung im Krieg bezeichnet. Holzhausens Handeln ist ein Beispiel für ambivalentes Handeln: Er organisierte mitten im Krieg eine vom Publikum angenommene Ausstellung und verschaffte einem Künstler, der in der NS-Zeit Einschränkungen

283 Vgl. Holzhausen an SMV, Abt. IV/7, 17.11.1943, HStA Dresden, 11125, Nr. 23087, fol. 76.

284 Kupke, Leonore: Kostbarkeiten im Grünen Gewölbe, in: DZ, 25.9.1943, o. S.

285 Weitere Stationen in Chemnitz, Dortmund und Hanau waren vorgesehen, mussten jedoch kriegsbedingt unterbleiben. Vgl. HStA Dresden, 11125, Nr. 23087, fol. 71, 74, $93 \mathrm{ff}$. 
erlitt, nicht nur Einnahmen durch die Ausstellungsarbeit, sondern auch einen Ankauf.

Im März 1944 beantragte Holzhausen ,in Anbetracht der Tatsache, daß mit den Blättern durch Ausstellungen gerade auch in luftgefährdeten Gebieten eine wirkungsvolle Kulturpropaganda für die Dresdner Museen getrieben werden kann ${ }^{\text {“286 }}$, die 150 Fotografien der Ausstellung von Kesting anzukaufen. Dies wurde innerhalb weniger Tage genehmigt und ein Betrag von 1950 RM an Kesting ausgezahlt. ${ }^{287}$

\section{Ausstellung „Veit Stoß“}

Ein weiteres Beispiel für eine Ausstellung, die ohne Originalobjekte auskam, ist die Schau „Veit Stoß", die das Historische Museum vom August bis Oktober 1944 im Lichthof des Johanneums zeigte. ${ }^{288}$ Es war eine Wanderausstellung, die im Auftrag des RMWEV entstanden war und über die Publikationsstelle Berlin-Dahlem vermittelt wurde. Die Weitergabe zwischen zwei Präsentationsorten organisierten die jeweiligen Museen direkt bei Teilung der anfallenden Transportkosten. Ein Katalog wurde bei der Druckerei Korn in Breslau, wo 1938 die erste dieser „Veit Stoß"-Ausstellungen stattgefunden hatte, gedruckt - inhaltsgleich, doch jeweils mit anderem Umschlagblatt. ${ }^{289}$ In Dresden äußerte man spätestens im April 1943 Interesse an der Übernahme, an der $>$ Fritz Fichtner sowie $\triangleright$ Walter Holzhausen und $\triangleright$ Erna von Watzdorf beteiligt waren. ${ }^{290}$

\footnotetext{
286 Holzhausen an SMV, Abt. IV/7, 4.3.1944, ebd., fol. 78.

287 Vgl. ebd. fol. 78 f. Der Antrag erfolgte am 6.3.1944, die Auszahlung an Kesting am 13.3.1944. Die 150 Fotografien (je $30 \times 40 \mathrm{~cm}$ ) müssen als Kriegsverlust gelten - sie wurden auf der Festung Königstein ausgelagert, doch danach verliert sich ihre Spur. Vgl. Holzhausen an Reichsstatthalter, Landesregierung, Abt. IV S, 26.3.1945, SKD Archiv, 02/VA 50, fol. 165-166. Vgl. auch Schmidt, Werner: Kesting in Dresden, in: Staatl. Kunstsammlungen Dresden, Kupferstich-Kabinett (Hg.): Edmund Kesting. Gemälde, Zeichnungen und farbige Blätter, Graphik, Photographien, Ausstellungskatalog, Dresden 1988, S. 3 f. Vgl. Müller-Kelwing, Karin: Ein Museum ohne Objekte?, in: Staatliche Kunstsammlungen Dresden, Marion Ackermann und Noura Dirani (Hg.): Museum of untold stories. Objekte und Geschichten aus den Staatlichen Kunstsammlungen Dresden. Ausgewählt und erzählt von den Mitarbeiterinnen und Mitarbeitern unserer Sammlungen, Band 1, Dresden 2018, S. 63-64. 288 Veit Stoß. Ausstellung Dresden 1944, Ausstellungskatalog, Breslau 1944, SKD, Kunstbibliothek. Vgl. Nagel 2015, S. 27.

289 Vgl. BArch, R 43/II/1236/a; R 55/717; R 153/778; R 153/779. Kataloge sind bekannt für Stationen in Dresden, Görlitz, Krakau und Berlin. Dort wurde die Ausstellung 1941 im KaiserFriedrich-Museum gezeigt. Vgl. Grabowski/Winter 2013, S. 445.

290 Die näheren Umstände sind unbekannt. Vgl. HStA Dresden, 11125, Nr. 22884, fol. 121 u. Nr. 23087, fol. 80 .
} 
In der Ausstellung wurden keine Originalobjekte, d.h. keine Schnitzereien, gezeigt, sondern riesige, monumentale Fotografien, u. a. vom Bamberger Altar und vom Marienaltar aus Krakau. Letztere stammten vom polnischen Fotografen Stanisław Kolowca. Die überlieferten Ausstellungsansichten lassen zunächst eine erzählerisch-dokumentarische Foto-Schau vermuten. Doch diese

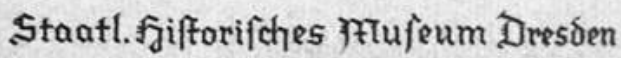

\section{Deít Stoß}

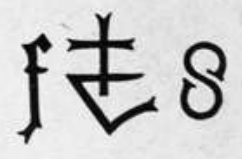

fusfellung Dresten 194,43

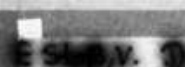

57 Katalog der Ausstellung „Veit Stoß“, Dresden 1944 diente eindeutig ideologischen Zielen.

Bereits anlässlich der ersten Station der Wanderausstellung hatte im Juli 1938 eine Presseanweisung informiert:

Hinter der Breslauer Ausstellung steht das Propagandaministerium, was aber nicht gesagt werden darf. Die Ausstellung ist ausgesprochenermassen eine Abwehrausstellung, die die künstlerische Herkunft, die Genealogie, das Werk selbst und die Auswirkung der Kunst von Veit Stoss im Osten zeigen wird. In erster Linie handelt es sich also um eine politische Ausstellung, bei der das Kuenstlerische als Deckmantel benutzt wird. Diesen Mangel moege man aber etwas mit dem Mantel der christlichen Naechstenliebe zudecken. ${ }^{291}$

Der politisch-ideologische Impetus der Ausstellung war damals kaum zu erkennen; anders 1944, bei ihrer Station in Dresden. Krakau war nach dem Einmarsch der deutschen Wehrmacht im Oktober 1939 zum Verwaltungssitz des besetzten Gebietes geworden. Im Spätherbst 1939 bereisten deutsche Museumsbeamte darunter $\triangleright$ Hans Posse, $\triangleright$ Fritz Fichtner und $\triangleright$ Hans Kummerlöwe $e^{292}-$ das „Gene-

\footnotetext{
${ }^{291}$ Pressemeldung 7. Juli 1938, in: Peter, Karin (Hg.): NS-Presseanweisungen der Vorkriegszeit. Edition und Dokumentation, Bd. 6/I, 1938, München 1999, S. 632.

292 Siehe S. $142 \mathrm{f}$.
} 


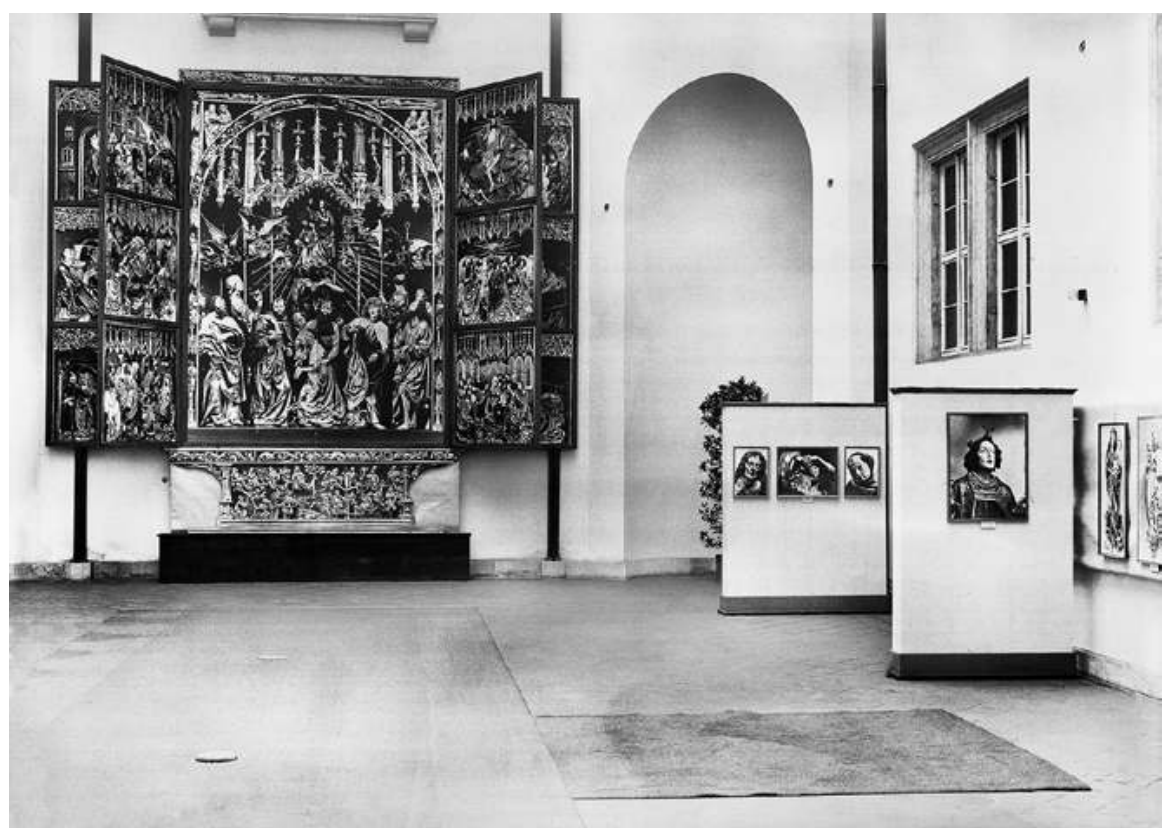

58 Blick in die Ausstellung „Veit Stoß“ im Historischen Museum, 1944

ralgouvernement", um deutsche Kunst in den bisher polnischen Museen und Privatsammlungen aufzuspüren und diese nach Deutschland zu bringen. Auch der Marienaltar in Krakau wurde abtransportiert - am 5. Januar 1940 teilte Albert Speer, Generalbauinspektor für Berlin, der Reichskanzlei mit: „Der Führer hat mich gestern Mittag [...] beauftragt, die Überführung des Krakauer Marienaltars von Veit Stoss nach Nürnberg in die Wege zu leiten. “293

Eingedenk dieses historischen Kontextes hatte die Stoß-Ausstellung eine klare ideologische Dimension: Sie propagierte und feierte den Kunstraub der Nationalsozialisten, indem sie mit den großformatigen Fotos des Marienaltars an ein Kunstwerk erinnerte, das durch die Nationalsozialisten geraubt worden war. Damit diente die Ausstellung primär politischen Interessen und ist ein Beispiel für die ideologische Instrumentalisierung von Kulturgut.

293 Speer an Reichskanzlei, Lammers, 5.1.1940, BArch, R 43/II/1236/a, fol. 96. Im Herbst 1944 lagerte der Altar zum Schutz vor Bomben in Nürnberg im Bunker unter der Burg. Erst 1946 wurde er an Polen zurückgegeben. Vgl. Dehnel 2004, S. 308 f. und Waltoś, Stanisław: Die Entführung des Marienaltars von Veit Stoß nach Nürnberg, in: Löw/Nuding 2014, S. $127-$ 138. 


\section{Ausstellung „Serienporzellan für Küche, Keller, Kantine und Kaserne“}

1944, als die seit vier Jahren fertiggestellten, neuen Räume der Porzellansammlung im Zwinger kriegsbedingt noch immer nicht eröffnet werden konnten, ${ }^{294}$ entschied $\triangleright$ Fritz Fichtner, sein berufliches Netzwerk zu nutzen, um die leeren Räume mit einer Ausstellung zu füllen. Er plante, im Februar 1944 eine Ausstellung von „Serienporzellan für Küche, Keller, Kantine und Kaserne“ zu zeigen. ${ }^{295}$ Allerdings war diese eher ein sporadisches „work in progress“, denn Fichtner fehlte aufgrund seiner vielen Aufgaben die nötige Zeit, um die Idee konsequent umzusetzen, auch hinderten ihn die Zeitläufte daran.

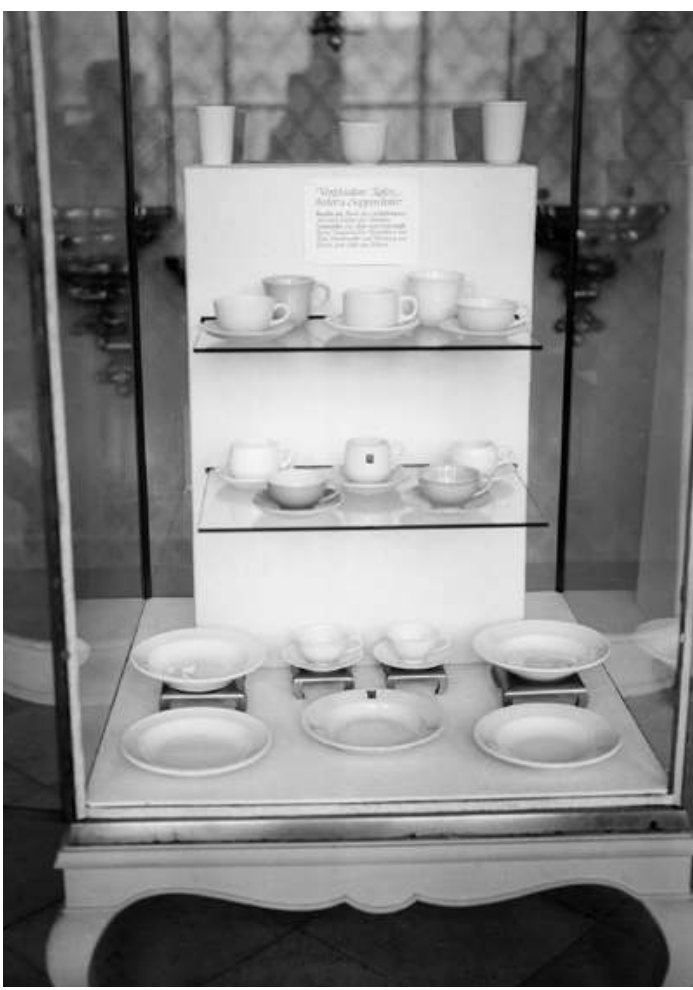

59 Vitrine in der Ausstellung „Serienporzellan für Küche, Keller, Kantine und Kaserne“ in der Porzellansammlung, 1944

Als Mitglied der Deutschen Keramischen Gesellschaft kontaktierte er diverse Porzellanfabriken. Erste Einlieferungen, u. a. von der Staatlichen Porzellanmanufaktur Meißen, erreichten Dresden ab März 1944. Danach wurde die Ausstellung bei jeder weiteren Objekteinlieferung erweitert, ebenfalls nach der Ankunft der Stücke aus der Geschirrserie „Amt Schönheit der Arbeit" der Porzellanfabrik Bauscher aus Weiden. Fichtner machte aus der Not eine Tugend: Indem er die aktuelle industrielle Kriegsproduktion von Porzellan zum musealen Objekt erhob und damit das Museum letztlich die Aufgabe einer Messe übernehmen ließ, versuchte er, über die längst nicht mehr vorhandene Funktionsfähigkeit der Museen hinwegzutäuschen.

Indes bewirkte der „Erlass des Führers über den totalen Kriegseinsatz" vom 25. Juli 1944, dass Joseph Goebbels als Reichsbevollmächtigter für den totalen Kriegseinsatz im August 1944

\footnotetext{
294 Siehe S. $187 \mathrm{f}$.

295 Vgl. Staatliche Sammlungen, Jahresbericht, 1943/1944, HStA Dresden, 11125, Nr. 23053 , fol. 151 und diverse Akten, SKD Archiv, 01/PS 54, Bd. 1.
} 


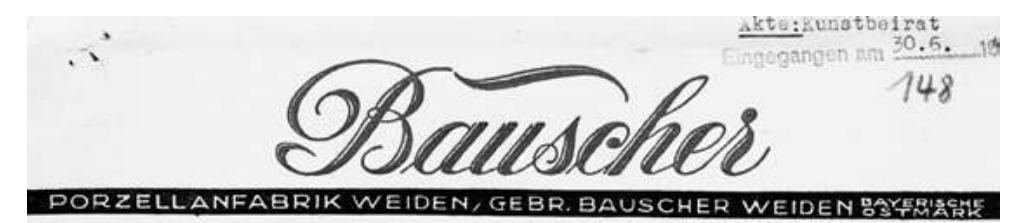
WeiBe und dokorierte Hoteporzellane
Reuerfeste Koch- Und Backgesohirro
Tochnische Porzellane
"Luzifer"

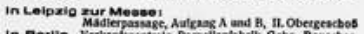

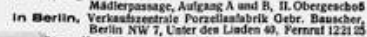

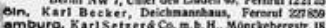
tber so Jahreast

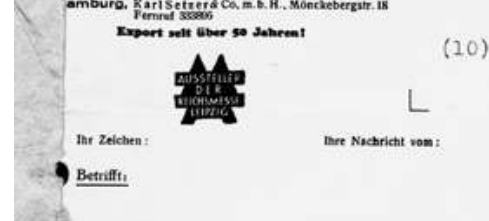
Herrn Direktor Profeseor Dr.F.Pichtner 10) $\frac{\text { Dresden A I }}{\text { Zwinger }}$

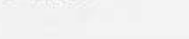

Unsere Zeichen: $\mathrm{AB} / \mathrm{Z} 1$.

60 Brief der Porzellanfabrik Gebr. Bauscher, Weiden, an Fritz Fichtner, Porzellansammlung Dresden, 28.6.1944
Sehr geehrter Herr Propessor !

Ihr an unseren Herrn Direktor Lang ferichtetes Schreiben vom 20. Juni wurde una zur Brledigung ibergeben, und wir gind gerne bereit, Ihnen fir die in August vorgegehene Ausstellung von Kriegserienware zwei Satze der von uns jetzt noch gefertigten Geschirrform "Amt Sohönheit der Arbeit"

zur Verfugung zu stellen. Ba ist dies die einzige Gegchirrserie, die wir - wenn auch in der Kriegszusammenstellung gegenwartic noch zeicen können.

Vir werden an die aufgegebene Adresse die zugedachten Stlicke Anfang Juli per Bxpressgut senden, sodaß Sie rechtzeitig in den Beaitz der Gegenstande kommen werden.

Wir winschen der Ausstellung einen vollen Brfolg und begríken Sie mit

\section{1 sulstellung.}

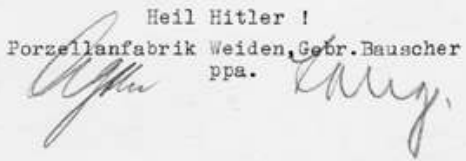

\section{Sadtbearbeiter. Herr} ALLE VON UNS DEKORIERTEN GESCHIRRE TRAGEN DIESEN

die Schließung der letzten Kultureinrichtungen verfügte, was auch das Ausstellungswesen komplett zum Erliegen brachte. ${ }^{296}$ Fichtner sah sich nun gezwungen, den Leihgebern mitzuteilen:

296 Vgl. Erlaß des Führers über den totalen Kriegseinsatz, 25.7.1944, in: RGBl., Teil I, Nr. 34, 1944, S. 161. 
Die Ausstellung steht, wird keramischen Interessenten auch zugängig gemacht. Leider muß sie vorläufig der Öffentlichkeit vorenthalten werden, da Ausstellungen usw. nach dem bekannten Erlaß des Herrn Reichsministers z. Zt. nicht erlaubt sind. ${ }^{297}$

Er war davon überzeugt, dass die Ausstellung bald wieder öffnen könne. Nur wenige Tage zuvor hatte er, trotz des „Erlasses über den totalen Kriegseinsatz“ eine Leihgabe aus dem Münzkabinett für eine Ausstellung des „Heimatwerks Sachsen“ genehmigt. ${ }^{298}$ Die Interimslösung in der Porzellansammlung war jedoch nicht mehr lange aufrechtzuerhalten, ohne die Objekte zu gefährden. Nach der Zerstörung des Museums für Tierkunde am 7. Oktober 1944 hatte der Schutz der Objekte absoluten Vorrang und wurde zur alleinigen Aufgabe der Museumsmitarbeiter. Damit endete die in der Öffentlichkeit wahrnehmbare Museumsarbeit in Dresden. Doch Fichtner ließ die Leihgaben in der Porzellansammlung, in der Hoffnung, „daß zu späterer Zeit die Ausstellung sofort wieder aufgestellt werden kann“299, erst Anfang Dezember 1944 verpacken.

Einen Monat später ordnete Reichsstatthalter Mutschmann an:

Für die Leiter der Sammlungen darf es zurzeit keine andere Sorge geben, als Tag und Nacht über die letzten Möglichkeiten der Erhaltung aller ihnen anvertrauten Gegenstände einschließlich der Büchereien und des Inventars nachzudenken und entsprechend zu handeln. Die laufenden wissenschaftlichen Arbeiten haben demgegenüber völlig zurückzutreten. ${ }^{300}$

Bis nach Kriegsende blieben alle Staatlichen Sammlungen geschlossen.

\footnotetext{
297 Porzellansammlung, Fichtner, an Carstens-Uffrecht K. G. Haldensleben, 5.9.1944, SKD Archiv, 01/PS 54, Bd. 1, fol. 94.

298 Vgl. HStA Dresden, 11125, Nr. 22894, fol. 82 ff.

299 Porzellansammlung, Fichtner, an Deutsche Keramische Gesellschaft, 1.12.1944, SKD Archiv, 01/PS 54, Bd. 1, fol. 186.

300 Reichsstatthalter Mutschmann an Direktoren der Staatlichen Sammlungen, 19.1.1945, SKD, MK, 1945, fol. 2.
} 


\section{Ausblick - Die Situation der Staatlichen Sammlungen nach Kriegsende}

Bei den Luftangriffen auf Dresden in der Nacht vom 13. auf den 14. Februar 1945 wurden auch die Museumsgebäude weitgehend zerstört. Durch den Angriff am 2. März 1945 brannte das Japanische Palais mit der Sächsischen Landesbibliothek vollständig aus. Damit war keines der bisher von den Staatlichen Sammlungen genutzten Gebäude noch voll funktionsfähig. Die vorsorgliche Auslagerung der Sammlungsobjekte außerhalb der Stadt erwies sich als Rettung vor der ansonsten gewiss gewesenen Zerstörung. Im Wesentlichen überstanden sie den Krieg. ${ }^{1}$ Unmittelbar nach Kriegsende wurde - bereits unter Aufsicht der sowjetischen Trophäenbrigaden - damit begonnen, die ausgelagerten Objekte nach Dresden bzw. die Kunstwerke nach Schloss Pillnitz zurückzuführen, bevor sie von dort in die Sowjetunion abtransportiert wurden. ${ }^{2}$

Viele Mitarbeiterinnen und Mitarbeiter der Staatlichen Sammlungen hatten bei den Luftangriffen auf Dresden selbst ihre Wohnung und ihren Besitz verloren, $\triangleright$ Kurt Hoppe bereits im Oktober 1944. Im Februar 1945 waren davon betroffen: $>$ Alfred Beck, $>$ Ragna Enking, $>$ Fritz Fichtner, $>$ Klaus Günther, -Walter Holzhausen, $\triangleright$ Wilhelm Meise, $\triangleright$ Walter Müller, $>$ Rudolf Schwarze, $\triangleright$ Hermann Voss, $\triangleright$ Fritz Wiedemann und $\triangleright$ Siegfried Wolf aus den Museen sowie von der Sächsischen Landesbibliothek $>$ Bruno Faass, $>$ Hans Hofmann, $\triangleright$ Charlotte Holzhausen, $\triangleright$ Jacob Jatzwauk, $\triangleright$ Hermann Neubert, $\triangleright$ Hubert Richter und $\triangleright$ Dorothee von Watzdorf. Sie fanden Unterkunft bei Verwandten, Freunden oder Kollegen, z. B. C. Holzhausen bei $>$ Martin Bollert und Hofmann bei $\triangleright$ Ewald Jammers. Mehrere lebten für einige Tage oder Wochen - z.T. mit ihren Familien - an den Auslagerungsorten, wie W. Holzhausen auf der Festung

\footnotetext{
1 Beschädigungen, Zerstörung und Verlust von Werken sind nicht Thema dieser Studie. Weiterführend vgl. u. a. zur Gemäldegalerie Rudert 2015; Merseburger, Carina und Claudia Müller: Kriegsverluste der Dresdner Gemäldegalerie. Eine aktuelle Bestandsaufnahme, in: Dresdener Kunstblätter. 62. Jg., H. 4, 2018, S. 26-37. Noch heute gelten 410 Werke der Gemäldegalerie Alte Meister und 160 Werke der Galerie Neue Meister sowie über 200.000 Bände der Sächsischen Landebibliothek als kriegsbedingt vermisst. Vgl. Staatliche Kunstsammlungen Dresden, Abteilung Forschung und wissenschaftliche Kooperation und Daphne-Projekt 2018, S. 59 und https://nsraubgut.slub-dresden.de/slub-projekte/ns-raubgut-erw-nach-1945/ und https:// www.slub-dresden.de/recherche/kriegsverluste/nachweiskatalog/, Zugriff: 6.12.2019.

2 Vgl. Lupfer/Nagel 2016, S. 281-286. Vgl. Enking 2004, S. 84-92; Schmidt, Werner: Die Staatlichen Sammlungen Dresden nach dem 2. Weltkrieg, in: ebd., S. 93-112, hier: 93-96.
} 
Königstein und Günther, Schwarze, Voss sowie Wiedemann im Schloss Weesenstein. $^{3}$

Beim Luftangriff im Februar 1945 kam Landesbibliothekar $\gg$ Gottfried Benndorf beim Versuch, den brennenden Dachstuhl seines Dienstortes, des Japanischen Palais, zu löschen, ums Leben. Von zwei weiteren Mitarbeitern der Bibliothek starben nahe Angehörige in dieser Nacht: $\triangleright$ Karl Assmann verlor seine Tochter und $\triangleright$ Hubert Richter seine Frau. Zwei weitere, damals noch als Mitarbeiter der Staatlichen Sammlungen geführte Personen, die allerdings im Militärdienst standen, kamen während des Krieges ums Leben: $>$ Helmut Schneider starb im März 1945 in einem Dresdner Lazarett und $\triangleright$ Franz Schubert muss als kriegsbedingt vermisst gelten. ${ }^{4}$

Ab April 1945 verließen mehrere Mitarbeiter die Staatlichen Sammlungen und auch die Stadt freiwillig. Die Gründe dafür waren vielfältig und lassen sich im Einzelfall nicht eindeutig belegen. Ursächlich waren u. a. die Verzweiflung nach der Zerstörung der Stadt, der erlebte Verlust des eigenen Wohnraumes und Besitzes, die durch die nationalsozialistische Ideologie geschürte Angst vor den nahenden sowjetischen Truppen sowie die damit verbundene Furcht, sich für die Tätigkeit im Nationalsozialismus verantworten zu müssen. Noch vor Kriegsende, im April 1945, verließ • Walter Holzhausen mit seiner Familie Dresden. Über Halsbach bei Freiberg ging er nach Altenburg und von dort 1947 nach Bonn, wo er später Leiter der Städtischen Kunstsammlungen wurde. \& Walter Müller, der bereits aufgrund seines Gesundheitszustandes seit 1942, obwohl er das entsprechende Alter hatte, vergeblich um seine Pensionierung gekämpft hatte, zog im Mai 1945 zu Verwandten nach Oberschlema im Erzgebirge und später ins bayerische Riederau am Ammersee. Im Juni 1945 verließ $\triangleright$ Ewald Jammers gemeinsam mit seiner Familie Sachsen. Zunächst lebte er in Bergheim bei Köln und arbeitete als Lehrer, ab 1951 wurde er wieder im Bibliotheksdienst tätig, erst in Düsseldorf, später in Heidelberg.

Mit $\triangleright$ Fritz Fichtner und $>$ Hermann Voss flohen zwei der während der NS-Zeit hauptverantwortlichen Museumsdirektoren aus Dresden in die westlichen Besatzungszonen. Fichtner setzte sich im Mai 1945 nach Bayern ab. Nachdem er im März 1948 von der Spruchkammer als „Mitläufer“ eingestuft worden

\footnotetext{
3 Vgl. Müller-Kelwing, Karin: Mitarbeiter der Staatlichen Sammlungen für Kunst und Wissenschaft als Akteure im Schloss Weesenstein von 1942 bis 1946, in: Staatliche Schlösser, Burgen und Gärten Sachsen 2018, S. 93-101.

4 Von den wissenschaftlichen Mitarbeitern, die bereits während der NS-Zeit die Staatlichen Sammlungen verlassen hatten, um andernorts zu arbeiten, waren $\triangleright$ Walter Grünberg und $\triangleright$ Walter Kersten im Krieg gefallen, $\triangleright$ Artur Krüss und $\triangleright$ Berthold Pfaul gelten als kriegsbedingt vermisst.
} 
war, wurde er ab dem Wintersemester 1948/49 wieder in der Lehre tätig, zunächst in Erlangen, später auch in Bamberg. Voss nahm seine Arbeit als Direktor der Gemäldegalerie wieder auf. Von seiner Dienstreise im Juli 1945 nach Wiesbaden kehrte er allerdings nicht mehr zurück. Er war in der amerikanischen Besatzungszone verhaftet worden und lebte nach seiner Entlassung als freischaffender Kunsthistoriker in München. Da er nie Mitglied der NSDAP war und seine Mitarbeit am „Sonderauftrag Linz" verschwieg, galt er als „unbelastet. ${ }^{5}$

Weiterhin als Mitarbeiter der Staatlichen Sammlungen wurden sechs Personen geführt, die sich bei Kriegsende in Kriegsgefangenschaft befanden. Sie kehrten ab August 1945 nach Dresden zurück. Erst $\gg$ Robert Oertel, 1947 -Erhart Kästner und $~$ Artur Pietzsch. 1948 folgten im Frühjahr - Walther Häntzschel und im Juni $>$ Wilhelm Meise. $>$ Michael Hesch ging direkt aus der Kriegsgefangenschaft in die westli-

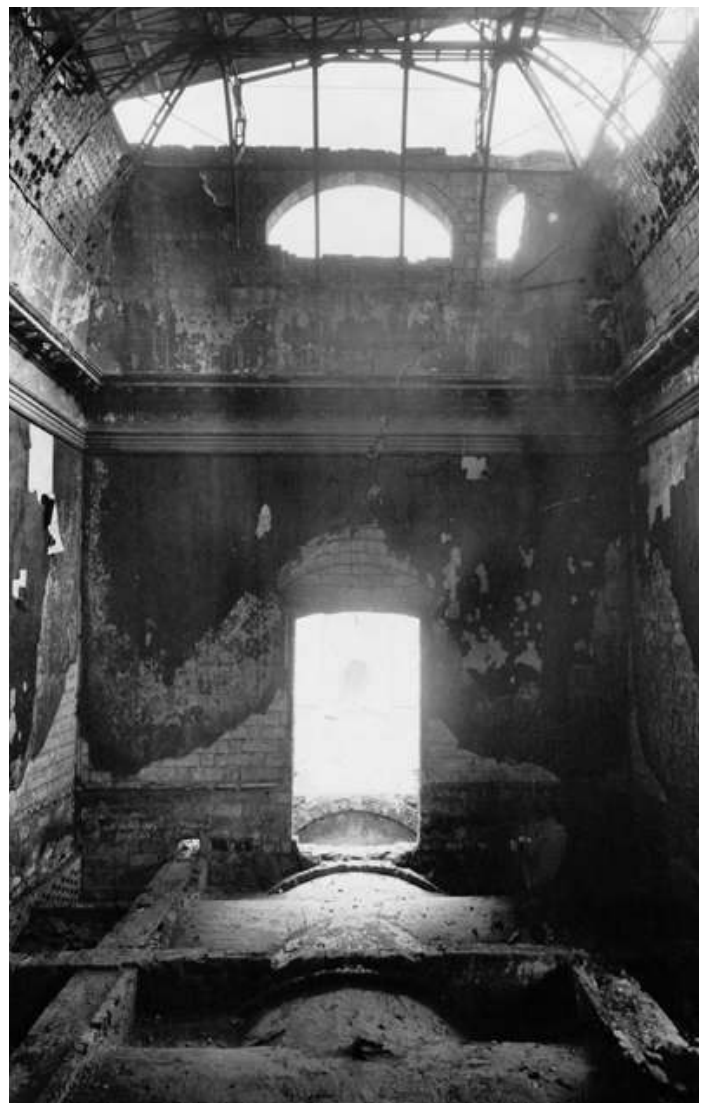

61 Zerstörte Sempergalerie, Dresden, nach Februar 1945 chen Besatzungszonen.

Als ehemalige NSDAP-Mitglieder kehrten Kästner und Meise nicht wieder an die Staatlichen Sammlungen zurück. Kästner war in Abwesenheit 1945 entlassen worden und arbeitete nach seiner Rückkehr als freischaffender Publizist. Meise zog nach Berlin, wo er als Zoologe an der Humboldt-Universität tätig wurde, bevor er 1954 über Westberlin nach Hamburg übersiedelte. Eine Ausnahme bildet Oertel, der trotz früherer NSDAP-Mitgliedschaft zunächst weiterhin an der Gemäldegalerie tätig war. ${ }^{6}$

\footnotetext{
5 Vgl. Iselt 2010, S. 387-395.

6 Vgl. Iselt, Kathrin: Robert Oertel (1907-1981) - Kustos der Gemäldegalerie Dresden 1939-1946. Eine biografische Skizze, in: Dresdener Kunstblätter, H. 1, 2012, S. 45-54, hier: $49-52$.
} 
Im Herbst 1945 kam es zu einer ersten Entlassungswelle - infolge der „Verordnung über den personellen Neuaufbau der öffentlichen Verwaltung", am 17. August 1945 von der Sowjetischen Militäradministration Deutschland (SMAD) erlassen, begann man mit der Entnazifizierung. ${ }^{7}$ Mitarbeiter, die Mitglieder der NSDAP oder ihrer Gliederungen waren, mussten entlassen werden. Dies galt auch für die Staatlichen Sammlungen. ${ }^{8}$ Viele der auf den Entlassungslisten notierten Mitarbeiter wurden jedoch vorerst aus pragmatischen Gründen in den Sammlungen belassen, da man ihre Kenntnisse über die ausgelagerten Kunstwerke benötigte. Als Argument wurde seitens der Sächsischen Landesverwaltung gegenüber der SMAD in Dresden deren „Befehl Nr. 85 “ aufgeführt, der im Oktober 1945 die Erfassung und Sicherstellung der musealen Werte und die Erneuerung der Tätigkeit der Museen in der Sowjetischen Besatzungszone anordnete.

Zunächst waren vor allem die Mitarbeiterinnen und Mitarbeiter der Sächsischen Landesbibliothek von den Entlassungen betroffen. Am 30. September 1945 wurde $\triangleright$ Jacob Jatzwauk entlassen, der kein Parteimitglied gewesen war. Zwei Wochen später folgten $>$ Helene Barthel, $\triangleright$ Dorothee Denecke, $\triangleright$ Dorothee von Watzdorf und Ende Oktober 1945 Direktor $\triangleright$ Hermann Neubert. Mitte November 1945 setzten sich diese Entlassungen fort mit $\gg$ Ulrich Dähnert, $>$ Bruno Faass und $\triangleright$ Erhart Kästner. Nun waren auch 22 Mitarbeiter der Museen betroffen, darunter $\triangleright$ Kurt Hoppe, $\triangleright$ Kurt Köhn, $>$ Arthur Leuschner, $>$ Paul Täubrich, •Fritz Wiedemann und $\triangleright$ Johannes Draeseke, der zwar kein NSDAP-Mitglied, aber förderndes Mitglied der SS gewesen war. ${ }^{9}$

Mehrere ehemalige Parteimitglieder, wie $\triangleright$ Robert Oertel, $\triangleright$ Alfred Unger, -Alfred Beck, $>$ Hans Loos, $\triangleright$ Curt Sander, $>$ Klaus Günther und $>$ Rudolf Schwarze verblieben vorerst an den Museen. $\triangleright$ Siegfried Wolf wurde als früherer Mitarbeiter trotz seiner NSDAP-Mitgliedschaft erst nach dem Krieg wieder eingestellt. Möglich war dies aufgrund der „Direktive 24“ vom Januar 1946, die eine Weiterbeschäftigung nomineller Parteimitglieder gestattete. ${ }^{10}$

\footnotetext{
Vgl. „Verordnung über den personellen Neuaufbau der öffentlichen Verwaltung“, 17.8.1945, Amtliche Nachrichten der Landesverwaltung Sachsen 1945, Nr. 4/5. Vgl. Widera, Thomas: „... eine gute saubere anständige politische Gesinnung“. Entnazifizierung als Instrument der Diktaturdurchsetzung in Dresden 1945, in: Behring, Rainer und Mike Schmeitzner (Hg.): Diktaturdurchsetzung in Sachsen. Studien zur Genese der kommunistischen Herrschaft 1945-1952, Köln/Weimar/Wien 2003, S. 269-296.

8 Vgl. SKD Archiv, 02/VA 162. Vgl. Iselt 2010, S. $323 \mathrm{ff}$.

9 Vgl. SKD Archiv 02/VA 162. Köhn arbeitete von 1958 bis 1971 erneut als Restaurator am Grünen Gewölbe.

10 Vgl. ebd., fol. 43-67; 02/VA 172, fol. 153.
} 
Drei der ehemaligen wissenschaftlichen Mitarbeiterinnen und Mitarbeiter der Staatlichen Sammlungen, die der NSDAP nie beigetreten waren, wurden jetzt wichtige Aufgaben übertragen: $>$ Karl Assmann, $>$ Ragna Enking und - Walther Fischer. Assmann wurde mit der Entlassung von Neubert im Oktober 1945 zum Direktor der Sächsischen Landesbibliothek ernannt. Fischer wurde am 14. Oktober 1945 zum Leiter der Zentralkanzlei der Sammlungen, Enking zu seiner Stellvertreterin ernannt. Enking und Fischer nutzten diese neue Position, um sich für den Verbleib ihrer Kolleginnen und Kollegen an den Sammlungen einzusetzen, hatten allerdings wenig Erfolg damit. ${ }^{11}$

Im April 1946 wurde Fischer zum Direktor des Museums für Mineralogie und Geologie sowie zum Direktor der naturwissenschaftlichen Museen ernannt, während Enking, die seit November 1945 Direktorin der Skulpturensammlung war, zur Direktorin der Staatlichen Kunstsammlungen ernannt wurde. In dieser Funktion hielt sie zur Eröffnung des neuen Zentralmuseums in Pillnitz eine Rede. Wenige Tage danach wurde sie mit 16 anderen Mitarbeitern zum 31. Juli 1946 fristlos entlassen. ${ }^{12}$ Betroffen waren acht Wissenschaftler und neun technische Mitarbeiter, darunter $>$ Herbert Bellmann, $>$ Ragna Enking, $>$ Walther Fischer, •Klaus Günther, $>$ Robert Oertel, ^Gottfried Reimer, $\triangleright$ Erna von Watzdorf, - Siegfried Wolf sowie $\bullet$ Alfred Unger, $\triangleright$ Curt Sander und $\triangleright$ Rudolf Schwarze. Fünf davon - Bellmann, Enking, Fischer, Reimer, Watzdorf - waren keine Mitglieder der NSDAP gewesen, allerdings hatten Reimer und Oertel für den „Sonderauftrag Linz“ gearbeitet.

Enking verließ Dresden und arbeitete freiberuflich in Berlin und in Rom. Oertel zog im Herbst 1946 nach Freiburg i. Br. Nachdem er dort an der Universität tätig war, kehrte er 1958 in den Museumsdienst zurück, erst in München, ab November 1964 als Direktor der Gemäldegalerie in Westberlin. Watzdorf arbeitete freiberuflich und siedelte nach Hessen über. Reimer, der im Dezember 1946 von der SMAD kurzzeitig verhaftet wurde, gelang es, seine Mitarbeit am „Sonderauftrag Linz“ zu verschleiern und in Döbeln freiberuflich zu arbeiten. Nach anfänglich freiberuflicher Tätigkeit siedelte Fischer 1948 nach Idar-Oberstein über, wo er die Fachschule für Edelsteinbearbeitung leitete. Günther arbeitete nach der Entlassung zunächst ebenfalls freiberuflich, bevor er nach Berlin

${ }_{11}$ Vgl. Walther Fischer und Ragna Enking an Landesverwaltung Sachsen, Kulturabteilung, Grohmann, 3.8.1945, SKD Archiv, 012/VA 166, fol. 3-7. Vgl. SKD Archiv, 02/VA 162.

12 Vgl. SKD Archiv, 02/VA 172, fol. 154. Beck und Loos waren im April 1946 entlassen worden. Vgl. Rudert, Thomas: Museale Praxis zwischen Besatzungsmacht und kulturellem Anspruch. Die Eröffnung des Pillnitzer Zentralmuseums des Landes Sachsen am 6. Juli 1946, in: Jahrbuch der Staatlichen Kunstsammlungen Dresden, Bd. 36, 2010, Dresden 2012, S. 192-201. Vgl. auch Iselt 2010, S. $327 \mathrm{ff}$. 
zog, dort erst an der Humboldt-Universität arbeitete und 1949 an die Freie Universität Berlin wechselte, wo er sich habilitierte.

Der Protest von Enking gegen diese Entlassungen blieb erfolglos. Sie warnte:

Mit dieser Kündigung von 17 Angestellten, unter denen sich, bis auf 2, auch sämtliche Wissenschaftler befinden, entfällt für die Zukunft jede Möglichkeit, die Bestände der Sammlungen je wieder zu ordnen, zu katalogisieren und aufzustellen, da bei der Vernichtung der meisten Inventare nur die Kenntnis des Museumspersonals ein allmähliches Wieder-Ordnen gewährleisten. ${ }^{13}$

Zum neuen Direktor der Staatlichen Kunstsammlungen wurde im September 1946 - Wolfgang Balzer ernannt, der, nachdem ihn die Nationalsozialisten 1933 aus politischen Gründen entlassen hatten, am 22. Mai 1945 mit der kommissarischen Leitung des Kunstgewerbemuseums beauftragt worden war. Allerdings blieb auch Balzer nicht lange in seinem neuen Amt - er wurde zum 31. Januar 1951, abermals politisch motiviert, entlassen. ${ }^{14}$

Damit waren an den ehemals zu den Staatlichen Sammlungen für Kunst und Wissenschaft in Dresden zählenden Institutionen nur noch folgende Mitarbeiter beschäftigt, die bereits in der NS-Zeit dort gearbeitet hatten und keine Mitglieder der NSDAP gewesen waren: Konservator $\triangleright$ Robert Reichert am Museum für Tierkunde, der im Januar 1950 zum Direktor des Museums ernannt worden war, -Artur Pietzsch am Landesmuseum für Vorgeschichte. ^Georg Bierbaum, der 1946 zum Direktor des Landesmuseums für Vorgeschichte ernannt worden war, war zum 31. Januar 1949 gekündigt worden. Erneut eingestellt worden war 1947 trotz früherer NSDAP-Mitgliedschaft $\triangleright$ Rudolf Schwarze, der bis 1963 am Museum für Mineralogie und Geologie arbeitete. An der Sächsischen Landesbibliothek verblieben $\triangleright$ Margarethe Storch, $\triangleright$ Karl Assmann als Direktor und - Helmut Deckert, der ab 1952 mehrfach die kommissarische Leitung der Bibliothek übernahm. An den Staatlichen Kunstsammlungen hingegen war kein Personal aus der NS-Zeit mehr vorhanden.

\footnotetext{
13 Direktion Staatliche Museen, Enking, an Präsidenten der Landesverwaltung Sachsen, Friedrichs, 30.7.1946, SKD Archiv, 02/VA 166, fol. 30.

${ }_{14}$ Vgl. Rudert, Thomas: Betrug und Untreue im Amt oder ethisch-moralisch gebotene Sicherung gefährdeter Kunstwerke? Wolfgang Balzer und die Grafiksammlung des sächsischen Königs Friedrich August II., in: Dresdener Kunstblätter, 54. Jg., H. 2, 2010, S. 116-126.
} 


\section{Die Institutionen der Staatlichen Sammlungen}

\section{Gemäldegalerie}

26.9.1938-19.10.1938

28.8.1939

Direktoren

1.4.1910-7.12.1942

4.4.1938-18.6.1938

$12.1942-3.1943$

9.3.1943-31.3.1943

1.4.1943-24.7.1945

$11.8 .1944-5.1945$
Schließung der Schausammlung

Schließung der Schausammlung

Hans Posse (1879-1942) Direktor

Walter Müller (1877-1952) Kommissarischer Leiter

Robert Oertel (1907-1981) Kommissarischer Leiter

Hermann Voss (1884-1969) Kommissarischer Direktor

Hermann Voss (1884-1969) Direktor

Alfred Unger (1896-1980) Depotverantwortlicher

\section{Kupferstich-Kabinett}

[9.1938]-10.10.1938

28.8.1939-19.1.1940

$2.1941-3.1942$

30.4 .1942

6.1943

Direktoren

1.1.1924-10.1.1941

25.1.1941-7.12.1942

9.3.1943-24.7.1945

11.8.1944-5.1945
Schließung der Schausammlung

Schließung der Schausammlung

Nutzung im Studiensaal möglich

Schließung der Schausammlung

im Ausnahmefall Nutzung am Auslagerungsort Weesenstein möglich

Kurt Zoege von Manteuffel (1881-1941) Direktor

Hans Posse (1879-1942) Kommissarischer Direktor

Hermann Voss (1884-1969) Kommissarischer Leiter

Max Hahn (1883-1969) Depotverantwortlicher

\section{Skulpturensammlung}

26.6.1939

16.1 .1942

Direktoren

1.8.1925-18.5.1934

1.6.1934-5.1945

14.2.1945-31.10.1945

1.11.1945-31.7.1946

11.8.1944-5.1945
Wiederöffnung Abgusssammlung

Schließung der Schausammlung

Bruno Schröder (1878-1934) Direktor

Walter Müller (1877-1952) Direktor

Ragna Enking (1898-1975) Kommissarische Leiterin

Ragna Enking (1898-1975) Direktorin

Paul Täubrich (1884-1960) Depotverantwortlicher 


\section{Porzellansammlung}

ab 21.4.1937

6.4 .1939

29.9.1938-22.10.1938

27.8.1939

Direktoren

1.7.1912-15.12.1933

15.12.1933-9.2.1937

10.2.1937-7.5.1945

11.8.1944-11.1944

11.1944-5.1945

\section{Grünes Gewölbe}

29.9.1938-22.10.1938

28.8.1939-31.12.1939

15.6.1942

Direktoren

1.4.1924-26.12.1940

15.1.1941-30.6.1942

$1.7 .1942-4.1945$

1.11.1945-31.7.1946

11.8.1944-5.1945
Umzug vom Johanneum in den Zwinger, Eröffnung geplant für 21.9.1939

Umbenennung in „Staatliche Porzellangalerie Dresden“

Schließung der Schausammlung im Johanneum

Schließung der Schausammlung im Johanneum

Ernst Zimmermann (1866-1940) Direktor

Fritz Fichtner (1890-1969) Leiter

Fritz Fichtner (1890-1969) Direktor

Arthur Leuschner (1883-1960) Depotverantwortlicher

Richard Schmidt (1895-1973) Depotverantwortlicher

Schließung der Schausammlung

Schließung der Schausammlung

Schließung der Schausammlung

Erich Haenel (1875-1940) Direktor

Walter Müller (1877-1952) Kommissarischer Leiter

Walter Holzhausen (1896-1968) Kommissarischer Leiter

Erna von Watzdorf (1892-1976) Kommissarische Leiterin

Kurt Köhn (1894-1975) Depotverantwortlicher

\section{Historisches Museum}

30.8.1939-31.12.1939 Schließung der Schausammlung

16.1 .1942

Schließung der Schausammlung

Direktoren

1907-31.1.1913 Erich Haenel (1875-1940) Leiter

1.2.1913-26.12.1940 Erich Haenel (1875-1940) Direktor

15.1.1941-23.11.1942 Walter Müller (1877-1952) Kommissarischer Leiter

23.11.1942-4.1945 Walter Holzhausen (1896-1968) Kommissarischer Leiter

1.11.1945-31.7.1946 Erna von Watzdorf (1892-1976) Kommissarische Leiterin

11.8.1944-5.1945 Curt Sander (1884-1949) Depotverantwortlicher

\section{Münzkabinett}

28.8.1939

Schließung der Schausammlung

Direktoren

1.1.1924-30.6.1937 Walter Schwinkowski (1884-1938) Leiter 
16.6.1937-31.3.1938

$1.4 .1938-31.12 .1939$

$11.1939-12.1942$

5.9.1942-23.8.1944

8.9.1944-4.1945

1.11.1945-31.7.1946

$11.8 .1944-5.1945$
Erich Haenel (1875-1940) Kommissarischer Leiter

Rolf Hetsch (1903-1946) Kommissarischer Leiter

Walter Müller (1877-1952) Kommissarischer Leiter

Klaus Günther (1907-1975) „mit der Überwachung und Betreuung der Bestände beauftragt"

Walter Holzhausen (1896-1968) Kommissarischer Leiter

Erna von Watzdorf (1892-1976) Kommissarische Leiterin

Kurt Hoppe (1887-?) Depotverantwortlicher

\section{Kunstgewerbemuseum}

$\begin{array}{ll}\text { 29.9.1939-14.11.1939 } & \text { Schließung der Schausammlung } \\ \text { 15.2.1940 } & \text { Schließung der Schausammlung } \\ \text { [bis 3.1943] } & \text { Zugang nach Anmeldung möglich }\end{array}$

Direktoren

1.10.1923-30.11.1933 Wolfgang Balzer (1884-1968) Direktor

15.12.1933-7.5.1945 Fritz Fichtner (1890-1969) Leiter

22.5.1945-31.10.1945 Wolfgang Balzer (1884-1968) Kommissarischer Direktor

1.11.1945-31.1.1951 Wolfgang Balzer (1884-1968) Direktor

11.8.1944-5.1945 Reinhard Schmelzer (1874-?) Depotverantwortlicher

\section{Mathematisch-Physikalischer Salon}

9.1939

\section{Direktoren}

$1.4 .1925-13.5 .1938$

$1938-26.12 .1940$

$12.1940-9.12 .1942$

$9.12 .1942-5.1945$

7.6.1943-31.7.1946

$11.8 .1944-5.1945$
Schließung der Schausammlung

Paul Werkmeister (1878-1944) Direktor

Erich Haenel (1875-1940) Leiter

Fritz Fichtner (1890-1969) Kommissarischer Leiter

Alfred Beck (1896-1976) mit Leitung beauftragt

Walther Fischer (1897-1979) Kommissarischer Leiter

Rudolf Schwarze (1883-1967) Depotverantwortlicher

\section{Museen für Tierkunde und Völkerkunde}

bis 1918

ab 1918-31.12.1942

$1.1 .1942-5.1945$

4.10 .1937

1.10 .1940

7.10 .1944
Königlich Zoologisches und Anthropologisch-Ethnographisches Museum Museen für Tierkunde und Völkerkunde

Museen für Tierkunde, Rassenkunde und Völkerkunde

Eröffnung Museum für Tierkunde (Ostra-Allee)

[Schließung 1938 bzw. 1939 nicht dokumentiert]

Schließung der Schausammlung Museum für Völkerkunde

Zerstörung/Schließung Museum für Tierkunde 
Direktoren

1.10.1906-30.4.1935 Arnold Jacobi (1870-1948) Direktor

1.5.1935-31.12.1935 Bernhard Struck (1888-1971) Kommissarischer Direktor

1.1.1936-31.8.1939 Hans Kummerlöwe (1903-1995) Direktor

10.1939-30.6.1940 Martin Heydrich (1889-1969) Kommissarischer Leiter

1.7.1940-31.8.1941 Michael Hesch (1893-1979) Kommissarischer Leiter

1.9.1941-8.10.1942 Michael Hesch (1893-1979) Direktor

8.10.1942-23.8.1944 Klaus Günther (1907-1975) Kommissarischer Leiter

23.8.1944-7.9.1944 Robert Reichert (1897-1959) Kommissarischer Leiter

8.9.1944-31.7.1946 Walther Fischer (1897-1979) Leiter

11.8.1944-5.1945 Johannes Draeseke (1892-1970) Depotverantwortlicher

11.8.1944-5.1945 Robert Reichert (1897-1959) Depotverantwortlicher

\section{Museum für Mineralogie, Geologie und Vorgeschichte}

bis 1918

$1918-31.3 .1938$

ab 1.4 .1938

6.9.1943

30.12 .1944

Direktoren

1920-31.3.1943

4.7.1936-31.3.1938

7.4.1943-31.3.1946

1.4.1946-31.7.1946

11.8.1944-5.1945
Königliches Mineralogisch-Geologisches und Prähistorisches Museum

Museum für Mineralogie, Geologie und Vorgeschichte

Museum für Mineralogie und Geologie (Ausgliederung des Landesmuseums für Vorgeschichte)

Reduzierung der Schausammlung auf Hirschsaal

Schließung der Schausammlung

Eberhard Rimann (1882-1944) Direktor

Georg Bierbaum (1889-1953) Kommissarischer Leiter

Walther Fischer (1897-1979) Kommissarischer Leiter

Walther Fischer (1897-1979) Direktor

Rudolf Schwarze (1883-1967) Depotverwalter

\section{Landesmuseum für Vorgeschichte}

ab 1.4 .1938

16.6.1944

Direktoren

1.4.1938-9.1946

9.1946-31.1.1949

$11.8 .1944-5.1945$ aus Museum für Mineralogie, Geologie und Vorgeschichte ausgegliedert

Schließung der Schausammlung

Georg Bierbaum (1889-1953) Leiter

Georg Bierbaum (1889-1953) Direktor

Rudolf Schwarze (1883-1967) Depotverwalter 


\section{Sächsische Landesbibliothek}

bis 1.5 .1917

2.5.1917-11.1918

ab 11.1918

26.8.1939

18.9.1939

12.1943

2.1944

Direktoren

1.10.1920-30.9.1937

1.10.1937-31.5.1939

1.6.1939-31.10.1945

1.10.1945-30.4.1948
Königliche Öffentliche Bibliothek

Königliche Landesbibliothek ${ }^{1}$

Sächsische Landesbibliothek

Beginn der Auslagerung

Schließung des Buchmuseums

Schließung für 2 Wochen

Einschränkung des Leihverkehrs, nach 13.2.1945 nur noch

Buchrückgabe

Martin Bollert (1876-1968) Direktor

Hermann Neubert (1892-1980) Kommissarischer Direktor

Hermann Neubert (1892-1980) Direktor

Karl Assmann (1890-1970) Direktor

\section{Sächsisches Armeemuseum}

31.8.1939-26.12.1939 Schließung der Schausammlung

18.1.1940

Umbenennung in Heeresmuseum Dresden und rückwirkend zum 1.11.1939 Übergang in Reichseigentum, dem Chef der Heeresmuseen unterstellt, damit nicht mehr zu den Staatlichen Sammlungen für Kunst und Wissenschaft gehörig

Direktoren

1.11.1929-5.1945 Ernst von Koerner (1880-1968) Leiter

$1 \quad$ Siehe Jahresbericht der Königlichen Landesbibliothek 1917 und Jahresbericht der Sächsischen Landesbibliothek 1918, SLUB, Hist.Sax.A242.mb-1910, https://digital.slub-dresden.de/ werkansicht/dlf/77122/7/, SLUB, Hist.Sax.A242.mb-1910 sowie https:/digital.slub-dresden. de/id31018566Z/7, Zugriff: 6.12.2019. 


\section{Ausstellungen zwischen 1933 und 1945}

Dieses Verzeichnis listet erstmals die Ausstellungen der Staatlichen Sammlungen für Kunst und Wissenschaft in Dresden während der NS-Zeit auf. Es bemüht sich um größtmögliche Genauigkeit, erhebt jedoch keinen Anspruch auf Vollständigkeit.

Die Aufzählung der Ausstellungen folgt einer chronologischen Ordnung. Die einzelnen Einträge benennen zuerst den Titel; bei Überlieferung mehrerer Titel sind diese aufgeführt. In Klammern gesetzt werden die Veranstaltungsreihen „Kunstwerk des Monats“ bzw. „Museumswoche“ - genannt, denen die Ausstellung zugeordnet werden konnte. Es folgt die Laufzeit und die veranstaltende Sammlung, die in den meisten Fällen zugleich der Veranstaltungsort ist. Kuratoren sind nicht in jedem Fall überliefert. Ebenfalls genannt werden diejenigen Sammlungen, die sich an der Ausstellung beteiligten, anderweitige Kooperationspartner sind aus Platzgründen nicht verzeichnet. Konnte ein Katalog nachgewiesen werden, so ist er erwähnt. Entstand die Ausstellung in Zusammenarbeit mit anderen Organisationen oder für einen besonderen Anlass, wird diese Information angefügt. Angaben, die nur indirekt durch Querbezüge ermittelt werden konnten, stehen in eckigen Klammern.

Als Grundlage für dieses Verzeichnis dienten primär die Ankündigungen und Rezensionen von Ausstellungen in den zeitgenössischen Dresdner Tageszeitungen (Dresdner Anzeiger, Dresdner Nachrichten, Dresdner Neueste Nachrichten, Dresdner Volkszeitung, Dresdner Zeitung und Der Freiheitskampf) sowie die Jahresberichte der Staatlichen Sammlungen und Protokolle der Dienstberatungen, die in den sammlungsrelevanten Archivalien im Sächsischen Staatsarchiv, Hauptstaatsarchiv Dresden (insbesondere HStA Dresden, 11125, Nr. 23053, Nr. 23054, Nr. 23087) und vereinzelt in Akten im Archiv der SKD überliefert sind. Auf eine Nennung der Einzelnachweise wurde aus Platzgründen verzichtet. 
1933

Gedächtnisausstellung Emil Orlik

18.11.1932-5.3.1933

Kupferstich-Kabinett

Medaillen und Plaketten aus Porzellan

(Sammlung Arno Eckard)

1.1933- [?]

Münzkabinett

Metallarbeiten von Georg Mendelsohn

5.2.1933-10.1933

Kunstgewerbemuseum

Familie der Weißlinge

2.1933- [?]

Museen für Tierkunde und Völkerkunde

(Tierkunde)

Gedächtnisausstellung Walter Zeising

11.3.1933-4.1933

Kupferstich-Kabinett

Werke von Robert Sterl und Otto Hettner 11.3.1933- [?]

Kupferstich-Kabinett

Holzschnitte von Lucas Cranach

11.3.1933-6.1933

Kupferstich-Kabinett

Jubiläumsausstellung 25 Jahre Dresdner Museumsverein. Erwerbungen für die

Dresdner Sammlungen

3.1933-4.1933

Gemäldegalerie, Brühlsche Terrasse

August der Starke und seine Zeit

13.4.1933-13.10.1933

Residenzschloss, Georgenbau

Kuratoren: Erich Haenel unter Mitwirkung von Hans Posse, Walter Holzhausen, Erna von Watzdorf, Rudolf von Arps-Aubert, Walther Fischer
Beteiligung: alle Staatlichen Sammlungen für Kunst und Wissenschaft u.a.

Katalog

Sächsische Zeichnungen aus vier Jahrhunderten (Von Cranach bis Klinger)

23.6.1933-26.11.1933

Kupferstich-Kabinett

Kurator: Peter Halm

Katalog

Malerei des Barock

24.6.1933-3.9.1933

Sächsischer Kunstverein Dresden

Kurator: Hans Posse

Beteiligung: Gemäldegalerie, Kupferstich-

Kabinett

Katalog

Meisterwerke der Webkunst und Stickerei im Zeitalter Augusts des Starken

1.7.1933-10.1933

Kunstgewerbemuseum

Medaillen- und Plakettenkunst von Fritz Hörnlein

13.8.1933- [?]

Skulpturensammlung

Deutsche Landschaftsgraphik des 15 . und 16. Jahrhunderts

3.12.1933-14.3.1934

Kupferstich-Kabinett

1934

Aus der Frühzeit der Lithographie. Alois Senefelder zum 100. Todestag

11.3.1934-21.10.1934

Kupferstich-Kabinett

Neuerwerbungen von deutschen Handzeichnungen und Aquarellen des 19. Jahrhunderts 4.1934- [?]

Kupferstich-Kabinett 
Bienen und Prachtkäfer

5.1934- [?]

Museen für Tierkunde und Völkerkunde

(Tierkunde)

Zwei unbekannte Apostel aus Meißner

Porzellan

1.5.1934-17.5.1934

Porzellansammlung, Johanneum

Ludwig Richter zum 50. Todestag

25.5.1934-25.6.1934

Gemäldegalerie, Brühlsche Terrasse

Beteiligung: Gemäldegalerie,

Kupferstich-Kabinett

Katalog

Historische Theaterschau in Sachsen

27.5.1934- [?]

Residenzschloss

Kurator: Erich Haenel, in Zusammenarbeit mit der Reichstheaterkammer

Beteiligung: Gemäldegalerie, KupferstichKabinett, Historisches Museum, Porzellansammlung und Dresdner Theater

(zur Reichstheaterfestwoche)

Spitze

12.6.1934-8.1934

Kunstgewerbemuseum

Kurator: Fritz Fichtner

Jahresschau 1934 [Studienarbeiten der

Kunstgewerbeakademie?]

[6.1934- ?]

Kunstgewerbemuseum

Die sächsische Landschaft um 1800

10.7.1934-21.10.1934

Kupferstich-Kabinett

Arbeiten von Gustav Weidanz, Halle

15.7.1934- [?]

Kunstgewerbemuseum
Altes und neues Zinn (Sächsisches Zinn aus alter und neuer Zeit)

13.10.1934-24.2.1935

Kunstgewerbemuseum

Kurator: Fritz Fichtner

Beteiligung: Kunstgewerbemuseum, Museum für Mineralogie, Geologie und Vorgeschichte u.a.

Hans Baldung Grien zum 400. Todestag

2.12.1934-6.2.1935

Kupferstich-Kabinett

\section{5}

Adolph Menzel zum 30. Todestag

14.2.1935-28.4.1935

Kupferstich-Kabinett

Sächsisch-Polnische Kunst (Meisterwerke aus sächsisch-polnischer Zeit)

22.2.1935-12.3.1935

Historisches Museum, Turniersaal

Kurator: Erich Haenel

Beteiligung: Historisches Museum, Grünes Gewölbe, Gemäldegalerie, Kupferstich-

Kabinett, Porzellansammlung, Skulpturensammlung, Sächsische Landesbibliothek

Katalog

Polnische Musikalien

2.1935-4.3.1935

Sächsische Landesbibliothek, Musiklesesaal

Brettchenweberei (Arbeiten von Gertrud

Staudigl-Scharlau)

19.2.1935-28.4.1935

Kunstgewerbemuseum

(mit Verband der deutschen Frauen-

kultur e. V., Ortsgruppe Dresden)

Wettkampf und Siegeszeichen

16.4.1935-23.6.1935

Kunstgewerbemuseum

Kurator: Fritz Fichtner 
Beteiligung: Kunstgewerbemuseum,

Porzellansammlung

Eugen Kirchner zum 70. Geburtstag

5.5.1935-23.6.1935

Kupferstich-Kabinett

Neuerworbene Handzeichnung aus der Zeit der Romantik

5.5.1935- [?]

Kupferstich-Kabinett

Heinrich Schütz und seine Zeit

19.5.1935-26.5.1935

Historisches Museum

Kurator: Erich Haenel

Beteiligung: Historisches Museum, Kupferstich-Kabinett, Münzkabinett, Sächsische

Landesbibliothek

(zum Reichs-Schütz-Fest 1935)

Geschichte der Sächsischen Landesbibliothek (Pläne zum Japanischen Palais)

5.1935-7.1935

Sächsische Landesbibliothek, Buchmuseum

Beteiligung: Sächsische Landesbibliothek,

Kupferstich-Kabinett

Stammbücher

5.1935-6.1935

Sächsische Landesbibliothek, Buchmuseum

Atlas Royal

5.1935- [?]

Sächsische Landesbibliothek, Buchmuseum

Hirsch-, Pilz- und Schildkäfer

5.1935- [?]

Museen für Tierkunde und Völkerkunde

(Tierkunde)

Kanada-Sammlung von Max Hinsche

5.1935- [?]

Museen für Tierkunde und Völkerkunde

(Tierkunde)
225 Jahre Staatliche Porzellanmanufaktur Meissen. Porzellangestaltung einst und jetzt 6.1935-31.12.1935

Porzellansammlung, Johanneum

Kurator: Fritz Fichtner

Gedächtnisausstellung Leopold von

Kalckreuth und Hans Olde

30.6.1935-10.1935

Kupferstich-Kabinett

Dichter und ihre Handschrift

7.1935-6.10.1935

Sächsische Landesbibliothek, Buchmuseum

Beteiligung: Sächsische Landesbibliothek,

Kupferstich-Kabinett

Chinesische Tuschmalerei der Ming- und Tsing-Periode

15.8.1935-29.9.1935

Kunstgewerbemuseum

Kurator: Fritz Fichtner

Beteiligung: Kunstgewerbemuseum, Museen für Tierkunde und Völkerkunde, Privatsammlung Hartl

Moderne Goldschmiedekunst. Jubiläumssonderschau Johannes Eckert

10.9.1935-11.10.1935

Kunstgewerbemuseum

Abessinien

[9.1935- ?]

Museen für Tierkunde und Völkerkunde

(Völkerkunde)

Kurator: Martin Heydrich

Kriegsbilder von Rudolf Krüger

[9.1935-11.1935]

Sächsisches Armeemuseum

Deutsche und ausländische Majoliken und Fayencen

[9.1935] -10.10.1935

Kunstgewerbemuseum 
Shakespeare-Geschichte

10.1935- [?]

Sächsische Landesbibliothek

Meister E. S. und sein Kreis (Altdeutscher

Kupferstich)

27.10.1935-1.1936

Kupferstich-Kabinett

Kurator: Peter Halm

Neue kirchliche Kunst

13.10.1935-21.1.1936

Kunstgewerbemuseum

Kunst um Friedrich den Weisen (Kunstwerk des Monats)

11.1935

Gemäldegalerie, Brühlsche Terrasse

Alte Kinderbücher

11.1935-4.2.1936

Sächsische Landesbibliothek, Buchmuseum

Chinesische Ahnenbilder (Sammlung

Dubois-Reymond, Potsdam)

14.11.1935- [?]

Kunstgewerbemuseum

Kurator: Fritz Fichtner

Christliche Legende (Kunstwerk des Monats) 12.1935

Gemäldegalerie, Brühlsche Terrasse

Beteiligung: Grünes Gewölbe, Historisches Museum, Kupferstich-Kabinett, Mathematisch-Physikalischer Salon, Skulpturensammlung, Sächsische Landesbibliothek

Schmetterlinge (Stutzer und Bären) 12.1935- [?]

Staatliche Museen für Tierkunde und Völkerkunde (Tierkunde)
1936

Gedächtnisausstellung zum 200. Todestag von Matthäus Daniel Pöppelmann

17.1.1936-3.1936

Kupferstich-Kabinett

Kurator: [Franz Schubert]

Beteiligung: Kupferstich-Kabinett, Münzkabinett, Sächsische Landesbibliothek u. a.

Katalog

Rokoko (Kunstwerk des Monats)

1.1936

Gemäldegalerie, Brühlsche Terrasse

Beteiligung: Gemäldegalerie, Grünes

Gewölbe, Porzellansammlung, Skulpturen-

sammlung, Münzkabinett

Das wehrhafte Deutschland

26.2.1936-5.4.1936

Sächsische Landesbibliothek, Buchmuseum (mit Landesleiter Sachsen zur Förderung des Deutschen Schrifttums und Gauschulungsamt der NSDAP)

Kunstwerk als Schmuck (Kunstwerk des Monats)

2.1936

Gemäldegalerie, Brühlsche Terrasse Beteiligung: Grünes Gewölbe, Historisches Museum, Kunstgewerbemuseum, Porzellansammlung, Skulpturensammlung

Das Porträt des Klassizismus (Kunstwerk des Monats)

3.1936

Gemäldegalerie, Brühlsche Terrasse

Beteiligung: Gemäldegalerie, Kupferstich-Kabinett, Münzkabinett, Skulpturensammlung

Soldat und Handwerk. Fritz Tröger

19.4.1936-3.6.1936

Sächsisches Armeemuseum

Die Vase

21.4.1936-[9.1936] 
Kunstgewerbemuseum

Kurator: Fritz Fichtner

Beteiligung: Kunstgewerbemuseum,

Porzellansammlung, Gemäldegalerie

Alte Blumenmalerei

24.5.1936-4.10.1936

Sächsische Landesbibliothek, Buchmuseum

Deutsche Turnierschau

28.5.1936-30.9.1936

Historisches Museum

Kurator: Erich Haenel

Beteiligung: Historisches Museum, Kupferstich-Kabinett, Sächsische Landesbibliothek, Staatstheater, Wehrmacht u. a. dazu

Turnierspiele

27.6.1936-2.9.1936

Stallhof

Die Bronzen der Kurfürstlichen

Kunstkammer

6.6.1936-15.10.1936

Skulpturensammlung

Kurator: Walter Müller

Beteiligung: Skulpturensammlung, Grünes

Gewölbe

Katalog

Hl. Georg, Holzstatuette aus dem Deutschen Museum Berlin (Kunstwerk des Monats)

7.1936

[?]

Elbwanderung von der Mündung bis zur

Quelle

5.7.1936-25.10.1936

Kupferstich-Kabinett

Sächsisches Edelgestein. Zum 200. Geburtstag von Johann Christian Neuber

2.8.1936-[1937]

Residenzschloss, Festräume

Kuratoren: Erich Haenel, Walther Fischer

Beteiligung: Museum für Mineralogie,

Geologie und Vorgeschichte, Grünes
Gewölbe, Kupferstich-Kabinett, Porzellansammlung u.a.

Rudolf Trache zum 70. Geburtstag

19.8.1936-19.9.1936

Sächsisches Armeemuseum

Schmuckkasten von Nikolaus Schmidt

(Kunstwerk des Monats)

10.1936

Grünes Gewölbe im Historischen Museum, Lichthof

Kultur und Volksgemeinschaft, Beispiele volksverbundener deutscher Kunst

10.1936- [?]

Gemäldegalerie

(mit KdF zur sächsischen Gaukulturwoche)

Die sächsische Schule als schöner Arbeitsplatz 3.10.1936- [11.1936]

Kunstgewerbemuseum

Musik in Sachsen (Sachsen als Musikland)

12.10.1936-17.1.1937

Sächsische Landesbibliothek, Buchmuseum

Kuratorin: Charlotte Boden

(zur sächsischen Gaukulturwoche)

Anton Graff und seine Dresdner Zeitgenossen. Zum 200. Geburtstag

1.11.1936-1.1937

Gemäldegalerie, Kupferstich-Kabinett

Kurator: [Gert Adriani]

Beteiligung: Gemäldegalerie, Kupferstich-

Kabinett, Sächsisches Armeemuseum u. a.

Ludwig von Hofmann zum 70. Geburtstag 11.1936-1.1937

Kupferstich-Kabinett

Ernst Moritz Geyger zum 75. Geburtstag

11.1936-1.1937

Kupferstich-Kabinett 
Drei Zeichnungen von Matthias Grünewald (Kunstwerk des Monats)

11.1936

Kupferstich-Kabinett im Historischen

Museum, Lichthof

Lucas Cranach d. Ä. „Heilige Nacht“

(Kunstwerk des Monats)

12.1936

Gemäldegalerie im Historischen Museum,

Lichthof

Afrikanische Insektenfauna

[1936]

Museen für Tierkunde und Völkerkunde

(Tierkunde)

Südamerikanische Insektenfauna

[1936]

Museen für Tierkunde und Völkerkunde

(Tierkunde)

\section{7}

Albrecht Dürers Skizzenbuch (Kunstwerk des Monats)

1.1937

Sächsische Landesbibliothek im Historischen

Museum, Lichthof

Kuratorin: Charlotte Boden

Beteiligung: Sächsische Landesbibliothek,

Kupferstich-Kabinett

Biedermeier

6.1.1937-14.3.1937

Kunstgewerbemuseum

Das ehrsame Handwerk

24.1.1937-27.4.1937

Sächsische Landesbibliothek, Buchmuseum

Kuratorin: Charlotte Boden

Antiker Porträtkopf, römisch, 250 v. Chr.

(Kunstwerk des Monats)

2.1937

Skulpturensammlung im Historischen

Museum, Lichthof
Heldengräber sächsischer Truppenteile.

Fotografien aus den Jahren des Weltkrieges

2.1937

Sächsisches Armeemuseum

Kurator: Ernst von Koerner

Ritter, Landsknecht und Soldat in den zeichnenden Künsten

6.2.1937-5.1937

Kupferstich-Kabinett

Der Parforcejäger Wenzel (Kunstwerk des Monats)

3.1937

Porzellansammlung im Historischen

Museum, Lichthof

Christliche Kunst

3.1937- [?]

Kunstgewerbemuseum

(mit Katholischem Kunstkreis)

Medaillen von Tobias Wolf (Kunstwerk des Monats)

4.1937

Münzkabinett im Historischen Museum, Lichthof

Dichterhandschriften und -bildnisse

5.4.1937-10.4.1937

Sächsische Landesbibliothek

(zur Gautagung des NSLB)

Gärten der Augusteischen Zeit

[4.1937]

Sächsische Landesbibliothek, Buchmuseum (zu einer Veranstaltung der Dante-

Gesellschaft)

Ahnenkult der Südsee (Kunstwerk des Monats)

5.1937

Staatliche Museen für Tierkunde und

Völkerkunde im Historischen Museum, Lichthof 
Die Welt im Kartenbild

6.5.1937-30.9.1937

Sächsische Landesbibliothek, Buchmuseum Kuratorin: Charlotte Boden

Beteiligung: Sächsische Landesbibliothek,

Mathematisch-Physikalischer Salon

Dresden als Musikstadt

25.5.1937- [?]

Sächsische Landesbibliothek

(zum Internationalen Musikfest)

Kupferstiche und Radierungen deutscher

Künstler des 17. und 18. Jahrhunderts

6.6.1937-9.1937

Kupferstich-Kabinett [Kurator: Adriani]

Jagdgarnitur Friedrich August II. (Kunstwerk des Monats)

6.1937

Historisches Museum, Lichthof

Licht und Leuchter (Sammlung Alfred

Bösenberg)

10.6.1937-9.1937

Kunstgewerbemuseum

Turnierspiele

20.6.1937-26.9.1937

Stallhof

25 Jahre Ausbau des Historischen Museums.

Erwerbungen 1913-1937

2.7.1937-30.9.1937

Historisches Museum

Kurator: Erich Haenel

Verklungene Feste und Feiern in Sachsen

1.10.1937-25.1.1938

Sächsische Landesbibliothek, Buchmuseum

Kuratorin: Charlotte Boden

Ansichten sächsischer Städte

(Museumswoche)

2.10.1937-1.1938

Kupferstich-Kabinett
Sächsische Forscher und Sammler

(Museumswoche)

2.10.1937- [?]

Staatliche Museen für Tierkunde und

Völkerkunde

Sächsische Erzlagerstätten im Rahmen des Vierjahresplanes (Museumswoche)

2.10.1937- [?]

Museum für Mineralogie, Geologie und

Vorgeschichte

Zur Rassenkunde des sächsischen Stammes (Museumswoche)

2.10.1937- [?]

Museen für Tierkunde und Völkerkunde

(Anthropologie)

Lucas Cranach der Ältere und der Jüngere.

Ausstellung von Werken aus dem Besitz der

Staatlichen Sammlungen (Museumswoche)

2.10.1937-12.1937

Gemäldegalerie

Kurator: Hans Posse, Gert Adriani

Beteiligung: Gemäldegalerie, Kupferstich-

Kabinett

Katalog

Soldaten und Jäger aus der Zeit August des Starken (Museumswoche)

2.10.1937-17.10.1937

Kunstgewerbemuseum

Beteiligung: Kunstgewerbemuseum, Porzellansammlung, Sächsisches Armeemuseum

Sächsische Klöppel- und Vogtländische Maschinenspitzen (Museumswoche)

2.10.1937-31.10.1937

Kunstgewerbemuseum

Instrumente und Uhren Sächsischer Meister

(Museumswoche)

2.10.1937-10.1937

Mathematisch-Physikalischer Salon 
Werke sächsischer Plattner und Goldschmiede aus drei Jahrhunderten (Waffen- und

Goldschmiedekunst) (Museumswoche)

2.10.1937- [?]

Historisches Museum

Beteiligung: Historisches Museum, Grünes Gewölbe

Der soldatische Mensch. Arbeiten von Fritz Tröger

[10.1937] -21.11.1937

Sächsisches Armeemuseum

Pokal aus Bergkristall (Kunstwerk des Monats)

10.1937

Grünes Gewölbe im Historischen Museum, Lichthof

Musik der Renaissance

10.11.1937-16.11.1937

Sächsische Landesbibliothek

(zur Tagung der Deutschen Musikwissenschaftlichen Gesellschaft)

Achate aus Idar-Oberstein

11.1937- [?]

Museum für Mineralogie, Geologie und

Vorgeschichte

Morette (Kunstwerk des Monats)

11.1937

Gemäldegalerie im Historischen Museum,

Lichthof

Dante-Ausstellung

17.11.1937-25.11.1937

Sächsische Landesbibliothek

(zur Tagung der Deutschen Dante-Gesellschaft)

Beteiligung: Sächsische Landesbibliothek,

Kupferstich-Kabinett

„Dom im Winter“ von Ernst Ferdinand

Oehme (Kunstwerk des Monats)

12.1937

Gemäldegalerie, Brühlsche Terrasse
Brauchtum in den germanischen Ländern 12.1937- [?]

Museen für Tierkunde und Völkerkunde (Völkerkunde)

Pommersche Fischerteppiche

2.12.1937- [?]

Kunstgewerbemuseum

Kurator: Fritz Fichtner

Vermächtnis Johann Friedrich Lahmann, Handzeichnungen (1. Teil)

26.12.1937-3.1938

Kupferstich-Kabinett

Beteiligung: Gemäldegalerie, Kupferstich-

Kabinett

1938

Georg Lührig zum 70. Geburtstag (und Nachlass des Malers Anton Dietrich)

$1.1938-4.1938$

Kupferstich-Kabinett

Dresdner Gebetbuch (Kunstwerk des Monats)

1.1938

Sächsische Landesbibliothek im Historischen Museum, Lichthof

Tierpräparate von Max Hinsche

1.1938- [?]

Museen für Tierkunde und Völkerkunde (Tierkunde)

Unser Erzgebirge in Buch und Bild 30.1.1938-30.4.1938

Sächsische Landesbibliothek, Buchmuseum Kuratorin: Charlotte Boden Beteiligung: Sächsische Landesbibliothek, Kupferstich-Kabinett

Ägyptische Bildnisskulptur. Die Statuette des Imeri (Kunstwerk des Monats)

2.1938

Skulpturensammlung im Historischen

Museum, Lichthof 
Die Entwicklung der Taschenuhr in drei Jahrhunderten

6.2.1938- [?]

Mathematisch-Physikalischer Salon

Kunsthandwerk aus Sachsen/Reiseandenken aus drei Jahrhunderten/Sächsische Reiseandenken aus der Gegenwart

10.2.1938- [?]

Kunstgewerbemuseum

Große Meißner Porzellanvase im chinesischen Stil von Johann Gregorius Höroldt (Kunstwerk des Monats)

3.1938

Porzellansammlung im Historischen

Museum, Lichthof

Wiener Porzellan (Kunstwerk des Monats)

4.1938

Porzellansammlung im Historischen

Museum, Lichthof

Edelsteinschau

4.1938- [?]

Museum für Mineralogie und Geologie

Beteiligung: Museum für Mineralogie und

Geologie, Grünes Gewölbe

Vermächtnis Johann Friedrich Lahmann, Handzeichnungen (2. Teil)

17.4.1938- [?]

Kupferstich-Kabinett

Wiener Harnisch (Kunstwerk des Monats)

5.1938

Historisches Museum, Lichthof

Altjapanische No-Maske (Kunstwerk des Monats)

5.1938

Staatliche Museen für Tierkunde und

Völkerkunde im Historischen Museum, Lichthof
Dichter der Gegenwart als Maler, Zeichner und Bildhauer

15.5.1938-15.9.1938

Sächsische Landesbibliothek, Buchmuseum

Kurator: Erhart Kästner

Österreichisches Buch (Kunstwerk des Monats)

6.1938

Sächsische Landesbibliothek im Historischen Museum, Lichthof

Prunkharnisch Kaiser Ferdinand I. (Kunstwerk des Monats)

6.1938

Historisches Museum, Lichthof

Rauschgifte und ihre Verwendung

6.1938- [?]

Museen für Tierkunde und Völkerkunde

(Völkerkunde)

Deutsche Kunst vom 16. bis 18. Jahrhundert (Museumswoche)

11.6.1938-30.9.1938

Gemäldegalerie, Kupferstich-Kabinett

Kurator: Hans Posse

Beteiligung: Gemäldegalerie, Kupferstich-Kabinett, Skulpturensammlung

Schmuck und Gerät der fürstlichen Tafel

(Museumswoche)

11.6.1938-30.9.1938

Grünes Gewölbe

Ton- und Porzellanfiguren aus alter und neuer Zeit (Deutsche Art in Gefäßformen vergangener Jahrhunderte) (Museumswoche) 11.6.1938-30.9.1938

Porzellansammlung, Johanneum

Meisterwerke deutscher Münzkunst

(Museumswoche)

11.6.1938-30.9.1938

Münzkabinett 
Alte Wehr im deutschen Heer

(Museumswoche)

11.6.1938-30.9.1938

Historisches Museum

Beteiligung: Historisches Museum, Sächsisches Armeemuseum

Deutsche Meisterwerke aus Zinn

(Museumswoche)

11.6.1938-30.9.1938

Kunstgewerbemuseum

Erstausgaben deutscher Dichter

(Museumswoche)

11.6.1938-17.7.1938

Sächsische Landesbibliothek

Erd- und Himmelsfernrohre aus drei Jahrhunderten (Museumswoche)

11.6.1938-30.9.1938

Mathematisch-Physikalischer Salon

Kurator: Alfred Beck

Germanen in Sachsen (Museumswoche)

11.6.1938-30.9.1938

Landesmuseum für Vorgeschichte

Tierwelt deutscher Kolonien

(Museumswoche)

11.6.1938-30.9.1938

Museen für Tierkunde und Völkerkunde (Tierkunde)

Rassen und Völker in den deutschen

Kolonien (Museumswoche)

11.6.1938-30.9.1938

Museen für Tierkunde und Völkerkunde

(Völkerkunde)

Kurator: Martin Heydrich

Sachsens keramische Rohstoffe und ihre Verwendung (Museumswoche)

11.6.1938-30.9.1938

Museum für Mineralogie und Geologie
Tiroler Textilien (Kunstwerk des Monats)

7.1938

Kunstgewerbemuseum im Historischen

Museum, Lichthof

Der „Teuerdank“ als Meisterwerk der

Buchkunst (Kunstwerk des Monats)

7.1938

Sächsische Landesbibliothek im Historischen

Museum, Lichthof

Österreichische Graphik (Kunstwerk des

Monats)

8.1938

Kupferstich-Kabinett im Historischen

Museum, Lichthof

Vermächtnis Johann Friedrich Lahmann, Handzeichnungen (17.-19. Jahrhundert)

(3. Teil)

13.8.1938- [?]

Kupferstich-Kabinett

Sudetengau

[1938]

Museen für Tierkunde und Völkerkunde

(Völkerkunde)

Kurfürstlich-sächsisches Normalgewicht

(Kunstwerk des Monats)

9.1938

Kunstgewerbemuseum im Historischen

Museum, Lichthof

Sachsen in aller Welt

18.9.1938-2.10.1938

Sächsische Landesbibliothek

Kuratorin: Charlotte Boden

(zum Tag des deutschen Volkstums, mit

Volksbund für das Deutschtum im Ausland)

Ernst Gabler

13.10.1938- [?]

Kupferstich-Kabinett 
Die Zeichnungen des Vermächtnisses Johann Friedrich Lahmann (4. Teil)

13.10.1938- [?]

Kupferstich-Kabinett

Jahresschau des deutschen Schrifttums

30.10.1938-13.11.1938

Sächsische Landesbibliothek

(zur 1. Großdeutschen Buchwoche)

Das Zeitgeschehen im Bildbuch

30.10.1938-13.11.1938

Sächsische Landesbibliothek

Kuratorin: Charlotte Boden

(zur 1. Großdeutschen Buchwoche)

Spielkartenkästchen (Kunstwerk des Monats)

11.1938

Grünes Gewölbe im Historischen Museum,

Lichthof

Kostbarer Spielkasten aus Wien (Kunstwerk des Monats)

11.1938

Historisches Museum im Historischen

Museum, Lichthof

Mitwinter

[1938]

Museen für Tierkunde und Völkerkunde

(Völkerkunde)

Winters Ende

[1938]

Museen für Tierkunde und Völkerkunde

(Völkerkunde)

Masken aus aller Welt

[1938]

Museen für Tierkunde und Völkerkunde (Völkerkunde)

Brauchtum um Ostern

[1938]

Museen für Tierkunde und Völkerkunde (Völkerkunde)
Wohnkultur im Biedermeier

11.1938-3.1939

Kunstgewerbemuseum

Kurator: Fritz Fichtner

Die sächsische Kunst der Perlmutterbehandlung 11.1938- [?]

Kunstgewerbemuseum

Kurator: Fritz Fichtner

Arthur Schopenhauer. In Erinnerung an seinen 150. Geburtstag

13.11.1938-11.12.1938

Sächsische Landesbibliothek, Buchmuseum

Kuratorin: Charlotte Boden

Ludwig Richter „Böhmische Landschaft“

(Kunstwerk des Monats)

12.1938

Gemäldegalerie im Historischen Museum, Lichthof

Deutsche Kolonien

12.1938- [?]

Museen für Tierkunde und Völkerkunde

(Völkerkunde)

1939

Kopien antiker Wandmalereien aus Pompeji 1.1939- [?]

Skulpturensammlung

Zwei Zeichnungen von Julius Schnorr von

Carolsfeld

1.1939- [?]

Kupferstich-Kabinett

Photographien

1.1939- [?]

Kupferstich-Kabinett

Vermächtnis Johann Friedrich Lahmann, Deutsche Druckgraphik des 15. bis 18. Jahrhunderts (5. Teil) 15.1.1939- [?]

Kupferstich-Kabinett 
Reisen und Entdeckungen

29.1.1939-7.5.1939

Sächsische Landesbibliothek, Buchmuseum

Kuratorin: Charlotte Boden

Alte chinesische Kulttrommel (Kunstwerk des Monats)

2.1939

Museen für Tierkunde und Völkerkunde

(Völkerkunde) im Historischen Museum,

Lichthof

Auguste Rodin "Jean Paul Laurens“

(Kunstwerk des Monats)

2.1939

Skulpturensammlung im Historischen

Museum, Lichthof

Vermächtnis Johann Friedrich Lahmann, Europäische Druckgraphik vom 15. bis

18. Jahrhundert ( 5. Teil)

3.1939- [?]

Kupferstich-Kabinett

Zwei Radierungen mit Prager Ansichten von Caspar Pluth nach [Franz?, Philipp?] Heger (Kunstwerk des Monats)

4.1939

Kupferstich-Kabinett im Historischen

Museum, Lichthof

Intarsienschrank Kurfürst Augusts (Kunstwerk des Monats)

5.1939

Historisches Museum

Der Vogelzug und seine Erscheinungen in Sachsen (Museumswoche)

20.5.1939-31.8.1939

Museen für Tierkunde und Völkerkunde

(Tierkunde)

Kurator: Wilhelm Meise

Carl Gustav Carus. Zum 150. Geburtstag (Museumswoche)

21.5.1939-31.8.1939
Gemäldegalerie

Kurator: Hans Posse

Beteiligung: Gemäldegalerie, Kupferstich-

Kabinett

Italienische Graphik des 15. bis 18. Jahrhunderts (Museumswoche)

21.5.1939-31.8.1939

Kupferstich-Kabinett

Mineralien und Fossilien aus dem Sudetengau (Museumswoche)

21.5.1939-31.8.1939

Museum für Mineralogie und Geologie

Kuratoren: Walter Häntzschel, Walther

Fischer

Festkleid, Schmuck und Orden

(Museumswoche)

21.5.1939-31.8.1939

Historisches Museum

Kurator: Erich Haenel

Beteiligung: Historisches Museum, Grünes

Gewölbe, Sächsisches Armeemuseum

Deutsches Kriegs- und Notgeld (Der

Weltkrieg im Spiegel des deutschen Münzwesens) (Museumswoche)

21.5.1939-31.8.1939

Münzkabinett

[Kurator: Rolf Hetsch]

Gold und Bernstein in Sachsens Vorzeit

(Museumswoche)

20.5.1939-31.8.1939

Landesmuseum für Vorgeschichte

Die Frühzeit der Feinmechanik in Sachsen und ihre Förderung durch Kurfürst August (Museumswoche)

20.5.1939-31.8.1939

Mathematisch-Physikalischer Salon

Japanische Kleinkunst des 18. und 19. Jahrhunderts (Museumswoche)

21.5.1939-31.8.1939 
Kunstgewerbemuseum

Kurator: Fritz Fichtner

Beteiligung: Kunstgewerbemuseum, Porzellansammlung, Kupferstich-Kabinett, Museen für Tierkunde und Völkerkunde

Jugoslawien und Albanien (Museumswoche) 21.5.1939-31.8.1939

Museen für Tierkunde und Völkerkunde (Völkerkunde)

Schöne Tierbilder im Buch (Museumswoche) 20.5.1939-30.9.1939

Sächsische Landesbibliothek, Buchmuseum

Kuratorin: Charlotte Boden

25-jährige Wiederkehr des 1. Mobilmachungstages

2.8.1939- [?]

Sächsisches Armeemuseum

Der Vogelflug

25.12.1939-31.3.1940

Museen für Tierkunde und Völkerkunde (Tierkunde)

Neuerwerbungen

25.12.1939-31.3.1940

Museen für Tierkunde und Völkerkunde (Völkerkunde)

Die Rassen der Erde

25.12.1939-31.3.1940

Museen für Tierkunde und Völkerkunde (Anthropologische Abteilung)

Kurator: Michael Hesch

Das heutige Italien

26.12.1939-29.2.1940

Sächsische Landesbibliothek

Erbeutete polnische Waffen- und

Ausrüstungsgegenstände

26.12.1939-31.3.1940

Sächsisches Armeemuseum
1940

Gemeinschaftsausstellung

1.1.1940- [?]

Grünes Gewölbe

Beteiligung: Grünes Gewölbe, Kupferstich-Kabinett, Porzellansammlung,

Skulpturensammlung

Spätgotische Miniaturen

19.1.1940-20.5.1940

Sächsische Landesbibliothek, Buchmuseum Kurator: Erhart Kästner

Dem Gedenken an Hieronymus Schaffhirt (Kunstwerk des Monats)

4.1940

[?]

Vogel- und Insektennester (Biologische

Gruppen aus dem Insektenleben)

(Museumswoche)

4.5.1940-30.9.1940

Museen für Tierkunde und Völkerkunde

(Tierkunde)

Caspar David Friedrich zum 100. Todestag (Museumswoche)

4.5.1940-30.9.1940

Gemäldegalerie, Brühlsche Terrasse

Beteiligung: Gemäldegalerie, Kupferstich-

Kabinett

Katalog

Vermächtnis Johann Friedrich Lahmann, Japanische Farbholzschnitte (6. Teil)

21.1.1940-5.1940

Kupferstich-Kabinett

Vermächtnis Johann Friedrich Lahmann, Japanische Farbholzschnitte des 18./19. Jahrhunderts (Museumswoche)

4.5.1940-30.9.1940

Kupferstich-Kabinett

Kostbarkeiten in Silber, Bronze und Porzellan 4.5.1940-31.8.1940 
Gemeinschaftsausstellung im Grünen Gewölbe Beteiligung: Grünes Gewölbe, KupferstichKabinett, Porzellansammlung, Skulpturensammlung

Gewehr und Pistole (Museumswoche)

4.5.1940-30.9.1940

Historisches Museum

Beteiligung: Historisches Museum, Heeresmuseum Dresden

Kulturgut der Insel Hainan (Sammlung Hans Stübel) (Museumswoche)

5.1940-31.8.1940

Museen für Tierkunde und Völkerkunde (Völkerkunde)

Die Rassen der Erde (Museumswoche)

[Wiederholung?]

4.5.1940-30.9.1940

Museen für Tierkunde und Völkerkunde

(Anthropologische Abteilung)

Sammlung des Oberbergrates Richard

Baldauf (Museumswoche)

4.5.1940-30.9.1940

Museum für Mineralogie und Geologie

Gutenberg und seine Jünger. Zur 500-JahrFeier der Erfindung der Buchdruckerkunst 19.5.1940-30.9.1940

Sächsische Landesbibliothek, Buchmuseum Kuratorin: Charlotte Boden

Vermächtnis Johann Friedrich Lahmann, Deutsche Radierungen und Lithographien des 19. Jahrhunderts 21.7.1940- [?]

Kupferstich-Kabinett

Jakob Krause und seine Zeit

28.9.1940-30.9.1940

Sächsische Landesbibliothek, Buchmuseum

Kuratorin: Ilse Schunke

(zur Bibliophilentagung)
Die wertvollsten und schönsten Bilderhandschriften des 14. Jahrhundert. Farbige Wiedergabe der Heidelberger Liederhandschrift und des Dresdner Sachsenspiegels 1.11.1940-1.1941

Sächsische Landesbibliothek, Buchmuseum Kuratorin: Charlotte Boden

Otto Fischer. Zum 70. Geburtstag 11.1940- [?] Kupferstich-Kabinett

Mineralien aus Deutsch-Südwest-Afrika $11.1940-[?]$

Museum für Mineralogie und Geologie

Sachsens keramische Rohstoffe und ihre Verwertung 12.1940- [?]

Museum für Mineralogie und Geologie

Seladon-Ausstellung

12.1940- [?]

Porzellansammlung

Vorlagen für die Goldschmiedekunst

[1940]

Grünes Gewölbe

Beteiligung: Grünes Gewölbe,

Kupferstich-Kabinett

Kinderbuch-Ausstellung

[1940]

Sächsische Landesbibliothek

Colorado-Käfer. Kartoffelgroßschädling [1940]

Museen für Tierkunde und Völkerkunde (Tierkunde)

(mit Gaupropagandaamt Sachsen der NSDAP) 
Neue Mineralienschätze der Baldaufsammlung 6.1941- [9.1941]

Die Minerale des Plauenschen Grundes 15.1.1941- [?]

Museum für Mineralogie und Geologie

Georg Jahn-Gedächtnisausstellung

2.2.1941- [?]

Kupferstich-Kabinett

Klöppelspitze im 17. Jahrhundert

3.1941-4.1941

Kunstgewerbemuseum

Albrecht der Beherzte und die Gotik in Sachsen 13.4.1941-6.1941

Grünes Gewölbe

Beteiligung: Grünes Gewölbe, Kupfer-

stich-Kabinett u.a.

Ostasiatische Textilien sowie Lack-, Elfenbein- und Flechtarbeiten

4.1941-6.1941

Kunstgewerbemuseum

Bildnisse großer Deutscher. Sammlung Johann Friedrich Lahmann

4.1941- [6.1941]

Kupferstich-Kabinett

Die sächsische Buchillustration des

18. Jahrhunderts

21.5.1941-9.1941

Sächsische Landesbibliothek

Kurator: Helmut Schneider

Frühe Stoffe/Buntstickereien des Balkans

5.1941-2.1942

Kunstgewerbemuseum

Früchte und Samen aus der Lausitzer Braunkohle (Die Funde von Wiesa bei Kamenz)

5.1941-7.1941

Museum für Mineralogie und Geologie

Neuerwerbungen. Handzeichnung und Druckgraphik des 18. und 19. Jahrhunderts

8.6.1941-[9.1941]

Kupferstich-Kabinett

Stoffe des 18. Jahrhunderts. Frankreich und Italien

7.1941- [?]

Kunstgewerbemuseum

Europäische Stoffe des 16. und 17. Jahrhunderts. Italienische und Spanische Samte und Damaste

8.1941- [?]

Kunstgewerbemuseum

Städte und Landschaften des Sudetengaues und Böhmens

31.8.1941- [?]

Kupferstich-Kabinett

Genähte Spitzen, Filetarbeiten und

Weißstickereien

9.1941- [?]

Kunstgewerbemuseum

Buntstickereien, Applikationen, Goldstickereien 10.1941- [?]

Kunstgewerbemuseum

Volk und Recht

27.10.1941-1.11.1941

Sächsische Landesbibliothek (zur

Kriegsbuchwoche)

Thailandausstellung

30.11.1941- [?]

Porzellansammlung

Beteiligung: Porzellansammlung, Kunstgewerbemuseum, Museen für Tierkunde und Völkerkunde, Privatsammlungen

Karl Döhring und Kurt Posse 
1942

Deutsche Eisenerzlagerstätten

15.1.1942-4.1942

Museum für Mineralogie und Geologie

Die Wehrmacht

11.10.1942-17.10.1942

Sächsische Landesbibliothek, Lesesaal

(zur Buchwoche)

\section{3}

Klöppelspitzen/Buntstickereien der Völker des Balkans

[1943]-7.1943

Kunstgewerbemuseum

Die deutsche Form. Leistungsschau

moderner Keramik

3.1943-6.1943

Porzellansammlung im Grünen Gewölbe

Kostbarkeiten des Grünen Gewölbes im Lichtbild (Fotografien von Edmund Kesting)

19.9.1943-15.11.1943

Grünes Gewölbe, Residenzschloss

Kurator: Walter Holzhausen

anschließend in Posen (29.11.1943-12.1943)

und Zwickau (8.1944-31.8.1944)

[Sonderschau aus Gruppe 3]

[1943] (in Direktorenkonferenz angemeldet, Realisierung bisher nicht nachgewiesen)

[Kupferstich-Kabinett]

[10 Jahre Gesellschaft deutscher

Goldschmiede]

[1943] (in Direktorenkonferenz angemeldet,

Realisierung bisher nicht nachgewiesen)

[Grünes Gewölbe]

[Moderne Textilien]

[1943] (in Direktorenkonferenz angemeldet,

Realisierung bisher nicht nachgewiesen)

[Kunstgewerbemuseum im Grünen Gewölbe]
[500 Jahre Zirkel]

[1943] (in Direktorenkonferenz angemeldet, Realisierung bisher nicht nachgewiesen)

[Mathematisch-Physikalischer Salon im

Grünen Gewölbe]

\section{4}

Serienporzellan aus Küche, Keller, Kantine und Kaserne

3.1944-9.1944 [12.1944]

Porzellansammlung, Zwinger

Kurator: Fritz Fichtner

Veit Stoß

8.1944-10.1944

Historisches Museum, Johanneum

(Wanderausstellung des RMWEV)

Katalog 
Die wissenschaftlichen Mitarbeiterinnen und Mitarbeiter 


\section{Gert Adriani}

12.1.1908 Vlotho - 2.3.1989 Göttingen

Kunsthistoriker

Kupferstich-Kabinett

1.7.1936-31.12.1937

Freiwilliger Wissenschaftlicher Hilfsarbeiter

1.3.1938-31.12.1938

Freiwilliger Wissenschaftlicher Hilfsarbeiter

Gemäldegalerie

1.1.1938-28.2.1938 Freiwilliger Wissenschaftlicher

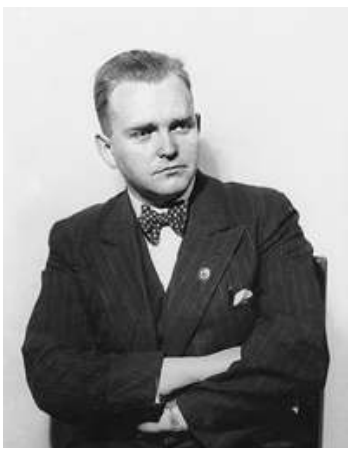

Hilfsarbeiter

Gert Adriani wurde am 12. Januar 1908 als Sohn des Rechtsanwalts und Notars Erich Adriani und dessen Frau Emilie Mathilde Dieckerhoff, geb. Karpen, im ostwestfälischen Vlotho geboren. Nach dem Besuch der Realgymnasien in Bad Oeynhausen und Bünde begann er, an der Universität in Göttingen Kunstgeschichte, Archäologie sowie Mittlere und Neuere Geschichte zu studieren. Später wechselte er an die Universitäten in Berlin, München und Graz, bevor er 1933 in Jena promovierte. Ab Oktober 1933 war er als Wissenschaftliche Hilfskraft am Kunsthistorischen Institut der Universität Graz tätig. 1934 heiratete er Renate, geb. Goedecke, mit der er drei Kinder hatte.

An den Staatlichen Sammlungen in Dresden arbeitete Adriani ab Juli 1936 als Freiwilliger Wissenschaftlicher Hilfsarbeiter, zunächst bis zum Jahrsende 1937 im Kupferstich-Kabinett unter - Kurt Zoege von Manteuffel. Adriani führte Katalogisierungsarbeiten durch, unterstützte Ausstellungsvorbereitungen, betreute die Benutzer im Studiensaal und hielt Vorträge und Führungen. Auf eigenen Wunsch wechselte er zum Jahresanfang 1938 in die Gemäldegalerie. Doch bereits nach zwei Monaten kehrte Adriani im März 1938, auf die Bitte Zoege von Manteuffels hin, ans Kupferstich-Kabinett zurück, wo er bis zum Jahresende, finanziell unterstützt durch einen Werkvertrag, den Nachlass von Johann Friedrich Lahmann bearbeitete. Währenddessen war er auch an der Vorbereitung der Ausstellungsserie mit Werken aus diesem Vermächtnis beteiligt. Im Sommer 1938 wurde kurzzeitig erwogen, Adriani die Stelle des Wissenschaftlichen Hilfsarbeiters im Kupferstich-Kabinett zu übertragen, wenn deren Inhaber $>$ Franz Schubert zum Kustos ernannt würde. Doch letztlich kam es dazu nicht. Schubert, der noch immer dem Druck eines Parteieintritts widerstand, blieb Wissenschaftlicher Hilfsarbeiter und Adriani, der im Mai 1937 in die NSDAP eingetreten war, suchte weiter nach einer Einstellung. Da ihm diese in Dresden nicht geboten werden konnte, bewarb sich Adriani im Herbst 1938 am Mecklenburgischen Landesmuseum in Schwerin, wobei er von $>$ Fritz Fichtner unterstützt wurde, denn es „verfügen weder das Kupferstichkabinett, noch die Gemäldegalerie über Mittel und freiwerdende Stellen, um Dr. Adriani in Dresden zu halten "1. Doch erst seine Bewerbung in Wien, mit einer Empfehlung von Galeriedirektor $\gg$ Hans Posse, hatte im Dezember 1938 Erfolg, und er verließ Dresden.

1 Leiter SMV, Fichtner, an das Mecklenburgische Staatsministerium, Abt. Kunst, 19.9.1938, HStA Dresden, 11125, Nr. 18964, fol. 378. 
Ab Januar 1939 arbeitete Adriani in Wien, erst in der Staatlichen Graphischen Sammlung Albertina, dann im Kunsthistorischen Museum. Im Februar 1941 wurde er Leiter der Gemäldegalerie des Kunsthistorischen Museums. Eine Dienstreise führte ihn im Dezember 1941 u. a. auch nach Dresden, wo er sich über die Bergungsmaßnahmen informierte. Adriani stand in Kontakt mit der „Dienststelle Mühlmann“ und war am nationalsozialistischen Kunstraub beteiligt. Bereits im Oktober 1940 hatte er mit Fritz Dworschak das Gemälde „Malkunst“ von Jan Vermeer, das damals zur Sammlung der Familie Czernin gehörte, nach München gebracht, weil Adolf Hitler sein Kaufinteresse geäußert hatte. Anfang 1945 war Adriani als Bergungsleiter im Salzbergwerk Lauffen bei Bad Ischl eingesetzt. In den letzten Kriegstagen befand er sich mit seiner Familie im Bergungsort Stift Klosterneuburg. Anfang September 1945 stellte er den Antrag auf Entlassung in Wien, um nach Deutschland zurückzugehen. Zunächst arbeitete er ab 1948 als Kustos am Kunstmuseum in Düsseldorf, wo er 1954 zum Direktor ernannt wurde. Im Juli 1958 wechselte er nach Braunschweig, wo er bis zu seiner Pensionierung Ende April 1970 das Herzog Anton Ulrich-Museum leitete. Gert Adriani starb am 2. März 1989 in Göttingen.

\section{Auswahlbibliografie}

Die Klosterbibliotheken des Spätbarock in Österreich und Süddeutschland. Ein Beitrag zur Bauund Kunstgeschichte des 17. und 18. Jahrhunderts, Graz, Leipzig, Wien 1935 (Zugl. Jena, Univ., Diss., 1933).

Anton van Dyck. Italienisches Skizzenbuch, Wien 1940 (Hg.).

Landschaftszeichnungen Wolf Hubers, in: Kunst dem Volk, H. 11, 1942, S. 28-32.

Aquarelle und Zeichnungen des 19. Jahrhunderts, in: Kunst dem Volk, H. 12, 1943, S. 15-25.

Raffaels Handzeichnungen, in: Kunst dem Volk, H. 7, 1944, S. 3-30.

Peter Paul Rubens 1577-1640, in: Kunst dem Volk, H. 11-12, 1944, S. 14-25.

Kunst und Künstler bei Goethe, Düsseldorf 1949 (Ausstellungskatalog Kunstsammlungen der Stadt Düsseldorf).

Schloß Richmond, München, Berlin 1966.

Herzog-Anton-Ulrich-Museum Braunschweig, Verzeichnis der Gemälde, Braunschweig 1969.

\section{Quellen und Literatur}

HStA Dresden, 11125, Nr. 18964; Nr. 22889

HStA Dresden, 11127, Nr. 29

Wex, Reinhold: Adriani, Gert, in: Camerer, Luitgard, Manfred R. W. Garzmann und WolfDieter Schuegraf (Hg.): Braunschweiger Stadtlexikon, Braunschweig 1992, S. 10.

Iselt, Kathrin: „Sonderbeauftragter des Führers“. Der Kunsthistoriker und Museumsmann Hermann Voss (1884-1969), Köln 2010, S. 181-182.

Löscher, Monika: Gert Adriani, in: Lexikon der österreichischen Provenienzforschung, www.lexikon-provenienzforschung.org/adriani-gert, Zugriff: 2.12.2019. 


\title{
Heinz Amberger
}

\author{
30.3.1907 Oberstein a. d. Nahe - 24.8.1974 Mannheim \\ Prähistoriker \\ Museum für Mineralogie, Geologie und Vorgeschichte \\ 1.7.1935-28.2.1938 Wissenschaftlicher Hilfsarbeiter
}

\begin{abstract}
Als Sohn des Arztes Jakob Peter Georg Amberger und dessen Frau Juliane Rosalie Luise Wilhelmine, geb. Ohl, wurde Georg Philipp Heinrich (Heinz) Amberger am 30. März 1907 in Oberstein an der Nahe geboren. Nach der Reifeprüfung, die er 1925 in Frankfurt am Main ablegte, studiert er in Jena, später in Heidelberg und Wien, Vor- und Frühgeschichte, Geschichte, Geologie und Zoologie. Im Dezember 1930 promovierte Amberger als Schüler von Oswald Menghin in Wien. Im Rahmen seines Volontariates an der archäologischen Sammlung des Hessischen Landesmuseums in Darmstadt von 1931 bis 1934 war er an der Neuaufstellung der prähistorischen Sammlung und mehreren Ausgrabungen beteiligt. Trotz dieser Berufserfahrungen bleib er nach dem Volontariat zunächst arbeitslos.
\end{abstract}

Erst im Juli 1935 wurde Amberger auf Vermittlung von Bolko von Richthofen am Museum für Mineralogie, Geologie und Vorgeschichte in Dresden als Wissenschaftlicher Hilfsarbeiter in der Prähistorischen Abteilung bei Kustos $\gg$ Georg Bierbaum angestellt. Wiederum beteiligte er sich an Ausgrabungen. Seine Hauptaufgabe war jedoch die vom Museumsdirektor $>$ Eberhard Rimann übertragene Ausstellungsarbeit. In enger Zusammenarbeit mit dem Zeichner Hermann Dengler kuratierte Amberger 1936 die Wanderausstellung „Sachsen im deutschen Lebensraum 5000 Jahre sächsische Geschichte" für die Landesbauernschaft Sachsen. Ebenfalls im Auftrag Rimanns führte er 1938 die Neuaufstellung der prähistorischen Abteilung des Museums unter dem Titel „Germanen in Sachsen“ aus. Bierbaum, in dessen Zuständigkeit diese Aufgabe gehört hätte, wurde dabei übergangen. So nahmen die Spannungen zwischen ihm und Amberger infolge von Kompetenzstreitigkeiten und politischen Differenzen zu. Sie kulminierten mit der inoffiziellen Eröffnung der „Germanen in Sachsen“ durch Amberger im Februar 1938. ${ }^{1}$ Amberger engagierte sich im Reichsbund für Deutsche Vorgeschichte und gründete im November 1936 mit Kurt Poland von der NSDAP-Kreisleitung eine Dresdener Ortsgruppe. Sein politisches Engagement begann schon in der Schulzeit. Bereits 1922 war er Mitglied des Großdeutschen Jugendbundes. Während des Studiums trat er in die Burschenschaft Germania und 1929 in den Stahlhelm ein, leitete die Stahlhelm-Hochschulgruppen an seinen Studienorten. Im November 1933 wurde er aus dem Stahlhelm in die SA übernommen, drei Jahre lang zählte er zum Reitersturm der SA. In die NSDAP trat er im Mai 1937 ein. Als sich ihm die Möglichkeit eines beruflichen Aufstieges bot, beendete Amberger Ende Februar 1938 seine Tätigkeit in Dresden.

Im März 1938 wechselte er als Kustos an die vorgeschichtliche Abteilung des Stadtmuseums in Düsseldorf und wurde zugleich ehrenamtlicher Pfleger für die kulturgeschichtlichen Bodenaltertümer der Stadt und des Landkreises Düsseldorf. Bereits damals war er ehrenamtlicher Mitarbeiter des Rasse- und Siedlungshauptamtes der SS (RuSHA). Nach mehrfacher Teilnahme an Reserveübungen wurde Amberger zu Beginn des Zweiten Weltkrieges zur Wehrmacht einberufen und diente in einem Fallschirmjägerbataillon. 1941 erlitt er in Korinth schwere Verletzungen, ebenso

1 Vgl. Schachtmann 2010, S. 62 f. 
1943 in Tunesien. Längere Zeit verbrachte er in Lazaretten. Ab Sommer 1941 zählte er zur SS, als SS-Hauptscharführer im RuSHA, wo er bis zum SS-Obersturmführer befördert wurde. Trotz des Kriegseinsatzes konnte er sich im Mai 1942 bei Hans Reinerth in Berlin habilitieren. Seine 1943 mit Hanna, geb. Wolff, geschlossene Ehe wurde nach einem Jahr geschieden. Nach Kriegsende engagierte sich Amberger als Schriftleiter der Burschenschaftlichen Blätter und Herausgeber eines Burschenschafter-Handbuches. Als Archäologe war er nicht mehr hauptamtlich tätig. Ab 1958 arbeitete er in einer Frankenthaler Firma und leitete ehrenamtlich das Museum Frankenthal. Heinz Amberger starb am 24. August 1974 in Mannheim.

\section{Auswahlbibliografie}

Die fränkische Goldfibel von Mölsheim (Rheinhessen), in: Germania. Anzeiger der RömischGermanischen Kommission des Deutschen Archäologischen Instituts, Bd. 15, 3, 1931, S. $180-182$.

Zur Herkunft und Verbreitung der Rheinischen Mischkultur der Eisenzeit, in: Mannus. Deutsche Zeitschrift für Vor- und Frühgeschichte, Bd. 24, 1932, S. 420-445 (Zugl. Wien, Univ., Diss., 1930).

Frühlatènegräber bei Crumstadt, Kr. Groß-Gerau, in: Germania, Bd. 17, 2, 1933, S. 88-91.

Zur Herkunft der Runen, in: Die Sonne. Monatsschrift für nordische Weltanschauung und Lebensgestaltung, Bd. 12, 8, 1935, S. 344-354.

Kelten und Westgermanen. Grundfragen ihres Verhältnisses (Berlin, Univ., Habil., 1942).

Burschenschafter-Handbuch, Bochum-Langendreer 1953 (Hg.).

Dero Stadt Franckenthal. Streiflichter aus der Franckenthaler Stadtgeschichte, Franckenthal 1962.

\section{Quellen und Literatur}

BArch, R 9361-III/2109; R 9361-III/514479

BArch, R 9361-IX/Kartei/431414

Schachtmann, Judith: Heinz Amberger (1907-1974) und die archäologischen Ausstellungen des Dresdner Museums für Vorgeschichte zwischen 1935 und 1938, in: Archaeo. Archäologie in Sachsen, 12/2015, 2016, S. 44-49. 


\title{
Rudolf Von ARps-Aubert
}

\author{
10.4.1894 Halle a. d. Saale - 15.11.1945 Bautzen
}

Kunsthistoriker

Grünes Gewölbe

1.2.1932-30.9.1936 Freiwilliger Wissenschaftlicher

Hilfsarbeiter

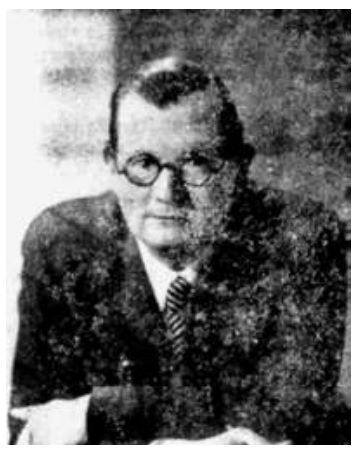

Rudolf Ernst von Arps-Aubert wurde am 10. April 1894 als Sohn des Geheimen Konsistorialrats Arnold von Arps-Aubert und dessen Frau Helene, geb. Boeck, in Halle an der Saale geboren. Nach dem Umzug der Familie besuchte er das Schiller-Gymnasium in Berlin-Lichterfelde, wo er 1913 die Reifeprüfung ablegte. Im August 1914 zog Arps-Aubert als Freiwilliger in den Ersten Weltkrieg. Bereits wenige Monate später, im Dezember 1914, geriet er in Gefangenschaft, die er in Sibirien verbrachte. Nach der Rückkehr im Juli 1920 studierte er drei Semester Rechtswissenschaften und arbeitete als Angestellter im Bankhaus H. F. Lehmann in Halle. Sein Studium der Kunstgeschichte begann er im Oktober 1926 an der Universität in Halle und wurde dort im Dezember 1931 promoviert.

Ab Februar 1932 war Arps-Aubert als Freiwilliger Wissenschaftlicher Hilfsarbeiter im Grünen Gewölbe in Dresden tätig. Er arbeitete unter anderem an der Ausstellung „August der Starke und seine Zeit" mit. Im Mai 1933 trat er in die NSDAP ein, für die er als Schulungsleiter und später als Blockwart tätig war. Seine Tätigkeit in Dresden endete im September 1936.

Arps-Aubert wechselte nach Zwickau, wo er ab Oktober 1936 als Leiter des König-AlbertMuseums Sigfried Asche nachfolgte. Vermutlich war er bereits damals „Vertrauensmann“ des Sicherheitsdienstes des Reichsführers SS (SD). 1938 heiratete er Luise, geb. Matz, die Enkelin des Berliner Architekten Martin Gropius, ${ }^{1}$ mit der er zwei Kinder hatte. Ab Sommer 1940 bewarb sich Arps-Aubert in Dresden für die Stelle des Direktors des Grünen Gewölbes und Historischen Museums, die durch die nahende Pensionierung von $>$ Erich Haenel, unter dem er einst gearbeitet hatte, bald frei werden sollte. Als die Stelle nach Haenels Tod im Dezember 1940 tatsächlich vakant war, intensivierte Arps-Aubert seine Bemühungen. Zu dieser Zeit war er als SS-Sturmbannführer für den SD tätig, der ihn als einen „der besten V-Männer der Außenstelle

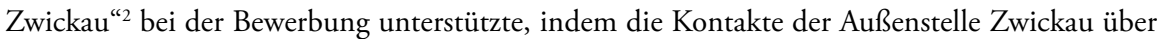
Chemnitz nach Dresden aktiviert wurden. Zunächst bemerkte $>$ Fritz Fichtner als Referent der Staatlichen Sammlungen, dass Arps-Aubert „als ernster Kandidat zu werten“ sei, denn er war Mitarbeiter von Haenel, „kennt die Dresdner Verhältnisse sehr gut - er hat sich durch Heraus-

\footnotetext{
1 Luise Matz war die Tochter des Regierungsbaurats Johannes Matz und seiner Frau Luise, Tochter von Martin Gropius und dessen zweiter Frau Julie, geb. de Greiff. Vgl. Körte, Arnold: Martin Gropius: Leben und Werk eines Berliner Architekten 1824-1880, Berlin 2013, S. 169, 250.

2 SS-Obersturmbannführer Hirschberg an SS-Hauptsturmführer Pröbsting, SD-Leitabschnitt Dresden, 9.1.1941, HStA Dresden, 13471, Nr. ZD 7921 A6, fol. 18.
} 
gabe seines Möbelbuches einen Namen gemacht“" ${ }^{\text {.3 }}$ Daher stand Arps-Aubert im April 1941 auf Rang zwei der Kandidatenliste hinter $>$ Walter Holzhausen. Im Dezember 1942 wurde ArpsAubert allerdings nicht mehr als Bewerber geführt - die Unterstützung des SD hatte ihm vermutlich nicht geholfen. ${ }^{4}$ Unklar bleibt, ob diese über ein Empfehlungsschreiben hinausging und welche Aufgaben er im SD übernahm. Letztlich blieb er Museumsleiter in Zwickau, wo er nach Kriegsende aufgrund seiner NSDAP-Mitgliedschaft fristlos entlassen wurde. Er wurde in ein Internierungslager der Sowjetischen Militäradministration, das "Speziallager Nr. 4“ in Bautzen, gebracht. Dort starb Rudolf von Arps-Aubert am 15. November 1945.

\section{Auswahlbibliografie}

Die Entwicklung des reinen Tierbildes in der Kunst des Paulus Potter, Halle/Saale 1932 (Zugl. Halle-Wittenberg, Univ., Diss., 1931).

Meisterstücke der Görlitzer Tischler aus dem 18. Jahrhundert, in: Die Heimat, Görlitz, 1936, S. $165-166$.

Sächsische Lackmöbel des 18. Jahrhunderts, in: Zeitschrift des Deutschen Vereins für Kunstwissenschaft, Bd. 3, 1937, S. 342-368.

Carl Gottlob Mittenzwey. Ein Zwickauer Porträtmaler des 19. Jahrhunderts. Verzeichnis seiner Bilder anlässlich der Ausstellung in Zwickau, Zwickau 1937.

Neues zur Dinglinger-Forschung, in: Dresdner Geschichtsblätter, Bd. 46, 1938, S. 5-13.

Sächsische Barockmöbel 1700-1770, Reihe Forschungen zur deutschen Kunstgeschichte, 33, Berlin 1939.

25 Jahre König-Albert-Museum, Zwickauer Kreismuseum, Zwickau 1939.

Sächsische Familienbilder, in: Sachsen. Zeitschr. d. Heimatwerkes Sachsen, Bd. 5, 1941, 1, S. $10-11$.

Berliner Kristallspiegel der Spätbarockzeit [im Dresd. Residenzschloß], in: Pantheon. Internationale Jahreszeitschrift für Kunst, 1942, S. 280-281.

\section{Quellen und Literatur}

HStA Dresden, 13471, Nr. ZD 7921 A6

Schreiber, Carsten: Elite im Verborgenen: Ideologie und regionale Herrschaftspraxis des Sicherheitsdienstes der SS und seines Netzwerks am Beispiel Sachsens, München 2008, S. 433-434.

\footnotetext{
3 SMV, Fichtner, 10.1.1941, SKD Archiv, 01/PS 53, Bd. 2, fol. 117.

4 Vgl. Schreiber 2008, S. 434. Schreiber erwähnt, dass die Bewerbung von Arps-Aubert scheiterte, weil die Stelle nicht neu besetzt wurde. Doch es muss andere Gründe dafür gegeben haben: Nach der Entscheidung, sammlungsintern einen kommissarischen Leiter zu berufen, standen im Dezember 1942 noch drei Kandidaten auf der Berufungsliste, nicht aber Arps-Aubert. Siehe S. 82 ff.

5 Für die Auskunft dankt die Autorin Ralf Marten von der Stiftung Sächsische Gedenkstätten, Gedenkstätte Bautzen.
} 


\section{Karl Assmann}

27.7.1890 Friedrichsberg - 1.4.1970 Pirna

Wissenschaftlicher Bibliothekar

Sächsische Landesbibliothek

(bis 1.5.1917 Königliche Öffentliche Bibliothek,

2.5.1917-11.1918 Königliche Landesbibliothek)

1.1.1915-31.3.1919 Volontär

1.4.1919-30.6.1920 Wissenschaftlicher Hilfsarbeiter

1.7.1920-31.12.1922 Bibliotheksassistent

1.1.1923-30.9.1945 Landesbibliothekar

1.10.1945-30.4.1948 Direktor

1.5.1948-31.10.1952 Wissenschaftlicher Bibliothekar, Stellvertretender Direktor

1.11.1952-31.8.1953 Kommissarischer Direktor

1.9.1953-30.9.1957 Direktor

(Militärdienst 29.1.1915-12.12.1918, 1.11.1940-27.7.1941)

Karl Heinrich Ernst Assmann wurde am 27. Juli 1890 als Sohn des Kaufmanns Johann Josef Heinrich Assmann und dessen Ehefrau Anna Marie Auguste, geb. Kägeler, in Friedrichsberg, Kreis Niederbarnim geboren. Nach dem Abitur, das er 1910 in Nauen ablegte, studierte er an den Universitäten in Marburg, Berlin und Greifswald Neuere Sprachen und Philosophie. 1913 wurde er in Greifswald promoviert. Im Dezember 1914 heiratete er Luise Emilie Agnes Ottilie, geb. Freiherr, mit der er zwei Kinder hatte.

Im Januar 1915 begann Assmann ein Volontariat an der Königlichen Öffentlichen Bibliothek in Dresden. Nur wenige Wochen später wurde er zum Militärdienst eingezogen und kehrte erst im Dezember 1918 aus dem Ersten Weltkrieg zurück. Im ersten Quartal 1919 arbeitete er erneut als Volontär an der nunmehr in Sächsische Landesbibliothek umbenannten Einrichtung, bevor er zum April 1919 als Wissenschaftlicher Hilfsarbeiter angestellt wurde. Im Juli 1920 erfolgte seine Ernennung zum Bibliotheksassistenten, zum Jahresbeginn 1923 zum Landesbibliothekar. Als Leiter des Benutzungsdienstes war er „mit der Leitung der Ausleihe und Dienstregelung des einfachen Dienstes betraut " ${ }^{\text {, }}$, darüber hinaus war er Fachreferent für Anglistik. Diese Aufgaben führte er während der NS-Zeit fort. Sein 1925 erstmals veröffentlichter „Führer für die Benutzer der Sächsischen Landesbibliothek" erschien in mehreren Auflagen. Assmann war kein NSDAP-Mitglied, was sein Kollege $>$ Helmut Deckert später damit erklärte, dass er „das Glück gehabt hatte, noch vor dem Termin, als die wissenschaftlichen Bibliothekare unter Druck gesetzt wurden, der Nazipartei beizutreten, zur Wehrmacht verpflichtet zu werden"2. Dies ist jedoch nicht schlüssig, da der politische Druck bereits 1937 zunahm, Assmann aber erst im November 1940 zum Militärdienst einberufen wurde und nach acht Monaten wieder an der Landesbibliothek tätig war. Ein Schicksalsschlag ereilte ihn, als seine 25-jährige Tochter im Februar 1945 bei der Bombardierung Dresdens ums Leben kam. Da Assmann lediglich Mitglied des RDB und des Opferringes der NSDAP war, nicht aber der Partei selbst, wurde er nach dem Zweiten Weltkrieg ohne Unterbrechung weiterbeschäftigt. Am 1. Oktober 1945 wurde er zum Direktor ernannt, ein „Posten, nach dem ich mich [d. h. Assmann

Bollert an Dähnert, 23.4.1940, SLUB, PA Dähnert, fol. 99.

2 Deckert 1987, S. 263, SLUB, Mscr.Dresd.App.2600,A1. 
sich, Anm. d. A.] wahrlich nicht gedrängt habe“"3. Im Auftrag des Ministeriums teilte er seinem Amtsvorgänger $\triangleright$ Hermann Neubert am 2. Oktober 1945 persönlich mit, dass er am Vortag „,von Herrn Staatssekretär Dr. Menke-Glückert als Kommissarischer Direktor der Sächsischen Landesbibliothek verpflichtet worden sei“‘ . Assmann selbst wurde wenige Jahre später degradiert. Ab Mai 1948 war er unter den Direktoren Erwin Hartsch und Alfred Fellisch als Wissenschaftlicher Bibliothekar nur noch stellvertretender Direktor. Erst im November 1952 wurde er Kommissarischer Direktor, ab September 1953 erneut Direktor. 1957 wurde Assmann, ähnlich wie zwölf Jahre zuvor Neubert, aus dem Amt gedrängt. Am 9. September legte ihm Staatssekretär Wilhelm Girnus nahe, seinen Dienst zum 1. Oktober zu beenden. In aller Stille verließ Assmann am 14. September 1957 die Bibliothek, von seinen Mitarbeitern verabschiedete er sich schriftlich: „Sie werden es mir nachfühlen, dass es mir sehr nahe geht, die Bibliothek zu verlassen, nachdem ich 42 Jahre [...] mit der Bibliothek dienstlich verbunden bin und mir 1945 die Aufgabe zugefallen war, unsere vollkommen zerstörte Bibliothek wieder aufzubauen. ${ }^{\text {" }}$ In der Tat hatte er sich nach dem Zweiten Weltkrieg für die Sicherung des früheren Bestands und den Aufbau funktionierender Bibliotheksstrukturen engagiert. Anlässlich des 400-jährigen Bestehens der Landesbibliothek initiierte er 1956 eine Festschrift.

Wenige Monate vor seinem 80. Geburtstag starb Karl Assmann am 1. April 1970 in Pirna.

\section{Auswahlbibliografie}

Miltons epische Technik nach Paradise Lost, (Greifswald, Univ., Diss., 1913).

Danteschätze der Sächsischen Landesbibliothek in Dresden, Dresden 1921.

Führer für die Benutzer der Sächsischen Landesbibliothek, Dresden 1925 (mehrere Aufl.).

Schatzkammer der Bildungsbeflissenen: die Sächsische Landesbibliothek in Dresden, in: Tägliche Rundschau, Nr. 81, 6.4.1946.

Die Sächsische Landesbibliothek zu Dresden im Wiederaufbau, in: Zentralblatt für Bibliothekswesen, Bd. 62, 1948, S. 5-26.

Sächsische Landesbibliothek Dresden 1556-1956. Festschrift zum 400-jährigen Bestehen, Leipzig 1956 (Hg.).

Die Anfänge der Sächsischen Landesbibliothek Dresden in: Sächsische Landesbibliothek Dresden 1556-1956, Leipzig 1956, S. 15-25.

Die Sächsische Landesbibliothek v. 1945 bis 1955. Zerstörung, Wiederaufbau u. gegenwärtiger Stand d. Arbeit, in: Sächsische Landesbibliothek Dresden 1556-1956, Leipzig 1956, S. 29-85.

\section{Quellen und Literatur}

HStA Dresden, 13859, Nr. 131

HStA Dresden, 19117, Karton 1781 PA Karl Assmann

Habermann, Alexandra, Klemmt, Rainer u. Frauke Siefkes: Lexikon Deutscher Wissenschaftlicher Bibliothekare 1925-1980, Frankfurt a. M. 1985, S. 7-8.

Bürger, Thomas u. Konstantin Hermann (Hg.): Das ABC der SLUB. Lexikon der Sächsischen Landesbibliothek - Staats- und Universitätsbibliothek Dresden, Dresden 2006, S. 17-18.

Nitzschke, Katrin: Assmann, Karl, in: Sächsische Biografie, 2010, Online-Ausgabe: http://saebi. isgv.de/biografie/Karl_Assmann_(1890-1970), Zugriff: 2.1.2020.

3 Assmann an Jammers, 5.6.1946, SLUB, PA Jammers.

4 Niederschrift von Neubert, 6.10.1945, SLUB, PA Neubert.

5 Assmann an die Mitarbeiter der Sächsischen Landesbibliothek, 14.9.1957, SLUB, Mscr.Dresd. App.2600,F. 


\section{Wolfgang BaLzer}

6.6.1884 Dresden - 11.5.1968 Radebeul

Kunsthistoriker

Kunstgewerbemuseum

1.10.1923-30.11.1933 Direktor

22.5.1945-31.10.1945 Kommissarischer Direktor

1.11.1945-31.1.1951 Direktor

Staatliche Kunstsammlungen

1.9.1946-31.1.1951 Direktor

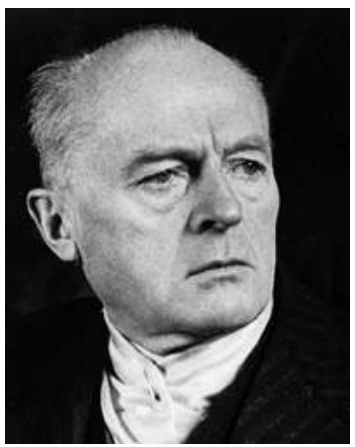

Am 6. Juni 1884 wurde Gustav Johann Wolfgang Balzer in Dresden geboren. Seine Eltern waren der Kaufmann Gustav Bruno Balzer und dessen Frau Emma Klara, geb. Magister. Nach dem Besuch der Volksschule lernte Balzer am Realgymnasium in Dresden-Neustadt, wo er 1903 die Reifeprüfung ablegte. Anschließend studierte er an den Universitäten in Tübingen, München und Leipzig Kunst- und Literaturwissenschaft, Neuere Sprachen und Philosophie. 1907 promovierte er als Schüler von August Schmarsow in Leipzig. Anschließend verbrachte er einen längeren Studienaufenthalt in Paris, bevor er 1909 seinen Militärdienst als Einjährig Freiwilliger leistete. Ab 1910 arbeitete Balzer als Kunstreferent für die Leipziger Volkszeitung. Mehrere Studienreisen führten ihn damals nach Frankreich, Belgien und in die Schweiz. Nach seinem Militärdienst im Ersten Weltkrieg war er von 1919 bis 1923 als Feuilleton-Redakteur der SPD-Tageszeitung „Freie Presse“ in Leipzig tätig und schrieb auch für andere Tageszeitungen. Darüber hinaus wirkte er als Literarischer Beirat an den Städtischen Bücherhallen Leipzig und arbeitete als Dozent an den Volkshochschulen in Leipzig und Dresden.

Am 1. Oktober 1923 wurde Balzer zum Direktor des Kunstgewerbemuseums in Dresden berufen, das damals der Kunstgewerbeakademie angegliedert war. So hielt er ab 1926 auch Vorträge an der Akademie. ${ }^{1}$ Im März 1933 wurde Balzer aufgrund seines Engagements für die SPD für einige Tage von den Nationalsozialisten verhaftet. Vorerst blieb er im Amt, doch zum 1. Dezember 1933 wurde er aufgrund des $\$ 6$ des „Gesetzes zur Wiederherstellung des Berufsbeamtentums“ 49-jährig in den Ruhestand versetzt. Zuvor hatte er seit September 1933 gemeinsam mit Inspektor $\triangleright$ Reinhard Schmelzer eine Revision der Bestände durchgeführt. ${ }^{2}$

Da Balzer bei der Entlassung seine Pensionsansprüche belassen worden waren, konnte er in den Folgejahren bis zum Kriegsbeginn 1939 regelmäßig mehrwöchige Aufenthalte in Zürich und Paris verbringen, wo er zur neueren Französischen Grafik, wie Daumier, und zur Europäischen Malerei forschte. Auch fertigte er Übersetzungen aus dem Französischen an. Vom Kulturleben und von öffentlichen Veranstaltungen in Dresden hielt er sich jedoch fern. Durch den Luftangriff auf Dresden am 13. Februar 1945 verlor Balzer sowohl seine private Kunstsammlung als auch sein wissenschaftliches Material.

\footnotetext{
Vgl. Bericht der Staatlichen Akademie für Kunstgewerbe Dresden 1926/1930, HfBK Archiv, 02/70, S. 22.

2 Vgl. Kunstgewerbemuseum, Balzer, an Wirtschaftsministerium Abt. Handel und Gewerbe, 29.11.1933, SKD Archiv, 01/KGM 5, fol. 323.
} 
Knapp zwei Wochen nach Kriegsende, am 22. Mai 1945, wurde Balzer mit der kommissarischen Leitung des Kunstgewerbemuseums beauftragt. Nachdem sich sein von den Nationalsozialisten eingesetzter Nachfolger in diesem Amt, $\triangleright$ Fritz Fichtner, nach Bayern abgesetzt hatte, war Balzer derjenige mit der größten Bestandskenntnis. Er arbeitete an der Rückführung der Objekte von den Auslagerungsorten mit und erlebte deren Abtransport durch die sowjetischen Trophäenbrigaden. Mit seinem vielfältigen Engagement sorgte Balzer dafür, dass die Dresdner Sammlungen weiter existierten. Bereits im Sommer 1945 engagierte er sich auch wieder politisch und trat in die KPD ein. Nach der Parteienfusion im April 1946 war er Mitglied der SED. Mit Vehemenz setzte er sich für die Übernahme des früheren Personals ein, denn ihm war bewusst, dass für die Fortführung der Museumsarbeit in der angespannten Situation der Nachkriegszeit eine gute Bestandskenntnis dringend erforderlich war. So erklärte er im Zuge der Entlassungswelle aus den Dresdner Sammlungen im Juli 1946, dass er sein „eigenes Verbleiben davon abhängig mache, daß mir für jedes der mir unterstellten Kulturinstitute mindestens je eine von früher her eingearbeitete Kraft zur Verfügung steht “ ${ }^{\text {“3 }}$ Im September 1946 wurde Balzer zum Direktor der Staatlichen Kunstsammlungen ernannt. Drei Monate später wurde er zusätzlich mit dem Aufbau der Grafischen Sammlung und einer Zentralen Kunstbibliothek beauftragt, wofür er Bestände aus der ehemaligen Kunstgewerbebibliothek auswählen sollte. ${ }^{4}$ Darüber hinaus baute er das Barockmuseum Schloss Moritzburg auf, dessen Gründungsdirektor er ab Mai 1947 war. Sein „stärkstes Mißfallen über die Handhabung der Personalangelegenheiten durch das Hauptpersonalamt der Landesregierung" brachte er auch in der Direktorenkonferenz vom September 1948 zum Ausdruck, denn die Museumsarbeit wurde „durch die Ablehnung der Einstellung von Wissenschaftlern und sonstigen [sic!] unbedingt notwendigen Fachpersonal, die ehemalige PG's waren, jetzt aber entnazifiziert sind, nicht nur verzögert, sondern teilweise fast unmöglich gemacht " ${ }^{\text {"5 }}$. So geriet Balzer ab Mai 1950 selbst zunehmend in Schwierigkeiten. Er musste sich wegen seines Fernbleibens von Partei- und Gewerkschaftsschulungen rechtfertigen und begründete dies mit seinem Gesundheitszustand - ein ärztliches Attest bestätigte ihm, dass er der Schonung bedürfe. Auch kam es zu Kompetenzstreitigkeiten zwischen Balzer und seiner vorgesetzten Dienststelle, insbesondere mit Gertrud Rudloff-Hille vom Referat für Bildende Kunst im Ministerium für Volksbildung. Noch im Januar 1951 schrieb Balzer an Rudloff-Hille: „Dank dem engagierten Personalabbau, wie er seit etwa einem halben Jahr geübt wird, befinden sich die Staatlichen Kunstsammlungen in einer Krise, man kann sogar sagen: es droht ihnen der Verfall“ und beklagte, dass er „[b]ei allen Personalveränderungen (Entlassungen, Neu- und Umbesetzungen, Abkommandierungen usw.) [...] grundsätzlich nicht zu Rate gezogen, manchmal sogar nicht rechtzeitig benachrichtigt "6 werde. Wenige Tage später, am 15. Januar 1951, wurde Balzer im Kunstgewerbemuseum mündlich zum Monatsende gekündigt. Am 31. Januar 1951 wurde er, abermals politisch motiviert, entlassen.

\footnotetext{
3 Kunstgewerbemuseum, Balzer, Landesverwaltung Sachsen, Abt. Kunst und Literatur, Ministerialdirektor Gute, 30.7.1946, SKD Archiv, 02/VA 41, Bd. 1, fol. 97.

4 Vgl. Landesverwaltung Sachsen, Volksbildung, Abt. Kunst und Literatur, an Hochschule für Werkkunst, 14.12.1946, HfBK Archiv, 02/62, o. Pag.

5 Vgl. Protokoll der Direktionssitzung, 6.9.1948, SKD Archiv, 02/VA 4, fol. 61 ff., hier: 62r.

6 Direktor der Staatlichen Kunstsammlungen, Balzer, an das Ministerium für Volksbildung, Referat Bildende Kunst, Rudloff-Hille, 10.1.1951, SLUB, Mscr.Dresd.App.2550, fol. 55.
} 
Knapp drei Monate danach wurde Balzer am 25. April 1951 wegen Untreue im Amt verhaftet. Die Ermittlungen gegen ihn hatten bereits 1950 begonnen, wegen des im September 1945 von ihm vorgenommenen heimlichen Abtransportes der Grafiksammlung von Friedrich August II. aus Schloss Moritzburg und deren Sicherstellung im Kunstgewerbemuseum. Erst nach zwei Wochen, am 10. Mai 1951, wurde der Haftbefehl aufgehoben und Balzer entlassen. Das Bemühen einiger Freunde, wie Eberhard Hempel, Professor für Kunstgeschichte an der Technischen Hochschule Dresden, und Ludwig Justi, Generaldirektor der Staatlichen Museen in Berlin, um die Wiedereinsetzung Balzers als Direktor der Gemäldegalerie scheiterte 1955. In den Folgejahren nahm er seine frühere private Sammeltätigkeit wieder auf, hielt Vorträge und publizierte rege. Wolfgang Balzer starb am 11. Mai 1968 in Radebeul. Seine umfangreiche Kunstsammlung mit über 3500 Objekten sowie seine kunsthistorische Bibliothek gingen als Vermächtnis an die Staatlichen Kunstsammlungen in Dresden über. Bereits 1961 hatte er dem Museum Bautzen 125 Gemälde Dresdner Künstler gestiftet. Eine Ausstellung mit Werken aus diesem Vermächtnis wurde in Dresden am 27. Oktober 1968 mit einer Feier zum Gedenken an Balzer eröffnet.

\section{Auswahlbibliografie}

Gustave Planche. Eine Untersuchung zur Geschichte der französischen Kunstkritik im 19. Jahrhundert, Leipzig 1908 (Zugl. Leipzig, Univ., Diss., 1907).

Leipziger Bildnismalerei von 1700-1850, in: Leipziger Kalender. Illustriertes Jahrbuch u. Chronik, Leipzig, Bd. 10, 1913, S. 237-252.

Kunst in Leipzig, in: Leipziger Kalender. Illustriertes Jahrbuch u. Chronik, Bd. 11, 1914, S. 209-220.

Paul Wilhelm. Gemälde, Aquarelle, Handzeichnungen aus den Jahren 1908-1948, Dresden 1948.

Fritz Schulze. Künstler und Kämpfer, Dresden 1950.

Ludwig Richter. Frühe Zeichnungen 1823 bis 1826, Dresden 1954.

Dresdner Galerie. 120 Meisterwerke des 15. bis 18. Jahrhunderts, Leipzig 1956.

Josef Hegenbarth. Zeichnungen zu fünf Shakespeare-Dramen, Berlin 1957.

Der französische Impressionismus: die Hauptmeister in der Malerei, Dresden 1958.

Der junge Daumier und seine Kampfgefährten: politische Karikatur in Frankreich 1830 bis 1835, Dresden 1965.

\section{Quellen und Literatur}

SLUB, Mscr.Dresd.App. 2550

SLUB, Mscr.Dresd.App.1689

HStA Dresden, 19117, Karton 1784 PA Wolfgang Balzer

SKD Archiv, 02/VA 41, Bd. 1 u. 2

SKD Archiv, 01/KGM 5

Löffler, Fritz: Erinnerung an einen schweren Neubeginn. Zum 80. Geb. v. Prof. Dr. Wolfgang Balzer, in: Die Union, Bd. 19, Ausg. 127, 1964.

Leben und Wirken für die Kunst. Zeichnungen aus dem Vermächtnis von Wolfgang Balzer. Vortrag von Werner Schmidt, Direktor des Kupferstichkabinetts Dresden, in: Die Union, 14.11.1968.

Rudert, Thomas: Betrug und Untreue im Amt oder ethisch-moralisch gebotene Sicherung gefährdeter Kunstwerke? Wolfgang Balzer und die Grafiksammlung des sächsischen Königs Friedrich August II., in: Dresdener Kunstblätter, 54. Jg., H. 2, 2010, S. 116-126. 


\title{
HeLene Barthel
}

\author{
8.2.1900 Grimma - [nach 1968 Hamburg] \\ Lehrerin, Wissenschaftliche Bibliothekarin \\ Sächsische Landesbibliothek
}

25.9.1936-15.10.1945 Wissenschaftliche Hilfsarbeiterin

Martha Marianne Helene Barthel, als Tochter des Baumeisters Karl Louis Barthel und dessen Frau Marie Helene, geb. Fröhlich, am 8. Februar 1900 in Grimma geboren, studierte in Leipzig Germanistik, Geschichte und Philosophische Propädeutik. Im Dezember 1926 legte sie in Leipzig ihre Lehramtsprüfung ab und wurde 1930 an der Universität Münster promoviert. Von Oktober 1930 bis September 1932 arbeitete sie als Volontärin an der Universitätsbibliothek Leipzig. Nach ihrer Prüfung für den Höheren Dienst an wissenschaftlichen Bibliotheken im März 1933 war Barthel an der Universitätsbibliothek Leipzig tätig. Von Januar bis August 1934 erstellte sie im Rahmen der Wissenschaftlichen Akademikerhilfe der Notgemeinschaft der Deutschen Wissenschaft an der Deutschen Bücherei Leipzig eine „Gesamtbibliographie des nationalsozialistischen Schrifttums“. Nach einer kurzen Beschäftigung im Kanzleidienst des Städtischen Steueramtes absolvierte Barthel ab Oktober 1935 einen einjährigen Vorbereitungsdienst an einer Leipziger Oberschule, um später gegebenenfalls ins Lehramt zurückkehren zu können.

Erst im September 1936 fand Barthel eine Anstellung im Bibliothekswesen. Sie wurde an der Sächsischen Landesbibliothek in Dresden als Wissenschaftliche Hilfsarbeiterin beschäftigt, „um in dem Kreise der wissenschaftlichen Beamten einen Parteigenossen zu haben "1. Der NSDAP war sie bereits zum 1. April 1932 beigetreten. Doch ihre Parteimitgliedschaft hat sie, nach Aussage des späteren Direktors > Hermann Neubert, „nie zu moralischem Zwang oder Denunziationen missbrauch ${ }^{\text {“2 }}$. Ihre mehrfachen Bemühungen um eine Beförderung zum Landesbibliothekar blieben erfolglos, da eine solche Stelle laut Stellenplan nicht zur Verfügung stand. Barthel übernahm das Fachreferat der Wirtschafts- und Sozialwissenschaften. Zu ihren Aufgaben zählte auch die „Mitarbeit an der Bibliographie zur Sächsischen Geschichte und an der Redaktion des Jahreskataloges der Neuerwerbungen, Bearbeitung der Wochenausstellungen der Neuerwerbungen im Lesesaal und - als politische Aufgabe - die Durchsicht der bestellten Bücher auf ihre Ausleihfähigkeit" ${ }^{\text {"3 }}$. Nach der Auslagerung einiger Bestände der Landesbibliothek nach Schloss Weesenstein weilte sie für deren Betreuung im April 1945 in Weesenstein. ${ }^{4}$ Aufgrund ihrer NSDAP-Mitgliedschaft wurde sie im Juni 1945 suspendiert und zum 15. Oktober 1945 entlassen.

Über ihr Leben und ihre berufliche Tätigkeit nach Ende des Zweiten Weltkrieges - sie war damals 45-jährig - liegen nur wenige Informationen vor. 1949 lebte sie in Wuppertal-Elberfeld.

\footnotetext{
$1 \quad$ Neubert an Wegner, 28.6.1945, SLUB, PA Barthel (Hervorhebung im Original). Hier täuschte sich Neubert - zum Zeitpunkt der Einstellung Barthels 1936 gab es bereits NSDAP-Mitglieder unter den Mitarbeitern: $\triangleright$ Dorothee von Watzdorf (seit 1925) und ^Ulrich Dähnert (seit 1933).

2 Neubert an Wegner, 28.6.1945, SLUB, PA Barthel.

3 Ebd.

4 Vgl. Ministerium für Volksbildung, Abt. IV, an Bürgermeister von Weesenstein, 24.4.1945, HStA Dresden, 10701, Nr. 320/55, Bd. 2, fol. 280.
} 
Von dort zog sie zunächst nach Flechtorf bei Braunschweig um, 1953 nach Villingen-Schwenningen, wo sie als Bibliothekarin und Kosmetikerin arbeitete. Im März 1965 siedelte sie nach St. Georgen über. Wenige Monate später war Helene Barthel in Hamburg wohnhaft, wo sie bis mindestens Juni 1968 lebte. $^{5}$

\section{Auswahlbibliografie}

Der Emmentaler Bauer bei Jeremias Gotthelf, in: Veröffentlichungen der Volkskundlichen Kommission des Provinzialinstituts für Westfälische Landes- und Volkskunde, Münster 1931 (Zugl. Münster, Univ., Diss., 1930).

\section{Quellen und Literatur}

SLUB, PA Barthel, Helene

HStA Dresden, 13471, Nr. ZW 119, Akte 1

BArch, R 9361-IX/Kartei/1460007

Villingen-Schwenningen, Bürgeramt, Altkartei

\footnotetext{
5 Vgl. Villingen-Schwenningen, Bürgeramt, Altkartei. Für diese Informationen sei Julia Hornung,
} Bürgeramt Villingen-Schwenningen, Abt. Servicezentrum Schwenningen gedankt. 


\section{Alfred Beck}

29.9.1896 Dresden - 18.6.1976 Dresden

Restaurator

Mathematisch-Physikalischer Salon

1.10.1928-30.4.1946 Restaurator

9.12.1942-5.1945 mit der Leitung beauftragt

(Militärdienst 15.8.1939-7.10.1939, 7.6.1943-5.1945)

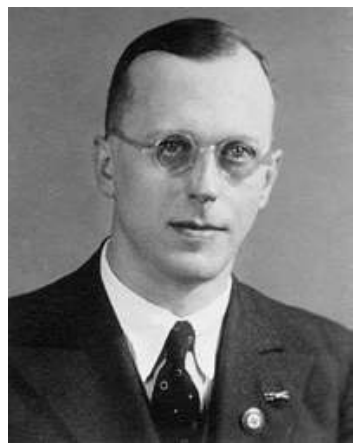

Richard Alfred Beck wurde am 29. September 1896 als Sohn des Lagerfahrers Friedrich Hermann Beck und dessen Frau Rosalie Minna, geb. Kuntzsche, in Dresden geboren. Nach dem Besuch der Volksschule erlernte er den Beruf des Uhrmachers und Feinmechanikers. Außerdem verfügte er über eine kaufmännische Ausbildung. Während des Ersten Weltkrieges diente er von April 1916 bis Januar 1919 in Fliegerabteilungen in Berlin und Großenhain. Danach war Beck wieder in Dresden als Feinmechaniker tätig, vermutlich bei den Werkstätten für Feinmechanik und Optik, G. Heyde KG. Im Sommer 1920 heiratete er Johanna Elisabeth, geb. Zimniak, mit der er eine Tochter hatte.

Am 1. Oktober 1928 wurde Beck als Restaurator am Mathematisch-Physikalischen Salon tätig, womit er Max Engelmann im Amt folgte. Nach dem Bewerbungsgespräch beim damaligen Direktor $\triangleright$ Paul Werkmeister im Juli 1928 hatte sich Beck gegen den langjährigen Mitarbeiter Werkmeisters am geodätischen Institut der Technischen Hochschule Dresden, Hermann Emil Krebs, durchgesetzt. Nach seiner Einarbeitung übernahm er neben der konservatorischen Betreuung der Objekte bald auch den Schriftverkehr des Museums, beantwortete Anfragen, versandte Fotos. Er hielt Führungen und Vorträge, schrieb zahlreiche Beiträge für Dresdner Tageszeitungen, für die „Uhrmacher Woche“ und die „Uhrmacherkunst. Verbandszeitung der deutschen Uhrmacher". Nicht zuletzt deshalb bescheinigte 1946 sein Vorgesetzter $\triangleright$ Walther Fischer vom Museum für Mineralogie und Geologie, Beck dessen „pädagogische[s] Talent, die Ergebnisse der Forschung der Öffentlichkeit zu vermitteln “1. Nach der vorzeitigen Pensionierung des Direktors Werkmeister im Mai 1938 erledigte Beck all seine Aufgaben in Eigenverantwortung. Darüber hinaus kuratierte er die Sonderausstellungen „Erd- und Himmelsfernrohre aus drei Jahrhunderten“ (1938) und „Die Frühzeit der Feinmechanik in Sachsen“ (1939) als Beiträge des Mathematisch-Physikalischen Salons zu den jeweiligen Museumswochen. Mitte August 1939 wurde er zum Militärdienst eingezogen, jedoch infolge einer Erkrankung bereits zwei Monate später wieder entlassen. So konnte Beck in den Museumsdienst zurückkehren. Nach der Schließung des Salons im September 1939 bestand nun seine Aufgabe in der Verpackung und Auslagerung der Bestände. Seine loyale und zuverlässige Arbeit veranlasste den Sammlungsreferenten des Sächsischen Ministeriums für Volksbildung, \Fritz Fichtner, im Mai 1941 beim Ministerium die zukünftige Leitung des Salons durch Beck zu beantragen. Fichtner sah darin einen „Ausnahmefall“, denn dadurch würde „der Nachweis erbracht werden, daß tüchtige Spezialisten auch mit der verantwortlichen Leitung betraut werden können" - so hatte er

1 Fischer, Arbeitszeugnis für Beck, 30.4.1946, SKD Archiv, 02/VA 166, fol. 2. 
von Becks „Haltung und Dienstauffassung [...] den besten Eindruck“ und nahm an, „daß er es verstehen wird, sich als verantwortlicher Führer der Sammlung Ansehen zu verschaffen und zu

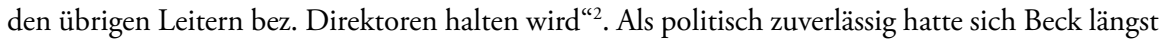
erwiesen. Im Mai 1933 war er in die NSDAP eingetreten. Aufgrund seiner Kenntnisse im Morsen und Funken, die er bei Kursen des Deutschen Amateur-Sende- und Empfangsdienstes erworben hatte, übernahm er schon bald eine wichtige propagandistische Aufgabe: In der Funktion eines Betriebsfunkwartes zeichnete er für die technische Realisierung des Empfanges der NS-Rundfunk-Propagandareden verantwortlich, der für die „Gefolgschaft" der Staatlichen Sammlungen in der Gemäldegalerie veranstaltet wurde. ${ }^{3} 1937$ ließ er sich für die Teilnahme am Reichsparteitag in Nürnberg vom Dienst freistellen. Seine Partei- und Gesetzestreue erwies er auch, als er sich nach einer fachlichen Anfrage des Juristen und Hauptmanns der Reserve Hans Pick bei der NSDAP-Kreisleitung nach dessen Abstammung erkundigte. ${ }^{4} 1938$ wurde Beck durch das Landesfinanzamt die Begutachtung einer Uhrensammlung übertragen, die ihrem jüdischen Eigentümer durch die „Reichsfluchtsteuer“ vom NS-Staat entzogen worden war. ${ }^{5}$ Im Januar 1939 kontaktierte er in Eigeninitiative die Gestapo, um für das Museum die Übernahme der Uhrensammlung des verstorbenen jüdischen Arztes Dr. Rosenthal zu erreichen. ${ }^{6}$ Am 9. Dezember 1942 beauftragte der Leiter des Ministeriums für Volksbildung, Arthur Göpfert, Beck schließlich „mit sofortiger Wirkung, und zwar zunächst auf die Dauer des Krieges mit der stellvertretungsweisen Verwaltung des Mathematisch-Physikalischen Salons"7. Doch bereits zum 7. Juni 1943 wurde Beck zur Wehrmacht einberufen. Die vertretungsweise Leitung übernahm Fischer, während $\triangleright$ Rudolf Schwarze vom Museum für Mineralogie und Geologie mit der Überwachung und Verpackung der Objekte beauftragt wurde. Nach Kriegsende, im Mai 1945, kehrte Beck nach Dresden zurück. Da seine Wohnung bei den Luftangriffen auf Dresden am 13. Februar 1945 zerstört worden war, wohnte er zunächst bei Verwandten seiner Frau. Die Arbeit für die Staatlichen Sammlungen hatte er offensichtlich sofort wieder aufgenommen. Aufgrund seiner Berufserfahrung und Bestandskenntnis und weil Fischer im August und November 1945 mehrfach hartnäckig insistierte, wurde Beck weiterhin am Mathematisch-Physikalischen Salon beschäftigt. Erst zum 30. April 1946 wurde er aufgrund seiner vorherigen NSDAP-Mitgliedschaft entlassen.

Nach seiner Entlassung arbeitete Beck bei der Dresdner Uhrenfabrik Albrecht Költzsch, die auch Auftragsarbeiten für den Mathematisch-Physikalischen Salon ausführte. So wurde im November 1946 in der Verwaltung der Museen die Auftragserteilung an Költzsch diskutiert, da diese als verdeckte Beauftragung Becks und damit als „Durchstechung der dienstlichen Maßnahme der

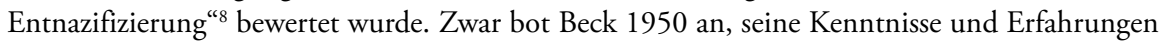

2 Fichtner, Bericht über Maßnahmen zur Wahrnehmung der Dienstaufsicht, 1.5.-31.5.1941, SKD Archiv, 01/PS 53, Bd. 1, fol. 173 ff., hier: 174.

3 Vgl. SKD, MPS, 1934, A.-Reg. 182; 1935 A.-Reg. 134 u. 1936, A.-Reg. 5. Vgl. S. 112 f.

4 Vgl. Mathematisch-Physikalischer Salon, Beck, an NSDAP-Kreisleitung, 9.11.1936, SKD, MPS, 1936, A.-Reg. 337.

Vgl. Beck an Werkmeister, 10.5.1938, HStA Dresden, 13859, Nr. 299, fol. 21v.

6 Vgl. Mathematisch-Physikalischer Salon, Beck, an Geheime Staatspolizei, 23.1.1939, SKD, MPS, 1939, A.-Reg. 25. Diese private Sammlung kam letztlich nicht in die Museumssammlung.

7 Ministerium für Volksbildung, Göpfert, an Beck, Mathematisch-Physikalischer Salon, 9.12.1942, SKD, MPS, Akten 1942, E.-Reg. 265 u. HStA Dresden, 13859, Nr. 299, fol. 40.

8 Protokoll der Direktorenkonferenz, 4.11.1946, SKD Archiv, 02/VA 158, fol. 49. 
an den ihm nachfolgenden Restaurator weiterzugeben, doch ein entsprechender Kontakt ist nicht überliefert. Alfred Beck starb am 18. Juni 1976 in Dresden.

\section{Auswablbibliografie}

Einhundertfünfzig Jahre Zeitdienst, in: Deutsche Uhrmacher Zeitung, 58. Jg., 1934, H. 1 u. 3. Von alten Uhren - und wie sie in unsere Sammlung gelangten, in: Die Uhrmacher-Woche, Leipzig, 43. Jg., Nr. 1 v. 1.1.1936; Nr. 2 v. 11.1.1936.

Der Mathematisch-Physikalische Salon in Dresden, in: Der Spezialhandwerker, Fachliches Schulungsblatt der Deutschen Arbeitsfront, Nr. 4, 27.4.1938.

Vom Zirkelschmied zum Mechanikus. Ein Beitrag zur Geschichte der Feinmechanik in Sachsen, in: Photographie und Forschung, Bd. 3, H. 8, 1941.

Wunderwerke der Technik im Mathematisch-Physikalischen Salon im Zwinger zu Dresden, in: Das ist Dresden, Dresden 1942, S. 20-25.

\section{Quellen und Literatur}

HStA Dresden, 13859, Nr. 299

HStA Dresden, 13471, Nr. ZW 232, Akte 5

SKD Archiv, 01/PS 49, Bd. 1; 01/PS 53, Bd. 1 u. 3

SKD Archiv, 02/VA 162

SKD, MPS, Akten 1933-1945

BArch, R 9361-VIII Kartei/1310313; R 9361-IX Kartei/1900967 


\section{Herbert Bellmann}

8.1.1903 Dresden - 9.6.1961 Dresden

Chemiker, Volkskundler

Museen für Tierkunde und Völkerkunde

(ab 1.1.1942 Museen für Tierkunde, Rassenkunde und

Völkerkunde)

1.1.1932-30.9.1934 Freiwilliger Wissenschaftlicher

Hilfsarbeiter

23.5.1938-31.1.1939 Wissenschaftlicher Hilfsarbeiter

22.2.1939-31.8.1940 Freiwilliger Wissenschaftlicher

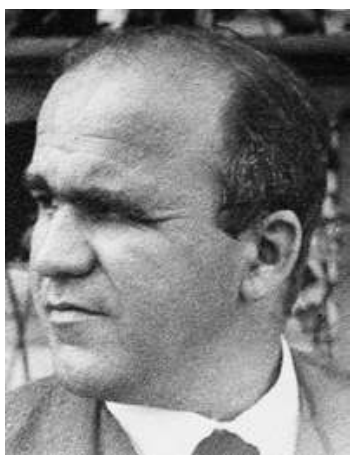

Hilfsarbeiter

1.9.1940-31.3.1942 außerordentlicher Wissenschaftlicher Hilfsarbeiter

13.11.1945-31.7.1946 Mitarbeiter

(Militärdienst 9.1939-12.1939)

Am 8. Januar 1903 wurde Robert Hermann Bellmann als Sohn des Schlossers und Obermaschinenmeisters Moritz Robert Bellmann und dessen Frau Alma Clara, geb. Wohlwarth, in Dresden geboren. Nach dem Besuch der Volksschule und des Wettiner Gymnasiums studierte Bellmann ab 1922 an der Technischen Hochschule Dresden Chemie. 1924 wechselte er für zwei Semester an die Universität in Wien, wo er zusätzlich Anthropologie und Völkerkunde studierte. Nach seiner Rückkehr nach Dresden setzte er das Studium der Chemie bis zum Diplom im Sommer 1931 fort, ergänzt um die Fächer Anthropologie, Völkerkunde, Germanistik und Volkskunde. Anschließend studierte er hier bis 1934 Anthropologie und Völkerkunde bei $>$ Bernhard Struck sowie Volkskunde bei Adolf Spamer, für den er als freiwilliger Assistent tätig war.

Parallel dazu arbeitete Bellmann bereits ab Januar 1932 als Freiwilliger Wissenschaftlicher Hilfsarbeiter an den Staatlichen Museen für Tierkunde und Völkerkunde in Dresden, wo Struck als Kustos tätig war, und inventarisierte deren Bildbestand. Ab Oktober 1934 erhielt er auf Empfehlung seiner Lehrer ein Stipendium der Deutschen Forschungsgemeinschaft, um Spamer in der Abteilung Volkskunde der Reichsgemeinschaft der deutschen Volksforschung als Assistent beim Aufbau eines „Wort- und Bildarchives der deutschen Volkskunde“ zu unterstützen. Mit Auflösung der Reichsgemeinschaft im März 1938 endete diese Tätigkeit. Durch die Vermittlung von Struck, der mittlerweile in Jena lehrte, ${ }^{1}$ wurde Bellmann ab Mai 1938 vertretungsweise dessen Kustodenstelle für Anthropologie übertragen, denn der eigentliche Vertreter, \Berthold Pfaul, war zum Militärdienst eingezogen worden. Nach der Rückkehr Pfauls blieb Bellmann im Museum und übernahm, als dieser im Oktober 1938 nach Berlin wechselte, dessen Stelle. Allerdings endete sein Vertrag, als der neue Kustos $\triangleright$ Michael Hesch eingestellt wurde. Bellmann arbeitete unentgeltlich weiter. Das setzte sich fort, als er im Februar 1939 per Vertrag als Freiwilliger Wissenschaftlicher Hilfsarbeiter eingestellt wurde. Nur für seine Tätigkeit für die „Erb- und rassenbiologische Forschungsstelle" der Anthropologischen Abteilung, bei der er Vaterschaftsuntersuchungen durchführte, erhielt er eine Vergütung. Nebenher schrieb Bellmann, gedrängt von Struck, an seiner Dissertation. Im Juli 1939 wurde er in Jena promoviert. Im Zuge der allgemei-

$1 \quad$ Vgl. Struck an Kummerlöwe, 11.5.1938, HStA Dresden, 13842, Nr. 114, Bd. 2, o. Pag. 
nen Mobilmachung im September 1939 wurde Bellmann eingezogen und bis mindestens Dezember 1939 zu einem Kommando der Technischen Nothilfe am Gaswerk Dresden-Reick abgeordnet. Im September 1940 wurde er als außerordentlicher Wissenschaftlicher Hilfsarbeiter eingestellt und für die Leitung des Umzugs des Museums für Völkerkunde in das Johanneum mehrfach uk-gestellt. ${ }^{2}$ Darüber hinaus hielt er Führungen in der anthropologischen und völkerkundlichen Sammlung, sprach z. B. über Brauchtum und „Rassen in den deutschen Kolonien“. Als sich im Januar 1942 abzeichnete, dass die Umzugsarbeiten kriegsbedingt nicht fortgeführt würden, endete seine Beschäftigung wie auch die Uk-Stellung. Möglicherweise wurde auch aus einem anderen Grund nicht stärker um den Verbleib Bellmanns am Museum gekämpft: Er hatte die Drucklegung seiner Dissertation mehrfach verzögert und damit seinen Doktorvater wie auch die Kommissarischen Museumsleiter > Martin Heydrich und Hesch verärgert, die breits die entsprechenden Mittel wie das Papierkontingent für die Publikation beantragt hatten. Da eine Bewerbung Bellmanns bei der Kriegsmarine erfolglos blieb, wirkte er zunächst noch an der Bergung der Objekte mit, wofür er eine Vergütung erhielt.

Am 9. Mai 1942 wurde Bellmann zur Wehrmacht einberufen. Zunächst in Gotenhafen und später in Hamburg beim Wetterdienst eingesetzt, zeichnete er Wetterkarten und erlernte das Funken. 1943 wurde er erst nach Frankreich, dann nach Greifswald und später zur Küstenartillerie nach Albanien abkommandiert. Während des Militärdienstes nutzte er jede sich bietende Gelegenheit zu Museumsbesuchen und erweiterte sein privates Bildarchiv. Da er von der Front mit einer Lungenentzündung zurückkehrte, wurde er im Januar 1945 im Lazarett in Dresden-Loschwitz behandelt. Wieder genesen, beteiligte er sich nach der Bombardierung der Stadt an den Bergungsarbeiten des zerstörten Museums.

Im November 1945 erhielt Bellmann eine Anstellung als Mitarbeiter am Museum für Völkerkunde. In den Folgemonaten unterstützte er primär die Rückführung der Objekte aus den Auslagerungsorten. Doch am 31. Juli 1946 wurde er entlassen. Begründet wurde dies mit seiner Mitgliedschaft in der SA von 1933 bis Mai 1934. Der von Bellmann eingelegte Widerspruch blieb erfolglos.

Nachfolgend übernahm Bellmann gelegentlich private Aufträge, wie zum Beispiel 1947 die Sicherstellung der im Krieg aus Hamburg in Sachsen ausgelagerten Kunstschätze. Auch gab er Lateinunterricht und hielt volkskundliche Vorträge. Von 1952 bis 1953 war er als Dokumentarist bei der Zentralstelle für wissenschaftliche Literatur tätig. 1954 wirkte er neun Monate am Institut für Völkerkunde in Berlin an der „Internationalen Volkskundlichen Bibliographie“ mit. Nachdem \Siegfried Wolf als Direktor des Museums für Völkerkunde in Dresden eingestellt worden war, engagierte dieser Bellmann, den er seit seiner Zeit als Freiwilliger Wissenschaftlicher Hilfsarbeiter kannte, ab 1958 auf Honorarbasis für die Zeitschriftenauswertung im Museum. Diese Arbeit kam den Interessen und Fähigkeiten Bellmanns entgegen, der Zeit seines Lebens akribisch sammelte und dokumentierte und so ein privates Bildarchiv mit etwa 12.000 Dokumenten zusammentrug. Infolge einer fortschreitenden Multiple-Sklerose-Erkrankung starb Herbert Bellmann am 9. Juni 1961 in Dresden.

2 Vgl. Staatliche Sammlungen, Fichtner, an Wehrbezirkskommando Dresden I, 13.12.1940, SKD Archiv, 01/PS 53, Bd. 3, fol. 174. 


\section{Auswahlbibliografie}

Jahresweiser für die Volksfeste in Sachsen, in: Frenzel, Walter, Fritz Karg und Adolf Spamer (Hg.): Grundriß der Sächsischen Volkskunde, Bd. 2, Leipzig 1933, S. 65-103.

Volkskundliche Organisationen im In- und Ausland, in: Spamer, Adolf: Die deutsche Volkskunde, 1, Leipzig 1934, S. 627-632.

Volkskundliches Schrifttum, in: Spamer, Adolf (Hg.): Die Deutsche Volkskunde, 2, Leipzig 1935, ab S. 513 (88 S.).

Weihnachten vor 150 Jahren in Dresden aus dem Reisebericht einer Engländerin, in: Mitteldeutsche Blätter für Volkskunde, 11, 1936, S. 189-191.

Die Tatauierung, in: Pessler, Wilhelm (Hg.): Handbuch der deutschen Volkskunde, 3, Potsdam 1936, S. 57-65.

Bestandsaufnahme der in sächsischen Museen befindlichen menschlichen Schädel und Skelette, in: Hesch, Martin und Günther Spannaus (Hg.): Kultur und Rasse. Otto Reche zum 60. Geburtstag; gewidmet von Schülern u. Freunden, Bd. 60, München 1939, S. 31-38.

Frühgeschichtliche Schädel vom Mittelrhein. Ein Beitrag zur Rassenkunde der heutigen Rheinlande (Jena, Univ., Diss., 1939).

Die Destillation bei den Naturvölkern, in: Wissenschaftliche Zeitschrift der Friedrich-SchillerUniversität Jena, 3, 1953/1954, S. 179-185.

Miszelle. Radmähen oder Kreishauen, in: Schweizer Archiv für Volkskunde, Bd. 50, 1954, S. 35-36.

\section{Quellen und Literatur}

HStA Dresden, 11125, Nr. 18991, Bd. 1

HStA Dresden, 13842, Nr. 115 (Einzeldokumente)

SKD, MfV Archiv, Nachlass Herbert Bellmann

SKD, MfV Archiv, MVD n20;25/2

Martin, Petra: Volks- und Völkerkunde in Bildern. Das Bildarchiv von Robert Herbert Bellmann, in: Martin, Andreas (Hg.): Digitale Bilderwelten. Zur elektronischen Erschließung von Bildsammlungen, Volkskunde in Sachsen, Bd. 8, Dresden 2003, S. 131-149 (mit Schriftenverzeichnis). 


\title{
Rudolf BemmanN
}

\author{
7.6.1881 Hamburg - 21.5.1948 Dresden
}

Historiker, Wissenschaftlicher Bibliothekar

Sächsische Landesbibliothek

(bis 1.5.1917 Königliche Öffentliche Bibliothek, 2.5.1917-11.1918 Königliche

Landesbibliothek)

16.1.1911-31.5.1914 Wissenschaftlicher Hilfsarbeiter

1.6.1914-30.5.1918 Bibliotheksassistent

1.4.1941-15.10.1945 Landesbibliothekar, Bibliotheksrat, Stellvertretender Direktor

Franz Rudolf Bemmann wurde am 7. Juni 1881 in Hamburg als Sohn des Kaufmanns Friedrich Rudolf Bemmann und dessen Frau Elise, geb. Nacke, geboren. Nach dem Umzug der Familie nach Dresden besuchte er eine Privatschule in Dresden-Blasewitz und lernte später am Königlichen Gymnasium in Dresden-Neustadt, wo er 1901 die Reifeprüfung bestand. Sein Studium der Geschichte, Philosophie, Kunstgeschichte, Germanistik und Nationalökonomie an den Universitäten in Tübingen, Heidelberg und Leipzig schloss Bemmann 1906 in Leipzig als Schüler von Gerhard Seeliger mit einer Promotion ab. Von Juli 1907 bis Januar 1911 arbeitete er als Stadtarchivar in Mühlhausen in Thüringen, wo er zugleich die Städtische Bibliothek leitete.

Mitte Januar 1911 kehrte Bemmann nach Dresden zurück und war als Wissenschaftlicher Hilfsarbeiter an der Königlichen Öffentlichen Bibliothek tätig. Als Nachfolger von Viktor Hantzsch arbeitete er an der „Bibliographie der Sächsischen Geschichte“, deren ersten Band er 1918 gemeinsam mit \Jacob Jatzwauk herausgab, der diese Arbeit später allein fortführte. Im Juni 1914 wurde Bemmann zum Bibliotheksassistenten ernannt. Im Juni 1916 ehelichte er Hildegard, geb. Luckwald. Im April 1918 bewarb er sich erfolgreich als Bibliothekar der Ständeversammlung, wofür ihm der Direktor der Königlichen Landesbibliothek, Hubert Ermisch, in einem Zeugnis Fleiß, Pflichttreue und Gewissenhaftigkeit bescheinigte.

Im Juni 1918 wechselte Bemmann als sogenannter ständischer Bibliothekar ins Ständehaus. Er erklärte sich bereit, die „Bibliographie der Sächsischen Geschichte“ fortzuführen, wofür er bis mindestens 1931 eine geringe zusätzliche Vergütung erhielt. Nach der Novemberrevolution wurde die von ihm geleitete Bibliothek 1919 zur Landtagsbücherei und er selbst 1927 zum Landtagsbibliothekar. Im Februar 1934 wurde er von seinen Dienstaufgaben in Dresden beurlaubt und zum Abteilungsleiter im Stabsamt des Reichsbauernführers in Berlin berufen. Zunächst galt dies nur für einige Monate, doch die Beurlaubung in Sachsen wurde mehrfach verlängert, Bemmann jedoch nicht in eine Anstellung nach Berlin übernommen. Erst als die sächsische Staatskanzlei im Januar 1941 die Entscheidung des Reichsstatthalters mitteilte, dass eine „weitere Beurlaubung über den 31.3.1941 hinaus [...] infolge zahlreicher Einberufungen zur Wehrmacht und infolge der Abordnung von Beamten in die besetzten Gebiete ausgeschlossen $^{\text {"1 }}$ ist, lenkte der Reichsbauernführer ein.

1 Sächsische Staatskanzlei an Reichsbauernführer, Verwaltungsamt, Berlin, 9.1.1941, HStA Dresden, 13859, Nr. 335, fol. 69. 
Im Frühjahr 1941 wechselte Bemmann wieder nach Dresden. Da seine bisherige Stelle als Landtagsbibliothekar eingezogen worden war, kehrte er zum 1. April 1941 an die Sächsische Landesbibliothek zurück. Als Landesbibliothekar und Erster Bibliotheksrat war er sogleich Stellvertreter des Direktors $>$ Hermann Neubert. Zum 15. Oktober 1945 wurde er entlassen

Rudolf Bemmann starb am 21. Mai 1948 in Dresden.

\section{Auswablbibliografie}

Zur Geschichte des deutschen Reichstages im XV. Jahrhundert, in: Leipziger Historische Abhandlungen, 7, Leipzig 1907 (Zugl. Leipzig, Univ., Diss., 1906).

Zur Geschichte des Mühlhäuser Handels und Gewerbes, in: Mühlhäuser Geschichtsblätter, X, 1909, S. 75-94.

Die Stadt Mühlhausen in Thür. im späten Mittelalter, Neujahrsblätter Historische Kommission für die Provinz Sachsen und das Herzogtum Anhalt, 39, Halle a. d. Saale, 1915.

Bibliographie der sächsischen Geschichte: Bd. 1, Aus den Schriften der Kgl. Sächs. Kommission für Geschichte, Leipzig, Berlin, Dresden 1918 (mit Jacob Jatzwauk).

E. T. A. Hoffmanns Beziehungen zu Dresden, in: Dresdner Geschichtsblätter, 27, 1918, S. $120-129$.

Thomas Münzer, Mühlhausen i. Thür. und der Bauernkrieg, in: Festgabe Gerhard Seeliger zum 60. Geburtstage, Leipzig 1920, S. 167-175.

Aus dem Leben Johann Gottlob von Quandts, in: Neues Archiv für sächsische Geschichte und Altertumskunde, 46, 1925, S. 1-45.

100 Jahre sächsische Verfassung. Ein Führer durch die Verfassungs-Ausstellung im Landtagsgebäude, Dresden 1931.

Bücherverzeichnis des sächsischen Landtages, Bd. 1-3, Ergänzungsheft 1, Dresden 1928-1933.

\section{Quellen und Literatur}

HStA Dresden, 13859, Nr. 335

SLUB, PA Bemmann, Rudolf

Habermann, Alexandra, Klemmt, Rainer u. Frauke Siefkes: Lexikon Deutscher Wissenschaftlicher Bibliothekare 1925-1980, Frankfurt a. M. 1985, S. 18.

Nitzschke, Katrin: Bemmann, Franz Rudolf, in: Sächsische Biografie, 2004, Online-Ausgabe: http://saebi.isgv.de/biografie/Rudolf_Bemmann_(1881-1948), Zugriff: 2.1.2020.

Bürger, Thomas u. Konstantin Hermann (Hg.): Das ABC der SLUB. Lexikon der Sächsischen Landesbibliothek - Staats- und Universitätsbibliothek Dresden, Dresden 2006, S. 27. 


\section{GotTFried BenNDORF}

12.4.1894 Roitzschen - 13./14.2.1945 Dresden

Wissenschaftlicher Bibliothekar

Sächsische Landesbibliothek

1.10.1919-30.9.1921 Volontär

11.10.1921-31.12.1922 außerordentlicher Wissenschaftlicher Hilfsarbeiter

1.1.1923-31.3.1927 Wissenschaftlicher Hilfsarbeiter

1.4.1927-13./14.2.1945 Landesbibliothekar (Bibliotheksrat)

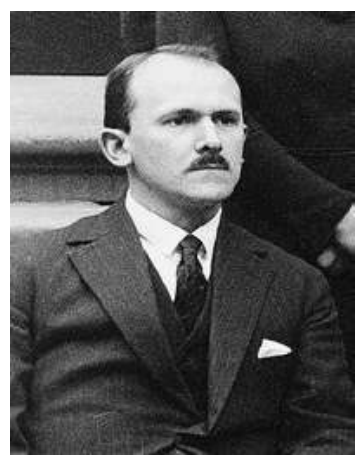

Johann Gottfried Benndorf wurde am 12. April 1894 in Roitzschen bei Meißen als Sohn des Eisenbahnbeamten Johann Adolf Benndorf und seiner Frau Christiane Helene, geb. Francke, geboren. Nach dem Tod des Vaters zog seine Mutter mit ihm und seiner Schwester 1899 nach Dresden, wo er 1913 am König-Georg-Gymnasium sein Abitur ablegte. Danach studierte er an der Universität Leipzig Germanistik, Geschichte und Geografie. 1917 wurde Benndorf als Schüler von Hans Meyer am Kolonialgeographischen Institut der Universität Leipzig promoviert. Nach der 1918 abgelegten Staatsprüfung für das Höhere Lehramt begann er das obligatorische Probejahr am Schiller-Realgymnasium in Leipzig. Doch aufgrund einer Kehlkopferkrankung musste er im Frühjahr 1919 den Lehrerberuf aufgeben. Er entschied sich, nachdem er bereits als Student an der Bibliothek des Historischen Seminars assistiert hatte, ins Bibliothekswesen zu wechseln.

Nach einer zunächst abgelehnten Bewerbung wurde Benndorf im Oktober 1919 als Volontär an der Sächsischen Landesbibliothek angenommen. Zwei Jahre später bestand er die Prüfung für den Höheren Bibliotheksdienst. Ab Oktober 1921 arbeitete er als außerordentlicher Wissenschaftlicher Hilfsarbeiter an der Bibliothek, bevor er Anfang 1923 zum Wissenschaftlichen Hilfsarbeiter und im April 1927 zum Landesbibliothekar ernannt wurde. Er war Leiter der Kartensammlung und Fachreferent für Geografie. Während seiner Bibliothekslaufbahn war Benndorf nicht mehr wissenschaftlich tätig, sondern veröffentlichte kleinere Beiträge in Dresdner Tageszeitungen. Als der allgemeine politische Druck zunahm, stellte Benndorf im Juli 1937 einen Aufnahmeantrag in die NSDAP, eine Mitgliedskarte wurde ihm im April 1938 mit dem Eintrittsdatum 1. Mai 1937 ausgestellt. In der Nacht vom 13./14. Februar 1945 war Benndorf zum Luftschutzdienst im Japanischen Palais, dem Standort der Sächsischen Landesbibliothek, eingeteilt. Beim Versuch, den brennenden Dachstuhl des Gebäudes zu löschen, kamen er und drei seiner Kollegen ums Leben. ${ }^{1}$ Erst nach über einem Jahr konnten die sterblichen Überreste, „kleine Bruchstücke ausgeglühter Knochen und Knochen-Kalkstaub“2, geborgen werden. Anhand von persönlichen Gegenständen, die daneben gefunden worden waren, musste ihn seine

1 Dies waren der Bibliotheksgehilfe Ernst Dressler (2.3.1881-13./14.2.1945), der Heizer und Hausmeister Kurt Schuhmann (1.6.1886-13./14.2.1945) und der Hilfsheizer Arthur Hess (21.11.1889-13./14.2.1945). Vgl. Direktor der Sächsischen Landesbibliothek, Neubert, 7.3.1945 u. Direktor der Sächsischen Landesbibliothek, Assmann, 4.6.1946, beide: SLUB, PA Benndorf.

2 Direktor der Sächsischen Landesbibliothek, Assmann, 4.6.1946, SLUB, PA Benndorf. 
Frau, die Bibliothekarin Helene Benndorf, geb. Richter, die er 1929 geheiratet hatte, identifizieren. Am 16. Mai 1946 wurde Gottfried Benndorf in Radebeul beerdigt.

\section{Auswahlbibliografie}

Der koloniale Verkehr Deutsch-Ostafrikas. Ein wirtschafts-geographischer Versuch, Weida 1918 (Zugl. Leipzig, Univ., Diss., 1917).

Der Atlas Royal. Zum 200. Todestag August des Starken, in: Velhagen \& Klasings Monatshefte, Bd. 47, 1932, S. 553-560.

Die Sächsische Landesbibliothek 1920-1936, in: H. Neubert (Hg.), Festschrift Martin Bollert zum 60. Geburtstage, Dresden 1936, S. 1-14 (mit Hans Hofmann).

\section{Quellen und Literatur}

SLUB, PA Benndorf, Gottfried

BArch, R 9361-IX/Kartei/2391414; R 9361-VIII/Kartei/1831334

Habermann, Alexandra, Klemmt, Rainer u. Frauke Siefkes: Lexikon Deutscher Wissenschaftlicher Bibliothekare 1925-1980, Frankfurt a. M. 1985, S. 18-19.

Bürger, Thomas u. Konstantin Hermann (Hg.): Das ABC der SLUB. Lexikon der Sächsischen Landesbibliothek - Staats- und Universitätsbibliothek Dresden, Dresden 2006, S. 27-28.

Hermann, Konstantin: Benndorf, Johann Gottfried, in: Sächsische Biografie, 2011, Online-Ausgabe: http://saebi.isgv.de/biografie/Gottfried_Benndorf_(1894-1945), Zugriff: 2.1.2020. 


\title{
Rudolf Berge
}

\author{
17.4.1903 Freiberg - [?] \\ Kunsthistoriker \\ Grünes Gewölbe
}

1.4.1932-31.5.1933 Freiwilliger Wissenschaftlicher Hilfsarbeiter

$\mathrm{Zu}$ Leben und Werk von Rudolf Berge sind nur wenige Informationen überliefert. Er wurde am 17. April 1903 als Sohn von Richard Berge und dessen Frau Martha, geb. Scharschmidt, in Freiberg geboren. Von 1913 bis 1922 besuchte er das Gymnasium in Dresden-Neustadt. Anschließend arbeitete Berge fünf Jahre im Buchhandel, bevor er ab Sommer 1927 an den Universitäten in Wien, Freiburg i. Br. und München Kunstgeschichte, Archäologie und Ägyptologie studierte. Im Dezember 1931 wurde er als Schüler von Wilhelm Pinder an der Universität München promoviert.

Von April 1932 bis Mai 1933 arbeitete Berge als Freiwilliger Wissenschaftlicher Hilfsarbeiter im Grünen Gewölbe. Damals waren $>$ Erich Haenel Direktor und $>$ Walter Holzhausen Wissenschaftlicher Hilfsarbeiter. Beide unterstützte Berge bei den Vorbereitungen der Ausstellung „August der Starke und seine Zeit" (1933). Darüber hinaus lässt sich ein Vortrag nachweisen, den Berge am 22. Januar 1933 über „Die Kurfürsten von Sachsen und ihre Kunstsammlungen“ in Dresden gehalten hat. ${ }^{1}$ Nach Mai 1933 verliert sich seine Spur. Lediglich in einem Schreiben von Rudolf Gackstatter fand Berge im Juli 1933 Erwähnung als „Jude, Volontär im Grünen Gewölbe“, der „[i]nfolge des Arier-Nachweises beurlaubt“, aber durch Haenel „unter Umgehung der Reichsgesetze als Privatperson eingestellt “2 ${ }^{2}$ worden sei. Demnach war Berge vermutlich jüdischer Herkunft. Diesbezügliche Dokumente, wie eine Personalakte oder ein Entlassungsschreiben aufgrund der Bestimmungen zum "Gesetz der Wiederherstellung des Berufsbeamtentums“ sind nicht überliefert.

\section{Auswablbibliografie}

Mittelalterliche Plastik in Meissen vom Ende des 13. Jahrhunderts bis zur Mitte des 15. Jahrhunderts, 1933 (München, Univ., Diss., 1931).

Das Schicksal der Dresdner Kunstkammer. Zu ihrer Auflösung vor hundert Jahren, in: Wissenschaftliche Beilage des Dresdner Anzeigers, 10, Nr. 1, 3.1.1933, S. 1-3.

\section{Quellen und Literatur}

HStA Dresden, 11125, Nr. 19003, fol. 148, 189

Ludwig-Maximilians-Universität München: Abgeschlossene Dissertationen am Institut für Kunstgeschichte 1873-2001, www.kunstgeschichte.uni-muenchen.de/forschung/diss_abgeschl/ index.html, Zugriff: 2.12.2019.

\footnotetext{
1 Vgl. Die Kurfürsten von Sachsen und ihre Sammlungen, in: DA, 23.1.1933, S. 2; Sachsens Kurfürsten als Sammler, in: DNN, 25.1.1933, S. 4.

2 Gackstatter an Kulturpolitische Abteilung und Abteilung Film, 5.7.1933, HStA Dresden, 11125, Nr. 22882, fol. 21. Unklar bleibt, wer Gackstatter war: Er hatte offensichtlich Zugang zu Informationen über das Personal der Staatlichen Sammlungen, war aber nicht dort angestellt.
} 


\section{Georg Bierbaum}

13.8.1889 Neugersdorf - 22.6.1953 Dresden

Prähistoriker

Museum für Mineralogie, Geologie und Vorgeschichte

1.10.1923-31.3.1927 Wissenschaftlicher Hilfsarbeiter

1.4.1927-31.3.1938 Kustos

4.7.1936-31.3.1938 Kommissarischer Leiter

Landesmuseum für Vorgeschichte

1.4.1938-9.1946 Leiter

9.1946-31.1.1949 Direktor

(Militärdienst 10.1944-5.1945)

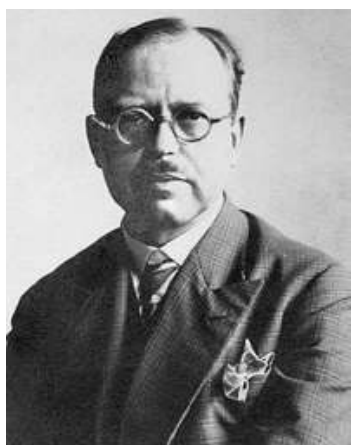

Am 13. August 1889 wurde Georg Karl Alexander Bierbaum als Sohn des Sanitätsrats Gregor Bierbaum und dessen Frau Alma, geb. Augustin, in Neugersdorf in der Oberlausitz geboren. Nach dem Besuch einer Privatschule in seinem Heimatort legte er am Gymnasium in Zittau 1909 die Abiturprüfung ab. Das anschließend in Marburg begonnene Studium der Medizin brach er nach einem Semester im Oktober 1909 für den einjährigen Militärdienst ab. Davon zurückgekehrt, studierte Bierbaum ab Herbst 1910 in Leipzig Naturwissenschaften, d. h. Zoologie, Botanik, Geologie und Mineralogie. Im Dezember 1913 wurde er mit einer zoologischen Arbeit an der Universität Leipzig promoviert. Im August 1914 bestand er das Staatsexamen für den Höheren Schuldienst. Unmittelbar danach wurde er zum Militärdienst einberufen, den er hauptsächlich im Sanitätsdienst in den Lazaretten in Zeithain und Leipzig absolvierte. Parallel dazu setzte er sein Medizinstudium in Leipzig fort. Im Juli 1918 bestand er das Physikum und wurde als Feldunterarzt an der Westfront eingesetzt. Nach Kriegsende kehrte Bierbaum nach Dresden zurück, wo er zunächst eine Vorbereitungszeit an der Dreikönigsschule absolvierte, um in den Schuldienst wechseln zu können. Im April 1919 wurde er am Mineralogisch-Geologischen Institut der Technischen Hochschule als Assistent der Professoren Ernst Kalkowsky und -Eberhard Rimann, die zugleich das Museum für Mineralogie, Geologie und Vorgeschichte leiteten, tätig. Bierbaum arbeitete sich in die prähistorische Forschung ein und sammelte unter der Leitung von Kustos Johannes Deichmüller erste Erfahrungen bei Ausgrabungen. Kalkowsky, der ihm diese Assistenz angeboten hatte, führte ihn auch in die Naturwissenschaftliche Gesellschaft „Isis“ ein, wo Bierbaum bald schon aktiv mitwirkte, Vorträge hielt und 1921 den Vorsitz der Abteilung für Vorgeschichte übernahm.

Ab Oktober 1923 arbeitete Bierbaum als Wissenschaftlicher Hilfsarbeiter am Museum für Mineralogie, Geologie und Vorgeschichte. Für seine Einstellung als Nachfolger des pensionierten Deichmüller hatte sich Rimann bereits im Juni eingesetzt. Im Dezember 1923 heiratete Bierbaum Annemarie Margarete, geb. Lenzner, doch diese Ehe wurde bereits vier Jahre später geschieden. Am Museum betreute Bierbaum die prähistorische Abteilung und wurde im Juli 1927 zum Kustos ernannt. Unter seiner Leitung gewann die Burgwallforschung in Sachsen mit über 700 Fundplätzen an Bedeutung. Mit Jahresbeginn 1931 wurde Bierbaum, ebenfalls als Nachfolger Deichmüllers, zum Leiter des Archivs urgeschichtlicher Funde aus Sachsen berufen, womit er für die archäologische Denkmalpflege und die Ausgrabungstätigkeit in Sachsen verantwortlich war. Er initiierte die Ausgrabungen auf der Heidenschanze in Dresden-Coschütz, deren Leitung er den Wissenschaftlichen Hilfsarbeitern $>$ Walter Kersten und später $>$ Otto Kleemann über- 
trug. 1934 wurde Bierbaum nebenamtlich Landespfleger für Bodenaltertümer in Sachsen und übernahm einen Lehrauftrag für Vorgeschichte an der Technischen Hochschule Dresden. In Zusammenarbeit mit dem Seminar für Vorgeschichte der Universität Leipzig publizierte er zwischen 1937 und 1942 fünf Bände des Jahrbuchs „Sachsens Vorzeit“. Bei der Verselbständigung des Landesmuseums für Vorgeschichte am 1. April 1938 wurde Bierbaum unter Beibehaltung seiner Nebenämter zum Leiter des Museums ernannt. Die Parteileitung hatte seine „Einstellung zum heutigen Staat und zur Bewegung “ als „bejahend“ beurteilt, er sei „als fleißiger, freundlicher Mann geschätzt" ${ }^{\text {"1 }}$. Doch Bierbaum war, obwohl er politisch konservativ, nämlich deutsch-national eingestellt war, weder zu diesem Zeitpunkt, noch später Mitglied der NSDAP. Dies erstaunt, da in der NS-Zeit bei Beförderungen im Bereich der Staatlichen Sammlungen auf die Parteimitgliedschaft geachtet wurde. ${ }^{2}$ Trotz seiner politischen Differenzen gegenüber dem Vorsitzenden Hans Reinerth war Bierbaum Mitglied im Reichsbund für Deutsche Vorgeschichte. Auch in den Reichsbund Deutscher Beamter trat er 1936 ein. In seinen Tagebuchaufzeichnungen und Briefen, z. B. an Kleemann, zeigt sich Bierbaums anfängliche Kriegsbegeisterung. Auch notierte er alle Luftschutzalarme in Dresden akribisch. Im November 1942 wurden Bierbaum persönlich wie auch das Landesmuseum für Vorgeschichte in die SS-Forschungs- und Lehrgemeinschaft „Das Ahnenerbe“ aufgenommen. ${ }^{3}$ Als Kustos und später als Leiter des Museums scharte Bierbaum junge Wissenschaftler um sich, denen er verantwortungsvolle Aufgaben überließ. So übernahm $>$ Heinz Amberger einen Teil der Neugestaltung der Schausammlung, die 1938 mit dem Titel „Germanen in Sachsen“ eröffnet wurde. Auch war Bierbaum für die kriegsbedingte Auslagerung der Sammlungsobjekte verantwortlich, wobei er die Schausammlung noch bis Juni 1944 offenhielt. Im Oktober 1944 wurde Bierbaum zum Volkssturm in Dresden-Mockritz einberufen. Aufgrund der Traumatisierung durch den Luftangriff auf Dresden am 13. Februar 1945 war Bierbaum krankgeschrieben, erst ab Juni 1945 durfte er wieder stundenweise arbeiten. Doch auch in den Folgejahren bedingte sein labiler Gesundheitszustand verkürzte Arbeitszeiten und viele Kuraufenthalte. 1946 wurde er zum Direktor des Landesmuseums ernannt. In jenem Jahr trat er in die LDP ein. Obwohl ihm im Oktober 1948 noch zum 25-jährigen Dienstjubiläum gratuliert worden war, erhielt Bierbaum im Dezember 1948 seine Kündigung zum 31. Januar 1949. Offiziell wurde diese mit Etatkürzungen begründet, weshalb sein Widerspruch erfolglos blieb.

Durch Vermittlung des Prähistorikers Martin Jahn erhielt Bierbaum von der Sächsischen Akademie der Wissenschaften den Auftrag, ab 1949 den sächsischen Teil einer „Bibliographie zur Vor- und Frühgeschichte" zu bearbeiten. Dieser wurde allerdings erst posthum publiziert, denn sein Gesundheitszustand verschlechtere sich weiter. Georg Bierbaum starb am 22. Juni 1953 in Dresden.

\section{Auswahlbibliografie}

Untersuchungen über den Bau der Gehörorgane von Tiefseefischen, in: Zeitschrift für wissenschaftliche Zoologie, 111, 1914, H. 3, S. 281-380, (Zugl. Leipzig, Univ., Diss., 1913).

\footnotetext{
1 Kreisleiter der NSDAP, Beurteilung über Bierbaum, 2.11.1936, HStA Dresden, 13859, Nr. 521, fol. 62 .

2 Siehe S. 89 ff. Lizzy Bierbaum, seine Schwester, war seit 1937 als Referentin für Kulturerziehung in der NS-Frauenschaft tätig und trat im Januar 1940 in die NSDAP ein.

3 Reichshauptstelle Das Ahnenerbe an den Landespfleger für Bodenaltertümer in Sachsen, Bierbaum, 13.11.1942, BArch, NS 21/1060, fol. 43.
} 
Vesuvian- und Fibrolithbeilchen aus dem Bodensee, in: Sitzungsberichte und Abhandlungen der Naturwissenschaftlichen Gesellschaft Isis, Dresden e. V., 1919, S. 3-29.

Münzfunde der vor- und frühgeschichtlichen Zeit aus dem Freistaat Sachsen, in: Mannus, 16, 1924, S. 279-301.

Der Stand des Denkmalschutzes in Sachsen, in: Nachrichtenblatt für deutsche Vorzeit, Bd. 2, 1926, S. 15-16.

Zur Frage nach der Enddatierung der Billendorfer Kultur in Sachsen, in: Mannus, Bd. 6, 1928, S. $127-137$.

Vorgeschichtliches aus dem Jahnatal, in: Mitteilungen des Landesvereins Sächsischer Heimatschutz, XXI, Dresden, 1932, S. 1-8.

Das sächsische Gesetz zum Schutze von Kunst-, Kultur- und Naturdenkmalen (Heimatschutzgesetz) vom 13. Januar 1934, in: Nachrichtenblatt für deutsche Vorzeit, Bd. 9, 1933, S. 211-224.

Goldfunde aus der ältesten Bronzezeit in Sachsen, in: Mitteilungen aus dem Museum für Mineralogie, Geologie und Vorgeschichte zu Dresden, 1934, S. 123-131.

Stichbandkeramische Brandgräber von Kötitz, Kreis Meißen, in: Sachsens Vorzeit, Bd. 3, 1939, 1/2, S. 9-20.

Bibliographie zur Vor- u. Frühgeschichte. Land Sachsen, 3 Bde., Berlin 1957-1970.

\section{Quellen und Literatur}

HStA Dresden, 13859, Nr. 521

HStA Dresden, 19117, Nr. 1794

HStA Dresden, 12820, insbesondere Nr. 7; Nr. 12; Nr. 73

Coblenz, Werner: Georg Bierbaum 1889-1953, in: Arbeits- und Forschungsberichte zur sächsischen Bodendenkmalpflege, Bd. 4, 1954, S. 11-20.

Ficker, Friedbert: Ein verdienter sächsischer Vorgeschichtsforscher, Zum 20. Todestag von Dr. Georg Bierbaum, in: Dresdner Monatsblätter. Rundbrief der Dresdner Heimatfreunde in Westdeutschland, Bd. 24, 1973, 6/7, S. 191-193.

Coblenz, Werner: In Memoriam Georg Bierbaum (13.8.1889-22.6.1953), in: Arbeits- und Forschungsberichte zur sächsischen Bodendenkmalpflege, Bd. 33, 1989, S. 357-367.

Geupel-Schischkoff, Kristina: Um die Früchte der eigenen Arbeit gebracht ... Georg Bierbaum. Sachsens erster Landesarchäologe, in: Archaeo. Archäologie in Sachsen, Bd. 5, 2008, S. 48-53.

Geupel-Schischkoff, Kristina: Dr. Georg Bierbaum (13. August 1889 - 22. Juni 1953). Der Weg vom Zoologen, Mediziner und Lehrer zum Direktor des Landesmuseums für Vorgeschichte Dresden und Landespfleger für Bodenaltertümer Sachsens, in: Arbeits- und Forschungsberichte zur sächsischen Bodendenkmalpflege, Bd. 21, 2010, S. 19-26. 


\section{Charlotte Boden}

15.1.1900 Dresden - 9.2.1994 Dresden

Juristin, Wissenschaftliche Bibliothekarin

Sächsische Landesbibliothek

1.12.1929-30.11.1940 Wissenschaftliche Hilfsarbeiterin

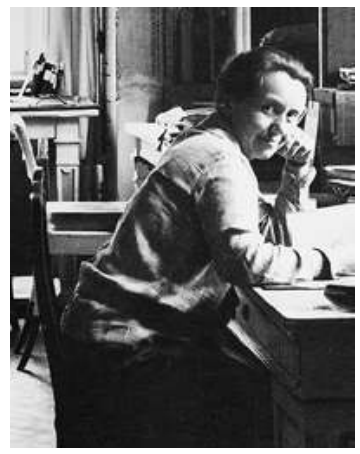

Klara Charlotte Boden, als Tochter des Musterzeichners und Tapetenfabrikanten Heinrich Boden und dessen Frau Ida, geb. Frenzel, am 15. Januar 1900 in Dresden geboren, legte 1921 ihr Abitur ab. Beeindruckt von der Frauenrechtlerin Helene Lange studierte Boden in Jena und Leipzig Rechtswissenschaft. 1925 bestand sie in Leipzig die Erste juristische Staatsprüfung. Im Dezember 1927 wurde sie in Leipzig promoviert. Doch statt für den bezahlten juristischen Vorbereitungsdienst hatte sie sich längst für eine Bibliothekslaufbahn entschieden. Bereits im Oktober 1926 hatte sie eine unbezahlte Volontärsstelle an der Stadtbibliothek und Bibliothek der Gehe-Stiftung Dresden angenommen. Das zweite Jahr als Volontärin absolvierte sie an der Universitätsbibliothek in Leipzig, wo unter Einfluss von Otto Glauning ihr Interesse an illustrierten Büchern geweckt wurde. Ab Dezember 1928 arbeitete Boden erneut an der Stadtbibliothek und Bibliothek der Gehe-Stiftung Dresden, nun als Wissenschaftliche Hilfsarbeiterin.

Ab 1. Dezember 1929 wechselte Boden als Wissenschaftliche Hilfsarbeiterin an die Sächsische Landesbibliothek. Dort war sie als juristische Fachreferentin tätig und unterstützte $>$ Erhart Kästner im Buchmuseum. Nach seinem Weggang übernahm sie dessen Leitung. Sie kuratierte zahlreiche Ausstellungen, wie „Das ehrsame Handwerk“ (1937), „Unser Erzgebirge in Buch und Bild“, „Arthur Schopenhauer“ (beide 1938), „Reisen und Entdeckungen“ (1939), durch die sie Führungen anbot und die sie in der Dresdner Tagespresse beschrieb. Sie soll für die Prüfung von Privatbibliotheken jüdischer Eigentümer zuständig gewesen sein, dabei jedoch „den politisch Verfemten niemals Ihre hilfreiche Hand und Ihre ehrliche Hochachtung" versagt haben, auch soll sie ihren Kollegen „verbotwidrig antifaschistisches Schrifttum zugänglich“1 gemacht haben. Doch unter dem zunehmenden politischen Druck entschied sie sich im Mai 1937 für einen Eintritt in die NSDAP. Dieser Schritt begünstigte ihre spätere Beförderung.

Zum 16. Oktober 1940 wurde sie als Leiterin der Dresdner Gemeinschaftlichen Ministerialbibliothek abgeordnet, deren Leiter Karl Otto überraschend gestorben war. Sie bekam damit eine Beamtenstelle, die sie in der Landesbibliothek beantragt, aber nicht erhalten hatte, ${ }^{2}$ und wurde im Dezember 1941 zur Bibliotheksrätin ernannt. Nach dem Ende des Zweiten Weltkrieges

1 Sonderausschuss des Antifaschistisch-Demokratischen Blocks Sachsen an Boden, 16.5.1946, HStA Dresden, 13471, Nr. ZB II 4473, fol. 288.

2 Vgl. SKD Archiv, 01/PS 139, Nr. 115, Antrag von Charlotte Boden vom 24.1.1940. 
wurde Boden im Mai 1946 entnazifiziert, ${ }^{3}$ was ihr die weitere Tätigkeit im öffentlichen Dienst ermöglichte. In den Folgejahren arbeitete sie beim Landeshauptarchiv Dresden, beim Landesverband der Liberaldemokratischen Partei und als Rechtsberaterin für den Demokratischen Frauenbund. Nach dem Tod von $>$ Hubert Richter übernahm Boden im Dezember 1948 die Leitung ihrer früheren Dienststelle, der Gemeinschaftlichen Ministerialbibliothek, nun Zentralbibliothek der Landesverwaltung Sachsen. Ab Januar 1953 baute sie als Direktorin die Bibliothek der neugegründeten Hochschule für Verkehrswesen in Dresden auf. Nach ihrer Pensionierung Ende 1969 engagierte sie sich in der Rechtskommission des Bibliotheksverbandes der DDR und separierte von 1971 bis 1986 in Honorartätigkeit seltene und künstlerische Drucke aus dem Bestand der Deutschen Staatsbibliothek in Berlin für den Aufbau einer entsprechenden Sonderabteilung. Charlotte Boden starb am 9. Februar 1994 in Dresden.

\section{Auswahlbibliografie}

Der Anspruch des Ehegatten auf Herstellung der ehelichen Lebensgemeinschaft nach deutschem Recht im Vergleich mit den neuen skandinavischen Ehegesetzen (Leipzig, Univ., Diss., 1927).

Der biografische Katalog u. das Personalrepertorium der Sächs. Landesbibliothek, in: Festschrift Martin Bollert zum 60. Geburtstage, Dresden 1936, S. 21-37.

Das Buchmuseum in den Semper-Räumen des Japanischen Palais, in: Festschrift Martin Bollert zum 80. Geburtstag am 11. Okt. 1956, Dresden 1956, S. 46-51.

Die Dresdener Fachkataloge, in: Zentralblatt für Bibliothekswessen, 73. Jg., H. 1, 1959, S. $10-17$.

Das Schumann-Album. Eine Kostbarkeit der Sächsischen Landesbibliothek in Dresden, in: Marginalien. Zeitschrift für Buchkunst und Bibliophilie, Ausg. 8, 1960, S. 8-23.

Rechts-ABC für Bibliothekare, Leipzig 1975 (Hg.).

\section{Quellen und Literatur}

SLUB, PA Boden, Charlotte

BArch, R9361-IX/Kartei/3401108; R9361-VIII/Kartei/2941040

HStA Dresden, 13471, Nr. ZB II 4473, fol. 285-289

Bibliothek d. Hochschule für Verkehrswesen „Friedrich List“ Dresden: Zusammenstellung der Veröffentlichungen von Dr. Charlotte Boden: aus Anlaß ihres 80. Geburtstages am 15.1.1980, Dresden 1979.

Kunze, Horst: Frau Dr. Charlotte Boden 1900-1994, in: Marginalien. Zeitschrift für Buchkunst und Bibliophilie, Ausg. 135, 1994, S. 80-81.

Zesewitz, Helmut: Charlotte Boden 1900-1994, in: Zeitschrift für Bibliothekswesen und Bibliographie, Bd. 41, Ausg. 3, 1994, S. 366-368.

Voigt, Helmut: Erinnerungen an Charlotte Boden, Freital 2000.

Bürger, Thomas u. Konstantin Hermann (Hg.): Das ABC der SLUB. Lexikon der Sächsischen Landesbibliothek - Staats- und Universitätsbibliothek Dresden, Dresden 2006, S. 40.

Hermann, Konstantin: Boden, Klara Charlotte, in: Sächsische Biografie, 2011, Online-Ausgabe: http://saebi.isgv.de/biografie/Charlotte_Boden_(1900-1994), Zugriff: 2.1.2020.

\footnotetext{
3 Vgl. Sonderausschuss des Antifaschistisch-Demokratischen Blocks Sachsen an Boden, 16.5.1946 (Abschrift), HStA Dresden, 13471, Nr. ZB II 4473, fol. 288v.
} 


\section{Martin Bollert}

11.10.1876 Frankfurt a. d. Oder - 6.3.1968 Roettgen

Philologe, Wissenschaftlicher Bibliothekar

Sächsische Landesbibliothek

1.10.1920-30.9.1937 Direktor

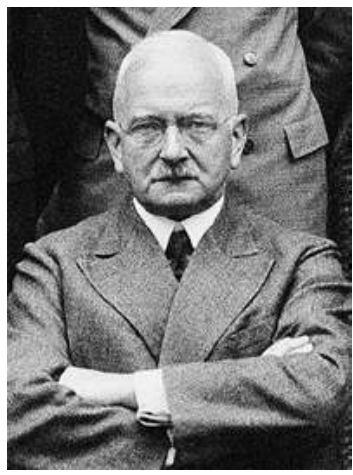

Martin Bollert wurde am 11. Oktober 1876 als Sohn des Pfarrers Julius Bollert und dessen Ehefrau Marie, geb. Cattien, in Frankfurt an der Oder geboren. Nach dem Abitur am KönigFriedrich-Gymnasium in Frankfurt studierte Bollert an den Universitäten in Jena und Berlin Philosophie, Germanistik und Theologie. Im Juli 1899 legte er die Staatsprüfung für das Höhere Lehramt ab. Nach dem obligatorischen Jahr als Schulamtskandidat in Frankfurt ging Bollert nach Straßburg, wo er im März 1901 promoviert wurde. Ab April 1901 absolvierte er ein Volontariat an den Universitätsbibliotheken in Berlin und Göttingen und ließ sich zum Bibliothekar ausbilden. Es folgte ein für ihn sehr prägendes Jahr als Hilfsbibliothekar an der Kruppschen Bücherhalle in Essen, deren damaliger Direktor Paul Ladewig die Bibliothek als Dienstleistungsbetrieb für die Öffentlichkeit ansah. Ab Oktober 1904 arbeitete Bollert als Hilfsbibliothekar an der Königlichen Universitätsbibliothek in Bonn, wo er im Oktober 1906 zum Bibliothekar ernannt wurde. Im selben Jahr heiratete er Elsa, geb. Noack, mit der er vier Kinder hatte. Nach 9 Jahren Tätigkeit in Bonn bewarb sich Bollert andernorts und wurde am 1. Oktober 1913 zum Direktor der Stadtbibliothek in Bromberg ernannt. Der Bonner Bibliotheksdirektor Wilhelm Adolf Erman blieb ein väterlicher Freund und hätte ihn gern als seinen Nachfolger gesehen. Bollert aber ging andere Wege. 1916 kandidierte er für das Direktorat der Deutschen Bücherei in Leipzig. Als ihm dieses im Mai 1917 angetragen wurde, lehnte er jedoch ab und blieb in Bromberg, wo man ihm fortan einen jährlichen Bonus zahlte und den Professorentitel verlieh. Seine Berufung zum Direktor der Kaiser-Wilhelm-Bibliothek in Posen im November 1918 scheiterte aufgrund der Angliederung der Provinz Posen an den polnischen Staat im Zuge des Versailler Vertrages. Bollert blieb deshalb weiter in Bromberg, auch als diese Stadt im Januar 1920 ebenfalls polnisch wurde. Ab April 1920 verhandelte das Sächsische Ministerium für Volksbildung (SMV) mit Bollert, um ihn als Nachfolger für den in den Ruhestand tretenden Direktor der Sächsischen Landesbibliothek, Hubert Ermisch, zu gewinnen.

Im Oktober 1920 übernahm Bollert das Amt als Direktor der Sächsischen Landesbibliothek. Zeitgleich wurde er zum stellvertretenden Vorsitzenden des Prüfungsamtes für Bibliothekswesen in Leipzig bestellt. Auch innerhalb der Landesbibliothek achtete er auf die Qualität der Ausbildung des Bibliotheksnachwuchses. 1925 wurde er für drei Jahre in den Verwaltungsrat der Deutschen Bücherei Leipzig gewählt. Bereits damals hatte Bollert mehrfach auf die Notwendigkeit der Erneuerung der Sächsischen Landesbibliothek hingewiesen und sich für den Um- und Ausbau des Japanischen Palais eingesetzt, der von 1927 bis 1935 erfolgte. Bollert war „,[b]egeisterter 
Bibliothekar und engagierter Reformer"1. Unter seiner Leitung wandelte sich die Sächsische Landesbibliothek von einer Gelehrtenbibliothek in eine der modernsten Bibliotheken in Deutschland und stand nun erstmals allen Bevölkerungsschichten offen. Bollert war „rastlos bedacht, den Bibliotheksbetrieb zu verbessern“, geleitet von dem Gedanken, „daß die Bibliothek für den Benutzer da sei. "2 Dies zeigte sich auch in der umfangreichen Öffentlichkeitsarbeit, die neben Führungen durch die Bibliothek und das Buchmuseum mit seinen Sonderausstellungen auch Vorträge umfasste, vor allem aber in den nach der Einweihung im Mai 1935 stark steigenden Benutzungszahlen. Bereits 1932 hatte Bollert die große Goethe-Ausstellung im Sächsischen Kunstverein in Dresden kuratiert, an der sich mehrere der Staatlichen Sammlungen beteiligten. Darüber hinaus publizierte er rege zu buchkundlichen und bibliothekshistorischen Themen. Im April 1935 übernahm Bollert in der Nachfolge von > Arnold Jacobi die Geschäftsführung der Direktorenkonferenz der Staatlichen Sammlungen. Den Mühen des Bibliotheksumbaus und den arbeitsintensiven wie erfolgreichen Monaten nach deren Wiedereröffnung folgte 1936 ein schweres Jahr für Bollert. Es begann mit einem ärztlich attestierten Erschöpfungszustand. Unterdessen nahm der politische Druck, unter dem er stand, zu. Bereits im Herbst 1935 wurde ihm vorgeworfen, dass die Schriften von Alfred Rosenberg in der Landesbibliothek absichtlich versteckt würden. Bollert erklärte dies diplomatisch mit der komplizierten Titelaufnahme und bat, „diese sehr bitteren Vorwürfe, die in einem langen Amtsleben noch nie gegen mich gerichtet worden sind“, zurückzunehmen, denn er könne seine „viel Takt, Sachkenntnis und Staatstreue erfordernde Arbeit nur leisten, wenn er von dem Vertrauen seines vorgesetzten Ministeriums gestützt wird“3. Hatte er bei seinen Reden zur Wiedereröffnung der Bibliothek den geforderten nationalsozialistischen Sprachduktus noch weitgehend vermieden, ${ }^{4}$ eröffnete er im Februar 1936 die gemeinsam mit der Reichsstelle zur Förderung des deutschen Schrifttums organisierte Ausstellung „Das wehrhafte Deutschland“ mit politischen Floskeln. Sprachgewaltig betonte er: „Wehrhaftigkeit ist nicht gebunden an das Waffenhandwerk, sondern ist eine Geisteshaltung "5 und offenbarte in der bewusst gewählten Ambivalenz des Satzes seinen inneren Widerstand. Auch ließ er sich mittels weiterer ärztlicher Atteste vom obligatorischen NS-Beamten-Schulungskurs auf der Augustusburg und der Teilnahme an den NS-Feierlichkeiten zum 1. Mai freistellen. ${ }^{6}$ Es folgten, wie er seinem Leipziger Kollegen Otto Glauning mitteilte, „eine in der Form leidlich maßvolle doch törichte u. unberechtigte Vermahnung des Hilfsschullehrers" und „eine ärgerl. Denunziantengeschichte in der unteren Region“".

1 Nitzschke, Katrin: Begeisterter Bibliothekar und engagierter Reformer. Martin Bollert zum 130. Geburtstag, in: SLUB-Kurier, Dresden, Bd. 15, H. 4, 2001, S. 10 f.

2 Jammers, Antonius: Im Japanischen Palais, wie ein Freiherr ... Erinnerungen meines Vaters Ewald Jammers an seine alte Sächsische Landesbibliothek, in: Thomas Bürger und Ekkehard Henschke (Hg.): Bibliotheken führen und entwickeln. Festschrift für Jürgen Hering zum 65. Geburtstag, München 2002, S. 305-317, hier: 311.

3 Bollert an SMV, Messmer, 2.11.1935, SLUB, Bibl.-Arch. III.J.859.b. Vgl. Hermann 2011, S. 297.

4 Überliefert sind verschiedene Reden für unterschiedliche Zielgruppen. In das Manuskript seiner Rede am 11.5.1935 fügte er erst nachträglich das Wort „Volksgenosse“ mehrfach ein, damit sie den parteipolitischen Anforderungen besser entsprach - auch daraus lässt sich auf seine Haltung schließen. Vgl. SLUB, Mscr.Dresd.App.1378.a,38-44, besonders: 38.

5 Bollert, Rede zur Eröffnung der Ausstellung „Das wehrhafte Deutschland“, 26.2.1936, SLUB, Mscr.Dresd.App.1378.a,48.

6 Überliefert ist dies für 1935 und 1937. Vgl. SLUB, PA Bollert, o. Pag.

7 Bollert an Glauning, 28.10.1936, UB Leipzig, Nachlass 226 Otto Glauning. Zitiert nach: Hermann 2011, S. 294. Mit „Hilfsschullehrer“ bezieht sich Bollert auf Arthur Göpfert, der als Volksschul- 
Seine berufliche Energie verwendete Bollert damals primär für die Organisation und Durchführung des 32. Deutschen Bibliothekartages, der im Juni 1936 in Dresden stattfand. Unmittelbar vor Weihnachten 1936 traf ihn mit dem Tod seiner 24-jährigen Tochter ein persönlicher Schicksalsschlag. In Anbetracht dieser Situation verwundert es wenig, dass sich Bollert aufgrund ärztlicher Empfehlung beurlauben ließ. Im Februar 1937 stellte er ohne Nennung von Gründen, wohl aber „aus Überdruß und Protest gegen die nazistischen Eingriffe“8, einen Antrag auf Versetzung in den vorzeitigen Ruhestand. Dieser wurde genehmigt und Bollert zum 30. September 1937 pensioniert. ${ }^{9}$ Doch erst am 26. Oktober 1937 wurde er offiziell in Anwesenheit vom Leiter des SMV, Arthur Göpfert, und dem Referenten für die Staatlichen Sammlungen im Ministerium, Museumsdirektor $\triangleright$ Fritz Fichtner, im Japanischen Palais verabschiedet. Als seinen Nachfolger hatte er $>$ Hermann Neubert empfohlen..$^{10}$

Über die folgenden Jahre ist wenig bekannt, wohl aber pflegte Bollert seine Kontakte zur Sächsischen Landesbibliothek. Für seine Verdienste um das Büchereiwesen wurde er kurz nach seinem 65. Geburtstag, im Dezember 1941, mit der Goethe-Medaille für Kunst und Wissenschaft geehrt. ${ }^{11}$ Als in der Nachkriegszeit unklar war, ob ihm weiterhin Rentenbezüge gezahlt würden, bemühte sich Bollert im Mai 1946 um eine erneute Tätigkeit in der Landesbibliothek. Vorerst fand er einen bescheidenen Nebenverdienst durch das Kolorieren von Linoldrucken, bevor er über 70-jährig auf Honorarbasis als Hilfsarbeiter an die Landesbibliothek zurückkehrte. ${ }^{12} \mathrm{Zu}$ seinem 75. Geburtstag organisierte $\gg$ Hans Hofmann eine Feier an der Landesbibliothek, fünf Jahre später, im September 1956, hielt Bollert bei der 400-Jahr-Feier der Bibliothek eine Festrede. 1958 siedelte er zur Familie seiner Tochter Friederike nach Roettgen bei Bonn über. Nach einem Schlaganfall 1964 verschlechterte sich sein Gesundheitszustand. Am 6. März 1968 starb Martin Bollert in Roettgen, wo er am 11. März beerdigt wurde. Als seine jüngste Tochter Maria zwei Monate später in Dresden weilte, organisierten ehemalige Mitarbeiterinnen und Mitarbeiter zwei Gedenkfeiern, am 10. Mai 1968 im Pfarrhaus der Heilandskirche und am nächsten Tag in der Wohnung von $>$ Hans Hofmann. ${ }^{13}$ Obwohl die damaligen politischen Verhältnisse verhindert hatten, dass „Labianer" an der Trauerfeier in Westdeutschland teilnahmen, konnten sich so elf von ihnen, darunter $>$ Helmut Deckert, $>$ Dorothee Denecke, Hans Hofmann und - Margarethe Storch, von „ihrem Direktor“ verabschieden. Bollert galt als „Seele der Bibliothek ${ }^{\text {“14 }}$ und war ihnen durch seine Arbeit und in seinem ,ganzen menschlichen Verhalten [...] ein Vorbild“15.

lehrer einen rasanten parteipolitischen Aufstieg nahm und ab März 1935 Kommissarischer Leiter des für die Staatlichen Sammlungen zuständigen Sächsischen Ministeriums für Volksbildung war.

8 Jammers 2002, S. 314. Hermann sprach hingegen von einem „erzwungenen Rücktritt“ (Hermann 2011, S. 292). Dafür konnten bisher keine eindeutigen Nachweise gefunden werden.

9 Die Presse berichtete, er sei im Juli ausgeschieden. Siehe Professor Bollert im Ruhestand, in: DA, 29.7.1937, S. 3.

10 Vgl. Notizen von Bollert, undatiert, vermutl. 1937, SLUB, Mscr.Dresd.App.1378.a,122.

11 Vgl. Stgm.: Goethe-Medaille für Professor Dr. Bollert, in: DNN, 2.12.1941, S. 3.

12 Vgl. Bollert an Jammers, 18.9.1946 u. 24.8.1950, SLUB, Mscr.Dresd.App.2830,9 u. 16.

13 Vgl. Programmzettel der Gedenkfeier am 18.5.1968, SLUB, Mscr.Dresd.App.2600F,93 u. In memoriam Martin Bollert, Dresden 1968.

14 Jammers 2002, S. 311.

15 Jammers an Bollert, 3.10.1956, SLUB, Mscr.Dresd.App.2830,30. 


\section{Auswahlbibliografie}

Materie in Kants Ethik, in: Archiv für Geschichte der Philosophie, Bd. 13, H. 4, Berlin 1900, S. 483-501 (Zugl. Straßburg, Univ., Diss., 1901).

Gottfried Kinkels Kämpfe um Beruf und Weltanschauung bis zur Revolution, Studien zur Rheinischen Geschichte, H. 10, Bonn 1913.

Gottfried Kinkel im Zuchthause, in: Preussische Jahrbücher, Bd. 158, H. 3, 1914, S. 405-430.

Ferdinand Freiligrath und Gottfried Kinkel, Veröffentlichungen der Abteilung für Literatur der Deutschen Gesellschaft für Kunst und Wissenschaft in Bromberg, Bromberg 1916.

Lederschnittbände des XIV. Jahrhunderts, Leipzig 1925.

Johann Joachim Winckelmann als Bibliothekar des Grafen Bünau, in: Festschrift für Georg Leidinger, München 1930, S. 20-24.

Größere Nutzbarmachung der „Deutschen Nationalbibliographie“ für die Bibliotheken, in: Börsenblatt für den deutschen Buchhandel, 99, 1932, S. 899.

Johann Joach. Winckelmann und Joh. Mich. Francke, in: Otto Glauning zum 60. Geburtstag. Festgabe aus Wissenschaft und Bibliothek, Leipzig 1936, S. 11-17.

Die Vereinigung der Bücherfreunde in Dresden 1926-1938, in: Aus dem Antiquariat, 6, 1950, 94, S. $949 \mathrm{f}$.

\section{Quellen und Literatur}

SLUB, Mscr.Dresd.App.1378.a; Mscr.Dresd.App.1378.b; Mscr.Dresd.App.1378,I-III

SLUB, PA Bollert, Martin

SLUB, Mscr.Dresd.App. 2830

ULB, S 2611 (NL Bollert); S 2611a

HStA Dresden, 11125, Nr. 19345

Assmann, Karl: M. Bollerts Schriften, zsgest. zu seinem 75. Geb., in: Zentralblatt für Bibliothekswesen, Bd. 65, 1951, S. $341 \mathrm{ff}$.

Hofmann, Hans (Hg.): Martin Bollert zum 80. Geburtstag am 11. Okt. 1956, Festschrift, Dresden 1956.

In memoriam Martin Bollert, Dresden 1968.

Deckert, Helmut: Erbe und Verpflichtung. Zum Tode Martin Bollerts, in: Zentralblatt für Bibliothekswesen, 82, 8, 1968, S. 479-482.

Habermann, Alexandra, Klemmt, Rainer u. Frauke Siefkes: Lexikon Deutscher Wissenschaftlicher Bibliothekare 1925-1980, Frankfurt a. M. 1985, S. 29 f.

Hebig, Christel: Ein großes Leben durch ein großes Werk. Zum Gedenken an Prof. Dr. Martin Bollert, in: Biblos, Wien, Bd. 41, 1992, 2, S. 75-81.

Bürger, Thomas u. Konstantin Hermann (Hg.): Das ABC der SLUB. Lexikon der Sächsischen Landesbibliothek - Staats- und Universitätsbibliothek Dresden, Dresden 2006, S. 41 f.

Hermann, Konstantin: Die sächsische Landesbibliothek 1933-1945. Martin Bollert und Hermann Neubert - zwei Epochen in zwölf Jahren?, in: Knoche, Michael (Hg.): Wissenschaftliche Bibliothekare im Nationalsozialismus: Handlungsspielräume, Kontinuitäten, Deutungsmuster, Wolfenbütteler Schriften zur Geschichte des Buchwesens, Bd. 46, Wiesbaden 2011, S. 289-308.

Nitzschke, Katrin: Bollert, Martin, in: Sächsische Biografie, 2012, Online-Ausgabe: http://saebi. isgv.de/biografie/Martin_Bollert_(1876-1968), Zugriff: 2.1.2020. 


\section{Hellmuth Buck}

5.1.1892 Düren - 14.3.1983 Lauffen a. Neckar

Konservator

Museen für Tierkunde und Völkerkunde

1.5.1928-31.3.1940 Konservator

Sächsisches Ministerium für Volksbildung, Referat Staatliche

Sammlungen

1.4.1940-30.9.1942 Konservator

1.10.1942- [?] Inspektor

(Beurlaubung an Zoologischen Garten Dresden 13.2.1934-

31.10.1934; an Gauschule Hammerleubsdorf 15.4.1936-

31.3.1940 und NSDAP-Truppenbetreuung 14.3.1942-5.1942)

Albert Otto Hellmuth Buck wurde am 5. Januar 1892 in Düren geboren. Nach dem Abitur ließ er sich an der Tierärztlichen Hochschule und der Kunstgewerbeschule zum Präparator ausbilden. In diesem Beruf arbeitete er von Oktober 1912 bis August 1914 am Zoologischen Institut der Universität Leipzig, bevor er sich als Kriegsfreiwilliger meldete und an der Westfront kämpfte. 1916 geriet er in Kriegsgefangenschaft, aus der er im November 1919 zurückkehrte. Er heiratete Sidonie Elisabeth, geb. Seiffarth, mit der er zwei Töchter hatte, und setzte ab Dezember 1919 seine Tätigkeit als Präparator am Zoologischen Institut der Universität Leipzig fort. Ab 1923 betrieb Buck eine eigene Lehrmittel-Werkstatt in Leipzig, wodurch er gelegentlich auch dem Direktor der Dresdner Museen für Tierkunde und Völkerkunde, \Arnold Jacobi, Tierpräparate anbot.

Im Mai 1928 wurde Buck auf Wunsch von Jacobi als Konservator an den Museen für Tierkunde und Völkerkunde in Dresden angestellt. Er war „zweifellos ein tüchtiger und sehr gewissenhaft arbeitender Präparator, direkt ausgezeichnetes leistete er beim Aufstellen von Skeletten “1 , wie Johannes Meisenheimer vom Zoologischen Institut der Universität Leipzig damals bestätigte, für den Buck bis 1923 tätig gewesen war. Doch wenige Monate nach der „Machtübernahme“ durch die Nationalsozialisten kam es im Sommer 1933 zu erheblichen Spannungen zwischen Buck, der bereits im April 1930 der NSDAP beigetreten war, und Jacobi. Letzterer beklagte gegenüber dem Sächsischen Ministerium für Volksbildung (SMV), dass Bucks „eifrige politische Betätigung mehr und mehr in einen Zwiespalt zu seinen amtlichen Obliegenheiten tritt" ${ }^{\text {“2 }}$ In der Tat wurde für Buck das politische Engagement zunehmend wichtiger. Bereits Anfang 1934 war er als Kreisschulungsleiter der NSDAP tätig und nahm an diversen Parteischulungen teil. 1934 wurde er für acht Monate von seiner Tätigkeit im Museum beurlaubt, um den Zoologischen Garten Dresden während dessen Konkurszeit zu leiten. Seine Bewerbung als Leiter der Museen für Tierkunde und Völkerkunde im April 1935 wurde vom Ministerium nicht berücksichtigt, obwohl er 1933 einen „Vorschlag zur Neugestaltung und Belebung der zoologischen und völkerkundlichen $\mathrm{Mu}$ seen Deutschlands" eingereicht hatte. Im April 1936 wurde Buck von der Gauleitung Sachsen der NSDAP mit der „Leitung von Lehrgängen für Lehrer aller Schulgattungen, Lehrkräfte an

Meisenheimer an Jacobi, 11.2.1928, HStA Dresden, 13842, Nr. 114, Bd. 1, o. Pag.

Jacobi an SMV, 27.6.1933, HStA Dresden, 13842, Nr. 047, o. Pag. 
Volksbildungsstätten und sozialen Fachschulen, DAF-Walter und Betriebsvertrauensleute sowie als Redner der Partei ${ }^{\text {“ }}$ an der Gauschule Hammerleubsdorf bei Chemnitz beauftragt, deren Leitung er 1937 übernahm. Unter Fortzahlung seines Gehaltes wurde er bis Ende März 1940 mehrfach in Folge für diese Aufgabe vom Museumsdienst beurlaubt. Ab April 1940 wieder in Dresden, wurde Buck an das SMV abgeordnet, wo er für den Referenten der Staatlichen Sammlungen, $\triangleright$ Fritz Fichtner, arbeitete. Sein Aufgabengebiet umfasste die Organisation der Öffentlichkeitsarbeit, der politischen Arbeit der Sammlungen und des Umzuges des Museums für Völkerkunde. Eine Ernennung Bucks zum Technischen Direktor der Sammlungen sowie seine direkte inhaltliche Mitarbeit versuchten die Sammlungsdirektoren zu verhindern. So war er hauptsächlich für die Zusammenarbeit mit der Dresdner Volksbildungsstätte zuständig. Nach einer zweimonatigen Beurlaubung zur Truppenbetreuung in Norwegen im Auftrag der Gauleitung der NSDAP Sachsen im Frühjahr 1942, wurde Buck im Juni 1942 auch als nebenamtlicher Museumspfleger in Sachsen eingesetzt. Trotz seiner Beförderung zum Inspektor im Oktober 1942 änderten sich Bucks Aufgaben nicht. Im Januar 1943 trat er in den Sammlungen „kaum noch oder gar nicht mehr in Erscheinung “4.

Über sein Leben und seine Berufstätigkeit nach dem Zweiten Weltkrieg ist wenig bekannt. Zuletzt lebte er als Handelsvertreter in Offenau am Neckar. Am 14. März 1983 starb Hellmuth Buck in Lauffen am Neckar.

\section{Quellen und Literatur}

HStA Dresden, 13859, Nr. 844

HStA Dresden, 13842, Nr. 047; Nr. 048; Nr. 114, Bd. 1 u. 2; Nr. 115

SKD Archiv, 01/PS 53, Bd. 1 u. 3

BArch, R 9361-IX/Kartei/4931618, 4931619; R 9361-VIII/Kartei/4380766

Stadtarchiv Lauffen a. N., Sterberegister C Nr. 35/1983

Der Freiheitskampf, 8.3.1937, in: BArch, NS 5 - VI/299

3 Leiter SMV, Göpfert, an Direktor der Museen für Tierkunde und Völkerkunde, Dresden, 14.4.1936, HStA Dresden, 13842, Nr. 048, o. Pag. Vgl. BArch, R 76/I/59, fol. 84.

4 Günther an Kummerlöwe, 27.1.1943, HStA Dresden, 13842, Nr. 114, Bd. 2, o. Pag. 


\section{ULRICH DÄHNERT}

25.11.1903 Dresden - 18.4.1999 Dresden

Philologe, Historiker, Wissenschaftlicher Bibliothekar, Organologe

Sächsische Landesbibliothek

6.11.1933-8.2.1936 Volontär

8.6.1936-15.11.1945 Wissenschaftlicher Hilfsarbeiter

(Teilzeitabordnung an Gemeinsame Ministerialbibliothek, Dresden, 4.1940-9.1940; Militärdienst und Kriegsgefangenschaft 15.10.1942-10.9.1945)

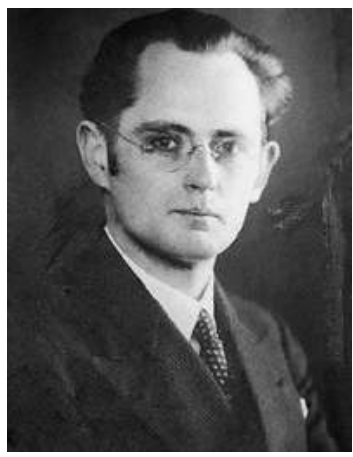

Am 25. November 1903 wurde Hans Karl Ulrich Dähnert als Sohn des Reichsbahnoberinspektors Ernst Oskar Dähnert und dessen Frau Mathilde, geb. Straßburg, in Dresden geboren. Nachdem er 1923 am Annen-Realgymnasium das Abitur abgelegt hatte, studierte er an der Universität Leipzig Germanistik, Geschichte, Geografie, Philosophie und Jura. 1932 wurde er in Leipzig promoviert, wo er im Januar 1934 auch das Staatsexamen für das Höhere Lehramt ablegte.

Mit seiner Zulassung zur Ausbildung für den Höheren Dienst an wissenschaftlichen Bibliotheken begann Dähnert im November 1933 seine Tätigkeit als Volontär an der Sächsischen Landesbibliothek in Dresden. Nach der Prüfung im Herbst 1935 arbeitete er unentgeltlich für die Landesbibliothek, erst im Juni 1936 wurde er als Wissenschaftlicher Hilfsarbeiter angestellt. Zunächst vertrat er bis Ende 1937 den beurlaubten $\triangleright$ Erhart Kästner im Fachreferat der Deutschen Literatur und in der Leitung der Sondersammlungen. Später verwaltete Dähnert die Fachkataloge der Mathematik und naturwissenschaftlichen Fächer und arbeitete am Schlagwortkatalog und in der Kartensammlung mit. Diverse Arbeitszeugnisse bestätigen ihm wissenschaftliche Begabung und große Gewissenhaftigkeit. Von April bis September 1940 war er stunden- bzw. tageweise an die Gemeinsame Ministerialbücherei teilabgeordnet. Ab Januar 1942 übernahm Dähnert die Stelle von >Charlotte Boden. Doch bereits im Oktober 1942 wurde er zum Militärdienst einberufen. Erst nach seiner Entlassung aus amerikanischer Kriegsgefangenschaft im September 1945 kehrte er nochmals für einige Wochen an die Landesbibliothek zurück. Bei seinen Dienstreisen zu den Auslagerungsorten der Bibliothek hat er „,besonders benötigte oder kostbare Bücher zurückgebracht soviel [...] zu tragen möglich war" ${ }^{\text {"1. }}$. Aufgrund seiner seit April 1933 bestehenden NSDAP-Mitgliedschaft wurde Dähnert zum 15. November 1945 entlassen.

Über sein privates Leben und die Zeit unmittelbar nach 1945 ist wenig bekannt. Mit der Hochzeit mit Gudrun Harlan aus Berlin hatte er in eine berühmte wie umstrittene Künstlerfamilie eingeheiratet. ${ }^{2}$ Er selbst konnte sehr gut Klavier und Orgel spielen und entwickelte sich in den

\footnotetext{
Dähnert an SMV, 21.3.1951, SLUB, PA Dähnert.

2 Gudrun Dähnert, geb. Harlan (1907-1976) war die Tochter des Schriftstellers und Dramaturgen Walter Harlan und Schwester von Veit Harlan, dem Regisseur der NS-Propagandafilme "Jud Süss" und „Kolberg“, sowie des Musikers Peter Harlan. Ihr Urgroßvater war der Mühlenbesitzer Gottlieb Traugott Bienert aus Plauen bei Dresden, womit sie eine Verwandte 2. Grades von dessen mit der Tänzerin Gret Palucca verheirateten Enkel Fritz Bienert war. Gudrun Dähnert war mit der jüdischen Schriftstellerin Nelly Sachs (1891-1970) befreundet, der sie durch Fürsprache bei Selma Lagerlöff und
} 
Nachkriegsjahren zu einem der Spezialisten auf dem Gebiet der Historie des sächsischen Orgelbaus. ${ }^{3}$ Dähnert war einer der ersten Organologen, die historische Orgelforschung aus denkmalpflegerischer Sicht betrieben, und wurde ab 1952 als erster Orgelsachverständiger für das sächsische Landesamt für Denkmalpflege tätig. Er erfasste den Bestand an historischen Orgeln, begleitete deren konservatorische Betreuung, dokumentierte Instandsetzungen und Restaurierungen. In zahlreichen Publikationen widmete er sich unter anderem den Instrumenten von Gottfried Silbermann und Zacharias Hildebrandt. Seine akribische Forschung mündete $1980 \mathrm{im}$ bis heute in Tiefe und Qualität des Inhaltes unerreichten Handbuch „Historische Orgeln in Sachsen“. Ulrich Dähnert starb am 18. April 1999 in Dresden.

\section{Auswahlbibliografie}

Die Erkenntnislehre des Albertus Magnus gemessen an den Stufen der „abstractio“; mit einem Sachverzeichnis und einer monographischen Bibliographie Albertus Magnus, Studien und Bibliographien zur Gegenwartsphilosophie, Bd. 4, Leipzig 1934 (Zugl. Leipzig, Univ., Diss., 1932).

Die Orgeln Gottfried Silbermanns in Mitteldeutschland, Leipzig 1953.

Gottfried Silbermann als Erbauer von Orgeln und Klavierinstrumenten, in: Musik und Gesellschaft, 3. Jg., H. 8, 1953, S. 13-17.

Das Positiv im Stadt- und Bergbaumuseum zu Freiberg, in: Walcker Hausmitteilung Nr. 25, Jan. 1961, S. 3-9.

Der Orgel- und Instrumentenbauer Zacharias Hildebrandt. Sein Verhältnis zu Gottfr. Silbermann u. Joh. Seb. Bach, Leipzig 1962 (hg. v. Institut für Denkmalpflege Dresden).

Betstuben-Orgelwerke im Bergbaugebiet um Freiberg, in: Der Anschnitt. Zs. f. Kunst und Kultur im Bergbau, Bochum, 15. Jg., 1963, S. 26-34.

Die Donat-Trost-Orgel in der Schloßkirche zu Eisenberg in Thüringen, Walcker Hausmitteilung, Nr. 31, Juli 1963, S. 10-24.

Die Orgellandschaft Sachsen und Thüringen, in: Acta Organologica. Bd. 1, 1967, S. 46-62.

Historische Orgeln in Sachsen. Ein Orgelinventar, Leipzig 1980 (Manuskriptfassung: Hubert Henkel).

\section{Quellen und Literatur}

SLUB, PA Dähnert, Ulrich

SLUB, Mscr.Dresd.App.2600,F

BArch, R 9361-IX/Kartei/5680304

Orgeln als Lebenswerk. Orgeldenkmalpfleger Ulrich Dähnert ist 95jährig verstorben, in: Dresdner Neueste Nachrichten, 22.4.1999.

Prinz Eugen von Schweden im Sommer 1939 und die Hinterlegung einer Garantiesumme für deren Lebensunterhalt 1940 zur Flucht aus Deutschland nach Schweden verhalf. Vgl. Eichmann-Leutenegger, Beatrice: Vor den Pforten des Paradieses. Schicksale jüdischer Flüchtlinge während der Nazizeit in Schweden, in: Stimmen der Zeit, 139, 2014, S. 766-777, www.herder.de/stz/hefte/archiv/139-2014/ 11-2014/vor-den-pforten-des-paradieses-schicksale-juedischer-fluechtlinge-waehrend-der-nazizeit-inschweden/, Zugriff: 6.12.2019.

3 Vgl. Deckert 1987, S. 113, SLUB, Mscr.Dresd.App.2600,A1. Für wichtige Hinweise dankt die Autorin Horst Hodick, Orgel- und Glockensachverständiger, Landesamt für Denkmalpflege Sachsen. 


\section{Helmut Deckert}

18.1.1913 Klotzsche - 18.2.2005 Radebeul

Bibliothekar

Sächsische Landesbibliothek

3.4.1934-2.1936 Praktikant

16.9.1936-11.1945 Bibliothekar (Mittlerer Dienst)

11.1945-1949 Bibliothekar (Höherer Dienst)

1949-1972 Bibliothekar (Höherer Dienst), Stellvertreten-

der Direktor

1952 Kommissarischer Leiter

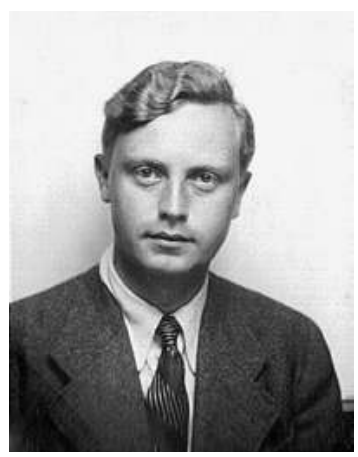

1957-1959 Kommissarischer Leiter

1962-1964 Kommissarischer Leiter

1972-31.10.1981 Bibliotheksrat, Stellvertretender Direktor

(Militärdienst und Kriegsgefangenschaft 10.1944-11.1945; Erkrankung 1948)

Helmut Deckert wurde am 18. Januar 1913 als Sohn des Ingenieurs Friedrich Eduard Deckert und dessen Frau Helene, geb. Lechner, in Klotzsche bei Dresden geboren. Das nach dem Abitur am Wettiner Gymnasium in Dresden 1933 begonnene Studium der Germanistik und Philosophie an der Universität Leipzig brach er ab, um in den Bibliotheksdienst zu wechseln.

Von März 1934 bis Februar 1936 absolvierte er eine Ausbildung für den Mittleren Bibliotheksdienst und war währenddessen als Praktikant an der Sächsischen Landesbibliothek in Dresden tätig. Im September 1936 wurde Deckert als Bibliothekar im Mittleren Dienst an der Landesbibliothek angestellt. Statt sich mit den neuen Machthabern einzulassen, engagierte er sich innerhalb der evangelischen Kirche. 1938 wurde er zum Kirchenvorstand der Gemeinde der Friedenskirche Radebeul ernannt. Dieses Amt bekleidete er während der folgenden vierzig Jahre - also in zwei Diktaturen. 1939 heiratete Deckert Waltraud, geb. Compter, mit der er zwei Söhne hatte. In der Landesbibliothek wurden ihm indes stets neue Aufgaben zugewiesen. Sollte er ab März 1941 die Privatbibliothek des Gauamtsleiters des NS-Lehrerbundes und damaligen Leiters des Sächsischen Ministeriums für Volksbildung, Arthur Göpfert, neu ordnen, so hatte er ab Juli $1941 \mathrm{im}$ Ausleihdienst zu arbeiten. Deckert vermutete, „einer schikanösen Willkür Neuberts

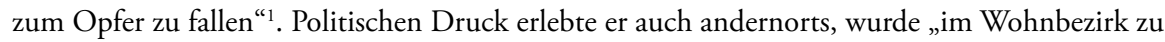
einer SA-Versammlung befohlen [...], auf der in einem Werbevortrag zum Eintritt in sog. ,Wehrmannschaften' aufgefordert wurde“2, der er sich nur mit Mühe entziehen konnte. Ab 1942 übernahm Deckert Dienste bei der sogenannten Heimatflak. Jede dritte Woche war für ihn daher

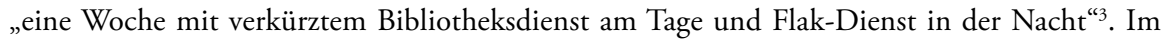
Oktober 1944 wurde er als Soldat zum Militärdienst eingezogen. Am Kriegsende gelangte er bei Pilsen in amerikanische Kriegsgefangenschaft, aus der er im November 1945 entlassen wurde. Ab Dezember 1945 wurde Deckert erneut in der Sächsischen Landesbibliothek tätig und war zunächst für die Entnazifizierung des Buchbestandes zuständig. Die mit der Entnazifizierung des

Deckert 1987, S. 205, SLUB, Mscr.Dresd.App.2600,A1.

Ebd., S. 207.

Ebd., S. 212. 
Bibliothekspersonals einhergehenden Entlassungen ermöglichten Deckert, der nie in die NSDAP eingetreten war, den Wechsel in den wissenschaftlichen Dienst. Begünstigend für seinen nachfolgenden beruflichen Aufstieg wirkte, dass er seit 1945/46 Mitglied der CDU war, wodurch ihm in der DDR der Druck eines SED-Eintrittes erspart blieb. Wegen einer TuberkuloseErkrankung wurde er 1948 für ein Jahr vom Dienst freigestellt. ${ }^{4} 1949$ erfolgte seine Ernennung zum stellvertretenden Direktor der Sächsischen Landesbibliothek. Als solcher übernahm Deckert in den Folgejahren dreimal, nämlich 1952, 1957-1959 sowie 1962-1964, deren kommissarische Leitung. 1972 wurde ihm der Titel Bibliotheksrat verliehen. Deckert engagierte sich bei der Reorganisation der Landesbibliothek nach dem Zweiten Weltkrieg und bei der Rückführung der kriegsbedingt ausgelagerten Bestände. 1958 übernahm er die Leitung der Musikabteilung, später leitete er das Buchmuseum sowie die Sondersammlungen, die Handschriften- und die Inkunabelsammlung. Er bearbeitete zahlreiche Nachlässe, publizierte Texte über die Handschriftenbestände, edierte Faksimile-Ausgaben der Bücher von Maria Sibylla Merian und der als Codex Dresdensis bekannten Maya-Handschrift.

Ende Oktober 1981 nach 45 Dienstjahren pensioniert, blieb Helmut Deckert der Sächsischen Landesbibliothek bis zu seinem Tod am 18. Februar 2005 in Radebeul eng verbunden.

\section{Auswahlbibliografie}

Das Buchmuseum der Sächsischen Landesbibliothek Dresden, Dresden 1956.

Katalog der Inkunabeln der Sächsischen Landesbibliothek zu Dresden, Leipzig 1957.

Sächsische Landesbibliothek. Benutzungsführer, Dresden 1960 (mit Burghard Burgemeister).

Maya-Handschrift der Sächsischen Landesbibliothek Dresden. Codex Dresdensis. Geschichte und Bibliographie, Berlin 1962.

M. S. Merian. Neues Blumenbuch. Begleittext zur Faksimileausgabe, Leipzig 1966.

Erbe und Verpflichtung. Zum Tode Martin Bollerts, in: Zentralblatt für Bibliothekswesen, 82, 8, 1968, S. 479-482.

M. S. Merian. Methamorphosis insectorum Surinamensium. Begleittext zur Faksimileausgabe, Leipzig 1975.

Codex Dresdensis. Kommentar, Graz 1975 (mit Ferdinand Anders).

Führer durch die Handschriftensammlung der Sächsischen Landesbibliothek zu Dresden, Dresden 1976.

\section{Quellen und Literatur}

SLUB, Mscr.Dresd.App. 2600

Deckert, Helmut: Bibliothekar aus Leidenschaft, Lebens- und Bibliothekserinnerungen (Typoskript), 4 Bde., 1987, SLUB, Mscr.Dresd.App.2600,A1.

Bürger, Thomas u. Konstantin Hermann (Hg.): Das ABC der SLUB. Lexikon der Sächsischen Landesbibliothek - Staats- und Universitätsbibliothek Dresden, Dresden 2006, S. 57.

Schmidmaier, Dieter: Bibliothekar und Bücherfreund aus Leidenschaft. Zum Gedenken an Helmut Deckert, in: Marginalien. Zeitschrift für Buchkunst und Bibliophilie, Blätter der Pirckheimer Gesellschaft, 2005, 178, S. 105 f.

Schwanitz, Henrik: Deckert, Helmut, in: Sächsische Biografie, 2014, Online-Ausgabe: http:// saebi.isgv.de/biografie/Helmut_Deckert_(1913-2005), Zugriff: 2.1.2020.

4 Vgl. C. Holzhausen an Jammers, 16.4.1948, SLUB, Mscr.Dresd.App.2830,89. 


\section{Dorothee Denecke}

28.1.1895 Dresden - 7.12.1977 Dresden

Bibliothekarin (Mittlerer Dienst)

Sächsische Landesbibliothek

(2.5.1917-11.1918 Königliche Landesbibliothek)

1.4.1918-31.3.1920 Volontärin

10.1.1921-30.4.1921 Freiwillige Hilfsarbeiterin

1.5.1921-31.10.1931 Bibliotheksgehilfin

1.2.1931-15.10.1945 Oberbibliothekssekretärin (Abordnung an Prinzlich Lippische Bibliothek, Baruth, 4.8.1919-15.12.1919 und Gemeinschaftliche Ministerial-

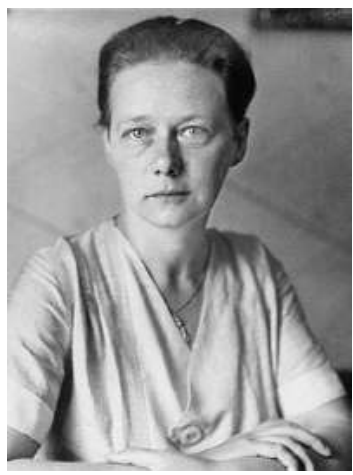

bibliothek, Dresden, 4.8.1937-4.9.1937)

Im Januar 1895 als Tochter des Studienrates Arthur Gottlob Theodor Denecke und dessen Frau Margarethe, geb. Hoffarth, in Dresden geboren, ließ sich Dorothee Marie Amalie Denecke an einer privaten Sprach- und Handelsschule sowie einem Buchhandelslehrinstitut in Dresden ausbilden. Ab April 1915 arbeitete sie für drei Jahre als Verlagsgehilfin in C. A. Koch’s Verlagsbuchhandlung.

Ab April 1918 war Denecke als Volontärin an der Königlichen Landesbibliothek in Dresden angestellt. Allerdings wurde sie ab August 1919 für fünf Monate an die Prinzlich Lippische Bibliothek auf Schloss Baruth abgeordnet. Ab März 1920 setzte Denecke ihr Volontariat in Leipzig fort, wo sie im Oktober 1920 ihre Diplomprüfung für den Mittleren Bibliotheksdienst ablegte. Am 10. Januar 1921 kehrte sie als Freiwillige Hilfsarbeiterin an die Sächsische Landesbibliothek zurück. Im Mai 1921 wurde sie zur Bibliotheksgehilfin ernannt, zehn Jahre später, im Februar 1931, zur Oberbibliothekssekretärin. Bereits damals führte sie das Fortsetzungsamt, bearbeitete alle Bücherreihen und Zeitschriften. Bis auf eine einmonatige Abordnung an die Gemeinschaftliche Ministerialbibliothek im August 1937 setzte sie diese Tätigkeit bis nach Ende des Zweiten Weltkrieges fort. Nur im Juni 1945 war sie „durch Überanstrengung beim Munitionssammeln u. Abtransport", wozu sie „in der Gemeinde kommandiert worden war" ${ }^{\text {" }}$, arbeitsunfähig. Aufgrund ihrer seit Mai 1937 bestehenden Mitgliedschaft in der NSDAP wurde Denecke zum 15. Oktober 1945 entlassen. Bereits 1920 war sie Mitglied der Deutschnationalen Volkspartei und ab 1933 Mitglied in diversen NS-Organisationen, u. a. in der NS-Frauenschaft.

Ein erneutes Gesuch um Wiedereinstellung an der Sächsischen Landesbibliothek wurde im Juli 1948 abgelehnt, da keine Stellen zur Verfügung stünden. Ihre späteren beruflichen Stationen sind nicht lückenlos überliefert. In den 1950er-Jahren war sie erneut an der Landesbibliothek beschäftigt. Um 1962 arbeitete sie als Honorarkraft für die Sächsische Bibliographie. ${ }^{2}$ Dorothee Denecke verbrachte ihre letzten Lebensjahre in Dresden-Niederwartha und starb am 7. Dezember 1977 in Dresden. ${ }^{3}$

Denecke an Sächsische Landesbibliothek, 6.1945, SLUB, PA Denecke.

2 Vgl. Bollert, Rede-Manuskript, 11.9.1956, SLUB, Mscr.Dresd.App.1378.b,52 u. Deckert an Jammers, 23.8.1962, SLUB, Mscr.Dresd.App.2830,69.

3 Vgl. Denecke an Deckert, 25.1.1977, SLUB, Mscr.Dresd.App.2600F,184. 


\section{Auswablbibliografie}

Bibliographie der sächsischen Geschichte, Bd. 4. Register, Leipzig 1918-1932 (bearb. v. Dorothee Denecke - Hg. v. Rudolf Bemmann u. Jacob Jatzwauk).

Quellen und Literatur

SLUB, PA Denecke, Dorothee

HStA Dresden, 13859, Nr. 1051

BArch, R 9361-IX/Kartei/6010916; R 9361-VIII/Kartei/5871283

Landeshauptstadt Dresden, Stadtarchiv, Meldekartei Sign. 15.7.3 und 15.7.4 


\title{
Johannes Draeseke
}

\author{
6.1.1892 Untersiemau - 9.11.1970 Dresden \\ Präparator
}

Museen für Tierkunde und Völkerkunde

(ab 1.1.1942 Museen für Tierkunde, Rassenkunde und

Völkerkunde)

1.9.1920-6.11.1921 Präparator

7.11.1921-30.9.1927 Oberpräparator

1.10.1927-31.3.1936 Konservator

1.4.1936-15.11.1945 Oberkonservator

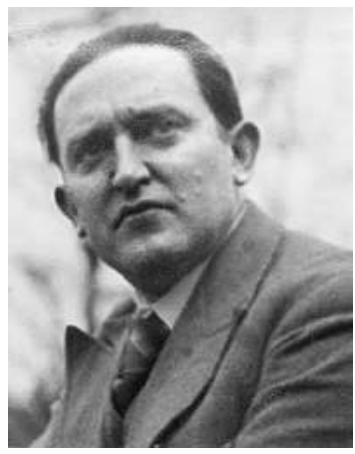

11.8.1944-5.1945 Depotverantwortlicher

9.1948-31.12.1956 Oberkonservator

Als drittes Kind des Pfarrers Hilmar Draeseke und dessen Ehefrau Emma Auguste, geb. Gagel, am 6. Januar 1892 im fränkischen Untersiemau geboren, absolvierte Johannes Draeseke zunächst eine kaufmännische Ausbildung in der Korbwarenfabrik seines Onkels C. Gagel in Coburg. Mehrere Jahre war Draeseke in diesem Beruf tätig, u. a. im Kaufhaus Tietz in Berlin. Seit seiner Kindheit interessierte er sich jedoch für Zoologie und begann 1914, als Autodidakt in der Naturalien- und Buchhandlung Alexander Heyne in Berlin-Wilmersdorf zu arbeiten. Nachdem er durch deren Schließung bereits nach sechs Monaten arbeitslos geworden war, meldete er sich freiwillig zum Kriegsdienst. Doch aufgrund seiner schwachen Konstitution wurde er bald wieder entlassen. Von Oktober 1915 bis August 1920 war Draeseke bei der Insektenhandlung Dr. O. Staudinger \& A. Bang-Haas in Dresden-Blasewitz als Präparator tätig. In dieser Zeit heiratete er 1917 Frieda Martha, geb. Hohlfeld.

Ab September 1920 arbeitete Draeseke als Präparator an den Museen für Tierkunde und Völkerkunde in Dresden. Nach sechs Monaten wurde er zum Oberpräparator, im Oktober 1927 zum Konservator der Lepidopteren (Schmetterlinge) ernannt. Seine Aufgaben bestanden „im Präparieren von Insekten [...] Inventarisieren dieser und Einordnen in die Sammlung. Ausserdem Neuaufstellung von Insektengruppen nach dem neuesten Stand der Wissenschaft. Selbständiges Bestimmen von Schmetterlingen und mikroskopische Untersuchungen, sowie Veröffentlichungen von Neubeschreibungen in den Fachzeitschriften [...] Ändern der Wechselausstellungen [...] Zusammenstellen von Leihsendungen an wiss. Mitarbeiter des In- und Auslandes " ${ }^{\text {"1 }}$. Dabei entwickelte er sich zu einem Kenner seines Fachgebietes. Besondere Verdienste erwarb sich Draeseke bei der Präparation und Bestimmung der von Emil Funke gesammelten Lepidopteren aus der Sammlung des Ostasienforschers Walther Stötzner, deren Großteil das Dresdner Museum angekauft hatte. Eine Denunziation als „unglaublicher Hetzer gegen Hitler, Kirche, Gott“2 blieb für Draeseke folgenlos. Im April 1936 wurde er zum Oberkonservator befördert. Positiv wirkte sich dabei wohl seine Mitgliedschaft in mehreren NS-Organisationen aus. So war er 1934 nicht nur Förderndes Mitglied der SS, sondern auch in den RDB, NSV und RLB eingetreten. Aufgrund

\footnotetext{
Draeseke über seine Tätigkeit am Museum, o. Dat., HStA Dresden, 13842, Nr. 048, o. Pag.

2 Gackstatter an die Politische Abteilung der NSDAP, 5.7.1933, HStA Dresden, 13859, Nr. 1193, fol. $2 \mathrm{~b}$.
} 
der prekären Personalsituation am Museum für Tierkunde und seiner gewissenhaften Mitwirkung an den Bergungsmaßnahmen der Sammlungen wurde Draeseke gemeinsam mit seinem Kollegen $\triangleright$ Robert Reichert am 11. August 1944 durch $>$ Fritz Fichtner als im Bereich der Museen für Tierkunde, Rassenkunde und Völkerkunde „für den sachgemäßen Zustand der Depots verantwortlich“3 benannt. Draeseke war für die Betreuung der ausgelagerten Sammlungsbestände im Schloss Weesenstein zuständig, mindestens im Mai 1945 wohnte er auch dort. Darüber hinaus hatte er die Kontrolle der auf der Rochsburg ausgelagerten Sammlung des Zoologischen Museums der Universität Hamburg übernommen. Im November 1945 führte eine lediglich vermutete NSDAP-Mitgliedschaft zu seiner Entlassung, allerdings war er förderndes Mitglied der SS gewesen.

In den Folgejahren war er erneut bei Dr. O. Staudinger \& A. Bang-Haas tätig. Im Herbst 1948 wurde er, nachdem $>$ Wolfgang Balzer heftig gegen die Ablehnung seiner Wiedereinstellung protestiert hatte, ${ }^{4}$ wieder am Museum für Tierkunde beschäftigt, wo er bis zum Eintritt in den Ruhestand Ende 1956 arbeitete. Darüber hinaus wirkte er noch weitere sechs Jahre an der Ordnung der Lepidopterensammlung mit, bis sein Gesundheitszustand das Ende dieser Tätigkeit erzwang. Nach langer Krankheit starb Johannes Draeseke am 9. November 1970 in Dresden.

\section{Auswahlbibliografie}

Die Schmetterlinge der Stötznerschen Ausbeute, in: Deutsche entomologische Zeitschrift, Iris, 1923-1925, Bd. 37, S. 53-60; Bd. 38, S. 1-8, 53-60; Bd. 39, S. 48-57, 211-231.

Eine neue Lasiocampide (Schmetterling) aus Java, in: Deutsche entomologische Zeitschrift, Iris, Bd. 56, 1942.

Die Firma Dr. O. Staudinger \& A. Bang-Haas, in: Entomologische Nachrichten, Bd. 6, 1962, S. 49-53.

Lycaenidae, Pars 72, in: W. Junk: Lepidopterorum Catalogus, 1911-1939.

\section{Quellen und Literatur}

HStA Dresden, 13859, Nr. 1193

HStA Dresden, 13842, Nr. 048

SKD Archiv, 02/VA 162, fol. 40; 02/VA 172

Hertel, Rolf: In memoriam Johannes Draeseke, in: Entomologische Abhandlungen. Zeitschrift für entomologische Taxonomie, hg. vom Staatlichen Museum für Tierkunde in Dresden, Bd. 27, 1969-1971, S. VII-IX.

\footnotetext{
3 Sammlungsreferent Fichtner an Reichsstatthalter Mutschmann, 11.8.1944, HStA Dresden, 11125, Nr. 23058, fol. 84b.

4 Vgl. Protokoll der Direktionssitzung, 6.9.1948, SKD Archiv, 02/VA 5, fol. 61 ff., hier: 62r.
} 


\section{FRITZ VAN EMDEN}

3.10.1898 Amsterdam - 2.9.1958 London

Zoologe, Entomologe

Museen für Tierkunde und Völkerkunde

1.4.1927-30.9.1933 Kustos

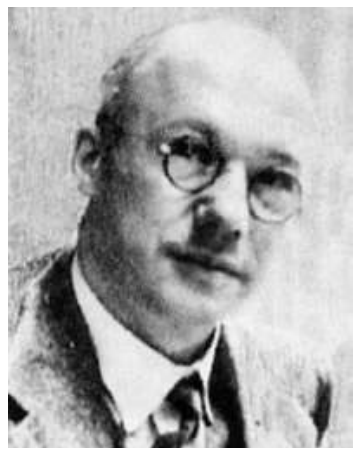

In Amsterdam als Sohn des niederländischen Textilhändlers Abraham van Emden und dessen jüdischer Frau Konstanze Irma, geb. Lippmann, geboren, kam Fritz Isidor van Emden 1900 mit seiner Familie nach Deutschland. In Leipzig besuchte er zunächst die Höhere Bürgerschule und von 1909 bis 1912 die Nikolaischule, bevor er am Gymnasium in Waldenburg 1918 das Abitur bestand. Anschließend studierte Emden an der Universität in Leipzig Naturwissenschaften, wo er 1921 bei Johannes Meisenheimer promoviert wurde. Zunächst arbeitete er als Assistent bei Walther Horn am Deutschen Entomologischen Institut in Berlin. Da Emden ab Mai 1923 auch über das Staatsexamen für den Höheren Schuldienst verfügte, unterrichtete er im Probedienst an der Nikolaischule in Leipzig. Bereits zu dieser Zeit war er bei der Naturwissenschaftlichen Werkgemeinschaft der Universität Leipzig als Entomologe tätig. Von März 1924 bis Juni 1926 arbeitete er bei der Firma Caesar \& Loretz in Halle an der Saale, für die er zuvor bereits nebenamtlich gewirkt hatte. Im Juli 1926 wechselte er an die Versuchsstation für Pflanzenkrankheiten der Landwirtschaftskammer für die Provinz Sachsen in Halle.

Ab 1. April 1927 arbeitete Emden als Kurator für Entomologie an den Museen für Tierkunde und Völkerkunde in Dresden. Für diese Tätigkeit war er aufgrund der Fürsprache durch Meisenheimer von seinem Vorgänger Karl Maria Heller empfohlen worden. ${ }^{1}$ Emdens Spezialgebiet waren die Laufkäfer (Carabidae). Er ordnete und katalogisierte die entomologische Abteilung systematisch und ermöglichte so anderen Wissenschaftlern den Zugang, wodurch „der wissenschaftliche Wert der Sammlung bedeutend gestiegen ist “2. Aufgrund des „Gesetzes zur Wiederherstellung des Berufsbeamtentums" sah sich Direktor \Arnold Jacobi im Juli 1933 gezwungen, die jüdische Abstammung Emdens an das Ministerium für Volksbildung in Dresden zu melden. Er schrieb: „van Emden ist nicht arischer Abstammung und [...] würde also voraussichtlich zu entlassen sein. Die daraus für ihn aus seinem Familienstand erwachsenden persönlichen Folgen ausser acht gelassen, muss hervorgehoben werden, dass der Verlust seiner Arbeitskraft für die Leistungsfähigkeit und den Ruf der Anstalt auf dem wissenschaftlich entomologischen Gebiete ein sehr schwerer, in gewisser Richtung sogar unersetzlicher sein würde. "3 Am 18. September 1933 verfügte der Reichsstatthalter in Sachsen die Entlassung Emdens - der zum 30. September 1933 im Alter von 34 Jahren vorzeitig in den Ruhestand versetzt wurde. Doch Jacobi gestattete

Vgl. Heller an Jacobi, 28.10.1926, HStA Dresden, 13842, Nr. 114, Bd. 1, o. Pag. Jacobi, Arbeitszeugnis für Fritz van Emden, 24.11.1933, HStA Dresden, 13842, Nr. 114, o. Pag. Jacobi an SMV, 12.7.1933, HStA Dresden, 13842, Nr. 047, o. Pag. 
Emden die weitere Nutzung der Bibliothek und der Bestände der Entomologischen Sammlung, sodass er zumindest noch privat wissenschaftlich arbeiten konnte. Jacobi bestätigte ihm sogar im April 1934, er setze „seine wissenschaftliche Tätigkeit mit allem Eifer fort“, „seine Arbeiten erstrecken sich nach wie vor auf Gegenstände des zoologischen Pflanzenschutzes, worin er seit Jahren neben der Museumsarbeit der Landwirtschaft und Gärtnerei nicht unwichtige Dienste geleistet hat “4. Dennoch war eine erneute Anstellung Emdens in Deutschland aufgrund der „Nürnberger Gesetze“ unmöglich geworden.

1936 emigrierte Emden mit seiner Frau Margarethe Emma Maria Franziska, geb. Berndt, und den beiden Söhnen nach Großbritannien. Noch 1940 wurde er als Nr. E41 auf der Sonderfahndungsliste des Reichssicherheitshauptamtes verzeichnet, wodurch ihm im Falle der deutschen Okkupation Großbritanniens eine Verhaftung durch ein SS-Sonderkommando gedroht hätte. Emden konnte zunächst ab November 1936 in London als Stipendiat der Society for the Protection of Science and Learning am Natural History Museum arbeiten. Ab November 1937 war er als Entomologe am Imperial Institute of Entomology (Commonwealth Institute of Entomology) in London angestellt. Sein Arbeitsplatz befand sich im Natural History Museum. Dort widmete er sich einem neuen Fachgebiet, den Raupenfliegen (Tachinidae). 1947 erhielt er die britische Staatsbürgerschaft. Im Alter von 59 Jahren starb Fritz van Emden am 2. September 1958 in London.

\section{Auswahlbibliografie}

Versuch einer Aufstellung von Gattungsbestimmungstabellen der Carabidenlarven (Col.), Berlin 1919.

Zur Kenntnis der Brutpflege von Asellus aquaticus nebst Bemerkungen über die Brutpflege anderer Isopoden, Berlin 1922 (Zugl. Leipzig, Univ., Diss., 1921).

Vier neue Carabiden des Museums für Tierkunde zu Dresden, in: Berliner entomologische Zeitschrift, 1928, S. 375-384.

Zur Kenntnis der Brutpflege der Morphologie und Ökologie des Brotkäfer-Parasiten Cephalonomia quadridentata duchaussoy, in: Zeitschrift für Morphologie und Ökologie der Tiere, 23, 1931, S. 425-574.

Einige neue Carabinae des Staatlichen Museums für Tierkunde zu Dresden, in: Zeitschrift f. wissenschaftliche Insektenbiologie. Beil.: Neue Beiträge zur systematische Insektenkunde, 1932, Bd. 5, Nr. 4/5, S. 62-69.

Revision der Gattung Cratosomus (Col.Cur.), Leipzig 1933.

Coleopterorum catalogus; mehrere Teile, 1931-1939 (mit Karl Wilhelm von Dalla Torre).

Larvae of British Beetles, 7 Bde., 1939-1949.

Tachinidae/Calliphoridae, in: Royal Entomological Society of London: Handbooks for the Identification of British Insects, 1954 (Mitarbeit).

The fauna of British India, Bd. 1 (Diptera), Dehli 1965.

British Coleoptera Larvae. A guide to the families and major subfamilies, 2019 (bearbeitet von Helmut van Emden, Max Barclay u. Beulah Garner).

4 Jacobi über Fritz van Emden, 23.4.1934, ebd. 


\section{Quellen und Literatur}

HStA Dresden, 13842, Nr. 047; Nr. 114, Bd. 1

BArch, R 58/9609

Entomologische Chronik. Gestorben: Dr. Fritz I. van Emden, Beiträge zur Entomologie, Bd. 8, Nr. 5/6, 1958, S. $761 \mathrm{f}$.

Sachtleben, Hans: (Nachruf van Emden), in: Beitrage zur Entomologie, 8, 1958, S. 761-762.

Schmidt, Gerhard: (Nachruf van Emden), in: Mitteilungen der Deutschen Entomologischen Gesellschaft, 17, 1958, S. 95 f.

Hennig, Willi: F. I. van Emden †, in: Zoologischer Anzeiger, Supplement, 23 (Verhandlungen der Deutschen Zoologischen Gesellschaft), 1959, S. 528 f.

Schmitt, Michael: Willi Hennig, the cautious revolutioniser, in: Palaeodiversity, 3, Supplement, 3-9, Stuttgart 2010, S. 3-9, hier: 4 ff., www.researchgate.net/publication/236173502_ Willi_Hennig_the_cautious_revolutioniser, Zugriff: 2.12.2019.

Emden, Helmut van: Erinnerungen an Leben und Arbeit eines großen Käferlarven-Pioniers, Fritz Isidore van Emden (1898-1958), in: Entomologische Nachrichten und Berichte, Bd. 61, Nr. 3-4, 2017, S. 237 ff.

E-Mail von Helmut van Emden an die Autorin, 12.3.2018. 


\title{
RAGNA ENKING
}

\author{
25.4.1898 Köln - 18.7.1975 Rom \\ Klassische Archäologin, Etruskologin \\ Skulpturensammlung \\ 15.12.1926-30.6.1929 Freiwillige Wissenschaftliche \\ Hilfsarbeiterin \\ 1.7.1929-31.10.1945 Wissenschaftliche Hilfsarbeiterin \\ 14.2.1945-31.10.1945 Kommissarische Leiterin \\ 1.11.1945-31.7.1946 Direktorin \\ Zentralkanzlei der Sammlungen
}

14.10.1945-31.3.1946 Stellvertretende Leiterin

Staatliche Kunstsammlungen

1.4.1946-31.7.1946 Direktorin

(Abordnung an Sächsische Landesbibliothek 19.1.1942-7.1942 und "Heimatwerk Sachsen"

7.1942-31.10.1943)

Ragna Marie Dora Enking wurde am 25. April 1898 in Köln als Tochter des Schriftstellers Ottomar Enking und dessen Frau Maria Johanna Emma, geb. Seyler, geboren. Nach dem Umzug ihrer Familie lernte sie am Mädchengymnasium in Dresden, wo sie ihre Reifeprüfung ablegte. Anschließend studierte sie an den Universitäten in München und Jena Archäologie und Kunstgeschichte. In Jena wurde Enking 1921 als Schülerin von Herbert Koch promoviert. Erste Berufserfahrungen sammelte sie bis Dezember 1922 als Freiwillige Wissenschaftliche Hilfsarbeiterin an der Ägyptischen Abteilung der Staatlichen Museen in Berlin. Danach leitete sie bis Juli 1923 die Grafische Abteilung des Verlages Bruno Cassirer. Von August bis Dezember 1923 arbeitete sie als Freiwillige Wissenschaftliche Hilfsarbeiterin in der Vorderasiatischen Abteilung des Berliner Museums für Völkerkunde. Im Mai 1924 heiratete sie Oskar Mau, Wissenschaftlicher Hilfsarbeiter dieses Museums, doch diese Ehe wurde bereits nach drei Jahren geschieden.

Unterdessen war Enking nach Dresden umgezogen, wo sie ab Mitte Dezember 1926 als Freiwillige Wissenschaftliche Hilfsarbeiterin in der Skulpturensammlung tätig war. Nach zweieinhalb Jahren, im Juli 1929 wurde sie als Wissenschaftliche Hilfsarbeiterin eingestellt. Nach dem Tod von Direktor $>$ Bruno Schröder war sie ab Sommer 1934 neben dem ehemaligen Kustos - Walter Müller, der nun Direktor wurde, die einzige Wissenschaftlerin an der Sammlung. Sie führte Inventarisations- und Katalogarbeiten aus, wirkte an der Neuaufstellung mit und übernahm ab 1935 zahlreiche Führungen. Nach Kriegsbeginn zählten auch die Bergungs- und Auslagerungsarbeiten zu ihren Aufgaben. Nach der Schließung der Skulpturensammlung wurde Enking im Januar 1942 an die Sächsische Landesbibliothek abgeordnet. Dass ihr die andersartige Bibliotheksarbeit missfiel, äußerte sie deutlich. Sie erkrankte auffällig oft, nicht zuletzt auch, weil sie an einer chronischen Atemwegserkrankung litt. Als sie dann zu einer Kur nach Bad Reichenhall fuhr, unterstellte ihr Bibliotheksdirektor $>$ Hermann Neubert im Juli 1942 einen

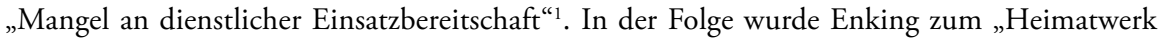

1 Neubert, Beurteilung Ragna Enking, 16.7.1942, HStA Dresden, 11125, Nr. 18991, Bd. 2, fol. 83 . 
Sachsen" versetzt, um dort die Arbeit der nach Straßburg wechselnden $>$ Elfriede SchulzeBattmann fortzuführen. In der Skulpturensammlung arbeitete Enking damals aufgrund dieser Aufgaben nur noch einen Tag pro Woche. Dies hatte zur Folge, dass $\gg$ Fritz Fichtner unter Berufung auf die Kriegswichtigkeit ihrer Tätigkeit die Rückversetzung Enkings reklamierte, schließlich führte sie das Inventar über die ausgelagerten Kunstschätze der Skulpturensammlung. Zunächst konnte Enking diese Arbeit wöchentlich an drei Arbeitstagen fortsetzen, doch erst im November 1943 wurde ihre Abordnung komplett aufgehoben. Ungeachtet der Querelen in Dresden wurde Enking, in Anerkennung ihrer wissenschaftlichen Leistungen, vor allem ihrer „Arbeiten zur Nachwirkung der ägyptischen und römischen Kunst in Renaissance und Klassizismus $^{\text {“2 }}$, im Oktober 1942 zum korrespondierenden Mitglied des Archäologischen Institutes des Deutschen Reiches ernannt. Unterdessen hatte sie mit Einwilligung des Ministeriums in Vertretung von Walter Böckelmann die Übungen zur Kunstbetrachtung an der Abteilung für Kunsterziehung an der Kunstgewerbeakademie übernommen, die sie bis Mai 1944 durchführte. Anfang Februar 1945 organisierte sie, wohl ebenfalls in einer Abordnung, die Verpflegung in einem in der Technischen Hochschule eingerichteten Flüchtlingslager. ${ }^{3}$ Durch die Bombardierung der Stadt am 13./14. Februar 1945 verlor Enking ihre Wohnung. Zunächst fand sie in Hellerau bei Dresden eine Notunterkunft, doch im April 1945 zog sie in ihr Dienstzimmer ins Albertinum, da es „notwendig war, die Bestände der Skulpturensammlung ständig unter Aufsicht zu haben“4. Bereits im Februar 1945, als Müller aus gesundheitlichen Gründen beurlaubt wurde, übernahm Enking die kommissarische Leitung der Skulpturensammlung und war damit für deren Schutz und Erhaltung verantwortlich, nach Kriegsende für deren Rückführung nach Dresden. Im November 1945 wurde sie zur Direktorin der Skulpturensammlung ernannt, nachdem sie im Vormonat bereits mit der Stellvertretung für den Leiter der neu eingerichteten Zentralkanzlei der Sammlungen, - Walther Fischer, beauftragt worden war. ${ }^{5}$ In dieser Funktion setzte sie sich für den Verbleib der Fachkräfte in den Museen ein, wie zum Beispiel für Restaurator $>$ Kurt Köhn. Nicht zuletzt dadurch sah sich Enking Denunziationen ausgesetzt, auch durch $\triangleright$ Arthur Leuschner, früher Aufseher der Skulpturensammlung und nun Regierungsassistent in der Porzellansammlung. Ihr wurde die Mitgliedschaft in der NS-Frauenschaft vorgeworfen, der sie 1937 beigetreten war. Dagegen protestierte sie, denn sie hatte „keine Lust“, sich „wieder so behandeln zu lassen wie zu Zeiten des Nationalsozialismus" ${ }^{\text {"6 }}$. Enking war kein Mitglied der NSDAP gewesen, dennoch war 1936 anonym über sie berichtet worden: „An ihrer nationalsozialistischen Zuverläs-

2 Archäologisches Institut des Deutschen Reiches an Enking, Abschrift, 10.1942, HStA Dresden, 11125, Nr. 18991, Bd. 2, fol. 88.

3 Vgl. Enking, Skulpturensammlung, an SMV, Abt. IV, 9.2.1945, HStA Dresden, 11125, Nr. 23044, fol. 139.

4 Skulpturensammlung, Enking, an Verwaltung der Schlösser und Gärten, Abschrift, 15.9.1945, HStA Dresden, 11125, Nr. 18991, Bd. 3, fol. 10.

5 Vgl. Landesverwaltung Sachsen, Zentralverwaltung für Wissenschaft, Kunst und Erziehung, Ministerialdirektor Grohmann, an Balzer, Direktion Staatliche Kunstsammlungen, 14.10.1945, SLUB, Mscr.Dresd.App.2550, fol. 138.

6 Enking an die Landesverwaltung Sachsen, Grohmann, 12.11.1945, SKD Archiv, 02/VA 166, fol. 47. Vgl. auch Skulpturensammlung, Enking, Bescheinigung für Kurt Köhn, 7.9.1945, SKD Archiv, 02/VA 172, fol. 150. Den Hintergrund der Denunziationen bildete, wie so oft, das Gefühl der Ungleichbehandlung - Enking setzte sich für Köhn ein, nicht aber für Leuschner, doch beide waren Mitglieder der NSDAP gewesen. Letztlich wurden beide am 15.11.1945 entlassen. 
sigkeit bestehen einige Zweifel. [...] Sie besitzt einen gewissen Standesdünkel und ist bei der Gefolgschaft der Skulpturensammlung nicht sehr beliebt ${ }^{\text {"7 }}$. Nach der Trennung der naturwissenschaftlichen von den kunst- und kulturhistorischen Museen wurde Enking am 1. April 1946 zur Direktorin der Staatlichen Kunstsammlungen ernannt. Allerdings wirkte sie nur kurz in diesem Amt. Wenige Tage nachdem sie am 6. Juli 1946 das neu eingerichtete „Zentralmuseum“ im Schloss Pillnitz eröffnet hatte, wurde sie am 31. Juli 1946 fristlos entlassen. Enking protestierte dagegen beim Präsidenten der Landesverwaltung Sachsen, Rudolf Friedrichs, allerdings erfolglos. ${ }^{8}$

Nach dem erlittenen Verlust ihrer Wohnung durch den Bombenangriff führte nun die, für die 48-jährige Enking nach ihrem Einsatz für die Sammlungen unverständliche, fristlose Entlassung dazu, dass sie Dresden verließ. In den 1950er-Jahren lebte sie in Berlin, später in Rom, wo sie Privataufträge ausführte und weiterhin rege publizierte. ${ }^{9}$ Am 18. Juli 1975 starb Ragna Enking in Rom.

\section{Auswahlbibliografie}

Beiträge zur Darstellung des Engels in der altchristlichen Kunst (Jena, Univ., Diss. 1931).

Der Apis-Altar Johann Melchior Dinglingers. Ein Beitrag zur Auseinandersetzung des Abendlandes mit dem alten Ägypten, Leipziger ägyptologische Studien, 11, 1939.

Andrea Riccio und seine Quellen, in: Jahrbuch der Preußischen Kunstsammlungen, Bd. 62, H. 3, 1941, S. 11-107.

Die Dresd. Skulpturensammlung, in: Das ist Dresden, 1942, S. 37 ff.

Lasa, in: Mitteilungen des Deutschen Archäologischen Instituts, Römische Abteilung, Bd. 57, 1942.

Culsú und Vanth, in: Mitteilungen des Deutschen Archäologischen Instituts, Römische Abteilung, Bd. 58, 1943, S. 48-69.

Etruskische Geistigkeit, Berlin 1947.

S. Andrea Cata Barbara e S. Antonio Abbate sull'Esquilino (in via Carlo Alberto), La chiesi di Roma illustrate, Bd. 83, Rom 1964.

Die sächsischen staatlichen Museen in Kriegs- und Nachkriegszeit, in: Sächsische Heimat, Zeitschrift der Bundeslandsmannschaft Sachsen e. V., der Stiftung Land Sachsen und des Arbeitskreises „Sachsen in Europa“, Bd. 19, H. 2, 1973, S. 44-54.

\footnotetext{
o. A., Beurteilung Ragna Enking, 14.10.1936, HStA Dresden, 11125, Nr. 18991, Bd. 2., fol. 53.

Vgl. Rudert 2012. Siehe S. 227 f.

9 Martin Miller erwähnt, dass Ragna Enking, ,seit ihrer Entlassung wegen allzu großer Verstrickungen mit dem Naziregime im Jahre 1946 in Rom" lebte - allerdings ließen sich keine Belege für eine derartige Aktivität in der NS-Zeit finden, ebenso wenig für eine Übersiedlung nach Rom im Jahr 1946. Vgl. Miller, Martin: Wissenschaft für Laien, in: Haack, Marie-Laurence u. Martin Miller (Hg.): L'étruscologie dans l'Europe d'après-guerre. Actes des journées d'études internationales des $14 \mathrm{au}$ 16 septembre 2015, Bordeaux 2017, S. 219.
} 


\section{Quellen und Literatur}

HStA 11125, Nr. 18991, Bd. 2 u. 3

Ragna Enking, in: Schuder, Werner (Hg.): Kürschners Deutscher Gelehrten-Kalender. Begründet von Joseph Kürschner, 12. Aufl., Berlin 1976, S. 650.

Enking, Ragna: Dresden im Mai 1945. Ein Bericht, in: Die Dresdner Kunstsammlungen in fünf Jahrhunderten, 2004, S. 84-92 (posthum).

Enking, Ragna: Die Dresdner Kunstsammlungen gegen Ende des Zweiten Weltkrieges, aus: Georga. Zwei Welten, in: Kolb, Karin u. Staatliche Kunstsammlungen Dresden (Hg.): Zukunft seit 1560, Bd. 3, Berlin 2010, S. 206-214.

Rudert, Thomas: Museale Praxis zwischen Besatzungsmacht und kulturellem Anspruch. Die Eröffnung des Pillnitzer Zentralmuseums des Landes Sachsen am 6. Juli 1946, in: Jahrbuch der Staatlichen Kunstsammlungen Dresden, Bd. 36, 2010, Dresden 2012, S. 192-201. 


\section{BRUNO FAASS}

2.11.1882 Deerenburg - 29.12.1951 Göttingen

Wissenschaftlicher Bibliothekar

Sächsische Landesbibliothek

(bis 1.5.1917 Königliche Öffentliche Bibliothek,

2.5.1917-11.1918 Königliche Landesbibliothek)

1.2.1908-31.5.1914 Wissenschaftlicher Hilfsarbeiter

1.6.1914-31.3.1919 Bibliotheksassistent

1.4.1919-30.9.1927 Bibliothekar

1.10.1927-8.1942 Landesbibliothekar

8.1942-15.11.1945 Bibliotheksrat

(Militärdienst 29.3.1915-30.12.1918)

Als Sohn des Apothekers Carl Heinrich Theodor Faass und dessen Frau Agnes Elise Adelheid, geb. Sas, am 2. November 1882 in Deerenburg im Harz geboren, besuchte Bruno Faass zunächst die Lateinische Hauptschule der Franckeschen Stiftungen in Halle an der Saale. Nach dem Abitur am Königlichen Domgymnasium zu Halberstadt studierte er ab 1901 Geschichte und Klassische Philologie in Halle und Göttingen. 1907 wurde er in Göttingen promoviert, mit dem Bestehen des Staatsexamens erwarb er zugleich die Lehrbefähigung.

Zum 1. Februar 1908 wurde er als Wissenschaftlicher Hilfsarbeiter an der Königlichen Öffentlichen Bibliothek in Dresden angestellt. Sechs Jahre später, im Juni 1914, wurde er nach der Beförderung seines Kollegen $>$ Hubert Richter zum Bibliotheksassistenten ernannt. Diese Tätigkeit unterbrach Faass, um ab März 1915 seinen Militärdienst im Ersten Weltkrieg abzuleisten. Zum Jahresende 1918 als Vizefeldwebel entlassen, kehrte er an die Sächsische Landesbibliothek zurück, wo er wenige Monate später zum Bibliothekar und 1927 zum Landesbibliothekar befördert wurde. Er entwickelte den ab 1927 genutzten Systematischen Katalog, den Fachkatalog der Bibliothek, mit dem Erwerbungen nach Numerus currens, d. h. nach laufender Zugangsnummer, sachlich erschlossen wurden. Seine 1933 von Direktor $>$ Martin Bollert vorgeschlagene Ernennung zum Oberbibliothekar blieb jedoch aus. Unklar bleibt, ob dies oder der allgemein größer werdende politische Druck Faass bewogen haben, am 25. Oktober 1939 den Antrag auf Parteimitgliedschaft zu stellen. Seine Aufnahme in die NSDAP erfolgte zum Jahresbeginn 1940. Ein späteres parteipolitisches Engagement ist nicht überliefert. Jedoch wirkte sich die Parteimitgliedschaft positiv auf seine Ernennung zum Bibliotheksrat 1942 aus. Bei der Bombardierung Dresdens am 13./14. Februar 1945 wurde seine Wohnung zerstört. Gemeinsam mit seiner Frau Dora Hermine Ida, geb. Eberwien, die er 1908 geheiratet hatte, kam er bei Freunden in Dresden-Blasewitz unter. Aufgrund seiner NSDAP-Mitgliedschaft wurde Faass nach 37 Berufsjahren an der Landesbibliothek zum 15. November 1945 entlassen.

Diese Erfahrungen und die nachfolgenden entbehrungsreichen Jahre führten zu seiner körperlichen wie seelischen Erschöpfung und schweren Erkrankung. Während er zumindest stundenweise bei der Witwe des Künstlers Ludwig von Hofmann dessen Bibliothek ordnete, versuchte seine Frau, den Lebensunterhalt mit Stricken zu verdienen, die früheren Ersparnisse waren von der russischen Besatzungsmacht beschlagnahmt worden. 1946 beantragte Faass seine Wiedereinstellung, musste aber nach zweijährigem Hoffen feststellen, dass er in Dresden keine Arbeit als 
Bibliothekar finden würde. Enttäuscht verließ er Ende 1948 die Stadt, um seiner Frau zu deren Familie in den Westen zu folgen. Zum Jahresanfang 1949 erhielt er eine Zuzugsgenehmigung für Göttingen, wo er gemeinsam mit seiner Frau und seiner verwitweten Schwägerin fortan einen Raum bewohnte. Doch auch in Göttingen fand er keine Anstellung, sondern arbeitete auf Honorarbasis am Schlagwortkatalog der Universitätsbibliothek mit. Am 29. Dezember 1951 starb Bruno Faass in Göttingen.

\section{Auswahlbibliografie}

Studien zur Überlieferungsgeschichte der römischen Kaiserurkunden, (Göttingen, Univ., Diss., 1907).

Dresdner Bibliothekenführer, Dresden 1915 (Hg.).

Die neuen Fachkataloge der Sächsischen Landesbibliothek, Leipzig 1937.

\section{Quellen und Literatur}

SLUB, PA Faaß, Bruno

SLUB, Mscr.Dresd.App.2830,77

BArch, R 9361-IX/Kartei/8220149; R 9361-VIII/Kartei/8640247

Habermann, Alexandra, Klemmt, Rainer u. Frauke Siefkes: Lexikon Deutscher Wissenschaftlicher Bibliothekare 1925-1980, Frankfurt a. M. 1985, S. 74.

Bürger, Thomas u. Konstantin Hermann (Hg.): Das ABC der SLUB. Lexikon der Sächsischen Landesbibliothek - Staats- und Universitätsbibliothek Dresden, Dresden 2006, S. 75.

Nitzschke, Katrin: Faass, Bruno, in: Sächsische Biografie, 2010, Online-Ausgabe: http://saebi. isgv.de/biografie/Bruno_Faass_(1882-1951), Zugriff: 2.1.2020. 


\section{Fritz FichtNeR}

16.6.1890 Dresden - 9.9.1969 Erlangen

Kunsthistoriker

Porzellansammlung

1929-15.12.1933 Freiwilliger Wissenschaftlicher

Hilfsarbeiter

15.12.1933-9.2.1937 Kustos und Leiter

10.2.1937-7.5.1945 Direktor

Kunstgewerbemuseum

15.12.1933-7.5.1945 Leiter

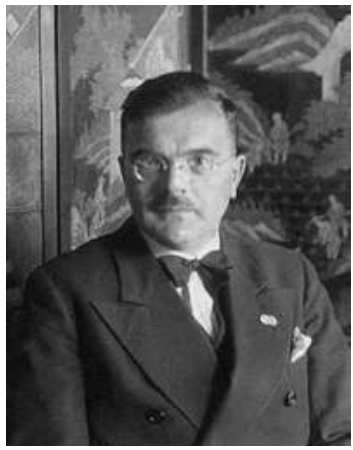

Mathematisch-Physikalischer Salon

12.1940-9.12.1942 Kommissarischer Leiter

Sächsisches Ministerium für Volksbildung, Referat Staatliche Sammlungen

1.4.1937-14.09.1944 Referent

(Militärdienst in Dresden ab 1.12.1941)

Paul Fritz Fichtner, am 16. Juni 1890 als Sohn des Oberlehrers Franz Paul Fichtner und dessen Frau Antonie Elisabeth, geb. Fleck, in Dresden geboren, besuchte bis 1910 das Staatsgymnasium in Dresden und das Lehrerseminar in Zschopau im sächsischen Erzgebirge. Nach einjährigem Militärdienst arbeitete Fichtner an der Volksschule in Dresden-Lockwitz, bevor er ab 1912 in Dresden an der Kunstgewerbeakademie Kunstpädagogik studierte und an der Kunstakademie Anatomiekurse belegte. Im Ersten Weltkrieg diente er von August 1914 bis Januar 1918 als Freiwilliger im Sanitätsdienst. Nach dem Krieg legte er die Staatsprüfung für das Höhere Lehramt ab. Parallel zur Arbeit als Oberlehrer an der Ersten Realschule in Leipzig und ab 1919 am Staatsgymnasium Dresden-Neustadt studierte er bis 1921 an der Universität Leipzig und zeitgleich an der Technischen Hochschule in Dresden Kunstgeschichte wie auch Geschichte, Archäologie, Architektur und Philosophie. Zu seinen Professoren zählten unter anderem August Schmarsow, Wilhelm Pinder, Robert Bruck und Cornelius Gurlitt. Im Juli 1921 wurde Fichtner in Leipzig bei Pinder promoviert; im Dezember 1923 habilitierte er sich in Dresden mit einer Arbeit über „Die Wohlgemuth-Schule und früheste Arbeiten des jungen Albrecht Dürer“. Danach arbeitete Fichtner noch immer als Lehrer am Gymnasium Dresden-Neustadt, wo er 1927 zum Studienrat befördert wurde, und gleichzeitig als Dozent an der Technischen Hochschule, in der Zeichenlehrerabteilung der Kunstgewerbeakademie sowie an der Akademie der bildenden Künste. Diverse Studienreisen führten ihn in den 1920er-Jahren nach Italien, Frankreich, England, Griechenland, Ägypten sowie in die Türkei. Im Dezember 1928 wurde er zum außerordentlichen Professor für allgemeine Kunstgeschichte an der Technischen Hochschule ernannt, wo er bis 1945 lehrte. Von 1929 bis 1932 war er Abteilungsleiter am praktisch-pädagogischen Seminar dieser Hochschule. Darüber hinaus schrieb er Beiträge für das Kunstreferat des Dresdner Anzeigers. ${ }^{1}$

$1 \quad$ Vgl. Prof. Fichtner - Nachfolger Prof. Zimmermanns, in: DA, 11.12.1933, S. 7. 
Parallel dazu begann Fichtner 1929, 39-jährig, seine Museumslaufbahn als Freiwilliger Wissenschaftlicher Hilfsarbeiter in der Porzellansammlung in Dresden unter $>$ Ernst Zimmermann. ${ }^{2}$ Nach dessen Pensionierung 1933 wurde Fichtner, der über reichlich Erfahrung in der Lehre, aber vergleichsweise kaum über Museumserfahrung verfügte, zum Kustos und Leiter der Porzellansammlung ernannt und zugleich nach der Entlassung von $>$ Wolfgang Balzer als Leiter des Kunstgewerbemuseums eingesetzt. Ausschlaggebend für diesen Karrieresprung war seine nationalsozialistische Haltung. Fichtner war im Januar 1933 der SA beigetreten und wurde im Mai 1933 Mitglied der NSDAP. In den Folgejahren trat er in mehrere nationalsozialistische Organisationen ein, u. a. in den NSLB. Im November 1933 unterzeichnete Fichtner das „Bekenntnis der Professoren an den deutschen Hochschulen zu Adolf Hitler ${ }^{\text {“3 }}$. Für das Kreisschulungsamt der NSDAP war er als Referent für Kunsterziehung und als Ausbilder aktiv, für das Rassenpolitische Amt der NSDAP als Berater. Er referierte im Rahmen von Parteischulungen und veranstaltete als SA-Sturmmann Kurse für die NS-Frauenschaft. Sein politisches Engagement führte dazu, dass Fichtner im Februar 1937 zum Direktor der Porzellansammlung ernannt wurde und im April 1937 zum Referenten für die Staatlichen Sammlungen im Sächsischen Ministerium für Volksbildung (SMV). Nach der neuen Ämterteilung im Ministerium wurde Fichtner im April 1940 Abteilungsleiter, womit er für sämtliche Personalbelange der Sammlungen verantwortlich war und Rechenschaft nur gegenüber dem Leiter des SMV und Reichsstatthalter Mutschmann ablegen musste. ${ }^{4}$ Bereitwillig stellte er die Staatlichen Sammlungen in Dresden in den Dienst des neuen Staates. Er fühlte sich für die Leitung der Museen „im Dienste der nationalsozialistischen Idee“ und die „Verlebendigung der Museen"s verantwortlich. Zu Fichtners Arbeitsalltag zählten Gespräche mit dem NSDAP-Gauleiter von Sachsen, Reichsstatthalter Martin Mutschmann, und dem Leiter des SMV, Arthur Göpfert. Als Referent der Staatlichen Sammlungen im Ministerium arbeitete er eng mit den Mitarbeitern aller Sammlungen sowie mit den Beamten im Ministerium zusammen. Vermutlich war Fichtner gelegentlich für den Sicherheitsdienst der SS tätig. In den Kunstraub der Nationalsozialisten war er zumindest eindeutig involviert. Im Rahmen der Beschlagnahmung der Sammlung des Dresdner jüdischen Bankiers Gustav von Klemperer 1938 hatte er Kontakt zur Geheimen Staatspolizei. ${ }^{6}$ Ab 1937 engagierte sich Fichtner in der Deutschen Keramischen Gesellschaft, als Mitglied ihres Kunstbeirates beriet er die keramische Industrie in Deutschland. Letztlich erstreckte sich das Netzwerk, in dem Fichtner agierte, in Politik und Verwaltung, in Museen, Universitäten und Industrie. Teilweise profitierte er davon auch bei seiner kuratorischen Arbeit. Diese bestand einerseits in der Konzeption und Einrichtung der Porzellansammlung in ihren neuen Räumen im Zwinger, die kriegsbedingt nicht eröffnet werden konnte, andererseits in mehreren Ausstellungen vor allem im Kunstgewerbemuseum, wie „Altes und neues Zinn“, „Wettkampf und Siegeszeichen“, „Die Vase“, oder in der Porzellansammlung, wie 1944 „Serienporzellan aus Küche, Keller, Kantine und Kaserne“. Bei seiner Arbeit im Kunstgewerbemuseum nahm ihm $>$ Reinhard Schmelzer zahlreiche Aufgaben ab, während ihn $>$ Rolf Hetsch, 1938 für Porzellangalerie und Münzkabinett eingestellt, durch seine häufige Abwesenheit kaum unterstützte. Trotz der Mehrbelastung durch

\footnotetext{
2 In den Personalakten in Dresden ist keine exakte Datierung überliefert. Nach 1945 gab Fichtner in diversen Meldebögen abweichende Zeiten an (1924-1926 bzw. 1925-1928), die nicht nachgewiesen sind und im Zusammenhang mit seinen anderen Tätigkeiten wenig glaubhaft erscheinen.

3 Nationalsozialistischer Lehrerbund Deutschland/Sachsen 1933, S. 132.

4 Vgl. Fichtner, Protokoll einer Beratung, 16.4.1940, SKD Archiv, 01/PS 43, Bd. 3, fol. $81 \mathrm{f}$.

5 Fichtner an das SMV, 30.12.1939, SKD Archiv, 01/PS 43, Bd. 1, fol. 36-39, hier: 37.

6 Vgl. Protokoll der Beratung, SMV, 23.1.1939, SKD Archiv, 01/PS 43, Bd. 2, Bl. 91-96. Siehe S. 101.
} 
die Arbeit in seiner Dreifach-Funktion - als Referent im Ministerium und Leiter bzw. Direktor zweier Museen (womit er sich quasi selbst beaufsichtigte) - absolvierte Fichtner Nachtwachen im Museum und inspizierte regelmäßig die einzelnen Sammlungen. Bei personellen Engpässen übernahm er kurzzeitig die Vertretung anderer Direktoren. So war Fichtner im August 1940 auch für das Münzkabinett, das Historische Museum, das Grüne Gewölbe, die Skulpturensammlung und den Mathematisch-Physikalischen Salon verantwortlich, in der Summe für sieben Sammlungen, wobei er die kommissarische Leitung des Mathematisch-Physikalischen Salons erst Ende 1942 an - Alfred Beck abgab. ${ }^{7}$ Selbst nach der Einberufung zum Militärdienst als Kriegsverwaltungsrat beim Heeresmuseum Dresden zum 1. Dezember 1941 führte Fichtner all seine Aufgaben weiter. Nachdem er 1942 mit der Leitung der Bergungsmaßnahmen der Staatlichen Sammlungen beauftragt worden war, bereiste er die Bergungsdepots zur Revision.

Bei den Luftangriffen auf Dresden am 13./14. Februar 1945 war Fichtners Wohnung und Elternhaus zerstört worden. Seine Frau, Johanne Paula, geb. Lomatzsch, die er im September 1938 geheiratet hatte, zog zu ihren Eltern nach Dorfchemnitz, wo sie im Mai 1945 starb, während er seine Aufgaben in Dresden weiter erfüllte. Doch unmittelbar bei Kriegsende, am 8. Mai 1945, verließ Fichtner Sachsen, da er befürchtete, aufgrund seiner NSDAP-Mitgliedschaft und Tätigkeit im „Dritten Reich“ zur Verantwortung gezogen zu werden. Er ging nach Bayern, woher seine Vorfahren stammten und wohin er persönlich durch seine Arbeit für die Deutsche Keramische Gesellschaft gute Kontakte hatte. Ab 15. Mai 1945 wohnte er in Coburg. ${ }^{8}$ Dort wurde er im Rahmen der Entnazifizierung im März 1948 von der Spruchkammer Coburg-Stadt als „Mitläufer“ eingestuft. Als „Sühnemaßnahme“ hatte er „eine Geldsühne von je RM 50.00 zu zahlen“ oder „für je RM 10.00 ein Tag [sic!] Arbeit abzuleisten “9 . Damit galt er als rehabilitiert. Ab Dezember 1946 wohnte er zeitweise im Pfarrhaus in Lettenreuth im Kreis Lichtenfels. Ab Mai 1947 erarbeitete Fichtner im Auftrag des Bamberger Erzbischofs Josef Otto Kolb einen „Realschematismus des Erzbistums Bamberg" und wurde in dieser Zeit im Priesterseminar der Erzdiözese als Gast aufgenommen. ${ }^{10}$ Ab Wintersemester 1948/49 übernahm Fichtner zusätzlich einen Lehrauftrag für Kirchliche Archäologie und Denkmalpflege an der Universität in Erlangen. In den Folgejahren lehrte er an der Theologischen Fakultät, wofür er sich im April 1951 an die Universität Erlangen umhabilitierte und dort anschließend zum Privatdozenten und außerplanmäßigen Professor für Christliche Archäologie und Kirchliche Kunst ernannt wurde. Erst 1951 zog Fichtner nach Erlan-

7 Vgl. Fichtner, Bericht über Dienstaufsicht, 8.1940, SKD Archiv, 01/PS 53, Bd. 1, fol. 209 u. Leiter SMV an Beck, 9.12.1942, SKD, MPS, 1942, E.-Reg. 265.

8 Laut Auskunft von Laura Hamberger, Stadt Coburg, Stadtarchiv, vom 27.8.2019. Dass Fichtner vor der Ankunft in Coburg in Kriegsgefangenschaft war, wie ein Brief des Rektorates der Universität Erlangen erwähnt, konnte bisher nicht nachgewiesen werden. Möglicherweise beruht diese Aussage auf einer Fehlinformation, mit Hilfe derer Fichtner seine Integrität demonstrieren wollte. Vgl. Rektorat der Universität Erlangen, Regierungsrat Panzer, 8.11.1952, Friedrich-Alexander-Universität Erlangen-Nürnberg, Universitätsarchiv Erlangen, F2/1 Nr. 2245a, o. Pag.

9 Spruchkammer Coburg-Stadt, Aktenzeichen K III 453 - R II 364/48, beglaubigte Abschrift, 11.3.1948, BayHStA, MK 43591, o. Pag.

10 Vgl. Archiv des Erzbistums Bamberg, Rep. 4/3 Nr. 105; Erzbischof Dr. Josef Schneider: Vorwort, in: Erzbischöfliches Ordinariat Bamberg (Hg.): Realschematismus des Erzbistums Bamberg, Bd. 1, Bamberg 1960, S. V; Amtsblatt der Erzdiözese Bamberg, Jg. 70, H. 10, 1947, 4.5.1947, S. 69; Amtsblatt der Erzdiözese Bamberg, Jg. 78, H. 13, 1955, 2.6.1955, S. 125. Für diese Informationen dankt die Autorin Andreas Hölscher, Archivar des Erzbistums Bamberg. 
gen um. Ab Herbst 1950 nahm er zusätzlich einen Lehrauftrag an der Philosophisch-Theologischen Hochschule Bamberg wahr, der infolge von Etatkürzungen im Herbst 1954 nicht mehr verlängert wurde. ${ }^{11}$ Doch bereits wenige Monate später erhielt Fichtner an der Universität Erlangen eine der extra „für heimatvertriebene und amtsverdrängte Hochschullehrer"12 geschaffenen Stellen und wurde im Juni 1955 zum ordentlichen Professor ernannt. Zu diesem Zeitpunkt übergab er das Buchprojekt für die Erzdiözese unvollendet an einen weiteren Bearbeiter. Wenige Monate später, im Dezember 1955, heiratete Fichtner in Erlangen in zweiter Ehe die verwitwete Ruth Richter, geb. Jühling, die in die Ehe drei Kinder mitbrachte. Nach seiner regulären Emeritierung Ende Juni 1958 übernahm er noch bis 1961 die kommissarische Vertretung des Lehrstuhls. Diese zweite akademische Karriere war möglich, da Fichtner selbst aktiv zur Verunklärung seiner früheren Tätigkeit in Dresden beigetragen hatte. So beantwortete er die Frage, ob er Vorteile durch die NSDAP-Mitgliedschaft gehabt habe, 1950 in einem Meldebogen mit „nein“ und behauptete „im Gegenteil dauernde Nachteile“13, obwohl er seine Karriere vor 1945 vor allem seiner Parteimitgliedschaft verdankte und mehrfach uk-gestellt worden war. Seinen falschen Behauptungen folgend, berichtete der Dekan der Theologischen Fakultät der Universität Erlangen später: „Als er die Sixtinische Madonna in einen Betonbunker nach Bayern (Kronach) überführen wollte, geriet er in Konflikt mit dem Reichsstatthalter [...]. Er verlor deshalb 1944 seine bisherigen Amtsfunktionen und zog sich auf sein akademisches Lehramt zurück. "14 Doch Fichtner hatte sich weder um eine solche Überführung des Raffael-Gemäldes bemüht, noch war er 1944 entlassen worden. Im Gegenteil, bis Mai 1945 war er in Sachsen als zweifacher Museumsdirektor und Kriegsverwaltungsrat eng in das nationalsozialistische Verwaltungssystem eingebunden. Dieses weitverzweigte Netzwerk nutzte er nach 1945 erfolgreich, um nach seiner Flucht nach Bayern seinen früheren Lebenslauf so anzupassen, dass er als „ostzonaler Flüchtling "15 galt, der Wohnung, Ehefrau und Arbeit im Zweiten Weltkrieg verloren hatte, wie es Briefe von Oscar Reuther und Hans Lehmann, zwei Bekannten aus seiner Dresdener Zeit, belegen. ${ }^{16}$ Als Fritz Fichtner am 9. September 1969 in Erlangen starb, feierte ihn die Presse als Helden, denn die „Nachwelt verdankt seinen weitschauenden Maßnahmen [...] die Rettung unersetzlicher Kulturschätze“"17.

\section{Auswablbibliografie}

Die Dresdner Bildhauerschule des 16. und beginnenden 17. Jahrhunderts (Die Walther), (Leipzig, Univ., Diss., 1921).

Chinesische Sung-Seladone in Ägypten und ihre Nachbildungen in Fustât, Ostasiatische Zeitschrift, N. F. 6, H. 2, 1930, S. 74-86.

11 Im Sommer 1951 musste er die Lehrtätigkeit aufgrund einer Operation unterbrechen. Seine Lehrveranstaltungen sind im Vorlesungsverzeichnis aufgeführt, wurden jedoch nicht vergütet.

12 Bayerisches Staatsministerium für Unterricht und Kultus an den Evang.-Luth. Landeskirchenrat München, 8.1954, BayHStA, MK 78130, o. Pag.

13 Fichtner, Meldebogen, 1.12.1950, BayHStA, MK 43591, o. Pag.

14 Dekan der Theologischen Fakultät an das Bayerische Staatsministerium für Unterricht und Kultus, 31.7.1954, BayHStA, MK 78130, o. Pag.

15 Meldebogen Fichtner, 1952, BayHStA, MK 43591, o. Pag.

16 Vgl. Reuther, 16.1.1953 u. Lehmann, 15.1.1953, beide: ebd.

17 Prof. D. Fichtner verstorben. Forschung, Lehre und Ethos, in: Erlanger Volksblatt 11.9.1969, Stadtarchiv Erlangen, III.115.F.1. Fichtner war nicht allein für die Rettung der Dresdener Kunstschätze verantwortlich - siehe S. 147-160. 
Wandmalereien der Athos-Klöster. Grundsätzliches zu den Planungen der Bildfolgen des 14.17. Jahrhunderts. Welt- und Lebensanschauung, Ritus, Architektur, Malerei, Berlin 1931.

Die Bedeutung E. Zimmermanns für die Chinaforschung und die Ostasiat. Abt. der Staatl. Porzellansammlung Dresden, in: Ostasiatische Zeitschrift, 22, 1936, S. 195 f.

Chinesische Porzellane aus der Provinz Fukien unter europäischem Einfluß, in: Keramische Rundschau, 45, 1937, Nr. 4, S. 33-35 und Nr. 5, S. 47-50.

Der Einfluß Ostasiens auf die Keramik Europas, in: Berichte der Deutschen Keramischen Gesellschaft e. V., 19. Jg., 1938, S. 65-84.

Von der kurfürstlichen Kunstkammer zur Porzellangalerie Zwinger. Das Schicksal der Dresdner Porzellanschätze, in: Berichte der Deutschen Keramischen Gesellschaft e. V., 20. Jg., H. 7 , 1941, S. 293-309.

Meißner Porzellan für Polen und Rußland, in: Berichte der Deutschen Keramischen Gesellschaft e. V., 21. Jg., H. 12, 1941, S. 487-520.

Die Blütezeit der türkischen Fliese, in: Berichte der Deutschen Keramischen Gesellschaft e. V., 24. Jg., 1943, H. 6/7, S. 173-200 und H. 8/9, S. 237-263.

Deutsche Porzellankunst der Zukunft, Berichte der Deutschen Keramischen Gesellschaft e. V., 25. Jg., 1944, S. 159-173.

\section{Quellen und Literatur}

HStA Dresden, 13859, Nr. 1553; Nr. 1960

BayHStA, MK 43491; MK 78130

Stadtarchiv Erlangen, III.115.F.1; 258.A.113

Friedrich-Alexander-Universität Erlangen, Universitätsarchiv, F2/1 Nr. 2245a

Friedrich-Alexander-Universität Erlangen, Universitätsbibliothek, Personen- und Vorlesungsverzeichnisse 1949-1961

Otto-Friedrich-Universität Bamberg, Universitätsarchiv, V B 511; V B 512; V B 513; V K 21; V A 341; V A 343

Otto-Friedrich-Universität Bamberg, Universitätsarchiv, Vorlesungsverzeichnisse 1945-1954

BArch, R 9361-IX/Kartei/8641222

Landeshauptstadt Dresden, Stadtarchiv Dresden, Personenstandsregister, Sign. 6.4.25

Stadtarchiv Erlangen, Historische Meldekartei und Sterberegister Nr. 1168/1969

Poscharsky, Peter: Die Geschichte des Seminars für christliche Archäologie und Kunstgeschichte der theologischen Fakultät der Friederich-Alexander-Universität Erlangen-Nürnberg und die Behandlung der christlichen Archäologie und des Kirchenbaues der Gegenwart an den übrigen evangelisch-theologischen Fakultäten in Deutschland, Erlangen 1965.

Poscharsky, Peter: In memoriam Fritz Fichtner, in: Kirche und Kunst, 47, 1969, S. 58 f.

Wittern, Renate und Friedrich-Alexander-Universität Erlangen-Nürnberg (Hg.): Die Professoren und Dozenten der Friedrich-Alexander-Universität 1743-1960. Teil 1: Theologische Fakultät, Juristische Fakultät, Erlanger Forschungen, Sonderreihe (5), Erlangen 1993, http:// nbn-resolving.de/urn:nbn:de:bvb:29-opus-20866, Zugriff: 2.1.2020.

Petschel, Dorit: 175 Jahre TU Dresden. Band 3: Die Professoren der TU Dresden 1828-2003. Hrsg. im Auftrag der Gesellschaft von Freunden und Förderern der TU Dresden e. V. von Reiner Pommerin, Köln u. a. 2003, S. 209.

Heid, Stefan: Paul Fritz Fichtner. In: Heid, Stefan u. Martin Dennert (Hg.): Personenlexikon zur Christlichen Archäologie. Forscher und Persönlichkeiten vom 16. bis zum 21. Jahrhundert, Bd. 1, Regensburg 2012, S. 493 f. 


\section{Otto Fiebiger}

18.1.1869 Leipzig - 23.1.1946 Dresden

Philologe, Wissenschaftlicher Bibliothekar

Sächsische Landesbibliothek

(bis 1.5.1917 Königliche Öffentliche Bibliothek,

2.5.1917-11.1918 Königliche Landesbibliothek)
1.5.1895-31.3.1896 Volontär
1.4.1896-31.12.1897 Wissenschaftlicher Hilfsarbeiter
1.1.1898-31.12.1907 Kustos
1.1.1908-31.10.1921 Bibliothekar

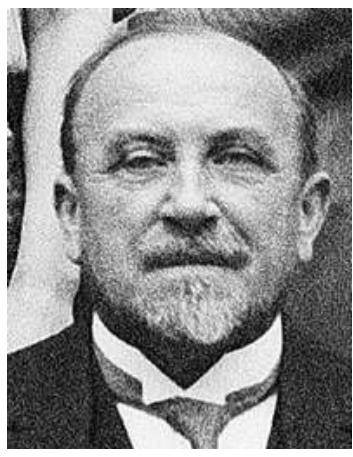

1.11.1921-31.12.1925 Landesbibliothekar

1.1.1926-31.12.1933 Oberbibliothekar, Stellvertretender Direktor

Heinrich Otto Fiebiger wurde am 18. Januar 1869 als Sohn des Rechtsanwaltes und Bankdirektors Gustav Reinhold Otto Fiebiger und dessen Ehefrau Bertha Agnes, geb. Hagsphil, in Leipzig geboren. Nachdem er sein Abitur an der Thomasschule abgelegt hatte, studierte er in München und Leipzig Klassische Philologie und Alte Geschichte. Während des Studiums leistete er seinen Militärdienst als Einjährig-Freiwilliger ab. 1893 wurde Fiebiger in Leipzig promoviert, ein Jahr danach legte er die Prüfung für das Lehramt an Höheren Schulen ab. Nach einer halbjährigen Studienreise durch Italien und Griechenland begann er Ostern 1895 seinen Probedienst am Gymnasium Dresden-Neustadt, den er jedoch bereits nach kurzer Zeit aufgab, um in den Bibliotheksdienst zu wechseln.

Zum 1. Mai 1895 begann Fiebiger seinen Dienst als Volontär an der Königlichen Öffentlichen Bibliothek in Dresden, noch unter dem Direktor Franz Schnorr von Carolsfeld. Bereits ein Jahr später wurde er zum Wissenschaftlichen Hilfsarbeiter ernannt und bekam zum Jahresbeginn 1898 den Titel Kustos verliehen. 1897 heiratete er Antonie Elisabeth, geb. Nake, mit der er zwei Kinder hatte. 1908 wurde Fiebiger zum Bibliothekar befördert. Zum 1. November 1921 wurde er zum Landesbibliothekar und zum Jahresbeginn 1926 zum Oberbibliothekar und damit zum Stellvertretenden Direktor berufen. Fiebiger arbeitete hauptsächlich für die Handschriftensammlung. Daneben war er wissenschaftlich tätig, vor allem auf literaturwissenschaftlichem und historischem Gebiet. Gemeinsam mit seinem älteren Kollegen Ludwig Schmidt gab er ab 1917 die „Inschriftensammlung zur Geschichte der Ostgermanen“ heraus. Für seine Verdienste erhielt er 1916 das Ritterkreuz Erster Klasse des Albrechtsordens und wurde zum 2. April 1919 zum Professor ernannt. Fiebiger war von 1920 bis 1930 Mitglied der Deutschnationalen Volkspartei, in die NSDAP trat er nicht ein. Im September 1933 reichte er sein Rücktrittsgesuch ein, um mit Erreichen der Altersgrenze in den Ruhestand zu treten. Zum Jahresende 1933 wurde er nach fast vier Jahrzehnten im Bibliotheksdienst pensioniert.

Danach setzte er seine Publikationstätigkeit fort. In Anerkennung seiner wissenschaftlichen Leistungen nahm das Archäologische Institut des Deutschen Reiches Fiebiger 1940 als Ordentliches Mitglied auf. Am 23. Januar 1946 starb Otto Fiebiger in Dresden. 


\section{Auswahlbibliografie}

De classium Italicarum historia et institutis quaestiones selectae, Leipziger Studien zur classischen Philologie, 15,3, 1894 (Zugl. Leipzig, Univ., Diss., 1893).

Unedierte Inschriften aus dem römischen Afrika, in: Jahreshefte des Österreichischen Archäologischen Institutes in Wien/Österreichisches Archäologisches Institut, Wien, Bd. 5, 1902, 2, S. 42-52.

Johann Gottlieb Fichtes kritische Pläne während der Jahre 1799-1801, Leipzig 1909.

K. Schinkels Beziehungen zu Dresden, in: Dresdner Geschichtsblätter, 19, 1910, S. 97-102.

Johann Friedrich August Tischbein und August Wilhelm Schlegel, in: Die Grenzboten. Zeitschrift für Politik, Literatur und Kunst, Bd. 76, 1917, S. 302-313.

Inschriftensammlung zur Geschichte der Ostgermanen; Bd. 1 u. 2, Denkschriften. Akademie der Wissenschaften, Philosophisch-Historische Klasse, Wien 1917, 1939 u. 1944 (mit Ludwig Schmidt).

Dreizehn Briefe Wielands, zumeist an Luise von Goechhausen, in: Jahrbuch der Goethegesellschaft, 11, 1925, S. 253-297.

Moritz v. Schwind und E. Rietschel, in: Münchner Jahrbuch der bildenden Kunst, N. F. 6, 1929, S. $282-287$.

Ludwig Tieck und Ida von Lüttichau in ihren Briefen, Dresden 1937.

Aus unbekannten Briefen Ida von Lüttichaus an Friedrich von Raumer, Dresden 1941.

\section{Quellen und Literatur}

SLUB, PA Fiebiger, Otto

SLUB, Mscr.Dresd.App.1378.b,22, 33, 33a

SLUB, Mscr.Dresd.App.1681-1683

Otto Fiebigers Abschied von der Landesbibliothek, Dresden, 20. Januar 1934

Hohe Auszeichnung für Professor Fiebiger, in: Dresdner Anzeiger, 11.12.1940, S. 9.

Habermann, Alexandra, Klemmt, Rainer u. Frauke Siefkes: Lexikon Deutscher Wissenschaftlicher Bibliothekare 1925-1980, Frankfurt a. M. 1985, S. 77.

Bürger, Thomas u. Konstantin Hermann (Hg.): Das ABC der SLUB. Lexikon der Sächsischen Landesbibliothek - Staats- und Universitätsbibliothek Dresden, Dresden 2006.

Hermann, Konstantin: Fiebiger, Heinrich Otto, in: Sächsische Biografie, 2009, Online-Ausgabe: http://saebi.isgv.de/biografie/Otto_Fiebiger_(1869-1946), Zugriff: 2.1.2020. 


\section{WALTHER FisCher}

16.6.1897 Rochlitz - 15.2.1979 Nürnberg

Mineraloge, Ingenieur

Museum für Mineralogie, Geologie und Vorgeschichte

(ab 1.4.1938: Museum für Mineralogie und Geologie)

1.10.1925-31.12.1929 Wissenschaftlicher Hilfsarbeiter

1.1.1930-6.4.1943 Kustos

7.4.1943-31.3.1946 Kustos, Kommissarischer Leiter

1.4.1946-31.7.1946 Direktor

Mathematisch-Physikalischer Salon

7.6.1943-31.7.1946 Kommissarischer Leiter

Museen für Tierkunde, Rassenkunde und Völkerkunde

8.9.1944-31.7.1946 Leiter

Zentralkanzlei der Sammlungen

14.10.1945-31.7.1946 Leiter

Am 16. Juni 1897 wurde Carl Walther Fischer in Rochlitz als Sohn des Stadtaktuars Robert Richard Fischer und seiner Ehefrau Ida, geb. Kirsten, geboren. 1903 in Rochlitz eingeschult, lernte er ab 1910 an der Fürsten- und Landesschule Grimma. Bereits als Schüler interessierte er sich für naturwissenschaftliche Themen und korrespondierte mit Ernst Haeckel und Wilhelm Ostwald. In den Ferien 1914 absolvierte er eine Ausbildung zum Krankenträger und -pfleger beim Roten Kreuz. Nach dem Notabitur im Juni 1915 meldete er sich als Freiwilliger an die Front. Im August 1918 kam er an der Westfront in französische Kriegsgefangenschaft, aus der er erst im Februar 1920 zurückkehrte. Ursprünglich 1916 an der Technischen Hochschule in Dresden eingeschrieben, studierte Fischer dort erst ab 1920 Chemie bei Fritz Foerster sowie Mineralogie und Geologie bei $\gg$ Eberhard Rimann. Nach der Chemie-Diplomprüfung arbeitete Fischer ab Oktober 1923 als Assistent am Institut für Mineralogie und Geologie, wo er im März 1925 bei Rimann promoviert wurde.

Wenige Monate später, im Oktober 1925, wurde Fischer Wissenschaftlicher Hilfsarbeiter am Museum für Mineralogie, Geologie und Vorgeschichte in Dresden, das sein Doktorvater im Nebenamt leitete. Fischer übernahm die mineralogisch-petrografische Sammlung, führte den Mineralienkatalog fort und erstellte einen Fundortkatalog. Außerdem verwaltete er die Museumsbibliothek. An der Seite seines Kollegen $>$ Karl Wanderer, eines der besten geowissenschaftlichen Ausstellungsgestalter jener Zeit, sammelte er erste museologische Erfahrungen. Für die Jubiläums-Gartenbau-Ausstellung in Dresden 1926 bereitete Fischer den Teil „Verwitterung und Bodenkunde" vor. Anfang April 1930 wurde die von Fischer nach modernen Grundsätzen und chemischen Gesichtspunkten neu geordnete Mineralien-Schausammlung unter dem Titel „Bildung und wirtschaftliche Bedeutung der Mineralien“ eröffnet. Erst wenige Monate vorher, zum 1. Januar 1930, war er zum Kustos ernannt worden. Fischer wirkte an mehreren großen Ausstellungsprojekten in Dresden mit, unter anderem erarbeitete er 1932 „Goethes geologische Beziehungen zu Sachsen“ für die Goethe-Ausstellung des Kunstvereins und 1933 „Die mineralogische Durchforschung Sachsens“ für „August der Starke und seine Zeit“. Für die im Sommer 1936 im Dresdner Residenzschloss gezeigte Schau „Sächsisches Edelgestein“ schuf er die Bereiche zu Edelsteinvorkommen und -gewinnung in Sachsen sowie über den Mineralogen Abraham Gottlob Werner. Gemeinsam mit $\gg$ Walter Häntzschel kuratierte Fischer 1939 die Ausstellung „Minera- 
lien und Fossilien aus dem Sudetengau“. Um die jeweiligen Themen einer breiten Öffentlichkeit zu erschließen, publizierte er parallel zu den Ausstellungen kürzere Texte in den Tageszeitungen. Aus Anlass des 200-jährigen Bestehens des Museums verfasste er eine Museumsgeschichte, die allerdings erst 1939 erscheinen konnte. Aus der intensiven Beschäftigung mit der Geschichte des Dresdner Museums und der Mineralogie verfasste er Denkschriften, die er 1935 und 1940 an das Ministerium für Volksbildung übergab, worin er Vorschläge für die zukünftige Unterbringung und Gestaltung des Museums unterbreitete. Im Februar 1944 beantragte er eine Umbenennung in Agricola-Museum, die $>$ Fritz Fichtner als zuständiger Referent zwar befürwortete, Reichsstatthalter Mutschmann jedoch ablehnte. Durch Publikationen und regelmäßige Teilnahmen an wissenschaftlichen Tagungen hatte sich Fischer gut mit seinen Fachkollegen vernetzt. 1942 wurde er zum Vorsitzenden der naturwissenschaftlichen Gesellschaft „Isis“ zu Dresden ernannt, der er seit 1926 angehörte. Aufgrund der Verschlechterung der Gesundheit von Direktor Rimann übernahm Fischer häufiger die Verwaltungsarbeiten am Museum. Daher war für ihn ab November 1940 die Uk-Stellung beantragt worden mit der Begründung, er sei „mit der Vertretung Prof. Rimanns beauftragt und wird dadurch noch besonders benötigt " ${ }^{\text {"1 }}$. So übernahm er gemeinsam mit Häntzschel auch die geologischen Übungen und Exkursionen an der Technischen Hochschule. Da ihn Rimann mehrfach als Nachfolger vorgeschlagen hatte, musste Fischer seine politischen Aktivitäten nachweisen. Als ehemaliges Mitglied der Deutschnationalen Volkspartei war er jedoch nicht in die NSDAP eingetreten. Daher konnte Fischer nicht zum Direktor ernannt werden, sondern wurde stattdessen im April 1943 mit der kommissarischen Leitung des Museums für Mineralogie und Geologie beauftragt und autorisiert, mit „mit der Leitung beauftragt $^{\text {“ }}{ }^{2}$ zu zeichnen. Aufgrund des sich durch Einberufungen zur Wehrmacht weiter reduzierenden Personals in den Staatlichen Sammlungen wurde ihm ab Juni 1943 die kommissarische Leitung des Mathematisch-Physikalischen Salons und ab September 1944 die Leitung der Museen für Tierkunde, Rassenkunde und Völkerkunde übertragen. ${ }^{3}$ Damit war Fischer im letzten Kriegsjahr für drei Museen, deren Auslagerung und Sicherung an diversen Auslagerungsorten verantwortlich. In der Nacht vom 13. Februar 1945 war er zum Luftschutzdienst im Zwinger eingeteilt und erlebte hautnah die Zerstörung der Museumsgebäude und der Innenstadt. An den Aufräumungsarbeiten wenige Tage danach wirkte er ebenso mit wie an der Rückführung der ausgelagerten Bestände nach Kriegsende. Da er kein Mitglied der NSDAP gewesen war, konnte er 1945 zunächst weiterbeschäftigt werden. Im Oktober 1945 wurde Fischer zum Leiter der neu errichteten Kanzlei der Staatlichen Sammlungen ernannt, Anfang November 1945 auch zum Direktor des Museums für Mineralogie und Geologie. Das Amt als Direktor der naturwissenschaftlichen Museen in Dresden, das ihm Anfang April 1946 übertragen wurde, übte Fischer allerdings nur wenige Monate aus, denn am 31. Juli 1946 wurde er entlassen.

In den folgenden zwei Jahren erforschte Fischer als freischaffender Mineraloge und Geologe in Dresden unter anderem den Werkstoff Mineralwolle und die Rohstoffversorgung für die Porzellanherstellung. Im Frühjahr 1947 bewarb er sich erfolglos auf den Lehrstuhl für Mineralogie an der Universität Köln, auch seine Überlegungen, als Mineraloge in Mexiko zu arbeiten, zerschlugen sich.

\footnotetext{
Antrag auf Uk-Stellung Walther Fischer, 12.1940, HStA Dresden, 13843, Nr. 267, fol. 66.

SMV, Fichtner, an Museum für Mineralogie und Geologie, 22.4.1943, ebd., fol. 144.

Vgl. Fischer, Jahresbericht Mathematisch-Physikalischer Salon, 1943, 30.5.1944, HStA Dresden, 11125, Nr. 23053, fol. 99v, 113 u. Reichsstatthalter Sachsen, Landesregierung, i. A. Fichtner an Landeshauptkasse, 8.9.1944, HStA Dresden, 11125, Nr. 22895, fol. 55.
} 
So bewarb er sich um die Direktorenstelle an der Gewerblichen Berufs- und Fachschule Kreis Birkenfeld in Idar-Oberstein. Im Oktober 1948 übersiedelte er mit seiner Frau Margarethe, geb. Herzberg, die er im Mai 1930 geheiratet hatte, und der Tochter nach Idar-Oberstein. Im August 1949 übernahm er zunächst die kommissarische Leitung dieser Fachschule für Edelsteinbearbeitung. Trotz der Belastungen durch den Auf- und Neubau der Schule, veröffentlichte er 1953 eine viel beachtete, als Lehrbuch verwendete „Praktische Edelsteinkunde“. Nach seiner vorzeitigen Pensionierung Ende September 1959 zog Fischer nach Stuttgart, wo er seine wissenschaftliche Tätigkeit fortsetzte, rege publizierte und zu Tagungen reiste. Nach Dresden und an das Museum für Mineralogie und Geologie kehrte er ab 1965 mehrfach besuchsweise zurück. Ende Oktober 1972 übersiedelte er aus familiären Gründen nach Nürnberg. Dort starb Walther Fischer am 15. Februar 1979.

\section{Auswahlbibliografie}

Die Helvinlagerstätte von Casa La Plata. Zur Kenntnis der Konstitution von Helvin und Danalith, in: Centralblatt für Mineralogie, 1926, Abt. A, Stuttgart 1926, S. 33-42 (Zugl. Dresden, TH, Diss., 1925).

Die Mineralien im Syenite des Plauenschen Grundes bei Dresden, in: Festschrift Isis Dresden 1934, S. 126-170.

Die wirtschaftliche Bedeutung des sächsischen Erzbergbaues nach den amtlichen Angaben für die Jahre 1913 bis 1934, in: Sitzungsberichte und Abhandlungen der Naturwissenschaftlichen Gesellschaft Isis Dresden, Jg. 1935, Dresden 1936, S. 97-124.

Mineralogie in Sachsen von Agricola bis Werner. Die ältere Geschichte des Staatlichen Museums für Mineralogie und Geologie zu Dresden (1560-1820), Dresden 1939.

400 Jahre Sächsisches Oberbergamt (1542-1942). Die Bedeutung dieser Dienststelle für die Entwicklung der Geologie und Lagerstättenkunde, in: Zeitschrift der Deutschen Geologischen Gesellschaft, Bd. 95, H. 3, 1943, S. 143-183.

Zum 450. Geburtstag Agricolas, des „Vaters der Mineralogie“ und Pioniers des Berg- und Hüttenwesens, in: Neues Jahrbuch für Mineralogie, Abt. A, Stuttgart 1944, S. 113-225.

Praktische Edelsteinkunde (Opuscula mineralogica et geologica 3), Kettwig/Ruhr 1953.

Die kulturgeschichtliche Bedeutung des sächsischen Bergbaus, in: Jahrbuch zur Pflege der Künste, Bd. 4, 1956, S. 167-186.

Gesteins- und Lagerstättenbildung im Wandel der wissenschaftlichen Anschauung, Stuttgart 1961.

Abbau und Bearbeitung des Porphyrtuffs auf dem Rochlitzer Berge (Sachsen). Gedanken über die Herkunft d. Steinbruchtechnik, in: Abhandlungen des Staatlichen Museums für Mineralogie und Geologie zu Dresden, Bd. 14, 1969, S. 1-110.

\section{Quellen und Literatur}

HStA Dresden, 13859, Nr. 1659

HStA Dresden, 13843, Nr. 267

SKD Archiv, 01/PS 53, Bd. 3

Metz, R.: Walther Fischer zum 75. Geburtstag, in: Aufschluß, Heidelberg, 23, 1972, S. 209-222. Prescher, Hans: Carl Walther Fischer (1897-1979). Mineraloge, Museumsmann, Schuldirektor, Wissenschaftshistoriker, in: Abhandlungen des Staatlichen Museums für Mineralogie und Geologie zu Dresden, Bd. 39, 1993, S. 21-54.

Voss, Waltraud: Fischer, Walther (1897-1979), in: Voss, Waltraud: Von Dresden in die Welt. II. Frühe Promovenden der TU Dresden in Wirtschaft, Wissenschaft und Gesellschaft, Dresden 2010, S. 16-23, 399. 


\section{WALTHER Frieser}

30.3.1887 Hohenkirchen - 18.7.1949 Dresden

Lehrer, Wissenschaftlicher Bibliothekar

Sächsische Landesbibliothek

1.4.1920-21.7.1920 Volontär

1.8.1920-30.9.1920 Wissenschaftlicher Hilfsarbeiter

1.10.1920-31.3.1923 Bibliotheksassistent

1.4.1923-30.4.1944 Landesbibliothekar

1940-30.4.1944 Bibliotheksrat

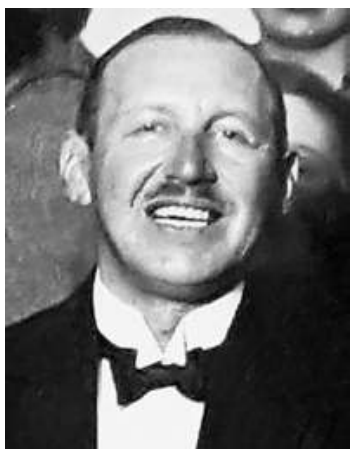

Louis Georg Walther Frieser wurde am 30. März 1887 in Hohenkirchen als Sohn von Hermann Oscar Louis Frieser und dessen Frau Adolphine Hedwig, geb. Sitte, geboren. An der Universität Leipzig studierte Frieser Neue Philologie. 1909 wurde er in Leipzig promoviert. Nach dem Studium war er zunächst als Pädagoge tätig, von 1914 bis 1918 unterrichtete er als Oberlehrer an einer städtischen Realschule, möglicherweise in Dresden, denn dort hatte er im Mai 1912 Helene Charlotte Ella geheiratet.

Ab April 1920 arbeitete Frieser als Volontär an der Sächsischen Landesbibliothek. Wenige Monate später, Anfang August 1920, wurde er als Wissenschaftlicher Hilfsarbeiter eingestellt. Dagegen protestierte $>$ Hermann Neubert, der sich als durch die Kriegsteilnahme Invalidisierter und bereits seit Herbst 1919 an der Landesbibliothek tätiger Volontär benachteiligt sah: „Herr Frieser hatte das Glück während des ganzen Krieges fünf Jahre lang Oberlehrer an einer Städtischen Realschule zu sein. Jetzt hat er alle Beziehungen zur Stadt abgebrochen und volontiert seit vier Monaten an der Landesbibliothek. Meine Tätigkeit dagegen ist seit langem auf den Biblio-

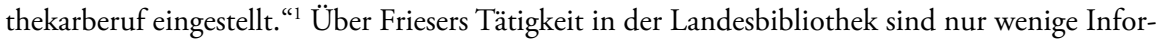
mationen überliefert. Als ehemaliger Lehrer war er Fachreferent für Pädagogik. Im Oktober 1920 wurde er zum Bibliotheksassistenten ernannt, im April 1923 zum Landesbibliothekar. 1940 erfolgte seine Beförderung zum Bibliotheksrat. Zum 1. Mai 1944 wurde er krankheitsbedingt frühzeitig in den Ruhestand versetzt.

Am 18. Juli 1949 starb Walther Frieser an den Folgen eines schweren Skiunfalles in Dresden.

\section{Auswahlbibliografie}

Die Schulen bei Dickens, auf ihre geschichtliche Wahrheit geprüft. Ein Beitrag zur Geschichte der Erziehung in England, Halle a. d. Saale 1909 (Zugl. Leipzig, Univ., Diss., 1909).

Das Sprichwort in den dramatischen Werken John Lyl's, in: Jahrbuch der Philosophischen Fakultät Leipzig, Leipzig 1921.

Die Bibliotheksausgabe des Wöchentlichen Verzeichnisses, in: Börsenblatt für den deutschen Buchhandel, 89, 1922, S. 549 f.

Neubert an SMV, 8.8.1920, SLUB, PA Neubert, o. Pag. 


\section{Quellen und Literatur}

SLUB, PA, Frieser, Walther

HStA Dresden, 11125, Nr. 18959, Bl. 22v

Landeshauptstadt Dresden, Stadtarchiv, Personenstandsregister Sign. 6.4.25

Deckert 1987, S. 104, SLUB, Mscr.Dresd.App.2600,A1

Habermann, Alexandra, Klemmt, Rainer u. Frauke Siefkes: Lexikon Deutscher Wissenschaftlicher Bibliothekare 1925-1980, Frankfurt a. M. 1985, S. 85 f.

Jammers, Antonius: Im Japanischen Palais, wie ein Freiherr ... Erinnerungen meines Vaters Ewald Jammers an seine alte Sächsische Landesbibliothek, in: Bürger, Thomas u. Ekkehard Henschke (Hg.): Bibliotheken führen und entwickeln. Festschrift für Jürgen Hering zum 65. Geburtstag, München 2002, S. 305-317, hier: 312. 


\title{
WALTER GRÜNBERG
}

\author{
2.10.1906 Hammerbrück - 25.7.1943 bei Belgorod \\ Prähistoriker \\ Museum für Mineralogie, Geologie und Vorgeschichte \\ (ab 1.4.1938: Landesmuseum für Vorgeschichte) \\ 10.1937-30.11.1941 Wissenschaftlicher Hilfsarbeiter \\ (Militärdienst 27.5.1940-11.1941)
}

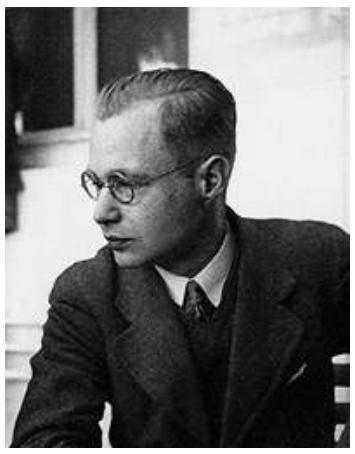

Walter Grünberg wurde am 2. Oktober 1906 in Hammerbrück im Vogtland als Sohn eines Pfarrers geboren. Nachdem er seine Reifeprüfung in Chemnitz abgelegt hatte, begann er in Dresden eine Ausbildung zum Bauingenieur. Doch bereits nach der Diplom-Vorprüfung begann er ein Studium der Baugeschichte und Archäologie in Berlin. 1933 wechselte Grünberg an das Vorgeschichtliche Institut der Universität Marburg, wo er im Januar 1938 bei Gero Merhart von Bernegg promoviert wurde. Schon während des Studiums war er Mitglied des NS-Studentenbundes.

Im Oktober 1937 begann Grünberg seine Tätigkeit als Wissenschaftlicher Hilfsarbeiter bei - Georg Bierbaum in der prähistorischen Abteilung des Museums für Mineralogie, Geologie und Vorgeschichte in Dresden. Diesen kannte er seit seinem Studium, als er 1933, vermittelt durch Merhart, an der Ausgrabung an der Heidenschanze von Dresden-Coschütz unter der Leitung von $>$ Walter Kersten teilnahm. Am 27. Mai 1940 wurde Grünberg zur Wehrmacht eingezogen und nach einer kurzen Ausbildung zum Zollgrenzschutz versetzt, bald aber für die Vorbereitung der Drucklegung seiner Dissertation beurlaubt, die er allerdings erst 1943 publizierte. ${ }^{1}$ Ende November 1941 verließ er Dresden.

Durch Kersten, den er seit 1933 kannte und der mittlerweile das Landesamt für Vorgeschichte im „Reichsgau Wartheland“ in Posen leitete, wurde Grünberg zum 1. Dezember 1941 zum Leiter der Außenstelle Litzmannstadt des Landesamtes ernannt. Zugleich wurde er Kustos am Städtischen Museum für Vorgeschichte in Litzmannstadt. Als Nachfolger von Walter Frenzel, der den Freitod gewählt hatte, war er für die Neuaufstellung des Museums verantwortlich und in die Abgabe der ethnografischen Sammlung involviert. Den ursprünglich vorgesehenen Tausch wandelte Grünberg in einen Verkauf, an dem die Ethnologen Fritz Krause in Leipzig, Franz Termer in Hamburg, Hans Plischke in Göttingen und > Martin Heydrich in Köln beteiligt waren. ${ }^{2}$ Letzteren kannte Grünberg als früheren Dresdner Kollegen. Grünbergs Frau, die er 1937 gehei-

\footnotetext{
1 Vgl. Merhart 1944, S. 129. Unklar bleibt, wann diese Freistellung erfolgte, die wohl durch Ernst Sprockhoff, den Herausgeber der Schriftenreihe, in der die Arbeit erscheinen sollte, beantragt wurde, und wer sich dafür einsetzte, dass sie weiterhin wirksam blieb.

2 Vgl. Herrmann, Beate: Doppelt sensibel. Die Ethnographische Sammlung Łódź als Zeugnis polnisch deutscher Zeitgeschichte, in: Brandstetter, Anna-Maria und Vera Hierholzer (Hg.): Nicht nur Raubkunst! Sensible Dinge in Museen und universitären Sammlungen, Göttingen 2018, S. 93-108, hier: $100 \mathrm{f}$.
} 
ratet hatte, zog mit den beiden Söhnen erst 1942 von Dresden nach Litzmannstadt. Anfang 1943 wurde er wieder zum Militärdienst eingezogen. Nur wenige Monate später, am 25. Juli 1943, ist Walter Grünberg nordöstlich von Belgorod gefallen.

\section{Auswahlbibliografie}

Weitere Burgundenfunde in Bautzen-Seidau, in: Sachsens Vorzeit, Bd. 1, 1937, S. 135-144.

Das reiche Hügelgrab von Stenn bei Zwickau, in: Sachsens Vorzeit, Bd. 2, 1938.

Zwei bronzezeitliche Hortfunde auf Dresdner Flur, in: Sachsens Vorzeit, Bd. 2, 1938, S. 133-139.

Rasiermesser mit Pferdekopf in lausitzischen Gräbern, in: Marburger Studien (Gero Merhart von Bernegg gewidmet), Bd. 70, 76, 1938, S. 70-76.

Frühbronzezeitliche Steinkistengräber von Burk bei Bautzen, in: Sachsens Vorzeit, Bd. 3, 1939, S. $21-51$.

Vorgeschichte des Plauenschen Grundes, in: Häntzschel, Walter: Bilder aus der Erdgeschichte des Plauenschen Grundes, Freital 1939, S. 41-60.

Der Bronzefund von Rackel, Kr. Bautzen, in: Sachsens Vorzeit, Bd. 5, 1941, S. 5-12.

Die bronzezeitlichen Schmuckscheiben Sachsens, in: Sachsens Vorzeit, Bd. 5, 1941, S. 17-25.

Die Grabfunde der Jüngeren und Jüngsten Bronzezeit im Gau Sachsen, Vorgeschichtliche Forschungen, Bd. 13, Berlin 1943 (Zugl. Marburg, Univ., Diss., 1938).

\section{Quellen und Literatur}

Merhart von Bernegg, Gero: Walter Grünberg, in: Posener Jahrbuch für Vorgeschichte, hg. v. Landesamt für Vorgeschichte im Reichsgau Wartheland, 1. Jg., 1944, S. 127-129. 


\section{KLAUs GÜNTHER}

\subsubsection{Berlin - 1.8.1975 Berlin (West) \\ Zoologe, Entomologe \\ Museen für Tierkunde und Völkerkunde \\ (ab 1.1.1942 Museen für Tierkunde, Rassenkunde und \\ Völkerkunde)}

22.3.1934-31.7.1946 Wissenschaftlicher Hilfsarbeiter

8.10.1942-23.8.1944 Kommissarischer Leiter

Münzkabinett

5.9.1942-23.8.1944 „mit Überwachung und Betreuung

der Bestände beauftragt"

(Militärdienst 23.8.1944-9.5.1945)

Klaus Alfred Günther wurde mit seinem Zwillingsbruder Ulrich am 7. Oktober 1907 als Sohn des Landgerichtspräsidenten Alfred Gustav Hermann Günther und dessen Ehefrau Elfriede Clara Adelheid, geb. Volprecht, in Berlin-Wilmersdorf geboren. Als seine Mutter 1911 bei der Geburt eines weiteren Kindes starb, wurde er mit seinen Geschwistern von Verwandten in Freienwalde und später in Cottbus betreut. Nach dem Abitur, das er 1926 am Friedrich-WilhelmGymnasium in Cottbus ablegte, studierte Günther an den Universitäten in München und Berlin Zoologie und Botanik, daneben auch Paläontologie, Geografie, Chemie, Numismatik und Philosophie. Im Juli 1931 wurde er in Berlin bei Carl Zimmer promoviert. Bereits während des Studiums war Günther von April 1929 bis März 1930 als Assistent am Zoologischen Museum der Universität Berlin tätig gewesen, nun arbeitete und forschte er dort bis 1934 freiwillig und unbezahlt weiter. Schon damals war Günther Außerordentliches Mitglied der Gesellschaft Naturforschender Freunde zu Berlin, in deren Sitzungsberichten er mehrfach publizierte. Im September 1933 kontaktierte er $>$ Arnold Jacobi in Dresden. Als dieser ihm mitteilte, dass durch die voraussichtliche Entlassung $>$ Fritz van Emdens eine Stelle neu zu besetzen sei, bewarb sich Günther. Im Dezember 1933 beantragte Jacobi dessen Anstellung, denn „[u]nter den jüngeren Zoologen von entomologischer Arbeitsrichtung empfiehlt er sich einerseits durch tüchtige literarische Leistungen [...], andererseits durch eine vorhandene museale Erfahrung "1. Doch das "Misstrauen der auch in wissenschaftlichen Personalfragen ausschlaggebenden Parteistellen " 2 verzögerte die Einstellung von Günther, der zwar Mitglied des Kampfbundes für deutsche Kultur, nicht aber der NSDAP war.

Erst am 22. März 1934 trat Günther seinen Dienst als Wissenschaftlicher Hilfsarbeiter bei den Museen für Tierkunde und Völkerkunde in Dresden an, als Nachfolger des 1933 aus rassistischen Gründen entlassenen Emden. Primär war Günther für die entomologische Sammlung verantwortlich, publizierte auf diesem Gebiet und nahm regelmäßig an Tagungen und Kongressen teil. Von 1936 bis 1944 gab er die Deutsche Entomologische Zeitschrift „Iris“ heraus. In seinen zahlreichen Führungen und Vorträgen im Museum für Tierkunde widmete er sich neben den Insekten auch den Vögeln, Lurchen und Säugetieren. Beim letzten Vortrag in den Staatli-

Jacobi an SMV, 23.12.1933, HStA Dresden, 13842, Nr. 047, o. Pag. Jacobi an Günther, 18.2.1934, HStA Dresden, 13842, Nr. 114, Bd. 1, o. Pag. 
chen Sammlungen für Kunst und Wissenschaft während des Krieges sprach Günther am 22. September 1944 über den Hamster. ${ }^{3}$ Als Autodidakt referierte und publizierte er ab etwa 1938 auch zu numismatischen Themen. Wohl deshalb sprach $\triangleright$ Hans Kummerlöwe im Oktober 1939 mit ihm über eine mögliche Übernahme der Leitung des Münzkabinetts. Doch Günthers Bewerbung um diese Stelle scheiterte am Widerstand der NSDAP-Gauleitung. Unter Druck gesetzt, beantragte er im Februar 1941 seine Aufnahme in die NSDAP und wurde zum 1. April 1941 Parteimitglied. ${ }^{4}$ Anfang September 1942 wurde Günther dann zusätzlich zu seinen Aufgaben im Museum für Tierkunde „mit der laufenden Überwachung und Betreuung der Bestände des Staatlichen Münzkabinetts"s beauftragt. Im Oktober 1942 hatte er obendrein seinen zur Wehrmacht eingezogenen Vorgesetzten, $>$ Michael Hesch, Direktor der Museen für Tierkunde, Rassenkunde und Völkerkunde, zu vertreten. Damit war Günther in beiden Museen für die Bergungsarbeiten verantwortlich. Nachdem für ihn mehrfach uk-Anträge genehmigt worden waren, zumal er „der einzige Zoologe, der beim Museum für Tierkunde noch vorhanden ist“, sei und bei seiner Einberufung „die ganze wissenschaftliche Arbeit abgebrochen und das Museum geschlossen werden “6 müsste, wurde er Ende Juli 1944 doch für die Wehrmacht „freigegeben“. Kurz darauf, zum 23. August 1944 wurde er einberufen. Seine Aufgaben an den Staatlichen Sammlungen übernahmen Oberkonservator $>$ Robert Reichert und Kustos $\triangleright$ Walter Holzhausen. Nach einer kurzen militärischen Ausbildung in Chemnitz wurde Günther an die Ostfront versetzt. Der Versuch, ihn nach der Zerstörung des Museums für Tierkunde im Oktober 1944 für die Aufräumarbeiten freistellen zu lassen, schlug fehl. Erst nach Kriegsende kam Günther nach Dresden zurück. Die Wohnung der Familie war bei der Bombardierung der Stadt am 13./14. Februar 1945 zerstört worden. Seine Ehefrau, Hildegard Marie Louise, geb. Kaufhold, die er im April 1935 geheiratet hatte, und seine Schwiegermutter fanden eine Notunterkunft im Schloss Weesenstein, wo ein großer Teil der Sammlungen des Museums für Tierkunde geborgen war. Ab Mai 1945 lebte auch Günther dort und wirkte an der Organisation der Objekttransporte nach Dresden und Pillnitz mit. Obwohl ihn $>$ Walther Fischer im August 1945 als „unentbehrlich bei der Bestandsaufnahme der Depots “7 bezeichnet hatte, da er die Bergungsarbeiten der Museen für Tierkunde und Völkerkunde durchgeführt hatte, wurde Günther aufgrund seiner früheren NSDAP-Mitgliedschaft zum 31. Juli 1946 entlassen.

Günther blieb jedoch bis 1948 als Arbeiter auf Schloss Weesenstein. Daneben wirkte er freiberuflich. Auf Empfehlung von Erwin Stresemann kam Günther 1948, vermittelt durch Hans Nachtsheim, als wissenschaftlicher Assistent an das Institut für Genetik der Humboldt-Universität und wechselte mit diesem im April 1949 zur Freien Universität in Berlin-Dahlem. 1950 habilitierte sich Günther dort. Nach einigen Jahren als Privatdozent wurde er im Januar 1960 zum Professor und Mitdirektor des 1. Zoologischen Instituts der Freien Universität ernannt. Nachdem seine Frau Anfang 1969 gestorben war, ließ er sich 1970 vorzeitig pensionieren. Erst nach der Heirat mit seiner zweiten Frau Waltraut, geb. Wolf, die er durch die Arbeit am Genetischen

3 Vgl. Staatliche Museen für Tierkunde, Rassenkunde und Völkerkunde, i. V. Günther, an Reichsstatthalter, Abt. IV/7, 13.4.1944, HStA Dresden, 11125, Nr. 23080, fol. 159.

4 Siehe S. $79 \mathrm{ff}$.

5 SMV an Günther, 5.9.1942, HStA Dresden, 11125, Nr. 22897, fol. 13.

6 Museum für Tierkunde und Völkerkunde, Hesch, an Leiter SMV, 18.6.1941, HStA Dresden, 13859, Nr. 2571, fol. 55.

7 Fischer, Landesverwaltung Sachsen, Inneres und Volksbildung an Grohmann, Kulturabteilung, 3.8.1945, SKD Archiv, 02/VA 162, fol. 1 ff., hier: 2r. 
Institut kannte, gewann er neuen Lebensmut. Nach einer längeren schweren Krankheit starb Klaus Günther am 1. August 1975 in Berlin (West).

\section{Auswahlbibliografie}

Bau und Funktion der Mundwerkzeuge bei Crustaceen aus der Familie der Cymothoidae (Isopoda), in: Zeitschrift für Morphologie und Ökologie der Tiere, 23, 1931, S. 1-79.

Phasmoiden von den Talaud-Inseln und von der Insel Mortal, mit kritischen Bemerkungen über einzelne Arten und einem zoogeographischen Anhang, in: Sitzungsberichte der Gesellschaft Naturforschender Freunde zu Berlin, Jg. 1934, S. 75-94.

Revision der Acrydiinae, I. Sectiones Tripetalocerae, Discotettigiae, Lophotettigiae, in: Mitteilungen aus dem Zoolog. Museum in Berlin, Bd. 23, H. 2, Berlin 1938.

Studien über die Münzporträts der tetrarchischen und constantinischen Kaiser, in: Deutsches Jahrbuch für Numismatik, 1, 1938, S. 23-38.

Versuch einer Erklärung der Incusenform großgriechischer Münzen, in: Deutsches Jahrbuch für Numismatik, 3/4, 1940/1941, S. 53-68 (mit Gerhard Wolff).

Altgriechische Bauerngötter und Hirtengötter (Acheloos, Karneios und Aristaios auf Münzen von Metapont), 1944.

Bericht über die Neuerwerbung dreier entomol. Sammlungen für das Staatl. Museum für Tierkunde zu Dresden, in: Deutsche entomologische Zeitschrift Iris, 1943, S. 3-6.

Byzantinische Kunst, Berlin 1948.

Wunderwelt der Tiefsee, Berlin 1950 (mit Kurt Deckert).

Morphologisch-anatomische und vergleichende ökologische Untersuchungen über die Leistungen des Viszeralapparates bei Tiefseefischen der Gattung Cyclothone (Teleostei, Isospondyli), in: Zeitschrift für Morphologie und Ökologie der Tiere, 42, 1953, S. 1-66 (mit Kurt Deckert).

\section{Quellen und Literatur}

HStA Dresden, 13859, Nr. 2571

HStA Dresden, 11125, Nr. 22897

HStA Dresden, 13842, Nr. 114, Bd. 1

HStA Dresden, 13471, ZB II 3958

SKD Archiv 01/PS 53, Bd. 3

SKD Archiv 02/VA 59, Bd. 2

SKD, MK, 1942-1944

Herter, Konrad u. Hildegard Strübing: In memoriam Klaus Günther, in: Sitzungsberichte der Gesellschaft Naturforschender Freunde zu Berlin, N. F., Bd. 15, Beih., Berlin 1975, S. 4-10. 


\section{Erich Haenel}

22.6.1875 Dresden - 26.12.1940 Dresden

Kunsthistoriker

Historisches Museum

1.6.1903-31.12.1905 Wissenschaftlicher Hilfsarbeiter

1906-31.1.1913 Direktorialassistent

1907-31.1.1913 Leiter

1.2.1913-26.12.1940 Direktor

Grünes Gewölbe

1.4.1924-26.12.1940 Direktor

Münzkabinett

16.6.1937-31.3.1938 Kommissarischer Leiter

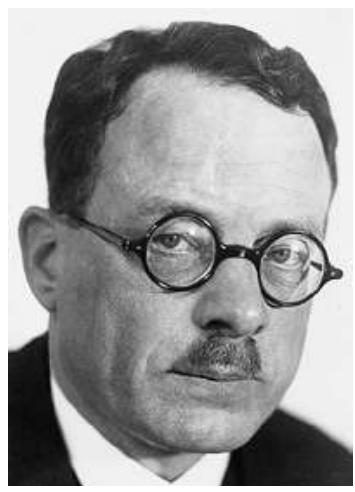

Mathematisch-Physikalischer Salon

1938-26.12.1940 Leiter

Erich Anton Haenel wurde am 22. Juni 1875 in Dresden als Sohn des Augenarztes Georg Friedrich Haenel und dessen Frau Louise Marie Feodore, geb. Linger, geboren. Nach der 1893 am Vitzthumschen Gymnasium in Dresden bestandenen Reifeprüfung studierte er an den Universitäten in Freiburg i. Br. und München Jura. Später wechselte er zu einem Studium der Geschichte, Kunstgeschichte und Archäologie nach Leipzig und Heidelberg. 1898 wurde Haenel bei August Schmarsow in Leipzig promoviert. Anschließend wirkte er als wissenschaftlicher Assistent von Cornelius Gurlitt an der Technischen Hochschule in Dresden an der Inventarisation der sächsischen Bau- und Kunstdenkmäler mit. Ab 1900 unternahm Haenel eine Weltreise, die ihn in die Südsee, nach Amerika und Australien führte. Im australischen Adelaide heiratete er im Januar 1901 Alice, geb. Wendt, Tochter eines Juweliers.

Seine Museumslaufbahn begann Haenel im Juni 1903 als Wissenschaftlicher Hilfsarbeiter am Historischen Museum in Dresden. Bereits nach drei Jahren wurde er zum Direktorialassistenten ernannt und 1907 mit der Leitung des Museums, zu dem Rüstkammer und Gewehrgalerie zählten, beauftragt. Im Februar 1913 wurde er zum Direktor ernannt. Ein reichliches Jahrzehnt später, im April 1924, wurde er in der Nachfolge von Jean Louis Sponsel gleichfalls Direktor des Grünen Gewölbes. Bereits seit 1908 verwaltete er zusätzlich die Bibliothek der Akademie für bildende Künste in Dresden, wo er ab 1913 zum Professor der Kunstgeschichte berufen wurde. Als er sich 1927 aufgrund seiner Aufgaben in den Staatlichen Sammlungen von den Lehrverpflichtungen an der Akademie entbinden ließ, beteiligte er sich jedoch weiterhin an deren Verwaltungsaufgaben. Bis Februar 1932 nahm er an den Sitzungen des Lehrkörpers teil und protokollierte sie. Haenel stand dadurch in engem Kontakt zu Künstlern und Akademieprofessoren wie Robert Sterl, Otto Gussmann, Oskar Kokoschka und Richard Müller, auch entschied er u. a. über die Berufung von Otto Dix mit. Darüber hinaus engagierte sich Haenel im Denkmalrat und im Vorstand des Sächsischen Kunstvereins. Nicht zuletzt dadurch kam es zu einigen Kooperationen zwischen dem Kunstverein und den Staatlichen Sammlungen, wie bei der „Goethe-Ausstellung" 1932. Haenel publizierte rege, gelegentlich schrieb er auch in der Tagespresse über Gegenwartskunst, wobei er konservative Positionen förderte, und Themen aus den Staatlichen Sammlungen. Sein Spezialgebiet war jedoch die historische Waffenkunde. Bereits 1907 hatte Haenel die Herausgeberschaft der „Zeitschrift für historische Waffen- und Kostümkunde“ über- 
nommen, für die er selbst mehr als 40 Beiträge verfasste. Als langjähriges Mitglied des Vereins für Historische Waffenkunde wurde er 1938 zu dessen Vorsitzendem ernannt. Große Verdienste erwarb sich Haenel als Wissenschaftler und Kurator. Die Basis seiner Arbeit bildete eine intensive, quellengestützte stilkritische Forschung. Zwischen 1914 und 1924 verantwortete er eine Neuaufstellung des Historischen Museums, wobei neben den Waffen und Rüstungen auch die Sammlung der Kostüme des 16. bis 18. Jahrhunderts zur Geltung kam. Der Stallhof wurde wiederhergestellt und die Präsentation des Grünen Gewölbes überarbeitet. Dabei verstand es Haenel geschickt, Nachwuchswissenschaftler, wie $>$ Erna von Watzdorf vom Historischen Museum und $>$ Walter Holzhausen vom Grünen Gewölbe, in diese Prozesse einzubinden. Die Sammlungen selbst ergänzte er gezielt durch den Erwerb von Einzelstücken. Aufgrund seines Engagements avancierte das Historische Museum zu einem Zentrum der historischen Waffenforschung mit exzellentem Ruf im In- und Ausland. Haenel wurde in Anerkennung seiner Verdienste 1934 zum Mitglied der Sächsischen Kommission für Geschichte ernannt. Auch das Ausstellungsgeschehen der Staatlichen Sammlungen in den 1930er-Jahren prägte Haenel maßgeblich. Er kuratierte u. a. „Kurfürstin Anna von Sachsen“ (1932), „Heinrich Schütz“ (1935), „Sächsisch-Polnische Kunst“ (1935) und „25 Jahre Ausbau des Historischen Museums. Erwerbungen 1913-1937“ (1937). In Zusammenarbeit mit der Reichstheaterkammer erarbeitete er die „Historische Theaterschau“ (1934). Bei den Ausstellungen „Alte Wehr und altes Heer“ (1938) und "Gewehr und Pistole“ (1940) arbeitete er mit $>$ Ernst von Koerner, dem Leiter des Sächsischen Armeemuseums bzw. Heeresmuseums Dresden, zusammen, der 1927 als Freiwilliger Wissenschaftlicher Hilfsarbeiter im Historischen Museum tätig gewesen war. Die wichtigsten Ausstellungen, die Haenel kuratierte, an denen sich mehrere der Staatlichen Sammlungen beteiligten, waren „August der Starke und seine Zeit“ (1933), und die „Deutsche Turnierschau“ (1936). Letztere war verbunden mit „Turnierspielen“ im Stallhof, die er gemeinsam mit dem Oberspielleiter des Dresdner Staatstheaters, Hans Strohbach, inszenierte. ${ }^{1}$ Von politischen Querelen ließ sich Haenel, der kein Mitglied der NSDAP war, nicht beeindrucken, zumal er in seiner Ausstellungspolitik ns-affin agierte. Auch als er denunziert wurde, er habe $>$ Rudolf Berge „unter Umgehung der Reichsgesetze als Privatperson eingestellt“2, schadete ihm dies nicht und er konnte seine Arbeit fortsetzen. Zusätzlich zu seinen Aufgaben im Grünen Gewölbe und Historischen Museum wurde Haenel von Juni 1937 bis März 1938 die kommissarische Leitung des Münzkabinetts übertragen. Ab 1938 übernahm er auch noch die Leitung des Mathematisch-Physikalischen Salons. Doch bereits ab etwa 1937 verschlechterte sich sein Gesundheitszustand. Häufige Krankmeldungen und mehrfache Klinikaufenthalte führten dazu, dass Holzhausen und Watzdorf seine Aufgaben zunehmend übernahmen und dass im September 1940 seine Versetzung in den Ruhestand geprüft wurde. Unter der Beteiligung von $>$ Fritz Fichtner reichte das Ministerium für Volksbildung im November 1940 einen entsprechenden Antrag bei der Staatskanzlei ein. Darin stand: „Mit Rücksicht auf die Zugehörigkeit Prof. Dr. Haenels zur Demokratischen Partei und am Rotary Club überlasse ich es Ihrer Entschliessung ob Prof. Haenel der Dank des Führers für seinen geleisteten Dienst ausgesprochen werden soll “3. Doch noch bevor diese Entscheidung getroffen und Erich Haenel in den Ruhestand verabschiedet werden konnte, starb er nach 37-jähriger Tätigkeit im Historischen Museum am 26. Dezember 1940 in

Siehe S. 192 f.

2 Gackstatter an Kulturpolitische Abteilung und Abteilung Film, 5.7.1933, HStA Dresden, 11125, Nr. 22882, fol. 21. Siehe S. 135.

3 SMV, Fichtner und Dedering, an Staatskanzlei, HStA Dresden, 11125, Nr. 22884, fol. 59 f. 
Dresden. Bei der Trauerfeier am 2. Januar 1941 sprachen neben dem Sammlungsreferenten Fichtner auch sein Direktorenkollege Koerner sowie der Bildhauer und Akademieprofessor Karl Albiker. Die Nachrufe in der Presse erwähnten Haenel als „Mensch von großem inneren Reichtum “4 und betonten „seine lebhafte Anteilnahme an allen Dingen der deutschen Kultur“"

\section{Auswablbibliografie}

Spätgotik und Renaissance. Ein Beitrag zur Geschichte der deutschen Architektur vornehmlich im 15. Jahrhundert, Stuttgart 1899 (Zugl. Leipzig, Univ., Diss., 1898).

Der sächsischen Kurfürsten Turnierbücher. In ihren hervorragendsten Darstellungen auf $40 \mathrm{Ta}$ feln, Frankfurt a. M. 1910.

Gartenstadt Hellerau. Ein Bericht über den Zweck, die Organisation, die Ansiedelungs-Bedingungen, die bisherigen Erfolge und die Ziele, Hellerau 1912.

Alte Waffen, Berlin 1913.

Zur Geschichte der Dresd. Rüstkammer, in: Zeitschrift für historische Waffen- und Kostümkunde. Organ des Vereins für Historische Waffenkunde, 1920, S. 181-192.

Deutscher Barock in Dresden, Deutsche Baukunst der Vergangenheit, Bd. 1, Dresden 1922.

Ehemaliges Residenzschloss Dresden, Lustschloss Pillnitz, Dresden 1923.

Kostbare Waffen aus der Dresdner Rüstkammer, Leipzig 1923.

August der Starke. Kunst und Kultur des Barock, Dresden 1933 (mit Erna von Watzdorf).

Der alte Stallhof in Dresden 1937.

\section{Quellen und Literatur}

SKD Archiv, 01/PS 53, Bd. 2, fol. 96

HStA Dresden, 11125, Nr. 22884, Bl. 59-60

HfBK Archiv, 01/191

Landeshauptstadt Dresden, Stadtarchiv, Personenstandsregister, Sign. 6.4.25 und Meldekartei, Sign. 15.7.3 und 15.7.4

Professor Erich Haenel 60-jährig, in: Dresdner Anzeiger, 22.6.1935, S. 3.

Post, Paul: Erich Haenel zum Gedächtnis († 26.12.40), in: Zeitschrift für historische Waffenund Kostümkunde. Organ des Vereins für Historische Waffenkunde, Berlin, Bd. 7, 1941, S. $126 \mathrm{ff}$.

Erich Haenel, in: Pantheon. Internationale Jahreszeitschrift für Kunst, München, Bd. 27, H. 3, 1941, S. 72.

Schulze, Friedrich: Erich Haenel †, in: Mitteldeutsche Blätter für Volkskunde, Bd. 16, H. 1, 1941, S. 53.

Watzdorf, Erna von: E. Haenel gestorben, in: Neues Archiv für sächsische Geschichte, 62, 1941, S. 82-85.

Watzdorf, Erna von: Erich Haenel, in: Neue deutsche Biographie, 7, Berlin 1966, S. 441 f.

Abschied von Erich Haenel, in: DNN, 3.1.1941, S. 4.

Professor Erich Haenel †, in: DNN, 28.12.1940, S. 4. 


\section{Max Hahn}

27.7.1883 Oschatz - 14.1.1969 Dresden

Buchbinder, Restaurator

Kupferstich-Kabinett

1.4.1909-31.3.1920 Aufseher

1.4.1920-10.2.1938 Sammlungshandwerksmeister

11.2.1938-16.1.1939 Restauratorengehilfe

17.1.1939-30.6.1950 Restaurator

11.8.1944-5.1945 Depotverantwortlicher

(Militärdienst 1914-1918)

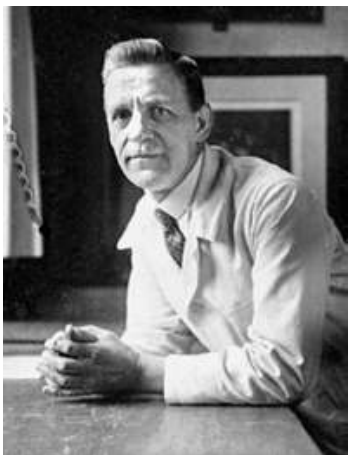

Carl Max Hahn wurde am 27. Juli 1883 in Oschatz als Sohn von August Hahn und Auguste, geb. Buchmann, geboren. Nach dem Besuch der Bürger- und Fortbildungsschule erlernte er den Beruf des Buchbinders, den er zunächst auch ausübte. Von 1903 bis 1906 absolvierte er seinen Militärdienst.

Seine Tätigkeit im Kupferstich-Kabinett in Dresden begann Hahn am 1. April 1909 als Aufseher. Bereits damals führte er zusätzlich Buchbinderarbeiten aus und legte Grafiken auf. Nach seinem Militärdienst im Ersten Weltkrieg kehrte Hahn ans Kupferstich-Kabinett zurück und wurde zum Sammlungshandwerker ernannt. Im Juli 1927 heiratete er, nachdem seine erste Frau, Elfriede Margarethe, geb. Weiske, nach 14 Jahren Ehe 1926 gestorben war, in zweiter Ehe Auguste Ida, geb. Münch. Im Kupferstich-Kabinett führte er vor allem Buchbinderarbeiten aus und unterstützte zunehmend den Restaurator $\triangleright$ Eduard Samtleben. Als dieser im Juli 1937 starb, übernahm Hahn dessen Aufgaben. Allerdings wurde er erst 1938 zum Restauratorengehilfen befördert, 1939 zum Restaurator. Zuvor hatte die Kreisleitung der NSDAP festgestellt: „Seine Einstellung zum heutigen Staat und zur Bewegung ist gut "1. Mit Beginn der Auslagerung der Sammlungsbestände des Kabinetts 1942 war Hahn für „die Verpackung und die Vorbereitung zum Transport des Museumsgutes nach auswärts“2 verantwortlich. Regelmäßig absolvierte er Wachdienste am Hauptauslagerungsort der Sammlung in Weesenstein. Gelegentlich arbeitete er zusätzlich für das Historische Museum. Nachdem auch der letzte noch am Kabinett verbliebene Wissenschaftler, der Wissenschaftliche Hilfsarbeiter $>$ Franz Schubert, Anfang 1944 zum Militärdienst eingezogen worden war, oblagen Hahn alle im Zusammenhang mit dem Kupferstich-Kabinett anfallenden Arbeiten. Am 11. August 1944 benannte ihn $\gg$ Fritz Fichtner deshalb gegenüber dem Reichsstatthalter als „für den sachgemäßen Zustand der Depots verantwort-

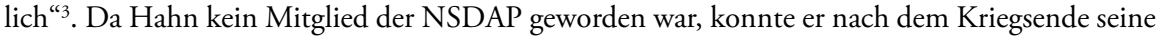
Tätigkeit am Kupferstich-Kabinett fortsetzen. Als er zum 30. Juni 1950, mittlerweile 67-jährig, pensioniert wurde, zog er sein Fazit: „42 Jahre stand ich im Dienste des Staates, 4 verschiedene 
politische [sic!] Richtungen diente ich, und jedem Regime leistete ich Arbeit in gewissenhafter Weise bis zum Tage meines Ausscheidens. " ${ }^{4}$

Max Hahn starb am 14. Januar 1969 in Dresden.

\section{Quellen und Literatur}

HStA Dresden, 13859, Nr. 2687

SKD Archiv, 01/KK 3, Bd. 8; Bd. 9

HStA Dresden, 11125, Nr. 22888

SLUB, Mscr.Dresd.App. 2550

Simon, Olaf: Zur Geschichte der Restaurierung im Kupferstich-Kabinett, in: Dresdener Kunstblätter, H. 1, 2004, S. 47-52, hier: 49.

4 Hahn an Balzer, 5.7.1950, SLUB, Mscr.Dresd.App.2550, fol. 81. 


\section{Peter Halm}

7.11.1900 München - 26.4.1966 München

Kunsthistoriker

Kupferstich-Kabinett

1.9.1927-31.8.1935 Wissenschaftlicher Hilfsarbeiter

(Stipendiat am Kunsthistorischen Institut Florenz

1.10.1930-30.6.1931)

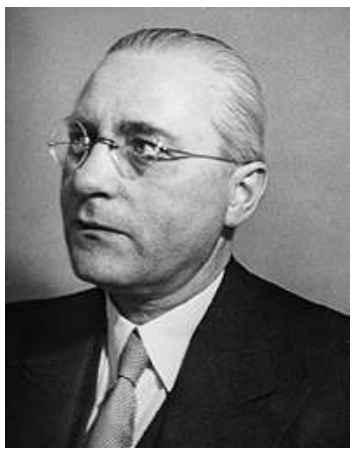

Am 17. November 1900 wurde Peter Halm als Sohn des Generaldirektors des Bayerischen Nationalmuseums Philipp Maria Halm in München geboren, sein Onkel war der Radierer und Münchner Akademieprofessor Peter von Halm. Da Halm seine Schulzeit für den Militärdienst im Ersten Weltkrieg unterbrach, legte er seine Abiturprüfung erst 1920 ab. Anschließend studierte er Kunstgeschichte, Archäologie und Geschichte an der Universität München und in Gastsemestern an den Universitäten in Rostock, Berlin und Wien. 1927 wurde er bei Heinrich Wölfflin in München promoviert.

Ab September 1927 arbeitete Halm als Wissenschaftlicher Hilfsarbeiter am Kupferstich-Kabinett in Dresden. Ausschlaggebend für seinen Wechsel nach Dresden war vermutlich, dass hier Max Lehrs, der nunmehr pensionierte Kabinetts-Direktor, ein Freund der Familie Halm, lebte. Zwei Jahre später, im Dezember 1929, unterstützte ihn Direktor $>$ Kurt Zoege von Manteuffel bei seiner erfolgreichen Bewerbung für ein Stipendium am Kunsthistorischen Institut Florenz. Halm weilte von Oktober 1930 bis Juni 1931 als Reichsstipendiat in Florenz, währenddessen er in Dresden durch $>$ Franz Schubert vertreten wurde. ${ }^{1}$ Ab Juli 1931 setzte Halm seine Tätigkeit in Dresden fort und war unter anderem an der Vorbereitung der Ausstellung „August der Starke und seine Zeit" beteiligt. 1933 kuratierte er gemeinsam mit Zoege von Manteuffel die Schau „Sächsische Zeichnungen aus vier Jahrhunderten“ im Kupferstich-Kabinett, für deren Katalog er einen Text verfasste. Auch rezensierte er Ausstellungen für Dresdner Tageszeitungen.

Nach acht Jahren folgte er im September 1935 dem Ruf als Kurator an die Badische Kunsthalle in Karlsruhe. Im Mai 1939 wechselte er als Konservator an die Bayerischen Staatsgemäldesammlungen in München. Doch bereits am 30. August 1939 wurde Halm zum Militärdienst eingezogen. Mindestens von März 1941 bis Juli 1941 war er in einer Propaganda-Staffel in Südwestfrankreich als Sachbearbeiter für Schrifttum und Kulturfragen eingesetzt. Zu dieser Zeit versuchte das Sächsische Ministerium für Volksbildung, ihn als Leiter des Kupferstich-Kabinetts in Dresden zu gewinnen, denn der plötzlich verstorbene Zoege von Manteuffel hatte ihn bereits früher als einen möglichen Nachfolger vorgeschlagen. ${ }^{2}$ Doch obwohl Halm im Dezember 1942 auf dem ersten Rang der Bewerberliste stand und ihn auch der Berliner Generaldirektor Otto Kümmel für diese Stelle empfahl, ${ }^{3}$ schei-

Vgl. Jahresbericht Kupferstich-Kabinett 1931, HStA Dresden, 11125, Nr. 19003, fol. 12-19, hier: 18. Fichtner, Dienstaufsichtsbericht, 2.1941, SKD Archiv, 01/PS 53, Bd. 1, fol. 182 ff., hier: 182.

Vgl. SMV, Dedering, an RMWEV, Ministerialrat Herrmann, 29.12.1942 u. Generaldirektor Staatliche Museen Berlin, Kümmel, 15.1.1943, Abschrift, HStA Dresden, 11125, Nr. 22896, fol. 67 f., 70. 
terten die Bemühungen. Halm blieb beim Militär, wurde Sonderführer beim Chef der Heeresmuseen und für Kunstschutzaufgaben sowie für die Sammlung erbeuteten Kriegsmaterials zu musealen Ausstellungszwecken eingesetzt, zunächst ab September 1942 im Gebiet der Sowjetunion, ein Jahr später in Italien. Nach der Entlassung aus der Kriegsgefangenschaft im September 1945 kehrte Halm nach München zurück. Im Mai 1948 wurde er zum Direktor der Staatlichen Graphischen Sammlung ernannt, die er bis zu seiner Pensionierung Ende November 1965 leitete. Eine seiner wichtigsten Ausstellungen dort war 1955 „Deutsche Zeichnungen 1400-1900“. Peter Halm starb am 26. April 1966 in München.

\section{Auswahlbibliografie}

Die Landschaftszeichnungen des Wolfgang Huber, 1930 (München, Univ., Diss., 1927).

Das unvollendete Fresko des Filippino Lippi in Poggio a Caiano, in: Mitteilungen des Kunsthistorischen Institutes in Florenz, Bd. 3, Ausg. 7, 1932, S. 393-427.

Sächsische Zeichnungen aus vier Jahrhunderten, Ausstellungskatalog, Dresden 1933 (Hg.).

Altdeutsche Kupferstiche, Frankfurt a. M. 1935.

Das graphische Werk von Carlos Grethe, Karlsruhe 1938.

Zur Geschichte der Graphischen Sammlung, in: Bayerische Kulturpflege. Beiträge zur Geschichte der Schönen Künste in Bayern, München 1949, S. 109-118.

Deutsche Zeichnungen 1400-1900, München 1956.

Deutsche Zeichenkunst der Goethezeit. Handzeichnungen und Aquarelle aus der Sammlung Winterstein, München 1958.

Moritz von Schwind. Jugendgedanken und reifes Werk, in: Ruhmer, Eberhard (Hg.): Festschrift Eberhard Hanfstaegl, München 1961, S. 136-169.

Das Reich der Wissenschaften. Deckengemälde und das Schicksal einer alten kostbaren Bibliothek, Amorbach im Odenwald 1962.

\section{Quellen und Literatur}

SKD Archiv, 01/KK 3, Bd. 8

SMB-ZA, III/VKI 26

BArch, R 9361-II/356280

Military Government of Germany, Fragebogen, Peter Halm, 16.9.1946, in: Ardelia Hall Collection: Munich Administrative, The National Archives, M1946 (NARA M1946), pages 98104, https://www.fold3.com/image/270049172, Zugriff: 2.12.2019.

Ludwig-Maximilians-Universität München: Abgeschlossene Dissertationen am Institut für Kunstgeschichte 1873-2001, online: www.kunstgeschichte.uni-muenchen.de/forschung/ diss_abgeschl/index.html, Zugriff: 2.12.2019.

Immatrikulation von Peter Halm, Universität Rostock, http://matrikel.uni-rostock.de/ id/200018840, Zugriff: 2.12.2019.

Wegner, Wolfgang: Peter Halm †, in: Pantheon. Internationale Zeitschrift für Kunst, 24. Jg., Juli/August, 1966, S. 255-256.

Berndt, Iris: Wissenschaftler für alte deutsche Kunst. Max Lehrs und seine Mitarbeiter, Peter Halm, Werner Schade, in: Dresdener Kunstblätter, 48. Jg., H. 1, 2004, S. 38-41, hier: 40.

Semff, Michael (Hg.): Künstler zeichnen - Sammler stiften. 250 Jahre Staatliche Graphische Sammlung München, Bd. 3, Ostfildern 2008, S. $144 \mathrm{f}$. 


\title{
Anneliese Hanisch (Anneliese Rohne)
}

\author{
16.4.1918 Oschatz - 16.2.2012 Leipzig \\ Kunsthistorikerin \\ Kupferstich-Kabinett
}

12.1943-5.1945 Wissenschaftliche Hilfsarbeiterin

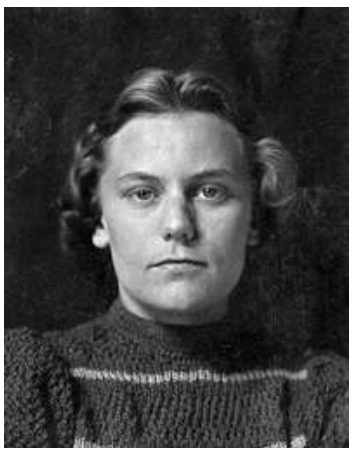

Als Anneliese Margarete Ullrich am 16. April 1918 in Oschatz geboren, lebte sie später, da sie jeweils den Nachnamen ihrer Ehemänner annahm, unter den Namen Gehl, Rohne und Hanisch. ${ }^{1}$ Nach der 1936 in Oschatz bestandenen Abiturprüfung, studierte sie ab 1937 in Leipzig und München Kunstgeschichte, Archäologie und Germanistik. Im August 1943 wurde sie in Leipzig als Schülerin von Theodor Hetzer promoviert, ihre Dissertation veröffentlichte sie als Anneliese Gehl.

Vermutlich bewarb sie sich anschließend um eine Stelle in Dresden, zumindest war sie Galeriedirektor $>$ Hermann Voss bekannt. Dieser schlug dem Sächsischen Ministerium für Volksbildung (SMV) ihre Einstellung vor, als sich abzeichnete, dass die Uk-Stellung des Wissenschaftlichen Hilfsarbeiters des Kupferstich-Kabinetts, $>$ Franz Schubert, nicht verlängert werden würde. Wahrscheinlich wurde sie noch im Dezember 1943 als Wissenschaftliche Hilfsarbeiterin am Kupferstich-Kabinett eingestellt, spätestens jedoch nach Schuberts Einberufung im Januar 1944. Im Februar 1944 meldete sie als Anneliese Rohne der Verwaltung der Staatlichen Sammlungen ihre erneute Verheiratung. ${ }^{2}$ Rohne war in die Bergungsarbeiten und die Bestandskontrollen an den Auslagerungsorten, insbesondere in Weesenstein, involviert. Im September 1944 wies das SMV an, ihr die Kontrollarbeiten in den Bergungsdepots zu übertragen. Nachdem auch noch der Kustos der Gemäldegalerie, \ Robert Oertel, zum Militärdienst eingezogen worden war, war sie ab 23. Oktober 1944 neben Voss die einzige Wissenschaftlerin an Kupferstich-Kabinett und Gemäldegalerie. Auf einer im Februar 1945 korrigierten Liste der für die Kontrolle der Bergungsorte und notwendige Transporte noch verfügbaren Mitarbeiter steht ihr Name, ${ }^{3}$ vermutlich war sie bis Mai 1945 in Dresden tätig.

Nach dem Krieg arbeitete sie als Lehrerin in Oschatz und unterrichtete Kunsterziehung, Zeichnen und Deutsch. Von 1951 bis zu ihrer Pensionierung 1980 war sie Wissenschaftliche Mitarbeiterin, später Kustodin am städtischen Kunstgewerbemuseum/Grassimuseum bzw. Museum des Kunsthandwerks/Grassimuseum in Leipzig, das sie von 1959 bis 1961 leitete. Darüber hinaus lehrte sie an der Universität und der Fachschule für angewandte Kunst in Leipzig sowie an

\footnotetext{
1 Die Autorin dankt Eberhard Patzig, Leiter der Bibliothek und Grafischen Sammlung des Grassi Museums für Angewandte Kunst in Leipzig. Ohne seine Hilfe wäre die Identifizierung der Person nicht möglich gewesen.

2 Vgl. Eintrag 9a/2, Personal Kupferstich-Kabinett, 10.2.1944, HStA Dresden, 11125, Nr. 22875.

3 Vgl. Mitarbeiterliste, undatiert (berichtigt nach dem 13.2.1945), SKD Archiv, 02/VA 166, fol. 1.
} 
der Burg Giebichenstein in Halle. Als Spezialistin für Textil, Zinn und Goldschmiedekunst übernahm sie gelegentlich auch andere Aufgaben, wie 1956 die fachwissenschaftliche Beratung für den Film „Eine geklöppelte Geschichte“ des Regisseurs Hans-Günther Kaden. Als Anneliese Hanisch starb sie am 16. Februar 2012 in Leipzig.

\section{Auswablbibliografie}

(A. Gehl) Die Kapelle des Jagdschlosses Hubertusburg. Ein Beitrag zur Geschichte der sächsischen Bau- und Dekorationskunst im 18. Jahrhundert (Leipzig, Univ., Diss., 1944).

(A. Rohne) Neuerwerbungen 1950-1955. Museum für Kunsthandwerk im Grassimuseum, Leipzig 1955.

(A. Hanisch) Die Klöppelspitze und ihre geschichtliche Entwicklung, Berlin 1959.

(A. Hanisch) Kunsthandwerk und Plastik aus Deutschland im Museum des Kunsthandwerks Leipzig, Leipzig 1961 (Hg.).

(A. Hanisch) Zinn. Aus der Sammlung des Museums, Leipzig 1972.

(A. Hanisch) Kunsthandwerk im Grassimuseum, 17. und 18. Jahrhundert, Schriftenreihe des Museums des Kunsthandwerks Leipzig, Bd. 20, Leipzig 1975 (beteiligt).

(A. Hanisch) Kunsthandwerk im Grassimuseum, Antike bis Renaissance, Schriftenreihe des Museums des Kunsthandwerks Leipzig, Bd. 21, Leipzig 1976 (Redaktion).

(A. Hanisch) Kunsthandwerk im Grassimuseum, Von 1790 bis 1930, Schriftenreihe des Museums des Kunsthandwerks Leipzig, Bd. 25, Leipzig 1980 (beteiligt).

(A. Hanisch) Plastische Stickereien. Aus der Textilsammlung des Museums des Kunsthandwerks Leipzig, Leipzig 1988.

(A. Hanisch) Europäisches Zinn im Museum des Kunsthandwerks Leipzig, Leipzig 1989.

\section{Quellen und Literatur}

HStA Dresden, 11125, Nr. 22889, fol. 142, 152, 153

Grassi Museum für Angewandte Kunst, Leipzig, Personalakte Anneliese Hanisch ${ }^{4}$

E-Mail von Eberhard Patzig, Leiter der Bibliothek und Grafischen Sammlung, Grassi Museum für Angewandte Kunst, an die Autorin, 18.6.2019.

4 Aus Datenschutzgründen war die Einsicht der Personalakte in Leipzig nicht möglich. 


\section{WALTER HÄNTZSCHEL}

16.11.1904 Dresden - 10.5.1972 Hamburg

Geologe, Paläontologe

Museum für Mineralogie und Geologie

24.3.1938-5.1945 Kustos

(Militärdienst 27.4.1942-5.1945)

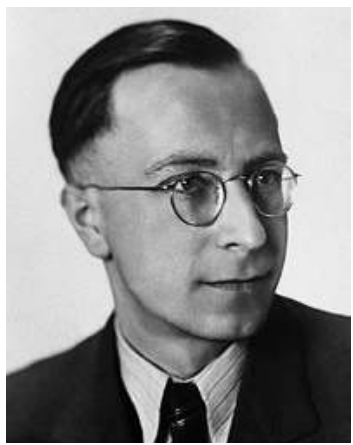

Am 16. November 1904 wurde Walter Helmut Häntzschel als Sohn des Oberlehrers Johannes Theodor Häntzschel und dessen Ehefrau Minna Emilie Henriette, geb. Müller, in Dresden geboren. Nachdem er an der Dreikönigsschule 1924 seine Reifeprüfung abgelegt hatte, studierte er an der mathematisch-naturwissenschaftlichen Abteilung der Technischen Hochschule Dresden Geologie, Mineralogie, Zoologie, Botanik und Chemie. Im Dezember 1929 bestand er das Staatsexamen für das Höhere Lehramt und arbeitete bis 1934 zunächst als Referendar, dann als Studienassessor an der Freiherr von Fletcherschen Aufbauschule und Deutschen Oberschule in Dresden-Neustadt. Parallel wurde er im Dezember 1932 an der Technischen Hochschule Dresden bei $>$ Eberhard Rimann und Hans Gallwitz promoviert. Von 1934 bis 1938 leitete Häntzschel die Forschungsanstalt für Meeresgeologie und Meerespaläontologie der Senckenbergischen Naturforschenden Gesellschaft in Wilhelmshaven, wo er 1936 im Auftrag der Kriegsmarine praktisch-geologische Aufgaben für die Hafenerweiterung übernahm. Im Mai 1936 heiratete er Agnes Marianne, geb. Krauße, die er seit 1928 kannte und mit der er zwei Töchter hatte. Bereits im Oktober 1936 bewarb er sich um die Stelle des bald in den Ruhestand tretenden Kustos -Karl Wanderer am Museum für Mineralogie, Geologie und Vorgeschichte in Dresden. Seine Kontakte zum Museum pflegte Häntzschel seit seiner Studienzeit, in der er dort gelegentlich als freiwillige Hilfskraft tätig war. Nach Wanderers Pensionierung, im April 1937, galt er als Rimann-Schüler trotz dreier Mitbewerber als Favorit.

Doch erst im März 1938 wechselte Häntzschel nach Dresden und wurde zum Kustos am Museum für Mineralogie, Geologie und Vorgeschichte ernannt. Bemerkenswert ist, dass in den Unterlagen zu seiner Ernennung angegeben ist, er sei kein Mitglied der NSDAP, obwohl er bereits im Juli 1937 den Aufnahmeantrag gestellt hatte und rückwirkend zum 1. Mai 1937 in die Partei aufgenommen worden war, die entsprechende Mitgliedskarte wurde am Jahresende 1937 ausgestellt. Der in ähnlichen Fällen vorhandene parteiamtliche Schriftwechsel ist nicht überliefert. Der Fakt, dass ihn Direktor Rimann und Kustos $>$ Walther Fischer bereits seit seiner Studienzeit kannten, hatte sich gewiss bei der Berufung positiv ausgewirkt. In Dresden setzte Häntzschel seine Beschäftigung mit sächsischen Themen wie auch seine meeresgeologische Forschung fort. Einen über das Reichsministerium für Wissenschaft, Erziehung und Volksbildung vermittelten Italienaufenthalt zur Mitarbeit an der Monografie der paläontologischen Funde der Monte Pisani von Alberto Fucini im April 1940 musste er wegen des Todes seines Vaters abbrechen. Aufgrund seiner Aufgaben im Museum konnte Häntzschel zunächst mehrfach vom Militärdienst zurückgestellt werden, da er als einziger Paläontologe am Museum zugleich für dessen Bibliothek zuständig war. Auch hatte er gemeinsam mit Fischer die geologischen Übungen und 
Exkursionen von Rimann an der Technischen Hochschule Dresden übernommen. Doch im April 1942 wurde er zur Wehrmacht eingezogen, wo er als Wehrgeologe tätig war und mehrfach befördert wurde, zuletzt im Juli 1944 zum Leutnant der Reserve. Häntzschel geriet im Mai 1945 in Kriegsgefangenschaft, die er zunächst in Dresden-Reick, später in Tscherepowetz in der Sowjetunion verbrachte. Da er am 8. Mai 1945 aufgrund des Militärdienstes bzw. der Kriegsgefangenschaft nicht im Dienst der Staatlichen Sammlungen stand, galt er nicht mehr als dort eingestellt. ${ }^{1}$

Erst zweieinhalb Jahre nach Kriegsende, im Frühjahr 1948, kehrte Häntzschel nach Dresden zurück. Obwohl sein früherer Kollege Fischer bereits 1945 geäußert hatte, er sei „ein stiller, fleißiger und begabter Wissenschaftler, der nie im politischen Leben hervorgetreten ist ${ }^{\text {" }}$, konnte Häntzschel aufgrund seiner früheren NSDAP-Mitgliedschaft seine Museumstätigkeit in Dresden nicht fortsetzen. Seine Frau verdiente indes mit Näharbeiten und Nachhilfestunden den Familienunterhalt. Ab September 1948 arbeitete Häntzschel für vier Monate als Assistent am Geologisch-Paläontologischen Institut der Universität Halle a. d. Saale bei Gallwitz, seinem früheren akademischen Lehrer. 1949 zog Häntzschel nach Hamburg, wo er fortan am Geologischen Staatsinstitut, dem Geologisch-Paläontologischen Institut der Universität in Hamburg, tätig war. 1955 wurde er in Hamburg zum Abteilungsleiter und Hauptkustos ernannt. Er baute die dortige Institutsbibliothek auf und übernahm in den Folgejahren die Schriftleitung mehrerer Fachzeitschriften. Bereits seit 1926 hatte er zahlreiche Beiträge für das Zentralblatt für Geologie und Paläontologie verfasst. Ab 1962 war Häntzschel zusätzlich Lehrbeauftragter an der Universität Hamburg und wurde 1964 zum Honorarprofessor ernannt. Seine wissenschaftliche Arbeit, die er auch nach seiner Pensionierung im November 1969 fortsetzte, dominierten drei Themengebiete - die Geologie seiner sächsischen Heimat, die Meerespaläontologie und -geologie sowie die Spurenfossilien. Walter Häntzschel starb am 10. Mai 1972 in Hamburg.

\section{Auswahlbibliografie}

Die geschichtliche Entwicklung der Anschauungen über die Hohnsteiner Überschiebung, in: Sitzungsberichte und Abhandlungen der naturwissenschaftlichen Gesellschaft Isis Dresden, Festschrift Richard Baldauf, Dresden 1928, S. 28-36.

Pyrit-Konkretionen im Turon-Quader des Elbsandsteingebirges und ihre Bedeutung für die chemische Verwitterung, in: Mitteilungen aus dem Museum für Mineralogie, Geologie und Vorgeschichte zu Dresden, Bd. 10, 1929.

Das Cenoman und die Plenus-Zone der sudetischen Kreide, Abhandlungen der Preuß. Geol. Landesanst., N. F., 150, Berlin 1933 (Zugl. Dresden, TH, Diss., 1932).

Zur Fauna der Pläner und Konglomerate im Ratssteinbruch Dresden-Dölzschen, in: Sitzungsberichte und Abhandlungen der Naturwissenschaftlichen Gesellschaft Isis, Dresden e. V., Bd. 39, 1938, S. 187-192.

Die Lebensspuren von Corophium volutator (Pallas) und ihre paläontologische Bedeutung, in: Senckenbergiana, 21, Frankfurt a. M. 1939, S. 215-227.

1 Vgl. Kanzlei der Museen, Fischer, an Landesverwaltung Sachsen, Zentralverwaltung für Wissenschaft, Kunst und Erziehung, Grohmann, 24.11.1945, SKD Archiv, 02/VA 162, fol. 40v.

2 Landesverwaltung Sachsen, Inneres und Volksbildung, Abt. Museen, Fischer, an Landesverwaltung, Kulturabteilung, Grohmann, 3.8.1945, ebd., fol. 1 ff., hier: 3r. 
Paläontologische Anmerkungen, in: Fischer, Walther: Mineralogie in Sachsen von Agricola bis Werner, Dresden 1939, S. 261-269.

Mineralien und Fossilien aus dem Sudetengau im Staatlichen Museum für Mineralogie und Geologie zu Dresden, in: Mitteilungen aus dem Staatlichen Museum für Mineralogie und Geologie zu Dresden, N. F. 52, 1939, S. 23-29 (mit Walther Fischer).

Zur jüngsten geologischen Entwicklung der Jade-Bucht. I. Das Alluvium und der vor-alluviale Untergrund im nordöstlichen Stadtgebiet von Wilhelmshaven, in: Senckenbergiana, 23, Frankfurt a. M. 1940, S. 35-48.

Trace fossils and problematica, in: Moore, R. C. (Hg.): Treatise on invertebrate paleontology, Part W, New York 1962, W 177-245.

Vestigia Invertebratorum et problematica, in: Westphal, F. (Hg.): Fossilium catalogus. 1, Animalia, Bd. 108, Den Haag 1965.

\section{Quellen und Literatur}

HStA Dresden, 13859, Nr. 2646

HStA Dresden, 13843, Nr. 267

BArch, R 9361-IX/Kartei/12940872; R 9361-VIII/Kartei/9130370

BArch, R 601/2079

Hertweck, Günther: Walter Häntzschel. 16.11.1904-10.5.1972, in: Paläontologische Zeitschrift, 46, 1972, S. 105-112.

Voss, Waltraud: Häntzschel, Walter (1904-1973), in: Voss, Waltraud: Von Dresden in die Welt. II. Frühe Promovenden der TU Dresden in Wirtschaft, Wissenschaft und Gesellschaft, Dresden 2010, S. 30-40, 400. 


\section{Michael Hesch}

12.9.1893 Waltersdorf/Siebenbürgen - 22.8.1979 Bad

Reichenhall

Ethnologe, Anthropologe

Museen für Tierkunde und Völkerkunde

(ab 1.1.1942 Museen für Tierkunde, Rassenkunde und Völkerkunde)

1.1.1939-31.8.1941 Kustos

6.5.1940-31.8.1941 Kommissarischer Leiter

1.9.1941-5.1945 Direktor

(Beurlaubung an Rasse- und Siedlungshauptamt SS (RuSHA)

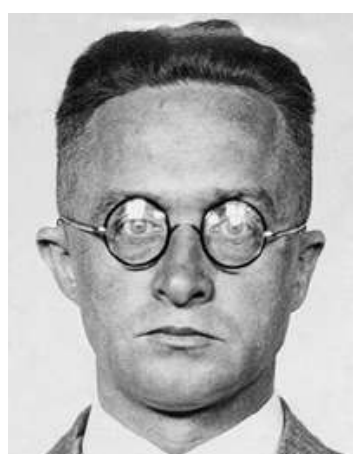

1.1940-5.1940, 1.1941, 5.1941-6.1941; Militärdienst beim RuSHA ab 8.10.1942)

Am 12. September 1893 wurde Michael Hesch in Waltersdorf in Siebenbürgen als Sohn des Bauern Michael Hesch und dessen Frau Maria, geb. Benesch, als ungarischer Staatsbürger geboren. Seine Reifeprüfung bestand er 1912 am deutschen Obergymnasium in Bistritz. Im Anschluss studierte Hesch an den Universitäten in Leipzig, Kiel und Budapest Naturwissenschaften, d.h. Botanik, Zoologie, Mineralogie und Chemie, bevor er 1914 an die Universität nach Wien wechselte. Dort studierte er bei Rudolf Pöch Anthropologie und Ethnografie und führte in einem Kriegsgefangenenlager in Eger anthropologische Untersuchungen durch. 1916 legte er in Budapest die Lehramtsprüfung ab. Anschließend war er bis 1917 als Probekandidat an der deutschen Knabenschule im siebenbürgischen Schäßburg und an einer Oberrealschule in Budapest tätig. Danach setzte er sein Studium in Wien fort und erwarb 1918 die österreichische Staatsbürgerschaft. Ab 1919 arbeitete Hesch als Hilfskraft am Anthropologischen Institut der Universität. Nach einem Forschungssemester im schwedischen Uppsala bei Herman Lundborg wurde er 1921 in Wien bei Pöch promoviert. Auch unter dessen Nachfolger Otto Reche setzte Hesch seine 1921 begonnene Assistententätigkeit fort. Im Oktober 1927 folgte er Reche an das Institut für Rassen- und Völkerkunde der Universität Leipzig. Dort widmete er sich der Untersuchung von Zwillingen und erhob ab 1934 anthropologische Daten von Strafgefangenen in sächsischen Haftanstalten. Bereits im März 1932 hatte er die deutsche Staatsbürgerschaft angenommen. Während des Studiums war er Mitglied des Nordischen Ringes und der Burschenschaft Moldavia geworden. In die NSDAP trat Hesch am 1. Mai 1933 ein und war schon bald nebenamtlich als „Fachberater für Rasse“ in der Kulturpolitischen Abteilung der Kreisleitung Leipzig der NSDAP tätig. Ab Januar 1934 galt er als SS-Anwärter, seine Aufnahme erfolgte 1935. Er nahm an diversen NS-Schulungskursen teil, beteiligte sich teilweise mit eigenen Referaten. Da Hesch bereits damals in Fachkreisen gut bekannt war, erfuhr er rasch von der durch den Wechsel von - Bernhard Struck nach Jena frei werdenden Kustodenstelle in Dresden. Er bewarb sich erfolgreich, doch die Stellenbesetzung verzögerte sich. Als Hesch im November 1938 endlich eingestellt werden sollte, musste er zunächst zu seiner schwer erkrankten Mutter nach Siebenbürgen reisen.

Ab Januar 1939 arbeitete Hesch dann endlich als Kustos für Anthropologie an den Museen für Tierkunde und Völkerkunde in Dresden. Wenige Monate später, im Juni 1939, habilitierte er sich an der Technischen Hochschule Dresden. Eine seiner ersten Tätigkeiten in Dresden war die Mitwirkung an der Vorbereitung der „Deutschen Kolonialausstellung“ 1939. Im Januar 1940 
forderte das Rasse- und Siedlungshauptamt der SS (RuSHA) in Berlin Hesch zur Durchführung wissenschaftlicher Untersuchungen zur Besiedlung der Ostgebiete an. Er wurde in Dresden beurlaubt und führte bis Ende April 1940 in der Einwandererzentrale des RuSHA in Litzmannstadt rassenkundliche Untersuchungen an Wolhynien- und Galizien-Deutschen durch, die als Basis für die Entscheidung über deren Einbürgerung dienten. Zurück in Dresden wurde er für einen Tag in der Woche beurlaubt, um die Untersuchungsergebnisse in Berlin wissenschaftlich auszuwerten. Darüber hinaus weilte er einen Tag in der Woche in Leipzig, um seinen Lehrauftrag fortzuführen. Auch in Dresden erhielt er die Lehrbefugnis und wurde an der Technischen Hochschule zum Dozenten ernannt. Außerdem hielt er Vorträge über Rassenkunde und Rassenpolitik an der Volksbildungsstätte in Dresden. Anfang Mai 1940 wurde Hesch zum Kommissarischen Leiter des Museums ernannt, nachdem der bisherige Direktor $\gg$ Hans Kummerlöwe im August 1939 nach Wien gegangen war und nun der Kommissarische Leiter $\gg$ Martin Heydrich nach Köln wechselte. Weitere Beurlaubungen folgten, so im August 1940 für die Arbeit als Referent bei einem Lehrgang in Hohenwerfen im Salzburger Land, im Januar 1941 für einen weiteren Einsatz für das RusHA in Ostpreußen, im April 1941 für eine Vortragsreihe im Luftgau Münster, wo er vor Wehrmachtsangehörigen über „Das Judentum als Feind der europäischen Völker und Kulturen“ und „Die deutsche Erb- und Rassenpflege und die deutsche Zukunft" sprach. Für Mai und Juni 1941 wurde Hesch vom Reichsführer SS in Berlin „eine besonders vordringliche und vertrauliche Aufgabe im Protektorat Böhmen und Mähren übertragen “1. Erneut hatte er über die Einbürgerung der Bewohner in annektierten Gebieten zu entscheiden. Seine guten Beziehungen nach Wien pflegte er weiterhin, wenngleich er die ihm von Kummerlöwe angetragene Mitarbeit an der anthropologischen Untersuchung in Amsterdam absagen musste. Jedoch tauschte er mit der Wiener Anthropologischen Sammlung Rasseplastiken zur Ergänzung der Dresdner Sammlung. Obwohl Hesch durch seine Tätigkeit für das RuSHA selten in Dresden anwesend war, galt er im November 1940 als „Spitzenkandidat“ für die vakante Direktorenstelle, auf die er sich wenige Monate zuvor beworben hatte. Nach einigen Verzögerungen wurde er im September 1941 zum Direktor des Museums ernannt. ${ }^{2}$ Auch in der dazugehörigen „Erb- und rassenbiologischen Forschungsstell “ führte er Untersuchungen durch, erstellte Abstammungsnachweise und verfasste Gutachten für Gerichte. ${ }^{3}$ Darüber hinaus engagierte er sich für die Umwandlung der Anthropologischen Abteilung zu einem Museum für Rassenkunde. ${ }^{4}$ Hesch kuratierte im Herbst 1939 die Ausstellung „Die Rassen der Erde“ und eine ähnliche Schau für die Museumswoche 1940. In seinen Vorträgen thematisierte er "Rassen der Welt" und „Vererbung der Rassenmerkmale“. Auch sprach er über „Rassen und Rassenforschung in Polen und den Baltischen Staaten“, d. h. über seine Arbeit für das RuSHA. Am 8. Oktober 1942 wurde Hesch einberufen und dem RuSHA als hauptamtlicher Mitarbeiter zugeordnet. Zunächst wurde er als Leiter der RuSHA-Dienststellen in Königgrätz, Pardubitz und Jitschin eingesetzt. Im Juni 1943 wurde ihm die Leitung der Landesstelle Sudeten des RuSHA, Außenstelle Böhmen-Mähren in Prag übertragen. Damit war er, wie schon 1940 in Litzmannstadt, als „Eignungsprüfer“ unmittelbar in die Entscheidungen involviert, wer von den Bewohnern dieser Gebiete als „Deut-

\footnotetext{
1 Der Reichsführer der Schutzstaffel der NSDAP RuSHA, Berlin, an Leiter SMV, 15.4.1941, Abschrift, HStA Dresden, 13859, Nr. 3205, fol. 58.

2 Siehe S. $73 \mathrm{ff}$.

3 Vgl. Hesch an Kriegswirtschaftsstelle im Reichsforschungsrat, 22.3.1941, SKD, MfV Archiv, Nachlass Herbert Bellmann, o. Pag.

4 Siehe S. $189 \mathrm{ff}$.
} 
scher" anerkannt wurde. Außerdem bildete er weitere „Eignungsprüfer“ aus. Durch diese Tätigkeiten stieg Hesch, der „zu den besten Dienststellenleitern des RuS-Führers Böhmen-Mähren “5 zählte, in der SS-Hierarchie auf, wurde im Mai 1943 zum SS-Hauptsturmführer befördert. Doch noch vor März 1944 wurde er aus heute unbekannten Gründen zum SS-Schützen degradiert. Trotz der Arbeit für das RuSHA in Prag blieb er in Dresden formal als Museumsdirektor im Amt und kam regelmäßig tageweise in die Stadt, um Museumsangelegenheiten zu erledigen und seinen Lehrauftrag an der Technischen Hochschule fortzuführen. So referierte er im März 1943 beim Sonntagsvortrag im Museum über „Das Judentum als Feind der europäischen Völker und Kulturen (rassenkundlich betrachtet) "6. Im April 1944 wurde er sogar zum außerordentlichen Professor ernannt und zum Direktor des Instituts für Soziologie und soziale Anthropologie in Dresden bestellt, das er zum Institut für Rassenbiologie ausbauen sollte. ${ }^{7}$ Dies erreichte er infolge der Zeitläufte ebenso wenig wie den „Ausbau des Museums für Rassenkunde“, den er nach seinen „durch den Herrn Reichsstatthalter gebilligten und geförderten Plänen weiter und zu Ende führen"8 ${ }^{\text {w }}$ wollte.

Kurz vor Kriegsende geriet Hesch in Kriegsgefangenschaft. Noch im September 1947 befand er sich in einem Kriegsgefangenenlager in Österreich. Von dort aus zog er in die westlichen Besatzungszonen. Über seine weitere Berufstätigkeit ist nichts bekannt. Im Dezember 1952 heiratete er in Münster Martha Stamm. Unklar bleibt, wann er sich in Wuppertal niederließ, von wo aus er 1973 nach Bad Reichenhall übersiedelte. Am 22. August 1979 starb Michael Hesch 85-jährig in Bad Reichenhall.

\section{Auswablbibliografie}

Die Rassenstellung der Letten, Litauer und Weissrussen (Univ., Diss., 1921).

Die Photographie in der Anthropologie, Wien 1928, S. 114-147.

Papillarmuster bei Eingeborenen der Loyalty-Inseln. Beziehungen zwischen Papillarmustern und Blutgruppen bei diesen und einer deutschen Vergleichsgruppe, in: Zeitschrift für Rassenphysiologie, Bd. 5, 1932, S. 163-168.

Letten, Litauer, Weissrussen. Ein Beitrag zur Anthropologie des Ostbaltikums mit Berücksichtigung der siedlungs- und stammesgeschichtlichen Grundlagen, Wien 1933.

Rasse und Rassenpflege im deutschen Volk. Grundlagen, Ziel und Weg, in: Der Deutsche Buchhandlungsgehilfe. Zeitschrift der Buchhandlungsgehilfen im DBV, Hamburg, 11.1933, S. 132-138.

Der Rasse- und Gesundheitspass als Nachweis erblicher Gesundheit, 1933 (zusammen mit Alfred Eydt).

Verbreitung der Kenntnisse über Rasse und Rassenpflege, 1933.

Der rassische Aufbau des deutschen Volkes, Berlin 1935.

Rassenkundliche Bestimmungs-Tafeln für Augen-, Haar- und Hautfarben und für die Iriszeichnung, München 1935 (mit Bruno Kurt Schulz).

5 Der RuS-Führer Böhmen-Mähren, Entwurf Dienstleistungszeugnis SS-Hauptsturmführers (F) Dr. Hesch, o. Dat., BArch, R 9361-III/530867.

6 Fichtner an Leiter SMV, 10.1942, HStA Dresden, 11125, Nr. 23081, fol. 59 ff., hier: 61.

7 Entsprechende Akten, die im online-Findbuch des Historischen Archivs der Stadt Köln verzeichnet sind, wurden beim Einsturz des Archivs 2009 stark beschädigt und befinden sich in Restaurierung.

8 Museen für Tierkunde, Rassenkunde und Völkerkunde an den Reichsstatthalter, Landesregierung IV/7, Dresden, 20.6.1944, Abschrift, HStA Dresden, 13859, Nr. 3205, o. Pag. 
Kultur und Rasse. Otto Reche zum 60. Geburtstag, gewidmet von Schülern u. Freunden, München 1939 (Hg. mit Günther Spannaus).

\section{Quellen und Literatur}

HStA Dresden, 13859, Nr. 3205

HStA Dresden, 13842, Nr. 114, Bd. 1 u. 2; Nr. 115

BArch, NS 33/2580; NS 33/2613

BArch, R 4901/13266

BArch, R 9361-III/530867

BArch, R 9361-VI/1172

BArch, R 9361-IX/Kartei/15341155

Archivauskunft, Stadtarchiv Bad Reichenhall, Johannes Lang, 14.11.2018.

Petschel, Dorit: 175 Jahre TU Dresden. Band 3: Die Professoren der TU Dresden 1828-2003. Hrsg. im Auftrag der Gesellschaft von Freunden und Förderern der TU Dresden e. V. von Reiner Pommerin, Köln u. a. 2003.

Harten, Hans-Christian, Uwe Neirich u. Matthias Schwerendt: Rassenhygiene als Erziehungsideologie des Dritten Reichs: Bio-bibliographisches Handbuch, Berlin 2006, S. 275.

Klee, Ernst: Das Personenlexikon zum Dritten Reich, Frankfurt a. M. 2007, S. 248 f.

Martin, Petra: Die Negation des Individuums. Zur Rassenbüsten-Sammlung am Museum für Völkerkunde Dresden, in: Staatliche Kunstsammlungen Dresden 2016, S. 26 f.

Scheppe, Wolfgang: Wissenschaft als Rassenpolitik. Der SS-Offizier und Anthropologe Michael Hesch, in: Staatliche Kunstsammlungen Dresden 2016, S. 28. 


\section{Rolf Hetsch}

30.6.1903 Berlin-Charlottenburg - 26.12.1946

Berlin-Hohenschönhausen

Jurist, Kunsthistoriker

Kunstgewerbemuseum

1.10.1934-30.9.1935 Freiwilliger Wissenschaftlicher

Hilfsarbeiter

Münzkabinett

1.4.1938-31.12.1939 Kommissarischer Leiter

Porzellansammlung

1.4.1938-31.12.1939 Kustos

(Abordnung an Reichsministerium für Volksaufklärung und Propaganda, Berlin, 19.8.1938-

30.11.1938, 13.12.1938-16.12.1938, 12.1.1939-27.1.1939, 31.1.1939-9.2.1939, danach

tageweise und 22.8.1939-31.12.1939; Wehrmachtslehrgang 26.6.1939-24.7.1939)

Am 30. Juni 1903 wurde Rolf Reinhold Bernhard Hetsch als Sohn des Generaloberarztes Heinz Karl Wilhelm Hetsch und dessen Ehefrau Ella, geb. Weyland, in Berlin-Charlottenburg geboren. Da die Familie aufgrund des väterlichen Berufes mehrfach umzog, lernte Hetsch an Gymnasien in Berlin, Freiburg i. Br., Hannover und Homburg v. d. Höhe, bevor er 1924 seine Reifeprüfung in Heidelberg ablegte. Nach dem Militärdienst als Zeitfreiwilliger begann er noch im selben Jahr in Marburg Jura und Staatswissenschaft zu studieren. Nach der Ersten Juristischen Staatsprüfung arbeite er als Referendar im Bezirks- und Oberlandesgericht in Frankfurt am Main. Im November 1930 wurde er in Marburg promoviert. ${ }^{1}$ Bereits während seines Jurastudiums hatte Hetsch in Marburg und Frankfurt kunsthistorische Vorlesungen von Richard Hamann und Hans Jantzen besucht. 1932 ließ er sich vom Reichsministerium der Justiz für ein Studium der Kunstgeschichte, Archäologie und mittelalterlichen Geschichte in München freistellen. Währenddessen absolvierte er 1933 einen Studienkurs am Kunsthistorischen Institut in Florenz und heiratete in Kassel Mariamalie, geb. Rudeloff.

Ab Oktober 1934 arbeitete Hetsch für ein Jahr als Freiwilliger Wissenschaftlicher Hilfsarbeiter am Kunstgewerbemuseum in Dresden, wo er Sonderausstellungen und Vorträge organisierte und die Zinnsammlung inventarisierte. Im Frühjahr 1935 wurde er für die Beendigung seiner kunsthistorischen Dissertation vom Dienst freigestellt, im Juni 1935 wurde er bei Wilhelm Pinder in München promoviert.

\footnotetext{
1 In der Datierung gab es bisher erhebliche Diskrepanzen. Eine überlieferte Abschrift der Promotionsurkunde trägt das Datum 26.2.1931. Vgl. BArch, R 9361-V/2981, fol. 20. Laut Auskunft von Katharina Schaal, Archiv der Philipps-Universität Marburg, fand ein erstes Rigorosum, das mit „mangelhaft" bewertet wurde, am 15.11.1929 statt. Hetsch wiederholte die Prüfung am 24.11.1930 und bestand. Siehe Archiv der Philipps-Universität Marburg, Uni A Marburg 307b, Nr. 1447, laut E-Mail Katharina Schaal an die Autorin, 25.4.2019. Vgl. Hetsch: Handschriftlicher Lebenslauf, o. Dat., BArch, NS 21/1520, fol. 187 ff., hier: 187 u. Hetsch an Wirtschaftsministerium Dresden, 20.8.1934, HStA Dresden, 11292, Nr. 2, o. Pag. Ein anderer, maschinenschriftlicher Lebenslauf von Hetsch, 12.4.1937, BArch, R 9361-V/2981, fol. 16a,b datiert die Promotion irrtümlich auf 24.11.1929. Dieser Datierung folgt Fuhrmeister 2006, S. 108.
} 
Von Oktober 1935 bis zum Frühjahr 1937 war er als wissenschaftlicher Mitarbeiter an den Staatlichen Kunstsammlungen Kassel tätig. Unterdessen war er endgültig aus dem juristischen Staatsdienst ausgeschieden. Ab Frühjahr 1937 bearbeitete er einen Forschungsauftrag der Deutschen Forschungsgemeinschaft zur "Sammlung alter hessischer Hausinschriften im Kreis Hofgeismar“. Im August 1937 wurde Hetsch in das Sonderreferat „Entartete Kunst“ der Präsidialabteilung der Reichskammer der bildenden Künste berufen, die sein Vetter, der Maler Adolf Ziegler, seit Dezember 1936 leitete, „um als Kunsthistoriker die im Auftrag des Führers in deutschem Museumsbesitz sichergestellten Werke von Verfallskunst zu inventarisieren und katalogisieren“2.

Zum 1. April 1938 wechselte Hetsch als Kustos an die Staatlichen Sammlungen in Dresden, wo er als „Assistent an der Staatl. Porzellansammlung und stellvertretender Leiter des Münzkabinetts“3 arbeitete. Um diese Stelle hatte er sich bereits im Vorjahr beworben, als er vom pensionierten Direktor der Porzellansammlung $\triangleright$ Ernst Zimmermann von der Vakanz erfahren hatte. Doch Hetschs Tätigkeit in Dresden währte nicht lange. Bereits im August 1938 forderte der Reichs- und Preußische Minister für Wissenschaft in Berlin ihn „zur Bearbeitung des Aktenmaterials über Einziehung der Produkte Entarteter Kunst" ${ }^{\text { }}$ an. Er wurde in Dresden freigestellt und koordinierte für zwei Monate die „Verwertung“ der beschlagnahmten Werke „Entarteter Kunst“ in Berlin. Ende November 1938 beantragte der Reichsminister für Volksaufklärung und Propaganda, Joseph Goebbels, beim Leiter des Sächsischen Ministeriums für Volksbildung, Hetsch „hin und wieder für einige Tage (3 bis 4 Tage monatlich) jeweils auf unmittelbaren Abruf zu Verfügung zu stellen "5, was in der Tat 1939 mehrfach erfolgte. Auch von August bis Dezember 1939 wurde er an das Reichsministerium für Volksaufklärung und Propaganda (RMVP) in Berlin abgeordnet. Obwohl sein Dresdner Vorgesetzter $>$ Fritz Fichtner zunächst erfreut war, dass Hetsch „gerade von der Stelle anerkannt [war, Anm. d. A.], die für die nationalsozialistische Haltung der heutigen Kunstpolitik verantwortlich sei“" ${ }^{\text {"6 }}$, verärgerte ihn dessen seltene Anwesenheit, denn „,[d]ie von Dr. Hetsch in Dresden verbrachte Zeit hat weder genügt, sich mit der Sammlung in wünschenswerter Weise vertraut zu machen, noch war er in der Lage, einfache übertragene Aufgaben so zu Ende zu führen, daß für den Direktor eine nur einigermaßen spürbare Entlastung eingetreten wäre. ${ }^{\text {“7 }}$ In mehreren Gesprächen mit dem Generaldirektor der Berliner Museen, Otto Kümmel, und mit den Verantwortlichen im Reichsministerium für Wissenschaft, Erziehung und Volksbildung sowie im RMVP versuchte Fichtner, zuletzt im August 1939, eine Übernahme Hetschs nach Berlin zu erreichen.

Doch erst zum 1. Januar 1940 wechselte Hetsch endgültig als Referent der Abteilung Bildende Kunst in das RMVP nach Berlin, wo er hauptamtlich für die „Verwertung“ der Werke „Entarteter Kunst“ zuständig war. Innerhalb kurzer Zeit wurde er dort, nach seiner im Juli 1941 erfolgten, späten Aufnahme in die NSDAP, verbeamtet und im Oktober 1941 zum Regierungsrat er-

2 Hetsch, Handschriftlicher Lebenslauf, o. Dat., BArch, NS 21/1520, fol. 187 ff., hier: 188. Sein Verwandtschaftsverhältnis zu Ziegler wurde von Hetsch persönlich erwähnt, ist bisher jedoch nicht nachgewiesen. Siehe Fuhrmeister 2006, S. 109 u. 120 f., Anm. 24.

3 Hetsch, Handschriftlicher Lebenslauf, o. Dat., BArch, NS 21/1520, fol. 187 ff., hier: 188. Vgl. auch HStA Dresden, 11125, Nr. 22891, fol. 42. Siehe S. 78 f.

4 Posteingangsbuch der Porzellansammlung, SKD Archiv, 01/PS 136, Nr. 109 (Eintrag August 1938).

RMVP an RMWEV, 30.11.1938, BArch, R 9361-V/2981, fol. 78.

Fichtner, Beurteilung der Veröffentlichungen des Dr. Hetsch, o. Dat., ebd., fol. 33 ff., hier: 35.

Fichtner, Porzellansammlung, an Leiter SMV, 26.7.1939, ebd., fol. 101 ff., hier: 103. 
nannt, 1943 zum Oberregierungsrat befördert. Unklar bleibt, warum Hetsch erst 1941, also vergleichsweise spät, in die Partei aufgenommen wurde, einen entsprechenden Antrag hatte er bereits 1937 gestellt. $^{8}$ Ab 1933 war er Mitglied in verschiedenen nationalsozialistischen Organisationen: 1933 trat er in die SA ein, die er nach einem Jahr aus gesundheitlichen Gründen verließ, 1935 wurde er förderndes Mitglied der SS, 1937 des Opferringes der NSDAP. In seiner Arbeit für die Abteilung Bildende Kunst des RMVP war er in die deutsche Kulturpropaganda im Ausland eingebunden, organisierte Ausstellungen, hielt Vorträge. Von 1943 bis 1945 leitete Hetsch den „Führerauftrag Monumentalmalerei“, der die Wand- und Deckenmalerei im „Großdeutschen Reich" dokumentieren sollte. Parallel arbeitete er an einer 50 Bände umfassenden „Enzyklopädie der Bildenden Künste Europas“. Unklar bleibt, ob er in den letzten Kriegstagen noch zur Wehrmacht einberufen wurde. Rolf Hetsch starb am 26. Dezember 1946 im sowjetischen Speziallager Berlin-Höhenschönhausen.?

\section{Auswahlbibliografie}

Die Erfüllung fremder Schuld, Würzburg 1930 (Marburg, Univ., Diss., 1930).

Paula Modersohn-Becker. Ein Buch der Freundschaft, Berlin 1932.

Ruth Schaumann Buch, Berlin 1933.

Das ewig Göttliche. Vom Geist und Glauben deutscher Kunst des Mittelalters, Dresden 1935.

Die Altarwerke von Heinrich Douvermann. Ein Beitrag zur Geschichte der niederrheinischen Plastik, Würzburg 1937 (Zugl. München, Univ., Diss., 1935).

Tizian, Berlin 1938.

Niederdeutsche Landschaft. Zu Gemälden von Otto Modersohn, in: Die Kunst im Deutschen Reich, Ausgabe B, 1940, S. 336-343.

Fritz Mackensen. Zum 75. Geburtstag des Künstlers, in: Die Kunst im Deutschen Reich, Ausgabe B, 1941, S. 120-127.

\section{Quellen und Literatur}

SKD Archiv, 01/PS 136

SKD, MK, 1938-1939

HStA Dresden, 11292, Nr. 2

HStA Dresden, 11125, Nr. 22894 (Einzeldokumente)

BArch, R 55/22234

BArch, R 9361-V/2981

BArch, R 9361-IX/Kartei/15420952; R 9361-VIII/Kartei/10760503

Fuhrmeister, Christian: Dr. iur. Dr. phil. Rolf Hetsch, „einziger zünftiger Kunsthistoriker“ im Reichsministerium für Volksaufklärung und Propaganda, in: Fuhrmeister, Christian, Stephan Klingen, Iris Lauterbach u. a.: „Führerauftrag Monumentalmalerei“. Eine Fotokampagne 1943-1945, Köln 2006, S. 107-126.

Hoffmann, Meike: Rolf Hetsch und die Verwaltung der Restbestände „Entarteter Kunst“. In: Meike Hoffmann, Matthias Wemhoff u. Dieter Scholz (Hg.): Der Berliner Skulpturenfund. „Entartete Kunst“ im Bombenschutt. Entdeckung, Deutung, Perspektiven, Begleitpublikation der Ausstellung mit Beiträgen des Berliner Symposiums, Regensburg 2012, S. 85-99.

8 Vgl. Fuhrmeister 2006, S. 112, 122, Anm. 50.

9 Vgl. Stiftung Gedenkstätte Berlin-Hohenschönhausen (Hg.): Totenbuch: Sowjetisches Speziallager Nr. 3 und Haftarbeitslager Berlin-Hohenschönhausen 1945-1949, Berlin 2014, S. 41. 


\title{
Martin HeYdrich
}

\author{
29.12.1889 Ottendorf (Bahretal) - 8.2.1969 Köln \\ Ethnologe \\ Museen für Tierkunde und Völkerkunde \\ 1.4.1919-31.3.1927 Wissenschaftlicher Hilfsarbeiter \\ 1.4.1927-30.6.1940 Kustos \\ 10.1939-30.6.1940 Kommissarischer Leiter \\ (Militärdienst 22.4.1940-5.1940)
}

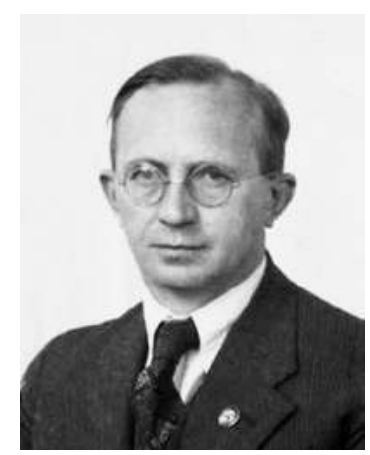

Max Martin Heydrich wurde am 29. Dezember 1889 in Ottendorf bei Pirna als Sohn des evangelisch-lutherischen Pfarrers Max Heydrich und dessen Frau Berta, geb. Schmidt, geboren. Nach der Übersiedlung der Familie nach Krögis bei Meißen besuchte Heydrich die dortige Volksschule. Ab 1904 lernte er am humanistischen Gymnasium Albertinum in Freiberg, wo er 1910 das Reifezeugnis erhielt. Danach absolvierte er als Einjährig-Freiwilliger die Militärdienstpflicht. Ab Frühjahr 1911 studierte Heydrich an den Universitäten in Freiburg i. Br., Dresden und München Völkerkunde, Geografie, Kunstgeschichte, Geschichte und Philosophie. Im Herbst 1912 wechselte er an die Universität in Leipzig, wo er, nach einem einsemestrigen Studienaufenthalt in Edinburgh, im Dezember 1914 bei Karl Weule promoviert wurde. Im Ersten Weltkrieg diente Heydrich als Leutnant bei der Infanterie an der Westfront, ab 1916 als Fliegerbeobachtungsoffizier vor Verdun und Arras, und leitete ab 1917 eine Fliegerabteilung an der Irak-Front, zuletzt war er stellvertretender Kommandeur einer Fliegerschule.

Aus dem Krieg, in dem er mehrfach verwundet wurde, zurückgekehrt, begann Heydrich im April 1919 unter Direktor \Arnold Jacobi seine Museumslaufbahn als Wissenschaftlicher Hilfsarbeiter an den Museen für Tierkunde und Völkerkunde in Dresden. Im Juli legte er noch das Staatsexamen für das Höhere Lehramt in Leipzig ab. Ab 1924 arbeitete er zusätzlich als Herausgeber des Ethnologischen Anzeigers, dessen Schriftleitung er 1928 übernahm und für den er bis 1944 mehrfach Druckkostenzuschüsse von der Deutschen Forschungsgemeinschaft erhielt. Im April 1925 wurde Heydrich zum Kustos ernannt. Ihm oblag damit die wissenschaftliche Betreuung der völkerkundlichen Museumsbestände. Er stellte die Schausammlung „nach neuen Gesichtspunkten auf und führte ausserdem verschiedene museumstechnische Verbesserungen durch" ${ }^{1}$. Zwischen 1934 und 1937 unternahm er mehrere Reisen zum Sammeln von Objekten, u.a. ins Baskenland, nach Dalmatien, Italien und Nordafrika. Aufgrund der Empfehlung seines Kollegen - Bernhard Struck übernahm Heydrich ab Herbst 1936 dessen Vorlesungen und Übungen an der Technischen Hochschule in Dresden. Ab Frühjahr 1939 las er dann auch „Völkerkunde“ und wurde im Juli 1939 zum Honorarprofessor ernannt. Daneben hielt Heydrich zahlreiche Vorträge über kolonialpolitische und -wirtschaftliche Themen an der Volksbildungsstätte, der Führerinnenschule des Arbeitsdienstes und für das Rassenpolitische Amt der NSDAP. In die NSDAP war Heydrich im Mai 1933 eingetreten. In der Partei-Ortsgruppe Klotzsche war er als Volkstumswart und 1938 als Hauptstellenleiter für Kultur tätig. Ebenfalls 1933 gehörte er kurzzeitig der SA an,

Heydrich, Lebenslauf, 23.6.1938, BArch, R 4901/24789, fol. 3456 f., hier: 3457. 
ist „jedoch ausgeschieden, da er durch ein Beinleiden (Kriegsbeschädigung) an der Ausübung seines Dienstes verhindert war" ${ }^{\text {“2 }}$. Heydrich zählte 1929 zu den Mitbegründern der „Gesellschaft für Völkerkunde“. Bei deren Tagung in Leipzig 1936 referierte er über „Aufgaben und Arbeiten der Völkerkundemuseen“. In Dresden sprach er ein Jahr später über „Die Deutschen Völkerkundemuseen im Dienste des kolonialen Gedankens“. Ansonsten referierte er über einzelne Sammlungsbereiche und führte durch die Sonderausstellungen. 1939 kuratierte er den völkerkundlichen Teil der „Deutschen Kolonialausstellung“. Nachdem > Hans Kummerlöwe nach Wien berufen worden war, wurde Heydrich im Oktober 1939 zum Kommissarischen Leiter des Museums ernannt. Bereits damals bewarb er sich wie auch sein ehemaliger Dresdner Kollege - Bernhard Struck und andere Kollegen für das Ordinariat für Völkerkunde an der Universität Köln, wobei er 1938 zunächst an vierter Stelle stand. Letztlich entschied man sich für ihn. Mitten in den Berufungsverhandlungen, über die er vertraulich mit Kummerlöwe korrespondierte, wurde Heydrich im April 1940 zur Wehrmacht einberufen, konnte aber rasch uk-gestellt werden.

Zum 1. Juli 1940 wechselte Heydrich, der in Dresden ohne Fortzahlung seiner Bezüge freigestellt wurde, nach Köln. Seine Frau Ellen Sophie, geb. Fritzsche, die er im März 1929 geheiratet hatte, blieb mit den drei gemeinsamen Kindern in Dresden-Klotzsche. Für Heydrich bedeutete die Entscheidung für Köln einen großen Karrieresprung. Statt Kustos war er nun Ordinarius für Völkerkunde an der Universität und im Nebenamt Direktor des Rautenstrauch-Joest-Museums. Unter Anerkennung seiner Publikation „Koreanische Landwirtschaft“ als Habilitation wurde er im September 1940 zum ordentlichen Professor ernannt. Seine Antrittsvorlesung über „Europäisierung als völkerkundliches Problem" hielt er erst im Juni 1941. Seine Museumsarbeit in Köln begann er mit einem Tausch der vorgeschichtlichen Sammlung des Museums gegen die ethnografische Sammlung des Museums in Wuppertal. ${ }^{3}$ Auch beteiligte sich Heydrich später am Kunstraub der Nationalsozialisten, indem er einen Teil der durch Walter Frenzel bzw. \ Walter Grünberg veräußerten Ethnographischen Sammlung des Museums in Litzmannstadt ankaufte und durch die Gestapo beschlagnahmte Ethnografica aus Bonn übernahm. ${ }^{4}$ Im Februar 1941 hielt er Vorträge vor Angehörigen der Luftwaffe in der Ostmark, im Protektorat Böhmen und Mähren sowie im Rheinland. Seine Verbindungen zum Dresdner Museum pflegte er weiterhin, auch nutzte er diese, um kriegsbedingt Objekte des Kölner Museums nach Liebstadt bei Dresden auszulagern. Vom Luftangriff auf Köln war Heydrich an der Universität und privat betroffen. Daher folgte er im Herbst 1944 der Universität Köln an ihren Interimsstandort und siedelte nach Marburg über, wo er seine Lehrtätigkeit fortsetzte. Im Februar 1945 holte er seine Familie nach Marburg. Nach Kriegsende war Heydrich zunächst arbeitslos, den Lebensunterhalt der Familie verdienten seine Frau als Schneiderin und die Kinder auf einem Bauernhof. Derweil bemühte sich Heydrich, seine Haltung während der NS-Zeit als oppositionell darzustellen. Doch seine „Entnazifizierung“ verlief nach den Verhören durch die Militärregierung im Februar 1946 schleppend. Ab November 1947 wurde er zunächst an der Kölner Universität für Aufräumarbeiten eingesetzt. Aufgrund der Beurteilung als „Mitläufer“ wurde er nicht für seine früheren Ämter zugelassen. Mit anwaltlicher

SD-Führer des SS-Oberabschnittes Elbe an SMV, 28.1.1938, BArch, R 4901/24789, fol. 3474.

Vgl. Hutterer, Rainer, Oskar Schröder u. Gustav Peters: Ausverkauf in Wuppertal: Zur Sammlungsgeschichte eines Sumatra-Nashorns (Dicerorhinus sumatrensis) im Kontext der nationalsozialistischen Kulturpolitik, in: Jahresbericht der Naturwissenschaftlichen Vereinigung Wuppertal, 62, 2012, S. 7-36, hier: $18 \mathrm{ff}$.

4 Siehe S. 318, Anm. 2. Vgl. auch Haupts 2007, S. 323 sowie Pützstück 1995, S. 328 f. 
Unterstützung erreichte Heydrich eine erfolgreiche Revision. Später als „unbelastet“ eingestuft, konnte er ab September 1948 wieder als Direktor des Rautenstrauch-Joest-Museums, ab Juni 1949 bis zu seiner Emeritierung 1958 auch als Ordinarius für Ethnologie an der Universität Köln tätig sein. Ebenfalls 1949 wurde Heydrich zum Vorsitzenden der Deutschen Gesellschaft für Völkerkunde gewählt. In dieser Funktion setzte er sich für Kollegen ein, unter anderem schlug er 1956 - Siegfried Wolf, den er durch die gemeinsame Arbeit in den 1930er-Jahren kannte, als Leiter des Museums für Völkerkunde in Dresden vor. Nach einem Schlaganfall 1967 pflegebedürftig, starb Martin Heydrich am 8. Februar 1969 in Köln.

\section{Auswahlbibliografie}

Afrikanische Ornamentik. Beiträge zur Forschung der primitiven Ornamentik und Geschichte der Forschung, Suppl. Vol. XXII des internationalen Archivs für Anthropologie, Leiden 1914. (Zugl. Leipzig, Univ., Diss., 1914).

Völkerkundliche Theorien und ihre museale Auswertung, in: Bericht über die allgemeine Versammlung der Deutschen Gesellschaft für Anthropologie in Halle 1925, S. 52-54.

Grundsätzliche Fragen völkerkundlicher Bibliographie, in: Africa, Bd. 1, 1928, S. 381-386.

Ursprung und Bedeutung der Roland-Säulen, in: Rolandblätter, 1929, S. 223-226.

Koreanische Landwirtschaft. Beiträge zur Völkerkunde von Korea I, in: Abhandlungen und Berichte der Museen für Tierkunde und Völkerkunde zu Dresden Bd. XIX, Leipzig 1930. (Zugl. Köln, Univ., Habil., 1940).

Ärzte als Entdecker und Forscher in Asien, in: Ciba-Zeitschrift, Nr. 12, 1934, S. 1-12.

Museumsfragen. Abgrenzungen und Gestaltung der Völkerkundemuseen, in: Gesellschaft für Völkerkunde (Hg.), Tagungsberichte der 2. Tagung 1936 in Leipzig, Leipzig 1937, S. 181-190.

Gustav Klemm und seine kulturhistorische Sammlung, in: Michael Hesch und Günther Spannaus (Hg.), Kultur und Rasse. Otto Reche zum 60. Geburtstag, München und Berlin 1939, S. 305-316.

Der heutige Stand der deutschen Völkerkunde. Schrifttumsbericht, in: Rasse. Monatsschrift der Nordischen Bewegung/Monatsschrift für den Nordischen Gedanken, 8, 1941, S. 276-280.

Stand und Aufgaben der afrikanischen Kunstforschung, in: Tagungsbericht I der Beiträge zur Kolonialforschung im Auftrag des Reichsforschungsrates und der Deutschen Forschungsgemeinschaft, Hg. v. Günter Wolff, Berlin 1943, S. 33-44.

\section{Quellen und Literatur}

SKD Archiv, 01/PS 53, Bd. 3 (Einzeldokumente)

HStA Dresden, 13842, Nr. 048; Nr. 114, Bd. 2; Nr. 115 (Einzeldokumente)

BArch, R 73/10300; R 73/16162

BArch, R 4901/24789

BArch, R 9361-IX/Kartei/15501777; R 9361-VIII/Kartei/10860769

Pützstück, Lothar: „Symphonie in Moll“ Julius Lips und die Kölner Völkerkunde, Pfaffenweiler 1995 (Zugl. Köln, Univ., Diss., 1993).

Haupts, Leo: Die Universität zu Köln im Übergang vom Nationalsozialismus zur Bundesrepublik, Köln/Weimar/Wien 2007.

Kreide-Damani, Ingrid: Julius Lips, Martin Heydrich und die (Deutsche) Gesellschaft für Völkerkunde, in: Kreide-Damani, Ingrid (Hg.): Ethnologie im Nationalsozialismus. Julius Lips und die Geschichte der „Völkerkunde“, Wiesbaden 2010, S. 23-284.

Wessel, Ursula: Martin Heydrich. Sein Leben und Wirken, 2012. 


\section{Helmut Hofer}

22.10.1912 Mährisch Weißkirchen - 26.7.1989 Kassel Zoologe, Morphologe

Museen für Tierkunde und Völkerkunde

(ab 1.1.1942 Museen für Tierkunde, Rassenkunde und Völkerkunde)

5.12.1938-31.3.1945 Wissenschaftlicher Hilfsarbeiter

(Militärdienst 12.2.1940-mind. 8.1944)

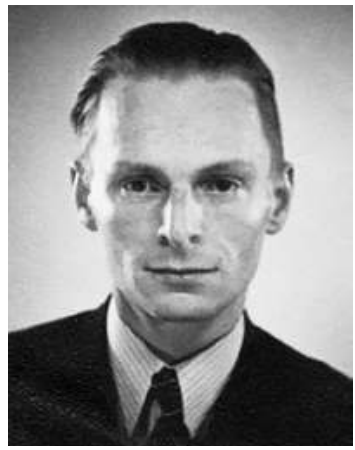

Helmut Hofer wurde am 22. Oktober 1912 als Sohn des Gymnasialprofessors Ewalt Hofer und dessen Frau Ferdinande, geb. Grohmann, in Mährisch Weißkirchen geboren. Nach dem Abitur studierte er in Wien Zoologie, wo er 1937 promoviert wurde. Bereits damals war Hofer Parteimitglied. Er war der NSDAP im Mai 1933 beigetreten und als Zellenleiter und Mitglied einer Nationalsozialistischen Betriebsorganisation (NSBO) in Wien aktiv, auch nach deren Verbot in Österreich. > Hans Kummerlöwe, zu dem er seit 1933 einen kollegialen Kontakt unter Parteifreunden pflegte, bat er, „, [w] enn Sie mir schreiben, dann vorsichtig und ohne Absender, bin in letzter Zeit überwacht ${ }^{\text {“1 }}$. Im Dezember 1937 weilte Hofer in Dresden, auch bei Kummerlöwe im Museum. Dieser bot ihm im Frühjahr 1938 eine Stelle als Wissenschaftlicher Hilfsarbeiter in Dresden an. Doch Hofer, der den zu Parteizwecken freigestellten $\triangleright$ Hellmuth Buck vertreten sollte, konnte dieses Angebot nicht sofort annehmen. Er weilte vom Juni bis November 1938 am Deutsch-Italienischen Institut für Meeresbiologie in Rovigno, wo er schon im Herbst 1937 geforscht hatte.

Erst im Dezember 1938 kam Hofer als Wissenschaftlicher Hilfsarbeiter an die Museen für Tierkunde und Völkerkunde nach Dresden, wo er die „Abteilung für Säugetiere, Fische und Wirbellose (ausser Insekten) “2 leitete. Seine Tätigkeit dauerte nur etwas mehr als ein Jahr, denn im Februar 1940 wurde er zur Wehrmacht eingezogen. Weil seine Weiterbeschäftigung am Museum indes in seiner Abwesenheit mehrfach genehmigt wurde, blieb er pro forma bis Ende März 1945 beschäftigt. Mehrere Versuche der Museumsleitung und des Sammlungsreferenten, > Fritz Fichtner, Hofer für den Umzug des Museums für Völkerkunde oder für die Fertigstellung seiner Habilitationsschrift vom Militärdienst beurlauben zu lassen, scheiterten. Selbst als seine Frau Lieselotte, geb. Aé, eine Bibliothekarin, die er im August 1940 geheiratet hatte und mit der er ein Kind hatte, im Juli 1942 nach kurzer Krankheit in Wien verstarb, wurde er nicht länger freigestellt. Hofer war zu dieser Zeit in Stettin stationiert, wo er bis mindestens Februar 1944 an der Pathologischen Untersuchungsstelle des Wehrkreises II arbeitete.

Hofer an Kummerlöwe, 23.1.1938, HStA Dresden, 13842, Nr. 114, Bd. 2, o. Pag.

2 Museen für Tierkunde und Völkerkunde, Kummerlöwe, an SMV, 7.12.1938, HStA Dresden, 13842, Nr. 237, fol. 17. 
Im August 1944 bot sich ihm „eine Möglichkeit, am Naturhistorischen Museum in Wien eine planmäßige und aussichtsreichere Stellung zu erlangen "3. So konnte er sich noch im selben Jahr in Wien habilitieren. Ab 1949 war Hofer als Wissenschaftliche Hilfskraft am Zoologischen Institut der Universität Wien tätig, 1954 wechselte er zum Max-Planck-Institut für Hirnforschung nach Gießen und Frankfurt a. M. Von 1965 bis zu seiner Emeritierung 1977 arbeitete er am Primate Research Center in Covington, Louisiana, USA. In seiner wissenschaftlichen Arbeit widmete er sich vorwiegend der Gehirnanatomie und der Primatologie, auch nach seiner Rückkehr nach Deutschland an der Universität Kassel. Helmut Hofer starb am 26. Juli 1989 in Kassel.

\section{Auswahlbibliografie}

Der Formenkreis Carduelis carduelis und die phylogenetische Ableitung seiner Rassen, in: Verhandlungen der Zoologisch-Botanischen Gesellschaft in Wien, 85, 1936, S. 60-87.

Über Gehirn und Schädel von Megaladapis edwardsi G. Grandidier (Lemuroidea), nebst Bemerkungen über einige airorhynche Säugerschädel und die Stirnhöhlenfrage, in: Z. f. wiss. Zoologie, 157, Leipzig 1953, S. 220-284.

Stammesgeschichte der Säugetiere. Eine Übersicht über Tatsachen und Probleme der Evolution der Säugetiere, Berlin, Göttingen, Heidelberg 1960 (mit Erich Thenius).

Über die Interpretation der ältesten fossilen Primatengehirne, in: Bibliotheca primat., 1, Basel, New York 1962, S. 1-31.

Primatologia. Handbuch der Primatenkunde, mehrbändig, Basel 1958-1973 (Hg.).

Die Sonderstellung des Menschen. Naturwissenschaftliche und geisteswissenschaftliche Aspekte, Stuttgart 1972 (mit Guenter Altner).

\section{Quellen und Literatur}

HStA 13842, Nr. 114; Nr. 237

BArch, R 9361-II/427459

BArch, R 9361-IX/Kartei/16221415; R 9361-VIII/Kartei/11700631

Hofer, Helmut, in: ZOBODAT (Zoologisch-Botanische Datenbank), Biologiezentrum des Oberösterreichischen Landesmuseums Linz, www.zobodat.at/personen.php?id=23376\&bio=full, Zugriff: 3.12.2019.

3 Museen für Tierkunde, Rassenkunde und Völkerkunde, Günther, an Reichsstatthalter, Abt. IV/7, 9.8.1944, HStA Dresden, 13842, Nr. 237, fol. 68. 


\section{Hans Hofmann}

28.5.1890 Möckern - 2.3.1979 Dresden

Historiker, Wissenschaftlicher Bibliothekar

Sächsische Landesbibliothek

1.1.1921-31.10.1921 Wissenschaftlicher Hilfsarbeiter

1.11.1921-31.8.1944 Bibliotheksrat

(Abordnung an Staatsbibliothek Krakau 1942-1944)

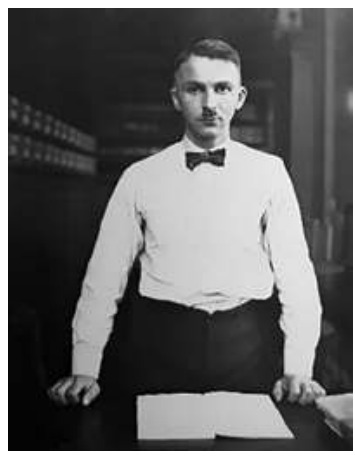

Als Sohn des Arztes Johannes Hofmann am 28. Mai 1890 in Möckern geboren, studierte Hans Hofmann nach dem Abitur am Humanistischen Gymnasium in Leipzig Geschichte und Philosophie in München und Leipzig, wo er gleichzeitig die Bibliothekarschule der Universität besuchte. 1920 wurde er in Leipzig promoviert und bestand ebenfalls die Prüfung zum wissenschaftlichen Bibliothekar.

Zum Jahresbeginn 1921 wurde er als Wissenschaftlicher Hilfsarbeiter an der Sächsischen Landesbibliothek in Dresden angestellt. Bereits ein Jahr später wurde er zum Bibliotheksrat ernannt und 1925 zum Landesbibliothekar befördert. Ab 1927 betraute Direktor \Martin Bollert ihn mit dem Umbau des Japanischen Palais zu einer der modernsten deutschen Bibliotheken. ${ }^{1}$ Nach deren Eröffnung im Mai 1935 übernahm Hofmann zahlreiche Führungen durch die „neue“ Bibliothek. D Ewald Jammers, sein Kollege aus der Musikabteilung, erinnerte sich später an Hofmann: „Mit Neubert war er der Mann des Bibliotheksumbaues, mit mir der Inspirator der Neuordnung der Musikabteilung. Er verstand es, die Benutzer durch Schilder schnell an die gesuchten Kataloge oder Abteilungen des bibliographischen Apparates oder der Lesesaalbibliothek zu leiten. Er war der Auskunftsbeamte - unser Instruktor bei den schwierigen Bestellzet-

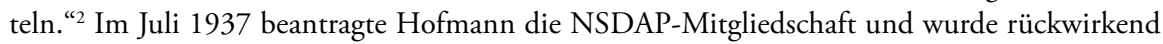
zum Mai 1937 aufgenommen. Nach 22 Jahren im Dienst der Sächsischen Landesbibliothek wurde Hofmann von 1942 bis 1944 an die Staatsbibliothek Krakau abgeordnet.

Nach seiner Rückkehr nach Dresden wechselte er zum 1. September 1944 als Nachfolger von Ernst Koch als Kommissarischer Direktor zur Bibliothek der Technischen Hochschule. In dieser Funktion verantwortete er die kriegsbedingte Auslagerung von deren Beständen sowie deren Rückführung nach der Zerstörung der Bibliothek im Februar 1945. Selbst ausgebombt, lebte er von Februar bis April 1945 bei seinem Kollegen Jammers in Radebeul, später in der Sächsischen Schweiz, wie er 1947 berichtete: „Mit Erklärung Dresdens zur Festung verließen wir auf Befehl des Arztes Ihr freundliches Quartier und begaben uns in die Sächsische Schweiz unter Mitnahme von nur 2 Koffern mit dem notdürftigsten Bestand. [...] Ich kehrte mit meiner Frau am 7. Mai 1945 [...] kurz nach Radebeul zurück, um die in mehreren Privathäusern Radebeuls verstreut befindlichen Kapseln des AK der Bibliothek der Technischen Hochschule, an dem ich von mei-

1 Siehe Bollert, Rede zur Eröffnung der Bibliothek, 11.5.1935, SLUB, Mscr.Dresd.App.1378.b,40 u. Mscr.Dresd.App.1378.III,6.

2 Jammers 2002, S. 312. Gemeint ist $\triangleright$ Hermann Neubert. 
nem Krankenbett aus in Radebeul mit meiner Gefolgschaft arbeitete, aus diesen Einzelhäusern in Ihrem [d.h. im Haus von Jammers, Anm. d. A.] Keller unter Gerümpel versteckt sicherzustellen. “3 Am 15. November 1945 wurde Hofmann aufgrund seiner NSDAP-Mitgliedschaft entlassen. Allerdings unterstützte er als Hilfskraft noch bis September 1946 seinen Amtsnachfolger Christian Janentzky. In den Folgejahren erarbeitete er als freier Mitarbeiter des Ministeriums für Bauwirtschaft der UdSSR eine Fachbibliografie und erledigte Hilfsarbeiten zur Vorbereitung wissenschaftlicher Vorträge für das städtische Kulturamt in Dresden, während seine Frau, die Pianistin Eva Babette Hofmann, als Korrepetitorin arbeitete. Von 1956 bis 1960 erstellte Hofmann im Auftrag der Sächsischen Akademie der Wissenschaften eine umfangreiche DresdenBibliografie. Von 1961 bis 1970 arbeitete er auf Honorarbasis in der Bibliothek des Staatlichen Museums für Mineralogie und Geologie in Dresden, die er zu einer fundierten Fachbibliothek ausbaute. Als Bibliothekar, Heimatforscher und begeisterter Bergsteiger hatte sich Hofmann bereits vor 1945 als Verwalter der Fachbibliothek der Sektion Dresden des Deutschen Alpenvereins engagiert und arbeitete später im Arbeitskreis Sächsische Schweiz der Geografischen Gesellschaft der DDR mit, gab von 1960 bis 1964 den „Postreiter Bergkalender“ heraus. Auch engagierte er sich in und für die Jugendburg Hohnstein in der Sächsischen Schweiz, zu der das ehemalige Konzentrationslager und spätere Kriegsgefangenenlager ab 1949 umgebaut worden war. Seine enge Verbundenheit mit der Sächsischen Landesbibliothek, insbesondere mit dem früheren Direktor Bollert, manifestierte sich in Hofmanns Engagement für die Bollert-Festschrift 1956 und in der Organisation einer Gedenkfeier in Dresden 1968. ${ }^{4}$ Nach dem Tod seiner Frau im Dezember 1973 lebte er sehr zurückgezogen und nutzte die trotz gesundheitlicher Beschwerden verbleibende Kraft zur Fertigstellung seiner umfangreichen „Selbstbiographie“. Hans Hofmann starb am 2. März 1979 in Dresden.

\section{Auswahlbibliografie}

Hofrat und landesherrliche Kanzlei im meissnisch-albertinischen Sachsen vom 13. Jahrhundert bis 1547/48 (Leipzig, Univ., Diss., 1920).

Der Volksbibliothekar: seine Aufgabe, sein Beruf, seine Ausbildung, Schriften zur Büchereifrage, Leipzig 1927 (Hg. mit Rudolf Angermann).

Zum kommunalen und staatlichen Aufbau des volkstümlichen Büchereiwesens, Leipzig 1928.

Die Sächsische Landesbibliothek 1920-1936, in: Neubert, Hermann (Hg.), Festschrift Martin Bollert zum 60. Geburtstage, Dresden 1936, S. 1-14 (mit Gottfried Benndorf).

Martin Bollert zum 80. Geburtstag am 11. Oktober 1956, Festschrift, Dresden 1956 (Hg.).

Deutsche Alpen, Dresden 1957.

Sächsische Schweiz, Dresden 1958.

Schneckenhaus und Dom. Ein Buch vom Zweifel und vom Glauben, Dresden 1965.

\section{Quellen und Literatur}

HStA Dresden, 11125, Nr. 18959 (Einzeldokumente)

Hofmann, Hans: Selbstbiographische Mitteilungen, 4 Bde., Dresden 1974, SLUB, Mscr.Dresd. App. 1830

3 Hofmann an Jammers, 26.11.1947, SLUB, Mscr.Dresd.App.2830,79. AK bezeichnet den Allgemeinen Katalog.

4 Vgl. Programmzettel der Gedenkfeier am 18.5.1968, SLUB, Mscr.Dresd.App.2600F,93 u. In memoriam Martin Bollert, Dresden 1968. 
SLUB, Mscr.Dresd.App.2600,F

SLUB, Mscr.Dresd.App.2830,82

BArch, R 9361-IX/Kartei/16370142; R 9361-VIII/Kartei/11820696

Habermann, Alexandra, Klemmt, Rainer u. Frauke Siefkes: Lexikon Deutscher Wissenschaftlicher Bibliothekare 1925-1980, Frankfurt a. M. 1985, S. 131.

Hebig, Christel: Zum Gedenken an Dr. Hans Hofmann - Bibliothekar und Heimatforscher, in: Zentralblatt für Bibliothekswesen, Leipzig, 104, 1990, S. 268-271.

Wüstling, Hans-Dieter: Dr. phil. Hans Hofmann (1944-1945), in: Wüstling 2005, S. 60 f.

Bürger, Thomas u. Konstantin Hermann (Hg.): Das ABC der SLUB. Lexikon der Sächsischen Landesbibliothek - Staats- und Universitätsbibliothek Dresden, Dresden 2006, S. 112.

Wüstling, Hans-Dieter: Hofmann, Hans, in: Sächsische Biografie, 2015, Online-Ausgabe: http://saebi.isgv.de/biografie/Hans_Hofmann_(1890-1979), Zugriff: 2.1.2020. 


\section{Charlotte Holzhausen}

31.1.1886 Rabenau - 13.7.1967 Bad Hersfeld

Bibliothekarin (Mittlerer Dienst)

Sächsische Landesbibliothek

(bis 1.5.1917 Königliche Öffentliche Bibliothek,

2.5.1917-11.1918 Königliche Landesbibliothek)

1.10.1913-28.10.1915 Volontärin

1.4.1916-31.8.1922 Bibliotheksgehilfin

1.9.1922-31.3.1925 Bibliothekssekretärin

1.4.1925-21.1.1931 Oberbibliothekssekretärin

1.2.1931-31.12.1950 Oberbibliotheksinspektorin

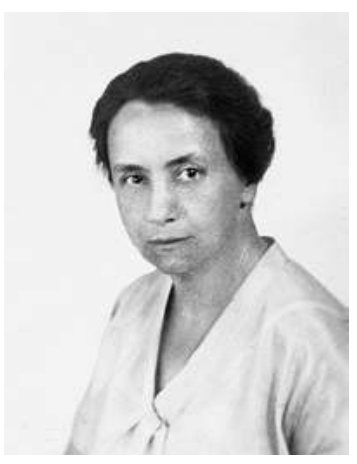

Am 31. Januar 1886 in Rabenau bei Dresden als Tochter des Poliermeisters Carl Gustav Kroll und der Marie Elisabeth Clara Backhaus geboren, wuchs Charlotte Martha Hedwig Holzhausen als Adoptivtocher des Majors Richard Holzhausen und dessen Frau Marie, geb. Haenel, auf. ${ }^{1}$ Sie wurde an mehreren Privatschulen unterrichtet und legte im Herbst 1910 nach einem zweimonatigen Frankreichaufenthalt ihr Examen als Französischlehrerin ab. Nach dreijähriger Tätigkeit als Privatlehrerin ging Holzhausen im Mai 1913 nach Oxford, um Englisch zu lernen. Nach ihrer Rückkehr bewarb sie sich im August 1913 an der Königlichen Öffentlichen Bibliothek in Dresden.

Ihre bibliothekarische Laufbahn begann Holzhausen im Oktober 1913 als Volontärin an der Königlichen Öffentlichen Bibliothek zu Dresden. Nach einer fünfmonatigen Unterbrechung aus gesundheitlichen Gründen arbeitete sie ab April 1916 als Bibliotheksgehilfin. Im September 1922 wurde sie an der nunmehr umbenannten Sächsischen Landesbibliothek zur Bibliothekssekretärin befördert, im April 1925 zur Oberbibliothekssekretärin, im Februar 1931 zur Oberbibliotheksinspektorin. \Ewald Jammers beschrieb in seinen Memoiren Holzhausen, die Leiterin der Buchbindeabteilung, als „,kluge, sehr musikalische Dame mit feinem Geschmack“2. Durch den Luftangriff auf Dresden im Februar 1945 ausgebombt, fand sie zunächst Unterkunft beim ehemaligen Bibliotheksdirektor $\gg$ Martin Bollert. ${ }^{3}$ Holzhausen war in der NS-Zeit Mitglied im RDB und im Opferring der NSDAP, trat jedoch nicht in die NSDAP ein. Daher konnte sie auch nach dem Zweiten Weltkrieg weiterhin in der Landesbibliothek tätig bleiben. Erst zum Jahresende 1950 wurde sie nach 37 Dienstjahren an der Sächsischen Landesbibliothek pensioniert.

Im Sommer 1963 siedelte Charlotte Holzhausen nach Westdeutschland zu ihrer Cousine nach Bad Hersfeld über, wo sie vier Jahre später, am 13. Juli 1967 starb.

\section{Quellen und Literatur}

HStA Dresden, 13859, Nr. 3427

SLUB, PA Holzhausen, Charlotte

SLUB, Mscr.Dresd.App.2600,F

\footnotetext{
1 Vgl. HStA Dresden, 13859, Nr. 3427, fol. 1a, 2a, 53-62. Aus dem Aktenbestand SLUB, PA Holzhausen, Charlotte geht die Adoption nicht hervor.

2 Jammers 2002, S. 313.

3 Vgl. Deckert 1987, S. 115, SLUB, Mscr.Dresd.App.2600,A1.
} 


\title{
Walter Holzhausen
}

\author{
23.7.1896 Bonn - 31.10.1968 Bonn
}

Kunsthistoriker

Grünes Gewölbe

15.5.1925-30.9.1927 Freiwilliger Wissenschaftlicher Hilfsarbeiter

1.10.1928-31.3.1942 Wissenschaftlicher Hilfsarbeiter

1.4.1942-4.1945 Kustos

1.7.1942-4.1945 Kommissarischer Leiter

Historisches Museum

1.10.1928-31.3.1942 Wissenschaftlicher Hilfsarbeiter

1.4.1942-4.1945 Kustos

23.11.1942-4.1945 Kommissarischer Leiter

Münzkabinett

8.9.1944-4.1945 Kommissarischer Leiter

(Teilabordnung an Statistisches Landesamt, Dresden, ab 7.1944)

Walter Heinrich Caecilius Holzhausen wurde am 23. Juli 1896 als Sohn des Gymnasialprofessors Paul Otto Franz Holzhausen und dessen Frau Marie Magdalene Louise Clara, geb. Hüneke, in Bonn geboren. Sein Abitur legte Holzhausen 1914 am Königlichen Gymnasium Bonn ab, an dem sein Vater unterrichtete. Im Anschluss studierte er zunächst bei Wilhelm Döringer und Willy Spatz an der Düsseldorfer Kunstakademie, ab 1916 an der Universität Bonn Kunstgeschichte, Philosophie und Archäologie, wo u. a. Paul Ortwin Rave und Heinrich Lützeler zu seinen Kommilitonen zählten. Für den Studienabschluss wechselte Holzhausen an die Universität München, wo er im Dezember 1919 bei Heinrich Wölfflin promoviert wurde. Vom Oktober 1920 bis September 1921 absolvierte Holzhausen den Vorkurs bei Johannes Itten am Bauhaus in Weimar. Damals begann die Freundschaft zu Naum Slutzky, auch hatte er Kontakt zu Walter Gropius, Oskar Schlemmer und Paul Klee. Ab Herbst 1921 studierte Holzhausen für ein Semester in der Gold- und Silberschmiedeklasse von Ernst Riegel an der Kunstgewerbeschule in Köln. Nach dieser umfangreichen kunsthistorischen wie künstlerischen Ausbildung arbeitete er jedoch zunächst als kaufmännischer Angestellter in Köln, später bis 1925 bei der Max Elb AG in Dresden.

Seine Museumslaufbahn begann Holzhausen Mitte Mai 1925 als Freiwilliger Wissenschaftlicher Hilfsarbeiter am Grünen Gewölbe in Dresden. Diese unterbrach er ab Oktober 1927 für ein Jahr, um als sächsischer Stipendiat am Kunsthistorischen Institut in Florenz tätig zu sein und eine Studienreise nach Paris zu unternehmen. Als er im Oktober 1928 nach Dresden zurückkehrte, wurde er als Wissenschaftlicher Hilfsarbeiter am Grünen Gewölbe und Historischen Museum, die beide unter der Leitung von $>$ Erich Haenel standen, eingestellt. Da im Stellenplan dieser Museen damals keine Kustodenstellen enthalten waren und ein beruflicher Aufstieg daher unmöglich erschien, bewarb sich Holzhausen im Oktober 1931 um die mit der nahenden Pensionierung von $\triangleright$ Ernst Zimmermann zu besetzende Direktorenstelle der Porzellansammlung. Allerdings hatte er damit ebenso wenig Erfolg wie zwei Jahre später Haenel mit dem Vorschlag, Holzhausen als Kustos in der Porzellansammlung einzusetzen. ${ }^{1}$ Diese Stelle erhielt stattdessen

$1 \quad$ Details siehe S. $69 \mathrm{ff}$. 
>Fritz Fichtner, während Holzhausen als Wissenschaftlicher Hilfsarbeiter am Grünen Gewölbe und am Historischen Museum verblieb. An der Seite von Haenel arbeitete er an mehreren Ausstellungen mit, insbesondere 1933 an „August der Starke und seine Zeit“. Die letzte von Holzhausen in Dresden eigenständig kuratierte Ausstellung „Kostbarkeiten des Grünen Gewölbes im Lichtbild“ (1943) war zugleich eine der letzten Ausstellungen der Staatlichen Sammlungen während des Zweiten Weltkrieges. ${ }^{2}$ Auch für die Museumswochen engagierte sich Holzhausen. Gemeinsam mit $\gg$ Hans Kummerlöwe war er 1939 für die dafür benötigte Öffentlichkeitsarbeit verantwortlich und arbeitete mit $\gg$ Michael Hesch und $>$ Hellmuth Buck in der Kommission zur Vorbereitung der Museumswoche 1941. Nebenher verfasste Holzhausen zahlreiche Artikel und Aufsätze für diverse Zeitschriften und für Dresdner Tageszeitungen, wie den Dresdner Anzeiger. Die thematische Bandbreite reichte dabei von den barocken Goldschmiedearbeiten des Johann Melchior Dinglinger bis hin zur zeitgenössischen Kunst, wie den Fotografien von Edmund Kesting. Diese reiche Publikationstätigkeit endete 1939 vorerst. Bereits im Januar 1938 war Holzhausen durch Fichtner, der inzwischen Referent der Staatlichen Sammlungen im Ministerium für Volksbildung war, mit der Vertretung des erkrankten Direktors Haenel beauftragt worden. Einerseits hatte Holzhausen damit mehr Verantwortung für die Sammlung zu übernehmen, andererseits war er seit Juli 1927 mit der Kunsthandwerkerin und Weberin Erika Große-Leege aus Duisburg verheiratet, mit der er zwei Söhne hatte, und stand somit in finanzieller Verantwortung für seine Familie. Aus diesem Grunde bemühte er sich ab 1938 mehrfach um die Umwandlung seiner Stelle in eine finanziell besser dotierte Kustodenstelle. Ab März 1939 bewarb er sich um die Direktorenstelle seines Vorgesetzten, die durch die reguläre Pensionierung Haenels absehbar frei werden würde. Doch trotz der Empfehlungen von den Direktoren des Germanischen Nationalmuseums Nürnberg und des Schloßmuseums in Berlin verliefen Holzhausens Bemühungen auch nach Haenels Tod erfolglos. Daher reichte Holzhausen 1941 eine „Denkschrift zur weiteren Führung des Historischen Museums und des Grünen Gewölbes" ein und erklärte, daß er ,jederzeit rückhaltlos für den nationalsozialistischen Staat eintrete und eintreten werde“3. Bereits zwei Jahre zuvor hatte Holzhausen angekündigt: „Es ist mein unbedingter Wille und mein Ehrgeiz, die Gedanken der heutigen Zeit, in der ich als Pg. und als langgedienter SA-Mann meine Pflicht erfüllte, auf dem Gebiet der Museumsarbeit an leitender Stelle immer stärker in die Tat umzusetzen zu helfen. " ${ }^{4}$ In der Tat war er seit Juni 1933 Mitglied im Opferring der NSDAP. Als Mitglied des Stahlhelms wurde er im Februar 1934 in die SA zwangsüberführt. Ab 1936 trat er weiteren NS-Organisationen, wie RDB, RLB und NSV, bei. Mitglied der NSDAP wurde Holzhausen erst 1937, als eine berufliche Weiterentwicklung längst an die Parteimitgliedschaft gekoppelt war. Der erhoffte Karriereschub blieb allerdings weiterhin aus. Obwohl Holzhausen im Frühjahr 1941 auf der Kandidatenliste für die Wiederbesetzung der Haenel-Stelle an erster Stelle vor $>$ Rudolf von Arps-Aubert stand, wurde er nicht zum Direktor ernannt. Fichtner war überzeugt, daß Holzhausen „ein sehr umgänglicher Kollege sein wird, sobald er von der Sorge um die Zukunft befreit ist“ ${ }^{\text {“ }}$, verwies aber darauf, dass er „ein ausgezeichneter Kunstgewerbler und daher wohl für das Grüne Gewölbe in leitender Stellung geeignet sei, [...] aber hinsichtlich der Waffenkunde also als Leiter des Historischen Museums nicht die nöti-

Siehe S. 214-217.

W. Holzhausen, Erklärung, 9.6.1941, HStA Dresden, 13859, Nr. 3429, fol. 17.

W. Holzhausen an SMV, 2.3.1939, HStA Dresden, 11125, Nr. 22882, fol. 70 f., hier: 70.

Fichtner an Kohlhaussen, Germanisches Nationalmuseum Nürnberg, 4.1.1941, SKD Archiv, 01/ PS 53, Bd. 2, fol. 78. 
gen Kenntnisse besitze“6. Letztlich blieb die Direktorenstelle bis Kriegsende und auch danach unbesetzt. Stattdessen wurde Holzhausen im April 1942 zum Kustos ernannt. Drei Monate später, Anfang Juli 1942, wurde ihm die kommissarische Leitung des Grünen Gewölbes übergeben. Allerdings blieb er weiterhin Kustos und hatte auf allen Schriftstücken „mit der Leitung beauftragt " ${ }^{\text {"7 }}$ zu zeichnen. Im November 1942 übernahm Holzhausen auch die kommissarische Leitung des Historischen Museums. Das Jahr 1942 war somit für ihn ein beruflich erfolgreiches, allerdings auch ein persönlich schicksalhaftes Jahr, denn seine Schwester starb in der Heil- und Pflegeanstalt in Bernburg an der Saale. ${ }^{8}$ In Dresden als Kustos „mit der Leitung beauftragt“, also als Kommissarischer Leiter zweier Sammlungen, war Holzhausen nun auch für deren Bergung zuständig. Aufgrund seiner Sachkenntnis wurde er uk-gestellt: „Er ist der einzige, der über die einzelnen Werke nach Art, Erhaltung, Wert und Anzahl Bescheid weiß. Ihre kriegsmässige Bergung in nicht musealen Räumen macht eine ständige Kontrolle durch ihn als einzigen Sachverständigen notwendig. ${ }^{\text {"9 }}$ Wegen der sich durch den Krieg verstärkenden Personalengpässe wurde Holzhausen ab Juli 1944 an das Statistische Landesamt abgeordnet. Damit stand er nur noch an zwei Wochentagen für das Historische Museum und das Grüne Gewölbe zur Verfügung. Zusätzlich wurde ihm im September 1944 die kommissarische Leitung des Münzkabinetts übertragen, nachdem > Klaus Günther zum Militär einberufen worden war. Damit zeichnete Holzhausen für die Betreuung und Verwaltung dreier Sammlungen verantwortlich, die er auch an ihren Auslagerungsorten betreute.

Bei den Bombenangriffen auf Dresden am 13./14. Februar 1945 wurde die Holzhausen'sche Wohnung zerstört. Holzhausen erlitt einen Schock und ging mit seiner Familie zunächst nach Königstein, dem Hauptauslagerungsort des Grünen Gewölbes. Später, vermutlich im April 1945, zog er nach Halsbach bei Freiberg und schließlich zur Familie des befreundeten Künstlers Heinrich Burkhardt nach Altenburg. Dort leitete Holzhausen von November 1945 bis Oktober 1946 das Heimatmuseum Poschwitz. Im folgenden Jahr verließ er die sowjetische Besatzungszone und kehrte - wiederum gefolgt von seiner Familie - in seine Geburtsstadt Bonn zurück. Dort leitete er ab Oktober 1947 die Städtischen Kunstsammlungen und beteiligte sich am Aufbau des Ausstellungswesens im Rheinland nach dem Krieg. Ab Juni 1957 bis zu seiner regulären Pensionierung Ende Juli 1961 war Holzhausen Direktor der Städtischen Kunstsammlungen Bonn. Deren Sammlung des Rheinischen Expressionismus erweiterte er maßgeblich, unter anderem durch ein großes Werkkonvolut aus dem Nachlass von August Macke. Im Rheinland setzte Holzhausen seine frühere Publikationstätigkeit fort. 1966 konnte endlich sein Buch über die Kunstschätze des Grünen Gewölbes mit Fotografien von Edmund Kesting erscheinen, dessen Manuskript er im Zweiten Weltkrieg vollendet hatte. Walter Holzhausen starb am 31. Oktober 1968 in Bonn.

6 [Betr. Berufung, 2.1941], HStA Dresden, 11125, Nr. 22882, fol. 96-100, hier: 97 f. Siehe S. 83 f. 7 Fichtner an Leiter SMV, 2.7.1942, SKD Archiv, 01/PS 53, Bd. 2, fol. 64. Den entsprechenden Amtseid als Kustos leistete W. Holzhausen sogar erst Ende Mai 1942 bei Fichtner.

8 Vgl. W. Holzhausen, handschriftlicher Lebenslauf, nach 1945, StAB, PA 1978/4377, Bd. 1, o. Pag. Vermutlich hat er damals noch nicht gewusst, dass sie von den Nationalsozialisten ermordet wurde.

9 Leiter SMV, 16.11.1942, HStA Dresden, 11125, Nr. 22882, fol. 213. 


\section{Auswahlbibliografie}

Die Entwicklung des deutschen Ornamentstichs im Zeitalter des Barocks, Wien 1922 (Zugl. München, Univ., Diss., 1919).

Die Bronzen der kurfürstlich sächsischen Kunstkammer zu Dresden, in: Jahrbuch der Preußischen Kunstsammlungen, Bd. 54, 1933, S. 45-88.

Meisterwerke der Juwelierkunst des 16. und 17. Jahrhunderts: Studien, in: Jahrbuch der Kunsthistorischen Sammlungen in Wien. N. F. Bd. 9, Wien 1935, S. 167-182.

Das Grüne Gewölbe zu Dresden. Führer durch seine Geschichte und seine Sammlungen, Dresden 1937.

Die Rolle der Graphik im Werk Johann Melchior Dinglingers, in: Die graphischen Künste, N. F. Bd. 4, 1939, S. 93-115.

Sächsische Gläser des Barock, in: Zeitschrift für Kunstgeschichte, Bd. 8, 1/2, 1954, S. 95-124

August Macke, München 1956.

Die Blütezeit bergmännischer Kunst, in: Der Bergbau in der Kunst, Essen 1958, S. 113-218.

Lackkunst in Europa: ein Handbuch für Sammler und Liebhaber, Braunschweig 1958.

Prachtgefäße, Geschmeide, Kabinettstücke. Goldschmiedekunst in Dresden, Tübingen 1966.

\section{Quellen und Literatur}

HStA Dresden, 13859, Nr. 3429

HStA Dresden, 11125, Nr. 19192; Nr. 22882; Nr. 22884; Nr. 22891; Nr. 22895

SKD Archiv, 01/PS 53, Bd. 1 u. 2

StAB, PA 1978/4377, Bd. 1

StAB, Pr 42/965, Bd. 1

BArch, R 9361-IX/Kartei/16741264; R 9361-VIII/Kartei/12260507

Interview Peter Holzhausen, 19.7.2018

Interview Hans-Jürgen Holzhausen, 29.8.2018 


\title{
Kurt Hoppe
}

\author{
$6.12 .1887-[?]$ \\ Präparator \\ Grünes Gewölbe \\ 1.12.1913-31.12.1922 [?] \\ 1.1.1923-28.2.1938 Sammlungsaufseher \\ Münzkabinett \\ 1.3.1938-30.4.1938 Hilfspräparator \\ 1.5.1938-15.11.1945 Präparator \\ 11.8.1944-5.1945 Depotverantwortlicher
}

Über das Leben von Kurt Hoppe sind nur wenige Fakten überliefert. Am 6. Dezember 1887 geboren, arbeitete Hoppe ab Dezember 1913 im Grünen Gewölbe, wo er zum 1. Januar 1923 zum Sammlungsaufseher ernannt wurde. Hoppe wurde im März 1938 als Hilfspräparator zum Münzkabinett versetzt, um dort von Präparator Johannes Neubert innerhalb von zwei Monaten eingearbeitet zu werden und nach dessen Pensionierung im Mai 1938 die Aufgaben als Präparator zu übernehmen. Die entsprechende Ernennungsurkunde wurde ihm im Juni 1938 überreicht. Da der Leiter des Münzkabinetts, $\triangleright$ Walter Schwinkowski, bereits ein Jahr zuvor in den Ruhestand getreten war, sollte diese Übergangsregelung eine gewisse Kontinuität in der Arbeit des Kabinetts wahren helfen. In der Tat war Hoppe derjenige der während der NS-Zeit tätigen Sammlungsverantwortlichen im Münzkabinett, der über die beste Objektkenntnis verfügte, anders als z. B. der zeitgleich mit ihm eingestellte $>$ Rolf Hetsch, der die stellvertretende Leitung übernahm. Nachdem Hetsch Dresden wieder verlassen hatte und es mehrere Interimslösungen gab, wurde Hoppe im Juli 1942 die „selbständige und in der praktischen Durchführung allein verantwortliche Ausführung der Bergungsarbeiten der kulturellen und künstlerischen Sammlungsbestände des Staatl. Münzkabinetts"1 übertragen. In dieser Funktion besprach er im März 1940 mit $>$ Fritz Fichtner das Procedere für die Beseitigung der sogenannten Bleipest am Bestand des Münzkabinetts. Am 11. August 1944 wurde Hoppe die Depotverantwortung und die Betreuung der kriegsbedingt geborgenen Objekte übertragen. Als er als einer der wenigen Mitarbeiter der Staatlichen Sammlungen durch den Luftangriff auf Dresden am 7. Oktober 1944 seine Wohnung verlor, genehmigte man ihm ausnahmsweise das vorübergehende Unterstellen seiner Möbel in den leeren Räumen des Münzkabinetts. Aufgrund seiner seit Mai 1937 bestehenden NSDAP-Mitgliedschaft wurde Kurt Hoppe zum 15. November 1945 aus dem Dienst der Staatlichen Sammlungen entlassen ${ }^{2}$ Danach verliert sich seine Spur.

\section{Quellen und Literatur}

HStA Dresden, 11125, Nr. 22895

SKD, MK, 1938

BArch, R 9361-VIII/Kartei/12380479

1 W. Holzhausen, Grünes Gewölbe, an Fichtner, Porzellangalerie, 10.7.1942, SKD Archiv, 01/PS 53, Bd. 2, fol. 61r.

2 Vgl. Kanzlei der Staatlichen Museen, Fischer, an Landesverwaltung Sachsen, Zentralverwaltung für Wissenschaft, Kunst und Erziehung, Grohmann, 24.11.1945, SKD Archiv, 02/VA 162, fol. 40. 


\section{ARNOLD JaCOBI}

31.1.1870 Leipzig - 16.6.1948 Dresden

Zoologe, Ornithologe, Ethnograf

Museen für Tierkunde und Völkerkunde

(bis 11.1918 Königliches Zoologisches und AnthropologischEthnographisches Museum)

1.10.1906-30.4.1935 Direktor

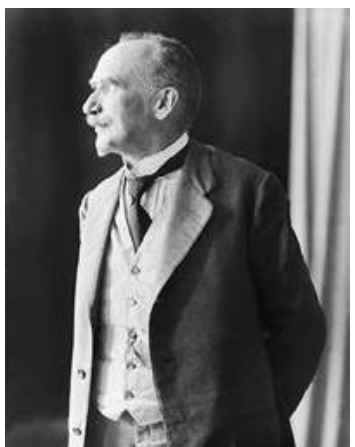

Arnold Friedrich Victor Jacobi, der Sohn des Philosophieprofessors Victor Friedrich Leopold Jacobi und dessen Frau Flora, geb. Heiner, wurde am 31. Januar 1870 in Leipzig geboren. Seine Reifeprüfung legte er 1890 an der Leipziger Thomasschule ab. Danach studierte Jacobi in Leipzig Naturwissenschaften, neben Zoologie bei Rudolf Leuckart und William Marshall auch Geografie, Ethnografie sowie Russisch und Arabisch. Sein Ziel war es, später zoologische Forschung im Ausland zu leisten. Nachdem er im Januar 1895 promoviert worden war, ${ }^{1}$ meldete er sich im Frühjahr 1896 zum Kolonialdienst, doch seine Bewerbung wurde abgelehnt. So wechselte Jacobi in den Schuldienst. Zunächst absolvierte er das obligatorische Vorbereitungsjahr in Leipzig, bevor er als Realschullehrer in Stollberg im Erzgebirge tätig wurde. Im Februar 1899 legte er die Prüfung für das Lehramt an Höheren Schulen ab. Doch bereits einen Monat vorher hatte er eine Anstellung als technischer Hilfsarbeiter in der Biologischen Abteilung für Land- und Forstwirtschaft beim Kaiserlichen Gesundheitsamt in Berlin gefunden. Dort war er vor allem mit entomologischen Untersuchungen im Rahmen des Pflanzenschutzes betraut, hatte aber auch Gelegenheit, auf der Weltausstellung in Paris den Beitrag des Kaiserlichen Gesundheitsamtes zu betreuen. Im Herbst 1900 weilte er für einen sechswöchigen Studienaufenthalt in der Biologischen Anstalt Helgoland. Parallel dazu vertiefte er seine privaten Studien über die Systematik der Zikaden (Cicadariae) und beschrieb mehrere Gleichflügler (Homoptera). Seine Bewerbung um die Stelle eines Kustos der Senckenbergischen Naturwissenschaftlichen Gesellschaft am Frankfurter Museum scheiterte an der Vielzahl der Bewerber. 1902 heiratete er Olga, geb. Dolberg, mit der er vier Kinder hatte. Ein neuer beruflicher Weg eröffnete sich Jacobi ab April 1903 mit seiner Berufung auf den Lehrstuhl für Zoologie an der Königlichen Forstakademie zu Tharandt bei Dresden. Zunächst als außerordentlicher Professor, ab Juni 1904 als ordentlicher Professor widmete er sich vor allem Fragen der Forstzoologie.

Am 1. Oktober 1906 wurde Jacobi unter Belassung des Professorentitels zum Direktor des Königlichen Zoologischen und Anthropologisch-Ethnographischen Museums in Dresden ernannt. Er übernahm das Museum, als der frühere Direktor Adolf Bernhard Meyer aufgrund einer Verfehlung suspendiert worden war, und führte es durch die Kriegs- und Nachkriegsjahre, erweiterte die zoologischen wie auch die ethnologischen Bestände durch Ankäufe und Sammelreisen. Jacobi selbst unternahm zwei große Studienreisen in das nordeuropäische Polargebiet 1908 nach Schwedisch-Lappland und 1913 nach Rußland, insbesondere zu den Samojeden der

Petschel 2003, S. 406 und Meier 2010 datieren die Promotion auf 1896. 
Halbinsel Kanin - die zoologisch ausgerichtet waren, aber auch ethnografische Studien und den Erwerb von Objekten für das Dresdner Museum einschlossen. Ebenso engagierte er sich bei der Erschließung der Sammelausbeuten anderer Forscher, wie z. B. der Expeditionen von Walther Stötzner. So trug er eine äußerst umfangreiche Zikadensammlung zusammen. Jacobi verteilte die zur Verfügung stehenden Etatmittel gleichmäßig auf die Abteilungen des Museums, besetzte die Stellen mit Zoologen, Ethnologen und Anthropologen, die parallel Lehraufträge wahrnahmen. Er setzte die Umbenennung in Museen für Tierkunde und Völkerkunde durch und strebte die Trennung in zwei selbständige Museen an. Mit seinen ungewöhnlich vielseitigen Kenntnissen trug er maßgeblich zur Entwicklung und Profilierung des Museums bei. Er engagierte sich für den Ausbau der Ausstellungstätigkeit und eine Modernisierung des Museums. Während seines Direktorates wurde es zu einer in der Dresdner Öffentlichkeit sehr beliebten Institution. Parallel zu seiner Tätigkeit als Museumsdirektor war Jacobi von Oktober 1908 bis zum Sommer 1936 Honorarprofessor für Allgemeine Zoologie an der Technischen Hochschule Dresden und damit für die dort bestehende zoologische Sammlung verantwortlich. Er pflegte intensive Verbindungen zu seinen Fachkollegen, engagierte sich in diversen Fachverbänden und Vereinen. Bereits seit 1892 war er Mitglied der Deutschen Ornithologischen Gesellschaft. In der Naturwissenschaftlichen Gesellschaft „Isis“ zu Dresden, der er 1904 beitrat, übernahm er mehrfach leitende Funktionen, ebenso im Verein Sächsischer Ornithologen. Als die naturwissenschaftlichen Museen reichsweit begannen, ihre Interessen gemeinschaftlich zu vertreten, engagiert sich Jacobi ab April 1928 als Erster Beisitzer des Bundes der Deutschen naturwissenschaftlichen Museen. 1929 zählte er zu den Mitbegründern der Gesellschaft für Völkerkunde. Kollegen beschrieben Jacobi als aufrechten Menschen, so auch Rudolph Zaunick: „Nur an der Forderung seiner Lebensgestaltung, seiner Lebenshaltung, seiner wissenschaftlichen und politischen Anschauungen hielt er unverrückbar fest. “2 Diese innere Haltung ermöglichte es Jacobi, in seinem Amt als Museumsdirektor eigentlich dem NS-Staat verpflichtet, den jüdischen Kustos $\gg$ Fritz van Emden zu unterstützen, nachdem dieser auf Anweisung von Reichsstatthalter Mutschmann entlassen worden war. ${ }^{3}$ Eine NSDAP-Mitgliedschaft ist von Jacobi nicht überliefert, allerdings unterzeichnete er im November 1933 das „Bekenntnis der Professoren an den deutschen Hochschulen zu Adolf Hitler $^{\text {“4 }}$. Zum 30. April 1935 wurde Jacobi aufgrund des Erreichens der Altersgrenze regulär in den Ruhestand versetzt. Gleichzeitig trat er nach sieben Jahren von der Geschäftsführung der Direktorenkonferenz der Staatlichen Sammlungen zurück und übergab diese dem Direktor der Sächsischen Landesbibliothek $>$ Martin Bollert. ${ }^{5}$

Nach seiner Pensionierung war Jacobi noch ehrenamtlich am Museum tätig, forschte und publizierte weiterhin. Auch bearbeitete er die Ausbeuten verschiedener zoologischer Sammlungsreisen für Institutionen und Einzelpersonen im In- und Ausland wissenschaftlich. Über 600 Arten wur-

\footnotetext{
2 Zaunick, Rudolph: Arnold Jacobi (1870-1948), ein sächsischer Zoologe und Ethnograph, in: Beiträge zur Vogelkunde, Bd. 8, 1962, S. 170-205, hier 198.

3 Siehe Biografie $\gg$ Fritz van Emden und S. 50 ff.

4 Nationalsozialistischer Lehrerbund Deutschland/Sachsen 1933, S. 132.

5 Vgl. Jacobi an Direktoren der Staatlichen Sammlungen, 6.4.1935, SKD, MK, 1935-1936, fol. 11 u. SLUB, Bibl.-Arch.III.G,Vol.686.c, o. Pag.; Jahresbericht 1935 St. Museen für Tierkunde und Völkerkunde, HStA Dresden, 11125, Nr. 19003, fol. 230.8. Vgl. DA, 30.4.1935 u. DNN, 1.5.1935, S. 15. Eine Abschiedsfeier für Jacobi, bei der Bollert sprach, fand am 2.5.1935 statt. Vgl. SLUB, Mscr. Dresd.App.1378b, fol. 37. Emmrich 1980, S. 35 und Meier 2010 datieren die Pensionierung Jacobis ohne Quellenangaben auf 1936.
} 
den von ihm neu beschrieben. Seine Publikationsliste umfasst zahlreiche wissenschaftliche Veröffentlichungen über unterschiedlichste Themen, von der Biogeografie über vergleichende Anatomie, Systematik der Säugetiere, Vögel und Kerbtiere, allgemeine und forstliche Zoologie, Parasitologie, Naturschutz bis hin zu Geografie und Ethnografie. Im März 1941 heiratete er Hildegard, geb. Bösch. Arnold Jacobi starb am 16. Juni 1948 in Dresden.

\section{Auswahlbibliografie}

Anatomische Untersuchungen an malayischen Landschnecken (Amphidromus chloris und Amphidromus interruptus), in: Archiv für Naturgeschichte, 61, 1, 1895, S. 293-318 (Zugl. Leipzig, Univ., Diss., 1895).

Lage und Form biogeographischer Gebiete, in: Zeitschrift der Gesellschaft für Erdkunde, 35, 1900, S. 147-238.

Tiergeographie, Leipzig 1904.

Die Bedeutung der Farben im Tierreiche, Brackwede/Westf. 1904.

Homoptera Andina, Bd. 1: Cicadidae, in: Abhandlungen und Berichte des Zoologischen und Anthropologisch-Ethnographischen Museums zu Dresden, Bd. 5, 1907.

Grundriß der Zoologie für Forstleute, Tübingen 1906.

Mimikry und verwandte Erscheinungen, Braunschweig 1913.

Eine völkerkundliche Sammlung von den europäischen Samojeden, in: Abhandlungen und Berichte des Zoologischen und Anthropologisch-Ethnographischen Museums zu Dresden, Bd. 15.2, 1917.

Das Rentier. Eine zoologische Monographie der Gattung Rangifer, Leipzig 1931.

Der Seeotter, Monographien der Wildsäugetiere, Bd. 6, Leipzig 1938.

\section{Quellen und Literatur}

HStA Dresden, 13842, insbes. Nr. 047; Nr. 114; Nr. 204; Nr. 210

Kumerloeve, Hans: Arnold Jacobi $\dagger$, in: Naturwissenschaftliche Rundschau, 5. Jg., 1952, H. 3 , S. 130.

Zaunick, Rudolph: Arnold Jacobi (1870-1948), ein sächsischer Zoologe und Ethnograph, in: Beiträge zur Vogelkunde, Bd. 8, 1962, S. 170-205.

Gebhardt, Ludwig: Die Ornithologen Mitteleuropas, Gießen 1964, S. 171.

Emmrich, Rainer: Professor Arnold Jacobi 1870-1948, in: Blick ins Museum. Mitteilungen aus den Staatlichen Wissenschaftlichen Museen, Dresden, 24/25, 1980, S. 32-35.

Petschel, Dorit: 175 Jahre TU Dresden. Band 3: Die Professoren der TU Dresden 1828-2003. Hrsg. im Auftrag der Gesellschaft von Freunden und Förderern der TU Dresden e. V. von Reiner Pommerin, Köln u. a. 2003, S. 406.

Petzsch, Hans: Arnold Jacobi, in: Neue Deutsche Biographie, Bd. 10, Berlin 1947, S. 220 ff.

Meier, Gudrun; Jacobi, Arnold Friedrich Victor, in: Sächsische Biografie, 2010, Online-Ausgabe: http://saebi.isgv.de/biografie/Arnold_Jacobi_(1870-1948), Zugriff: 2.1.20209. 


\title{
Karl Wilhelm JäHNig
}

\author{
4.12.1888 Hohenstein-Ernstthal - 15.11.1960 Basel \\ Kunsthistoriker \\ Gemäldegalerie \\ 15.6.1915- [1918] Freiwilliger Wissenschaftlicher Hilfsarbeiter \\ [1918] -31.3.1926 Wissenschaftlicher Hilfsarbeiter \\ 1.4.1926-1.11.1937 Kustos
}

Karl Wilhelm Jähnig wurde am 4. Dezember 1888 in Hohenstein-Ernstthal als Sohn des Bürgerschullehrers Carl Wilhelm Jähnig und dessen Frau Minna Marie, geb. Milkner, geboren. Von 1901 bis 1908 lernte er am Königlichen Gymnasium in Chemnitz. Nach bestandener Abiturprüfung studierte er an den Universitäten in München, Kiel und Leipzig Germanistik, Geschichte und Kunstgeschichte. 1914 wurde Jähnig als Schüler von August Schmarsow in Leipzig promoviert.

Ab Juni 1915 arbeitete Jähnig als Freiwilliger Wissenschaftlicher Hilfsarbeiter unter Direktor - Hans Posse in der Gemäldegalerie Dresden. 1918 wurde er als Wissenschaftlicher Hilfsarbeiter eingestellt und zum 1. April 1926 zum Kustos ernannt. Jähnig hielt zahlreiche Führungen in der Gemäldegalerie, auch referierte er gelegentlich bei den sonntäglichen Museumsvorträgen, so im April 1934 über „Caspar David Friedrich“. Er verfasste kleinere Beiträge für Tageszeitungen und Zeitschriften. Unterstützt von der damaligen Freiwilligen Wissenschaftlichen Hilfsarbeiterin Klara Steinweg, bearbeitete Jähnig den ersten „Katalog der modernen Galerie“ im Sekundogenitur-Gebäude auf der Brühlschen Terrasse. Insbesondere mit seinen Forschungen zu Caspar David Friedrich erarbeitete er sich einen über Dresden hinausreichenden Ruf als Spezialist für die Dresdner Romantik. Nach der erneuten Überprüfung der Personalien der Mitarbeiter, wobei die „arische Abstammung“ der Ehegatten nachgewiesen werden musste, wurde Jähnig zum 1. November 1937 gemäß $\$ 6$ des „Gesetzes zur Wiederherstellung des Berufsbeamtentums“ vom 7.4.1933 in den dauernden Ruhestand versetzt. Grund dafür war seine Ehe mit der jüdischen Ärztin Britta Jähnig; eine Scheidung von ihr hatte Jähnig abgelehnt. Bereits Monate vorher war die Kunde seiner bald zu erwartenden Entlassung durch Kunsthistorikerkollegen über Berlin bis nach Florenz gedrungen, weshalb der Direktor des Kunsthistorischen Instituts, Friedrich Kriegbaum, bereits im September 1937 - Robert Oertel als Nachfolger vorschlug, der diese Stelle später tatsächlich bekam. ${ }^{1}$

Jähnig emigrierte und folgte seiner Ehefrau nach Basel in die Schweiz. Als ihm 1944 die deutsche Staatsbürgerschaft aberkannt wurde, verlor er damit seinen in Deutschland zurückgelassenen Besitz, wie das 1935 gebaute Haus in Dresden-Strehlen. Im Exil arbeitete er als freiberuflicher Kunsthistoriker. Seine Expertise war gefragt, gemeinsam mit Helmut Börsch-Supan bereitete er eine umfassende Publikation über Friedrich vor, wofür er u. a. im Dezember 1959 in München weilte. ${ }^{2}$ Die Veröffentlichung erfolgte jedoch erst posthum. Karl Wilhelm Jähnig starb am 15. November 1960. Seine Urne wurde nach München überführt und dort am 12. April 1961 beigesetzt.

Siehe S. 399 f.

2 Vgl. Jähnig an Schoene, 9.12.1959, SMB-ZA, II/VA 15857, o. Pag. 


\section{Auswahlbibliografie}

Die Darstellungen der Kreuzabnahme, der Beweinung und der Grablegung Christi in der altniederländischen Malerei von Rogier van der Weyden bis zu Quentin Metsys (Leipzig, Univ., Diss., 1914).

Caspar David Friedrichs „Friedhofseingang“ in der Dresdner Galerie, in: Zeitschrift für bildende Kunst, N. F., 55, 1920, S. 145-147.

Tizian, München 1921.

Sächsische Maler des 18. und 19. Jahrhunderts, in: Jahrbuch Sachsen. Politik u. Wirtschaft, Kunst u. Wissenschaft im Freistaat Sachsen, Dresden 1925, S. 98-113.

C. D. Friedrichs früheste Bilder „Sommer“ und „Winter“, in: Die Kunst für alle. Malerei, Plastik, Graphik, Architektur, München, Bd. 42, 1927/28, S. 255-257.

Ein Jugendselbstbildnis von C. D. Friedrich, in: Kunst und Künstler. Illustrierte Monatsschrift für bildende Kunst und Kunstgewerbe, Berlin, Bd. 26, 1928, S. 312-314.

Die Staatliche Gemäldegalerie zu Dresden - Katalog der Modernen Galerie, Dresden 1930 (Hg., mit Hans Posse u. Klara Steinweg).

Eine unbekannte Elbtallandschaft von C. D. Friedrich, in: Kunst und Künstler. Illustrierte Monatsschrift für bildende Kunst und Kunstgewerbe, Berlin, Bd. 31, 1932, S. 366-368.

Caspar David Friedrich, in: Pommersche Lebensbilder, Pommern des 19. und 20. Jahrhunderts, Bd. 19, 1934, S. 25-42.

Caspar David Friedrich: Gemälde, Druckgraphik u. bildmäßige Zeichnungen, Jahresgabe des Deutschen Vereins für Kunstwissenschaft, Studien zur Kunst des 19. Jahrhunderts, Sonderband 1974/75, München 1973 (mit Helmut Börsch-Supan).

\section{Quellen und Literatur}

Spitzer, Gerd: Caspar David Friedrich in der Dresdener Galerie. Karl Wilhelm Jähnig zum Gedächtnis, in: Dresdener Kunstblätter, 54 Jg., H. 4, 2010, S. 245-250. 


\title{
EWALD JAMMERS
}

\author{
1.1.1897 Köln - 24.6.1981 Plankstadt
}

Musikwissenschaftler, Wissenschaftlicher Bibliothekar

Sächsische Landesbibliothek

1.10.1925-30.9.1927 Volontär

1.10.1927-31.3.1932 Wissenschaftlicher Hilfsarbeiter

1.4.1932-5.1945 Landesbibliothekar, Bibliotheksrat

(Militärdienst 10.1938, 9.1939, 25.9.1944-5.1945)

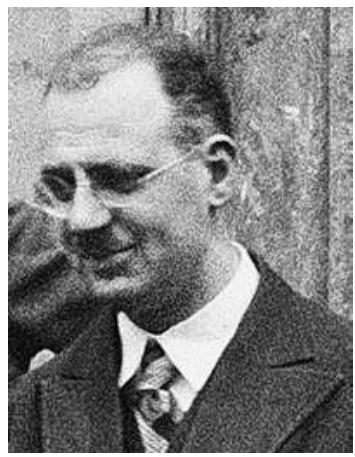

Ewald Karl Hubert Maria Jammers wurde als Sohn des Obersteuerkontrolleurs Ewald Jammers und dessen Frau Elvire, geb. Strom, am Neujahrstag 1897 in Köln geboren. Nach dem Abitur am Königlichen Gymnasium in Bonn studierte er ab 1915, unterbrochen durch den Militärdienst im Ersten Weltkrieg von März 1917 bis November 1918, in Bonn Musikwissenschaft, Geschichte, Literaturgeschichte, Ethnologie, Philosophie, Geografie und Kunstgeschichte nach seinen „Wünschen, nicht nach den Prüfungsordnungen“1. Von November 1921 bis Ende Januar 1924 arbeitete er als Angestellter im Versorgungskrankenhaus Köln, bevor er im Dezember 1924 an der Universität Bonn promoviert wurde. Im Mai 1925 legte er außerdem das Staatsexamen in Germanistik ab. Auf der Suche nach einem Volontariat wandte er sich zunächst an die Universitätsbibliothek in Leipzig, wurde jedoch von deren Direktor Otto Glauning nach Dresden verwiesen, wo er sich im August 1925 bewarb.

Im Oktober 1925 begann Jammers sein Volontariat an der Sächsischen Landesbibliothek in Dresden. Wie damals üblich, absolvierte er dessen zweiten Teil in Leipzig, wo er im September 1927 die Prüfung für den Höheren Dienst in wissenschaftlichen Bibliotheken inklusive einer Sonderprüfung in Verwaltung von Musikalien ablegte. Während des Volontariats erhielt er von der Notgemeinschaft der deutschen Wissenschaft ein Stipendium zur Erforschung der „Antiphonen des gregorianischen Chorales“, die er erst Ende der 1930er-Jahre weiterführte. Nach seinem Examen wurde er im Oktober 1927 als Wissenschaftlicher Hilfsarbeiter in der Sächsischen Landesbibliothek angestellt, um Arno Reichert in der Musikabteilung zu unterstützen. Als dieser 1931 in den Ruhestand ging, übernahm Jammers die Leitung der Musikabteilung. Einige Monate später, im April 1932, erfolgte seine Beförderung zum Landesbibliothekar, mit der er den Titel eines Bibliotheksrates erhielt. Im Oktober 1935 ordnete Arthur Göpfert als Leiter des Ministeriums für Volksbildung an, Jammers „die Verwaltung der weltanschaulichen Fächer “2 zu entziehen, offensichtlich galt er, da er nicht in die NSDAP eintrat, sondern lediglich Mitglied im RDB und RLB war, als politisch nicht zuverlässig. Gegenüber $>$ Martin Bollert beteuerte Jammers, dass er sich bemüht habe, „die Fächer, insbesondere was Gesinnung und Gewissenhaftigkeit anbetrifft, so zu verwalten, wie man es von einem nationalsozialistischen Beamten verlangt “3 - damit war für alle Seiten die Angelegenheit geklärt. Nachdem Jammers bereits während

Jammers 2002, S. 307.

Jammers an Direktion der Sächsischen Landesbibliothek, 28.10.1935, SLUB, PA Jammers.

Ebd. 
der „Sudetenkrise“ im Oktober 1938 und unmittelbar nach Beginn des Zweiten Weltkrieges, im September 1939, für wenige Tage bzw. Wochen zum Militärdienst eingezogen worden war, konnte er zunächst zu Beginn der 1940er-Jahre uk-gestellt werden. Doch am 25. September 1944 wurde er erneut zur Wehrmacht eingezogen, wodurch de facto seine Tätigkeit an der Landesbibliothek endete.

Nach dem Krieg kam er zwar an seinen Wohnort Radebeul zurück, jedoch nicht an die Landesbibliothek - im Mai 1945 wurde er beurlaubt, um seine Frau Maria Elisabeth Hubertine, geb. Ruland, die er 1932 geheiratet hatte, und die sechs gemeinsamen Kinder zu suchen, zu denen in den letzten Kriegswochen der Kontakt abgebrochen war. Im Juni 1945 verließ Jammers gemeinsam mit seiner Familie Sachsen und kehrte in seine rheinische Heimat zurück. In Bergheim bei Köln fand er zunächst eine Arbeit als Gymnasiallehrer. Im Herbst 1947 reiste er für einen kurzen Besuch nach Dresden und Radebeul. Seine Kontakte zu den befreundeten Kollegen an der Landesbibliothek pflegte Jammers bis ins hohe Alter, wie sein umfangreicher Briefwechsel belegt. Erst 1951 kehrte er in den Bibliotheksdienst zurück und nahm eine Stelle an der Landesund Stadtbibliothek Düsseldorf an. Zum 1. Januar 1952 wechselte er als Leiter der Handschriftenabteilung an die Universitätsbibliothek Heidelberg, deren stellvertretender Direktor er von 1957 bis zu seiner Pensionierung 1961 war. Darüber hinaus hatte er bereits 1953 einen Lehrauftrag für musikalische Paläografie am musikwissenschaftlichen Institut der Universität Heidelberg inne und wurde 1956 zum Honorarprofessor für ältere Musikgeschichte ernannt. Diese Lehrtätigkeit setzte er bis 1972 fort und publizierte auch weiterhin. Als Spezialist für ältere Musikgeschichte widmete er sich vor allem mittelalterlichen Liederhandschriften und der Choralforschung. Im Januar 1981 zog Ewald Jammers gemeinsam mit seiner Frau in ein Altersheim in Plankstadt nahe Heidelberg, wo er am 26. Juni 1981 starb.

\section{Auswahlbibliografie}

Untersuchungen über die Rhythmik und Melodik der Melodien der Jenaer Liederhandschrift, in: Zeitschrift für Musikwissenschaft 7, 1924/25, S. 265-304 (Zugl. Bonn, Univ., Diss., 1924). Carmina vagantium quatuor, Dresden 1927 (mit H. Schreiber).

Das Karlsoffizium „Regali natus“, Leipzig 1934.

Der gregorianische Rhythmus, Leipzig u. a. 1937.

Die Essener Neumenhandschrift der Landes- und Stadt-Bibliothek Düsseldorf, Ratingen 1952.

Der mittelalterliche Choral, Mainz 1954.

Anfänge der abendländischen Musik, Straßburg, Kehl 1955.

Musik in Byzanz, im päpstlichen Rom und im Frankenreich, Heidelberg 1962.

Das königliche Liederbuch des deutschen Minnesangs, Heidelberg 1965.

Das Alleluia in der Gregorianischen Messe, Münster 1973.

Die sangbaren Melodien zu Dichtungen der Manessischen Handschrift, Wiesbaden 1979 (Hg.).

\section{Quellen und Literatur}

HStA Dresden, 13859, Nr. 3696

SLUB, PA Jammers, Ewald

SLUB, Mscr.Dresd.App.2600F

SLUB, Mscr.Dresd.App.2830

BArch, R 73/11926 
Jammers, Antonius: Im Japanischen Palais, wie ein Freiherr ... Erinnerungen meines Vaters Ewald Jammers an seine alte Sächsische Landesbibliothek, in: Thomas Bürger und Ekkehard Henschke (Hg.): Bibliotheken führen und entwickeln. Festschrift für Jürgen Hering zum 65. Geburtstag, München 2002, S. 305-317.

Bürger, Thomas: Bibliotheksbriefe aus der Nachkriegszeit aus dem Nachlass von Ewald Jammers (1-3), SLUB-Kurier, 21. Jg., 2007, H. 1, S. 16-17 (Teil 1); H. 2, S. 13-15 (Teil 2); H. 3, S. 14-16 (Teil 3).

Schwanitz, Henrik: Jammers, Ewald Karl Hubert Maria, in: Sächsische Biografie, 2014, Online-Ausgabe: http://saebi.isgv.de/biografie/Ewald_Jammers_(1897-1981), Zugriff: 2.1.2020. 


\title{
JaCOB JaTZWAUK (JaKub WJaCSŁaWK)
}

\author{
15.2.1885 Horka bei Kamenz - 3.9.1951 Bautzen
}

Slawist, Wissenschaftlicher Bibliothekar

Sächsische Landesbibliothek

(bis 1.5.1917 Königliche Öffentliche Bibliothek,

2.5.1917-11.1918 Königliche Landesbibliothek)
1.4.1913-31.3.1914 Volontär
1.4.1914-31.5.1914 Hilfskraft
1.6.1914-31.5.1918 Wissenschaftlicher Hilfsarbeiter
1.6.1918-30.9.1921 Bibliotheksassistent
1.10.1921-30.9.1945 Landesbibliothekar

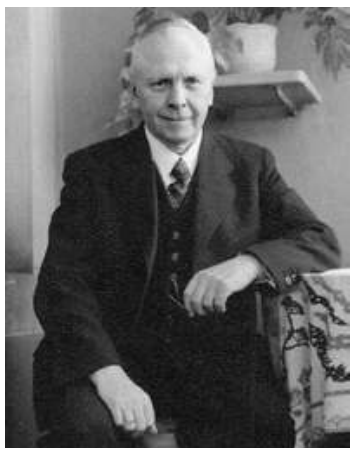

Als Sohn des Steinbrucharbeiters und Häuslers Michael Jatzwauk und dessen Frau Käthe, geb. Skale, am 15. Februar 1885 in Horka bei Kamenz geboren, wurde Jacob Jatzwauk am Wendischen Seminar in Prag ausgebildet, bevor er bis 1907 das deutsche Kleinseitner Gymnasium in Prag besuchte. Im Anschluss studierte er bis 1910 an der Karls-Universität in Prag Theologie, Philosophie und Slawistik, danach in Leipzig Geschichte und Germanistik. Seine theologische Prüfung legte er im April 1910 ab. Im Oktober 1912 wurde er in Leipzig promoviert.

Zum 1. April 1913 wurde Jatzwauk für ein Jahr als Volontär an der Königlichen Öffentlichen Bibliothek in Dresden angenommen, die ihn danach noch zwei Monate als Hilfskraft beschäftigte. Im Juni 1914 erhielt er an der Bibliothek eine Stelle als Wissenschaftlicher Hilfsarbeiter. Vier Jahre später wurde er zum Bibliotheksassistenten befördert. Bereits damals, 1918, arbeitete er außerhalb seiner Arbeitszeit gemeinsam mit seinem Kollegen $\triangleright$ Rudolf Bemmann an Band 1 der durch Viktor Hantzsch begonnenen „Bibliographie der Sächsischen Geschichte“, deren weitere Bände er in den Folgejahren allein zusammenstellte. Zum 1. Oktober 1921 wurde Jatzwauk an der nunmehr in Sächsische Landesbibliothek umbenannten Bibliothek zum Landesbibliothekar befördert. Nach der Heirat mit Margareta, geb. Zimmermann, vermittelte er im Herbst 1934 der Landesbibliothek über Kontakte seines Schwiegervaters die Übernahme der Bibliothek der ehemaligen Loge zur goldenen Mauer zu Bautzen nach deren Liquidation. ${ }^{1}$ Auch als Bibliograf des Schrifttums über die Sorben engagierte sich Jatzwauk. Seine zahlreichen Veröffentlichungen zur sorbischen Geschichte in deutscher und sorbischer Sprache markieren den Beginn der sorbischen sozialhistorischen Forschung. Sein Engagement für die Sorben veranlasste das Sächsische Ministerium für Volksbildung, unter Mitwirkung des Sammlungsreferenten $>$ Fritz Fichtner, im Februar 1938 bei der Geheimen Staatspolizei Ermittlungen gegen ihn zu fordern. Im Mai beantragte der Reichsstatthalter in Sachsen beim Reichsminister für Wissenschaft, Erziehung und Volksaufklärung, Jatzwauk in einen anderen Teil Deutschlands zu versetzen. Doch trotz dieser Stimmung gegen ihn und der Veränderung des politischen Klimas in der Landesbibliothek seit der Pensionierung von $>$ Martin Bollert blieb er in Dresden, widerstand dem politischen Druck und trat als ehemaliges, kurzzeitiges Mitglied der Deutschen Zentrumspartei

1 Vgl. Jatzwauk, Sächsische Landesbibliothek, an P. Zimmermann, Bautzen, 6.9.1934 u. Liquidatoren der ehemaligen Loge zur goldenen Mauer zu Bautzen an Sächsische Landesbibliothek, 11.10.1934, beide: SLUB, Bibl.-Arch.III.J.859.d. 
(DZP) nicht in die NSDAP ein. ${ }^{2}$ Nur in deren Opferring, im NSV und RDB wurde er Mitglied. Auch nutzte er die Gelegenheit, sich im Juni 1940 als Leiter der bis dahin von Ernst Koch kommissarisch geleiteten Bibliothek der Technischen Hochschule Dresden zu bewerben, doch ein neuer Direktor wurde nicht eingestellt. Jatzwauk verblieb an der Landesbibliothek. Zum 30. September 1945 wurde er entlassen und siedelte, da er beim Bombenangriff auf Dresden im Februar 1945 seine Wohnung verloren hatte, zunächst nach Schirgiswalde über.

Im Oktober 1945 zog er nach Bautzen, wo er ab 1. Oktober 1945 die Leitung der Stadtbibliothek und des Stadtarchivs übernahm. 1946 wurde er Vorsitzender der wissenschaftlichen Gesellschaft „Maćia Serbska“, 1950 ordentliches Mitglied der Historischen Kommission der Sächsischen Akademie der Wissenschaften zu Leipzig. Aus gesundheitlichen Gründen lehnte er sowohl 1948 als auch 1950 eine Berufung als Direktor an die Universitätsbibliothek Leipzig, die mit einer Professur für Bibliothekswissenschaft verbunden gewesen wäre, ab. Erst 66-jährig starb Jacob Jatzwauk am 3. September 1951 in Bautzen.

\section{Auswahlbibliografie}

Bevölkerungs- und Vermögensverhältnisse der Stadt Bautzen zu Anfang des 15. Jahrhunderts, (Leipzig, Univ., Diss., 1912).

Das wendische Volk und seine Sprache, in: Görlitzer Illustrierte, Wöchentliche Bildbeilage der Görlitzer Nachrichten, 1919, Nr. 1-2, S. 2-4, 7-8.

Die geschichtliche und kulturelle Entwicklung des wendischen Volkes im Laufe des 19. Jahrhunderts, in Oberlausitzer Heimatblätter, 3, 1920, S. 183 f.

Die lausitzer Wenden. Ein Blick in ihre Geschichte, Sitten und Gebräuche, in: St. Benno Kalender, 72, 1922, S. 134-148.

Bibliographie der sächsischen Geschichte: Bd. 1-5, Aus den Schriften der Kgl. Sächs. Kommission für Geschichte, Leipzig, Berlin, Dresden 1918-1932 (Bd. 1 mit Rudolf Bemmann).

Katalog serbskeho wotdźéla knihownje Maćicy Serbskeje, in: Časopis Maćicy Serbskeje 76/1923, S. 55-199.

Serbskolužiska kniha a serbsko-lužiske knihownistwo (Das Sorbische Buch und das sorbische Buchwesen), in: Knižní kultura doby staré i nové, 1926, S. 28-34.

Wendische (Sorbische) Bibliographie, Veröffentlichungen des Slawischen Instituts an der Friedrich-Wilhelm-Universität Berlin, Reihe 2, Leipzig 1929.

\section{Quellen und Literatur}

HStA Dresden, 13859, Nr. 3710

Reuther, Martin: Jakob Jatzwauk. Eine Würdigung, in: Zentralblatt für Bibliothekswesen, Bd. 65, 1951, S. 407-415.

Habermann, Alexandra, Klemmt, Rainer u. Frauke Siefkes: Lexikon Deutscher Wissenschaftlicher Bibliothekare 1925-1980, Frankfurt a. M. 1985, S. 143 f.

\footnotetext{
2 Kunze 2011 begründete dies mit einer Gastprofessur in den USA. Doch eine Gastprofessur Jatzwauks an der Columbia-Universität in New York (USA) 1938 ließ sich bisher nicht verifizieren. Siehe Columbia University in the City of New York, Catalogue Number for the sessions of 1938-1939, hdl.handle.net/2027/nnc2.ark:/13960/t84j1678m, Zugriff: 6.12.2019. Vgl. E-Mails von Annett Bresan und Uta Jatzwauk an die Autorin, 30.5.2019.
} 
Zwahr, Hartmut: Dr. Jacob Jatzwauk zum 100. Geburtstag, in: Bautzener Kulturschau. Monatsschrift über das kulturelle Geschehen des Kreises Bautzen, Bd. 35, Ausg. 2, 1985, S. 2-5.

Bürger, Thomas u. Konstantin Hermann (Hg.): Das ABC der SLUB. Lexikon der Sächsischen Landesbibliothek - Staats- und Universitätsbibliothek Dresden, Dresden 2006, S. $120 \mathrm{f}$.

Kunze, Peter: Wjacsławk (Jatzwauk), Jakub (Jacob), in: Sächsische Biografie, 2011, Online-Ausgabe: http://saebi.isgv.de/biografie/Jakob_Jatzwauk_(1885-1951), Zugriff: 2.1.2020.

Zwahr, Hartmut: Der Bibliograph und sein Magaziner. Zum Gedenken an Dr. Jacob Jatzwauk und Max Schneider, in: Neues lausitzisches Magazin. Zeitschrift der Oberlausitzischen Gesellschaft der Wissenschaften, Bd. 17, 136, 2014, S. 83-102. 


\section{ERHART KäSTNER}

\subsubsection{Schweinfurt - 3.2.1974 Staufen}

Wissenschaftlicher Bibliothekar, Schriftsteller

Sächsische Landesbibliothek

1.12.1927-30.4.1929 Volontär

1.11.1929-18.8.1944 Wissenschaftlicher Hilfsarbeiter

19.8.1944-15.11.1945 Bibliotheksrat

(Beurlaubung zur Arbeit für Gerhart Hauptmann 8.6.193631.12.1937 und Mitarbeit an der Gutenberg-Reichsausstellung in Leipzig 1.7.1938-31.12.1939; Militärdienst und Kriegsgefangenschaft 21.4.1940-1946)

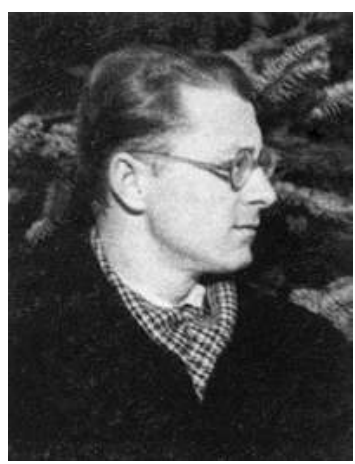

Am 13. März 1904 wurde Hermann Heinrich Ludwig Erhart Kästner als Sohn des Oberstudienrates Heinrich Friedrich Kästner und dessen Ehefrau Elisabeth, geb. Seidl, in Schweinfurt am Main geboren. Nach dem Abitur, das er 1922 in Augsburg ablegte, war er bis April 1924 in K. F. Koehlers Antiquarium in Leipzig tätig. Kästner studierte Germanistik, Geschichte und Philosophie an den Universitäten in Freiburg i. Br., Kiel und Leipzig. ${ }^{1}$ Noch bevor er im November 1927 in Leipzig bei August Korff promoviert wurde, war er zur Ausbildung für die Höhere bibliothekarische Laufbahn zugelassen worden und bat im Sommer 1927 um die Aufnahme als Volontär an der Sächsischen Landesbibliothek.

Von Dezember 1927 bis April 1929 absolvierte Kästner sein Volontariat an der Sächsischen Landesbibliothek in Dresden. Kurz nachdem er für den letzten Teil des Volontariats nach Leipzig gegangen war, offerierte ihm $>$ Martin Bollert eine feste Stelle in Dresden, denn er beabsichtigte, „einen jungen Fachmann heranzuzüchten“2. Die Einstellung Kästners als Wissenschaftlicher Hilfsarbeiter an der Landesbibliothek erfolgte nach seinem Examen für den Höheren Dienst an wissenschaftlichen Bibliotheken im November 1929. Neben der Arbeit am systematischen Katalog war er für die Ausstellungsarbeit der Bibliothek zuständig und maßgeblich an der GoetheAusstellung 1932 beteiligt, bevor er die Verantwortung für die Fachgebiete der Inkunabel-, Einband- und Handschriftensammlung übernahm. Als sich Kästner im Herbst 1934 freiwillig zur Grenzschutzausbildung der Reichswehr meldete, verweigerten seine Vorgesetzten die Beurlaubung „aus dienstlichen Gründen“, die „auf unüberwindliche Schwierigkeiten stößt, da wir im letzten Stadium der Einrichtung der Museumsräume stehen “3. Kästners Aufgabe bestand in der Konzeption und Einrichtung des neu zu schaffenden Buchmuseums. Ein Jahr nach der erfolgreichen Eröffnung des Museums, 1936, wurde er zum Leiter der Handschriftenabteilug ernannt. Im Juni 1936 ließ sich Kästner für seine Tätigkeit als Sekretär von Gerhart Hauptmann ohne Fortzahlung seiner Dienstbezüge vom Bibliotheksdienst beurlauben, um den Dichter auf seinen

1 Hier divergieren die Überlieferungen. Einerseits gibt Kästner selbst eine Studienzeit 10.5.19226.10.1927 an, andererseits existiert ein Lehrzeugnis von Koehler Antiquarium Leipzig, das seine Tätigkeit 30.4.1922-30.4.1924 bescheinigt. Damit hätte Kästner parallel studiert und für Koehler gearbeitet. Vgl. Kästner an SMV, 28.11.1929 u. K. F. Koehler Antiquarium Leipzig, Lehrzeugnis für Erhart Kästner, 30.4.1924, beide: SLUB, PA Kästner.

2 Bollert an Kästner, 29.8.1929, SLUB, PA Kästner.

3 Sächsische Landesbibliothek, i. V. Neubert, an Kästner, 20.10.1934, SLUB, PA Kästner. 
Reisen zu begleiten und bei der Vollendung seines Spätwerkes zu unterstützen. Erst im Januar 1938 kehrte Kästner an die Landesbibliothek zurück, um ein halbes Jahr später erneut beurlaubt zu werden, diesmal zur Vorbereitung der historischen Abteilung der für 1940 geplanten Gutenberg-Reichsausstellung in Leipzig. Doch nach Beginn des Zweiten Weltkrieges wurde dieses Vorhaben nicht mehr realisiert. Zum Jahresanfang 1940 nahm Kästner erneut seine Tätigkeit an der Landesbibliothek auf. In diese Zeit fällt seine Aufnahme in die NSDAP, den entsprechenden Antrag hatte er am 10. Dezember 1939 gestellt, seine Mitgliederkarte erhielt er erst 1941. Im April 1940 wurde Kästner zum Militärdienst eingezogen, den er zunächst bei der Luftwaffen-Bauabteilung absolvierte, bevor er nach Griechenland abkommandiert wurde. Während Kästner im März 1941 kurzzeitig vom Militärdienst freigestellt war für einen „Arbeitsurlaub, weil ich den Auftrag erhalten habe, eine ausländische Privatbibliothek für den Führer zu erwerben“" , wurde sein Antrag auf Übernahme als Kriegsberichterstatter in eine Propaganda-Kompagnie abschlägig beschieden. Ein Angebot, als Dramaturg am Theater in Straßburg zu arbeiten, konnte er nicht annehmen, da er im Herbst 1941 nicht uk-gestellt wurde. 1944 zum Feldwebel befördert und in Abwesenheit zum Bibliotheksrat ernannt, kam Kästner 1945 auf Kreta in britische Kriegsgefangenschaft, die er bis Ende 1946 in einem Gefangenenlager in der ägyptischen Wüste nahe Kairo verbrachte. Unterdessen war er aufgrund seiner NSDAP-Mitgliedschaft in Abwesenheit an der Landesbibliothek in Dresden entlassen worden.

Nach der Entlassung aus der Kriegsgefangenschaft kehrte Kästner 1947 wohl nach Dresden, aber nicht in den Bibliotheksdienst zurück, sondern arbeitete als freischaffender Publizist. Erste eigene literarische Texte hatte er bereits in Griechenland und Ägypten geschrieben und seit 1942 veröffentlicht. Letztlich ersparte ihm diese Entscheidung ein Entnazifizierungsverfahren, denn für den Verbleib im öffentlichen Dienst hätte er „erst entbräunt werden “5 müssen. Kästner verließ Dresden und zog zu seiner Mutter nach Augsburg. Fünf Jahre nach Kriegsende, 1950, wurde er zum Direktor der Herzog August Bibliothek in Wolfenbüttel ernannt. In dieser Funktion erwarb er sich unter anderem Verdienste beim Aufbau einer Malerbuchsammlung und bei der Pflege des historischen Bestands. 1957 heiratete er die Restauratorin Anita Kästner, geb. Vogel. Nach seiner Pensionierung 1968 zog Erhart Kästner nach Staufen im Breisgau, wo er am 3. Februar 1974 starb.

\section{Auswahlbibliografie}

Wahn und Wirklichkeit im Drama der Goethezeit. Eine dichtungsgeschichtliche Studie über die Formen der Wirklichkeitserfasssung, Leipzig 1929 (Zugl. Leipzig, Univ., Diss., 1927).

Bekränzter Jahreslauf, Leipzig 1934.

Griechenland, Berlin 1942.

Kreta, Berlin 1946.

Zeltbuch von Tumilad, Wiesbaden 1949.

Ölberge. Weinberge, Wiesbaden 1953.

Die Stundentrommel vom heiligen Berg Athos, Wiesbaden 1956.

Die Lerchenschule, Frankfurt a. M. 1964.

Aufstand der Dinge, Frankfurt a. M. 1973.

4 Kästner an RMVP, 12.3.1941, BArch, R 55/23637, fol. 6. Vgl. Sächsische Landesbibliothek, Neubert, 12.03.1941, SLUB, PA Kästner.

5 Bollert an Jammers, 28.7.1947, SLUB, Mscr.Drsd.App.2830,11. 


\section{Quellen und Literatur}

HStA Dresden, 13859, Nr. 3833

SLUB, PA Kästner, Erhart

BArch, R 55/23637

BArch, R 9361-IX/Kartei/18881285

Kästner, Anita und Reinhart Kästner (Hg.): Erhart Kästner. Leben und Werk in Daten und Bildern, Frankfurt a. M. 1980.

Habermann, Alexandra, Klemmt, Rainer u. Frauke Siefkes: Lexikon Deutscher Wissenschaftlicher Bibliothekare 1925-1980, Frankfurt a. M. 1985, S. 150.

Lehmann, Hans-Ulrich (Hg.): Kunstwirklichkeiten. Erhart Kästner. Bibliothekar - Schriftsteller - Sammler, Wolfenbütteler Schriften zur Geschichte des Buchwesens, Bd. 21, Wiesbaden 1994.

Bürger, Thomas u. Konstantin Hermann (Hg.): Das ABC der SLUB. Lexikon der Sächsischen Landesbibliothek - Staats- und Universitätsbibliothek Dresden, Dresden 2006, S. 123 f.

Nitzschke, Katrin: Kästner, Erhart, in: Sächsische Biografie, 2015, Online-Ausgabe: http://saebi. isgv.de/biografie/Erhart_Kastner_(1904-1974), Zugriff: 2.1.2020. 


\title{
WALter Kersten
}

\author{
4.11.1907 Zittau - 7.4.1944 bei Pleskau \\ Prähistoriker \\ Museum für Mineralogie, Geologie und Vorgeschichte \\ (Archiv urgeschichtlicher Funde aus Sachen) \\ 2.1.1933-31.12.1933 Wissenschaftlicher Hilfsarbeiter
}

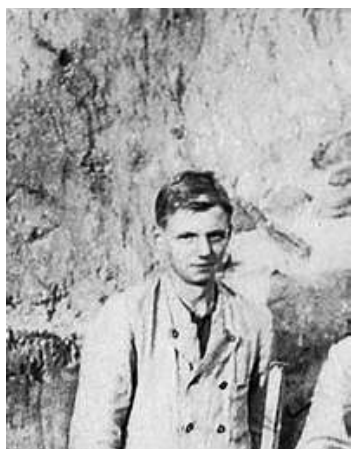

In Zittau am 4. November 1907 als Sohn des Oberingenieurs und Studienrates Carl Kersten geboren, wuchs Walter Kersten in Dresden und Berlin auf. Nach der Abiturprüfung, die er 1927 in Berlin ablegte, studierte er zunächst in Berlin bei Max Ebert, später in Marburg bei Gero Merhart von Bernegg Vorgeschichte. Bei letzterem wurde er im Juli 1931 promoviert. Bereits als Student nahm er an den Ausgrabungen in Sachsen teil, unter anderem in Köllmichen unter - Georg Bierbaum, Kustos am Museum für Mineralogie, Geologie und Vorgeschichte in Dresden und Leiter des Archivs urgeschichtlicher Funde aus Sachsen. Bierbaums Versuch, Kersten bereits 1931 in Dresden einzustellen, scheiterte an den Sparmaßnahmen der Sächsischen Regierung infolge der Weltwirtschaftskrise.

Erst im Januar 1933 wurde Kersten am Archiv urgeschichtlicher Funde aus Sachsen als Wissenschaftlicher Hilfsarbeiter beschäftigt, jedoch über das Standesnotopfer des Landesverbandes der Höheren Beamten Sachsens bezahlt. Von April bis Mai 1933 wirkte er an der Ausgrabung auf der Bosel bei Sörnewitz nahe Meißen mit, danach bis Juni in Skassa bei Großenhain. Von Bierbaum beauftragt, leitete Kersten von August bis November 1933 die Ausgrabungen auf der Heidenschanze von Dresden-Coschütz. Dafür betrieb er eine intensive Öffentlichkeitsarbeit inklusive Führungen für die Presse, Radiointerview und Betrieb eines kleinen Grabungsmuseums vor Ort. ${ }^{1}$ Auch war Kersten, der bereits im Mai 1932 der NSDAP beigetreten war, als Sachberater für Vorgeschichte der NSDAP-Gauleitung Sachsen tätig. Mit diesem öffentlichkeitswirksamen und nationalsozialistisch-politischen Engagement trug er zur Durchsetzung des „Sächsischen Gesetzes zum Schutze von Kunst-, Kultur- und Naturdenkmalen“ (Heimatschutzgesetz) bei und unterstützte Bierbaum in seinem Bemühen um die Anerkennung der Archäologie sowie gegen die fachliche Konkurrenz Hans Reinerths. Auch arbeitete Kersten an der Neugestaltung der Prähistorischen Sammlung des Museums mit.

Im Januar 1934 nahm Kersten das einen zuverlässigen Lebensunterhalt versprechende Angebot aus Bonn an und wechselte als Assistent von Franz Oelmann an das Rheinische Landesmuseum. Wenig später wurde er zum Stellvertretenden Vertrauensmann für Kulturgeschichtliche Bodenaltertümer ernannt. 1935 heiratete er Martha Lübeck, mit der er vier Kinder hatte. Nach 1938

\footnotetext{
1 Vgl. auch Jünger, Konstanze u. Judith Schachtmann: „Eine 3000 Jahre alte Stadt“. Die Ausgrabungen auf der Heidenschanze von Dresden-Coschütz und ihre Darstellung in der Öffentlichkeit, in: Arbeits- und Forschungsberichte zur sächsischen Bodendenkmalpflege, Bd. 21, 2010, S. 27-35. Siehe S. $165,177$.
} 
leitete er die Bonner Abteilung im Landesamt für die vor- und frühgeschichtliche Denkmalpflege der Rheinprovinz. 1940 meldete sich Kersten freiwillig zum Militärdienst in einer SS-Totenkopfstandarte, wurde jedoch freigestellt und im Oktober 1940 als Leiter des Landesamtes für Vorgeschichte im „Reichsgau Wartheland“ in Posen berufen. Dort reorganisierte er die archäologische Denkmalpflege nach Maßgabe der NS-Politik. Im März 1943 wurde Walter Kersten zur Wehrmacht einberufen. Erst 36-jährig ist er am 7. April 1944 in der Nähe von Pleskau gefallen.

\section{Auswahlbibliografie}

Der Beginn der La-Tène-Zeit in Nordostbayern, in: Prähistorische Zeitschrift, Bd. 24, 1933, S. 96-174 (Zugl. Marburg, Univ., Diss., 1931).

Latènefunde aus Hessen-Kassel, in: Mannus. Deutsche Zeitschrift für Vor- und Frühgeschichte, Bd. 25, 1933, S. 110-115.

Der Ringwall auf dem Petersberg im Siebengebirge, in: Germania. Anzeiger der Römisch-Germanischen Kommission des Deutschen Archäologischen Instituts, Bd. 21, H. 2, 1937, S. 71-75.

Die germanische Siedlung von Haffen, in: Germania. Anzeiger der Römisch-Germanischen Kommission des Deutschen Archäologischen Instituts, Bd. 21, H. 2, 1937, S. 75-78.

Bilder zur rheinischen Vorgeschichte, Frankfurt a. M. 1937 (Hg. mit Eduard Neuffer).

Spuren der nordeurasischen Wohnplatzkultur am Niederrhein, in: Germania. Anzeiger der Römisch-Germanischen Kommission des Deutschen Archäologischen Instituts, Bd. 22, H. 2, 1938, S. 71-77.

\section{Quellen und Literatur}

Strobel, Michael: Anmerkungen zur Institutionalisierung der archäologischen Denkmalpflege in Sachsen zwischen 1918 und 1945, in: Schachtmann/Strobel/Widera 2009, S. 169-192, $183 \mathrm{f}$.

Joachim, Hans-Eckart: Aus der Hausgeschichte - Walter Kersten 1907-1944, Berichte aus dem LVR-Landesmuseum Bonn, H. 1, 2013, S. 25 ff.

Schachtmann, Judith u. Thomas Widera: Wissenschaftler und Nationalsozialist. Der Vorgeschichtler Walter Kersten (1907-1944) in Sachsen, in: Archaeo. Die Archäologie der Kriege. Die Burgen von Hohburg in der Hohburger Schweiz, Bd. 10, 2013, S. 30-36. 


\section{Otto KLeEManN}

10.2.1911 Straßburg - 6.9.1996 Schweinfurt

Prähistoriker, Archäologe

Museum für Mineralogie, Geologie und Vorgeschichte

15.1.1934-31.3.1935 Wissenschaftlicher Hilfsarbeiter

Am 10. Februar 1911 wurde Otto Richard Max Kleemann als Sohn des Postrates Max Kleemann und dessen Frau Lina, geb. Sieblist, in Straßburg geboren. Aufgrund häufiger berufsbedingter Versetzungen seines Vaters besuchte er zunächst die Volksschule in Krefeld, bevor er 1929 seine Abiturprüfung in Breslau ablegte. Danach studierte Kleemann in Breslau und Marburg Vorgeschichte, Archäologie, Germanistik, alte Geschichte und Rassenkunde. Bereits während seines Studiums war Kleemann mehrfach als Freiwilliger Wissenschaftlicher Hilfsarbeiter tätig, u. a. am Landesamt für Vorgeschichte Niederschlesiens in Breslau, am Landesamt für Vorgeschichte Oberschlesiens in Radibor und am Kurländischen Provinzialmuseum in Mitau. Im Herbst 1933 arbeitete er am Prussia-Museum in Königsberg, wo er die Ausgrabung eines Wikingerfriedhofs nahe Cranz leitete. Im Mai 1934 wurde er in Breslau promoviert.

Damals war Kleemann bereits in Dresden tätig, wo er ab Januar 1934 als Wissenschaftlicher Hilfsarbeiter am Museum für Mineralogie, Geologie und Vorgeschichte arbeitete. Da er über Erfahrungen in der Museums- und Ausgrabungsarbeit verfügte, wurde er durch Kustos \Georg Bierbaum in der Nachfolge von $>$ Walter Kersten mit der Leitung der Ausgrabungen an der Heidenschanze Dresden-Coschütz von August 1934 bis Januar 1935 beauftragt. ${ }^{1}$ Doch schon nach 14 Monaten verließ Kleemann Dresden wieder.

Im April 1935 kehrte er als Assistent von Wilhelm Gaerte an das Prussia-Museum in Königsberg zurück. Ehrenamtlich engagierte er sich als stellvertretender Staatlicher Vertrauensmann für Kulturgeschichte und Bodenaltertümer in der Provinz Ostpreußen. Nach dem Militärdienst von November 1935 bis September 1936 heiratete er Elfriede Charlotte Ottilie, geb. Joppien, mit der er zwei Kinder hatte. Im Rahmen der Mobilmachung während der „Sudetenkrise“ wurde er 1938 zu einer Reserveübung eingezogen. Seine angestrebte Aufnahme in die SS verzögerte sich, da seine Abstammung aufgrund seines Nachnamens, weswegen der NS-Staat jüdische Vorfahren vermutete, genauestens überprüft wurde. Nachdem er als Schüler Mitglied im Deutschnationalen Jugendbund und bei den Pfadfindern aktiv war, trat er im Herbst 1932 in den NS-Studentenbund ein. Im April 1933 wurde er SA-Mitglied, trat jedoch Ende 1934 wieder aus. Unterdessen war er im Mai 1933 der NSDAP beigetreten. Ab April 1939 galt er als SS-Anwärter. Im Januar 1939 wurde er als Museumsassistent am Prussia-Museum mit einer Planstelle am Landesamt für Vorgeschichte Ostpreußens verbeamtet. Doch bereits im August 1939 wurde er zum Militärdienst einberufen und zur Luftwaffe versetzt. Während er sich von einer schweren Verletzung erholte, konnte er sich 1942 in Königsberg habilitieren. Nach der Kriegsgefangenschaft in England setzte Kleemann seine akademische Laufbahn fort. Ab 1947 lehrte er an der Pädagogischen Hochschule Iburg bei Osnabrück und ab 1948 an der Universität Bonn, deren Abteilung für Vor- und Frühgeschichtliche Archäologie er über drei Jahrzehnte leitete. Otto Kleemann starb am 6. September 1996 in Schweinfurt.

1 Vgl. Jünger/Schachtmann 2010, S. $31 \mathrm{f}$. 


\section{Auswahlbibliografie}

Neue frühgermanische Fibelfunde, in: Altschlesien. Mitteilungen des Schlesischen Altertumsvereins, Bd. 3, 1931, 2, S. 239-241.

Einige älterbronzezeitliche Funde aus dem Silinggau in Schlesien, in: Mitteilungen des Schlesischen Altertumsvereins, Bd. 5, 1934, S. 132-138.

Burgwallgrabung in Dresden-Coschütz im Jahre 1934, in: Nachrichtenblatt für deutsche Vorzeit, Bd. 11, 1935, 8, S. 148-152.

Schlesische Funde im Dresdener Museum für Vorgeschichte, in: Altschlesien. Mitteilungen des Schlesischen Altertumsvereins, Bd. 7, 1937, 1, S. 11-28.

Der Bronzefund von Weissig und seine Bedeutung für die Kulturgruppenforschung Osteuropas, in: Prähistorische Zeitschrift, Bd. 32/33, 1941/42, 1942, S. 60-168 (Zugl. Königsberg, Univ., Habil., 1942).

Die dreiflügeligen Pfeilspitzen in Frankreich. Studie zur Verbreitung und historischen Aussage der bronzenen Pfeilspitzen, in: Abhandlungen der Geistes- und Sozialwissenschaftlichen Klasse. Akademie der Wissenschaften und der Literatur, Mainz 1954.

Die Anfänge der Geschichte Schlesiens. Konzept einer landeskundlichen Vorgeschichte, in: Osteuropa und der deutsche Osten, Rheinische Friedrich-Wilhelms-Universität Bonn, 5, 1959.

Der erste Fund vorgeschichtlicher Eisenbarren in Franken, in: Mainfränkisches Jahrbuch für Geschichte und Kunst, 1966, S. 121-134.

Vor- und Frühgeschichte des Kreises Ahrweiler, Archiv für Dt. Heimatpflege, Köln 1971.

Die Mittlere Bronzezeit in Schlesien, Bonner Hefte zur Vorgeschichte, 12/13, 1977 (Text von 1939; Zugl. Breslau, Univ., Diss., 1934).

\section{Quellen und Literatur}

BArch, R 4901/13268

BArch, R 9361-III/96673

BArch, R 9361-IX/Kartei/20550894

Schäfer, Klaus (Hg.): Professor Dr. Otto Kleemann zum 80. Geburtstag, in: Pellenz-Museum, 5, Nickenich 1991.

Schallmayer, Egon: Otto Richard Max Kleemann (1911-1996), in: Archäologisches Nachrichtenblatt, Bd. 2, 1997, S. 409 f. 


\section{ERnST VON KoERner}

16.3.1880 Dresden - 26.5.1968 Radeburg

Major

Historisches Museum

2.1927 - [mind. 6.1928] Freiwilliger Wissenschaftlicher Hilfsarbeiter

Sächsisches Armeemuseum

(ab 18.1.1940 Heeresmuseum Dresden)

1.11.1929-5.1945 Leiter

Nur wenige Angaben sind über das Leben und die berufliche Tätigkeit von Richard Paul Ernst von Koerner, der 15 Jahre das Sächsische Armeemuseum in Dresden leitete, überliefert. Er wurde am 16. März 1880 als Sohn des Finanzassessors Paul Ernst Koerner und dessen Frau Charlotte, geb. Wahle, in Dresden geboren. Zunächst schlug er eine aktive Militärlaufbahn ein. Danach wechselte er im Alter von 46 Jahren als Major a. D. in eine Tätigkeit am Museum.

Ab Februar 1927 arbeitete er als Freiwilliger Wissenschaftlicher Hilfsarbeiter unter Direktor - Erich Haenel im Historischen Museum in Dresden. Am 1. November 1929 wurde Koerner als Nachfolger von Oberst Johannes Schurig zum Leiter des Sächsischen Armeemuseums ernannt. Er nahm regelmäßig an den Direktorenkonferenzen der Staatlichen Sammlungen teil und beteiligte sich u. a. an der Ausbildung von Fremdenführern für die Staatlichen Sammlungen. Im Dezember 1938 beantragte Koerner im Sinne einer Gleichstellung mit den anderen Sammlungsdirektoren seine Verbeamtung, die jedoch aufgrund seines Alters abgelehnt wurde. ${ }^{1}$ Auch nach der Überführung des Sächsischen Armeemuseums als Heeresmuseum Dresden in Reichseigentum ab November 1939 blieb Koerner dessen Leiter. Im Januar 1941 schlug der Referent für die Staatlichen Museen beim Sächsischen Ministerium für Volksbildung, \Fritz Fichtner, vor, Koerner zum Kommissarischen Leiter des Historischen Museums zu ernennen, denn er besitze „die hierzu notwendigen internationalen Beziehungen und den militärischen Rang “2. Der Vorschlag Fichtners, Koerner, der ein „anerkannter Fachmann“ sei und „eine Reihe von Gemeinschaftsarbeiten mit den Staatlichen Museen erfolgreich durchgeführt ${ }^{\text {“3 }}$ habe, zumindest halbtags im Historischen Museum einzusetzen, scheiterte. Das Heeresmuseum Dresden leitete Koerner bis Mai 1945.

Unklar bleibt, wo er sich nach Kriegsende aufhielt. ${ }^{4}$ Er war geschieden und lebte zumindest im hohen Alter in Sachsen. Ernst von Koerner starb 88-jährig am 26. Mai 1968 in Radeburg.

\section{Auswahlbibliografie}

„Französische“ Stangenwaffen in der Dresdner Rüstkammer, in: Zeitschrift für historische Waffen- und Kostümkunde, 12=N. F. 3, 1929/31, S. 11-19.

König Albert von Sachsen. Der Soldat und Feldherr, Berlin 1936.

\footnotetext{
1 Vgl. Porzellansammlung, Fichtner, an SMV, 12.12.1938, SKD Archiv, 01/PS 43, Bd. 3, fol. $36 \mathrm{f}$.

2 SMV, Fichtner, 7.1.1941, SKD Archiv, 01/PS 53, Bd. 2, fol. 120 f.: hier: 121.

3 SMV, Fichtner, an Leiter SMV, 6.2.1941, ebd., fol. 108.

4 Vgl. Landesverwaltung Sachsen, Abt. Museen, Schlösser und Gärten, Fischer, an Landesverwaltung Sachsen, Kulturabteilung, 28.9.1945, SKD Archiv, 02/VA 20, Bd. 1, fol. 32.
} 
J. E. Hottenroth gest., in: Neues Archiv für sächsische Geschichte, Bd. 58, 1937, S. 223.

Die Blankwaffen der ehemaligen Kurfürstl. und Königl. Sächs. Kavallerie von dem Beginn der Neuzeit bis zur Auflösung des sächsischen Heeres, in: Jahrweiser der ehemaligen Soldaten, 1941, S. 50-62.

Zwei Bekleidungsvorschläge für die Königlich-Sächsische Armee aus den Jahren 1843 und 1867, in: Zeitschrift für Heereskunde, 120/121, 1942, S. 33-52.

\section{Quellen und Literatur}

HStA Dresden, 11125, Nr. 18964, fol. 115

HStA Dresden, 11125, Nr. 19273, Bd. 1, fol. 12

SKD Archiv, 01/PS 53, Bd. 1, fol. 108, 120 f.

Landeshauptstadt Dresden, Stadtarchiv, Personenstandsregister, Sign. 6.4.25

Landkreis Meißen, Kreisarchiv, Standesamt Radeburg, Sterbeurkunde Nr. 48/1968 


\title{
KuRT KöHN
}

\author{
25.4.1894 Dresden - 15.4.1975 Radebeul \\ Goldschmied, Restaurator \\ Grünes Gewölbe \\ 22.2.1931-12.1937 Hilfsaufseher \\ 12.1937-15.11.1945 Konservator \\ 11.8.1944-5.1945 Depotverantwortlicher \\ 1.12.1958-30.11.1971 Restaurator
}

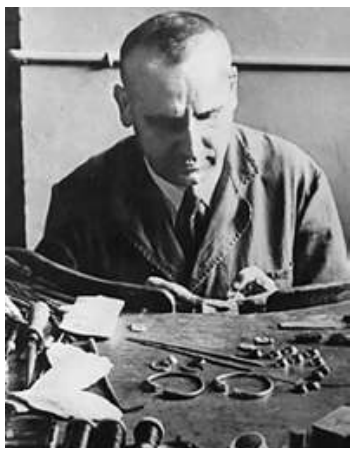

Kurt Gottfried Köhn wurde am 25. April 1894 als Sohn eines Schreibers und einer Damenschneiderin in Dresden geboren. Nach dem Besuch der Volksschule und Handwerkerfachschule erlernte Köhn in der damals von Goldschmied Jordan geführten Werkstatt des Hofjuweliers Elimeyer das Goldschmiedehandwerk. Auch nach seiner Hochzeit mit Erna Franziska, geb. Mensch, 1920 blieb er dort als Geselle tätig.

Im Februar 1931 wechselte Köhn in eine Anstellung als Hilfsaufseher im Grünen Gewölbe in Dresden. Bereits in dieser Funktion unterstützte er den Oberkonservator, Goldschmied Richard Schönherr, bei Restaurierungsarbeiten. ${ }^{1}$ Als dieser pensioniert wurde, wurde Köhn zum Konservator befördert, mit dem üblichen Jahr Probezeit. Köhn führte die Bergungsarbeiten der Kunstschätze des Grünen Gewölbes durch und organisierte und begleitete gemeinsam mit Kustos - Walter Holzhausen Transporte zur kriegsbedingten Auslagerung auf die Festung Königstein. Ebenso wurde er für die Bewachung und Überprüfung der ausgelagerten Kunstwerke eingesetzt. Als Köhn 1943 die Einberufung zum Militärdienst erhielt, konnte er aus dienstlichen Gründen uk-gestellt werden. Am 11. August 1944 benannte ihn $>$ Fritz Fichtner gegenüber dem Reichsstatthalter als „für den sachgemäßen Zustand der Depots verantwortlich“2. Nach Kriegsende konnte Köhn nur noch einige Monate in den Staatlichen Sammlungen arbeiten, denn aufgrund seiner Mitgliedschaft in der NSDAP, der er zum 1. April 1933 beigetreten war, wurde er zum 15. November 1945 entlassen. Für die NSDAP hatte er sich ab 1937 als Blockleiter und ab 1943 als stellvertretender Zellenleiter engagiert, außerdem war er politischer Leiter bei der SA. ${ }^{3}$ Nicht zuletzt deshalb scheiterten die nicht ganz zutreffend begründeten Bemühungen der Kommissarischen Leiterin der Skulpturensammlung, $>$ Ragna Enking, die versuchte, Köhn weiter in den Sammlungen zu beschäftigen, da er aufgrund seiner Erfahrungen und Objektkenntnis eine un-

\footnotetext{
1 Dr. W. H. (Walter Holzhausen): Der Goldschmied vom Grünen Gewölbe. Zum Tod von Oberkonservator Schönherr, in: DA, 4.1.1938, S. 3.

2 SMV, Fichtner, an Reichsstatthalter Mutschmann, 11.8.1944, HStA Dresden, 11125, Nr. 23058, fol. 84b.

3 Vgl. Kanzlei der Staatlichen Museen, Fischer, an Landesverwaltung Sachsen, Zentralverwaltung für Wissenschaft, Kunst und Erziehung, Grohmann, 24.11.1945, SKD Archiv, 02/VA 162, fol. 40 u. Rat der Stadt Dresden, Personalfragebogen, 20.7.1945, SKD Archiv, 02/VA 172, fol. 146, 151 u. Liste Mittlere Beamte der Staatl. Kunstsammlungen, o. Dat. (vermutl. 8.1945), SKD Archiv, 02/VA 166, fol. 8 .
} 
ersetzliche Fachkraft sei und ,sich immer nur seiner Arbeit gewidmet hat und sich von jeglicher Betätigung im Sinne der Partei ferngehalten " ${ }^{4}$ habe.

Erst dreizehn Jahre später wurde Köhn, mittlerweile 64-jährig, aufgrund seiner Sammlungskenntnis und praktischen Erfahrung auf Wunsch des damaligen Generaldirektors Max Seydewitz im Dezember 1958 erneut als Restaurator am Grünen Gewölbe angestellt. Diese Tätigkeit führte er bis zu seiner Pensionierung im November 1971 aus.

Am 15. April 1975 starb Kurt Köhn in Radebeul.

\section{Quellen und Literatur}

HStA Dresden, 11125, Nr. 22882

Stadtarchiv Radebeul, SR RL Nr. 263/1975 u. Sammelakte

BArch, R 9361-IX/Kartei/21761018

Ein Restaurator des Grünen Gewölbes erzählt, in: Dresdener Galerieblätter. Monatsschr. d. Staatlichen Kunstsammlungen Dresden, Dresden, H. 12, 1959, S. $291 \mathrm{ff}$.

Menzhausen, Joachim: Kurt Köhn zum Gedenken, in: Dresdener Kunstblätter, 19. Jg., H. 3, 1975, S. $93 \mathrm{f}$.

4 Skulpturensammlung, Enking, 7.9.1945, SKD Archiv, 02/VA 172, fol. 150. 


\section{ArTUR KRÜSS}

17.6.1909 Helgoland - 23.11.1944 vermisst

Präparator

Museen für Tierkunde und Völkerkunde

14.7.1936-31.3.1938 Hilfspräparator

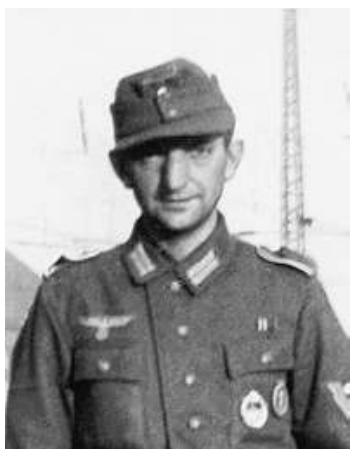

Artur Emil Krüss wurde am 17. Juni 1909 als jüngstes von fünf Kindern des Oberpostschaffners Henry Ludwig Krüss und dessen Frau Maria Friederike, geb. Kröger, in Helgoland geboren. Nach dem Schulabschluss arbeitete Krüss in der Biologischen Anstalt Helgoland.

Von dort kam er im Juli 1936 nach Dresden, um bis März 1938 unter Anleitung von > Robert Reichert als Hilfspräparator an den Museen für Tierkunde und Völkerkunde zu arbeiten und den beurlaubten Konservator $>$ Hellmuth Buck zu vertreten. Der Kontakt zu Krüss war durch - Hans Kummerlöwe zustande gekommen, der seit seiner Tätigkeit als sächsischer Stipendiat auf Helgoland 1926 engen Kontakt zur Biologischen Anstalt Helgoland pflegte. 1938 betonte Kummerlöwe im Arbeitszeugnis für Krüss, der seit April 1930 Mitglied der NSDAP war: „In weltanschaulich-politischer Hinsicht war sein Verhalten, wie es einem alten Nationalsozialisten geziemt, ebenfalls einwandfrei. “"

Im April 1938 wieder an die Biologische Anstalt Helgoland zurückgekehrt, heiratete Krüss im April 1939 in Helgoland Hedwig Elsa, geb. Heische, aus Seifersdorf (Wachau bei Radeberg), die er in Dresden kennengelernt hatte. Über sein weiteres Leben ist wenig bekannt. Seit November 1944 gilt Artur Krüss als vermisst, im Januar 1958 wurde er für tot erklärt. ${ }^{2}$

\section{Quellen und Literatur}

HStA Dresden, 13842, Nr. 048; Nr. 114, Bd. 1; Nr. 115

Familiendatenbank Helgoland, www.online-ofb.de/famreport.php?ofb=helgoland \&ID=I227\& nachname $=\mathrm{KR} \% \mathrm{FC} \% \mathrm{DF} \&$ modus=\&lang=de, Zugriff: 3.12.2019.

1 Kummerlöwe, Arbeitszeugnis für Artur Krüss, Dresden, 30.3.1938, HStA Dresden, 13842, Nr. 114, Bd. 1, o. Pag.

2 Für Informationen über das Leben von Krüss nach 1938 dankt die Autorin Christian Salewski, Archiv für deutsche Polarforschung (AdP) Bremerhaven. 


\section{Hans Kummerlöwe (Hans Kumerloeve)}

5.9.1903 Leipzig - 11.8.1995 München

Zoologe, Ornithologe

Museen für Tierkunde und Völkerkunde

1.1.1936-31.8.1939 Direktor

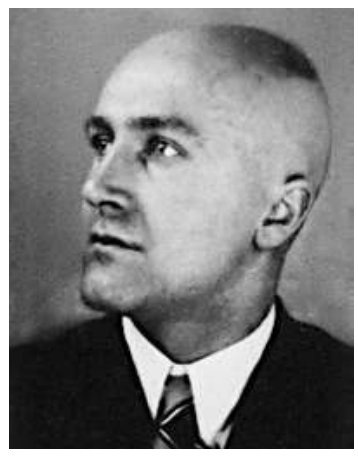

Am 5. September 1903 als Sohn des Verwaltungsinspektors Arthur Kummerlöwe und dessen Frau Palma, geb. Schenk, in Leipzig geboren, bestand Richard Arthur Hans Kummerlöwe 1923 an der Humboldtschule, der Leipziger Städtischen Oberrealschule, sein Abitur. Anschließend studierte er an der Universität Leipzig Naturwissenschaften, mit den Schwerpunkten Zoologie und Vergleichende Anatomie. Im Juni 1930 wurde er bei Johannes Meisenheimer in Leipzig promoviert. Differenzen zwischen ihm als aufstrebendem Nationalsozialisten und seinem jüdischen Doktorvater führten dazu, dass Kummerlöwe nicht als Assistent am Leipziger Lehrstuhl verblieb. Stattdessen legte er im November 1931 das Staatsexamen für das Höhere Lehramt ab und absolvierte den Vorbereitungsdienst in Leipzig. Ein Zeugnis bestätigte, „daß er seinen Unterricht weltanschaulich abzurunden versteht" und „zweifellos eine bedeutende Lehrerpersönlichkeit $^{\text {" }}{ }^{1}$ sei. Kummerlöwe blieb im Schuldienst, zunächst in Riesa, später in Leipzig, wo man ihm bescheinigte: „Er bietet die Gewähr für eine einwandfreie Amtsführung im Sinne des nationalsozialistischen Staates, zumal da er eine ausgezeichnete Führerpersönlichkeit ist. "2 Aufgrund seiner mehrfachen Freistellung für Studienfahrten, wie 1933 für eine von der Deutschen Forschungsgemeinschaft geförderte ornithologische Kleinasien-Reise, hatte er allerdings nur selten unterrichtet. Nebenberuflich engagierte sich Kummerlöwe seit 1934 als Kulturpolitischer Kreisabteilungsleiter des NS-Lehrerbundes und als Abteilungsleiter für die Deutschen Heimatschulen beim Kreisschulungsamt der NSDAP Leipzig. Bereits 1921 war er Mitglied der SA geworden und zum 1. Juni 1925 in die NSDAP eingetreten. Im November 1926 hatte Kummerlöwe die erste nationalsozialistische Studentengruppe in Leipzig mitgegründet. ${ }^{3}$ Bereits im Frühjahr 1933 strebte er danach, zukünftig als Akademiker in einem Museum oder an einer Universität zu arbeiten und kontaktierte diverse Parteigremien und das Sächsische Ministerium für Volksbildung (SMV). Gegenüber Minister Wilhelm Hartnacke betonte Kummerlöwe dabei, dass er „alter Strei-

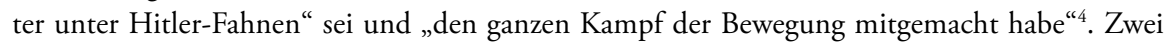

Empfehlung für Hans Kummerlöwe, 23.3.1933, BArch, R 76/I/59, fol. 40.

2 Rat der Stadt Leipzig an SMV, 9.6.1934, ebd., fol. 79.

3 Vgl. Kummerlöwe, Hans: Leipzig - Geburtsort der ersten NS-Hochschulgruppe. Die Gründung am 17. November 1925, in: Offenes Visier. Sächsische Hoch- und Fachschulzeitung. Kampfblatt des Gaustudentenbundes Sachsen der NSDAP, 23, 1936, 6.2.1936, S. 2 u. Kummerlöwe, Hans: Leipzig als Keimzelle des NSDStB. Wie die erste nationalsozialistische Hochschulgruppe entstand, in: Pauliner-Zeitung. Mitteilungen des Verbandes der Alten Pauliner, 48, H. 2, 1936, S. 30 ff.

4 Kummerlöwe an Minister Hartnacke, SMV, 24.7.1933, BArch, R 76/I/59, fol 43 f., hier: 44v. 
Jahre später, im April 1935, war sein parteipolitisches Engagement ausschlaggebend dafür, dass das SMV ihn, obwohl er über keinerlei Museumserfahrung verfügte, als Direktor der Museen für Tierkunde und Völkerkunde in Dresden vorschlug, da er „allen Anforderungen der ihm zu übertragenden Stelle gewachsen erscheint und ein besonders bewährter Vorkämpfer der Bewegung ist."

Kummerlöwes Ernennung zum Museumsdirektor in Dresden erfolgte zum 1. Januar 1936. Von seinen Mitarbeitern im Museum wurde er kritisch beobachtet, denn sie stellten bald fest, dass bei ihm „nicht einmal museale Interessen vorhanden “6 waren. Diesen Eindruck erweckte er, da er sich, kaum in Dresden angekommen, als Freiwilliger zu einer Übung der Luftwaffe meldete, zu der er jedoch erst im Herbst 1936 eingezogen wurde. Noch im März 1936 nahm Kummerlöwe an einer Tagung zur Säugetierkunde in Berlin teil, einen Monat später reiste er zur Vogelwarte der Biologischen Anstalt Helgoland, wo er bereits während seines Studiums zweimal für Forschungsaufenthalte weilte. Auch in den nachfolgenden Jahren nahm er rege an Tagungen teil, oftmals in Begleitung seiner Frau Gertraude, geb. Doller, die er im März 1935 geheiratet hatte. So zählte er im Mai 1938 beim 9. Internationalen Ornithologen-Kongress in Rouen mit -Wilhelm Meise zur deutschen Delegation. Fünf Monate später reiste Kummerlöwe zum II. Internationalen Kongress für Anthropologie und Ethnologie nach Kopenhagen. Die vielen Tagungsteilnahmen boten ihm die Möglichkeit der Vernetzung unter Fachkollegen. 1936 kontaktierte Kummerlöwe den Museumsbund, um „sowohl dienstlich als auch vom Parteigesichtspunkte her"7 mehr über die Erneuerung des Museumswesens zu erfahren. Er engagierte sich, weilte mehrfach in Berlin und referierte bei der 5. Tagung des Bundes der deutschen naturwissenschaftlichen Museen im Oktober 1936 „Über die Notwendigkeit eines internationalen wissenschaftlichen Museologen-Austausches" ${ }^{8}$ Darüber hinaus erhielt er im Herbst 1936 einen Lehrauftrag an der Technischen Hochschule in Dresden und übernahm in Nachfolge von -Arnold Jacobi ein halbes Jahr später die Leitung des dortigen Zoologischen Instituts. Rege knüpfte Kummerlöwe weitere Kontakte zu Personen aus Politik und Verwaltung, denn er hatte ein starkes Interesse am Fortgang seiner Karriere. Im Museum war er indes selten anwesend. Die fachliche Arbeit delegierte er an seine Mitarbeiter. So beauftragte er Meise mit der Organisation des Umzuges des Tierkundemuseums vom Zwinger in das ehemalige Logenhaus an der OstraAllee. Zur Eröffnung des Museums am neuen Standort hielt Kummerlöwe am 4. Oktober 1937 eine programmatische, an nationalsozialistischem Vokabular reiche Rede, in der er betonte, die Hauptaufgabe der Museen sei es „zu leiten, zu beeinflussen und zu erziehen “9. Er hielt Vorträge über die einheimische Tierwelt, insbesondere über Vögel und den Vogelzug. Für Mitarbeiter der Staatlichen Sammlungen offerierte er im Mai 1936 einen Spaziergang im Großen Garten zum Entdecken einheimischer Vogelstimmen. Ab Herbst 1937 arbeitete er mehrfach für die Volks-

\footnotetext{
SMV an Reichsstatthalter in Sachsen, 27.4.1935, ebd., fol. 84. Siehe auch S. $72 \mathrm{ff.}$

Struck an Thorbecke, 23.07.1937, SKD, MfV Archiv, MVD n20;25/7/8, o. Pag.

Kummerlöwe an Museumsbund, Zimmer, 16.6.1936, HStA Dresden, 13842, Nr. 204, o. Pag.

8 Vgl. Kummerlöwe, Hans: Über die Notwendigkeit eines internationalen wissenschaftlichen $\mathrm{Mu}-$ seologen-Austausches, Bund der deutschen naturwissenschaftlichen Museen (Abt. B des Deutschen Museumsbundes), 30. Flugblatt, Berlin, November 1936, S. 1-6.

9 Kummerlöwe, Hans: Geschichte und Aufgaben des Staatlichen Museums für Tierkunde in Dresden. Rede zur Eröffnung des Museums für Tierkunde 4. Oktober 1937, in: Abhandlungen und Berichte aus den Staatlichen Museen für Tierkunde und Völkerkunde in Dresden, Bd. 20, N. F., Bd. 1, H. 1, Leipzig 1939, S. 1-15, hier: 12. Siehe S. 186 f.
} 
bildungsstätte, wo er auch über politische Themen referierte, wie über „Polen als politischer Faktor der Gegenwart" oder „Grundsätze und Wege nationalsozialistischer Außenpolitik“. ${ }^{10}$ Von seinen Mitarbeitern verlangte er generell ein klares Bekenntnis zum Nationalsozialismus. So forderte er von $>$ Michael Hesch noch vor der dessen Einstellung eine enge Zusammenarbeit mit dem Rassenpolitischen Amt der NSDAP. ${ }^{11}$ Auch bei der Auswahl des am Museum beschäftigten wissenschaftlichen Nachwuchses achtete Kummerlöwe auf dessen Parteizugehörigkeit, wie bei -Arthur Krüss oder > Helmut Hofer. Im Herbst 1938 kontaktierte ihn das Ministerium für innere und kulturelle Angelegenheiten in Wien, um ihn als Museumsdirektor zu gewinnen. Nach einer Reise nach Wien im November 1938 benannte Kummerlöwe in seinen Zukunftsplänen für das Naturhistorische Museum unter anderem Rassenkunde, Bevölkerungspolitik und koloniale Aufgaben als neue Hauptthemen. Vom Wiener Ministerium ausdrücklich als der Kandidat empfohlen, „der als Zoologe, als Völkerkundler und als Politiker die besten Voraussetzungen mitbringt ${ }^{\text {"12 }}$, wurde Kummerlöwe im Juni 1939 mit der kommissarischen Leitung der Wissenschaftlichen Museen in Wien beauftragt.

Ende August 1939 trat Kummerlöwe das neue Amt in Wien an. Sogleich begann er mit der nationalsozialistischen Umformung des Naturhistorischen Museums. Doch seine Ernennung zum Direktor verzögerte sich aufgrund verwaltungsinterner Schwierigkeiten und erfolgte erst im August 1940. Als Forschungsprojekte ließ er anthropologische Untersuchungen in Kriegsgefangenenlagern und an Juden im Amsterdamer Ghetto durchführen, wofür er seinen früheren Dresdner Kollegen Hesch zu rekrutieren versuchte. ${ }^{13}$ Auch in Wien arbeitete Kummerlöwe in enger Verbindung zur Politik, z. B. in Kontakt zum Reichsminister, Stellvertretenden Generalgouverneur und späteren Reichskommissar für die Niederlande, Arthur Seyß-Inquart. Im November 1939 reiste er zur Inspektion mehrerer polnischer Museen durch das Generalgouvernement, vor allem nach Krakau und Warschau. ${ }^{14}$ Nach anfänglichen Rückstellungen wurde Kummerlöwe im Frühjahr 1941 zur Wehrmacht einberufen und an der Ostfront eingesetzt. Die Museumsarbeit in Wien konnte er dadurch nur noch eingeschränkt fortsetzen. Nach dem Kriegsende lebte er in Osnabrück, später in Gräfelfing bei München. In den Museumsdienst kehrte Kummerlöwe nicht zurück. Auch übernahm er kein öffentliches Amt mehr, wodurch er sich keinem Entnazifizierungsverfahren stellen musste. Stattdessen bezeugt die Namensänderung in Kumerloeve den skurilen Versuch, sich für den Wissenschaftsbetrieb seiner NS-Vergangenheit zu entledigen. Er arbeitete fortan als Privatgelehrter, reiste, forschte - häufig als Gast in der Ornithologischen Abteilung des Museums König Bonn - und publizierte. Mehrfach erhielt er Fördermittel von der Deutschen Forschungsgemeinschaft. Insgesamt veröffentlichte er über 400 Aufsätze, teilweise

10 Vgl. DA, 1.3.1938, S. 8 u. 29.9.1938, S. 8.

11 Siehe S. 73.

12 Ministerium für innere kulturelle Angelegenheiten, Wien, an RMVP, Berlin, o. Dat., BArch, R 76/I/59a, fol. 69.

13 Zu den anthropologischen Untersuchungen vgl. Teschler-Nicola 2012, S. 286-300 sowie Teschler-Nicola, Maria u. Margit Berner: Die Anthropologische Abteilung des Naturhistorischen Museums in der NS-Zeit: Berichte und Dokumentation von Forschungs- und Sammlungsaktivitäten, in: Senatsprojekt der Universität Wien. Untersuchungen zur anatomischen Wissenschaft in Wien 19381945, Wien 1998, S. 333-358 (Für die Einsicht in diese Studie dankt die Autorin Maria TeschlerNicola). Vgl. Kummerlöwe an Hesch, 29.3.1941 u. 18.4.1941, HStA Dresden, 13842, Nr. 114, Bd. 2, o. Pag.

14 Vgl. Kummerlöwe an Heydrich, 30.10.1939, 13.11 .1939 u. 28.11.1939, ebd. Siehe S. 143. 
gemeinsam mit Kollegen. In den 1970er-Jahren war er gelegentlich als Studienreiseleiter tätig und leitete unter anderem Reisen in die Türkei, aber auch auf die Galapagosinseln. Am 11. August 1995 starb Hans Kummerlöwe in München.

\section{Auswahlbibliografie}

Vergleichende Untersuchungen über das Gonadensystem weiblicher Vögel. Mit besonderer Berücksichtigung des Persistierens von rechtsseitigen Keimgewebselementen im normalen Weibchen, in: Zeitschrift für mikroskopisch-anatomische Forschung, Bd. 21, 1930, S. 1-156; Bd. 22, 1930, S. 259-413; Bd. 24, 1931, S. 455-631; Bd. 25, 1931, S. 311-319 (Zugl. Leipzig, Univ., Diss., 1930).

Beiträge zur Kenntnis der Avifauna Kleinasiens (Paphlagonien-Galatien), in: Journal für Ornithologie, Bd. 82, H. 4, 1934, S. 506-552; Bd. 83, H. 1, 1935, S. 62-75 (mit Günther Niethammer).

Das Landesmuseum für Tierkunde in Dresden und der Heimatschutz, in: Landesverein Sächsischer Heimatschutz (Hg.): Denkmalpflege, Heimatschutz, Naturschutz: Erfolge, Berichte, Wünsche, 1936, S. 215-225.

Hinweise auf die Vogelwelt des Tatra-Gebietes und der Waldkarpathen, in: Leipziger Vierteljahresschrift für Südosteuropa, 1.1937, 2, S. 58-74.

Geschichte und Aufgaben des Staatlichen Museums für Tierkunde in Dresden. Rede zur Eröffnung des Museums für Tierkunde 4. Oktober 1937, in: Abhandlungen und Berichte aus den Staatlichen Museen für Tierkunde und Völkerkunde in Dresden, Bd. 20, Reihe A, N. F. Bd. 1, H. 1, Leipzig 1939, S. 1-15.

Zur Neugestaltung der Wiener wissenschaftlichen Staatsmuseen. In: Annalen des naturhistorischen Museums in Wien 50, 1940, S. XXIV-XXXIX.

Zur Kenntnis der Avifauna Kleinasiens: mit besonderer Berücksichtigung der südlichen Landesteile Taurus, Kilikien Nordwest-Mesopotamien, Bonner zoologische Beiträge, 12, Sonderheft, 1962.

Die Säugetiere (Mammalia) der Türkei. Zoologische Staatssammlung, München 1975.

Die Säugetiere (Mammalia) Syriens und des Libanon, in: Veröffentlichungen der Zoologischen Staatssammlung München, 18, 1975, S. 161-225.

Bibliographie der Säugetiere und Vögel der Türkei (rezente Fauna), Bonner zoologische Monographien, 21, Bonn 1986.

\section{Quellen und Literatur}

SKD, MfV Archiv, MVD n20;25/ 7/8

HStA Dresden, 13471, Nr. ZA VI 2801, 12

HStA Dresden, 13842, Nr. 048; Nr. 114, Bd. 1 u. 2

BArch, R 76/I/59; R 76/I/59a; R 76/I/59b

BArch, R 73/12517

BArch, R 4901/2932; R 4901/13269

BArch, NS 12/8602

BArch, R 9361-IX/Kartei/24131334

SMB-ZA, III/DMB 003

ZFMK, NL Kummerlöwe

Niethammer, Günther: Am 5. September 1973 vollendet Museumsdirektor a. D. Dr. phil. Hans Kumerloeve sein 70. Lebensjahr, in: Bonner Zoologische Beiträge, 24. Jg., H. 3, 1973, S. 161-164. 
Naumann, Clas Michael: Zum Gedenken an Hans Kumerloeve, in: Bonner zoologische Beiträge, Bd. 47, 1997, S. 189 f.

Nowak, Eugeniusz: Erinnerungen an Ornithologen, die ich kannte (3. Teil), in: Mitteilungen des Vereins Sächsischer Ornithologen, Bd. 9, H. 1, 2002, S. 1-46, hier: 27 ff.

Stamm, H. C.: Kummerlöwe [= Kumerloeve], Hans, in: Neumann, Joachim, Siegfried Eck, u. a., in: Lebensbilder sächsischer Ornithologen, Mitteilungen des Vereins Sächsischer Ornithologen, Bd. 10, Sonderheft 3, Hohenstein-Ernstthal 2010, S. 117 f.

Nowak, Eugeniusz: Wissenschaftler in turbulenten Zeiten. Erinnerungen an Ornithologen, Naturschützer und andere Naturkundler, Hohenwarsleben 2010, o. S.

Teschler-Nicola, Maria: Richard Arthur Hans Kummerlöwe alias Kumerloeve (1903-1995). Erster Direktor der wissenschaftlichen Museen in Wien in der NS-Zeit, in: Mitteilungen der Anthropologischen Gesellschaft in Wien (MAGW), Bd. 142, 2012, S. 279-304.

Klösch, Christian: Hans Kummerlöwe, in: Lexikon der österreichischen Provenienzforschung, www.lexikon-provenienzforschung.org/kummerl\%C3\%B6we-hans, Zugriff: 3.12.2019. 


\section{Arthur Leuschner}

12.9.1883 Dittmannsdorf - [22.5.]1960 Dresden

Aufseher, Regierungsassistent

Historisches Museum

1.7.1922-31.12.1927 Oberwächter

Skulpturensammlung

1.1.1928-31.1.1936 Aufseher

1.2.1936-31.1.1940 Oberaufseher

Porzellansammlung

1.2.1940-31.10.11.1940 Oberaufseher

1.11.1940-30.11.1942 Kanzleiassistent

1.12.1942-15.11.1945 Regierungsassistent

11.8.1944-11.1944 Depotverantwortlicher

[11.1945]-30.9.1948 Mitarbeiter

(Abordnung an Sächsisches Ministerium für Volksbildung 12.1939-1.1940)

Arthur Eduard Leuschner wurde am 12. September 1883 im zwischen Meißen und Freiberg gelegenen Dittmannsdorf als Sohn des Zimmermanns Julius Eduard Leuschner und dessen Ehefrau Emilie Auguste, geb. Kunze, geboren. Nach dem Besuch der Volks- und Fortbildungsschule arbeitete er als Gemeindediener, unterbrochen vom Militärdienst, den er vom Oktober 1903 bis September 1905 sowie im Ersten Weltkrieg vom August 1914 bis Februar 1919 leistete.

Im Juli 1922 begann Leuschner seine Tätigkeit in den Staatlichen Sammlungen als Oberwächter im Historischen Museum. 1926 starb seine Frau Hedwig Emma, geb. Schubert, die er 1907 geheiratet hatte. In zweiter Ehe heiratete er im Juli 1929 Clara Ernestine, verw. Boden, geb. Thiele. Anderthalb Jahre zuvor, zum Jahresbeginn 1928, war Leuschner vom Historischen Museum als Aufseher zur Skulpturensammlung gewechselt, wo er im Februar 1936 zum Oberaufseher befördert wurde. Vier Jahre später, im Februar 1940 wechselte er in die Porzellansammlung, allerdings als Oberaufseher und nicht, wie es Direktor $\triangleright$ Fritz Fichtner im Dezember 1939 beantragt hatte, als Nachfolger des pensionierten Kanzleiassistenten Albin Spiegler. Unmittelbar zuvor war Leuschner noch für zwei Monate in das Sächsische Ministerium für Volksbildung abgeordnet gewesen. Ob er dort bereits für Fichtner arbeitete, geht aus den Akten nicht hervor. Nur wenige Tage nach dem Wechsel an die Porzellansammlung, stellte Leuschner am 7. Februar 1940 seinen Aufnahmeantrag in die NSDAP. Seine Parteimitgliedschaft begann im April 1940, sieben Monate später wurde er schließlich zum Kanzleiassistenten ernannt. Ab Mai 1942 wurde Leuschner für die Mittlere Beamtenlaufbahn zugelassen. Unmittelbar nachdem er die erforderlichen Prüfungen bestanden hatte, wurde er Anfang Dezember 1942 zum Regierungsassistenten befördert. Im April 1943 wurde er pro forma an die Sächsische Landesbibliothek und im April 1944 an das Historische Museum versetzt, blieb aber durch Abordnung jeweils weiterhin in der Porzellansammlung tätig. Hinter diesen Anordnungen standen verwaltungstechnische Entscheidungen, die infolge von Einberufungen und Sparmaßnahmen zu einer Reduktion des Verwaltungspersonals geführt hatten. Fichtner benötigte den Regierungsassistenten, der über reichlich Erfahrung verfügte und mittlerweile seit mindestens drei Jahren zuverlässig für ihn arbeitete, aufgrund seiner eigenen vielfältigen Verpflichtungen dringend, denn Leuschner betreute „längere Zeitperioden hindurch nicht nur die Porzellangalerie, das Grüne Gewölbe, die Skulpturensammlung, das 
Historische Museum mit allen anfallenden Verwaltungsgeschäften, sondern zeitweise sogar alle Museen" "1. Zusätzlich wurde Leuschner, der in Stellvertretung Fichtners auch die Bergung der Porzellansammlung organisierte, am 11. August 1944 durch diesen als Depotverantwortlicher benannt. ${ }^{2}$ Doch diese vielen Aufgaben führten alsbald zu einer chronischen Überlastung Leuschners und einer Verschlechterung seiner Gesundheit. Als er infolge einer Nervenerschöpfung ab November 1944 nur noch halbtags arbeiten konnte, wurde die Verantwortung für die Porzellansammlung und ihre Auslagerungsdepots auf den Sammlungsaufseher $>$ Richard Schmidt übertragen. Obwohl Leuschner aufgrund seiner NSDAP-Mitgliedschaft am 15. November 1945 entlassen wurde, blieb er „arbeitsdienstverpflichtet im Museum tätig “3, denn die Museumsverwaltung war nach der Flucht Fichtners auf Leuschners Erfahrung und Bestandskenntnis angewiesen. Ab 28. Juni 1946 wurde seine stundenweise Weiterbeschäftigung genehmigt, da sie laut der Direktive 24 für „nominelle Parteimitglieder“ zulässig war. Nach dem Urteil der Entnazifizierungskommission vom 16. Januar 1948 wurde beantragt, Leuschner in seiner alten Stelle einzusetzen. Doch mit Erreichen des Pensionierungsalters wurde er Ende September 1948 auf eigenen Wunsch verabschiedet.

Arthur Leuschner ist 1960 in Dresden gestorben.

\section{Quellen und Literatur}

HStA Dresden, 13859, Nr. 4970

HStA Dresden, 11125, Nr. 22891

SKD Archiv, 02/VA 41, Bd. 2

BArch, R 9361-IX/Kartei/25661359

SMV, Fichtner, an Leiter SMV, 1.9.1942, SKD Archiv, 01/PS 53, Bd. 1, fol. 29-35, hier: 32.

Vgl. SMV, Fichtner, an Reichsstatthalter Mutschmann, 11.8.1944, HStA Dresden, 11125, Nr. 23058, Bl. 84b.

3 Kunstgewerbemuseum an Buchwitz, Vorsitzender der SED, 20.8.1946, SKD Archiv, 02/VA 41, Bd. 1, fol. 95. 


\section{Hans Loos}

14.4.1890 Leubnitz b. Werdau - 25.12.1969 Dresden

Zeichner, Retuscheur, Präparator

Kupferstich-Kabinett

1.1.1930-30.4.1946 Präparator

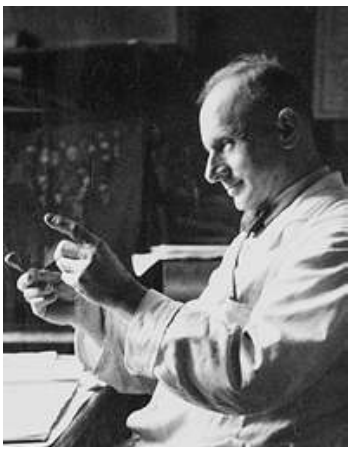

Hans Ewald Loos wurde am 14. April 1890 als Sohn von August Wilhelm Loos und dessen Frau Minna Karoline, geb. Könitzer, in Leubnitz, heute ein Ortsteil von Werdau, geboren. Nach der Bürgerschule absolvierte er in Dresden sowohl Kurse an der Kunstgewerbeschule als auch an der Polizeibeamtenschule. Von März 1908 bis Dezember 1923 arbeitete Loos in der Retusche-Abteilung der Kunstanstalt Stengel \& Co GmbH in Dresden, die für ihre Licht- und Offsetdrucke bekannt war. Unterbrochen wurde diese Tätigkeit von seinem Militärdienst von Oktober 1909 bis September 1911 sowie im Ersten Weltkrieg von August 1914 bis Dezember 1918. Im Juli 1922 heiratete er Wally Elise, geb. Pfüller, mit der er eine Tochter hatte. Im Dezember 1923 wechselte Loos in den Staatsdienst. Zunächst arbeitete er bei der Amtshauptmannschaft Glauchau als Polizeioberwachtmeister, Grafischer Zeichner und Retuscheur. Als Vollzugsbeamter der sächsischen Schutzpolizei in Glauchau und Chemnitz war er vorübergehend auch als Hilfsrechnungsführer einer Polizeikasse beschäftigt, bevor er ins Polizeipräsidium nach Chemnitz wechselte, wo er im Außendienst tätig war. Ab Oktober 1928 arbeitete er als kartografischer Zeichner für das Stadtvermessungsamt Chemnitz.

Als Ende 1929 die Präparatorenstelle im Kupferstich-Kabinett in Dresden vakant war, bewarb sich Loos. Für Direktor $>$ Kurt Zoege von Manteuffel war er der Favorit unter den Bewerbern, da er aufgrund seiner Berufserfahrungen „die graphischen Techniken und die Behandlung von graphischen Blättern kennen dürfte " ${ }^{\text {, }}$, außerdem sprach er Französisch und Englisch und konnte fotografieren. Ab Januar 1930 wurde Loos im Kupferstich-Kabinett als Präparator angestellt. Als ein Jahr später seine Bewerbung als Oberkonservator im Hauptstaatsarchiv Dresden erfolglos verlief, blieb er im Dienst der Staatlichen Sammlungen. Er war primär für alle Fotoarbeiten und nach der Auslagerung der Bestände des Kupferstich-Kabinetts für deren Betreuung an den Bergungsorten zuständig. Während der Wachdienste in Weesenstein fertigte er für das Kabinett fotografische Reproduktionen an, die er auf eigene Rechnung verkaufen durfte. Obwohl er, nach eigenen Angaben, zuvor SPD-Mitglied gewesen war, trat er im Mai 1937 in die NSDAP ein, für die er ab 1938 als Blockwart tätig war. Trotz dieser Parteimitgliedschaft wurde Loos nach dem Kriegsende bis Ende April 1946 weiterbeschäftigt.

Wie der damals 56-Jährige nach seiner Entlassung seinen Lebensunterhalt verdiente, ist nicht überliefert. Im März 1948 beantragte er bei der Hauptverwaltung der Staatlichen Museen „Laut

Kupferstich-Kabinett, Zoege von Manteuffel, an SMV, 19.12.1929, SKD Archiv, 01/KK 3, Bd. 8, fol. $112 \mathrm{f}$. 
Befehl Nr. 35 [...] Wiedereinstellung nomineller Pgs. [...] meine Einstellung als Repr.-Photograph $^{\text {“2 }}$ und bot im Gegenzug seine umfangreiche Negativsammlung zur Übernahme an, jene Aufnahmen, die er einst für das Kupferstich-Kabinett angefertigt hatte. Diesem Antrag wurde nicht stattgegeben. Hans Loos starb am 25. Dezember 1969 in Dresden.

\section{Quellen und Literatur}

HStA Dresden, 13859, Nr. 5153

SKD Archiv, 02/VA 162

BArch, R 9361-IX/Kartei/26390940

2 Vgl. Loos an die Hauptverwaltung der Staatlichen Museen, 10.3.1948, HStA Dresden, 11401, Nr. 2414, fol. 153. Unklar bleibt, ob er rechtmäßiger Eigentümer dieser Sammlung war. Er hatte die Fotos von Objekten aus dem Kupferstich-Kabinett im Auftrag des Kabinetts für externe Auftraggeber angefertigt und durfte die Kosten dafür direkt mit diesen abrechnen. 

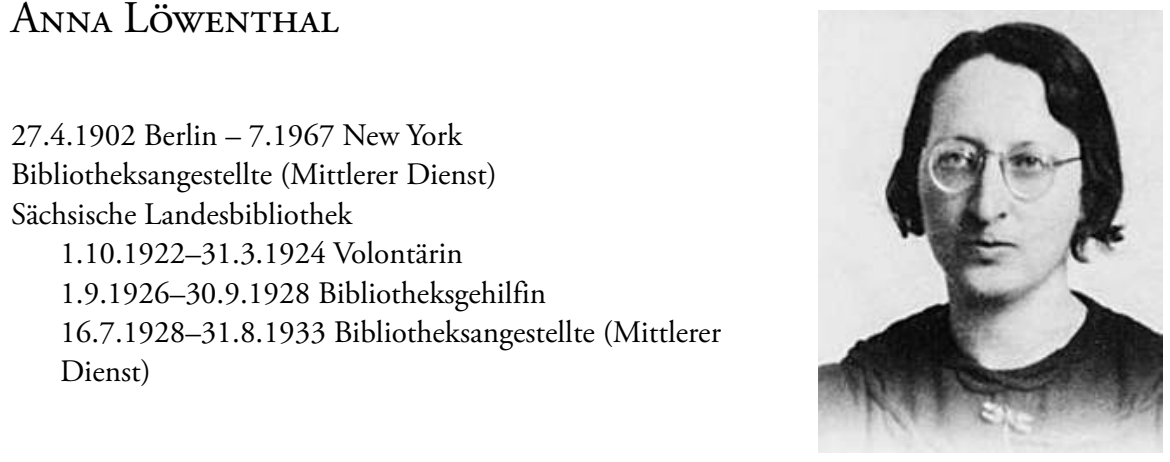

Als vierjähriges Kind kam die am 27. April 1902 in Berlin als Tochter des Kaufmanns Moses Löwenthal und dessen Ehefrau geborene Anna Löwenthal mit ihrer Familie nach Dresden. Nach dem Schulbesuch war sie zwei Jahre in der Hauswirtschaft tätig, bevor sie 1919 für ein Jahr in einem Mädchenpensionat in Baden-Baden unterrichtet wurde. 1920 kehrte Löwenthal nach Dresden zurück und lernte in den folgenden beiden Jahren an der Altstädter Frauenschule.

Am 14. Mai 1922 bat sie um Aufnahme als Praktikantin an der Sächsischen Landesbibliothek in Dresden, doch erst im Oktober 1922 wurde sie zum Volontariat und zur Ausbildung für den Mittleren Dienst an wissenschaftlichen Bibliotheken zugelassen. Dafür wechselte sie im Frühjahr 1924 an die Universitätsbibliothek Leipzig, wo sie ihre Prüfung am 24. September 1924 mit Erfolg ablegte. Nach einem Jahr noch immer auf der Suche nach einer Anstellung, bat Löwenthal Ende 1925, sie weiterhin als Bewerberin für den Mittleren Dienst an der Landesbibliothek zu führen. Auch ihre durch $>$ Martin Bollert unterstützte Bewerbung um eine Stelle beim Landesstaatsbauverein blieb erfolglos. Ab September 1926 konnte ihr Bollert einen befristeten Vertrag als Bibliotheksgehilfin für täglich 5 Stunden in der Musikabteilung anbieten. Da sie ihre Arbeit zuverlässig erledigte, setzten sich ihre Kollegen Arno Reichert, $>$ Hans Hofmann und $\gg$ Ewald Jammers im April 1928 für ihren Verbleib an der Landesbibliothek ein: „Dass man daran denkt, ihr diese neue Stelle vorzuenthalten, weil Fräulein Löwenthal Jüdin ist, nehmen wir nicht an; aus diesem Grunde darf sich eine Zurücksetzung nicht rechtfertigen lassen. " Ab Mitte Juli 1928 war sie als Bibliotheksangestellte an der Sächsischen Landesbibliothek tätig. Doch zum 31. Januar 1931 erhielt Anna Löwenthal, wie > Lucie Walter und acht weitere Kolleginnen und Kollegen, aufgrund der staatlich angeordneten Sparmaßnahmen ihre Kündigung, wurde allerdings nach einer Gehaltskürzung doch weiterbeschäftigt. Im Fragebogen, den alle Angestellten im öffentlichen Dienst im Zuge des „Gesetzes zur Wiederherstellung des Berufsbeamtentums“ im Juni 1933 auszufüllen hatten, schrieb Löwenthal, wie ihre Kollegin Walter, nur „Ich bin Jüdin“. Am 20. Juli 1933 verfügte das Sächsische Ministerium für Volksbildung ihre Entlassung zum 31. August 1933. Vier Tage später übermittelte ihr Bollert die Kündigung. Das Einzige, was er in dieser Situation noch für Löwenthal tun konnte, war, ihr ein gutes Arbeitszeugnis auszustellen. So bescheinigte er: „Sie besitzt gute Gaben des Geistes und ist geschickt im praktischen Anfassen ihrer Aufgaben. Ihr Fleiss und ihre Arbeitsfreude sind gross und sie ist erfüllt von ernstem Verantwor-

Reichert, Hofmann u. Jammers an Direktor Bollert, 18.4.1928, SLUB, PA Löwenthal. 
tungsgefühl. Ihre Leistungen waren stets zuverlässig und überaus befriedigend. Ihr persönliches Auftreten war von grosser Bescheidenheit und Zurückhaltung“2.

Der jäh beendeten Bibliothekslaufbahn folgten schwere Jahre. Von einer Besuchsreise nach New York 1937 kehrte Löwenthal zunächst nach Dresden zurück. Doch am 30. November 1938 konnte sie an Bord des Dampfschiffs „Washington“ von Hamburg aus auswandern. Die entsprechenden Papiere hatte sie erst erhalten, nachdem sie eidesstattlich erklärt hatte, nie wieder deutschen Boden zu betreten. Am 9. Dezember 1938 kam sie in New York an. Rückblickend berichtete sie: „Nach manchen Schwierigkeiten ist es mir erst im Dezember 1938 ermöglicht worden auszuwandern. Meine Geschwister haben Gefängnis, Konzentrationslager und Tropen überstanden und leben auch hier, ein seltenes Glück. “3 Doch der Start in den USA war trotz ihrer Englischkenntnisse keineswegs unproblematisch. Löwenthal arbeitete zunächst drei Jahre als Dienstmädchen, bevor sie 1942 eine Stelle als ungelernte Arbeiterin in einer Fabrik annahm. Der Besuch eines Abendkurses in Buchhaltung ermöglichte ihr 1952 den Wechsel in eine kaufmännische Tätigkeit. Doch im Dezember 1961 wurde sie entlassen. In ihrem letzten überlieferten Brief berichtete sie 1962 gegenüber Jammers, den sie im Sommer 1961 in New York getroffen hatte, eine schlecht bezahlte Stellung gefunden zu haben und trug sich mit dem Gedanken, diese aufzugeben. ${ }^{4}$ Anna Löwenthal starb im Juli 1967 in New York. ${ }^{5}$

\section{Quellen und Literatur}

SLUB, PA Löwenthal, Anna

SLUB, Mscr.Dresd.App.2830, Bl. 101-106

„New York, Southern District, U.S District Court Naturalization Records, 1824-1946," database with images, FamilySearch (https://familysearch.org/ark:/61903/1:1:QP7X-8N52, Zugriff: 3.12.2019), Anna Loewenthal, 1939; citing Immigration, New York, United States, 280350, NARA microfilm publication M1972, Southern District of New York Petitions for Naturalization, 1897-1944. Records of District Courts of the United States, 1685-2009, RG 21. National Archives at New York.

Bürger, Thomas: Dresdner Bibliothekare - emigriert, geflohen, geblieben. Briefe der Nachkriegszeit aus dem Nachlass von Ewald Jammers (Teil 2), in: SLUB-Kurier, 21. Jg., 2007, H. 2, S. 13-15.

\footnotetext{
2 Bollert, Arbeitszeugnis für Anna Löwenthal, 26.7.1933, SLUB, PA Löwenthal. Siehe S. 50 f.

3 Löwenthal an Jammers, 2.11.1958, SLUB, Mscr.Dresd.App.2830, fol. 101.

4 Löwenthal an Jammers, 26.8.1962, SLUB, Mscr.Dresd.App.2830, fol. 106.

5 Für diese Information und die Erschließung der amerikanischen Quellen dankt die Autorin Marisa Bourgoin, Archives of American Art, Smithsonian Institution.
} 


\section{Wilhelm Meise}

12.9.1901 Essen - 24.8.2002 Hamburg

Zoologe, Ornithologe

Museen für Tierkunde und Völkerkunde

(ab 1.1.1942 Museen für Tierkunde, Rassenkunde und

Völkerkunde)

15.5.1929-31.10.1941 Wissenschaftlicher Hilfsarbeiter

1.11.1941-[1945] Kustos

(Beurlaubung an das Musée Royal d'Histoire naturelle, Brüssel,

15.11.1937-14.12.1937, 24.5.1938-23.6.1938; Militärdienst

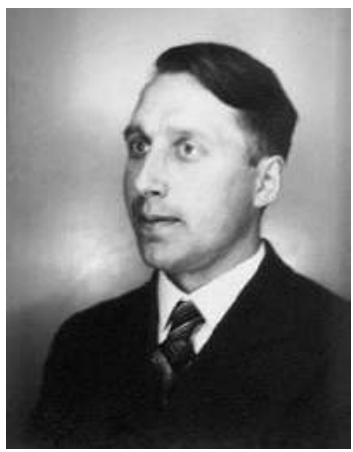

22.9.1938-5.10.1938, 9.1.1939-21.1.1939, ab 22.8.1939)

Wilhelm Konrad Louis Georg Meise wurde am 12. September 1901 als Sohn des Malermeisters Wilhelm Meise und dessen Ehefrau Karoline Marie Elise, geb. Albrecht, in Essen geboren. Nach dem Besuch der Volks- und Mittelschule sowie von 1917 bis 1921 des Lehrerseminars in Essen arbeitete er zunächst als Hilfskraft seines Vaters, als Schreiber in einem Steuerbüro und schließlich als Hauslehrer in der Oberförsterei Redlitz bei Zerbst. Später bestand er als externer Prüfling am Realgymnasium in Düsseldorf die Abiturprüfung. Ab 1924 studierte Meise in Berlin Zoologie, Botanik, Chemie und Mathematik. Nach dem Staatsexamen wurde er 1928 bei Erwin Stresemann in Berlin promoviert. Bereits während des Studiums begann er sich in der Fachwelt zu vernetzen und trat in die Deutsche Ornithologische Gesellschaft ein, später auch in den Verein Sächsischer Ornithologen. Bis ins hohe Alter nahm er an zahlreichen ornithologischen Tagungen teil. Ab Februar 1928 arbeitete er als Assistent und stellvertretender Bibliothekar im Zoologischen Museum in Berlin.

Am 15. Mai 1929 begann Meise seine Arbeit als Wissenschaftlicher Hilfsarbeiter an den Museen für Tierkunde und Völkerkunde in Dresden. Als Assistent des Direktors \Arnold Jacobi war er für alle zoologischen Fachgebiete außer der Entomologie zuständig und betreute die Schausammlung. Da Meise mit „,ungewöhnlicher Vielseitigkeit und raschester Auffassung [...] in bewusster Wahrnehmung seiner wissenschaftlichen Pflichten [...] alle Kraft auf die Förderung der heimischen Tierkunde und den Schutz unserer Tierwelt ${ }^{\text {"1 }}$ verwendete, bemühte sich Jacobi, ihn am Dresdner Museum zu halten und eine Kustodenstelle zu schaffen, z. B. als das Berliner Zoologische Museum ihn 1933 abwerben wollte. Auch nach der Entlassung des jüdischen Kustos - Fritz van Emden gelang es Jacobi nicht, dessen Stelle an Meise zu übertragen. Der neue Direktor $>$ Hans Kummerlöwe beauftragte Meise im Oktober 1936 mit der Organisation des Umzuges des Museums für Tierkunde. In dessen Eröffnungsjahr 1937 habilitierte sich Meise. Ende 1937 und im Juni 1938 weilte er zu Forschungszwecken am Musée Royal d'Histoire Naturelle in Brüssel. Unterdessen hatte er 1930 Klara Elisabeth Eva, geb. Lehmann, geheiratet, mit der er drei Kinder hatte. Wenige Tage vor Beginn des Zweiten Weltkrieges wurde Meise, wie bereits während der „Sudetenkrise“, zur Wehrmacht einberufen. Er diente zunächst als Gefreiter beim Flugmeldedienst in Dresden, von wo aus er 1940 kurzzeitig nach Norwegen abkommandiert wurde. Damals war er in der Nachfolge Kummerlöwes als Direktor des Museums im Gespräch,

Jacobi an SMV, 26.10.1933, HStA Dresden, 13842, Nr. 047, o. Pag. 
doch $>$ Fritz Fichtner teilte dem Leiter des Ministeriums für Volksbildung mit: „Meise scheidet

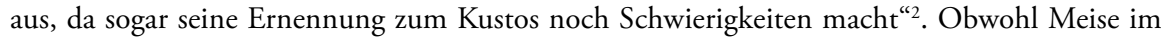
November 1933 in die SA und im Mai 1937 in die NSDAP eingetreten war, wurde ihm im Juli 1937 seitens der Partei vorgeworfen, dass er „seine Kenntnisse als Biologe nicht in den Dienst der Idee der Bewegung gestellt habe und nichts zur Vertiefung des Verständnisses der Rassenpolitik der Bewegung getan habe" ${ }^{\text {, }}$, auch stigmatisierte ihn sein parteipolitisch engagierter Kollege - Hellmuth Buck mehrfach als „Gegner der Bewegung“. Daher verzögerte sich seine Ernennung zum Kustos. Die Urkunde über die Vereidigung konnte Meise erst im Januar 1942 bei einem Heimaturlaub unterzeichnen, die Ernennungsurkunde war im November 1941 ausgefertigt worden. Doch er konnte nicht an das Museum zurückkehren, sondern musste im Militärdienst verbleiben. Ab 1943 war er an der Ostfront eingesetzt, wurde im April 1943 an die LuftwaffenSchule nach Rudolstadt versetzt und 1944, unterdessen zum Leutnant befördert, in Breslau stationiert. Der Versuch, Meise nach der Zerstörung des Tierkundemuseums durch einen Luftangriff auf Dresden im Oktober 1944 für die Aufräumarbeiten beurlauben zu lassen, scheiterte. ${ }^{4}$ Während er weiterhin in der Wehrmacht diente, verlor seine Familie durch die Bombardierung Dresdens im Februar 1945 die Wohnung. Meise selbst geriet in Kriegsgefangenschaft und wurde nach Sibirien verbracht. In seiner Abwesenheit wurde er aufgrund seiner Mitgliedschaft in der NSDAP aus dem Museumsdienst in Dresden entlassen.

Erst im Juni 1948 kehrte Meise aus der sowjetischen Kriegsgefangenschaft zurück. Um wieder am Dresdner Tierkundemuseum arbeiten zu können, ließ er sich von seinem früheren Kollegen - Bernhard Struck bestätigen, dass er „infolge der politischen Verfolgung durch Buck widerwillig" in SA und Partei eingetreten war. $~$ Walther Fischer betonte, dass Meise „nur um den dauernden Anfeindungen seitens des Konservators Buck zu entgehen, zunächst in die SA [...] und 37 in die NSDAP eingetreten ist" und sich ,nie parteipolitisch im Sinne der NSDAP betätigt hat, sondern sich sehr ablehnend verhielt" ${ }^{\text {"6 }}$. Doch diese Bemühungen hatten keinen Erfolg. Meise zog nach Berlin, wo er ab September 1949 als Assistent am Zoologischen Museum der Humboldt-Universität arbeitete. 1954 kündigte er und verlegte seinen Wohnsitz von Ost- nach Westberlin. Wenig später zog er nach Hamburg, wo er ab 1955 Lehrbeauftragter und Kustos am Zoologischen Staatsinstitut und Museum der Universität war. ${ }^{7}$ Zunächst verantwortlich für die Abteilung für Mollusken, übernahm er 1956 die Leitung der ornithologischen Abteilung des Zoologischen Museums in Hamburg, wo er bis zu seiner Pensionierung 1969 tätig war. Wilhelm Meise starb am 24. August 2002 in Hamburg.

\footnotetext{
2 SMV, Fichtner, an Leiter SMV, 4.11.1940, SKD Archiv, 01/PS 53, Bd. 3, fol. 130 ff., hier: 130.

3 Fischer an Landesverwaltung Sachsen, Kulturabteilung, Grohmann, 8.1945, SKD Archiv, 02/VA 162, fol. 1 ff., hier: $1 \mathrm{v}-2 \mathrm{r}$.

4 Vgl. Posteingangsregistrande SMV, Abt. Sammlungen, 1944, Nr. 10a/41, 17.10.1944, HStA Dresden, 11125, Nr. 22875.

5 Meise an Struck, 9.7.1948, SKD, MfV Archiv, MVD n20;25/ 8/9/10, o. Pag.

6 Fischer an Landesverwaltung Sachsen, Kulturabteilung, Grohmann, 8.1945, SKD Archiv, 02/VA 162, fol. 1 ff., hier: 2 r.

7 Vgl. Meise an Struck, 12.6.1955, SKD, MfV Archiv, MVD n20;25/ 8/9/10, o. Pag.
} 


\section{Auswahlbibliografie}

Die Verbreitung der Aaskrähe (Formenkreis Corvus corone L.), in: J. Ornithol., 67, 1928, S. 1-203 (Zugl. Berlin, Univ., Diss., 1928).

Der Kuckuck, Die Brehm Reihe, Bd. 14, Berlin 1931.

Menschenhaar, in: Die Rohstoffe des Tierreichs, Bd. 1, Lfg. 2, Berlin 1933, S. 1312-1364.

Die Vogelwelt der Mandschurei, in: Abhandlungen und Berichte der Museen für Tierkunde und Völkerkunde zu Dresden, 18, 2, Leipzig 1934.

Zur Systematik und Verbreitungsgeschichte der Haus- und Weidensperlinge, Passer domesticus (L.) und hispaniolensis (T.). Über Artentstehung durch Kreuzung in der Vogelwelt, in: J. Orntihol. 84, 1936, S. 631-672 (Zugl. Dresden, TH, Habil., 1936).

Ueber vom Uhu geschlagene Rehe, in: Ornithologische Monatsberichte, Bd. 44, H. 2, 15, 1936, S. 56-58 (mit Rudolf Zimmermann).

Der Abendsegler, Die neue Brehm-Reihe, Bd. 42, Leipzig 1951.

Naturgeschichte der Vögel, 3 Bde., Stuttgart 1958-1966 (mit Rudolf Berndt).

Handbuch der Oologie, 4 Bde., Berlin 1960-1992 (mit Max Schönwetter).

Grzimeks Tierleben, Vögel, Bd. 7-9, Zürich 1968-1970 (Mithg.).

\section{Quellen und Literatur}

HStA Dresden, 13859, Nr. 5435

HStA Dresden, 13842, Nr. 047; Nr. 048; Nr. 115

SKD Archiv, 01/PS 53, Bd. 3

SKD, MfV Archiv, MVD n20;25/ 8/9/10

BArch, ZA VI 1219

BArch, R 9361-IX/Kartei/28151630

Unserem Ehrenmitglied Professor Dr. Wilhelm Meise zum 100. Geburtstag am 12. September 2001, in: Mitteilungen des Vereins Sächsischer Ornithologen, Bd. 8, H. 6, 2001, S. 691 f.

Eck, Siegfried: Wilhelm Meise, in: Zoologische Abhandlungen, Staatliche Naturhistorische Sammlungen Dresden, Museum für Tierkunde, Bd. 53, 2002, S. 3 f.

Haffer, Jürgen: In memoriam. Wilhelm Meise 1901-2002, in: The Auk, 120, 2003, S. 540.

Hoerschelmann, H.: Wilhelm Meise. 12. September 1901 - 24. August 2002, in: Verh. naturwiss. Ver. Hamburg, N. F., 40, 2003, S. 141 f.

Verzeichnis der Publikationen von Wilhelm Meise, in: Mitteilungen aus dem Hamburgischen Zoologischen Museum und Institut, Bd. 100, 2004. 


\section{WALter MÜLler}

8.7.1877 Bremen - 16.9.1952 Bremen

Klassischer Archäologe

Skulpturensammlung

1.8.1913-31.3.1920 Wissenschaftlicher Hilfsarbeiter

1.4.1920-31.5.1934 Kustos

1.6.1934-5.1945 Direktor

Gemäldegalerie

4.4.1938-18.6.1938 Kommissarischer Leiter

Grünes Gewölbe

15.1.1941-[11.1942] Kommissarischer Leiter

Historisches Museum

15.1.1941-23.11.1942 Kommissarischer Leiter

Münzkabinett

11.1939-12.1942 Kommissarischer Leiter

(Militärdienst 17.8.1914-31.1.1919, Beurlaubung 14.2.1945-5.1945)

Walter August Müller ${ }^{1}$ wurde am 8. Juli 1877 in Bremen als Sohn des zwölf Jahre zuvor aus Havanna zugezogenen Kaufmannes Wilhelm Friedrich Georg Müller und dessen aus New Orleans stammender Ehefrau Clara Elisabeth, geb. Potts, geboren. 1896 erhielt Müller am humanistischen Gymnasium in Bremen sein Reifezeugnis und begann an der Universität in Freiburg im Breisgau Archäologie, Kunstgeschichte und Philologie zu studieren. Für den Militärdienst musste er sein Studium von 1897 bis 1899 unterbrechen, setzte es aber danach an den Universitäten in München und Leipzig fort. 1905 wurde er in Leipzig promoviert. In den Jahren danach unternahm Müller verschiedene Studienreisen nach Italien, Griechenland, Kleinasien und Ägypten, auch beteiligte er sich an Ausgrabungen und arbeitete an den Archäologischen Instituten in Rom und Athen. 1910 weilte er in Berlin. Von Oktober 1911 bis Juli 1913 war er als Wissenschaftlicher Hilfsarbeiter an der prähistorischen Abteilung der Archäologischen Reichsanstalt in Frankfurt am Main tätig.

Als Wissenschaftlicher Hilfsarbeiter kam Müller im Juli 1913 an die Skulpturensammlung in Dresden, wo er, unterbrochen von seinem Militärdienst im Ersten Weltkrieg, drei Jahrzehnte tätig war. 1920 erfolgte seine Beförderung zum Kustos, vierzehn Jahre später, 1934, nach dem Tod von - Bruno Schröder, wurde er Direktor der Sammlung. Infolge dieser Ernennung ließ er sich von seinen Lehrverpflichtungen entbinden, die er, wie bereits sein Vorgänger Schröder, seit März 1927 mit der Verleihung des Professorentitels an der Technischen Hochschule in Dresden übernommen hatte. In der Skulpturensammlung führte Müller die von Schröder begonnene Neuaufstellung konsequent fort und eröffnete bis zum Mai 1940 weitere Säle. Er hielt zahlreiche Vorträge und bot monatliche Führungen durch die Sammlung an. Sein Hauptinteresse galt der antiken griechischen

1 Er selbst hat seinen Vornamen nur in der Form Walter benutzt. Da er bibliografisch als Walter Müller zu finden ist, hat sich auch die Autorin für diese Schreibweise entschieden. In den standesamtlichen Unterlagen ist allerdings die Schreibweise „Walther Müller" überliefert. Siehe Staatsarchiv Bremen, Einwohnermeldekartei Walther August Müller (4,82/1-1069 (215)). Für diesen Hinweis sei Monika Marschalck, Staatsarchiv Bremen, gedankt. 
Skulptur, allerdings widmete er sich ebenfalls der moderneren Plastik, wie den Werken von Ernst Rietschel. Zusätzliche Sonderausstellungen kuratierte er selten. Die wichtigste war im Sommer 1936 „Die Bronzen der Kurfürstlichen Kunstkammer“ in Kooperation mit \Erich Haenel, dem Direktor des Grünen Gewölbes. Ab 1938 musste Müller vorübergehend die Verantwortung für andere Sammlungen übernehmen, was bald zu einer erheblichen Mehrbelastung führte. So beauftragte ihn der Leiter des Sächsischen Ministeriums für Volksbildung, Arthur Göpfert, 1938 „vom 4. April ds. Js. ab bis auf Weiteres die Dienstgeschäfte des Direktors der Gemäldegalerie vertretungsweise zu übernehmen “2 , denn $>$ Hans Posse war gedrängt worden, seinen Ruhestand zu beantragen. Da Posse jedoch an der Gemäldegalerie lediglich seine Amtsgeschäfte als Direktor ruhen ließ, ansonsten aber tätig blieb, nahm Müller diese Aufgabe nur formal wahr. ${ }^{3}$ Doch im November 1939 wurde er zum Kommissarischen Leiter des Münzkabinetts ernannt, ein Amt, das er drei Jahre später sukzessive an $\triangleright$ Klaus Günther übergab. ${ }^{4}$ Unterdessen war Müller seit Kriegsbeginn auch noch für die Bergungsmaßnahmen der Sammlung verantwortlich. Zeit für wissenschaftliche Arbeit blieb dabei nicht mehr. Nach der Schließung der Skulpturensammlung am 15. Januar 1941 beauftragte ihn Göpfert, „bis zur Ernennung eines Nachfolgers für den verstorbenen Direktor des Historischen Museums und des Grünen Gewölbes [...] die Leitung dieser Sammlungen vertretungsweise zu übernehmen" ${ }^{\text {" }}$ Fast gleichzeitig wurde im Januar 1941 gegen Müller ein Verfahren „wegen Staatsfeindlicher Gesinnung, Beleidigung der Partei und Unterlassung des ,Deutschen Grusses "“6 eröffnet, das erst im Juli 1942 mit einem Verweis für ihn endete. Die genauen Umstände, die dazu führten, sind unbekannt. Müller war zwar von 1918 bis zu deren Auflösung Mitglied der Deutschnationalen Volkspartei gewesen, trat aber nie in die NSDAP ein. Aufgrund dieser Umstände, der zusätzlichen Belastung durch die Verantwortung für mehrere Sammlungen einerseits und der psychischen Belastung durch das Verfahren gegen ihn andererseits, verschlechterte sich seine Gesundheit rapide; immerhin hatte er fast das Pensionsalter erreicht. Dennoch versuchte er bis März 1942, das öffentliche Interesse an der Skulpturensammlung trotz deren Schließung durch weiterhin angebotene Führungen aufrechtzuerhalten. Bei Vollendung seines 65. Lebensjahres, im Juli 1942, beantragte Müller seine Versetzung in den Ruhestand. Doch diese wurde im Herbst 1942 „unter Hinweis auf die Kriegsnotwendigkeiten "7, „im Hinblick auf den Mangel an wissenschaftlichen Beamten der Museen“ abgelehnt und ihm lediglich erlaubt, „bis auf weiteres nur halbtagsweise " ${ }^{\text {" }} \mathrm{zu}$ arbeiten. Allerdings setzte gleichzeitig \Fritz Fichtner, der im September 1942 „dienstlich abkommandiert“ war, Müller als seine „Vertretung als Museumsdirektor und als Sachbearbeiter Metallabgabe der Museen“ ein, womit dieser für einen Monat „nicht nur die Geschäfte an der Staatlichen Porzellangalerie und dem staatl. Kunstgewerbemuseum, sondern auch die Verwaltung des Mathema-

2 Leiter SMV, Göpfert, an Müller, Skulpturensammlung, 2.4.1938, HStA Dresden, 13859, Nr. 5861, fol. 93. Vgl. auch Tagebuch Hans Posse, 17.3.1938, erwähnt bei Rudert, Thomas: Konservativer Galeriedirektor - Kulturdiplomat der Weimarer Republik - NS-Sonderbeauftragter. Bausteine zu einer Biografie Hans Posses, in: Lupfer/Rudert 2015, S. 61-149, hier: 141.

3 Vgl. ebd., S. 136-143. Siehe S. 407.

4 Siehe S. $79 \mathrm{ff}$.

5 Leiter SMV, Göpfert, an Müller, Skulpturensammlung, 15.1.1941, HStA Dresden, 13859, Nr. 5861, fol. 128.

6 Müller, Skulpturensammlung, an SMV, 8.11.1945, SKD Archiv, 01/SKS 413, o. Pag.

7 Ebd.

8 Leiter SMV, Dedering, an Müller, Skulpturensammlung, 17.9.1942, HStA Dresden, 13859, Nr. 5861, fol. 154. 
tisch-Phys. Salons und des Historischen Museums ${ }^{\text {“9 }}$ übernahm, die sich alle mitten in der Auslagerung befanden. Somit war Müller kurzzeitig für sieben Sammlungen verantwortlich, wodurch eine Halbtagsbeschäftigung von vornherein illusorisch und eine Überlastung abzusehen war. Im November 1942 übergab Müller die Leitung des Historischen Museums an Kustos $>$ Walter Holzhausen, ${ }^{10}$ womit sein Aufgabengebiet wieder überschaubarer wurde. Doch erst im Juli 1944 wähnte sich Müller seiner Pensionierung nahe und benannte Carl Blümel aus Berlin, Willy Zschietzschmann aus Gießen und Wolfgang Züchner aus Leipzig als mögliche Nachfolger. Statt mit einer würdevollen Pensionierung endete Müllers Tätigkeit in Dresden jedoch im Chaos. Infolge der Bombardierung der Stadt am 13./14. Februar 1945 verlor er seine Wohnung. Zunächst fand Müller Unterkunft bei seinem Mitarbeiter Formermeister Walther Kuhn. Aufgrund der Verschlechterung seines Gesundheitszustandes wurde ihm noch im Februar eine Beurlaubung gewährt. Er erkannte „[a]ngesichts des Trümmerhaufens, den die Skulpturensammlung darstellt, [...] klar“, dass er „mit 68 Jahren nicht mehr die Kraft habe, die Trümmer wieder aufzubauen" ${ }^{11}$ und verließ Dresden.

Zunächst ging er zu Freunden nach Bad Oberschlema im Erzgebirge, im April 1945 dann zu Verwandten nach Riederau am Ammersee. Im Oktober 1948 siedelte Walter Müller nach Bremen über, wo er am 16. September 1952 starb.

\section{Auswahlbibliografie}

Nacktheit und Entblößung in der altorientalischen und älteren griechischen Kunst, Leipzig 1906 (Zugl. Leipzig, Univ., Diss., 1905).

Bibliographie zur römisch-Germanischen Forschung für die Jahre 1910 und 1911, in: Bericht der Römisch-Germanischen Kommission, 6, 1910/11, 1913, S. 182-277.

Die griechische Kunst. Ein Taschenbuch in 475 Bildern, München 1925.

Johannes der Täufer in der Hofkirche zu Dresden, in: Jahrbuch der Preußischen Kunstsammlungen, Bd. 47, 1926, S. 112-117.

Aus der Dresdner Skulpturensammlung, in: Der Kunstwanderer, Bd. 8, 1927, S. 493-494.

Die Bildhauerei in Sachsen, in: Hundert Jahre Sächsischer Kunstverein, Jubiläums-Festschrift, Bd. 2, Dresden 1928, S. 37-49.

Antike Bronzestatuetten im Albertinum, in: Archäologischer Anzeiger, 1931, S. 338-360.

Neuaufstellung in der Dresdner Skulpturen-Sammlung, in: Museumskunde, N. F. 6, 1934, S. 131-135.

Die plastischen Bildnisse Winckelmanns, in: Jahrbuch des Deutschen Archäologischen Instituts, Bd. 55, 1940, S. 265-275.

Zum Pothos des Skopas, Sonderabdruck aus dem Jahrbuch des Deutschen Archäologischen Instituts, Berlin 1941, S. 122-150.

\section{Quellen und Literatur}

HStA Dresden, 13859, Nr. 5861

HStA Dresden, 11125, Nr. 23044

SKD Archiv, 01/SKS 353; 01/SKS 413

Staatsarchiv Bremen, Einwohnermeldekartei Walther August Müller (4,82/1-1069 (215))

9 Porzellansammlung, Fichtner, an Müller, Skulpturensammlung, 15.9.1942, ebd., fol. 152.

10 Vgl. Leiter SMV, Göpfert, an Müller, Skulpturensammlung, 23.11.1942, HStA Dresden, 11125, Nr. 22884, fol. 108; ebenso SKD Archiv, 01/PS 53, Bd. 3, fol. 79.

11 Müller, Skulpturensammlung, an SMV, 8.11.1945, SKD Archiv, 01/SKS 413, o. Pag. 


\title{
Hermann Neubert
}

\author{
9.12.1892 Leipzig - 20.4.1980 Berlin (West) \\ Wissenschaftlicher Bibliothekar \\ Sächsische Landesbibliothek \\ 1.10.1919-30.9.1921 Volontär \\ 1.10.1921-31.3.1923 Wissenschaftlicher Hilfsarbeiter \\ 1.4.1923-30.6.1925 Bibliotheksassistent \\ 1.7.1925-31.10.1929 Landesbibliothekar \\ 1.1.1934-31.5.1939 Oberbibliothekar, Stellvertretender \\ Direktor
}

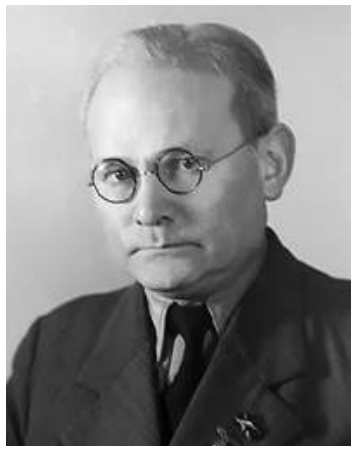

1.7.1937-31.5.1939 Kommissarischer Direktor

1.6.1939-31.10.1945 Direktor

Hermann Rudolf Neubert, als Sohn des Postsekretärs Emil Neubert und dessen Frau Emma Johanna Maria am 9. Dezember 1892 in Leipzig-Reudnitz geboren, lernte an der Bürgerschule in Oschatz und legte 1912 an der Fürsten- und Landesschule Grimma sein Abitur ab, bevor er an der Universität Leipzig Mathematik, Physik und Geografie studierte. Im August 1914 meldete er sich als Kriegsfreiwilliger. Doch nach einer schweren Verwundung, die zum Verlust seiner rechten Hand führte, wurde er bereits im März 1915 aus dem Militärdienst entlassen und setzte sein Studium fort. Von Mai 1916 bis Dezember 1918 arbeitete er als Hilfsassistent am Geographischen Seminar der Leipziger Universität, wo er im Juli 1919 promoviert wurde.

Am 1. Oktober 1919 begann Neubert zeitgleich mit $\gg$ Gottfried Benndorf ein Volontariat an der Sächsischen Landesbibliothek in Dresden. Im Herbst 1920 erlangte er mit bestandener Fachprüfung an der Universitätsbibliothek Leipzig die Befähigung zum Höheren Dienst an wissenschaftlichen Bibliotheken. Ab Oktober 1921 wurde Neubert als Wissenschaftlicher Hilfsarbeiter angestellt und bereits nach anderthalb Jahren zum Bibliotheksassistenten befördert. Kurz darauf, im Mai 1923 heirate er Ilse, geb. Gravelius, mit der er später 4 Söhne hatte. Im Juli 1925 wurde er zum Landesbibliothekar ernannt. Im Rahmen des Bibliotheksumbaus war er als technischer Berater auch für den Magazinumbau zuständig. Zum 1. November 1929 übernahm Neubert als Nachfolger von Felician Geß als erster hauptamtlicher Direktor die Leitung der Bibliothek der Technischen Hochschule Dresden, die er nach bibliothekswissenschaftlichen Gesichtspunkten umstrukturierte und in der er eine Lehrbuchsammlung aufbaute. Ab Juni 1933 versuchte - Martin Bollert, Neubert für die mitten im Umbau befindliche Landesbibliothek zurückzugewinnen und bot ihm die Stelle des bald zu pensionierenden Oberbibliothekars $\gg$ Otto Fiebiger an. Gegenüber dem Ministerium begründete Bollert seine Bemühungen mit Neuberts „,bedeu-

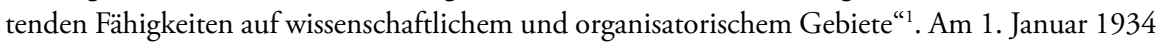
kehrte Neubert als Oberbibliothekar und stellvertretender Direktor an die Sächsische Landesbibliothek zurück, wo er erneut maßgeblich am Umbau mitwirkte. Wie er später bekundete, war für ihn „die schönste und lehrreichste Zeit die Zusammenarbeit mit Martin Bollert während des

1 Bollert, Sächsische Landesbibliothek, an SMV, 27.11.1933, HStA Dresden, 11125, Nr. 19345, fol. 201. 
Umbaus“2. In der NS-Zeit oblag Neubert außerdem die Aufgabe, „sowohl im Börsenblatt als auch im Sächsischen Fahndungsblatt die Schriften [...], die in die ,Liste verbotener Bücher' aufzunehmen sind“"3, zu markieren. Im Herbst 1935 wurde er stundenweise an die Bibliothek der Technischen Hochschule abgeordnet. Im Juli 1937 schlug Bollert Neubert als seinen Nachfolger vor, denn dieser sei „klug, klar“ und ein „fleißiger Arbeiter“, habe sich „in Vertretungszeiten als geschickt und zuverlässig bewährt" und „dürfte bald Pg. werden“ “ 4 . In der Tat datierte Neuberts Aufnahmeantrag in die NSDAP vom 28. Juni 1937, die Aufnahme erfolgte rückwirkend zum 1. Mai 1937. Doch er wurde erst am 1. Juni 1939, mehr als anderthalb Jahre nachdem Bollert in den Ruhestand eingetreten war, zu dessen Nachfolger ernannt und leitete in der Zwischenzeit die Bibliothek als Kommissarischer Direktor. \Ewald Jammers schrieb später in seinen Memoiren, Neubert sei in der NS-Zeit „ein serviler Direktor der Bibliothek“" gewesen, allerdings war es für die Landesbibliothek „gut, daß er den Wünschen der Regierung gehorchte, denn die Bibliothek galt als, rot "“5. Wie sein Vorgänger engagierte sich Neubert in der Ausbildung des Bibliotheksnachwuchses. 1938 wurde er Vorsitzender des Prüfungsausschusses für den Mittleren Bibliotheksdienst an wissenschaftlichen Bibliotheken, ab 1942 war er Stellvertretender Vorsitzender dieses Ausschusses. Während des Zweiten Weltkrieges verantwortete er die Organisation der Auslagerung der Buchbestände. Als Betriebsluftschutzleiter der Landesbibliothek hatte er regelmäßig an den entsprechenden Lehrgängen und Luftschutzübungen teilzunehmen. Beim Bombenangriff auf Dresden am 13./14. Februar 1945 wurde auch die Wohnung von Neubert zerstört, der ein Notquartier am Stadtrand fand. Nach dem Kriegsende blieb er zunächst als Direktor der Landesbibliothek im Amt. Doch aufgrund seiner NSDAP-Mitgliedschaft erhielt Neubert zum 31. Oktober 1945 seine Kündigung. Bereits am 2. Oktober 1945 wurde er aus dem Direktorenzimmer verdrängt, als einer der bisherigen Landesbibliothekare, \Karl Assmann, kam und erklärte, dass er „am 1. Oktober von Herrn Staatssekretär Dr. Menke-Glückert als Kommissarischer Direktor der Sächsischen Landesbibliothek verpflichtet worden sei “" .

Als seine Bemühungen um eine Wiedereinstellung in der Landesbibliothek scheiterten, nahm Neubert, um den Lebensunterhalt für sich und seine Familie zu verdienen, eine Tätigkeit im Büro einer Tiefbaufirma an. ${ }^{7}$ Unklar bleibt, wann er Dresden verließ. Ab Juni 1950 verantwortete er als Direktor den Wiederaufbau der Bibliothek der Technischen Universität Berlin, die nach dem Krieg erst 1951 ihren Ausleihbetrieb wieder aufnahm. In dieser Funktion, in der er sich insbesondere für die Verstärkung der Etatmittel einsetzte, arbeitete er bis zu seiner Pensionierung Ende September 1958. ${ }^{8}$ Für sein bibliothekarisches Wirken wurde er 1962 durch die Verleihung des Bundesverdienstkreuzes erster Klasse geehrt. Hermann Neubert starb am 20. April 1980 in Berlin (West).

\footnotetext{
$2 \quad$ Neubert 1956, S. 27.

3 Bollert, Sächsische Landesbibliothek, an SMV, o. Dat. (ca. 1935), SLUB, Bibl.-Arch. III.J859.b.

4 Notizen von Bollert, o. Dat. (ca. 2.1937), SLUB, Mscr.Dresd.App.1378.a, 122.

5 Jammers 2002, S. 312. Siehe auch Deckert 1987, S. 99, SLUB, Mscr.Dresd.App.2600,A1: „Sein Beamtenbewußtsein zwang ihn, die Weisungen der Nazi-Behörden sehr ernst zu nehmen und um der Bibliothek willen [...] alles zu tun, um ja nicht unangenehm aufzufallen."

6 Niederschrift von Neubert, 6.10.1945, SLUB, PA Neubert.

7 Vgl. Neubert an Struck, 21.4.1948, SKD, MfV Archiv, MVD n20;25/8,9,10.

8 Für Hinweise auf Neuberts Wirken in Berlin dankt die Autorin Irina Schwab, Universitätsarchiv der Technischen Universität Berlin. Vgl. auch Sonntag, Helmut (Hg.): Aus den Chroniken der Universitätsbibliothek 1884-1984, Berlin 1984, S. 44 f.
} 


\section{Auswahlbibliografie}

Karte der Grundsteuer-Reinerträge des Ackerlandes von Rheinland und Westfalen (Leipzig, Univ., Diss., 1919).

Zur Geschichte der Sächsischen Landesbibliothek, Leipzig 1936.

Festschrift Martin Bollert zum 60. Geburtstage, Dresden 1936 (Hg.).

Der Umbau der Sächsischen Landesbibliothek 1927-1935, in: Zentralblatt für Bibliothekswesen 53/1936, S. 45-61.

Martin Bollerts Wirken für Gegenwart und Zukunft, in: Festschrift Martin Bollert zum achtzigsten Geburtstag am 11. Oktober 1956, Dresden 1956, S. 23-28.

Sächsische Landesbibliothek Dresden 1556-1956, 1957.

\section{Quellen und Literatur}

HStA Dresden, 13859, Nr. 6025

SLUB, PA Neubert, Hermann

BArch, R 9361-IX/Kartei/30290715

Habermann, Alexandra, Klemmt, Rainer u. Frauke Siefkes: Lexikon Deutscher Wissenschaftlicher Bibliothekare 1925-1980, Frankfurt a. M. 1985, S. 230 f.

Wüstling, Hans-Dieter: Dr. phil. Hermann Neubert (1929-1933), in: Wüstling 2005, S. 50 f.

Bürger, Thomas u. Konstantin Hermann (Hg.): Das ABC der SLUB. Lexikon der Sächsischen Landesbibliothek - Staats- und Universitätsbibliothek Dresden, Dresden 2006, S. 173.

Wüstling, Hans-Dieter: Neubert, Hermann Rudolf, in: Sächsische Biografie, 2009, Online-Ausgabe: http://saebi.isgv.de/biografie/Hermann_Neubert_(1892-1980), Zugriff: 2.1.2020.

Hermann, Konstantin: Die sächsische Landesbibliothek 1933-1945. Martin Bollert und Hermann Neubert - zwei Epochen in zwölf Jahren?, in: Knoche, Michael (Hg.): Wissenschaftliche Bibliothekare im Nationalsozialismus: Handlungsspielräume, Kontinuitäten, Deutungsmuster, Wolfenbütteler Schriften zur Geschichte des Buchwesens, Bd. 46, Wiesbaden 2011, S. 289-308. 


\section{Robert Oertel}

30.10.1907 Leipzig - 1.12.1981 Freiburg i. Br.

Kunsthistoriker

Gemäldegalerie

1.8.1939-31.7.1946 Kustos

12.1942-3.1943 Kommissarischer Leiter

"Sonderauftrag Linz"

1.8.1939-5.1945 [?]

12.1942-3.1943 Kommissarischer Leiter (mit Gottfried

Reimer)

(Militärdienst 23.10.1944-8.5.1945, Kriegsgefangenschaft

9.5.1945-30.8.1945)

Christian Gottfried Robert Oertel wurde am 30. Oktober 1907 in Leipzig als Sohn des Amtsrichters Paul Robert Oertel und dessen Frau Johanna Clara, geb. Schmidt, geboren. Nach dem Besuch der Volksschule wechselte er an die Thomasschule, wo er 1927 die Reifeprüfung ablegte. Im Anschluss daran studierte Oertel Kunstgeschichte, Geschichte, Klassische Archäologie und Philosophie, zunächst in Leipzig, später in Wien, München, Hamburg und Freiburg i. Br. Im Februar 1932 wurde er bei Hans Jantzen in Frankfurt a. M. promoviert. ${ }^{1}$ Von April bis Juli 1932 reiste Oertel nach Paris. In Freiburg absolvierte er im Herbst 1932 ein Volontariat im Augustinermuseum, das er vorzeitig beendete, weil er von Dezember 1932 bis April 1933 ein Stipendium an der Biblioteca Hertziana in Rom erhielt. Anschließend nahm er eine Assistentenstelle bei seinem Doktorvater am Kunsthistorischen Seminar der Universität Frankfurt an, die er „jedoch angesichts des radikalen nationalsozialistischen Kurses an der Universität Frankfurt ${ }^{\text {"2 }}$ wieder aufgab. Ab Oktober 1933 arbeitete Oertel in den Staatlichen Museen in Berlin als Freiwilliger Wissenschaftlicher Hilfsarbeiter erst an der Islamischen Abteilung unter Ernst Kühnel, dann an der Frühchristlich-Byzantinischen Sammlung und später im Kupferstichkabinett unter Friedrich Winkler und Willy Kurth. Nach zwei Jahren wechselte er im Oktober $1935^{3}$ als Wissenschaftlicher Hilfsarbeiter an das Deutsche Kunsthistorische Institut in Florenz, wo er die Fotosammlung betreute, die Gelegenheit zu zahlreichen Studienreisen durch Italien nutzte und seine Studien zur italienischen Wandmalerei fortzusetzte. Auch schrieb er Rezensionen und Ausstellungsbesprechungen für die „Zeitschrift für Kunstgeschichte“ und „Pantheon“. Als der Direktor des Florentiner Instituts, Friedrich Kriegbaum, durch Heinrich Zimmermann aus Berlin erfah-

\footnotetext{
1 Vgl. Jäger, Christian 2014, S. 14. Jäger weist nach, dass Oertel nicht in Frankfurt studierte, sondern aufgrund seines Antrages eine Sondergenehmigung von Dekan Paul Tillich zur Promotion in Frankfurt erhielt. Die mündliche Prüfung fand im Juli 1932 statt, womit das Verfahren bestanden war, nach der Publikation wurde die Promotionsurkunde am 14.8.1933 ausgestellt. Die Autorin dankt Christian Jäger für die Bereitstellung seiner unveröffentlichten Bachelorarbeit.

2 Oertel, Lebenslauf, 31.5.1964, SMB-ZA II/VA 7032, o. Pag.

3 Hier divergieren Oertels eigene Angaben. 1938 notierte er, seine Arbeit in Florenz im Oktober 1935 begonnen zu haben, 1964 schrieb er September 1935. Hier könnte die zeitliche Distanz zu einem Erinnerungsfehler geführt haben. Vgl. Personalbogen Oertel, 17.10.1938, HStA Dresden, 13859, Nr. 6178, o. Pag. u. Personalbogen, o. Dat. (ca. 1964), SMB-ZA II/VA 7032, o. Pag.
} 
ren hatte, dass der Kustos der Dresdner Gemäldegalerie $>$ Karl Wilhelm Jähnig entlassen werden würde, empfahl er sofort Oertel als „besten Mitarbeiter“, der „einer der wenigen wirklichen Italienkenner innerhalb der jüngeren Generation" "4 sei. Noch im September 1937 bewarb sich Oertel um die Dresdner Kustodenstelle. Galeriedirektor $>$ Hans Posse, der ihn persönlich kannte, setzte ihn im Dezember 1937 an die Spitze der Kandidatenliste, denn er sei „ein guter Bilderkenner vor allem der italienischen Malerei“ und gehöre „nach dem übereinstimmenden Urteil aller Fachleute zu den begabtesten jüngeren Kunsthistorikern, die zurzeit zur Verfügung stehen ". Begünstigend wirkte, dass Oertel bereits im Juni 1937 die Mitgliedschaft in der NSDAP beantragt hatte und im Oktober 1937 in die Partei aufgenommen wurde. Wenige Monate später bestätigte diese, dass Oertel „sich der Ortsgruppe Florenz der NSDAP zur Mitarbeit mehrfach zur Verfügung" stellte und ,in jeder Hinsicht den Anforderungen, die an ihn gestellt worden sind, nachgekommen " ${ }^{\text {" sei. }}$

Doch trotz dieser Unterstützung wurde Oertel aufgrund der politischen Querelen um Posse erst im August 1939 zum Kustos der Dresdner Gemäldegalerie ernannt. ${ }^{7}$ Durch den Kriegsbeginn wurde die Auslagerung der Galeriebestände zu Oertels Hauptaufgabe. Auch übernahm er mehrfach stellvertretend für Posse, der im Juni 1939 zum "Sonderbeauftragten für Linz" ernannt worden und daher häufig abwesend war, die Aufgaben des Direktors. Knapp zwei Jahre später, im Juli 1941, urteilte $\triangleright$ Fritz Fichtner, Oertel, den ein ,aufgeschlossener, zugleich ein kritischer Geist“ kennzeichne, „nimmt an erster Stelle die Interessen seines Museums und seines Direktors

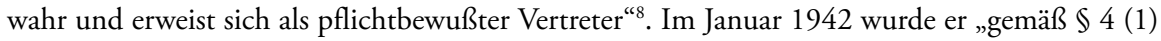
der Verfahrensordnung der Reichskammer der bildenden Künste“ ${ }^{9}$ zum „Sachverständigen für Gemälde“ ernannt, damit er im Falle einer Verhinderung Posses zur Begutachtung „sichergestellten" Kulturgutes aus jüdischem Besitz herangezogen werden konnte. Damit vertrat Oertel Posse in allen Bereichen seiner Tätigkeit. Nach Posses Tod im Dezember 1942 bis zur Amtseinführung des neuen Direktors \ Hermann Voss im März 1943 leitete Oertel kommissarisch die Gemäldegalerie, ebenso zeichnete er in dieser Zeit gemeinsam mit $\triangleright$ Gottfried Reimer für den „Sonderauftrag Linz" verantwortlich, für den er zuvor bereits Inventarisierungsarbeiten ausgeführt hatte und nun auch Erwerbungsverhandlungen führte. ${ }^{10}$ Trotz vorheriger Uk-Stellung wurde Oertel im Oktober 1944 doch noch zum Militärdienst einberufen, den er als Artillerist an der Ostfront ableistete. Am Kriegsende geriet er in sowjetische Kriegsgefangenschaft, aus der er Ende August 1945 entlassen wurde. Ab September 1945 arbeitete Oertel wieder in den Dresdner Sammlungen und war, da Voss die Stadt verlassen hatte, neben Reimer der einzige wissenschaftliche Mitarbeiter in der Gemäldegalerie. Er wirkte an der Rückführung der ausgelagerten Bestände nach Dresden bzw. Pillnitz mit. Doch Ende Juli 1946 wurde auch Oertel aufgrund seiner NSDAPMitgliedschaft entlassen.

\footnotetext{
4 Kunsthistorisches Institut Florenz, Kriegbaum, an Gemäldegalerie, Posse, 7.9.1937, HStA Dresden, 13859, Nr. 6178, fol. 6.

Gemäldegalerie, Posse, an SMV, 1.12.1937, ebd., fol. $1 \mathrm{f}$.

6 NSDAP Gauleitung Sachsen, Gaupersonalamt, Bär, an SMV, 13.4.1938, ebd., fol. 13.

Siehe S. 407.

SMV, Fichtner, Bericht zur Dienstaufsicht, 1.7.1941, SKD Archiv, 01/PS 53, Bd. 1, fol. 168 f.

9 SMV, Dedering, an Gemäldegalerie, Oertel, 9.1.1942, HStA Dresden, 13859, Nr. 6178, fol. 73.

10 Zu Oertel und seiner Tätigkeit für den „Sonderauftrag Linz“vgl. Iselt 2010, S. 319-329.
} 
Er verließ die sowjetische Besatzungszone und siedelte im Herbst 1946 nach Freiburg i. Br. über. An der dortigen Universität habilitierte er sich bei Kurt Bauch, der wie er 1932 bei Jantzen promoviert worden war, und erhielt im Mai 1949 eine Dozentur. Im August 1955 wurde er zum außerplanmäßigen Professor ernannt. Im April 1950 heiratete er Ilsabe, geb. Brandis, mit der er ein Kind hatte. Als sich Oertel nach seiner Kontaktaufnahme zum Generaldirektor Ernst Buchner in München die Gelegenheit bot, wieder an ein Museum zu wechseln, ging er im Juni 1958 als Hauptkonservator der Alten Pinakothek an die Bayerischen Staatsgemäldesammlungen in München, wo er 1960 zum Oberkonservator und 1962 zum Landeskonservator ernannt wurde. Zum 1. November 1964 wechselte Oertel in den Dienst der Staatlichen Museen zu Berlin (West). Dort leitete er die Gemäldegalerie in Berlin-Dahlem, verantwortete die neue Präsentation der Abteilung der Italienischen Malerei der Renaissance, plante und konzipierte den Neubau der Gemäldegalerie am Tiergarten. In Berlin, wie zuvor bereits in München, war Oertel weiterhin auch in der Lehre tätig. Nach seiner Pensionierung im Oktober 1972 siedelte er nach Kirchzarten bei Freiburg i. Br. über. Am 1. Dezember 1981 starb Robert Oertel in Freiburg i. Br.

\section{Auswablbibliografie}

Masaccios Frühwerke, Marburg 1933 (Zugl. Frankfurt a. M., Univ., Diss., 1932)

Michelangelo. Die Sixtinische Decke, Burg 1940.

Wandmalerei und Zeichnung in Italien. Die Anfänge der Entwurfszeichnung und ihre monumentalen Vorstufen, Mitteilungen des Kunsthistorischen Instituts in Florenz, Bd. 4, 1940, S. 217-314 (veränderte Neuausgabe 1966).

Fra Filippo Lippi, Wien 1942.

Studien zu Giottos nachpaduanischen Stil (Freiburg i. Br., Univ., Habil., 1948).

Die Frühzeit der italienischen Malerei, Stuttgart 1953.

Frühe italienische Tafelbilder. 20 Meisterwerke des Lindenau-Museums in Altenburg, Leipzig 1956.

Deutsche und italienische Malerei, München 1960 (mit Ernst Buchner).

Italienische Malerei bis zum Ausgang der Renaissance, München 1960.

Gemäldegalerie Berlin, Berlin 1969.

\section{Quellen und Literatur}

HStA Dresden, 13859, Nr. 6178

SMB-ZA II/VA 7032

BArch, R 9361-IX/Kartei/31101224

Bock, Henning: Prof. Oertel zum Abschied, in: Jahrbuch Preussischer Kulturbesitz, Bd. XI, 1973, S. $242 \mathrm{f}$.

Isermeyer, Christian Adolf: Robert Oertel. 1907-1981, in: Zeitschrift für Kunstgeschichte, Nr. 4, 1982, S. 437-440.

Iselt, Kathrin: „Sonderbeauftragter des Führers“. Der Kunsthistoriker und Museumsmann Hermann Voss (1884-1969), Köln 2010 (Zugl. Dresden, Univ., Diss., 2009), S. 319-329.

Iselt, Kathrin: Robert Oertel (1907-1981) - Kustos der Gemäldegalerie Dresden 1939-1946. Eine biografische Skizze, in: Dresdener Kunstblätter, H. 1, 2012, S. 45-54.

Jäger, Christian: Robert Oertel und die Fotografie. Eine wissenschaftliche Untersuchung, Leipzig, Hochschule für Technik, Wirtschaft und Kultur, Bachelorarbeit, 2014 (unveröffentlicht). 


\section{Berthold Pfaul}

13.1.1911 Dresden - [10.1942 vermisst $]$

Anthropologe

Museen für Tierkunde und Völkerkunde

1.3.1937-31.5.1937 Freiw. Wissenschaftlicher Hilfsarbeiter

1.6.1937-30.9.1938 Wissenschaftlicher Hilfsarbeiter

(Militärdienst 23.5.1938-27.7.1938)

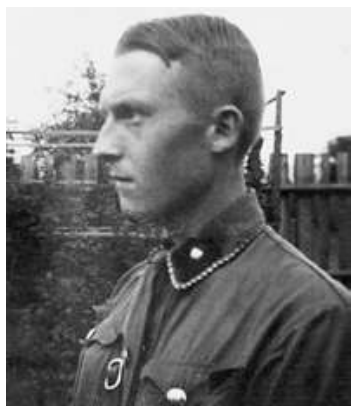

Bereits während seines Studiums der Anthropologie, Mathematik und Philosophie war Berthold Erdmann Curt Pfaul durch seine Leistungen aufgefallen, weshalb ihn sein Lehrer $>$ Bernhard Struck, bei dem er 1937 in Jena promoviert worden war, protegierte. Vermutlich auf Fürsprache Strucks kam Pfaul im März 1937 als Freiwilliger Wissenschaftlicher Hilfsarbeiter an die Museen für Tierkunde und Völkerkunde nach Dresden, wo er ab Juni 1937 als Wissenschaftlicher Hilfsarbeiter in Vertretung der ehemals Struck'schen Stelle die Leitung der Anthropologischen Sammlung übernahm. Von Mai bis Juli 1938 war er zum Militärdienst einberufen und wurde am Museum von \Herbert Bellmann vertreten. Als jedoch sein Kollege $\triangleright$ Michael Hesch als Nachfolger Strucks zum Kustos berufen wurde, wechselt Pfaul im Oktober 1938 als Assistent zu Hans F. K. Günther an das Institut für Rassenkunde, Völkerbiologie und ländliche Soziologie der Universität Berlin. Wiederum war es Struck, der den Kontakt vermittelt hatte. Im Januar 1938 hatte er in Dresden Alice Margarethe Pfaul geheiratet. Für Pfauls Karriere während der NS-Zeit hat sich ohne Zweifel seine frühe Mitgliedschaft in der NSDAP und SA seit 1931 als hilfreich erwiesen. Spätestens 1941 war er zum Militärdienst einberufen worden. Struck, der noch immer in Kontakt mit seinem Schüler stand, berichtete, dass Pfaul „als Artillerist über Dünaburg und Cholm (Lowat) an die Waldai-Höhen gelangt war und nun jedenfalls in der nördlichen Zange mitwirkt " ${ }^{\text {"1 }}$ also an der Ostfront eingesetzt war. Allerdings soll er 1942 als Anthropologe für das „Sonderkommando Kaukasus“ des SS-Ahnenerbes tätig gewesen sein. ${ }^{2}$ Dem Briefwechsel von Struck und Bruno K. Schultz, der Pfaul damals als Assistenten am Lehrstuhl für Erb- und Rassenhygiene in Prag einstellen wollte, zufolge galt Pfaul seit Oktober 1942 als vermisst. ${ }^{3}$

\section{Auswahlbibliografie}

Biometrie der Rassenkunde. Ihre Voraussetzungen, Möglichkeiten und Grenzen, Jena, Gustav Fischer, 1938 (Zugl. Jena, Univ., Diss., 1937).

Rassenkundliches über eine Asozialen-Gruppe, in: Volk und Rasse, 15, 1940, S. 20-23.

\section{Quellen und Literatur}

HStA Dresden, 13842, Nr. 048; Nr. 115

SKD, MfV Archiv, MVD n20;25/11u12

BArch, ZA VI 0883 A9; BArch, R 9361-II/803289

BArch, R 9361-IX/Kartei/32231277; R 9361-VIII/Kartei/15311454

1 Struck an Keil, 11.10.1941, SKD, MfV Archiv, MVD n20;25/7u8, o. Pag.

2 Vgl. Hauschild, Thomas (Hg.): Lebenslust und Fremdenfurcht. Ethnologie im Dritten Reich, Frankfurt a. M. 1995, S. $181 \mathrm{f}$.

3 Vgl. Schultz an Struck, 15.10.1942, SKD, MfV Archiv, MVD n20;25/11u12, o. Pag. Vgl. Landeshauptstadt Dresden, Stadtarchiv, Sign. 15.7.3 u. 15.7.4, Meldekartei, Alice Margarethe Pfaul. 


\section{Artur Pietzsch}

23.12.1901 Kesselsdorf - 1.5.1975 Dresden

Präparator

Museum für Mineralogie, Geologie und Vorgeschichte

(ab 1.4.1938: Landesmuseum für Vorgeschichte)

1.2.1935-31.7.1935 Zeichner

1.8.1936-[?] Präparator

[?]-15.8.1972 Konservator

(Militärdienst und Kriegsgefangenschaft 4.3.1941-8.8.1947)

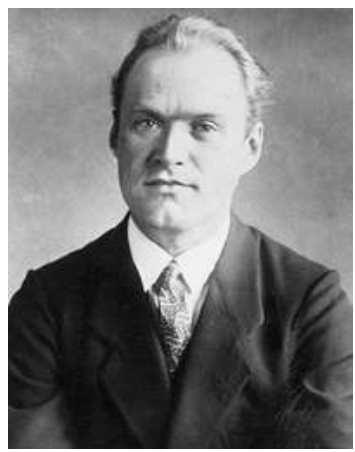

Am 23. Dezember 1901 wurde Artur Emil Pietzsch ${ }^{1}$ als Sohn des Bergarbeiters Bruno Pietzsch und dessen Frau Anna, geb. Schuster, in Kesselsdorf bei Dresden geboren. Nach dem Besuch der Volksschule war er in verschiedenen Bereichen tätig, in der Landwirtschaft, in einer Maschinenfabrik in Freital-Deuben, im Steinkohlebergbau und als Waldarbeiter in Schlesien. Von 1921 bis 1931 arbeitete er in der Dresdner Zigarettenfabrik A. M. Eckstein \& Söhne als Tabakmischer und Reklamezeichner. 1924 heiratete er Marie Erna, geb. Raport, mit der er ein Kind hatte. ${ }^{2}$ In seiner Freizeit folgte Pietzsch seinen Interessen und nahm von 1924 bis 1927 Zeichenunterricht bei Karl Enderlein an der Abendschule der Staatlichen Akademie für Kunstgewerbe in Dresden, wie auch ein Jahr Privatunterricht an der Akademie für Zeichnen, Malen und Modellieren von Hofrat Ernst Oskar Simonson-Castelli.

Nach drei Jahren Arbeitslosigkeit und verschiedenen Gelegenheitsarbeiten arbeitete Pietzsch ab Oktober 1934, zunächst noch über den Arbeitsdienst, bei der Ausgrabung in Dresden-Coschütz für den Landespfleger für Bodenaltertümer und das Museum für Mineralogie, Geologie und Vorgeschichte mit, ab Februar 1935 als Zeichner des Museums. Als er 1935 anonym als „Kommunist“ denunziert wurde, setzte sich $\triangleright$ Georg Bierbaum für ihn ein. Im August 1936 wurde Pietzsch zum Präparator ernannt. Nach der Trennung der Vorgeschichtlichen Abteilung vom Museum für Mineralogie und Geologie zählte er mit Bierbaum zum Personal des neuen Landesmuseums für Vorgeschichte. Anfang März 1941 wurde Pietzsch zur Wehrmacht einberufen. Im August 1944 geriet er in Kriegsgefangenschaft und kehrte erst 1947 nach Dresden und an das Landesmuseum für Vorgeschichte zurück. Bis August 1972 leitete er dessen Werkstätten und war als Konservator tätig. Maßgeblich beteiligte er sich an wichtigen Ausgrabungen der 1950er- und 1960er-Jahre, so auch erneut an der Heidenschanze Dresden-Coschütz. Große Anerkennung fand er für seine Rekonstruktionen ur- und frühgeschichtlicher Werkzeuge sowie für seine Ausstellungsarbeiten.

Artur Pietzsch starb am 1. Mai 1975 in Dresden.

1 Er selbst hat seinen Vornamen Arthur, wie er amtlich registriert ist und in den Personalunterlagen von 1935 angegeben wurde, später nur in der Form Artur benutzt. Bibliografisch ist er als Artur Pietzsch zu finden. Aus diesem Grund hat sich auch die Autorin für diese Schreibweise entschieden.

2 Unklar bleibt, wann diese Ehe endete und wann er in 2. Ehe Margarete, geb. Hänel, heiratete. 


\section{Auswahlbibliografie}

Der Schmied und seine Kunst in der Vorgeschichte, in: Sachsens Vorzeit, Bd. 2, 1938/1939, S. 149-154.

Die Schmuckscheibe von Rackel, Kr. Bautzen, in: Sachsens Vorzeit, Bd. 5, 1941, S. 13-16.

Zur Entwicklung des Pfluges und der steinernen Pflugschar, in: Jahresschrift für mitteldeutsche Vorgeschichte, Bd. 34, 1950, S. 9-19.

Technologische Bemerkungen zum Bronzegefässfund von Dresden-Dobritz, in: Arbeits- und Forschungsberichte zur sächsischen Bodendenkmalpflege, Bd. 2, 1952, S. 162-172.

Rettungsgrabung auf der Heidenschanze bei Dresden-Coschütz, in: Ausgrabungen und Funde, Bd. 2, 1957, 1, S. 27-33 (mit Hans Kaufmann).

Zur Technik der Wendelringe, Arbeits- und Forschungsberichte zur sächsischen Bodendenkmalpflege Bd. 4, Berlin 1964.

Rekonstruktionen getriebener Bronzegefässe, in: Arbeits- und Forschungsberichte zur sächsischen Bodendenkmalpflege, Bd. 18, 1968, S. 237-283.

Bronzeschmelzstätten auf der Heidenschanze in Dresden-Coschütz. Versuch einer Rekonstruktion, in: Arbeits- und Forschungsberichte zur sächsischen Bodendenkmalpflege, Bd. 19, 1971, S. 35-68.

Rekonstruktionen kaiserzeitlicher Fibeln, in: Arbeits- und Forschungsberichte zur sächsischen Bodendenkmalpflege, Bd. 20/21, 1976, S. 279-298.

\section{Quellen und Literatur}

HStA Dresden, 13859, Nr. 6452

Landeshauptstadt Dresden, Stadtarchiv, Meldekartei Sign. 15.7.3 u. 15.7.4

Coblenz, Werner: Artur Pietzsch 1901-1975, in: Arbeits- und Forschungsberichte zur sächsischen Bodendenkmalpflege, 22, 1978, S. $17 \mathrm{ff}$.

Jünger, Konstanze u. Judith Schachtmann: „Eine 3000 Jahre alte Stadt“. Die Ausgrabungen auf der Heidenschanze von Dresden-Coschütz und ihre Darstellung in der Öffentlichkeit, in: Arbeits- und Forschungsberichte zur sächsischen Bodendenkmalpflege, Bd. 21, 2010, S. 27-35. 


\section{Hans Posse}

6.2.1879 Dresden - 7.12.1942 Berlin

Kunsthistoriker

Gemäldegalerie

1.4.1910-7.12.1942 Direktor

Kupferstich-Kabinett

25.1.1941-7.12.1942 Kommissarischer Direktor

"Sonderauftrag Linz"

26.6.1939-7.12.1942 „Sonderbeauftragter des Führers“

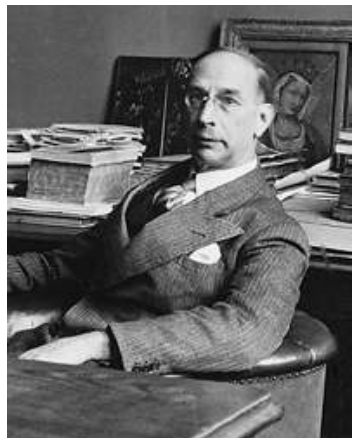

Hans Posse wurde am 6. Februar 1879 als Sohn des späteren Direktors des königlich-sächsischen Hauptstaatsarchivs Dresden, Otto Posse, und dessen Frau Helene, geb. Tischer, in Dresden geboren. Ab 1889 lernte er am Gymnasium zum Heiligen Kreuz in Dresden. Nach der Reifeprüfung 1898 absolvierte er seinen Militärdienst als Einjährig-Freiwilliger. Anschließend studierte Posse zunächst Historiografie, Historische Hilfswissenschaften und Germanistik an der Universität Marburg. Im Herbst 1900 wechselte er für ein Studium der Kunstgeschichte, u. a. bei Franz Wickhoff, Alois Riegl, Julius von Schlosser und Max Dvořák, an die Universität Wien. Nach einer ausgedehnten Studienreise durch Italien 1902 wurde Posse 1903 als Schüler von Wickhoff in Wien promoviert; seine Dissertation über den italienischen Barockmaler Andrea Sacchi publizierte er jedoch erst 1925. Ab 1. Oktober 1903 arbeitete Posse als Freiwilliger Wissenschaftlicher Hilfsarbeiter an der Gemäldegalerie Berlin. 1904 war er, mittlerweile zum Wissenschaftlichen Hilfsarbeiter ernannt, am Umzug der Galerie in das neue KaiserFriedrich-Museum beteiligt. Seine Berliner Tätigkeit unterbrach er 1905 für einen einjährigen Studienaufenthalt am Kunsthistorischen Institut in Florenz. Für das Kaiser-Friedrich-Museum bearbeitete Posse das Gemäldeverzeichnis, das 1911 erschien, und für das Galeriewerk der Berliner königlichen Museen die Italienische Malerei des 17. und 18. Jahrhunderts, wobei er an die Resultate seiner Dissertation anschließen konnte. Während seiner Berliner Tätigkeit wurde Posse maßgeblich durch Wilhelm Bode gefördert, der ihn im April 1909 zum Direktorialassistenten beförderte.

Zum 1. April 1910 wurde Posse zum Direktor der Dresdner Gemäldegalerie ernannt, obwohl er noch im Sommer 1909 nur an letzter Stelle der Kandidatenliste gestanden hatte. In Dresden engagierte er sich im Zuge der reichsweiten Museumsreformbewegung erfolgreich für eine Neugestaltung der Gemäldegalerie. Während des Ersten Weltkrieges stand Posse ab August $1914 \mathrm{im}$ aktiven Heeresdienst. Dank mehrerer Beurlaubungen war er während des Krieges aber nicht völlig außerhalb des Amtes, sondern konnte die Direktionsgeschäfte der Gemäldegalerie phasenweise selbst weiterführen; während seiner Abwesenheit übernahm diese Aufgabe neben Generaldirektor Woldemar von Seidlitz der Direktionskollege Posses aus dem Kupferstich-Kabinett, Max Lehrs. Posse überlebte den Einsatz an der Ost- und Westfront - einer seiner Brüder war an der Westfront gefallen - und kehrte im September 1918 nach Dresden zurück. Seine Pläne und die bereits begonnenen Vorarbeiten für einen Neubau für die Gemäldegalerie wurden jedoch in der Weimarer Republik durch das Finanzministerium gestoppt. Erst zwanzig Jahre später wurden die Planungen wieder aufgegriffen und im Mai 1939 von Posse und $\triangleright$ Fritz Fichtner dem Generalbauinspektor für Berlin, Albert Speer, in Dresden vorgestellt, freilich, ohne dass eine 
Realisierung dadurch wahrscheinlicher geworden wäre. ${ }^{1}$ Wichtige Veränderungen gelangen Posse dennoch: Ab November 1924 konnten moderne Werke in einem zur Präsentation von Gemälden allerdings wenig geeigneten Palais in der Parkstraße 7 präsentiert werden, bevor ab August 1931 die „Moderne Abteilung“ mit Werken von der Romantik bis zum Impressionismus - also überwiegend des 19. Jahrhunderts - im Gebäude der Sekundogenitur auf der Brühlschen Terrasse gezeigt wurde. Unterdessen wurde der Marmorsaal im Zwinger rekonstruiert und im Januar 1933 als „Deutscher Saal“ der Galerie wiedereröffnet. Die von Posse getätigten Ankäufe waren eher konservativ - bis zur Streichung aller Ankaufsmittel 1933 erwarb er u. a. Werke von Caspar David Friedrich, Lovis Corinth, Ferdinand von Rayski, aber auch von Oskar Kokoschka, den er besonders schätzte. ${ }^{2}$ Bei Erwerbungen zeitgenössischer Kunst agierte Posse taktisch abwartend. Bis auf wenige Ausnahmen - neben Kokoschka auch Edvard Munch, Lovis Corinth, Emil Nolde, Max Beckmann sowie der persönliche Freund Robert Sterl - ergaben sich seine Entscheidungen aus der Beobachtung der reichsweiten musealen Kanonbildung. Zeitgenössische Werke wurden überwiegend durch den Patronatsverein der Gemäldegalerie erworben. Posse ließ sich diese sowie zahlreiche moderne Werke aus dem Bestand des Stadtmuseums leihweise zur Verfügung stellen. Zu Recht galt Posse als ,einflussreicher, hoch professioneller, strategisch handelnder Museumsdirektor " ${ }^{\text {"3 }}$. Als erfahrenem, im europäischen Museumswesen bestens vernetztem Ausstellungsmacher und „Kulturdiplomat " ${ }^{\text {“4 }}$ wurde ihm 1922 und 1930 vom Auswärtigen Amt das Kommissariat für den deutschen Pavillon der Biennale in Venedig übertragen. Dabei agierte er vorrangig kulturpolitisch. In Dresden übernahm Posse indes, als die Künstlerauswahl im Wesentlichen bereits entschieden war, vom erkrankten Akademieprofessor Sterl, dem er freundschaftlich verbunden war, den Vorsitz der „Künstlerischen Leitung“ der „Internationalen Kunstausstellung 1926".5 Schon im Umfeld der Biennale 1930 hatte es in der Presse heftige Angriffe gegen Posse gegeben. In Dresden setzten sich diese fort: Im April 1933 erschienen einige NSDAP-Aktivisten, darunter Walther Gasch, in der Galerie und forderten die Aussonderung zahlreicher Bilder. Posse kam dieser Forderung nur vorläufig und teilweise nach; Werke von Lovis Corinth, Otto Dix, Karl Hofer, Emil Nolde, Edvard Munch und Max Liebermann blieben in der Präsentation oder wurden nach einiger Zeit wieder ausgestellt. ${ }^{6}$ Anlässlich der Ausstellung „Entartete Kunst“ im Lichthof des Dresdner Rathauses ab September 1933, auf der keine Werke aus Galereieigentum präsentiert wurden, forderte Gasch „die Absetzung des schwer belasteten und für uns Nationalsozialisten längst untragbaren Galeriedirektors Posse" ". Auch der Direktor des Grünen Gewölbes und Historischen Museums, \Erich Haenel, hatte einen Text gegen Posse verfasst, das zuständige Ministerium für Volksbildung hielt jedoch noch zu Posse und bedauerte „lebhaft“, dass Haenel „einen so offensichtlichen Mangel an Sorgfalt und kollegialem Empfinden an den Tag gelegt " ${ }^{\text {" }}$ habe. Posse gelang es, die sachlich offensichtlich unbegründeten Angriffe durch eine Denkschrift zu entkräften und sich, auch dank der Unterstützung durch Minister

Siehe S. $128 \mathrm{f}$.

Eine Übersicht findet sich bei Rudert 2015b, S. 96 f.

Rudert 2015b, S. 115.

Ebd., S. 117.

Vgl. K. Rudert 2015, S. 308 f., 317 f.

Vgl. Rudert 2015b, S. 132 f.

Gasch, Walther: Sumpfblüten der Kunst, in: FK, 26.9.1933, S. 15-16, hier: 16.

SMV, Woelker, an Haenel, 15.2.1934, zitiert nach Lupfer/Rudert 2015, S. 388. 
Wilhelm Hartnacke, im Amt zu halten. ${ }^{9}$ Im April 1933 beantragte Posse eine NSDAP-Mitgliedschaft, erhielt seine Interimskarte jedoch erst im Dezember 1933 mit dem Beitrittsvermerk 1. Mai 1933. Doch 1934 wurde seine Mitgliedschaft aus bisher unbekannten Gründen wieder gestrichen - die entsprechende Karte der NSDAP-Mitgliederkartei vermerkt „Aufnahme abgelehnt“. Seine langjährige Haushälterin, Frida Elise Käpernik, die er im Juli 1933 in Dresden geheiratet hatte, war hingegen wahrscheinlich seit 1930 Parteimitglied. Nach Hitlers Rede zur „Entarteten Kunst“ im Juli 1937 entfernte Posse weitere Werke der „Entarteten Kunst“ wie auch Werke von Liebermann aus der Gemäldegalerie, soweit diese noch ausgestellt waren, und deponierte sie. Am 7. März 1938 wurde Posse ins Ministerium einbestellt und von dessen Kommissarischem Leiter Göpfert gedrängt, seine Versetzung in den Ruhestand zu beantragen, was er allerdings nicht tat, sondern nur seine vorzeitige Pensionierung mit Erreichen des 60. Lebensjahres zum Februar 1939 in Aussicht stellte. Nach einem vierwöchigen Erholungsurlaub war Posse ab Mitte April wieder in der Galerie tätig, allerdings nominell nicht mehr als Direktor. Diese Funktion war seinem Kollegen aus der Skulpturensammlung, $>$ Walter Müller, übertragen worden. So berichtete > Martin Heydrich an $>$ Bernhard Struck: „Die Gemäldegalerie ist augenblicklich völlig verwaist. Posse geht in Pension und Jähnig ist abgebaut. " ${ }^{10}$ Doch bis auf weiteres blieb Posse in der Galerie tätig, zwar nicht nominell, aber faktisch durchaus auch mit direktorialen Aufgaben. So führte er Ankaufsverhandlungen und bereitete die Ausstellung „Deutsche Kunst vom 16. bis 18. Jahrhundert" vor, die am 11. Juni 1938 anlässlich der Museumswoche eröffnet wurde. ${ }^{11}$ Als Adolf Hitler bei einem Aufenthalt zur Reichstheaterwoche am 18. Juni 1938 in der Gemäldegalerie erschien, und sich, wie bei früheren Besuchen üblich, von Posse führen lassen wollte, war dieser nicht anwesend. Stattdessen wurde Hitler von dem ihm bis dahin persönlich nicht bekannten Fichtner begrüßt, der ihm den Freiwilligen Wissenschaftlichen Hilfsarbeiter $\checkmark$ Gert Adriani als Führer durch die Galerie vorstellte - was zu einem Eklat führte in dessen Folge Posse herbeizitiert wurde, um die Galerieführung persönlich durchzuführen. Danach entspannte sich die berufliche Situation Posses deutlich. Nach der persönlichen Intervention Hitlers wurde er am 22. Juli 1938 wieder in das Amt als Galeriedirektor eingesetzt. ${ }^{12}$ Nicht zuletzt durch die Führung im Juni 1938, bei der er Hitler die Ausstellung „Lucas Cranach“, die Werke des Italienischen Barock und die Deutsche Malerei des 19. Jahrhunderts zeigte, hatte sich Posse für die Aufgabe, die er ein Jahr später erhielt, „qualifiziert“. Hitler berief ihn am 26. Juni 1939 zum „Sonderbeauftragten“, um das in Linz geplante „Führermuseum“ aufzubauen, und um ein europaweites (Um-)verteilungsprogramm beschlagnahmter, aber auch angekaufter Kunstwerke zu realisieren. Posse wurde damit zu einem Hauptverantwortlichen des nationalsozialistischen Kunstraubs, in dessen Netzwerke er bis zu seinem Tode eingebunden blieb. Bei seiner Reise nach Krakau und Warschau im November 1939 kooperierte er u. a. mit dem „Sonderbeauftragten für den Schutz und die Sicherung von Kunstwerken in den besetzten Ostgebieten“ Kajetan

9 Vgl. Denkschrift von Dr. Posse zur Widerlegung der gegen ihn erhobenen Vorwürfe, undatiert [1934], SKD Archiv, Nachlass Hans Posse 41, Bd. 3, Lage 6, S. 1-22, publiziert in: Lupfer/Rudert 2015, S. 389-401.

10 Heydrich an Struck, 3.5.1938, SKD, MfV Archiv, MVD n20;25/6, o. Pag. \ Karl Wilhelm Jähnig war bereits 1937 aufgrund seiner Ehe mit einer Jüdin von den Nationalsozialisten entlassen worden.

11 Vgl. Rudert 2015b.

12 Vgl. Hans Posse, Tagebuch-Einträge vom 18.6., 21.6. und 22.7.1938, Germanisches Nationalmuseum Nürnberg, Deutsches Kunstarchiv, Nachlasse Posse, Hans, I,B-1, publiziert in Lupfer/Rudert 2015, S. 402-408, hier: 405. 
Mühlmann. ${ }^{13}$ Zahlreiche Reisen in die von Deutschland besetzten Gebiete zum Zwecke der Aquise von Kunstwerken für den „Führerauftrag“ folgten. Ab März 1940 hatte Posse die SSForschungsgemeinschaft „Deutsches Ahnenerbe“ bei der „Sicherstellung und Rückführung des gesamten deutschen Kultur- und Archivgutes der Umsiedler" ${ }^{\text {"14 }}$ aus Südtirol zu unterstützen. Obwohl er durch diese Aufgaben und insbesondere durch den „Sonderauftrag“ bereits sehr beansprucht und ,außerordentlich häufig im persönlichen Auftrage des Führers an den verschiedensten Orten Deutschlands tätig "15 war und deshalb selten in Dresden weilte, wurde Posse nach dem plötzlichen Tod von > Kurt Zoege von Manteuffel im Januar 1941 zusätzlich zum Kommissarischen Direktor des Kupferstich-Kabinetts ernannt. ${ }^{16}$ Ab April 1942 musste sich Posse aufgrund seiner schweren Krebserkrankung zunächst in München, dann in der Landhausklinik in Berlin-Wilmersdorf u. a. bei dem aus dem Libanon stammenden Radiologen Henri Chaoul einer Behandlung unterziehen. Im Juli 1942 nahm der bereits Todkranke vorübergehend seine Tätigkeit als Galeriedirektor und „Sonderbeauftragter" wieder auf, wobei er meist von zu Hause aus arbeitete, wo ihn seine Mitarbeiter $\triangleright$ Robert Oertel, $\triangleright$ Gottfried Reimer und $\triangleright$ Fritz Wiedemann regelmäßig aufsuchten. Doch ab August 1942 folgten weitere stationäre Behandlungen in der Berliner Klinik, wo Hans Posse am 7. Dezember 1942 starb. Sein Leichnam wurde nach Dresden überführt und im Marmorsaal im Zwinger aufgebahrt. Auf Anordnung Hitlers, der selbst nicht anwesend war, fand am 11. Dezember 1942 ein Staatsakt für Posse im Ausstellungsgebäude auf der Lennéstraße statt. Die Trauerrede hielt Joseph Goebbels.

\section{Auswahlbibliografie}

Die Umgestaltung der Dresdner Gemäldegalerie, in: Mitteilungen aus den Sächsischen Kunstsammlungen, 3, 1912, S. 49-60.

Das Deckenfresko des Pietro da Cortona im Palazzo Barberini und die Deckenmalerei in Rom, in: Jahrbuch der Preußischen Kunstsammlungen 40, 1919, S. 92-118, 126-173.

Die Gemälde-Galerie zu Dresden, Bd. 1-2, Dresden 1920, 1921.

Raffaels Sixtinische Madonna, Berlin 1922.

Die 4 Altargemälde des Antonio da Corregio, Dresden 1923.

Der römische Maler Andrea Sacchi. Ein Beitrag zur Geschichte der klassizistischen Bewegung im Barock, Leipzig 1925 (= Italienische Forschungen, N. F. 1) (Zugl. Wien, Univ., Diss., 1903).

Die Staatliche Gemäldegalerie zu Dresden - Katalog der Modernen Galerie, Dresden 1930 (mit Karl Wilhelm Jähnig und Klara Steinweg).

Die Briefe des Grafen Francesco Algarotti an den sächsischen Hof und seine Bilderkäufe für die Dresdner Galerie 1743-1747, in: Jahrbuch der Preußischen Kunstsammlungen 52, 1931, Beiheft, S. 1-73.

Die neue Galerie des neunzehnten Jahrhunderts in Dresden, in: Kunst und Künstler 31, 1932, S. 355-364.

Lucas Cranach d. Ä., Wien 1942.

Siehe S. $142 \mathrm{ff}$.

Himmler an Bormann, 28.2.1940, BArch, NS 21/2157.

Fichtner an SMV, 10.1940, SKD Archiv, 01/PS 53, Bd. 1, fol. 194.

Vgl. SMV, Fichtner, an Posse, 25.1.1941, HStA Dresden, 11125, Nr. 22888, fol. 25. 


\section{Quellen und Literatur}

BArch, R 9361-VIII/Kartei/1625088

Stadtarchiv Dresden, Standesamt I, Reg.-Nr. 1132/1933

Kommentierte Online-Edition der fünf Reisetagebücher Hans Posses (1939-1942), https:// editionhansposse.gnm.de/, Zugriff: 3.12.2019.

Oertel, Robert: H. Posse zum Gedächtnis, in: Neues Archiv für sächsische Geschichte, Bd. 63, 1943, S. 170-174.

Dalbajewa, Birgit: „Träger bewegteren Lebensgefühls“. Erwerbungen von Oskar Kokoschka durch Ludwig Justi, Hans Posse und Paul Ferdinand Schmidt nach der Novemberrevolution 1918, in: Jahrbuch der Staatlichen Kunstsammlungen Dresden, 30, 2002/2003, S. 131-145.

Schwarz, Birgit: Hitlers Sonderbeauftragter Hans Posse, in: Dresdner Hefte. Beiträge zur Kulturgeschichte, Bd. 22, H. 1, 2004, S. 77-85.

Winter, Petra: Hans Posse - „ein nahezu unbeschriebenes Blatt“. Protokoll einer Ernennung, in: Maaz, Bernhard (Hg.): Kunst- Welt- und Werkgeschichten. Die Korrespondenz zwischen Hans Posse und Wilhelm von Bode von 1904 bis 1928, Köln/Weimar/Wien 2012, S. 29-48.

Schwarz, Birgit: Auf Befehl des Führers. Hitler und der NS-Kunstraub, Darmstadt 2014.

Rudert, Thomas: Konservativer Galeriedirektor - Kulturdiplomat der Weimarer Republik NS-Sonderbeauftragter. Bausteine zu einer Biografie Hans Posses, in: Lupfer/Rudert 2015, S. 61-149.

Dalbajewa, Birgit: „Mittelgut können wir nicht gebrauchen.“ Hans Posse als Kommissar des deutschen Pavillons in Venedig 1922 und 1930, in: Lupfer/Rudert 2015, S. 219-238.

Lupfer, Gilbert u. Thomas Rudert (Hg.): Kennerschaft zwischen Macht und Moral. Annäherungen an Hans Posse (1879-1942), Wien/Köln/Weimar 2015 (mit Schriftenverzeichnis Hans Posse).

Schwarz, Birgit: Hitlers Sonderauftrag Ostmark. Kunstraub und Museumspolitik im Nationalsozialismus, Schriftenreihe der Kommission für Provenienzforschung 7, herausgegeben von Eva Blimlinger u. Heinz Schödl, Wien/Köln/Weimar 2018.

Rudert, Thomas: Wassily Kandinskys Gemälde „Einige Kreise“ in Dresden (1926-1937), Dresdener Kunstblätter, 63. Jg., H. 1, 2019, S. 32-41. 


\section{Robert ReICHERT}

24.3.1897 Öhringen - 9.12.1959 Dresden

Dermoplastiker, Oberkonservator

Museen für Tierkunde und Völkerkunde

(ab 1.1.1942 Museen für Tierkunde, Rassenkunde und

Völkerkunde)

1.1.1924-1945 Oberkonservator

11.8.1944-5.1945 Depotverantwortlicher

23.8.1944-7.9.1944 Kommissarischer Leiter

1945-30.11.1947 Inspektor

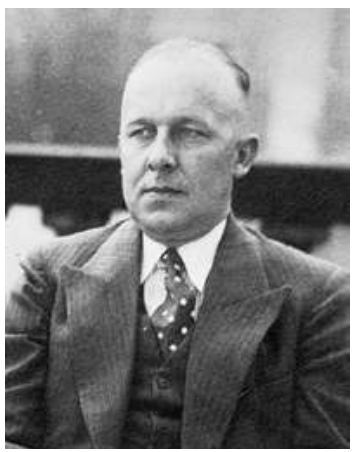

1.12.1947-31.12.1949 Kommissarischer Leiter

1.1.1950-1957 Direktor

1957-9.12.1959 Abteilungsleiter

Robert Reichert wurde am 24. März 1897 in Öhringen in Württemberg geboren. Nach dem Schulbesuch absolvierte er bei seinem Onkel Robert Banzer in Öhringen, der Hofpräparator der Grafen von Hohenlohe-Öhringen war, eine Ausbildung zum Tierpräparator. Obwohl er bereits als gut ausgebildet gelten konnte, ging Reichert im März 1914 bewusst als Hilfspräparator an das Zoologische Institut der Universität Leipzig, um sich bei dem berühmten Dermoplastiker Herman H. ter Meer weiterzubilden. Von März 1916 bis Januar 1919 leistete Reichert seinen Militärdienst im Ersten Weltkrieg. Nach seiner Rückkehr wurde er am Leipziger Zoologischen Institut zum Präparator ernannt. Im April 1920 ging er für sechs Monate als Präparator an die Biologische Anstalt Helgoland. Ab November 1920 arbeitete Reichert am Fränkischen Museum für Naturkunde in Würzburg, im Juli 1921 wechselte er nach Hamburg an das Zoologische Museum und Institut der Universität.

Ab 1. Januar 1924 war Reichert als Oberkonservator an den Museen für Tierkunde und Völkerkunde in Dresden angestellt, wo er die Werkstatt für Dermoplastik leitete. Als er nur sechs Jahre später ein Stellenangebot aus Königsberg erhielt, gelang es dem damaligen Direktor -Arnold Jacobi, seinen Mitarbeiter, wohlwissend, dass dieser über eine außerordentlich gute Ausbildung und reichlich Erfahrung als Dermoplastiker verfügte, in Dresden zu halten. Selbst Sammler, Ornithologe und Jäger, nahm Reichert vom Mai 1931 bis Juli 1932 an einer Expedition in das ostafrikanische Matengo-Hochland teil, von wo er eine reiche Ausbeute an Vögeln und Säugetieren für das Dresdner Museum mitbrachte. Reichert, der zu den besten Dermoplastikern und wissenschaftlichen Präparatoren Deutschlands zählte, bildete in Dresden selbst aus, so den als Vertretung für $>$ Hellmuth Buck eingestellten > Artur Krüss. Reichert wirkte maßgeblich an der Neugestaltung der Schausammlung des Museums bei dessen Umzug 1937 mit, für die er Dioramen wie den Helgoländer Lummenfelsen, Schneeleoparden und Gruppen aus der heimischen Tierwelt schuf. Auch für die Kolonialausstellung 1938 gestaltete er Dioramen, die das Tierleben am Kilimandscharo und beim Waterberg in Afrika sowie auf den polynesischen Inseln veranschaulichten. Im September 1939 heiratete er Elisabeth Gertrud, geb. Andrich. Nach Beginn des Zweiten Weltkrieges konnte er mehrfach uk-gestellt werden, da er als einer der wenigen verbliebenen Mitarbeiter mit der Auslagerung und Betreuung der Bestände der Museen für Tierkunde und Völkerkunde beauftragt war. Gemeinsam mit seinem Kollegen > Johannes Draeseke wurde Reichert am 11. August 1944 durch $>$ Fritz Fichtner als 


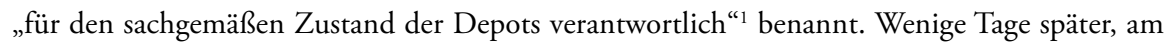
23. August 1944, übernahm er anstelle des zur Wehrmacht eingezogenen $>$ Klaus Günther die kommissarische Leitung der Museen für Tierkunde, Rassenkunde und Völkerkunde. Bei der Bergung des Museumsgutes zwei Tage nach dem Luftangriff am 7. Oktober 1944 zog er sich, als beim Abtragen von Mauerresten der Mitteldachboden durchbrach, eine schwere Verletzung zu. Erst einen Monat später konnte er wieder arbeiten.

Nach dem Zweiten Weltkrieg konnte Reichert im Amt bleiben, da er nie in die NSDAP eingetreten war und sich nicht politisch engagiert hatte. Nur der Mitgliedschaft in anderen NS-Organisationen wie dem RDB, NSV und RLB hatte er sich durch die Anstellung in einer staatlichen Institution in der NS-Zeit nicht entziehen können. Reichert engagierte sich nun als Inspektor für den Wiederaufbau des Museums, womit er die Voraussetzungen für die Fortführung der wissenschaftlichen Arbeit der Institution nach dem Krieg schuf. Im Dezember 1947 wurde er zum Kommissarischen Leiter, drei Jahre später, ab Januar 1950, zum Direktor des Staatlichen Museums für Tierkunde Dresden ernannt und wirkte maßgeblich an mehreren Sonderausstellungen und der Popularisierung des Museums mit. Mit der Übertragung der Direktion des Museums an Wilhelm Götz 1957 wurde Reichert wieder Abteilungsleiter des Präparatoriums, eine Aufgabe, die er noch zwei Jahre erfüllte. Am 9. Dezember 1959 starb Robert Reichert auf dem Arbeitsweg bei einem Verkehrsunfall in Dresden.

\section{Auswahlbibliografie}

Ein Stück Museumsgeschichte, in: Abhandlungen und Berichte aus dem Staatlichen Museum für Tierkunde, Forschungsinstitut, Dresden, Bd. 12, 1954, S. 1-11.

Neue Wege in der Museumgestaltung, in: Abhandlungen und Berichte aus dem Staatlichen Museum für Tierkunde, Forschungsinstitut, Dresden, Bd. 22, 1955, S. 99-110.

Über 200 Jahre Museumsgeschichte, in: Dresdner Wissenschaftliche Museen. Beiträge zur 750-Jahr-Feier unserer Stadt, Dresden 1956, S. 1-7.

Persönlichkeiten, von denen unsere Sammlungen erzählen, in: Dresdner Wissenschaftliche Museen. Beiträge zur 750-Jahr-Feier unserer Stadt, Dresden 1956, S. 8-21.

\section{Quellen und Literatur}

HStA Dresden, 13859, Nr. 6777

Frommhold, Erhard: Robert Reichert zum Gedenken, in: Der Falke, Bd. 7, 1960, S. 136-138. Hertel, Rolf: Robert Reichert $\dagger$, in: Sächsische Heimatblätter, 6. Jg., H. 1, 1960, S. 55.

Kumerloeve, Hans: Robert Reichert zum Gedächtnis, in: Beiträge zur Vogelkunde, Bd. 8, 1963, S. 463-466.

1 SMV, Fichtner, an Reichsstatthalter Mutschmann, 11.8.1944, HStA Dresden, 11125, Nr. 23058, fol. $84 \mathrm{~b}$. 


\title{
Gottrried Reimer
}

\author{
18.2.1911 Döbeln - 19.1.1992 Döbeln \\ Kunsthistoriker \\ Gemäldegalerie \\ 1.6.1939-30.11.1940 Freiwilliger Wissenschaftlicher \\ Hilfsarbeiter \\ "Sonderauftrag Linz“ \\ 1940-5.1941 Assistent \\ 1.6.1941-5.1945 Referent \\ 12.1942-3.1943 Kommissarischer Leiter (mit Robert \\ Oertel) \\ [ohne Angabe] \\ 1.2.1946-31.7.1946 Wissenschaftlicher Hilfsarbeiter
}

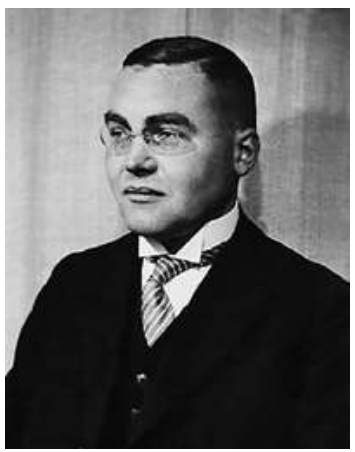

Am 18. Februar 1911 wurde Hermann Arthur Gottfried Reimer als Sohn des Rechtsanwalts Arthur Reimer und dessen aus der Industriellenfamilie Greiner stammenden Frau in Döbeln geboren. Hier legte Reimer 1930 auch die Reifeprüfung ab. Anschließend studierte er in Würzburg Kunstgeschichte, Geschichte, Deutsche Literatur, Bibliotheks- und Rechtswissenschaft, auch Chemie. Das Sommersemester 1932 verbrachte er in Wien. Im Juli 1934 wurde Reimer in Würzburg promoviert. Anschließend arbeitete er bis 1937 als Assistent in Wien, bevor er an die Bayerische Staatsbibliothek und das Bayerische Nationalmuseum in München wechselte. Von München aus bewarb er sich im Februar 1939 in Dresden.

Ab Juni 1939 arbeitete Reimer als Freiwilliger Wissenschaftlicher Hilfsarbeiter in der Gemäldegalerie in Dresden. Zunehmend wurde er von Direktor $>$ Hans Posse zu Arbeiten für den „Sonderauftrag Linz" herangezogen. Unklar bleibt, wann Reimer 1940 als Assistent in den Dienst des „Sonderauftrags Linz“ wechselte. Im Mai 1941 ging er zunächst nach Wien, wurde aber nach wenigen Tagen durch Posse nach Dresden zurückgerufen und als Assistent für den „Sonderauftrag“" angestellt, ab Juni dann als Referent. ${ }^{1}$ Nach Posses Tod, bis zur Berufung von $>$ Hermann Voss als "Sonderbeauftragter" und Galeriedirektor, d.h. von Dezember 1942 bis März 1943, übernahm Reimer gemeinsam mit Kustos $>$ Robert Oertel die kommissarische Leitung des „Sonderauftrags Linz“. Reimer zeichnete primär für die erforderlichen Bergungsarbeiten der Sammlung verantwortlich, während Oertel die Erwerbungen abwickelte. ${ }^{2}$ Ab Januar 1944 war Reimer neben Voss für die Bergung der Kunstwerke für das „Führermuseum Linz“ in das Salzbergwerk Altaussee verantwortlich, wobei er Kontakt zu Reichsminister Martin Bormann und dessen persönlichem Referenten, Ministerialrat von Hummel, hatte. ${ }^{3}$ Im März 1945 bereitete Reimer auf Anordnung von Bormann für Mitte April 1945 einen Transport der Werke und Akten des „Sonderauftrags Linz" von ihrem sächsischen Auslagerungsort in Weesenstein nach Altaussee

\footnotetext{
1 Posse beantragte Reimers Weiterbeschäftigung am 10.5.1941. Vgl. HStA Dresden, 11125, Nr. 22874, E.-Nr. 1940. Vgl. auch Iselt 2010, S. 197.

2 Vgl. Chef der Reichskanzlei, Lammers, an Reimer, 25.1.1943, BArch, R 43/II/1653a, fol. $139 \mathrm{ff}$. Vgl. auch Iselt 2010, S. 197 ff., Iselt 2012, S. 48.

3 Vgl. Obersalzberg an Partei-Kanzlei und Reichsfinanzministerium Berlin, 23.1.1944, BArch, R 9361-VI/3283, o. Pag.
} 
vor. ${ }^{4}$ Nach dem Kriegsende war Reimer weiterhin an den Staatlichen Kunstsammlungen tätig. Als Wissenschaftlicher Hilfsarbeiter unterstützte er ab Februar 1946 die Sicherung der Auslagerungsdepots und die Rückführung der Objekte nach Dresden bzw. Pillnitz und führte Inventarisationsarbeiten aus. Doch zum 31. Juli 1946 wurde Reimer, obwohl er kein Mitglied der NSDAP gewesen war, entlassen. ${ }^{5}$

Dies steht im Gegensatz zu dem, was Reimer Jahre später, 1950, schilderte: Ich „bin ab Januar 1941 an das Kunsthistorische Museum nach Wien übergesiedelt, da ich es ablehnte, Parteimitglied der NSDAP oder aktives Mitglied einer ihrer Gliederungen zu werden, und ohne eine solche Zugehörigkeit keine dauernde Beschäftigung oder Anstellung im sächsischen Staatsdienst möglich war. "6 Eine Übersiedlung nach Wien konnte bisher nicht nachgewiesen werden. Diese Widersprüche zeigen, dass Reimer seine Beteiligung am nationalsozialistischen Kunstraub später aktiv zu verbergen versuchte. Von der Sowjetischen Militäradministration im Dezember 1946 verhaftet, gelang es Reimer, seine Rolle im „Sonderauftrag Linz“ zu verschleiern. Er entging einer Verurteilung und kehrte nach seiner Freilassung nach Döbeln zurück. In den folgenden Jahren arbeitete er als freiberuflicher Kunsthistoriker, erstellte Expertisen und engagierte sich als ehrenamtlicher Denkmalpfleger im Kreis Döbeln, wofür er bis 1975 eine monatliche Aufwandspauschale erhielt. Hilfreich für seine Existenz im Halbverborgenen war, dass er kein Mitglied der NSDAP gewesen und 1945, kurz nach ihrer Gründung, in die CDU eingetreten war. Auch lebte er seit seiner Rückkehr nach Döbeln im Haus seiner Eltern. Diese Abgeschiedenheit teilte er mit seiner Frau, die er 1950 heiratete. Zu Beginn der 1980er-Jahre ermittelte das Ministerium für Staatssicherheit der DDR gegen Reimer, da man vermutete, er würde aufgrund seiner Vergangenheit die NS-Verstecke von Kunstschätzen kennen. Am 19. Januar 1992 starb Gottfried Reimer in Döbeln.7

\section{Auswahlbibliografie}

Die Verwendung des Wassers in der Gartenkunst vom Mittelalter bis zur Gegenwart in Deutschland. Erscheinungsformen und Einflüsse, Bad Mergentheim 1935 (Zugl. Würzburg, Univ., Diss., 1934).

\section{Quellen und Literatur}

HStA Dresden, 11125, Nr. 18964

Iselt, Kathrin: „Sonderbeauftragter des Führers“. Der Kunsthistoriker und Museumsmann Hermann Voss (1884-1969), Köln 2010 (Zugl. Dresden, Univ., Diss., 2009), S. 196-210, 216-240.

Schade, Thomas: Der furchtsame Sonderling, in: Sächsische Zeitung, 1.11.2018, S. 3.

4 Gemäldegalerie, Führersonderbeauftragte für Linz, Reimer, an Leiter Sächsische Staatskanzlei, 27.3.1945, HStA Dresden, 10701, Nr. 320/55, Bd. 3, fol. 10.

5 Vgl. Hempel an Präsidenten der Beratenden Kammer des Landes Sachsen, Hickmann, 3.8.1945, SKD Archiv, 02/VA 166, fol. 41-46 u. Betriebsrat der Staatlichen Museen, Reichert, an Ministerium für Volksbildung, Weinholz, 28.4.1948, SKD Archiv, 02/VA 172, fol. 154.

6 Reimer an Ministerium für Volksbildung, Hauptverwaltung der Staatlichen Museen, Schlösser und Gärten, Jenke, 25.10.1950, SKD Archiv, 02/VA 159, fol. 46.

7 Thomas Schade erwähnt in der Sächsischen Zeitung, 1.11.2018, S. 3, 1987 als Sterbejahr. Laut Auskunft des Standesamtes Döbeln starb Reimer jedoch am 19.1.1992 in Döbeln. E-Mail von Mandy Neumüller, Standesamt Döbeln, an die Autorin, 2.4.2019. 


\section{Hubert Richter}

26.6.1882 Dresden - 15.2.1948 Dresden

Historiker, Wissenschaftlicher Bibliothekar

Sächsische Landesbibliothek

(bis 1.5.1917 Königliche Öffentliche Bibliothek, 2.5.1917-

11.1918 Königliche Landesbibliothek)

1.7.1906-31.5.1907 Volontär

1.6.1907-31.12.1908 Wissenschaftlicher Hilfsarbeiter

1.1.1909-31.5.1914 Bibliotheksassistent

1.6.1914-30.9.1922 Landesbibliothekar

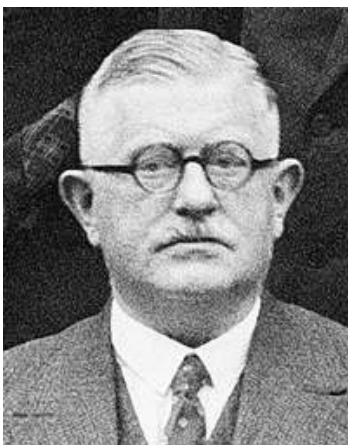

1.1.1926-30.4.1945 Landesbibliothekar, Bibliotheksrat

(Abordnung an Zentralbücherei der Landesverwaltung und Gemeinschaftliche Ministerialbücherei,

Dresden, 1.10.1922-31.12.1925)

Am 26. Juni 1882 in Dresden als Sohn des Oberbibliothekars an der Königlichen Öffentlichen Bibliothek Dresden, Paul Emil Richter, und dessen Ehefrau Martha, geb. John, geboren, war der Berufsweg von Hubert Richter gewissermaßen vorgezeichnet. Nach dem Militärdienst begann er 1902 in Leipzig ein Studium der Geografie, Germanistik und Geschichte. Dieses schloss er 1906 am Historischen Seminar der Universität Leipzig als Schüler von Erich Brandenburg mit der Promotion ab.

Ab Juli 1906 war Richter als Volontär an der Königlichen Öffentlichen Bibliothek in Dresden tätig, wo sein Vater als Oberbibliothekar angestellt war. Zunächst unterstützte er den Hilfsbibliothekar Konrad Haebler bei der Inkunabelkatalogisierung. Nach dessen Weggang wurde Richter im Juni 1907 Wissenschaftlicher Hilfsarbeiter. Zwei Jahre später erfolgte seine Ernennung zum Bibliotheksassistenten, im Juni 1914 zum Landesbibliothekar. Abgeordnet durch das zuständige Ministerium für Volksbildung, übernahm Richter ab Oktober 1922 die Leitung der Zentralbücherei der Landesverwaltung und der Gemeinschaftlichen Ministerialbücherei in Dresden. Erst vier Jahre später, zum 1. Januar 1926, kehrte er an die Sächsische Landesbibliothek als Landesbibliothekar und Bibliotheksrat zurück. Er übernahm das Referat Geschichte und leitete den Alphabetischen Katalog. ${ }^{1}$ Trotz seiner nunmehrigen Leitungserfahrung wurde er bei der Ernennung des neuen Oberbibliothekars 1926 nicht berücksichtigt - die Stelle erhielt $\triangleright$ Bruno Faass und nicht der dienstältere Richter, der „durch einen Konflikt mit dem Ministerium belastet ${ }^{{ }^{2}}$ war. Aufgrund seiner historischen Forschung berief ihn Gauleiter Mutschmann, obwohl Richter kein Parteimitglied war, am 7. Januar 1939 zum fördernden Mitglied der Sächsischen Kommission für Geschichte. Infolge seiner Diabetes-Erkrankung verschlechterte sich Richters Gesundheitszustand. Ab 1943 konnte er deshalb nur noch halbtags arbeiten. In der Nacht der Zerstörung Dresdens am 13./14.2.1945 traf ihn ein schwerer Schicksalsschlag - seine Wohnung wurde komplett zerstört, seine Frau Eva, geb. Helbig, eine Bibliothekarin, die er 1928 in zweiter Ehe geheiratet hatte, ${ }^{3}$ wurde auf der Flucht in den Großen Garten durch Bombensplitter getötet. Richter erlitt einen Nervenzusammenbruch. Im März 1945 stellte er einen Antrag auf Verset-

Vgl. Deckert 1987, S. 100, SLUB, Mscr.Dresd.App.2600,A1.

Jammers 2002, S. 312. Unklar bleibt, was für ein Konflikt dies war.

In erster Ehe war Hubert Richter 1916-1925 mit Klara Elisabeth, geb. Bürkner, verheiratet. 
zung in den vorzeitigen Ruhestand. Mit dessen Bewilligung endete seine Tätigkeit an der Landesbibliothek am 30. April 1945.

Vermutlich aufgrund der geringen Höhe seiner Pensionsbezüge erklärte sich Richter im Herbst 1945 wieder für dienstfähig. Im November 1945 nahm er die Tätigkeit als Leiter der Zentralbücherei der Landesregierung Sachsen (vormals Bücherei der Landesregierung) auf, die er bis zu seinem Tod fortführte. Die sofortige Wiedereinstellung Richters im Herbst 1945 war möglich, weil dringend Fachkräfte gesucht wurden und er kein NSDAP-Mitglied gewesen war, weshalb er sich keinem langwierigen Entnazifizierungsverfahren unterziehen musste. Allerdings war Richter von 1931 bis zu dessen Auflösung 1934 Mitglied des Stahlhelms. Auch zählte er zu den Mitgliedern des NSV und NSLB. ${ }^{4}$ Zuvor hatte er von 1928 bis zu ihrer Auflösung im Rahmen der „Gleichschaltung“ Ende Juni 1933 der linksliberalen Deutschen Demokratischen Parteien (ab 1930 Deutsche Staatspartei) angehört. 1945 trat er der Liberal-demokratischen Partei Deutschlands bei. Hubert Richter beschrieb sich als „Gegner der Naziregierung“, er sei ein „logisch

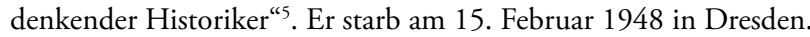

\section{Auswahlbibliografie}

Die Verhandlungen über die Aufnahme der Reformierten in den Religionsfrieden auf dem Friedenskongreß zu Osnabrück 1645-48, (Leipzig, Univ., Diss., 1906).

Reise König Friedrich Augusts II. von Sachsen nach Kroatien und Dalmatien im Jahre 1845. Nach d. bisher unveröffentl. Reisejournal seines Flügeladjutanten, in: Neues Archiv für sächsische Geschichte, Bd. 35, 1914, S. 113-124.

Bismarck in der historischer Literatur seit 1898, Leipzig, Berlin 1915.

Generalregister über die Literatur der Jahre 1909-1917. T. 1-3 Literatur der Landes- und Volkskunde und Geschichte des vormaligen Königreichs Sachsen, Dresden 1919 (mit Paul Emil Richter).

Aus kritischen Tagen. Berichte des Königl. Sächs. Gesandten in Berlin, Graf Hohenthal und Bergen, aus dem Jahre 1889-1890, in: Deutsche Rundschau, 5, 1922, S. 151-172.

Sachsen und Bismarcks Entlassung, Dresden 1928.

Aus der Geschichte der Sächsischen Landesbibliothek, in: Zentralblatt für Bibliothekswesen, 63, 1936, S. 519-531.

Georg Friedrich Alfred von Fabrice, in: Sächsische Lebensbilder, Bd. 2, Leipzig 1938, S. 70-96.

\section{Quellen und Literatur}

HStA Dresden, 13859, Nr. 6906

HStA Dresden, 19117, Karton 2011 PA Hubert Richter

SLUB, PA Richter, Hubert

Habermann, Alexandra, Klemmt, Rainer u. Frauke Siefkes: Lexikon Deutscher Wissenschaftlicher Bibliothekare 1925-1980, Frankfurt a. M. 1985, S. 275 f.

Hermann, Konstantin: Richter, Hubert, in: Sächsische Biografie, 2011, Online-Ausgabe: http:// saebi.isgv.de/biografie/Hubert_Richter_(1882-1948), Zugriff: 2.1.2020.

4 Vgl. HStA Dresden, 19117, Karton 2011 PA Hubert Richter. Konstantin Hermann beschreibt Richter hingegen als „nicht Mitglied nationalsozialistischer Vereine“ - Hermann, Konstantin: Richter, Hubert, in: Sächsische Biografie, 2011, Online-Ausgabe: http://saebi.isgv.de/biografie/Hubert_ Richter_(1882-1948), Zugriff: 2.1.2020.

5 Ebd. 


\section{EBERHARD RIMANN}

25.8.1882 Hirschberg/Schlesien - 15.5.1944 Dresden Geologe, Mineraloge

Museum für Mineralogie, Geologie und Vorgeschichte

(ab 1.4.1938: Museum für Mineralogie und Geologie)

1920-31.3.1943 Direktor

(Erkrankung 14.9.1940-30.4.1941, 16.7.1942-31.3.1943)

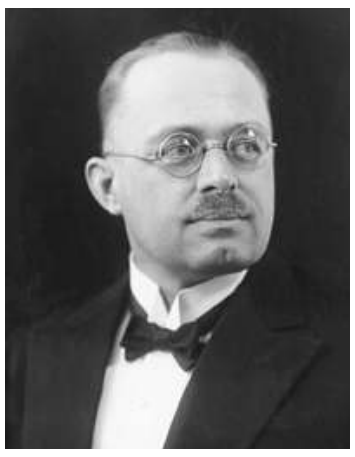

Eberhard Rimann wurde am 25. August 1882 im schlesischen Hirschberg geboren. Nach der 1902 in Hirschberg bestandenen Reifeprüfung studierte er an den Universitäten in Tübingen und Leipzig sowie an der Bergakademie Freiberg Geologie und Mineralogie. 1906 wurde er in Leipzig promoviert, außerdem legte er in Freiberg die Prüfungen zum Markscheider und Bergingenieur ab. Nach einer einjährigen Assistenz am Geologischen Institut der Bergakademie Freiberg wechselte Rimann 1909 als Assistent an das Mineralogisch-Geologische Institut der Technischen Hochschule in Dresden, wo er sich 1910 habilitierte. In den nachfolgenden zwei Jahren war er als Geologe und Bergingenieur für die Metallurgische Gesellschaft Frankfurt a. M. (Hanseatische Minengesellschaft) in Deutsch-Südwestafrika tätig. Ab 1912 arbeitete er als Chefpetrograph der Brasilianischen Geologischen Landesanstalt in Rio de Janeiro. Von 1916 bis 1919 erforschte er in Argentinien für die Academia Nacional de Ciencias Diamantvorkommen und Erzlagerstätten.

Nach seiner Rückkehr nach Deutschland wurde Rimann 1920 als Nachfolger von Ernst Kalkowsky zum Professor für Mineralogie und Geologie an der Technischen Hochschule in Dresden berufen. Im Nebenamt oblag ihm damit die Leitung des Museums für Mineralogie, Geologie und Vorgeschichte in Dresden. Rimann engagierte sich im Bund der deutschen naturwissenschaftlichen Museen, der Abteilung B des Deutschen Museumsbundes, und trat dafür ein, dass „die naturkundliche Sektion des Museumsbundes als völlig gleichberechtigt neben die histo-

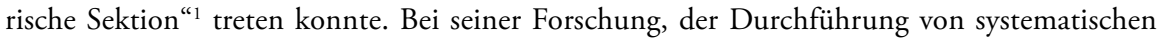
Untersuchungen über die qualitative und quantitative Verbreitung wirtschaftlich wichtiger Schwermineralien in sächsischen Gesteinen, wurde er in den 1930er-Jahren durch die Deutsche Forschungsgemeinschaft und den Reichsforschungsrat finanziell unterstützt. Rimann zählte zu den Personen, die 1933 das „Bekenntnis der Professoren an den deutschen Universitäten und Hochschulen zu Adolf Hitler und dem nationalsozialistischen Staat ${ }^{\text {“2 }}$ unterzeichneten. Allerdings stellte er erst im August 1937 einen Aufnahmeantrag in die NSDAP. Parteiamtliche Tätigkeiten Rimanns sind nicht überliefert. Stattdessen engagierte er sich wissenschaftlich-praktisch in seinem Fachgebiet, wobei er durch die Wahl der Themen, wie Erkundung von Ressourcen und Erschließung von Rohstoffen, seine Arbeit in den Dienst des NS-Staates stellte. Obwohl

1 Rimann an Zimmer, Zoologisches Museum der Universität Berlin, 13.3.1928, SMB-ZA III/ DMB 003, o. Pag.

2 Nationalsozialistischer Lehrerbund Deutschland/Sachsen 1933, S. 312. 
Rimann primär Professor und Hochschullehrer war, betrachtete er die Museumsarbeit keineswegs als Nebenamt. In seiner Amtszeit als Direktor kam es zu einer umfassenden Modernisierung des Museums für Mineralogie, Geologie und Vorgeschichte und zu einer Öffnung hin zum Publikum. Dies war möglich, weil es Rimann gelang, aus seiner Schülerschaft zwei hervorragende Fachwissenschaftler mit Interesse an museologischen Aufgaben als Museumsmitarbeiter zu gewinnen $-\triangleright$ Walther Fischer und $\gg$ Walter Häntzschel. Doch ab Herbst 1940 verschlechterte sich Rimanns Gesundheitszustand zusehends. In den Folgejahren musste er sich mehreren Operationen unterziehen, wofür er von der Arbeit freigestellt wurde. Mehrfach schlug er vor, seine beiden Dienstaufgaben - das Ordinariat für Mineralogie und Geologie an der Technischen Hochschule sowie das Direktorat am Museum für Mineralogie und Geologie - voneinander zu trennen und ihn von der Museumsleitung zu entbinden sowie Walther Fischer als seinen Nachfolger einzusetzen, der ebenfalls über gute Beziehungen zur Wirtschaft und Industrie verfügte. Doch erst Anfang April 1943 wurde die Trennung der Museumsleitung vom Ordinariat durch das Ministerium für Volksbildung bestätigt und Rimann mit Wirkung vom 31. März 1943 von seinem Nebenamt als Museumsdirektor entbunden. ${ }^{3}$

Als Ordinarius für Mineralogie und Geologie verblieb Rimann im Amt und stellte weitere Förderanträge für Forschungsprojekte. Doch aufgrund seiner fortschreitenden Erkrankung musste er die bereits bewilligten Gelder 1944 zurückgeben. Eberhard Rimann starb am 15. Mai 1944 in Dresden.

\section{Auswahlbibliografie}

Beitrag zur Kenntnis der Diabase des Fichtelgebirges, im besonderen des Leukophyrs Gümbels, Stuttgart 1906 (Zugl. Leipzig, Univ., Diss., 1906).

Der geologische Bau des Isergebirges und seines nördlichen Vorlandes, in: Jahrbuch der Königl. Preuß. Geologischen Landesanstalt, 1910, Teil 1, H. 3, S. 482-533 (Zugl. Dresden, Univ., Habil., 1910).

Geologische Karte des Khauas-Hottentottenlandes in Deutsch-Südwestafrika (Westliche Kalahari), Berlin 1913.

Geologische Untersuchungen des Bastardlandes in Deutsch-Süd-Westafrika, Berlin 1915.

Festschrift für Richard Baldauf, den unermüdlichen Förderer der mineralogischen Wissenschaft, zu seinem 80. Geburtstag am 7. März 1928, Sitzungsberichte und Abhandlungen der Naturwissenschaftlichen Gesellschaft Isis, Dresden e. V., Dresden 1928 (Hg.).

Die geologischen Ergebnisse des Tharandter Stollenbaus, in: Mitteilungen aus dem Museum für Mineralogie, Geologie und Vorgeschichte zu Dresden, Bd. 19, 1931.

Das Lausitzer Massiv, in: Zeitschrift der deutschen geologischen Gesellschaft, 86, 1934, S. 509-534.

Museum für Mineralogie, Geologie und Vorgeschichte, Dresden 1937.

Nephrit, Carcaro und Asbest im ostthüringisch-vogtländischen Schiefergebirge, in: Mitteilungen aus dem Staatlichen Museum für Mineralogie und Geologie zu Dresden, Bd. 43, 1938.

Ernst Kalkowsky, sein Leben und sein Werk, in: Mitteilungen aus dem Staatlichen Museum für Mineralogie und Geologie zu Dresden, Bd. 61, 1940, S. 69-95.

3 Vgl. SMV an Rimann, Museum für Mineralogie und Geologie, 7.4.1943, HStA Dresden, 13843, Nr. 267, fol. 136. Prescher 1956, S. 58 erwähnt fälschlicherweise den 31.3.1941 als Tag des Niederlegens des Museumsdirektorates durch Rimann. 


\section{Quellen und Literatur}

HStA Dresden, 13843, Nr. 267

SKD Archiv, 01/PS 53, Bd. 3

BArch, R 9361-VI/2478

BArch, R 9361-IX/Kartei/34920897; R 9361-VIII/Kartei/16890160

Prescher, Hans: Eberhard Rimann 1920-1944, in: Dresdner wissenschaftliche Museen. Beiträge zur 750-Jahr-Feier unserer Stadt, Dresden 1956, S. 56 ff.

Petschel, Dorit: 175 Jahre TU Dresden. Band 3: Die Professoren der TU Dresden 1828-2003. Hrsg. im Auftrag der Gesellschaft von Freunden und Förderern der TU Dresden e. V. von Reiner Pommerin, Köln u. a. 2003, S. 779 f. 


\section{Anneliese Rohne}

$>$ Anneliese Hanisch 


\section{EduARD SAMTLEBEN}

23.9.1876 Hamburg - 26.7.1937 Dresden

Restaurator

Kupferstich-Kabinett

1.4.1901-7.1937 Restaurator

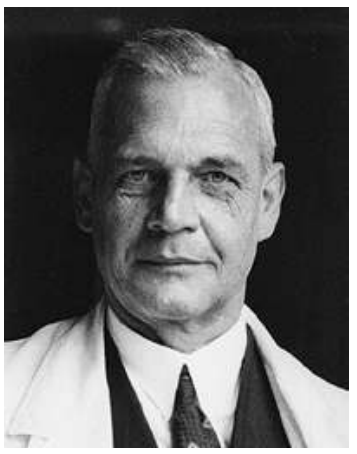

Obwohl Eduard Heinrich August Samtleben über 35 Jahre als Restaurator am KupferstichKabinett in Dresden tätig war, sind nur sehr wenige biografische Angaben überliefert. Er wurde am 23. September 1876 als Sohn des Kastellans der Hamburger Kunsthalle Karl Heinrich Christian Samtleben und dessen Frau Auguste Karoline, geb. Döring, vermutlich in Hamburg geboren. Er hatte fünf Geschwister und war mit Elsa Ida, geb. Winkler, verheiratet.

Seine Tätigkeit als erster festangestellter Restaurator am Kupferstich-Kabinett begann Samtleben im April 1901, nachdem er als Volontär bei Restaurator E. Hauser am Kupferstichkabinett in Berlin eine Ausbildung erhalten hatte. In Dresden bestand seine Aufgabe im Restaurieren und Montieren von Zeichnungen und grafischen Blättern und in der Vorbereitung von Ausstellungen. Ab 1909 wurde er dabei teilweise vom als Aufseher eingestellten Buchbinder > Max Hahn unterstützt. Noch im Berufsleben stehend, starb Eduard Samtleben am 26. Juli 1937 im Alter von 60 Jahren in Dresden.

\section{Quellen und Literatur}

Landeshauptstadt Dresden, Stadtarchiv, Personenstandsregister, Sign. 6.4.25

Restaurator Eduard Samtleben †, in: Dresdner Neueste Nachrichten, 28.7.1937, S. 4.

Restaurator Samtleben $\dagger$, in: Dresdner Anzeiger, 29.7.1937.

Datenbankeintrag Eduard Samtleben, https:/www.geni.com/people/Eduard-Samtleben/ 6000000076678590848, Zugriff: 4.12.2019.

Simon, Olaf: Zur Geschichte der Restaurierung im Kupferstich-Kabinett, in: Dresdener Kunstblätter, H. 1, 2004, S. 47-52, hier: 49. 


\section{Curt Sander}

29.6.1884 Dresden - 11.10.1949 Dresden

Tapezierer, Konservator

Historisches Museum

1.7.1922-31.3.1934 Sammlungsaufseher

1.4.1934-30.9.1938 Sammlungshandwerker

1.10.1938-31.7.1946 Konservator

11.8.1944-5.1945 Depotverantwortlicher

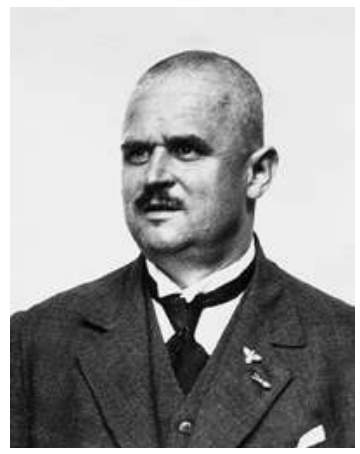

Am 29. Juni 1884 wurde Curt Max Theodor Sander als Sohn von Carl Friedrich Ernst Sander und Aurora Cäcilie Clara, geb. Kretzschmar, in Dresden geboren. Nach dem Abschluss der Volksschule erlernte er den Beruf des Tapezierers, in dem er zunächst, unterbrochen vom Militärdienst von 1904 bis 1906 und 1916 bis 1918, auch arbeitete. So war Sander, nachdem er im April 1910 Pauline Minna, geb. Fischer, heiratete, mit der er einen Sohn hatte, unter anderem von 1911 bis 1919 als Tapezierer beim Königlichen Hofmarschallamt beschäftigt. Danach arbeitete er bis Juni 1922 in den Reichsbahnwerken in Dresden-Friedrichstadt.

Ab Juli 1922 begann Sander seine Tätigkeit als Sammlungsaufseher im Historischen Museum, wo er auch in der Werkstatt arbeitete und am Umbau mitwirkte, indem er u.a. Vitrinen mit Satinrückwänden ausstattete und Polsterarbeiten übernahm. Im April 1934, nach der Beförderung von Richard Sattler zum Konservator, wurde Sander als dessen Nachfolger zum Sammlungshandwerker ernannt. Dies verwundert, da er im Vorjahr von seinem Kollegen, Hilfsaufseher Habich, denunziert worden war, weil er sich „vor dem Wahltag über Hitler und die Bewegung abfällig ausgesprochen "1 habe. Als sich abzeichnete, dass Konservator Sattler in den Ruhestand gehen würde, ließ das Ministerium für Volksbildung 1936 Sanders politische Zuverlässigkeit überprüfen. Die NSDAP-Kreisleitung Dresden stellte fest, dass diese „nicht einwandfrei“ und „ihm doch ein gewisser Widerstand nicht abzusprechen“ sei, damit sei eine „gewisse

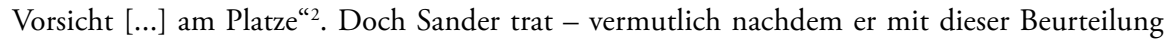
konfrontiert worden war - zum 1. Mai 1937 in die NSDAP ein. Im August 1938 berichtete die NSDAP-Gauleitung Sachsen, Sander „arbeitet aktiv mit“, „,g]egen die politische Zuverlässigkeit bestehen keine Bedenken“"3. Nun konnte Sander im Oktober 1938 zum Konservator befördert werden und Sattlers Stelle übernehmen. In dieser Funktion war er im Zweiten Weltkrieg für die sachgemäße Bergung der Objekte des Historischen Museums verantwortlich. Seiner Umsicht ist es zu verdanken, dass die wertvolle Textilsammlung den Krieg überstand. Im August 1943 war er für die Organisation der Bergung von Privateigentum der Mitarbeiter der Staatlichen Sammlungen zuständig. ${ }^{4}$ Knapp 60-jährig wurde er im Mai 1944 noch „kriegsverwendungsfähig“ gemustert, aber letztlich dann doch nicht zum Militärdienst eingezogen. Am 11. August 1944

\footnotetext{
Historisches Museum an SMV, 29.8.1933, HStA Dresden, 13859, Nr. 7305, fol. 2G.

NSDAP Kreisleitung Dresden an SMV, 7.7.1936, ebd., o. Pag.

NSDAP Gauleitung Sachsen an Leiter SMV, 12.8.1938, ebd.

Vgl. SMV, Fichtner, an Direktoren der Staatlichen Sammlungen, 20.8.1943, HStA Dresden, 12821, Nr. 426, fol. 106.
} 
benannte ihn $\triangleright$ Fritz Fichtner deshalb gegenüber dem Reichsstatthalter als „für den sachgemäßen Zustand der Depots verantwortlich" ${ }^{\text {". }}$. Regelmäßig weilte Sander daher zur konservatorischen Betreuung und Überprüfung der Objekte auf der Festung Königstein. Nach Kriegsende wurde er zunächst wegen seiner umfangreichen Bestandskenntnisse bei den Staatlichen Sammlungen weiterbeschäftigt. Doch zum 31. Juli 1946 wurde er aufgrund seiner früheren NSDAP-Mitgliedschaft entlassen. ${ }^{6}$

Ab April 1947 arbeitete Sander erneut für das Historische Museum, nun allerdings freiberuflich. Er sortierte die in Dresden verbliebenen Restbestände des Museums und wirkte an Aufbauarbeiten im Schloss Moritzburg und in der Gemäldegalerie in Schloss Pillnitz mit. Diese Tätigkeit, mit der er vermutlich vom Direktor der Staatlichen Kunstsammlungen $>$ Wolgang Balzer beauftragt worden war, endete im August 1948, als die Hauptverwaltung der Staatlichen Museen, Schlösser und Gärten einer Neueinstellung Sanders nicht zustimmte. ${ }^{7}$ Am 11. Oktober 1949 starb Curt Sander in Dresden.

\section{Quellen und Literatur}

HStA Dresden, 13859, Nr. 7305

Landeshauptstadt Dresden, Stadtarchiv, Personenstandsregister, Sign. 6.4.25

BArch, R 9361-IX/Kartei/36341634

5 SMV, Fichtner, an Reichsstatthalter Mutschmann, 11.8.1944, HStA Dresden, 11125, Nr. 23058, fol. $84 \mathrm{~b}$.

6 Vgl. Betriebsrat der Staatlichen Museen an das Ministerium für Volksbildung, Abt. Kunst und Literatur, 28.4.1948, SKD Archiv, 02/VA 172, fol. 154.

7 Vgl. Direktor der Staatlichen Kunstsammlungen, Balzer, an Sander, 3.1.1949 u. Hauptverwaltung Staatliche Museen, Schlösser und Gärten an Balzer, 28.8.1948, SKD Archiv, 02/VA 41, Bd. 2, fol. $267,271 \mathrm{v}$. 


\title{
ReINHARd SCHMELZER
}

\author{
30.8.1874 Reichenau/Sa. - [?] \\ Inspektor \\ Kunstgewerbemuseum \\ 1.11.1892-31.12.1907 Assistent \\ 1.1.1908-31.5.1937 Inspektor \\ 1.1940-9.1945 Inspektor \\ 11.8.1944-5.1945 Depotverantwortlicher
}

Obwohl Reinhard Schmelzer fünf Jahrzehnte am Kunstgewerbemuseum in Dresden tätig war, sind nur wenige Angaben zu seiner Biografie überliefert. ${ }^{1}$ Er wurde am 30. August 1874 in Reichenau/Sa. als Sohn des Karl Johann Schmelzer und der Amalie Auguste, geb. Trenkler, geboren.

Seine Tätigkeit am Kunstgewerbemuseum, das damals noch als Studiensammlung zur Akademie für Kunstgewerbe zählte, begann Schmelzer 1892 als Assistent. Zum Jahresbeginn 1908 wurde er zum Inspektor ernannt. Wenige Monate später, im April 1908, heiratete er in Dresden Elisabeth Johanna, geb. Klopfleisch. Als Inspektor im Kunstgewerbemuseum war er für die Inventarisation der Objekte, für die Kartothek, die Führung der Bücher und die Organisation des Leihverkehres verantwortlich. Er hatte den Zustand der Schausammlung zu überprüfen, den Besucherverkehr zu regeln und Führungen durch die Sammlung abzuhalten. Im Laufe der Jahre entwickelte er sich zu einem Spezialisten für Textilien. Im Alter von 62 Jahren beantragte Schmelzer im Januar 1937 seine Pensionierung zu Ende Mai 1937, die genehmigt wurde. Seinen Ruhestand konnte er allerdings nur kurz genießen. Infolge des Aufrufs an Pensionäre, sich nach Kriegsbeginn ihren ehemaligen Arbeitgebern wieder zur Verfügung zu stellen, der Anfang September 1939 in der Presse veröffentlicht worden war, kehrte Schmelzer, von Direktor $>$ Fritz Fichtner angefordert, pflichtbewusst wieder in seine alte Tätigkeit im Kunstgewerbemuseum zurück. Zunächst arbeitete er ehrenamtlich, denn das Sächsische Ministerium für Volksbildung fand erst im Januar 1940 eine Möglichkeit, ihn erneut anzustellen. ${ }^{2}$ Schmelzer übernahm die Organisation des technischen Museumsbetriebes, musste „die erforderlichen Museumsführungen durchführen und das zum großen Teil geborgene Museumsgut - soweit sich dies ermöglichen lässt - den Studierenden und sonstigen Museumsinteressierten [...] vorführen " ${ }^{\text {"3 }}$. So lobte Fichtner im Jahresbericht 1941/1942 anerkennend, dass Schmelzer „unverdrossen und sachkundig das Museum über dieses Kriegsjahr gebracht hat und dem Leiter des Museums jederzeit eine zuverlässige Stütze war“ “4 . Da Fichtner aufgrund seiner vielen Verantwortlichkeiten nur selten im

1 Die Personalakte wurde im November 1936 vom Kunstgewerbemuseum an die Akademie für Kunstgewerbe übergeben. Dort, d.h. im Archiv der Hochschule für Bildende Künste Dresden, wo deren Akten aufbewahrt werden, ist sie nicht erhalten. Siehe Akademie für Kunstgewerbe an Kunstgewerbemuseum, 20.11.1936, SKD Archiv, 01/KGM 14, fol. 110.

2 Siehe S. 61 f. Vgl. Einträge im Posteingangsbuch, 6.10.1939 u. 11.11.1939, SKD Archiv, 01/ KGM 2, 1939, E.-Nr. 390, 419 u. Direktion der Staatlichen Kunstsammlungen, Balzer, an Schmelzer, 22.11.1948, SKD Archiv, 02/VA 41, Bd. 2, fol. 286.

3 Kunstgewerbemuseum, Fichtner, an Leiter SMV, 10.11.1941, HStA Dresden, 13859, Nr. 4722, fol. $1 \mathrm{f}$.

4 Kunstgewerbemuseum, Jahresbericht 1941/1942, SKD Archiv, 01/KGM 11, fol. $27 \mathrm{c1}$. 
Kunstgewerbemuseum anwesend war, organisierte Schmelzer das Verpacken der Sammlungsobjekte und deren Transport zu den Auslagerungsorten. Am 11. August 1944 benannte ihn Fichtner deshalb auch gegenüber dem Reichsstatthalter als „für den sachgemäßen Zustand der Depots verantwortlich"5, obwohl Schmelzer, unterdessen 70-jährig, seit Mai 1944 nur noch halbtags beschäftigt war. Nachdem alle Objekte der Sammlung geborgen waren, reduzierte Schmelzer seine Arbeitszeit auf drei Tagen in der Woche. Auch nach Kriegsende arbeitete er noch am Museum, wirkte an den Rücktransporten von den Auslagerungsorten nach Dresden bzw. Pillnitz mit. Da er nach seinem erneuten Gesuch um Eintritt in den Ruhestand vom Mai 1945 noch immer keinen Bescheid erhalten hatte, sprach er deshalb am 26. September 1945 im Ministerium für Volksbildung vor. ${ }^{6}$ Ein Ergebnis des Gesprächs ist nicht bekannt, aber es bleibt anzunehmen, dass er im Herbst 1945 endgültig pensioniert wurde. Danach verliert sich seine Spur.

\section{Quellen und Literatur}

SKD Archiv, 01/KGM 11; 01/KGM 14; 01/KGM 15

SKD Archiv, 02/VA 53, Bd. 1 u. Bd. 2 (Einzeldokumente)

Landeshauptstadt Dresden, Stadtarchiv, Personenstandsregister, Sign. 6.4.25

5 SMV, Fichtner, an Reichsstatthalter Mutschmann, 11.8.1944, HStA Dresden, 11125, Nr. 23058, fol. 84b.

6 Vgl. Notiz Ministerium für Volksbildung, Gruve, 26.9.1945, HStA Dresden, 11125, Nr. 22886, fol. 64 . 


\section{RiCHARD SCHMIDT}

\subsubsection{Niederlößnitz - 17.6.1973 Dresden}

\section{Aufseher}

Porzellansammlung

[1.4.1936-31.1.1938 Wächter]

1.2.1938-5.1945 Aufseher

11.1944-5.1945 Depotverantwortlicher

Max Gustav Richard Schmidt wurde am 23. Dezember 1895 in Niederlößnitz als Sohn des Schuhmachers Friedrich Wilhelm Gustav Schmidt und dessen Frau Anna Marie Hedwig, geb. Wobst, geboren. Von Beruf war er Musiker. Nach dem Militärdienst während des Ersten Weltkrieges entschied er sich, ab März 1923 für zwölf Jahre beim Militär in Königsbrück und Altenburg zu dienen, u. a. in einem Musikkorps. Welche Tätigkeit er unmittelbar nach seiner Entlassung 1935 ausübte, ist nicht überliefert.

Vermutlich arbeitete Schmidt bereits ab April 1936 als Wächter in der Porzellansammlung in Dresden. Im Februar 1938 wurde er jedenfalls als Aufseher eingestellt. ${ }^{1}$ Nachdem er bereits während der „Sudetenkrise“ von der Einberufung zur Wehrmacht zurückgestellt worden war, ${ }^{2}$ beantragte Direktor $>$ Fritz Fichtner während des Zweiten Weltkrieges mehrfach erfolgreich eine Uk-Stellung für ihn, schließlich wurde er „zur Beaufsichtigung des Gebäudes, der Kontrolle der Depots, zur Aufrechterhaltung des täglichen Dienstbetriebes und zur Durchführung der Vorträge für Wehrmacht, Partei usw. benötigt " ${ }^{\text {"3 }}$. Einen Aufnahmeantrag in die NSDAP hatte Schmidt im Dezember 1939 gestellt, zum Januar 1940 wurde er Parteimitglied. Für einen Propagandamarsch der NSDAP am 30. Januar 1944 wurde seine Freistellung vom Museumsdienst beantragt. ${ }^{4}$ In der Porzellansammlung gingen seine Aufgaben weit über den Aufsichtsdienst hinaus. Aufgrund der vielfachen Verpflichtungen des Direktors stand die „Bergung der Schätze der Porzellangalerie [...] in letzter Zeit allein unter seiner Leitung“, darüber hinaus gehörte zu „seinen ständigen dienstlichen Verrichtungen [...] auch die Kontrolle der Außendepots"s. Im November 1944 wurde Schmidt die Verantwortung für die Porzellansammlung und ihre Auslagerungsdepots übertragen, nachdem sein Kollege, der Regierungsassistent $>$ Arthur Leuschner, diese aufgrund einer Erkrankung nicht mehr übernehmen konnte. ${ }^{6}$ Im März 1945 übernahm Schmidt Wachdienste am Auslagerungsort Festung Königstein. Vermutlich war er bis mindestens zum Kriegsende im Mai 1945 in der Porzellansammlung tätig.

\footnotetext{
Vgl. Leiter SMV an die Porzellansammlung, 8.2.1938, SKD Archiv, 01/PS 136, fol. 13.

Vgl. Porzellansammlung, Fichtner, an SMV, 9.8.1938, SKD Archiv, 01/PS 45, Bd. 1, fol. 20.

3 Porzellansammlung, Fichtner, an Leiter SMV, 24.10.1942, HStA Dresden, 11125, Nr. 22891, fol. 104 .

4 Im Posteingangsbuch ist ein entsprechender Brief von der NSDAP-Kreisleitung Dresden an die Porzellansammlung vermerkt. Vgl. SKD Archiv, 01/PS 143, Eintrag Nr. 19, 29.1.1944.

5 SMV, Fichtner, an Leiter SMV, 1.9.1942, SKD Archiv, 01/PS 53, Bd. 1, fol. 29-35, hier: 33.

6 Vgl. SMV, Fichtner, an Reichsstatthalter Mutschmann, 11.8.1944, HStA Dresden, 11125, Nr. 23058, fol. 84b.
} 
Über sein Leben nach dem Zweiten Weltkrieg waren keine Informationen zu ermitteln. Richard Schmidt starb am 17. Juni 1973 in Dresden.

\section{Quellen und Literatur}

HStA Dresden, 11125, Nr. 22891 (Einzeldokumente)

Stadtarchiv Radebeul, GR StAmt Kötzschenbroda 361/1895 u. Sammelakte

BArch, R 9361-IX/Kartei/38360060; R 9361-VIII/Kartei/19881712 


\section{Helmut Schneider}

27.4.1896 Dresden - 19.3.1945 Dresden

Wissenschaftlicher Bibliothekar

Sächsische Landesbibliothek

1.10.1922-30.9.1924 Volontär

1.4.1925-30.6.1926 außerordentlicher Wissenschaftlicher

Hilfsarbeiter

1.7.1929-31.10.1929 Wissenschaftlicher Hilfsarbeiter

1.11.1929-19.3.1945 Landesbibliothekar

(Militärdienst 27.8.1939-4.4.1940, 27.2.1945-19.3.1945)

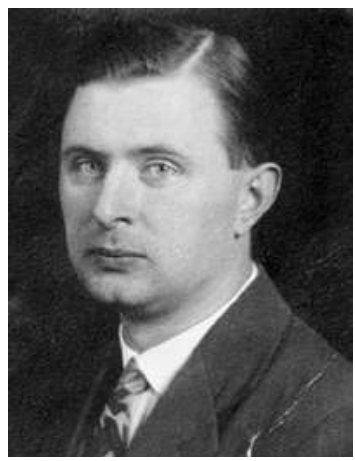

Als Sohn des Oberlehrers Moritz Richard Schneider und dessen Frau Helene Elisabeth, geb. Christmann, am 27. April 1896 in Dresden geboren, legte Helmut Richard Schneider seine Abiturprüfung am Wettiner Gymnasium ab, als der Erste Weltkrieg begann. Nach einem halbjährigen Freiwilligendienst als Kriegskrankenpfleger studierte er bis Oktober 1916 an den Universitäten in München, Jena und Leipzig Germanistik und Kunstgeschichte, bevor er als Soldat an die Westfront zog. Aus dem Militär entlassen, setzte Schneider ab Frühjahr 1919 sein Studium an den Universitäten in München und Leipzig fort. Nach seiner Promotion im November 1921 arbeitete er in einem Antiquariat, sein Ziel war jedoch eine Tätigkeit als Bibliothekar.

Ab Oktober 1922 war Schneider als Volontär an der Sächsischen Landesbibliothek Dresden tätig. Im September 1924 legte er die Prüfung für den Höheren Dienst an wissenschaftlichen Bibliotheken ab. Direktor $\gg$ Martin Bollert erkannte das berufliche Potential von Schneider und erwirkte für ihn eine befristete Stelle als außerordentlicher Wissenschaftlicher Hilfsarbeiter ab April 1925, die im Juli 1929 in eine Stelle für einen Wissenschaftlichen Hilfsarbeiter umgewandelt wurde. Vier Monate später wurde Schneider zum Landesbibliothekar ernannt. Er war Fachreferent für Kunst und Leiter der Lesesäale. ${ }^{1}$ Nach 1933 wurde er Mitglied im Opferring, im RDB und NSV, trat aber nicht in die NSDAP ein. Ein besonderer Schicksalsschlag traf ihn im Februar 1935 - seine Frau Irmgard, geb. Goldfriedrich, die er 1930 geheiratet hatte, starb wenige Tage nach der Geburt des gemeinsamen Sohnes. Obwohl er nun mit seinem Sohn allein war, wurde er Ende August 1939 zum Militär einberufen und in einer Nachrichtenabteilung in Prag eingesetzt. Infolge einer Erkrankung im April 1940 vom Militär entlassen, kehrte er an die Landesbibliothek zurück. Doch am 27. Februar 1945 wurde Helmut Schneider zum Volkssturm eingezogen. Nur zehn Tage später kam er ins Garnisonslazarett Dresden, wo er am 19. März 1945 infolge einer Lungenentzündung starb.

\section{Auswahlbibliografie}

Das Leben und Wirken Jakob Bernhard Eisentucks: ein Beitrag zur sächsischen Geschichte, (Leipzig, Univ., Diss., 1921) (Auszug veröffentlicht in: Jahrbuch der Philosophischen Fakultät zu Leipzig, 1922, S. 69-71).

1 Vgl. Deckert 1987, S. 104, SLUB, Mscr.Dresd.App.2600,A1. 


\section{Quellen und Literatur}

HStA Dresden, 13859, Nr. 8089

SLUB, PA Schneider, Helmut

Habermann, Alexandra, Klemmt, Rainer u. Frauke Siefkes: Lexikon Deutscher Wissenschaftlicher Bibliothekare 1925-1980, Frankfurt a. M. 1985, S. 304. 


\section{BRUNO SCHRÖDER}

25.10.1878 Rostock - 18.5.1934 Dresden

Klassischer Archäologe

Skulpturensammlung

1.8.1925-18.5.1934 Direktor

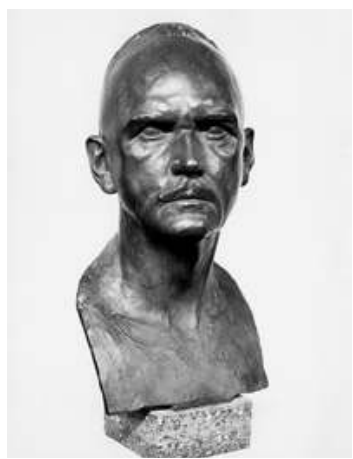

Walter Bruno Schröder wurde am 25. Oktober 1878 in Rostock als Sohn des Kaufmanns Hermann Benjamin Alexis Schröder und dessen Frau Martha Henriette Friederike, geb. Ludewig, geboren. Seine Schulbildung erhielt er in Rostock, wo er nach dem Abitur 1897 begann, Archäologie und Philologie zu studieren. Im zweiten Studienjahr, 1898, wechselte er an die Universität Bonn. Dort wurde er 1901 als Schüler von Georg Loeschcke promoviert, der seinerseits bei Reinhard Kekulé von Stradonitz studiert hatte. Dank eines Stipendiums des Deutschen Archäologischen Instituts konnte Schröder in den Jahren 1902 und 1903 für zwölf Monate Griechenland, Kleinasien und Italien bereisen. Dabei wirkte er kurzzeitig bei Ausgrabungsarbeiten im Gymnasion von Pergamon mit. Ab Oktober 1903 arbeitete er als Wissenschaftlicher Hilfsarbeiter an der Antikensammlung der Königlichen Museen zu Berlin. Im April 1905 wurde er zum Direktorialassistenten bei Kekulé von Stradonitz ernannt, 1918 zum Kustos und Professor. Schröder wirkte an der Neugestaltung der Ausstellung antiker Skulpturen im Alten Museum mit. Die von ihm erarbeitete Dokumentationskartei der Sammlung bildete später die Grundlage für den von Carl Blümel publizierten Bestandskatalog. Schröder selbst verfasste bereits damals diverse Führer zur Sammlung und publizierte rege im „Archäologischen Anzeiger“ und in „Der Kunstwanderer".

Im August 1925 folgte Schröder dem Ruf als Direktor der Skulpturensammlung in Dresden in Nachfolge von Paul Herrmann. Schröder vollzog eine Neuordnung und Modernisierung der Ausstellung, baute die klassizistische Abteilung der Sammlung aus und zeigte Interesse an zeitgenössischer Bildhauerkunst. Seine Hauptgebiete waren jedoch die griechische Malerei und Plastik des 5. Jahrhunderts v. Chr. und die Kunst des 19. Jahrhunderts. Als Honorarprofessor las er an der Technischen Hochschule Dresden Antike Kunstgeschichte. 1933 unterzeichnete Schröder das „Bekenntnis der Professoren an den deutschen Universitäten und Hochschulen zu Adolf Hitler und dem nationalsozialistischen Staat ${ }^{\text {"1 }}$, in die NSDAP trat er jedoch nicht ein. Er galt als ein auf seine Forschung und Arbeit konzentrierter „Gelehrter der alten Schule“, der „in Dresden außer bei seinen wissenschaftlichen Vorträgen und Führungen wenig in die Öffentlichkeit “ ${ }^{2}$ trat und ein empfindsames Wesen hatte. Am 18. Mai 1934 wählte Bruno Schröder den Freitod. Die Presse berichtete zwei Tage später, dass der Grund dafür „,nicht in dienstlichen Verfehlungen zu suchen ist“, sondern in „Erpressungen“ und dass „[i]n diesem Zusammenhange [...] ein hiesiger

Nationalsozialistischer Lehrerbund Deutschland/Sachsen 1933, S. 133.

2 Degen, Kurt: Bruno Schröder $\dagger$, in: DA, 19.5.1934, Abendausgabe, S. 2. 
Rechtsanwalt festgenommen und der Staatsanwaltschaft zugeführt worden “3 sei. Bereits Ende Juni 1933 fühlte sich Schröder wohl auch persönlich angegriffen, als die Gaufachgruppe der bildenden Künste der NSDAP die Integration der Werke von Gerhard Marcks in die Dauerausstellung der Skulpturensammlung kritisierte und forderte, diese zu entfernen. ${ }^{4}$

\section{Auswablbibliografie}

Studien zu den Grabdenkmaelern der roemischen Kaiserzeit, Bonn 1902 (Zugl. Bonn, Univ., Diss., 1901).

Thrakische Helme, in: Jahrbuch des Deutschen Archäologischen Instituts, Bd. 27, 1912, S. 317-344.

Mikon und Paionios, in: Jahrbuch des kaiserlich deutschen archäologischen Instituts, Bd. 29, H. 3, Berlin 1914, S. 124-168.

Griechische Gewandstatuen im alten Museum zu Berlin, in: Kunst und Künstler. Illustrierte Monatsschrift für bildende Kunst und Kunstgewerbe, Berlin, Bd. 13, 1915, S. 537-556.

Griechische Idealköpfe, in: Kunst und Künstler. Illustrierte Monatsschrift für bildende Kunst und Kunstgewerbe, Berlin, Bd. 20, 1922, S. 87-96, 136-144.

Anselm Feuerbach und die Antike, in: Jahrbuch der Preußischen Kunstsammlungen, Bd. 45, 1924, S. 85-111.

Die Erneuerung des Dresd. Zwingers, in: Der Große Garten. Wege und Ziele der Kunst und Kultur in Dresden 1925, Dresden 1925, S. 17-20.

Der Sport im Altertum, Berlin 1927.

Rietschel als Zeichner, in: Der Grosse Garten. Hundert Jahre Sächsischer Kunstverein. Jubiläums-Festschrift, Bd. 2, 1928, S. 168-172.

Einige Bildwerke aus der Staatl. Skulpturensammlung, in: Das Schöne Sachsen. Monatsschrift für sächsische Kultur, Wirtschaft und Verkehr, 1931, S. 134-136.

\section{Quellen und Literatur}

Archivauskunft, Stadtarchiv Rostock, 11.7.2019

Universität Rostock, Matrikelportal, http://purl.uni-rostock.de/matrikel/200005609 und http:// purl.uni-rostock.de/matrikel/200007738, Zugriff: 2.1.2020.

Degen, Kurt: Bruno Schröder †, in: Dresdner Anzeiger, 19.5.1934, Abendausgabe, S. 2.

Rodenwaldt Gerhart: Bruno Schröder †, in: Archäologischer Anzeiger, 1934, S. 314 f.

Heres, Huberta: Bruno Schröder zum 50. Todestag, in: Dresdener Kunstblätter, 28. Jg., H. 6, 1984, S. $187 \mathrm{ff}$.

Heres, Huberta: Bruno Schröder 1879-1934, in: Lullies, Reinhard u. Wolfgang Schiering (Hg.): Archäologenbildnisse. Porträts und Kurzbiografien von Klassischen Archäologen deutscher Sprache, Mainz 1988, S. 200 f.

Zum Tode von Prof. Schröder, in: DNa, 20.5.1934, S. 7 sowie DA, 20.5.1934, S. 7.

Vgl. Gaufachgruppe der bildenden Künste, Paul Lindau und Ernst Born, an die Skulpturensammlung, 27.6.1933; Gaufachgruppe der Bildenden Künste, Gasch, an die Direktion der Skulpturensammlung, 30.6.1933, SKD Archiv, 01/SKS 179, fol. 20 f. Siehe S. 140 f. 


\section{Franz Schubert}

9.9.1901 Dresden - [1945/1946 vermisst $]$

Kunsthistoriker

Kupferstich-Kabinett

15.11.1929-30.9.1930 Freiwilliger Wissenschaftlicher Hilfsarbeiter

1.10.1930-30.6.1931 Wissenschaftlicher Hilfsarbeiter

1.2.1933-31.7.1933 Freiwilliger Wissenschaftlicher

Hilfsarbeiter

1.10.1933-31.12.1933 Freiwilliger Wissenschaftlicher

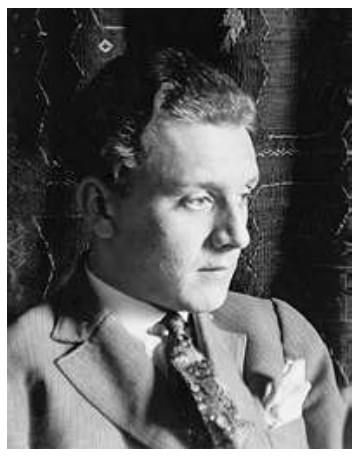

Hilfsarbeiter

1.9.1935-1945 Wissenschaftlicher Hilfsarbeiter

Gemäldegalerie

20.8.1931-31.1.1933 Freiwilliger Wissenschaftlicher Hilfsarbeiter

1.8.1933-30.9.1933 Freiwilliger Wissenschaftlicher Hilfsarbeiter

1.1.1934-20.4.1935 Freiwilliger Wissenschaftlicher Hilfsarbeiter

„Sonderauftrag Linz“

7.1939-5.1945 [?]

(Militärdienst ab 31.1.1944)

Am 9. September 1901 wurde Franz Georg Curt Schubert als Sohn des Konzertmeisters der Sächsischen Staatskapelle, Friedrich Louis Franz Schubert, und dessen Frau Juliane Antonie Luise, geb. Nehrhoff von Holderberg, in Dresden geboren. Nachdem er 1921 seine Reifeprüfung am König-Georg-Gymnasium abgelegt hatte, begann Schubert in München bei Heinrich Wölfflin Kunstgeschichte, Archäologie und Geschichte zu studieren. Im Mai 1923 wechselte er an die Universität in Berlin als Schüler von Adolph Goldschmidt, zwei Jahre später an die Universität Leipzig. Im Mai 1927 kehrte er nach München zurück, wo er im Juli 1929 als Schüler von Wilhelm Pinder promoviert wurde.

Ab November 1929 wurde Schubert als Freiwilliger Wissenschaftlicher Hilfsarbeiter am Kupferstich-Kabinett in Dresden angestellt, nicht zuletzt auch weil sich Pinder dafür verbürgte, „dass seine Annahme [...] kein Fehlgriff sein würde“, da er „schon eine Vorbildung gerade in Frage der graphischen Künste, die ihn zu einem wertvollen Mitarbeiter zu machen verspricht," habe und „als lauterer Charakter, als Mensch von ehrenhaften [sic!], fleissigen Streben in jeder Weise würdig "1 sei. Ab Oktober 1930 vertrat er für ein Jahr den Wissenschaftlichen Hilfsarbeiter $\triangleright$ Peter Halm, der als Stipendiat in Florenz weilte. Danach wechselte Schubert als Freiwilliger Wissenschaftlicher Hilfsarbeiter an die Gemäldegalerie, wo er bis zum April 1935 tätig blieb. Allerdings kehrte er von Februar bis Juli und von Oktober bis Dezember 1933, von der Nothilfe des Landesverbandes der Höheren Beamten Sachsens unterstützt, an das Kupferstich-Kabinett zurück, um an der Ausstellung „August der Starke und seine Zeit" mitzuarbeiten und die Neubearbeitung des topografischen Kataloges fortzusetzen. Vermutlich bereits neben seiner Tätigkeit an der Gemäldegalerie wirkte er, über einen Werkvertrag von der Deutschen Forschungsgemeinschaft

1 Pinder über Schubert, Abschrift, 11.10.1929, SKD Archiv, 01/KK 3, Bd. 8, fol. 94v. 
bezahlt, am kritischen Katalog der Sächsisch-Polnischen Architekturzeichnungen mit, den Eberhard Hempel an der Technischen Hochschule Dresden bearbeitete. Diese Tätigkeit setzte Schubert bis Ende August 1935 fort. Ab September 1935 erhielt er die Stelle als Wissenschaftlicher Hilfsarbeiter am Kupferstich-Kabinett, die durch die Berufung von Halm nach Karlsruhe frei wurde und für die er sich bereits im Mai beworben hatte. Der Vertragsunterzeichnung, die erst am 18. Oktober 1935 bei Direktor $\gg$ Kurt Zoege von Manteuffel stattfand, ging ein Gespräch von Oberregierungsrat Groß vom Sächsischen Ministerium für Volksbildung (SMV) mit Schubert voraus, denn es bestanden Zweifel an dessen politischer Einstellung, obwohl er schriftlich versichert hatte: „Ich erkläre, daß ich jederzeit rückhaltlos für den nationalsozialistischen Staat eintrete und eintreten werde. “2 Doch auch die Akademische Selbsthilfe hatte „keinen für diese Stelle fachlich erfahrenen Pg. ermitteln können, der sich in Berufsnot befindet“ und „aus dem Kreise der von ihr betreuten Jungakademiker ebenfalls Dr. Franz Schubert für die Stellenbesetzung empfohlen“"3. 1937 und 1938 bemühten sich sowohl Zoege von Manteuffel als auch $>$ Fritz Fichtner mehrfach vergeblich, Schubert die Stelle eines Kustos zuweisen zu können, insbesondere als Schubert das Angebot erhielt, Halm als Kustos nach Karlsruhe zu folgen. Trotz der Verzögerung der Beförderung und des zunehmenden politischen Drucks, der auf Schubert ausgeübt wurde, trat er nicht in die NSDAP ein und blieb in seiner Stellung als Wissenschaftlicher Hilfsarbeiter in Dresden. ${ }^{4}$ Er arbeitete unter anderem an der „Gedächtnisausstellung zum 200. Todestag von Matthäus Daniel Pöppelmann“ 1936 mit, für deren Katalog er einen Text schrieb. 1939 übernahm er zusätzlich die wissenschaftliche Leitung der vom „Heimatwerk Sachsen“ im Sächsischen Kunstverein Dresden gezeigten Ausstellung „Große Männer Sachsens“ und erarbeitete deren Katalog. Neben seiner Tätigkeit im Kupferstich-Kabinett zeichnete Schubert für die Herausgabe des 9. Bandes von Max Lehrs' „Geschichte und kritischer Katalog des deutschen, französischen und niederländischen Kupferstichs im 15. Jahrhundert" verantwortlich und arbeitete am von Otto Schmidt herausgegebenen „Reallexikon zur Kunstgeschichte“ mit. ${ }^{5}$ Als Direktor Zoege von Manteuffel im Januar 1941 plötzlich starb, übernahm Schubert die wissenschaftliche Verantwortung für das Kupferstich-Kabinett. Offensichtlich tolerierte Fichtner, dass Schubert das Kupferstich-Kabinett nun de facto leitete, obwohl er kein Parteimitglied geworden war. Eine offizielle Beauftragung ist nicht überliefert. Schubert selbst wies den Leiter des SMV im Herbst 1941 darauf hin, „dass mir bisher keinerlei schriftlicher Auftrag zur unmittelbaren Dienstaufsicht über die Gefolgschaft des Staatl. Kupferstichkabinetts zugegangen ist. Herr Prof. Dr. Fichtner hat mir lediglich gesprächsweise erklärt, dass ich seit dem Tode des Herrn Direktor von Manteuffel die wissenschaftliche Verantwortung, aber auch nur die wissenschaftliche, für das Kabinett trüge und Herr Direktor Dr. Posse hat mir bei Erhalt seines Auftrages zur stellvertretenden Übernahme des Direktorates des Kupferstichkabinetts erklärt, dass ich selbstverständlich alle

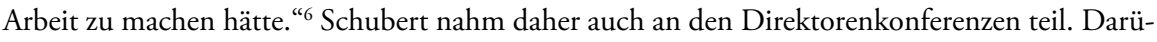
ber hinaus übernahm er Katalogisierungsarbeiten für die grafische Sammlung des „Sonderauftrags Linz“. Im Januar 1942 wurde er zum „Sachverständigen für Graphik“ ernannt, um Posse in

Schubert, 29.8.1935, HStA Dresden, 11125, Nr. 22889, fol. 11.

SMV, Groß, an den Reichsstatthalter, 19.9.1935, ebd., fol. 19.

Siehe hierzu S. $93 \mathrm{f}$.

Vgl. Fichtner, Bericht über Maßnahmen zur Wahrnehmung der Dienstaufsicht, KupferstichKabinett, 31.3.1941, SKD Archiv, 01/PS 53, Bd. 1, fol. 179 f., hier: 180.

6 Kupferstich-Kabinett, Schubert, an Leiter SMV, 22.9.1941, HStA Dresden, 11125, Nr. 22889, fol. $97 \mathrm{f}$. 
dieser Funktion bei der Reichskammer der bildenden Künste vertreten zu können. Ebenfalls 1942 wurde Schubert „mit der Durchführung der Bergungsmaßnahmen im Schloß Weesenstein "7 beauftragt, nachdem er bereits in die Auswahl und Vorbereitung des Schlosses Weesenstein als Auslagerungsort involviert gewesen war. In Absprache mit Fichtner erarbeitete Schubert die Dienstvorschrift für das Wachpersonal. Regelmäßig, meist zweimal wöchentlich, fuhr er zur Inspektion nach Weesenstein. Aufgrund seiner Verantwortung für die Bestände des Kupferstich-Kabinetts und der Wichtigkeit ihrer Bergung wurde Schubert mehrfach uk-gestellt. Auch waren ihm „im Einverständnis mit dem Führer die millionenschweren und reichen Bestände der graphischen Sammlung des Führermuseums zur Aufbewahrung und Sicherung übergeben worden"8. Als Anfang November 1943 erneut seine Einberufung drohte, erwirkte Fichtner letztmalig eine Zurückstellung. ${ }^{9}$ Am 16. Januar 1944 konnte Schubert im Rahmen der sonntäglichen Museumsvorträge noch über „Altdeutsche Graphik und ihre Beziehungen zur Plastik des 15. und 16. Jahrhunderts" sprechen, Ende Januar 1944 wurde er zum Militärdienst eingezogen. Im August 1944 wurde er nochmals für zwei Wochen von der Front beurlaubt, um die geborgenen Werke des Kabinetts zu kontrollieren.

Nach dem Kriegsende war es vorgesehen, Schubert aufgrund seiner umfassenden Bestandskenntnisse als Kustos an das Kupferstich-Kabinett in Dresden zurückzuholen, doch seine ehemalige Kollegin - Ragna Enking berichtete im Januar 1946, dass er sich in Kriegsgefangenschaft befinde. ${ }^{10}$ Damit verliert sich seine Spur. Franz Schubert muss seit 1945/1946 als kriegsbedingt vermisst gelten.

\section{Auswablbibliografie}

Mair von Landshut. Ein niederbayerischer Stecher und Maler des ausgehenden XV. Jahrhunderts, in: Verhandlungen des Historischen Vereins für Niederbayern, Bd. 63, 1930 (Zugl. München, Univ., Diss., 1929).

Sachsen - Mittelpunkt der deutschen Romantik. Die romantische Landschaftsmalerei, in: Das Schöne Sachsen, 6, 1936, S. 90-92.

Matthes Daniel Pöppelmann und der „Grand Salon“ im Sächsischen Garten zu Warschau, in: Zeitschrift des Deutschen Vereins für Kunstwissenschaft, 7, 1940, S. 267-285.

Zeichnungensammlung dt. Romantiker im Staatl. Kupferstichkabinett, in: Das ist Dresden, 1942, S. 36-37.

\section{Quellen und Literatur}

HStA Dresden, 11125, Nr. 18964; Nr. 22889

SKD Archiv, 01/KK 3, Bd. 8; Bd. 9

Historisches Archiv der Sächsischen Staatstheater, NL Franz Schubert, 30, 175

Ludwig-Maximilians-Universität München: Abgeschlossene Dissertationen am Institut für Kunstgeschichte 1873-2001, www.kunstgeschichte.uni-muenchen.de/forschung/diss_abgeschl/ index.html, Zugriff: 4.12.2019.

\footnotetext{
7 Leiter SMV an Landrat des Kreises Pirna, 4.8.1942, SKD Archiv, 01/KK 17, Bd. 1, fol. 108v.

8 Kupferstich-Kabinett, i.V. Posse, an Leiter SMV, 29.8.1942, HStA Dresden, 11125, Nr. 22889, fol. 122 .

9 Siehe S. $64 \mathrm{f}$.

10 Vgl. Enking an Hartlaub, 6.1.1946, SKD Archiv, 02/VA 166, fol. 20.
} 


\section{Elfriede Schulze-BattMann}

18.2.1910 Berlin-Schöneberg - 11.3.2001 Freiburg i. Br. Kunsthistorikerin

Historisches Museum und Grünes Gewölbe

1.11.1937-31.10.1938 Freiwillige Wissenschaftliche Hilfsarbeiterin

1.4.1939-9.1939 Freiwillige Wissenschaftliche

Hilfsarbeiterin

(Beurlaubung an „Heimatwerk Sachsen“ 16.5.1938-10.1938,

1.4.1939-9.1939)

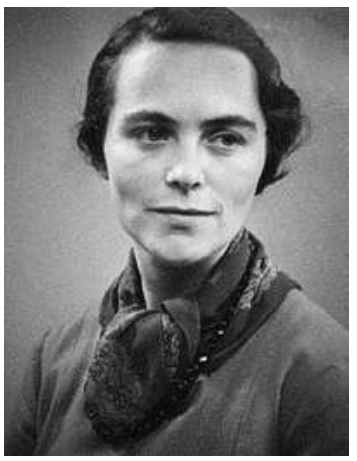

Eva Erika Elfriede Schulze-Battmann wurde am 18. Februar 1910 in Berlin-Schöneberg als Tochter des Juristen und Berliner Regierungsbeamten Dr. jur. Alfred Schulze und dessen Frau Eva, geb. Battmann, geboren. Als der Vater 1919 zum Ministerialdirektor und Chef der Staatskanzlei in den sächsischen Staatsdienst berufen wurde, zog die Familie nach Dresden um. Nachdem Schulze-Battmann 1929 ihre Abiturprüfung in Dresden bestanden hatte, studierte sie an den Universitäten in München, Leipzig, Zürich, Lille und Rom Romanistik, Kunstgeschichte und Archäologie. Im April 1936 wurde sie bei Wilhelm Pinder in München promoviert. Bereits vorher, von März 1934 bis Januar 1935, war sie als Sekretärin beim DAAD in Berlin tätig. Im Sommer 1936 arbeitete sie an der „Olympischen Kunstausstellung“ mit, die in Berlin-Charlottenburg gezeigt wurde. Ihre Bewerbung als Freiwillige Wissenschaftliche Hilfsarbeiterin an den Staatlichen Sammlungen in Dresden im November 1936 scheiterte. Doch nach ihrer zweiten Bewerbung im Mai 1937 wurde sie zunächst von Mai bis September 1937 im Büro der im Stallhof veranstalteten „Turnierspiele“ angestellt. ${ }^{1}$

Ab November 1937 arbeitete Schulze-Battmann als Freiwillige Wissenschaftliche Hilfsarbeiterin am Historischen Museum und Grünen Gewölbe. Ursprünglich war dafür ein Jahr vorgesehen, doch bereits im Mai 1938 wurde sie beurlaubt, um für das „Heimatwerk Sachsen“ an der Schau „Sachsen am Werk“ mitzuarbeiten. Da sie für das „Heimatwerk Sachsen“ weitere Aufgaben übernahm und auch noch längere Zeit erkrankt war, bat sie um eine Verlängerung der Volontariatszeit, die ihr zunächst für den Sommer 1939 gewährt wurde. Doch im April und Mai 1939 arbeitete sie stattdessen an der Ausstellung „Große Männer Sachsens“ des „Heimatwerks Sachsen“ mit. Als sie ihre Arbeit an den Staatlichen Sammlungen erneut verschieben wollte, forderte - Fritz Fichtner als Referent der Sammlungen eine klare Entscheidung von ihr, denn „vom Museumsnachwuchs fordern wir zunächst eine intensive Beschäftigung im Museum selbst mit ungeteiltem Interesse ${ }^{\text {"2 }}$. Schulze-Battmann entschied sich im September 1939 für die Zusammenarbeit mit dem „Heimatwerk Sachsen“. Aus den Staatlichen Sammlungen, wo sie abzüglich der Beurlaubungen insgesamt nur fünf Monate tätig gewesen war, schied sie aus.

Die Arbeit für das „Heimatwerk Sachsen“ setzte sie bis Juni 1942 fort. In dieser Zeit bewarb sie sich noch zweimal erfolglos als Wissenschaftliche Hilfsarbeiterin an den Staatlichen Sammlungen Dresden. Inwiefern sie sich mit den nationalsozialistischen Zielen des „Heimatwerks Sach-

Siehe S. 192 f.

2 SMV, Fichtner, an Schulze-Battmann, 19.7.1939, HStA Dresden, 11125, Nr. 18964, fol. 445. 
sen" identifizierte, ist bisher nicht abschließend zu beurteilen. Primär galt ihr Interesse kulturellen Themen. Sie trat weder in die NSDAP ein noch engagierte sie sich politisch. Davon zeugt eine Beurteilung von 1936, in der die NSDAP-Kreisleitung Dresden festhielt: „Würde sie stark bejahend für unsere Bewegung eintreten, wäre sie gewiß bei allen Kundgebungen anwesend. [...] Der Hitlergruß ist ihr nicht geläufig und [sie] muß erst daran erinnert werden. ${ }^{\text {"3 }} 1942$ wechselte Schulze-Battmann als wissenschaftliche Angestellte zur Generaldirektion der Oberrheinischen Museen in Straßburg, wo sie unter Kurt Martin die wissenschaftliche Bearbeitung der mittelalterlichen Glasfenster übernahm, die im Rahmen des Kunstschutzes in elsässischen Kirchen geborgen worden waren. 1944 floh ihre Abteilung vor der heranrückenden Front und blieb an einem Bergungsort am Bodensee. Anfang 1946 ging sie von dort nach Freiburg i. Br. an das Landesamt für Museen, Sammlungen und Ausstellungen. Für dieses und das Landesamt für Denkmalpflege und Heimatschutz arbeitete sie bis zu ihrer Pensionierung 1975. Nach der Sicherung und Rückführung des ausgelagerten Kunstgutes zählte die Denkmalsicherung zu ihren Aufgaben. Auch initiierte sie in Freiburg i. Br. Ausstellungen moderner Kunst, die ersten nach der Diffamierung der Moderne durch die Nationalsozialisten, wie zum Beispiel „Die Meister französischer Malerei der Gegenwart" 1947. Nach dem Krieg konnte sie auch wieder Kontakt zu ihrem in Paris lebenden Bruder, dem Künstler WOLS (Wolfgang Schulze), aufnehmen. Nach dessen frühem Tod 1951 engagierte sie sich für seine künstlerische Anerkennung. Ihr denkmalpflegerisches Engagement setzte sie auch nach der Pensionierung fort. Elfriede Schulze-Battmann starb am 11. März 2001 in Freiburg i. Br.

\section{Auswablbibliografie}

Giuseppe Valadier, ein klassizistischer Architekt Roms 1762-1839 (München, Univ., Diss., 1936).

Wols, München 1959.

Die heimatgeschichtlichen Sammlungen der Stadt Gengenbach, in: Nachrichtenblatt der Denkmalpflege in Baden-Württemberg, 3, 1960, S. 71-73.

Alte evangelische Kirche St. Nikolaus in Buchenberg. Landkreis Villingen, Baden-Württemberg, Kleine Kunstführer, Nr. 757, München 1962.

Probleme bei der Erhaltung und Instandsetzung von Schmuck an Wänden und Decken historischer Gebäude, in: Nachrichtenblatt der Denkmalpflege in Baden-Württemberg, 8, 1965, 1, S. $10-18$.

Österreichisches Schlößchen Radolfzell a. B. Baugeschichte, Instandsetzungen, kunsthistorische Würdigung, Singen 1968.

Baitenhausen. Wallfahrtskapelle Maria zum Berge Karmel. Stadtpfarrgemeinde Meersburg, Kleine Kunstführer, Nr. 923, München 1969.

Die Kirchen und Kapellen der Gemeinde Heiligenberg. Bodenseekreis, Erzbistum Freiburg, Br., Kleine Kunstführer, Nr. 1428, München 1983.

„Composition Aubergine“ von Wols. Zur Schenkung e. Gemäldes an d. Staatl. Kunstsammlungen Dresden, in: Jahrbuch der Staatlichen Kunstsammlungen Dresden, Bd. 22, 1993, S. 77-78.

Wols in Dresden, in: Jahrbuch der Staatlichen Kunstsammlungen Dresden. Berichte, Beiträge, Bd. 22, 1993, S. 78-82.

3 NSDAP Kreisleitung Dresden an SMV, 16.11.1936, ebd., fol. 411. 


\section{Quellen und Literatur}

HStA Dresden, 11125, Nr. 18964

Ludwig-Maximilians-Universität München: Abgeschlossene Dissertationen am Institut für Kunstgeschichte 1873-2001, www.kunstgeschichte.uni-muenchen.de/forschung/diss_abgeschl/ index.html, Zugriff: 4.12.2019.

Stopfel, Wolfgang E.: Frau Dr. Elfriede Schulze-Battmann †, in: Denkmalpflege in Baden-Württemberg. Nachrichtenblatt der Landesdenkmalpflege, Bd. 30, Ausg. 4, 2001, S. 229 f.

Wörner, Hans Jakob: Zum Tod der Freiburger Kunsthistorikerin, Museumsspezialistin und Denkmalpflegerin Elfriede Schulz-Battmann, in: Badische Heimat. Mein Heimatland, Zeitschrift für Landes- und Volkskunde, Natur-, Umwelt- und Denkmalschutz, Bd. 81, 2001, S. $575 \mathrm{f}$. 


\section{RUdolf SCHWARZE}

\subsubsection{Dohna - 25.11.1967 Dresden}

Präparator

Museen für Tierkunde und Völkerkunde

(bis 11.1918 Königlich Zoologisches und Anthropologisch-

Ethnographisches Museum)
1.1.1910-31.5.1913 Wächter
1.6.1913-7.8.1914 Hilfsaufseher
1.1919-30.6.1919 Hilfsaufseher

Museum für Mineralogie, Geologie und Vorgeschichte

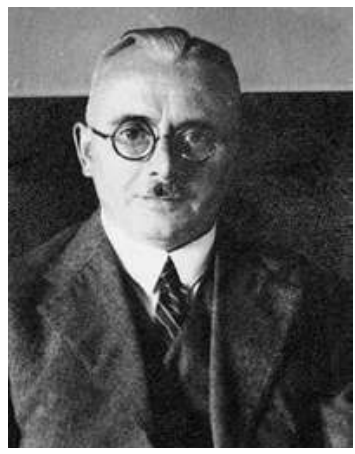

(ab 1.4.1938: Museum für Mineralogie und Geologie)

1.7.1919-30.4.1927 Aufseher

1.5.1927-31.10.1942 Präparator

1.11.1942-31.7.1946 Konservator

11.8.1944-5.1945 Depotverantwortlicher

1947-1963 Konservator

Landesmuseum für Vorgeschichte

11.8.1944-5.1945 Depotverantwortlicher

Mathematisch-Physikalischer Salon

11.8.1944-5.1945 Depotverantwortlicher

Am 27. Dezember 1883 wurde Rudolf Emil Schwarze, Sohn des Fabrikarbeiters Ernst Emil Schwarze und dessen Frau Marie Ernestine, geb. Baumgarten, in Dohna bei Pirna geboren. Nach dem Besuch der Bürgerschule erlernte er den Beruf eines Dekorationsmalers, in dem er zunächst, unterbrochen vom Militärdienst von 1905 bis 1907, auch arbeitete.

Ab Januar 1910 war Schwarze als Wächter und Garderobier im Königlich Zoologischen und Anthropologisch-Ethnographischen Museum in Dresden tätig. Im selben Jahr heiratete er Elsa, geb. Teichmann, mit der er zwei Töchter hatte. Am 1. Juni 1913 wurde er zum Hilfsaufseher ernannt. Diese Tätigkeit beendete er, um ab August 1914 im Ersten Weltkrieg zu dienen, aus dem er im Januar 1919 als Sergeant nach Dresden zurückkehrte. Zum 1. Juli 1919 wechselte er als Aufseher an das Museum für Mineralogie, Geologie und Vorgeschichte. Da er bereitwillig neben technischen Aufgaben auch Präparations- und Ausstellungsarbeiten im Museum ausführte, wurde er, als der Präparator Gustav Sauer in den Ruhestand ging, im Mai 1927 zu dessen Nachfolger ernannt. Zu seinen Aufgaben zählte fortan „die Präparation paläontologischer Objekte, die Anfertigung von Zeichnungen und Schaustücken für die Schausammlung und das Photographieren “1. Er unterstützte zum Beispiel Kustos > Karl Wanderer bei der Neugestaltung der Dauerausstellung. Nach dem Kriegsbeginn wurde er „mit der Bergung der Fossiliensammlung, zuletzt auch bei der Verpackung der Mineralien beauftragt ${ }^{\text {“2 }}$. Mit der Ernennung zum

1 Beschreibung der Aufgaben von Rudolf Schwarze, o. Dat., vermutl. 1942, HStA Dresden, 11125, 19295, Bd. 2, fol. 115-120.

2 Museum für Mineralogie und Geologie, Rimann, an Staatskanzlei, 30.6.1942, SKD Archiv, 01/ PS 53, Bd. 3, fol. 39. 
Konservator ab November 1942 übernahm Schwarze die freigewordene Stelle von $>$ Hellmuth Buck, der zum Inspektor ernannt worden war. Bereits seit Dezember 1942 wurde Schwarze im auswärtigen Wachdienst an den Bergungsorten des Museums eingesetzt, bevorzugt in Weesenstein. Im Juni 1943 wurde ihm die „laufende Überwachung der Verpackung des abzutransportierenden Teiles der Bestände “3 des Mathematisch-Physikalischen Salons übertragen, da dessen Restaurator und Sammlungsverantwortlicher $>$ Alfred Beck zum Militärdienst einberufen worden war. Aufgrund der äußerst angespannten Personalsituation in den Staatlichen Sammlungen wurde Schwarze am 11. August 1944 durch $>$ Fritz Fichtner für drei Museen als „für den sachgemäßen Zustand der Depots verantwortlich “4 benannt. Damit hatte er neben den Beständen des Museums für Mineralogie und Geologie fortan auch jene des Landesmuseums für Vorgeschichte und des Mathematisch-Physikalischen Salons zu betreuen. Im April 1945 wohnte er, da er in Dresden ausgebombt war, gemeinsam mit seiner Frau und einigen anderen Sammlungsmitarbeitern auf Schloss Weesenstein. ${ }^{5}$

Nach Kriegsende konnte Schwarze zunächst weiter beschäftigt werden, denn neben $>$ Walther Fischer war er „der Einzige, der als Fachkraft des grossen und bekannten Museums eingearbeitetet ist“" ${ }^{\text {". }}$. Doch ein Jahr später zählte er zu jenen Mitarbeitern der Staatlichen Sammlungen, die aufgrund ihrer NSDAP-Mitgliedschaft zum 31. Juli 1946 entlassen wurden. In die Partei war er rückwirkend im Mai 1937 aufgenommen worden, sein Aufnahmeantrag datierte auf den 4. November 1937. Im Juni 1947 entschied die Direktorenkonferenz, den Antrag zu unterstützen, dass er „als Fachmann, der mit den vorhandenen Beständen absolut Bescheid weiss, vorläufig im freiberuflichen Verhältnis wieder beschäftigt werden könne"7. Kurze Zeit später arbeitete Schwarze wieder am Museum für Mineralogie und Geologie, vermutlich bis weit über seine reguläre Pensionierung hinaus, bis 1963. Am 25. November 1967 starb Rudolf Schwarze in Dresden.

\section{Quellen und Literatur}

HStA Dresden, 13859, Nr. 8495

HStA Dresden, 13843, Nr. 267

BArch, R 9361-IX/Kartei/40771464; R 9361-VIII/Kartei/22410052

\footnotetext{
3 Mathematisch-Physikalischer Salon, i. V. Fischer, an Landesregierung Abt. Z6, SKD, MPS, 1943, A.-Reg. 87.

4 Sammlungsreferent Fichtner an Reichsstatthalter Mutschmann, 11.8.1944, HStA Dresden, 11125, Nr. 23058, fol. 84b.

5 Vgl. SMV, Abt. IV, an Bürgermeister von Weesenstein, 24.4.1945, HStA Dresden, 10701, Nr. 320/55, Bd. 2, fol. 280.

6 Begründung der Weiterbeschäftigung von Schwarze, 4.1.1946, SKD Archiv, 02/VA 162, fol. 67.

7 Protokoll der Direktionsbesprechung, 5.6.1947, SKD Archiv, 02/VA 158, fol. 81 f., hier: 82r.
} 


\title{
WALTER SCHWINKOWSKI
}

\author{
11.3.1884 Barten - 14.2.1938 Königsberg \\ Historiker, Numismatiker \\ Münzkabinett
}

1.7.1909-30.9.1911 Wissenschaftlicher Hilfsarbeiter

1.10.1911-31.12.1923 Direktorialassistent

1.1.1924-30.6.1937 Kustos und Leiter

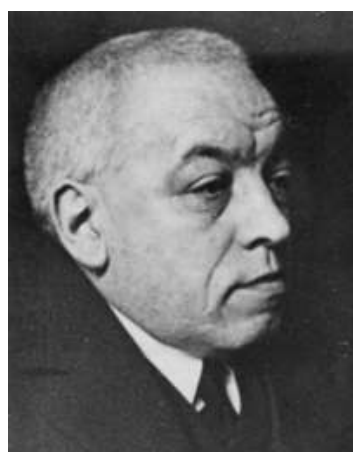

Walter Karl Schwinkowski wurde am 11. März 1884 im ostpreußischen Barten bei Rastenburg als Sohn des Schuldirektors Carl David Schwinkowski und dessen Frau Karoline, geb. Goerke, geboren. Nach dem Abitur studierte er ab 1904 an der Universität in Königsberg Geschichte, Neuere Sprachen und Volkswirtschaftslehre, unter anderem bei Otto Krauske. Ab 1907 widmete er sich bei Julius Menadier am Münzkabinett der Staatlichen Museen in Berlin der numismatischen Wissenschaft. 1909 wurde Schwinkowski in Königsberg promoviert.

Unter Direktor Jean Louis Sponsel, der damals gleichzeitig das Grüne Gewölbe leitete, begann Schwinkowski am 1. Juli 1909 im Münzkabinett zu arbeiten. Zwei Jahre später wurde er zum Direktorialsassistenten berufen und lenkte die Geschicke des Kabinetts. Aber erst mit Sponsels Pensionierung und der verwaltungstechnischen wie räumlichen Trennung des Münzkabinetts vom Grünen Gewölbe wurde Schwinkowski im Januar 1924 zum Kustos und Leiter des Münzkabinetts ernannt. 1927 erhielt er den Professorentitel. Schwinkowski konzipierte die erste ständige Ausstellung des Münzkabinetts in neuen Räumen im ehemaligen Kanzleigebäude des Stallhofes. Er legte eine Sammlung von Notgeld der Inflationszeit an, die „als ein warnendes Zeichen [...] die Erinnerung an Zeiten tiefster Erniedrigung nach dem Kriege wachhäl ${ }^{\text {" }}$, wie sein Kollege • Walter Holzhausen vom Grünen Gewölbe und Historischen Museum anerkennend schrieb. Darüber hinaus erwarb sich Schwinkowski Verdienste um die Erweiterung, Ordnung und Erschließung der Handbibliothek des Kabinetts. ${ }^{2}$ Sein wissenschaftliches Interesse galt primär der Erforschung der sächsischen Münzgeschichte. Unter Numismatikern und Sammlern genoss er ein hohes Ansehen. So war er über viele Jahre Mitglied, später auch Vorsitzender des Numismatischen Vereins. In die NSDAP trat Schwinkowski nicht ein, sondern nur in die für Staatsbeamte unausweislichen NS-Organisationen. Als sich sein Gesundheitszustand ab 1933 verschlechterte, nahm er dies zum Anlass, im Alter von nur 53 Jahren am 30. März 1937 um seine Pensionierung zu bitten. Dabei räumte er ein, für „weitergehende Nutzbarmachung der Sammlung durch Vorträge und Sonderausstellungen konnte ich [W. S., Anm. d. A.] schon früher nicht sorgen “3. In der Tat zeigte Schwinkowski nach „Medaillen und Plaketten aus Porzellan“ 1933 keine weiteren Sonderausstellungen im Kabinett, sondern beteiligte sich nur noch an Gemeinschaftsprojekten mit anderen Sammlungen, wie der Ausstellung „Heinrich Schütz und

1 Holzhausen, Walter: Dr. Walter Schwinkowski $\dagger$, in: DA, 17.2.1938.

2 Vgl. Lewerken, Sabine: Die Bibliothek des Dresdner Münzkabinetts, in: Dresdner Numismatische Hefte, Nr. 1, hg. vom Numismatischen Verein zu Dresden e. V., Dresden 1996, S. 46-51, hier: 48.

3 Schwinkowski an SMV, 30.3.1937, HStA Dresden, 11125, Nr. 22896, fol. 9. 
seine Zeit“ 1935 und der Rokoko-Schau im Rahmen der Reihe „Kunstwerk des Monats“ 1936. Die beiden Radio-Vorträge im Reichssender Leipzig, bei denen er über „Münzsammlungen und Münzfälschungen“ und „Münzsammlungen und Münzforschungen“ sprach, bezeugen sein Bemühen, Numismatik auch Laien näherzubringen. ${ }^{4}$ In Sorge um das Kabinett und sein Lebenswerk schlug er im Mai 1937 Fritz Fichtner namhafte Numismatiker als seine Nachfolger vor. ${ }^{5}$ Am 30. Juni 1937 wurde Schwinkowski nach 28 Dienstjahren pensioniert. Unmittelbar zuvor übergab er seine Dienstgeschäfte im Münzkabinett an $>$ Erich Haenel, Direktor des Historischen Museums und des Grünen Gewölbes, der ihn bereits mehrfach während des Urlaubs und im Krankheitsfalle vertreten hatte. Um zumindest eine minimale Kontinuität in der wissenschaftlichen Arbeit des Münzkabinetts zu erhalten und sich die Expertise Schwinkowskis zu sichern, beantragte Haenel vorsorglich, dessen stundenweise Tätigkeit für das Kabinett über die Pensionierung hinaus.

Doch dazu kam es nicht mehr. Walter Schwinkowski kehrte in seine ostpreußische Heimat zurück. Dort starb er in Königsberg, nur wenige Monate später, am 14. Februar 1938.

\section{Auswahlbibliografie}

Das Geldwesen in Preußen unter Herzog Albrecht (1525-1569), in: Zeitschrift für Numismatik, 27, Berlin 1909 (Zugl. Königsberg/Pr., Univ., Diss., 1909).

Die ersten sächsischen Goldgulden und die deutsche Goldprägung im Mittelalter, in: Zeitschrift für Numismatik, Bd. 28, 1910, S. 317-350.

Die Reichsmünzreformbestrebungen in den Jahren 1665-1670 und der Vertrag von Zinna 1667. Mit besonderer Berücksichtigung der obersächsischen Münz- und Geldgeschichte, in: Vierteljahrschrift für Sozial- und Wirtschaftsgeschichte, Bd. 14, 1916, S. 1-87.

Das Geld- und Münzwesen Sachsens. Beiträge zu seiner Geschichte, in: Neues Archiv für sächsische Geschichte, Bd. 38, 1917, S. 140-181, 355-395.

Inschriften und Medaillen und Denkmünzen des Albertinischen Hauses und Landes Sachsen, in: Jahrbuch des Numismatischen Vereins zu Dresden, 20, 1919, S. 1-40.

Meißnische Pfennige und Heller der Groschenwährung bis 1500, in: Blätter für Münzfreunde. Monatsschrift für Münz- und Schaumünzkunde. Organ des Numismatischen Vereins zu Dresden, N. F. Ausg. 275, 1925, S. 327-330.

Der Brakteatenfund von Meißen 1925, in: Blätter für Münzfreunde. Monatsschrift für Münzund Schaumünzkunde. Organ des Numismatischen Vereins zu Dresden, Bd. 61, 1926, S. 449-454.

Münz- und Geldgeschichte der Mark Meißen und Münzen der weltlichen Herren nach meißnischer Art (Brakteaten) vor der Groschenprägung, Bd. 1, Frankfurt a. M. 1931.

Die Meißnischen Brakteaten, 1932 (mit Willy Schwabacher).

Zur Münzgeschichte der ehemaligen Wettinischen Lande um 1180-1230. Der Brakteatenfund von Etzoldshain bei Grimma 1933, Halle 1936.

\footnotetext{
4 Gehalten am 14.11.1935 u. 14.11.1936. Vgl. HStA Dresden, 11125, Nr. 19003, Bl. 221.5 u. SKD, MK, 1935-1936, fol. 44.

5 Vgl. Schwinkowksi an Fichtner, 7.5.1937, HStA Dresden, 11125, Nr. 22896, fol. 3 ff. Siehe S. $77 \mathrm{ff}$
} 


\section{Quellen und Literatur}

HStA Dresden, 11125, Nr. 22894; Nr. 22895; Nr. 22896

SKD, MK, 1936-1937

Holzhausen, Walter: Dr. Walter Schwinkowski †, in: Dresdner Anzeiger, 17.2.1938.

Kretzschmar, Hellmut: Walter Schwinkowski, in: Neues Archiv für Sächsische Geschichte, Bd. 61, 1940, S. 86 f.

Arnold, Paul: Walter Schwinkowski, in: Dresdener Kunstblätter, 32. Jg., H. 3, 1988, S. 84-91.

Arnold, Paul: Walter Schwinkowski in memoriam, in: Erfurter Münzblätter, 5, 1997, S. 17-22.

Arnold, Paul: Schwinkowski, Walter, Leiter des Staatlichen Münzkabinetts Dresden, in: Bürger, Klaus (Hg.): Altpreußische Biographie, Bd. V, Marburg 2015, S. 1698 f. 


\title{
Margarethe Storch
}

\author{
9.2.1894 Dresden - 14.3.1977 Dresden \\ Bibliothekarin (Mittlerer Dienst) \\ Sächsische Landesbibliothek \\ 1.1.1920-30.9.1920 Volontärin \\ 1.4.1922-31.3.1923 außerplanmäßige Hilfsarbeiterin \\ 1.4.1923-31.3.1927 Bibliotheksgehilfin \\ 1.4.1927-1959 Oberbibliothekssekretärin
}

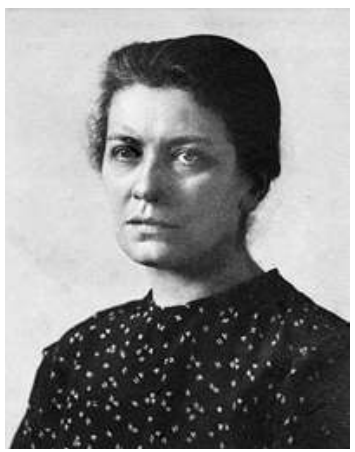

Obwohl sie über mehrere Jahrzehnte, von der Weimarer Republik bis in die DDR-Zeit, im Mittleren Dienst der Sächsischen Landesbibliothek tätig war, sind nur wenige biografische Informationen zu Elisabeth Margarethe Storch überliefert. Am 9. Februar 1894 als Tochter von Ludwig Emil Otto Storch und seiner Frau Katharina Maria Pauline Anna, geb. Ochs, in Dresden geboren, lernte sie zunächst an einer Privatschule in Blasewitz bei Dresden. Im November 1918 legte sie eine Englische Fachprüfung ab.

Zum Jahresanfang 1920 trat sie als Volontärin in den Dienst der Sächsischen Landesbibliothek. Parallel begann Storch eine Ausbildung an der Bibliothekarschule in Leipzig, die sie nach einem zweiten Volontariat an der Universitätsbibliothek Leipzig am 8. Oktober 1921 mit der Prüfung für den Mittleren Dienst an wissenschaftlichen Bibliotheken erfolgreich abschloss. Vom November 1921 bis Ende März 1922 arbeitete sie als Bibliothekarin am Deutschen Hygiene-Museum in Dresden, bevor sie am 1. April 1922 als außerplanmäßige Hilfsarbeiterin an die Sächsische Landesbibliothek zurückkehrte. Dort erhielt sie ein Jahr später eine Stelle als Bibliotheksgehilfin und wurde im April 1927 zur Oberbibliothekssekretärin befördert. Bis zu ihrer regulären Pensionierung 1959 blieb Storch an der Landesbibliothek tätig, wo sie sich zur Bibliotheksinspektorin weiterqualifizierte. Als Bestände der Bibliothek kriegsbedingt auf Schloss Weesenstein ausgelagert wurden, weilte sie 1945 „vom 1. Mai bis 23. Juni in Weesenstein bei unseren nassen Sachen "1. Storch führte über Jahrzehnte das Zugangsverzeichnis der Landesbibliothek, leitete nach 1945 den Standortkatalog, betreute den biografischen Katalog. Sie zählte zu den wenigen Mitarbeiterinnen und Mitarbeitern, die nach dem Zweiten Weltkrieg ohne Unterbrechung weiterbeschäftigt wurden. Dies war möglich, weil sie nie in die NSDAP eingetreten war. Allerdings war sie - wie die meisten ihrer Kollegen - Mitglied im NSV, Opferring der NSDAP, RDB und RLB. Selbst nach ihrer Pensionierung arbeitete Storch noch stundenweise in der Titelstelle. Den Kontakt zu den Kollegen in der Sächsischen Landesbibliothek hielt sie auch später noch. ${ }^{2}$ Am 14. März 1977 starb Margarethe Storch in Dresden.

\section{Quellen und Literatur}

HStA Dresden, 13859, Nr. 8703

Deckert, Helmut: Margarethe Storch, in: Sächsische Landesbibliothek. Neuerwerbungen und Nachrichten, April 1977, S. 81 f.

1 Storch an Jammers, 25.11.1945, SLUB, Mscr.Dresd.App.2830, fol. 114.

2 Vgl. Deckert an Jammers, 23.8.1962, ebd., fol. 69 u. Jammers an Deckert, 19.12.1976, SLUB, Mscr.Dresd.App.2600,F,527. 


\section{BERNHARD STRUCK}

28.8.1888 Heidelberg - 8.10.1971 Jena

Ethnologe, Anthropologe, Afrikanist

Museen für Tierkunde und Völkerkunde

(bis 11.1918 Königlich Zoologisches und Anthropologisch-

Ethnographisches Museum)

1.5.1913-30.9.1923 Wissenschaftlicher Hilfsarbeiter

1.10.1923-30.11.1937 Kustos

1.5.1935-31.12.1935 Kommissarischer Direktor

(Militärdienst 11.1.1915-30.1.1919; Beurlaubung für

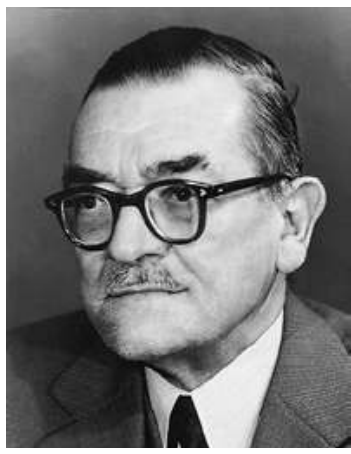

Expedition 11.11.1930-15.5.1931 und an Universität Jena

9.1936-30.11.1937)

Friedrich Bernhard Eduard Struck wurde am 28. August 1888 in Heidelberg als Sohn des Kaufmanns Ludwig Struck und dessen Frau Edith, geb. Winkelmann, geboren. Nach dem Besuch der Volksschule und des Gymnasiums in Heidelberg studierte er zunächst in Heidelberg Naturwissenschaften und Geografie. 1907 wechselte Struck an die Universität Berlin, wo er bis 1911 Physische Anthropologie, Geografie, Völkerkunde und Afrikanische Sprachen studierte. Zu seinen akademischen Lehrern zählten Carl Meinhof und Felix von Luschan. Bei Letzterem arbeitete Struck als Assistent. Ab 1908 war er auch als Freiwilliger Wissenschaftlicher Hilfsarbeiter am Königlichen Museum für Völkerkunde in Berlin tätig. Aufgrund der Fürsprache von Luschan lud $>$ Arnold Jacobi im Januar 1913 Struck für ein Bewerbungsgespräch nach Dresden ein, das offenbar erfolgreich verlief.

Anfang Mai 1913 begann Struck seine Tätigkeit als Wissenschaftlicher Hilfsarbeiter in der Anthropologischen Abteilung des Königlich Zoologischen und Anthropologisch-Ethnographischen Museums in Dresden. Im Januar 1915 verließ er Dresden, um als Freiwilliger im Ersten Weltkrieg zu dienen. Erst im Januar 1919 kehrte er ans Museum zurück. Im März 1921 wurde Struck an der Universität Tübingen promoviert. Wenige Monate danach, im August 1921, heiratete er Paula Johanna, geb. Walde, mit der er ein Kind hatte. ${ }^{1}$ Zum Kustos der Anthropologischen Abteilung wurde Struck im Oktober 1923 ernannt. Ein Jahr danach, im Dezember 1924, habilitierte er sich an der Technischen Hochschule in Dresden. Fortan übernahm er Lehraufträge. 1927 erhielt er den Professorentitel für Völkerkunde und Anthropologie. Neben der Lehre und Museumsarbeit verfasste er zahlreiche Veröffentlichungen, im Laufe seines Lebens publizierte er 265 Arbeiten zu ethnografischen, anthropologischen, linguistischen und kartografischen Themen sowie zahlreiche Rezensionen. Dennoch war Struck mit seinen beruflichen Möglichkeiten in Dresden unzufrieden. Verstärkt versuchte er, an ein anderes Museum oder eine andere Universität zu wechseln. Trotz seiner Berufserfahrungen bewarb er sich vergeblich an den Völkerkundemuseen in München und Freiburg im Breisgau. Auch die zahlreichen Berufungsverhandlungen, die Struck führte, scheiterten aus unterschiedlichen Gründen, wie 1922 in Berlin, 1926 in Bres-

1 Der Sohn leistete im Zweiten Weltkrieg Militärdienst und kehrte nicht zurück. Eine letzte Nachricht schickte er im Januar 1945. Vgl. Struck an Zaunick, 17.5.1948, SKD, MfV Archiv, MVD n20;25/15u16, o. Pag. 
lau und Bonn, 1927 in Wien, 1928 erneut in Breslau und 1930 jene für das Extraordinariat für Afrikanische Sprachen in Leipzig. So nutzte Struck die Gelegenheit und ging von November 1930 bis April 1931 gemeinsam mit dem Wiener Reiseschriftsteller und Fotografen Hugo Bernatzik auf Forschungsreise nach Portugiesisch Guinea. Finanziert wurde diese Expedition nach Westafrika im Wesentlichen durch das Sächsische Forschungsinstitut für Völkerkunde Leipzig und die Deutsche Forschungsgemeinschaft sowie durch den nachträglichen Verkauf der mitgebrachten völkerkundlichen Sammelobjekte. Im Juni 1933 erfolgte Strucks Ernennung zum außerplanmäßigen Professor an der Technischen Hochschule in Dresden. Noch im selben Jahr unterzeichnete er das „Bekenntnis der Professoren an den deutschen Universitäten und Hochschulen zu Adolf Hitler und dem nationalsozialistischen Staat ${ }^{\text {“2 }}$. Eine Mitgliedschaft in der NSDAP ist jedoch nicht nachweisbar. Lediglich in den NSLB trat er im November 1933 ein. Schon 1932 hatte er betont: „Ich bin übrigens nicht eingeschriebener Pg., da ich es [...] für taktisch richtiger halte, im gegebenen Moment als Nichtparteimitglied für die gemeinsame Sache zu wirken "3. Diese Haltung führte Struck in seiner Tätigkeit als Wissenschaftler, der sich als Ethnologe, Anthropologe und Afrikanist insbesondere auch mit den Themen Abstammung und „Rasse“ befasste, dennoch in die unmittelbare Nähe der nationalsozialistischen Ideologie, wobei zwischen Indienstnahme und Indienststellung kaum zu unterscheiden ist. So beteiligte er sich im Februar 1934 mit drei Vorträgen an einem „Einführungskursus über Rassenkunde und Rassenpflege" für sächsische Lehrer am Deutschen Hygiene-Museum in Dresden, zu dessen Beirat er von 1927 bis 1933 zählte. Auch im Museum sprach er gelegentlich über „Die Rassen Europas“ und im Rahmen der Sonntagsvorträge im März 1935 über „Rassenkunde Sachsens“, allerdings präsentierte er in Führungen auch die „Altertümer von Benin und Westafrika“ oder „Afrikanische Musikinstrumente“. Doch den Museumsdienst „mit seinen aussichtslosen Quidproquos und der wahrhaft ungeheuerlichen, unproduktiven Zeitverschwendung " ${ }^{\text {"i }}$ empfand Struck sowohl unter Direktor Jacobi als auch unter $>$ Hans Kummerlöwe als eine Last. Er fühlte sich „nicht ganz am Platze und vor allem nicht hinreichend nutzbringend“, wohingegen ihm die Lehrtätigkeit „als geistiges Gegengewicht gegen die verknöchernde Museumsbeamtenluft ${ }^{\text {“5 }}$ diente. Noch immer hoffte er, das Museum verlassen und komplett in die akademische Lehre wechseln zu können. Doch auch die Bewerbung in Köln 1934 blieb erfolglos. Seine Fachkollegen und Freunde, mit denen er eine umfangreiche Korrespondenz führte, unterstützten ihn. So fragte Hans Plischke, ob Struck in Göttingen kandidieren wolle, und Franz Thorbecke benannte ihn 1935 als Kandidaten für ein Ordinariat für Völkerkunde in Köln. Die Situation veränderte sich für Struck erst im Mai 1935 mit der Aufforderung, seine Bewerbungsunterlagen als Nachfolger von Hans F. K. Günther nach Jena zu senden. Bereits im Frühjahr 1936 beauftragte ihn das Reichsministerium für Wissenschaft, Erziehung und Volksbildung, vertretungsweise an der Universität in Jena zu lehren. Ab September 1936 übernahm Struck die Vertretung in Jena komplett, wofür er in Dresden beurlaubt wurde. Doch zuvor organisierte er noch eine Tagung der Physischen Anthropologie. Als seinen Vertreter für die Vorlesungen an der Technischen Hochschule empfahl er $>$ Martin Heydrich. Ebenso setzte er sich später für eine Beschäftigung seiner Doktoranden $\gg$ Berthold Pfaul und $\gg$ Herbert Bellmann ein.

Nationalsozialistischer Lehrerbund Deutschland/Sachsen 1933, S. 132.

Struck an Berner, 11.8.1932, SKD, MfV Archiv, MVD, n20;25/1, o. Pag.

Struck an Danzel, 14.8.1936, SKD, MfV Archiv, MVD, n20;25/2, o. Pag.

Struck an Berner, 11.8.1932, SKD, MfV Archiv, MVD n20;25/1, o. Pag. 
Im Oktober 1936 wechselte Struck ganz nach Jena. Allerdings erhielt er seine Bestallungsurkunde, mit der er zum 1. Dezember 1937 als ordentlicher Professor an die Universität Jena berufen wurde, erst Anfang März 1938. Seine Aufgabe in Jena bestand im Ausbau des neuen Instituts für Anthropologie und Völkerkunde. Noch 1938 wurde Struck auf der Vorschlagsliste für das Ordinariat für Völkerkunde in Köln an erster Stelle vor Kohl-Larsen, Plischke und Heydrich geführt. Diesen Ruf nahm er nicht an, wodurch der Wechsel von Heydrich nach Köln möglich wurde. Die Sehnsucht nach besseren Bedingungen für seine wissenschaftliche Betätigung blieb Struck und so schrieb er 1940: „Mit meinen Wünschen und Gedanken bin ich [...] bei den künftigen deutschen Kolonien oder sagen wir schon beherzter: beim grossen deutschen Mittelafrika. Dort gäbe es gerade für mich so viel nützlichere Arbeit zu tun als zufällig hier an einer doch sehr kleinen Uni mit ihren ganz ungenügenden Hilfsmitteln und wenig Hörern “6. In Fachkreisen galt er als „der beste Kenner der Völker und Rassen Afrikas, deren Sprachen er zahlreich beherrscht[e] ${ }^{\text {“7 }}$. Im November 1940 nahm er an der Kolonialtagung in Göttingen teil. Von 1940 bis 1943 wirkte er beratend für die Kolonialwissenschaftlichen Abteilung des Reichsforschungsrates, ab Januar 1941 als Leiter der Fachgruppe Koloniale Völkerkunde. Nach Kriegsende wurde Struck in seinen Ämtern an der Universität Jena belassen. Ihm war keine NSDAPMitgliedschaft nachweisbar und seine Freunde und Kollegen hatten ihm sogenannte „Persilscheine" ausgestellt. Struck berichtete später, dass sein früherer Dresdner Vorgesetzter Jacobi ihm „postwendend ein ganz ausgezeichnetes Gutachten zur Verfügung gestellt“ habe, „mit diesem [...] hat dann der Rektor beim Kurator meine einstweilige Belassung in allen Funktionen erwirkt ${ }^{\text {“8 }}$. Im November 1945 wurde Struck das Dekanat an der Universität Jena übertragen. Doch als Professor für Ethnologie und Anthropologie konnte er erst ab Herbst 1946 wieder tätig werden, da beide Fächer aufgrund ihrer Nähe zum Nationalsozialismus zunächst nicht zugelassen waren. Mit Erreichen der Altersgrenze wurde Struck Ende August 1955 in Jena emeritiert, übernahm jedoch die kommissarische Vertretung des Lehrstuhles, bis er seinen Rücktritt im März 1961 erklärte. Am 8. Oktober 1971 starb Bernhard Struck in Jena.

\section{Auswahlbibliografie}

Collections towards a bibliography of the Bantu languages of British East Africa, in: Journal of the African Society, 6, 1907, S. 390-404.

Linguistische Kongostudien, in: Mitteilungen des Seminars für Orientalische Sprachen zu Berlin 16, 1912, Abt. 3, S. 93-112.

Der Schlüssel der Sudansprachen, in: Allgemeine Missionszeitschrift, 40, 1913, H. 8, S. $347-$ 357 und H. 9, S. 408-422.

Entwurf einer Übersichtskarte der Hauptsprachfamilien in Afrika, Berlin 1914.

Die Gbaya-Sprachen (Dar-Fertit), in: Mitteilungen des Seminars für Orientalische Sprachen zu Berlin, Berlin, 21, 1918, Abt. 3, S. 53-100.

Versuch einer Karte des Kopfindex im mittleren Afrika, in: Zeitschrift für Ethnologie, 54, 1922, S. 51-113 (Zugl. Tübingen, Univ., Diss., 1921).

Somatische Typen und Sprachgruppen im Kordofan. Ein Beitrag zur Methodik der Typenanalysen, in: Zeitschrift für Ethnologie, 52/53, 1921, S. 129-170.

6 Struck an Petzsch, 23.8.1940, SKD, MfV Archiv, MVD n20;25/9u10, o. Pag.

7 h.b.: Dank an einen Dresdner Forscher. Professor Dr. Bernhard Struck zum 50. Geburtstag, in: DA, 27.8.1938.

8 Struck an Schüz, 28.12.1950, SKD, MfV Archiv, MVD n20;25/11u12, o. Pag. 
Die Chronologie der Benin-Altertümer, in: Zeitschrift für Ethnologie, 55. Jg., H. 5/6, 1923, S. 113-166.

Anthropologische Ergebnisse aus Portugiesisch-Guinea, in: Bernatzik, Hugo Adolf: Äthiopien des Westens, Bd. 1, Wien 1932, S. 249-278.

Sachgebiet Koloniale Völkerkunde, in: Kolonialwissenschaftliche Abteilung des Reichsforschungsrates (Hg.): Aufgaben der deutschen Kolonialforschung, Stuttgart 1942, S. 69-76.

\section{Quellen und Literatur}

SKD, MfV Archiv, MVD n20;25

HStA Dresden, 13842, Nr. 114, Bd. 2

BArch, R 4901/13278; R 4901/24789, fol. 3487

BArch, R 9361-IX/Kartei/43690155

SMB-ZA, EM, Archiv, I/MV 0817

Bescherer, Johannes: Zur Geschichte des Institutes für Anthropologie und Völkerkunde der Friedrich-Schiller-Universität Jena in den Jahren 1936-1953, in: Bernhard Struck zum 65. Geburtstag am 28. August 1953. Beiträge zur Anthropologie und Ethnologie gewidmet von Schülern und Freunden, Wissenschaftliche Zeitschrift der Friedrich-Schiller-Universität Jena, 3. Jg., 1953/54, Mathematisch-Naturwissenschaftliche Reihe, H. 1, S. 2-12.

Wolf, Siegfried: Bernhard Struck 75 Jahre, in: Abhandlungen und Berichte des Staatlichen Museums für Völkerkunde, Dresden, 22, 1963, S. V-VI.

Bach, H.: In memoriam. Bernhard Struck, 1888-1971, in: Anthropologischer Anzeiger, 34, 1973, S. 83.

Nützsche, Sigrun: Verzeichnis der Schriften des Anthropologen und Völkerkundlers Prof. Dr. Bernhard Struck (1888-1971): mit einer biographischen Einführung und Anmerkungen zum Verzeichnis, in: Abhandlungen und Berichte des Staatlichen Museums für Völkerkunde Dresden, Forschungsstelle, 49, 1996, S. 293-341.

Petschel, Dorit: 175 Jahre TU Dresden. Band 3: Die Professoren der TU Dresden 1828-2003. Hrsg. im Auftrag der Gesellschaft von Freunden und Förderern der TU Dresden e. V. von Reiner Pommerin, Köln u. a. 2003, S. 948 f.

Pittelkow, Jörg u. Uwe Hoßfeld: „Der Letzte seiner Zunft“. Bernhard Struck (1888-1971) als Anthropologe und Völkerkundler, in: Mitteilungen der Berliner Gesellschaft für Anthropologie, Ethnologie und Urgeschichte, Bd. 37, 2016, S. 65-82.

Dolz, Silvia: Seelenfiguren als Expeditionsertrag. Sammeln und das Ideal der Vollständigkeit, in: Staatliche Kunstsammlungen Dresden 2016, S. 22 f.

Scheppe, Wolfgang: Die Grenze als Wissenschaftsideal. Der Anthropologe und Völkerkundler Bernhard Struck, in: Staatliche Kunstsammlungen Dresden 2016, S. 17-21.

Dolz, Silvia: Bernhard Struck (1888-1971): „Afrika erkennen“. Von Konstruktion und Dekonstruktion eines Weltbildes. Eine wissenschaftskritische Annäherung, in: Abhandlungen und Berichte der Staatlichen Ethnographischen Sammlungen Sachsen, Bd. 55, 2020 (im Druck). 


\title{
Paul TäUbrich
}

\author{
12.3.1884 Dresden - 28.1.1960 Dresden \\ Gipsformer, Präparator \\ Skulpturensammlung \\ 20.6.1904-8.12.1906 Gipsformer \\ 4.5.1909-30.6.1916 Gipsformer \\ 1.7.1916-31.3.1920 Gipsformer und Aufseher \\ 1.4.1920-31.3.1926 Sammlungshandwerker \\ 1.4.1926-28.2.1934 Sammlungshandwerksmeister \\ 1.3.1934-31.3.1938 Formermeister \\ 1.4.1938-15.11.1945 Präparator \\ 11.8.1944-5.1945 Depotverantwortlicher \\ (Militärdienst 5.3.1917-3.2.1919)
}

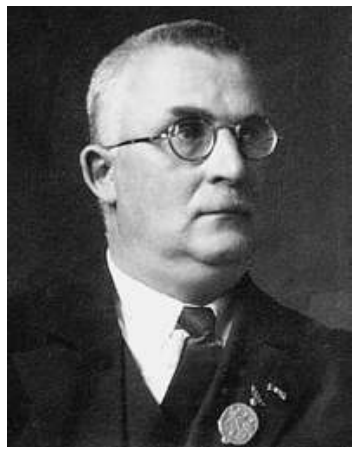

Am 12. März 1884 wurde Paul Gustav Täubrich als Sohn von Karl Gustav Adolph Täubrich und seiner Frau Anna Maria, geb. Lasch, in Dresden geboren. Nach dem Besuch der Volksschule und der Fortbildungsschule des Allgemeinen Fortbildungsvereins Dresden war er ab April 1898 als Gipsformer tätig.

Von Juni bis Dezember 1906 sowie von Mai 1909 bis Juni 1916 arbeitete Täubrich als Gipsformer in der Skulpturensammlung. Doch bereits ab Januar 1916 wurde er als Aufseher in der Skulpturensammlung in den Staatsdienst übernommen. Seit August 1910 war er mit Frieda Maria, geb. Eichler, verheiratet und hatte zwei Kinder. Im Ersten Weltkrieg diente er von März 1917 bis Februar 1919 als Soldat an der Westfront. Nach Dresden zurückgekehrt, setzte er seine Arbeit an der Skulpturensammlung fort, wo er im April 1920 die Stelle eines Sammlungshandwerkers annahm. Sechs Jahre später wurde er zum Sammlungshandwerksmeister ernannt. Der Direktor der Skulpturensammlung, \Bruno Schröder, beantragte im Januar 1931, Täubrich die frei werdende Formermeisterstelle zu übertragen, denn er „wird dann in der Formerei allein beschäftigt sein und Abformungen und Abgüsse herzustellen haben“ und „auch die bisher von Formermeister Gottschalk und Oberkonservator Tamme verrichteten Conservierungs-Arbeiten und die Leitung bei Umstellung von Bildwerken allein zu besorgen haben " ${ }^{\text {.1 }}$ Aber erst im März 1934 wurde Täubrich zum Formermeister ernannt. Im April 1938 erhielt er die Präparatorenstelle des verstorbenen Gustav Gottschalk und leitete die Formerei sowie die Aufstellungsarbeiten im Museum. Im Juni 1941 wies \Fritz Fichtner als Vertreter des Sächsischen Ministeriums für Volksbildung an, dass Täubrich wieder Aufsichtsdienste übernehmen müsse, um die Sammlung trotz Personalknappheit weiter offenzuhalten, auch war er als ständige Luftschutzwache im Museum eingeteilt. Darüber hinaus war er an der Auslagerung der Objekte und deren Betreuung an den Bergungsorten beteiligt. Am 11. August 1944 wurde ihm die Verantwortung für die magazinierten Bestände der Skulpturensammlung übertragen. ${ }^{2}$ Die enorme Arbeitsanstrengung führte dazu, dass er ab September 1944 aufgrund von massiven Schlafstörungen bis zum Jahres-

Skulpturensammlung, Schröder, an SMV, 31.1.1931, HStA Dresden, 13859, Nr. 9020, fol. 26.

Vgl. SMV, Fichtner, an Reichsstatthalter Mutschmann, 11.8.1944, HStA Dresden, 11125, Nr. 23058, fol. 84b, 
ende von den Nachtdiensten befreit wurde. Nach der Bombardierung Dresdens im Februar 1945 wurde Täubrich infolge eines Nervenschocks krankgeschrieben. ${ }^{3}$ Ab wann er wieder dienstfähig war, bleibt unklar. Aufgrund seiner Mitgliedschaft in der NSDAP, in die er im Mai 1937 eingetreten war, wurde er zum 15 . November 1945 entlassen. ${ }^{4}$

Paul Täubrich starb am 28. Januar 1960 in Dresden.

Quellen und Literatur

HStA Dresden, 13859, Nr. 9020

BArch, R 9361-IX/Kartei/44060436

3 Vgl. Dr. med. Fabian, 13.9.1944, HStA Dresden, 11125, Nr. 23044, fol. 134v.

4 Vgl. Kanzlei der Staatlichen Museen, Fischer, an Landesverwaltung Sachsen, Zentralverwaltung für Wissenschaft, Kunst und Erziehung, Grohmann, 24.11.1945 u. Skulpturensammlung, Enking, an die Verwaltung der Staatlichen Sammlungen, 20.2.1945, SKD Archiv, 02/VA 162, fol. 40 u. 02/VA 50, fol. 161 . 


\section{Alfred Unger}

3.6.1896 Großbardau - 25.12.1980 Bochum

Akademischer Maler, Restaurator

Gemäldegalerie

1.4.1929-31.3.1934 Restauratorengehilfe

1.4.1934-31.7.1946 Restaurator

11.8.1944-5.1945 Depotverantwortlicher

"Sonderauftrag Linz"

[7.1939]-5.1945 [?]

(Militärdienst 11.1.1937-13.2.1937, 26.8.1939-[?])

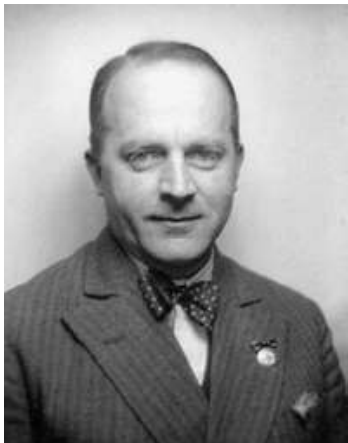

Julius Alfred Unger wurde am 3. Juni 1896 in Großbardau bei Grimma geboren. Nach dem Besuch der Bürgerschule ließ er sich ab 1910 an der Königlichen Zeichenschule in Dresden ausbilden. Von 1913 bis 1923 studierte er als Schüler von Richard Müller an der Akademie der bildenden Künste in Dresden. Dieses Studium wurde durch seinen Militärdienst von Oktober 1915 bis Januar 1919 unterbrochen, bei dem er an der Westfront vor Verdun kämpfte. Nach dem Studienabschluss arbeitete er zunächst als freischaffender Künstler in Dresden. Im Februar 1929 bewarb er sich mit einem Empfehlungsschreiben von Müller als Restauratorengehilfe an der Gemäldegalerie, deren Direktor $\gg$ Hans Posse sein Einstellungsgesuch befürwortend weiterleitete, da er sich „für diese Stelle eignen dürfte“"

Ab Juni 1929 wurde Unger für die Pflege und Erhaltung der Gemälde in der Gemäldegalerie Dresden als Restauratorengehilfe eingestellt. Im Juli 1931 heiratete er Maria Frieda, geb. Dietze, die zwei Kinder mit in die Ehe brachte, ein gemeinsames wurde später geboren. Zum 1. April 1934 wurde Unger zum Restaurator ernannt, nachdem der bisherige Stelleninhaber, Theodor Krause, in den Ruhestand gegangen war. Nebenher durfte er mit der Zustimmung seines Vorgesetzten auch private Aufträge annehmen, nur musste er diese der Gemäldegalerie melden. Im März 1933 trat Unger in die NSDAP ein, ein Gutachten der NSDAP-Kreisleitung Dresden bestätigte ihm 1936, er habe die aktive Mitarbeit trotz mehrmaliger Aufforderung „wegen Zeit-

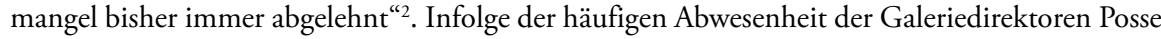
und später \ Hermann Voss, die ab 1939 für den „Sonderauftrag Linz“ unterwegs waren, musste Unger gemeinsam mit Kustos > Robert Oertel die Verantwortung für die Gemäldegalerie übernehmen. Im Auftrag seiner Vorgesetzten arbeitete er auch als Restaurator für den „Sonderauftrag Linz “3. Unmittelbar vor Kriegsbeginn, im August 1939, wurde Unger zum Militärdienst eingezogen. Unklar bleibt, wann er wieder nach Dresden zurückkehrte. Ab Januar 1940 konnte er jedoch mehrfach uk-gestellt werden, wodurch er einer erneuten Einberufung entging. Seine Freistellung vom Militär erfolgte aufgrund seiner Aufgaben in der Gemäldegalerie, denn er hatte die Werke in den Auslagerungsdepots konservatorisch zu betreuen und berichtete dem Referenten der Staatlichen Sammlungen, $\triangleright$ Fritz Fichtner, regelmäßig über deren Zustand. Dadurch

Posse, Anmerkung auf einem Brief von Unger an die Direktion der Gemäldegalerie vom 15.2.1929, 29.3.1929, HStA Dresden, 13859, Nr. 9129, fol. 1 K.

NSDAP Kreisleitung Dresden, an SMV, 19.6.1936, ebd., o. Pag.

Vgl. Iselt 2010, S. 141, insbesondere Anm. 246. 
weilte Unger häufig im Schloss Weesenstein. Am 11. August 1944 wurde Unger durch Fichtner als Depotverantwortlicher für die Gemäldegalerie benannt. Das Sächsische Ministerium für Volksbildung erinnerte Ende März 1945 nochmals ausdrücklich an seine Aufgabe der konservatorischen Überwachung. ${ }^{4}$ Nach Kriegsende wurde Unger zunächst weiter beschäftigt. Zu verdanken hatte er dies seiner Bestandskenntnis und seinen konservatorischen Fähigkeiten, aber auch den Bemühungen von Will Grohmann. ${ }^{5}$ So war Unger auch an den Rücktransporten von Gemälden nach Dresden bzw. Pillnitz beteiligt, auf dem Rückweg seiner Dienstaufenthalte in Weesenstein transportierte er im Herbst 1945 meist Gemälde nach Dresden. Doch Ende Juli 1946 wurde er im Alter von 50 Jahren aufgrund seiner früheren NSDAP-Mitgliedschaft entlassen.

In den folgenden Jahren arbeitete er als freischaffender Künstler und Restaurator. Wann er Dresden verließ, ist nicht überliefert. Alfred Unger starb am 25. Dezember 1980 in Bochum.

\section{Quellen und Literatur}

HStA Dresden, 13859, Nr. 9129

SKD Archiv, 02/VA 162; 02/VA 53, Bd. 1

Standesamt Bochum, Sterbeurkunde Nr. 2627/1980

BArch, R 9361-IX/Kartei/45570438; R 9361-VIII/Kartei/23771199

\footnotetext{
4 Vgl. SMV, Fichtner, an Reichsstatthalter Mutschmann, 11.8.1944, HStA Dresden, 11125, Nr. 23058, fol. 84b u. SMV, Graefe, an Direktor Gemäldegalerie, 31.3.1945, SKD Archiv, 02/VA 53, Bd. 1, fol. 126.

5 Vgl. Niederschrift nach einer Besprechung von Grohmann, General Dubrowsky und Präsident Friedrichs, 4.1.1946, SKD Archiv, 02/VA 162, fol. 43.
} 


\section{Hermann Voss}

30.7.1884 Lüneburg - 28.4.1969 München

Kunsthistoriker

Gemäldegalerie

9.3.1943-31.3.1943 Kommissarischer Direktor

1.4.1943-24.7.1945 Direktor

Kupferstich-Kabinett

9.3.1943-24.7.1945 Kommissarischer Leiter „Sonderauftrag Linz“

15.3.1943-5.1945 „Sonderbeauftragter des Führers“

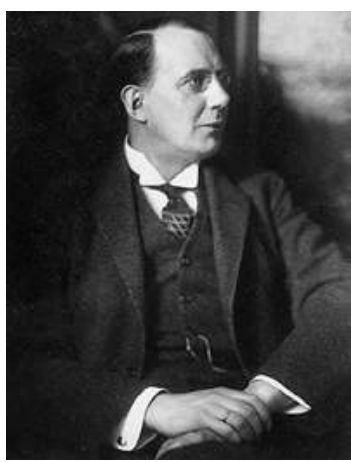
Gesamtverwaltung der Staatlichen Museen

9.7.1945-24.7.1945 Leiter

Hermann Georg August Voss wurde am 30. Juli 1884 in Lüneburg als Sohn des Kaufmanns Heinrich Hermann Louis Voss und dessen Frau Sophie Emilie Auguste, geb. Erzgräber, geboren. Nach dem Besuch der Gymnasien in Lüneburg und, nach dem Umzug der Familie, in Stralsund, erhielt er 1903 sein Reifezeugnis. Im Anschluss studierte er u. a. bei Henry Thode und Heinrich Wölfflin an den Universitäten Heidelberg und Berlin Kunstgeschichte, Musikgeschichte sowie Geschichte. Als Schüler von Thode wurde Voss 1906 in Heidelberg promoviert. Ein längerer Italienaufenthalt schloss sich an. Ab 1908 arbeitete Voss als Freiwilliger Wissenschaftlicher Hilfsarbeiter an den Königlich Preußischen Kunstsammlungen zu Berlin, zunächst in der Abteilung christlicher Bildwerke und Gipsabdrücke, später in der Gemäldegalerie und im Kupferstichkabinett, wo er zum Kustos ernannt wurde. Unter dem prägenden Einfluss von Wilhelm Bode begann er seine Kennerschaft zu entwickeln und mit verschiedenen Kunsthändlern zusammenzuarbeiten. Nach einer mehrwöchigen Studienreise in die Niederlande, nach Frankreich und Italien war Voss ab Oktober 1910 als Assistent am Kunsthistorischen Institut in Florenz tätig. Seit dieser Zeit lag sein Forschungsschwerpunkt bei der Italienischen Kunst. Im November 1912 wechselte er als Direktorialassistent an das Museum der bildenden Künste in Leipzig, dessen Graphische Sammlung er bald leitete. Im Ersten Weltkrieg zum Reservedienst eingezogen und ab 1915 beim Kriegspresseamt in Berlin eingesetzt, kehrte Voss erst im November 1918 nach Leipzig zurück. An der Universität Leipzig habilitierte er sich im Oktober 1919. Seine Habilitationsschrift über die Italienische Malerei der Spätrenaissance, die er 1920 veröffentlichte, avancierte zum Standardwerk. Neben seiner Tätigkeit im Museum lehrte er ab Sommersemester 1920 als Privatdozent an der Leipziger Universität. Ende 1921 legte Voss beide Ämter in Leipzig nieder, um zum Jahresbeginn 1922 dem Ruf als Kustos an die Gemäldegalerie der Staatlichen Museen zu Berlin anzunehmen. Unter dem stellvertretenden Leiter Max J. Friedländer, der nach dem Tod Bodes 1929 Direktor der Gemäldegalerie wurde, übernahm er Verwaltungsaufgaben und wirkte an den Erwerbungen mit. Er arbeitete in enger Vernetzung mit dem Kunsthandel und führte eine Neuordnung der italienischen Gemälde im Kaiser-Friedrich-Museum durch. Seine primär auf Stilkritik und Quellenforschung basierende Forschung mündete in zahlreiche Publikationen in nationalen und internationalen Periodika, auch rezensierte er Bücher und Ausstellungen. Vortrags- und Studienreisen führten ihn 1928 und 1931 in die USA, wo er die wichtigsten Museen besuchte. Nach zehn Jahren als Kustos sah er keine beruflichen Perspektiven in Berlin, zumal er, nachdem Friedländer aufgrund seiner jüdischen Abstammung 1933 entlassen 
worden war, bei der Wiederbesetzung nicht berücksichtigt wurde. Anfang April 1935 ging Voss als Direktor der Städtischen Kunstsammlung des Nassauischen Landesmuseums nach Wiesbaden. Er ordnete die Sammlung neu, was durch die Entfernung der „Entarteten Kunst“ notwendig geworden war, tätigte zahlreiche Ankäufe und Tauschgeschäfte. Daneben arbeitete er als Gutachter, z. B. als Sachverständiger des Wiesbadener Polizeipräsidiums und für das Auswärtige Amt im besetzten Frankreich. Bereits damals war Voss privilegiert, denn als einer von nur drei Fachkollegen genehmigte ihm das Auswärtige Amt im Sommer 1942 die Teilnahme an der Kunsthistorikertagung in Venedig.

Im März 1943 wechselte Voss nach Dresden. Galeriedirektor $>$ Hans Posse hatte ihn kurz vor seinem Tod als Nachfolger vorgeschlagen. Nachdem Adolf Hitler im Februar 1943 ein persönliches Gespräch mit Voss geführt hatte, ernannte er ihn zum Direktor der Gemäldegalerie in Dresden und zum „Sonderbeauftragten“ für den "Sonderauftrag Linz“. Voss nahm die Galerieleitung zunächst kommissarisch wahr und erhielt ab April 1943 die entsprechende Planstelle. Die Gemäldegalerie in Wiesbaden leitete er indes ehrenamtlich weiter, wobei er alle Aufgaben an die dort tätige Mitarbeiterin Juliane Harms delegierte. In Dresden leitet Voss zwar eine Galerie von Weltrang, allerdings waren deren Bestände kriegsbedingt ausgelagert, wodurch er nicht kuratorisch tätig werden konnte. Auch publizierte er in seinen Dresdner Jahren nicht und hielt lediglich zwei Vorträge, im Dezember 1943 über „Lorenzo Bernini. Der Meister des römischen Barock“ und im Februar 1944 über „Die venetianische Stadtansicht im 18. Jahrhundert“. ${ }^{2}$ Er weilte selten vor Ort, sondern war häufig als „Sonderbeauftragter für Linz“ zwischen Berlin, München, Linz und Wien unterwegs, um über ein weitverzweigtes Netzwerk von Kunsthändlern und Sammlern Werke für Linz zu erwerben. Seine Ankäufe für die Dresdner Galerie waren demgegenüber gering, vielmehr hatte er für die Sicherheit der kriegsbedingt ausgelagerten Bestände Sorge zu tragen, die Außendepots zu kontrollieren und beim Näherrücken der Front deren Umlagerungen zu organisieren. Hinzu kam, dass Voss allein 1944 über zwölf Wochen zur Kur verbrachte. Daher blieben $>$ Robert Oertel und $>$ Gottfried Reimer de facto auch nach seinem Amtsantritt für die Dienstgeschäfte der Gemäldegalerie und des "Sonderauftrags Linz“ verantwortlich. Nachdem seine Wohnung beim Luftangriff auf Dresden am 13. Februar 1945 zerstört worden war, lebte Voss gemeinsam mit seiner Frau Marianne, geb. Boese, Tochter des Berliner Akademieprofessors Konrad Heinrich August Boese, die er 1919 geheiratet hatte, auf Schloss Weesenstein, einem der Auslagerungsorte der Gemäldegalerie. Von dort aus ließ er während seiner Krankmeldung von Februar bis Juni 1945 seine Mitarbeiter nach Anweisungen agieren. Mitte Juni 1945 wurde er wieder als Galeriedirektor aktiv. Da er nie der NSDAP angehörte und die sowjetische Besatzungsmacht noch keine Kenntnis über seine Tätigkeit für den „Sonderauftrag Linz" erlangt hatte, wurde Voss am 9. Juli 1945 zum „Bergungsbeauftragten“ ernannt und mit der Leitung der Gesamtverwaltung der Staatlichen Museen in Dresden betraut. Doch nur zwei Wochen später, am 24. Juli 1945, begab sich Voss auf eine Dienstreise nach Wiesbaden, von der er nicht zurückkehrte.

\footnotetext{
1 Die anderen waren Hans Posse, Direktor der Gemäldegalerie Dresden, und Theodor Demmler vom Berliner Kaiser-Friedrich-Museum. Posse, mit dem Voss im Vorfeld Kontakt hatte, musste jedoch aufgrund seiner fortschreitenden Erkrankung auf die Teilnahme verzichten. Vgl. Iselt 2010, S. 158, $184 \mathrm{f}$.

2 Vgl. Einladungskarte u. Plakat für den Vortrag am 12.12.1943, HStA Dresden, 11125, Nr. 23081, fol. 184 f. u. Kupke, Leonore: Malerauge oder Kamera Obscura, in: DZ, 19.2.1944, S. 3.
} 
Kurz nach seiner Ankunft in Wiesbaden, am 1. August 1945, wurde Voss von amerikanischen Militärs verhaftet und nach Bad Aussee gebracht, wo er bis Mitte September 1945 mehrfach verhört wurde. Nach der Entlassung lebte Voss in München, wo er sich für Befragungen im dortigen Central Collecting Point bereithalten musste. Seine Gattin folgte ihm erst 1953 nach München. Das im Sommer 1946 gegen Voss angestrebte Verfahren verzögerte sich und wurde letztlich am 24. März 1949 eingestellt. Da er im Meldebogen infolge des „Gesetzes zur Befreiung von Nationalsozialismus und Militarismus“ im April 1946 seine Tätigkeit für das „Führermuseum Linz" verschwiegen hatte und nie Mitglied der NSDAP gewesen war, galt er als „unbelastet“. Er musste sich nie wegen seiner Beteiligung am NS-Kunstraub als „Sonderbeauftragter des Führers“ verantworten. Aber er hat nie wieder eine Stellung im öffentlichen Dienst erlangt. Stattdessen genoss Voss weiterhin eine uneingeschränkte Reputation als Spezialist für die Deutsche Malerei des 19. Jahrhunderts und die Italienische Malerei der Renaissance und des Barocks. Er arbeitete fortan als freiberuflicher Kunsthistoriker, wodurch er weiteren Untersuchungen über seine Tätigkeit im NS-Staat entging, und publizierte ab 1951 erneut zahlreiche Aufsätze, Rezensionen und Ausstellungsbesprechungen. Auch wurde er als Gutachter für Museen, Galerien und Privatpersonen tätig und erforschte von 1957 bis 1964 mit Gerhard Ewald in einem DFG-geförderten Projekt die „Malerei des Barock in Florenz“. Hermann Voss starb am 28. April 1969 in München.

\section{Auswahlbibliografie}

Der Ursprung des Donaustiles. Ein Stück Entwicklungsgeschichte deutscher Malerei, (Kunstgeschichtliche Monographien, Bd. 7), Leipzig 1907 (Zugl. Leipzig, Univ., Diss., 1906: Ueber Wolf Huber als Maler und einige Meister des Donaustiles).

Albrecht Altdorfer und Wolf Huber, (Meister der Graphik, Bd. 3), Leipzig 1910.

Die Malerei der Spätrenaissance in Rom und Florenz, Bd. 1-2, Berlin 1920.

Die Malerei des Barock in Rom, Berlin 1924.

Zeichnungen der italienischen Spätrenaissance (Die Zeichnung, Folge 2: Die Italiener, Bd. 4), München 1928.

Der Meister der Wiesbadener Heimsuchung, Wiesbaden 1936.

Amtlicher Katalog der Gemäldegalerie Wiesbaden, Wiesbaden 1937.

Die Frühwerke von Carlo Carlone in Österreich, in: Arte Lombarda, 6, 1961, S. 238-255.

Pietro Ricchi, in: Arte Veneta, 5, 1951, S. 65-72.

Johann Heinrich Schönfeld. Ein schwäbischer Maler des 17. Jahrhunderts, Biberach an der Riss 1964.

\section{Quellen und Literatur}

HStA Dresden, 13859, Nr. 9267

HStA Dresden, 10701, Nr. 320/55, Bd. 1

SKD Archiv, 01/PS 53, Bd. 1 u. 2

Eisenlöffel, Lars: Hitlers Kurator Hermann Voss. Bodes Schüler an den Abgründen der Museumskultur, in: Jahrbuch der Berliner Museen, N. F., Bd. 47, 2005, S. 117-124.

Iselt, Kathrin: Hermann Voss. Seine Ernennung zum „Sonderbeauftragten für Linz“ und Direktor der Staatlichen Gemäldegalerie Dresden, in: Dresdener Kunstblätter, 52. Jg., H. 1, 2008, S. 26-35.

Iselt, Kathrin: „Sonderbeauftragter des Führers“. Der Kunsthistoriker und Museumsmann Hermann Voss (1884-1969), Köln, 2010 (Studien zur Kunst 20) (Zugl. Dresden, Univ., Diss., 2009) (mit Schriftenverzeichnis Hermann Voss). 


\section{Lucie Walter}

27.9.1895 Bromberg - [nach 9.1961 Jerusalem]

Bibliotheksangestellte (Mittlerer Dienst)

Sächsische Landesbibliothek

1.12.1923-31.3.1929 Bibliotheksgehilfin

1.12.1930-31.8.1933 Bibliotheksangestellte (Mittlerer

Dienst)

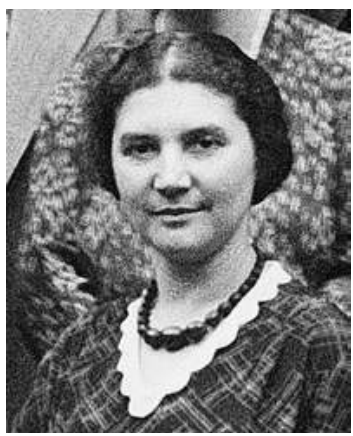

Lucie Rosa Walter, am 27. September 1895 als Tochter des Rabbiners Gotthilf Walter und dessen Ehefrau Selma, geb. Kohn, in Bromberg geboren, arbeitete nach dem Besuch der Höheren Mädchenschule ab Mai 1914 als Volontärin in der Stadtbibliothek zu Bromberg. Gleichzeitig bildete sie sich an der Frauenschule weiter. Ab Oktober 1915 lebte Walter in Berlin, wo sie sich im Lette-Verein, der sich in der Berufsausbildung für Frauen engagierte, und an der von August Wolfstieg, dem Bibliotheksdirektor des preußischen Abgeordnetenhauses in Berlin, gegründeten ersten Bibliothekarinnenschule ausbilden ließ. Im Dezember 1916 absolvierte sie erfolgreich die Prüfung an dieser Schule. Anschließend kehrte Walter nach Bromberg zurück, wo sie bis Januar 1918 als Praktikantin an der Stadtbibliothek arbeitete, die damals von > Martin Bollert geleitet wurde, dem sie später in Dresden wiederbegegnen sollte. Von Mai bis September 1918 weilte Walter erneut in Berlin und legte die Diplomprüfung für den Mittleren Bibliotheksdienst an wissenschaftlichen Bibliotheken ab. Danach arbeitete sie bis zum Sommer 1919 als außerordentliche Hilfsarbeiterin an der Bromberger Stadtbibliothek, bevor sie für zwei Jahre als Bibliothekarin beim Centralverein deutscher Staatsbürger jüdischen Glaubens in Berlin tätig wurde. Diese Stellung gab Walter auf, um ihren Eltern ins hessische Kassel zu folgen.

Im Frühjahr 1923 offerierte ihr Bollert, der unterdessen von Bromberg als Direktor an die Sächsische Landesbibliothek berufen worden war, eine Anstellung in Dresden. Anfang April sagte sie zu und begann ihre Arbeit als Bibliotheksgehilfin ab Dezember 1923. Um in den Höheren Bibliotheksdienst wechseln zu können, studierte sie nebenher an der Technischen Hochschule Dresden. Nach einer anderthalbjährigen unbezahlten Beurlaubung nach Leipzig zur Ausbildung für den Höheren Bibliotheksdienst, legte Walter im November 1930 auch ihr Examen als Diplomvolkswirtin an der Technischen Hochschule Dresden ab. Ab Dezember 1930 war sie als Bibliotheksangestellte an der Sächsischen Landesbibliothek tätig. Wie \Anna Löwenthal und acht weitere Personen erhielt Walter aufgrund der staatlich angeordneten Sparmaßnahmen zum 31. Januar 1931 ihre Kündigung, wurde allerdings nach einer Gehaltskürzung weiterhin beschäftigt. Im Fragebogen, den alle Angestellten im öffentlichen Dienst im Zuge des „Gesetzes zur Wiederherstellung des Berufsbeamtentums“ auszufüllen hatten, schrieb Walter im Juni 1933, wie ihre Kollegin Löwenthal, lediglich „Ich bin Jüdin“. Am 20. Juli 1933 wies das Sächsische Ministerium für Volksbildung den Direktor der Landesbibliothek, Bollert, an, Walter zum 31. August 1933 zu entlassen. Vier Tage später übermittelte Bollert die Kündigung. Das Einzige, was er in dieser Situation noch für Walter, die er zuvor protegiert hatte, tun konnte, war, ihr ein hervorragendes Arbeitszeugnis auszustellen. So bescheinigte er ihr am 26. Juli 1933, „dass sie zu den allertüchtigsten Mitarbeiterinnen gehört hat. Sie ist mit vorzüglichen Gaben des 
Geistes ausgestattet und besitz ein hohes Maß von Arbeitsfreude und Pflichtgefühl, so dass ihre Leistungen auch bei schwierigen und verantwortlichen Aufgaben stets meine volle Zufriedenheit fanden. Ihr persönliches Auftreten ist gewandt und liebenswürdig." ${ }^{11}$

Wie lange Walter nach ihrer Entlassung noch in Dresden blieb, ist aufgrund fehlender Überlieferung ebenso unklar wie das Datum ihrer Auswanderung nach Palästina. Jedenfalls hat sie Deutschland „rechtzeitig verlassen “2 und lebte später in Jerusalem. ${ }^{3}$ Belegt ist ihre besuchsweise Rückkehr nach Deutschland im Sommer 1957, bei der sie ehemalige Mitarbeiter der Landesbibliothek, die mittlerweile in Westdeutschland lebten, darunter $\triangleright$ Ewald Jammers und $\triangleright$ Charlotte Holzhausen, in Stuttgart traf, und eine Reise in die Schweiz im Herbst 1961. ${ }^{4}$ Danach verliert sich ihre Spur.

\section{Quellen und Literatur}

SLUB, PA Walter, Lucie

SLUB, Mscr.Dresd.App.2830

Bürger, Thomas: Dresdner Bibliothekare - emigriert, geflohen, geblieben. Briefe der Nachkriegszeit aus dem Nachlass von Ewald Jammers (Teil 2), SLUB-Kurier, 21. Jg., 2007, 2, S. 13-15.

Bollert, Arbeitszeugnis für Lucie Walter, 26.7.1933, SLUB, PA Walter.

Jammers 2002, S. 313.

3 Ihre Eltern blieben in Deutschland. Der Vater, ein Rabbi, wurde am 26.10.1942 in Berlin ermordet, die Mutter am 10.11.1943 im KZ Theresienstadt. Vgl. Einträge zu Selma Walter, geb. Kohen, und Gotthilf Eliezer Walter, The Central Database of Schoah Victim's Names, Yad Vashem, Jerusalem, 6.5.2019. Für diese Auskunft dankt die Autorin Rachel Shapiro, Yad Vashem, Jerusalem.

4 Vgl. Walter an Jammers, 6.6.1957 u. Vierneisel an Walter, C. Holzhausen, Jammers, 22.6.1957, sowie Löwenthal an Jammers, 21.12.1961, SLUB, Mscr.Dresd.App. 2830, fol. 115, 119, 105. 


\section{KARL WANDERER}

15.9.1876 Kitzingen - 19.11.1945 Bad Schliersee Geologe, Paläontologe

Museum für Mineralogie, Geologie und Vorgeschichte (bis 1918: Königliches Mineralogisch-Geologisches und Prähistorisches Museum)

1906-1920 Wissenschaftlicher Hilfsarbeiter

1920-31.3.1937 Kustos

(Militärdienst 8.1914-11.1918)

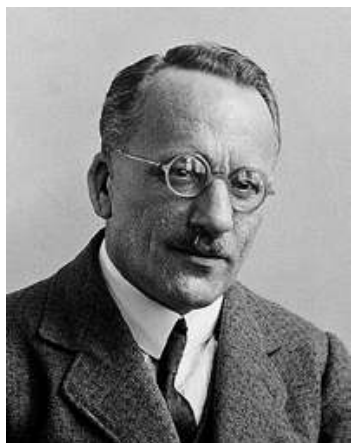

Karl Wanderer wurde am 15. September 1876 als Sohn eines Kaufmanns in Kitzingen am Main geboren. Nach dem Abitur studierte er zunächst ab 1898 Philosophie und Jura an der Universtität Berlin. Nach zwei Jahren wechselte er an die Universität München, wo er 1905 sein Studium der Geologie und Paläontologie mit der Promotion bei Josef Felix Pompeckj und Karl Alfred von Zittel abschloss. Danach arbeitete Wanderer als Assistent am Königlichen Naturalienkabinett in Stuttgart.

1906 holte Ernst Kalkowsky den dreißigjährigen Wanderer als Wissenschaftlichen Hilfsarbeiter an das Königliche Mineralogisch-Geologische und Prähistorische Museum in Dresden, wo er 1908 zum Direktorialassistenten befördert wurde. Diese Arbeit unterbrach Wanderer, um am Ersten Weltkrieg teilzunehmen. Zuletzt war er in Frankreich als Geologe eingesetzt, bevor er, in seiner Abwesenheit 1915 zum Professor ernannt, im November 1918 an das Museum nach Dresden zurückkehrte. Dort wurde er 1920 zum Kustos der geologisch-paläontologischen Abteilung des Museums ernannt. Sein wissenschaftliches Interesse galt vorrangig den Versteinerungen aus der sächsischen Kreide und den Säugetierresten aus Dresdens Umgebung. 1909 verfasste er ein Standardwerk über die Kreidefossilien Sachsens. Im Museum legte er eine Sammlung quartärer Knochenfunde an und trennte die Schausammlung von der wissenschaftlichen Studiensammlung, die er unter besonderer Berücksichtigung der Geologie Sachsens ausbaute. Zu seinen Verdiensten zählte die grundsätzliche Neugestaltung der geologischen Ausstellung im Zwinger als allgemeine geologische Formationssammlung, bei der er vom Präparator $\gg$ Rudolf Schwarze praktisch unterstützt wurde. Wanderer überwand dabei die bisher übliche Präsentation in Form der Aneinanderreihung von Pulten mit unzähligen Fossilien in streng wissenschaftlicher Ordnung ohne Erläuterungen, indem er aus jeder Periode der erdgeschichtlichen Entwicklung nur die wichtigsten Ereignisse auswählte, die er mittels ausgewählter Präparate veranschaulichte und durch selbst entworfene Skizzen, Karten, Tabellen und Texttafeln ergänzte. Für diese neu gestaltete, lehrreiche Ausstellung, die als „Muster volkstümlicher Darstellung wissenschaftlichen Museumsgutes $^{\text {"1 }}$ angesehen wurde, erhielt Wanderer internationale Anerkennung. Er galt als einer der besten geowissenschaftlichen Ausstellungsgestalter seiner Zeit. ${ }^{2}$ Bereits 1930 hatte sein Frankfurter Kollege Friedrich Ernst Drevermann angeregt, dass Wanderer bei der in Dresden stattfinden-

1 W. F.: Gelehrter, Schriftsetzer und Künstler. Karl Wanderers Dresdner Museumswerk, in: DA, 31.3.1937.

2 Vgl. Lange, Jan-Michael u. Ellen Kühne (Hg.): Geschichte des Museums für Mineralogie und Geologie in den Staatlichen Naturhistorischen Sammlungen Dresden. Von der kurfürstlichen Kunstkammer zum staatlichen Forschungsmuseum, Dresden 2006, S. 47. 
den Tagung der Paläontologischen Gesellschaft diese Neuaufstellung vorstellte. Wenige Jahre später ließ sich Wanderer zum 1. April 1937 aus gesundheitlichen Gründen vorzeitig pensionieren, obwohl sein Lebenswerk, die Umgestaltung der Schausammlung, damals noch nicht vollständig abgeschlossen war. Ob dies als Vorwand diente und er sich aus politischen Gründen zu diesem Schritt gezwungen sah, geht aus den überlieferten Akten nicht eindeutig hervor. ${ }^{3}$ Sein Amt als Beisitzer im Vorstand des Deutschen Museumsbundes, Abteilung deutsche naturwissenschaftliche Museen, das er erst 1936 übernommen hatte, setzte er bis 1938 fort. $^{4}$

Nach seiner Pensionierung zog Karl Wanderer gemeinsam mit seiner Frau nach Bayern, wo er am 19. November 1945 in Bad Schliersee starb.

\section{Auswablbibliografie}

Die Jura-Ablagerungen am Westrande des Bayrischen Waldes zwischen Regenstauf und der Bodenwöhrerbucht, in: Neues Jahrbuch der Mineralogie, Geologie und Paläontologie, Beil.-Bd. 21, Stuttgart 1906, S. 468-539 (Zugl. München, Univ., Diss., 1905).

Rhamphorhynchus Gemmini H. v. Meyer. Ein Exemplar mit teilweise erhaltener Flughaut aus dem Kgl. Mineralog.-Geol. Museum zu Dresden, in: Palaeontographica, 55, Stuttgart 1908, S. $195-216$.

Die wichtigsten Tierversteinerungen aus der Kreide des Königreiches Sachsen, Jena 1909.

Der erste Fund eines Moschusochsen im Diluvium des Königreiches Sachsen, in: Sitzungsberichte und Abhandlungen der naturwissenschaftlichen Gesellschaft Isis Dresden, Jg. 1909, Dresden 1909, S. 79-85.

Die ersten Funde von Kalkalgen (Lithothamnien) aus der Kreide von Sachsen, in: Sitzungsberichte und Abhandlungen der naturwissenschaftlichen Gesellschaft Isis Dresden, Jg. 1919, Dresden 1920, S. 9.

Die erdgeschichtliche Entwicklung der Stadt Freital und Umgebung, in: Deutschlands Städtebau, Berlin 1924, S. 6-13.

Geologischer Museumsbrief aus dem Dresdner Zwinger, in: Museumskunde, N. F. 1, 1930, S. 82-93.

Ein „Silberfisch“ aus dem Mansfelder Kupferschiefer, in: Mitteilungen aus dem Museum für Mineralogie, Geologie und Vorgeschichte zu Dresden, Bd. 25, 1932, S. 169 f.

Der erste Nachweis von Elephas trogontherii Pohl. in Sachsen, in: Mitteilungen aus dem Museum für Mineralogie, Geologie und Vorgeschichte zu Dresden, Bd. 30, 1934, S. 172-182.

\section{Quellen und Literatur}

SKD Archiv, 01/PS 53, Bd. 3

HStA Dresden, 11125, Nr. 19295

Häntzschel, Walter: Zum Gedenken an Karl Wanderer (1876-1945), in: Jahrbuch des Staatlichen Museums für Mineralogie und Geologie zu Dresden, 1956/57, S. 6-14.

3 Hans Prescher beschrieb die Pensionierung von Wanderer als „vorzeitige[n] - fast einer Flucht gleichende[n] - Abgang “, Wanderer verließ ,aus politischen Gründen 1938 Dresden“. Prescher 1993, S. 29 u. Prescher 1978, S. 56.

4 Vgl. Rauther an Jacob-Friesen, 19.10.1936 und Rauther, an Schneider, Museum für Angewandte Geologie der Preuß. Geologischen Landesanstalt, 15.10.1938, beide: SMB-ZA, III/DMB 333, III, o. Pag. 


\section{DOROTHEE VON WATZDORF}

30.6.1890 Freiberg - 9.7.1956 Helmstedt

Bibliothekarin (Mittlerer Dienst)

Sächsische Landesbibliothek

(bis 1.5.1917 Königliche Öffentliche Bibliothek,

2.5.1917-11.1918 Königliche Landesbibliothek)

1.10.1915-30.9.1917 Volontärin

1.10.1917-31.5.1918 Hilfsarbeiterin

1.12.1918-31.3.1927 Bibliotheksgehilfin

1.4.1927-31.1.1931 2. Oberbibliothekssekretärin

1.2.1931-15.10.1945 1. Oberbibliothekssekretärin

(Erkrankung 8.1931-8.1932, Abordnung an Universitäts- und Staatsbibliothek Straßburg

1.1.1941-31.3.1943 und Bibliothek der Technischen Hochschule Dresden ab 19.3.1945;

Beurlaubung ab 6.1945)

Am 30. Juni 1890 in Freiberg als Tochter des Generalmajors Camillo von Watzdorf und dessen Frau Anna Louise, geb. von Platen, geboren, entstammte Anna Dorothee von Watzdorf einer ehemals thüringischen Adelsfamilie. ${ }^{1}$ Sie wurde zunächst privat und später an diversen Höheren Töchterschulen in Dresden unterrichtet, bevor sie 1907 für fünf Monate eine Haushaltungsschule absolvierte. Da sie auch über eine kurze Ausbildung zur Rotkreuzhelferin verfügte, war sie im Ersten Weltkrieg als Helferin des Roten Kreuzes im Königlichen Lazarett Parkstraße in Dresden tätig.

Ihre bibliothekarische Laufbahn begann Watzdorf im Oktober 1915 als Volontärin an der Königlichen Öffentlichen Bibliothek in Dresden, wo sie zwei Jahre später zur Hilfsarbeiterin und im Dezember 1918 zur Bibliotheksgehilfin ernannt wurde. Im April 1927 wurde sie zur 2. Oberbibliothekssekretärin, knappe vier Jahre später zur 1. Oberbibliothekssekretärin der Sächsischen Landesbibliothek befördert, wo sie den Porträtkatalog führte. Eine Erkrankung zwang sie ab August 1931 zu einer einjährigen Unterbrechung dieser Tätigkeit. Über ihre Arbeit an der Landesbibliothek während der NS-Zeit sind nur wenige Details überliefert. Da sie bereits seit August 1925 Mitglied der NSDAP war und als Einzige in der Bibliothek das Goldene Parteiabzeichen besaß, hielt sie anlässlich der Aufstellung der Hitlerbüste in der Landesbibliothek am 30. Januar 1935 eine Rede. ${ }^{2}$ Watzdorf war bereits früher Mitglied in der Deutsch-Nationalen Volkspartei und von 1919 bis 1927 im Altdeutschen Verband gewesen, bevor sie in mehrere NS-Organisationen eintrat, auch in die NS-Frauenschaft. > Ewald Jammers erinnerte sich Jahre später, dass die NSDAP-Mitgliedschaft von Watzdorf zum Vorteil der Landesbibliothek und deren Angestellten gereichte: Watzdorf „war adliger Herkunft, träumte von der Größe Deutschlands und seiner Geschichte, über die sie ganz hervorragend einschließlich der Territorialgeschichte Bescheid wußte“, auch gehörte sie „der Partei von Anbeginn an, besaß den entsprechen-

\footnotetext{
1 Auch $\triangleright$ Erna von Watzdorf, Mitarbeiterin des Grünen Gewölbes und Historischen Museums, stammte aus diesem Adelsgeschlecht, jedoch aus einer Linie, die sich acht Generationen zuvor, im 17. Jahrhundert getrennt hatte.

2 Vgl. Weihe einer Hitlerbüste in der Landesbibliothek, in: DNN, 31.1.1935, S. 7; Eine Hitlerbüste in der Landesbibliothek, in: DA, 31.1.1935, S. 6. Siehe S. 108.
} 
den Orden und konnte daher viel Gutes wirken und uns, die Bibliothek als Institut und z. B. auch mich selber vor bösen Angriffen schützen. “3 Im Januar 1941 wurde sie durch das Reichsministerium für Wissenschaft Erziehung und Volksbildung an die Universitäts- und Staatsbibliothek Straßburg abgeordnet. Erst im März 1943 kehrte sie an die Landesbibliothek in Dresden zurück. Im März 1945 wurde sie erneut abgeordnet, diesmal innerhalb von Dresden, an die Bibliothek der Technischen Hochschule. Nach Kriegsende, am 23. Juni 1945, wurde Watzdorf aufgrund ihrer NSDAP-Mitgliedschaft mit sofortiger Wirkung beurlaubt. Nach einer kurzen bibliothekarischen Tätigkeit auf Schloss Baruth im September 1945 wurde sie zum 15. Oktober 1945 endgültig aus dem Bibliotheksdienst entlassen.

Da sie nach ihrer Entlassung in Dresden keine Lebensmöglichkeit mehr sah, zumal die Wohnung, die sie sich mit ihrer verwitweten Cousine Marie von Otterstedt teilte, bei den Luftangriffen im Februar 1945 zerstört worden war, zog sie mit dieser zu einer Freundin nach Helmstedt, wo sie am 1. April 1946 in der Bahnhofsmission ankam. ${ }^{4}$ Der Pfarrer der Heilig-Geist-Kirchgemeinde, zu der sie in Dresden gehörten, hatte sie für den Weg in die ungewisse Zukunft noch mit einem Schreiben ausgestattet, das besagte, „daß die beiden Damen mit steigender Ablehnung, ja wachsender Empörung die Entwicklung des Nationalsozialismus verfolgt und über ihre Gesinnung andere nicht im Unklaren gelassen haben. Geradezu vorbildlich und mutig war ihre kirchliche Haltung" ". Ab 1. März 1949 verwaltete Watzdorf die Ehemalige Universitätsbibliothek Helmstedt, worüber sie Jammers berichtete: „Ich selbst bin wieder bibliothekarisch tätig ich ordne und verwalte die hier noch vorhandenen Bestände der ehemaligen Universitätsbibliothek. "6 Wenige Monate nach einem schweren Unfall starb Dorothee von Watzdorf am 9. Juli 1956 in Helmstedt.

\section{Auswahlbibliografie}

Aus der Geschichte der Universitätsbibliothek, in: 1000 Jahre Helmstedt (952-1952). Jubiläumsausgabe der Helmstedter Allgemeinen Zeitung, 6.9.1952.

Verzeichnis der Leichenpredigten der ehemaligen Universitätsbibliothek Helmstedt, Helmstedt 1957 (Hg. mit Rolf Volkmann).

\section{Quellen und Literatur}

HStA Dresden, 13859, Nr. 9397

HStA Dresden, 12624, Familiennachlaß Grafen von Watzdorf, Nr. 163; Nr. 203

SLUB, PA Watzdorf, Dorothee von

SLUB, Mscr.Dresd.App.2830,121

BArch, R 9361-IX/Kartei/47030519

3 Jammers 2002, S. $313 \mathrm{f}$.

4 Für die Informationen zum Leben von Watzdorf in Helmstedt dankt die Autorin Ilse MoshagenSiegl, Stadtarchiv Helmstedt. Siehe Todesanzeige und Nachruf in der Braunschweiger Zeitung.

5 Pfarrer Eduard Wauer, Heilig-Geist-Kirchgemeinde zu Dresden-Blasewitz, Abschrift, 24.2.1946, HStA Dresden, 12624, Nr. 203, o. Pag.

6 D. v. Watzdorf an Jammers, 25.5.1951, SLUB, Mscr.Dresd.App.2830,121. 


\section{ERNA VON WATZDORF}

15.2.1892 Dresden - 17.9.1976 Kassel

Kunsthistorikerin

Kupferstich-Kabinett

1.9.1921-31.12.1921 Freiwillige Wissenschaftliche

Hilfsarbeiterin

Gemäldegalerie

12.1.1925-31.12.1925 Freiwillige Wissenschaftliche

Hilfsarbeiterin

Grünes Gewölbe

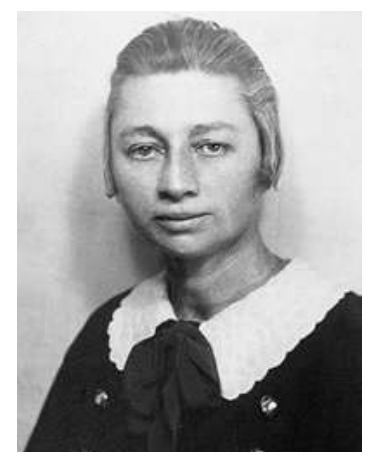

1.10.1928-31.10.1929 Freiwillige Wissenschaftliche

Hilfsarbeiterin

1.11.1945-31.7.1946 Kommissarische Leiterin

Historisches Museum

1.11.1929-30.6.1937 Freiwillige Wissenschaftliche Hilfsarbeiterin

1.7.1937-31.10.1945 Wissenschaftliche Hilfsarbeiterin

1.11.1945-31.7.1946 Kustos, Kommissarische Leiterin

Münzkabinett

1.11.1945-31.7.1946 Kommissarische Leiterin

(Abordnung an Gemeinschaftliche Ministerialbibliothek und Sächsische Landesbibliothek

16.1.1942-30.4.1942, sowie tageweise an Statistisches Landesamt ab 15.7.1944-[?])

Am 15. Februar 1892 als Tochter des königlich-sächsischen Generalleutnants Hans Rudolf von Watzdorf und dessen Frau Louise, geb. Ebert, in Dresden geboren, entstammte Erna von Watzdorf einer weitverzweigten, ursprünglich thüringischen Adelsfamilie. ${ }^{1}$ Nach dem Besuch einer Privatschule legte sie ihre Reifeprüfung am Neustädter Gymnasium in Dresden ab. Von 1917 bis 1920 studierte Watzdorf an den Universitäten in Berlin, Heidelberg, München, Berlin und Marburg Kunstgeschichte, Geschichte und Archäologie.

Im Herbst 1921 arbeitete sie für vier Monate als Freiwillige Wissenschaftliche Hilfsarbeiterin am Kupferstich-Kabinett in Dresden. Von Herbst 1922 bis März 1924 inventarisierte Watzdorf im Rahmen eines Werkvertrages unter der Leitung von Walther Biehl die Bestände des grafischen Kabinetts im Stadtmuseum Bautzen. Währenddessen wurde sie 1923 in Marburg als Schülerin von Richard Hamann promoviert. Nach einer längeren Italienreise arbeitete sie ab Jahresanfang 1925 für ein Jahr als Freiwillige Wissenschaftliche Hilfsarbeiterin in der Gemäldegalerie in Dresden. Wenige Jahre später, 1928, wirkte Watzdorf an den Vorbereitungen der Ausstellung „Kunst in Sachsen vor hundert Jahren " des Sächsischen Kunstvereins in Dresden mit. Spätestens durch diese Tätigkeit kam sie in Kontakt zu $\triangleright$ Erich Haenel, der sich als Direktor des Grünen Gewölbes und Historischen Museums auch im Vorstand des Sächsischen Kunstvereins engagierte. Ab Oktober 1928 arbeitete Watzdorf als Freiwillige Wissenschaftliche Hilfsarbeiterin im Grünen Ge-

\footnotetext{
1 Auch $>$ Dorothee von Watzdorf, Mitarbeiterin der Sächsischen Landesbibliothek, stammte aus diesem Adelsgeschlecht, jedoch aus einer Linie, die sich acht Generationen zuvor, im 17. Jahrhundert getrennt hatte.
} 
wölbe, wobei sie ein Jahr später zusätzlich auch im Historischen Museum tätig wurde. Nachdem ihre Bewerbung um eine Kustodenstelle in der Porzellansammlung 1933 erfolglos geblieben war, eingestellt wurde $>$ Fritz Fichtner, blieb sie in ihrer unbezahlten Position am Historischen $\mathrm{Mu}$ seum. Direktor Haenel, der ihre Arbeit schätzte, gelang es zumindest, ihr ab 1930 eine geringe Vergütung für die Neubearbeitung des Verzeichnisses der Jagdwaffen der Gewehrgalerie zu sichern. Erst im Juli 1937, nach mehrmaligen vergeblichen Versuchen Haenels, wurde Watzdorf als Wissenschaftliche Hilfsarbeiterin eingestellt. Der Versuch, sie 1940 zur Kustodin ernennen zu lassen, schlug fehl, weil „die Frage der Errichtung“ einer Kustodenstelle „während des Krieges nicht weiter verfolgt werden " 2 könne. Zu Watzdorfs Aufgaben in beiden Museen, dem Grünen Gewölbe wie dem Historischen Museum, zählte neben der fachwissenschaftlichen Korrespondenz und der Betreuung der Bibliothek auch die Mitarbeit an Ausstellungen. So unterstützte sie Haenel bei den Vorbereitungen der Ausstellung „August der Starke und seine Zeit“ (1933) und der „Deutsche[n] Turnierschau“ (1936).

Watzdorf erforschte den im Grünen Gewölbe aufbewahrten Schmuck aus Renaissance und Barock. Ab 1937 arbeitete sie parallel an ihrer erst 1962 erschienenen, zweibändigen Dinglinger-Monografie, für die sie mehrfach Sachbeihilfen der DFG erhielt, u. a. zur Fotobeschaffung. Darüber hinaus wirkte Watzdorf an der kriegsbedingten Auslagerung der Bestände mit und kontrollierte die im Museum verbliebenen Objekte, wovon ihre Tagebuchaufzeichnungen zeugen. So ist ihr die Rettung der alten Inventare des Grünen Gewölbes zu verdanken. Nach Kriegsende war Watzdorf die einzige Wissenschaftlerin in Dresden, die über exzellente Bestandskenntnisse der Sammlungen des Grünen Gewölbes und Historischen Museums verfügte. Ende November 1945 wurde sie, rückwirkend zum 1. November, zum Kustos ernannt und „mit der stellvertretungsweisen Leitung des Historischen Museums, des Grünen Gewölbes und des Münzkabinetts beauftragt “"3. Doch nur wenige Monate später, am 31. Juli 1946, wurde Watzdorf fristlos entlassen, wie viele ihrer Wissenschaftler-Kollegen, die zuvor Mitglieder der NSDAP gewesen waren. Allerdings war sie zu keiner Zeit in die Partei der Nationalsozialisten, sondern lediglich ab Dezember 1935 in die NS-Frauenschaft eingetreten. 1933 war sie kurzeitig Mitglied der Deutschnationalen Volkspartei gewesen. Die Beurteilungen durch die NSDAP-Kreisleitung Dresden, die im Rahmen der Beförderungsanträge eingeholt worden waren, betonten ihr „zurückgezogenes Leben“ und „den zweifellos vorhandenen Standesdünkel“ ${ }^{\text {“4 }}$ und kamen zu dem Fazit, dass ihre „Einstellung zum Staat und zur Bewegung [...] als bejahend anzusprechen sein [dürfte]; in einer überzeugenden Art kommt sie allerdings nicht zum Ausdruck. Sie entspricht vielmehr Zweckmässigkeitsgründen. ${ }^{\text {5 }}$

Über die Jahre nach ihrer Entlassung, in denen sie weiterhin über Dresdner Goldschmiede- und Steinschnittkunst publizierte, sind nur wenige Informationen überliefert. So bleibt unklar, wann sie Dresden verließ und nach Hessen übersiedelte. Ihre letzten Lebensjahre verbrachte Erna von Watzdorf in einer Seniorenresidenz in Kassel. Dort starb sie am 17. September 1976.

\footnotetext{
Notiz von Fichtner, 24.4.1940, HStA Dresden, 11125, Nr. 18991, Bd. 4, fol. 56.

3 Landesverwaltung Sachsen, Zentralverwaltung für Wissenschaft. Kunst und Erziehung, Staatssekretär Menke-Glückert, an E. v. Watzdorf, 26.11.1945, ebd., fol. 101.

4 NSDAP Kreisleitung Dresden an SMV, 5.5.1941, ebd., o. Pag.

$5 \quad$ NSDAP Kreisleitung Dresden an SMV, 29.12.1937, ebd.
} 


\section{Auswahlbibliografie}

Der deutsche Holzschnitt im 19. Jahrhundert, Marburg 1923 (Zugl. Marburg, Univ., Diss., 1923).

Brandenburgisch-sächsische Wachsplastik des XVI. Jahrhunderts. Studien aus den Kunstkammern in Berlin und Dresden, in: Jahrbuch der Preußischen Kunstsammlungen, Bd. 52, 1931, S. 235-357 (mit Walter Holzhausen).

August der Starke. Kunst und Kultur des Barock, Dresden 1933 (mit Erich Haenel).

Gesellschaftsketten und Kleinode vom Anfang des XVII. Jahrhunderts. Zur Geschichte der Goldschmiedekunst in Sachsen, in: Jahrbuch der Preußischen Kunstsammlungen, Bd. 54, 1933, S. 167-187.

Fürstlicher Schmuck der Renaissance aus dem Besitz der Kurfürstin Anna von Sachsen, in: Münchner Jahrbuch der bildenden Kunst, N. F., Bd. 11, 1934, S. 50-64.

Kursächsische Jagdwaffen von Gabriel Gipfel in der Dresdner Rüstkammer, in: Zeitschrift für historische Waffen- und Kostümkunde. Organ des Vereins für Historische Waffenkunde, Bd. 14, 1935, S. 4-14.

Die Dresdner Fußturnier-Ordnung von 1650, in: Zeitschrift für historische Waffen- und Kostümkunde. Organ des Vereins für Historische Waffenkunde, Bd. 6, 1937, S. 31-38.

Der Dresdner Goldschmied Abraham Schwedler und sein Kreis, in: Zeitschrift für Kunstwissenschaft, Bd. 16, 1/2, 1962, S. 81-128.

Johann Melchior Dinglinger. Der Goldschmied des deutschen Barock, Berlin 1962.

Der Dresdner Edelsteinschneider Johann Christoph Hübner um 1665 bis 1739, in: Zeitschrift des Deutschen Vereins für Kunstwissenschaft, Bd. 26, 1972, S. 15-42.

\section{Quellen und Literatur}

HStA Dresden, 11125, Nr. 18991, Bd. 4

HStA Dresden, 12624 Familiennachlaß Grafen von Watzdorf, Nr. 134; Nr. 150; Nr. 163

BArch, R 73/15519

Stadtarchiv Kassel, Sterbebucheintrag Nr. 2535/76

Menzhausen, Joachim: Erna von Watzdorf zum Gedächtnis, in: Dresdener Kunstblätter, 22. Jg., H. 2, 1978, S. 62 f. 


\section{Paul Werkmeister}

\subsubsection{Stuttgart - 12.12.1944 Stuttgart}

Vermessungsingenieur

Mathematisch-Physikalischer Salon

1.4.1925-13.5.1938 Direktor

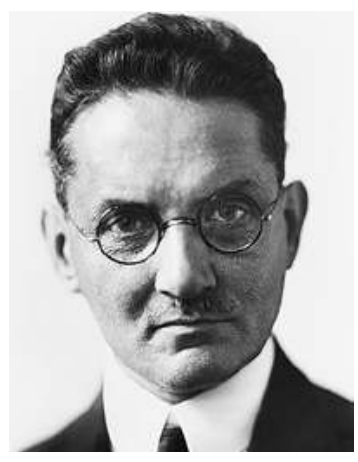

Paul Georg August Werkmeister wurde am 9. April 1878 in Stuttgart als Sohn des Holzschneiders Albrecht Wilhelm Werkmeister und seiner Frau Pauline, geb. Bühler, geboren. Nach der Reifeprüfung absolvierte Werkmeister eine dreijährige Lehre als Vermessungstechniker und arbeitete ein Jahr bei einem Katastergeometer in Stuttgart, bevor er 1899 ein Studium der Geodäsie und angewandten Mathematik an der Technischen Hochschule in Stuttgart aufnahm. 1902 legte er die Diplomprüfung ab. Im Anschluss arbeitete er für ein Jahr bei der Württembergischen Kommission für die Internationale Erdmessung, bevor er von 1903 bis 1907 als Topograf in der Topographischen Abteilung des Württembergischen Statistischen Landesamts in Stuttgart tätig war. Im Oktober 1906 heiratete er Martha Marie, geb. Scherer, mit der er drei Kinder hatte. 1907 übernahm Werkmeister einen Lehrauftrag für Geodäsie an der Technischen Hochschule Stuttgart. Noch im selben Jahr wechselte er als Lehrkraft für die geodätischen Fächer und angewandte Mathematik an die Kaiserlich Technische Schule in Straßburg. 1912 wurde er an der Technischen Hochschule Karlsruhe zum Dr.-Ing. promoviert. Als Kriegsfreiwilliger wurde Werkmeister im Ersten Weltkrieg ab 1915 in einer Vermessungsabteilung eingesetzt. Als Elsass-Lothringen nach Kriegsende an Frankreich fiel, musste er seine Tätigkeit in Straßburg aufgeben. Für kurze Zeit war er 1918 als Lehrbeauftragter der Vermessungskunde an der Technischen Hochschule in Berlin-Charlottenburg tätig, bevor er von 1919 bis 1925 an der Höheren Maschinenbauschule in Esslingen und an der Technischen Hochschule Stuttgart Trigonometrie lehrte. 1922 habilitierte er sich als Privatdozent für wissenschaftliches Rechnen an der Technischen Hochschule Stuttgart.

Zum 1. April 1925 wurde Werkmeister als Nachfolger von Bernhard Pattenhausen als Ordinarius für Vermessungskunde und Direktor des Geodätischen Instituts an die Technische Hochschule Dresden berufen. Damit übernahm er nebenamtlich auch das Direktorat des Mathematisch-Physikalischen Salons. Werkmeister erwarb sich große Verdienste bei der Neuordnung und Erweiterung der Sammlung, weshalb er in den Vorstand des Deutschen Museums in München berufen wurde. Darüber hinaus engagierte er sich im Beirat für das Vermessungswesen. Eine Vielzahl an Aufgaben im Mathematisch-Physikalischen Salon delegierte er an Restaurator -Alfred Beck, da ihn die Arbeit im Geodätischen Institut stark beanspruchte. Infolge einer schweren Erkrankung ließ sich Werkmeister im Alter von 60 Jahren vorzeitig emeritieren und wurde im Juni 1938 von der Verpflichtung als Professor entbunden. ${ }^{1}$ Von seinem Nebenamt als

1 Vgl. RMWEV an Leiter SMV, 27.6.1938, BArch, R 9361-VI/3404. 
Direktor des Mathematisch-Physikalischen Salons war er bereits Mitte Mai 1938 entpflichtet worden. ${ }^{2} \mathrm{Zu}$ diesem Entschluss wird neben dem persönlichen Familienschicksal - zwei seiner drei Kinder waren 1917 und 1933 gestorben - auch der zunehmende politische Druck in beiden Ämtern geführt haben. Werkmeister war Mitglied der nationalliberalen Deutschen Volkspartei gewesen. 1933 hatte er zwar das „Bekenntnis der Professoren an den deutschen Universitäten und Hochschulen zu Adolf Hitler und dem nationalsozialistischen Staat ${ }^{\text {"3 }}$ unterzeichnet, trat jedoch nicht in die NSDAP ein.

Nach der Pensionierung zog er zurück in seine Heimat nach Degerloch bei Stuttgart, wo er weiterhin wissenschaftlich publizierte und 1941 vertretungsweise Vermessungskunde an der Technischen Hochschule Stuttgart lehrte. Am 12. Dezember 1944 erlag Paul Werkmeister seiner Krankheit und starb in Stuttgart.

\section{Auswahlbibliografie}

Vermessungskunde, Bd. 1-3, Berlin/Leipzig 1910.

Das württembergische Präzisionsnivellement, in: Jahreshefte des Vereins für Vaterländische Naturkunde in Württemberg, 68, Stuttgart 1912 (Zugl. Karlsruhe, Techn. Hochsch., Diss., 1912).

Über die Zeitmesser des Straßburger Münsters insbesondere die Sonnenuhren am Giebel der Südseite, in: Straßburger Münsterblatt, 6, 1912, S. 62-74.

Einführung in die ebene Trigonometrie, Stuttgart 1921.

Das Entwerfen von graphischen Rechentafeln (Nomographie), Berlin 1923.

Die astronomische Uhr im Münster zu Straßburg, Braunschweig 1927.

Einführung in die Ausgleichsrechnung, Stuttgart 1928.

Topographie. Leitfaden für das topographische Aufnahmen, Berlin 1930.

Geodätische Instrumente, Leipzig 1940.

Lexikon der Vermessungskunde, Berlin 1943 (Hg.).

\section{Quellen und Literatur}

SKD, MPS, 1925-1938

BArch, R 4901/13280

BArch, R 9361-VI/3404

Peschel, Horst: Zum 100. Geburtstag von Prof. Dr.-Ing. Paul Werkmeister, in: Wissenschaftliche Zeitschrift der Technischen Universität Dresden, Bd. 27, H. 6, 1978, S. 1283 f.

Festschrift. Geodäsie im Wandel - Einhundertfünfzig Jahre Geodätisches Institut, Dresdner Beiträge aus geodätischer Forschung und Lehre. Schriftenreihe des Geodätischen Instituts, Heft 1, Dresden 2002, hier: S. 14-20.

Petschel, Dorit: 175 Jahre TU Dresden. Band 3: Die Professoren der TU Dresden 1828-2003. Hrsg. im Auftrag der Gesellschaft von Freunden und Förderern der TU Dresden e. V. von Reiner Pommerin, Köln u. a. 2003, S. 1031 f.

Rößler, Horst: Werkmeister, Paul Georg August, in: Sächsische Biografie, 2008, Online-Ausgabe: http://saebi.isgv.de/biografie/Paul_Werkmeister_(1878-1944), Zugriff: 2.1.2020.

2 Mathematisch-Physikalischer Salon, Beck, an Hugershoff, TH Dresden, 9.11.1938, SKD, MPS, 1938, A.-Reg. 298.

3 Nationalsozialistischer Lehrerbund Deutschland/Sachsen 1933, S. 132. 


\section{FRITZ WiedemanN}

14.8.1897 Cotta - 27.5.1974 Dresden

Kanzleiangestellter

Gemäldegalerie

[mind. 1.1931]-15.11.1945 Kanzleiangestellter

"Sonderauftrag Linz"

[6.1939]-5.1945 Rechnungsführer

12.1942-3.1943 Kommissarischer Leiter

(Abordnung an Sächsisches Ministerium für Volksbildung mind. 4.1938)

Carl Paul Fritz Wiedemann, über den nur wenige Informationen überliefert sind, wurde am 14. August 1897 als Sohn von Carl Paul Wiedemann und seiner Frau Ida Wilhelmine, geb. Förster, in Cotta bei Dresden geboren.

Seit mindestens Januar 1931 war Wiedemann an der Gemäldegalerie in Dresden als Kanzleiangestellter tätig. Er erledigte diverse Büroarbeiten und führte die Registranden. 1933 engagierte er sich als Vorsitzender des Angestelltenrates für die Belange der Mitarbeiter der Staatlichen Sammlungen. ${ }^{1}$ Im April 1938 wurde Wiedemann kurzzeitig an das Sächsische Ministerium für Volksbildung abgeordnet, kam aber bald an die Gemäldegalerie zurück, wo er sich insbesondere bei Abwesenheit von Direktor \ Hans Posse bewährte. Im Zweifelsfalle telegrafierte er ihm, um Entscheidungen abzufragen, wie im März 1940, als Generalbauinspektor Albert Speer die Pläne für den Luftschutzkeller der Gemäldegalerie anforderte. ${ }^{2}$ Aufgrund seiner Zuverlässigkeit übertrug Posse im Sommer 1939 Wiedemann die Büroarbeiten für den „Sonderauftrag Linz“. Nach Posses Tod war er mit Kustos > Robert Oertel für die Weiterführung des „Sonderauftrags Linz“ verantwortlich. Auch unter dem nachfolgenden Galeriedirektor $\gg$ Hermann Voss erfüllte Wiedemann Aufgaben in beiden Tätigkeitsbereichen. Im Zusammenhang mit dem „Sonderauftrag Linz“ fand er mehrfach Erwähnung als „Rechnungsführer“, darüber hinaus verzeichnete er in der überlieferten, sogenannten „Wiedemann-Liste“ von Dezember 1942 bis April 1945 alle Ankäufe für den „Sonderauftrag Linz“. ${ }^{3}$ Als Reichsstatthalter Martin Mutschmann im März 1945 die weitere Vereinfachung der Verwaltung anordnete, wurde Wiedemann „mit sofortiger Wirkung bei der Abteilung IV,7 der Landesregierung - Museen, Schlösser, und Gärten - verwendet, soweit er nicht zur Erledigung der laufenden Dienstgeschäfte bei der Gemäldegalerie, dem Kupferstichkabinett [...] benötigt wird“4. Mitte April 1945 veränderte sich sein Dienstort, denn die Verwaltung der Staatlichen Sammlungen wurde kriegsbedingt nach Schloss Weesenstein verlegt, wo er fortan gemeinsam mit Arthur Graefe sämtliche, für die Staatlichen Sammlungen anfallenden Büroarbeiten ausführte. ${ }^{5} \mathrm{Da}$ Wiedemann beim Luftangriff auf Dresden seine Wohnung verloren hatte, wohnte er mit seiner Frau Marie, geb. Große, und dem gemeinsamen Sohn im

\footnotetext{
Vgl. Aufstellung Gesamtbetriebsrat, 9.10.1933, SKD, MPS, 1933, E.-Reg. Nr. 187.

2 Vgl. Gemäldegalerie, Wiedemann, an Posse in Wien, 4.3.1940, SKD Archiv, 02/VA 53, Bd. 1, fol. 162.

3 Vgl. Iselt 2010, S. 145, $166 \mathrm{f}$.

4 SMV, Graefe, an Direktion Gemäldegalerie, 31.3.1945, HStA Dresden, 11402, Nr. 28, fol. 59.

5 Vgl. SMV, Abteilung Sammlungen, an Bürgermeister von Weesenstein, 24.4.1945, HStA Dresden, 10701, Nr. 320/55, Bd. 2, fol. 279.
} 
April und Mai 1945 auf Schloss Weesenstein, wie auch Hermann Voss und $\triangleright$ Klaus Günther und deren Familien. ${ }^{6}$ Ab Mai 1945 führte Wiedemann die Registrande der Abteilung Museen, Schlösser und Gärten des Ministeriums für Volksbildung. Im Oktober 1945 beauftragte ihn Regierungsamtmann Albert Gruve, eine Sammlungsregistrande zur besseren Verwaltung aller Sammlungen anzulegen. ${ }^{7}$ Doch nur wenige Wochen später, am 15. November 1945, wurde Wiedemann aufgrund seiner Mitgliedschaft in der NSDAP, in die er im Mai 1933 eingetreten war, entlassen. ${ }^{8}$

Nicht überliefert ist, wo der erst 48-Jährige nach seiner Entlassung tätig war. Nach dem Ende seiner ersten Ehe, vermutlich nach 1945, heiratete er Ilse, geb. Vetters. Fritz Wiedemann starb am 27. Mai 1974 in Dresden.

\section{Quellen und Literatur}

HStA Dresden, 11127, Nr. 27 (Einzeldokumente)

Landeshauptstadt Dresden, Stadtarchiv, Personenstandsregister, Sign. 6.4.25 und Meldekartei, Sign. 15.7.3 und 15.7.4

BArch, R 9361-IX/Kartei/48411296

Iselt, Kathrin: „Sonderbeauftragter des Führers“. Der Kunsthistoriker und Museumsmann Hermann Voss (1884-1969), Köln 2010 (Zugl. Dresden, Univ., Diss., 2009), S. 145, 177-179, $344-351$.

\footnotetext{
$6 \quad$ Vgl. Gemäldegalerie, Wiedemann, an SMV, Abt. IV/7, 12.3.1945 u. Verwaltung der Staatlichen Sammlungen an Baurat Pusch, 23.5.1945, SKD Archiv, 02/VA 53, Bd. 1, fol. 123 u. 02/VA 59, Bd. 2, fol. 162 sowie SMV, Abt. IV, an Bürgermeister von Weesenstein, 24.4.1945, HStA Dresden, 10701, Nr. 320/55, Bd. 2, fol. 280.

7 Vgl. Museum für Mineralogie und Geologie, Fischer, an Landesverwaltung, Abt. Museen, Schlösser und Gärten, 4.10.1945, SKD Archiv, 02/VA 166, fol. $14 \mathrm{f}$.

8 Vgl. Kanzlei der Staatlichen Museen, Fischer, an Landesverwaltung Sachsen, Zentralverwaltung für Wissenschaft, Kunst und Erziehung, Grohmann, 24.11.1945, SKD Archiv, 02/VA 162, fol. 41.
} 


\section{JaKub WJACSŁAWK}

Jacob Jatzwauk 


\section{Siegfried Wolf}

17.3.1907 Rammenau - 21.8.1986 Dresden

Zoologe, Afrikanist

Museen für Tierkunde und Völkerkunde

(ab 1.1.1942 Museen für Tierkunde, Rassenkunde und

Völkerkunde)

1.6.1933-31.12.1933 Stipendiat des wiss. Arbeitsdienstes

1.10.1935-3.1939 Freiwilliger Wissenschaftlicher

Hilfsarbeiter

11.1945-31.7.1946 Wissenschaftlicher Hilfsarbeiter

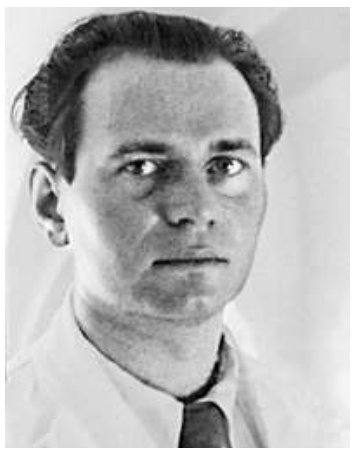

Museum für Völkerkunde

1.1.1957-31.8.1972 Direktor

(Abordnung an „Heimatwerk Sachsen" 5.1938-3.1939)

Ernst Wilhelm Siegfried Wolf wurde am 17. März 1907 als Sohn des Lehrers Ernst Gustav Wolf und dessen Frau Hedwig Hildegard, geb. Schiller, in Rammenau geboren. Nach dem Besuch der Volks- und Realschule in Radeberg legte er an der Sächsischen Landesschule in Dresden 1925 die Abiturprüfung ab. Anschließend studierte Wolf an der Technischen Hochschule in Dresden Naturwissenschaften, aber auch Kultur- und Kunstgeschichte, Anthropologie, Ethnografie, Philosophie und Psychologie. 1930 erwarb er mit der Staatsprüfung für das Höhere Lehramt die Lehrberechtigung für Chemie, Botanik und Zoologie. Im August 1932 wurde er in Dresden im Fach Zoologie promoviert.

Von Juni bis Dezember 1933 arbeitete Wolf als Stipendiat des wissenschaftlichen Arbeitsdienstes an den Museen für Tierkunde und Völkerkunde in Dresden, wobei er an der Inventarisierung der Anatomischen Sammlung mitwirkte. Ab Oktober 1935 wurde er als Freiwilliger Wissenschaftlicher Hilfsarbeiter beschäftigt. Immerhin gelang es dem neuen Museumsdirektor $\triangleright$ Hans Kummerlöwe, ihn von Januar bis Juli 1937 für den Umzug des Museums für Tierkunde in dieser ansonsten unvergüteten Position projektbezogen bezahlen zu lassen. Kummerlöwe war von Wolfs Arbeit überzeugt, hielt ihn für eine „wissenschaftlich durchaus ernst und verantwortungsbewusst eingestellte Person“, er sei „bestimmt kein Gegner des Neuen Deutschlands, wenn er auch nicht aktiv weiter hervortritt“, „kein ausgesprochen politischer Mensch“ und keine „,ölkische Kampfnatur" ${ }^{\text {"1 }}$ sei. Allerdings beantragte Wolf im November 1937 seine Aufnahme in die NSDAP, die rückwirkend zum 1. Mai 1937 erfolgte. Im Rahmen der Zusammenarbeit mit dem Deutschen Volksbildungswerk hielt Wolf in den Museumsräumen Kurse für die Volksbildungsstätte Dresden, z. B. im Herbst 1936 über „Volksmärchen aus aller Welt“. Ab Mai 1938 wurde Wolf für die Mitarbeit an der Ausstellung „Sachsen am Werk“ an das „Heimatwerk Sachsen“ abgeordnet, wo er unter anderem mit $>$ Elfriede Schulze-Battmann zusammenarbeitete. Allerdings übernahm er auch weiterhin Führungen durch die völkerkundliche Sammlung.

Im März 1939 wechselte er aus dem Dienst in den Staatlichen Sammlungen zum „Heimatwerk Sachsen“. Im Herbst 1940 wurde er zum Militärdienst einberufen, den er zunächst beim Flug-

1 Kummerlöwe an NSDAP, Reichsdozentenführer in München, o. Dat. (etwa 12.1937), HStA Dresden, 13842, Nr. 114, Bd. 2, o. Pag. 
meldedienst in Riesa absolvierte. Von dort aus bewarb er sich im Januar 1941 in Dresden um die Kustodenstelle an den Museen für Tierkunde und Völkerkunde, die durch den Wechsel von - Martin Heydrich nach Köln vakant war. Vom Sammlungsreferenten > Fritz Fichtner wurde er dabei ausdrücklich unterstützt, denn „,[a]nläßlich des Umzuges des Museums für Völkerkunde wurde Dr. Wolf ausersehen, die wissenschaftliche Leitung [...] zu übernehmen“, da er bereits „den Umzug des Museums für Tierkunde zur Zufriedenheit des Ministeriums und der Fachzoologen geleitet “2 hatte. Doch der Uk-Antrag für Wolf wurde nicht bewilligt, er blieb weiterhin im Militärdienst. 1942 heiratete er Margot, geb. Kind. Doch erst nach Kriegsende kehrte Wolf nach Dresden zurück. Aufgrund der Bemühungen des Leiters der Zentralkanzlei der Staatlichen Museen, $\triangleright$ Walter Fischer, und eines Gesprächs des Verantwortlichen der Kulturabteilung der Landesverwaltung Sachsen, Will Grohmann, mit Generalmajor Dubrowski von der SMA Dresden, konnte Wolf trotz seiner früheren NSDAP-Mitgliedschaft wieder am Museum arbeiten. ${ }^{3}$ Doch bereits nach wenigen Monaten, zum 31. Juli 1946 wurde er entlassen. Danach übernahm er zunächst private Arbeitsaufträge und war in der Textilforschung tätig. Später arbeitete Wolf am Phyletischen Museum in Jena und hielt 1955/56 Vorlesungen an der Friedrich-SchillerUniversität. > Bernhard Struck, ehemaliger Direktor der Museen für Tierkunde und Völkerkunde in Dresden und damals Professor an der Universität Jena, berichtete $>$ Herbert Bellmann gegenüber, dass „Wolf jetzt hier am Phyletischen Museum Chefoid ist - ganz ohne mein Zutun eine gr[oße] Überraschung!“‘ .

Nach zehn Jahren kehrte Wolf nach Dresden zurück: Zum Januar 1957 wurde er als Direktor an das Staatliche Museum für Völkerkunde berufen, wo er bis zu seiner Pensionierung Ende August 1972 tätig war. Unter seiner Leitung zog das Museum ins Japanische Palais, wo er u.a. die Sonderausstellung „Waffen ferner Völker“ kuratierte. Wolf nahm die im Krieg unterbrochene Herausgabe der „Abhandlungen und Berichte“ wieder auf und betreute die Bände 21 bis 33 redaktionell. Er forschte und publizierte weiterhin rege, vor allem zur Geschichte, Kultur und Kunst des altafrikanischen Königreiches Benin sowie über die Metallverarbeitung in Afrika.

Seine letzten Lebensjahre verbrachte Siegfried Wolf in Dresden, wo er am 21. August 1986 starb.

\section{Auswahlbibliografie}

Zur Kenntnis von Bau und Funktion der Reptilienlunge, in: Zoolog. Jahrbücher, Bd. 57, Jena 1933, S. 140-190 (Zugl. Jena, Univ., Diss., 1932).

Zur Revision der Untergattung Rhacophorus, in: Bull. Raffles. Mus. Singapore, H. 2, 1936, S. 137-217.

Zum Problem der Nasenflöte, in: Abhandlungen und Berichte aus den Staatlichen Museen für Tierkunde und Völkerkunde in Dresden. Reihe B, Völkerkunde, Bd. 20, Leipzig 1941.

Mottenfraß an Chemiefaserstoffen in Fasergemischen und Mischtextilgut, in: Faserforschung und Textiltechnik, Bd. 5, Berlin 1954, S. 68-77.

Affenmythen, in: Arch. Int. Etnografia e Preistoria, Bd. 1, Turin 1958, S. 97-110.

Bemerkungen zu den neuirländischen Reibhölzern der Völkerkundemuseen Dresden und Leipzig, in: Jahrbuch des Museums für Völkerkunde zu Leipzig, Bd. 17, Berlin 1958, S. 52-66.

SMV, Fichtner, an SMV, 6.1.1941, SKD Archiv, 01/PS 53, Bd. 3, fol. 173.

Vgl. mehrere Dokumente in: SKD Archiv, 02/VA 162. Siehe auch S. 266.

Struck an Bellmann, 3.11.1955, SKD, MfV Archiv, MVD 20, Netz Nr. 123. 
Zwei Benin-Arbeiten im Staatlichen Museum für Völkerkunde Dresden. Vogelgestaltiges Zeremonialgerät und Reliefplatte mit Vogel, in: Beiträge zur Völkerforschung, Bd. 11, 1961, S. 719-738.

Die Gelbguß-Köpfe der Dresdener Benin-Sammlung. Beschreibung und Vergleich, in: Abhandlungen und Berichte des Staatlichen Museums für Völkerkunde, Dresden, Bd. 21, 1962, S. 91-120.

Bemerkungen zu den Benin-Gelbgußköpfen des Museums f. Völkerkunde Leipzig, in: Abhandlungen und Berichte des Staatlichen Museums für Völkerkunde, Dresden, Bd. 22, 1963, S. 109-126.

Elfenbein und Bronze. Vergleich zwischen Benin-Arbeiten verschiedenen Materials, in: Abhandlungen und Berichte des Staatlichen Museums für Völkerkunde, Dresden, Bd. 30, 1970, S. 151-214.

\section{Quellen und Literatur}

HStA Dresden, 13842, Nr. 048

BArch, R 9361/V/40635

BArch, R 9361-IX/Kartei/49580072

Israel, Heinz: Siegfried Wolf zum 65. Geburtstag, in: Abhandlungen und Berichte des Staatlichen Museums für Völkerkunde Dresden, Bd. 34, 1975, S. 1-5.

Israel, Heinz und Peter Neumann: Zum Gedenken. Siegfried Wolf 1907-1986, in: Kleine Beiträge aus dem Staatlichen Museum für Völkerkunde Dresden, 8, 1986, S. 43.

Israel, Heinz und Peter Neumann: Siegfried Wolf zum Gedenken, in: Ethnographisch-archäologische Zeitschrift, 28. Jg., 1987, H. 1, S. 163 f.

Archivauskunft, Stadtarchiv Bischofswerda, Jan Gülzau, 8.4.2019. 


\title{
ERNST ZiMMERMANN
}

\author{
3.11.1866 Hamburg - 6.1.1940 Dresden \\ Kunsthistoriker \\ Porzellansammlung \\ 1.7.1898-[?] Wissenschaftlicher Hilfsarbeiter \\ [?] Direktorialassistent \\ 1.10.1907-30.6.1912 Leiter \\ 1.7.1912-15.12.1933 Direktor
}

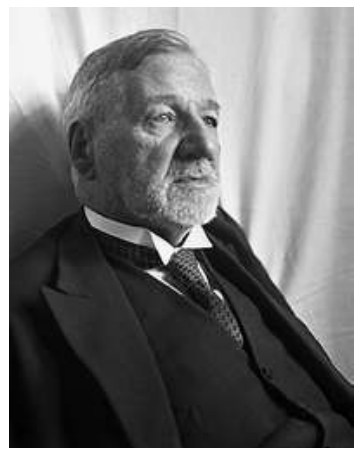

Ernst Albert Zimmermann wurde am 3. November 1866 in Hamburg geboren. An den Universitäten in Florenz, München, Berlin und Leipzig studierte er Kunstgeschichte, bevor er als Schüler von Heinrich Brockhaus 1892 in Leipzig promoviert wurde. Nach diversen Studienreisen nach England, Frankreich, Belgien und Holland arbeitete er für zwei Jahre als Freiwilliger Wissenschaftlicher Hilfsarbeiter am Kunstgewerbemuseum in Köln. 1897 lebte Zimmermann in Wiesbaden, wo er an den Vorarbeiten zur Inventarisation der Kunstdenkmäler von Hessen-Nassau beteiligt war.

Im Juli 1898 kam Zimmermann als Wissenschaftlicher Hilfsarbeiter an die Porzellansammlung in Dresden, die damals im Johanneum untergebracht war. Schnell arbeitete er sich intensiv in die Sammlung ein, deren Bestände er 1901 neu aufstellte. Er widmete sich intensiv der Erforschung des ostasiatischen und Meißner Porzellans und war der Erste, der darüber zusammenfassend auf Deutsch publizierte. Sein Werk „Die Erfindung und Frühzeit des Meißner Porzellans“ von 1908 wurde ebenso wie die von ihm vorgenommene Neubearbeitung des Buches der Porzellanmarken von Johann Georg Graesse zum Standardwerk. Nach kurzer Zeit als Direktorialassistent wurde Zimmermann im Oktober 1907 mit der Leitung der Sammlung beauftragt, jedoch erst im Juli 1912 zum Direktor ernannt. Er setzte sich für eine bessere Unterbringung und Präsentation der Porzellansammlung ein. Dafür favorisierte er den Zwinger, wie er u. a. 1910 in einem Aufsatz in den „Mitteilungen aus den sächsischen Kunstsammlungen“ schrieb. Doch diese Pläne wurden erst Jahrzehnte später verwirklicht. Zimmermann präsentierte unterdessen die „Neuerwerbungen“ und eine Ausstellung „Johann Friedrich Böttger zum 250. Geburtstag" (beide 1932). Obwohl sich Zimmermann, mittlerweile bereits 66-jährig, Anfang 1933 in den Ruhestand verabschieden wollte, erklärte er sich, als im März 1933 noch immer kein Nachfolger feststand, bereit, die Porzellansammlung vorerst weiterhin zu leiten. Das Ministerium für Volksbildung beließ ihm daher „für die Dauer der Weiterführung der Verwaltung der Porzellansammlung alle diejenigen dienstlichen Befugnisse, die [...][ihm] als Direktor der staatlichen Porzellansammlung zugestanden haben" ${ }^{\text {" }}$ Weiterhin im Amt, musste sich Zimmermann, der nicht in die NSDAP eintrat und sich nicht politisch äußerte, im Oktober 1933 gegenüber dem Ministerium rechtfer-

1 SMV, Woelker, an Zimmermann, Porzellansammlung, 6.3.1933, SKD Archiv, 01/PS 36, Bd. 2, fol. 474. Die Presse hatte bereits sein Ausscheiden aus dem Amt zum 1. März 1933 verkündet - Siehe: Der Direktor der Staatlichen Porzellansammlung in Dresden tritt in den Ruhestand, in: DNa, 26.2.1933, S. 6. Zur Suche eines Nachfolgers siehe S. 69 ff. 
tigen, warum er „mehr oder weniger absichtlich bei jüdischen Firmen Ankäufe für die Samm-

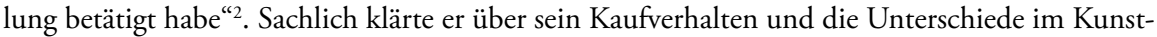
handel auf. Zwei Monate später, am 15. Dezember 1933, übergab Zimmermann nach über drei Jahrzehnten Tätigkeit in der Porzellansammlung die Dienstgeschäfte an $>$ Fritz Fichtner, der, seit drei Jahren als Freiwilliger Wissenschaftlicher Hilfsarbeiter an der Sammlung tätig, nun zum Kustos und Leiter ernannt wurde, woran Zimmermann einen erheblichen Anteil hatte. ${ }^{3}$

Nach seiner Pensionierung stand Zimmermann seinem Nachfolger über Jahre beratend zur Seite, u. a. bei der Anfertigung von Expertisen. Selbst 1938 war er zeitweise während der Abwesenheit Fichtners für die Porzellansammlung tätig und beantwortete fachliche Anfragen. ${ }^{4} \mathrm{Im}$ November 1936 veranstalteten die Staatlichen Sammlungen im Johanneum eine Feierstunde für Zimmermann zum 70. Geburtstag. Dabei würdigte Fichtner dessen in 30 Jahren getätigten Neuerwerbungen für die Sammlung, die die drei wesentlichen Sammelgebiete China, Japan und Meißen auf das Beste ergänzten. ${ }^{5}$ Doch in den Folgejahren verschlechterte sich Zimmermanns Gesundheit. Dennoch meldete er sich nach Kriegsbeginn, dem entsprechenden Aufruf in der Presse folgend, im September 1939 freiwillig zum Dienst in der Porzellansammlung, ${ }^{6}$ de facto war er in den Jahren zuvor ohnehin häufiger für die Sammlung tätig gewesen. Nun aber war dies aufgrund seiner Erkrankung nicht mehr möglich. Stattdessen ließ er Fichtner seine Kontakte pflegen, der im April 1940 Ludwig Schnorr von Carolsfeld in Berlin informierte: „Wenn Zimmermann überhaupt über diese Krankheit hinwegkommt, so ist es ein Wunder. Ich bin täglich bei ihm und werde ihm Ihre Grüße und Wünsche ausrichten "7. Nach schwerer Krankheit starb Ernst Zimmermann am 6. Januar 1940 in Dresden. Obwohl er zuvor in seiner Bescheidenheit ausdrücklich keine posthume Ehrung gewünscht hatte, fand am 16. Januar 1940 eine Gedenkfeier für ihn statt, an der neben den Direktoren und Wissenschaftlern der Staatlichen Sammlungen auch der Leiter des Ministeriums für Volksbildung sowie Vertreter mehrerer Ministerien teilnahmen.

\section{Auswahlbibliografie}

Die Landschaft in der venezianischen Malerei bis zum Tode Tizians, Beiträge zur Kunstgeschichte, 20, Leipzig 1893 (Zugl. Leipzig, Univ., Diss., 1892).

Die Inkunabeln des Meißner Porzellans, in: Jahrbuch der Preußischen Kunstsammlungen, Bd. 25, 1904, S. 159-174.

\footnotetext{
2 Zimmermann an das SMV, handschriftliches Konzept, 10.1933, SKD Archiv, 01/PS 37, fol. $111-$ 120, hier: 111. Vgl. Brief, 27.10.1933, HStA Dresden, 11125, Nr. 19192, fol. 154-163. Zimmermann war zuvor durch den Dresdner Kunsthändler Karl Schulze bei der Gaufachgruppe der bildenden Künste denunziert worden.

3 Siehe S. $69 \mathrm{ff}$.

4 Vgl. Zimmermann an Fichtner, 21.2.1934, u. Porzellansammlung, Zimmermann, an Schriftleitung „Der Freiheitskampf“, 10.10.1938, SKD Archiv, 01/KGM 95, fol. 14 u. 01/PS 45, Bd. 3, o. Pag. 5 Vgl. Glückwunschgäste im Johanneum, in: FK, 4.11.1936, S. 7; L.: Festaktus in der Porzellansammlung. Eine Ehrung für Prof. Ernst Zimmermann, in: DNa, 4.11.1936, S. 5; p. r.: Das Johanneum unter Zimmermann, in: DNN, 5.11.1936, S. 3.

6 Vgl. Porzellansammlung an SMV, 9.9.1939, SKD Archiv, 01/PS 138, Nr. 165. Siehe S. 61 f.

7 Porzellansammlung, Fichtner, an Schnorr von Carolsfeld, Staatliche Museen Berlin, 4.4.1939, SKD Archiv, 01/PS 42, Bd. 2, fol. 434.
} 
Die Erfindung und Frühzeit des Meissner Porzellans. Ein Beitrag zur Geschichte der deutschen Keramik, Berlin 1908.

Die Unterbringung der Porzellansammlung im Zwinger, in: Mitteilungen aus den sächsischen Kunstsammlungen, Bd. 1, 1910, S. 31-39.

Führer für Sammler von Porzellan und Fayence, Steinzeug, Steingut usw.: vollständiges Verzeichnis d. auf älterem Porzellan, Fayence, Steingut usw. befindlichen Marken, Berlin 1910 (13. völlig umgearb. Aufl.) (Hg. mit Johann Georg Graesse, Friedrich Jaennicke).

Chinoiserien Höroldts, in: Mitteilungen aus den sächsischen Kunstsammlungen, Bd. 3, 1912, S. 71-83.

Die alten Bestände von japanischem Porzellan in der Dresdner Porzellansammlung, in: Mitteilungen aus den sächsischen Kunstsammlungen, Bd. 7, 1916, S. 81-111.

Chinesisches Porzellan. Seine Geschichte, Kunst und Technik, Leipzig 1913.

Meissner Porzellan, Leipzig 1926.

Altchinesische Porzellane im alten Serail, Meisterwerke der tuerkischen Museen zu Konstantinopel, Bd. 2, Berlin 1930.

\section{Quellen und Literatur}

SKD Archiv, 01/PS 36, Bd. 1 u. 2; 01/PS 37, Bd. 1 u. 2; 01/PS 42, Bd. 1

HStA Dresden, 11125, Nr. 19192; Nr. 22891

Fichtner, Fritz: Die Bedeutung E. Zimmermanns für die Chinaforschung und die Ostasiat. Abt. der Staatl. Porzellansammlung Dresden, Ostasiatische Zeitschrift, 22, 1936, S. 195 f.

Fichtner, Fritz: E. Zimmermann zum Gedächtnis, in: Neues Archiv für Sächsische Geschichte, 61. Jg., H. 1, Dresden 1940, S. 88-94.

Fichtner, Fritz: Ernst Zimmermann zum Gedächtnis, Sonderdruck aus Ostasiatische Zeitschrift, 1940.

Reichel, Friedrich: Ernst Zimmermann zum Gedächtnis, in: Dresdener Kunstblätter, 9. Jg., 1965, S. $110 \mathrm{f}$.

Seyffarth, Richard: In Memoriam Prof. Dr. Ernst Zimmermann, in: Mitteilungsblatt Keramik-Freunde der Schweiz, 49, 1960, S. 23 f. 


\title{
Kurt Zoege von Manteuffel
}

\author{
20.8.1881 Reval - 10.1.1941 Konitz \\ Kunsthistoriker \\ Kupferstich-Kabinett
}

1.1.1919-31.12.1923 Direktorialassistent, Kustos

1.1.1924-10.1.1941 Direktor

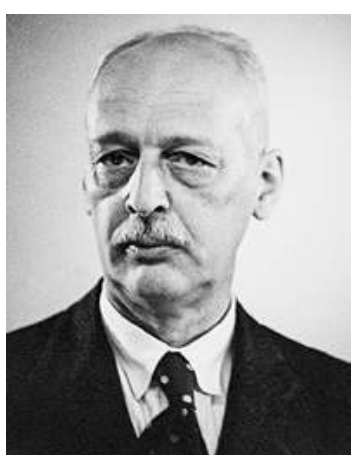

Am 20. August 1881 wurde Kurt Nikolai Baron Zoege von Manteuffel in Reval als Sohn des Juristen und estländischen Landespolitikers Günther Zoege von Manteuffel und Henriette Julie Emilie, geb. von Ramm, geboren. Seine Kindheit verbrachte er in Estland. Später besuchte er Gymnasien in Kassel und Königsberg. Ab 1902 studierte Zoege von Manteuffel an den Universitäten in München, Berlin und Halle Jura und Kunstgeschichte. 1909 wurde er in Halle promoviert. Anschließend arbeitete er bis Oktober 1910 als Wissenschaftlicher Hilfsarbeiter am Städtischen Museum Aachen. In den folgenden Jahren schrieb er Beiträge für das in Leipzig erscheinende Allgemeine Künstlerlexikon. Ab 1914 arbeitete er am Kunsthistorischen Institut in Florenz. Als dessen Direktor zum Kriegsdienst einberufen wurde, avancierte Zoege von Manteuffel bis zur kriegsbedingten Schließung des Instituts im Mai 1915 zum Stellvertreter des Direktors. Er selbst diente später ebenfalls für kurze Zeit als Soldat im Ersten Weltkrieg. Danach war Zoege von Manteuffel von 1916 bis 1918 als Wissenschaftlicher Hilfsarbeiter in Berlin am Kaiser-Friedrich-Museum und am Kupferstichkabinett unter Wilhelm Bode und Max J. Friedländer tätig.

Zum 1. Januar 1919 wechselte Zoege von Manteuffel an das Kupferstich-Kabinett in Dresden, wo er unter Max Lehrs als Direktorialassistent und Kustos arbeitete. Nach dessen Pensionierung wurde Zoege von Manteuffel Anfang Januar 1924 zum Direktor des Kupferstich-Kabinetts ernannt. Im Jahr zuvor hatte er Alexandra Luise Eveline Gerta Reichsgräfin von Schwerin geheiratet, mit der er drei Kinder hatte. Zoege von Manteuffel war gut unter Fachkollegen vernetzt, nicht zuletzt durch seine Mitarbeit in verschiedenen Fachverbänden. Regelmäßig nahm er an den Versammlungen des „Internationalen Verbands von Museumsbeamten zur Abwehr von Fälschungen und Unlauterem Geschäftsgebaren“ teil, dem er 1924 beigetreten war. 1930 reiste er zum XII. Kunsthistoriker-Kongress nach Brüssel. Im Deutschen Verein für Kunstwissenschaft wurde er 1934 gemeinsam mit Friedrich Winkler, Direktor des Kupferstichkabinetts in Berlin, zum Leiter der Abteilung "Graphik“ gewählt. In seiner Funktion als Direktor am Kupferstich-Kabinett in Dresden förderte er die junge Kunsthistorikergeneration, wie $>$ Peter Halm, den er bei seiner Bewerbung um das Stipendium für Florenz unterstützte, und $\triangleright$ Franz Schubert, für dessen Ernennung zum Kustos er sich über mehrere Jahre einsetzte. ${ }^{1}$ Als Zoege von Manteuffel, der selbst kein Mitglied der NSDAP war, 1937 durch das Ministerium für Volksbildung angewiesen wurde, Schubert zum Parteieintritt aufzufordern, belegte er dessen nationalsozialisti-

1 Vgl. hierzu SKD Archiv, 01/KK 3, Bd. 8. Siehe S. 432. 
sche Haltung u. a. lapidar durch die Kaufquittung einer Hakenkreuzfahne. ${ }^{2}$ Den zunehmenden politischen Druck gab er an die Mitarbeiter nicht mit Entschiedenheit oder gar proaktiv weiter, wie sein Bericht über die nationalsozialistischen Aktivitäten im Kupferstich-Kabinett von 1935 sowie seine Anmerkung „zur Kenntnisnahme und mit dem Hinweis darauf, daß eine zahlreiche Teilnahme höchst erfreulich wäre“3 auf der offiziellen Aufforderung zur Teilnahme am Gauappell der NSDAP im Juni 1936 belegen. Die Bandbreite der unter seinem Direktorat im Kupferstich-Kabinett gezeigten Ausstellungen reichte von Meister E. S. und Lucas Cranach, über Leopold von Kalckreuth und Adolph Menzel, bis hin zu Ludwig von Hofmann. Hervorzuheben sind „Sächsische Zeichnungen aus vier Jahrhunderten“ (1933) und die „Gedächtnisausstellung zum 200. Todestag von Matthäus Daniel Pöppelmann“ (1936) sowie die mit $>$ Hans Posse ausgerichteten Ausstellungen „Ludwig Richter zum 50. Todestag“ (1934) und „Anton Graff und seine Dresdner Zeitgenossen“ (1936/37). Selbst „Japanische Farbholzschnitte“ präsentierte Zoege von Manteuffel im Rahmen einer Ausstellungsreihe mit Werken aus dem Vermächtnis des Kunstsammlers Johann Friedrich Lahmann. Im Wesentlichen forschte und publizierte Zoege von Manteuffel jedoch über Niederländische Malerei und Grafik des Barocks sowie über Zeichnung und Grafik des 19. Jahrhunderts. Unvollendet blieb seine Alfred-Rethel-Monografie, an der er seit 1910 arbeitete und für die er im September 1940 einen Publikationszuschuss der Deutschen Forschungsgemeinschaft erhielt. Während einer Reise nach Westpreußen, wo er nach dem Tod seiner Schwester seine Nichte abholen wollte, erkrankte er an einer schweren Grippe. Nur wenige Tage später, am 10. Januar 1941, starb Kurt Zoege von Manteuffel überraschend und erst 59-jährig in Konitz. Am 13. Januar 1941 wurde er in Göhren bei Woldegk in Mecklenburg beigesetzt. An der Trauerfeier nahm sein langjähriger Mitarbeiter Schubert als Vertreter der Staatlichen Sammlungen teil.

\section{Auswahlbibliografie}

Die Gemälde und Zeichnungen des Antonio Pisano aus Verona, Halle 1909, (Zugl. Halle-Wittenberg, Univ., Diss., 1909).

Bilder David Ryckaerts d. J. in Dresden und Leipzig, in: Mitteilungen aus den sächsischen Kunstsammlungen, Bd. 6, 1915, S. 53-71.

Leonardo da Vinci. Eine Auswahl aus seinen Gemälden, Handzeichnungen und Schriften, München 1920.

Hans Holbein - der Maler und Hans Holbein - der Zeichner für Holzschnitt und Kunstgewerbe, München 1920.

Der deutsche Holzschnitt. Sein Aufstieg im XV. Jahrhundert und seine grosse Blüte in der ersten Hälfte des XVI. Jahrhunderts, München 1921.

Der deutsche Kupferstich von seinen Anfängen bis zum Ende des 16. Jahrhunderts, München 1922.

Die niederländische Radierung von den Anfängen bis zum Ende des siebzehnten Jahrhunderts, München 1925.

Pieter Breughels Landschaften, 1934.

2 Vgl. SMV, Gesprächsprotokoll, 18.1.1937, HStA Dresden, 11125, Nr. 22889, fol. 41. Siehe S. $93 \mathrm{f}$.

3 NSDAP Gauleitung Sachsen an die Behördenvorstände, 18.6.1936, SKD Archiv, 01/KK 3, Bd. 9, fol. 302. Vgl. Zoege von Manteuffel an SMV, 10.5.1935, ebd., fol. $98 \mathrm{f}$. 
Niederländische Meister des 17. Jahrhunderts. Rubens Rembrandt, Gerard Terborch und Jan Steen, die Künstlerfamilie van de Velde, Bielefeld 1937.

Zur Geschichte der Karlsfresken Alfred Rethels im Aachener Rathaus, in: Zeitschrift des Aachener Geschichtsvereins, Bd. 61, 1940, S. 65-131.

\section{Quellen und Literatur}

SKD Archiv, 01/PS 53, Bd. 2

SKD Archiv, 01/KK 3, Bd. 8

HStA Dresden, 11125, Nr. 22888; Nr. 22889

HStA Dresden, 12810

BArch, R 73/16034

K. Zoege von Manteuffel gest., in: Pantheon. Internationale Jahreszeitschrift für Kunst, Bd. 27, H. 3, 1941, S. $71 \mathrm{f}$.

Kurt Zoege von Manteuffel, in: Lüdtke, Gerhard (Hg.): Kürschners Deutscher Gelehrtenkalender 1940/41, 6. Ausg., Bd. 1, Berlin 1941.

Holzhausen, Walter: Kurt Zoege von Manteuffel †, in: Die graphischen Künste, N. F. 6, 1941, S. $76 \mathrm{f}$. 


\section{Personen aus dem Umfeld der wissenschaftlichen Mitarbeiterinnen und Mitarbeiter}

Авв, Gustav (1886-1945), Bibliothekar, 1935 Direktor Universitätsbibliothek Berlin, 1941 „Kommissar für die Sicherung der Bibliotheken und Betreuung des Buchgutes im östlichen Operationsgebiet“ im Einsatzstab Reichsleiter Rosenberg.

BaLDAuf, Richard (1848-1931), Eigentümer von Braunkohlegruben in Nordböhmen, Mineraliensammler und Mäzen.

Bauch, Kurt (1897-1975), Kunsthistoriker, 1933-1962 Professor Universität Freiburg i. Br. BernatziK, Hugo (1897-1953), Ethnologe, Reiseschriftsteller und Fotograf, 1930/1931 Forschungsreise mit Bernhard Struck nach Portugiesisch-Guinea.

Bernhart, Max (1883-1952), Numismatiker, ab 1908 Münzsammlung München, 19331949 Direktor.

BIEDER, Alfred, Sammlungshandwerker Mathematisch-Physikalischer Salon Dresden.

BieHL, Walther (1882-1963), Kunsthistoriker, 1919-1946 Direktor Bautzener Stadtmuseum.

BLÜMEL, Carl (1893-1976), Bildhauer u. Klassischer Archäologe, 1927-1961 Staatliche Museen Berlin, ab 1947 Leiter Antikensammlung.

Bode, Wilhelm (1845-1929), Kunsthistoriker, ab 1872 Königlich Preußische Kunstsammlungen Berlin, 1890 Direktor Gemäldegalerie, 1905-1920 Generaldirektor, 1920-1929 Direktor Gemäldegalerie.

Boese, Konrad Heinrich August (1852-1938), Maler, Professor Vereinigte Staatsschule für Freie und Angewandte Kunst Berlin.

Boetticher, Hans von (1886-1958), Zoologe, Ornithologe u. Entomologe, 1931-1955 Leiter Naturwissenschaftliches Museum Coburg.

Born, Johannes Ernst (1884-1958), Bildhauer, Studium in Dresden bei Karl Groß u. Georg Wrba, ab 1908 freischaffend in Dresden.

Brandenburg, Erich (1868-1946), Historiker u. Genealoge, 1904-1935 Leiter Historisches Seminar Universität Leipzig.

Breitinger, Emil (1904-2004), Anthropologe, 1940 Professor für Biologie der Leibesübungen Universität München, Schulungsleiter im Rasse- und Siedlungshauptamt der SS, 1957 Professor für Anthropologie Universität Wien.

BrockHaus, Heinrich (1858-1941), Kunsthistoriker, Sohn des Verlegers Eduard Brockhaus, 1897-1912 Leiter Kunsthistorisches Institut Florenz, 1913 Privatgelehrter in Dresden, ab 1917 in Leipzig.

BRUCK, Robert (1863-1942), Kunsthistoriker, 1903-1931 TH Dresden, 1927-1928 Rektor. Buchieit, Hans (1878-1961), Kunsthistoriker, 1920-1931 Direktor Staatliche Kunstsammlungen Stuttgart, 1931-1947 Direktor Bayerisches Nationalmuseum München.

Buchner, Ernst (1892-1962), Kunsthistoriker, 1922 Residenzmuseum München, 1928 Direktor Wallraf-Richartz-Museum Köln, 1932-1945 u. ab 1953 Generaldirektor Bayerische Staatsgemäldesammlungen München.

Burkhardt, Heinrich (1904-1985), Maler u. Graphiker, Studium in Dresden bei Otto Gussmann u. Georg Lührig, Mitglied der Dresdner Sezession 1932, freischaffend in Dresden, ab 1945 Altenburg. 
CAssirer, Bruno (1872-1941), Verleger u. Galerist, bis 1901 Verlag u. Kunsthandlung mit Cousin Paul Cassirer in Berlin, 1901 Verlag Bruno Cassirer, 1937 Entzug der Mitgliedschaft in Reichsschrifttumskammer durch Nationalsozialisten, 1938 Emigration nach England.

Danzel, Theodor Wilhelm (1886-1954), Ethnologe, 1923-1928 Privatdozent für Völkerkunde, 1928-1933 u. 1945-1954 Professor Universität Hamburg.

DeichmülleR, Johannes (1854-1944), Prähistoriker u. Paläontologe, 1877-1923 Museum für Mineralogie, Geologie und Vorgeschichte Dresden, 1900 Leiter Archiv urgeschichtlicher Funde in Sachsen.

Dedering, Kurt (1890-?), 1933 Direktor Staatsbauschule Leipzig, 1937 Regierungsdirektor SMV.

Degenhardt, Bernhard (1907-1999), Kunsthistoriker, Staatsgemäldesammlungen München, 1932 Stipendiat Kunsthistorisches Institut Florenz, 1933-1939 Assistent Bibliotheca Hertziana Rom, 1939-1945 Registrar in Wien, ab 1949 Staatliche Graphische Sammlungen München.

Dengler, Hermann (1890-1945), Hilfsarbeiter u. Zeichner Museum für Mineralogie, Geologie und Vorgeschichte Dresden u. Archiv urgeschichtlicher Funde in Sachsen, 1940-1941 Leitung Ausgrabung Heidenschanze Dresden-Coschütz.

DöRINGER, Wilhelm (1862-1926), Maler u. Lithograf, 1908-1926 Professor Kunstakademie Düsseldorf.

Drevermann, Friedrich Ernst (1875-1932), Geologe u. Paläontologe, Senckenberg Naturforschende Gesellschaft Frankfurt a. M., 1914 Ordinarius Geologisches Institut Universität Frankfurt a. M.

Drost, Rudolf (1892-1971), Ornithologe, Staatliche Biologische Anstalt Helgoland, 1926 Leiter Vogelwarte Helgoland.

DvoŘÁk, Max (1874-1921), Kunsthistoriker u. Denkmalpfleger, 1909 Ordinarius Universität Wien.

DwORSCHAK, Fritz (1890-1974), Numismatiker u. Kunsthistoriker, ab 1913 Kunsthistorisches Museum Wien, 1938 Direktor, 1941-1947 erster Direktor, am NS-Kunstraub beteiligt, ab 1942 „Münzen und Medaillen“ im „Sonderauftrag Linz“, 1947-1958 Leiter Kulturamt u. Stadtarchiv Krems.

Eвert, Max (1879-1929), Prähistoriker, 1906-1914 Vorgeschichtliche Abteilung Berliner Museen, 1922-1924 Professor für Vorgeschichte Universitäten Königsberg u. Riga, 1927-1929 Professor für Ur- und Frühgeschichte Universität Berlin.

Ehrler, Ottomar (1881-?), ab 1908? Verwaltungsinspektor Gemäldegalerie Dresden.

Enderlein, Karl (1872-1954), Maler u. Grafiker, Studium in Dresden bei Ferdinand Wilhelm Pauwels u. Leon Pohle, 1913-1947 Lehrer Akademie für Kunstgewerbe Dresden.

Engelmann, Max (1874-1928), Uhrmacher, 1910-1928 Restaurator Mathematisch-Physikalischer Salon Dresden.

Erman, Wilhelm Adolf (1850-1932), Bibliothekar u. Geograf, 1901-1907 Direktor Universitätsbibliothek Breslau, 1907-1920 Direktor Universitätsbibliothek Bonn.

Еrмisch, Hubert Georg (1883-1951), Architekt, Leiter Zwingerbauhütte Dresden, 19271935 Restaurierung Japanisches Palais, Tätigkeit im SMV, nach 1945 Leiter Wiederaufbau Zwinger.

Ermisch, Hubert Maximilian (1850-1932), Archivar u. Historiker, 1875-1907 Hauptstaatsarchiv Dresden, 1907-1920 Direktor Sächsische Landesbibliothek. 
Feluisch, Alfred (1884-1973), Handschuhmacher u. sächsischer Politiker, 1918-1926 Mitglied Sächsischer Landtag, 1921-1924 Wirtschaftsminister, 1923/1924 Ministerpräsident, ab 1932 Amtshauptmann Großenhain, 1946-1948 Staatssekretär, 1948/49 Minister für Wirtschaft, 1949-1952 Direktor Sächsische Landesbibliothek.

Foerster, Fritz (1866-1931), Chemiker, 1895 Professor TH Dresden, 1917/1918 Rektor.

Frenzel, Walter (1898-?), Angestellter Aufsichts- und Kanzleidienst Staatliche Sammlungen Dresden.

FrenZel, Walter (I 892-I94I) Archäologe, 1924-1936 Lehrer in Bautzen, 1936-1941 Dozent Hochschule für Lehrerbildung Frankfurt a. d. O., 1940-1941 Direktor Museum Litzmannstadt, beteiligt am NS-Kunstraub.

FriedläNdER, Max J. (1867-1958), Kunsthistoriker, 1894 Assistent Wallraf-Richartz-Museum Köln, 1896-1933 Gemäldegalerie Berlin, ab 1924 Erster Direktor, 1908-1930 zugleich Direktor Kuferstichkabinett Berlin, 1933 aufgrund jüdischer Abstammung von Nationalsozialisten entlassen, Emigration in die Niederlande.

FrIEDRICHs, Rudolf (1892-1947), 1926-1933 Regierungsrat Sächsisches Innenministerium, 1930-1933 Stadtrat Dresden, 1933 seiner Ämter enthoben, 1945 Oberbürgermeister Dresden, 1946 Präsident Landesverwaltung Sachsen, 1946/1947 Ministerpräsident Sachsen.

Fritsch, Karl (1901-1944), Politiker, 1923 Stellv. Bezirksleiter NSDAP Oberfranken, Innenminister Sachsen, 1927 Gaugeschäftsführer Gauleitung Sachsen, 1929-1933 NSDAP-Fraktion Sächsischer Landtag, 1933-1943 Sächsischer Innenminister, 1943 Waffen-SS.

Fucıni, Alberto (1864-1941), Paläontologe, 1892 Institut für Geologie und Paläontologie Pisa, 1906-1913 Professor für Paläontologie Universität Pisa, 1917 Professor Universität Catania.

Gaerte, Wilhelm (1890-1958), Archäologe u. Volkskundler, 1925-1938 Direktor PrussiaMuseum Königsberg, Vorsitzender Altertumsgesellschaft Prussia.

Gaettens, Richard (1886-1965), Chemiker u. Numismatiker, 1913 Herausgeber der Zeitschrift „Archiv für Medaillen- und Plakettenkunde“, 1923 Schriftenreihe Münzstudien.

Gallwitz, Hans (1896-1958), Geologe u. Paläontologe, 1935 Professor TH Dresden, 1939-1945 Wehrgeologe und Ordinarius TH Wien, 1946 Professor Universität Halle, 1950-1952 Dekan.

GASCH, Walther (1886-1962), Maler u. Grafiker, Vorsitzender NS-Gaufachgruppe der bildenden Künste Dresden.

Gebhart, Hans (1900-1960), 1923 Staatliche Münzsammlung München, 1933 Kustos, 1938 Dozent für Münzkunde und Geldgeschichte Universität München.

Germann, Paul (1884-1966), Ethnologe u. Kunsthistoriker, 1912 Museum für Völkerkunde Leipzig, 1920 Kustos, 1944 Leiter.

Gess, Felician (1861-1938), Historiker, 1908-1928 Direktor Bibliothek TH Dresden.

Gilardone, Georg, Direktor Bayerisches Armeemuseum München.

GIRnus, Wilhelm (1906-1985), Literaturwissenschaftler u. Politiker, 1928 Lehrer, KPD, 1933 Verhaftung, KZ-Überlebender, 1945 Leiter Höheres Schulwesen Thüringen, 1949 Redakteur „Neues Deutschland“, 1953 ZK der SED, 1957-1962 Staatssekretär für Hoch- und Fachschulwesen.

Glauning, Otto (1876-1941), Bibliothekar, 1899 Hof- und Staatsbibliothek München, 1921-1937 Direktor Universitätsbibliothek Leipzig.

GöPEL, ERHARD (1906-1966), Kunsthistoriker, in NS-Kunstraub involviert, Tätigkeit "Sonderauftrag Linz“ unter Hermann Voss. 
GöpferT, Arthur Hugo (1902-1986), Politiker, Volksschullehrer Glauchau, 1930 Gauobmann NSLB Sachsen, 1933 Beigeordneter des Staatskommissars für Sachsen, Ministerialrat im SMV, 1935-1945 Kommissarischer Leiter SMV.

Goldschmidt, Adolph (1863-1944), Kunsthistoriker, 1903 Professor Universität Berlin, 1904 Universität Halle, 1912-1929 Professor Universität Berlin, 1914-1938 Mitglied Akademie der Wissenschaften Berlin, 1938 von Nationalsozialisten ausgeschlossen, 1939 Emigration in Schweiz.

GotтsChalk, Gustav (1873-1938), 1908 Formermeister Skulpturensammlung Dresden, 1934-1938 Präparator.

Graefe, Arthur (1890-1967), 1920 Redakteur u. Kunstschriftsteller in Dresden, 1928 Pressechef u. Kulturreferent bei sächsischer Regierung, Regierungsdirektor Staatskanzlei, 1944 Nachfolger Fichtners als Referent für Staatliche Sammlungen im SMV, 1945 Verhaftung, 7 Jahre Internierung.

Gropius, Martin (1824-1880), Architekt, 1865 Sozietät Gropius \& Schmieden, 1869 Direktor Unterrichtsanstalt des Kunstgewerbemuseums Berlin.

Groß, [?], Oberregierungsrat SMV.

Grotemeyer, Paul (1904-1975), 1933 Assistent Universität München, 1939 Kustos Staatliche Münzsammlung München.

GrÜNDer, Hellmuth (1901- ?), Hilfsaufseher Porzellansammlung Dresden, 1933 Arbeiterrat.

Gruve, Albert (1887-1973), vor 1945 Regierungsamtmann SMV, nach 1945 Wiss. Hilfskraft Kupferstich-Kabinett u. Historisches Museum Dresden, 1947-1948 Bergungsbeauftragter der Sächsischen Museumsgüter, Leiter Hauptverwaltung Staatliche Museen, Schlösser und Gärten.

GüNDEL, Christian (1903-?), Kunsthistoriker in Breslau, um 1943 militärischer Kunstschutz Pleskau, nach 1945 Kustos Diözesanmuseum Mainz.

Günther, Hans F. K. (1891-1968), Philologe u. NS-Rassentheoretiker, einer der Urheber der NS-Rassenideologie, 1922 „Rassenkunde des deutschen Volkes“, 1922 Museen für Tierkunde und Völkerkunde Dresden, 1923-1929 Norwegen Aufträge für Universitäten u. a. Hermann Lundborg Universität Uppsala, 1930 Lehrstuhl Sozialanthropologie Universität Jena, 1935 Professor für Rassenkunde und Völkerbiologie Universtität Berlin, 1940-1945 Ordinarius Universität Freiburg i. Br.

Gurlitt, Cornelius (1850-1938), Architekt u. Kunsthistoriker, 1878-1887 Asssistent

Kunstgewerbemuseum Dresden, 1889 Privatdozent Berlin, 1893-1920 Professor TH Dresden, Inventarisierung der Kunstdenkmäler in Sachsen, 1920-1926 Präsident Bund Deutscher Architekten.

Навісн, [?], Hilfsaufseher Historisches Museum in Dresden.

Haeberlein, Fritz (1895-?), Maler, Restaurator u. Kunsthistoriker, Volontär Alte Pinakothek München u. Graphische Sammlung Bayerisches Nationalmuseum, „Vertrauensmann“ der NSDAP, 1934 Hauptkonservator Bayerische Verwaltung der Schlösser und Gärten München, 1940 Mitarbeiter Doerner-Institut München.

HaEbler, Konrad (1857-1946), Bibliothekar, Einbandforscher u. Buchwissenschaftler, 1907 Königliche Bibliothek Berlin, 1914-1921 Leiter Handschriftenabteilung, 1923 Dresden, enge Verbindung zum Bankier Victor von Klemperer.

Haeckel, Ernst (1834-1919), Mediziner u. Zoologe, 1861-1909 Professor Universität Jena, lehrte Darwin'sche Evolutionstheorie, 1866/1867 Reise Kanarische Inseln, später TropenReisen, 1876 Prorektor Universität Jena, Aufbau Zoologisches Insitut Universität Jena. 
HävernicK, Walter (1905-1983), Numismatiker, 1935 Kustos Herzogliches Münzkabinett Gotha, Dozent Universität Jena, 1945 Privatdozent Universität Hamburg, 1946 Leiter Museum für Hamburgische Geschichte u. Professor für Volkskunde, 1973 Emeritierung.

Hamann, Richard (1879-1961), Kunsthistoriker, 1911-1913 Professor Akademie Posen, 1913-1945 Ordinarius Universität Marburg, 1947-1957 Gastprofessur Universität Berlin.

Hammitzsch, Martin (1878-1945), Architekt u. Kommunalpolitiker, Assistent bei Cornelius Gurlitt Dresden, 1909 freier Architekt, 1920 Leiter Bauschule Dresden, 1938 Regierungsdirektor u. Leiter Bauabteilung Sächs. Ministerium des Innern, 1943 Leiter Abteilung Technik Sächsische Landesregierung.

Hanfstaengel, Eberhard (1886-1973), Kunsthistoriker, 1925 Direktor Städtische Galerie Lenbachhaus München, 1934 Direktor Nationalgalerie Berlin, 1937 Amtsenthebung durch Nationalsozialisten, 1945-1953 Generaldirektor Bayerische Staatsgemäldesammlungen.

Hantzsch, Viktor (1868-1910), Geograf u. Historiker, Lehrer Cossebaude u. Löbtau, 18991902 Freiwilliger Wissenschaftlicher Hilfsarbeiter Königliche Öffentliche Bibliothek Dresden.

Hartnacke, Wilhelm (1878-1952), Pädagoge, 1910 Schulinspektor Bremen, 1919 Stadtschulrat Dresden, 1933-1935 Minister für Volksbildung in Sachsen, nach Röhm-Putsch 1934 „beurlaubt“.

HaRTsCH, Erwin (1890-1948), Politiker, 1926-1932 SPD-Abgeordneter Sächsischer Landtag, 1933 von Nationalsozialisten aus Schuldienst entlassen, Verhaftung, nach 1945 Schuldirektor, 1946-1948 Kultusminister Sachsen, 1948 Direktor Sächsische Landesbibliothek.

Hauptmann, Gerhart (1862-1946), Dramatiker u. Schriftsteller, 1912 Nobelpreis für Literatur.

Hauser, E., Restaurator Kupferstichkabinett Berlin.

Heller, Karl Maria (1864-1945), Zoologe u. Entomologe, 1885 Zoologisches und Anthropologisch-Ethnographisches Museum Dresden, ab 1890 Kustos.

Hellige, Walter (1910-1984), Wissenschaftlicher Hilfsassistent Staatliches Münzkabinett Berlin.

Hempel, Eberhard (1886-1967), Kunsthistoriker, 1920-1921 Assistent Universität Graz, 1921-1923 Albertina Wien, 1931 Professor Universität Graz, 1933-1956 Professor TH Dresden.

Hetzer, Theodor (1890-1946) Kunsthistoriker, Studium bei Wilhelm Pinder, 1929-1946 Professor Leipzig.

Hofmann, Ludwig von (1861-1945), Maler u. Grafiker, Studium in Dresden, Karlsruhe u. Paris, 1890 freischaffend Berlin, 1913 Professor Großherzogliche Kunstschule Weimar, 1916 Professor Kunstakadmie Dresden.

Hoffmann, Tassilo (1887-1951), Numismatiker, 1911 Münzkabinett Stettin, 1919-1927 Münzhändler Berlin, 1932 Münzkabinett Gotha, 1935 Privatdozent Universität Berlin, 1929-1945 Vorsitzender Numismatische Gesellschaft Berlin.

Horn, Walther (1871-1939), Arzt u. Entomologe, 1909 Direktor Deutsches Entomologisches Institut Berlin-Dahlem, 1926-1936 Sekretär Wanderversammlung Deutscher Entomologen.

JAHN, Martin (1888-1974), Prähistoriker, Kustos Museum Breslau, 1931 Direktor Landesamt für vorgeschichtliche Denkmalpflege Breslau, 1934-1945 Ordinarius Universität Breslau, 1945 Professor Universität Halle, 1946 auch Direktor Landesmuseum für Vorgeschichte Halle. 
JaneNTZKY, Christian (1886-1968), Literaturwissenschaftler, 1916 Privatdozent später Professor Universität München, 1922-1952 Professor TH Dresden, von Nationalsozialisten angedrohte Emeritierung, 1945-1946 Leiter Bibliothek der TH Dresden.

Jantzen, Hans (1881-1967), Kunsthistoriker, 1916-1931 Professor Universität Freiburg i. Br., 1931-1935 Professor Universität Frankfurt a. M., 1935-1951 Professor Universität München.

Jentsch, Georg (1908-1968), Diplombraumeister, Brauereibesitzer Zittau u. Kunstsammler, 1931 NSDAP, Obersturmführer im SD, Leiter Kulturreferat Gau Sachsen, 1945 Bamberg (unter falschem Namen), 1960 Dresden.

Justi, Ludwig (1876-1957), Kunsthistoriker, 1909-1933 Direktor Nationalgalerie Berlin, 1933 von den Nationalsozialisten zum Kustos degradiert u. an Kunstbibliothek versetzt, 1941 pensioniert, 1946-1957 Generaldirektor Staatliche Museen Berlin.

KaLKowsky, Ernst (1851-1938), Geologe, 1894-1919 Ordinarius Mineralogie und Geologie TH Dresden u. Direktor Museum für Mineralogie, Geologie und Vorgeschichte Dresden.

Kekulé von Stradonitz, Reinhard (1839-1911), Klassischer Archäologe, 1870-1889

Professor Universität Bonn, 1889 Direktor Antikensammlung Königliche Museen Berlin u. 1890 Professor Universität Berlin.

Kesting, Edmund (1892-1970) Maler, Grafiker u. Fotograf, Studium in Dresden u. a. bei Otto Gussmann, ab 1922 freiberuflich, 1919-1933 „Der Weg - Kunstschule für Gestaltung“, nach 1945 Lehraufträge in Dresden, Berlin, Potsdam-Babelsberg.

KLEMPerer, Victor (1881-1960), Romanist, 1920-1935 Professor TH Dresden, Zwangspensionierung durch Nationalsozialisten, Werke: LTI (Lingua Tertii Imperii), Tagebücher (u. a. 1933-1945).

Klemperer, Gustav von (1852-1926), eigentlich Gustav Klemperer Edler von Klemenau, Bankdirektor, 1890-1913 Leiter Stammhaus Sachsen der Dresdner Bank, ab 1914 Aufsichtsrat der Dresdner Bank, Kunstsammler (Meißner Porzellan).

KLEMPERER, Victor von (1876-1943), Bankdirektor, Sohn von Gustav von Klemperer, 19091913 Leiter Leipziger Niederlassung Dresdner Bank, 1914-1934 Leiter Dresdner Bank Dresden, Kunstsammler (Inkunabeln), Zwangspensionierung durch Nationalsozialisten, 1938 Emigration, Kunstsammlung von Nationalsozialisten beschlagnahmt u. an Staatliche Sammlungen überwiesen.

Krebs, Hermann Emil (1874-?), Maschinenschlosser, 1902 Mitarbeiter Geodätisches Institut TH Dresden.

КocH, Ernst (1899-1973), Bibliothekar, 1935-1944 Leiter Bibliothek TH Dresden.

Косн, Herbert (1880-1962), Klassischer Archäologe, 1910-1913 Deutsches Archäologisches Institut Rom u. Athen, 1918 Professor Universität Jena, 1929 Professor Universität Leipzig, 1931-1950 Professor Universität Halle.

Kohl-Larsen, Ludwig (1884-1969), Arzt, Paläontologe u. Forschungsreisender, 1939-1945 Professor für Völkerkunde Universität Tübingen, 1949 Universität Tübingen.

Kohlhaussen, Heinrich (1894-1970) Kunsthistoriker, 1922-1933 Museum für Kunst und Gewerbe Hamburg, 1933-1936 Direktor Städtische Museen Breslau,1937-1945 Direktor Germanisches Nationalmuseum Nürnberg, 1950-1955 Direktor Kunstsammlung Veste Coburg.

KorfF, Hermann August (1882-1963), Germanist u. Literaturhistoriker, 1925-1954 Professor Universität Leipzig.

Kraus, Ferdinand, vermutlich: Franz Ferdinand Kraus Münzhandlung Braunschweig in den 1920er-Jahren. 
Krause, Fritz (1881-1963), Ethnologe, 1905 Museum für Völkerkunde Leipzig, 1927 Leitung, daneben 1925-1945 Professor Universität Leipzig.

KrauSE, Theodor (1868-?), 1919-1935 Restaurator Gemäldegalerie Dresden.

Kriegbaum, Friedrich (1901-1943), Kunsthistoriker, 1935-1943 Direktor Kunsthistorisches Institut Florenz.

KRUG, Gerhard, publizierte über numismatische Themen.

Kuehnel, Ernst (1882-1964), Orientalist u. Kunsthistoriker, 1909 Kunstgewerbemuseum Berlin, ab 1911 islamische Abteilung Staatliche Museen Berlin, 1931-1951 Direktor Museum für islamische Kunst Berlin.

Kunn, Walther (1887-?), 1912 Skulpturensammlung Dresden, u. a. Formermeister.

KüMmel, Otto (1874-1952), Kunsthistoriker, Gründer u. Direktor Museum für ostasiatische Kunst Berlin, 1934-1945 Generaldirektor Staatlichen Museen Berlin.

KurTh, Willy (1881-1963), Kunsthistoriker, 1913-1946 Staatliche Museen Berlin, 1924 Kustos Kupferstichkabinett Berlin, 1946-1963 Direktor Staatliche Schlösser und Gärten Potsdam-Sanssouci.

LadeWIG, Paul (I 858-I940), Archivar u. Bibliothekar, 1889 Landesbibliothek Baden, 1898-1909 Aufbau Allgemeine Bibliothek Firma Krupp Essen: Kruppsche Bücherhallen, 1909 Berlin, 1915-1931 Zentralinstitut für Erziehung und Unterricht, Leiter Zentrale für Volksbücherei.

Lahmann, Johann Friedrich (1858-1937), Jurist u. Kunstsammler Dresden, Bruder des Arztes u. Naturheilers Johann Heinrich Lahmann.

Lange, Helene (1848-1930), Pädagogin, Frauenrechtlerin u. Politikerin (Deutsche Demokratische Partei), 1919-1921 Mitglied der Hamburger Bürgerschaft.

Lassé, Walter (1893- ?), Klempner, 1934 Hilfsaufseher Skulpturensammlung Dresden, 1942 Abordnung Grünes Gewölbe u. Museum für Tierkunde, 1933 Betriebsrat.

Lehmann, Hans (1904-1989), Dr.-Ing., 1928 u. 1944-1945 Direktor Steingutfabrik Villeroy \& Boch Dresden, 1942 Lehrauftrag Bergakademie Clausthal, 1945 Clausthal, 1951 Ordinarius Institut für Steine und Erden Bergakademie Claustahl.

LeHrs, Max (1855-1938), Kunsthistoriker, 1883 Gemäldegalerie Königliche Sammlungen Dresden, 1895 Kupferstich-Kabinett, 1904-1908 Direktor Kupferstichkabinett Berlin, 1908-1923 Direktor Kupferstich-Kabinett Dresden.

LenK, Torsten Rickard (1890-1957), schwedischer Waffen- u. Kostümhistoriker, 1924 Livrustkammaren Stockholm, ab 1944 Direktor.

LeucKart, Rudolf (1822-1898), Zoologe, 1855-1869 Professor Universität Gießen, 1869 Professor Zoologie und Zootomie Universität Leipzig.

Lindau, Paul (1881-1945), Bildhauer, Studium in Dresden bei Richard Müller, Robert Diez u. Selmar Werner, ab 1914 freischaffend in Dresden.

LoeschCKe, Georg (1852-1915), Klassischer Archäologe, 1879-1889 Professor Universität Dorpat, 1889-1912 Professor Universität Bonn, 1912 Universität Berlin.

LüTZELER, Heinrich (1902-1988), Kunsthistoriker, 1930 Assistent Universität Bonn, 1940 Entzug der venia legendi durch Nationalsozialisten, 1946-1970 Professor Universität Bonn.

Lundborg, Hermann (1868-1943), schwedischer Rassentheoretiker, Neurologe u. Psychiater, 1903 Dozent für Psychiatrie und Neurologie Universität Uppsala Schweden, 1915 auch für Rassenbiologie u. Medizinische Genetik, 1921 Professor u. Leiter Staatliches Institut für Rassenbiologie Universität Uppsala. 
Luschan, Felix von (1854-1924), Arzt, Anthropologe, Ethnograph, Militär- und Krankenhausarzt, 1885-1910 Direktorialassistent Königliches Museum für Völkerkunde Berlin, 1909-1924 Professor für Physische Anthropologie Charité Berlin.

Marshall, William (1845-1907), Zoologe, 1880 Assistent Museum Leipzig, ab 1880 Professor Universität Leipzig.

Martin, Kurt (1899-1975), Kunsthistoriker, 1934-1956 Direktor Kunsthalle Karlsruhe, 1940 zusätzlich Leiter Städtisches Museum Straßburg, im NS „Generalbevollmächtigter für die Museen im Elsass und in Baden".

Meinhof, Carl (1857-1944), Pastor u. Afrikanist, Sprachlehrer Seminar für Orientalische Sprachen Berlin, 1909-1936 Professor Universität Hamburg.

Meisenheimer, Johannes (1873-1933), Zoologe, 1909 Professor Universität Jena, 1914-1933 Professor Universität Leipzig.

Menadier, Julius (1854-1939), Numismatiker, 1898-1921 Direktor Münzkabinett Berlin.

Menghin, Oswald (1888-1973), Prähistoriker, Gründer Wiener Prähistorische Gesellschaft, 1917-1945 Ordinarius Urgeschichtliches Institut Universität Wien, 1938 Unterrichtsminister im Kabinett Seyß-Inquart.

Menke-Glückert, Emil (1878-1948), Historiker u. Politiker, 1920 Ministerialrat Ministerium für Kultus und Öffentlichen Unterricht Sachsen, 1922 Professor TH Dresden, 1934 von Nationalsozialsiten zwangspensioniert, 1945 Kommissarische Leitung Abteilung Volksbildung Sachsen, 1946 Staatssekretär der Abteilung Wissenschaft und Forschung.

Merhart von Bernegg, Gero (1886-1959), Prähistoriker, 1927-1942 Ordinarius für Vor- und Frühgeschichte Universität Marburg, 1938 durch Nationalsozialisten „beurlaubt“ infolge eines Konfliktes mit Hans Reinerth, 1946-1949 Professor Universität Marburg.

Mertens, Eberhard, Pfarrer in Dölau, später Direktor Landesmünzkabinett Halle.

Messmer, [?] Architekt, um 1933-1945 Hilfsreferent SMV.

Meyer, Adolf Bernhard (1840-1911), Naturwissenschaftler u. Anthropologe, ab 1870 Forschungsreisen, 1874-1906 Direktor Königliches Naturhistorisches Museum Dresden, ab 1878 Königlich Zoologisches und Anthropologisch-Ethnographisches Museum.

Mühlmann, Kajetan (1898-1958), Kunsthistoriker, Protagonist des NS-Kunstraubes, 1938 unter Seyß-Inquardt Staatssekretär für Kunst, 1939 „Sonderbeauftragter für den Schutz und die Sicherung von Kunstwerken in den besetzten Ostgebieten “, 1940 Dienststelle „Mühlmann“ in Den Haag, 1944 Wien, 1945 Verhaftung durch US-Armee.

MüLleR, Richard (1874-1954), Maler u. Grafiker, 1900-1935 Professor Kunstakademie Dresden, 1933-1935 Rektor.

Musper, Heinrich Theodor (1895-1976), Kunsthistoriker, 1925 Leiter Graphische Sammlung Staatsgalerie Stuttgart, 1946-1960 Direktor Staatsgalerie Stuttgart.

Mutschmann, Martin (1879-1947), Unternehmer, NSDAP-Politiker, 1907-1930 Plauener Spitzenfabrik Mutschmann \& Eisentraut, 1925-1945 NSDAP-Gauleiter von Sachsen, 1933-1945 Reichsstatthalter von Sachsen, 1945 Verhaftung, 1947 Verurteilung u. Erschießung.

Nachtsheim, Hans (1890-1979), Zoologe u. Genetiker, vor 1945 Professor für Genetik Universität Berlin u. Kaiser-Wilhelm-Institut für Anthropologie, 1945-1948 Professor Universität u. Max-Planck-Gesellschaft.

Neubert, Johannes (1873-1941), 1913-1938 Königliche Sammlungen Dresden, zuletzt Präparator Münzkabinett. 
Niggemeyer, Hermann (1908-2005), Ethnologe, 1934 Assistent Frobenius-Institut Frankfurt a. M., 1940-1945 Kriegsdienst, bis 1947 Kriegsgefangenschaft, wieder Museum für Völkerkunde Frankfurt a. M., 1966-1972 Direktor.

Nippold, Walter (1892-1970), Anthropologe, 1935-1937 Assistent Anthropologische Sammlung Göttingen, später Kurator.

Oelmann, Franz (1883-1963), Archäologe, 1930-1949 Direktor Rheinisches Landesmuseum Bonn u. Honorarprofessor für Klassische Archäologie Universität Bonn.

Ostwald, Wilhelm (1853-1932), Chemiker, 1880 Privatdozent Universität Dorpat, 1881 Universität Riga, 1887-1906 Professor für Physikalische Chemie Universität Leipzig, 1909 Nobelpreis für Chemie.

Pattenhausen, Bernhard (1855-1926), Geodät, 1889 Vermessungsingenieur Herzogliche Forsteinrichtungsanstalt Braunschweig, 1893-1926 Professor TH Dresden u. 1884-1926 Direktor Mathematisch-Physikalischer Salon Dresden.

Pfeiffer, Max Adolf (1875-1957), Maschinenbauingenieur, 1913 Kaufmännischer Direktor Porzellanmanufaktur Meißen, 1918 Generaldirektor Porzellanmanufaktur Meißen, von Nationalsozialisten 1934 entlassen, 1938-1946 Direktor Königliche Porzellan-Manufaktur Berlin u. 1941-1945 Leiter Glasmanufaktur Karlsbad.

Pinder, Wilhelm (1878-1947), Kunsthistoriker, Schüler von August Schmarsow, 1911 Ordinarius TH Darmstadt, 1916 Universität Breslau, 1918 Universität Straßburg, 1919 Universität Breslau, 1920 Universität Leipzig, 1927 Universität München, 1935 Universität Berlin.

PlischKe, Hans (1890-1972), Ethnologe, 1934-1946 u. 1949-1959 Ordinarius Institut für Völkerkunde Universität Göttingen.

Pöch, Rudolf (1870-1921), Arzt, Ethnograph u. Anthropologe, 1895 Assistenzarzt Wien, 1900 Studium Anthropologie bei Felix von Luschan Berlin, ab 1913 Professor für Anthropologie und Ethnographie Universität Wien.

Poland, Kurt (1900 - nach 1948), NSDAP-Kreisleitung Dresden.

PoмpeскJ, Josef Felix (1867-1930), Geologe u. Paläontologe, 1904 Geologische Reichsanstalt Wien, 1907 Professor Universität Göttingen, 1913 Universität Tübingen, 1917 Ordinarius Universität Berlin.

Rave, Paul Ortwin (1893-1962), Kunsthistoriker, 1922 Nationalgalerie Berlin, 1937 Kommissarischer Leiter Sammlung Kronprinzenpalais u. Direktor Nationalgalerie Berlin, Rücktritt 1950, 1950-1961 Leiter Kunstbibliothek Berlin.

Reche, Otto (1879-1966), Anthropologe, Ethnologe u. „Rassenkundler“, Museum Breslau, 1911 Museum für Völkerkunde Hamburg, 1924 Professor für Anthropologie und Ethnologie Universität Wien, 1927 Universität Leipzig, 1925 Gründer der Wiener Gesellschaft für Rassenpflege, Vorstand in Deutscher Gesellschaft für Rassenhygiene und Deutscher Gesellschaft für Rassenforschung.

Reichel, Anton (1877-1945), Kunsthistoriker u. Komponist, ab 1908 Graphische Sammlung Albertina Wien, 1918 Kustos, 1938 Kommissarischer Direktor, 1942-1945 Direktor.

Reichert, Arno (1866-1933), Musiker, 1904-1931 Leiter Musikabteilung Königliche Öffentliche Bibliothek/Sächsische Landesbibliothek Dresden.

Reidemeister, Leopold (1900-1987), Kunsthistoriker, ab 1924 Staatliche Museen Berlin, 1932 Kustos Ostasiatische Abteilung, 1946 Leiter Städtische Museen Köln, 1950 Direktor Wallraf-Richartz-Museum Köln, 1954 Generaldirektor Städtische Kölner Museen, 1957 Generaldirektor Staatliche Museen Berlin (West), 1967-1987 Gründungsdirektor Brücke-Museum Berlin. 
Reinerth, Hans (1900-1990), Archäologe, ab 1934 Professor Universität Berlin, Abteilungsleiter für Vor- und Frühgeschichte bei Nationalsozialistischer Kulturgemeinde, Leiter Reichsbund für Deutsche Vorgeschichte, 1940 Leiter "Sonderstab Vorgeschichte“ Einsatzstab Reichsleiter Rosenberg, involviert in NS-Kulturgutraub, nach 1945 Direktor Pfahlbaumuseum Unteruhldingen.

Reisinger, Erich (1900-1978), Zoologe, 1932 Dozent Universität Köln, 1933 Institutsleiter Köln, 1939 Professor, bis 1945 Wehrmacht u. Kriegsgefangenschaft.

Rentsch, Bernhard (1900-1990), Biologe, Zoologe u. Verhaltensforscher, 1925-1937 Museum für Naturkunde Berlin; 1937-1956 Direktor Landesmuseum für Naturkunde Münster, 1944-1945 Professor für Zoologie Deutsche Universität Prag, 1947 Professor Universität Münster.

Reuter, Hans (1898-?), Ministerialrat SMV.

Reuther, Oscar (1880-1954), Bauforscher, 1905-1912 Grabungsarchitekt Babylon, 1920 Lehrstuhl für Geschichte der Baukunst TH Dresden, 1920-1934 Rektor TH Dresden, 1945 Heidelberg, 1949-1950 Lehrtätigkeit Universität Heidelberg.

Richthofen, Bolko von (1899-1983), Prähistoriker, 1929-1933 Museum für Völkerkunde Hamburg, 1933-1942 Ordinarius für Vor- und Frühgeschichte Universität Königsberg.

Riegel, ERnSt (1871-1939), Goldschmied u. Bildhauer, Studium München, ab 1913 Leiter Gold- und Silberschmiedeklasse Kunstgewerbeschule Köln.

Riegl, Alois (1858-1905), Kunsthistoriker u. Denkmalpfleger, Professor Universität Wien.

Roeder, Kurt, Kunsthistoriker, um 1933 Kustos Großherzogliche Porzellansammlung Darmstadt.

RüHLE, Siegfried (1896-?), Studienrat Leipzig.

Rudloff-Hille, Gertrud (1900-1983), Kunsthistorikerin, 1925-1930 Deutsches Theatermuseum München, 1946 Leiterin Städtisches Museum Zwickau, 1950 Referat Bildende Kunst im Ministerium für Volksbildung Dresden, 1951-1960 Direktorin Staatliche Kunstsammlungen Dresden.

Rupprecht, Leopold, Waffenhistoriker, Direktor Waffensammlung Kunsthistorisches Museum Wien.

Rust, Bernhard (1883-1945), NSDAP-Politiker, 1933/1934 Leiter Preußisches Kultusministerium, 1934-1945 Reichsminister für Wissenschaft, Erziehung und Volksbildung.

Salzmann, Heinrich (1891-?), NSDAP-Politiker, 1933 Propagandaleiter NSDAP-Gauleitung Sachsen, 1934 Landeskulturwalter, 1939 Abgeordneter Reichstag, ab 1939 Militärdienst.

SATtLeR, Richard (1873-?), Konservator Historisches Museum in Dresden.

SAUER, Gustav, Präparator Museum für Mineralogie, Geologie und Vorgeschichte in Dresden.

Schlosser, Julius von (1866-1938), Kunsthistoriker, 1901 Direktor Sammlung Plastik und Kunstgewerbe Kunsthistorisches Museum Wien, ab 1905 Professor Universität Wien.

Schmarsow, August (1853-1936), Kunsthistoriker, Professuren Universitäten Göttingen u. Breslau, 1892 Vorbereitung Gründung Kunsthistorisches Institut Florenz, 1893-1919 Professor Universität Leipzig.

Schмidt, Ludwig (1862-1944), Historiker u. Bibliothekar, Königliche Öffentliche Bibliothek Dresden, 1919 Oberbibliothekar, 1921-1925 Stellv. Direktor.

Schnorr von Carolsfeld, Franz (1842-1915), Bibliothekar, 1887-1907 Direktor Königliche Öffentliche Bibliothek Dresden.

Schnorr von Carolsfeld, Ludwig (1877-1945), Kunsthistoriker, Studium bei August Schmarsow, Kustos Schloßmuseum Berlin. 
SchöNHerR, Richard (1872-1938), Konservator Grünes Gewölbe in Dresden.

Schultz, Bruno K. (1901-1997), Anthropologe u. SS-Standartenführer, 1924 Assistent bei Otto Reche in Leipzig, 1927 Mitarbeiter Universität Wien, 1928 München, 1936 Professor Reichsakademie für Leibesübungen, 1938 Professor für „Rassenbiologie“ Universität Berlin, 1941 Universität Prag.

Schurig, Johannes (?-1929), bis 1929 Leiter Sächisches Armeemuseum in Dresden.

ScHÜтZ, Ernst (1901-1991), Ornithologe, ab 1927 Naturkundemuseen Hannover u. Dresden, 1929-1943 Vogelwarte Rossitten, ab 1936 Direktor, 1945 Gründung Vogelwarte Radolfzell, 1946-1969 Staatliche Museum für Naturkunde Stuttgart, ab 1959 Direktor.

Seeliger, Gerhard (1860-1921), Historiker, 1895-1921 Professor für Historische Hilfswissenschaften, Mittlere und Neuere Geschichte Universität Leipzig.

Seiduitz, Woldemar von (1850-1922), Kunsthistoriker, 1878-1884 Kupferstichkabinett Berlin, 1884-1919 Vortragender Rat in Generaldirektion der Königlichen Sammlungen Dresden.

Seydewitz, Max (1892-1987), als ehemaliger SPD-Politiker 1933-1945 im Exil, 1947-1952 Ministerpräsident von Sachsen, 1955-1968 Generaldirektor Staatliche Kunstsammlungen Dresden.

SEYLER, Alfred (1880-1950), Kunsthistoriker, 1906 Graphische Sammlungen München, 1937 Kommissarischer Direktor, 1940-1948 Direktor.

Seyss-InQuart, Arthur (1892-1946), Jurist, NS-Funktionär, 1938 Innen- und Sicherheitsminister Österreich, mit „Anschluss“ Bundeskanzler dann Reichsstatthalter, 1939-1945

Reichsminister ohne Geschäftsbereich, 1939 Stellvertreter Generalgouverneur Hans Frank, 1940 Reichskommissar für die Niederlande.

Simonson-Castelli, Ernst Oskar (1864-1929), Maler, 1893 freischaffend in Dresden, 1896 Übernahme der privaten Akademie für Zeichnen, Malen und Modellieren.

SLutzky, Naum (1894-1965), ukrainischer Goldschmied, 1912 Wiener Werkstätten, 1919-1924 Bauhaus Weimar, ab 1924 Innenarchitekt, 1927 Hamburg, 1933 Emigration nach England.

Spamer, Adolf (1883-1953), Volkskundler, 1926-1936 Professor für deutsche Philologie und Volkskunde TH Dresden, ab 1936 Professor Universität Berlin, ab 1942 Dresden, 1945 Gründung Institut für Volkskunst und Volksbrauch TH Dresden, 1947 Direktor Kulturwissenschaftliches Institut TH Dresden.

Spatz, Willy (1861-1931), Maler u. Litograf, 1897-1926 Professor Kunstakademie Düsseldorf.

SpeER, Albert (1905-1981), Architekt, 1937 Generalbauinspektor Berlin, 1942 Reichsminister für Bewaffnung und Munition.

Spiegler, Albin (1875-?), Kanzleiassistent Porzellansammlung Dresden.

SPONSEL, Jean Louis (1858-1930), 1902-1908 Professor für Architektur und Kunstgewerbe TH Dresden, 1908-1924 Direktor Kunstgewerbemuseum, Historisches Museum u. Münzkabinett in Dresden, 1914-1923 auch Direktor Grünes Gewölbe.

Steinweg, Klara (1903-1972), Kunsthistorikerin, 1929/1930 Freiwillige Wissenschaftliche Hilfsarbeiterin Gemäldegalerie Dresden, ab 1935 Kunsthistorisches Institut Florenz.

STÖTZNER, Walther (1882-1965) Asienforscher.

Strohbach, Hans (1890-1949), Studium in Dresden, ab 1919 Bühnenbildner u. Regisseur u. a. Berliner Volksbühne, ab 1934 Oberspielleiter Staatstheater Dresden, 1946-1949 Frankfurt a. M. 
StudentKowski, Werner (1903-1945 /1951), Kontorist, 1925 Mitbegründer NSDAP Studentengruppe Leipzig mit Hans Kummerlöwe, 1930-1933 Mitglied Sächsischer Landtag, 1933-1945 Mitglied Reichstag, 1933-1941 Gauamtsleiter u. Gauschulungsleiter NSDAPGauleitung Sachsen, 1934-1941 Leiter Hochschulabteilung u. Amt für NS-Erwachsenenbildung SMV, 1941-1945 Reichsamtsleiter Reichspropagandaleitung der NSDAP u. Mitarbeiter RMVP.

StÜLPNER, Kurt (1901-1980), Ethnologe, 1931 Mozambique-Expedition Staatliches Forschungsinstitut für Völkerkunde Leipzig.

Stresemann, Erwin (1889-1972), Zoologe, ab 1921 Zoologisches Museum Berlin, Leiter ornithologische Abteilung, 1946 Professor, 1946-1959 kommissarischer Direktor Zoologisches Museum der Humboldt-Universität Berlin.

Sydow, Jürgen (1921-1995), Studium Historische Hilfswissenschaften u. Geschichte München, Ausbildung zum Archivar in Dresden u. Weimar, 1942 Promotion in München zu Münzinschriften, 1951 Landesarchiv Brandenburg, 1953 Stadtarchivar Regensburg. Ter Meer, Hermanus Hendrikus (1871-1934), Tierpräparator u. Dermoplastiker, ab 1907 Zoologisches Institut Universität Leipzig.

Tамме, Gustav (1868-?), 1905-1934 Skulpturensammlung in Dresden, zuletzt Oberkonservator.

Termer, Franz (1894-1968), Ethnologe, 1929-1935 Professor für Geografie und Ethnologie Universität Würzburg, 1935-1962 Direktor Museum für Völkerkunde Hamburg.

Thode, Henry (1857-1920), Kunsthistoriker, 1889-1891 Direktor Städelsches Kunstinstitut Frankfurt a. M., 1896-1911 Ordinarius für Kunstgeschichte Universität Heidelberg.

Thomas, Bruno (1910-1988) Kunsthistoriker u. Waffenkundler, 1934 Volontär Kunsthistorisches Museum Wien, 1940-1945 Militärdienst, Leiter Waffensammlung Kunsthistorisches Museum Wien u. Leiter Waffensammlung Schloss Ambras Innsbruck.

Thomsen, Peter (1875-1954) Schulrektor u. Orientalist, ab 1930 Rektor Oberrealschule Dresden.

Thorbecke, Franz (1875-1945), Geograf, Kamerun-Forscher, Assistent Geografisches Institut Heidelberg, Dozent Handelshochschule Mannheim, ab 1917 Professor Handelshochschule Köln.

Uhlemann Heinz (1903-2000), Kunsthistoriker, Waffen- und Kostümkunde, 1930-1931 Freiwilliger Wissenschaftlicher Mitarbeiter Grünes Gewölbe Dresden, ab 1932 Berlin (Kupferstichkabinett, Kunstgewerbemuseum, Zeughaus), 1943-1944 Festungsmuseum Metz, bis 1948 Erzgebirge, dann Düsseldorf, 1954-1968 Direktor Deutsches Klingenmuseum Solingen.

WAETzold Wilhelm (1880-1945), Kunsthistoriker, 1912 Ordinarius für Neuere Kunstgeschichte Universität Halle, 1920 Vortragender Rat Preußisches Kultusministerium, 1927-1933 Generaldirektor Staatliche Museen Berlin, Amtsenthebung durch Nationalsozialisten, ab 1934 Universität Halle.

Walther, Rolf, Berlin, Einrichten der Münzausstellung der Reichskolonialausstellung Dresden im Auftrag des Reichskolonialbundes.

Weidensdorfer, Helmuth (1907-?), 1937 Inspektor Kunstgewerbemuseum Dresden, 1939 Wehrmacht.

Wernke, [Ernst?], Schüler des Historikers u. Archivars Alfred Brackmann.

Weule, Karl (1864-1926), Geograf u. Ethnologe, 1899 Zweiter Direktor Grassimuseum Leipzig, 1907 Direktor Völkerkundemuseum Leipzig, 1901 Professor für Ethnologie und Urgeschichte, 1920 Professor für Völkerkunde Universität Leipzig. 
WickHOFF, Franz (1853-1909, Kunsthistoriker, 1879-1895 Kustos Österreichisches Museum für Kunst und Industrie, 1882 Universität Wien.

Wieland, Friedrich (1906-1996), Numismatiker, Leiter Münzkabinett Karlsruhe.

WINKLER, Friedrich (1888-1965), Kunsthistoriker, 1913 Volontär Gemäldegalerie in Dresden, 1915 Zentralbibliothek Berliner Museen, später Leiter, 1933-1957 Direktor Kupferstichkabinett Berlin.

Wölfflın, Heinrich (1864-1945), Kunsthistoriker, 1893 Professor Universität Basel, 1901 Universität Berlin, 1912 Universität München u. 1924 Universität Zürich.

Wolfstieg, August, Direktor Bibliothek Preußisches Abgeordnetenhaus Berlin.

WOLS, (Wolfgang Schulze) (1913-1951), Fotograf, Maler, Grafiker, Bruder von Elfriede Schulze-Battmann, ab 1932 in Frankreich, meist Paris, Vertreter des Tachismus u. Informel.

ZaUnick, Rudolph (1893-1967), Wissenschaftshistoriker, 1927 Privatdozent TH Dresden, nach 1945 Lehrtätigkeit Universität Halle.

ZIEGLER, Adolf (1892-1959), Maler u. NS-Kulturfunktionär, 1936 Präsident Reichskammer der bildenden Künste, 1937 Beauftragter für „Säuberung“ deutscher Museen und Galerien von „entarteter Kunst“.

Zimmer, Carl (1873-1950), Zoologe, 1923-1937 Professor für systematische Zoologie u. Direktor Zoologisches Museum Universität Berlin.

Zimmermann, Heinrich (1886-1971), Kunsthistoriker, 1915-1918 Assistent Österreichische Staatsgalerie Wien, 1919 Direktorialassistent Kunstgewerbemuseum Berlin, 1920-1936 Direktor Germanisches Nationalmuseum Nürnberg, 1936 Direktor Gemäldegalerie Berlin, 1938 suspendiert, 1940-1943 Deutscher Kunstschutz, 1948-1957 Generaldirektor Staatliche Museen Berlin.

Zittel, Karl Alfred von (1839-1904), Geologe u. Paläontologe, 1862 Geologische Reichsanstalt Wien, 1863 Privatdozent Universität Wien u. Karlsruhe, 1866 Universität München, 1880 Professor Universität München.

ZöRNER, Ernst (1895-1945), Kaufmann, NSDAP-Politiker, 1933-1939 Oberbürgermeister Dresden, 1939-1940 Bürgermeister Krakau, 1940-1943 Gouverneur Distrikt Lublin.

Zschietzschmann, Willy (1900-1976), Klassischer Archäologe, 1932-1937 Privatdozent Universität Berlin, 1937-1945 Professor für Archäologie Universität Gießen, 1945-1967 Wissenschaftlicher Rat Universität Gießen.

ZüCHNER, Wolfgang (1906-1981), Klassischer Archäologe, 1934-1939 Staatliche Museen Berlin, 1939-1946 Assistent Archäologisches Institut Universität Leipzig, 1953-1971 Professor Universität Erlangen. 


\section{Abkürzungsverzeichnis}

\begin{tabular}{ll} 
BArch & Bundesarchiv Berlin \\
BayHStA & Bayerisches Hauptstaatsarchiv München \\
DA & Dresdner Anzeiger \\
DAF & Deutsche Arbeitsfront \\
DFG & Deutsche Forschungsgemeinschaft \\
DNa & Dresdner Nachrichten \\
DNN & Dresdner Neueste Nachrichten \\
DVz & Dresdner Volkszeitung \\
DZ & Dresdner Zeitung \\
FK & Der Freiheitskampf \\
Gestapo & Geheime Staatspolizei \\
HStA Dresden & Sächsisches Staatsarchiv, Hauptstaatsarchiv Dresden \\
KdF & Kraft durch Freude \\
KPD & Kommunistische Partei Deutschlands \\
MFV & Museum für Völkerkunde \\
MK & Münzkabinett \\
MPS & Mathematisch-Physikalischer Salon \\
MVD & Museum für Völkerkunde Dresden \\
NL & Nachlass \\
NSBO & Nationalsozialistische Betriebszellenorganisation \\
NSDAP & Nationalsozialistische Deutsche Arbeiterpartei \\
NSLB & Nationalsozialistischer Lehrerbund \\
NSV & Nationalsozialistische Volkswohlfahrt \\
PA & Personalakten \\
RDB & Reichsbund der Deutschen Beamten \\
RGBl. & Reichsgesetzblatt \\
RLB & Reichsluftschutzbund \\
RMVP & Reichsministerium für Volksaufklärung und Propaganda \\
RMWEV & Reichsministerium für Wissenschaft, Erziehung und Volksbildung \\
RSHA & Reichssicherheitshauptamt \\
RuSHA & Rasse- und Siedlungs-Hauptamt SS \\
SA & Sturmabteilung (der NSDAP) \\
SD & Sicherheitsdienst des Reichsführers SS \\
SKD Archiv & Archiv der Staatlichen Kunstsammlungen Dresden \\
SKD & Staatliche Kunstsammlungen Dresden \\
SLUB & Sächsische Landesbibliothek - Staats- und Universitätsbibliothek Dresden \\
SMB-ZA & Staatliche Museen zu Berlin, Zentralarchiv \\
SMV & Sächsisches Ministerium für Volksbildung \\
SPD & Sozialdemokratische Partei Deutschlands \\
SS & Schutzstaffel (der NSDAP) \\
StA Dresden & Landeshauptstadt Dresden, Stadtarchiv \\
StAB & Stadtarchiv und Stadthistorische Bibliothek Bonn \\
TH & Technische Hochschule \\
ULB & Universitäts- und Landesbibliothek Bonn \\
ZFMK & Zoologisches Forschungsmuseum Alexander König Bonn \\
& \\
\hline
\end{tabular}




\section{Quellenverzeichnis}

Sächsisches Staatsarchiv, Hauptstaatsarchiv Dresden (HStA Dresden)

\section{Staatskanzlei}

Nr. 320/1 Auslagerung Bergungsgut Allgemeines

Nr. 320/55 Bergungsgut in Schloss Weesenstein

\section{Ministerium des Kultus und öffentlichen Unterrichts}

Nr. 14602 Ausstellungen

Nr. 14612 Tätigkeitsberichte

Nr. 14618 Personalfragen

Nr. 14647 Kunstangelegenheiten, Ernennungen, Beurlaubungen

Nr. 18959 Staatsdiener und Hilfspersonen

Nr. 18960 Staatsdiener und Hilfspersonen

Nr. 18961 Staatsdiener und Hilfspersonen

Nr. 18962 Staatsdiener und Hilfspersonen

Nr. 18964 Freiwillige Hilfsarbeiter

Nr. 18991/1 Personal Bellmann, Herbert

Nr. 18991/2-3 Personal Enking, Ragna

Nr. 18991/4 Personal Watzdorf, Erna von

Nr. 19003 Jahresberichte aus den Sammlungen

Nr. 19028 Jahresberichte aus den Sammlungen

Nr. 19116 Personalunterlagen

Nr. 19192 Porzellansammlung

Nr. 19241 Kunstgewerbemuseum

Nr. 19252 Historisches Museum

Nr. 19273 Armeemuseum

Nr. 19294 Museum für Mineralogie, Geologie und Vorgeschichte

Nr. 19295 Museum für Mineralogie, Geologie und Vorgeschichte

Nr. 19295/2 Museum für Mineralogie, Geologie und Vorgeschichte

Nr. 19313 Museen für Tier- und Völkerkunde, Personal

Nr. 19312 Museen für Tier- und Völkerkunde

Nr. 19336 Landesbibliothek

Nr. 19338 Landesbibliothek

Nr. 19345 Personal Landesbibliothek

Nr. 22873 Registrande

Nr. 22874 Brieftagebuch

Nr. 22875 Eingangsregistrande Referat Sammlungen

Nr. 22878 Gemäldegalerie

Nr. 22879 Neue Gemäldegalerie

Nr. 22881 Grünes Gewölbe

Nr. 22882 Grünes Gewölbe

Nr. 22883 Historisches Museum

Nr. 22884 Historisches Museum 
Nr. 22885 Kunstgewerbemuseum

Nr. 22886 Kunstgewerbemuseum

Nr. 22887 Kupferstichkabinett

Nr. 22888 Kupferstichkabinett

Nr. 22889 Kupferstichkabinett

Nr. 22890 Porzellansammlung

Nr. 22891 Porzellansammlung

Nr. 22892 Porzellansammlung

Nr. 22894 Münzkabinett

Nr. 22895 Münzkabinett

Nr. 22896 Münzkabinett

Nr. 22897 Münzkabinett

Nr. 22899 Skulpturensammlung

Nr. 23044 Skulpturensammlung

Nr. 23053 Jahresberichte

Nr. 23054 Direktorenbesprechungen

Nr. 23056 Ehrungen

Nr. 23057 Dienstreisen

Nr. 23058 Staatsdiener und Hilfspersonal

Nr. 23059 Berichte über Besichtigung versch. Dt. Museen

Nr. 23063 Eingang 1942 Fragment Referat S

Nr. 23064 Eingang 1943 Fragment Referat S

Nr. 23072 Kriegsmaßnahmen

Nr. 23073 Personalangelegenheiten/Luftschutz

Nr. 23078 Luftschutzmaßnahmen

Nr. 23080 Führungen

Nr. 23081Vorträge

Nr. 23084 Veröffentlichungen, Amtl. Bekanntgaben

Nr. 23087 Sonderausstellungen

Nr. 23089 Besucherzahlen, Öffnungszeiten

\section{Gemäldegalerie}

Nr. 7 Jahresberichte

Nr. 8 Planung Luftschutzmaßnahmen

Nr. 27 Personalakten

Nr. 28 Personal

Nr. 29 Personal

Nr. 29/1 Personal Posse

Nr. 41 Amtliche Veröffentlichungen

\section{Kunstgewerbemuseum}

Nr. 2 Personalakten

12624 Familiennachlass Grafen von Watzdorf

Nr. 134 Dr.-Diplom Erna von Watzdorf

Nr. 150 Nachlass Erna von Watzdorf, Tagebuch

Nr. 163 Stammbaum Familie Watzdorf

Nr. 203 Anna Dorothee von Watzdorf

12810 Personennachlass Kurt Zoege von Manteuffel 


\section{Personennachlass Georg Bierbaum}

Nr. 7 Korrespondenz Landesmuseum für Vorgeschichte

Nr. 12 Entlassung Bierbaum

Nr. 72 familiengeschichtl. Dokumente

Nr. 73 familiengeschichtl. Dokumente

Nr. 76 familiengeschichtl. Dokumente

Nr. 77 familiengeschichtl. Dokumente

Nr. 114 Tagebuch

Nr. 115 Tagebuch

Nr. 125 Tagebuch

Nr. 126 Tagebuch

Nr. 127 Tagebuch

Nr. 128 Tagebuch

12821 Personennachlass W. Coblenz

Nr. 426 Auslagerung Schloss Weesenstein

13471 NS-Archiv des MfS

Nr. ZA VI 2901, Akte 12 Hans Kummerlöwe

Nr. ZB II 3958 Klaus Günther

Nr. ZB II 4473 Charlotte Boden

Nr. ZD 7921, Akte 6 Rudolf von Arps-Aubert

Nr. ZW 119, Akte 1 Helene Barthel

Nr. ZW 232, Akte 5 Alfred Beck

13842 Staatliches Museum für Tierkunde Dresden

Nr. 047 Briefwechsel Direktion

Nr. 048 Briefwechsel Direktion

Nr. 072 Briefwechsel Direktion

Nr. 114 Personalakten van Emden, Günther, Heller, Jacobi

Nr. 115 Verordnungen

Nr. 135 Akten der Entomologischen Abteilung

Nr. 204 Briefwechsel Museumsbund

Nr. 210 Briefwechsel und Notizen Jacobi

Nr. 211 Briefwechsel Verwaltung

Nr. 237 Personalakte H. Hofer Verwaltung

Nr. 267 Reiseberichte

13843 Staatliches Museum für Mineralogie und Geologie

Nr. 122 Schriftverkehr Rimann

Nr. 205 Schriftwechsel Museum wiss. Verwaltung

Nr. 267 Personalakten Verwaltung

Nr. 268 Stammblätter für Verw.-MA

13859 Reichsstatthalter (Staatskanzlei), Personalamt

Nr. 131 Assmann, Karl

Nr. 299 Beck, Alfred

Nr. 335 Bemmann, Rudolf

Nr. 521 Bierbaum, Georg

Nr. 844 Buck, Helmuth

Nr. 1051 Denecke, Dorothee 
Nr. 1193 Draeske, Johannes

Nr. 1553 Fichtner, Fritz

Nr. 1659 Fischer, Walther

Nr. 1960 Fichtner, Fritz

Nr. 2571 Günther, Klaus

Nr. 2687 Hahn, Max

Nr. 2646 Häntzschel, Walter

Nr. 3205 Hesch, Michael

Nr. 3427 Holzhausen, Charlotte

Nr. 3429 Holzhausen, Walter

Nr. 3696 Jammers, Ewald

Nr. 3710 Jatzwauk, Jacob

Nr. 3833 Kästner, Erhart

Nr. 4970 Leuschner, Arthur

Nr. 5153 Loos, Hans

Nr. 5435 Meise, Wilhelm

Nr. 5861 Müller, Walter

Nr. 6025 Neubert, Hermann

Nr. 6178 Oertel, Robert

Nr. 6452 Pietzsch, Artur

Nr. 6777 Reichert, Robert

Nr. 6906 Richter, Hubert

Nr. 7305 Sander, Curt

Nr. 8089 Schneider, Helmut

Nr. 8495 Schwarze, Rudolf

Nr. 8703 Storch, Margarethe

Nr. 9020 Täubrich, Paul

Nr. 9129 Unger, Alfred

Nr. 9267 Voss, Hermann

Nr. 9397 Watzdorf, Dorothee von

19117 Personalunterlagen sächsischer Behörden, Gerichte und Betriebe ab 1945,

Personalakten der LRS, Sammelbestand

Karton 1781 PA Karl Assmann

Karton 1784 PA Wolfgang Balzer

Karton 1794 PA Georg Bierbaum

Karton 2011 PA Hubert Richter

Staatliche Kunstsammlungen Dresden, Archiv (SKD Archiv)

\section{Kupferstich-Kabinett}

01/KK 3, Bd. 8-9

$01 / \mathrm{KK} 17, \mathrm{Bd} .1$

\section{Kunstgewerbemuseum}

$01 /$ KGM 2

01/KGM 5 
01/KGM 7

01/KGM 10

01/KGM 11

01/KGM 14

01/KGM 95

\section{Porzellansammlung}

01/PS 36, Bd. 1-2

01/PS 37, Bd. 1-2

01/PS 38

01/PS 40

01/PS 41, Bd. 1

01/PS 42, Bd. 1-2

01/PS 43, Bd. 1- 4

01/PS 44, Bd. 1-2

01/PS 45, Bd. 1-3

01/PS 48

01/PS 49, Bd. 1

01/PS 50

01/PS 53, Bd. 1-3

01/PS 54, Bd. 1-2

01/PS 131

01/PS 133

01/PS 136

01/PS 137

01/PS 138

01/PS 139

01/PS 141

01/PS 142

01/PS 143

Skulpturensammlung

01/SKS 44

01/SKS 171

01/SKS 172

01/SKS 173

01/SKS 174

01/SKS 179

01/SKS 184

01/SKS 345

01/SKS 353

01/SKS 413

\section{Vorakten}

02/VA 4

02/VA 5

02/VA 20

02/VA 41, Bd. 1-2

02/VA 50 
02/VA 53, Bd. 2

02/VA 59

02/VA 158

02/VA 159

02/VA 162

02/VA 166

02/VA 172

Staatliche Kunstsammlungen Dresden, Mathematisch-Physikalischer Salon (SKD, MPS) Akten 1933-1945

Staatliche Kunstsammlungen Dresden, Münzkabinett (SKD, MK)

Akten 1925-1945

Staatliche Kunstsammlungen Dresden, Museum für Völkerkunde (SKD, MfV Archiv)

MVD n20;25 Nachlass Bernhard Struck

MVD 20, Netz Nr. 123 Nachlass Bernhard Struck

Nachlass Herbert Bellmann

Sächsische Landesbibliothek - Staats- und Universitätsbibliothek (SLUB)

\section{Handschriftenabteilung}

Mscr.Dresd.App.1378.a; Mscr.Dresd.App.1378.b. Nachlass Bollert, Martin

Mscr.Dresd.App.1378,I-III Nachlass Bollert, Martin

Mscr.Dresd.App.1681-1683 Nachlass Fiebiger, Otto

Mscr.Dresd.App.1689 Briefe und Karten an Balzer, Wolfgang

Mscr.Dresd.App.1830 Hofmann, Hans: Selbstbiographische Mitteilungen, 4 Bde., 1974

Mscr.Dresd.App.2550 Nachlass Balzer, Wolfgang

Mscr.Dresd.App.2600 Nachlass Deckert, Helmut

Mscr.Dresd.App.2600,A1 - Deckert, Helmut: Bibliothekar aus Leidenschaft, Lebens- und Bibliothekserinnerungen [Typoskript], 4 Bde., 1987

Mscr.Dresd.App.2830 Briefwechsel Ewald Jammers

\section{Personalakten}

PA Barthel, Helene

PA Bemmann, Rudolf

PA Benndorf, Gottfried

PA Boden, Charlotte

PA Bollert, Martin

PA Dähnert, Ulrich

PA Denecke, Dorothee

PA Faass, Bruno

PA Fiebiger, Otto

PA Frieser, Walther

PA Holzhausen, Charlotte

PA Jammers, Ewald

PA Kästner, Erhart

PA Löwenthal, Anna

PA Neubert, Hermann 
PA Richter, Hubert

PA Schneider, Helmut

PA Walter, Lucie

PA Watzdorf, Dorothee von

\section{Bibliotheksarchiv}

Bibl.Arch.III.G,Vol.686

Bibl.Arch.III.G,Vol.686.a

Bibl.Arch.III.G,Vol.686.c

Bibl.Arch.III.G,Vol.686.d

Bibl.Arch.III.J,Vol.859.b

Bibl.Arch.III.J,Vol.859.d

Bibl.Arch.III.J,Vol.859.e

\section{Tageszeitungen}

Dresdner Anzeiger

Dresdner Nachrichten

Dresdner Neueste Nachrichten

Dresdner Volkszeitung

Dresdner Zeitung

Der Freiheitskampf

\section{Landeshauptstadt Dresden, Stadtarchiv}

Personenstandsregister, Sign. 6.4.25

Meldekartei, Sign. 15.7.3 und 15.7.4

Hochschule für Bildende Künste Dresden, Archiv (HfBK Archiv)

\section{Bestand Akademie der bildenden Künste}

$01 / 191$

\section{Bestand Kunstgewerbeschule/HfW}

$02 / 62$

$02 / 70$

Historisches Archiv der Sächsischen Staatstheater - Staatsoper Dresden und Staatsschauspiel Dresden
NL Franz Schubert 30
NL Franz Schubert 175
NL Franz Schubert 557
NL Franz Schubert 558

\section{Bundesarchiv Berlin (BArch)}

\section{NS 5-VI Deutsche Arbeitsfront - Zentralbüro, Arbeitswissenschaftliches Institut}

NS 5-VI/299 Gaue der NSDAP, Sachsen, u. a. Gauschule Hammerleubsdorf 
NS 5-VI/17538 Persönlichkeiten d. Öff. Lebens - Sammelakten - Bollert, Martin

NS 5-VI/17594 Haenel, Erich

NS 5-VI/17701 Posse, Hans

NS 5-VI/17750 Voss, Hermann

NS 12 Hauptamt für Erzieher/Reichwaltung des Nationalsozialistischen Lehrerbundes

NS 12/8602 Kummerlöwe, Hans

NS 12 MF A0057 Fichtner, Fritz

NS 12 MF B0045 Kummerlöwe, Hans

NS 12 MF C0067 Struck, Bernhard

NS 15 Der Beauftragte des Führers für die Überwachung der gesamten geistigen und weltanschaulichen Schulung und Erziehung der NSDAP

NS 15/35 Voss, Hermann

NS 15/81a Voss

NS 21 Forschungs-und Lehrgemeinschaft „Das Ahnenerbe“

NS 21/1060 Bierbaum, Georg

NS 21/1520 Hetsch, Rolf

NS 21/2157 Posse, Hans

NS 33 SS-Führungshauptamt

NS 33/2580 Hesch, Michael

NS 33/2582 Amberger, Heinz

NS 33/2613 Hesch, Michael

NS 33/2616 Hesch, Michael

NS-Archiv des MfS

ZA VI 0883 A9 Pfaul, Berthold

ZA VI 1219 A10 Hetsch, Rolf

R 43/II Reichskanzlei

R 43/II/1236a Museen, Kunstsammlungen, Kunstwerke 1933-1945 u. a. Heeresmuseen

R 55 Reichsministerium für Volksaufklärung und Propaganda

R 55/717 Bd. 3 - u. a. Veit-Stoß-Ausstellung

R 55/22234 Hetsch, Rolf

R 55/23637 Kästner, Erhart

R 55/33544 Hetsch, Rolf

R 58 Reichssicherheitshauptamt

R 58/4259 Barthel, Helene

R 58/4359 Bellmann, Herbert

R 58/9609 Emden, Fritz van

R 73 Deutsche Forschungsgemeinschaft

R 73/10300 Heydrich, Martin

R 73/11675 Heydrich, Martin

R 73/11926 Jammers, Ewald

R 73/12517 Kummerlöwe, Hans

R 73/13352 Neu, W. - Kummerlöwe, Hans

R 73/15172 Jacobi, Arnold

R 73/15519 Watzdorf, Erna von

R 73/16141 Fichtner, Fritz

R 73/16162 Heydrich, Martin 
R 73/16349 Bierbaum, Georg

R 73/21988 Rimann, Eberhard

R 76-I Kurator der wissenschaftlichen Hochschulen in Wien/Personalakten

R 76-I/59 Kummerlöwe, Hans

R 76-I/59a Kummerlöwe, Hans

R 76-I/59b Kummerlöwe, Hans

R 76-I/59c Kummerlöwe, Hans

R 601 Präsidialkanzlei/2 Abteilung B (Innenpolitik)/2.6.2 Beamtenwesen - Personalwesen R 601/2078 Fichtner, Fritz

R 601/2079 Häntzschel, Walter

R 4901 Reichsministerium für Wissenschaft, Erziehung und Volksbildung

R 4901/2737 Int. Kongresse und Tagungen

R 4901/2748 Int. Kongresse und Tagungen

R 4901/2794 Int. Kongresse und Tagungen

R 4901/2842 Int. Kongresse und Tagungen

R 4901/2932 Int. Kongresse und Tagungen

R 4901/13266 Hesch, Michael

R 4901/13268 Kleemann, Otto

R 4901/13278 Struck, Bernhard

R 4901/13280 Werkmeister, Paul

R 4901/13282 Naturwiss. Hochschullehrer A-M

R 4901/13283 Naturwiss. Hochschullehrer N-Z

R 4901/24789 Heydrich, Martin

R 9361-II Sammlung Berlin Document Center (BDC). Personenbezogene Unterlagen der NSDAP/Parteikorrespondenz

R 9361-II/356280 Halm, Peter

R 9361-II/427459 Hofer, Helmut

R 9361-II/803289 Pfaul, Berthold

R 9361-III Sammlung Berlin Document Center (BDC). Personenbezogene Unterlagen der SS und SA

R 9361-III/2109 Amberger, Heinz

R 9361-III/96673 Kleemann, Otto

R 9361-III/514479 Amberger, Heinz

R 9361-III/530867 Hesch, Michael

R 9361-V Sammlung Berlin Document Center (BDC). Personenbezogene Unterlagen der

Reichskulturkammer (RKK)

R 9361-V/2981 Hetsch, Rolf

R 9361-V/23746 Kaestner, Erhart

R 9361-V/40635 Wolf, Siegfried

R 9361-V/100977 Hetsch, Rolf

R 9361-VI Sammlung Berlin Document Center (BDC). Personenbezogene Unterlagen von

Gliederungen der NSDAP und angeschlossenen Verbänden

R 9361-VI/1172 Hesch, Michael

R 9361-VI/2478 Rimann, Eberhard

R 9361-VI/3283 Voss, Hermann

R 9361-VI/3404 Werkmeister, Paul 


\section{R 9361-VIII/KARTEI/ (NSDAP-Zentralkartei) \\ R 9361-IX/KARTEI/ (NSDAP-Gaukartei)}

Staatliche Museen zu Berlin, Zentralarchiv (SMB-ZA)

I/KFM 43

I/SKS 91

II/VA 7032

II/VA 15857

III/VKI 23

III/VKI 26

EM, Archiv, I/MV 0817

Deutscher Museumsbund

III/DMB 003

III/DMB 005

III/DMB 326

III/DMB 329

III/DMB 333

III/DMB 393

III/DMB 397

Universitäts- und Landesbibliothek Bonn (ULB)

S 2611a Korrespondenz

S 2611 (NL Bollert)

Stadtarchiv und Stadthistorische Bibliothek Bonn (StAB)

PA 1978/4377, Bd. 1-2 Walter, Holzhausen

Pr 42/965, Bd. 1-2 Personalakte Holzhausen, Walter

Zoologische Forschungsmuseum Alexander Koenig Bonn (ZFMK)

NL Kummerlöwe

Friedrich-Alexander-Universität Erlangen-Nürnberg, Universitätsarchiv Erlangen F2/1 Nr. 2245a

Personen- und Vorlesungsverzeichnisse 1949-1961

\section{Stadtarchiv Erlangen}

III.115.F.1 Zeitungsausschnittsammlung, Fritz Fichtner 258.A.113 Bürgermeister- und Presseamt, Fritz Fichtner Historische Meldekartei und Sterberegister Nr. 1168/1969 
Otto-Friedrich-Universität Bamberg, Universitätsarchiv

V A 341 Personal, Allg. Angelegenheiten, Bd. 3

V A 343 Personal, Allg. Angelegenheiten, Bd. 5

V B 511 Lehrauftragsvergütungen, Bd. 1

V B 512 Lehrauftragsvergütungen, Bd. 2

V B 513 Lehrauftragsvergütungen, Bd. 3

V K 21 Korrespondenz, Rektorat, Bd. 1

Vorlesungsverzeichnisse 1945-1954

Bayerisches Hauptstaatsarchiv München (BayHStA)

MK 43591 Bayer. Staatsministerium für Unterricht und Kultus, Fritz Fichtner

MK 78130 Bayer. Staatsministeriums für Unterricht und Kultus, Universität Erlangen 


\section{Literaturverzeichnis}

A. G.: Kunst im Luftschutzraum. Luftschutz auch für die deutschen Kunstschätze, in: Die Sirene. Illustrierte Zeitschrift des Reichsluftschutzbundes, Nr. 13, Juni 1941, S. 291-293.

Adressbuch für Dresden und Vororte, Bde. 1933-1945, Dresden, online: http://adressbuecher. sachsendigital.de/startseite/, Zugriff: 5.12.2019.

Amlung, Ullrich: Schulwesen, in: Starke/John 2006, S. 454-461.

Amlung, Ullrich: Die Abteilung „Schule und Museum“ am Staatlichen Museum für Deutsche Volkskunde in Berlin und ihr Leiter Adolf Reichwein 1939-1944, in: Grabowski/Winter 2013, S. 409-426.

Arnauld, Andreas von: Rechtsfragen des Biographieschreibens, Teil 1: Recherche, Teil 2: Publikation, in: Klein, Christian (Hg.): Grundlagen der Biographik, Stuttgart 2002, S. 219264.

Arnold, Paul: Walter Schwinkowski, in: Dresdener Kunstblätter, 32. Jg., H. 3, 1988, S. 84-91.

Arnold, Paul: Walter Schwinkowski in memoriam, in: Erfurter Münzblätter, 5, 1997, S. 17-22.

Arnold, Paul: Schwinkowski, Walter, Leiter des staatlichen Münzkabinetts Dresden. Altpreußische Biographien, V,1, Marburg 2000, S. 1698-1699.

Assmann, Karl: Führer für die Benutzer der Sächsischen Landesbibliothek, 1925.

Assmann, Karl: M. Bollerts Schriften, zsgest. zu seinem 75. Geb., in: Zentralblatt für Bibliothekswesen, Bd. 65, 1951, S. 341-343.

Bach, H.: In memoriam. Bernhard Struck, 1888-1971, in: Anthropologischer Anzeiger, 34, 1973, S. 83.

Baensch, Tanja, Kristina Kratz-Kessemeier u. Dorothee Wimmer (Hg.): Museen im Nationalsozialismus. Akteure - Orte - Politik, Köln/Weimar/Wien 2016.

Bayer, Karen, Sparing Frank u. Wolfgang Woelk (Hg.): Universitäten und Hochschulen im Nationalsozialismus und in der frühen Nachkriegszeit, Stuttgart 2004.

Benndorf, Gottfried u. Hans Hofmann: Die Sächsische Landesbibliothek 1920-1936, in: Neubert, Hermann (Hg.): Festschrift Martin Bollert zum 60. Geburtstage, Dresden 1936, S. 1-14.

Benz, Wolfgang, Graml, Hermann u. Hermann Weiß (Hg.): Enzyklopädie des Nationalsozialismus, Digitale Bibliothek, Bd. 25, Berlin 1999.

Berichte über die Verwaltung der Staatlichen Sammlungen für Kunst und Wissenschaft zu Dresden 1929-1937, Dresden o. J. (1940) (Berichte über die Verwaltung ... o. J.).

Berndt, Iris: Wissenschaftler für alte deutsche Kunst. Max Lehrs und seine Mitarbeiter, Peter Halm, Werner Schade, in: Dresdener Kunstblätter, 48. Jg., H. 1, 2004, S. 38-41.

Bescherer, Johannes: Zur Geschichte des Institutes für Anthropologie und Völkerkunde der Friedrich-Schiller-Universität Jena in den Jahren 1936-1953, in: Bernhard Struck zum 65. Geburtstag am 28. August 1953. Beiträge zur Anthropologie und Ethnologie gewidmet von Schülern und Freunden, Wissenschaftliche Zeitschrift der Friedrich-Schiller-Universität Jena, 3. Jg., 1953/54, Mathematisch-Naturwissenschaftliche Reihe, H. 1, S. 2-12.

Bibliothek d. Hochschule für Verkehrswesen „Friedrich List“ Dresden: Zusammenstellung der Veröffentlichungen von Dr. Charlotte Boden: aus Anlaß ihres 80. Geburtstages am 15.1.1980, Dresden 1979.

Bock, Henning: Prof. Oertel zum Abschied, in: Jahrbuch Preussischer Kulturbesitz, Bd. XI, 1973, S. 242-243. 
Bosman, Suzanne: The National Gallery in Wartime, London 2008.

Brenner, Hildegard: Die Kunstpolitik des Nationalsozialismus, Reinbek bei Hamburg 1963.

Bürger, Thomas: Wandel und Kontinuität in 450 Jahren.Von der kurfürstlichen Liberey zur Sächsischen Landesbibliothek - Staats- und Universitätsbibliothek Dresden, in: Wissenschaftliche Zeitschrift der Technischen Universität Dresden, 55, 2006, 1-2, S. 29-36, https://nbn-resolving.org/urn:nbn:de:bsz:14-ds-1204804136305-26740, Zugriff: 5.12.2019.

Bürger, Thomas: Dresdner Bibliothekare - emigriert, geflohen, geblieben. Briefe der Nachkriegszeit aus dem Nachlass von Ewald Jammers (Teil 2), in: SLUB-Kurier, 21. Jg., H. 2, 2007, S. $13-15$.

Bürger, Thomas: Entnazifizierung mit knurrenden Mägen. Bibliotheksbriefe aus der Nachkriegszeit aus dem Nachlass von Ewald Jammers (Teil 1), SLUB-Kurier, 21. Jg., H. 1, 2007, S. 16-17.

Bürger, Thomas: Von Trümmern und klatschnassen Handschriften. Bibliotheksbriefe aus der Nachkriegszeit aus dem Nachlass von Ewald Jammers (Teil 3), in: SLUB-Kurier, 21. Jg., H. 3, 2007, S. 14-16.

Bürger, Thomas u. Konstantin Hermann (Hg.): Das ABC der SLUB. Lexikon der Sächsischen Landesbibliothek - Staats- und Universitätsbibliothek Dresden, Dresden 2006.

Coblenz, Werner: Georg Bierbaum 1889-1953, in: Arbeits- und Forschungsberichte zur sächsischen Bodendenkmalpflege, Bd. 4, 1954, S. 11-20.

Coblenz, Werner: Artur Pietzsch 1901-1975, in: Arbeits- und Forschungsberichte zur sächsischen Bodendenkmalpflege, Bd. 22, 1978, S. 17-19.

Coblenz, Werner: In Memoriam Georg Bierbaum (13.8.1889-22.6.1953), in: Arbeits- und Forschungsberichte zur sächsischen Bodendenkmalpflege, Bd. 33, 1989, S. 357-367.

Colorado Castellary, Arturo: Éxodo y exilio del arte. La odisea del Museo del Prado durante la Guerra Civil, Madrid 2008.

Colorado Castellary, Arturo: Arte, revancha y propaganda. La instrumentalización franquista del patrimonio durante la Segunda Guerra Mundial, Madrid 2018.

Dalbajewa, Birgit: „Träger bewegteren Lebensgefühls.“ Erwerbungen von Oskar Kokoschka durch Ludwig Justi, Hans Posse und Paul Ferdinand Schmidt nach der Novemberrevolution 1918, in: Jahrbuch der Staatlichen Kunstsammlungen Dresden, 30, 2002/2003, S. 131-145.

Dalbajewa, Birgit: Hans Posse und die „Moderne Galerie“, in: Bischoff, Ulrich: Galerie Neue Meister. Illustrierter Katalog in 2 Bänden, Köln 2010, S. 373-375.

Dalbajewa, Birgit: Hans Posse und sein Wirken für die „Moderne Galerie“ in Dresden. Zu Forschungsansätzen, in: Jahrbuch der Staatlichen Kunstsammlungen Dresden, 36, 2010/2012, S. 184-191.

Dalbajewa, Birgit: Hans Posse an Robert Sterl 1931: „Im ,Dritten Reich` geht es mir sicher schlechter!", in: Dresdener Kunstblätter, 57. Jg., H. 2, 2013, S. 34-41.

Dalbajewa, Birgit: „Mittelgut können wir nicht gebrauchen.“ Hans Posse als Kommissar des deutschen Pavillons in Venedig 1922 und 1930, in: Lupfer/Rudert 2015, S. 219-238.

Dalbajewa, Birgit: „... selbst auf die Gefahr einzelner Irrtümer hin ...“ - Die „Sammlung moderner Malerei“ in der Gemäldegalerie unter Hans Posse 1918 bis 1933, in: Lupfer/Rudert 2015, S. 239-270.

Deckert, Helmut: Erbe und Verpflichtung. Zum Tode Martin Bollerts, in: Zentralblatt für Bibliothekswesen, 82, 8, 1968, S. 479-482.

Deckert, Helmut: Margarethe Storch, in: Sächsische Landesbibliothek. Neuerwerbungen und Nachrichten, April 1977, S. 81-82. 
Dehnel, Regine: Der nationalsozialistische Kunstraub in Polen 1939-1945 und die Restitution von Kunstwerken durch die Alliierten 1945-1949: ausgewählte Beispiele, in: Langer, Andrea (Hg.): Der Umgang mit dem kulturellen Erbe in Deutschland und Polen im 20. Jahrhundert, Warschau 2004, S. 307-333.

Dilly, Heinrich: Deutsche Kunsthistoriker 1933-1945, Berlin 1988.

Doll, Nikola, Fuhrmeister, Christian u. Michael H. Sprenger (Hg.): Kunstgeschichte im Nationalsozialismus. Beiträge zu Geschichte einer Wissenschaft zwischen 1930-1950, Weimar 2005.

Dolz, Silvia: Seelenfiguren als Expeditionsertrag. Sammeln und das Ideal der Vollständigkeit, in: Staatliche Kunstsammlungen Dresden 2016, S. 22-23.

Dolz, Silvia: Bernhard Struck (1888-1971): „Afrika erkennen“. Von Konstruktion und Dekonstruktion eines Weltbildes. Eine wissenschaftskritische Annäherung, in: Abhandlungen und Berichte der Staatlichen Ethnographischen Sammlungen Sachsen, Bd. 55, 2020 (im Druck).

Dresdener Geschichtsverein e. V. (Hg.): Die Ausstellung „Entartete Kunst“ und der Beginn der NS-Kulturbarbarei in Dresden, Dresdner Hefte. Beiträge zur Kulturgeschichte, 22. Jg., H. 77, 1/2004.

Dresdner Geschichtsverein e. V. (Hg.): Die Dresdner Kunstsammlungen in fünf Jahrhunderten, Dresdner Hefte, Sonderausgabe 2004.

Dresdner Geschichtsverein e. V. (Hg.): Dresden. Das Jahr 1945, Dresdner Hefte, 13. Jg., Nr. 41, H. 1, 1995.

Dresdner Geschichtsverein e. V. (Hg.): Dresden 1933-1945. Zwischen Verblendung und Angst, Dresdner Hefte, 11. Jg., Nr. 35, H. 3, 1993.

Dresdner Wissenschaftliche Museen. Beiträge zur 750-Jahr-Feier unserer Stadt, Dresden 1956.

Eck, Siegfried: Wilhelm Meise, in: Zoologische Abhandlungen, Staatliche Naturhistorische Sammlungen Dresden, Museum für Tierkunde, Bd. 53, 2002, S. 3-4.

Eckardt, André: Im Dienst der Werbung. Die Boehner-Film 1926-1967, Berlin 2004.

Eduard Samtleben, https:/www.geni.com/people/Eduard-Samtleben/6000000076678590848, Zugriff: 5.12.2019.

Eichmann-Leutenegger, Beatrice: Vor den Pforten des Paradieses. Schicksale jüdischer Flüchtlinge während der Nazizeit in Schweden, in: Stimmen der Zeit, 139, 2014, S. 766-777, www.herder.de/stz/hefte/archiv/139-2014/11-2014/vor-den-pforten-des-paradieses-schicksalejuedischer-fluechtlinge-waehrend-der-nazizeit-in-schweden/, Zugriff: 5.12.2019.

Ein Restaurator des Grünen Gewölbes erzählt, in: Dresdener Galerieblätter. Monatsschr. d. Staatlichen Kunstsammlungen Dresden, Dresden, H. 12, 1959, S. 291-293.

Eisenlöffel, Lars: Hitlers Kurator Hermann Voss. Bodes Schüler an den Abgründen der Museumskultur, in: Jahrbuch der Berliner Museen, N. F., Bd. 47, 2005, S. 117-124.

Emden, Helmut van: Erinnerungen an Leben und Arbeit eines großen Käferlarven-Pioniers, Fritz Isidore van Emden (1898-1958), in: Entomologische Nachrichten und Berichte, Bd. 61, 2017, Nr. 3-4, S. 237-239.

Emmrich, Rainer: Professor Arnold Jacobi 1870-1948, in: Blick ins Museum. Mitteilungen aus den Staatlichen Wissenschaftlichen Museen, Dresden, 24/25, 1980, S. 32-35.

Enke, Roland: Schloss Weesenstein als Auslagerungsort für die Werke der Dresdner Gemäldegalerie; in: Staatliche Schlösser, Burgen und Gärten Sachsen 2018, S. 61-74.

Enking, Ragna: Dresden im Mai 1945 - ein Bericht, in: Dresdner Geschichtsverein e. V. 2004, S. 84-92. 
Enking, Ragna: Die Dresdner Kunstsammlungen gegen Ende des Zweiten Weltkrieges, aus: Georga. Zwei Welten, in: Kolb, Karin u. Staatliche Kunstsammlungen Dresden (Hg.): Zukunft seit 1560, Bd. 3, Berlin 2010, S. 206-214.

Entomologische Chronik. Gestorben: Dr. Fritz I. van Emden, Beiträge zur Entomologie, Bd. 8, 1958, Nr. 5/6, S. 761-762.

Erich Haenel, in: Pantheon. Internationale Jahreszeitschrift für Kunst, München, Bd. 27, 1941, H. 3, S. 72.

Familiendatenbank Helgoland, www.online-ofb.de/famreport.php?ofb=helgoland \&ID=I227\& nachname $=\mathrm{KR} \% \mathrm{FC} \% \mathrm{DF} \&$ modus=\&lang=de, Zugriff: 5.12.2019.

Festschrift. Geodäsie im Wandel - Einhundertfünfzig Jahre Geodätisches Institut, Dresdner Beiträge aus geodätischer Forschung und Lehre. Schriftenreihe des Geodätischen Instituts, H. 1, Dresden 2002, hier: S. 14-20.

Fichtner, Fritz: Die Bedeutung E. Zimmermanns für die Chinaforschung und die Ostasiat. Abt. der Staatl. Porzellansammlung Dresden, Ostasiatische Zeitschrift, 22, 1936, S. 195-196.

Fichtner, Fritz: E. Zimmermann zum Gedächtnis, in: Neues Archiv für Sächsische Geschichte, 61. Jg., H. 1, Dresden 1940, S. 88-94.

Fichtner, Fritz: Ernst Zimmermann zum Gedächtnis, Sonderdruck aus Ostasiatische Zeitschrift, 1940.

Ficker, Friedbert: Ein verdienter sächsischer Vorgeschichtsforscher. Zum 20. Todestag von Dr. Georg Bierbaum, in: Dresdner Monatsblätter. Rundbrief d. Dresdner Heimatfreunde in Westdeutschland, Bd. 24, 1973, 6/7, S. 191-193.

Fischer, Hans: Völkerkunde im Nationalsozialismus. Aspekte der Anpassung, Affinität und Behauptung einer wissenschaftlichen Disziplin, Berlin 1990.

Fleckner, Uwe (Hg.): Angriff auf die Avantgarde. Kunst und Kunstpolitik im Nationalsozialismus. (Schriften der Forschungsstelle „Entartete Kunst“, Bd. 1) Berlin 2007.

Fleckner, Uwe u. Max Hollein (Hg.): Museum im Widerspruch. Das Städel und der Nationalsozialismus, Schriften der Forschungsstelle „Entartete Kunst“, Bd. VI, Berlin 2011.

Fritz, Uwe, Raffael Ernst u. Uwe Kallweit u. a.: The Senckenberg Natural History Collections Dresden, in: Beck, Lothar A. (Hg.): Zoological Collections of Germany. The Animal Kingdom in its Amazing Plenty at Museums and Universities, Cham 2018, S. 341-354.

Frommhold, Erhard: Robert Reichert zum Gedenken, in: Der Falke, Bd. 7, 1960, S. 136138.

Fuhrmeister, Christian: Dr. iur. Dr. phil. Rolf Hetsch, „einziger zünftiger Kunsthistoriker“ im Reichsministerium für Volksaufklärung und Propaganda, in: Fuhrmeister, Christian, Stephan Klingen, Iris Lauterbach u. a.: „Führerauftrag Monumentalmalerei“. Eine Fotokampagne 1943-1945, Köln 2006, S. 107-126.

Gebhardt, Ludwig: Die Ornithologen Mitteleuropas, Gießen 1964.

Geldmacher, Elisabeth: NS-Raubgut. Zum Stand der Provenienzforschung in Sachsen, Ohorn 2019.

Geupel-Schischkoff, Kristina: Um die Früchte der eigenen Arbeit gebracht ... Georg Bierbaum. Sachsens erster Landesarchäologe, in: Archaeo. Archäologie in Sachsen, Bd. 5, 2008, S. 48-53.

Geupel-Schischkoff, Kristina: Dr. Georg Bierbaum (13. August 1889 - 22. Juni 1953). Der Weg vom Zoologen, Mediziner und Lehrer zum Direktor des Landesmuseums für Vorgeschichte Dresden und Landespfleger für Bodenaltertümer Sachsens, in: Arbeits- und Forschungsberichte zur sächsischen Bodendenkmalpflege, Bd. 21, 2010, S. 19-26. 
Grabowski, Jörn: „Versäumen Sie ihren arischen Nachweis nicht!“. Die Staatlichen Museen zu Berlin und ihr Umgang mit Bürgern jüdischer Abkunft 1933-1939, in: Grabowski/Winter 2013, S. 29-59.

Grabowski, Jörn u. Petra Winter (Hg.): Zwischen Politik und Kunst. Die Staatlichen Museen zu Berlin in der Zeit des Nationalsozialismus (Schriften zur Geschichte der Berliner Museen, Bd. 2), Wien/Köln/Weimar 2013.

Greve, Anna (Hg.): Museum und Politik - Allianzen und Konflikte (Kunst und Politik. Jahrbuch der Guernica-Gesellschaft, Bd. 13), Osnabrück 2011.

Grüttner, Michael: Biographisches Lexikon zur nationalsozialistischen Wissenschaftspolitik (Studien zur Wissenschafts- und Universitätsgeschichte 6), Heidelberg 2004.

Grunwald, Susanne: Potentiale der Burgwallforschung. Sächsische Archäologie in der ersten Hälfte des 20. Jahrhunderts, in: Schachtmann/Strobel/Widera 2009, S. 149-168.

Günther, Gisela: Charlotte Boden zum 70. Geburtstag, in: Zentralblatt für Bibliothekswesen, Leipzig, Bd. 84, 1970, S. 99-101.

Haase, Günther: Kunstraub und Kunstschutz. Eine Dokumentation, 2 Bde., 2. Aufl. Norderstedt 2008.

Haase, Yorck Alexander: Die Bibliothekertage in der Zeit des Nationalsozialismus, in: Plassmann/Syré 2000, S. 81-100.

Habermann, Alexandra, Klemmt, Rainer u. Frauke Siefkes: Lexikon Deutscher Wissenschaftlicher Bibliothekare 1925-1980, Frankfurt a. M. 1985.

Haffer, Jürgen: In memoriam. Wilhelm Meise 1901-2002, in: The Auk, 120, 2003, S. 540.

Hänel, Alexander: Die Auslagerung von Kunst- und Kulturgütern in die Burgen und Schlösser Sachsens, in: Staatliche Schlösser, Burgen und Gärten Sachsen (Hg.): Bombensicher! Kunstversteck Weesenstein 1945, Dresden 2018, S. 33-43.

Häntzschel, Walter: Zum Gedenken an Karl Wanderer (1876-1945), in: Jahrbuch des Staatlichen Museums für Mineralogie und Geologie zu Dresden, 1956/57, S. 6-14.

Harten, Hans-Christian, Uwe Neirich u. Matthias Schwerendt: Rassenhygiene als Erziehungsideologie des Dritten Reichs: Bio-bibliographisches Handbuch, Berlin 2006, S. 275.

Haupts, Leo: Die Universität zu Köln im Übergang vom Nationalsozialismus zur Bundesrepublik, Köln/Weimar/Wien 2007.

Hauschild, Thomas (Hg.): Lebenslust und Fremdenfurcht. Ethnologie im Dritten Reich, Frankfurt a. M. 1995.

Hausmann, Frank-Rutger (Hg.) unter Mitarbeit von Elisabeth Müller-Luckner: Die Rolle der Geisteswissenschaften im Dritten Reich 1933-1945 (Schriften des Historischen Kollegs: Kolloquien 53), München 2002.

Hebig, Christel: Zum Gedenken an Dr. Hans Hofmann - Bibliothekar und Heimatforscher, in: Zentralblatt für Bibliothekswesen, Leipzig, 104, 1990, S. 268-271.

Hebig, Christel: Ein großes Leben durch ein großes Werk. Zum Gedenken an Prof. Dr. Martin Bollert, in: Biblos, Wien, Bd. 41, 1992, 2, S. 75-81.

Heftrig, Ruth, Peters, Olaf u. Barbara Schellewald (Hg.): Kunstgeschichte im „Dritten Reich“. Theorien, Methoden, Praktiken (Schriften zur modernen Kunsthistoriographie, Bd. 1), Berlin 2008.

Heid, Stefan: Paul Fritz Fichtner, in: Heid, Stefan u. Martin Dennert (Hg.): Personenlexikon zur Christlichen Archäologie. Forscher und Persönlichkeiten vom 16. bis zum 21. Jahrhundert, Bd. 1, Regensburg 2012, S. 493-494.

Held, Jutta u. Martin Papenbrock (Hg.): Kunstgeschichte an den Universitäten im Nationalsozialismus (Kunst und Politik. Jahrbuch der Guernica-Gesellschaft, Bd. 5), Göttingen 2003. 
Hennig, Willi: F. I. van Emden $\dagger$, in: Zoologischer Anzeiger, Supplement, 23 (Verhandlungen der Deutschen Zoologischen Gesellschaft), 1959, S. 528-529.

Heres, Huberta: Bruno Schröder zum 50. Todestag, in: Dresdener Kunstblätter, 28. Jg., H. 6, 1984, S. 187-189.

Heres, Huberta: Bruno Schröder 1879-1934, in: Lullies, Reinhard u. Wolfgang Schiering (Hg.): Archäologenbildnisse. Porträts und Kurzbiographien von Klassischen Archäologen deutscher Sprache, Mainz 1988, S. 200-201.

Hermann, Konstantin: Die sächsische Landesbibliothek in der nationalsozialistischen Zeit, in: Neues Archiv für sächsische Geschichte, 80, 2009, S. 277-290.

Hermann, Konstantin: Benndorf, Johann Gottfried, in: Sächsische Biografie, 2011, Online-Ausgabe: http://saebi.isgv.de/biografie/Gottfried_Benndorf_(1894-1945), Zugriff: 2.1.2020.

Hermann, Konstantin: Boden, Klara Charlotte, in: Sächsische Biografie, 2011, Online-Ausgabe: http://saebi.isgv.de/biografie/Charlotte_Boden_(1900-1994), Zugriff: 2.1.2020.

Hermann, Konstantin: Die sächsische Landesbibliothek 1933-1945. Martin Bollert und Hermann Neubert - zwei Epochen in zwölf Jahren?, in: Knoche/Schmitz 2011, S. 289-308.

Hermann, Konstantin (Hg.): Führerschule, Thingplatz, „Judenhaus“. Orte und Gebäude der nationalsozialistischen Diktatur in Sachsen, Dresden 2014.

Hermann, Konstantin: Fiebiger, Heinrich Otto, in: Sächsische Biografie, 2009, Online-Ausgabe: http://saebi.isgv.de/biografie/Otto_Fiebiger_(1869-1946), Zugriff: 2.1.2020.

Hermann, Konstantin: Richter, Hubert, in: Sächsische Biografie, 2011, Online-Ausgabe: http:// saebi.isgv.de/biografie/Hubert_Richter_(1882-1948), Zugriff: 2.1.2020.

Hermann, Konstantin: Arthur Göpfert. Zehn Jahre kommissarischer Leiter des Volksbildungsministeriums, in: Pieper/Schmeitzner/Naser 2012, S. 222-227.

Herrmann, Beate: Doppelt sensibel. Die Ethnographische Sammlung Łódź als Zeugnis polnisch deutscher Zeitgeschichte, in: Brandstetter, Anna-Maria und Vera Hierholzer (Hg.): Nicht nur Raubkunst! Sensible Dinge in Museen und universitären Sammlungen, Göttingen 2018, S. 93-108.

Hertel, Rolf: Robert Reichert †, in: Sächsische Heimatblätter, 6. Jg., H. 1, 1960, S. 55.

Hertel, Rolf: In memoriam Johannes Draeseke, in: Entomologische Abhandlungen. Zeitschrift für entomologische Taxonomie, hg. vom Staatlichen Museum für Tierkunde in Dresden, Bd. 27, 1969-1971, S. VII-IX.

Herter, Konrad u. Hildegard Strübing: In memoriam Klaus Günther, in: Sitzungsberichte der Gesellschaft Naturforschender Freunde zu Berlin, N. F., Bd. 15, Beih., Berlin 1975, S. 4-10.

Hertweck, Günther: Walter Häntzschel. 16.11.1904-10.5.1972, in: Paläontologische Zeitschrift, 46, 1972, S. 105-112.

Hill, Kate (Hg.): Museums and Biographies: Stories, Objects, Identities, (Heritage Matters, Bd. 9) Suffolk 2014.

Hirschfeld, Gerhard u. Tobias Jersak (Hg.): Funktionseliten zwischen Mitwirkung und Distanz, Frankfurt a. M. 2004.

Hoffmann, Meike: Rolf Hetsch und die Verwaltung der Restbestände „Entarteter Kunst“, in: Hoffmann, Meike, Matthias Wemhoff u. Dieter Scholz (Hg.): Der Berliner Skulpturenfund. „Entartete Kunst“ im Bombenschutt. Entdeckung, Deutung, Perspektiven, Begleitpublikation der Ausstellung mit Beiträgen des Berliner Symposiums, Regensburg 2012, S. 85-99.

Hofmann, Hans (Hg.): Martin Bollert zum 80. Geburtstag am 11. Oktober 1956, Festschrift, Dresden 1956. 
Hoerschelmann, H.: Wilhelm Meise. 12. September 1901 - 24. August 2002, in: Verh. naturwiss. Ver. Hamburg, N. F., 40, 2003, S. 141-145.

Hofer, Helmut, in: ZOBODAT (Zoologisch-Botanische Datenbank), Biologiezentrum des Oberösterreichischen Landesmuseums Linz, www.zobodat.at/personen.php?id=23376\&bio=ful, Zugriff: 5.12.2019.

Holzhausen, Walter: Kurt Zoege von Manteuffel †, in: Die graphischen Künste, N. F. 6, 1941, S. 76-77.

Hoppe, Gisela: Die Dresdner Stadtverwaltung in der Zeit der Weimarer Republik 1919 bis 1933, in: Stadtmuseum Dresden (Hg.): Dresdner Geschichtsbuch, Bd. 8, 2002, S. 163-180.

Hutterer, Rainer, Oskar Schröder u. Gustav Peters: Ausverkauf in Wuppertal: Zur Sammlungsgeschichte eines Sumatra-Nashorns (Dicerorhinus sumatrensis) im Kontext der nationalsozialistischen Kulturpolitik, in: Jahresbericht der Naturwissenschaftlichen Vereinigung Wuppertal, 62, 2012, S. 7-36.

Immatrikulation von Peter Halm, Universität Rostock, http://matrikel.uni-rostock.de/id/ 200018840, Zugriff: 5.12.2019.

In memoriam Martin Bollert, Dresden 1968.

Institut für Sächsische Geschichte und Volkskunde e. V. (Hg.): Sächsische Biografie, Bearb. v. Martina Schattkowsky, Online-Ausgabe: http://saebi.isgv.de/ (Sächsische Biografie), Zugriff: 2.1.2020.

Internationaler Verband von Museumsbeamten zur Abwehr von Fälschungen und Unlauterem Geschäftsgebaren (Hg.): Verzeichnis der Mitglieder des Internationalen Verbandes von Museumsbeamten, Berlin, August 1936, www.digishelf.de/objekt/berl66/1/LOG_0003/, Zugriff: 5.12.2019.

Iselt, Kathrin: Hermann Voss - Seine Ernennung zum „Sonderbeauftragten für Linz“ und Direktor der Staatlichen Gemäldegalerie Dresden, in: Dresdener Kunstblätter, 52. Jg., H. 1, 2008, S. 26-35.

Iselt, Kathrin: „Sonderbeauftragter des Führers“. Der Kunsthistoriker und Museumsmann Hermann Voss (1884-1969), Köln 2010 (Studien zur Kunst 20) (Zugl. Dresden, Univ., Diss., 2009).

Iselt, Kathrin: Hermann Voss. Direktor der Staatlichen Gemäldegalerie Dresden und Hitlers „Sonderbeauftragter für Linz“, in: Pieper/Schmeitzner/Naser 2012, S. 270-277.

Iselt, Kathrin: Robert Oertel (1907-1981) - Kustos der Gemäldegalerie Dresden 1939-1946. Eine biografische Skizze, in: Dresdener Kunstblätter, 56. Jg., H. 1, 2012, S. 45-54.

Iselt, Kathrin: Raubkunst oder legitimer Erwerb? Die Provenienzforschung und die Recherche nach NS-verfolgungsbedingt entzogenen Kunstwerken in den Staatlichen Kunstsammlungen Dresden, in: Dresdener Kunstblätter, 56. Jg., H. 2, 2012, S. 107-113.

Isermeyer, Christian Adolf: Robert Oertel. 1907-1981, in: Zeitschrift für Kunstgeschichte, Nr. 4, 1982, S. 437-440.

Israel, Heinz: Siegfried Wolf zum 65. Geburtstag, in: Abhandlungen und Berichte des Staatlichen Museums für Völkerkunde Dresden, Bd. 34, 1975, S. 1-5.

Israel, Heinz u. Peter Neumann: Zum Gedenken. Siegfried Wolf 1907-1986, in: Kleine Beiträge aus dem Staatlichen Museum für Völkerkunde Dresden, 8, 1986, S. 43.

Israel, Heinz u. Peter Neumann: Siegfried Wolf zum Gedenken, in: Ethnographisch-archäologische Zeitschrift, 28. Jg., 1987, H. 1, S. 163-164.

Jäger, Christian: Robert Oertel und die Fotografie. Eine wissenschaftliche Untersuchung, Leipzig, Hochschule für Technik, Wirtschaft und Kultur, Bachelorarbeit, 2014 (unveröffentlicht). 
Jammers, Antonius: Im Japanischen Palais, wie ein Freiherr ... Erinnerungen meines Vaters Ewald Jammers an seine alte Sächsische Landesbibliothek, in: Bürger, Thomas u. Ekkehard Henschke (Hg.): Bibliotheken führen und entwickeln. Festschrift für Jürgen Hering zum 65. Geburtstag, München 2002, S. 305-317.

Jank, Dagmar: Frauen im Höheren Bibliotheksdienst vor dem Zweiten Weltkrieg, in: Plassmann/Syré 2000, S. 302-313.

Joachim, Hans-Eckart: Aus der Hausgeschichte - Walter Kersten 1907-1944, in: Ber. LVR-Landesmuseum Bonn, H. 1, 2013, S. 25-27.

Joachimides, Alexis: Die Museumsreformbewegung in Deutschland und die Entstehung des modernen Museums 1880-1940, Dresden 2001.

Jünger, Konstanze u. Judith Schachtmann: „Eine 3000 Jahre alte Stadt“. Die Ausgrabungen auf der Heidenschanze von Dresden-Coschütz und ihre Darstellung in der Öffentlichkeit, in: Arbeits- und Forschungsberichte zur sächsischen Bodendenkmalpflege, Bd. 21, 2010, S. 27-35.

K. Zoege von Manteuffel gest., in: Pantheon. Internationale Jahreszeitschrift für Kunst, Bd. 27, H. 3, 1941, S. 71-72.

Kästner, Anita u. Reinhart Kästner (Hg.): Erhart Kästner. Leben und Werk in Daten und Bildern, Frankfurt a. M. 1980, verb. Nachauflage Frankfurt a. M. u. Leipzig 1994.

Keller, Katrin: Landesgeschichte Sachsen, Stuttgart 2002.

Klee, Ernst: Das Personenlexikon zum Dritten Reich. Wer war was vor und nach 1945?, Frankfurt a. M. 2003 (akt. Ausg. 2007).

Klee, Ernst: Das Kulturlexikon zum Dritten Reich. Wer war was vor und nach 1945, Frankfurt a. M. 2007 (überarb. Ausg. 2009).

Klösch, Christian: Hans Kummerlöwe, in: Lexikon der österreichischen Provenienzforschung, https://www.lexikon-provenienzforschung.org/kummerl\%C3\%B6we-hans, Zugriff: 5.12.2019.

Knoche, Michael u. Wolfgang Schmitz (Hg.): Wissenschaftliche Bibliothekare im Nationalsozialismus. Handlungsspielräume, Kontinuitäten, Deutungsmuster, Wolfenbütteler Schriften zur Geschichte des Buchwesens, Bd. 46, Wiesbaden 2011.

Koch, Christine: Das Bibliothekswesen im Nationalsozialismus. Eine Forschungsstandanalyse, Marburg 2003.

Kocourek, Jana u. Norman Köhler: Spurensuche. Im April 2009 startete an der SLUB ein Projekt zur Provenienzerschließung, in: BIS - Das Magazin der Bibliotheken in Sachsen 3, 2010, 2, S. 110-111, http://nbn-resolving.de/urn:nbn:de:bsz:14-qucosa-39121, Zugriff: 5.12.2019.

Körte, Arnold: Martin Gropius. Leben und Werk eines Berliner Architekten 1824-1880, Berlin 2013.

Köstering, Susanne: Ein Museum für Weltnatur. Die Geschichte des Naturhistorischen Museums in Hamburg, Abhandlungen des Naturwissenschaftlichen Vereins Hamburg, N. F., Bd. 46, Hamburg 2018.

Kolb, Karin u. Staatliche Kunstsammlungen Dresden (Hg.): Zukunft seit 1560, 3 Bde., Berlin 2010.

Kommentierte Online-Edition der fünf Reisetagebücher Hans Posses (1939-1942), https:// editionhansposse.gnm.de/, Zugriff: 5.12.2019.

Kott, Christina u. Bénédicte Savoy (Hg.): Mars und Museum: Europäische Museen im Ersten Weltkrieg, Köln 2016. 
Kreide-Damani, Ingrid: Julius Lips, Martin Heydrich und die (Deutsche) Gesellschaft für Völkerkunde, in: Kreide-Damani, Ingrid (Hg.): Ethnologie im Nationalsozialismus. Julius Lips und die Geschichte der „Völkerkunde“, Wiesbaden 2010, S. 23-284.

Kretzschmar, Hellmut: Walter Schwinkowski, in: Neues Archiv für Sächsische Geschichte, Bd. 61, 1940, S. 86-87.

Kübler, Thomas u. Hans-Peter Lühr: Dresden zwischen 1933 und 1990 - Stadtgeschichtsschreibung in einem unaufgearbeiteten Feld?, in: Landeshauptstadt Dresden 2001, S. 33-42.

Kuhlmann-Hodick, Petra: Der Einzug des Kupferstich-Kabinetts in Sempers Galeriegebäude 1856, in: Dresdener Kunstblätter, 4. Jg., H. 1, 2004, S. 31-37.

Kühne, Ellen, Jan-Michael Lange u. Daniela Erler: Die Geschichte des Museums für Mineralogie und Geologie in Dresden, in: Lange/Kühne 2006, S. 13-95.

Kühnel-Kunze, Irene: Bergung - Evakuierung - Rückführung. Die Berliner Museen in den Jahren 1939-1959, Jahrbuch Preußischer Kulturbesitz, Sonderband 2, Berlin 1984.

Kumerloeve, Hans: Arnold Jacobi †, in: Naturwissenschaftliche Rundschau, 5. Jg., H. 3, 1952, S. 130.

Kumerloeve, Hans: Robert Reichert zum Gedächtnis, in: Beiträge zur Vogelkunde, Bd. 8, 1963, S. 463-466.

Kummerlöwe, Hans: Leipzig - Geburtsort der ersten NS-Hochschulgruppe. Die Gründung am 17. November 1925, in: Offenes Visier. Sächsische Hoch- und Fachschulzeitung. Kampfblatt des Gaustudentenbundes Sachsen der NSDAP, 23, 1936, 6.2.1936, S. 2.

Kummerlöwe, Hans: Leipzig als Keimzelle des NSDStB. Wie die erste nationalsozialistische Hochschulgruppe entstand, in: Pauliner-Zeitung. Mitteilungen des Verbandes der Alten Pauliner, 48, 1936, H. 2, S. 30-32.

Kummerlöwe, Hans: Über die Notwendigkeit eines internationalen wissenschaftlichen Museologen-Austausches, Bund der deutschen naturwissenschaftlichen Museen (Abt. B des Deutschen Museumsbundes), 30. Flugblatt, Berlin, November 1936, S. 1-6.

Kummerlöwe, Hans: Geschichte und Aufgaben des Staatlichen Museums für Tierkunde in Dresden. Rede zur Eröffnung des Museums für Tierkunde 4. Oktober 1937, in: Abhandlungen und Berichte aus den Staatlichen Museen für Tierkunde und Völkerkunde in Dresden, Bd. 20, N. F., Bd. 1, H. 1, Leipzig 1939, S. 1-15.

Kunze, Horst: Über den motorisierten Bibliothekar, in: Hofmann, Hans (Hg.): Martin Bollert zum 80. Geburtstag am 11. Oktober 1956, Festschrift, Dresden 1956, S. 29-35.

Kunze, Horst: Frau Dr. Charlotte Boden 1900-1994, in: Marginalien. Zeitschrift für Buchkunst und Bibliophilie, Ausg. 135, 1994, S. 80-81.

Kunze, Peter: Wjacsławk (Jatzwauk), Jakub (Jacob), in: Sächsische Biografie, 2011, Online-Ausgabe: http://saebi.isgv.de/biografie/Jakob_Jatzwauk_(1885-1951), Zugriff: 2.1.2020.

Kurt Zoege von Manteuffel, in: Lüdtke, Gerhard (Hg.): Kürschners Deutscher Gelehrtenkalender 1940/41, 6. Ausg., Bd. 1, Berlin 1941.

Lange, Jan-Michael u. Ellen Kühne (Hg.): Geschichte des Museums für Mineralogie und Geologie in den Staatlichen Naturhistorischen Sammlungen Dresden. Von der kurfürstlichen Kunstkammer zum staatlichen Forschungsmuseum, Dresden 2006.

Lange, Jan-Michael u. Ulf-Gerhard Linnemann: Das Museum für Mineralogie und Geologie in Dresden. Von der kurfürstlichen Kunstkammer zum modernen Forschungsmuseum, in: GMIT, Nr. 56, Juni 2014, S. 6 ff.

Lapp, Benjamin: Der Aufstieg des Nationalsozialismus in Sachsen, in: Pommerin 1998, S. 1-24. 
Leben und Wirken für die Kunst. Zeichnungen aus dem Vermächtnis von Wolfgang Balzer. Vortrag von Werner Schmidt, Direktor des Kupferstichkabinetts Dresden, in: Die Union, 14.11.1968.

Lehmann, Hans-Ulrich (Hg.): Kunstwirklichkeiten. Erhart Kästner. Bibliothekar - Schriftsteller - Sammler, Wolfenbütteler Schriften zur Geschichte des Buchwesens, Bd. 21, Wiesbaden 1994.

Lehmann, Hartmut u. Otto Gerhard Oexle (Hg.): Nationalsozialismus in den Kulturwissenschaften. Bd. 1: Fächer-Milieus-Karrieren (Veröffentlichung des Max-Planck-Instituts für Geschichte, Bd. 200), Göttingen 2004.

Lepenies, Wolf: Kultur und Politik. Deutsche Geschichten, München/Wien 2006.

Lewerken, Sabine: Die Bibliothek des Dresdner Münzkabinetts, in: Dresdner Numismatische Hefte, Nr. 1, hg. vom Numismatischen Verein zu Dresden e. V., Dresden 1996, S. 46-51.

Lisewski, Eugen u. Hans Mehlhorn: Von der Arsenal-Sammlung zum Armeemuseum Dresden (1897-1945), in: Prittwitz und Gaffron/Militärhistorisches Museum Dresden 1997, S. 9-26.

Loesch, Anette: Das Schicksal der Porzellansammlung Gustav von Klemperers, in: Häder, Ulf (Bearb.): Beiträge öffentlicher Einrichtungen der Bundesrepublik Deutschland zum Umgang mit Kulturgütern aus ehemaligem jüdischen Besitz (= Veröffentlichungen der Koordinierungsstelle für Kulturgutverluste, 1), Magdeburg 2001, S. 56-77.

Loesch, Anette: Vom Silberbuffet zum Porzellankabinett im Hausmannsturm des Dresdener Residenzschlosses, in: Dresdener Kunstblätter, H. 4, 2019, S. 14-23.

Löffler, Fritz: Erinnerung an einen schweren Neubeginn. Zum 80. Geb. v. Prof. Dr. Wolfgang Balzer, in: Die Union, Bd. 19, Ausg. 127, 1964.

Löhr, Hanns Christian: Das Braune Haus der Kunst - Hitler und der „Sonderauftrag Linz“. Visionen, Verbrechen, Verluste, Berlin 2005.

Löscher, Monika: Gert Adriani, in: Lexikon der österreichischen Provenienzforschung, www.lexikonprovenienzforschung.org/adriani-gert, Zugriff: 5.12.2019.

Löscher, Monika u. Susanne Hehenberger: Akteurinnen und Akteure im Kunsthistorischen Museum Wien. Personelle Kontinuitäten und Brüche 1933/34 - 1938 - 1945, in: Baensch/KratzKessemeier/Wimmer 2016, S. 129-146.

Löw, Luitgard Sofie u. Matthias Nuding (Hg.): Zwischen Kulturgeschichte und Politik. Das Germanische Nationalmuseum in der Weimarer Republik und der Zeit des Nationalsozialismus, Nürnberg 2014.

Ludwig-Maximilians-Universität München: Abgeschlossene Dissertationen am Institut für Kunstgeschichte 1873-2001, http://www.kunstgeschichte.uni-muenchen.de/forschung/ diss_abgeschl/index.html, Zugriff: 5.12.2019.

Lupfer, Gilbert: Die Staatlichen Sammlungen für Kunst und Wissenschaft von 1918 bis 1945: Fürstenabfindung und 2. Weltkrieg, in: Dresdner Geschichtsverein e. V. (Hg.): Die Dresdner Kunstsammlungen in fünf Jahrhunderten, Dresdner Hefte, Sonderausgabe 2004, S. 71-83 (Lupfer 2004a).

Lupfer, Gilbert: Forschungsprojekt zur Geschichte der Dresdner Sammlungen zwischen 1928 und 1989, in: Dresdener Kunstblätter, 48. Jg., H. 5, 2004, S. 342-345 (Lupfer 2004b).

Lupfer, Gilbert: „Daphne“. Das Provenienzrecherche-, Erfassungs- und Inventurprojekt der Staatlichen Kunstsammlungen Dresden, in: Koordinierungsstelle für Kulturgutverluste Magdeburg (Hg.): Die Verantwortung dauert an. Beiträge deutscher Institutionen zum Umgang mit NS-verfolgungsbedingt entzogenem Kulturgut, Magdeburg 2010, S. 127-136. 
Lupfer, Gilbert: Provenienzforschung und Kunstgeschichte. Spannungen und Perspektiven, in: Die Herausforderung des Objekts. 33.Internationaler Kunsthistoriker-Kongress Nürnberg 2012, Congress Proceedings - Part 4, Nürnberg 2013 (32. Wissenschaftlicher Beiband zum Anzeiger des Germanischen Nationalmuseums, Bd. 32,4), S.1385-1387.

Lupfer, Gilbert: Planungen für das Gauforum Dresden, in: Hermann 2014, S. 94-97.

Lupfer, Gilbert: Museen und ihre Auslagerungsorte im Zweiten Weltkrieg. Ein Blick über die Grenzen, in: Kunst im Krieg, Dresdener Kunstblätter, H. 3, 2015, S. 56-67.

Lupfer, Gilbert: Das Daphne-Projekt der Staatlichen Kunstsammlungen Dresden. Eine kurze Bestandsaufnahme nach acht Jahren Arbeit, in: Provenienz \& Forschung, H. 1, 2016, S. 48-53.

Lupfer, Gilbert: Bibliotheken und Kunstsammlungen in Dresden. Eine Familiengeschichte, in: Bonte, Achim u. Juliane Rehnolt (Hg.): Kooperative Informationsinfrastrukturen als Chance und Herausforderung. Thomas Bürger zum 65. Geburtstag, Berlin/Boston 2018, S. 372383.

Lupfer, Gilbert u. Christine Nagel: Die Staatlichen Kunstsammlungen für Kunst und Wissenschaft im Zweiten Weltkrieg, in: Schölnberger/Loitfellner 2016, S. 271-286.

Lupfer, Gilbert u. Thomas Rudert (Hg.): Kennerschaft zwischen Macht und Moral. Annäherungen an Hans Posse (1879-1942), Wien/Köln/Weimar 2015.

Maaz, Bernhard (Hg.): Kunst- Welt- und Werkgeschichten. Die Korrespondenz zwischen Hans Posse und Wilhelm von Bode von 1904 bis 1928, Köln/Weimar/Wien 2012.

Martin, Petra: Volks- und Völkerkunde in Bildern. Das Bildarchiv von Robert Herbert Bellmann, in: Martin, Andreas (Hg.): Digitale Bilderwelten. Zur elektronischen Erschließung von Bildsammlungen, Volkskunde in Sachsen, Bd. 8, Dresden 2003, S. 131-149.

Martin, Petra: Ein dunkles Kapitel mit weitreichenden Folgen. Das Dresdener Völkerkundemuseum von 1939 bis 1957, in: Kunst im Krieg, Dresdener Kunstblätter, H. 3, 2015, S. 30-43.

Martin, Petra: Die Negation des Individuums. Zur Rassenbüsten-Sammlung am Museum für Völkerkunde Dresden, in: Staatliche Kunstsammlungen Dresden 2016, S. 26-27.

Mehlhorn, Hans: Vorstände, Direktoren und Leiter der Museen im Dresdner Arsenal, in: Prittwitz und Gaffron/Militärhistorisches Museum Dresden 1997, S. 225-226.

Meier, Gudrun; Jacobi, Arnold Friedrich Victor, in: Sächsische Biografie, 2010, Online-Ausgabe: http://saebi.isgv.de/biografie/Arnold_Jacobi_(1870-1948), Zugriff: 2.1.2020.

Menzhausen, Joachim: Kurt Köhn zum Gedenken, in: Dresdener Kunstblätter, 19. Jg., H. 3, 1975, S. 93-94.

Menzhausen, Joachim: Erna von Watzdorf zum Gedächtnis, in: Dresdener Kunstblätter, 22. Jg., H. 2, 1978, S. 62-63.

Merhart von Bernegg, Gero: Walter Grünberg, in: Posener Jahrbuch für Vorgeschichte, hg. v. Landesamt für Vorgeschichte im Reichsgau Wartheland, 1. Jg., 1944, S. 127-129.

Merseburger, Carina und Claudia Müller: Kriegsverluste der Dresdner Gemäldegalerie. Eine aktuelle Bestandsaufnahme, in: Dresdener Kunstblätter. 62. Jg., H. 4, 2018, S. $26-37$.

Metz, R.: Walther Fischer zum 75. Geburtstag, in: Aufschluß, Heidelberg, 23, 1972, S. 209-222.

Miller, Martin: Wissenschaft für Laien, in: Haack, Marie-Laurence u. Martin Miller (Hg.): L'étruscologie dans l'Europe d'après-guerre. Actes des journées d'études internationales des 14 au 16 septembre 2015, Bordeaux 2017, S. 219.

Ministerium für Volksbildung zu Dresden (Hg.): Führer durch die Staatlichen Sammlungen zu Dresden, Dresden 1932. 
Müller, Claudia Maria u. Carina Merseburger: Provenienzforschung an den Staatlichen Kunstsammlungen Dresden. Visualisierung und Vermittlung, in: Provenienz \& Forschung, H.1, 2018, S. 52-58.

Müller-Kelwing, Karin: „Die Dresdner Sezession 1932“ - Eine Künstlergruppe im Spannungsfeld von Kunst und Politik, Hildesheim u. a. 2010 (Zugl. Dresden, Univ., Diss., 2008).

Müller-Kelwing, Karin: Ein Museum ohne Objekte?, in: Staatliche Kunstsammlungen Dresden, Marion Ackermann und Noura Dirani (Hg.): Museum of untold stories. Objekte und Geschichten aus den Staatlichen Kunstsammlungen Dresden. Ausgewählt und erzählt von den Mitarbeiterinnen und Mitarbeitern unserer Sammlungen, Band 1, Dresden 2018, S. 63-64.

Müller-Kelwing, Karin: Mitarbeiter der Staatlichen Sammlungen für Kunst und Wissenschaft als Akteure im Schloss Weesenstein von 1942 bis 1946, in: Staatliche Schlösser, Burgen und Gärten Sachsen 2018, S. 93-101.

Musée du Louvre (Hg.): Le Louvre pendant la guerre. Regards photographiques 1938-1947, Ausstellungskatalog, Paris 2009.

Nagel, Christine: Kriegsbedingte Auslagerungen des Grünen Gewölbes und des Historischen Museums, in: Kunst im Krieg, Dresdener Kunstblätter, H. 3, 2015, S. 18-29.

Nationalsozialistischer Lehrerbund Deutschland/Sachsen (Hg.): Bekenntnis der Professoren an den deutschen Universitäten und Hochschulen zu Adolf Hitler und dem nationalsozialistischen Staat. Dresden 1933, in: https://archive.org/details/bekenntnisderpro00natiuoft, Zugriff: 5.12.2019 (Nationalsozialistischer Lehrerbund Deutschland/Sachsen 1933).

Naumann, Clas Michael: Zum Gedenken an Hans Kumerloeve, in: Bonner Zoologische Beiträge, Bd. 47, 1997, S. 189-190.

Neubert, Hermann (Hg.): Festschrift Martin Bollert zum 60. Geburtstage, Dresden 1936.

Neubert, Hermann: Martin Bollerts Wirken für Gegenwart und Zukunft, in: Festschrift Martin Bollert zum achtzigsten Geburtstag am 11. Oktober 1956, Dresden 1956, S. 23-28.

Niethammer, Günther: Am 5. September 1973 vollendet Museumsdirektor a. D. Dr. phil. Hans Kumerloeve sein 70. Lebensjahr, in: Bonner Zoologische Beiträge, 24. Jg., H. 3, 1973, S. 161-164.

Nitzschke, Katrin: Herausforderungen und Anregung. Die Dresdner Zeit, in: Lehmann, Hans-Ulrich (Hg.): Kunstwirklichkeiten. Erhart Kästner. Bibliothekar - Schriftsteller Sammler, Wolfenbütteler Schriften zur Geschichte des Buchwesens, Bd. 21, Wiesbaden 1994, S. 23-27.

Nitzschke, Katrin: Begeisterter Bibliothekar und engagierter Reformer. Martin Bollert zum 130. Geburtstag, in: SLUB-Kurier, Dresden, Bd. 15, 2001, H. 4, S. 10-11.

Nitzschke, Katrin: Bemmann, Franz Rudolf, in: Sächsische Biografie, 2004, Online-Ausgabe: http://saebi.isgv.de/biografie/Rudolf_Bemmann_(1881-1948), Zugriff: 2.1.2020.

Nitzschke, Katrin: Bibliotheken als Kunstsammlungen. Das Buchmuseum der SLUB gestern und heute, in: BIS - Das Magazin der Bibliotheken in Sachsen, 2. Jg., 2009, H. 4, S. 250 253, https://nbn-resolving.org/urn:nbn:de:bsz:14-qucosa-25828, Zugriff: 5.12.2019.

Nitzschke, Katrin: Assmann, Karl, in: Sächsische Biografie, 2010, Online-Ausgabe: http://saebi. isgv.de/biografie/Karl_Assmann_(1890-1970), Zugriff: 2.1.2020.

Nitzschke, Katrin: Faass, Bruno, in: Sächsische Biografie, 2010, Online-Ausgabe: http://saebi. isgv.de/biografie/Bruno_Faass_(1882-1951), Zugriff: 2.1.2020.

Nitzschke, Katrin: Bollert, Martin, in: Sächsische Biografie, 2012, Online-Ausgabe: http://saebi. isgv.de/biografie/Martin_Bollert_(1876-1968), Zugriff: 2.1.2020. 
Nitzschke, Katrin: Kästner, Erhart, in: Sächsische Biografie, 2015, Online-Ausgabe: http://saebi. isgv.de/biografie/Erhart_Kastner_(1904-1974), Zugriff: 1.1.2020.

Nowak, Eugeniusz: Erinnerungen an Ornithologen, die ich kannte (3. Teil), in: Mitteilungen des Vereins Sächsischer Ornithologen, Bd. 9, H. 1, 2002, S. 1-46, hier: 27-29.

Nowak, Eugeniusz: Wissenschaftler in turbulenten Zeiten. Erinnerungen an Ornithologen, Naturschützer und andere Naturkundler, Schwerin 2005, o. S.

Nützsche, Sigrun: Verzeichnis der Schriften des Anthropologen und Völkerkundlers Prof. Dr. Bernhard Struck (1888-1971): mit einer biographischen Einführung und Anmerkungen zum Verzeichnis, in: Abhandlungen und Berichte des Staatlichen Museums für Völkerkunde Dresden, Forschungsstelle, 49, 1996, S. 293-341.

Oertel, Robert: H. Posse zum Gedächtnis, in: Neues Archiv für sächsische Geschichte, Bd. 63, 1943, S. 170-174.

Office International des Musées u. Josep Renau (Hg.): Lorganisation de la défense du patrimoine artistique espagnol pendant la guerre civil, Extrait de la revue Mouseion, Bd. 39-40, 1937.

Orgeln als Lebenswerk. Orgeldenkmalpfleger Ulrich Dähnert ist 95jährig verstorben, in: Dresdner Neueste Nachrichten, 22.4.1999.

Peschel, Horst: Zum 100. Geburtstag von Prof. Dr.-Ing. Paul Werkmeister, in: Wissenschaftliche Zeitschrift der Technischen Universität Dresden, Bd. 27, H. 6, 1978, S. 1283-1284.

Peter, Karin (Hg.): NS-Presseanweisungen der Vorkriegszeit. Edition und Dokumentation, Bd. 6/I, 1938, München 1999.

Petschel, Dorit: 175 Jahre TU Dresden. Band 3: Die Professoren der TU Dresden 1828-2003. Hrsg. im Auftrag der Gesellschaft von Freunden und Förderern der TU Dresden e. V. von Reiner Pommerin, Köln u. a. 2003.

Petzsch, Hans: Arnold Jacobi, in: Neue Deutsche Biographie, Bd. 10, Berlin 1947, S. 220 ff.

Pieper, Christine: Hans Posse. Museumsdirektor und Kunsträuber Hitlers, in: Pieper/Schmeitzner/Naser 2012, S. 262-269.

Pieper, Christine, Schmeitzner, Mike u. Gerhard Naser (Hg.): Braune Karrieren. Dresdner Täter und Akteure im Nationalsozialismus, Dresden 2012.

Pittelkow, Jörg u. Uwe Hoßfeld: „Der Letzte seiner Zunft“. Bernhard Struck (1888-1971) als Anthropologe und Völkerkundler, in: Mitteilungen der Berliner Gesellschaft für Anthropologie, Ethnologie und Urgeschichte, Bd. 37, 2016, S. 65-82.

Plassmann, Engelbert u. Ludger Syré (Hg.): Verein Deutscher Bibliothekare 1900-2000, Festschrift, Wiesbaden 2000.

Poscharsky, Peter: Die Geschichte des Seminars für christliche Archäologie und Kunstgeschichte der theologischen Fakultät der Friederich-Alexander-Universität Erlangen-Nürnberg und die Behandlung der christlichen Archäologie und des Kirchenbaues der Gegenwart an den übrigen evangelisch-theologischen Fakultäten in Deutschland, Erlangen 1965.

Poscharsky, Peter: In memoriam Fritz Fichtner, in: Kirche und Kunst, 47, 1969, S. 58-59.

Pommerin, Reiner (Hg.): Dresden unterm Hakenkreuz, Köln/Weimar/Wien 1998.

Pommerin, Reiner (Hg.): 175 Jahre TU Dresden, hg. im Auftrag der Gesellschaft von Freunden und Förderern der TU Dresden e. V., Köln u. a. 2003 - Bd. 3: Die Professoren der TU Dresden 1828-2003, 175 Jahre TU Dresden, bearb. von Petschel, Dorit.

Post, Paul: Erich Haenel zum Gedächtnis $(† 26.12 .40)$, in: Zeitschrift für historische Waffenund Kostümkunde. Organ des Vereins für Historische Waffenkunde, Berlin, Bd. 7, 1941, S. $126-128$. 
Prescher, Hans: Aus der Geschichte des ältesten mineralogisch-geologischen Museums, in: Dresdner Wissenschaftliche Museen, Beiträge zur 750-Jahr-Feier unserer Stadt, Dresden und Leipzig 1956, S. 51-59.

Prescher, Hans: Eberhard Rimann 1920-1944, in: Dresdner wissenschaftliche Museen. Beiträge zur 750-Jahr-Feier unserer Stadt, Dresden 1956, S. 56-58.

Prescher, Hans: Das Staatliche Museum für Mineralogie und Geologie Dresden, in: Blick ins Museum. Mitteilungen aus den Staatlichen Wissenschaftlichen Museen Dresden, Heft 20/21, 1978, S. 46-56.

Prescher, Hans: Carl Walther Fischer (1897-1979). Mineraloge, Museumsmann, Schuldirektor, Wissenschaftshistoriker, in: Abhandlungen des Staatlichen Museums für Mineralogie und Geologie zu Dresden, Bd. 39, 1993, S. 21-54.

Prittwitz und Gaffron, Christian Wilhelm von u. Militärhistorisches Museum Dresden (Hg.): 100 Jahre Museum im Dresdner Arsenal (1897-1997). Eine Schrift zum Jubiläum, Dresden 1997.

Pützstück, Lothar: „Symphonie in Moll“ Julius Lips und die Kölner Völkerkunde, Pfaffenweiler 1995 (Zugl. Köln, Univ., Diss., 1993).

Ragna Enking, in: Schuder, Werner (Hg.): Kürschners Deutscher Gelehrten-Kalender. Begründet von Joseph Kürschner, 12. Aufl., Berlin 1976, S. 650.

Rave, Paul Ortwin: Kunstdiktatur im Dritten Reich, Hamburg 1949.

Reichel, Friedrich: Ernst Zimmermann zum Gedächtnis, in: Dresdener Kunstblätter, 9. Jg., 1965, S. 110-111.

Reichert, Robert: Über 200 Jahre Museumsgeschichte, in: Dresdner Wissenschaftliche Museen, Dresden 1956, S. 1-7.

Reichert, Robert: Persönlichkeiten, von denen unsere Sammlungen erzählen, in: Dresdner Wissenschaftliche Museen, Dresden 1956, S. 8-21.

Reuther, Martin: Jakob Jatzwauk. Eine Würdigung, in: Zentralblatt für Bibliothekswesen, Bd. 65, 1951, S. 407-415.

Richter, Dirk: Chronik (Auswahl), in: Prittwitz und Gaffron/Militärhistorisches Museum Dresden 1997, S. 227-232.

Rimann, Eberhard: Das Museum für Mineralogie, Geologie und Vorgeschichte, Sonderdruck aus dem Führer durch die Staatlichen Sammlungen zu Dresden, herausgegeben vom Ministerium für Volksbildung zu Dresden, 1932.

Rodenwaldt, Gerhart: Bruno Schröder †, in: Archäologischer Anzeiger, 1934, S. 314 f.

Rohne, Anneliese: Neuerwerbungen 1950-1955. Museum für Kunsthandwerk im Grassimuseum, Leipzig 1955.

Rößler, Horst: Werkmeister, Paul Georg August, in: Sächsische Biografie, 2008, Online-Ausgabe: http://saebi.isgv.de/biografie/Paul_Werkmeister_(1878-1944), Zugriff: 2.1.2020.

Roth, Martin: Menschenökonomie oder Der Mensch als technisches und künstlerisches Wunderwerk, in: Beier, Rosmarie und Martin Roth (Hg.): Der Gläserne Mensch - Eine Sensation. Zur Kulturgeschichte eines Ausstellungsobjekts, Stuttgart 1990, S. 39-67.

Rudert, Konstanze: Paul Ferdinand Schmidt, Robert Sterl, Alois Schradt, Will Grohmann und Hans Posse - Allianzen zur Förderung der Moderne in Dresden während der Weimarer Republik, in: Lupfer/Rudert 2015, S. 295-318.

Rudert, Thomas: Betrug und Untreue im Amt oder ethisch-moralisch gebotene Sicherung gefährdeter Kunstwerke? Wolfgang Balzer und die Grafiksammlung des sächsischen Königs Friedrich August II., in: Dresdener Kunstblätter, 54. Jg., H. 2, 2010, S. 116-126. 
Rudert, Thomas: „Ein junger Neuling, den vorgesetzten Behörden gefügig“. Vor 100 Jahren wurde Hans Posse Direktor der Dresdner Gemäldegalerie, in: Dresdener Kunstblätter, 54. Jg., H. 3, 2010, S. 171-179.

Rudert, Thomas: Museale Praxis zwischen Besatzungsmacht und kulturellem Anspruch. Die Eröffnung des Pillnitzer Zentralmuseums des Landes Sachsen am 6. Juli 1946, in: Jahrbuch der Staatlichen Kunstsammlungen Dresden, Bd. 36, 2010, Dresden 2012, S. 192-201.

Rudert, Thomas: Die kriegsbedingte Bergung der Kunstwerke aus der Staatlichen Gemäldegalerie Dresden ab August 1939, in: Kunst im Krieg 1939-1945, Dresdener Kunstblätter, H. 3, 2015, S. 5-17 (Rudert 2015a).

Rudert, Thomas: Konservativer Galeriedirektor - Kulturdiplomat der Weimarer Republik NS-Sonderbeauftragter. Bausteine zu einer Biografie Hans Posses, in: Lupfer/Rudert 2015, S. 61-149 (Rudert 2015b).

Rudert, Thomas: Wassily Kandinskys Gemälde „Einige Kreise“ in Dresden (1926-1937), Dresdener Kunstblätter, 63. Jg., H. 1, 2019, S. 32-41.

Saalmann, Timo: Kunstpolitik der Berliner Museen 1919-1959, Schriften zur modernen Kunsthistoriographie, Bd. 6, hg. v. Anne-Marie Bonnet, Olaf Peters u. Barbara Schellewald, Berlin 2014.

Saalmann, Timo: Die Staatlichen Museen Berlin im „Dritten Reich“, in: Löw/Nuding 2014, S. 169-182.

Sachtleben, Hans: (Nachruf van Emden), in: Beitrage zur Entomologie, 8, 1958, S. 761762.

Savoy, Bénédicte: „Vom Faustkeil zur Handgranate“ Filmpropaganda für die Berliner Museen 1934-1939, Köln/Weimar/Wien 2014.

Sbardella, Emanuele: Das Dresdener Münzkabinett im Nationalsozialismus, in: Dresdener Kunstblätter, 63. Jg., H. 2, 2019, S. 48-55.

Schachtmann, Judith: Von der Prähistorischen Sammlung zum Landesmuseum für Vorgeschichte - Die vorgeschichtlichen Ausstellungen im Dresdner Wallpavillon, in: Archäologische Informationen, 33/1, 2010, S. 59-68.

Schachtmann, Judith: Heinz Amberger (1907-1974) und die archäologischen Ausstellungen des Dresdner Museums für Vorgeschichte zwischen 1935 und 1938, in: Archaeo. Archäologie in Sachsen, Bd. 12, 2015, S. 44-49.

Schachtmann, Judith, Michael Strobel u. Thomas Widera (Hg.): Politik und Wissenschaft in der prähistorischen Archäologie. Perspektiven aus Sachsen, Böhmen und Schlesien, Berichte und Studien 56, Göttingen 2009.

Schachtmann, Judith u. Thomas Widera: Wissenschaftler und Nationalsozialist. Der Vorgeschichtler Walter Kersten (1907-1944) in Sachsen, in: Archaeo. Die Archäologie der Kriege. Die Burgen von Hohburg in der Hohburger Schweiz, Bd. 10, 2013, S. 30-36.

Schachtmann, Judith u. Thomas Widera: Von der Prähistorischen Sammlung zum Sächsischen Landesmuseum für Vorgeschichte - Überlegung zur Museumspolitik, in: Jahrbuch der Staatlichen Kunstsammlungen Dresden, Bd. 36, 2010, Dresden 2012, S. 132-140.

Schade, Thomas: Der furchtsame Sonderling, in: Sächsische Zeitung, 1.11.2018, S. 3.

Schäfer, Klaus (Hg.): Professor Dr. Otto Kleemann zum 80. Geburtstag, in: Pellenz-Museum, 5, Nickenich 1991.

Schallmayer, Egon: Otto Richard Max Kleemann (1911-1996), in: Archäologisches Nachrichtenblatt, Bd. 2, 1997, S. 409-410. 
Schattkowsky, Martina, Konstantin Hermann u. Roman Rabe (Hg.): Dresdner Bibliothekarinnen und Bibliothekare, Leipzig 2014.

Schawe, Martin: Vor 50 Jahren - Die Bayerischen Staatsgemäldesammlungen im Zweiten Weltkrieg, in: Bayerische Staatsgemäldesammlungen. Jahresbericht 1994, S. 9-27.

Scheppe, Wolfgang: Die Grenze als Wissenschaftsideal. Der Anthropologe und Völkerkundler Bernhard Struck, in: Staatliche Kunstsammlungen Dresden 2016, S. $17-$ 21.

Scheppe, Wolfgang: Wissenschaft als Rassenpolitik. Der SS-Offizier und Anthropologe Michael Hesch, in: Staatliche Kunstsammlungen Dresden 2016, S. 28.

Schmeitzner, Mike: Totale Herrschaft durch Kader? - Parteischulung und Kaderpolitik von NSDAP und KPD/SED, in: Totalitarismus und Demokratie. Zeitschrift für internationale Diktatur- und Freiheitsforschung, 2, 2005, S. 71-99.

Schmeitzner, Mike: Martin Mutschmann und Manfred von Killinger. Die „Führer der Provinz", in: Pieper/Schmeitzner/Naser 2012, S. 22-31.

Schmeitzner, Mike: Hammerleubsdorf eine „Schmiede des Nationalsozialismus“, in: Hermann 2014, S. 50-51.

Schmeitzner, Mike u. Andreas Wagner (Hg.): Von Macht und Ohnmacht. Sächsische Ministerpräsidenten im Zeitalter der Extreme 1919-1952, Beucha 2006.

Schmeitzner, Mike: Tödlicher Hass: Antisemitismus und Judenverfolgung in Dresden 19331945, in: Medaon. Magazin für jüdisches Leben in Forschung und Bildung, 10, 2016, https://www.medaon.de/de/artikel/toedlicher-hass-antisemitismus-und-judenverfolgungin-dresden-1933-1945/, Zugriff: 5.12.2019.

Schmidmaier, Dieter: Bibliothekar und Bücherfreund aus Leidenschaft. Zum Gedenken an Helmut Deckert, in: Marginalien. Zeitschrift für Buchkunst und Bibliophilie, Blätter der Pirckheimer Gesellschaft, 2005, 178, S. 105-106.

Schmidt, Gerhard: (Nachruf van Emden), in: Mitteilungen der Deutschen Entomologischen Gesellschaft, 17, 1958, S. 95-96.

Schmidt, Werner: Kesting in Dresden, in: Staatliche Kunstsammlungen Dresden, Kupferstich-Kabinett (Hg.): Edmund Kesting. Gemälde, Zeichnungen und farbige Blätter, Graphik, Photographien, Ausstellungskatalog, Dresden 1988, S. 3-4.

Schmidt, Werner: Die Staatlichen Sammlungen Dresden nach dem 2. Weltkrieg, in: Dresdner Geschichtsverein (Hg.): Die Dresdner Kunstsammlungen in fünf Jahrhunderten, Dresdner Hefte, Sonderausgabe 2004, S. 93-112.

Schmitt, Michael: Willi Hennig, the cautious revolutioniser, in: Palaeodiversity 3, Supplement, 3-9, Stuttgart 2010, S. 3-9, hier: 4-6, https://www.researchgate.net/publication/ 236173502_Willi_Hennig_the_cautious_revolutioniser, Zugriff: 5.12.2019.

Schneider, Hansjörg: Dresdner Theater 1933-1945. „Spiel war die Lust und Spiel die Gefahr", Berlin 2003.

Schöfert, Arne: Das größte Projekt des Reichskolonialbundes: Die Kolonialausstellung Dresden 1939, in: Internetmagazin des Traditionsverband ehem. Schutz und Überseetruppen e. V. 2010, überarb. 2013, http://www.traditionsverband.de/download/pdf/ Kolonialausstellung_Dresden.pdf, Zugriff: 5.12.2019.

Schölnberger, Pia u. Sabine Loitfellner: Bergung von Kulturgut im Nationalsozialismus. Mythen - Hintergründe - Auswirkungen, Köln/Weimar/Wien 2016.

Scholz, Dieter u. Maria Obenaus für die Nationalgalerie, Staatliche Museen zu Berlin (Hg.): Die schwarzen Jahre. Geschichten einer Sammlung 1933-1945, Berlin 2015. 
Schreiber, Carsten: Elite im Verborgenen: Ideologie und regionale Herrschaftspraxis des Sicherheitsdienstes der SS und seines Netzwerks am Beispiel Sachsens, München 2008.

Schulze, Friedrich: Erich Haenel †, in: Mitteldeutsche Blätter für Volkskunde, Bd. 16, 1941, 1, S. 53.

Schwanitz, Henrik: Deckert, Helmut, in: Sächsische Biografie, 2014, Online-Ausgabe: http://saebi.isgv.de/biografie/Helmut_Deckert_(1913-2005), Zugriff: 2.1.2020.

Schwanitz, Henrik: Jammers, Ewald Karl Hubert Maria, in: Sächsische Biografie, 2014, Online-Ausgabe: http://saebi.isgv.de/biografie/Ewald_Jammers_(1897-1981), Zugriff: 2.1.2020.

Schwarz, Birgit: Hitlers Museum. Die Fotoalben „Gemäldegalerie Linz“, Wien/Köln/Weimar 2004.

Schwarz, Birgit: Hitlers Sonderbeauftragter Hans Posse, in: Dresdner Hefte, Nr. 77, H. 1, 2004, S. 77-85.

Schwarz, Birgit: Hitlers Museumspolitik und ihre Auswirkungen bis heute, in: Kunst und Staat. Beiträge zu einem problematischen Verhältnis, Wien 2007, S. 83-99.

Schwarz, Birgit: Der sogenannte Linz-Bestand im Kupferstich-Kabinett der Staatlichen Kunstsammlungen Dresden, in: Dresdener Kunstblätter, 56. Jg., H. 2, 2012, S. 143-149.

Schwarz, Birgit: Auf Befehl des Führers. Hitler und der NS-Kunstraub, Darmstadt 2014.

Schwarz, Birgit: Hans Posse als Sonderbeauftragter, in: Lupfer/Rudert 2015, S. 329-348.

Schwarz, Birgit: Ein Schlüsseldokument zum NS-Kunstraub. Die Reisetagebücher von Hans Posse, in: Provenienz \& Forschung, 2, 2017, S. 51-52.

Schwarz, Birgit: Hitlers Sonderauftrag Ostmark. Kunstraub und Museumspolitik im Nationalsozialismus, Schriftenreihe der Kommission für Provenienzforschung 7, herausgegeben von Eva Blimlinger u. Heinz Schödl, Wien/Köln/Weimar 2018.

Semff, Michael (Hg.): Künstler zeichnen - Sammler stiften. 250 Jahre Staatliche Graphische Sammlung München, Bd. 3, Ostfildern 2008.

Seyffarth, Richard: In Memoriam Prof. Dr. Ernst Zimmermann, in: Mitteilungsblatt Keramik-Freunde der Schweiz, 49, 1960, S. 23-24.

Simon, Olaf: Zur Geschichte der Restaurierung im Kupferstich-Kabinett, in: Dresdener Kunstblätter, 48. Jg., H. 1, 2004, S. 47-52.

Smolnik, Regina u. Landesamt für Archäologie (Hg.): Umbruch 1945? Die prähistorische Archäologie in ihrem politischen und wissenschaftlichen Kontext, Workshop vom 24. bis 26. September 2009, Arbeits- und Forschungsberichte zur sächsischen Bodendenkmalpflege, 2012.

Sonntag, Helmut (Hg.): Aus den Chroniken der Universitätsbibliothek 1884-1984, Berlin 1984.

Spitzer, Gerd: Caspar David Friedrich in der Dresdener Galerie. Karl Wilhelm Jähnig zum Gedächtnis, in: Dresdener Kunstblätter, 54. Jg., H. 4, 2010, S. 245-250.

Staatliche Kunstsammlungen Dresden (Hg.): Kunst im Aufbruch. Dresden 1918-1933, Dresden 1980.

Staatliche Kunstsammlungen Dresden u. Werner Schmidt (Hg.): Unter „einer“ Krone. Kunst und Kultur der sächsisch-polnischen Union, Katalog der Ausstellung, Dresden 1997/1998, Leipzig 1997.

Staatliche Kunstsammlungen Dresden (Hg.): Das Kunstgewerbemuseum Dresden. Von der Vorbildersammlung zum Museum 1876-1907, anlässlich einer Ausstellung des Kunstgewerbemuseums 13.12.1998-14.3.1999, Eurasburg 1998. 
Staatliche Kunstsammlungen Dresden (Hg.): Die Vermessung des Unmenschen. Zur Ästhetik des Rassismus, Katalog der Ausstellung, Staatliche Kunstsammlungen Dresden, Kunsthalle im Lipsiusbau, 13.5-7.8.2016, S. 26-27.

Staatliche Kunstsammlungen Dresden, Abteilung Forschung und wissenschaftliche Kooperation und Daphne-Projekt (Hg.): Kunstbesitz Kunstverlust. Objekte und ihre Herkunft, Dresden 2018.

Staatliche Kunstsammlungen, Porzellansammlung, Anette Loesch (Hg.): Das Porzellankabinett im Hausmannsturm des Dresdner Residenzschlosses, Dresden 2019.

Staatliche Schlösser, Burgen und Gärten Sachsen (Hg.): Bombensicher! Kunstversteck Weesenstein 1945, Dresden 2018.

Stamm, H. C.: Kummerlöwe [= Kumerloeve], Hans, in: Neumann, Joachim, Siegfried Eck, u. a., in: Lebensbilder sächsischer Ornithologen, Mitteilungen des Vereins Sächsischer Ornithologen, Bd. 10, Sonderheft 3, Hohenstein-Ernstthal 2010, S. 117-118.

Starke, Holger u. Uwe John (Hg.): Geschichte der Stadt Dresden. Bd. 3, Von der Reichsgründung bis zur Gegenwart, Stuttgart 2006.

Stiftung Gedenkstätte Berlin-Hohenschönhausen (Hg.): Totenbuch: Sowjetisches Speziallager Nr. 3 und Haftarbeitslager Berlin-Hohenschönhausen 1945-1949, Zusammengestellt und erläutert von Peter Erler, mit einer Einführung von Hubertus Knabe, Berlin 2014, S. 41.

Stopfel, Wolfgang E.: Frau Dr. Elfriede Schulze-Battmann $\dagger$, in: Denkmalpflege in Baden-Württemberg : Nachrichtenblatt der Landesdenkmalpflege, Bd. 30, Ausg. 4, 2001, S. $229 \mathrm{f}$.

Strobel, Michael: Anmerkungen zur Institutionalisierung der archäologischen Denkmalpflege in Sachsen zwischen 1918 und 1945, in: Schachtmann/Strobel/Widera 2009, S. 169-192.

Strobel, Michael u. Thomas Widera: Einleitung, in: Schachtmann/Strobel/Widera 2009, S. 9-29.

Teschler-Nicola, Maria: Richard Arthur Hans Kummerlöwe alias Kumerloeve (19031995). Erster Direktor der wissenschaftlichen Museen in Wien in der NS-Zeit, in: Mitteilungen der Anthropologischen Gesellschaft in Wien (MAGW), Bd. 142, 2012, S. 279-304.

Teschler-Nicola, Maria u. Margit Berner: Die Anthropologische Abteilung des Naturhistorischen Museums in der NS-Zeit: Berichte und Dokumentation von Forschungs- und Sammlungsaktivitäten, in: Senatsprojekt der Universität Wien. Untersuchungen zur anatomischen Wissenschaft in Wien 1938-1945, Wien 1998, S. 333-358.

Themenheft: Provenienzforschung, Dresdener Kunstblätter, 56. Jg., H. 2, 2012.

Ulbricht, Gundula: Errichtung der NS-Herrschaft, in: Starke/John 2006, S. 413-424.

Ulbricht, Gundula: Kommunalpolitik und Stadtverwaltung, in: Starke/John 2006, S. 273 280.

Ulbricht, Gundula u. Olaf Glöckner (Hg.): Juden in Sachsen, Leipzig 2013.

Unserem Ehrenmitglied Professor Dr. Wilhelm Meise zum 100. Geburtstag am 12. September 2001, in: Mitteilungen des Vereins Sächsischer Ornithologen, 2001, Bd. 8, H. 6, S. 691-692.

Vaupel, Elisabeth u. Stefan L. Wolff (Hg.): Das Deutsche Museum in der Zeit des Nationalsozialismus. Eine Bestandsaufnahme, Deutsches Museum. Abhandlungen und Berichte, N. F., Bd. 27, Göttingen 2010. 
Veit Stoß. Ausstellung Dresden 1944, Ausstellungskatalog, Breslau 1944.

Verzeichnis der Publikationen von Wilhelm Meise, in: Mitteilungen aus dem Hamburgischen Zoologischen Museum und Institut, Bd. 100, 2004.

Victor Klemperer. Ich will Zeugnis ablegen bis zum Letzten. Tagebücher 1933-1945, hg. von. Walter Nowojski, überarbeitete Neuausgabe, 2 Bde., Berlin 2015.

Vogel, Klaus (Hg.): Das Deutsche Hygiene-Museum Dresden 1911-1990, Dresden 2003.

Voigt, Helmut: Erinnerungen an Charlotte Boden, Freital 2000.

Vollnhals, Clemens (Hg.): Sachsen in der NS-Zeit, Leipzig 2002.

Vollnhals, Clemens: Der gespaltene Freistaat: Der Aufstieg der NSDAP in Sachsen, in: Vollnhals 2002, S. 9-40.

Voss, Waltraud: Von Dresden in die Welt. II. Frühe Promovenden der TU Dresden in Wirtschaft, Wissenschaft und Gesellschaft, Dresden 2010.

Wagner, Andreas: „Machtergreifung“ in Sachsen. NSDAP und staatliche Verwaltung 19301935, Köln 2004.

Wagner, Andreas: Martin Mutschmann. Der braune Gaufürst (1935-45), in: Schmeitzner/Wagner 2006, S. 279-308.

Waltoś, Stanisław: Die Entführung des Marienaltars von Veit Stoß nach Nürnberg, in: Löw/ Nuding 2014, S. 127-138.

Watzdorf, Erna von: E. Haenel gestorben, in: Neues Archiv für sächsische Geschichte, 62, 1941, S. 82-85.

Watzdorf, Erna von: Erich Haenel, in: Neue deutsche Biographie, 7, Berlin 1966, S. 441-442.

Weber, Stephan: Die Gleichschaltung der Kunstakademie, in: Dresdner Hefte, 22. Jg., H. 77, 2004, S. 26-35.

Wedhorn, Katja: Licht und Schatten. Neue Gestaltungsweisen in der Fotografie von 1920 bis 1960 und der Beitrag Edmund Kestings, Marburg 2012 (Zugl. Greifswald, Univ., Diss., 2009).

Wegner, Wolfgang: Peter Halm $\dagger$, in: Pantheon. Internationale Zeitschrift für Kunst, 24. Jg., Juli/August, 1966, S. 255-256.

Werner, Klaus (Hg.): Edmund Kesting. Ein Maler fotografiert, Leipzig 1987.

Wessel, Ursula: Martin Heydrich. Sein Leben und Wirken, 2012.

Wex, Reinhold: Adriani, Gert, in: Camerer, Luitgard, Garzmann, Manfred R. W. u. Wolf-Dieter Schuegraf (Hg.): Braunschweiger Stadtlexikon, Braunschweig 1992, S. 10.

Widera, Thomas: „... eine gute saubere anständige politische Gesinnung“. Entnazifizierung als Instrument der Diktaturdurchsetzung in Dresden 1945, in: Behring, Rainer u. Mike Schmeitzner (Hg.): Diktaturdurchsetzung in Sachsen. Studien zur Genese der kommunistischen Herrschaft 1945-1952, Köln/Weimar/Wien 2003, S. 269-296.

Widera, Thomas: Politik, Wirtschaft und Verwaltung, in: Starke/John 2006, S. 531-545.

Widera, Thomas: Werner Coblenz und die prähistorische Archäologie in Sachsen nach 1945, in: Schachtmann/Strobel/Widera 2009, S. 193-217.

Winter, Petra: Hans Posse - „ein nahezu unbeschriebenes Blatt“. Protokoll einer Ernennung, in: Maaz 2012, S. 29-48.

Wittern, Renate u. Friedrich-Alexander-Universität Erlangen-Nürnberg (Hg.): Die Professoren und Dozenten der Friedrich-Alexander-Universität 1743-1960. Teil 1: Theologische Fakultät, Juristische Fakultät, Erlanger Forschungen, Sonderreihe (5), Erlangen 1993, http://nbnresolving.de/urn:nbn:de:bvb:29-opus-20866, Zugriff: 2.1.2020.

Wolf, Siegfried: Bernhard Struck 75 Jahre, in: Abhandlungen und Berichte des Staatlichen Museums für Völkerkunde, Dresden, 22, 1963, S. V-VI. 
Wörner, Hans Jakob: Zum Tod der Freiburger Kunsthistorikerin, Museumsspezialistin und Denkmalpflegerin Elfriede Schulz-Battmann, in: Badische Heimat: mein Heimatland, Zeitschrift für Landes- und Volkskunde, Natur-, Umwelt- und Denkmalschutz, Bd. 81, 2001.

Wüstling, Hans-Dieter: Die Direktoren der Universitätsbibliothek Dresden von 1828 bis 1996, Dresden 2005.

Wüstling, Hans-Dieter: Dr. phil. Hans Hofmann (1944-1945), in: Wüstling 2005, S. 60-61.

Wüstling, Hans-Dieter: Dr. phil. Hermann Neubert (1929-1933), in: Wüstling 2005, S. $50-51$.

Wüstling, Hans-Dieter: Neubert, Hermann Rudolf, in: Sächsische Biografie, 2009, Online-Ausgabe: http://saebi.isgv.de/biografie/Hermann_Neubert_(1892-1980), Zugriff: 2.1.2020.

Wüstling, Hans-Dieter: Hofmann, Hans, in: Sächsische Biografie, 2015, Online-Ausgabe: http://saebi.isgv.de/biografie/Hans_Hofmann_(1890-1979), Zugriff: 2.1.2020.

Zaunick, Rudolph: Arnold Jacobi (1870-1948), ein sächsischer Zoologe und Ethnograph, in: Beiträge zur Vogelkunde, 8, 1962, S. 170-205.

Zesewitz, Helmut: Charlotte Boden 1900-1994, in: Zeitschrift für Bibliothekswesen und Bibliographie, Bd. 41, Ausg. 3, 1994, S. 366-368.

Zuschlag, Christoph: „Entartete Kunst“. Ausstellungsstrategien in Nazi-Deutschland, Worms 1995 (Heidelberger Kunstgeschichtliche Abhandlungen, N. F., Bd. 21) (Zugl. Heidelberg, Univ., Diss., 1991).

Zuschlag, Christoph: Neues Rathaus Dresden: Die Ausstellung „Entartete Kunst“ 1933, in: Hermann, Konstantin (Hg.): Führerschule, Thingplatz, ,Judenhaus“. Orte und Gebäude der nationalsozialistischen Diktatur in Sachsen, Dresden 2014, S. 154-158.

Zuschlag, Christoph: Hans Posse und die „Entartete Kunst“, in: Lupfer/Rudert 2015, S. 319-328.

Zwahr, Hartmut: Dr. Jacob Jatzwauk zum 100. Geburtstag, in: Bautzener Kulturschau. Monatsschrift über das kulturelle Geschehen des Kreises Bautzen, Bd. 35, Ausg. 2, 1985, S. 2-5.

Zwahr, Hartmut: Der Bibliograph und sein Magaziner. Zum Gedenken an Dr. Jacob Jatzwauk und Max Schneider, in: Neues lausitzisches Magazin. Zeitschrift der Oberlausitzischen Gesellschaft der Wissenschaften, Bd. 17, 136, 2014, S. 83-102. 


\section{Abbildungsverzeichnis}

\section{Cover}

(v.o.l.n.u.r.): (1. Reihe) Karl Assmann, Alfred Beck, Johannes Draeseke, Max Hahn, Georg Bierbaum, Ragna Enking; (2. Reihe) Walter Holzhausen, Erhart Kästner, Wilhelm Meise, Eberhard Rimann, Peter Halm, Arnold Jacobi; (3. Reihe) Walter Schwinkowski, Erna von Watzdorf, Paul Werkmeister, Hans Posse, Hans Kummerlöwe, Hermann Neubert; (4. Reihe) Robert Reichert, Franz Schubert, Paul Täubrich, Kurt Zoege von Manteuffel, Wolfgang Balzer, Helmut Deckert; (5. Reihe) Michael Hesch, Jacob Jatzwauk, Anna Löwenthal, Robert Oertel, Eduard Samtleben

Bildnachweise siehe: Abbildungen in den Biografien

\section{Abbildungen im Haupttext}

Abb. 1

Dresden, Blick von der Sophienkirche auf den Zwinger, um 1935, Fotograf: Richard Peter sen. SLUB / Deutsche Fotothek / Richard Peter sen.

Abb. 2

Allgemeine Anordnung Nr. 99, Sächsisches Ministerium für Volksbildung, Arthur Göpfert, an alle Referenten und Geschäftsstellen, 28.4.1937

SKD, MPS, 1937, E.-Reg. Nr. 155

Abb. 3

Fritz Fichtner (1.v.l.) mit Reichsstatthalter Martin Mutschmann (2.v.l.) vor der Gemäldegalerie in Dresden, um 1940

SKD Archiv, SLG-SAL 7, 2

Abb. 4

Brief von Fritz Fichtner an Reichsstatthalter Martin Mutschmann, 8.9.1944

HStA Dresden, 13859, Nr. 1553, fol. 61

Abb. 5

Das Personal der Sächsischen Landesbibliothek im Innenhof des Japanischen Palais, 1932, Fotograf: Hermann Bähr (1.R.v.l.n.r.: Gottfried Benndorf, Walther Frieser, Jacob Jatzwauk, Hubert Richter, Martin Bollert, Otto Fiebiger, Bruno Faass, Karl Assmann, Hans Hofmann; 2.R.4.v.1.: Charlotte Boden; 3.R.4.v.1.: Lucie Walter; 4.R.v.1.: Helmut Schneider (2.), Charlotte Holzhausen (4.); 5.R.v.l.: Margarethe Storch (3.), Ewald Jammers (4.))

SLUB / Deutsche Fotothek/ Hermann Bähr

Abb. 6

Anna Löwenthal, Absichtserklärung für die Einwanderung in die USA, 17.5.1939 
„New York, Southern District, U.S District Court Naturalization Records, 1824-1946“, database, (https://familysearch.org/ark:/61903/1:1:QP7X-8N52, Zugriff: 3.12.2019), Anna Loewenthal, 1939; citing Immigration, New York, United States, 280350, NARA microfilm publication M1972, Southern District of New York Petitions for Naturalization, 1897-1944. Records of District Courts of the United States, 1685-2009, RG 21. National Archives at New York

Abb. 7

Reichsstatthalter Martin Mutschmann, Versetzung von Fritz van Emden in den Ruhestand, 18.9.1933

HStA Dresden, 13842, Nr. 047, o. Pag.

Abb. 8

Mitteilung der Geschäftsstelle der Staatlichen Sammlungen, Frenzel, an das Sächsische Ministerium für Volksbildung 25.10.1935

HStA Dresden, 11125, Nr. 18960, fol. 354

Abb. 9

Brief des Leiters des Sächsischen Ministeriums für Volksbildung an die Direktoren der Staatlichen Sammlungen, 18.11.1938

SKD Archiv, 01/PS 45, Bd. 1, fol. 35

Abb. 10

Brief des Sächsischen Ministeriums für Volksbildung an die Direktoren der Staatlichen Sammlungen, 30.8.1939

SKD Archiv, 02/VA 50, fol. 35

Abb. 11

Erlass des Reichsministers für Wissenschaft, Erziehung und Volksbildung, Betrieb der Museen während des Kriegszustandes, 8.12.1939

SKD Archiv, 02/VA 50, fol. 101-103, hier: 101-102

Abb. 12

Brief von Reichsstatthalter Martin Mutschmann an Fritz Fichtner, Abteilung IV/7 des Sächsischen Ministeriums für Volksbildung, 11.8.1944

HStA Dresden, 11125, Nr. 23058, fol. 84a

Abb. 13

Brief von Sammlungsreferent Fritz Fichtner an Reichsstatthalter Martin Mutschmann, 11.8.1944

HStA Dresden, 11125, Nr. 23058, fol. 84b

Abb. 14

Verabschiedung von Martin Bollert in der Sächsischen Landesbibliothek am 26.10.1937 (v.l.n.r.: Erhart Kästner, Fritz Fichtner, Arthur Göpfert, Martin Bollert)

SLUB, Mscr.Dresd.App.1378.a 
Abb. 15

Fritz Fichtner im Dresdner Zwinger, um 1939

SKD, Fotoarchiv der Porzellansammlung, FN_A_140

Abb. 16

Besuch von Adolf Hitler in der Gemäldegalerie am 18. Juni 1938 (v.l.n.r.: 1.R.: Adolf Hitler, Martin Bormann; 2.R.: Hans Posse, Gert Adriani, Fritz Fichtner, ?, ?; 3.R.: Alfred Unger, ?)

Nürnberg, Germanisches Nationalmuseum, Deutsches Kunstarchiv, NL Posse, Hans, I,B-1 (0204)

Abb. 17

Abschrift aus dem Sächsischen Verwaltungsblatt, Teil 1, Verordnungsblatt, 12.1.1934

SKD Archiv, 01/KK 3, Bd. 8, fol. 512

Abb. 18

Appell in der Porzellansammlung am 20.3.1936 (v.l.n.r.: Fritz Fichtner, Albin Spiegler, [?]

Kind, Albert Büttner, Willy Jentsch, Hellmuth Gründer)

SKD Archiv, SKD_KM_1331

Abb. 19

Allgemeine Anordnung Nr. 17, Leiter des Sächsischen Ministeriums für Volksbildung an alle Dienststellen, 26.4.1935

SKD, MPS, 1935, E.-Reg. Nr. 127

Abb. 20

Brief von Alfred Beck an die Kreisleitung der NSDAP, 7.8.1934

SKD, MPS, 1934, A.-Reg. Nr. 182

Abb. 21

„Maifeier des deutschen Sozialismus“ am 1.5.1934 am Elbufer in Dresden (Franz Schubert (1. stehend), Walter Holzhausen (2.v.r. sitzend), und Karl Wilhelm Jähnig (3.v.r. sitzend)),

Fotograf: Walter Naumann, Dresden

SKD, Kupferstich-Kabinett, Inv.-Nr. D 1981-102

Abb. 22

Anordnung eines Betriebsappells, Gemäldegalerie, Hans Posse, an das Personal der Gemäldegalerie, 22.5.1935

HStA Dresden, 11127, Nr. 28, fol. 437

Abb. 23

Brief des Kommissarischen Leiters des Sächsischen Ministeriums für Volksbildung, Arthur Göpfert, an die Direktoren der Staatlichen Sammlungen, 30.4.1936

SKD Archiv, 01/PS 40, fol. 92

Abb. 24

Notizen von Fritz Fichtner für den Betriebsappell am 19.8.1936

SKD Archiv, 01/PS 40, fol. 12 
Abb. 25

Brief von Fritz Fichtner, Porzellansammlung, an das Sächsische Ministerium für Volksbildung, 31.3.1936

HStA Dresden, 11125, Nr. 19192, fol. 265

Abb. 26

„Pfingstputzen“ in der Sächsischen Landesbibliothek, 1939 (1.R.v.l. Dorothee Denecke (1.), Hubert Richter (3.); 2.R.2.v.r. Gottfried Benndorf; 4.R.v.l. Hans Hofmann (2.), Charlotte

Holzhausen (3.), Ewald Jammers (6.), Jacob Jatzwauk (9.))

SLUB, Mscr.Dresd.App.1378.a

Abb. 27

Modell des Dresdner Museumsprojekts, 1938, Entwurf von Ernst Dutzmann, Fotograf: Martin Richter

SKD, Fotoarchiv der Porzellansammlung, FN_A_49

Abb. 28

Stempel auf der Post des Sächsischen Ministeriums für Volksbildung, September 1939

SKD Archiv, 01/KK 17, Bd. 1, fol. 59

Abb. 29

Bergungsarbeiten im Grünen Gewölbe während der „Sudetenkrise“, September 1938

SLUB / Deutsche Fotothek/ unbekannter Fotograf

Abb. 30

Brief vom Reichsminister für Wissenschaft, Erziehung und Volksbildung, Berlin, an die Landesregierungen, 28.8.1939

HStA Dresden, 10701, Nr. 320/1, Bd. 1, fol. 1.

Abb. 31

Einladung zur Direktorenkonferenz am 20.3.1940, Brief von Fritz Fichtner, Ministerium für Volksbildung, an Direktoren der Staatlichen Sammlungen, 14.3.1940

SKD Archiv, 01/KGM 7, fol. 16

Abb. 32

Franz Schubert im Bergungsraum des Kupferstich-Kabinetts im Semperbau, März 1941

Reproduktion aus: Die Sirene, Nr. 13, 1941, S. 292

Abb. 33

Einrichtung zum Mappentransport im Bergungsraum des Kupferstich-Kabinetts im Semperbau, März 1941

Reproduktion aus: Die Sirene, Nr. 13, 1941, S. 293

Abb. 34

Plakat für den Museumsvortrag von Hermann Voss über Lorenzo Bernini am 12.12.1943

HStA Dresden, 11125, Nr. 23081, fol. 184 
Abb. 35

Plakat der Ausstellung „Kostbarkeiten des Grünen Gewölbes im Lichtbild“, September 1943

HStA Dresden, 11125, Nr. 23058, fol. 60

Abb. 36

Faltblatt „Führungen in den Staatlichen Sammlungen für Kunst und Wissenschaft“, April bis September 1938

SKD Archiv, 01/PS 44, Bd. 2, fol. 204

Abb. 37

Szenen aus dem Dokumentarfilm „Mit Federbusch und Harnisch“, 1937, Fotograf: Christian Borchert

SLUB / Deutsche Fotothek / Christian Borchert

Abb. 38

Karl Wanderer (l.) und Rudolf Schwarze (r.) vor dem Schrank „Menschen und Raubtiere des Diluviums“, Neuaufstellung der geologisch-paläontologischen Sammlung, 1925

Senckenberg Naturhistorische Sammlungen Dresden

Abb. 39

Ernst von Koerner (1.v.l.?) am großen chinesischen Geschütz im Sächsischen Armeemuseum, Fotograf: Martin Richter

SKD, Fotoarchiv der Porzellansammlung, FN_D_3

Abb. 40

Saal für Sonderausstellungen im Buchmuseum der Sächsischen Landesbibliothek, Japanisches Palais, um 1935, Fotograf: Wilhelm Moeck

SLUB / Deutsche Fotothek/Wilhelm Moeck

Abb. 41

Fritz Fichtner im Johanneum bei der Besichtigung eines Probearrangements aus chinesischem Porzellan der Ära Kangxi, 1700-1720, für die Ausstellung im Zwinger, um 1937

SKD, Fotoarchiv der Porzellansammlung, SKD_PS_0089

Abb. 42

Bergung der Porzellansammlung im Zwinger, September 1939, Fotograf: Martin Richter SKD, Fotoarchiv der Porzellansammlung, FN_A_69

Abb. 43

Einladung zur Eröffnung der Ausstellung „August der Starke und seine Zeit“, April 1933

SKD, MPS, 1933, A.-Reg. Nr. 77

Abb. 44

„Deutsche Turnierschau“ im Historischen Museum, Johanneum, Mai bis September 1936, Fotograf: Walter Möbius

SLUB / Deutsche Fotothek/Walter Möbius 
Abb. 45

Ausstellung „Deutsche Meisterwerke aus Zinn“ im Kunstgewerbemuseum, Juni bis September 1938

SKD Archiv, SKD_KM_1218

Abb. 46

Tafelaufsatz von Johann Christian Neuber, 1775, in der Ausstellung „Sächsisches Edelgestein“ im Residenzschloss, August 1936, Fotograf: Walter Möbius

SLUB / Deutsche Fotothek/Walter Möbius

Abb. 47

Ausstellung „Instrumente und Uhren Sächsischer Meister“ im Mathematisch-Physikalischen Salon, Museumswoche 1937

SKD, Mathematisch-Physikalischer Salon

Abb. 48

Ausstellung „Alte Wehr im deutschen Heer“ im Historischen Museum, Juni bis September 1938

SLUB / Deutsche Fotothek / unbekannter Fotograf

Abb. 49

Führung durch die Sonderausstellung „Sachsens keramische Rohstoffe und ihre Verwertung“, Dezember 1940

SKD, Fotoarchiv der Porzellansammlung, FN_D_159

Abb. 50

Fritz Fichtner bei der Vorbereitung eines Führungsvortrages in der Porzellansammlung, um 1940

SKD, Fotoarchiv der Porzellansammlung, GN_A_81

Abb. 51

Ankündigung der Sonntagsvorträge in den Dresdner Nachrichten, 5.10.1941

HStA Dresden, 11125, Nr. 23081, fol. 12

Abb. 52

Eintrittskarte zum 2. Museumsvortrag 1943 am 28.11.1943

HStA Dresden, 11125, Nr. 23081, fol. 245

Abb. 53

Plakat für den Museumsvortrag von Klaus Günther über „Deutsche Münzkunst der Hohenstauferzeit" am 28.11.1943

HStA Dresden, 11125, Nr. 23081, fol. 172

Abb. 54

Einladungskarte für die Museumsvorträge im Winterhalbjahr 1943/1944

HStA Dresden, 11125, Nr. 23081, fol. 197 
Abb. 55

Bergkristallkugel, Fotografie von Edmund Kesting, um 1935

SKD, Grünes Gewölbe, V 174

Abb. 56

Leonor Kupke: Kostbarkeiten im Grünen Gewölbe, in: Dresdner Zeitung, 25.9.1943

HStA Dresden, 11125, Nr. 23087, fol. 65

Abb. 57

Katalog der Ausstellung „Veit Stoß“, Dresden 1944

SKD, Kunstbibliothek

Abb. 58

Blick in die Ausstellung „Veit Stoß“ im Historischen Museum, 1944

SLUB / Deutsche Fotothek/unbekannter Fotograf

Abb. 59

Vitrine in der Ausstellung „Serienporzellan für Küche, Keller, Kantine und Kaserne“ in der Porzellansammlung, 1944, Fotograf: Fritz Fichtner

SKD, Fotoarchiv der Porzellansammlung, FN_A_240

Abb. 60

Brief der Porzellanfabrik Gebr. Bauscher, Weiden, an Fritz Fichtner, Porzellansammlung Dresden, 28.6.1944

SKD Archiv, 01/PS 54, Bd. 1, fol. 148

Abb. 61

Zerstörte Sempergalerie, Dresden, nach Februar 1945

SKD Archiv, 102-3, Mappe 7, Foto 130

\section{Abbildungen in den Biografien}

Gert Adriani

KHM-Museumsverband, Wien, Fotografin: Elisabeth Schwenk

Rudolf von Arps-Aubert

Stadtarchiv Zwickau, NS-Tageszeitung für Zwickau, 1.5.1937

Karl Assmann, Porträtfoto aus den Personalakten

HStA Dresden, 13859, Nr. 131, o. Pag.

Wolfgang Balzer

SKD, Kupferstich-Kabinett, Album Max Hahn

Alfred Beck, Porträtfoto aus den Personalakten

HStA Dresden, 13859, Nr. 299, o. Pag. 
Herbert Bellmann, Porträtfoto aus den Personalakten

HStA Dresden, 11125, Nr. 18991, o. Pag.

Gottfried Benndorf

SLUB / Deutsche Fotothek/ Hermann Bähr (Ausschnitt), siehe Abb. 5

Georg Bierbaum, Porträtfoto aus den Personalakten

HStA Dresden, 13859, Nr. 521, o. Pag.

Charlotte Boden, um 1929 (Ausschnitt)

SLUB / Deutsche Fotothek/ unbekannter Fotograf

Martin Bollert

SLUB / Deutsche Fotothek/ Hermann Bähr (Ausschnitt), siehe Abb. 5

Helmuth Buck, Porträtfoto aus den Personalakten

HStA Dresden, 13859, Nr. 844, o. Pag.

Ulrich Dähnert

SLUB, PA Dähnert, fol. 66

Helmut Deckert

Nachlass Helmut Deckert

Dorothee Denecke, Porträtfoto aus den Personalakten

HStA Dresden, 13859, Nr. 1051, o. Pag.

Johannes Draeseke, Porträtfoto aus den Personalakten

HStA Dresden, 13859, Nr. 1193, o. Pag.

Fritz van Emden

List of World Diptera Taxonomists,

http://hbs.bishopmuseum.org/dipterists/images/emden.gif, Zugriff: 6.12.2019

Ragna Enking, Porträtfoto aus den Personalakten

HStA Dresden, 11125, Nr. 18991/2, o. Pag.

Bruno Faas

SLUB / Deutsche Fotothek/ Hermann Bähr (Ausschnitt), siehe Abb. 5

Fritz Fichtner, Porträtfoto aus den Personalakten

Porträt HStA Dresden, 13859, Nr. 1553, fol. 64

Otto Fiebiger

SLUB / Deutsche Fotothek/ Hermann Bähr (Ausschnitt), siehe Abb. 5 
Walther Fischer

Senckenberg Naturhistorische Sammlungen Dresden

Walther Frieser

SLUB / Deutsche Fotothek/Hermann Bähr (Ausschnitt), siehe Abb. 5

Walter Grünberg

Landesamt für Archäologie Sachsen

Klaus Günther

Senckenberg Naturhistorische Sammlungen Dresden

Erich Haenel, Fotografie von Genja Jonas (1895-1938), um 1930

SKD, Kupferstich-Kabinett, Inv.-Nr. D 2008-39

Max Hahn

SKD, Kupferstich-Kabinett, Album Max Hahn

Peter Halm

SKD, Kupferstich-Kabinett, Album Max Hahn

Anneliese Hanisch/Rohne, Porträtfoto aus den Personalakten

Grassi Museum für Angewandte Kunst, Leipzig

Walter Häntzschel

Senckenberg Naturhistorische Sammlungen Dresden

Michael Hesch, Porträtfoto aus den Personalakten

HStA Dresden, 13859, Nr. 3205, o. Pag.

Rolf Hetsch

BArch, NS 21/1520

Martin Heydrich

BArch, R 9361-VIII/Kartei/10860769

Helmut Hofer, Porträtfoto aus den Personalakten,

HStA Dresden, 13842, Nr. 237, o. Pag.

Hans Hofmann

SLUB

Charlotte Holzhausen, Porträtfoto aus den Personalakten

HStA Dresden, 13859, Nr. 3427, o. Pag.

Walter Holzhausen, Porträtfoto aus den Personalakten

HStA Dresden, 13859, Nr. 3429, o. Pag. 
Arnold Jacobi, um 1930, Fotografin: Ursula Richter

SLUB / Deutsche Fotothek/Ursula Richter

Ewald Jammers

SLUB / Deutsche Fotothek/ Hermann Bähr (Ausschnitt), siehe Abb. 5

Jacob Jatzwauk, um 1940

Nachlass Jacob Jatzwauk

Erhart Kästner, Porträtfoto aus den Personalakten

Porträt, HStA Dresden, 13859, Nr. 3833

Walter Kersten

Landesamt für Archäologie Sachsen

Kurt Köhn

SKD Archiv, 402, Mappe 1, Foto 860

Artur Krüss

DRK-Suchdienst München, Vermisstenbildlisten

Hans Kummerlöwe, Porträtfoto aus den Personalakten, um 1936

BArch, R 76/I/59b, fol. 17v

Arthur Leuschner, Porträtfoto aus den Personalakten

HStA Dresden, 13859, Nr. 4970, o. Pag.

Hans Loos

SKD, Kupferstich-Kabinett, Album Max Hahn

Anna Löwenthal, um 1939

Anna Löwenthal, USA Declaration of Intention, 17. 5.1939 (Ausschnitt), siehe Abb. 6

Wilhelm Meise, Porträtfoto aus den Personalakten

HStA Dresden, 13859, Nr. 5435, o. Pag.

Walter Müller, Skulptur von Hermann Alfred Raddatz (1906-1962), Bronze, 1932

SKD, Skulpturensammlung, Inv.-Nr. ZV 3635, Fotograf: Hans-Peter Klut

Hermann Neubert

SLUB

Robert Oertel, Porträtfoto aus den Personalakten

HStA Dresden, 13859, Nr. 6178, o. Pag.

Berthold Pfaul

BArch, R 9361-VIII/Kartei/15311454 
Artur Pietzsch, Porträtfoto aus den Personalakten

HStA Dresden, 13859, Nr. 6452, o. Pag.

Hans Posse

SKD, Kupferstich-Kabinett, Inv.-Nr. D 1986-59

Robert Reichert, Porträtfoto aus den Personalakten

HStA Dresden, 13859, Nr. 6777, o. Pag.

Gottfried Reimer

Archiv Andreas Förster

Hubert Richter

SLUB / Deutsche Fotothek/Hermann Bähr (Ausschnitt), siehe Abb. 5

Eberhard Rimann, um 1928, Fotografin: Ursula Richter

SLUB / Deutsche Fotothek/Ursula Richter

Eduard Samtleben

SKD, Kupferstich-Kabinett, Inv.-Nr. D 1986-59

Curt Sander, Porträtfoto aus den Personalakten

HStA Dresden, 13859, Nr. 7305, o. Pag.

Helmut Schneider, Porträtfoto aus den Personalakten

HStA Dresden, 13859, Nr. 8089, o. Pag.

Bruno Schröder, Skulptur von Peter Pöppelmann (1866-1947), Bronze, vor 1934

SKD, Skulpturensammlung, Inv.-Nr. ZV 3370, Fotograf: Hans-Peter Klut

Franz Schubert

Kupferstich-Kabinett, Inv.-Nr. D 1986-59

Elfriede Schulze-Battmann, Porträtfoto aus den Personalakten

HStA Dresden, 11125, Nr. 18964, fol. 399

Rudolf Schwarze, Porträtfoto aus den Personalakten

HStA Dresden, 13859, Nr. 8495, o. Pag.

Walter Schwinkowski

SKD, Münzkabinett, Fotoarchiv

Margarethe Storch, Porträtfoto aus den Personalakten

HStA Dresden, 13859, Nr. 8703, o. Pag.

Bernhard Struck

SKD, Museum für Völkerkunde Dresden 
Paul Täubrich, Porträtfoto aus den Personalakten

HStA Dresden, 13859, Nr. 9020, o. Pag.

Alfred Unger, Porträtfoto aus den Personalakten

HStA Dresden, 13859, Nr. 7305, o. Pag.

Hermann Voss

Nürnberg, Germanisches Nationalmuseum, Deutsches Kunstarchiv, NL Voss, Hermann, $138(0045)$

Lucie Walter

SLUB / Deutsche Fotothek/ Hermann Bähr (Ausschnitt), siehe Abb. 5

Karl Wanderer

Senckenberg Naturhistorische Sammlungen Dresden

Dorothee von Watzdorf, Porträtfoto aus den Personalakten

HStA Dresden, 13859, Nr. 9397, o. Pag.

Erna von Watzdorf, Porträtfoto aus den Personalakten

HStA Dresden, 11125, Nr. 18991, Bd. 1, o. Pag.

Paul Werkmeister, um 1928, Fotografin: Ursula Richter

SLUB / Deutsche Fotothek/Ursula Richter

Siegfried Wolf

BArch, R 9361/V-40635

Ernst Zimmermann, Fotograf: Martin Richter

SKD, Fotoarchiv der Porzellansammlung, GN_A_405

Kurt Zoege von Manteuffel

SKD, Kupferstich-Kabinett, Album Max Hahn

Sollten trotz der intensiven Bemühungen alle Urheber- und Reproduktionsrechte zu klären, Ansprüche übersehen worden sein, war dies unbeabsichtigt. 


\section{Personenregister}

Fett gesetzte Ziffern verweisen auf Einträge im Kapitel „Die wissenschaftlichen Mitarbeiterinnen und Mitarbeiter".

Adriani, Gert 85, 90, 96, 98, 111, 196, 203 f., 240, 242, 254 f., 407

Amberger, Heinz 23, 90, 95, 102, 161, 183, 256 f., 279

Arps-Aubert, Rudolf von 83 f., 101, 164, 236,258 f., 352

Assmann, Karl 49, 65, 202, 224, 227 f., 233, 260 f., 286, 397

Balzer, Wolfgang 28, 53, 71, 91, 228, 231, 262 ff., 296, 307, 422

Barthel, Helene 48, 89, 226, 265 f.

Beck, Alfred 12, 27, 61 f., 65, 82, 90, 100, 110, 113 f., 122, 174, 176, 196, 203, 212, 223, 226 f., 231, 245, 267 ff., 308, 438, 463

Bellmann, Herbert 61 f., 65, 136, 206, 227, 270 ff., 402, 444, 469

Bemmann, Rudolf 273 f., 364 f.

Benndorf, Gottfried 48 f., 90, 110 f., 125, 224, 275 f., 348, 396

Berge, Rudolf 53, 135, 277, 324

Bierbaum, Georg 28, 65, 91, 95, 106, 110, $161,164,182,202,228,232,256$,

278 ff., 318, 370, 372, 403

Boden, Charlotte 48 f., 90, 173, 196, 240 ff., 245-249, 281 f., 289

Bollert, Martin 28, 45, 49 f., 56 f., 75 ff., 91, 99, 107, 116, 118, 125 f., 166, 169, 177, 184 f., 223, 233, 283-286, 304, 347 f., 350, 357, 361, 364, 367, 388, 396 f., 427,454

Bormann, Martin 96, 412

Buck, Hellmuth 58, 67, 89, 112, 117, 121, 137 f., 287 f., 345, 352, 378, 391, 410, 438

Dähnert, Ulrich $30,48,57,65,90,226$, $265,289 \mathrm{f}$.
Deckert, Helmut 25, 28, 65, 99, 228, 260, 285, $291 \mathrm{f}$.

Dedering, Kurt 66, 94, 135, 478

Denecke, Dorothee 48, 57, 90, 125, 226, 285, $293 \mathrm{f}$.

Draeseke, Johannes 68, 110, 226, 232, 295 f., 411

Emden, Fritz van 29, 50 ff., 54, 57, 297 ff., 320, 357, 390

Enking, Ragna 25, 47, 57, 106, 155 f., 161, 164, 223, 227 ff., 300 ff., 376, 433

Faass, Bruno 49, 90 f., 223, 226, 304 f., 414

Fichtner, Fritz 12, 14, 23, 26, 28, 36, 39-43, 45 f., 61 f., 64-71, 74-79, 81-88, 90, 92 f., 96, 98, 100 ff., 106 ff., $111,118,120-124,128,131-137,142$, 146, 148, 150 ff., 155-160, 162-169, 173, 180 f., 186 ff., 194 ff., 198-207, 210, 213, 216 ff., 220-224, 230 f., 237-240, 243, 246, 248, 251, 254, 258, 263, 267, 285, 288, 296, 301, 306-310, 314, 324 ff., 340, 345, 352, 355, 364, 374, 376, 384, 391, 394, 400, 405, 407, 411, 422-425, 432 ff., 438, 440, 447, 449 f., 461, 469, 472

Fiebiger, Otto 28, 49, 125, 311 f., 396

Fischer, Walther 63 f., 75, 82, 86, 91, 106, 110, 133, 137, 161 f., 164, 173, 176, 181, 195 f., 202, 212, 227, 231 f., 236, 240, 247, 267 f., 301, 313 ff., 321, 332 ff., 391, 417, 438, 469

Frick, Wilhelm 105, 116, 186

Frieser, Walther 49, $316 \mathbf{f .}$

Fritsch, Karl 96, 115, 479

Gasch, Walther 103, 141, 406, 430, 479

Glauning, Otto 281, 284, 361, 479 
Goebbels, Joseph 86, 112 f., 220, 340, 408

Göpfert, Arthur 38-41, 75 ff., 118, 120, $128,155,170,173,185,188,199 \mathrm{ff} .$, 213, 268, 284 f., 291, 307, 361, 394, $407 \mathrm{f}$.

Göring, Hermann 128 f., 148

Graefe, Arthur 42, 159, 465, 480

Groß, [?] 39, 69, 70, 71, 93, 170, 432, 480

Grünberg, Walter 29, 65, 164, 224, 318 f., 343

Gruve, Albert 44, 466, 480

Günther, Klaus 45, 60, 63 ff., 75, 79 ff., 91 ff., 106, 111, 161 f., 164, 202, 206, 209, 212, 223 f., 226 f., 231 f., 320 ff., $353,394,411,466$

Gurlitt, Cornelius 306, 323, 480

Haenel, Erich 28, 49, 53, 59, 60, 70, 77 f., 80,82 f., 87, 91, 135, 145, 161, 164, 173, 177, 179 f., 191 ff., 195 f., 230 f., 236 ff., 240, 242, 247, 258, 277, 323 ff., 351 f., 374, 394, 406, 440, $460 \mathrm{ff}$.

Hahn, Max 68, 110, 145, 229, 326 f., 420

Halm, Peter 28, 84 f., 196, 236, 239, 328 f., $431 \mathrm{f}, 474$

Hanisch, Anneliese 30, 47, 330 f., 419

Häntzschel, Walter 63, 65, 89 ff., 106, 110, 133, 163 f., 196, 200, 202, 225, 247 . 313 f., 332 ff., 417

Hartnacke, Wilhelm 38 f., 70 f., 141, 183, $379,407,481$

Hempel, Eberhard 97, 165, 264, 432, 481

Hesch, Michael 58, 65 f., 73 ff., 80, 90, 102, 106, 108, 111, 189 ff., 202, 206, 209, 225, 232, 248, 270 f., 321, 335-338, $352,381,402$

Hetsch, Rolf 58, 78 f., 91, 111, 231, 247, 307,339 ff., 355

Heydrich, Martin 21, 63, 65, 73 f., 89 f., $110,136,160-165,196,202,206,232$, 238, 245, 271, 318, 336, 342 ff., 407, 444 f., 469

Hitler, Adolf 35 f., 67, 78, 82, 86, 94 ff., 98, 112 f., 119, 128, 143 f., 219, 255, 324, $340,368,407,408,433,452$

Hofer, Helmut 63, 65, 89, 125, 130, 345 f., 381
Hofmann, Hans 28, 49, 58, 90, 125, 202, 223, 276, 285, 347 ff., 388

Holzhausen, Charlotte 48 f., 125, 223, 350, 455

Holzhausen, Walter 57, 60, 62 f., 69 f., 82 ff., 90 f., 106, 115, 156, 164, 173, 176, 180, 196, 199, 200, 202, 214-217, 223 f., 230 f., 236, 251, 259, 277, 321, 324, 351 ff., 376, 395, 439, 462

Hoppe, Kurt 68, 78, 82, 90, 111, 223, 226, 231, 355

Jacobi, Arnold 45, 50, 52, 57, 72, 91 f., 99, 137, 161, 180, 232, 284, 287, 297 f., 320, 342, 356 ff., 380, 390, 410, 443 ff. Jähnig, Karl Wilhelm 28, 54, 99, 115, 359 f., $400,407,408$

Jammers, Ewald 28, 49, 63, 65, 99, 125, 135, 165, 223 f., 347 f., 350, 361 ff., $388 \mathrm{f.}, 397,455,458 \mathrm{f}$.

Jatzwauk, Jacob 49, 100, 110, 125, 223, 226, 273 f., 364 ff.

Kalkowsky, Ernst 278, 416, 456, 482

Kästner, Erhart 48, 65, 77, 90, 173, 196, 225 f., 244, 248, 281, 289, 367 ff.

Kersten, Walter 24, 95, 165, 177, 182, 224, 278, 318, 370 f., 372

Kleemann, Otto 29, 90, 95, 165, 278 f., $372 \mathrm{f}$.

Klemperer, Gustav von 101, 142, 307, 482

Koerner, Ernst von 27, 83, 97, 183 f., 233, 241, $324 \mathrm{f} ., 374 \mathbf{f}$.

Köhn, Kurt 68, 90, 226, 230, 301, 376 f.

Krüss, Artur 89, 224, 378, 381, 410

Kümmel, Otto 70 f., 79, 81, 83, 87, 142, $201,328,340,483$

Kummerlöwe, Hans 14, 28, 60, 72 f., 79, 87 ff., 92, 95 f., 106, 118 f., 130, 136, 143, 161-164, 166, 180, 186 f., 189, 206, 218, 232, 321, 336, 343, 345, 352, 378, 379-383, 390, 444, 468, 488

Lehrs, Max 328, 405, 432, 474, 483

Leuschner, Arthur 26, 57, 68, 90, 110, 124, 226, 230, 301, 384 f., 425

Loos, Hans 90, 110 f., 226 f., 386 f.

Löwenthal, Anna 29, 50 f., 54, 56, 388 f., 454 
Meisenheimer, Johannes 287, 297, 379, 484

Meise, Wilhelm 58, 61, 89 f., 92, 111, 125, 137, 156, 161-164, 196, 204, 223, 225, $247,380,390 \mathrm{ff}$.

Merhart von Bernegg, Gero 318, 370, 484

Messmer, [?] 40, 484

Mühlmann, Kajetan 142 f., 408, 484

Müller, Walter 66 f., 71, 79, 81 ff., 87, 91, 106, 110 f., 118, 126, 135, 151, 155, 160, 164, 185, 196, 202 f., 223 f., 229 ff., 240, 300 f., 393 ff., 407

Mutschmann, Martin 39-43, 51 f., 66 ff., 72, 78, 81, 86, 96, 100 f., 105, 115, 117, 127, 142, 156, 159, 185, 191, 199, 222, 297, 307, 309, 314, 326, 337, 357, 364, $376,414,422,424,465,484$

Neubert, Hermann 67, 75 f., 90, 102, 111, 135, 160, 202, 223, 226 f., 233, 261, 265, 274, 285, 291, 300, 316, 347,

\section{$396 \mathrm{ff}$.}

Neubert, Johannes 61, 78, 355, 484

Oertel, Robert 28, 62, 65, 86, 90, 99, 106, 135, 144, 162, 202, 211, 225 ff., 229, 330, 359, 399 ff., 408, 412, 449, 452, 465

Pfaul, Berthold 58, 73, 89, 224, 270, 402, 444

Pietzsch, Artur 65, 225, 228, 403 f.

Pinder, Wilhelm 277, 306, 339, 431, 434, 481, 485

Posse, Hans 11, 13, 18 f., 29, 64, 67, 70 f., 79, 82, 84-87, 94 f., 98, 102, 106, 115, 117 f., 124, 128, 135, 141-146, 161, 196, 202, 218, 229, 236, 242, 244, 247 . 254, 359 f., 394, 400, 405-409, 412, 432, 449, 452, 465, 475

Reche, Otto 73, 335, 485, 487

Reichert, Robert 63, 68, 75, 110, 140, 174, 228, 232, 296, 321, 378, 410 f.

Reimer, Gottfried 67, 95, 135, 144, 227, 399 f., 408, 412 f., 452

Reuter, Hans 40, 61, 76, 96, 101, 136, 486

Reuther, Oscar 70, 309, 486

Richter, Hubert 49, 125, 223 f., 282, 304, $414 \mathrm{f}$.
Rimann, Eberhard 64, 86, 90 ff., 133, 161, 164 f., 182, 203, 211, 232, 256, 278, 313 f., 332 f., 416 ff.

Rust, Bernhard 55, 62 f., 100, 102, 128, 149, 153, 169, 185, 202, 364, 486

Samtleben, Eduard 326, 420

Sander, Curt 68, 90, 110 f., 226 f., 230, $421 \mathrm{f}$.

Schmarsow, August 262, 306, 323, 359, 485, 486

Schmelzer, Reinhard 61 f., 68, 203, 231, $262,307,423 \mathbf{f}$.

Schmidt, Richard 62, 68, 90, 230, 385, $425 \mathrm{f}$.

Schneider, Helmut 49, 61, 65, 224, 250, $427 \mathrm{f}$.

Schröder, Bruno 71, 91 f., 141, 161, 185, 229, 300, 393, 429 f., 447

Schubert, Franz 44, 46, 62, 64 f., 85, 92 ff., $106,111,115,144,156$ f., 165, 176, 196, 202, 204, 212, 224, 239, 254, 326, 328, 330, 431 ff., $474 \mathrm{f}$.

Schulze-Battmann, Elfriede 47, 57, 301, 434 ff., 468

Schwarze, Rudolf 12, 68, 90, 110, 182, 223 f., 226, 227 f., 231, 232, 268, 437 f., 456

Schwinkowski, Walter 47, 59, 77 ff., 91, $162,177,230,355,439 \mathrm{ff}$.

Speer, Albert 128, 219, 405, 465, 487

Storch, Margarethe 48 f., 228, 285, 442

Struck, Bernhard 28, 44, 53, 72 ff., 92, 98, 115, 118 f., 136, 186 f., 189, 232, 270, 335, 342 f., 391, 402, 407, 443-446, 469, 477

Täubrich, Paul 68, 90, 110, 226, 229, $447 \mathrm{f}$.

Unger, Alfred 61 f., 68, 90, 96, 110, 144, 226 f., 229, 449 f.

Voss, Hermann 11, 13, 18, 29, 67, 86 f., 91, 95, 98, 102, 135, 143 f., 158, 175, 210, 223 ff., 229 f., 400, 412, 449, 451 ff., 465 f., 480

Walter, Lucie 29, 49 f., 54, 388, 454 f.

Wanderer, Karl 91, 161, 164, 181 f., 313, $332,437,456$ f. 
Watzdorf, Dorothee von 48, 58, 89, 107, 223, 226, 265, $458 \mathrm{f}$.

Watzdorf, Erna von 46 f., 57 f., 106, 162, 164 f., 177, 210, 217, 227, 230 f., 236, $324 \mathrm{f}, \mathbf{4 6 0} \mathbf{f f}$.

Werkmeister, Paul 82, 91 f., 122, 203, 231, 267, $463 \mathrm{f}$.

Wiedemann, Fritz 44, 57, 67, 90, 144, 223 f., 226, 408, 465 f.

Wölfflin, Heinrich 328, 351, 431, 451, 489
Wolf, Siegfried 57, 90, 164, 206, 223, 226 f., 271, 344, 468 ff.

Zimmermann, Ernst 46, 62, 69 ff., 91, 161, 181, 230, 306, 340, 351, $471 \mathrm{ff}$.

Zoege von Manteuffel, Kurt 28, 79, 84, 91, 93 f., 111, 116, 118, 145, 150, 161, 165, 176, 196, 202, 229, 254, 328, 386, 408, 432, $474 \mathrm{ff}$.

Zörner, Ernst 115, 185, 489 
